

\section{The University Library Leeds}

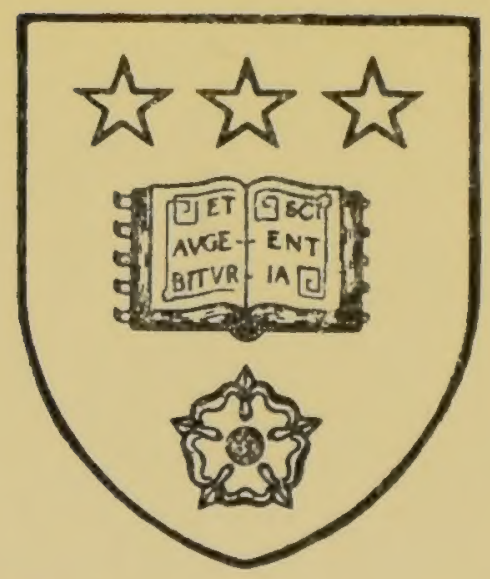

The Chastnn Chatiman Collortion

\section{LEEDS UNIVERSITY LIBRARY}

Classmark:
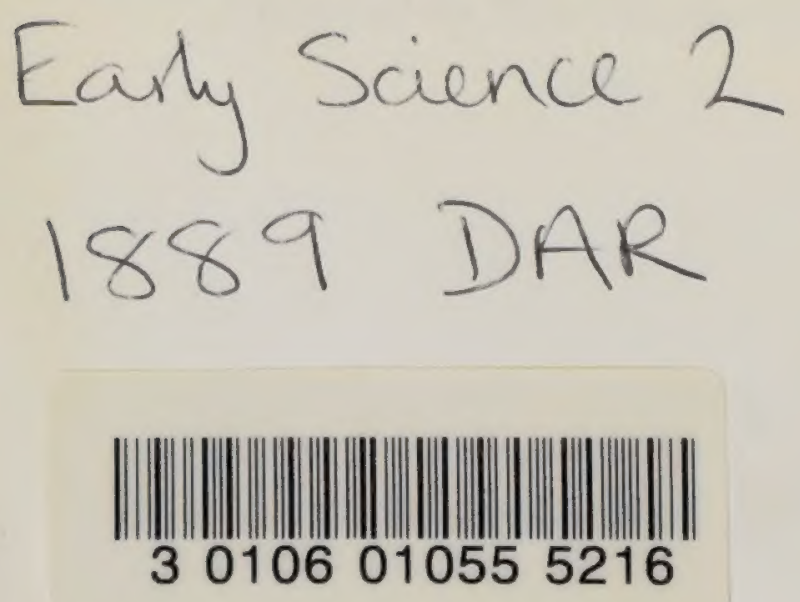
$7 / 6$ 
C. Chapmaso

tondos.

april 24"1syo. 



\section{Alfut C. Chapunans.}

\section{THE DESCENT OF MAN,}

$$
\text { AND }
$$

SELECTION IN RELATION TO SEX. 


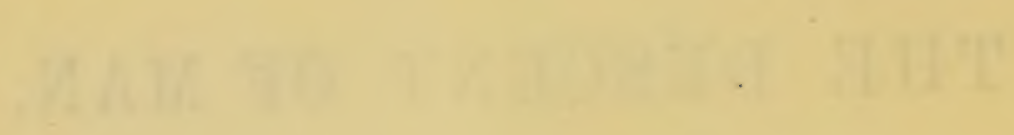




\section{THE}

\section{DESCENT OF MAN,}

A. ND

\section{SELECTION IN RELATION TO SEX.}

By CHARLES ¿ARIVIN, M.A., F.R.S.

SECOVD EDITIOY, REVTSED AND AUGMEVTED.

TWENTY-FIFTH THOUSAND.

שxaith $\mathbb{E l l u s t r a t i o n s . ~}$

L O N D N :

JOHN MURRAY, ALBEMARLE STREET. 1889.

The righ of Translation is reserved. 
WORKS BY THE SAME AUTHOR.

A NATURALIST'S JOURNAL OF RESEARCHES INTO the Naturat. Histokx axd Geologx of Countries visitho during a Voxagh KoUND THE WorLd. N neeenth Thousand. Woodcuts. 3s. 6d. MurRay.

THE ORIGIN OF SPECIES BY MEANS OH' NATURAL SELLCTION; or, The Preservation of Favoured Races in the STRUGGLE FOR LIFE. Thirty-third Thousand. Woodeuts, Large Type Edition. 2 vols. Crown 8vo, 128. Cheap Edition, 68. Murrax.

THE VARIOUS CONTRIVANCES BY WHICH ORCHIDS ARE FERTHLIZED BY INSLCIS. Fourth Thousand. Woodcuts, 78.6d. Murrax.

THE VARIA'IION OF ANIMALS AND PLAN'TS UNDER DOMESTICATION. Sixth Thousand. Illustrations, 158. MURRAT.

THE DESCEN'T OF MAN, AND SELECTION IN RELATION TO SEX. Twenty fifth Thousand. Illustrations. Large Type Edition. 2 vols. Crown 8 vo., 15s, Cheap Lditiun, 7s. 6 d. MURRA:.

THF EXPRESSION OF THE EMOTIONS IN MAN AND ANIMALS. Ninth Thousand. Illustrations. Murrar.

INSECTIVOROUS PLANTS. Fourth Thousand. Illustrations. 9:.

THE MOVEMENTS AND HABITS OF CLIMBING PLANTS. Third Thousund. Woodcuts. 68. MLuray.

THE EFEELTS OF CROSS AND SELF-EERTILIZATION IN THE VEGEIABLE KINGDOM. Third Thousand. Illustrations. 98. Murkax.

THE DIFEEREN'T FORMS OF FLOWERS ON PLANTS OF IHE SAME' SPECIES. Third Thousand. Illustrations. 7s.6d. MUrRaY.

'THE POWER OE MOVEMEN'I' IN PLANTS. Third Thousand. Woodcuts. Murray.

THE FORMATION OF VEGETABLE MOULD THROUGH THE ACTION OF WORMS. Eleventh Thousand. Woodcuts. Crown 8vo., 6s. MURRaY.

LIFE OF ERASMUS DARWIN. With a Study of his Scientific Works. Portrait. $7 s .6 d$. MURRAT.

IHE STRUCTURE AND DISTRIBUTION OF CORAL REEFS. Second Edition, revised, SMTTH, ELDER, \& Co.

GEOLOGICAL OBSERVATIONS ON VOLCANIC ISLANDS AND ON PARTS OF SOULH AMERICA, visited during the Voyage of H.M.S. 'Beagle.' Second Edition.

Smiti, Eider, \& Co.

A MONOGRAPH OE THE CIRRIPEDIA. With numerous lilustrations. 2 vols. 8 vo. RAI SOCIETY. HARDWICKE.

A MONOGRAPH OF' THE FOSSIL LEPADIDA, OR PEDUNCULATED CIRRIPEDS OF GREAT BRITAIN.

Patagontographical Societr.

A MONOGRAPH OF THE FOSSIL BALANIDAE AND VERRUCIDA OF GREAT BRITAIN. PAL FON ROGRAPHICAL SUCIEIX.

FACTS AND ARGUMENTS FOR DARWIN. By FrITz Mưllkr. From the German, with Additions by the Author. Translated by W. S. DAllas, F.L.S. Illustrations. 68 . Murray.

LONDON: PRINTED BI WLLLAM CLOWES AND SONS, LIMITED, STAMFORD GTREET

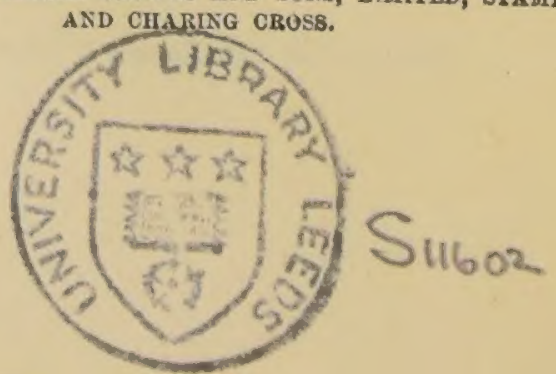




\section{PREFACE TO THE SECOND EDITION.}

DUing the successive reprints of the first cdition of this work, published in 1871 , I was able to introduce sereral important corrections; and now that more time has elapsed, I bave endeavoured to profit by the fiery ordeal through which the book has passed, and have taken advantage of all the criticisms which scem to me sound. I am also greatly indebted to a large number of correspondents for the communication of a surprising number of new facts and remarks. These have been so numerous, that I have been able to use only the more important ones; and of these, as well as of the more important corrections, I will append a list. Somo new illustrations have been introdnced, and four of the old drawings have been replaced by better ones, done from life by Mr. T. W. Wood. I must especially call attention to some observations which $I$ owe to the kindness of Prof. Huxley (given as a supplement at the end of Part I.), on the nature of the differences between the brains of man and the higher apes. I have been particularly glad to give these observations, because during the last fow years several memoirs on the subject have appeared on the Continent, and their importance has been, in some cases, greatly cxaggcrated by popular writers.

I may take this opportunity of remarking that my critics frequently assume that I attribute all changes of corporeal structure and mental power exclusively to the natural selection of such variations as are often called spontanenns; whereas, even in the first edition of the 'Origin of Species,' I distinetly' stated that great weight must be attributed to the inherited effects of use and disuse, with respect both to the body and mind. I also attributed some arnount of modification to the direct and prolonged action of changed conditions of life. Some allowance, too, must be made $f\left(r^{\circ}\right.$ occasional reversions of 
structure; nor must we forget what I have called "corrclated" growth, meaning, thereby, that various parts of the organisation are in some unknown manner so connected, that when one part varies, so do others; and if variations in the one are accumulsted by selection, other parts will be modificd. Again, it has been said by sereral critics, that when I found that many dotails of structure in man could not be explained through natural selection, I invented sexual selection; I gave, howerer, a tolerably clear sketch of this principle in the first edition of the 'Origin of Species,' and I there stated that it was applicable to man. 'This subject of sexual selection has beeu treated at full length in the present work, simply because an opportunity was here first afforded me. I have been struck with the likeness of many of the half-favourable criticisms on sexual selection, with those which appeared at first on natural selection; such as, that it would explain some few details, but certainly was not applicable to the extent to which I have employed it. $\mathrm{My}$ conviction of the power of sexual selection remains unshaken; but it is probable, or almost certain, that several of my conclusions will hereafter be found erroneous; this can hardly fail to be the case in the first treatment of a subject. When naturalists have become familiar with the idea of sexual selection, it will, as I believe, be much more largely accepted; and it has already been fully and favourably received by several caluli.e judges.

DOKN, BECKENHAY, KENT,

Septomber 187 . 


\section{T A BLE}

OF THE

PRINCIPAL ADDITIONS AND CORRECTIONS TO THE PRESENT EDITION.

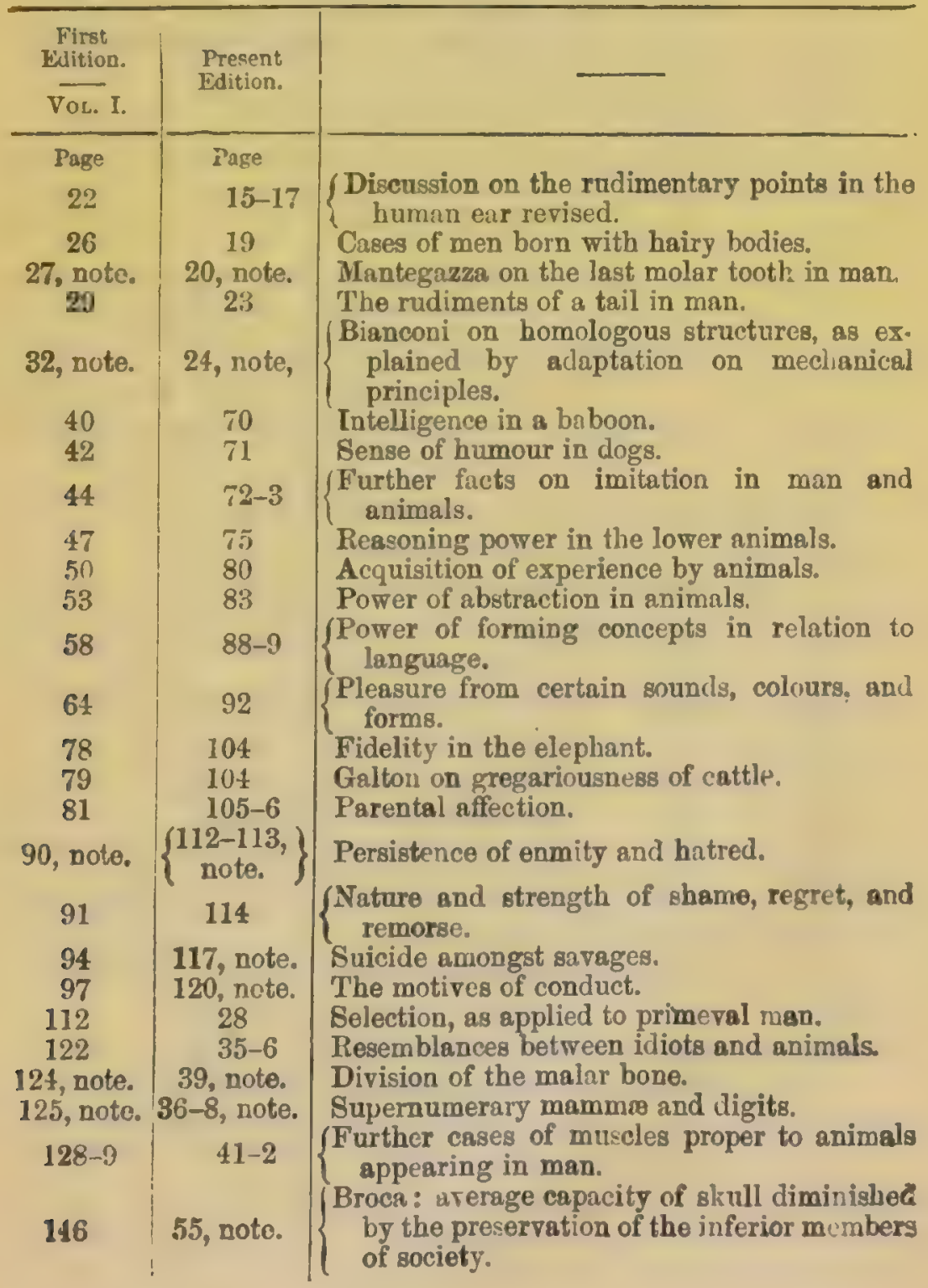




\begin{tabular}{|c|c|c|}
\hline $\begin{array}{l}\text { lirst } \\
\text { lition. } \\
\text { vol. I. }\end{array}$ & $\begin{array}{l}\text { l'resent } \\
\text { Ldition. }\end{array}$ & \\
\hline 1:xire & P'ige & \\
\hline $1+9$ & $\therefore 7$ & $\left\{\begin{array}{l}\text { Belt on advantages to man from his hair- } \\
\text { l'ss: ss. }\end{array}\right.$ \\
\hline 150 & $58-9$ & $\begin{array}{l}\text { Disapletrance of the tail in man and certain } \\
\text { monkeys. }\end{array}$ \\
\hline 169 & $1: 34-5$ & $\begin{array}{l}\text { Injurious forms of selection in civilised } \\
\text { nations. }\end{array}$ \\
\hline 180 & 143 & $\left\{\begin{array}{l}\text { Indolence of } m e n \text {, when free from a struggle } \\
\text { for existence. }\end{array}\right.$ \\
\hline 193 & 151 & $\begin{array}{l}\text { Gorilla protecting himself from rain with his } \\
\text { hands. }\end{array}$ \\
\hline $\begin{array}{l}\text { 208. note. } \\
209\end{array}$ & $\begin{array}{l}161 \text {, note } \\
163\end{array}$ & $\begin{array}{l}\text { Hermaphroditism in fish. } \\
\text { Rudimentary mamms in male manımals. }\end{array}$ \\
\hline 239 & $188-190$ & $\left\{\begin{array}{l}\text { Changed conditions lessen fertility and cause } \\
\text { ill-health amongst savages. }\end{array}\right.$ \\
\hline 215 & $195-6$ & $\begin{array}{l}\text { Darkness of skin a protection against the } \\
\text { sun. }\end{array}$ \\
\hline 250 & $199-206$ & $\left\{\begin{array}{l}\text { Note by Professor Huxley on the develop- } \\
\text { ment of the brain in man and apes. }\end{array}\right.$ \\
\hline 256 & $209-210$ & $\left\{\begin{array}{l}\text { Special organs of male parasitic worms for } \\
\text { holding the female. }\end{array}\right.$ \\
\hline $275-6$ & $224-5$ & $\left\{\begin{array}{l}\text { Greater variability of male than female: } \\
\text { direct action of the environment in causing } \\
\text { differences between the sexes. }\end{array}\right.$ \\
\hline 230 & 235 & $\left\{\begin{array}{l}\text { Period of development of protubernnces } \\
\text { on birds' heads determines their trans } \\
\text { mission to one or both sexes. }\end{array}\right.$ \\
\hline 301 & $243-4$ & Causes of excess of male births. \\
\hline $31 \pm$ & 254 & Proportion of the sexes in the bee finmily. \\
\hline 315 & $255-6$ & $\left\{\begin{array}{l}\text { Excess of males perhaps sometimes deter- } \\
\text { mined by selection. }\end{array}\right.$ \\
\hline$: 327$ & $26+$ & Bright colours of lowly organised animals. \\
\hline $\begin{array}{l}\$ 338 \\
3: 39\end{array}$ & $\begin{array}{l}272 \\
273\end{array}$ & $\begin{array}{l}\text { Sexuul selection amongst spiders. } \\
\text { Cause of snallness of male spiders. }\end{array}$ \\
\hline 345 & 277 & Use of phosphorescence of the glow-worm. \\
\hline 349 & 280 & The humming noises of tlies. \\
\hline 350 & 281 & Use of bright colours to Hemiptera (bugs). \\
\hline 351 & & Musical apparatus of Homoptera. \\
\hline $\begin{array}{l}: 54 \\
359\end{array}$ & $\begin{array}{c}284-5 \\
288, \text { note. }\end{array}$ & $\left\{\begin{array}{l}\text { Development of stridulating apparatus in } \\
\text { Orthoptera. }\end{array}\right.$ \\
\hline 366 & $292-3$ & $\left\{\begin{array}{c}\text { Hermann Müller on sexual differences of } \\
\text { bees. }\end{array}\right.$ \\
\hline $\begin{array}{l}387 \\
397\end{array}$ & $\begin{array}{l}308 \\
: 315\end{array}$ & $\begin{array}{l}\text { Sounds producer by moths. } \\
\text { Display of benuty by butterflies. }\end{array}$ \\
\hline 101 & 319 & $\left\{\begin{array}{c}\text { Femalo butterflies, taking the more active } \\
\text { part in courtship, brighter than their male }\end{array}\right.$ \\
\hline 412 & $324-5$ & $\left\{\begin{array}{l}\text { Further cases of minicry in butterflies and } \\
\text { moths. }\end{array}\right.$ \\
\hline 417 & $3: 6$ & $\left\{\begin{array}{l}\text { Cause of bright and diversificd colours of } \\
\text { catexpillars. }\end{array}\right.$ \\
\hline
\end{tabular}




\begin{tabular}{|c|c|c|}
\hline $\begin{array}{l}\text { First } \\
\text { Litition. } \\
\text { Vor. II. }\end{array}$ & $\begin{array}{l}\text { I'resent } \\
\text { f.hitiun. }\end{array}$ & \\
\hline $\begin{aligned} \text { Page } \\
2\end{aligned}$ & $\begin{array}{l}\text { Pago } \\
331\end{array}$ & \multirow{9}{*}{$\begin{array}{l}\text { Brush-like scales of male Mallotus. } \\
\text { Further facts on courtship of fishes, and the } \\
\text { spawning of Macropus. } \\
\text { Dufossé on the sounds nade by fishes. } \\
\text { Belt on a frog protected by bright colouring. } \\
\text { Further facts on mental powers of snakes. } \\
\text { Sounds produced by suakes; the rattlesnukis. } \\
\text { Combats of Chumeleons. } \\
\text { Mitrshill on protuberances on birds' head. } \\
\text { Further facts on display by the Argus } \\
\text { phi a-ant. }\end{array}$} \\
\hline 14 & 341 & \\
\hline 23 & 347 & \\
\hline 26 & $34 !$ & \\
\hline 30 & 352 & \\
\hline$: 32$ & 353 & \\
\hline :it; & $35 \overline{7}$ & \\
\hline 72 & 383 & \\
\hline 91 & 398 & \\
\hline $\begin{array}{l}103 \\
118\end{array}$ & $\begin{array}{l}411 \\
417\end{array}$ & $\begin{array}{l}\text { Attachment between paired birds. } \\
\text { Female pigeon rejecting certain males. }\end{array}$ \\
\hline 120 & 419 & Albino birds not finding partners, in a state \\
\hline $12 t$ & 423 & 'Direct action of climute on birds' colours. \\
\hline $147-150$ & $43 s^{\prime}-41$ & Further facts on the occlli in the Arirus \\
\hline $15^{22}$ & 443 & Display by humming-birds in co,urtship. \\
\hline 157 & 446 & $\left\{\begin{array}{l}\text { Cases with pigeons of colour transmitted to } \\
\text { one sex alone. }\end{array}\right.$ \\
\hline 232 & $495-6$ & $\left\{\begin{array}{l}\text { Taste for the beautiful permament enongl } \\
\text { to allow of sexual selection with the lower } \\
\text { animals. }\end{array}\right.$ \\
\hline 247 & 503 & $\left\{\begin{array}{l}\text { Horns of sheep originally a masculine } \\
\text { character. }\end{array}\right.$ \\
\hline 248 & 506 & Castration affecting horns of animals. \\
\hline 256 & $513-$ & Prong-Lomed variety of Cervus rirginianus. \\
\hline 260 & 516 & $\left\{\begin{array}{l}\text { Relative sizes of male and female whales anm } \\
\text { seals. }\end{array}\right.$ \\
\hline 266 & 521 & Absence of tusks in male miocene pigs. \\
\hline 286 & $5: i t$ & Debson on sexual differences of bats. \\
\hline 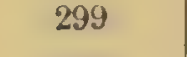 & $5+2-3$ & Reeks on advantage from peculiar colourin. \\
\hline 316 & 556 & $\left\{\begin{array}{l}\text { Ditterence of complexion in men and womes } \\
\text { of an African tribe. }\end{array}\right.$ \\
\hline 337 & 572 & Speech subsequent to singing. \\
\hline 356 & 586 & $\begin{array}{l}\text { Schopenhauer on importance of courtship to } \\
\text { mankind. }\end{array}$ \\
\hline B5Э et seq. & 588 e & $\left\{\begin{array}{l}\text { Revision of discussion on communal marriagi's } \\
\text { and promiscuity. }\end{array}\right.$ \\
\hline 373 & $59 S-9$ & $\left\{\begin{array}{l}\text { Power of choice of woman in marriage, } \\
\text { amongst savages. }\end{array}\right.$ \\
\hline 380 & 603 & $\left\{\begin{array}{l}\text { Long-continued habit of plucking out hair } \\
\text { may produse an inherited eff'et. }\end{array}\right.$ \\
\hline
\end{tabular}


. 


\section{CONTENTS.}

\section{INTroductic: \\ PART I. \\ THE DESCENT OR ORIGIN OF MAN.}

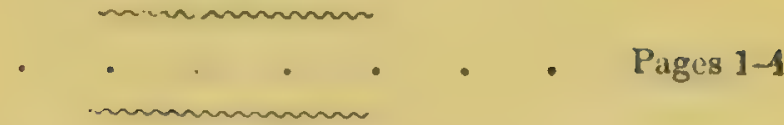

CHAPTER I.

The Evidence of the Descent of Max fron some Lower Forar.

Nature of the evidence bearing on the origin of man-Homologous PAG B structures in man and the lower animals-Miscellaneous points of correspondence - Development - Rudimentary structures, muscles, sense-orerans, hair, bones, reproductive organs, \&c.The bearing of these three great clisses of facts on the origin of man

\section{CHAPTER II.}

On the Manner of Development of Man from some Lowel ForM.

Variability of bndy and mind in man-Inheritance-Causes of variability-Laws of variation the same in man as in the lowar animals-Direct action of the conditions of life-Effects of the increased use and disuse of parts-Arrested development-Reversion-Correlated variation-Rate of Increase-Checks to increase-Nitural selection-Man the most dominant animal in the world-Impnrtauce of his corporeal structure-The causes which have led to his becoming erect-Consequent changes of structure-Decrease in size of the canine teeth-Increased size and altered shrpe of the skull-Nakedness-A bsence of a tailDefenceless condition of man . . . . .

\section{CHAPTER III.}

Comparigon of the Mental Powers of Man and the Lower Animals.

The difference in mental power between the highest ape and the lowest savage, immense-Certain instincts in common-Tho emotions - Curiosity - Imitution-Attention-Mernory-Inasi nation-Reason-Progressive improvement-Tools and weapnuia 
used by animals-Aistraction. Self-consciousuess-Langnage -Sense of bcauty-Belief in Gorl, spiritual agencies, superatilions

\section{CHAPTER IV.}

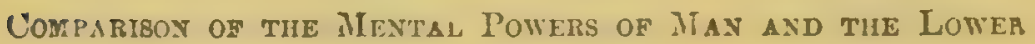
Avmals-contimued.

The moral sense-Fundamenial proposition-The qualitics of social animals-Origin of sociability-Struggle betwcen opposerl instinets-Man a social animal-The nore enduring social instincts conyuur other less pursistent instincts-The social virtues alone remardel by savages-The self-regardincr virtues acquired at a later stage of development-The importance of the judgment of the members of the same community on conduct'Transmission of moral tendencies-Summary .

\section{CHAPTER V.}

On the Develophent of tue Iftellecteal and Moral Faclites during Primeval axd Civilised Times.

Alvancement of the intellectnal porers through natural selection-Importance of imitation-Social and moral facultiesTheir development within the limits of the sane tribe- Natural selection as aftecting civilised uations- Tridence that civilised nations were once barbarous

\section{CHATTER VI.}

Ox the Affixities a.d Grienlogy of Max.

Position of man in the animal scries-'Tlue natural system genenlogical-Adaptive characters of slight value-Various small points of resemblance betreen man and the QualrumaniRauk of man in the natural system-Birthplare and antiquity of man-Abence of fossil connceting-links-I worer stages in the genealogy of man, as inferred, firstly from his affinities and secondly from his structure-Early androgynous condition of the Vertcbrata-Conclusion

\section{CHAPTER VII.}

\section{OY THE RACES OF MAN.}

The naturc and value of specifie, charucters-Application to the races of man-Arguments in favour of, and opposed to, rinking the so-citled ruces of man as distinct species-Sub-speciesMLonngenists and polronists - Convergenco of charucter - 
Numerous points of resemblance in body and mind between the most distiact races of man-The state of min when he tirst apread over the earth-Fuch race not descended from a siugle pair-The extinction of races-The formution of races-The 'fficts of crossing-Slight intluence of the dirct action of the conditions of life-slight or ac influence of natural selection sixual solection

\section{PART II.}

\section{SEXUAL SELECTIOY.}

\section{CHAPTER VIII.}

\section{Pitxctpleg of Sexdal Selectios.}

Becondary sexual characters-Sexual selection-Manner of action - Excess of males - Polymamy - The male alone generally moditiea through sexual selection-Eagerness of the maleVariability of the male-Choice exerted hy the female--Sexual compared with natural selection-Inheritance at corresponding prrinds of life, at corresponding seasons of the year, and ats Jimited by sex-Relations between the several forms of inheritance-Causes why one sex and the young are not modificd through sexual sulection-Supplement on the proportional numbers of the two sexes throughout the animal kingdom-The proportion of the sexes in relation tu natural selection .

\section{CHAPTEII IX.}

Secondary Srycal Characters in the Lower Classes of tue Aximal Kinidom.

These characters absent in the lowest classes-Brilliant coloursMollusca-Annelids-Crustacen, secondiry sexuil characters strongly develop.d; limurphism; coluur; characters not acquired before maturity-Spiders, sexual colours of; stridulation to the males-Mriupoda

\section{CHAPTER $\mathbf{I}$.}

\section{Secondary Sexcal Characters of Ixbects.}

I):versified structures possessed by the malcs for seizing the fenale -Differences between the sexes, of which the menuing is not understond-Difference in size between the sexesThysanura-Diptera-Hemintera-Homoptcra, musical powers 
posicgsor by the males alone-Orthoptera, cusicnl instrmments of tho misles, mucl diversified in structure; pugıacity; coloursNeuroptern sexual differences in colour-Hymenoptera, pugnacily and colours-Coleoptera, colours; furnishel with great horns, apparently as an ornament; battles; stridulating organs generally common to both sexes . . . .

\section{CHAP'TER XI.}

INSEcts, continued.-ORDER LEPIDOPTERA.

(BCTTERFLIES AND MOTHS.)

Cuurtship of butterflies-Battles-Ticking noiso-Colours common to both sexes, or more brilliant in the males-Examples-Not due to the direct action of the conditions of life-Colours adapted for protection-Colours of mothz-Disylay-Perceptivo powers of the Lepidoptera-Variability-Causes of the difference in colour between the males and females-Mimicry, female butterflies more brilliantly coluured than the wales-Brigit colours of caterpillars-Summary and concluding remarks on the secondary sezual characters of insects-Birds and insects compared

\section{CHAPTEK XI.}

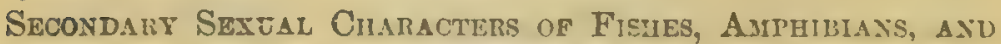
RePTiles.

Frshes: Courtship and battles of the wales-Lirger size of the fomales-Males, bright colours and ornamentul apluendages; other strunge characters-Colours and appenilages acijuired by the males during the breeding-season alone-Fishes with boti sexes brilliantly coloured-Protective colours-The less conspicuous colours of the female cannot be accounted for on the principle of protection-Male fishes building nests, and taking charge of the ova and young. Ampribiss: Differences in structure and colour between the sexes-Vocal organs. REPTILES : Chelonians-Crocodiles-Snakes, culours in sume cases protective - Lizards, battles of - Ornamentul appendages Strange differences in structure between the sexus-ColoursSexual differences almost as great as with birds .

\section{CHAPTER XIII.}

\section{Secondary Sexual Characters of Birds.}

Scxual differences - Law of battle-Special weapons - Vocal organs-Instrumental music-Love-antics and dances-Decurations, permanent and seasonal-Double and siugle annun! moulto-Display of ormaments by the males 


\section{CHAPTER XIV.}

BIRDs-continued.

Clwice oxerted by the femalo-Length of cuurtship-Unpaired birdo-Mental qualities and taste for the beautiful-Preference or antipathy shewn by the female for particular males-Variability of birds - Variations sometimes abrupt-Laws of variation-Formation of ocelli-Gradations of character-Case of Peacock, Argus pheasant, and Urosticte . .

\section{CHAPTER XV. \\ B1RDS-contirued.}

Discussion as to why the males alone of some specicy, and both sexes of others are brightly coloured-On sexually-limited inheritance, as applied to various structures and to brightlycoloured plumage-Nidification in relation to colour-Luss of nuptial plumage during the winter . . . .

\section{CHAPTER XVI.}

BIRDS-conoluded.

The immature plumage in relation to the character of the plumage in both sexes when adult-Six classes of caseg-Sexual differences between the males of closely-allied or representative species-The female assuming the characters of the malePlumage of the young in relation to the summer and winter plumage of the adults- $O n$ the incrcase of beauty in the birds of the world-Protective colouring-Conspicuously-coloured birds-Novelty appreciated-Summary of the four chapters on birds

\section{CHAPTER XVII.}

\section{Secondary Sexual Characters of Mammals.}

The law of battle-Special weapons, confined to the males-Cause of absence of weapons in the female-Weapons common to both sexes, yet primarily acquired by the male-Other uses of such weapons-'Their high importanco-Greater size of the maleMeaus of defence-On the preference shewn by either sex in the pairing of quadrupeds . . . . . .

\section{CHAPTER XVIII.}

Secondary Sexual Chabacters of Mammats-continued.

Voice-Remarkable sexual peculiarities in seals-Odour-Development of the hair-Colour of the hair and skin-Anumalous 
rase of the fomale being more ornamented than the malorolour and ornaments due to sexual selection-Colvur acquired for the sake of protection-Colour, though common to both sexes, often due to sexual selection-On the disappearance of spots anil stripes in adult quadrupeds-On the colours and ornaments of the Quadrumana-Summary . . .

PART III.

SEXUAL SELECTION IN RELATION TO MAN, AND CONCLUSION.

CHAPTER XIX.

\section{Secondary Sextal Characters of Man}

Differences between man and woman-Causes of such differences, and of certain characters common to both sexes-Law of battle -Differences in mental powers, and voice-On the influence of beauty in determining the marriages of mankind-Attention paid by savages to ornaments-Their ideas of beauty in woman -The tendency to exaggerate each natural peculiarity . 556

\section{CHAPTER XX.}

\section{Secuydary Sexual Cuaracters of Man-continued.}

On the effects of the continued selection of women according to a different standard of beauty in each race-On the causes which interfere with sexual selection in civilised and savage nations -Conditions favourable to sexual selection during primeval times-On the manner of action of sexual selection with mankind-On the women in savage tribes having some power to choose their husbands-Absence of hair on the body, and derelopment of the beard-Colour of the skin-Summary .

\section{CHAPTER XXI.}

\section{General Stmmary and Conclusio».}

Main conclusion that man is descended from some lower formManuer of development-Genealogy of nan-Intellectual and moral faculties-Sexual selection-Conchuding remarks

Scppledental Notz. LNDEX 


\title{
THE DESCENT OF MAN;
}

\author{
AND \\ SELECTION IN RELATION TO SEX.
}

\section{INTRODUCTION.}

THE nature of the following work will bo best understood by a brief account of how it came to be written. During many years I collected notes on the origin or descent of man, without any intention of publishing on the subject, but rather with the determination not to publish, as I thought that I should thus only add to the prejudices against my views. It seemed to me sufficient to indicate, in the first edition of my 'Origin of Species,' that by this work " light would be thrown on the "origin of man and his history;" and this implies that man must be included with other organic beings in any general conclusion respecting his manner of appearance on this earth. Now the case wears a wholly different aspect. When a naturalist like Carl Vogt ventures to say in his address as President of the National Institution of Geneva (1869), "personne, en Europe "au moins, n'ose plus soutenir la création indépendante et de "toutes pièces, des espèces," it is manifest that at least a largo number of naturalists must admit that species are the modified descendants of other species; and this especially holds good with the younger and rising naturalists. The greater number accent the agency of natural selection; though some urge, whether with justice the future must decide, that I have greatly overrated its importance. Of the older and honoured chiefs in natural science, many unfortunately are still opposed to evolution in every form.

In consequence of the vicws now adopted by most naturalists, and which will vltimately, as in every other ease, be followed by 
others who are not scientific, I have been led to put togethar my notes, so as to see how far the general conclusions arrived at in my former works were applicable to man. This seemed all the more desirable, as I had nerer delibcrately applied these views to a species taken singly. When we confine our attention to any one form, we are deprired of the reighty arguments derived from the nature of the affinitios which connect together whole groups of organisms-their geographical distribution in past and present times, and their geological succession. The homological structure, embryological derelopment, and rudimentary organs of a species remain to be considered, whether it be man or any other animal, to which our attention may be directed; but these great classes of facts afford, as it appears to me, ample and conclusive evidence in favour of the principle of gradual evolution. The strong support derived from the other arguments should, however, always be kept before the mind.

The sole object of this work is to consider, firstly, whether man, like every other species, is descended from some preexisting form; secondly, the manner of his derelopment; and thirdly, the value of the differences between the so-called races of man. As I shall confine myself to these points, it will not be necessary to describe in detail the differences between the sereral races-an enormous subject which has been fully discussed in many valuable works. The high antiquity of man has recently been demonstrated by the labours of a host of eminent men, beginning with $\mathbf{M}$. Boucher de Pcrthes; and this is the indispensable basis for understanding his origin. I shall, therefore, take this conclusion for granted, and may refer my readers to the admirable treatises of Sir Charles Lyell, Sir John Lubbock, and others. Nor shall I have occasion to do more than to allude to the amount of difference between man and the anthroponiorphous apes ; for Prof. Huxley, in the opinion of most competent judges, has conclusively shewn that in every visible character man differs less from the higher apes, than these do from the lower members of the same order of Primates.

This work contains hardly any original facts in regard to man; but as the conclusions at which I arrived, after drawing up a rough draft, appeared to me interesting, I thought that they might interest others. It has often and confidently been asserted, that man's origin can never be known: but ignorance more frequently begets confidence than does knowledgo: it is those who know little, and not those who know matuch, who so positively assert that this or that problem will never be solved by science. The conclusion that man is the co-descendant with other species of some ancient, lower, and extinct form, is not in 
nny degrce ner. Lamarck long ago came to this conclusion, which has lately been maintained by several eminent naturalists and philosophers ; for instance, by Wallace, Huxley, Lyell, Vogt, Lubbock, Biichner, Rolle, \&c., ${ }^{1}$ and especially by Häckel. This last naturalist, besides his great work, 'Generelle Morphologie' (1S66), has recontly (1868, with a second edit. in 1870), published his 'Naturliche Schöpfungsgeschichte', in which he fully discusses the genealogy of man. If this work had appeared before my essay had been written, I should probably never have completed it. Almost all the conclusions at which I have arrived I find confirmed by this naturalist, whose knowledge on many points is much fuller than mine. Wherever I have added any fact or view from Prof. Häckel's writings, I give his authority in the text; other statements I leave as they originally stood in my manuscript, occasionally giving in the foot-notes references to his works, as a confirmation of the more doubtful or interesting points.

During many years it has seemed to me highly probable that sexual selection has played an important part in differentiating the races of man; but in my 'Origin of Species' (first edition, $p$. 199) I contented myself by merely alluding to this belief. When I came to apply this view to man, I found it indispensable to treat the whole subject in full detail. ${ }^{2}$ Consequently the second part of the present work, treating of sexual selection, has extended to an inordinate length, compared with the first part; but this could not be aroided.

I had intended adding to the present volumes an essay on the expression of the various emotions by man and the lower animals. IIy attention was called to this subject many years ago by Sir Charles Bell's admirable work. This illustrious anatomist

1 As the works of the first-named authors are so well known, I need not give the titles; but as those of the latter are less well known in England, I will give them:-'Sechs Vorlesungen uber die Darwin'sche Theorie:' zweite Auflage, 1868, von Dr. I. Büchner; translated into French under the title 'Conférences sur la Thérie Darwinienne,' 1869. 'Der Mensch, im Lichte der Darwin'sche Lehre,' 1865, ron Dr. F. Rolle. I will not attempt to give references to all the authors who have taken the same side of the question. Thrs G. Canestrini has published ('Annuario della Soc. $d$
Nat.,' Modena, 1867, p. 81) a ver'y curious paper on rudimentary chrracters, as bearing on the origin of man. Another work has (1869) been published by Dr. Francesco Barrago, bearing in Italian the title of "Man, made in the image of God, "was also made in the image of the "ape."

2 Prof. Häckel was the only author who, at the time when this work first appeared, had discussed the subject of sexual selection, and had seen its full importance, since the publication of the 'Origin'; and this he did in a very able manner in his varjous works. 
maintains that man is endowed with certain muscles solely for the sake of expressing his emotions. As this view is obviously opposed to the belief that man is descended from some other and lower form, it was necessary for me to consider it. I likewise wished to ascertain how far the emotions are expressed in the same manner by the different races of man. But owing to the length of the present work, I have thought it better to reserve my essay for' sepalate publication. 
PART I.

\title{
THE DESCENT OR ORIGIN OF MAN.
}

\author{
CHAPTER I. \\ The Evidench of the Descent of MAN From some \\ LOWER Form.
}

Nature of the evidence bearing on the origin of man-Homologous structures in man and the lower animals-Miscellaneous points of correspondence-Development-Rudimentary structures, muscles, senseorgans, hair, bones, reproductive organs, \&c.-The bearing of these three great classes of facts on the origin of man.

HE who wishes to decide whether man is the modified descendant of some pre-existing form, would probably first enquire whether man varies, however slightly, in bodily structure and in mental faculties; and if so, whether the variations are transmitted to his offspring in accordance with the laws which prevail with the lower animals. Again, are the variations the result, as far as our ignorance permits us to judge, of the same general causes, and are they governed by the same general laws, as in the case of other organisms; for instance, by correlation, the inherited effects of use and disuse, \&c.? Is man subject to similar malconformations, the result of arrested development, of reduplication. of parts, \&c., and does he display in any of his anomalies reversion to some former and ancient type of structure? It might also naturally be enquired whether man, like so many other animals, has given rise to varieties and sub-races, differing but slightly from each other, or to races differing so much that they must be classed as doubtful species? How are such races distributed over the world; and how, when crossed, do they react on each other in the first and succeding generations? And so with many other points.

The enquirer would next come to the important point, whether man tends to incrense at so rapid a rate, as to lead to xcasional severe struggles for cxistence; and consequently to 
heneficial variations, whether in body or mind, being preserved, and injurious ones eliminated. Do the races or species of men, whichever term may be applied, encroach on and replace one another, so that some finally become extinct? We shall see that all these questions, as indeed is obvious in respect to most of them, must be answered in the affirmative, in the same manner as with the lower animals. But the several considerations just referred to may be convenicntly deferred for a time: and we will first see how far the bodily structure of man shows traces, more or less plain, of his descent from sume lower form. In succeeding chapters the mental powers of man, in comprarison with those of the lower animals, will be considered.

The Bodily Structure of Mun.-It is notorious that man is constructed on the same general type or model as other mammals. All the bones in his skeleton can be compared with corresponding bones in a monkey, bat, or scal. So it is with his muscles, nerves, blood-ressels and internal viscera. The brain, the most important of all the organs, follows the same law, as shewn by Huxlcy and other anatomists. Bischoff, ${ }^{1}$ who is a hostile witness, admits that every chief fissure and fold in the brain of man has its analogy in that of the orang; but he adds that at no period of development do their brains perfectly agree; nor could perfect agreement be expected, for otherwise their mental powers would have been the same. Vulpian " remarks: "Les différences réelles qui existent entre l'encéphale de "l'homme et celui des singes supérieurs, sont bien minimes. Il " ne faut pas se faire d'illusions à cet égard. L'homme est bien "plus près des singes anthropomorphes par les caractères " anatomiques de son cerreau que ceur-ci ne le sont non"seulement des autres mammifères, mais même de certains "quadrumanes, des guenons et des macaques." But it would be superfluous here to give furthcr details on the correspondenco between man and the higher mammals in the structure of the brain and all other parts of the body.

It may, howerer, be worth while to specify a few points, noi directly or obviously connected with structure, by which this correspondence or relationship is well shewn.

Man is liable to receive from the lower animals, and to com-

1 Grosshirnwindungen des Menschen,' 1868, s. 96. The conclusions of this anthor, as well as those of Gratiolet and Aeby, concerning the brain, will be discussed by Prof. Haxley in the Appeadix alluded to in the Preface to this edition.

2 'Leç. sur la Plirs.' 18666, p. 8900, as quosed by M. Dally, 'L'Orilre deg Primates et le Transformisme,' 186'o, p. 29. 
municate to them, certain diseases, as hydrophobia, variola, the glanders, syphilis, cholera, herpes, \&c. ${ }^{3}$ and this fact proves the close similarity of their tissues and blood, both in minute structure and composition, far more plainly than does their comparison under the best microscope, or by the aid of the best chemical analysis. Monkeys are liable to many of the same noncontagious diseases as we are; thus Rengger, ${ }^{5}$ who carefully observed for a long time the Cebus Azarce in its native land, found it liable to catarrh, with the usual sjmptoms, and which, when often recurrent, led to consumption. These monkeys suffered also from apoplexy, inflammation of the bowels, and cataract in the eyc. 'The younger ones when shedding their milk-tecth often died from ferer. Medicines produced the same effect on them as on us. Many kinds of monkeys hare a strong tasto for tea, coffee, and spirituous liquors: they will also, as I have myself seen, smoke tobacco with pleasure." Brehm asserts that the natives of north-eastern Africa catch the wild baboons by exposing vessels with strong becr, by which they are made drunk. He has seen some of these animals, which he kept in confinement, in this state; and he gives a laughable account of their behaviour and strange grimaces. On the following morning they were very cross and dismal; they held their aching heads with both hands, and wore a most pitiable expression: when beer or wine was offered them, they turned away with disgust, but relished the juice of lemons. ${ }^{3}$ An American monkey, an Ateles, after geiting drunk on brandy, would never touch it again, and thus was wiser than many men. These trifling facts prove how similar the nerves of taste must bo in monkeys ani man, and how similarly their whole nervous system is affected.

Man is infested with internal parasites, sometimes causing:

3 Dr. W. Lauder Lindsay has treated this subject at some length in the 'Journal of Mental Science,' July 1871 ; and in the 'Edinburgh Teterinary Reviow,' July 1858.

4 A Reviewer has criticised ('British Quarterly Review,' Oct. Ist, 1871, p. 472) what I have here said with much severity and contempt; but as I do not use the term identity, I cannot see that I am greatly in error. There appears to me a strong analogy between the same infection or contagion producing the same result, or one closely similar, in two distinct ancoals, and the testing of two dis- tinct fluids by the same chemical reagent.

5 "Naturgeschichte der' Suiuge. thiere von Paraguay,' 1830, s. 50.

- The same tastes are common to some animals much lower in the scale. Mr. A. Nicols informs me that he kept in Queensland, in Australia, three individuals of the Phaseolarctus cincreus; and that. without having been taught in any way, they acquired a strong taste for rum, and for smoking tobacco.

7 Brehm, 'Thierleben,' B.i. 186t. s. 75, 86. On the Ateles, 8. 105. For other analogous statemects, ses s. $25,107$. 
fatal effects; and is plagued by external parasites, all of which belong to the same genera or families as those infesting other mammals, and in the case of scabies to the same species. ${ }^{8}$ Mau is subject, like other mammals, birds, and even insects, ${ }^{9}$ to that mysterious law, which causes certain normal processes, such as gestation, as well as the maturation and duration of various diseases, to follow lunar periods. His wounds are repaired by the same process of healing; and the stumps left after the amputation of his limbs, especially during an early embryonic: period, occasionally possess some power of regeneration, as in the lowest animals. ${ }^{10}$

The whole process of that most important function, the reproduction of the species, is strikingly the same in all mammals, from the first act of courtship by the male, ${ }^{11}$ to the birth and nurturing of the young. Monkeys are born in almost as helpless a condition as our own infants; and in certain genera the young differ fully as much in appearance from the adults, as do our children from their full-grown parents. ${ }^{12}$ It has been urged by some writers, as an important distinction, that mith man the young arrive at maturity at a much later age than with any other animal: but if we look to the races of mankind which inhabit tropical countries the difference is not great, for the orang is believed not to be adult till the age of from ten to fiftecn years. ${ }^{13}$ Man differs from woman in size, bodily strength, hairiness, \&c., as well as in mind, in the same manner as do the

- Dr. W. Lauder Lindsay, 'Edinburgh Vet. Review,' July 1858 , p. 13.

B With respect to insects see Dr. Laycock, "On a General Law of Vital Periodicity," 'British Association, 1812. Dr. Macculloch, 'Sillimau's North Americ an Journal of Science,' rol. $x$ rii. p. 305 , has seen a dog sufferiug from tertian ague. Hereafter I shall return to this subject.

10 I have given the evidence on this head in my "Variation of Animals and Plants under Domestication,' vol. ii. p. 15, and nore could be added.

"1. "Mares a diversis generibus "Quadrumanorum sine dubio di"gnoscunt feminas humanas a ma" ribus. Primum, credo, odoratu, "postea aspectu. Mi. Youatt, qui " diu in Hortis Zonlogicis (Besti" ariis) medicus animalium erat, " vir in rebus observiuds cautus et "sagax, hoc mihi certissime pro" havit, et curatores ejusdem loci et "alii e ministris confirmarerunt. "Sir Andrew Smith et Brehm no"tabaut idem in Cynocephalo. I1"lustrissimus Cuvier etiam narrat " multa de hâc re, quâ ut opinor. " nihil turpius potest indicari inter "omnia hominibus et Quadrumanis "communia. Narrat enim Cyno" cephalum quendam in furoren in" cidere aspectu feminarum ali"quarum, sed nequaquam accend: "tanto furore ab omnibus. Sem" ler eligebat juniores, et dignos"cebat in turbâ, et advocabat roce "gestûque."

12 This remark is made with re. spect to Cynocephalus and the anturopomorphous apes by Geoffroy Saint-Hilaire and $\mathrm{l}$. Cuvier, "His:. Nat. des Mammiferes,' tom. i. 1824. 13 Huxley, 'Man's Place in 1 ia. tuxe,' 18 t.:., $3+$. 
two sexes of many mammals. So that the correspondence in general structure, in the minute structure of the tissues, in chemical compasition and in constitution, between man and the higher animals, especially the anthropomorphous apes, is extremely close.

Embryonic Development.-Man is developed from an ovule, about the 125th of an inch in diameter, which differs in no respect from the ovules of other animals. The embryo itself at a very carly period can hardly be distinguished from that of other mernbers of the vertebrate kingdom. At this period the arteries run in arch-like branches, as if to carry the blood to branchia which are not present in the higher vertebrata, though the slits on the sides of the neck still remain ( $f, g$, fig. 1 ), marking their former position. At a somewhat later period, when the extremities are developed, "the feet of lizards and "mammials," as the illustrious Von Bacr remarks, "the wings " and feet of birds, no less than the hands and feet of man, all "arise from the same fundamental form." It is, says Prof. Huxley," "quite in the later stages of derelopment that the young human being presents marked differences from the young "ape, while the latter departs as much from the dog in its "developments, as the man does. Startling as this last assertion "may appear to be, it is demonstrably true."

As some of my readers may never have seen a drawing of an ombryo, I have given one of man and another of a dog, at about the same early stage of development, carefully copied from two works of undoubted accuracy. ${ }^{15}$

After the foregoing statements made by such high authorities, it would be superfluous on my part to give a number of borrowed details, shewing that the embryo of man closely resembles that of other mammals. It may, however, be added, that the human embryo likewise resembles ccrtain low forms when adult in various points of structure. For instance, the heart at first exists as a simple pulsating vessel; the cxcreta: are voided through a cloacal passage; and the os coccyx projects

14 'Man's Place in Nature,' 1863, p. 67.

15 The human embryo (upper fig.) is from Ecker, 'Icones Phys.,' 1851-1859, tab. xxx. fig. 2. This embryo was ten lines in length, so that the drawiug is much magnified. The embryo of the dog is from lischoff, "Entwicklungsgeschichte des Hunde-Eies,' 1845, tab. xi. fig. 12 B This drawing is fire times magnified, the embryo being twentyfive days old. 'The internal viscero have been omitted, and the utcrine appendages in both drawings removed. I was directed to these figures by Prof. Huxley, from whose work, 'Man's Place in Nature,' the idea of giving then was taken. Häckel has also given analogous drawings in his 'Schöpfungsgeschichte.' 

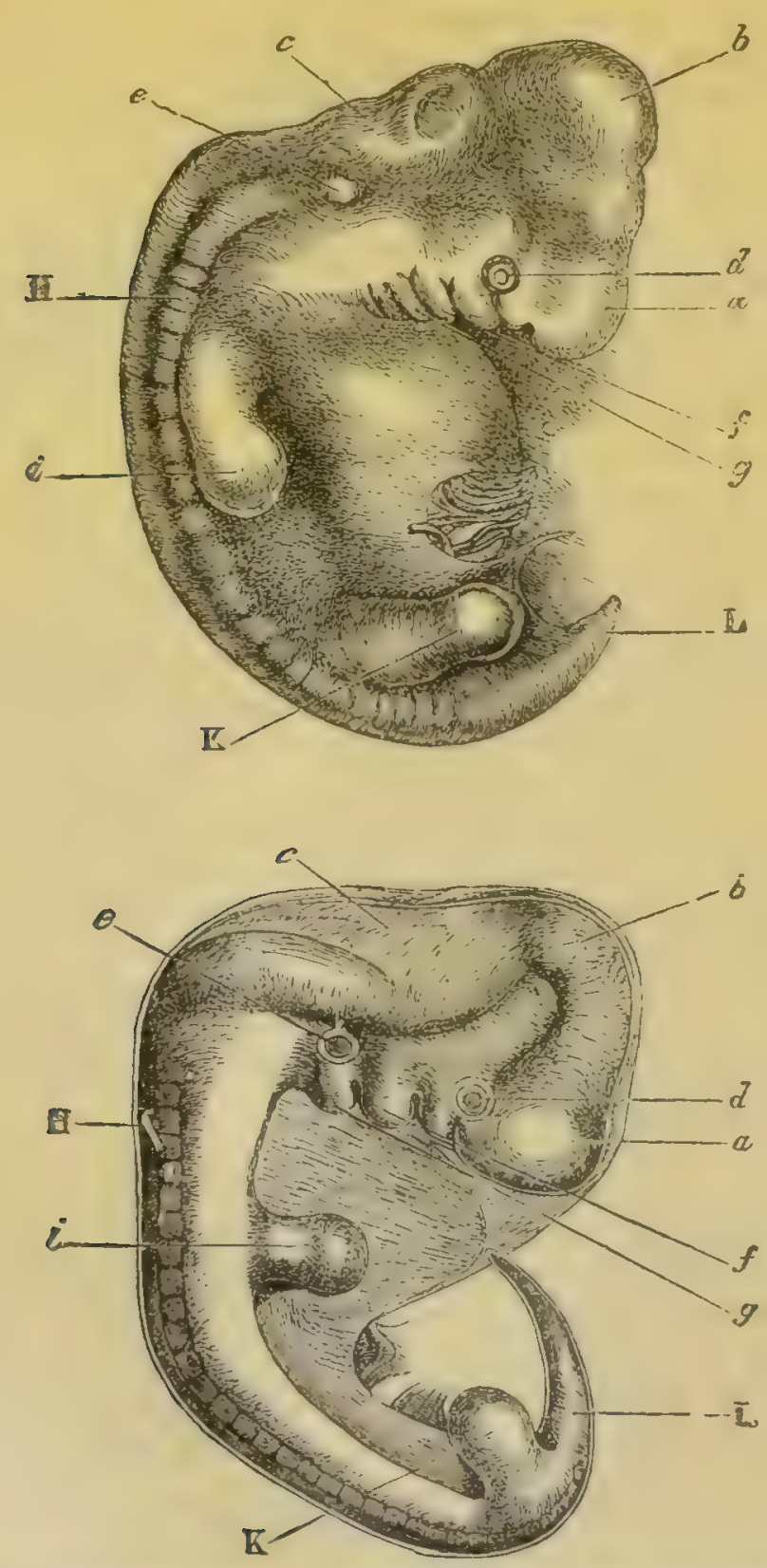

Fig. 1. Upper figure human embryo, from Feker. Lower figure that of a dog, from Bischuff.

a. Pore-brain, cerebral hemispheres, \&c. b. Mid-brain, corpora quadrigemina.

c. Hind-brain, cerebellum, medulla oblongata

d. Eye.

e Fir.

f. First visceral arch. a. Second visceral a.cih.

H. Vertebral colimmic and muscles in process of development.

i. Anterior $\}$ extremities.

L. Tail or os coces'x. 
like a true tail, "cxtending considerably beyond tho rudi"mentary legs." In the embryos of all air-breathing vertebrates, certain glands, called the corpora Wolfiana, correspond with, ind act like the kidneys of mature fishes. ${ }^{17}$ Even at a later embryonic period, some striking resemblances between man and the luwer animals may be observed. Bischoff says that the convolutions of the brain in a human foetus at the end of the seventh month reach about the same stage of development as in a baboon when adult. ${ }^{18}$ The great toe, as Prof. Owen remarks, ${ }^{19}$ "which forms the fulerum when standing or walking, is "perhaps the most characteristic peculiarity in the human structure;" but in an embryo, about an inch in length, Prof. Wyman" found "that the great toe was shorter than the others; " and, instead of being parallel to them, projected at an angle "from the side of the foot, thus corresponding with the per" manent condition of this part in the quadrúmana." I will conclude with a quotation from Huxley, ${ }^{21}$ who after asking, does man originate in a different way from a dog, bird, frog or fish? says, "the reply is not doubtful for a moment; without "question, the mode of origin, and the early stages of the "development of man, are identical with those of the animals " immediately below him in the scale: without a doubt in " these respects, he is far nearer to apes than the apes are to "the dog."

liudiments. - This subject, though not intrinsically more important than the two last, will for several reasons be treated here more fully.22 Not one of the higher animals can be named which does not bear some part in a rudimentary condition; and man forms no oxception to the rule. Rudimentary organs must be distinguished from those that are nascent; though in some cases the distinction is not easy. The former are either absoIutely useless, such as the mammæ of male quadrupeds, or the incisor teeth of ruminants which never cut through the gums; or they are of such slight service to their present possessors, that we can hardly suppose that they were developed under the

16 Prof. Wyman in 'Proc. of American Acad. of Sciences,' vol. iv. 1860, p. 17.

ii Uweu, 'Anatomy of Vertebrates,' vol. i. p. 533.

18 'Die Grosshirnwindungen des Menschen,' 1868, s. 95.

19 'Anatomy of Vertebrates,' vol. i. p. 553.

20 'Proc. Soc. Nat. Hist.' Boston, 1863, vol. ix. p. 185.

¿1 'Man's Place in Nature,' p. 65.
22 I had written a rough copy of this chapter before reading a valuable paper, "Caratteri rudimentali in ordine all' origine del nomo" ('Annuario della Soc. d. Nato,' Modena, 1867, p. 81), by G. Canestrini, to which paper I am considerably indebted. Häckel has given admirable discussions on this whole subject, under the title of Dysteleology, in his 'Gnnerelle: Morphologie' and ' Schöpfungugeschichta.' 
conditions which now exist. Organs in this latter state are not strictly rudimentary, but they are tending in this direction. Nascent organs, on the other hand, though not fully developed, are of high service to their possessors, and are capable of furthe: developıent. Rudimentary organs are eminently variable; and this is partly intelligible, as they are useless, or nearly uscless, and consequently are no longer subjected to natural selection. They often become wholly suppressed. When this occurs, they are nevertheless liable to occasional reappearance through reversion-a circumstance well worthy of attention.

Tho chief agents in causing organs to become rudimentary seem to have been disuse at that period of life when the organ is chiefly used (and this is generally during maturity), and also inheritance at a corresponding period of life. The term "disuse" does not relate merely to the lessened action of muscles, but includes a diminished flow of blood to a part or organ, from being subjected to fewcr alternations of pressure, or from becoming in any way less habitually active. Rudiments, however, may occur in one sex of those parts which are normally prescut in the other sex; and such rudiments, as we shall hercafter see, have often originated in a way distinct from those here referred to. In some cases, organs have been reduced by means of natural selection, from having become injurious to the species under changed habits of life. The process of reduction s probably often aided through the two principles of compensation and economy of growth; but the later stages of reduction, after disuse has done all that can fairly be attributed to it, and when the saving to be effected by the economy of growtin would be very small, ${ }^{23}$ are difficult to understand. The final and complete suppression of a part, already useless and much reduced in size, in which case neither compensation nor economy can come into play, is perhaps intelligible by the aid of the hypothesis of pangenesis. But as the whole subject of rudimentary organs has been discussed and illustrated in my former works, ${ }^{24}$ I necel here say no more on this head.

Rudiments of various muscles have been observed in many parts of the human body; ${ }^{25}$ and not a few muscles, which are

23 Some gond criticisms on this subject have been given by Messrs. Murie and Mivart, in "Transact. Zoolog. Soc.' 1869, vol. vii. p. 92.

24 "Variation of hnimals and Plants under Domestication,' vol. ii. pp. 317 and 397 See also 'Origin of Speries,' 5th edit. p. 535.

23 For instance II. I?icnard ( $\Delta n$ uales des Sciences Vian. ird crorer,
Zoolog. 18:i2, tom. xviii. p. 1j) (iescribes and figures rudiments of what he calls the "muscle pédieux de la main," which he says is sometimes "infiniment petit." Another muscle, called "le tibial postérieur," is senerally quite absent in tlie hand, but appears from time to tiat: in a more or less rulimentary cou. dition. 
regularly present in some of the lower animals can occasionally be detected in man in a greatly reduced condition. Every one unust have noticed the power which many animals, especially horses, possess of moving or twitching their skin; and this is effected by the punviculus carnosus. Remnants of this muscle in an efficient state are found in various parts of our bodies; for instance, the muscle on the forehead, by which the eyebrows are raised. The platysma myoiles, which is well dereloped on the neck, belongs to this system. Prof. Turner, of Edinburgh, has occasionally detected, as he informs me, muscular fasciculi in five different situations, namely in the axillæ, near the scapulæ, \&c., all of which must be referred to the system of the panniculus. He has also shewn ${ }^{26}$ that the musculus sternalis or sternalis brutvirum, which is not an extension of the rectus abdominalis, but is closely allied to the panniculus, occurred in the proportion of about three per cent. in upwards of 600 bodies: he adds, that this muscle affords "an excellent illustration of the statement "that occasional and rudimentary structures are especially "liable to variation in arrangement."

Some few persons have the porrer of contracting the superficial muscles on their scalps; and these muscles are in a variable and partially rudimentary condition. M. A. de Candolle has communicated to me a curious instance of the long-continued persistence or inheritance of this power, as well as of its unusual development. He knows a family, in which one member, the present head of the family, could, when a youth, pitch several heavy books from his head by the movement of the scalp alone; and he won wagers by performing this feat. His father, uncle, grandfather, and his three children possess the same power to the same unusual degree. This family became divided eight generations ago into two branches; so that the head of tine above-mentioned branch is cousin in the sevonth degree to the head of the other branch. This distant cousin resides in another part of France; and on being asked whether ho possessed the same faculty, immediately exhibited his power. This casc offers a good illustration how persistent may be the transmission of an absolutely useless faculty, probably derived from our remote scmihuman progenitors; since many monkeys have, and frequently use the power, of largely moving their scalps up and down ${ }^{27}$

The extrinsic muscles which serve to move the external ear, and the intrinsic muscles which move the different parts, are in a rudimentary condition in man, and they all belong to the system

26 Prof. W. Turner, 'Proc. Royal Soc. Edinburgh,' 1866-67, F. 55 .

29 Spe my' Espression f the
Emotions in Man and Assmals; 1872, p. 144. 
of the panniculus; they are also variable in development, or at least in function. I have seen one man who could draw the whole ear forwards; other men can draw it upwards; another who could draw it backwards $;^{28}$ and from what one of these persons told me, it is probable that most of us, by often iouching our ears, and thus directing our attention towards them, could recover some power of movement by repeated trials. The power of erecting and directing the shell of the ears to the various points of the compass, is no doubt of the highest service to many animals, as they thus perceive the direction of danger; but I have never heard, on sufficient evidence, of a man who possessed this power, the one which might be of use to him. The whole external shell may be considered a rudiment, together with the various folds and prominences (helix and arti-helix, tragus and anti-tragus, \&c.) which in the lower animals strengthen and support the ear when erect, without adding much to its weight. Some authors, however, suppose that the cartilage of the shell serves to transmit vibrations to the acoustic nerve; but $\mathrm{Mr}$. Toynbee, ${ }^{29}$ after collecting all the known evidence on this head, concludes that the external shell is of no distinct use. The ears of the chimpanzee and orang are curiously like those of man, and the proper muscles are likewise but very slightly developed. ${ }^{20}$ I am also assured by the keeper's in the Zoological Gardens that these animals never move or erect their ears; so that they are in an equally rudimentary condition with those of man, as far as function is concerned. Why these animals, as well as the progenitors of man, should have lost the power of erecting their ears, we cannot say. It may be, though I am not satisfied with this view, that owing to their arboreal habits and greut strength they were but little exposed to danger, and so during a lengthened period moved their ears but little, and thus gradually lost the power of moving them. This would be a parallel case with that of those large and heavy birds, which, from inhabiting oceanic islands, have not been exposed to the attacks of beasts of prey, and bave consequently lost the power of using their wings for flight. The inability to move the ears in man and several apes is, however, partly compensated by the freedom with which they can move the liead in

28 Canestrini quotes Hyrtl. ("Annmario della Soc. dei Naturalisti, Modena, 1867, p. 97) to the same effect.

29 'The Diseases of the Ear,' by J. Toynbee, F.R.S., 1860, p. 12. A distinguished physiologist, Prof. Preyer, informs me that he had lately been experimenting on the function of the shell of the ear, and has come to nearly the same conclusion as that given here.

30 Prof. A. Macalister, 'Annals and Mag. of Nat. History, rol rii., 1871 , p. 342 . 
a horizontal plane, so as to catch sounds from all directions. It has been asserted that the ear of man alone possesses a lobule; but " a rudiment of it is found in the gorilla;"31 and, as I hear from Prof. Preyer, it is not rarely absent in the negro.

The celebrated sculptor, Mrr. Woolner, informs me of one little peculiarity in the external ear, which he has often observed both in men and women, and of which he perceived the full significance. His attention was first called to the subject whilst at work on his figure of Puck, to which he had given pointed ears. He was thus led to examine the ears of various monkeys, and subsequently more carefully those of man. The peculiarity consists in a little blunt point, projecting from the inwardly folded margin, or helix. When present, it is dereloped at birth, and, according to Prof. Ludwig Meyer, more frequently in man than in woman. Mr. Woolner made an exact model of one such case, and sent me the accompanying drawing. (Fig. 2., These points not only project inwards towards the centre of the ear, but often a little outwards from its plane, so as to be visible when the head is viewed from directly in front or behind. They are variable in size, and somewhat in position, standing either a little higher or lower; and they sometimes occur on one ear and not on the other. They are not confined to mankind, for $I$ observed a case in one of the spidermonkeys (Ateles beelzebuth) in our Zoological Gardens; and Dr. E. Ray Iankester informs me of another case in a chimpanzee in the gardens at Hamburg. The helix obviously con-

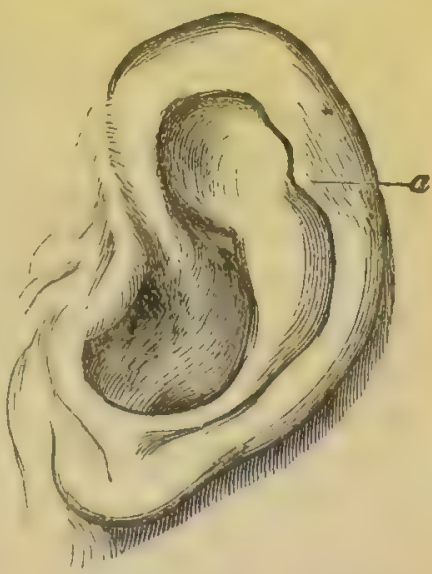

Fig 2. Human Ear, modelled and drawn by Mr. Woolner. a. The projecting point. sists of the extreme margin of the ear foldcd inwards: and this folding appears to be in some manner connected with the whole external ear hoing permanently pressed backwards. In many monkeys, which do not stand high in the order, as baboons and some species of macacus, ${ }^{32}$ the upper portion of the ear is slightly pointed, and the margin is not at all folded inwards; but if the margin were to be thus folded, a slight point would necossarily project inwards towards the centre, and probably as little outwards from the plane of the ear; and this I belicve to

31 Mr. St. George Mivart, 'Elementary Anatomy,' 1873, p. 396.

32 See also some remarks, and the drawings of the ears of the
Lemuroidea, in Messrs. Murie and Mivart's excellent paper in 'Transact. Zoolog. Soc.' vol. vii. 1869, pp 6 and 90. 
be their origin in many cases. On the other hand, Prof. L. Meyer, in an able paper recently published, ${ }^{33}$ maintains that the whole? case is one of mere variability ; and that the projections are not real ones, but are due to the internal cartilage on cach side of the points not having been fully developed. I am quite ready to admit that this is the correct explanation in many instances, as in those figured by Prof. Meyer, in which there are several minute points, or the whole margin is sinuous. I have myself seen, through the kindness of Dr. L. Down, the ear of a micr'cephalous idiot, on which there is a projection on the outside of the helix, and not on the inward folded edge, so that this point can have no relation to a former apex of the ear. Nevertheless in some cases, my original view, that the points are vestiges of the tips of formerly erect and pointed ears, still seems to me probable. I think so from the frequency of their occurrence, and from the general correspondence ir position with that of the tip of a pointed ear. In onc case, of which a photograph has been sent me, the projection is so large, that supposing, in accordance with Prof. Mleyer's view, the ear to be made perfect by the equal development of the cartilage throughout the whole extent of the margin, it rould have covered fully one-third of the whole ear. Two cases have been communicated to me, one in North America, and the other in England, in which the upper margin is not at all folded inwards, but is pointed, so that it closely resembles the pointed ear of an ordinary quadruped in outline. In one of these cases, which was that of a young child, the father compared the ear with tho drawing which I have given ${ }^{3 !}$ of the ear of a monkey, the C'ynopithecus niger, and says that their outlines are closely similar. If, in these two cases, the margin had been folded inwards in the normal manner, an inward projection must have been formed. I may add that in two other cases the outline still remains somewhat pointed, although the margin of the upper part of the ear is normally folded inwards-in one of them, however, very narrowly. The following woodcut (No. 3) is an accurate copy of a photograph of the foetus of an orang (kindly sent me by Dr. Nitsche), in which it may be seen how different the pointed ontline of the ear is at this period from its adult condition, when it bears a close general resemblance to that of man. It is evident that the folding over of the tip of such an ear, unless it changed greatly during its further development, would give riso to a point projecting inwards. On the whole, it still seems to

s3 Ueber das Darwin'sche Spitzohr, Archir fur Path. Anat. und Phys. 1871, p. 485.
${ }^{34}$ 'The Expression of the Ema tions, p. 136. 
me probable that the points in question are in some cases, bcth in man and apes, vestiges of a former condition.

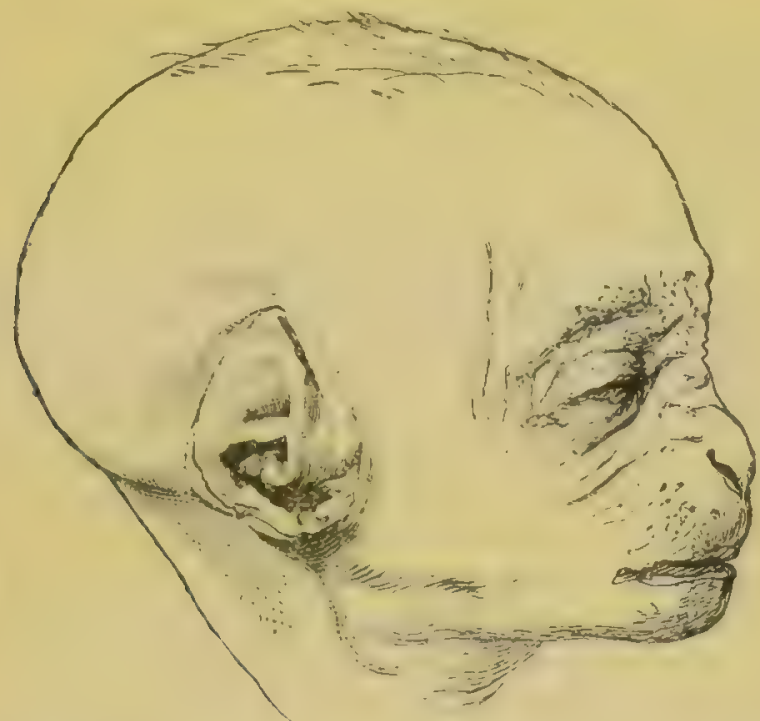

E.c. 3. Foctus of an Oranæ. Fxact cemp of a photegrapin, shewing the furm of the ear at this carly age.

The nictitating membrane, or third eyelid, with its nccesscry muscles and other structures, is especially wel' dereloped in birds, and is of much functional importance to them, as it can be rapidly drawn across the whole eye-bal!. It is found in some reptiles and amphibians, and in certain fishes, as in sharks. It is fairly well developed in the two lower divisions of the mammalian series, namely, in the monotremata and marsupials, and in some few of the higher mammals, as in the walrus. But in man, the quadrumana, and most other mammals, it exists, as is admitted by all anatomists, as a mere rudiment, called the semilunar fold. ${ }^{35}$

The sense of smell is of the highest importance to the greater number of mammals - to some, as the ruminants, in warning them of danger; to others, as the carnivora, in finding their prey; to others, again, as the wild boar, for both purposes combined. But the sense of smell is of extremely slight service, if any, even to the dark coloured races of men, in whom it is

35 Miiller's 'Elements of Physiology,' Eng. translat., 1842, vol. ii. p. 1117. Owen, 'Anatomy of Vertebrates,' vol. iii. p. 260 ; ibid. on the Wallus, 'Proe. Zoolog. Soc.' November 8th, 1854. See also R.
Knox, 'Great Artists and Anatomists,' p. 106. 'This rudiment ap. parently is somewhat larger in Negroes and Australians than in Europeans, see Carl Vogt, 'Lectures on Man,' Eng. translat. p. 129. 
much more highly developed than in the white and civilised races. ${ }^{36}$ Nevertheless it does not warn them of danger, nor guida them to their food; nor does it prerent the Esquimaux from sleeping in the most fetid atmosphere, nor many savages from eating half-putrid meat. In Europeans the power differs greatly in different individuals, as I am assured by an eminent naturalist who possesses this sense highly developed, and who has attended to the subject. Those who believe in the principle of gradual evolution, will not readily admit that the sense of smell in its present state was originally acquired by man, as he now exists. He inherits the power in an enfeebled and so far rudimentary condition, from some carly progenitor, to whom it was highly serviceable, and by whom it was continually used. In those animals which have this sense highly developed, such as dogs and horses, the recollection of persons and of places is strongly associated with their odour; and we can thus perhaps understand how it is, as Dr. Maudsley has truly remarked, ${ }^{37}$ that the sense of smell in man " is singularly effective " in recalling vividly the ideas and images of forgotten scenes "and places."

Man differs conspicuously from all the other Primates in being almost naked. But a few short straggling hairs are found over the greater part of the body in the man, and fine down on that of the woman. The different races differ much in hairiness; and in the individuals of the same race the hairs are highly variable, not only in abundance, but likewise in position: thus in some Europeans the shoulders are quite naked, whilst in others they bear thick tufts of hair. ${ }^{38}$ There can be little doubt that the hairs thus scattered over the body are the rudiments of the uniform hairy coat of the lower animals. This view is rendered all the more probable, as it is known that fine, short, and palccoloured hairs on the limbs and other parts of the body, occasion-

36 The account given by Humboldt of the power of smell possessed by the natives of South America is well known, and has been confirmed by others. M. Houzeau ('Etudes sur les Facultés Mentales," \&c., tom. i. 1872 , p. 91) asserts that he repeatedly made experiments, and proved that Negroes and Indians could recognise persons in the dark by their odour. Dr. W. Ogle has made some curious observations on the connection between the power of smell and ths colouring matter of the mucous membrane of the olfactory region, as well as of the skin of the body. I have, therefore, spoken in the text of the darkcoloured races having a finer sense of smell than the white races. See his paper, "Medico-Chirurgical Transactions,' London, vol. liii., 1870 , p. 276.

${ }^{37}$ 'The Physiology and Pathology of Mind,' 2nd edit. 1868, p. 134.

38 Eschricht, Ueber die Richtung der Haare an menschlichen Körper, 'Muiller's Archiv futr Anat. und Phys.' $1837,8.47$. I shall often have to efer to this very curious paper. 
ally become developed into "thichset, long, and rather coarse "dark hairs," when abnormally nourished near oill-standing intlamed surfaces. ${ }^{39}$

I am informed by Sir James Paget that often sercral members of a family have a few hairs in their cyebrows much longer than the others; so that even this slight peculiarity scems to be inherited. These hairs, too, seem to have their representatives; for in the chimpanzee, and in certain species of Macacus, there are scattered hairs of considerable length rising from the naked skin above the eyes, and corresponding to our eyebrows; similar long hairs project from the hairy covering of the superciliary ridges in some baboons.

'The fine wool-like hair, or so-called lanugo, with which the human fotus during the sixth month is thickly covered, offers a more curious case. It is first developed, during the fifth month, on the cyebrows and face, and especially round the mouth, where it is much longer than that on the head. A moustache of this kind was observed by Eschricht ${ }^{40}$ on a female fœetus; but this is not so surprising a circumstance as it may at first appear, for the two sexes generally resemble each other in all external characters during an early period of growth. The direction and arrangement of the hairs on all parts of the foetal body are the same as in the adult, but are subject to much variability. The whole surface, including even the forehead and ears, is thus thickly clothed; but it is a significant fact that the palms of the hands and the soles of the feet are quite naked, like the inferior surfaces of all four extremities in most of the lower animals. As this can hardly be an accidental coincidence, the woolly covering of the foetus probably represents the first permanent coat of hair in those mammals which are born hairy. Three or four cases have been recorded of persons born with their whole bodies and faces thickly covered with fine long hairs; and this strange sondition is strongly inherited, and is correlated with an abnormal condition of the teeth. ${ }^{41}$ Prof. Alex. Brandt informs me that he has compared the hair from the face of a man thus characrerised, aged thirty-five, with the lanugo of a fœtus, and finds it quite similar in texture; therefore, as he remarks, the case may ne attributed to an arrest of derelopment in the hair, together with its continued growth. Many delicate children, as I have

39 Paget, 'Lectures on Surgical Pathology,' 1853, vol. i. \%. 71.

40 Eschricht, ibid. s. $40,47$.

41 See my "Vartation of Animals and Plants zades Domestication,' vc!. ii. 9. 327. Prof. Alex. branai has recently sent me an additional case of a father and son, born in Russia, with these peculiarities. I have receired drawings of both from Paris. 
heen assured ly a surereon to a hospital for children, have their backs covered by rather long silky hairs; and such cases probably come under the same head.

It appears as if the posterior molar or wisdom-teeth were tending to become rudimentary in the more civilised races of man. These teeth are rather smaller than the other molars, as is likewise the case with the corresponding teeth in the chimpanzee and orang; and they have only two scparate fangs. They do not cut through the gums till about the seventeenth year, and I have been assured that they sire much more liahle to decay, and are carlier lost than the other teeth; but this is denied by some eminent dentists. They are also much more liable to vary, both in structure and in the period of their derelopment, than the other teeth." In the Melanian races, on the other hand, the wisdom-tecth are usually furnished with three separate fangs, and are generally sound; they also differ from the other molars in size, less than in the Caucasian races. ${ }^{43}$ Prof. Schaaffhatisen accounts for this difference between the races by "the posterior dental portion of the jaw being always "shortened" in those that are civilised," and this shortening may, I presume, be attributed to civilised men habitually feeding on soft, cooked food, and thus using their jaws less. I am informed by Mr. Brace that it is hecoming quite a common practice in the United States to remove some of the molar teeth of children, as the jaw does not giow large enough for the perfect development of the normal number. ${ }^{45}$

With respect to the alimentary canal, I have met with an account of only a single rudiment, namely the vermiform appendage of the cæum. The crecum is a branch or diverticulum of the intestine, ending in a cul-de-sac, and is extremely long in many of tho lower vegetable-feeding mammals. In the marsupial koala it is actually more than thrice as long as the whole body. ${ }^{46}$ It is sometimes produced into a long gradually-tapering point and is sometimes constricted in parts. It appears as if, in consequence of changed dict or habits, the crecum had become much

42 Dr. Webb, "Teeth in Man and the Anthropoid Apes,' as quoted by Dr. C. Carter Blake in 'Anthropological Review,' July 1867, p. 299.

43 Owen, 'Anatomy of Vertebrates, vol. iii. pp. 320, 321, and 325.

44 'On the Primitive Forin of the Skull,' Fng. translat. in 'Anthropological Review,' Oct. 1868, p. 426.

"Prof. Montegazza writes to ine from Florence, that he has lately been studying the last molar teeth in the different races of man, and has come to the same conclusion as that given in my text, viz., that in the higher or civilised races they are on the road towards atrophy or elimiuation.

4 Owen, 'Anatomy of Verte brates' vo's. i. pr. $+16,4 i 4,441$. 
s: hortened in rarious animals, the vermiform appendage being left as a rudiment of the shortened part. That this appendage is a rudiment, we may infer from its small size, and from the evidence which Prof. Canestrini ${ }^{47}$ has collected of its variability in man. It is occasionally quite absent, or again is largely developed. The passage is sometimes completely closed for h\&lf or two-thirds of its length, with the terminal part consisting of a flattened solid expansion. In the orang this appendage is long and convoluted: in man it arises from the end of the short cæcum, and is commonly from four to five inches in length, being only about the thircl of an inch in diameter. Not only is it useless, but it is sometimes the cause of death, of which fact I lave lately heard two instances: this is due to small hard bodies, such as seeds, entering the passage, and causing inflammatiou. ${ }^{48}$

In some of the lower Quadrumana, in the Lemuridæ and Carnivora, as well as in many marsupials, there is a passage near the lower end of the humerus, called the supra-condyloid foramen, through which the great nerve of the fore limb and often the great artery pass. Now in the humerus of man, there is generally a trace of this passage, which is sometimes fairly well developed, leing formed by a depending hook-like process of bone, completed by a band of ligament. Dr. Struthers, ${ }^{49}$ who has elosely attended to the subject, has now shewn that this neculiarity is sometimes inherited, as it has occurred in a father, and in no less than four out of his seren children. When present, the great nerve invariably passes through it; and this clearly inilicates that it is the homologue and rudiment of the supra-condyloid foramen of the lower animals. Prof. 'l'urner estimates, as he informs me, that it occurs in about one per cent. of recent skeletons. But if the occasional development of this structure in man is, as seems probable, due to reversion, it is a return to a very ancient state of things, because in the higher Quadrumana it is absent.

There is another loramen or perforation in the hunerus,

47 'Annurio della Soc. d. Nat.' Modepa, 1867, p. 94.

4 M. C. Martins ("De l'Unité Organique," in "Revue des Deux Mondes,' June 15, 1862, p. 16), and räckel ('Generelle Morphologie," B. ii. s. 278), have both remarked on the singular fact of this rudiment sometimes causing death.

ab With respect 10 inheritance, oee 11. Struthers in the 'Larret,
Feb. 15, 1873, and another important paper, ibid., Jan. 24, 1863, p. 83. Dr. Knox, as I am informed, was the first anatomist who drew attention to this peculiar structure in man; see his 'Great Artists und Anatomists,' p. 63. See also an important memoir on this process by Dr. Gruber, in the "Bulletin de l'Acal. Imp. de St. Pétersbourg, tom. xij. 18iti, p. 448. 
occusionally present in man, which may be called the intercondyloid. This occurs, but not constantly, in various anthropoid and other apes, ${ }^{50}$ and likewise in many of the lower animals. It is remarkable that this perforation seems to have been preseut in man much more frequently during ancient times than recently. Mr. Busk ${ }^{51}$ has collected the following evidence on this head: Prof. Broca "noticed the pcrforation in four and a "half per cent. of the arm-bones collected in the "Cimetiere du "Sud," at Paris; and in the Grotto of Orrony, the contents of "which are referred to the Bronze period, as mauy as eight "humeri out of thirty-two were perforated; but this cxtraordi"nary proportion, he thinks, might be due to the cavern having " "been a sort of 'family vault.' Again, M. Dupont found thirty' "per cent. of perforated bones in the cares of the Valley of the "Lesse, belonging to the Reindeer period; whilst M. Legruay, in " a sort of dolmen at Argenteuil, observed twenty-fire per cent. "to be perforated; and M. Prumer-Bey found twenty-six per" "cent. in the same condition in bones from Vauréal. Nor slıoul. "it be left unnoticed that M. Pruner-Bey states that this con"dition is common in Guanche skeletons." It is an interesting fact that ancient races, in this and several other cases, more frequently present structures which resemble those of the lom animals than do the modern. One chief cause seems to be that the ancient races stand somewhat nearer in the long line of descent to their remote animal-like progenitors.

In man, the os coccyx, together with certain other vertehræ hereafter to be described, though functionless as a tail, plainly represent this part in other vertebrate animals. At an early embryonic period it is free, and projects beyond the lower extremities; as may be secn in the drawing (Fig. 1.) of a human embryo. Even after birth it has been known, in certain rares and anomalous cases, ${ }^{52}$ to form a small external rudiment of is tail. The os coccyx is short, usually including only fort vertebre, all anchylosed together": and these are in a rudi-

so Mr. St. Genrge Mivart, "Transact. Phil. Soc.' 1867 , p. 310.

31 "On the Cares of Gibraltar,"

'Transact. Internat. Congress of Prehist. Arch.' Third Session, 1869, p. 159. Prof. Wyman has lately shewn (Fourth Annual Report, Peabody Iuseum, 1871, p. 20), that this perforation is present in thirty-one per cent. of some human remains from ancient monnd: in the Westeru United States, and in Filorida. It frcquently orcur's in the negro.
52 Quatrefages has lately collected the evidence on this subject. "Revuc des Cours Scientifiques,' 1867-1868. p. 625. In 1840 Fleischmann exhibited a human foctus bearing a free tail, which, as is not always the case, included vertebral bodies; an ? this tail was critically examined $\mathfrak{k}$. the many anatomists present at the meeting of naturalists at Erlangen (sce Marshali in Niederliandischeu Ardurtur \%oo!ogie, Iectmln:1871) 
mentary condition, for they consist, with the exception of the basal one, of the centrum alone. ${ }^{53}$ They are furnished with some small muscles; one of which, as I am informed by Prof. Turner, has been expressly described by 'Theile as a rudimentary repetition of the extensor of the tail, a muscle which is so largely developed in many mammals.

The spinal cord in man extends only as far downwards as the last dorsal or first lumbar vertebra; but a thread-like structure (the filum terminule) runs down the axis of the sacral part of the spinal canal, and even along the back of the coccygeal bones. The upper part of this filament, as Prof. Turner informs me, is undoubtedly homologous with the spinal cord. but the lower part apparently consists merely of the pia mater, or vascular investing membrane. Even in this case the os coccyx may be said to possess a vestige of so important a structure as the spinal cord, though no longer enclosed within a bony canal. The following fact, for which $I$ am also indebted to Prof. Turner, shews how closely the os coccyx corresponds with the true tail in the lower animals: Luschka has recently discovered at the extremity of the coccygeal bones a very peculiar convoluted body, which is continuous with the middle sacral artery; and this discovery led Krause and Meyer to examine the tail of a monkey (Macacus), and of a cat, in both of which they found a similarly convoluted body, thcugh not at the extremity.

The reproductive system offers various rudimentary structures; but these differ in one important respoet from the foregoing cases. Here we are not concerned with the vestige of a part which does not belong to the species in an efficient state, but with a part efficient in the one sex, and represented in the other by a mere rudiment. Nevertheless, the occurrence of such rudiments is as difficult to explain, on the belief of the separate creation of each species, as in the foregoing cases. Hereafter I shall have to recur to these rudiments, and shall shew that their presence generally depends merely on inheritance, that is, on parts acquired by one sex having been partially transmitted to the other. I will in this place only give some instances of such rudiments. It is well known that in the males of all mammals, including man, rudimentary mammæ exist. These in several instances have become rell developed, and have yielded a copious supply of milk. Their essential identity in the two seres is likewise shewn by their occasional sympathetic culurgement in both during an attack of the

s8 Exed, 'On the Nature of Lim 's,' 1349, p. 114. 
measles. The vesicula prostatica, which has been obscrved in many male mammals, is now universally acknowledged to be the homologue of the female uterus, together with the connected passage. It is impossible to read Lenckart's ahle description of this organ, and his reasoning, without admitting the justness of his conclusion. This is especially clear in the case of those mammals in which the true female uterus bifurcates, for in the males of these the resicula likewise bifurcates. ${ }^{3 t}$ Some other rudimentary structures belonging to the reproductive system might have been here adduced.55

The bearing of the three great classes of facts now given is unmistakeable. But it would be superfluous fully to recapitulate the line of argument given in detail in my ' Origin of Species.' The homological construction of the whole frame in the members of the same class is intelligible, if we admit their descent from a common pragenitor, together with their subsequent adaptation to liversified conditions. On any other view, the similarity of pattern between the hand of a man or monkey, the foot , is horse, the flipper of a scal, the wing of a bat, \&c., is utterly inexplicable..$^{56}$ It is no scientific explanation to assert that they have all been formed on the same ideal plan. With respect to development, we can cleariy understand, on the principle of

5s Leuckart, in T.ıdd's 'Cyclop. of Anat.' 1849-52, vol. iv. p. 1415. In man this organ is only from three to six lines in length, but, like so many sther rudimentary parts, it is variable in development as well as in other characters.

ss See, on this subject, Owen, 'Anatomy of Vertebrates,' vol. iii. pp. $675,676,706$.

58 Prof. Bianconi, in a recently published work, illustrated by admirable engravings (" $\mathrm{La}$ Theorie Darwinienne et la création dite indépendante, 1874), endeavours to show that homological structures, in the above and other cases, can be fully explained on mechanical princip'es, in accordance with their uses. No one has shewn so well, how admirably such structures are adapted for their final purpose; and this adaptation can, as I believe, be explained through natural selection. In considering the wing of a bat, he brings forward (p. 2ls) what appears $\omega$ tae (to use Aluguste Comte's words) a mere metaphysical principle, namely, the preservation "in "its integrity of the mammalian " nature of the animal." In only a few cases does he discuss rudiments, and then only those parts which are partially rudimentary, such as the little hoofs of the pig and ox, which do not touch the ground; these he shews clearly to be of service to the animal. It is unfortunate that he did not consider such cases as the minute teeth, which never cut through the jaw in the ox, or the mammæ of male quadrupeds, or the wings of certain beetles, existing under the soldered wing-covers, or the restiges of the pistil and stamens in various flowers, and many other such cases. Although I greatly admire Prof. Bianconi's work, yet the belief now held by most naturalists seems to me left unshaken, that homological structures are inexplicable un the principle of mere adiatation 
variations superrening at a rather late cmbryonic period, and being inherifed at a corresponding period, how it is that the embryos of wouderfully different forms should still retain, more a) less perfectly, the structure of their common progeritor. No other explauation has ever been given of the marvellous fact that, the cmbryos of a man, dog, seal, hat, reptile, \&c., can at first hardly be distinguished from each other. In order to understand the existence of rudimentary organs, we have only to suppose that a former progenitor possessed the parts in question in a ferfect state, and that under changed habits of life they became inreatly reduced, either from sinple disuse, or through the natural sclection of those individuals which were least encumbered with al superfluous part, aided by the other means previously indicated.

Thus we can understand how it has come to pass that man and all other vertebrate animals have been constructed on the same eneneral model, why they pass through the same early stages of clerelopment, and why they retain certain rudiments in common. Conserfuently we ought frankly to admit their community of descent; to take any other view, is to admit that our own structure, and that of all the animals around us, is a mere snare (aid to entray, our judgment. This conclusion is greatly strengthened, if we look to the members of the whole animal series, and consider the evidence derived from their affinities or classification, their geographical distribution and geologrical succession. It is only our natural prejudice, and that arrogance which made our forefathers declare that they wero descended from demi-gods, which leads us to demur to this conclusion. But the time will before long come, when it will bo thought wonderful that naturalists, who were well acquainted with the comparative structure and development of man, and other mammals, should have belierce that each was the rives if a seryarste act of creat ion. 


\section{CEAP'CER II.}

\section{ON TILE MANNER OF DEVELOPMENT OF MAN FROM 8 MIT Lowle ForM.}

Variability of body and mind in man-Inheritance-Causes of variability - Laws of variation the same in man as in the lower animals-Direct action of the conditions of life-Effects of the increased use and disuse of parts-Arrested development-Reversion-Correlated variationRate of increase-Checks to increase-Natural selection-Man the most dominant animal in the world-Importance of his corporeal structureThe causes which have led to his becoming erect-Consequent changes of structure-Decrease in size of the conine teeth-Increased size and altered shape of the skull-Nakedness-Absence of a tail-Defenceless condition of man.

IT is manifest that man is now subject to much rariability. No two individuals of the same race are quite alike. We may compare millions of faces, and each will be distinct. There is an equally great amount of diversity in the proportions and rimensions of the various parts of the body; the length of the legs leing one of the most variable points. ${ }^{1}$ Although in some quarters of the world an elongated skull, and in other quarters a short skull prevails, jet there is great diversity of shape even within the limits of the same race, as with the aborigines of Amcrica and South Australia-the latter a race "probably as "pure and homogeneous in blood, customs, and language as any "in cxistence"-and eren with the inhabitants of so confined an area as the Sandwich Islands. ${ }^{2}$ An eminent dentist assures me that there is nearly as much diversity in the teeth as in the features. The chicf arteries so frequently run in abnormal courses, that it has been found useful for surgical purposes to calculate from 1040 corpses how often each course prevails.3 The muscles are eminently variable: thus those of the foot wcre found by Prof. Turner ${ }^{4}$ not to be strictly alike in any two out of fifty bodies; and in some the deviations were considerable.

1 'Investigations in Military and Anthropolog. Statistics of American Soldiers, by B. A. Gould, 1869, p. 256.

2 With respect to the "Cranial forms of the American aborigines," nee Dr. Aitken Meigs in "Proc. Acad. Xist. Su.' Philidelphia, May, 1868. On the Australians, see
Huxley, in Iyell's 'Antiquity of Man,' 1863, p. 87. On the Sandwich Islanders, Prof. J. Wyman, 'Observations on Crania,' Boston, 1868, p. 18.

3 'Anatomy of the Arteries,' by R. Quain. Preface, vol. i. 1844.

- 'Transact. Royal Soc. Fidio krrgh,' rul. xxiv. pp. 175, 18!. 
He adds, that the power of performing the appropriate moroments must have been modifier in accordance with the several deviations. Mr. J. Wood has recorded the occurrence of 29:; muscular variations in thirty-six subjects, and in another set of the same number no less than 558 variations, those occurring on tooth sides of the body being only reckoned as one. In the last set, not one body out of the thirty-six was "found totally "wanting in departures from the standard descriptions of the " muscular system given in anatomical text books." A single body presented the extraordinary number of twenty-five distinct abnormalities. The same muscle sumetimes varies in many ways: thus Prof. Macalister describes ${ }^{6}$ no less than twenty distinct variations in the pulmaris accessorius.

Tho famous old anatomist, Wolfi, insists that the internal riscera are more variable than the external parts: Nulla particula tät qua non aliter et aliter in aliis se habeat hominibus. He has even written a treatise on the choice of typical examples of the viscora for representation. A discussion on the beau-ideal of the liver, lungs, kidueys, dec., as of the human face divine, sounds strange in our ears.

The variability or diversity of the mental faculties in men of the sume race, not to mention the greater difierences between the men of distinct races, is so notorious that not a word need here be said. So it is with the lower animals. All who have had charge of menageries admit this fact, and we see it plainly in our dogs and other domestic animals. Brehm especially insists that each individual monkey of those which he kept tame in Africa had its own peculiar disposition and temper: he mentions one baboon remarkable for its high intelligence; and the keepers in the Zoological Gardens pointed out to me a monkey, belonging to the New World division, equally remarkable for intelligence. Rengger, also, insists on the diversity in the rarious mental characters of the monkeys of the same species which he kept in Paraguay; and tlis diversity, as he adds, is partly innate, and partly the result of the manner in which they have been treated or educated. ${ }^{8}$

I have elsewhere ${ }^{9}$ so fully discussed the subject of Inheritance, that I need here add hardly anything. A greater number of

5 'Proc. Royal Soc.' 186i, p. 5 it; also 1868, pp. 483,524 . There is a previous paoer, 1866, p. 229.

' 'Proc. R. Irish Academy,' vol. х. 1868, p. 141.

'Act. Acarl. St. Petersbu:g,' 1778, fast :. f\%.213
- Brehm, 'Tuierleben,' B. 1. s. 58, 87. Renşser, 'Säungethiere rou Paraguay,' s. 57.

- 'Variation of Animals and Flants under Dornestication,' vol ii. chap. si:. 
facts have been collected with respect to the transmission of the most tritling, as well as of the most important characters in man, than in any of the lower animals; though the facts are copious enough with respect to the latter. So in regard to mental qualities, their transmission is manifest in our dogs, horses, and other domestic animals. Besides special tastes and babits, general intelligence, courage, bad and good temper, \&c., are certainly transnitted. With man we see similar facts in almost every family; and we now know, through the admirable labours of Mr. Galton, ${ }^{10}$ that genius which implies a wonderfully complex combination of high faculties, tends to be inherited; and, on the other hand, it is too certain that insanity and deteriorated mental powers likewise run in families.

With respect to the causes of variability, we are in all cases very ignorant; but we can see that in man as in the lower animals, they stand in some relation to the conditions to which each species has been exposed, during several generations. Domesticated animals vary more than those in a state of nature; and this is apparently dne to the diversified and changing nature of the conditions to which they have been subjected. In this respect the different races of man resemble domesticated animals, and so do the individuals of the same race, when inhabiting a very wide area, like that of America. We see the influence of diversified conditions in the more civilised nations; for the members belonging to different grades of rank, and following different occupations, present a greater range of character than do the members of barbarous nations. But the uniformity of savages has ofter been exaggerated, and in some cases can hardly he said to exist." It is, nevertheless, an error to speak of man, even if we look only to the conditions to which he has been exposed, as "far more domesticated"12 than any other animal. Some savage races, such as the Australians, are not exposed to more diversified conditions than are many species which have a wide range. In auother and much more important respect, man differs widely from any strictly domesticated animal; for his breeding has never long been controlled, cither by methodical or unconscious selection. No race or body of men has been so

10 'Hereditary Genius : an Inquiry into its laws and Consequences,' 1869.

"Mr. Bates remarts ("The Natualist on the A mazons,' 1863, vol. ii. p. 159), with respect to the Indians of the same Sonth American tribe, "so two of them were at all similas "Is the shuws of the head; oue "man had an oval visage with fine "features, and another" was quite "Mongolian in breadth and pro" minence of cheek, spread of mos" trils, and ouliquity of eyes."

12 Blumenbach, "Treatises on $\mathrm{An}$ thropolog.' Eng. translit., 1865, p. 205. 
completely subjugated by other men, as that certain indiriduals should be preserved, and thus unconsciously selected, from somehow excelling in utility to their masters. Nor have certain malo and female individuals been intentionally picked out and matched, except in the well-known case of the Prussian grenadiers; and in this case man obeyed, as might have been expected, the law of methodical selection; for it is asserted that many tall men were reared in the villages inhabited by the grenadiers and their tall wives. In Sparta, also, a form of selection was followed, for it was enacted that all children should be examined shortly after birth; the well-formed and vigorous being preserved, the others left to perish. ${ }^{13}$

If we cousider all the rilces of man as forming a single species, his range is enormous; but some separate races, as the Americans and Pulynesians, have very wide ranges. It is a well-known law that widely-ranging species are much more variable than species with restricted ranges; and the variability of man may with more truth be compared with that of widely-ranging species, than with that of domesticated animals.

Not only does variability appear to bo induced in man and the lower animals by the same general causes, but in both the same parts of the body are affected in a closely analogous manner. This, has been prored in such full detail by Godron and

13 Mitford's 'History of Greece, vol. i. p. "282. It appears also tiom a passage in Xenophon's 'Dlemorabilia,' B. ii. 4 (to which my attention has been called by the her. J. N. Hoare), that it was a well recognised principle with the Greeks, that mer ought to select their wives with a view to the health and vigour of their children. The Gre. cian poet, Theognis, who lived 550 B.c., clearly saw how important selection, if carefully applied, would be for the improvement of mankind. He saw, likewise, that wealth often checks the proper action of sexusid selection. He thus writes:

"With kine and horses, hurnus ! we proceed

By reasonable rules, and choose a breed

For profit and increase, at any price;

Of a sound stock, without defect or vice.

$\mathrm{But}$, in the daily matches that we make,

The price is everything: for money's sake,

Men marry: women are in marriage given

The churl or ruffian, that in wenith has thriven,

May match his offspring with the proudest race:

Thus everything is mix'd, noble and base!

If then in outward manner, form, and mind,

You find us a degraded, motley kind,

Wonder no more, my friend ! the cause is plain,

And to lament the consequence is vain."

(The Works of J. Hookham Freie, vol. ii. 1872, p. 334.) 
Quatreliages, that I need here only refer to their works. ${ }^{14}$ Monstrosities, which graduate into slight variations, are likewise sc similar in man and the lower animals, that the same classification and the same terms can be used for both, as has been shewn by Isidore Geoffroy St.-Hilaire. ${ }^{15}$ In my work on the variation of domestic animals, I have attempted to arrange in a rude fishion the laws of variation under the following heads:-The direct and definite action of changed conditions, as exhibited by all or nearly all the individuals of the same species, varying in the same mauner under the same circumstances. The effects of the long-continued inse or disuse of parts. The cohesion of homologous parts. The variability of multiple parts. Compensation of growth; but of this law I have found no good instance in the case of man. The effects of the mechanical pressure of one part on another; as of the pelvis on the cranium of the infant in the romb. Arrests of development, leading to the diminution or suppression of parts. The reappearance of long-lost characters through reversion. And lastly, correlated variation. All these so-called laws apply: equally to man and the lower animals; and most of them even to plants. It would be superfluous here to discuss all of them; ; but several are so important, that they must be treated at considerable length.

The direct and definite action of changed conditions.--This is a most perplexing subject. It cannot be denied that changed conditions produce some, and occasionally a considerable effect, on organisms of all kinds; and it seems at first probable that if sufficient time were allowed this would be the invariable result. But I have failed to obtain clear evidence in favour of this conclusion; and valid reasons may be urged on the other side, at least as far as the innumerable structures are concerned, which are adapted for special ends. There can, however, be no doubt that changed conditions induce an almost indefinite amount of fluctuating variability, by which the whole organisation is rendered in some degree plastic.

In the United States, abore 1,000,000 soldiers, who served in the late war, were measured, and the States in which they were

14 Godron, 'De l'Espèce,' 1859, tom. ii. livre 3. Quatrefages, 'Linite de l'Espèce Humaine,' 1861. Also Lectures on Anthropolngy, given in the 'Revue des Cours Scientifiques,' 1866-1868.

15 'Hist. Gén. à Part. des Anomalies de l'Organisation,' in three rolumes, tom. i. 1832.
16 I have fully discussed these. laws in $\mathrm{my}$ 'Variation of Arimal. and Plants under Domesticaticn, rol. ii. chap. xxii. and xxiii. M.J. $P$. Durand has lately (1868) published a valuable essay 'De l'Influence des Milieus.' \&c. He lays much stress, in the case of pliris, on the nature of the soil. 
horn and reared were recorded. ${ }^{17}$ From this astonishing numbcr of observations it is proved that local influences of some kind act directly on stature; and we further learn that "the Stats "where the physical growth has in great measure taken placo. "and the State of birth, which indicates the ancestry, seem to "exert a marked influence on the stature." For instance, it is established, "that residence in the Western States, during the "years of growth, tends to produce increase of stature." On the other hand, it is certain that with sailors, their life delays growth, as shewn "by the great difference between the statures of soldiers " and sailors at the ages of seventeen and eighteen years." Mr. B. A. Gould endeavoured to ascertain the nature of the influences which thus act on stature; but he arrived only at negative results, namely, that they did not relate to climate, the elevation of the land, soil, nor even " in any controlling degree" to the abundance or the need of the comforts of life. This latter conclusion is directly opposed to that arrived at by Villermé, from the statistics of the height of the conscripts in different parts of France. When we compare the differences in stature between the Polynesian chiefs and the lower orders within the same islands, or between the inhabitants of the fertile volcanic and low barren coral islands of the same ocean ${ }^{18}$ or again between the Fuegians on the eastern and western shores of their country, where the means of subsistence are very different, it is scarcely possible to aroid the conclusion that better food and greater comfort do influence stature. But the preceding statements shew how difficult it is to arrive at any precise result. Dr. Beddoe has lately proved that, with the inhabitants of Britain, residence in towns and certain occupations have a deteriorating influence on height; and he infers that the result is to a certain extent inherited, as is likewise the case in the United States. Dr. Beddoe further believes that wherever ¿ " race attains its maximum of physical development, it rises " highest in energy and moral vigour." 19

Whether external conditions produce any other direct effect on man is not known. It might have been expected that differences of climate would have had a marked influence, in as much as the lungs and kidneys are brought into activity under \& low

18 'Investigations in Military and Anthrop. Statistics,' \&cc. 1869, by B. A. Gould, p. 93, 107, 126, 131, 134.

18 For the Polynesians, see Prichard's 'Physical Hizt. of Mankind,' rol. $\mathrm{v} .1847$, p. 145,283 . Also Godron, 'De l'Espece," tom. ii. p.
289. There is also a remarkable difference in appearance between the closely-allied Hindoos inhabiting the Upper Ganges and Bengal; see Elphinstone's 'Fristory of India,' vol, i. p. 324 .

is 'Memoirs, Anthropolog. Soc. vol. iii. $1867-69$, pp. $561,565,587$. 
temperature, and the liver and skin under a high one. ${ }^{20}$ It wis formerly thought that the colour of the skin and the character of the hair were determined by light or heat; and although it can hardly be denied that some effect is thus produced, almost all observers now agree that the effect bas been very small, even after exposure during many ages. But this subject will be more properly discussed when we treat of the different races of mankind. With our domestic animals there are grounds for believing that cold and damp directly affect the growth of the hair; but I have not met with any evidence on this head in the case of man.

Effects of the increased Use and Disuse of Parts.-It is well known that use strengthens the muscles in the individual, and complete disuse, or the destruction of the proper nerve, weakens them. When the eye is destroyed, the optic nerve often becomes atrophied. When an artery is tied, the lateral channels increase not only in diameter, but in the thickness and strength of their conts. When one kidney ceases to act from discase, the other' increases in size, and does double work. Bones increase not: only in thickness, but in length, from carrying a greater weight." Different occupations, habitually followed, lead to changed. proportions in various parts of the body. Thus it was ascertained by the United States Commission ${ }^{22}$ that the legs of the sailors employed in the late war were longer by 0.217 of an inch than those of the soldiers, though the sailors were on an average shorter men; whilst their arms were shorter by 1.09 of an inch, and therefore, out of proportion, shorter in relation to their lesser height. This shortness of the arms is apparently due to their greater use, and is an unexpected result: but sailors chiefly use their arms in pulling, and not in supporting wcights. With sailors, the girth of the neck and the depth of the instep are greater, whilst the circumference of the chest, waist, and hips is less, than in soldiers.

Whether the several foregoing modifications wonld become hereditary, if the same habits of life were followed during many generations, is not known, but it is probable. Rengger ${ }^{23}$ attributes the thin legs and thick arms of the Payaguas Iudians to

20 Dr. Brakenridge, 'Theory of Diathesis,' 'Medical Times,' June 19 and July 17, 1869.

21 I have given authorities for these several statements in $\mathrm{my}$ - Variation of Animals ynder Domestication,' vol. ii. pp, 297-300.
Dr. Jaeger, "Ueber das Längenwachsthum der linnchen," "Jeuaischen Zeitschrift,' B. v. Heft i.

22 'Invest:zations,' \&c. By B. A, Gould, 1869 , p. 288.

23 'Säugethiere ron Paraguas, 1830, s. 4 . 
successive generations having passed nearly their whole lives in canoes, with their lower extremities motionless. Other writers have come to a similar conclusion in analogous cascs. According to Cranz, who lired for a long time with the Esquimaux, "tho "natives beliere that ingenuity and dexterity in seal-catching " (their lighest art and virtue) is hereditary; there is really " something in it, for the son of a celebrated seal-catcher will "distinguish himself, though he lost his father in childhood." But in this case it is mental aptitude, quite as much as bodily structure, which appears to to inherited. It is asserted that the hands of English labourers are at birth larger than those of the gentry. ${ }^{20}$ From the correlation which exists, at least in some cases, ${ }^{20}$ between the development of the cxtremitics and of the jaws, it is possible that in those classes which do not labour much with their hands and fuet, the jaws would be reduced in size from this cause. 'That they are generally smaller in refined and civilised men than in hard-working men or savages, is certain. But with sarages, as Mr. Herbert Spencer ${ }^{27}$ has remarked, the greater use of the jars in chewing coarse, uncooked food, would act in a direct manner on the masticatory muscles, and on the hones to which they are attached. In infants, long before birth, the skin on the soles of the feet is thicker than on any other part of the body; ${ }^{28}$ and it can hardly be doubted that this is due to the inherited effects of pressure during a long series of generations.

It is familiar to erery one that watchmakers and engravers are liable to be short-sighted, whilst men living much out of doors, and especially savages, are generally long-sighted. ${ }^{29}$ Shortsight and long-sight certainly tend to be inheritcd. ${ }^{30}$ The inferiority of Europeans, in comparison with savages, in eycsight and in the other senses, is no doubt the accumulated and transmitted effect of lessened use during many generations; for Rengger ${ }^{31}$ states that he has repeatedly observed Europeans,

84 'History of Greenland,' Eng. translat. 1767, vol. i. p. 230.

25 'Intermarriage.' By Alex.

Walker, 1838 , p. 377.

20 'The Variation of Animals under Domestication, ro!. i. p. 173. 27 'Principles of Biology' 'vol. i. r. 455

28 Paget, 'Lectures on Surgical Pathology, vol. ii. 1853 , p. 209.

32. It is a singular and unexpected fact that sailors are inferior to landsmen in their mean distinge of distinct vision. Dr. B. A. Gould
('Sanitary Memoirs of the War of the Rebellion,' 1869, p. 530), has proved this to be the case; and he accounts for it ly the ordinary range of vision in sailors being "re"stricted to the length of the vessel "and the height of the masts."

30 "The Variation of Animals under 'Domestication,' vol. i. p. 8.

31 'Säugethiere von Paraguay," s. 8, 10. I have had good opportunities for observing the extraordinaly power of eyesight in the Fuegians. see also Lawrence ("Juectures on 
who had been brought up and spent their whole lives with the wild Indians, who nevertheless did not equal them in the sharpness of their senses. The same naturalist oluserres that the cavities in the skull for the reception of the sereral scnse-organs are larger in the American aborigines than in Europeans; and this probably indicates a corresponding difference in the dimensions of the organs themselves. Blumenbach has also remarked on the large size of the nasal cavities in the skulls of the American aborigines, and connects this fact with their remarkably acute power of smell. The Mongolians of the plains of Northers Asia, according to Pallas, have wonderfully perfect senses; and Prichard believes that the great breadth of their skulls across the zygomas follows from their highly-developed sense-organs. ${ }^{32}$

The Quechua Indians inhabit the lofty plateaux of Peru; and Alcide d'Orbigny states ${ }^{33}$ that, from coutinually breathing a highly rarefied atmosphere, they have acquired chests and lungs of extraordinary dimensions. The cells, also, of the lungs are larger and more numerous than in Europeans. These observations have been doubted; but MIr. D. Forbes carefully measured many Aymaras, an allied race, living at the height of between 10,000 and 15,000 feet; and he informs me ${ }^{* 4}$ that they differ conspicuously from the men of all other races secn by him in the circumference and length of their bodies. In his table of measurements, the stature of each man is taken at 1000, and the other measurements are reduced to this standard. It is here seen that the extended arms of the Aymaras are shorter than those of Europeaus, and much shorter than those of Negroes. The legs are likewise shorter; and they jresent this remarkable peculiarity, that in every Aymara measured, the femur is actually shorter than the tibia. On an arerage, the length of the femur to that of the tibia is as 211 to 252 ; whilst in tro Europeans, measured at the same time, the femora to the tibiæ were as 244 to 230 ; and in three Negroes as 258 to 241 . The humerus is likewise shorter relatively to the forcarm. This shortening of that part of the limb which is nearest to the body, appears to be, as suggested to me by Mr. Forbes, a case of compensation in

Physiology, \&c., 1822, p. 404) on this same subject. M. Giraud-Teulon has recently collected ('Revue des Cours Scientifiques,' 1870 , p. 625) a large and valuable body of evidence proving that the cause of shortsight, "C"est le travail assidu, de près."

"Prichard, 'Phys. Hist. of Mankind,' on the authority of Blumen- bach, vol. i. 1851, p. 311 ; for the statement by Pallas, vol. iv. 1844, p. 407 .

38 Quoted by Prichard, 'Researches into the Phys. Hist. of Mankind,' rol. v. p. 463.

31 Mr. Forbes' valuable paper is now published in the 'Journal of the Ethnological Soc. of London, new series, vol. i. 1870 , p. 193. 
rclation with the greatly increased leugth of the trunk. The Aymaras present some ofler singular points of structure, for instance, the vers small projection of the hoel.

These men are so thoroughly acclimatised to their cold and lofty abode, that when formerly carried down by the Spaniards to the low eastern plains, and when now tempted down by high wages to the gold-washings, they suffer a frightful rate of mortality. Nevertheless Mr. Forbes found a few pure families which had survived during two generations : and he observed that they still inherited their characteristic peculiarities. But it was manifest, even withont measurement, that these peculiarities had all decreased; and on measurement, their bodies were found not to be so much elongated as thase of the men on the high plateau; whilst their femora had become somewhat lengthened, as had their tibir, although in a less degree. The actual measurements may be seen by consulting Mr. Forbes's memoir. From these observations, there can, I think, be no doubt that residence during many generations at a great elevation tends, both directly and iudirectly, to induce inherited modifications in the proportions of the body. ${ }^{38}$

Although man may not have been much modified during the latter stages of his existence through the increased or decreased use of parts, the facts now given shew that his liability in this respect has not been lost; and we positively know that the same law holds good with the lower animals. Consequently we may infer that when at a remote epoch tho progenitors of man were in a transitional state, and were changing from quadrupeds into bipeds, natural selcction mould probably have been greatly aided by the inherited effects of the increased or diminished use of the different parts of the body.

Arrests of Development.-There is a difference between arrested development and arrested growth, for parts in the former state continue to grow whilst still retaining their early condition. Various monstrosities come under this head; and some, as a cleft-palate, aro known to be occasionally inherited. It will suffice for our purpose to refer to the arrosted brain-development of microcephalous idiots, as described in Vogt's memoir. ${ }^{\text {s. }}$ Their skulls are smaller, and the convolutions of the brain are less complex than in normal men. The frontal sinus, or the

83 Dr. Wilckens ('Landwirthschaft. Wochenblatt,' No. 10, 1869) has lately published an interesting Essay shewing how domestic animals, which live in mountainous regions, have their frames modificd. 36 'Mémoire sur' les Microcéphales,' 1867 , pp. $50,125,169,171$, 184-198. 
projection orer the eye-brows, is largely developed, and the juws are prognathous to an "effrayant" degree; so that these idiots somewhat resemble the lower types of mankind. Their in. telligence, and most of their mental faculties, are extremely feeble. They cannot acquire the power of speech, and aro wholly incapable of prolonged attention, but are much given to imitation. They are strong and remarkably active, continually gamboling and jumping about, and making grimaces. They often ascend stairs on all-fours; and are curiously fond of climling up furniture or trees. We are thus reminded of the delight shewn by almost all boys in climbing trees; and this again rominds us how lambs and kids, originally alpine animals, delight to frisk on any hillock, however small. Idiots also resemble the lower animals in some other respects; thus several cases are recorded of their carefully smelling every mouthful of food before eating it. One idiot is described as often using his mouth in aid of his hands, whilst hunting for lice. They are often filthy in their habits, and have no sense of decency; and several cases have been published of their bodies being remarkably hairy. ${ }^{37}$

Reversion.-Many of the cases to be here gircn, might have been introduced under the last heading. When a structure is arrested in its development, but still continues growing, until it closely resembles a corresponding structure in some lower and adult member of the same group, it may in one sense be considered as a case of reversion. The lower members in a group give us some idea how the common progenitor was probably constructed; and it is hardly credible that a complex part, arrested at an early phase of embryonic development, should go on growing so as ultimately to perform its proper function, unless it had acquired such power during some earlier state of existence, when the present exceptional or arrested structure was normal. The simple brain of a microcephalous idiot, in as far as it resembles that of an ape, may in this sense be said to offer a case of reversion. ${ }^{38}$ There are other cases which come

37 Prof. Laycock sums tp the character of brute-like idiots by calling them theroid; 'Jourual of Mental Science,' July 1863. Dr. Scott ('The Deaf and Dumb,' 2nd edit., 1870 , p. 10) has often observed the imbecile smelling their food. See, on this same subject, and on the hairiness of idiots, Dr. Mauds!ey, 'Body and Mind', 1870 , pp. 46-51. Pinel has also given a striking case of hairiness in an idiot.

${ }^{38}$ In $\mathrm{my}$ "Variation of Animals under Domestication' (rol. ii. p. 5\%), I attributed the not very rare cases of supernumerary mamme in women to reversion. I was led to this as a probatile conclusion, hy the adrlitiousi mammat being generil! placed 
more strictly under our present heal of reversion. Certain structures, regularly occurriug in the lower members of the group

symmetrically on the breast; and more especially from one case, in which a single efficient mamma occurred in the inguinal region of \& woman, the daughter of another woman with supernumerary mamma. But 1 now find (see, for instance, Prof. Preyer, "Der Kampf um das Dasein,' 1869, s. 45) that mamma erratice occur in oiner situations, as on the back, in the armpit, and on the thigh; the nammx in this latter instance having given so much milk that the child was thus nourished. The prooability that the additional mamm $x$ are due to reversion is thus much weakened; nevertheless, it still scems to me probable, because two pairs are often found symmetrically on the breast; and of this I myself have received information in several cases. It is well known that some Lemurs normally have two pairs of mammæ on the breast. Five cases have been recorded of the presence of more than a pair of mammx (of course rudimentary) in the male sex of mankind; see 'Journal of Anat. and Physiology,' 1872, p. 56, for a case given by Dr. Handyside, in which two brothers exhibited this peculiarity; see also a paper by Dr. Bartels, in 'Reicher't's and du Bois Reymond's Archiv.,' 1872, p. 304. In one of the cases alluded to by Dr. Bartels, a man bore five mammx, one being medial and placed above the navel; Meckel von Hemsuach thinks that this latter case is illustrated by a medial mamma occurring in cerinin Cheiropiera. On the whole, we may well doubt if additional mammæ would ever have been developed in both seres of mankind, had not his early progenitors been provided with more than a single pair.

In the above work (rol. ii. p. 12), I also attributed, though with much besitation, the frequent cayes of polydactylism in men and various animals to reversion. I was partl. led to this through Prof. Owen's statement, that some of the Ichthyopterygia possess more than five digits, and therefore, as I supposed, had retained a primordial condition; but Prof. Gegenbaur ("Jenaischen 'Zeitschrift,' B. v. Heft 3, s. 341), disputes Owen's conclusion. On the other hand, according to the opinion lately adranced by $\mathrm{D}_{2}$. Guinther, on the paddle of Ceratodus, which is provided with articulated bony rays on both sides of a central chain of bones, there seems no great difficulty in admitting that six or more digits on one side, or on both sides, might reappear through reversion. I am informed by Dr. \%outeveen that there is a case on record of a man having twenty-four fingers and twenty-four toes! I was chiefly led to the conclusion that the presence of supernumerary digits might be due to reversion from the fact that such digits, not only are strongly inherited, but, as I then believer, had the power of regrowth after amputation, like the normal digits of the lower vertebrata. But I have explained in the Second Edition of $\mathrm{my}$ Variation under Domestication why I now place little reliance on the recorded cases of such regrowth. Nevertheless it deserves notice, in as much as arrested developmeni and reversion are intimately related processes; that various structures in an embryonic or arrested condition, such as a cleft palate, bifid uterus, \&c., are frequently acompanied by polydactylism. This has been strongly insisted on by Meckel and Isidore Geoffroy St.-Hilaire. But at present it is the safest course to give up altogether the idea that there is auy relation between the development of supernumerary digits and reversion to some lowly crginased progenion of mau. 
to which man belongs, occasionally make their appearance in him, though not found in the normal human embryo; or, if normally present in the human embryo, they become abnormally developed, although in a manner which is normal in the lower members of the group. These remarks will be rendered clcarer by the following illustrations.

In various mammals the uterus graduates from a double organ with tro distinct orifices and trro passages, as in the marsupials, into a single organ, which is in no way double except from having a slight internal fold, as in the higher apes and man. The rodents exhibit a perfect series of gradations between these two extreme states. In all mammals the uterus is developed from tro simple primitive tubes, the infurior portions of which form the cornua; and it is in the words of Dr. Farre, "by the coalescence of the tro cornua at their lower "extremities that the body of the uterus is formed in man; " while in those animals in which no middle portion or lyody " exists, the cornua remain ununited. As the dorelopment of " the uterus proceeds, the two cornua become gradually shorter, "until at length they are lost, or, as it were, absorbed into the "body of the uterus." The angles of the uterus are still produced into cornua, even in animals as high up in the scale as the lower apes and lemurs.

Now in women, anomalous cases are not very infrequent, in which the mature uterus is furnished with cornua, or is partially divided into two organs; and such cases, according to Oren, repeat "the grade of conccutrative development," attained by certain rodents. Here perhaps we have an instance of a simple arrest of embryonic devclopment, with subsequent growth and perfect functional development; for either side of the partially double uterus is capable of performing the proper oftice of gestation. In other and rarer cases, two distinct uterine cavities are formed, each having its proper orifice and passage. ${ }^{39}$ No such stago is passed through during the ordinary development of the embryo; and it is difficult to believe, though perhaps not impossible, that the tro simple, minute, primitive tubes should know how (if such an expression may be used) to grow into two

39 See Dr. A. Farre's well-known article in the "Cyclopedia of Anatomy and Phrsiolngy,' vol. v. 1859, p. 642. Owey, "Anatomy of Verte- brates,' rol. iii., 1868, p. 687. Professor Turner in 'Elinburgh Medj. cal Journal, February 186 i. $^{\circ}$ 
distinct uteri, each with a well-constructed orifice and passage, and each furnished with numerous muscles, nerves, glands and vessels, if they had not formerly passed through a similar course of development, as in the case of existing marsupials. No ono will pretend that so perfect a structure as the abnormal double uterus in woman could be the result of mere chance. But the principle of reversion, by which a long-lost structure is called buck into existence, might serre as the guide for its full development, even after the lapse of an enormous interval of time.

Professor Canestrini, after discussing the foregoing and various analogous cases, arrives at the same conclusion as that just given. He adduces another instance, in the case of the malar bone, ${ }^{40}$ which, in some of the Quadrumana and other mammals, normally consists of two portions. This is its condition in the human foetus when two months old; and through arrested development, it sometimes remains thus in man when adult, more especially in the lower prognathous races. Hence Canestrini concludes that some ancient progenitor of man must have had this bone normally divided into two portions, which afterwards became fused together. In man the frontal bone consists of a single piece, but in the embryo, and in children, and in almost all the lower mammals, it consists of two pieces separated by a distinct suture. This suture occasionally persists more or less distinctly in man after maturity; and more frequently in ancient than in recent crania, especially, as Canestrini has observed, in those exhumed from the Drift, and belonging to the brachycephalic type. Here again he comes to the same conclusion as in the analogous case of the malar hones. In this, and other instances presently to be given, the cause of ancient races approaching the lower animals in certain characters more frequently than do the modern races, appears to be, that the latter stand at a somerwhat

so 'Annuario della Soc. dei Naturnlisti in Modena,' 1867, p. 83. Prof. Canestrini gives extracts on this subject from various authorities. Laurillard remarks, that as he has found a complete similarity in the form, proportions, and connection of the two malar bones in several human subjects and in certain apes, he cannot consider this disposition of the parts as simply accidental. Another paper on this same anomaly has been published by Dr. Saviotti in the 'Gazzetta delle Cliniche, Turin, 1871, where he says that traces of the division may be de- tected in about two per cent. of adult skulls; he also remarks that it more frequently occurs in prognathous skulls, not of the Aryan race, than in others, See also G. Delorenzi on the same subject; 'Tre nuovi casi d'anomalia dell'osso, malare,' Torino, 1872. Also, E. Morselli, 'Sopra una rara anomalia dell' osso malare,' Modena, 1872. Still more recently Gruber has written a pamphlet on the division of this bone. I give these references because a reriewer, without agy grounds or scruples, has throw Coubts w my statements. 
greater distance in the long line of descent from their early semiluman progenitors.

Various other anomalies in man, more or less analogous to the foregoing, have been advanced by different authors, as cases of reversion; but these seem not a little doubtful, for wo have to descend extremely low in the mammalian series, before we find such structures normally present.11

In man, the canine tceth are perfectly efficient instruments for mastication. But their true canine character, as Owen ${ }^{2}$ remarks, "is indicated by the conical form of the crown, which "terminates in an obtuse point, is convex outward and flat or "sub-concave withiu, at the base of which surface thcre is a "feeble promineuce. The conical form is best expressed in the "Melanian races, especially the Australian. The canine is more "deeply implanted, and by a stronger fang than the incisors." Nevertheless, this tooth no longer serves man as a special weapon for tearing his enemies or prey; it may, therefore, as far as its proper function is concerned, be considered as rudimentary. In every large collection of human skulls some may be found, as Hiickel ${ }^{43}$ observes, with the canine teeth projecting considerably beyond the others in the same manner as in the anthropomorphous apes, but in a less degree. In these cases, open spaces between the teeth in the one jaw are left for the reception of the canines of the opposite jaw. An interspace of this kind in a Kaftir skull, figured by Wagner, is surprisingly wide." Considering how few are the ancient skulls which have been exarnined, compared to recent skulls, it is an interesting fact that in at least three cases the canines project largely; and in the Naulette jaw they are spoken of as enormous. ${ }^{45}$

41 A whole series of cases is given by Isid. Geoffroy St.-Hilaire, 'Hist. des Anomalies, tom. iii. p. 437. A reviewer ("Journal of Anat. and Physiology', 1871, p. 366) blames me much for not having discussed the numerous cases, which have been recorded, of various parts arrested in their development. He says that, according to my theory, "every transient condition of an "organ, during its development, is "not only a meass to an end, but " once was an end in itself." This does not seem to me necessarily to hold good. Why should not variatrions occur during an early period of development, having no relation to reversion; get such variations might be preser:ud and accimulited, if in any way servicenble, for instance, in shortening aud simplifying the course of devolopment? And again, why should not injurious abnormalities, such as atrophied or hypertrophied parts, which have no relation to a former state of existence, occur at an early period, as well as during maturity ?

42 'Anatomy of Vertebrates,' vol. iii. 1868, p. 323 .

‘3 'Generelle Morphoiogie,' 1866, B. ii. s. clv.

44 Carl Vogt's 'Lectures on Man,' Eng. trisnslat. 1864. p. 151.

45 C. Carter Blike, on a jaw from La Naulette, 'Anthropolog. Review,' 1867, p. 295. Scharehausen, ibid. 1868, p. 426. 
Of the anthropomorphous apes the males alone hare their canines fully developed; but in the female gorilla, and in a less degree in the female orang, these teeth project considerably beyond the others; therefore the fact, of which I have been assured, that women sometimes hare considerably projecting canines, is no serious objection to the belief that their occasional great development in man is a case of reversion to an ape-liku progenitor. He who rejects with scorn the belief that the shapo of his own canines, and their occasional great development in other men, are due to our early forefathers having been provided with these formidable weapons, will probably reveal, by sneering, the line of his descent. For though he no longer intends, nor has the porver, to use these teeth as weapons, he will unconsciously retract his "snarling muscles" (thus named by" Sir C. Bell), ${ }^{46}$ so as to expose them ready for action, like a dog prepared to fight.

Many muscles are occasionally developed in man, which are proper to the Quadrumana or other mammals. Professor Vlacovich "examined forty male subjects, and found a muscle, called by him the ischio-pubic, in nineteen of them; in three others there was a ligament which represented this muscle; and in the remaining eighteen no trace of it. In only two out of thirty female subjects was this muscle developed on both sides, but in three others the rudimentary ligament was present. This muscle, therefore, appears to be much more common in the male than in the fomale sex; and on the belief in the descent of man from some lower form, the fact is intelligible; for it has been detected in several of the lower animals, and in all of these it serves exclusircly to aid the male in the act of reproduction.

Mr. J. Wood, in his valuable series of papers, ${ }^{48}$ has minutely described a vast number of muscular variations in man, which resemble normal structures in the lower animals. The muscles

\footnotetext{
46 'The Anatomy of Expression, 1844 , pp. 110, 131.

4 Quoted by Prof. Canestrini in the 'Annuario,' \&c., 1867, p. 90.

48 These papers deserve careful study by any one who desires to learn how frequently our muscles vary, and in varying come to ronemble those of the Quadrumana. The following references relate to the few points touched on in $\mathrm{my}$ cert: 'Proc. Royal Soc. vol. xiv. 1865, pp. 379-384; vol. xv. 1866,
}

pp. 241,242 ; vol. xv. 1867, p. 544 ; vol. xvi. 1868, p.524. I may here add that Dr. Murie and Mr. St. George Mivart have shewn in their Mlemoir on the Lemuroidea ('Trassact. Zoolog. Soc.' vol, vil. 1869, p. 96), how extraordinarily variable some of the muscles are in these animals, the lowest members of the Primates. Gradations, also, in the muscles leading to structures found in animals still lower in the scale, are numemus in the Lemuroideit, 
which closely resemble those regularly present in our nearest allies, the Quadrumana, are too numerous to be here eren specified. In a single male subject, having a strong bodily frame, and well-formed skull, no less than seren muscular variations were observed, all of which plainly represented muscles proper to various kinds of apes. This man, for instance, had on both sides of his neck a true and powerful "levator claviculoe," such as is found in all kinds of apes, and which is said to occur in about one out of sixty human subjects.99 Again, this man had " a special abductor of the metatarsal bone of the fifth "digit, such as Professor Huxley and Mr. Flower have shewn " to exist uniformly in the higher and lower apes." I will give only two additional cases; the acromio-basilar muscle is found in all mammals below man, and seems to be correlated with a quadrupedal gait, ${ }^{50}$ and it occurs in about one out of sixty human subjects. In the lower extremities Mr. Bradley ${ }^{51}$ found an abductor ossis metatarsi quinti in both feet of man; this muscle had not up to that time been recorded in mankind, but is always present in the anthropomorphous apes. The muscles of the hands and arms-parts which are so eminently characteristic of man-are extremely liable to vary, so as to resemble the corresponding muscles in the lower animals. ${ }^{52}$ Such resemblances are either perfect or imperfect; yet in the latter case they aro manifestly of a transitional nature. Certain variations are more common in man, and others in woman, without our being able to assign any reason. Mr. Wood, after describing numerous variations, makes the following pregnant remark. "Notable departures from the ordinary type of the muscular" "structures run in grooves or directions, which must be taken "to indicate some unknown factor, of much importance to a "comprehensive knowledge of general and scientific anatomy."

49 See also Prof. Macalister in 'Proc. R. Irish Academy', vol. x. 1868 , p. 124 .

so Mr. Champneys in 'Journal of Anat. and Phys.' Nov., 1871, p. 178.

31 'Journal of Anat. and Phys.' May, 1872, p. 421.

52 Prof. Macalister (ibid. p. 121) has tahulated his observations, and finds that muscular abnormalities are most frequent in the fore-arms, secondly, in the face, thirdly, in the foot, \&c.

s3 The Rev. Dr. Haughton, after giving ('Proc. R. Irish Academy, June 27,1864, p. 715) a remark- able case of variation in the hums. flexor pollicis longus, adds, "This "remarkable example shews that "man may sometimes possess the "arrangement of tendons of thumb "and fingers characteristic of the "macaque; but whether such a "case should be regarded as a "Inacaque passing upwards into a " man, or a man passing downwards "into a macaque, or" as a congenital "fieak of nature, I canuot under"take to say." It is satisfactory to hear so capable an anatomist, and so embittred an opponent of evolutionism, admitting eres the 
That this unknown factor is reversion to a former state of existence may be admitted as in the highest degree probable ${ }^{\text {st }}$ It is quite incredible that a man should through mere accident abnormally resemble certain apes in no less than seven of his muscles, if there had been no genetic connection between them. On the other hand, if man is descended from some ape-like creature, no valid reason can be assigned why certain muscles should not suddenly reapnear after an interval of many thousand generations, in the same manner as with horses, asses, and mules, dark-coloured stripes suddenly reappear on the legs, and shouldcrs, after an interval of hundreds, or more probably of thousands of generations.

These various cases of reversion are so closely related to those of rudimentary organs given in the first chapter, that many of them might have been indifferently introduced either there or here. Thus a human uterus furnished with cornua may be said to represent, in a rudimentary condition, the same organ in its normal state in certain mammals. Some parts which are rudimentary in man, as the os coccyx in both sexes, and the mamma in the male sex, are always present; whilst others, such as the supracondyloid foramen, only occasionally appear, and therefore might have been introduced under the head of reversion. These several revcrsionary structures, as well as the strictly rucimentary ones, reveal the descent of man from some lower form in an unmistakable manner.

Correlated Variation.-In man, as in the lower animals, many structures are so intimately related, that when one part varies so does another, without our being ahle, in most cases, to assign any reason. We cannot say whether the one part governs the other, or whether both are governed by some earlier developed

possibility of either of his first propositions. Prof. Macalister has also described ('Proc. R. Irish Acad.' vol. $x .1864, p .138$ ) variations in the flexor pollicis longus, rematkable from their relations to the same muscle in the Quadrumana.

54 Since the first edition of this book appeared, Mr. Wood has published another memoir in the 'Phil. Transactions,' 1870 , p. 83 , on the varieties of the muscles of the human neck, shoulder, and chest. He here shews how extremely variable these muscles are, and how ofken an! how closely the rariations resemble the normal muscles of the lower animals. He sums up by remarking, "It will be enough for my purpose " if I have succeeded in shewing "the more important forms whici, "when occurring as varieties in the "human subject, tend to exhibit in " a sufficiently marked manner what "may be considered as proofs and "examples of the Darwinian prin"ciple of reversion, or law of in" heritance, in this department of " anatomical scicuce." 
part. Various monstrosities, as I. Geoffroy repeatedly insists, are thus intimately connected. Homologous structures are particularly liable to change together, as we sce on the opposite sides of the body, and in the upper and lower extremities. Meckel long ago remarked, that when the muscles of the arm depart from their proper type, they almost always imitate those of the leg; and so, conversely, with the muscles of the legs. The organs of sight and hearing, the teeth and hair, the colour of the skin and of the hair, colour and constitution, are more or less correlated. ${ }^{55}$ Professor Schaaffhausen first drew attention to the relation apparently existing between a muscular frame and the strongly-pronounced supra-orbital ridges, which are so characteristic of the lower races of man.

Besides the variations which can be grouped with more or less probability under the foregoing heads, there is a large class of variations which may be provisionally called spontaneous, for to our ignorance they appear to arise without any exciting cause. It can, however, be shewn that such variations, whether consisting of slight individual differences, or of strongly-marked and abrupt deviations of structure, depend much more on the constitution of the organism than on the nature of the conditions to which it has been subjected. ${ }^{36}$

Tate of Increase.-Civilised populations have been known under favourable conditions, as in the United States, to double their numbers in twenty-five years; and, according to a calculation by Euler, this might occur in a little over twelve years. ${ }^{37}$ At the former rate, the present population of the United States (thirty millions), would in 657 years cover the whole terraqueous globe so thickly, that four men would have to stand on each square yard of surface. The primary or fundamental check to the continued increase of man is the difficulty of gaining subsistence, and of living in comfort. We may infer that this is the case from what we see, for instance, in the United States, where subsistence is easy, and there is plenty of room. If such means were suddenly doubled in Great Britain, our number would be quickly doubled. With civilised nations this primary check acts chiefly by restraining marriages. The greater death-rate of infants in the poorest classes is also very important; as well as

\footnotetext{
ss The authorities for these several statements are given in my - Variation of Animals under Domestication,' vol. ii. pp. 320-335.

6 This whole subject has been discussed in chap. sxiil, vol. ii. of
}

my 'Variation of Animals and Plants under Domestication.'

\$7 See the ever memorable 'Essay on the Principle of Population,' by the Rev. T. Millthus, rol. i. 10\%o, p. 6,517 . 
tho greater mortality, from various diseases, of the inhevitants of crowded and miscrable houses, at all ages. The effects of sovero epidemics and wars are soon counterbalanced, and more than counterbalanced, in nations placed under farourable conditions. Emigration also comes in aid as a temporary check, but, with the extremely poor classes, not to any great extent.

There is reason to suspect, as Malthus has remarked, that the reproductive power is actually less in barbarous, than in civilised races. We know nothing positively on this head, for with savages no census has been taken; but frorn the concurrent testimony of missionaries, and of others who have long resided with such people, it appears that their families are usually small, and large ones rare. This may be partly accounted for, as it is believed, by the romen suckling their infants during a long time; but it is highly probable that savages, who often suffer much hardship, and who do not obtain so much nutritious food as civilised men, would be actually less prolific. I have shewn in a former work, ${ }^{58}$ that all our domesticated quadrupeds and birds, and all our cultivated plants, are more fertile than the corresponding species in a state of nature. It is no valid ohjection to this conclusion that animals suddenly supplied with an excess of food, or when grown very fat; and that most plants on sudden remoral from very poor to very rich soil, are rendered more or less sterile. We might, therefore, expect that civilised men, who in one sense are highly domesticated, would be more prolific than wild men. It is also probable that the increased fertility of civilised nations would become, as with our domestic animals, an inherited character: it is at least known that with mankind a tendency to produce twins runs in families. ${ }^{59}$

Notwithstanding that savages appear to be less prolific than civilised people, they would no doubt rapidly increaso if their numbers were not by some means rigidly kept down. The Santali, or hill-tribes of India, have recently afforded a good illustration of this fact; for, as shewn by Mr. Hunter, ${ }^{60}$ they have increased at an extraordinary rate since raccination has becn introduced, other pestilences mitigated, and war sternly repressed. This increase, however, would not have heen possible had not these rude people spread into the adjoining districts, and worked for hire. Savages almost always marry; yet there is some prudential restraint, for they do not commonly marry at the

so 'Variation of Animals and Plants under Domestication,' vol. ii. pp. $111-113,163$.

so Mr. Sergwick, 'Brstish and
Foreign Medico-Chirurg. Reriew, Julv, 1863, p. 170.

60 "The Anaals of Rural Bengal, by W. W. Hunter, 1868 \%. 259. 
earliest possibie age. The young men are often required to shew that they can support a wife; and they gencrally have first to earn the price with which to purchase her from her parents. With savages the difficulty of obtaining subsistence occasionally limits their number in a much more direct manner than with civilised people, for all tribes periodically suffer from screre famines. At such times savages are forced to devour much bad food, and their health can hardly fail to be injured. Many accounts have been pablished of their protruding stomachs and emaciated limbs after and during famines. They are then, also, compelled to wander much, and, as I was assured in Australia, their infants perish in large numbers. As famines are jeriodical, depending chiefly on extreme scasons, all tribes must fluctuate in number. They cannot steadily and regularly increase, as there is no artificial increase in the supply of food. Savages, when hard pressed, encroach on each other's territories, and war is the result; but they are indeed almost always at war with their neighbours. They are liable to many accidents on iand and water in their search for food; and in some countries they suffer much from the larger beasts of prey. Eren in India, districts have been depopulated by the ravages o: tigers.

Malthus has discussed these several checks, but he does not lay stress enough on what is probably the most important of all. nomely infanticide, especially of female infants, and the habit of procuring abortion. These practices now prevail in many quarters of the world; and infanticide seems formerly to have prevailed, as Mr. MI'Lennan ${ }^{61}$ has shewn, on a still more extensivo scale. These practices appear to have originated in savages recognising the difficulty, or rather the impossibility of supporting all the infants that are born. Licentiousness may also be added to the foregoing checks; but this does not follow from failing means of subsistence; though there is reason to believe that in some cases (as in Japan) it has been intentionally encourag:d as a means of keeping down the population.

If we look back to an extremely remote epoch, before man had arrived at the dignity of manhood, he would have been suided more by instinct and less by reason than are the lowest savages at the present time. Our early semi-human progenitors would. not have practised infanticide or polyandry; for the instincts of the lower animals are never so perverted ${ }^{62}$ as to lead them re-

61 'Primitive Marringe,' 1865.

2 A writer in the "Spectator" (March 12th, 1871, p. 320) com- ments as follows on this passage :"Mr. Darwin finds himsolf compelled " to reintroduce a new doctrine of the 
gularly to destroy their own offspring, or to be quite devoid of jealousy. There would have been no prudential restraint from marriage, and the sexes would have freely united at an early age. Hence the progenitors of man would have tended to increase rapidly; but checks of some kind, either periodical or constant, must have kept down their numbers, even more severely than with existing savages. What the precise nature of these checks were, we cannot say, any more than with most other animals. We know that horses aud cattle, which are not extremely prolific animals, when first turned loose in South America, increased at an enormous rate. The elephant, the slowest breeder of all known animals, would in a few thousand years stock the whole world. The increase of every species of munkey must be checked by some means; but not, as Brehm remarks, by the attacks of beasts of prey. No one will assume that the actual power of reproduction in the wild horses and cattle of America, was at first in any sensible degree increased; or that, as each district became fully stocked, this same power was diminished. No doubt in this case, and in all others, many checks concur, and different checks under different circumstances; periodical dearths, depending on unfarourable seasons, being probably the most important of all. So it will have been with the early progenitors of man.

Naturul Selection.-Wo have now seen that man is variable in body and mind; and that the variations are induced, either directly or indirectly, by the samo general causes, and obey the same general laws, as with the lower animals. Man has spread widely over the face of the earth, and must have been exposed, during his incessant migrations, ${ }^{63}$ to the most diversified conditions. The inhabitants of Tierra del Fuego, the Cape of Good Hope, and Tasmania in the one hemisphere, and of the Arctic regions in the other, must have passed through many climates,

" fall of man. He shews that the " instincts of the higher animals Bs are far nobler than the habits of "6 savage races of men, and he finds " himself, tharefore, compelled to "re-introduce, -in a form of the "s'sbstantiaj orthodory of which he "s appears to be quite unconscious, -

" and to introduce as a scientific " hypothesis the doctrine that man's "gain of knowledge was the cause of " a temporary but long-enduring " moral deterioration, as indicated "by the many foul customs, es"pecially as to marriage, of savage "tribes. What does the Jewish " tradition of the moral degenera"tion of man through his snatching "at a knowledge forbidden him " by his highest instinct assert " beyond this?"

${ }^{63}$ See some good remarks to this cffect by W. Stanley Jevons, "A " Deduction from Darwin's 'Theory, 'Nature,' 1869, p. 231. 
und changed their habits nany times, before they reached their present homes. ${ }^{\text {es }}$ The early progenitors of man must also havo twnded, like all other animals, to have increased beyond thcir means of subsistence; they must, therefore, occasionally have been exposed to a struggle for existence, and consequently to the rigid law of natural selection. Beneficial variations of all linds will thns, either occasionally or habitually, have been preserred and injurious ones climinated. I do not refer to strongly-marked deviations of structure, which occur only at long intervals of time, but to mere individual differences. We know, for instance, that the muscles of our hands and feet, which determine our powers of movement, are liable, like those of the lower animals, ${ }^{65}$ to incessant variability. If then the progenitor's of man inhabiting any district, especially one undergoing some change in its conditions, were divided into two equal bodies, the one half which included all the individuals best adapted by their powers of morement for gaining subsistence, or for defending themsel res, would on an average survive in greater numbers, and procreate more offspring than the other and less well endowed half.

Man in the rudest state in which he now exists is the most dominant animal that has ever appeared on this earth. He has spread more widely that any other highly organised form: and ill others hare yie!ded before bim. He manifestly owes this immense superiority to his intellectual faculties, to his social habits, which lead him to aid and defend his fellows, and to his corporeal structure. The supreme importance of these charactcrs has been proved by the final arbitrament of the battle for life. Through his powers of intellect, articulate langunge has been evolved; and on this his ronderful advancement has mainly depended. As Mr. Chaune Mr Tright remarks:66 " a psychological "analysis of the faculty of language shews, that even the smallest "proficieney in it might require more brain power than the "greatest proficiency in any other direction." He has invented and is able to use various weapons, tools, traps, dc., with which he defends himself, kills or catches prey, and otherwise obtains food. He has mado rafts or canoes for fishing or crossing orer to neighbouring fertile islands. He has discovered the art of

64 Latham, 'Man and his Migrations,' 1851, p. 135.

${ }_{65}$ Messrs. Murie and Mivart in their 'Anatomy of the Lemuroidea' ('Transact. Zoolog. Soc.' rol. vii. 1869, pp. 96-98) say, "some muscles " are so irregular in their distribu" tiog that they cannot be well "classed in any of the above " groups." These muscles differ even on the opposite sides of the same individual.

66 Limits of Natural Selection, 'North American herirw; ' Oct. 1870 , p. 295. 
making firo, by which hard and stringy roots can be rendered digestible, and poisonous roots or herbs innocuous. This discovery of fire, probably the greatest ever made by man, excepting language, dates from before the dawn of history. These several inventions, by which man in the rudest stato has become so preeminent, are the direct results of the development of his powers of observation, memory, curiosity, imagination, and reason. I cannot, therefore, understand how it is that Mr. Wallace ${ }^{67}$ maintains, that "natural selection could only have endowed the "savage with a brain a little superior to that of an ape."

Although the intellectual powers and social habits of man are of paramount importance to him, we must not underrate the importance of his bodily structure, to which subject the remainder of this chapter will be devoted; the development of the intellectual and social or moral faculties beirg discussed in a lator chapter.

Even to hammer with precision is no easy matter, as every one who has tried to learn carpentry will admit. To throw a stone with as true an aim as a Fuegian in defending himself, or in killing birds, requires the most consummate perfection in the correlated action of the muscles of the hand, arm, and shoulder, and, further, a fine sense of touch. In throwing a stone or spear, and in many other actions, a man mast stand firmly on his feet; and this again demands the perfect co-aclaptation of numerous muscles. To chip a flint into the rudest tool, or to form a larbed spcar or hook from a bone, demands the use of a perfect hand; for, as a most capable judge, Mr. Schoolcraft, ${ }^{68}$ remarks, the shaping fragments of stone into knires, lances, or arrow-heads,

"1 'Quarterly Review,' April 1869, p. 392. "This subject is more fully discussed in Mr. Wallace's 'Contributions to the Theory of Natural Selection,' 1870, in which all the essays referred to in this work are republished. The 'Essay on Man " has been ably criticised by Prof. Claparede, one of the most distinguished zoologists in Europe, in an article published in the 'Bibliothèque Universelle,' June 1870. The remark quoted in $\mathrm{my}$ text will surprise every one who has read Mr. Wallace's celebrated paper on 'The Origin of Human Races deduced from the Theory of Natural Selection,' originally publishel in the "Anthropological Reriew,' May 186t, p. clvini. I cannot here resist quoting a most just remark by Sir J. Lubbock ("Prehistoric Times,' 1865 , p. 479) in reference to this paper, namely, that Mr. Wallace, "with characteristic " unselfishness, ascribes it (i. e. the "ides of natural selection) unre"servedly to Mr. Darwin, althnugh, " as is well known, he struck ont "s the idea independently, and pub" lished it, though not with the "same elaboration, at tho same " time."

${ }_{68}$ Quoted by Mr. Lawson Talt in his 'Law of Natural Selection,''Dublia Quarterly Journal of Medical Science, 'Feb. 1869. Dr. Këler is likewise quoted to the same effect. 
shews "extraordinary ability and long practice." This is to a great extent proved by the fact that primeval men practised a division of labour; each man did not manufacture his own flint tools or rude pottery, but certain individuals appear to have devoted themselves to such work, no doubt receiving in exchange the produce of the chase. Archæologrists are convinced that an enormous interval of time clapsed hefore our ancestors thought of grinding chipped flints into smooth tools. One can hardly doubt, that a man-like animal who possessed a hand and arm sufficiently perfect to throw a stone with precision, or to form a flint into a ruảe tool, could, with sufficient practice, as far as mechanical skill alone is concerned, make almost anything which a civilised man can make. 'The structure of the hand in this respect may be compared with that of the rocal organs, which in the apes are used for uttering various signal-cries, or, as in one genus, musical cadences; but in man the closely similar vocal organs have become adapted through the inherited effects of use for the utterance of articulate language.

Turning now to the nearest allies of men, and therefore to tha best representatives of our early progenitors, we find that the hands of the Quadrumana are constructed on the same general pattern as our own, but are far less perfectly adapted for diversified uses. Their hands do not serve for locomotion so well as the feet of a dog; as may be seen in such monkeys as the chimpanzee and orang, which walk on the outer margins of the palms, or on the knuckles. ${ }^{69}$ Their hands, howeror, are admirably adapted for climbing trees. MIonkeys seize thin branches or ropes, with the thumb on one side and the fingers and fralm on the other, in the same manner as we do. They can thus also lift rather large objects, such as the neck of a bottle, to their mouths. Baboons turn orer stones, and scratch up roots with their hands. They seize nuts, insects, or other small oljects with the thumb in opposition to the fingers, and no doubt they thus extract eggs and the young from the nests of birds. American monkeys beat the wild oranges on the branches until the rind is cracked, and then tear it off with the fingers of the two hands. In a wild state they break open hard fruits with stones. Other monkeys open mussel-shells with the two thumbs. WVith their fingers they pull out thorns and burs, and hunt for each ather's parasites. They roll down stones, or throw them at their enemies: nerertheless, they are clumsy in these various actions, and, as $\mathrm{I}$ have myself seen, are quite unable to throw a stone with precision. 
It seems to me far from true that because "objects are grasped "clumsily" by monkeys, "a much less specialised organ of "prehension" would have served them "0 equally well with their present hands. On the contrary, I see no reason to doubt that more perfectly constructed hands would have been an autvantage to them, provided that they were not thus rendered. less fitted for climbing trees. We may suspect that a hand as perfect as that of man would have been disadvantageous for climbing; for the most arboreal monkeys in the world, namely, Ateles in America, Colobus in Africa, and Hylobates in Asia, are cither thumbless, or their toes partially cohere, so that their limbs are converted into mere grasping hooks. ${ }^{71}$

As soon as some ancient member in the great series of the Primates came to he less arboreal, owing to a change in its manner of procuring subsistence, or to some change in the surrounding conditions, its habitual manner of progression would have been modified: and thus it would have been rendered more strictly quadrupedal or bipedal. Baboons frequent hilly and rocky districts, and only from necessity climb high trees; ${ }^{72}$ and they have acquired almost the gait of a dog. Man alone has become a biped; and we can, I think, partly see how he has come to assume his crect attitude, which forms one of his most conspicuous characters. Man could not hare attained his present dominant position in the world without the use of his hands, which are so admirably adapted to act in obedience to his mill. Sir C. Bell ${ }^{73}$ insists that "the hand supplies all instruments, " and by its correspondence with the intellect gives him univer"sal dominion." But the hands and arms could hardly havo hecome perfect enough to have manufactured werpons, or to have hurled stones and spears with a true aim, as long as they were habitually used for locomotion and for supporting the whole weight of the body, or, as before remarked, so long as they were especially fitted for climbing trees. Such rough treatment would also have blunted the sense of touch, on which their delicate use largely depends. From these causes alone it would hove been an advantage to man to become a biped; but for

10 'Quarterly Review, April 1869, p. 392.

11 In Hylobates syndactylus, as the name expresses, two of the tnes Jeguiariy conere; and this, as $\mathrm{Mr}$. Blyth informs me, is occasionally the case with the toes of $H$. agilis, ler, and leuciscus. Colobus is strictly arboreal and extraordinanly active (Brehm, 'Thierleben,' B. i. s. 50), but whetiel a better climber than the species of the allied genera, I do not know. It deserves notice that the feet of the sloths, the most arboreal animals in the world, are wonderfully hook-like.

72 Brehm, 'Thierleben,' B. i. s. 80.

18 "The Hand," \&c. "Bridge water Treatise,' 1833, p. 38. 
many actions it is indispensable that the arms and whole upper part of the body should be free; and he must for this end stand firmly on his feet. To gain this great advantage, the fect have been rendered flat; and the great toe has been peculiarly modified, though this has entailed the almost complete loss of its power of prehension. It accords with the principle of the division of physiological labour, prevailing throughout the animal kingdom, that as the hands becamo perfected for prehension, the feet should have become perfected for support and locomotion. With some savages, howerer, the foot has not altogether lost its prehensile power, as shewn by their manner of climbing trees, and of using them in other ways. ${ }^{\text {it }}$

If it be an advantage to man to stand firmly on his feet and to have his hands and arms free, of which, from his pre-eminent success in the battle of life, there can be no doubt, then I can see no reason why it should not have been advantageous to the progenitors of man to have become more and more erect or bipedal. They would thus have been better able to defend themselves with stones or clubs, to attack their prey, or otherwise to obtain food. The best built individuals would in the long run have succeeded best, and have survived in larger numbers. If the gorilla and a few allied forms had become extinct, it might have been argued, with great force and apparent truth, that an animal could not have been gradually converteci from a quadruped into a biped, as all the individuals in ar intermediate condition would have been miserably ill-fitted for progression. But we know (and this is well worthy of reflection) that the anthropomorphous apes are now actually in an intermediate condition; and no one doubts that they are $c$ the whole well adapted for their conditions of life. Thus the gorilla runs with a sidelong shambling gait, but more commonly progresses by resting on its bent hands. The long-armed apes occasionally use their arms like crutches, swinging their bodies forward between them, and some kinds of Hylobates, without naving been taught, can walk or run upright with tolerable quickness; yet they move awkwardly, and much less securely than man. We see, in short, in existing monkeys a manner of progression intermediate between that of a quadruped and a

is Häckel has an excellent discussion on the steps by which min became a biped: "Naturliche Schöpfungsgeschichte,' 1868, s. 507. Dr. Buchner ('Conférences sur la Théorie Darwinienne,' 1869, p. 135) has given good cases of the use of the foot as a preinensile organ by man; and has also written on the manner of progression of the higher apes, to which I allude in the following paragraph : see also Owen ('Anatomy of Vertebrates,' rol. iii. p. 71) ou this !aiter subject. 
biped; lut, as an unprejudiced judge ${ }^{75}$ insists, the anthropomorphous apes approach in structure more nearly to tho bipedal than to the quadrupedal type.

As the progenitors of man became more and more erect, with their hands and arms more and more modified for prehension and other purposes, with their fect and legs at the same time transformed for firm support and progression, endless other changes of structure would have become necessary. The pelvis would have to be liroadened, the spine peculiarly curved, and the head fixed in an altered position, all which changes have been attained by man. Prof. Schaaff hausen ${ }^{76}$ maintains that "the " powrerful mastoid processes of the human skull are the result of " his erect position;" and these processes are abscnt in the oraug, chimpanzee, \&c., and are smaller in the gorilla than in man. Various other structures, which appear connected with man's erect position, might here have been added. It is very difficult to decide how far these correlated modifications are the result of natural selection, and how far of the inherited effects of the increased use of certain parts, or of the action of one part on another. No doubt these means of change often co-operate: thus when certain muscles, and the crests of bone to which they are attached, become enlarged by habitual use, this shews that certain actions are habitually performed and must he serviceable. Hence the individuals which performed them best, would tend to survive in greater numbers.

The free use of the arms and hands, partly the cause and partly the result of man's erect position, appears to have led in an indirect manner to other modifications of structure. The early male forefathers of man were, as previously stated, probably furnished with great canine teeth; but as they gradually acquired the habit of using stones, clubs, or other weapons, for fighting with their enemies or rivals, they would use their jaws and teeth less and less. In this casc, the jaws, together with the teeth, would become reduced in size, as we may feel almost sure from innumerable analogous cases. In a future chapter we shall meet with a closely parallel case, in the reduction or complete disapnearance of the canine tecth in male ruminants, apparcutly in relation with the development of their horns; and in horses, in relation to their habit of fighting with their incisor teeth and hoofs.

73 Piof. Broca, La Constitution Jes Verièbres caudales; 'La Rerue d'Anthropologie, 1872, p. 25. (separate copy).

" On the Primitive form of tile Skull,' translated in 'Anthropolugical Reriew, Oct. 1868, p. 4'28. Owen ('Anatomy of Vertebrates 'vol. ii. 1866, p. 551) on the mastoid processes in the higher apes. 
In the adult male anthropomorphous apes, as Ruitimeyer, ${ }^{77}$ and others, have insisted, it is the effect on the skull of the great development of the jaw-muscles that causes it to differ so greatly in many respects from that of man, and has given to theso animals "a truly frightful physiognomy." Therefore, as the jars and teeth in man's progenitors gradually became reduced in size, the adult skull would have come to resemble more aud more that of existing man. As we shall hereafter see, a great rerluction of the canine teeth in the males would almost certainly affect the teeth of the females through inheritance.

As the rarious mental faculties sradually developed themselves the brain would almost certainly become largur. No one, I presume, doubts that the large proportion which the size of man's brain bears to his body, compared to the same proportion in the gorilla or orang, is closely commected with his higher mental powers. We meet with closely aualogous facts with insects, for in ants the cerebral ganglia are of extraordinary dimensions, and in all the Hymenoptera these ganglia are many" times larger than in the less intelligent orders, such as buetles. ${ }^{.8}$ On the other hand, no one supposes that the intellect of any two animals or of any two men can be accurately gauged by the cubic contents of their skulls. It is certain that there may be extraordinary mental activity with an extremely small absolute mass of nervous matter: thus the wonderfully diversified instincts, mental powers, and affections of ants are notorious; yet their cercbral ganglia are not so large as the quarter of a small pin's head. Under this point of riew, the brain of an ant is oue of the most marvellous atoms of matter in the world, perhaps more so than the brain of a man.

The belief that there exists in man some close relation between the size of the brain and the development of the intellectual faculties is supported by the comparison of the skulls of savage and civilised races, of ancient and moderm people, and by the analogy of the whole vertebrate series. Dr. J. Barnard Davis has proved, ${ }^{79}$ by many careful measurements, that the mean interual capacity of the skull in Europeans is 92.3 cubic inches; in Americans 87.5; in Asiatics 87.1; and in Australians only 81.9 cubic inches. Professor Broca ${ }^{80}$ found that the nineteenth century

77 'Die Grenzen der Thierwelt, eine Betrachtung zu Darwin's Lehre, 1868, s. 51 .

78 Dujardin, 'Annales des Sc. Nat,' 3rd series Zoolog. tom. xiv. 1850, p. 203. See also Mr. Lowne, Anatomy and Phys, of the Musca romitoria,' 1870, p. 14. My son, Mr. F. Darwin, dissected for me the cerebral ganglia of the Formica rufa. i9 'Philosopinieal Trucsactions,
1869, p. 513.

Bo 'Les Sélections, M. P. Brom, 
skulls from graves in Paris were larger than those from vaalts of the twelfth century, in the proportiun of 1481 to 1426 ; and that the increased size, as ascertained by measurements, was exclusively in the frontal part of the skull-the seat of the intellectual faculties. Prichard is persuaded that the present inhabitants of Britain have " much more capacious brain-cases" than the ancient inhabitants. Nevertheless, it must be admitted that some skulls of very high antiquity, such as the famous one of Neanderthal, are well developed and capacious. ${ }^{81}$ With respect to the lower animals, MI. E. Lartet, ${ }^{82}$ by comparing the crania of tertiary and recent mammals belonging to the same groups, has come to the remarkable conclusion that the brain is generally larger and the convolutions are more complex in the more recent forms. On the other hand, I have shewn ${ }^{83}$ that the brains of domestic rabbits are considerably reduced in bulk, in comparison with those of the wild rabbit or hare; and this may be attributed to their having been closely confined during many generations, so that they have exerted their intellect, instincts, senses and voluntary movements but little.

The gradually increasing weight of the brain and skull in man must have influenced the development of the supporting spinal column, more especially whilst he was becoming erect. As this change of position was being brought about, the internal pressure of the brain will also have influenced the form of the skull; for many facts show how easily the skull is thus affected. Ethnologists believe that it is modified by the kind of cradle in which infants sleep. Habitual spasms of the muscles, and a cicatrix from a severe burn, have permanently modified the facial bones. In young persons whose heads have become fixed cither sideways or backwards, owing to disease, one of the two eyes has changed its pasition, and the shape of the skull has been altered

Revue d'Anthropologies,' 1873; see also, as quoted in C. Vogt's 'Lectures on Man,' Eng. translat. 1864, pp. 88, 90. Prichard, 'Phys. Hist. of Mankind,' vol. i. 1838, p. 305.

81 In the interesting article just referied to, Prof. Broca has well remarked, that in civilised natrons, the arerage capacity of the skull must ke lowered by the preservation of a considerable number of individuals, weak in mind and body, who would have beea promptly eliminated in the savage state. On the other hand, with savages, the average includes only the more capable individuals, who have been able to survive under extremely hard conditions of life. Broca thus explains the otherwise inexplicable fact, that the mean capacity of the skull of the ancient Troglodytes of Lozere is greater than that of modern Frenchmen.

82 'Comptes-rendus des Sciences,' \&c. June 1, 1868.

${ }^{83}$ 'The Variation of Animals and Plants under Domestication,' vol. i. pp. 12: 12y. 
apparently by the pressure of the brain in a new direction." I have shewn that with long-eared rabbits even so trifling $\Omega$ cause as the lopping forward of ono ear drags forward almost evcry bone of the skull on that side; so that the bones on the opposite side no longer strictly correspond. Lastly, if nny animal mere to increase or diminish much in general sire, without any change in its mental powers, or if the mental powers were to be much increased or diminished, without any great change in the size of the body, the shape of the skull would almost certainly be altered. I infer this from my observations on domestic rabhits, some kinds of which have become rery much larger than the wild animal, whilst others have retained nearly the same size, but in both cases the brain has been nuch reduced relatively to the size of the body. Now I was at first much surprised on finding that in all these rabbits the skull had become elongated or dolichocephalic; for instance, of two skulls of nearly equal breadth, the one from a wild rabbit and the other from a large domestic kind, the former was $3 \cdot 15$ and the latter 4.3 inches in length. ${ }^{85}$ One of the most marked distinctious in different races of men is that the skull in some is elongated, and in others rounded; and here the explanation suggested by the case of the rabbits may bold good; for Welcker finds that short "men incliue more " to brachycephaly, and tall men to dolichocephaly;" " and tall men may be compared with the larger and longer-bodier rabbits, all of which have elongated skulls, or are dolicliucephalic.

From these sereral facts we can understand, to a certain extent, the means by which the great size and more or less rounded form of the skull have been acquired by man ; and these are characters eminently distinctive of him in comparison $\pi$ ith the lower animals.

Another most conspicuous difference between man and the lower animals is the nakedness of bis skin. Whales and porpoises (Cetacea), dugongs (Sirenia) and the hippopotamus are naked; and this may be advantageons to them for gliding

84 Schaaffhausen gives from 131umenbach and Busch, the cases of the spasms and cicatrix, in 'Anthropolog. Review,' Oct. 1868 , p. 4:? Dr. Jarrold ('Anthroplologia,' 1808 , pp. 115, 116) adduces from Camper and from his own observations, cases of the modification of the stull from the head being fired in an unnatural pasition. He believes that in certain trades, such sos that of a shoe- maker, where the head is habitually held forward, the forehead becomes more rounded and prominent.

83 "Variation of Auimals," \& .. rol. i. $\Gamma .117$, on the elongation of the skull; P. 119, on the elfect of the lopring of one ear.

86 (Yuoted in Schaafthausen. in 'Anthropulog. Teriew, Oct. 1868, p. 419 . 
through the water; nor would it be injurious to them from the loss of marmth, as the species, which inhabit the colder regious, are protected by a thick lajer of blubber, serving the same purpose as the fur of seals and otters. Eleplants and rhinoceroses are almost hairless; and as certain extinct species, which formerly lived under an Arctic climate, were coverul with long wool or hair, it would almost appear as if the existing species of both genera had lost their hairy covering from exposure to heat. 'This appears the more probable, as the elephants in India which live on elevated and cool districts are more hairy ${ }^{87}$ than those on the lowlands. May we then infer that man became rivested of hair from having aboriginally inhabited some tropical land? That the hair is chiefly retained in the male sex on the chest and face, and in both sexes at the junction of all four limbs with the trunk, favours this inference-on the assumption that the hair was lost before man becaine erect; for the parts which now retain most hair would then have been most protected from the heat of the sun. The crown of the head, however, offers a curious exception, for at all times it must have been one of the most exposed parts, yet it is thickly clothed with hair. The fact, however, that the other members of tho order of Primates, to which man belongs, although inhabiting various hot regions, are well clothed with hair, generaliy thickest on the upper surface, ${ }^{88}$ is opposed to the supposition that man became naked through the action of the sun. Mr. Belt believes ${ }^{89}$ that within the tropics it is an advantage to man to be destitute of hair, as he is thus enabled to free himself of the multitude of ticks (acari) and other parasites, with which he is often infested, and which sometimes cause ulceration. But whether this evil is of sufficiont magnitude to have led to the denudation of his body thrcugh natural selection, may be doubted, since none of the many quadrupeds inhabiting the tropies hare, as far as I know, acquired any specialised means of relief. The view which seems to me the most probable is that man, or rather primarily woman,

s. Owea, 'Anatomy of Verteorates, vol. iii. p. 619 .

88 Isidore Geoffroy St.-Hilaire remarks ('Hist. Nat. Générale,' tom. 1i. 1859, pp. 215-217) on the head of man being covered with long hair; also $n$ the upper surfaces of monkeys and of other mammals being more thickly clothed than the lower surfaces. This has likewise been observed by various authors. Prof. P. Gervais ('Hist. Nat. des Mammiferes,' com. : $: 854$, p. '2s), how- ever, states that in the Gorilla the hair is thinner on the back, where it is partly rubbed off, than on the lower surfice.

89 'The 'Naturalist in Nicaragua,' 1874 , p. 209. As some confirmation of Mr. Belt's view, I may quote the forlowing passage from Sir W. Denısou ("Varieties of" Vice-Regal Life,' vol. i. 1870, p. 440): "It is stid "to be a practice with the Aus"tralians, when the rermin get "troulilcsome, to siuge themsilins." 
became divested of hair for ornamental purposes, as we shall see mnder Sexual Selection; and, according to this belief, it is not surprising that man should differ so greatly in hairiness from all other Primates, for characters, gained through sexual selection, often differ to an extraordinary degree in closely-related forms.

According to a popular impression, the absence of a tail is eminently distinctive of man; but as those apes which come nearest to him are destitute of this organ, its disappearance does not relate exclusively to man. The tail often differs remarkably in length within the same genus: thus in some species of Macacus it is longer than the whole body, and is formed of twenty-four vertebrr; in others it consists of a scarcely visible stump, containing only three or four vertebræ. In some kinds of baboons there are twenty-five, whilst in the mandrill there are ten very small stunted caudal vertebræ, or, according to Cuvier, ${ }^{90}$ sometimes only five. The tail, whether it be long or short, almost always tapers towards the end; and this, I presume, results from the atrophy of the terminal muscles, together with their arteries and nerves, through disuse, leading to the atrophy of the terminal bones. But no explanation can at present be given of the great diversity which often occurs in its length. Here, however, we are more specially concerned with the complete external disappearance of the tail. Professor Broca has recently shewn ${ }^{91}$ that the tail in all quadrupeds consists of two portions, generally separated abruptly from each other; the basal portion consists of vertebræ, more or less perfectly channelled and furnished with apophyses like ordinary vertebra; whereas those of the terminal portion are not channelled, are almost smooth, and scarcely resemble true vertebræ. A tail, though not externally visible, is really present in man and the anthropomorphous apes, and is constructed on exactly the same pattern in both. In the terminal portion the vertebræ, constituting the os coccyx, are quite rudimentary, being much reduced in size and number. In the basal portion, the vertebra are likewise few, are united firmly together, and are arrested in development; but they have been rendered much broader and flatter than the corresponding rertebræ in the tails of other animals: they constitute what Broca calls the accessory sacral vertebræ. These are of functional importance by supporting certain internal parts and in other ways; and their modification is directly connected with the erect

90 Mi. St. George Mivart, 'Proc. Zoolog. Soc.' 1865, pp. 562, 583. Dr. J. E. Gray, 'Cat. Brit. Mus. : Skeietons.' Owen, 'Anatomy of Ver tebrates,' vol సे. p. 517. Isidore
Geoffroy, 'Hist. Nat. Gén.' tom. ii. p. 244.

91 'Revue d' Anthropologie,' 1872; 'La Constitution des Vertèbres caudales, 
or semi-erect attitude of man and the anthropomorphous apes. 'This conclusion is the more trustworthy, as Broca formerly held a different view, which he has now abandoned. The modification, therefore, of the basal caudal vertebro in man and the higher apes may have been effected, directly or indirectly, through natural selection.

But what are we to say about the rudimentary and variable vertebræ of the terminal purtion of the tail, forming the os coscyx? A notion which has often been, and will no doubt again be ridiculed, namely, that friction has had something to do with the disappearance of the external portion of the tail, is not so ridiculous as it at first appears. Dr. Anderson ${ }^{92}$ states that the extremely short tail of Macacus brunneus is formed of eleven vertebræ, including the imbedded basal ones. The extremity is tendinous and contains no vertebræ; this is succeeded by five rudimentary ones, so minute that together they are only one line and a half in length, and these are permanently bent to one side in the shape of a hook. The free part of tho tail, only a little above an inch in length, includes only four more small vertebræ. This short tail is carried erect; but about a quarter of its total length is doubled on to itself to the left; and this terminal part, which includes the hook-like portion, serves " to fill up the interspace between the upper divergent portion " of the callosities;" so that the animal sits on it, and thus renders it rough and callous. Dr. Anderson thus sums up his observations: "These facts seem to me to have only one explanation; "this tail, from its short size, is in the monkey's way when it "sits down, and frequently becomes placed under the animal " while it is in this attitude; and from the circumstance that it " does not extend beyond the extremity of the ischial tuberosities " it seems as if the tail originally had been bent round, by the "will of the animal, into the interspace between the callosities, to " escape being pressed betricen them and the ground, and that " in time the curvature became permanent, fitting in of itself "when the organ happens to be sat, upon." Under these circumstances it is not surprising that the surface of the tail should have been roughened and rendered callous ' nnd Dr. Murie, ${ }^{93}$ who carefully observed this species in the Zoological Gardens, as well as three other closely allied forms with slightly longer tails, says that when the animal sits down, the tail "is necessarily thrust " to one side of the buttocks; and whether long or short its root "is consequently liable to be rubbed or chafed." As we now 510.

22 'Proc. Zooiog. Soc.' 187', p.

\footnotetext{
$780^{\circ}$.
} 
have evidence that mutilations occasionally produce an inherited effect, ${ }^{94}$ it is not very improbable that in short-tailed monkeys, the projecting part of the tail, being functionally useless, should after many generations have become rudimentary and distorted, from being continually rubbed and chafed. We see the projecting part in this condition in the Hacucus brurneus, and absolutely aborted in the M. ecaudatus and in several of the higher apes. Finally, then, as far as we can judge, the tail has disappeared in man and the anthropomorphous apes, owing to the terminal portion having been injured by friction during a long lapse of time; the basal and embedded portion having been reduced and modified, so as to become suitable to the erect or semi-erect position.

I have now endearoured to shew that some of the most distinctive characters of man have in all probability been acquired, either directly, or more commonly indirectly, through natural selection. We should bear in mind that modifications in structure or constitution, which do not serve to adapt an organism to its habits of life, to the food which it consumes, or passively to the surrounding conditions, cannot have been thus acquired. We must not, however, be too confident in deciding what modifications are of service to each being: we should remember how little we know about the use of many parts, ol' what changes in the blood or tissues may serve to fit an organism for a new climate or new kinds of food. Nor must we forget the principle of correlation, by which, as Isidore Geoffroy has shewn in the case of man, many strange deriations of structure are tied together. Independently of correlation, a change in one part often leads, through the increased or decreased nse of other parts, to other changes of a quite unexpected nature. It is also well to reflect on such facts, as the wonderful growth of galls on plants caused by the poison of an insect, and on the remarkable changes of colour in the plumage of purrots when fed on certain fishes, or inoculated with the poison of toads; ${ }^{95}$ for Tre can thus see that the fluids of the system, if altered for some special purpose, might induce other changes. We should especially bear in mind that modifications acquired

o4 I aliude to Dr. Brown-Séquard's observations on the transmitted effect of an operation causing epileps:y" in guinea-pigs, and likewise more recently ou the analogous efiects of cutting the srmpathetic nerve in the neck. I shall hereafter hare occasion to refer to MIr. Salvin's anteresting case of the appratiy inherited effects of mot-mots biting off the barbs of their own tail. feathers. See also on the general subject "Variation of Animals and Plants under Donestication,' rol. ii., pp. 22-24.

95. 'The Variation of Animals and Plants under Domestication,' rol. i. II. $2801,282$. 
and continually used during past ages for sonie useful purpose, would probably become firmly fixed, and might be long inherited.

Thus a large yet undefined extension may safely be given to the direct and indirect results of natural se!ection; but I now admit, after reading the essay by Nïgeli on plants, and the remarks by various authors with respect to animals, more especially those recently made by Professor Broca, that in the earlier editions of my 'Origin of Species' I perhaps attributed too much to the action of natural selection or the survival of the fittest. I have altered the fifth edition of the 'Origin' so as to confine my remarks to adaptive changes of structure; but I am convinced, from the light gained during even the last few years that very many structures which now appear to us useless, will hereafter be proved to be useful, and will therefore come within the range of natural selection. Nevertheless, I did not formerly consider sufficiently tho existence of structures, which, as far as we can at present judge, are neither beneficial nor injurious and this I believe to be one of the greatest oversights as yet detected in my work. I may be permitted to say, as some excuse, that I had two distinct objects in view; firstly, to shew that species had not been separately created, and sccondly, that natural selection had been the chief agent of change, though largely aided by the inherited effects of habit, and slightly by the direct action of the surrounding conditions. I was not, however, able to annul the influence of my former belief, then almost universal, that each specics had been purposely created; and this led to my tacit assumption that erery detail of structure, excepting rudiments, was of some special, though unrecognised, service. Any one with this assumption in his mind would naturally extend too far the action of natural selection, either during past or present times. Some of those who admit the principle of erolution, but reject natural selection, seem to forget, when criticising my book, that I had the above two objects in view; hence if I have erred in giving to natural selection great power, which I am very far from admitting, or in having exaggerated its power, which is in itself probable, I have at least, as I hope, done good service in aiding to overthrow the dogma of separate creations.

It is, as I can now see, probable that all organic beings, including man, possess peculiarities of structure, which neither are now, nor were formerly of any service to them, and which, therefore, are of no physiological importance. We know not what produces the numberless slight differences between tho individuals of each species, for reversion only carries the problem a fer steps backwards; but each peculiarity must 
have had its efficient cause. If these causes, whatever they may be, were to act more uniformly and energetically during a lengthened period (and against this no reason can be assigned), the result would probably be not a mere slight individual difference, but a well-marked and constant modification, though one of no physiological importance. Changed structures, which are in no way beneficial, cannot be kept uniform through natural selection, though the injurious will be thus eliminated. Uniformity of character would, however, naturally follow from the assumed uniformity of the exciting causes, and likewise from the free intercrossing of many individuals. During successive periods, the same organism might in this manner acquire successive modifications, which would be transmitted in a nearly uniform state as long as the exciting causes remained the same and there was free intercrossing. With respect to the exciting causes we can only say, as when speaking of so-called spontaneous variations, that they relate much more closely to the constitution of the varying organism, than to the nature of tho conditions to which it has been subjected.

Conclusion.-In this chapter we have seen that as man at the present day is liable, like every other animal, to multiform individual differences or slight variations, so no doubt were the early progenitors of man; the rariations being formerly induced by the same general causes, and governed by the same general and complex laws as at present. As all animals tend to multiply beyond their means of subsistence, so it must have been with the progenitors of man; and this would inevitably lead to a struggle for existence and to natural selection. The latter process would be greatly aided by the inherited effects of the increased use of parts, and these two processes would incessantly react on each other. It appears, also, as we shall hereafter see, that various unimportant characters have been acquired by man through sexual selection. An unexplained residuum of change must be left to the assumed uniform action of those unknown agencies, which occasionally induce strongly marked and abrupt deviations of structure in our domestic productions.

Judging from the habits of savages and of the greater number of the Quadrumana, primeval men, and even their ape-like progenitors, probably lived in society. With strictly social animals, natural selection sometimes acts on the individual, through the preservation of variations which are beneficial to the community. A community which includes a large number of well-endowed individuals increases in number, and is victorious over other less favoured ones; even although each separate 
member gains no advantage over the others of the same community. Associated insects have thus acquired many remarkable structures, which are of little or no service to the individual, such as the pollen-collecting apparatus, or the sting of the worker-bee, or the great jaws of soldier-ants. With the higher social animals, I am not aware that any structure has becn modified solely for the good of the community, though some are of secondary service to it. For instance, the horns of ruminants and the great canine teeth of baboons appear to have been acquired by the males as weapons for sexual strife, but they are used in defence of the herd or troop. In regard to certain mental powers the case, as we shall see in the fifth chapter, is wholly different; for these faculties have beell chiefly, or even exclusively, gained for the benefit of the community, and the individuals thereof, have at the same time gained an advantage indirectly.

It has often been objected to such viows as the foregoing, that man is one of the most helpless and defenceless creatures in the world; and that during his early and less well-developed condition he would have been still more helpless. The Duke of Argyll, for instance, insists" that "the human frame has " diverged from the structure of brutes, in the direction of " greater physical helplessness and weakness. That is to say, it " is a divergence which of all others it is most impossible to "ascribe to mcre natural selection." He adduces the naked and unprotected state of the body, the absence of great tecth or claws for defence, the small strength and speed of man, and his slight power of discovering food or of avoiding danger by smell. To these deficiencies there might we added ono still more serious, namely, that he cannot climb quickly, and so cscape from enemies. The loss of hair would not have been a great injury to the inhabitants of a warm country. For we know that the unclothed Fuegians can exist under a wretched climate. When we compare the defenceless state of man with that of apes, we must remember that the great canine teeth with which the latter are provided, are possessed in their full development by the males alone, and are chiefly used by them for fighting with their rivals; yet the females, which are not thus provided, manage to survive.

In regard to bodily size or strength, we do not know whether man is descended from some small species, like the chimpanzee, or from one as powerful as the gorilla; and, therefore, we cannot say whether man has become larger and stronger, or smaller 
and wcaker, than his ancestors. We should, however, bear in mind that an animal possessing great size, strength, and ferocity, and which, like the gorilla, could defend itself from all enemies, would not perhaps have become social; and this would most effectually have checked the acquirement of the higher mental qualities, such as sympathy and the love of his fellows. Hence it might have been an immense advantage to man to have sprung from some comparatively weak creature.

The small strength and speed of man, his want of natural weapons, \&c., are more than counterbalanced, firstly, by his intellectual powers, through which he has formed for himself weapons, tools, \&c., though still remaining in a barbarous state, and, secondly, by his social qualities which lead him to gire and receive aid from his fellow-men. No country in the world abounds in a greater degree with dangerous beasts than Southern Africa; no country presents more fearful physical hardships than the Arctic regious; yet one of the puniest of races, that of the Bushmen, maintains itself in Southern Africa, as do the dwarfed Esquimaux in the Arctic regions. The ancestors of man were, no doubt, inferior in intellect, and probably in social disposition, to the lowest existing sarages; but it is quite conceivable that the might have existed, or eren flourished, if they had advanced in intellect, whilst gradually losing their brute-like powers, such as that of climbing trees, \&c. But these ancestors would not have been exposed to any special danger, even if far more helpless and defenceless than any existing savages, had they inhabited some warm continent or large island, such as Australia, New Guinea, or Borneo, which is now the home of the orang. And natural selection arising from the competition of tribe with tribe, in some such large area as one of these, together with the inherited effects of habit, would, under favourable conditions, have sufficed to raise man to his preseut high mosition in the orgaric scale. 
CHAPTER III.

\section{Coyidalison of the Mental Powers of Mian and the Lower ANimals.}

The diflerence in mental power between the highest ape and the lowest savage, immense - Certain instincts in common - The emotions Curiosity - Initation - Attention - Nemory - Imagination - ReasonProgressive improvement - Tools and weapons used by animals Abstraction, self-consciousness-Language-Sense of beauty-Belief in God, spiritual agencies, superstitions.

$W_{E}$ have scen in the last two chapters that man bears in his bodily structure clear traces of his descent from some lower form; but it may be urged that, as man differs so greatly in his mental power from all other animals, there must be some error in this conclusion. No doubt the difference in this respect is enormous, even if we compare the mind of one of the lowest sarages, who has no words to express any number higher than four, and who uses hardly any abstract terms for common objects or for the affuctions, ${ }^{1}$ with that of the most highly organised ape. The difference would, no doubt, still remain immense, even if one of the higher apes had been improved or civilised as much as a dog has been in comparison with its parent-form, the wolf or jackal. The Fuegians rank amongst the lowest barbarians; but I was continually struck with surprise how closely the three natives on board H.M.S. "Beagle," who had lived some years in England, and could talk a littlo English, resembled us in disposition and in most of our mental faculties. If no organic being excepting man had possessed any mental power, or if his powers had been of a wholly different nature from those of the lower animals, then we should never have been able to convince ourselves that our high faculties had been gradually dereloped. But it can be shewn that there is no fundamental difference of this kind. Wo must also admit that there is a much wider interval in mental power between one of the lowest fishes, as a lamprey or lancelet, and one of the higher apes, than between an ape and man; yet this interval is filled up by numberless gradations.

Nor is the difference slight in moral disposition between a barbarian, such as the man described by the old navigator

1 See the evidence on those points, as given by Lubboc', "F'rehistoric Times, F. 354, \&c 
Byron, who dashed his child on the rocks iur dropjing a basket of sea-urchins, and a Hotrard or Clarkson; and in intellect, between a savage who uses hardly any abstract terms, and a Newton or Shakspeare. Differences of this kind between the highest men of the highest races and the lowest sarages, are connected by the finest gradations. Therefore it is possible that they might pass and be developed into each other.

My object in this chapter is to shew that there is no fundamental difference between man and the higher mammals in their mental faculties. Each division of the subject might have been extended into a scparate essay, but must here be treated briefly. As no classification of the mental powers has been universally accepted, I shall arrange my remarks in the order most convenient for my purpose; and will select those facts which have struck me most, with the hope that they may produce some effect on the reader.

With respect to animals very low in the scale, I shall give some additional facts under Sexual Selection, shewing that their mental powers are much higher than might have been expceted. The variability of the faculties in the individuals of the same species is an important point for us, and some few illustrations will here be giren. But it would be superfluous to enter into many details on this head, for I have found on frequent enquiry, that it is the unanimous opinion of all those who hare long attended to animals of many kinds, including birds, that the individuals differ greatly in every mental characteristic. In what manner the mental powers were first developed in the lowest organisms. is as hopeless an enquiry as how life itself first originated. These aro problems for the distant future, if they are ever to be solved by man.

As man possesses the same senses as the lower animals, his fundamental intuitions must be the same. Man has also some few instincts in common, as that of self-preservation, sexual love, the love of the mother for her ner-born offspring, the desire possessed by the latter to suck, and so forth. But man, perhaps, has somewhat ferver instincts than those possessed by the animals which come next to him in the series. The orang in the Eastern islands, and the chimpanzee in Africa, build platforms on which they sleep; and, as both species follow the same habit, it might be argued that this was due to instinct, but we cannot feul sure that it is not the result of both animals having similar wants, and possessing similar powers of reasoning. These apes, as we may assume, avoid the many poisonous fruits of the tropics, and man has no such knowledgo: but as our domestic animals, when taken to forcign lands, and when first 
turned out in the spring, nften eat poisonous herbs, which they afterwards aroid, we cannot feel sure that the apes do not learn from their own experience or from that of their parents what fruits to select. It is, however, certain, as we shall presently see, that apes have an instinctive dread of serpents, and probably of other dangerous animals.

The fermess and the comparative simplicity of the instincts in the higher animals are remarkable in contrast with those of the lower animals. Cuvier maintained that instinct and intelligence stand in an inverse ratio to each other; and some have thought that the intellectual faculties of the higher animals have been gradually developed from their instincts. But Pouchet, in an interesting essay, ${ }^{2}$ has shewn that no such inverse ratio really exists. Those insects which possess the most wonderful instincts are certainly tho most intelligent. In the vertebrate series, the least intelligent members, namely fishes and amphibians, do not possess complex instincts; and amongst mammals the animal most remarkable for its instincts, namely the beaver, is highly intelligent, as will be admitted by every one who has read Mr. Morgan's excellent work. ${ }^{3}$

Although the first dawnings of intelligence, according to $\mathrm{Mr}$. Herbert Spencer, ${ }^{4}$ have been developed through the multiplication and co-ordination of reflex actions, and although many of the simpler instincts graduate into reflex actions, and can hardly be distinguished from them, as in the case of young animals sucking, yet the more complex instincts seem to have originatea independently of intelligence. I am, however, very far from wishing to deny that instinctive actions may lose their fixed aud untaught character, and be replaced by others performed by the: aid of the free will. On the other hand, some intelligent actioms, after being performed during several generations, become converted into instincts and are inherited, as when birds on oceanic islands learn to aroid man. 'These actions may then be said to be degraded in character, for they are no longer performed through reason or from experience. But the greater number of the more complex instincts appear to have been gained in a wholly different manner, through the natural selection of variations of simpler instinctive actions. Such variations appear to arise from the same unknown causes acting on the cerebral organisation, which induce slight variations or individual differences in other parts of the body; and these variations, owing

2 'L'Instinct chez les Insectes.' 'Revue des Deux Mondes,' Feb. 1870, p. 690 .
3 'The American Beaver and 5 's Works,' 1868 .

4 'The Principles of Psychology. 2nd edit. 1870, pp. 418-443. 
to our ignorance, are often said to arise spontaneously. We can, I think, come to no other conclusion with respect to the origin of the more complex instincts, when we reflect on the marvellous instincts of sterile worker-ants and bees, which leare no offspring to inherit the effects of experience and of modificd habits.

Although, as we learn from the above-mentioned insects and the beaver, a high degree of intelligence is certainly compatiblo with complex instincts, and although actions, at first learnt voluntarily can soon through habit be performed with the "quickness and certainty of a reflex action, yet it is not improbable that there is a certain amount of interference between the development of free intelligence and of instinct,-which latter implies some inherited modification of the brain. Little is known about the functions of the brain, but we can perceive that as the intellectual powers become highly developed, the various parts of the brain must be connected by very intricate channels of the freest intercommunication; and as a consequence, each scparate part would perhaps tend to be less well fitted to answer to particular sensations or associations in a definite and inherited-that is instinctive-manner. There secms even to exist some relation between a low degree of intelligence and a strong tendency to the formation of fixed, though not inherited habits; for as a sagacious physician remarked to me, persons who are slightly imbecile tend to act in everything by routine or habit; and they are rendered much happier if this is encouraged.

I have thought this digression worth giving, because we may easily underrate the mental powers of the higher animals, and especially of man, when we compare their actions founded on the memory of past events, on foresight, reason, and imagination, with exactly similar actions instinctively performed by the lower animals; in this latter cesse the capacity of performing such actions has been gained, step by step, through the variability of the mental organs and natural selection, without any conscious intelligence on the part of the animal during each successive generation. No doubt, as MIr. Wallace has argued, ${ }^{5}$ much of the intelligent work done by man is due to imitation and not to reason; but there is this great difference between his actions and many of those performed by the lower animals, namely, that man cannot, on his first trial, make, for instance, a stone hatchet or a canoe, through his power of imitation. He has to learn his rrork by practice; a beaver, on the other hand, can make its dim or canal, and a bird its nest, as well, or nearly as well, and

' 'Contributions to the Theory of Natural Selection,' 1870, p. 212. 
a spider its wonderful web, quite as well, ${ }^{6}$ the first time it tries as when old and experienced.

To return to our immediate subject: the lower animals, like man, manifestly feel pleasure and pain, happiness and misery Liappiness is never better exhibited than by young animals, such as puppies, kittens, lambs, \&c., when playing together, like our own children. Even insects play together, as has been described by that excellent observer, P. Huber, ${ }^{7}$ who saw ants chasing and pretending to bite each other, like so many puppies.

The fact that the lower animals are excited by the same emotions as ourselves is so well established, that it will not be necessary to weary the reader by many details. Terror acts in the same manner on them as on us, causing the muscles to tremble, the heart to palpitate, the sphincters to be relaxed, and the hair to stand on end. Suspicion, the offspring of fear, is eminently characteristic of most wild animals. It is, $\mathrm{I}$ think, impossible to read the account given by Sir E. Tennent, of the behaviour of the female elephants, used as decoys, without almitting that they intentionally practise deceit, and well know what they are about. Courage and timidity are extremely variable qualities in the individuals of the same species, as is plainly seen in our dogs. Some dogs and horses are ill-tempered, and easily turn sulky; others are good-tempered; and these qualities are certainly inherited. Every one knows how liable animals are to furious rage, and how plainly they show it. Many, and probably true, anecdotes have been published on the long-delayed and artful revenge of rarious animals. Thr accurate Rengger, and Brehm ${ }^{8}$ state that the Amcrican and African monkeys which they kept tame, certainly revenged themselves. Sir Andrew Smith, a zoologist whose scrupulous accuracy was known to many persons, told me tho following story of which he was himself an eye-witness; at the Cape of Good Hope an officer had often plagrued a certain baboon, and the animal, sceing him approaching one Sunday for parade, poured water into a hole and hastily made some thicl: mud, which he skilfully dashed orer the officer as he passed by, to the amusement of many bystanders. For long afterwards the baboon rejoiced and triumphed whenever he saw his victim.

6 For the evidence on this lisad, see Mr. J. Traherne Morrgridge's most interesting work, 'Harresting Ants and 'Trap-doos' Spiders,' 1873, p. 126, 128.

7 'Recherches sur les Mcurs ies Fourmis,' 1810, p. 173.
- All the following statements, given on the authority of these two naturalists, are taken from Rengger's - Naturgesch. der Säugethiere roz Paraguar,' 1830, s. 41-57, and from Brehm's 'Thierleben,' B. i s. 1(1-8) 
The love of a dog for his master is notorious; as an old writer quaintly says," "A dog is the only thing on this earth "that luvs you more than he luvs himself."

In the agony of death a dog has been known to caress his master, and every one has heard of the dog suffering under vivisection, who licked the hand of the operator; this man, unless the operation was fully justified by an increase of our knowledge, or unless he had a heart of stone, must have felt remorse to the last hour of his life.

As Whowell ${ }^{10}$ has well asked, "who that reads the touching " instances of maternal affection, related so often of the women of " ail nations, and of the females of all animals, can doubt that the "principle of action is the same in the two cases?" We see maternal affection exhibited in the most trifling details; thus Rengger observed an American monkey (a Cebus) carefully driving away the flios which plagued her infant; and Duvaucel saw a Hylohates washing the faces of her young ones in a stream. So intense is the grief of female monkeys for the loss of their young, that it invariably caused the death of certain kinds liept under confinement by Brehm in N. Africa. Orphan monkey's were always adopted and carefully guarded by the other monkeys, both males and females. One female baboon had so capacious a heart that she not only adopted young monkeys of other species, but stole young dogs and cats, which she continually carried about. Her kindness, however, did not go so far as to share her food with her adopted offspring, at which Brehm was surprised, as his monkeys always divided everything quite fairly with their own young ones. An adopted kitten scratched this affectionate baboon, who certainly had a fine intellect, for she was much astonished at being scratched, and immediately examined the kitten's feet, and without more ado bit off tho claws. ${ }^{11}$ In the Zoological Gardens, I heard from the keeper that an old baboon (C. chacma) had adopted a Rhesus monkey; but when a young drill and mandrill were placed in the cage, she seemed to perceive that these monkeys, though distinct species, were her nearer relatives, for she at once rejected the Rhesus and adopted both of them. The young Rhesus, as I saw, was greatly discontented at being thus rejected, and it would, like a naughty child, annoy and attack the young drill and mandrill

9 Quoted by Dr. Lauder Lindsay, in his 'Physiology of Mind in the Lower Animals ;' 'Journal of Mental Science,' A pril 18\%', p. 38.

10 'Bridgewater Treatise,' p. 263.

i1 A crits, without any grounds ('Quarterly Review:' July 1871, p.
72), disputes the possibility of this act as described by Brehm, for the sake of discreciting my work. Therefore I tried and found that I could readily seize with my own teeth the sharp ittle claws of a kitten nearly five weeks old. 
whenever it could do so with safety; this conduct exciting great indignation in the old baboon. Monkeys will also, according to Trehm, defend their master when attacked by any one, as well as dogs to whom they are attached, from the attacks of other dogs. But we here trench on the subjects of sympatluy and fidelity, to which I shall recur. Some of Brehm's monkeys took much delight in teasing a certain old dog whom they disliked, as well as other animals, in various ingenious mays.

Most of the more complex emotions are common to the higher animals and ourselves. Every one has seen how jealous a dog is of his master's affection, if lavished on any other creature; and I have observed the same fact with monkeys. This shews that animals not only love, but have desire to be loved. Animals manifestly feel emulation. They love approhation or praise; and a dog carrying a basket for his master exhibits in a high degree self-complacency or pride. There can, I think, be no doubt that a dog feels shame, as distinct from fear, and something very like modesty when begging too often for food. A great dog scorns the snarling of a little dog, and this may be called magnanimity. Several observers have stated that monkeys ccrtainly dislike being laughed at; and they sometimes in rent imaginary offences. In the Zoological Gardens I saw a baboon who always got into a furious rage when his keeper took out a letter or book and read it aloud to him; and his rage was so violent that, as I witnessed on one occasion, he bit his own leg till the blood flowed. Dogs show what may be fairly called a sense of humour, as distinct from mere play; if a bit of stick or other such object be thrown to one, he will often earry it away for a short distance; and then squatting down with it on the ground close before him, will wait until his master comes quite close to take it away. The dog will then seize it and rush away in triumph, repeating the same manœuvre, and evidently enjoying the practical joke.

We will now turn to the more intellectual cmotions and faculties, which are very important, as forming the basis for the development of the higher mental powers. Animals manifestly enjoy excitement, and suffer from ennui, as may be seen with (logs, and, according to Rengger, with monkeys. All animals feel Wonder, and many exhibit Curiosity. They sometimes suffer from this latter quality, as when the hunter plays antics and thus attracts them; I have witnessed this with deer, and so it is with the wary chamois, and with some kinds of wild-ducks. Lrehm gives a curious account of the instinctive dread, which bis monkeys exhibited, for snakes; but their curiosity was so great that they conld not desist from occasionally satiating 
their horror in a most human fashion, by lifting up the lid of the box in which the snakes were kept. I was so much surprised at his account, that I took a stuffed and coiled-up snake into the monkey-house at the Zoological Gardens, and the excitement thus caused was one of tho most curious spectacles which I ever beheld. Threo species of Cercopithecus were the most alarmed; they dashed about their cages, and uttered sharp signal cries of danger, which were understood hy the other monkeys. A few young monkeys and one old Anubis baboon alone took no notice of the snake. I then placed the stuffed specimen on the ground in one of the larger compartments. After a time all the monkeys collected round it in a large circle, and staring intently, presented a most ludicrous appearance. They became extremely nervous; so that when a wooden ball, with which they reve familiar as a plaything, was accidentally moved in the straw, under which it was partly hidden, they all instantly starterl away. These monkeys behaved very differently when a dear fish, a mouse, ${ }^{12}$ a living turtle, and other new objects were placed in their cages; for though at first frightened, they soon approached, bandled and examined them. I then placed a live snake in a paper hag, with the mouth loosely closed, in one of the larger compartments. One of the monkeys immediately appronched, cautiously opened the bag a little, peeped in, and instantly dashed away. Then I witnessed what Brehm has described, for monkey after monkey, with head raised high and turned on one side, could not resist taking a momentary peep into the upright bag, at the dreadful object lying quictly at the bottom. It would almost appear as if monkeys had some notion of zoological affinities, for those kept by Brehm exhibited a strange, though mistaken, instinctive dread of innocent lizards and frogs. An orang, also, has been known to be much alarmed at the first sight of a turtle.13

The principle of Initution is strong in man, and especially, as I have myself observed, with savages. In certain morbid states of the brain this tendency is exaggerated to an extraordinary degree; some hemiplegic patients and others, at the commencement of inflammatory softening of the brain, unconsciously imitate every word which is uttered, whether in their own or in a foreign language, and every gesture or action which is performed near them. ${ }^{14}$ Desor ${ }^{15}$ has remarked that no animal

12 I have given a short account of their behaviour on this occrsion in my 'Expression of the Emotions,' p. 43 .

3 W. C. J., Martin, 'Nat, Hist.

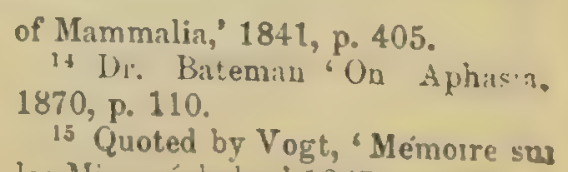
les Microcépluales,' 1865, 1). Ilis. 
roluntarily imitates an action performed by man, until in the; ascending scale wo come to monkeys, which are well known to he ridiculous mockers. Animals, however, sometimes imitato cach other's actions: thus two species of wolves, which had been reared by dogs, learned to bark, as does sometimes the jackal," but whether this can bo called voluntary imitation is another question. Birds imitate the songs of their parents, and sometimes of other birds; and parrots are notorious imitators of any sound which they often hear. Dureau de la Malle gives as account ${ }^{17}$ of a dog reared by a cat, who learnt to imitate the well-known action of a cat licking her paws, and thus wasling her ears and face; this was also witnessed by the celebrated naturalist Audouin. I have received several confirmatory accounts; in one of these, a dog had not been suckled by a cat, but had been brought up with one, together with kittens, and had thus acquired the above habit, which he ever aftcrwards practised during his life of thirteen years. Durean de la Malle's dog likewise learnt from the kittens to play with a ball by rolling it about with his fore paws, and springing on it. A correspondent assures me that a cat in his house used to put her paws into jugs of milk having too narrow a mouth for her head. A kitten of this cat soon learned the same trick, and practised it ever afterwards, whenever there was an opportunity.

The parents of many animals, trusting to the principle of imitation in their young, and more especially to their instinctive or inherited tendencies, may be said to educate thom. We see this when a cat brings a live mouse to her kittens; and Dureau de la Malle has given a curious account (in the paper above quoted) of his observations on bawks which taught their young dexterity, as well as judgment of distances, by first dropping through the air dead mice and sparrows, which the young generally failed to catch, and then bringing them live birds and letting them loose.

Hardly any faculty is more important for the intellectual progress of man than Attention. Animals clcarly manifest this power, as when a cat watches by a hole and prepares to spring on its prey. Wild animals sometimes become so absorbed wher thus engaged, that they may be easily approached. Mr. Bartlett has given me a curious proof how rariable this faculty is in monkeys. A man who trains monkeys to act in plays, used to purchase common kinds from the Zoolugrical Sccicty at the price? of five pounds for each; but he offered to give double the price.

16 'The Variation of Anima!s and Plants uoder Domest:cation,' vol. i. p. 27.
1; 'Annales dis Sc. Nat:' (1su Series), tom, xxii p. $39 \%$. 
if he might keep three or four of them for a few days, in order to select one. When asked how he could possibly learn so soon, whether a particular monkey would turn out a good actor, ho answered that it all depended on their power of attention. If, when he was talking and explaining anything to a monkey, its attention was easily distracted, as by a fly on the wall or other trifling object, the case was hopeless. If he tried by punishment to make an inattentive monkey act, it turned sulky. On the other hand, a monkey which carefully attended to him could always he trained.

It is almost superfluous to state that animals have excellent Iemories for persons and places. A baboon at the Cape of Good Hope, as I have been informed by Sir Andrew Snith, recognised him with joy after an absence of nine months. I had a dog who mas savage and averse to all strangers, and I purposely tried his memory after an absence of five years and two days. I went near the stable where he lived, and shouted to him in my old manner; he shewed no joy, but instantly followed me out walking, and obeyed me, exactly as if I had parted with him only half an bour before. A train of old associations, dormant during five years, had thus been instantaneously arrakened in his mind. Eren ants, as P. Huber ${ }^{18}$ has clearly shewn, recognised their fellow-ants belonging to the same community after a separation of four months. Animals can certainly by some means judge of the intervals of time between recurrent events.

The Imagination is one of the highest prerogatives of man. By this faculty he unites former images and ideas, independently of the will, and thus creates brilliant and novel results. A poet, as Jean Paul Richter remarks, ${ }^{19}$ " who must reflect whether he "shall make a character say yes or no-to the devil with him; "he is only a stupid corpse." Dreaming gives us the best notion of this power; as Jean Paul again says, "The dream is an in"voluntary art of poetry." The value of the products of our imagination depends of course on the number, accuracy, and clearness of our impressions, on our judgment and taste in sclecting or rejecting the involuntary combinations, and to a certain extent on our powcr of voluntarily combining them. As dngs, cats, horses, and probably all the higher animals, even birds ${ }^{20}$ havo vivid dreams, and this is shewn by their movements and the sounds utiered, we must admit that they possess some

\footnotetext{
18 'Les Mours des Fourmis,' 1810 , p. 150.

19 Quoted in Dr. Maudsley's 'Phy . siology and Pathology of Mind,' 1868 , pp. $19,220$.
}

20 Dr. Jerdon, 'Birds of India, vol. i. 1862, p. xxi. Houzeau says that his parokeets and canary-birds dreamt: "Facultes Meutiles,' tom ii. p. 136. 
power of imagination. There must be something special, which causes dogs to howl in the night, and especially during moonlight, in that remarkable and melancholy manner called baying. A1l dogs do not do so ; and, according to Houzeau, ${ }^{21}$ they do not then look at the moon, but at some fixed point near the horizon. Houzeau thinks that their imaginations are disturbed by tho vague outlines of the surrounding objects, and conjure up before thom fantastic images: if this be so, their feelings may almost be called superstitious.

Of all the faculties of the human mind, it will, I presume, be admitted that Reason stands at the summit. Only a few persons now dispute that animals possess some puwer of reasoning. Inimals may constantly be seen to pause, deliberate, and resolve. It is a significant fact, that the more the habits of any particular animal are studied by a naturalist, the moro he attributes to reason and the less to unlearnt instincts. ${ }^{22}$ In future chapters we shall see that some animals extremely low in the scale apparently display a certain amount of reason. No doubt it is often difficult to distinguish between the porver of reason and that of instinct. For instance, Dr. Hayes, in his work on "The Open Polar Ser,' repeatedly remarks that his dogs, instead of continuing to draw the sledges in a compact body, diverged and separated when they came to thin ice, so that their weight might bo more evenly distributed. This was often the first warning which the travellers received that the ice was becoming thin and langerous. Now, did the dogs act thus from the experience of each individual, or from the example of the older and wiser dogs, or from an inherited habit, that is from instinct? This instinct may possibly have arisen since the time, long ago, when dogs were first employed by the natives in drawing their sledges; or the Arctic wolves, the parent-stock of the Esquimaux dog, may have acquired an instinct, impelling them not to attack their prey in a close pack, when on thin ice.

We can only judge by the circumstances under which actions are performed, whether they are due to instinct, or to reason, or to the mere association of ideas: this latter principle, however, is intimately connected with reason. A curious case has becn given by Prof. Möbius, ${ }^{29}$ of a pike, separated by a plate of glass from an adjoining aquarium stocked with fish, and who often dashed himself with such violence against the glass in trying to

21 'Facultés Mentales des Animaux,'1872, tom. ii. p. 181.

22 Mr. L. H. Morgan's work on 'The Americnn Beaver,' 1868, offers a good illustration of this remark.
I cannot help thinking, howerer, that he goes too far in underrating the power of Instinct.

:3 'Die Bewegungen der Thiera \&c., 1873, p. 11. 
catch the other fishes. that he was sometimes completely stunned. The pike went on thus for three months, but at last learnt caution, and ceased to do so. The plate of glass was then remored, but the pike would not attack these particular fishes, though he would devour others which were afterwards introduced; so strongly was the idea of a violent shock associated in his feeble mind with the attempt on his former neighbours. If a savage, who had never seen a large plate-glass window, were to dash himself even once against it, he would for a long time afterwards associate a shock with a window-frame; but very differently from the pike, he would probably reflect on the nature of the impediment, and be cautious under analogous circumstances. Now with monkeys, as we shall presently see, a painful or merely a disagreeable impression, from an action once performed, is sometimes sufficient to prevent the animal from repeating it. If we attribute this difference between the monkey and the pike solely to the association of ideas being so much stronger and more persistent in the one than the other, though the pike often received much the more severe injury, can we maintain in the case of man that a similar difference implies the possession of a fundamentally different mind?

Honzeau relates ${ }^{24}$ that, whilst crossing a wide and arid plain in Texas, his two dogs suffered greatly from thirst, and that hetween thirty and forty times they rushed domn the hollows to search for water. These hollows were not valleys, and there were no trees in them, or any other difference in the vegetation. and as they were absolutely dry there could have been no smell of damp earth. The dogs behared as if they knew that a dip in the ground offered them the best chance of finding. water, and Houzeau has often witnessed the same behaviour in other animals.

I have seen, as I daresay have others, that when a small object is thrown on the ground beyond the reach of one of the elephants in the Zoological Gardens, he blows through his trunk on the ground beyond the object, so that the current reflected on all sides may drive the object within his reach. Again a wellknown ethnologist, Mr. Westropp, informs me that he observed in Vienna a bear. deliberately making with his par a current in some water, which was close to the bars of his cage, so as to draw a piece of floating bread within his reach. These actions of the elephant and bear can hardly be attributed to instinct or inherited habit, as they would be of little use to an animal in a state of nature. Now, what is the difference between such

$$
\text { "F 'Facultés Mentales des Animarux, 18i2, tom. :2. p. } 285 .
$$


actions, when performed by an uncultirated man, and by one of the higher animals?

The savage and the dog hare often found water at a low level, and the coincidence under such circumstances has become associated in their minds. A cultivated man would perhaps make somo general proposition on the subject; but from all that we know of savages it is extremely doubtful whether they would do so, and a dog certainly would not. But a sarage, as well as a dog, would search in the same way, though frequently disappointed; and in both it seems to be equally an act of reason, whether or not any general proposition on the subject is consciously placed before the mind. ${ }^{25}$ The same would apply to the elephant and the bear making currents in the air or water. s'he sarage would certainly neither know nor care by what law the desired movements were effected; yet his act would bo guidea by a rude process of reasoning, as surely as would a philosopher in his longest chain of deductions. There would no doubt be this difference between him and ono of the higher animals, that he would take notice of much slighter circumstances and conditions, and would observe any connection between them after much less experience, and this would be of paramount importance. I kept a daily record of the actions of one of my infants, and when he was about eleven months old, and before he could speak a single word, I was continually struck with the greater quickness, with which all sorts of objects and sounds were associated together in his mind, compared with that of the most intelligent dogs I ever knew. But the higher animals differ in exactly the same way in this power of association from those low in the scale, such as the pike, as well as in that of drawing inferences and of observation.

The promptings of reason, after very short experience, are well shewn by the following actions of American monkeys, which stand low in their order. Rengger, a most careful observer. states that when he first gave eggs to his monkeys in Paraguay, they smashed them, and thus lost much of their contents; afterwards they gently hit one end against some hard body, and picked off the bits of shell with their fingers. After cutting themselves only once with any sharp tool, they would not toucl? it again, or would handle it with the greatest caution. Lumps of sugar were often given them wrapped up in paper; and

¿s Prof. Huxley has analysed with sdmirable clearness the mental steps by which a man, as well as a dog, arives at a conclusion in a case enalogous to that given in my text
See his article, 'Mr. Darwin's Critics,' in the 'Contemporary Re. view,' Nor. 1871, p. 462, and in his 'Critiques and Essays,' 1873, p. 279. 
Rengger sometimes put a lire wasp in the paper, so that in hastily unfolding it they got stung; after this had once happened, they always first held the packet to sieir ears to dotect any movementwithin. ${ }^{26}$

The following cases relate to dogs. MIr. Colquhoun ${ }^{27}$ winged two wild-ducks, which fell on the further side of a stream; his retriever tried to bring over both at once, but could not succeed; she then, though never before known to ruffle a feather, deliberately killed one, brought over the other, and returned for the dead bird. Col. Hutchinson relates that two partridges were shot at once, one being killed, the other wounded; the latter ran away, and was caught by the retriever, who on her return came across the dead bird; "she stopped, evidently "greatly puzzled, and after one or two trials, finding she could "not take it up without permitting the escape of the winged "bird, she considered a moment, then deliberately murdered it "by giving it a severe crunch, and afterwards brought away "both together. This was the only known instance of her " ever having wilfully injured any game." Here we have reason though not quite perfect, for the retriever might have brought the wounded bird first and then returned for the dead one, as in the case of the two wild-ducks. I give the above cases, as resting on the evidence of two independent witnesses, and hecause in both instances the retrievers, after deliberation, broke through a habit which is inherited by them (that of not killing the game retrieved), and because they shew how strong their reasoning faculty must have been to orercome a fixed habit.

I will conclude by quoting a remark by the illustrious Humboldt. ${ }^{28}$ "The mulcteers in S. America say, 'I will not give " "you the mule whose step is easiest, but la mas racional,-- the " "one that reasons best;" and as he adds, "this populan (xpres"sion, dictated by long experience, combats the system of "animated machines, better perhaps than all the arguments of "speculative philosophy." Nevertheless some writers even yet deny that the higher animals possess a trace of reason; and they endeavour to explain away, by what appears to be mere verbiage, ${ }^{2 \theta}$ all such facts as those above given.

$26 \mathrm{Mr}$. Belt, in his most interesting work, "The Naturalist in Nicaragua,' 1874 (p. 119), likewise describes various actions of a tamed Cebus, which, I think, clearly shew that this animal possessed some reascning power.

27 'The Moor and the I.och, p. 45. Col. Hutchinson on 'Dog Breaking,' 1850 , p. 46.

28 'V'ersonal Narrative,' Eng. translat., vol. iii. p. 106.

${ }^{29}$ I am glad to find that so acuto a reasoner as Mr. Leslie Stephen "Darwinism and Divinity, Essays ca Free-thinking, 1873 , p. 80), in 
It has, I think, now been shewn that man and the higher animals, especially the Primates, have some few instincts in commou. All have the same senses, intuitions, and sensations,similar passions, affections, and emotions, even the more complex ones, such as jealousy, suspicion, emulation, gratitude, ancl magnanimity; they practise deceit and are revengeful ; they are sometimes susceptible to ridicule, and eren have a sense of humour; they feel wonder and curiosity ; they possess the sam t' faculties of imitation, attention, deliberation, choice, memory, imagination, the association of ideas, and reason, though in ver. different degrees. The individuals of the same species graduate in intellect from absolute imbecility to high excellence. Thcy are also liable to insanity, though far less often than in the casc of man. ${ }^{30}$ Nevertheless, many authors have insisted that man is divided by an insuperable barrier from all the lower animals in his mental faculties. I formerly mado a collection of above a score of such aphorisms, but they are almost worthless, as their wide difference and number prove the difficulty, if not the impossibility, of the attempt. It has been asserted that man alonc is capable of progressive improvement; that he alone makes use of tools or fire, domesticates other animals, or possesses property; that no animal has the power of abstraction, or of forming general concepts, is self-conscious and comprehends itsclf; that no animal employs language; that man alone has a sense of ireauty, is liable to caprice, has the feeling of gratitude, mystery, dic.; believes in God, or is endowed with \& conscience. I wili hazard a few remarks on the more important and interesting of these points.

Archbishop Sumner formerly maintained ${ }^{31}$ that man alone is capable of progressive improvement. That he is capable of incomparably greater and more rapid improvement than is any other animal, admits of no dispute; and this is mainly due to his power of speaking and handing down his acquired knowledge. TVith animals, looking first to the individual, ever? one who has had any experience in setting traps, knows that

speaking of the scpposed impassable barrier between the minds of man and the lower animals, says, "The " distinctions, indeod, which have "s been drawn, seem to us to rest " upon no better foundation than a great many other metaphysical " distinctions; that is, the assump" tion that because you can give " two things different names, they " must therefore have different na- "tures. It is difficult to under"stand how anybody who has ever " kept a dog, or seen an elephant, "can have any doubts as to an " animal's power of purforming the " essential processes of reasoning."

so See 'Madness in Animals,' by Dr. W. Lauder Lindsay, in 'Jour'nal of Mental Science,' July 1871.

${ }^{81}$ Quoted by Sir C. Lyell, 'Antiquity of Man,' p. 497. 
roung animals can be caught much more easily than old ones; and they can be much more easily approached by an enemy. Even with respect to old animals, it is impossible to catch many in ihe same place and in the same kind of trap, or to destroy them by the same kind of poison; yet it is improbable that all should have partaken of the poison, and impossible that all should have been caught in a trap. They must learn caution by seeing their brethren caught or poisoned. In North America, where the furbearing animals have long been pursued, they exhibit, according to the unanimous testimony of all observers, an almost incredible amount of sagacity, caution and cunning; but trapping has been there so long carried on, that inheritance may possibly have come into play. I have received several accounts that when telegraphs are first set up in any district, many birds kill themselves by flying against the wires, but that in the course of a very ferw years they learn to avoid this danger, by seeing, as it would appear, their comrades killed. ${ }^{32}$

If we look to successive generations, or to the race, there is $\mathrm{n}$ o doubt that birds and other animals gradually both acquire and lose caution in relation to man or other enemies; $; 3$ and this caution is certainly in chief part an inherited habit or instinct, but in part the result of individual experience. A good observer, Leroy, ${ }^{34}$ states, that in districts where foxes are much hunted, the young, on first leaving their burrows, are incontestably much more wary than the old ones in districts where they are not much disturbed.

Our domestic dogs are descended from wolves and jackals, and though they may not have gained in cunning, and may have lost in wariness and suspicion, yet they have progressed in ccrtain moral qualities, such as in affection, trust-worthincss, temper, and probably in general intelligence. The common rat has conquered and beaten several other species throughout Europe, in parts of North America, New Zealand, and recently in Eormosa, as well as on the mainland of China. Mr. Swinhoe, who describes these two latter cases, attributes the victory of the common rat over the large Mus coninga to its superior cunning; and this latter quality may probably be attributed to the habitual

32 For additional evidence, with aetails, see M. Honzeau, 'Les Eacultés Mentales,' tom. ii. 1872, p. 147.

${ }^{3}$ See, with respect to birds on oceanic islands, my 'Journal of Researches during the royage of the "Beagle," ' 1845, p. 398. "Origin of Species,' 5th edit. p. 262.
84 'Lettres Phil.sur l'Intelligence des Animaux, nouvelle édit. 1802, p. 86.

${ }^{85}$ See the evidence on this head in chap. i. vol. $i$. ' On the Variation of Animals and Plants under Do. mestication.' 186. 
cxercise of all its faculties in aroiding extirpation by man, as well as to nearly all the less cunning or weak-minded rats having leen continuously destroyed by lim. It is, however, possible that the success of the common rat may be due to its having possessed greater cunning than its fellow-species, before it became associated with man. To maintain, independently of any direct eridence, that no animal during the courso of ages has progressed in intellect or other mental faculties, is to beg the question of the evolution of species. We have seen that, according to Lartet, existing mammals lolonging to several orders have larger braius than their ancient tertiary prototypes.

It has often been said that no animal uses any tool; but the chimpanzee in a state of nature cracks a native fruit, somewhat like a walnut, with a stone. ${ }^{37}$ Rengger ${ }^{38}$ easily taught an American monkey thus to break open hard palm-nuts; and afterwards of its own accord, it used stones to open other kinds of nuts, as well as boxes. It thus also removed the soft rind of fruit that had a disagreeable flarour. Another monkey was; taught to open the lid of a large box with a stick, and afterwards it used the stick as a lever to more heavy bodies; and 1 have myself seen a young orang put a stick into a crevice, slip his hand to the other end, and use it in the proper manner as a lever. The tamed elephants in India are well known to break off branches of trees and use them to drive away the flies; and this same act has been observed in an elephant in a state of nature. ${ }^{39}$ I have seen a young orang, when she thought she was going to be whipped, cover and protect herself with a blanket or straiv. In these several cases stones and sticks wero employed as implements; but they aro likewiso used as weapons. Brehm ${ }^{40}$ states, on the authority of the well-known traveller Schimpcr, that in Abyssinia when the baboons belonging to one specios ( $($ '. gelad $a$ ) descend in troops from the mountains to plunder the fields, they sometimes encounter troops of another species (C. hamudryas), and then a fight ensues. The Geladas roll down great stones, which the Hamadryas try to avoid, and theu both species, making a great uproar, rush furionsily against each other. Brehm, when, accompanying the Duke of Colurg-Gotha, aided in an attack with fire-arms on a troop of laboons in the pass of Mensa in Abyssinia. The baboons in return rolled so many stones down the mountain, some as large as a man's head, that the attackers had to beat a hasty retreat; and the pass wiw

97 Savage and Wyman in 'Boston Journal of .Nat. Hist.' vol. iv. 184314, p. 383.

'Saugethiere von Paraguay,'

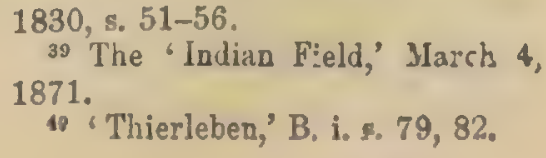


actually closed for a time against the caravan. It deserves notice that these baboons thus acted in concert. Mr. Wallace on three occasions saw female orangs, accompanied by their young, "breaking off branches and the great spiny fruit of the "Durian tree, with cvery appearance of rage; causing such a "shower of missiles as effectually kept us from approaching too "near the tree." As I have repeatedly seen, a chimpanzee will throw any object at hand at a person who offends him; and the before mentioned baboon at the Cape of Good Hope prepared mud for the purpose.

In the Zoological Gardens, a monkey, which had weak teeth, used to break open nuts with a stone; and I was assured by the keepers that after using the stone, he hid it in the straw, and would not lct any other monkey touch it. Here, then, we have the idea of property; but this idea is common to every dog with a bone, and to most or all birds with their nests.

The Duke of Argyll ${ }^{2}$ remarks, that the fashioning of an implement for a special purpose is absolutely peculiar to man; and he considers that this forms an immeasurable gulf between him and the brutes. This is no doubt a very important distinction; but there appears to me much truth in Sir J. Lubbock's suggestion, ${ }^{43}$ that when primeval man first used flint-stones for any purpose, he would have accidentally splintered them, and would then have used the sharp fragments. From this step it would be a small one to break the flints on purpose, and not a very wide step to fashion them rudely. This latter advance, however, may have taken long ages, if we may judge by the immense interval of time which elapsed before the men of the neolithic period took to grinding and polishing their stone tools. In breaking the flint3, as Sir J. Lubbock likewise remarks, sparks would have been emitted, and in grinding them heat would have been evolved: thus the two usual methods of "obtaining fire may have originated." The nature of fire would have been known in the many volcanic regions where lava occasionally flows through forests. The anthropomornhous apes, guided probably by instinct, build for themselves temporary platforms; but as many instincts are largely controlled by reason, the simpler ones, such as this of building a platform, might readily pass into a voluntary and conscious act. The orang is known to cover itself at night with the leaves of the Pandanus; and Brehm states that one of his baboons used to protect itself from the heat of the sun by throwing a straw-mat 41 'The Malay Archipelago,' vol. 145, 147. i. 1869, p. 87.

*3 'Primeral Man,' 1869, pp. 473, \&c.

43 'Prehistoric Times,' 1865, D. 
orer its head. In theso several habits, we probably see the first steps towards some of the simpler arts, such as rude architecturo and dress, as they arose amongst the early progenitors of man.

Alstruction, General Conceptions, Self-consciousness, Mental indiviluality.-It would be very difficult for any one with even much more knowledge than I possess, to determine how far animals exhibit any traces of these high mental powers. This difficulty arises from the impossibility of judging what passes through the mind of an animal; and again, the fact that writers cliffer to a great extent in the meaning which they attribute to the above terms, causes a further difficulty. If one may judge from various articles which have been published lately, the greatest stress seems to be laid on the supposed entire absence in animals of the power of abstraction, or of forming general concepts. But when a dog sees another dog at a distance, it is often clear that he perceives that it is a dog in the abstract; for when he gets nearer his wholo manner suddenly changes, if the other $\operatorname{dog}$ be a friend. A recent writer remarks, that in all such cases it is a pure assumption to assert that the mental act is not essentially of the same nature in the animal as in man. It either refers what he perceives with his senses to a mental concept, then so do both." When I say to my terrier, in an cager voice (and I have made the trial many times), "Hi, hi, where is it?" she at once takes it as a sign that something is to he hunted, and generally first looks quickly all around, and then rushes into the nearest thicket, to scent for any game, but finding nothing, she looks up into any neighbouring tree for a squirrel. Now do not these actions clearly shew that she had in her mind a general idea or concept that somo animal is to be discovered and hunted?

It may be freely admitted that no animal is self-conscious, if by this term it is implied, that he reflects on such points, as whence he comes or whither he will go, or what is life and death, and so forth. But how can we feel sure that an old dog with an excellent memory and some power of imagination, as shewn by his dreams, never reflects on his past pleasures or pains in the chase? And this would be a form of self-consciousness. On the other hand, as Büchner ${ }^{45}$ has remarked, how little can the hardworked wife of a degraded Australian savage, who uses very few abstract words, and cannot count abore four, exert her selfconsciousness, or reflect on the nature of her own existence. It is generally admitted, that the higher animals possess memory,

44 Mr. Hookham, in a letter to Prof. Mas Muiller, in th: 'Birmingbam News,' May 1873.
63 'Conférences sur la Théorie Darwinienne," French trasslat. 1860 p. 132. 
attention, association, and even some imagination and reason. If these powers, which differ much in different animals, are capable of improvement, there seems no great improbability in more complex faculties, such as the higher forms of abstraction, and self-consciousness, \&c., having been evolved through the development and combination of the simpler ones. It has been urged against the views here maintained, that it is impossible to say at what point in the ascending scale animals become capacle of abstraction, \&c.; but who can say at what age this occurs in our young children? We see at least that such powers ore developed in children by imperceptible degrees.

That animals retain their mental individuality is unquestionable. When my voice awakened a train of old associations in the mind of the before-mentioned dog, he must have retainect his mental individuality, although every atom of his brain liar probably undergone change more than once during the interral of five years. This dog might have brought forward thic argument lately advanced to crush all evolutionists, and said, "I abide amid all mental moods and all material changes. . . . "The teaching that atoms leave their impressions as legacies to "other atoms falling into the places they have vacate- $l$ is con"tradictory of the utterance of consciousness, and is therefore "false; but it is the teaching necessitated by erolutionism, con"sequently the hypothesis is a false one." 46

Language.-This faculty has justly been considered as one of the chief distinctions between man and the lower animals. But man, as a highly competent judge, Archbishop Whately remarks, " is not the only animal that can make use of language to express "what is passing in his mind, and can understand, more or less, "what is so expressed by another." 47 In Paraguay the ('ebus azarce when excited utters at least six distinct sounds, which excite in other monkeys similar emotions. ${ }^{48}$ The movements of the features and gestures of monkeys are understood by us, and they partly understand ours, as Rengger and others declare. It is a more remarkable fact that the dog, since being domesticated, has learnt to bark ${ }^{49}$ in at least four or fire distinct tones. Although barking is a new art, no doubt the wild parent-species of the dog expressed their feelings by cries of various kinds. With the domesticated dog wo have the bark of eagerness, as in the chase; that of anger, as well as growling; the yelp or howl of despair, as when shut up; the baying at night; the bark of joy, as

46 The Rev. Dr. J. M'Cann, 'AntiInrwinism,' 1869 , p. 13.

4T Quoted in 'Anthropological Reniew'1864, p. 158.
48 Rengger, ibid. 8. 45.

49 See my "Variation of Ari. mals and Plants under Domesewr. tion, vol. i. p. 27. 
when starting on a malk with his master; and the very distinct one of demand or supplication, as when wishing for a door or window to be opened. According to Houzenu, who paid particular attention to tho subject, the domestic fowl utter's at least a dozen significant sounds. ${ }^{\circ 0}$

'The habitual use of articulate language is, however, peculiar to man; but he uses, in common with the lower animals, inart1culate cries to express his meaning, aided by gestures and the movements of the muscles of the face." This especially holds good with tho more simple and vivid feelings, which are but little connected with our higher intelligence. Our cries of pain, fear, surprise, anger, together with their appropriate actions, and the murmur of a mother to her beloved child, are more expressive than any words. That which distinguishes man from the lower animals is not the understanding of articulate sounds, for, as every one knows, dogs understand many words and sentences. In this respect they are at the same stage of development as infants, hetween the ages of ten and twelve months, who understand many words and short sentences, but cannot yet utter a single word. It is not the mere articulation which is our distinguishing character, for parrots and other birds posscss this porrer. Nor is it the mere capacity of connecting definite sounds with definite ideas; for it is certain that some parrots, which have been taught to speak, connect unerringly words with things, and persons with events. ${ }^{52}$ The lower animals differ from man solely in his almost infinitely larger power of associating together the most diversified

so 'Facultés Mentales des Animaux, tom. î. 1872 , p. 346-349.

s1 See a discussion on this subject in $M$ 1. E. B. Tylor's very interesting work, "Researches into the Early" History of Mankind,' 1865, chaps. ii. to ir.

52 I have received several detailed ascounts to this effect. Admiral Six J. Sulivan, whom I know to be a careful observer, assures me that un African parrot, long kept in his father's house, invariably called certain persons of the household, as well as visitors, by their names. $\mathrm{He}$ said "good morniug" to every one at breakfust, and "good night " to each as they left the room at night, and never reversed these saiutations. T) Sir J. Sulivan's father, he usod to add to the "good morning" a short sentence, which Tras never once repeated after his father's death. He scolded violently a strange dog which came into the room through the open window; and he scolded another parrot (saying "you naughty polly") which had got out of its cage, and was eating apples on the kitchen table. See also, to the same effect, Houzeau on parrots, 'Facultés Mentales,' tom. ii. p. 309. Dr. A. Moschkau informs me that he knew a starling which never made a mistake in saying in German "good morning" to persuns arriving, and "goodbye, old tellow," to those departing. I could add serernl other such cases. 
sounds and ideas; and this obriously depends on the high development of his mental potwers.

As Horne Took, one of the founders of the noble science. of philology, observes, language is an art, like brewing or baking; but writing would have been a better simile. It certainly is not a true instinct, for every language has to be learnt. It differs, however, widely from all ordinary arts, for man has an instinctive tendency to speak, as we see in the babble of our young children; whilst no child has an instinctive tendency to brew, bake, or write. Moreover, no philologist now supposes that any language has becn deliberately invented; it has been slowly and unconsciously developed by many steps. ${ }^{53}$ The sounds uttered by birds offer in several respects the nearest analogy to language, for all the members of the same species utter the same instinctive cries expressive of their emotions; and all the kinds which sing, exert their porver instinctively; but the actual song, and even the call-notes, are learnt from their parents or foster-parents. These sounds, as Daines Barrington ${ }^{51}$ has proved, "are no more innate than language is in man." The first attempts to sing "may be compared to the imperfect " endeavour in a child to babble." The young males continue practising, or as the bird-catchers say, "recording;" for ten or" eleven months. Their first essays show hardly a rudiment of the future song; but as they grow older we can perceive what they are aiming at; and at last they are said "to sing their "song round." Nestlings which hare learnt the song of a distinet species, as with the canary-birds educated in the Tyrol, teach and transmit their nuw song to their offspring. The slight natural differences of song in the same species inlabiting different districts may be appositely compared, as Barrington remarks, "to provincial dialects;" and the songs of allied, though distinct species may be compared with the languages of distinct races of man. I have giren the foregoing details to shew that an instinctive teudency to acquire an art is not peculiar to man.

With respect to the origin of articulate language, aftor having read on the one side the highly interesting works of Mr. Heus-

63 See some good remarks on this neacl by Prof. Whitney, in his 'Oriental and Linguistic Studies,' ! 873, p. 354 . He observes that the ciesire of communication between man is the living force, which, in the develcpment of language, " norks butk cunsciously and un"sonsciously consciousily as re- "gards the immediate end to be "attained; unconsciously as regnids "the further consequeuces of the "act."

3t Hon. Daines Barrungton in 'Philosoph. Transactions,' 1773, p. 262. See also Dureau de lit Malle, iu 'Anu, les. Sc. Niat.' 3rd series, Zoolog. tom. x. y. 119. 
leigh Wedgrood, the Rev. F. Farrar, and Prof. Schleicher, ${ }^{35}$ and the celebrated lectures of Prof. Max Müller on tho other side, I caunot doubt that language owes its origin to the imitation and modification of various natural sounds, the voices of other animals, and man's own instinctive cries, aided by signs and mitues. When wo treat of sexual selection wo shall see that prineval man, or rather some early progenitor of man, probably first used his roice in producing true musical cadences, that is in singing, as do some of the gibbon-apes at the present day; and we may conclude from a widely-spread analogy, that this power would have been especially exerted during the courtship of the sexes,- - would have expressed various emotions, such as love, jealousy, triumph,-and would have served as a challenge to rivals. It is, therefore, probable that the imitation of musical cries by articulate sounds may have given rise to words expressive of various complex emotions. The strong tendency in our nearest allies, the monkeys, in microcephalous idiots, ${ }^{66}$ and in the barbarous races of mankind, to imitate whatever they hear deserves notice, as bearing on the subject of imitation. Since monkeys certainly understand much that is said to them by man, and when wild, utter signal-cries of danger to their fellows; ${ }^{77}$ and since fowls give distinct warnings for danger or the ground, or in the sky from hawks (both, as well as a third cry, intelligible to dogs), ${ }^{58}$ may not some unusually wiso ape-like animal hare imitated the growl of a beast of prey, and thus told his fellow-monkeys the nature of the expected danger? This would have been a first step in the formation of a language.

As the roice was used more and more, the vocal organs would liave been strengthened and perfected through the principle of the inherited effects of use; and this would have reacted on the power of speech. But the relation between the continued use of language and the development of the brain, has no doubt been far more important. The mental powers in some carly progenitor of man must have been more highly developed than in

53 'On the Origin of Language,' by H. Wedgwood, 1866. 'Chapters on Language,' by the Rev. F. W. Farrar, 1865. These works are most interesting. See also 'De la Phys. et de Parole, pal Albert Lemoine, 1865, p. 190. The work nn this subject, by the late Prof. Aug. Schleicher, has been translated by Dr. Bikker's into English, under the title of 'Darwinism tested by the Science of Langurge,' 1869
36 Vogt, 'Mémoire sur les Micro. céphales,' 1867, p. 169 . With r'c.. spect to savages, I have given some facts in my 'Journal of Researches,' \&c., 1845 , p. 206.

s7 See clear evidence on this head in the two works so often quoted, by Brehm and Rengger.

${ }_{58}$ Houzettu gives a very curious account of his observations $n \mathrm{n}$ this subject in his 'Facultés Mentales des Animaux,' tom. ii., p. 348. 
any existing ape, before even the most imperfect form of speech could have come into use; but we may confidently believe that the continued use and advancement of this powor would have reacted on the mind itself, by enabling and encouraging it to carry on long trains of thought. A complex train of thouglit can no more be carried on without the aid of words, whether spoken or silent, than a long calculation without the use of figures or algebra. It appears, also, that even an ordinary traiu of thought almost requires, or is greatly facilitated by some form of language, for the dumb, deaf, and blind girl, Laura Bridgman, was observed to use her finger's whilst dreaming. ${ }^{5 .}$ Nevertheless, a long succession of vivid and connected idcas may pass through the mind without the aid of any form of language, as we may infer from the movements of dogs during their dreams. We have, also, seen that animals are able to reason to a certain extent, manifestly without the aid of language. The intimate connection between the brain, as it is now developed in us, and the faculty of speech, is well shewn by those curious cases of brain-disease in which speech is specially affected, as when the power to remember substantives is lost, whilst other words can be correctly used, or where substantives of a certain class, or all except the initial letters of substantives and proper names are forgotten. ${ }^{60}$ There is no more improbability in the continued use of the mental and vocal organs leading to inherited changes in their structure and functions, than in the case of handwriting, which depends partly on the form of the hand and partly on the disposition of the mind; and hand-writing is certrinly inherited. ${ }^{61}$

Several writers, more especially Prof. Max Muiller, ${ }^{62}$ have lately insisted that the use of language implies the power of forming general concepts; and that as no animals are supposed to possess this power, an impossible barrier is formed betwcen them and man.63 With respect to animals, I have already

59 See remarks on this head by Dr. Maudsley, 'The Physiology and Pathology of Mind,'2nd edit. 1868, p. 199.

60 Many curious cases have been recorded. See, for instance, Dr. Bateman 'On Aphasia', 1870, p. 27, $31,53,100$, \&c. Also, 'Inquiries Concerning the Intellectual Powers,' by Dr. Nbercrombie, 1838, p. 150.

-1 'The Variation of Animals and 'Jants ualer Domestication,' vol. ii. y. 6 .
62 Lectures on 'Mr. Darwin's Philosophy of Language,' 1873.

${ }_{68}$ The judgment of a distinguished philologist, such as Prof. Whitney, will have far more weight on this point than anything that I can say. He remarks ('Oriental and Linguistic Studies,' 1873 , p. 297 ), in spenking of Bleek's views : "Because on the grand scale lan"guage is the necessary auxiliarv " of thought, indispensable to the "development of the power of 
endeavoured to show that they have this power, at least in a rudo and incipient degree. As far as concerns infants of from ton to cleven months old, and deaf-mutes, it seems to me incredible, that they should be able to connect certain sounds with certain general ideas as quickly as they do, unless such ideas were already formed in their minds. The same remark may be extended to the more intelligent animals; as Mr. Leslio Stephen observes, ${ }^{6 *}$ " A dog frames a general concept of cats or sheep, " and knows the corresponding words as well as a philosopher. "And the capacity to understand is as good a proof of rocal " intelligence, though in an inferior degree, as the capacity to "speak."

Why the organs now used for speech should have been originally perfected for this purpose, rather than any other orgaus, it is not difficult to see. Ants have considerable powers of intercommunication by means of their antennæ, as shewn by Huber, who devotes a whole chapter to their language. We might have used our fingers as efficient instruments, for a person with practice can report to a deaf man every word of a speech rapidly deliveren at a public meeting; but the loss of our hands, whilst thus employed, would have been a serious inconvenience. As all the higher mammals possess rocal organs, constructed on the same general plan as ours, and used as a means of communication, it was obviously probable that these same organs wonld be still further developed if the power of communication had to be improved; and this has been efieted by the aid of adjoining and well adapted parts, namely the tongue and lips. ${ }^{65}$ The fact of the higher apes not using their vocal organs for speech, no doubt depends on their intelligence not having been sufficiently advanced. The possession by them of

" thinking, to the distinctness and "variety and complexity of cogni4t tions to the full mastery of con"sciousness; therefore he would "fain make thought absolutely im"possible without speech, identify""ing the faculty with its instru. "ment. He might just as reason"ably assert that the human hand "cannot act without a tool. With " such a doctrine to start from, he "cannot stop short of Müller"s "worst paradoxes, that an infun' "(in fans, not speaking) is not a - human being, and that deaf-mutes " do not become possassed of reason "until they learla o twist thein" "fingers into imitation of spoken "words." Max Muller gives in italics ('Lectures on Mr. Darwin's Philosophy of Language, 1873, third lecture) the following aphorism: "There is no thought with" out words, as little as there are "words without thought." What a strange definition must here be given to the word thought !

of 'Essays on Free-thinking,' \&c., 1873, p. 8\%.

os See some good remarks to thit effect by Di". Maudsley, "The Phy. wiology and Pathoiogy of Miad, 1868, P. 199. 
organs, which with long-continued practice might have been used for speech, although not thus used, is paralleled by the case of many birds which possess organs fitted for singing, though they never sing. Thus, the nightingale and crow have rocal organs similarly constructed, these boing used by the former for diversified song, and by the latter only for croaking. ${ }^{66}$ If it be asked why apes have not had their intellects dereloped to the same degree as that of man, general causes only can be nssigned in answer, and it is unreasonable to expect anything more definite, considering our ignorance with respect to the successive stages of development through which each creature has passed.

The formation of different languages and of distinct species, and the proofs that both have been developed through a gradual process, are curiously parallel. ${ }^{67}$ But we can trace the formation of many words further back than that of species, for we can perceive how they actually arose from the imitation of various sounds. We find in distinct languages striking homologies due to community of descent, and analogies due to a similar process of formation. The manner in which certain letters or sounds change when others change is very like correlated growth. We have in both cases the reduplication of parts, the effects of longcontinued use, and so forth. The frequent presence of rudimonts, both in languages and in species, is still more remarkable. 'The letter $m$ in the word $\mathrm{am}$, means $I$; so that in the expression I um, a superfluous and useless rudiment has been retained. In the spelling also of words, letters often remain as the rudiments of ancient forms of pronunciation. Languages, like organic beings, can be classed in groups under groups; and they can be classed either naturally according to descent, or artificially by other characters. Dominant languages and dialects spread widely, and lead to the gradual extinction of other tongues. A language, like a species, when once extinct, never, as Sir C. Lyell remarks, reappears. The same language never has two birth-places. Distiuct languages may be crossed or hlended together. ${ }^{68}$ We see variability in crery tongue, and new

${ }^{68}$ Macgillivray, 'Hist. of British I3irds,' vol. ii. 1839 , p. 29. An excellent observer, Mr. Blackwall, remarks that the magpie learns to pronounce single words, and even short sertences, more readily than almost any other British bird; yet, as he adds, after long and ciosely investigating its habits, he has never knowr it, in is state of nature, display any unuscal capacity for imitation. 'Researches in Zoology,' 1834, p. 158.

67 See the very interesting parallelism between the development of species and languages, given $b_{y}$ Sir C. Lyell in "The Geolog. Evidences of the Antiquity of Man, 1863. chap. xxiii.

68 See remart's to this effect by 
words are continually cropping up; but as there is a limit to the powers of the memory, single words, like whole languages, gradually become extinct. As Max Müller ${ }^{60}$ has well remarked :- " A struggle for life is constantly going on amongst "the words and grammatical forms in each language. The " better, the shorter, the easier forms are constantly gaining the " upper hand, and they owe their success to their own inherent "virtue." To these more important causes of the survival of certain words, mere novelty and fashion may be added; for there is in the mind of man a strong love for slight changes in all things. The survival or preservation of certain favoured words in the struggle for existence is natural selection.

The perfectly regular and wonderfully complex construction of the languages of many barbarous nations has often been adranced as a proof, either of the clivine origin of these languagres, or of the high art and former civilisation of their founders. Thus F. von Schlegel writes: "In those languages "which appcar to be at the lowest grade of intellectual culture, "we frequently obscrve a very high and elaborate degree of art " in their grammatical structure. This is especially the case "with the Basque and the Lapponian, and many of the Ame"rican languages." any language as an art, in the sense of its having been elaborately and methodically formed. Philologists now admit that conjugrations, declensions, \&c., originally existed as distinct words, since joined together; and as such words express the most obvious relations between objects and persons, it is not surprising that they should have been used by the men of most races during the earliest ages. With respect to perfection, the following illustration will best shew how easily we may cre' a Crinoid sometimes consists of no less than 150,000 pieces of shell, ${ }^{12}$ all arranged with perfect symmetry in radiating lines; but a naturalist does not consider an animal of this kind as more perfect than a bilateral one with comparatively few parts, and with none of these parts alike, excepting on the opposite sides of the body. He justly considers the differentiation and specialisation of organs as the test of perfuction. So with languages. the most symmetrical and complex ought not to be ranked above irregular, abbreviated, and bastardised languages, which havo

the Rev. F. W. Farrar, in an interesting article, entitled 'Philology and Darwinism' in 'Nature,' March 24th, 1870 , p. 528.

69 'Nature,' Jan. 6 th, $187 \mathrm{C}, 0.257$.
10 Quoterl by C. S. Wake, 'E"hapter's on Minn,' 1868, p. 101.

i1 Buchland, 'Bridgernte: Trea. tise,' p. 411. 
borrowed cxpressive mords ard useful forms of construction from various conquering, conquered, or immigrant races.

From these few and imperfect remarks I conclude that the cxtremely complex and regular construction of many barbarous languages, is no proof that they ore their origin to a special act of creation. ${ }^{72}$ Nor, as we hare secn, does the faculty of articulate speech in itself offer any insuperable objection to the belief that man has been dereloped from some lower form.

Sense of Beauty. - This sense has been declared to be peculiar to man. I refer here only to the pleasure given by certain colours, forms, and sounds, and which may fairly bo called a sense of the beautiful ; with cultivated men such sensations are, however, jntimatoly associated with complex ideas and trains of thought. When we behold a male bird elaborately displaying his graceful plumes or splendid colours before the female, whilst other birds, not thus decorated, make no such display, it is impossible to doubt that she adnires the beauty of her male partner. As women everywhere deck themselves with these plumes, the beauty of such ornaments cannot be disputed. As we shall see later, the nests of humming-birds, and the playing passages of bower-birds are tastefully ormamented with gaily-coloured objects; and this shews that they must receive some kind of pleasure from the sight of such things. With the great majority of animals, however, the taste for the beautiful is confined, as far as re can judge, to the attractions of the opposite sex. The swect strains poured forth by many male birds during the season of love, are certainly admired by the females, of which fact evidence will hereafter be given. If female birds had been incapable of appreciating the beautiful colours, the ornaments, and roices of their male partners, all the labour und anxicty exhibited by the latter in displaying their charms before the females would have been thrown away; and this it is impossible to admit. Why certain bright colours should excite pleasurc cannot, I presume, be explained, any more than $\pi$ hy certain flarours and scents are agreeable; but habit has something to do with the result, for that which is at first unpleasant to our senses, ultimately becomes pleasant, and habits are inherited. With respect to sounds, Helmboltz has explaiued to a certain extent on physiological principles, why liarmonics and certain cadences are agreeable. But vesides this, sounds frequently recurring at irregular intervals are

72. Sie snme gool remariks on the 6:aplificaton of languages, by Sir
J. Lublock, 'Origiu of C. rilisaticy, 1870 , \& 278. 
highly disagreeable, as every one will admit who has listened at night to the irregular flapping of a rope on board ship. The same principle seems to come into play with vision, as the eyo prefers symmetry or figures with some regular recurrence. Patterns of this kind are employed by even the lowest savages as ornaments; and they have been developed through sexual selection for the adornment of some male animals. Whether we can or not give any reason for the pleasure thus derived from vision and hearing, yet man and many of the lower animals are alike pleased by the same colours, graceful shading and forms, and the same sounds.

The taste for the beautiful, at least as far as female beauty is concerned, is not of a special nature in the human mind; for it differs widely in the different races of man, and is not quite the same even in the different nations of the same race. Judging from the hideous ornaments, and the equally hideous music admired by most savages, it might be urged that their resthetic faculty was not so highly developed as in certain animals, for instance, as in birds. Obviously no animal would be capable of admiring such scenes as the hearens at night, a beautiful landscape, or refined music; but such high tastes are acquired through culture, and depend on complex associations; they are not enjoyed by barbarians or by uneducated persons.

Many of the faculties, which have been of inestimable service to man for his progressive advancement, such as the powers of the imagination, wonder, curiosity, an undefined sense of beauty, a tendency to imitation, and the love of excitement or novelty, could hardly fail to lead to capricious changes of customs and fashions. I have alluded to this point, because a recent writer ${ }^{i s}$ has oddly fixed on Caprice "as one of the most remarkable and "typical differences between savages and brutes." But not only can we partially understand how it is that man is from various conflicting influences rendered capricious, but that the lower animals are, as we shall hereafter see, likewise capricious in their affections, aversions, and sense of beauty. There is also reason to suspect that they love novelty, for it own sake.

Belief in God-Religion.-There is no evidence that man was aboriginally endowed with the ennobling belief in the existence of an Omnipotent God. On the contrary there is ample eridence, derived not from hasty travellers, but from men who have long resided with savages, that numerous races have existed, and still exist, who have no idea of one or more gods, and who have no

13 'The Spectator,' Dec. 4th, 1869, p. 1430. 
words in their languages to express such an idea. ${ }^{74}$ The question is of course wholly distinct from that higher one, whether there exists a Creator and Ruler of the universe; and this has boen answered in the affirmative by some of the highest intellects that have ever existed.

If, however, we include under the term "rcligion" the belief in unseen or spiritual agencies, the case is wholly different; for this belief seems to be universal with tho less cirilised races. Nor is it difficult to comprehend how it arose. As soon as tho important faculties of the imagination, wonder, and curiosity, together with some power of reasoning, had become partially developed, man would naturally crave to understand what was passing around him, and would have vaguely speculated on his own existence. As Mr. M'Lennan ${ }^{75}$ has remarked, "Some cxplan"ation of the phenomena of life, a man must feign for himself. " and to judge from the universality of it, the simplest hypothesis. " and the first to occur to men, seems to have been that natural "phenomena are ascribable to the presence in animals, plants, " and things, and in the forces of nature, of such spirits prompting "to action as men are conscious they themselves possess." It is also probable, as Mr. Tylor has shewn, that dreams may have first given rise to the notion of spirits; for savages do not readily distinguish betrveen subjective and objective impressions. When a savage dreams, the figures which appear before him are believed to have come from a distance, and to stand over him; or " the soul of the dreamer goes out on its travels, and comes " home with a remembrance of what it has scen." Bs But until

74 See an excellent article on this subject by the Rev. F. W. Farrar, in the "Anthropological Review, Aug. 1864, p. ccxvii. For further facts see Sir J. Lubbock, 'Pre. historic Times,' 2nd edit. 1869, p. 564 ; and especially the chapters on Religion in his 'Origin of Civilisation,' 1870.

75 "The Worship of Animals and Plants,' in the 'Fortnightly Review,' Oct. 1, 1869, p. 422 .

76 Tylor, 'Early History of MaDkind," 1865, p. 6 . See also the ihree striking chapters on the Development of Religion, in Lubbock's 'Origin of Civilisation,' 1870. In a iike manner $\mathrm{Mr}_{\mathrm{r}}$. Herbert Spencer, in his ingenious essay in the "Fortnightly Review' (May 1st, 1870 , p. 535), accounts for the earliest forms of religious belief throughout the world, by man being led through dreams, shadows, and other causes, to look at himself as a double essence, corporeal and spiritual. As the spiritual being is supposed to exist after death and to be powerful, it is propitiated by various gifts and ceremonies, and its aid invoked. He then further shews that names or nicknames given from some animal or other object, to the early progenitors or founders of a tribe, are supposed after a long interval to rzpresent the real progenitor of the tribe; and such animal or object is then naturally believed still to exist as a spirit, is held sacred, and worshipped as a god. Nevertheless I cannot but suspect that there is a still earlier and ruder stage, wher 
the. faculties of imagination, curiosity, reason, \&c., had been fairly well developed in the mind of man, his dreams would not have led him to believe in spirits, any more than in the case of a ling.

The tendency in savages to imagine that natural objects and agencies are animated by spiritual or living essences, is perhaps illustratcd by a little fact which I once noticed : my dog, a fullgrown and very sensible animal, was lying on the lawn during a hot and still day; but at a little distance a slight breeze occasionally moved an open parasol, which would havo been wholly disregarded by the dog, had any one stood near it. As it was, every time that the parasol slightly moved, the dog growled fiercely and barked. He must, I think, have reasoned to himself in a rapid and unconscious manner, that morement without any apparent cause indicated the presence of some strange living agent, and that no stranger had a right to be on his territory.

The belief in spiritual agencies would easily pass into the belief in the existence of one or more gods. For savages would naturally attribute to spirits the same passions, the same love of vengeance or simplest form of justice, and the same affections which they themselves feel. The Fuegians appear to be in this respect in an intermediate condition, for when the surgeon on board the "Beagle" shot some young ducklings as spocimens, York Minster declared in the most solemn manner, "Oh, Mr. Bynoe, " much rain, much snow, blow much;" and this was evidently a retributive punishment for wasting human food. So again he related how, when his brother killed a "wild man," storms long raged, much rain and snow fell. Yet we could never discovel. that the Fuegians believed in what we should call a God, or practised any religious rites; and Jemmy Button, with justifiable pride, stoutly maintained that there was no devil in his land. This latter assertion is the more remarkable, as with savages the belief in bad spirits is far more common than that in good ones.

The feeling of religious derotion is a highly complex one, consisting of love, complete submission to an cxalted and mysterious superior, a strong sense of dependcnce, ${ }^{77}$ fear, reverence, gratitude, hope for the future, and perhaps other elements. No being could experience so complex an emotion

anything which manifests power or movement is thought to be endowed with some form of life, and with mental faculties analcgers to our uwn.
17 See an able article on the 'Physical Elements of Religion,' by Mr. L. Owen Pike, in 'Anthropolog', Rorsew,' April, 1870, p. Ixiii. 
antil advanced in his intellectual and moral faculties to at least a moderately high level. Nevertheless, we see some distant approach to this state of mind in the diep love of a dog for his master, associated with complete submission, some fear, and perhaps other feelings. The behaviour of a dog when returning to his master after an absence, and, as I may add, of a monkey to his beloved keeper, is widely different from that towards their fellows. In the latter case the transports of joy appear to be somerwat less, and the sense of equality is shemn in every action. Professor Braubach goes so far as to maintain that a dog looks on his master as on a god. ${ }^{78}$

The same high mental faculties which first led man to believo in unseen spiritual agencies, then in fetishism, polytheism, and ultimately in monotheism, would infallibly lead him, as long as his reasoning powers remained poorly developed, to various strange superstitions and customs. Many of these are terrible to think of-such as the sacrifice of human beings to a bloodloving god; the trial of innocent persons by the ordeal of poison or fire; witchcraft, \&c.-yet it is well occasionally to reflect on these superstitions, for they shew us what an infinite debt of gratitude we owe to the improvement of our reason, to science, and to our accumulated knowledge. As Sir J. Lubbock ${ }^{79}$ has well observed, "it is not too much to say that the horrible dread of " unknown evil hangs like a thick cloud over savage life, and "embitters every pleasure." These miserable and indirect consequences of our highest faculties may be compared with the incidental and occasional mistakes of the instincts of the lower animals.

78 'Religion, Moral, \&c., der Darwin'schen Art-Lehre,' 1869, s. 53. It is said (Dr. W. Lauder Lindsay, 'Jcurnal of Mental Science,' 1871, p. 43), that Bacon long ago, and the poe. Burns, held the same notion. i9 'Prehistoric Times,' 2nd edit. p. 571. In this work (p. 571) there will be found an excellent account of the many strange ars capricious customs of sarages. 


\section{CHAP'TER IV.}

\section{Companison of tile Mental Powerg of MIAN and THz Lower animals-continued.}

The moral sense - Fundamental proposition - The qualities of social animals-Origin of sociability-Struggle between opposed instinctsMan a social animal-The more enduring social instincts conquer other less persistent instincts-The social virtues alone regarded by saragesThe self-regarding rirtues acquired at a later stage of developmentThe importance of the judgment of the members of the same community on conduct-Transmission of moral tendencies-Summary.

I FULLY sulscribe to the judgment of those writers ${ }^{1}$ who maintain that of all the differences between man and the lower animals, the moral sense or conscience is by far the most important. This sense, as Mackintosh" remarks, " has a "rightful supremacy over erery other principle of human "action;" it is summed up in that short but imperious word 'rught, so full of high significance. It is the most noble of all the attributes of man, leading him without a moment's hesitation to risk his life for that of a fellow-creature; or after due deliberation, impelled simply by the deep feeling of right or duty, to sacrifice it in some great cause. Immanuel Kant exclaims, "Duty! Wondrous thought, that workest neither by "fond insinuation, flattery, nor by any threat, but merely by "holding up thy naked law in the soul, and so extorting for "thyself al ways reverence, if not always obedience; before "whom all appetites are dumb, however secretly they rebel; "whence thy original?" 3

This great question has been discussed by many writers " of consummate ability; and my sole excuse for touching on it, is the impossibility of here passing it over ; and because, as far as I know, no one has approached it exclusively from the side of natural history. The investigation possesses, also, some in-

1 See, for instance, on this subject, Quatrefages, 'Unité de l'Espèce Humaine,' 1861, p. 21, \&c.

2 'Dissertation on Ethical Philosophy,' 1837, p. 231, \&c.

'Metaphysics of Ethics,' translated by J. W. Semple, Edinburgh, $: 836$, p. 136.

- Mr. Baiz gires a list ("Mental and Moral Science,' 1868, p. 543725) of twenty-six British authors who have written on this subject, and whose names are familiar to every reader; to these, Mr. Bain's own name, and those of Mr. Lecky, Mr. Shadworth Hodgson, Sir J. Lubbock, and others, might be added. 
dependent intarest, as an attempt to see how far the sturly of the lower animals throws liglit on one of the highest psychical faculties of man.

The following proposition seems to me in a high degree probable-namely, that any animal whatever, cndowed with well-marked social instincts, ${ }^{5}$ the parental and filial affections: being here included, would incvitably acquire a moral sense or conscience, as soon as its intellectual powers had become as well, or nearly as well developed, as in man. For, firstly, the social instincts lead an animal to take pleasure in the society of its fellows, to feel a certain amount of sympathy with them, and to perform various services for them. The services may be of a definite and evidently instinctive nature ; or there may be only a wish and readiness, as with most of the higher social animals: to aid their fellows in certain general ways. But these feelings and services are by no means extended to all the individuals of the same species, only to those of the same association. Secondly, as soon as the mental faculties had become lighlly dereloped, images of all past actions and motives rould be incessantly prassing through the brain of each indiridual; and that feeling of dissatisfaction, or even miscry, which invariably results, as ne: shall hereafter sce, from any ursatisfied instinct, nould arise, as often as it was perceived that the cnduring and always present social instinct had yielded to somo other instinct, at the time stronger, but neither enduring in its nature, nor leaving

${ }^{3}$ Sir B. Brodie, after observing that man is a social animal ('Psychological Enquiries,' 1854, p. 192), asks the pregnant question, "ought " not this to settle the disputed "question as to the existence of a " moral sense?" Similar ideas have probably occurred to many persons, as they did long ago to Marcus Aurelius. Mr. J. S. Mill speaks, in his celebrated work, 'Utilitarianism,' (1864, pp. 45, 46), of the social feelings as a "powerful natural "sentiment" and as "the natural "basis of sentiment for utilitarian " morality." Again he says, "Like " the other acouired capacities above "referred to, the moral faculty, if "not a part of our nature, is " a natural out-growth from it; " capable, like then, in a certain "small degree of springing up spon"tanennsly." But in opposition to all this, he also remarks, "if, as is " my own belief, the moral feelings "are not innate, but acquired, they" "are not for that reason less natu" ral." It is with hesitation that I venture to differ at all from so profound a thinker, but it can hardly be disputed that the social feelings are instinctive or innate in the lower animals; and why should they not be so in man? Mr. Bain (see, for instance, "The Emotions and the Will,' 1865, p.481) and others believe that the moral sense is acquired by each individual during his lifetime. On the general theors of evolution this is at least extremely improbable. The ignoring of all transmitted mental qualities will, as it seems to me, he hereafter judged as a most serious blemish io the works of Mr. Mill. 
behind it a rery vivid impression. It is clear that many instinctire desires, such as that of liunger, are in their nature of short duration; and after being satistied, are not readily or vividly recalled. Thirdly, after the potrer of language had been acquired, and the wishes of the community could be expressed, the common opinion how each member ought to act for the public good, would naturally become in a paramount degres: the guide to action. But it should bo borne in mind that horrover great weight we may attribute to public opinion, our regard for the approbation and disapprobation of our fellows depends on sympathy, which, as we shall see, forms an essential part of the social instinct, and is indeed its foundation-stone, Lastly, habit in the individual wonld ultimately play a very important part in guiding the condluct of each member; tor the social instinct, together with symuathy, is, like any other instinct, greatly strengthened by habit, aud so consequently would be obedience to the wishes and judgment of the community. Theso several subordinate propositions must now be discussed, and some of them at considerable length.

It may be well first to premise that I do not wish to maintain that any strictly social animal, if its intellectual faculties were to becomo as active and as highly developed as in man, would acquire exactly the same moral sense as ours. In the same manner as various animals have some sense of beauty, though they admire widely different oljects, so they might have a sense of right and wrong, though led by it to follow widely different lines of conduct. If, for iustance, to take an extreme case, men were reared under preciscly the same conditions as hive-bees, there can hardly be a doubt that our unmarried females would, like the worker-bees, think it a sacred duty to kill their brothers, and mothers wonld strive to kill their fertile daughters; and no one would think of interfering. ${ }^{6}$ Nerertheless, the bee, or any

- Mr. H. Sidgwick remarks, in an able discussion on this subject (the 'Academy,' June 15th, 1872, (p. 231), "a superior bee, we may " feel sure, would aspire to a milder" "solution of the population ques" tion." Judging, however, from the habits of many or most savages, man solves the problem by female infanticide, po.yandry and promiscuous intercourse; therefore it may well be doubted whether it would be by a milder method. Miss Cobbe, in commenting ('Darwinism in Morals,' 'Theological Review, April, 1872, p. 188-191) on the same illustration, says, the principles of social duty would be thus reversed; and by this, I presume, she means that the fulfilment of a social duty would tend to the injury of individuals; but she overlooks the fact, which she would doubtless admit, that the instincts of the bee have been acquired for the good of the community. She goes so far as to say that if the theory of ethics advocated in this chapter were crer" 
other sovial animal, woull gain in our supposerl ase, as it appears to me, some feeling of right or wrong, or a conscience. For each individual would baro an inward seuse of possessing certain stronger or more enduring instincts, and others less strong or enduring; so that there would often be a struggle as to which impulso should be followed; and satisfaction, dissatisfaction, or even misery would be felt, as past impressions were compared during their incessant passage through the mind. In this case an inward monitor would tell the animal that it would have been better to have followed the one impulse rather than the other. The one course ought to hare been followed, and the other ought mot; the one would have been right and the other wrong; but to these terms I shall recur.

Sociability.-Animals of many kinds are social; we find even distinct species living together; for example, some American monkeys; and united flocks of rooks, jackiars, and starlings Man shews the same feeling in his strong love for the dog, whic): the dog returns with interest. Every one must have noticed how miserable horses, dogs, sheep, \&c., are when separated from their companions, and what strong mutual affection the two former kinds, at least, shew on their reunion. It is curious to speculate on the feclings of a dog, who will rest peacefully for hours in a room with his master or any of the family, without the least notice being taken of him; but if left for a short time by himself, barks or howls dismally. We will confine our attention to the hicher social animals; and pass over insects: aithough some of these are social, and aid one another in many important ways. The most common mutual service in the higher animals is to warn one another of danger by means of rhe united senses of all. Every sportsman knows, as Dr. Jacger remarks, ${ }^{7}$ how difficult it is to approach animals in a herd or tros). Wild horses and cattle do not, I believe, make any danger-signal; but the attitude of any one of them who first discovers an enemy, warns the others. Rabbits stamp loudly on the ground with their hind-feet as a signal: sheep and rhamois do the same with their forefcet, uttering likewise a whistle. Many birds, and some mammals, post sentinels, whicli in the rase of seals are said ${ }^{8}$ generally to be the females. The leader

generally accepted, "I cannot but " believe that in the hour of their "triumph would be sounded the " knell of the virtue of mankind !" It is to lo hoped that the belie in tre permanence of virtue on this earth is not held by many persons on so weak a tenure. 101.

'Die Darwin'sche Theorie,"

8 Mr. R. Brown is 'Proc. Zonlog. Sac.' 1868, p. 409 . 
of a troop of monkeys acts as the sentinel, and utters cries expressive both of danger and of safety. ${ }^{9}$ Social animals perform many little services for each other: horses nibble, and cows lick each other, on any spot which itches: monkeys search each other for external parasites; and Brehm states that after a troop of the Cercopitiecus griseo-viridlis has rushed through a thorny brake, each monkey stretches itself on a branch, and anothor monkey sitting by, "conscientiously" examines its fur, and extracts every thorn or burr.

Animals also render more important services to one another: thus wolres and some other beasts of prey hunt in packs, and aid one another in attacking their victims. Pelicans fish is concert. The Hamadryas baboons turn over stones to find insects, cic.; and when they come to a large one, as many as can stand round, turn it over together and share the booty. Sociai animals mutually defend each other. Bull bisons in N. America, when there is danger, drire the cows and calres into the middle of the herd, whilst they defend the outside. I shall also in a future chapter give an account of trro young wild bulls at Chillingham attacking an old one in concert, and of two stallions together trying to drive away a third stallion from a troop of mares. In Abyssinia, Brehm encountered a great troop of baboons, who were crossing a valley: some had already ascended the opposite mountain, and some were still in the valley: the latter were attacked by the dogs, but the old males immediately hurried down from the rocks, and with mouths widely opened, roared so fearfully, that the dogs quickly drew back. 'They were again encouraged to the attack; but by this time all the baboons had reascended the heights, excepting a young one, about six months old, who, loudly calling for aid, climbed on a block of rock, and wa surrounded. Now one of the largest males, a true hero, came down again from the mountain, slowly went to the young one, coared him, and triumphantly led hinı away - the dogs being too much astonished to make an attack. I cannot resist giving another scene which was witnessed by this same naturalist; an eagle seized a young Cercopithecus, which, by clinging to a branch, was not at once carried off; it cried soudly for assistance, upon which the other members of tho troop, with much uproar, rushed to the rescue, surrounded the eagle,

9 Brehm, 'Thierleben,' B. i. 1864, s. 52, 79. For the case of the monkeys extracting thorns from eich other, see s. 54 . With respect to the Hamadryas turning over btones, the fact is given (s. 76) on the evi.lence of Alvarez, whose obserrations Brehm thinks quite trustworthy. For the cases of the old nalo laboor: attacking ine dogs, see $6.79 ;$ a 7 : with respect to the

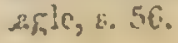


and palled out so many feathers, that he no longer thought of his prey, but only how to escape. This eagle, as Brehm remarks, assuredly would never again attack a single monkey of a troop. ${ }^{11}$

It is certain that associated animals have a fceling of love for sach other, which is not felt by non-social adult animals. How far in most cases they actually sympathise in the pains and pleasures of others, is more doubtful, especially with respect to pleasures. Mr. Buxton, however, who had excellent means of observation, ${ }^{11}$ states that his macam.s, which lived free in Norfolk, took "an extravagant interest" in a pair with a nest; and whenever the female left it, she was surrounded by a troop "scream"ing horrible acclamatious in her howour." It is often difficult to judge whether animals have any fecling for the sufferings of others of their kind. Who can say what cows feel, when they surround and stare intently on a dying or dead companion; apparently, however, as Houzeau remarks, they fecl no pity. That animals sometimes are far from feeling any sympathy is too certain; for they will expel a romiled animal from the herd, or gore or worry it to death. This is almost the blackest fact in natural history, unless, indecd, the explanation which has becn suggested is true, that their instinct or renson leads them to expel an injured companion, lest heasts of mey, including man, should be tempted to follow the troop. In this case their conduct is not much worse than that of the North American Indians, who leave their feeble comrades to perish on the plains; or the Fijians, who, when their parents get old, or fall ill, bury them alive. ${ }^{12}$

Many animals, howerer, certainly sympathise with each other's distress or clanger. This is the case eren with birds. Capt. Stansbury found on a salt lako in Utah an old and completely blind pelican, which was very fat, and must have been well fed for a long timo by his companions. Mr. Blyth, as he informs

$10 \mathrm{Mr}$. Belt gives the case of a spider-monkey (Ateles) in Nicaragua, which was heard screaming for mearly two hours in the forest, and was found with an eagle perched close by it. The bird apparently feared to attack as long as it remained face to face; and Mr. Belt believes, from what he has seen of the habits of these monkeys, that they protect themselres from eagles by keeping two or three together. "The Naturalist in Nicalargua,' $18 \div+\frac{1}{4}$ p. 118.
11 'Annals and Mag. of Nat. Hist., November, 1868, p. 382.

12 Sir J. Lubbock, 'Prehistorio Times,' 2 nd edit. p. 446.

13 As quoted by Mr. L. H. Morgan

'The American Beaver,' 1868, p. 272. Capt. Stansbury also gives an interesting account of the manner in which a very young pelican, carried away by a strong stream, was guided and encouraged in its attempts to reach the shore by Lals a dozes old birds 
me, saw Indian crows feeding two or three of their companions which were blind; and I have heard of an analogous case with the domestic cock. We may, if we choose, call these actions instinctive; but such cases are much too rare for the development of any special instinct. ${ }^{1+}$ I have myself seen a dog, who never passed a cat $\pi$ ho lay sick in a basket, and was a great friend of his, without giving her a few licks with his tongue, the surest sign of kind feeling in a dog.

It must be called sympathy that leads a courageous dog to tyy at any one who strikes his master, as he certainly will. I siw a person pretending to beat a lady, who had a very timid little dog on her lap, and the trial had never been made beforc; the little creature instantly jumped away, but after the pretended beating was over, it was really pathetic to see huw perseveringly he tried to lick his mistiess's face, and comfort her. Brehm ${ }^{15}$ states that when a baboon in confinement was pursued to bc punished, the others tried to protect him. It must have been sympathy in the cases above given which led the baboons and Cercopitheci to defend their young comrades from the dogs and the eagle. I will give only one other instance of sympathetic and heroic conduct, in the case of a little American monkey. S'everal years ago a keeper at tho Zoological Gardens shewed me some deep and scarcely healed wounds on the nape of his own neck, inflicted on him, whilst kneeling on the floor, by a fierce baboon. 'The little American monkey, who was a warm friend of this keeper, lived in the same large compartment, and was dreadfully afraid of the great baboon. Neverthelers, as soon as he saw his friend in peril, he rushed to the reseue, and by screams and bites so distracted the baboon that the man was able to escape, after, as the surgeon thought, ruming great risk of his life.

Besicles love and sympathy, animals exhibit other qualities connected with the social instincts, which in us would be called moral ; and I agree with Agassiz ${ }^{16}$ that dogs possess something very like a conscience.

Dogs possess some power of self-command, and this does not appear to be wholly the result of fcar. As Braubach ${ }^{17}$ remarks, they will refrain from stealing food in the absence of their mastcr. They have long been accepted as the very type of fidelity and obedience. But the elephant is likewiso very faith. ful to his driver or kecper, and probably considers him as tho

14 As Mr. Bain states, "effectire " aid to a sufferer springs from sym"pathy proper :" "Nentil and Moral Science," 1868 , p. 245. is - Thicis'sben, B. i. 3. 85 .
16 'De '"Lspece et de la Classe,' 18 e. p. 97.

17. Die Darwin'sche Art-Lehre, 1869, s. 5 t. 
leader of the herd. Dr. Hooker informs me that an elephant, which he was riding in India, became so deeply bogged that he remained stuck fast until the next day, when he was extricated by men with ropes. Under such circumstances elephants will seize with their trunks any object, dead or alive, to place under their knees, to prevent their sinking deeper in the mud; and the driver was dreadfully afraid lest the animal should have seized Dr. Hooker and crushed him to death. But the drirer himself, as Dr. Hooker was assured, ran no risk. This forbearance under an emergency so dreadful for a heavy animal, is a wonderful proof of noble fidelity. ${ }^{18}$

All animals living in a body, which defend themselres or attack their enemies in concert, must indeed be in some degree faithful to one another; and those that follow a lcader must be in some degree obedient. When the baboons in Abyssinia ${ }^{19}$ plunder a garden, they silently follow their leader; and if an imprudent young animal makes a noise, he reccives a slap from the others to teach him silence and obedience. $\mathrm{Mr}$. Galton, who has hail excellent opportunities for observing the half-wild cattle in $S$. Africa, says, ${ }^{20}$ that they cannot endure even a momentary separation from the herd. They are essentially slavish, and accept the common determination, seeking no better lot than to be led by any one ox who has envugh self-reliance to accept the position. The men who break in these animals for harness, watch assiduously for those who, by grazing apart, shew a self-reliant disposition, and these they train as fore-oxen. Mr. Galton adds that such animals are rare and valuable; and if many were born they would soon be climinated, as lions are always on the lookout for the individuals which wander from the herd.

With respect to the impulse which leads certain animals to associate together, and to aid one another in many ways, we may infer that in most cases they are impelled by the same. sense of satisfaction or pleasure which they experience in performing other instinctive actions; or by the same sense of dissatisfaction as when other instinctive actions are checked. We see this in innumerable instances, and it is illustrated in a striking manner by the acquired instincts of our domesticated animals; thus a young shepherd-dog delights in driving and running round a flock of sheep, but not in worrying them; a young fox-hound delights in hunting a fox, whilst some other. kinds of dogs, as I hare witnessed, utterly disregard foxes. What

\footnotetext{
is See also Honker's 'Himalayan Jourtals,' rol, ii., 185it, p. 333. 76.
}

20 See his extremely interesting paper on 'Gresariousness in Cattle, and in Man.' 'Macmililın's MI ig.' Fet 
a strong fecling of inward satisfaction must impel a bird, so fuil 'sf activity, to brood day after day over her eggs. Migratory birds are quite miserable if stopped from migrating; perhapss they crijoy starting on their long flight; but it is hard to believe that the poor pinioned goose, described by Audubon, which started on fuot at the proper time for its journey of probably more than a thousand miles, could have felt any joy in doing so. Some instincts are determined solely by painful feelings, as $b z$ fear, which leads to self-preservation, and is in some cases directed towards special enemies. No one, I presume, can analyse the sensations of pleasure or pain. In many instances, however, it is probable that instincts are persistently followed from the mere force of inheritance, without the stimulus of either pleasure or pain. A young pointer, when it first scents game, apparently camnot help pointing. A squirrel in a cage who pats the nuts which it cannot eat, as if to bury them in the ground, can hardly be thought to act thus, either from pleasure or pain. Hence the common assumption that men nust be impelled to every action by experiencing some pleasure or pain may be erroneous. Although a habit may be blindly and implicitly followed, independently of any pleasure or pain felt at the moment, yet if it bo forcibly and abruptly checked, a vague sense of dissatisfaction is generally experienced.

It has often been assumed that animals were in the first place rendered social, and that they feel as a consequence uncomfortable when separated from each other, and comfortable whilst together; but it is a more probable vierw that these sensations were first developed, in order that those animals which would profit by living in society, should be induced to live together, in the same manner as the sense of hunger and the pleasure of eating were, no doubt, first acquired in order to induce animals to ent. The feeling of pleasure from society is probably an extension of the parental or filial affections, since the social instiuct seems to be developed by the young remaining for a long time with their parents; and this cxtension may be attributed in part to habit, but chiefly to natural selection. With those animals which were benefited by living in close association, the individuals which took the greatest pleasure in society would best escape various dangers; whilst those that cared least for their oomrades, and lived solitary, would perish in greater numbers. With respect to the origin of the parental and filial affections, which aprarently lie at the base of the social instincts, we know not the steps by which they liave been gained; but we may infer that it has been to a large? extent through natural selection. So it has almost certainly 
been with the unusual and opposite feeling of hatred between the nearest relations, as with the morker-bees which kill their hrother-drones, and with the queen-bees which kill their daughter-queens; the desire to destroy their nearest relations having been in this case of service to the community. Parental affection, or some feeling which replaces it, has been developed in certain animals extremely low in the scale, for example, in star-fishes and spiders. It is also occasionally present in a fow nembers alone in a whole group of animals, as in the genus Forficula, or earwigs.

The all-important emotion of sympathy is distinct from that of love. A mother may passionately love her sleeping and nassive infant, but she can hardly at such times be said to fee] sympathy for it. The love of a man for his dog is distinct from :ympathy, and so is that of a dog for his master. Adam Smith lormerly argued, as has Mr. Bain recently, that the basis of sympathy lies in our strong retentiveness of former states of pain or pleasure. Hence, "the sight of another person en" luring hunger", cold, fatigue, revives in us some recollection of "these states, which are painful even in idea." We are thus impelled to relieve the sufferings of another, in order that our win painful feclings may be at the same time relieved. In like manner we are led to participute in the pleasures of others. ${ }^{21}$ But I cannot see how this view explains the fact that sympathy is crcited, in an immeasurably stronger degree, by a belored, than by an indifferent person. The mere sight of suffering, independently of love, would suffec to call up in us vivid recollections and associations. The explanation may lie in the iact that, with all animals, sympathy is directed solely towards the members of the same community, and therefore towards linown, and more or less beloved members, but not to all the inclividuals of the same species. This fact is not more sur. prising than that the fears of many animals should be directed against special enemies. Species which are not social, such as lions and tigers, no doubt feel sympathy for the suffering of their own young, but not for that of any other animal. With

21 See the first and striking chapter" in Adam Smith's "Theory of 'Hnral Sentiments.' Also Mr. Bain's 'Mental and Moral Science, 18188, p. 24t, and $275-282$. Mr. liain states, tinat "sympathy is, in"directly, a source of pleasure to "the synjuthiser" ;" and he accounts for this through reciprocity. He remarks that "the person bencfited, "or others in his stead, may make "up, by sympathy and good offices "returned, for all the sacrifice." But if, as appears to be the case, sympathy is strictly an instinct, its exercise would give direct plensure, in the same manner as the exercise, as before remarked, ot a! most erery other instinct. 
mankind, selfishness, experience, and imitation, probably add, as Mr. Bain has shewn, to the power of sympathy; for we are led by the hope of receiving good in return to perform acts of sympathotic kindness to others; and sympathy is muck strengthened by habit. In however complex a manner this feeling may have originated, as it is one of high importance to all those animals which aid and defend one another, it will have been increased through natural selection; for those communities, which included the greatest number of the most sympathetic members, would flourish best, and rear the grcatest number of offspring.

It is, however, impossible to decide in many cases whether certain social instincts have beun acquired through natural selection, or are the indirect result of othor instincts and faculties, such as sympathy, reason, experience, and a tendency to imitation; or again, whether they are simply the result of long-continued habit. So remarkable an instinct as the placing sentinels to warn the community of danger, can hardly have been the indirect result of any of these faculties; it must, therefore, have been directly acquired. On the other hand, the habit followed by the males of some social animals of defending the community, and of attacking their enemies or their prey in concert, may perhaps have originated from mutual sympathy; but courage, and in most cases strength, must have bcen previously acquired, probably through natural selection.

Of the various instincts and habits, some are much stronger than others; that is, some either give more pleasure in their performance, and more distress in their prevention, than othcrs; or, which is probably quite as important, they are, through inheritance, more persistently followed, without exciting any special feeling of pleasure or pain. Wo are ourselves conscious that some habits are much more difficult to cure or change than others. Hence a struggle may often be observed in animals between different instincts, or between an instinct and some habitual disposition; as when a dog rushes after a hare, is rebuked, pauses, hesitates, pursues again, or returns ashamed to his master; or as between the love of a female dog for her young puppies and for her master,-for she may be seen to slink away to them, as if half ashamed of not accompanying her master. But the most curious instance known to me of one instinct getting the better of another, is the migrator'y instinct conquering the matcrnal instinct. The former is wonderfully strong; 2. confined bird will at the proper season beat her breast against the wires of her cage, until it is bare and bloody. It causes young salmon to leap out of the fresh water, in which they could 
continue to exist, and tinus unintentionally to commit suicide. Every one knows how strong the maternal instinct is, leading eren timid birds to face great danger, though with hesitation, and in opposition to the instinct of self-prescrvation. Nevertheless, the migratory instinct is so powerful, that late in the autumn swallows, house-martins, and swifts frequently desert their tender young, leaving them to perish miserably in their nests. ${ }^{22}$

W'e can perceive that an instinctive impulse, if it be in any way more bencficial to a species than some othcr or opposed instinct, would be rendered the more potent of the two through natural selection; for the individuals which had it most strongly developed would survive in larger numbers. Whether this is the case with the migratory in comparison with the maternal instinct, may be doubtec. The great persistence, or steady action of the former at certain seasons of the year during the whole day, may give it for a time paramount force.

Man a sociul animal.-Every one will admit that man is a social being. We see this in his dislike of solitude, and in his wish for society beyond that of his own family. Solitary confinement is one of the severest punishments which can be inflicted. Some authors suppose that man primevally lived in single families; but at the present day, though single families, or only two or three together, roam the solitudes of some savage lands, they always, as far as I can discorer, hold friendly relations with other families inhabiting the same district. Such families occasionally meet in council, and unite for their common defence. It is no argument against savage man being a social animal, that the tribes inhabiting adjacent districts are almost always at war with each other; for the social instincts never extend to all the individuals of the same species. Judging from the analogy of the majority of the Quadrumana, it is probable that the early ape-like progenitors of man were likewise social; but this is not of much importance for us. Although man, as

22 This fact, the Rer. L. Jenyns states (see his edition of "White's Nat. Hist. of Selborne,' 1853, p. 204) was filst recorded by the illustrious Jenner, in 'Phil. Transact." 1824, and has since been confirmed by sereral observers, especially by Mr. Blackwall. This latter careful observer examined, late in the altumn, during two years, thirtysix nests; he found that twelve contained young dead birds, five contained eggs ou the point of being batched, and three, eggs cot nearly hatched. Many birds, not yet old enough for a prolonged flight, are likewise deserted and left behind. See Blackwall, "Researches in Zoology,' 1834, pp. 108, 118. For some additional evidence, although this is not wanted, see Leroy, 'Lettres Phil.' 1802, p. 217. Fur Swifts, Gould's 'Introduction to the Birds of Great Britain,' 1323 , p. 5. Similar cases hare been observed in Canada by Mr. Adams; Pop. Science Review, July 187.3, D 283. 
he now exists, has fow special instincts, having lost any which his early progenitors may have possessed, this is no reason why he should not have retained from an extremely remote period some degree of instinctive love and sympathy for his fellows. We are indeed all conscious that we do possess such sympathetic feelings; ${ }^{23}$ but our consciousness does not tell us whether they are instinctive, having originated long ago in the same mauner as with the lorrer animals, or whether they have been acquired lyy each of us during our early years. As man is a social animal, it is almost certain that ho would inherit a tendency to be faithful to his comrades, and obedient to the leader of his tribe; for these qualities are common to most social animals. He would consequently possess some capacity for self-command. He would from an inherited tendency be willing to defend, in concert with others, his fellow-men; and would be ready to aid them in any way, which did not too greatly interfere with his own welfare or his own strong desires.

The social animals which stand at the bottom of the scale are guided almost exclusively, and those which stand higher in the scale are largely guided, by special instincts in the aid which they give to the members of the same community; but they are likewise in part impelled by mutual love and sympathy, assisted apparently by some amount of reason. Although man, as just remarked, has no special instincts to tell him how to aid his fellow-men, he still has the impulse, and with his improved intellectual faculties would naturally be much guided in this respect by reason and experience. Instinctive sympathy would also cause him to value highly the approbation of his fellows; for, as Mr. Bain has clearly shewn, 24 the love of praise and the strong feeling of glory, and the still stronger horror of scorn and infamy, "are due to the workings of sympathy." Consequently man mould be influenced in the highest degree by the wishes, approbation, and blame of his fellow-men, as expressed by their gestures and language. Thus the social instincts, which must have been acquired by man in a very rude state, and probably even by his early ape-like progenitors, still give the impulse to some of his best actions; but his actions are in a higher degree determined by the expressed wishes and judgment

23 Hume remarks ('An Enquiry, Concerning the Principles of Morals,' edit. of 1751, p. 132), "There seems " a necessity for confessing that the " happiness and misery of others * are not spectacles altogether in- different to us, but that the vie;
" of the former ... communicates " a secret joy; the appearance of " the latter... throws a melan. "choly damp over the imagiza. "tion."

2. 'Mental aad Moral Scienca, 1863 , p. 254. 
of his fellow-men, and unfortunately very often by his own strong selfish desires. But as love, sympathy and self-command becomo strengthened by labit, and as the power of reasoning becomes clearer, so that man can value justly the judgments of his fellows, he will feel himself impelled, apart from any transitory pleasure or pain, to certain lines of conduct. He might ther declare-not that any barbarian or uncultivated man could thus think-I am the supreme judge of my orn conduct, and is the words of Kant, I will not in my own person violate the dignity of humanity.

The more enduring Social Instincts conquer the less persistent Instincts.-We have not, however, as yet considered the main point, on which, from our present point of view, the whole question of the moral sense turns. Why should a man feel that he ought to obey one instinctive desire rather than another? Why is he bitterly regretful, if he has yielded to a strong sense of solf-preservation, and has not risked his life to save that of a fellow-creature? or why does he regret having stolen food from hunger?

It is evident in the first place, that with mankind the instinctire impulses have different degrees of strength; a savage will risk his own life to save that of a member of the same community; but will be wholly indifferent about a stranger: a young and timid mother urged by the maternal instinct will, without a moment's hesitation, run the greatest danger for her own infaut, but not for a mere fellow-crcature. Nevertheless many a civilized man, or even boy, who never before risked his life for another, but full of courage and sympathy, has diregarded the instinct of self-preservation, and plunged at once into a torrent to save a drowning man, though a stranger. In this case man is impelled by the same instinctive motive, which made the heroic little American monkey, formerly described, save his kecper, by attacking the great and dreaded baboon. Such actions as the above appear to be the simple result of the greater strength of the social or maternal instincts than that of any other instinct or motive; for they are performed too instantaneously for reflection, or for pleasure or pain to be felt at the time; though, if prevented by any cause, distress or even misery might be felt. In a timid man, on the other hand, the instinct of self-preservation might be so strong, that he would be unable to force himself to run any such risk, perhaps not even for his own child.

I am aware that some persons maintain that actions performed impulsively, as in the above cases, do not come under the domicion of the moral sense, and cannot be called moral. They 
confine this term to actions done dcliberately, after a victory over opposing desires, or when prompted by some exalted motive. But it appears scarcely possible to draw any clear line of distinction of this kind. ${ }^{25}$ is far as exalted motives are concerned, many iustances haro been recorded of savages destitute of any feeling of general benevolence towards mankind and not guided by any religious motive, who have deliberatel: sacrificed their lives as prisoncrs, ${ }^{26}$ rather than betray thei" comrades; and surely their conduct onglat to be considered as moral. As far as deliberation, and the victory over opposing motives are concerned, animals may be seen doubting betweci opposed instincts, in rescuing their offspring or comrades from danger; yet their actions, though done for the good of others, are not called moral. Morcover, anything performed very often by us, will at last be done without deliberation or hesitation, and can then hardly be distinguished from an instinct; yet surely no one will pretend that such an action ceases to be moral. On the contrary, we all feel that an act cannot be considered as perfect, or as performed in the most noble manner, unless it be done inpulsively, without deliberation or effort, in the same manuer as by a man in whom the requisite qualities are innate. He who is forced to overcome his fear or waut of sympathy before he acts, deserves, however, in one way higher credit than the man whose innate disposition leads him to a good act without effort. As we cannot distinguish between motives, we rank all actions of a certain class as moral, if performed by a moral being. A moral being is one who is capable of comparing his past and future actions or motives, and of approving or disapproving of them. We have no reason to suppose that any of the lower animals have this capacity: therefore, when a Newfoundland dog drags a child out of the water, or a monkey faces danger to rescue its comrade, or takes charge of an orphan monkey, we do not call its conduct moral. But in the case of man, who alone can with certainty be ranked as a moral being, actions of a certain class are called moral, whether performed deliberately, after a struggle with opposing

2s I refer here to the distinction between what has been called material and formal morality. I am glad to find that Prof. Huxley ( ${ }^{6} \mathrm{Cri}-$ ¿iques and Addresses,' 1873, p. 287) takes the same view on this subject as I do. Mr. Leslie Stephen remarks ("Essays on Freethinking and Plain Speakin , 1873, p. 83), "the * metaphrsical Zstinction betweeu "material and formal morality is " as irrelevant as other such dis. "tinctions."

28 I have given one such case, namely of three Patagonian Indians who preferred being shot, one after the other, to betraying the plans of their companions in war ("Joursu' of Researches,' 1845, p. 103). 
motives, or impulsively through instinct, or from the effects of slowly-gained habit.

But to return to our more immediate subject. Although some instincts are more powrerful than others, and thus lead to corresponding actions, yet it is untenable, that in man the social instincts (including the love of praise and fear of blame) possess greater strength, or have, through long habit, acquired greater strength than the instincts of self-preservation, hunger, lust, vengeance, \&c. Why then does man regret, even though trying to banish such regret, that he has followed the one natural impulse rather than the other; and why does he further feel that he ought to regret his conduct? Man in this respect differs profoundly from the lower animals. Nerertheless we can, I think, see with some degree of clearness the reason of this difference.

Man, from the activity of his mental faculties, cannot avoid reflection: past impressions and images are incessantly and clearly passing through his mind. Now with those animals which live permanently in a body, the social instincts are ever present and persistent. Such animals are always ready to utter the danger-sigual, to defend the community, and to give aid to their fellows in accordance with their habits; they feel at all times, without the stimulus of any special passion or desire, some degree of love and sympathy for them; they are unhappy if long separated from them, and always happy to be again in their company. So it is with ourselres. Even when we are quite alone, how often do we think with pleasure or pain of what others think of us,- of their imagined approbation or disapprobation; and this all follows from sympathy, a fundamental olement of the social instincts. A man who possessed no trace of such instincts would be an unnatural monster. On the other hand, the desire to satisfy hunger, or any passion such as vengeance, is in its nature temporary, and can for a time be iully satisfied. Nor is it easy, perhaps hardly possible, to call up with complete vividness the feeling, for instance, of hunger; nor indeed, as has often becn remarked, of any suffering. The instinct of self-preservation is not felt except in tho presence of langer; and many a coward has thought himself brave until he has met his enemy face to face. The wish for another man's property is perhaps as persistent a desire as any that can be named; but even in this case the satisfaction of actual possession is generally a weaker feeling than the desire: many 8 . thicf, if not a habitual one, after success has wondered why he stole some article. ${ }^{27}$

${ }^{27}$ Enmity or hatred reems aiso to be a high!y prersistent feeling,

perhaps more so than any other that can in named. Envy is de. 
A man cannot prevent past impressions often repassing through his mind; he will thus be driven to make a comparison between the impressions of past hunger, vengeance satisfied, or danger shunned at other men's cost, with the almost ever-present instinct of sympathy, and with his early knowledge of what others consider as praiseworthy or blameabie. This knowledge cannot be banished from his mind, and from instinctive sympatly is esteemed of great moment. He will then feel as if he had been baulked in following a present instinct or habit, and this with all animals causes dissatisfaction, or even misery.

The above case of the swallow affords an illustration, though of a reversed nature, of a temporary though for the time strongis persistent instinct conquering another instinct, which is usually dominant over all others. At the proper season these birds seem all day long to be impressed with the desire to migrate: their habits change; they become restless, are noisy, and congregate in flocks. Whilst the mother-bird is feeding, or brooding orer her nestlings, the maternal instinct is probabiy stronger than the migratory; but the instinct which is the more persistent gains the rictory, and at last, at a moment when her young ones are not in sight, she takes flight and deserts them. When arrived at the end of her long journey, and the migratory instinct has ceased to act, what an agony of remorse the bird would feel, if, from being endowed with great mental activity, she could not prevent the image constantly passing through her mind, of her young ones perishing in the bleak north from cold and hunger.

fined as hatred of another for some excellence or success; and Bacon insists (Essay ix.), "Of all other "nffections envy is the most im" portune and continual." Dogs are very apt to hate both strange men and strange dogs, especially if they live near at hand, but do not belong to the same family, tribe, or clan; this feeling would thus seem to bo innate, and is certainly a most persistent one. It seems to be the complement and converse of the true social instinct. From what we hear of savages, it would appear that something of the same kind holds good with them. If this be 0 , it would be a small step in any one to transfer such feelings to any memher of the same tribe if he had done him an injuxy and had become his enemy. Nor is it probable that the primitive conscience would reproach a man $\mathrm{f} c \mathrm{c}$ injuring his enemy: rather it would reproach him, if he had not revenged himself. 'To do good in return for. evil, to love your enemy, is a height of morality to which it may be doubted whether the social instincts would, by themselves, have ever led us. It is necessary that these instincts, togethe: with sympathy, should have been highly cultivated and extended by the aid of reason, instruction, and the love or fear of God, before any such golden rule would ever be thought of and obeyed. 
At the moment of action, man will no doubt be apt to follow the stronger impuise; and though this may occasionally prompt him to the noblest deeds, it will more commonly lead him to gratify his own desires at the expense of other men. But after their gratification, when past and weaker impressions are judged by the ever-enduring social instinct, and by his deep regard for the good opinion of his fellows, retribution will surely come. He will then feel remorse, repentance, regret, or shame this lattcr feeling, however, relates almost exclusively to the judgment of others. He will consequently resolve more or less firmly to act differently for the future; and this is conscience; for conscience looks backwards, and serves as a guide for the future.

The nature and strength of the feelings which we call regret, shame, repentance or remorse, depend apparently not only on the strength of the violated instinct, but partly on the strength of the temptation, and often still more on the judgment of our fellows. How far each man values the apprcciation of others, depends on the strength of his innate or accuired fecling of sympathy; and on his own capacity for reasoning out the remote consequences of his acts. Another element is most important, although not necessary, the rererence or fear of the Gods, or Spirits believed in by each man: and this applies especially in cases of remorse. Sereral critics havo objected that though some slight regret or repentance may be explained by the view advocated in this chapter, it is impossible thus to rccount for tho soul-shaking feeling of remorse. But I can see little force in this objection. My critics do not define what they mean by remorse, and I can find no definition implying more than an overwhelming sense of repentance. Remorse seems to bear the same relation to repentance, as rage does to anger, or agony to pain. It is far from strange that an instinct so strong and so generally admired, as maternal love, should, if disobeyed, lead to the deepest misery, as soon as the impression of the past cause of disobedience is weakened. Even when an action is opposed to no special instinct, merely to know that our friends and equals despise us for it is enough to cause great miscry. Who can doubt that the refusal to fight a duel through fear has caused many men an agony of shame? Many a Hindoo, it is said, has been stirred to the bottom of his soul by having partaken of unclean food. Here is another case of what must, I think, be called remorse. Dr. Landor acted as a magistrate in West Australia, and relates, ${ }^{28}$ that a natire on his farm, after losing one of his wives from disease, came and said that "he was

ss 'Iasanity in Relation to Lav :' Ontrario, United States, 1871, p. it. 
"going to a distant tribe to spear a woman, to satisfy his sense " of duty to his wife. I told him that if he did so, I would "send him to prison for life. He remained about the farm for "som " he could not rest or eat, that his wife's spirit was haunting " him, because he had not taken a life for hers. I was in" cxorable, and assured him that nothing should save him if ho " diu." Nevertheless the man disappeared for more than a year, and then returned in high condition; and his other wife told Dr. Landor that her husband had taken the life of a woman belonging to a distant tribe; but it was impossible to obtain legal evidence of the act. The breach of a rule held sacred by the tribe, will thus, as it seems, give rise to the deepest feelings, -and this quite apart from the social instincts, excepting in so fin as the rule is grounded on the judgment of the community. How so mauy strange superstitions have arisen throughout the world we know not; nor can we tell how some real and great crimes, such as incest, have come to be held in an abhorrence (which is not however quite universal) by the lowest savages. It is even doubtful whether in some tribes incest would be looked on with greater horror, than would the marriage of a man with a woman bearing the same name, though not a relation. "To " violate this law is a crime which the Australians hold in the "greatest abhorrence, in this agreeing exactly with certain " tribes of North America. When the question is put in either " district, is it worse to kill a girl of a foreign tribe, or to marry " a girl of one's own, an answer just opposite to ours would be given without hesitation." ${ }^{29}$ We may, therefore, reject the belief, lately insisted on by some writers, that the abhorrence of incest is due to our possessing a special God-implanted conscience. On the whole it is intelligible, that a man urged by so powerful a sentiment as remorse, though arising as above explained, should be led to act in a manner, which he has been taught to believo serves as an expiation, such as delivering himself up to justice.

Man prompted by his conscience, will through long habit acquire such perfect self-command, that his dcsires and passicns will at last yield instantly and without a struggle to his social 6ympathies and instincts, including his feeling for the judgment of his fellows. The still hungry, or the still revengeful man will not think of stealing food, or of wreaking his vengeance. It is possible or as we shall hereafter see, even prolibie, that the habit of selfcommand may, like other habits, be inherited. Thus at lasst man

E. B. Tylor in 'Contemporary Revier,' April, 1873, p. 707. 
comes to fesl, through acquired and perhaj,s inherited habit, that it is best for him to obey his morr persistent impulses. The imperious word ouglit seems merely to imply the consciousness of the existonce of a rule of conduct, however it may have originated. Formerly it must have been often vehemently urged that an insulted gentleman ought to fight a duel. We even say that a pointer ouglit to point, and a retriever to retrieve game. If they fail to do so, they fail in their duty and act wrongly.

If any desire or instinct leading to an action opposed to the good of others still appears, when recalled to mind, as strong as, or stronger than, the social instinct, a man will fecl no keen regret at having followed it; but he will be conscious that if his conduct wero known to his fellows, it would meet with their disapprobation; and few are so destitute of sympathy as not to feel discomfort when this is realised. If he has no such sympathy, and if his desires leading to bad actions are at tho time strong, and when recalled are not over-mastered by the persistent social instincts, and the judgment of others, then he is essentially a bad man; ${ }^{30}$ and the sole restraining motive left is the fear of punishment, and the conviction that in the long run it would be best for his own selfish interests to regard the good of others rather than his own.

It is obvious that every one may with an easy conscience gratify his own desires, if they do not interfere with his socia? instincts, that is with the good of others; but in order to be quite free from self-reproach, or at least of anxiety, it is almost necessary for him to avoid the disapprobation, whether reasonable or not, of his fellow-men. Nor must he break through the fixed habits of his life, especially if these aro supported by reason; for if ho does, he will assuredly feel dissatisfaction. He must likewise avoid the reprobation of the one God or gods in whom, according to his knowledge or superstition, he may believe; but in this case the additional fear of divine punishment often supervenes.

The strictly Social Virtues at first alone regarded. - The above view of the origin and nature of the moral sense, which tells us what we ought to do, and of the conscience which reproves us if we disobey it, accords well with what we see of the early and undereloped condition of this faculty in mankind. The virtues which must be practised, at least generally, by rude men, so

so Dr. Prosper Despine, in his - Psychologie Naturelle,' 1868 (tom. 1 p. 243 ; tom. ii. $; .169$ ) gives many curious cases of the worst criminals, who apparently hare been entirely destitute of conscience. 
that they may associrte in a body, are those which are still rucognised as the most important. But they are practised almost exclusively in relation to the men of the same tribe; and their opposites are not regarded as crimes in relation to the men of other tribes. No tribe could hold together if murder: robbery, treachery, \&c., were common; consequently such crimes within the limits of the same tribe "are branded with "everlasting infamy;" these limits. A North-American Indian is well pleased with himself, and is honoured by others, when he scalps a man of another tribe; and a Dyak cuts off the head of an unoffending person, and dries it as a tropky. The murder of infants has prevailed on the largest scale throughout the world, ${ }^{32}$ and has met with no reproach; but infanticide, especially of females, has been thought to be good for the tribe, or at least not injurious. suicide during former times was not generally considered as a crime, ${ }^{33}$ but rather, from the courage displayed, as an honourable act; and it is still practised by some semi-civilised and savage nations without reproach, for it does not obviously concern others of the tribe. It has been recorded that an Indian Thug conscientiously regretted that he had not robbed and strangled as many travellers as did his father before him. In a rude state of civilisation the robbery of strangers is, indeed, generally considered as honourable.

Slavery, although in some ways beneficial during ancient times ${ }^{3+}$ is a great crime; yet it was not so regarded until quite recently, even by the most civilized nations. And this was especially the case, because the slaves belonged in general to a race different from that of their masters. As barbarians do not regard the opinion of their women, wives are commonly treated like slaves. Most savages aro utterly indifferent to the sufferings of strangers, or even delight in witnessing them. It is well

31 See an r.ble article in the North British Review, 1867, p. 395. See also MIr. W. Bugehot's articles on the Importance of Obelience and Coherence to Primitive 'Han, in the 'Fortnightly Review, $13+7$, p. 529 , and 1868 , p. 457 , \&c.

32 The fullest account which I have met with is by Dr. Gerland, in his 'Ueber dan Aussterben der Niturvölker,' 1868; but I shall have to recur to the subiect of infunticide in a future chapter.

33 See the very interesting discusaion i: Suicide in Lecky's 'History of European Morals,' vol. i. 1869, p. 223. With respect to savages, Mr. Winwood Reade informs me that the negroes of West Africa often commit suicide. It is well known how common it was amongst the miserable aborigines of South America, after the Spanish conquest. For New Zealand, see the voyage or the "Nuvara," and for the Aleutian Islinds, Muller, as quoted by Houzeau, 'Les Facultés Mlentales,' $\$$ '., tom. ii. p. 136.

34 Sre Mr. Bagehot, 'Plysics sus Politics:' 1872, 1. 72. 
known that the romen and children of the North-American Indians aided in torturing their enemies. Some sarages take a horrid pleasure in cruelty to animals, ${ }^{35}$ and humanity is an unknown virtue. Nevertheless, besides the family affections, kindness is common, especially during sickness, between the members of the same tribe, and is sometimes extended beyond these limits. Mungo Park's touching account of the kindness of the negro women of the interior to him is well known. Many instances could be given of the noble fidelity of savages towards each other, but not to strangers; common expericnce justifies the maxim of the Spaniard, "Never, nerer trust an Indian." There cannot be fidelity without truth; and this fundamental virtue is not rare between the members of the same tribe: thus Iungo Park heard the negro women teaching their young ehildren to love the truth. This, again, is one of the virtnes which becomes so deeply rooted in the mind, that it is sometimes practised by savages, even at a high cost, towards strangers; but to lie to your enemy has rarely been thought a sin, as the history of modern diplomacy too plainly shers. As soon as a tribe has a recognised leader, disobcdience becomes a crime, and even abject submission is looked at as a sacred virtuc.

As during rude times no man can be uscful or faithful to hic tribe without courage, this quality has unirersally been placed in the highest rank; and although in civilised countries at good yet timid man may be far more useful to the community than a brave one, we cannot help instinctivcly honouring the latter above a coward, howerer benevolent. Prudence, on the other hani, which does not concern the welfire of others, though a very useful virtue, has never been highly estcemed. As nc man can practiso the rirtnes necessary for the welfare of his tribe without self-sacrifice, self-command, and the power of endurance, these qualities have been at all times highly and most justly valued. The American savage voluntarily submits to the most horrid tortures without a groan, to prove and? strengthen his fortitude and courage; and we camnot help admiring him, or even an Indian Fakir, who, from a foolish religious motive, strings suspended by a hook buried in his flesh.

The other so called self-regarding virtues, which do not obviously, though they may really, affect the relfare of the tribe, have never been esteemed by savages, though now highly appreciated by cirilised nations. The greatest intemperance?

35 See, for irstance, Mr. Hamilton's account of the haffirs, "Anthropolegical lieriew,' $18 .(1$, !. $2 \mathrm{r}$. 
is no reproach with savages. Utter licentionsness, and unnatural crimes, prevail to an astoumding extent. ${ }^{36}$ As soon, however, as marriage, whether polygamous, or monogamous, becomes common, jealousy will lead to the inculcation of female virtue; and this, bcing honoured, will tend to spread to the unmarried fomales. How slowly it spreads to the male sex, we see at the present day. Chastity eminently requires selfcommand; therefore it has been honoured from a very early period in the moral history of cirilised man. As a consequence of this, the senseless practice of celibacy has been ranked from a remote period as a virtue. ${ }^{37}$ The hatred of indecency, which appears to us so natural as to be thought innate, and which is so valuable an aid to chastity, is a modern virtue, appertaining exclusively, as Sir G. Staunton remarks, ${ }^{38}$ to civilised life. This is shemn by the ancient religious rites of various nations, by the drawings on the walls of Pompeii, and by the practices of many savages.

We have now seen that actions are regarded by sarages, and were probably so regarded by primeral man, as good or. lad, solely as they obriously affect the welfare of the tribe,-not that of the species, nor that of an individual member of the tribe. 'This conclusion agrees well with the belief that the so-called moral sense is aboriginally derived from the social instincts, for both relate at first exclusirely to the community. The chief causes of the low morality of savagces, as judged by our standard, are, firstly, the confinement of sympatlyy to the same tribe. Secondly, powers of reasoning insufficient to recognise the bearing of many virtues, especially of the self-regarding virtues, on the general welfare of the tribe. Savages, for instance, fail to trace the multiplied evils conseruent on a want of temperance, chastity, \&e. And, thirdly, weak powcr of self-command; for this power has not been strengthened through long-continued, perhaps imherited, babit, instruction aud religion.

I hare entered into the above details on the immorality of savages, ${ }^{39}$ because some authors hare recently taken a high view of their moral nature, or hare attributed most of thcir crimes to mistaken benevolence. ${ }^{40}$ These authors appear to rest their

36 Mr. M'Lennan las giren ('Primitive Marriage,' 1865, p. 176) a good collection of fucts on this head.

${ }^{37}$ Lecky, "History of European Mcrale, " vol. 1. 1869, p. 109.
38 'Embassy to China,' vol. ii. p. 348.

${ }^{30}$ See on this subject copious evidence in Chap. vii. of Sir J. Lubbock, 'Origin of Civilisation,' 1870.

40 For' instance Lecky, 'Hist European Hicals, 'rol. 1. p. 121. 
conclusion on sarages possessing those virtues which are scrviceable, or eveu necessary, for the existence of the family and of tho tribe,- qualities which they undoubtedly do possess, and often in a high degree.

Concluling Remaris.-It was assumed formerly by philosophers of the derivative ${ }^{41}$ school of morals that the foundation of morality lay in a form of Selfislness; but more recently the "Greatest "happiness principle" has been brought prominently fortard. It is, however, more correct to speak of the latter principle as the standard, and not as the motive of conduct. Nerertheless, all the authors whose works I have consulted, with a few exceptions, write as if there must be a distinct motive for every action, and that this must be associated with some pleasure or displeasure. But man seems often to act impulsively, that is from instinct or long habit, without any consciousness of pleasure, in the same manner as does probably a bee or ant, when it blindly follows its instincts. Under circumstances of extreme peril, as during a fire, when a man endeavours to save a fellowcreature without a moment's hesitation, he can hardly feel pleasure; and still less has he time to reflect on the dissatisfaction which he might subsequently experience if he did not make the attempt. Should he afterwards reflect over his own conduct, he would feel that there lies within him an impulsive power widely different from a seurch after pleasure or happiness; and this seems to be the deeply planted social instinct.

In the case of the lower animals it seems much more appropriate to speak of their social instincts, as having been developed

11 This term is used in an able article in the 'Westminster Review,' Oct. 1869, p. 498 . For the "Greatest "happiness principle," see J. S. Mill, 'Utilitarianism,' p. 17.

42 Mill recognises ('System of Logic,' vol. ii., p. 422) in the clearest. manner, that actions may be performed through habit without the anticipation of pleasure. Mr. H. Sidgwick also, in his Essay on Pleasure and Desire ('The Contemporary Review,' April 1872, p. 671), remarks: "To sum up, in "contravention of the doctrine that " our conscious actire impulses are "always directed towards the pro" duction of agreeable seusations in " nurselves, I would maintain that is wiud every where in consclous- "ness extra-regarding impulse, di"rected towards something that is "not pleasure; that in many cases "the impulse is so far incompatibie "with the self-regarding that the "two do not easily co-exist in the " same moment of consciousness." A dim feeling that our impulses do not by any means always arise from any contemporaneous or anticipater pleasure, has, I cannot but think, been one chief cause of the acceptance of the intuitive theory of morality, and of the rejection of the utilitarian or "Greatest happiness " theory. With respect to the latter theory, the standard and the motire of conduct have no doubt often beec confused, but they are realty :some degree blendal. 
for the general good rather than for the gencral happiness of the species. The term, gencral good, may be defined as the rearing of the greatest number of individuals in full vigour and health, with all their fuculties perfect, under the conditions to which they are subjected. As the social instincts both of man and the lower animals have no doubt been developed by nearly the same steps, it, would be advisable, if found practicable, to use the same definition in both cases, and to take as the standard of morality, the general good or welfare of the community, rather than the general happiness; but this definition would perhaps require some limitation on account of political ethics.

When a man risks his life to save that of a fellow-creature, it secms also more correct to say that he acts for the general good, rather than for the general happiness of mankind. No doubt the welfare and the happiness of the individual usually coincide; and a contented, happy tribe will flourish better than one that is discontented and unhappy. We have seen that even at au early period in the history of man, the expressed wishes of the community will have naturally influenced to a large extent the conduct of each member; and as all wish for happiness, the "greatest happiness principle" will have become a most important secondary guide and object; the social instinct, however, together with sympathy (which leads to our regarding the approbation and disapprobation of others), having served as the primary impulse and guide. Thus the reproach is removed of laying the foundation of the noblest part of our nature in the base principle of selfishness; unless, indeed, the satisfaction which every animal feels, when it follows its proper instincts, and the dissatisfaction felt when prevented, be called selfish.

The wishes and opinions of the members of the same community, expressed at first orally, but later by writing also, either form the sole guides of our conduct, or greatly reinforce the social instincts; such opinions, however, have sometimes a tendency directly opposed to these instincts. This latter fact is well exemplified by the Law of Ilonour, that is, the law of the opinion of our equals, and not of all our countrymen. The breach of this law, ereu when the breach is known to be strictly accordant with true morality, has caused many a man more agony thin a real crime. Wo recognise the same influence in the burning sense of shame which most of us have felt, even after the interval of years, when calling to mind some accidental breach of a trifling, though fixed, rule of etiquette. The judgment of the community will gencrally be guided by some rude experience of what is best in the long run for all the members; but this jndgment will not rarely err from ignorance and weak powers of 
reasoning. Hence the strangest customs and superstitions, in complete opposition to the true welfare and happiness of mankind, have become all-powerful throughout the world. We seo this in the horror felt by a Hindoo who breaks his caste, and in many other such cases. It would be difficult to distinguish hetween the remorse felt by a Hindoo who has yielded to the temptation of eating unclean food, from that felt after committing a theft; but the former would probably be the more severe.

How so many absurd rules of conduct, as well as so many absurd religious beliefs, hare originated, we do not know; nor how it is that they have become, in all quarters of tho world, so deeply impressed on the mind of men; but it is worthy of remark that a belief constantly inculcated during the early years of life, whilst the brain is impressible, appears to acquire almost: the nature of an instinct; and the very essence of an instinct is that it is followed independently of reason. Neither can we say why certain admirable virtues, such as the love of truth, are much more highly appreciated by some sarage tribes than by others $; 3$ nor, again, why similar differences prevail even amongst jighly civilised nations. Knowing how firmly fixed mayy strange customs and superstitions hare become, we need feel no surprise that the sclf-regarding virtues, supported as they are lyy reason, should now appear to us so natural as to be thought innate, although they were not valued by man in his early. condition.

Notwithstanding many sources of doubt, man can generally and readily distinguish between the higher and lower morit rules. The hisher are founded on the social instincts, and relate to the welfare of others. They are supported by the approbation of our fellow-men and by reason. The lower rules, though son:" of them when implying self-sacrifice hardly deserve to be called lower, relate chiefly to self, and arise from public opinion, mintured by experience and cultivation; for they are not practiser? by rude tribes.

As man adrances in civilisation, and small tribes are united into larger communities, the simplest reason would toll each individual that he ought to extend his social instincts and sympathies to all the members of the same nation, though persoually unknown to him. This point being once reached, there is only an artificial barrier to prevent his sympathjes extending to the men of all nations and races. If, indeed, such mer are separated from him by great differences in appearance

13 Good instances are given by Mr. Wallace in 'Scientific Opinion,' Sept. 15, 1869 ; and more fully

in his 'Contributions to the Theors of Natural Select: 0 ,' 1870, p. 353. 
or habits, experience unfortunately shers us how long it is, before we look at them as our fellow-creatures. Sympathy beyond the confines of man, that is, humanity to the lower animals: scems to be one of the latest moral acquisitions. It is apparently unfelt by savages, except towards their pets. How little the old Romans knew of it is shewn by their abhorrent gladiatorial exhibitions. The very idea of humanity, as far as I could observe, was new to most of the Gauchos of the Pampas. This virtue, one of the noblest with which man is endowed, seems to arise incidentally from our sympathies becoming more tender and more widely diffused, until they are extended to all sontient beings. As soon as this virtue is honoured and practised iny some few men, it spreads through instruction and example to the young, and eventually becomes incorporated in public opinion.

The highest possible stage in moral culture is when we recognise that we ought to control our thoughts, and "not cven in " inmost thought to think again the sins that made the past so "pleasant to us." " Whaterer makes any bad action familiar to the mind, renders its performance by so much the easier. As Marcus Aurelius long ago said, "Such as are thy habitna? "thoughts, such also will be the character of thy mind; for the "soul is dyed by the thoughts." 45

Our great philosopher, Herbert Spencer, has recently explainer? his views on the moral sense. He says," "I believe that the " experiences of utility organised and consolidated through all "past generations of the human race, have been producing " corresponding modifications, which, by continued transmission. "and accumulation, have become in us certain faculties of "moral intuition-certain emotions responding to right and. "wrong conduct, which have no apparent basis in the individua! "experiences of utility." There is not the least inhrrent improbability, as it seems to me, in virtuous tendencics being more or less strongly inherited; for, not to mention the various dispositions and habits transmitted by many of our domestic animals to their offspring, I have heard of authentic cases in which a desire to steal and a tendency to lie appeared to run in families of the upper ranks; and as stealing is a rare crime in the wealthy classes, we can hardly account by accidental coincidence for the tendency occurring in two or three members of

14 Tennyson, 'Idylls of the King,' p. 244 .

45 "The Thoughts of the Emperor M. Aurelius Antoninus,' Eng. translat., 2nd edit, 1869, p. 112. Marcus
Aurelius was born A.D. 121.

46 Letter to Mr. Mill in Bain's 'Mental and Moral Science," Tstio p. 722. 
the same family. If bad tendencies are transmitted, it is probable that good ones are likewise transmitted. That the state of the body by affecting the brain, has great influence on the moral tendencies is known to most of those who have suffered from chronic derangements of the digestion or liver. The same fact is likewise shewn by tho "perversion or destruction of the " moral sense being often one of the earliest symptoms of mental "derangement;" 47 and insanity is notoriously often inherited. Except through the principle of the transmission of moral tendencies, we cannot undcrstand the differences believed to exist in this respect between the various races of mankind.

Even the partial transmission of virtuous tendencies would be an immense assistance to the primary impulse àerived directly and indirectly from the social instincts. Admitting for a moment that virtuous tendencies are inherited, it appears probable, at least in such cases as chastity, temperance, humanity to animals, \&c., that they become first impressed on the mental organization through habit, instruction and example, continued during several generations in the same family, and in a quite subordinato degree, or not at all, by the individuals possessing such virtues having succeeded best in the struggle for life. My chief source of doubt with respect to any such inheritance, is that senseless customs, superstitions, and tastes, such as the horror of a Hindoo for unclean food, ought on the same principle to be transmitted. I have not met with any evidence in support of the transmission of superstitious customs or senseless habits, although in itself it is perbaps not less probable than that animals should acquire inherited tastes for certain kinds of food or fear of certain foes.

Finally the social instincts, which no doubt were acquired by man as by the lower animals for the good of the community, will from the first have given to him some wish to aid his fellows, some feeling of sympathy, and have compelled him to regard their approbation and disapprobation. Such impulses will have served him at a very early period as a rude rule of right and wrong. But as man gradually advanced in intellectual power, and was enabled to trace the more remote consequences of his actions; as he acquired sufficient knowledge to reject haneful customs and superstitions; as he regarded more and more, not only the welfare, but the happiness of his fellow-men; as from habit, following on beneficial experience, instruction and cxample, his sympathies became more tender and widely diffused, extending to rnen of all races, to the imbecile, maimed,

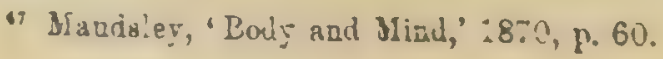


and other useless members of society, and finally to the lower animals, - so would the standard of his morality rise higher and higher. And it is admitted by moralists of the derivative school and by some intuitionists, that the standard of morality has risen since an early period in the history of man. ${ }^{48}$

As a struggle may sometimes be scen going on between the various instincts of the lower animals, it is not surprising that there should be a struggle in man between his social instincts, with their derived virtıes, and his lower, though momentarily stronger impulses or desires. This, as Mr. Galton ${ }^{49}$ has remarked, is all the less surprising, as man has emerged from a state of barbarism within a comparatively recent period. After having yielded to some temptation we feel a sense of dissatisfaction, shame, repentance, or remorse, analogous to the feelings caused by other powerful instincts or desires, when left unsatisfied or baulked. We compare the weakened impression of a past temptation with the ever present social instincts, or with habits, gained in early youth and strengthened during our whole lives, until they have become almost as strong as instincts. If with the temptation still before us we do not yield, it is because either the social instinct or some custom is at the moment predominant, or becanse we have learnt that it will appear to us hereafter the stronger, when compared with the weakened impression of the temptation, and we realise that its violation would cause us suffering. Looking to future generations, there is no cause to fear that the social instincts will grow weaker, and we may expect that virtuous habits will grow stronger, becoming perhaps fixed by inheritance. In this case the struggle between our higher and lower impulses will bo less severe, and virtue will be triumphant.

Summary of the last two Chapters. - There can be no doubt that the difference between the mind of the lowest man and that of the highest animal is immense. An anthropomorphous ape, if he could take a dispassionate view of his own case, would admit that though he could form an artful plan to plunder a gardenthough he could use stones for fighting or for breaking open nuts, yet that the thought of fashioning a stone into a tool was

48 A writer in the "North British Review' (July 1869, p. 531), well capable of forming a sound judgment, expresses himself strongly in farour of this conclusion. Mr. Lecky ('Hist. of Morals,' vol. i. p. 143) seems to a certain extent to coincide therein.

to See his remarkable work on 'Hereditary Genins,' 1869, p. 349. The Duke of Argyll ('Primeval Man,' 1869, p. 188) has some good remarks on the contest in man's nature between right and wrong. 
quito beyond his scope. Still less, as he rould admit, could he follow out a train of metaphysical reasoning, or solve a mathematical problem, or reflect on God, or admire a grand natural scenc. Some apes, howerer, would probally declare that they conld and did admire the beauty of the coloured skin and fur of their partners in marriage. 'I'hey would admit, that though they could make other apes understand by cries some of their perceptions and simpler wants, the notion of expressing definite ideas hy definite sounds had never crossed their minds. They might insist that they were ready to aid their fellow-apes of the same troop in many ways, to risk their lives for them, and to take charge of their orphans; but they would be forced to acknowledge that disinterested love for all living creatures, the most. noble attribute of man, was quite beyond their comprehension.

Nevertheless the difference in mind between man and the higher animals, great as it is, certainly is one of degrce and not of kind. We have seen that the senses and intuitions, the various emotions and faculties, such as love, memory, attentiou, curiosity, imitation, reason, \&c., of which man boasts, may be found in an incipient, or even sometimes in a well-developed condition, in the lower animals. They are also capable of some inherited improvement, as we see in the domestic dog compared with the wolf or jackal. If it could te proved that certain high mental powers, such as the formation of general concepts, self-conscionsness, \&c., were absolutely peculiar to man, which secms ixtremely doubtful, it is not improbable that these qualities are merely the incidental results of other highly-advanced intellectual faculties; and these again mainly the result of the continued use of a perfect language. At what age does the new-born infant possess the power of abstraction, or become self-conscious, and reflect on its own existence? We cannot answer; nor can we answer in regard to the ascending organic scale. The halt-art, half-instinct of language still bears the stamp of its gradual evolution. The ennobling belief in God is not universal with man; and the belief in spixitual agencies naturally follows from other mental powers. The moral sense jerhaps affords the best and highest distinction between man and the lower animals; but I need say nothing on this head, as I have so lately endeavoured to shew that the social instincts,the prime principle of man's moral constitution ${ }^{50}$-with the aid of active intellectual powers and the effects of habit, naturally lead to the golden rule, "As ye would that men should do to you, do yo to them likerise;" and this lies at the foundation of morality.

so : The The ughts of Marcus Aurelius,' Sic., p. 139. 
In the next chapter I shall make some few remarks on the probable steps and means by which the several mental and moral faculties of man have been gradually evolved. That such erolution is at least possible, ought not to be denied, for we daily see these faculties dereloping in every infant; and wo may trace a perfect grailation from the mind of an utter idiot, lower than that of an animal low in the scale, to the mind of a Nerton.

\section{CHAPTER $\nabla$.}

On the Develophent of the Intellectual and Morad Faculties during Primeval and Civilised Times.

Adrancernent of the intellectual powers through natural selectionImportance of imitation-Social and moral faculties-Their development within the limits of the same tribe-Naturas selection as affecting civilised nations-Evidence that civilised nations were once barbarous.

The subjects to be discussed in this chapter are of the highest interest, but are treated by me in an imperfect and fragmentary manner. Mr. Wallace, in an acimirable paper before referred to, ${ }^{1}$ argues that man, after he had partially acquired those inteltectual and moral faculties which distinguish him from tho lower animals, would have been but little liable to bodily modifications through natural selection or any other means. For man is enabled through his mental facultics "to keep with "an unchanged body in harmony with the changing universe." He has great power of adapting his habits to new conditions of iife. He invents weapons, tools, and various stratagems to procure food and to defend himself. When he migrates into a colder climato he uses clothes, builds sheds, and makes fires; and by the aid of fire cooks fond otherwise indigestible. He aids his fellow-men in many ways, and anticipates future events. Even at a remote period he practised some division of labour.

The lower animals, on the other hand, must have their bodily structure modified in order to survive under greatly changed conditions. They must be rendered stronger, or acquire more effective teeth or claws, for defence against new enemies; or they must be reduced in size, so as to escape detection and danger. When they migrate into a colder climate, they must become clothed with thicker fur, or have their constitutions altered. If they fail to be thus modified, they will cease to exist.

' 'Anthropological Review,' May 1864, p. clriii. 
The case, however, is widely different, as Mr. Wallace has with justice insisted, in rolation to the intellectual and moral faculties of man. 'These faculties are variable; and we hare every reason to believe that the variations tend to he inherited. 'Therefore, if they were formerly of high importance to primeval man and to his ape-like progenitors, they would have been perfected or advanced through natural selection. Of the high importance of the intellectual faculties there can be no doubt, for man mainly owes to them his predominant position in the world. We can see, that in the rudest state of socicty, the individuals who were the most sagacious, who invented and used the best weapons or traps, and who were best able to defend themselves, would rear the greatest number of offspring. The tribes, which included the largest number of men thus endowed, would increase in number and supplant other tribes. Numbers depend primarily on the means of subsistence, and this depends partly on the physical nature of the country, but in a much higher degree on the arts which are there practised. As a tribe increases and is victorious, it is often still further increased by the absorption of other tribes. ${ }^{2}$ The stature and strength of the men of a tribe are likewise of some importance for its success, and these depend in part on the nature and amount of the food which can be obtained. In Europe the men of the Bronze period were supplanted by a race more powerful, and, judging from their sword-handles, with larger hands; but their success was probably still more due to their superiority in the arts.

All that we know about savages, or may infer from their traditions and from. old monuments, the history of which is quite forgotten by the present inhabitants, shew that from the remotest times succesaful tribes have supplanted other tribes. Relics of extinct or forgotten tribes have been discovered throughout the civilised regions of the earth, on the wild plains of America, and on the isolated islands in the Pacific Ocean. At the present day civilised nations are everywhere supplanting barbarous nations, excepting where the climate opposes a deadly barrier; and thes succeed mainly, though not exclusively, through their arts, which are the products of the intellect. It is, therefore, highly probable that with mankind the intellectual faculties have been mainly and gradually perfected through natural selection; and this conclusion is sufficient for our purpose. Undoubtedly it wonld be interesting to trace the development of each separate faculty

2 After a time the members or tribes whica are absorbed into another trite issume, as Sir Henry baine remarks ("Ancicat Law,"

$1861, p .131)$, that they are the cor descendants of the same ancestors.

3 Morlot, 'Sor. Vaul. Sc. Nat1S60, p. 294. 
from the state in which it exists in the lower animals to that in which it exists in man; but neither my ability nor knowleclge permits the attempt.

It descrves notice that, as soon as the progenitors of man became social (and this probably occurred at a very carly period), the principle of imitation, and reason, and cxperience would have increased, and much modified the intellectual powers in a way, of which we see only traces in the lower animals. A pes are much giren to imitation, as are the lowest sarages; and the simple fact previously referred to, that after a time no animal can be caught in the same place by the same sort of trap, shews that animals learn by experience, and imitate the caution of others. $\mathrm{Now}$, if some one man in a tribe, more sagacious than the others, invented a new snare or weapon, or other means of attack or defence, the plainest self-interest, without the assistance of much reasoning power, would prompt the other members to imitate lim; and all would thus profit. The habitual practice of each new art must likewise in some slight degree strengthen the intellect. If the new invention were an important one, the tribe would increase in number, spread, and supplant other tribes. In a tribe thus rendered more numerous there would always be a rather greater chance of the birth of other superior and inventive members. If such men left children to inherit their mental superiority, the chance of the birth of still more ingenious members yrould be somewhat better, and in a very small tribe decidedly better. Even if they left no children, the tribe would still include their blood-relations; and it has been ascertained hy agriculturists "that by preserving and breeding from the family of an animal, which when slaughtered was found to be valuable, the desired character has been obtained.

Turning now to the social and moral faculties. In order that primeval mon, or the ape-like pregenitors of man, should become social, they must have acquired tho same instinctive feclings, which impel other animals to live in a body; and they no doubt exhibited the same general disposition. They would have felt uneasy when separated from their comrades, for whom they would have felt some degree of love; they would have warned crch other of danger, and have given mutual aid in attack or defence. All this implies some degree of sympathy, fidelity, and cournge. Such social qualities, the paramount importance of which to the lower animals is disputed by no one, were no doult

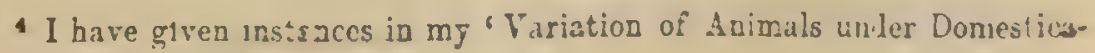
tion,' rol. ii. p. 196. 
acquired by the progenitors of man in a similar manner, namely, through natural selection, aided by inherited habit. When two tribes of primeval man, living in the same country, came into competition, if (other circumstances being equal) the one tribe jncluded a great number of courageous, sympathetic and faithfur members, who were always rerdy to warn each other of darger, to aid and defend each other, this tribe would succeed better and conquer the other. Let it be borne in mind how all-important in the never-ceasing wars of savages, fidelity and courage must be. The advantage which disciplined soldiers have over undisciplined hordes follows chiefly from the confidence which each man feels in his comrades. Obedience, as Mr. Bagehot has well shewn, ${ }^{5}$ is of the highest value, for any form of government is better than none. Selfish and contentious people will not cohere, and without coherence nothing can be effected. A tribe rich in the above qualities would spread and be victorious over other tribes: but in the course of time it would, judging from all past history, be in its turn overcome by some other tribe still more highly endowed. Thus the social and moral qualities would. tend slowly to advance and be diffused throughout the world.

But it may be asked, how within the limits of the same tribe did a large number of members first become endowed with these social and moral qualities, and how was the standard of excellence raised? It is extremely doubtful whether the offspring of the more sympathetic and benevolent parents, or of those who were the most faithful to their comrades, would be reared in greater numbers than the children of selfish and treacherous parents belonging to the same tribe. He who was ready to sacrifice his life, as many a savage bas been, rather than betray his comrades, would often lenre no offspring to inherit his noble nature. The bravest men, who were al ways willing to come to the front in war, and who freely risked their lives for others, would on an average perish in larger numbers than other men. Therefore it hardly seems probable, that the number of men gifted with such virtues, or that the standard of their excellence, could be increased through natural selection, that is, by the survival of the fittest; for we are not here speaking of one tribe being victorious over another.

Although the circumstances, leading to an increase in the number of those thus endowed within the same tribe, are ton complex to be clearly followed out, we can trace some of the probable steps. In the first place, as the reasoning powers and

- See a remarkable series of artiLles on 'Physies and Politics' in the - Forzightly Bewiew; Lior. 1867;

April 1, 1868 ; July 1, 1869, sino separately published. 
foresight of the members became improved, ench man would soon learn that if he aided his fellow-men, he would commonly receire aid in return. From this low motive he might acyuire the habit of aiding his fellows; and the habit of performing benerolent actions certainly strengthens the feeling of sympathy which gives the first impulse to benerolent actions. Habits, moreover, followed during many generations probably tend to be inherited.

But another and much more powerful stimulus to the dcvelopment of the social virtues, is afforded by the praise and the bame of our fellow-men. To the instinct of sympathy, as we have already seen, it is primarily due, that we habitually bestow both praise and blame on others, whilst we love the former and dread the latter when applied to ourselves; and this instinct no doubt was originally acquired, like all the other social instincts, through natural selection. At how early a pcriod the progenitors of man in the course of their development, became capable of feeling and being impelled hy, the praise or blame of their fellow-creatures, we cannot of course say. But it appears that even dogs appreciate encouragement, praise, and blame. The rudest savages feel the sentiment of glory, as they clearly show by preserving the trophies of their prowess, by their habit of excessire boasting, and even by the extreme care which they take of their personal appearance and decorations; for unless they regarded the opinion of their comrades, such habits would be senseless.

They certainly feel shame at the breach of some of their lesser rules, and apparently remorse, as shewn by the case of the Australian who grew thin and could not rest from having delayed to murder some other woman, so as to propitiate his dead wife's spirit. Though I have not met with any other recorded case, it is scarcely credible that a savage, who will sacrifice his life rather than betray his tribe, or one who will deliver himself up as a prisoner rather than break his parole, ${ }^{6}$ would not feel remorse in his inmost soul, if he had failed in a duty, which he held sacred.

We may therefore conclude that primeral man, at a very remote period, was influenced by the praisc and blame of his fellows. It is obvious, that the members of the same tribe would approve of conduct which appenred to them to be for the general good, and would reprobate that which appeared evil. To do good unto others- to do unto others as ye would they should do unto you -is the foundation-stone of morality. It is, therefore, hardly possible to exaggerate the importance during rude times

- Mr. Wallace gires cases in of Natural Selection, 1870, p Lit Conlributicns to the Theory 354. 
cf the lore of praise and the dread of blame. A man who was not impellor by any decp, instinctive feeling, to sacrifice his !ife for the good of others, yet was roused to such actions by a sense of glory, mould by his example excite the same wish for glory in other men, and would strengthen by exercise the noble feeling of admiration. He might thus do far more good to his tribe than by begetting offspring with a tendency to inherit his own high character.

With increased experience and reason, man perceives the nore remote consequences of his actions, and the self-regarding virtues, such as temperance, chastity, \&c., which during early times are, as we have before seen, utterly disregarded, come to be highly esteemed or even held sacred. I need not, however, repeat what I have said on this head in the fourth chapter. Ultimately our moral sense or conscience becomes a highly complex sentiment-originating in the social instincts, largely guided by the approbation of our fellow-men, ruled by reason, self-interest, and in later times by decp religious feelings, and confirmed by instruction and habit.

It must not be forgotten that although a high standard of morality gives but a slight or no adrantage to each individual man and his children orer the other men of the same tribe, yet that an increase in the number of well-endowed men and an advancement in the standard of morality will certainly give an immense advantage to one tribe over another. A tribe including many members who, from possessing in a high degree the spirit of patriotism, fidelity, obedience, courage, and sympathy, wcre always ready to aid one another, and to sacrifice themselves for the common good, would be victorious over most other tribes; and this would be natural selection. At all times thronghout the world tribes have supplanted other tribes; and as morality is one important elcment in their success, the standard of morality and the number of well-endowed men will thus everywhere tend to rise and increase.

It is, however, very difficult to form any judgment why one particular tribe and not another has been successful and has risen in the scale of civilisation. Many savages are in the same condition as when first discovered several centuries ago. As Mr. Bagehot has remarked, we are apt to look at progress as normal in human society; but history refutes this. The ancients did not even entertain the idea, nor do the Oriental nations at the present day. According to another high authority, Sir Heury Maine, "the greatest part of mankind has nerer shewn a

' 'Ancient Law,' 1861, p. 22. aightly Feriew.' April 1, 1868, p. For Mr. Bagehot's remarks, "Fort 452 
"marticle of desire that its civil institutions should be im" proved." Progress secms to depeud on many concurrent fitrourable conditions, far too complex to be followed out. But it has often been remarked, that a cool climate, from leading to industry and to the various arts, has been highly favourable thereto. The Esquimaux, pressed by hard necessity, hare succeeded in many ingenious inventions, but their climate has ieen too severe for continued progress. Nomadic habits, whether over wide plains, or through the dense forests of the tropies, or along the shrores of the sea, have in crery case been highly detrimental. Whilst olserving the barbarous inhabitants of 'Tierra del Fucgo, it struck me that the possession of somu lusoperty, a fixed abode, and the union of many families under a ehief, were the indispensable requisites for civilisation. Sucl l:abits almost necessitate the cultivation of the ground; and the first steps in cultivation would probably result, as I have elsewhere shewn, ${ }^{8}$ from some such accident as the sceds of a fruittree falling on a heap of refuse, and producing an unustally fine variety. The problem, however, of the first advance of savages towards civilisation is at present much ton clifficult to be solved.

Nuturul Selection as allecting Civitised Nations. - I have hithert" only considered the advancement of man from a semi-human condition to that of the modern savage. But some remarks on the action of natural selection on civilised nations may be worth adding. This subject has been ably discussed by Mr. W. Ii. (ireg, ${ }^{9}$ and previously by Mr. Wallace and Mr. Galton. ${ }^{10}$ Most of my remarks are taken from these three authors. Witl anvages, the weak in body or mind are soon eliminated; and those that survive commonly exhibit a vigorous state of health. Wo civilised men, on the other hand, do our utmost to check thr. jrocess of elimination; we build asylums for the imbceile, the niaimed, and the sick; we institute poor-laws; and our medica!

8 "The Variation of Animals aud Plants under Domestication,' vol. i. p. 309.

- 'Fraser's Magazine,'Sept. 1868, p. 353. This article seems to have struck many persons, and has given rise to two remarkable essays and a rejoinder in the 'Spectator,' Oct. ird and 17th, 1868. It has also been discussed in the ' $Q$. Journal of Science,' 1869, p. 152, and by Mr. Lawson Tait in the 'Dublin Q Lournal of Medicil Sciance,' Fet.
1869, and by Mr. E. Ray Lankester in his 'Comparative Lungevity,' 1870 , p. 128. Similar views ajpeared previously in the "Austritlasian,' July 13, 180̉7. I have borrowed idens from serelal of these writers.

10 For Mr. Wallace, see 'Anthrce polog. Review,' as before cited. M: Galton in 'Macmillan's Magazine, Aug. 1865 , p. 318 ; also his gyou? rork, 'Hereditatry lieuius,' iviu. 
men exert their utmost skill to save the life of every one to tho .ist moment. There is reason to believe that vaccination has preserved thousands, who from a weak constitution would rmerly have succumbed to small-pox. Thus the weak members "f civilised societies propagate their kind. No one who has attended to the breeding of domestic animals will doubt that this must be highly injurious to the race of man. It is surprisiug how soon a want of care, or care wrongly directed, luads to the legeneration of a domestic race; but excepting in the case of man himself, hardly any one is so ignorant as to allow his worst animals to breed.

The aid thich we feel impelled to give to the helpless is mainly in incidental result of the instinct of sjmpathy, which was 1.riginally acquired as part of the social instincts, but subaquentiy rendered, in the manner previously indicated, more ruder and more widely diffused. Nor could we check our i.ympathy, even at the urging of hard reason, without deterioraition in the noblest part of our nature. The surgeon may harden himself whilst performing an operation, for he knows that he is acting for the good of his patient; but if we rere intentionally to neglect the weak and helpless, it could only be for a contingent benefit, with an orerwhelming present eril. We must therefore bear the undoubtedly bad effects of the reak surviving and propagating their kind; but there appear's to be at least one wheck in steady action, namely that the weaker and inferior members of society do not marry so freely as the sound; and this check might be indefinitely increased by the weak in lody or mind refraining from marriage, though this is more to be hoped for than expected.

In every country in which a large standing army is kept up, inc finest young men are taken by the conscription or are culisted. They are thus exposed to early death during war, are niten tempted into vice, and are prevented from marrying during the prime of life. On the other hand the shorter and feebler men, with poor constitutions, are left at home, and consequently have " much better chance of marrying and propagating their kind."

Man accumulates property and bequeaths it to his children, in that the children of the rich have an advantage orer the poor :a the race for success, independently of bodily or mental suveriority. On the other hand, the children of parents who are short-lived, and are therefore on an arerage deficient in health and vigour, come into their property socner than other childres,

11 Prof. H. Fick ('Einfluss der on this head, and on other such Naturwissenschaft auf das Recht,' points. June, 1872) has some good rezaar's 
and will he likely to marry earlier, and leave a larger number of offispring to inherit their inferior constitutions. But the inheritance of property by itself is very fur from an evil; for without the accumulation of capital the arts cculd not progress; and it is chiefly through their power that the civilised races have extended, and are now everywhere extendiug their range, so as to take the place of the lower races. Nor does the moderate necumulation of wealth interiere with the process cf selection. When a poor man becomes moderately rich, his children enter trades or professions in which there is struggle enough, so that the able in body and mind succeed best. The presence of a body of well-instructed men, who have not to labour for their daily brearl, is important to a degree which cannot be over-estimater? as all bigh intellectual work is carried on by them, and on sach work, material progress of all kinds maiuly depends, not to mention other and higher adrantages. No doubt wealth when very great tends to convert men into useless drones, but their number is nerer large; and some degree of elimination here occurs, for we daily see rich men, who happen to be fools or profligate, squandering away their wealth.

Primogenitnre with entailed estates is a more direct evil, though it mas formerly have been a great advantage by the cruation of a dominant class, and any government is better than none. Nost eldest sons, though they may be weak in body or mind, marry, whilst the younger sons, however superior in these respects, do not so generally marry. Nor can worthless cllest sons with entailed estates squander their wealth. But here, as elsewhere, the relations of civilised life are so complex that some compensatory checks intervene. The men who are rich through primogeniture are able to select generation after generation the more beautiful and charming women; and these must generally be healthy in body and active in mind. The evil consequences, such as they may be, of the continued preservation of the same line of descent, without any sclection, are checked by men of rank always wishing to increase t $!_{1+i r}$ wealth and power; and this they effect by marrying heiresses. But the daughters of parents tho have produced single children, are themselves, as Mr. Galton has shewn, ant to lo sterile; and thus noble families are continually cut off in the direct line, and their wealth flows into some side channel; but unfortunately this channel is not determined by superiority of any kind.

Although civilisation thus checks in many ways the action of 12 'Hereditany Genius' 1870, pp. 132-140. 
natura, selection, it apparently favours the better development of the hody, by means of good food and the freedom from occasional hardships. This may te inferred from civilised men having been found, wherever compared, to be physically stronger than savages. ${ }^{13}$ They appear also to have equal porrers of endurance, as has been proved in many adventurous expeditions. Even the great luxury of the rich can be but little detrimental; for the cxpectation of life of our aristocracy, at all ages and of both sexes, is very little inferior to that of bealthy English lives in the lower classes. ${ }^{14}$

We will now look to the intellectual faculties. If in each grade of society the members were divided into two equal bodies, the one including the intellectually superior and the other the inferior, there can be little doubt that the former worild succeed best in all occupations, and rear a greater number of children. Eren in the lowest walks of life, skill and aibility must be of some advantage; though in many occupations, owing to the great division of labour, a very small one. Hence in civilised nations there will be some tendency to an increase. both in the number and in the standard of the intellectually able. But I do not wish to assert that this tendency may not be more than counterbalanced in other ways, as by the multiplication of the reckless and improvident; but even to such as these, ability must be some adrantage.

It has often been objected to viers like the foregoing, that the most eminent men who have ever lived have left no offspring to inherit their groat intellect. Mr. Galton says, ${ }^{15}$ " I regret I am $\therefore$ unable to solve the simple question whether, and how far, " men and women who are prodigies of genius are infertile. I " have, however, shewn that men of eminence are by no means "so." Great lawgivers, the founders of beneficent religions, rreat philosophers and discoverers in science, aid the progress of mankind in a far higher degree by their works than by leaving a numerous progeny. In the case of corporeal structures, it is the selection of the slightly better-endowed and the elimination of the slightly less well-endowed individuals, and not the prescrvation of strongly-marked and rare anomalies, that leads to the adrancement of a species. ${ }^{16}$ So it will be with the intellectual faculties, since the somewhat abler men in each grade of society

13 Quatrefages, 'Revue des Cours Scientitiques,' $1867-68$, p. 659.

14 See the fifth and sisth columns, compiled from good authorities, in the table given in Mr. $\mathrm{E}$. R. Lan. kester's 'Comparative longevity
1870, p. 115. 330.

is 'Hereditar? Genius,' 1870, [5.

16 'Origin of Species' (fifth tion, 1869), p. 104. 
succeed rather better than the less able, and consequently increase in number, if not otherwise prevented. When in any nation the standard of intellect and the number of intellectual men have increased, we may expect from the law of the deviation from an average, that prodigies of genius will, as - hewm by Mr. Galton, appear somerwat more frequently than before.

In regard to the moral qualities, some elimination of the worst dispositions is always in progress even in the most civilised nations. Malefactors are executed, or imprisoned for long periods, so that they cannot freely transmit their bad qualities. . Telancholic and insane persons are confined, or commit suicide. Tiolent anci quarrelsome men often come to a bloody end. The restless who will not follow any steady occupation-and this relic of larmarism is a great check to civilisation ${ }^{17}$ - emigrate to newly-settled countries, where they prove useful pioneers. Intemperance is so highly destructive, that the expectation of life of the intemperate, at the age of thirty for instance, is only 13.8 years; whilst for the rural labourers of England at the same age it is $40 \% 9$ years. $^{18}$ Profligate women bear few children, and profligate men rarely marry; both suffer from disease. In the breeding of domestic animals, the elimination of those individuals. though fow in number, which are in any marked manner inferior, is by no means an unimportant element towards success. This especially holds good with injurious characters which tend tc reappear through reversion, such as blackness in sheep; and with mankiurl some of the worst dispositions, which occasionally without any assignable cause make their appearance in families, may perhaps le reversions to a savage state, from which we are not removed by very many generations. This view seems indecd recognised in the common expression that such men are the black sheep of the family.

With eivilised nations, as far as an advanced standard of morality, and an increased number of fairly gond men are concerned, natural selection apparently effects but little; though the fundamental social instincts were originally thus gainer. But I have already said cnough, whilst treating of the lowch races, on the causes which lead to the advance of morality, namely, the approbation of our fellow-men-the strengthening: 347.

1: 'Hereditary Genius,' 1870, p.

18 E. Ray Laniester, 'Comparat:re Longerity,' 1370, p. 115. The table of the intmperate is from
Neison's 'Vital Statistics.' In re. gard to profligacy, see Dr. Far"; "Influence of Marriage on Mor. tality,' 'Nat. Assoc. for the Prome tion of Social Seience,' 1858. 
of our sympathies by habit-example and imitation-reasonexperience, and even self-interest-instruction during youth. and roligious feelings.

A most important obstacle in civilised countries to an increase in the number of mou of a superior class has been strongly insisted (1) by Mr. Greg and Mr. Galton, ${ }^{19}$ namely, the fact that the very poor and reckless, who are often degraded by rice, almost invariably marry early, whilst the careful and frugal, who are generally ctherwise virtuous, marry late in life, so that they may be able to support themselves and their children in comfort. Those who zwarry eariy produce within a given period not only a greater number of generations, but, as shewn by Dr. Duncan, ${ }^{20}$ they proince many more children. The children, moreover, that are born by mothers during the prime of life are beavier and larger, and therefore probably more vigorous, than those born at other periods. Thus the rechless, degraded, and often ricious members of society, tend to increase at a quicker rate than the provident and generally virtuous members. Or as Mr. Greg puts the case : "The careless, squalid, unaspiring Irishman multiplies like "rabbits: the frugal, foreseeing, sclf-respecting, ambitious Scot, "stern in his morality, spiritual in his faith, sagacious and dis"ciplined in his intelligence, passes his best years in struggle "and in celibacy, marries late, and leares few hehind him. "Given a land originally peolled by a thousand Saxons and a * thousand Celts-and in a dozen generations five-sixths of the "population would be Celts, but five-sixtlus of the property, of "the power, of the intcllect, would belong to the one-sixth of "Saxons that remained. In the eternal 'struggle for existence,' "it would be the inferior and less favoured race that had pre"vailed-and prevailed by virtue not of its good qualities but of "its faults."

There are, however, some checks to this downward tendency. We have seen that the intemperate suffer from a high rate of mortality, and the extremely profligate leave few offspring. The poorest classes crowd into towns, and it has been proved by Dr. Stark from the statistics of ten years in Scotland, ${ }^{21}$ that at all

10 'Fraser's Magazine, Sept. 1868, p. 353. 'Macmillan's Magazine, Aug. 1865, p. 318. The Rev. F. W. Farrar' ('Fraser's Mag,' Aug. $\$ 370$, p. 264) takes a different view.

2: $1 \mathrm{On}$ the Laws of the Fertility of Womer,' in 'Transact. Royal Soc.' Edinburgh, vol. xxiv. p. 287 ; now pablished separately under the title of 'Fecundity, Fertility, and Sterihity,' 1871. See, also, Mr Galton, 'Hereditary Genius?' pp. 35 - 357 , for obserrations to the above effect.

21 'Tenth Annual Report os Birtbs, Deaths, \&rco, :D Scorland, 1867, p. xrix. 
ages the death-rate is higher in towns than in rural districts, " and during the first five years of life the town death-rate is "almost exactly double that of the rural districts." As these returns includo both the rich and the poor, no doubt more than twice the number of births would be requisite to keep up the number of the very poor inhabitants in the towns, relatively to those in the country. With women, marriage at too early an age is highly injurious; for it has been found in France that, "twice as many wives under twenty die in the year, as died out "of the same number of the unmarried." The mortality, also, of husbands under twenty is "excessively high," ${ }^{22}$ but what the cause of this may be, seems doubtful. Lastly, if the men who prudently delay marrying until they can bring up their families in comfort, were to select, as they often do, women in the prime of life, the rate of increase in the better class would be only slightly lessenød.

It was established from an enormous body of statistics, taken during 18.53, that the unmarried men throughout France, between the ages of twenty and eighty, die in a much larger proportion than the marricd: for instance, out of every 1000 ummarried men, between the ages of twenty and thirty, 11.3 annually died, whilst of the married only 6.5 died. ${ }^{23}$ A simiJar law was proved to hold good, during the years 1863 and 1864, with the entire population above the age of twenty in Scotland: for iustance, out of every 1000 unmarried men, between the ages of twenty and thirty, 14.97 annually died, whilst of the married only $7.2 t$ dicd, that is less than half. ${ }^{24}$ Dr. Stark remarks on this, "Bachelorhood is more dustructive to life than the most "unwholesome trades, or than residence in an unwholesome " house or district where there has never been the most distant "attempt at sanitary improrement." $\mathrm{He}$ considers that the lossened mortality is the direct result of "marriage, and the "more regular domestic habits which attend that state." He admits, however, that the intemperate, profligate, and criminal classes, whose duration of life is low, do not commonly marry; and it must likewise be admitted that men with a weak constitu-

82 These quotations are taken from our highest authority on such questions, namely, Dr: Farr, in his paper 'On the Influence of Marriage on the Mortality of the French People, read before the Nat. Assoc. for the Promotion of Social Science, $185 \mathrm{~S}$

23 Dr. Farr, ibid. The quotations given below are extracted from the same striking paper.

24 I have taken the mean of the quinquennial means, given in 'The Tenth Annual Report of Births, Deaths, \&c., in Scotland,' 1867. The quotation from Dr. Stark is copied from an article in the "Daily News,' Oct. 17th, 1868, which Dr. Earr considers very carefally wrivten. 
tion, ill health, or any great infirmity in hody or mind, will often not wish to marry, or will be rejected. Ir. Stark seems to have come to the conclusion that marriage in itself is a main cause of prolonged life, from finding that aged married men still have a considerable advantage in this respect over the unmarried of the same advanced age; but every one must have known instances of men, who with weak health during youth did not marry, and yet hare survived to old age, though remaining weak, and therefore always with a lessened chance of life or of marrying. There is another remarkable circumstance which seems to support Dr. Stark's conclusion, namely, that widows and widowers in France suffer in comparison with the married a rery heavy rate of mortality; but Dr. Farr attributes this to the poverty and evil habits consequent on the disruption of the family, and to gricf. On the whole we may conclude with Dr. Farr that the lesser mortality of married than of unmarried men, which seerns to be a general law, "is mainly due to the constant elimination of imperfect "types, and to the skilful selection of the finest individuals out " of each successive gencration;" the selection relating only to the marriage state, and acting on all corporeal, intellectual, and moral qualities. ${ }^{25}$ Wo may, therefore, infer that sound and cood men who out of prudence remain for a time unmarried, do not suffer a high rate of mortality.

If the various checks specified in the two last paragraphs, and perhaps others as yet unknown, do not prevent the reckless, the vicious aud otherwise inferior members of socicty from increasing at a quicker rate than the better class of men, the nation will retregrade, as has too often occurred in the history of the world. We must remember that progress is no invariable rule. It is very difficult to say why one civilised nation rises, becomes more powerful, and spreads more widely, than another; or why the same nation progresses more quickly at one time than at another. We can only say that it depends on an increase in the actual number of the population, un the number of the men endorred with high intellectual and moral facultics, as well as on their standard of excellence. Corporeal structure appears to have little influence, except so fär as vigour of body leads to vigour of mind.

It has been urged by sereral writers that as high intellectual power's are advantageous to a nation, the old Greeks, who stood some grutes higluer in intellect than any race that has ever

os Irr l)uncan remarks ('Fecundity, Frrility, \&c., 1871, p. 33t) un this suhject; "At every age the cherithy and beartiful go over "from the unmarried side to the " married, learing the unmarrie? " columns crowded with the sickly" "and unfortunate." 
existed, ${ }^{26}$ vught, if the porrer of natural selection were renl, io have risen still higher in the scale, increased in number, aud stocked the whole of Europe. Here we have the tacit assumption, so often made with respect is corporeal structures, that there is some innate tendency towards continued development in mind aud body. But development of all kinds depends on many concurrent favourable circumstances. Natural selection acts conly tentatively. Individuals and races may have accuired certain indisputalle adrantages, and yet have perished from failing in other characters. The Greeks may have retrograded from a want of coherence between the many small states, from the small size of their whole country, from the practice of slavery, or from cxtreme sensuality; for they did not succumb until "they were "enervated and corrupt to the rery core." it T'he western nations of Europe, who now so immeasurably surpass their former savage progenitors, and stand at the summit of civilisation, owe little or none of their superiority to direct inheritance from the old Greeks, though they owe much to the written works of that wonderful people.

Who can positively say why the Spanish nation, so dominant. at one time, has been distanced in the race. The awakening of the nations of Europe from the dark ages is a still more perplexing problem. At that early period, as IIr. Galton has remarked. almost all the men of a gentle nature, those given to meditatio: or culture of the mind, had no refuge except in the bosom of a Church which demanded celibacy; ${ }^{28}$ and this could hardly fail to have had a deteriorating influence on each successivi: generation. During this same period the Holy Inquisition selected with extreme care the freest and boldest men in ordel to burn or imprison them. In Spain alone some of the best men-those who doubted and questioned, and without doubting there can be no progress-were eliminated during thrce ccnturies at the rate of a thousand a ycar. The evil which the Catholic Church has thus effected is incalculable, though no de $=$ bt counterbalanced to a certain, perhaps to a large, cxtent in other ways; nevertheless, Europe has progressed at an unparalleled rate.

28 See the ingenious and origian! argument on this subject by M: Galton, 'Hereditary Genius,' IY). 340-342.

${ }_{27}$ Mr. Greg, 'Fraser's Magazine,' Sept. 1868, p. 357.

'Hered:tary Geaius,' 1870, rp. 35:-359. The Rev. F. W. Farrit ('Fraser's Mag.' Aug. 1870, p.

257) advances arguments on the other sicle. Sir C. L.yell had already ('Principles of Geolngy,' vol. i. $1868, \mathrm{p} .489$ ) in a striking passage called attention to the evil influence of the Holy Inquisition in having, through selection, lowered the geas ral standard of Eivellignoce in Eurupe. 
The remarkable success of the English as colonists, compareul to other European nations, has been ascribed to their "darin." "and persistent energy;" a result which is well illustrated by comparing the progress of the Canadians of English and French oxtraction; but who can say how the English gained their energy? There is apparently much truth in the belief that the wonderful progress of the United States, as well as the character of the people, are the results of natural selection; for the more energetic, restless, and courageous men from all parts of Europe have emigrated during the last ten or twelve generations to that great country, and have there succeeded best. ${ }^{29}$ Looking to the distant future, I do not think that the Rev. Mr. Zincke takes an exaggerated view when he says:"30 "All other series of events"as that which resulted in the culture of mind in Greece, and "that which resulted in the empire of Rome-only appear to "have purpose and value when viewed in connection with, or "rather as subsidiary to .... the great stream of Anglo-Saxon "emigration to the west." Obscure as is the problem of the advance of civilisation, we can at least see that a nation which produced during a lengthened period the greatest number of highly intellectual, energetic, brave, patriotic, and benevolent men, would generally prevail over less favoured nations.

Natural selection follows from the struggle for existence; and this from a rapid rate of increase. It is impossible not to regret bitterly, but whether wisely is another question, the rate at which man tends to increase; for this leads in barbarous tribes to infanticide and many other evils, and in civilised nations to abject poverty, celibacy, and to the late marriages of the prudent. But as man suffers from the same physical evils as the lower animals, he has no right to expect an immunity from the evils consequent on the struggle for existence. Had he not been subjected during primeval times to natural selection, assuredly he would never have attained to his present rank. Since we see in many parts of the world enormous areas of the most fertile land capable of supporting numerous happy homes, but peopled only ly a few wandering savages, it might be argued that the struggle fror existence had not been sufficiently severe to force man upwards to his highest standard. Judging from all that we know of man and the lower animals, there has always been sufficient variability in their intellectual and moral faculties, for a steady ndvance through natural selection. No doubt such advance

2 Mr. Gaiton, 'Macmillan's Magazine,' August, 1865, p. 325. Soe also, "Nature," "On Darwinism and National Life,' Dec. 1869, p. 184. 30 'Last. Wintor' in the United States,' 1868 , p. 29. 
lemands many favourable concurrent circumstances; but it may well be doubted whether the most favourable would have suffecd, had not the rate of increase been rapid, and the consequent struggle for existence extremely severe. It even appears from what we see, for instance, in parts of S. Amcrica, that a people which may be called civilised, such as the Spanish settlers, is liable to become indolent and to retrograde, when the conditions of life are very easy. With highly civilised nations continued progress depends in a subordinate degree on natural selection; for such nations do not supplant and exterminate one another as do savage tribes. Nevertheless the more intelligent members within the same community will succeed better in the long run than the inferior, and leave a more numerous progeny, and this is a form of natural selection. The more efficient causes of progress seem to consist of a good education during youth whilst the brain is impressible, and of a high standard of excellence, inculcated by the ablest and best men, embodied in the laws, customs and traditions of the nation, and enforced by public opinion. It should, however, be borne in mind, that the enforcement of public opinion depends on our appreciation of the approbation and disapprobation of others; and this appreciation is founded on our sympathy, which it can hardly be doubtcd was originally developed through natural selection as one of the most important elements of the social instincts. ${ }^{31}$

On the evidence that all civilised nations were once barbarous.The present subject has been treated in so full and admirable a manner by Sir J. Lubbock, ${ }^{32} \mathrm{Mr}$. Tylor, Mr. M'Lennan, and others, that I need here give only the briefest summary of their results. The arguments recently advanced by the Duke of Argyll ${ }^{33}$ and formerly by Archbishop Whately, in favour of the helief that man came into the world as a civilised being, and that all savages have since undergone degradation, seem to me weak in comparison with those advanced on the other side. Many nations, no doubt, have fallen away in civilisation, and some may have lapsed into utter barbarism, though on this latter head I hare met with no evidence. The Fuegians were probably compelled by other conquering hordes to settle in their inhospitable country, and they may have become in consequence somewhat more degraded; but it would be difficult to provo

81 I am much indebted to Mr. John Morley for some good criticisms on this subject: see, also, Broca, 'Les Sélectious,' "Revue d'Antbropologie,' 1872.
32 'On the Origin of Civilisation, 'Proc, Ethnological Soc.' Nor. 28 1867.

33 'Primeval Man,' 1868. 
that they have fallen much below the Botocudos, who inhalit the finest parts of Brazil.

The evidence that all civilised nations are the descendants c1 barbarians, consists, on the one side, of clear traces of their former low condition in still-existing customs, beliefs, langruage, Wc.; and on the other side, of proofs that savages are inclependently able to raise themselves a few steps in the scale of civilisation, and have actually thus risen. The evidence on the first head is extremely curious, but cannot be here given: I refer to such cases as that of the art of enumeration, which, as Mr. Tylor clearly shews by reference to the words still used in some places, originated in counting the fingers, first of one hand and then of the other, and lastly of the toes. We have traces of this in our own decimal system, and in the Roman numerals, where, after the V., which is supposed to be an abbreviated picture of $a$ human hand, we pass on to VI., \&c., when the other hand no doubt was used. So again, "when we speak of three-score and "ten, we are counting by the vigesimal system, each score thus "ideally made, standing for 20-for 'one man' as a Mexican or "Carib would put it." " According to a large and increasing school of philologists, every language bears the marks of its slow and gradual evolution. So it is with the art of writing, for letters are rudiments of pictorial representations. It is hardly possible to read Mr. M'Lennan's work's5 and not admit that almost all civilised nations still retain traces of such rude habits as the forcible capture of wives. What ancient nation, as the same author asks, can he named that was originally monoramous? The primitive idea of justice, as shewn by the law of inattle and other customs of which vestiges still remain, was likewise most rude. Many existing superstitions are the remnants of former false religious beliefs. The highest form of religion-the grand idea of God hating sin and loring rightcousness-was unknown during primeval times.

Turning to the other kind of evidence: Sir J. Lubbock las shewn that some savages have recently improved a little in some of their simpler arts. From the extremely curious account which he gives of the weapons, tools, and arts, in use

3 'Royal Institution of Great Sritain,' March 15, 1867. Also, - Kerearches into the Early History of Mankind,' 1865.

" 'Primitive Marriage,' 1865. soe, likewise, an excellent article, evidently by the same author, in the 'North British Review, July, 1869. Also, Mi. L. H. Morgna,
'A Conjectural Solution of the Origin of the Class, System of Relationship,' in 'Pruc. American Acad. of Sciences' vol. vii. Feb. 1868. Prof. Schaaffhausen ('Anthropolog. Review,' Oct. 1869, F. 373) remarks on "the restiges of "human sacrifices found both in "Homer and the Old 'Pestament." 
amongst sarages in rarious parts of the world, it cannot be doubted that these have nearly all becn independent discoveries, excepting perhaps the art of making fire. ${ }^{36}$ Tiac Australian tromerang is a good instance of one such independent discovery. The Tahitians when first risited had advanced in many respects beyond the inlabitants of most of the other Polynesian islands. There are no just grounds for the belief that the high culture of the native Peruvians and Mexicans was derived from abroad ; $;^{37}$ many native plants were there cultirated, and a few native animals domesticated. We should bear in mind that, judging from the small influence of most missionarics, a wandering crew from some semi-civilised land, if washed to the shores of America, would not hare produced any marked effect on the natives, unless they had already become somewhat advanced. Looking to a very remote period in the history of the world, we find, to use Sir J. Lubbock's well-known terms, a paleolithic and nenlithic period; and no one will pretend that the art of grinding rough flint tools was a borrowed one. In all parts of Europe, as far tast as Grecee, in Palestine, India, Japan, New Zealand, and Africa, including Egylt, flint tools have been discorered in abundance; and of their use the existing inhabitants retain no tradition. There is also indirect evidence of their former use by the Chinese and ancient Jews. Hence there can hardly be a doubt that the inhabitants of these countries, which include nearly the whole civilised world, were once in a barbarous condition. To believe that man was aboriginally civilised and then suffered utter degradation in so many regions, is to take a pitiably low view of human nature. It is aplyarently a truer and more cheerful view that progress nas becn much more general than retrogression; that man has risen, though by slow and interrupted steps, from a lowly condition to the highest standard as yet attained by him in knowledge, morals and religion.

36 Sir J. Lubbock, 'Prehistoric Times,' 2nd edit. 1869, chap. xv. and $x$ vi. et pissin. See also the excellent 9th ciapter in 'Tylor's 'Early History of hisakind,' 2ud edit., 1870.

${ }^{37}$ Dr. F. Miiller has made soms good remarks to this effect in the: 'Reise der Novara: Anthropoing Theil,' Abtheil. i:j. 1868 s. 127. 
CHAPTEF $\mathrm{Yi}$.

\section{ON tite Affinities and Genealogy of Ma:}

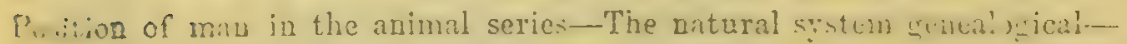
Alaptive characters of slight value-Various small points of resemblance between man and the Quadrumana-Ranis of man in the natura? system-Birthplace and antiquity of ma-Absence of tussil connectinglinks-Lower stares in the genealngy of man, as inferred, firstly from his affinities and secondly from his structure-Early androgynous condition of the Vertebrata-Conclusion.

FWr if it le granted that the difference hetween man and his renatust allies is as great in corporeal structure as some uatumists maintain, ank althongh we must grant that the diffi-n(nee between them is immense in mental porrer, set the facts inen in the carlice chapters appear to diclare, in the plaincst manner, that man is descended from some lower form, notwithintanding that connectiug-links have not hitherto been discovered.

Man is liallo to numerons, slight, and diversified variations. Which are induced by the saine gemeral causes, are goremed and tranmitter in accordanee with the same general laws, as in :he lower animals. Mran has multiplied so rapielly; that he has necessarily been exposed to strugge for cxistener, and conirguently to uatural selection. Ho has giren rise to many races, some of which diffe" so much frum eacl other, that they have Iften becn ranke hy uaturalists as clistinet species. His hody "s constructed ou the same homolocical plan as that of cflucr ammals. Ho passes through the same phases of emuryoiogical derelopment. Ife retilins many rudimentary and uscless

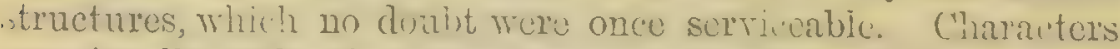
reasionally make their re-apporance in him, which we hare

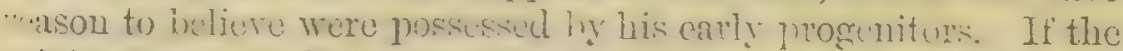
migin of man lial heen wholly disierent from that of all other animalu, these farious appcarancess would be mere ompty deceptions; but such an admission is incredible. These apuearanices, ou the otler hand, are intellicilule, at least to a large astent. if min is the co-descentant with other manmals of somis unknown and lower form.

Some naturalists, from leing deeply impressed with the mental and spiritual powers of man, have divided the whoio

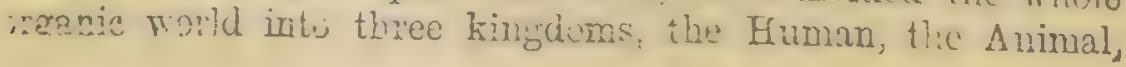


and the Tegetable, thus giving to man a separate kirgdom.? Spiritual nowers cannot be compared or classed by the naturalist: but he may endeavour to shew, as I have done, that the nental faculties of man and the lower animals do not differ in lind, although immensely in degree. A difference in degree, howerer great, does not justify us in placing man in a distinct kingdom, as will perhaps be best illustrated by comparing the mental powers of two insects, namely, a coccus or seale-insect ant an ant, which undoubtedly helong to the same class. The differcnee is here greater than, though of a somewhat different kind from, that between man and the highest mammal. The female coccus, whilst joung, attaches itself by its proboscis to a plant; suclis the sap, but nercr mores again; is fertilised and lays cggs; and this is its whole history. On the other hand, to describe the halits and mental powrers of worker-ants, would require, as Pierve IIuber bas shemn, a large volume; I may, however, briefly - . iecify a few points. Ants cortainly communicate information to ach ofler, and several unite for the same work, or for games of why. The recognise their fullow-ants after months of absence, and feel sympathy for ench other. They build great edifices, keep thom clcan, close the doors in the erening, and post seutrics. They make roads as well as tunnels under rivers, and tumporary bridges orer them, by clinging together. They collect food for the community, and when an object, too large for entrance, is brouglit to the nest, they enlarge the duor, aud afterwards luild it up again. They store up secds, of which they prevent the germination, and which, if damp, are brought up to the surface to dry. They keep aphides and other insects as milch-cows. They go out to battle in regular bands, and freely sacrifice their lives for the common weal. They cmigrate according to a preconcerted plan. They capture slaves. They move the eggrs of their aphides, as well as their own cogs and cocoons, 1nto warm parts of the nest, in order that they may be quickly hatched; and cndless similar facts could be given." On the whole, the diff.rence in mental power between an ant and a coccus is immense; yet no one has erer dreamed of ple cing these insects in distinct classes, much less in distinct king loms. No

${ }^{1}$ Isidure Geoffroy St.-Hilaire gives a detailed account of the position assigned to man by various naturalists in their classifications: 'H st. Nat. Gén.' tom. ii. 1859, pp. 1\%0189.

2 Some of the most interesting iscts eve? publisned on the habits of ants are given by $\mathrm{Mr}$. Belt, in in his 'Naturalist in Nicarigua,' 1874. See also Mr. Moggridge's admirable work, 'Harvesting Ants,' \&c., 1873, also 'L'Instinct chez les Insectes,' by M. George Pouchet, 'Revue des Deus Mondes,' Feb, 1870 p. 682 . 
dontht the difference is bridged over by other inscetc; and this is not the case with man and the higher apes. But we have evert reason to believe that the breaks in the series are simply the results of many forms having become extinct.

Professor Owen, relying chiefly on the structure of the brain, has divided the mammalian serios into four sub-classes. One of these he derotes to man; in another he places both the Marsupials and the Monotremata; so that he makes man as distinct from all other mammals as are these two latter groups conjoined. This view has not been accepted, as far as I am aware, by any naturalist capable of forming an independent judgment, and therefore need not here be further considered.

We can understand why a classification founded on any single character or organ-even an organ so wonderfully complex and important as the brain-or on the high derclopment of the mental faculties, is almost sure to prove unsatisfactory. This principle has indeed been tried with hymenopterous insects; but when thus classed by their habits or instincts, the arrangement proved thoroughly artificial. ${ }^{3}$ Classifications may, of course, be based on any character whatever, as on size, colour, or the element inhabited; but naturalists have long felt a profound conviction that there is a natural system. This system, it is now generally admitted, must be, as far as possible, genealogical in arrangement, - that is the co-descendants of the same form must be kept together in one group, apart from the co-descendants of any other form; but if the parent-forms are related, so will be their descendants, and the two groups tosether will form a larger group. The amount of difference between the several groups-that is the amount of modification which each has undergone-is expressed by such terms as genera, families, orders, and classes. As we have no record of the lines of descent, the pedigree can be discovered only by observing the degrees of resemblance between the beings which are to be classed. For this object numerous points of resemblance are of much more importance than the amount of similarity or dissimilarity in a few points. If two languages were found to resemble each other in a multitude of words and points of construction, they would be universally recognised as inving sprung from a common source, notwithstanding that they differed greatly in some few words or points of construction. But with organic beings the points of resemblance must nut consist of adaptations to similar habits of life: two animals may, lor instance, have had their whole frames modified for living in

'Westwont 'Mnderv C'ass of Insects, rol : 1840, p 87 
the water, and yet they will not be brought any nearer to each otler in the natural system. Hence we can see how it is that - esemblanees in several unimportant struetures, in useless and rudimcntary organs, or not now functionally active, or in an cmbryological condition, are by far the most serviceable fur classification; for they can hardly be duo to adaptations within a late perind; and thus they reveal the old tines of descent or of true affinity.

We can further see why a great amount of modification in some one character ought not to lead us to separate widely any two orgauisms. A part which already differs much from the same part in other allied forms has already, according to the theory of evolution, raried much; consequently it would (as long as the organism remained exposed to the same exciting conditions) be liable to further variations of the same kind; and these, if beneficial, would be preserred, and thus be continual!y augmented. In many cases the continued development of a part, for instance, of the beak of a bird, or of the tecth of a mammal, would not aid the species in gaining its food, or for any other object; but with man we can see no definite limit to the continued development of the brain and mental faculties, as far as advantage is concerned. Therefore in determining the position of man in the natural or genealogical system, the extreme development of his brain ought nut to outweigh a multitude ot resemblancess in other less important or quite unimportant points.

The greater number of naturalists who have taken into consideration the whole structure of man, including his mental faculties, have followed Blumenbach and Curier, and have placed man in a separate Order, under the title of the Bimaun, and therefore on an equality with the orders of the Quadrumana, Carnirora, de. Recently many of our best naturalists hare recurred to the riow first propounded by Limnæus, so remarkable for his sagacity, and have placed man in the same Order with the Quadiumana, under the title of the Primates. 'The justice of' this conclusion will be admitted: for in the first place, we must bear in mind the comparative insignificance for classification of the great development of the brain in man, and that the strongly-marked differcnces between the skulls of man and thes Quadrumana (lately insisted upon by Bischoff, Aeby, and others' apparently follow from their differently developed brains. In the second place, we must remember that nearly all the other and more important diffcrences between man and the Quadrumana are manifestly adaptive in their nature, and relato chiefly to tho arcet positiou of man; such as the structure of his hand form 
and prolris, the curvature of his spine, and the position of livs heal. The family of Scals offers a good illustration of the small importanco of adaptive characters for classification. Theso animals differ from all other Carnivora in the form of their bollies and in the structure of their limbs, far more than does man from the higher apes; yet in most systems, from that of Cuvier to the most recent one hy Mr. Flower, seals are rankel as a mere family in the Order of the Carnivora. If man hiul not been his own classifier, he would never have thonght of founding a separate order for his own reception.

It would be beyond my limits, and quite beyond my knowledse. even to name the innumerable points of structure in which man agrees with the other Primates. Our great anitomist and plilosopher, Prof. Huxley, has fully discussed this sulject, ${ }^{5}$ and concludes that man in all parts of his organisation differs les: from the higher apes, than these do from the lower members o: the same group. Consequently there "is no justification fol" "placing man in a distinct order."

In an early part of this work I brought furmard various facts, shewing how closely man agrees in constitution with the higher mammals; and this agrecment must depend on ou: close similarity in minute structure and chemical composition. I gave, as instances, our liability to the same discases, aud to the attacks of allied parasites; our tastes in common fir the same stimulants, and the similar effects produced by thcm, as well as by various drugs, and other such facts.

As small unimportant points of resemblance betwoen man and the Quadrumana are not commonly noticed in systcnuatic works, and as, when numcrous, they clcarly reveal our relationship, I will specify a few such points. The relative position of our features is manifestly the same; and the rarious emotious are displayed by nearly similar morements of the muscles and skin, chiefly above the eyebrows and round the mouth. Some few cxpressions are, inileed, almost the same, as in the reeping of certain kinds of monkeys and in tho langhing noise made by others, during which the corners of the mouth are drawn backwards, and the lower eyclids winkled. The extcrnal ears are curiously alike. In man the nose is much more prominent than in most monkeys; but we may trace the commencement of an aquiline curvature in the nose of the Hoolock Gibhon; and this in the Semnopithecus nasica is carried to a ridiculous extreme.

The faces of many monkeys are ornamented with beards, whiskers, or moustaches. The hair on the head grows to a great

1 'Pruc. Zoolog. Soc.' 1863, p. 4.

' 'Evidence as to Man's Piace in Nature,' 1863 , p. 70, ct passim. 
length in some species of scmnopithects;" and in the Bonsts

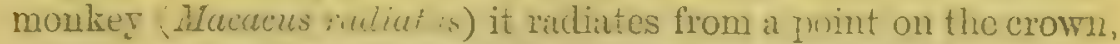
with a parting down the midhle. It is commonly said that thes forehead gives to man his nolle and intellectual alpeidruce; bat the thick hair on the heal of the lonnet monkey terminate: downwards abruptly, and is sincecelued by hair so short and fine? that at a little clistance the foicheal, with the exception of the eyebrows, appears cyuite melsul. It has becn erroncuus!y asserta that eychrows arc not present in any monkey. In the species just nimed the deree of kidichelness of the forelead differs in thifferent individuals; and Esehricht states ${ }^{7}$ that in onr children the limit hetwern the hairy scalp and the naked furchead is -ometimes not weil defined; so that here we seem to have a witling case of reversion to a grocenitor, in whom the forcheal had not as yet become quite naked.

It is well known that the hair on onr arins tends to converge :wom above and below to a puint at the clbow. This curious arrangement, so unlike that in must of the lower mammals, is "enmon to the grorilla, thimpanzee, orang, some species of liflobates, and even to sime fer American monkeys. But in: diylolates ayilis the hair ou the fore-arm is directed dowuwardis or towards the wrist in the ordinary manner; and in $H$. lar it is nearly crect, with only a sery slight forward inclination; so that in this lattur spering it is in a transitional state. It ain hardly he doubted that with must mamma's the thickness of the hair on the back and its direction, is adapice to throw off the rain; cren the transverse hairs on the fore-legs of a dog may w rre lor the and when he is coiled un asleep. Mr. Wallace, who has carefully studied the habits of the eaner remarks that the convergence of the hair tuwards the ellw, wh the arms of the orang may be explained as serving to throw of the min, for this animal during: mainy weather sits with its arus hent, and with the hauds clasperd round a brancly or over its head. Acenraing to Livingstone, the: corilla also "sits in pelting raiu mith his hands over his head." If the alove explanation is correct, as seems probable, the dires:tion of the hair on our own arms offers a curious record of our former state; for no one supposes that it is now of any use in throwing off the rain; nor, in our present crect condition, is it properly directed for this purpose.

It would, however, be rash to trust too much to the priveiple: of adaptation in regard to the direction of the hair in man or his

- Isid. Geoffroy, 'Hist. Nat. Gén.' tom. ii. 1859 , p. 21.7.

" Ueber die Richtung lier S.ure,' \&c., Mijller's 'Archiv t'iu'
Anat. und Phys:' 1837, s. 51.

Quoted by Reade, "The Africns Sketch Book,' rol. i., 1873, p. 152. 
carly progenitors; for it is impossible to sturly the figures given hy Eschricht of the arrangement of the hair on the lumuan foetus (this being the same as in the adult) and not agree with this "xcellent observer llat other and more complex canses havo intervened. The proints of convergence scem to stand in some relation to those proints in the cunbryo which are last closed in luring development. There appears, also, to exist some relation hetween the arrangement of the hair on the limbs, and the conise of the medullary arteries. ${ }^{9}$

It must not be supposed that the resemblances betrecn man and certain apes in the above and many other points-such as in having a naked forehead, long tresses on the head, dic.-are all necessarily the result of unbroken inheritance from a common progenitor, or of subsequent reversion. Many of these resemhlances are more probably due to analogons variation, which iollows, as I have elsewhere attempted to shew, ${ }^{10}$ from co-descended organisms having a similar constitution, and having been acted on by like causes inducing similar modifications. With respect to the similar direction of the hair on the fore-arms of man and rertain monkeys, as this character is common to almost all the antluropomorphous apes, it may probably be attributed to inheritance; but this is not certain, as some very distinct Amcrican monkeys are thus characterised.

Although, as we have now scen, man has no just right to form. a scparate Order for his own reception, he may perhaps claim a distinct Sub-order or Family. Prof. Huxley, in his last work," divides the Primates into three Sub-orders; namely, the Anthropida with man alone, the Simiadre including monkeys of all kinds, and the Lemuidie with the diversified genera of lemurs. As far as differences in certain important points of struciure are concerned, man may no doubt rightly claim the rank of a Suborder; and this rank is too low, if we look chictly to his mental faculties. Nevertheless, from a genealogical point of view it appears that this rank is too high, and that mau ought to form merely a Family, or possibly even only a Sub-family. If wo imagine three lines of descent proceeding from a common stock; it is quite conceivable that two of them might after the lapse of

- On the hair in Hylobates, see Nat. Hist. of Mammals,' by C. I. Martin, 1841, p. 415. Also, Isid. Geoffroy on the American monkers and other kinds, 'Hist. Nat. Gén.' rol. ii. 1859 , p. 216,243 . Eschricht, ibil. s. $46,55,61$. Owen, 'Anat. of Vertolinates,' rol. iii. p. 6i9. Wallace, 'Covtributious :o the Theory of Natural Selection.' 1870, p. 344.

10 'Origin of '3pecres, 5 th $\ldots . \cdot$ 1869 , p. 194. "The Variatio: : Animals and Plants under Domen:cation,' vol. ii. 1868, p. 348.

11 "An Introduction to the C"..ss ification of Animals; $13 B 9,1.5$. 
ages be so slightly changed as still to remain as sprecics of this same genus, whilst the third line might become so greatly molified as to deserve to rank as a distinct Sub-family, Family, or even Order. But in this case it is almost certain that the tlird line would still retain through inheritance numerous swall points of resemblance with the other two. Here, then, would occur the difficulty, at present insoluble, how much weight we ought to assign in our classifications to strongly-marked differences in some fer points, - that is, to the amount of modification undergone; and how much to close resemblance in numerous unimportant points, as indicating the lines of descent or genealogy. To attach much weight to the few but strong differences is the most obvious and perhaps the safest course, though it appears more correct to pay great attention to the many small resemblances, as giving a truly natural classification.

In forming a judgment on this head with reterence to man, we must glance at the classification of the Simiadx. This family is divided by almost all naturalists into the Catarhine group, or old World monkeys, all of which are characterised (as their name expresses) by the peculiar structure of their nostrils, and by having four premolars in each jaw; and into the Platyrhine group or New World monkess (including two rery distinct sub-groups), all of which are characterised by differently constructed nostrils, and loy having six premolars in each jaw. Some other small differcnces might be mentioned. Now man unquestionably belongs in his dentition, in the structure of his nostrils, and some other respects, to the Catarhine or Old Worlel division; nor does he resemble tho Platyrhines more closely than the Catarhines in any characters, excepting in a ferv of not much importance and apparently of an adaptive nature. It is therefore against all probability that some Nerv World species should have formerly varied and produced a man-like creature, with all the distinctive characters proper to the Old World division; losing at the same time all its own distinctive characters. 'There can, consequently, hardly be a doubt that man is an off-shoot from the: old World Simian stem; and that under a genen!ogical point of \&iew. he must be classed with the Catarhine division. ${ }^{12}$

The anthropomorphous apes, namely the gorilla, chimpanzec.

12 This is nearly the same classification as that provisionally adopted ivy Mr. St. George Mivirt ("Transict. Philosoph. Soc.' 1867, p. 30(1), who, after separating the Lemuribe, Livides the remaindel of the Primates into the Iumunidæ, the Sisi- adx which answer to the Cattarhine.. the Cebila, and the Hapralidx.thesc two latter groups answering to the Platyrhines. Mr. Mirint. still abides by the same view; see 'Nature, 1871, p. 48:. 
orang, and hylobates, ale by most naturalists separated from the uther Old World monkeys, as a distinct sub-croup. I am aware that Gratiolet, relying on the structure of the brain, does not adimit the existeuce of this sub-gromp, and no dunbt it is a broken one. Thus the orang, as Mr. St. G. Mirart remarks," "is one of the " most peculiar and aberrant forms to be found in the Order." 'The remaining non-anthropomorphous Old Trorld monlicys, are again divided by some naturalists into two or three smaller subgroups; the genus Semnopithecus, with its peculiar sacculatcd stomach, being the type of one such sub-grouj). But it appears from M. Gaudry's wonderful discoveries in Attica, that during the Miocene period a form existed there, which connected Scmnopithecus and Macacus; and this probably illustrates the manner in which the other and higher groups were once blended together.

If the anthropomorphous apes be admitted to form a natural sub-group, then as man agrees with them, not omiy in all those characters which he possesses in common with the whole Catarhine group, but in other peculiar characters, such as the absence of a tail and of callosities, and in general appearance, we may infer that some ancient member of the anthropomorphous sub-group gave birth to man. It is not probable that, through the law of analogous variation, a member of one of the other lower sub-groups should have given rise to a man-like creature, resembling the higher authropomonphous apes in so many respects. No doubt man, in comprarison with most of his allies, has undergone an extraordinary arnount of morlification, chiefy in consequence of the great development of his brain and his crect position; nevertheless, we shomld hear in mind that lie "is "but one of several exceptional forms of Prima! ('s." 1.

Every naturalist, who believes in the principle of crolution, will grant that the two main divisions of the simiadre, namely tho Catarhine and Platyruine monkeys, with their sub-groups, have all proceeded from some one extremely ancicnt progenitor'. The carly descendants of this progenitor, before they had diverged to any considerable extent from each other, would still have formed a single natural group; but some of the species or incipiont genera would have already begun to indicate by thei: diverging characters the future distinctive marks of the Catarhine ind Platyrhine divisions. Hence the members of this supposerl : ncient group would not have been so uniform in their (lentition, or in the structure of their nostrils, as are the existing:

13 'Transact. Zoolog. Soc.' vcl. vi. : $86^{-}$, p. 214.

14 Mr. St. G. Mliritt, 'Trazsazto Phil. Soc.' $1 \pm 67$, p. $4: 0$, 
Catarline monkeys in one ray and the Platyrhines in another way, but would have resembled in this respect the allied Lcmurida, which differ greatly from each other in the form of their muzzles, ${ }^{1.5}$ and to an extraordinary degree in their dentition.

The Catarhine and Platyrhine moukeys agree in a multitudo of characters, as is shewn by their unquestionably belongins to one and the same Order. The many characters whicis they possess in common can hardly have been independently irequired by so many distinct species; so that these claracter's must have been inherited. But a naturalist rould undoubtedly have ranked as an ape or a monkey, an ancient form which possessed many characters common to the Catirhine and Platyrhine monkeys, other characters in an intermediate conlition, and some tow, perhaps, distinct from those now found in either group. And as man from a genealogical point of view belongs to the Catarhine or Old World stock, we must conclude, however much the conclusion may revolt our pride, that our (arly progenitors would hare been properly thus designated." But we must not fall into the error of supposing that the early progenitor of the whole Simian stock, including man, was identical with, or even closely resembled, any existing ape or monkey.

On the birthplace und Antirnity of Itun.-We are naturally led to enquire, where was the birthplace of nan at that stage of descent when onr pregenitors diverged from the Catarhine stock? The fact that they belonged to this stock clearly shews: ihat they inhalited the old World; but not Australia nor any weanic island, as we may infer from the laws of geographical distribution. In each great region of the world the living: mammals are closely related to the extinct species of the same: region. It is therefore probable that Africa was formerly inhabited by extinct apes closcly allied to the gorilla and chiml)anzee; and as these two species are now man's nearest allics, it is somewhat more probable that our early progrenitors lived on the African continent than elsewhere. But it is useless to speculate on this subject; for two or three anthropomorphous rpes, one the Dryopithecus ${ }^{17}$ of Lartet, nearly as large as a man,

15 Messrs Murie and Mivart on the Lemuroidea, 'Transact. Zoolog. Soc.' vol. vii. 1869, p. 5.

16 Häckel has come to this same conclusion. See 'Ueber die Entschung des Menschengeschlechts," in Virchow's 'Sammlung. gemein. wisen. Vorträge,' 1868 , s. 61 . Also his 'Natürliche Schöpfungsgeschichte,' 1868, in which he gives in detail his views on tine genealogy of man.

${ }^{17}$ Dr. C. Forsyth Major, "Sur les Singes Fossiles trouvés en Italie: 'Soc.Ital. des Sc. Nat.' tom. x7. 1872 
fiml closely allicd to Hylobates, existed in Europe during the Jiocene age; and since so remote a period the earth lias ecrtainly undergone many great revolutions, and there has been ample time for migration on the largest scale.

At the period and place, whenever and wherever it was, when man first lost his hairy covering, lie probably inhabited a hot country; a circumstance favourable for the frugiferous dict on which, judging from analogy, he subsisted. W'e are far from knowing how long ago it was when man first diverged from the Catarhine stock; but it may have occurred at an epoch as remote as the Eocene pcriod; for that the higher apes had diverged from the lower apes as early as the Upper Miocene period is shewn by the existence of the Dryopithecus. We are also quite :gnorant at how rapid a rate organisms, whether high or low in the scale, may be modified under favourable circumstances; wo know, however, that some have retained the same form during :tu enormous lapse of time. From what we see going on under lomestication, we learn that some of the co-descendants of the s:ame species may be not at all, some a little, and some greatly whanged, all within the same period. Thus it may hare been with man, who has undergone a great amount of modificatiou in certain characters in comparison with the higher apes.

The great break in the organic chain between man and his nearest allies, which cannot be bridged over hy any extinct or iiving species, has often been advanced as a grave objection to the belief that man is descended from some lower form; but this objection will not appear of much weight to those who, from greneral reasons, believe in the general principle of evolution. Breaks often occur in all parts of the series, some being wide, sharp and defined, others less so in various degrees; as between the orang and its nearest allies-between the Tarsius and the other Lemuridæ-between the elephant, and in a more striking: manner between the Ornithorhynchus or Echidna, and a!l other mammals. But these breaks depend merely on the number of related forms which have become extinct. At some future period, not very distant as measured by centuries, the civilised races of man will alnost certainly exterminate, and replace, the savage races throughout the world. At the same time the anthropomorphous apes, as Professor Schaaffhausen has remarkcd," will no doubt be exterminated. The break between man and his nearest allies will then be wider, for it will intervene betwenn man in a more civilised state, as we may hope, eren than ti:o I rucasian, and some ape as low as a baboon, instead of as now between the negro or Australian and the gorilla.

\footnotetext{
- Anthropological Leview; A pril, 18ci, p. 236 .
} 
With respect to the absence of fossil remains, serving to zonncet man with his ape-like progenitors, no one will lay much stress on this finct who reads Sil C. Lyell's discussion, ${ }^{1 y}$ where he shews that in all the vertebrate classes the discovery of fossil remains has been a very slow and fortuitous process. Nor should it be forgotten that those regions which are tho most likely to afford remains connecting man with some extinct apelike creature, have not as yet been searched by geologists.

Lower Stuges in the Geneulo'yy of Mun.- We have seen that man appears to have diverged from the Catarhine or Old World (livision of the Simiada, after these had diverged from the New Wrorld division. We will now endeavour to follow the remote traces of his genealogy, trusting principally to the mutua: alinities befween the various classes and orders, with some silght reference to the periods, as far as ascertained, of their successive appearance on the earth. The Lemurida stand helow and near to the Simiadr, and constitute a very distinct family of the Primates, or, according to Häckel and others, a distinct Order. 'This group is diversified and broken to an extraorliuary degree, and includes many aberrant forms. It has, therefore, probably suffered much extinction. Ifost of the remmants survive on islands, such as Madagascar and the Malayan archipelago, where they have not been exposed to so severe a competition as they would have been on well-stocked continents. This group likewise presents many gradations, leading, as Huxicy remarks, "inscnsibly from the crown and " summit of the animal creation down to creatures from which " there is but a step, as it scems, to the lowest, smallest, and "least intelligent of the placental mammalia." From these varions considerations it is probable that the Simiadro were originally developed from the progenitors of the existing Lemuridæ; and these in their turu from forms standing very low in the rammalian series.

The Marsupials stand in many important characters below the placental mammals. They appeared at an earlier geological period, and their range was formerly much more extensive? than at jresent. Hence the Placentata are generally supposed to have been derived from the Implacentata or Marsupials; not, however, from forms closely resembling the existing Marsupials, but from their early progenitors. The Monotremata are plainly allied to the Marsupials, forming a third and still lower

$$
\text { “ 'Elements of Geology,' 1865, } 20 \text { 'Man's Place in Natnre, p }
$$
pp. : $3-585$. 'Antiquity of Mar,' 105.

1963, p. 145. 
division in the great mammalian series. They are represented at the present day solely by the Ornithorhynclius and Echidna; and these two forms may be safely considered as relies of a mulch larger group, representatives of which have been preserved in Australia through some favourable concurrence of circumstances. The MIonotremata are eminently interesting, as leading in several important points of structure towards the class of ieptiles.

In attempting to traer the genealogy of the Mammalia, anci therefore of man, lower down in the series, we become involrea in greater and greater obscurity; but as a most carahle judge Ir. Parker, has remarked, we hare good reason to beliere, that no true hird or reptile intervenes in the direct line of descent. He who wishes to sce mhat ingeuuity and knowledge can effect. may consult Prof. Häckel's works. ${ }^{21}$ I will content myself with $\therefore$ few general remarks. Every evolutionist will admit that the tive great rertebrate classes, namely, mammals, birds, repriles, :mphibians, and fishes, are descended from some nne prototype: for they have much in common, especially during their embryonic state. As the class of fishes is the most lowly organiced, and appearsd before the others, we may conchude that all the members of the vertebrate kingdom are derived from some fishiike animal. The belief that animals so distinct as a monkey, : wn elephant, a humming-bird, a snake, a frog, and a fish, \&c., conld : 211 have sprung from the same larents, will appear monstrous to those who have not attended to the recent progress of natural istory. For this belief implies the former existence of links :inding closely together all these forms, now so utterly unlike.

Nevertheless, it is certain that groups of animals hare cxisted, "1. do now exist, which serve to counnert sereral of the great rertebrate classes more or less closely. We have seen that the 1)rnithorhynchus graduates towards reptiles; and Prof. Ifuxley has discovered, and is confirmed hy MIr. Cone and others, that the Dinosaurians are in many improtant characters intermediate inetween certain reptiles and certain birds-the birls referred to being the ostrich-trilie (itself cridently a widely-diffused remnant of a larger group) and the Archeopteryx, that strange secondary bird, with a long lizard-like tail. Again, according to

${ }^{21}$ Elaborate tables are giren in his 'Generelle Morphologie' (B. ii. 5. cliii. and s. 425); and with more special reference to man in his ' 'atiirliche Schöpfungsgeschichte,' 1868. Prof. Huxley, in reviewing this latter work ("The Academy, 1869, p. 42) says, that he consider's the phylum or lines of descent of the Vertemiata to be admirabiy discussed by Häckel, aithough he differs; ou some points. $\mathrm{He}$ expresses, also, his high estimate of the general tenor and spirit of the whole work.

2: Palæontology,' 1860, p. 199. 
Frof. Oren, ${ }^{22}$ the Ichthyosaurians-great sea-lizards furnished with padules-present many affinities with fishes, or rathor, according to Inxley, with amphibians; a class which, including in its highest division frogs and toads, is plainly allied to the Tanoid fishes. These latter fishes swarmed during the carlior meological period, and were constructed on what is called a semeralised tylue, that is, they presented diversified affinities witl! other gromps of or anisms. The Lepidosiren is also so closely .:?ied to amphibians and fishes, that naturalists long disputed in: which of these two classes to rank it; it, and also some fer Gimoid fishes, hare been preserved from utter extinction by shalhiting rivers, which are harbours of refuge, and are relatec $\therefore$ the great waters of the ocean in the same way that islinds. are to continents.

Laskly, one single member of the immense and diversified class wi tishes, numely, the lancelet or amphioxus, is so different from a.th other fishes, that Irackel maintains that it ought to form a distinct class in the vertebrate kingdom. This fish is remarkable for its nemative characters: it can hardly be said to possess a brain, vertehral column, or heart, \&c.; so that it was classed by the older uaturalists amongst the worms. Many years ago Prof. Goodsir perenired that the lancelet presented some affinitics with the Ascidiuns, which are invertebrate, hermaphrodite, marine creatures permancutly attached to a support. They hardly alj)ear like anjmals, and consist of a simple, tough, leathery sack, with two small projecting orifices. They bels:kg to the Hhinscoida of Huxley - a lower division of the great kingdom of the Mollusca; but they hare recently been placed by some waturalists amougst the Vermes or worms. Their larva somewhat resemble tarlpoles in shape,"; and have the power of swimming freely aloout. M. Kovalevsky ${ }^{24}$ has lately ohserved that. the larvæ of Ascidians are related to the Vertehrata, in thicir manner of derelopment, in the relative position of the nervous system, and in possessing a structure closely like the cliordu clorsulis of rertebrite animals; and in this he has becn since

23 At the Fill:land Islands I had the satisfaction of seeing, in April 1833 , and therefore some years betore any other naturalist, the locomotive larva of a compound Ascidian, closely allied to Synoicum, but apparently generically distinct from it. The tail was about five times as long as the oblong head, ard terminated in a very fine filament. It was, as sketched by me under a simple microscope, plainly divided by transverse opaque partitions, which I presume represent the great cells figured by Kovalevsky. At an early stage of develop. ment the tail was closely coiled round the head of the lorva.

24 "Mémoires de l'Acrio. din Sciences de St. Pétershour'g,' toun. s. No. 15, 1866. 
ronfirmed y Jort. Kupifer. M. Kovalersky writes to me from Naples, that he has now carried these oloservations yet further, and should his results be well established, the whole will form a discovery of the very greatest value. Thus, if we may rely on embryology, ever the safest guide in classinfeation, it secms that we have at last gained a clue to the source whence the Vertebratis were derivel. ${ }^{2 j}$ We should then be justified in believing that at an cxtremely remote period a group of animals existed, resembling in many respects the larvæ of our present Ascidians, which diverged into two great branches - the one retrograding in development and producing the present class of Ascidians, the other rising to the crown and summit of the animal kingdom by giving birth to the Vertebrata.

We have thus far endeavoured rudely to trace the genealogy of the Vertebrata by the aid of their mutual affinities. We will now look to man as he exists; and we shall, I think, be able partially to restore the structure of our early progenitors, during successive periods, but not in due order of time. This can be effected by means of the rudiments which man still retains, by the characters which occasionally make their appcarance in hins through reversion, and by the aid of the principles of morphology and embryology. The various facts, to which I shall here allude, have been given in the previous chapters.

The early progenitors of man must have been once covered with hair, both sexes having beards; their ears were probably pointed, and capablo of movernent; and their bodies were provided with a tail, having the proper muscles. Their limbs and bodies were also acted on by many muscles which now only occasionally reappear, but are normally present in the Quadrumana. At this or some earlier period, the great artery and nervo of the humerus ran through a supra-condyloid foramen. The intestine gave forth a much larger diverticulum or crecum than that now existing. The foot was then prehunsile, judging from! the condition of the great toe in the foetus; and our progenitors, no droubt, were arboreal in then habits, and frequented some warm, forest-clad land. The males had great canine tecth, whicl

25 But I am bound to add that some competent judges dispute this conclusion; for instance, M. Giard, in a series of papers in the 'Archives de Zoologie Espérimentale, for 1872. Nevertheless, this naturalist remarks, p. 281, "L'organisation di la * larve ascidienne en dehors de to toute hypothèse et de toute thérie, s nous montre commat la nature "peut produire ia disposition fonda" mentale du type vertébré (l'ex" istence d'une corde dorsale) chez "un invertébré par la seule con"dition vitale de l'adaptation, "et cette simple possibilité du "passage supprime l'abîne entre "les deux sous-règnes, encore bien "qu'en ignore par où le passirg" " s'est fai: ez zós!ite." 
served them as formidable reapons. At a much carlicr period the uterus was double; the excreta were voided through $\Omega$ cloica; and the eye was protected by a third eyelid or nictitating membrane. At astill earlier period the progenitors of man must have been aquatic in their habits; for morphology plainly tells us that our lungs consist of a modified swim-bladder, which once served थs a float. The clefts on the neck in the embryo of man show where tho branchire once existed. In the lunar or weekly recurrent periods of some of our functions we apparently still retain traces of our primordial birthplace, a shore washed by the tides. At about this same carly period the true kidneys wero replaced by the corpora wolftiana. 'The heart existed as a simple pulsating vessel; and tho chorda dorsalis took the place of a vertebral column. These early ancestors of man, thus seen in the dim recesses of time, must have been as simply, or eren still more simply organised than the lancelet or amphioxus.

There is one other point deserving a fuller notice. It has long been known that in the vertebrate kingdom one scx bears rudiments of various accessory parts, appertaining to the reproductive system, which properly belong to the opposite scx; and it has now been ascertained that at a very early cmbryonic period both sexes possess true male and female glands. Hence some remote progenitor of the whole vertebrate kingdom appears to have been hermaphrodite or androgynous. ${ }^{26}$ But here we encounter a singular difficulty. In the mammalian class the males possess rudiments of a nterus with the adjacent passage, in their vesicula prostatice; they bear also rudiments of mammæ, and some male Marsupials have traces of a marsuy sack. ${ }^{27}$ Other analogous facts could be added. Are we, then, to suppose that some extremely ancient mammal continued androgynous, after it had acquired the chicf distinctions of its class, and therefore after if liad diverged from the lower classes of the. vertebrate kingdom? This seems very improbable, for we have to look to fishes, the lowest of all the classes, to find any still existent androgynous forms. ${ }^{28}$ That various accessory parts,

26 This is the conclusion of Prof. Gegenbaur, one of the highest authuities in comparative anatomy; see 'Grundzuge der' ver'gleich. Anat.' 1870 , s. 876 . The result has been arrived at chicfly from the study of the Amphibia; but it appears from the researches of Waldeyer (as quoted in 'Journal of Anat. and 'Dys?' $\$ 869$, p. 161), that the sexual irgass of even "the higher verte- "brata are, in their early condition, "hermaphrodite." Similar" views have long been held by some authors, though vatil recently without a firm basis.

27 The male Thylacinus offers the best instance, Owen, "Anatomy of Vertebrates,' vol. iii. p. 771.

28 Hermaphroditism has been observed in several species of Serranus, as welt as in some other fishow 
proner to each sex, are found in a rudimentary condition in the opposite scx, may be explained by such organs haring been gradually accuired by the one sex, and then transmitted in a more or less imperfect state to the other. When we treat of sexnal selection, we shall meet with innumerable instances of this form of transmission,-as in the case of the spurs, plumes, and brilliant colours, acquired for battle or ornament by male birds, aud inherited by the females in an imperfect or rudimentary condition.

The possession by malc mammals of functionally imperfect mammary organs is, in some respects, especiaily eurious. The Monotremata have the proper milk-secreting glands with orifices, hut no nipples; and as these animals stand at the rery base of the mammalian series, it is probable that the procenitors of the class also had milk-secreting glands, but no nipples. This conclusion is supported by what is known of their manner of development; for Professor Turner informs me, on the authority of Kölliker and Langer, that in the embryo the mammary glands can be distinctly traced before the nipples are in the least visible; and the development of successive parts in the individual generally represents and accords with the developunent of successive beings in the same line of descent. The Marsupials differ from the Monotremata by possessing niplies; so that probably these organs were first acquired by the MIarsupials, after they had diverged from, and risen above, the Monotremata, and were then truxsmitted to the placental mammals. ${ }^{29}$ No one will suppose that the Marsupials still remained androgynous. after they had approximately acquired their present structure. How then are we to account for male manmals possessing mammæ? It is possible that they were first developed in tho females and then transferred to the males; but from what follows this is hardly probable.

where it is either normal and symmetrical, or abnormal and unilateral. Dr. Zouteveen has given me leferences on this subject, more especially to a paper by Prof. Halbertsma, in the 'Transact. of the Dutch Acad. of Sciences,' vol. xvi. Dr. Günther doubts the fact, but it has now been recorded by too many good observers to be any longer disputed. Dr. M. Lessona writes to me, that he has verified the observations made by Cavolini on Serranus. Prof. Erculsni has recently shewn ("Accrd. delle Scienze,' Bologna, Dec. 28, 1871) that eels are androgynous.

29 Prof. Gegenbatur has sheirn ('Jenaische Zeitschrift,' Bd. vii. p. 212) that two distinct types of nipples prevail throughout the several mammalian orders, but that it is quite intelligible how both could have been derived from the nipples of the Marsupials, and the latter from those of the Monctremata. See, also, a memoir by Dr. Max IIuss, un tise manmar? glands, ibid. B. viii. p. 176. 
It may he suggested, as another view, that long after the progenitors of the whole mammalian class had ceased to he androgynous, both sexes yielded milk, and thus nonrished their young; and in the case of the Marsupials, that loth sexes carried their young in marsupial sacks. This will not appcar altogether improbable, if we reflect that the males of existing syngnathous fishes receive the eggs of the females in their abdominal pouches, hatch them, and afterwards, as some believe, nourish the young; ${ }^{30}$-that certain other male fishes hatch the eggs within their mouths or branchial cavities; - that certain male toads take the chaplets of eggs from the females, and wind them round their own thighs, kecping them there until the tadpoles are horn;-- that certain male birds undertake the whole duty of incubation, and that male pigeons, as well as the females, feed their nestlings with a secretion from their crops. But the above suggestion first occurred to me from the uammary glands of male mammals being so much more perfectly developed thar the rudiments of the other accessory reproductive parts, whick are found in the one sex though proper to the other. The mammary glauds and nipples, as they exist in male mammals. can indeed hardly be called rudimentary; they are merely not fully dereloped, and not functionally active. They are sympathetically affected unler the influence of ccrtain diseases, like the same organs in the female. They often secrete a few drops of milk at birth and at puberty: this latter fact occurred in the curious case, before referred to, where a young man possesser! two pairs of mammæ. In mar and some other male mammals these organs have been known cscasionally to become so well developed during maturity as to yicld a fair supply of milk. Now if we suppose that during a former prolonged period male mammals airled the females in nursing their offspring, ${ }^{31}$ and that afterwards from some cause (as from the production of a smaller in umber of young) the males ceased to give this aid, disuse of the organs during maturity would lead to their becoming inactive; ancl from two well-known principles of inheritance, this state of inactivity monld probably be transmitted to the males at the correspouding age of maturity. But at an earlier age these

so Mr. Lockwond believes (as quoted in 'Quart. Journal of Science, A pril. 1 sti8, p. 269), from what he hits observed of the development of Hippocampus, that the walls of the abdominal pouch of the male in gome waly ilford nourishment. On male fishes halching the ova in their mouths, see a vary interesting pape: by Prof. Wyman, in 'Proc. Bowlon Soc. wi' Nat. Hist.' Sept. 15, 1857 : also l'rof.' Turner, in 'Jourmal or Anat. and I'hys.' Nov. 1, 1866, p. 78. 1)r. Giunther has likewise described similar cases.

31 Natlle. C. Royer has surgested a similar riew in her 'Origne de l'Horcms' Sxc., 1870. 
organs would he left unaffected, so that they would the almost equally well developed in the young of both sexes.

Conclusion.- Von Bacr has llefined advancement or progress in the organic scale better than any oue else, as resting on the amount of differentiajion and spccialisation of the several parts of a being,--when arrived at maturity, as I should be inclined to add. Now as organisms have become slowly adapted to diversified lines of life by means of natural sclection, thcir parts will have become more and more differentiated and specialised for various functions, from the advantage gained by the division of plysiological labour. The same part appears often to hare been riodified first for one purpose, and then long afterwards for some other and quite distinct purpose; and thus all the parts are rendered more and more complex. But each organism still retains the general type of structure of the prorenitor from which it was aboriginally derived. In accordance with this view it seems, if we turn to gcological evidence, that organisation on the whole has advanced throughout the world by slow and interrupted steps. In the great kingdom of the Vertebratis it has culminated in man. It must not, however, be supposed that groups of organic beings are always supplanted, and disappear as soon as they have given birth to other and more perfect groups. The latter, though victorious over their predecessor's, may not have become better adapted for all places in the economy of nature. Some old forms appear to have survived from inhabiting protected sites, where they have not been exposed to very severe competition; and these often ajd us in constructing our genealogies, ly griving us a fair idea of former and lost populations. But we must not fall into the crror of looking at the existing members of any lowly-organised group as perfect representatives of their ancient predecessors.

The most ancient progenitors in the kingdom of the Vertebrata, at which we are able to olstain an obscure glance, apparently consisted of a gromp of marine animals, ${ }^{32}$ resembling the larvæ of existing Ascidians. These animals probably gave rise to a

32 The inhabitants of the scashore must be greatly affected $k y$ the tides; animals living either about the mean high-water mark, or about the mean low-water mark, rass through a complete cycle of ilcial changes in a fortnight. Consequently, their food supply will undergo marked changes week $b_{j}$ reok. The vital functions of such animals, living voder these con- ditions for many generatious, can hardly fail to run their course in regular weekly periods. Now it is a mysterious fact that in the higher and now terrestrial Vertebrata, as well as in other classes, many normal and abnormal processes have. one or more whole weeks as their periods; this would be rendered intelligible if the Vertebratia are de. scended from an animal allied to 
group of fishes, as lowly organised as the lancelet; and from these the Ganoids, and other fishes like the Lepidosiren, must hare been developed. From such fish a very small auvance would carry us on to the Amphibians. We have seen that birds and reptiles were once intimately connected together; and the Monotremata now connect mammals with reptiles in a slight degrec. But no one can at present say by what lino of descent the three higher and related classes, namely, mammals, birds, and reptiles, were acrived from the two lower vertebrate classes, mamely, amphibians and fishes. In the class of mammals the steps are not difficult to conceive which led from the ancient Monotremata to the ancient Marsupials; and from these to the early progenitors of the placental mammals. We may thus ascend to the Lemuridæ; and the interval is not very wide from these to the Simiadr. The Simialæ then branched off into two great stems, the New World and Old World monkeys; and from the latter, at a remote period, Man, the wonder and glory of the Universe, proceeded.

Thus we have given to man a pedigree of prodigious length, but not, it may be said, of noble quality. The world, it has often been remarked, appears as if it had long been preparing for the advent of man: and this, in one sense is strictly true, for he owes his birth to a long line of progenitors. If any single link in this chain had never existed, man would not have been exactly what he now is. Unless we wilfully close our eyes, we may, with our present knowledge, approximately recognise our parentage: nor need tre feel ashamed of it. The most humble organism is something much higher than the inorganic dust under our feet; and no one with an unbiassed mind can study any living creature, however humble, without being struck with enthusiasn at its marvellous structure and properties.

the existung tidal Ascidians. Many instances of such periodic processes might be given, as the gestation of marmals, the duration of fevers, \&c. The hatching of eggs affords also a good example, for, according to $\mathrm{Mr}$. Bartlett ('Land and Water, Jan. 7, 1871), the eggs of the pigeon are hatched in two weeks; those of the fowl in three; those of the duck in to $1 \mathrm{r}$; those of the goose in five; and those of the ostrich in seven weeks. As far as we can judge, a recurrent period, if approximately of the right duration for any pro- cess or function, would not, when once gained, be liable to chauge; consequently it might be thus trans. mitted through almost any numbes of generations. But if the function changed, the period would have to change, and would be apt to change almost abruptly by a vihole week. This conclusion, if sound, is Lighly remarkable; for the perioc of gestation in each maramal, and the hatching of eacn bird's cggs, and many other vital processes, thus betrny to us the primordial birthplace of these animals. 


\section{CHAPTER VII. \\ ON the RaCes of MaN.}

Ihe nature and value of specific characters-Applicution to tha races of man-Arguments in favour of, and opposed to, ranking the so-called races of man as distinct species-Sub-species-Monogenists and polycenists-Convergence of character-Numerous points uf renemblance in body and mind between the most distinct races of man-The state of man when he first spread over the earth-Each race not lescended from a single pair-The extinction of races-The formation of races-The effects of crossing-Slight influence of the direct action of the conditions of life-Slight or no influence of natural selection-Sexual selection.

IT is not my intention here to describe the sercral so-called mer.' of men; but I am about to enquire what is the value of the dirferences between them under a classificatory point of view, anc: how they have originated. In determining whether two or more allied forms ought to be ranked as species or varietics, naturalists are practically guided by the following considerations; namuly, the amount of difference between them, and whether such differences relate to few or many points of structure, and whether they are of physiological importance; but more especially whether they are constant. Constancy of character is what is chiefly valued and sought for by naturalists. Whenever it cau be shewn, or rendered proballe, that the forms in question have remained distinct for a long period, this becomes an argument of much weight in farour of treating them as species. Eren a slight degree of sterility between any two forms when first crossed, or in their offspring, is generally considered as a decisive test of their specific distinctness; and their continned persistence without blending within the same area, is usually accepted as sufficient evidence, either of some degree of mutual sterility, or in the case of animals of some mutual repugnance to pairing.

Independently of fusion from intercrossing, the complete ahsence, in a well-investigated region, of rarieties linking together any two closely-alliced forms, is probally the most. important of all the critcriuns of their specific distinctness; and this is a somewhat different consideration from mere constancy of character, for two forms may be highly variable and yet not yicld intermediate varieties. Geographical distribution is often brought into play unconsciously and sometimes consciously; so that forms living in two widely scparated areas, in which most 
of the other inhabitants are specifically distinct, are themeolves usially looked at as listinct; but in truth this atfords no aid in dis. timguishng geographical races from so-called good or true speries.

Now let us apply these generally-admitted prineiples to the races of man, viewing him in the simme spirit as a naturalist would any oficr animal. In regard to the amount of difference between the races, we must make some allowance for our nice powers of discrintination sained by the long habit of obserring ourselves. In India, as Elphiustone remarks, although a newly-arrived Europran camut at first distinguish the rarious native races, yet they soon aplear to him extremely dissimilar; and the Hiudi)o (aunot at first perecire any difference between the several Euripean nations. Even the most distinct races of man are mur.h more like ench other in form than would at first be supposed; ecrtain negro tribes must be excepted, whilst others, as I)r. Fohlis writes to me, and as I have myself secn, have Cincasiun fuatures. This generial similarity is well shewn by the French photographs in the Collection Anthropologique du Muséum de Paris of the men belonging to various races, the greater number of which might pass for Europeans, as many persons to whom I have shewn them have remarked. Nevertheless, these men, if secn alive, would undloubtedly appear very distinct, so that we are clearly much influenced in our judgment. by the mere colour of the skin and hair, by slight diffurences in the features, and by expression.

There is, however, no donbt that the rarious races, when carefully compared and neasured, differ much from each other, -as iu the texture of the hair, the relative proportions of all parts of the body, ${ }^{2}$ the capacity of the lungs, the form and capacity of the skull, and even in the convolutions of the brain. ${ }^{3}$ But it would be an endless task to specify the numerous points of ditierence. The races differ also in constitution, in acclinatisation and in liability to certain di-cases. Their montal characteristies are likervise very distinct; chicfly as it would appear in their emotional, but partly in their intellectual faculties. Every one who has had the oplortunity of comprison, must have been

1 'History of India,' 1841, vol. i. p. 323. Father Ripa makes exactly the same remark with respect to the Chinese.

2 A vast number of measurements $c$ ? Whites, Blacks, and Indians, are given in the 'Investigitions in the Military and Anthropolog. Statistics of American Soldiers, by B. A Gould, 1869, pp. 298-358;
'On the capacity of the lungs,' p. 471. See also the aumerous and valuable: tables, by Dr. Weisbach, from the observations of Dr. Scherzer and Dr. Schwarz, in the 'Reise der Novara: Anthropolog. Theil,' 1867.

'3ee, for instance, Mr. Marshall'y account of the brain of a Bushwoman, in 'Phil. 'Transact.' 1804, p. 519. 
struck with the contrast between tho taciturn, ever morose, aborigines of S. America and the light-hearted, talkative negroes. There is a nearly similar contrast between the MLalays and the Papuans, ${ }^{4}$ who live under the same physical conditicns, and are separated from each other only by a narrow space of sea.

We will first consider the argumeuts which may be adranced in favour of classing the races of man as distinct species, and then the arguments on the other side. If a naturalist, who hard never before seen a Negro, Hottentot, Australian, or Mongolian, were to compare them, he would at once perceive that they differed in a multitude of characters, some of slight and some of considerable importance. On enquiry he would find that they were adapted to live under widely different climates, and that they differed somewhat in bodily constitution and mental disposition. If he were then told that hundreds of similar specimens could be brought from the same countries, he would assuredly declare that they were as good species as many to which he had been in the habit of affixing specific names. This conclusion would be greatly strengthened as soon as he had ascertained that these forms had all retained the same character for many centuries; and that negroes, apparently identical with existing negroes, had lived at least 4000 years ago. ${ }^{5}$ He would also hear, on the authority of an excellent observer, Dr. Lumd, ${ }^{6}$ that the human skulls found in the caves of Brazil, entomberl with many extinct mammals, belonged to the same typo as that now prevailing throughout the American Continent.

- Wallace, "The Malay Archipelago, vol. ii. 1869 , p. 178.

5 With respect to the figures in the famous Ëgyptian caves of AbouSimbel, M. Pouchet says ("The Plurality of the Human Races,' Eng. translat. 1864, p. 50), that he was far from finding recognisable representations of the dozen or more nations which some authors believe that they can recognise. Even some of the most strongly-marked races cannot be illentified with that deguce of unanimity which might have been expected fiom what has been written on the subject. Thus Messis. Nott and Gliddon ('Types of Mankind,' p. 148) state that liamesos II., or the Great, has features superbly European; wheres $\mathrm{Kaos}$, another firm believer in the specific distinctness of the races of man ('Races of Man,' 1850, p. 201), speaking of young Memnon (the same as Rameses II., as I am informed by $M r$. Birch), insists in the strongest manner that he is identical in character with the Jews of Antwerp. Again, when I looked at the statue of Amunoph III., I agreed with two officers of the establishment, both competent judges, that he had a strongly marked negrn type of features; but Messis. Nott and Gliddon (ibid. p. 146, fig. 53) describe him as a hybrid, but not of "negro intermixture."

- As quoted by Nott and Gliddor, 'Types of Mankind,' 1854, p. 439 . They give also corroburative evidence; but C. Vogt thinks that the subject requires further investigo tion. 
Ou naturalist would then jerhaps turn to geogral hical d:-itribution, and he would probably declare that those forms must be distinct species, which differ not only in appearance, but are fitted for hot, as well as dimp or dry countries, and for tho Arctic regions. He might appeal to the fact that no species in the group next to man, namely the Quadrumaun, can resist a low temperature, or any considerable change of climate; and that the species which come nearest to man have never been reared to maturity, even under the temperate climate of Europe. He would be rechly impressed with the fact, first noticed hy Agassiz; that the different races of man are distributed over the world in the sane zoological provinces, as those inbabited by undonbtedly distinct species and genera of mammals. This is manifestly the case with the Australian, Mongolian, and Negro races of man; in a less well-narked manner with the Hottentots; but plainly with the Papuans and Malays, who are separated, as MIr. Wallace has shewn, by nearly the same line which divides the great. Malayan and Australian zoological provinces. The Aborigines of America range throughout the Continent; and this at first appears opposed to the above rule, for most of the productions of the Southern and Northern halves differ widcly: yet some few living forms, as the opossum, range from the one into the other, as did formerly some of the gigantic Edcntata. The Esquimaux, like other Arctic animals, extend round the whole polar regions. It should be observed that the amount of difference between the mammals of the several zoological provinces does not correspond with the degree of separation between the latter; so that it can Lardly be considered as an anomaly that the Nugro differs more, and the American much less from the other races of man, thar. to the mammals of the African and American continents from the mammals of the other prorinces. Man, it may be added, does not appear to have aboriginally inhabited any occanic island; and in this respect he resembles the other members of his class.

In detcrmining whether the supposed varieties of the same Find of domestic animal should be rauked as such, or as specifically distinct, that is, whether any of them are descended from distinct wild species, every naturalist would lay much stress on the fact of their external parasites being specifically distinct. All the more stress monld be laid on this fact, as it would be an exceptional one; for I am informed by MIr. Denny that the most different kinds of dogs, fowls, and pigenns, in England, are infested by the same species of Pediculi or lice. Now Mr. A. Murray has carefully examined the Pediculi collected in different

' 'Diversity of Origin of the Human Races,' in the 'Chrietian Examiner,' Juị 1850. 
countries from the diff(rent races of $\operatorname{man} ;{ }^{8}$ and he inds that they differ, not only in colour, but in the structure of their clitws and limbs. In cvery case in which many specimens were oittained the differences were constant. The surgeon of a whaling ship in the Pacific assured me that when the Pediculi, with which some sindwich Islanders on board strarmed, strayed ou to the bodies of the English sailors, they died in the course of three or four days. These Pediculi were darker coloured, and appeared different from those proper to the natires of Chiloe in South America, of which he gave me specimens. These, aga:n. ai,jeared larger and mucb softer than Enropean lice. Mr. Niturray procured four kirds from Africa, namely from the Negroes of the Eastern and Western coasts, from the Hottentots and Tiltirs; two kinds from the natives of Australia ; two from North and two from South America. In these latter cases it may be presumed that the Pediculi came from natives inlıabiting different districts. With insects slight structural differences, if constant. are generally esteemed of specific value: aud the fact of the races of man being infested by parasites, which appear to be sibecifically distinct, might fairly be urged as an argument that the races themselves ought to be classed as distinct species.

Our supposed naturalist haring proceeded thus far in his in restigation, would next enquire whether the races of men, when crossed, were in any degree sterile. He might consult the work ${ }^{9}$ of Professor Broca, a cautious and philosophical observer, and in this he would find good evidence that some races were quite Eertile together, but evidence of an opposite nature in regarl to other races. Thus it has been asserted that the native women of Australia and Tasmania rarely produce childron to European men; the evidence, however, on this head has now been shewn to be almost valucless. The half-castes are killed by the pure blacks: and an account has lately heen published of eleren halfcaste youths murdered and hurnt at the same time, whose remsins were found by the police." Again, it lias often been said that when mulattoes intermarry they produce few children; on the other hand, Dr. Bachman of Charleston ${ }^{11}$ positively

s 'Transact. R. Soc. of Edinburgh,' จงl. xxil. 1861, p. 567.

- "On the Phenomena of Hybrility in the Genus Homo,' Eng. translat. 1864 .

10 See the interesting letter by Mr. T. A. Murray, in the "Anthropolog. Review,' April 1868, p. liii. In this letter Count Strzeleck's statement, that Australina wores who have borne children to a whito man are afterwards sterile with their own race is disproved. M. A. de Quatrefages nas also collected ("Revue des Cours Scientifiques," March 1869, p. 239) much evidence that Australians and Europeans are not sterile when crossed.

11 'An Examination of Prof. Agassiz's Sketch of the Nat. Pro. 
gssarts that he has known mulatto families winch hare inter. married for several generations, and have continued on an average as fertile as either pure whites or pure blacks. Enquirier formerly made by sir C. Lyell on this subject led him, as he informs me, to the same conclusion." In the United States the census for the year 185 in included, according to Dr. Bachman, 405,751 mulattoes ; and this number, considering all the circumstances of the case, seems small; but it may partly le accounted for by the clegraded and anomalous position of the class, and by the profligacy of the women. A certain amount of absorption of mulattoos into negroes nust always be in progress; and this wovld lead to an apparent diminution of the former. The inferior vitality of mulattoes is spolien of in a trustworthy work ${ }^{13}$ as a well-kuown phenomenon; and this, although a different consideration from their lessened fertility, may perhaps be advanced as a proof of the specific distinctnéss of the parent races. No doubt lot hamimal and regetahle hybrids, when produced from extremely distinct species, are liable to premature death; but the parents of mulattoes cannot be put under the category of extremely distinct species. The common Mule, so notorious for long life and vigour, and yet so sterile, shems how little necessary conmection there is in hybrids between lessened fertility and vitality; other analogous eases could be cited.

Even if it should hereafter be proved that ali the races of men were perfectly fertile together, he who was inclined from other reasons to rank them as clistinct species, might with justice argue that fertility and sterility are not safe criterions of specific distinctmess. Wo know that these qualities are easily affected by changed couditions of life, or by close inter-breeding, and that they are governed by highly complex laws for instance, that of the unequal fertility of converse crosses between the samo two species. TVith forms which must be ranked as undoubted species, a perfect scries exists from those which are absolutely sterilo when crossed, to those which are almost or completely

vinces of the Animal World,' Charleston, 1855 , p. 44.

12 Dr. Rohifs writes to me that he found the mixed races in the Great Sahara, derived from Arabs, Berbers, and Negroes of three tribes, extraordinarily fertile. On the other band, Mr. Finwood Reade informs me that the Negroes on the Gold Coast, though admiring white men and mulattoes, have a maxim that mulattoes should not intermary, as the children are few and sickly. This belief, as Mr. Reade remarks, deserves attention, as white men have visited and resided on the Gold Coast for fuur hundred years, so that the natives have had ampls time to gain knowledge throug experience.

13 "Military and Anthropo:c Statistics of Amerioan Soldiers, B. A. Gould, 1869, p. 319 . 
fertile. The degrces of steriiity do not coincide strictly with the degrees of difference between the parents in external structure or habits of life. Mian in many respects may be compared with those animals which have long been domesticated, and a large body of evidence can be advanced in farour of the Pallasi:zn doctrine ${ }^{14}$ that domestication tends to eliminate the sterility which is so general a result of the crossing of species in a state of nature. From these several considerations, it may be justly urged that the perfect fertility of the intercrossed races of man, if estabiished, would not absolutely preclude us from ranking them as distinct species.

Independently of fertility, the characters presented hy the offspring from a cross have been thought to indicate whether or not the parent-forms ought to be ranked as species or varieties; but after carefully studying the evidence, I hare come to the conclusion that no gencral rules of this kind can be trusted. The ordinary result of a cross is the production of a blended or

14 'The Variation of Animals and Plants under Domestication, vol. ii. p. 109. I may here remind the reader that the sterility of species when crossed is not a speciallyacquired quality, but, like the incapacity of certain trees to be grafted together, is incidental on other acquired differences. The nature of these differences is unknown, but they relate more especially to the reproductive system, and much less so to external structure or to ordinary differences in constitution. One important element in the sterility of crossed species apparently lies in one or both having been long habituated to fired conditions; for we know that changed conditions have a special influence on the reproductive system, and we hare good "eason to believe (as before remarked) that the fluctuating conditions of domestication tend to 3iminate that sterility which is so general with species, in a natural state, when crossed. It has elsewhere been shewn by me (ibid. vol. ii. p. 185, and 'Origin of Species' 5th edit. p. 317), that the sterility of crossed species has not been ncquired through natural selection: we can see that when two forms intve already been rendered very sterile, it is scarcely possible that their sterility should be augmented by the preservation or survival of the more and more sterile individuals; for as the sterility increases, fewer and fewer offspring will be produced from which to breed, and at last onls single individuals will be produced, at the rarest intervals. But there is even a higher grate of sterility than this. Both Gälner and Foblyeuter. have proved that in genera of plants including many species, a series can be formed from species which when crossed yield fewer and fewer seeds, to species which never produce a single seed, but yet ale affected by the pollen of the other species, as shewn by the swelling of the germen. It is here manifestly impossible to select the more sterile individuals, which have already ceased to yield seeds; so that the acme of sterility, when the germen alone is affected, cannot have been gained through selection 'This acme, and no doubt the other grades of sterility, are the incijental results of certain unknown difjerences in the constitution of the reproductive system of the specier which are crossed. 
intermediate form; but in certain cases some of the offspring take closely after one parent-form, and some after the other. This is aspecially apt to occur when the parents differ in characters which first appeared as sudden variations or monstrosities. ${ }^{15}$ I refer to this point, becanse Dr. Rohlfs informs me that he has frequently seen in Africa the offispring of negroes crossed with members of other races, either completely black or completely white, or rarely piebsld. On the other hand, it is notorions that in America mulattoes commonly present an intermediate appearance.

Wo have now secn that a naturalist might feel himself fully justified in ranking the races of man as distinct species; for he has found that they are distinguished by many differences in structure and constitution, some being of importance. These differences have, also, remained nearly constant for very long periods of time. Our naturalist will have been in some degrec influenced by the enormous range of man, which is a great anomaly in the class of mammals, if mankind be viencd as a single species. He will hare been struck with the distribution of the several so-called races, which accords with that of other undoubtedly distinct species of mammals. Finally, he might urge that the mutual fertility of all the races has not as yet been fully proved, and even if proved would not be an absolute proof of their specific identity.

On the other side of the question, if our supposed naturalist were to enquire whether the forms of man keep distinct like ordinary species, when mingled together in large numbers in the same country, he would immediately discover that this was by no means the ease. In Brazil he would behold an immense mongrel population of Negroes and Portuguese; in Chiloe, and other parts of South America, he would behold the whole population consisting of Indians and Spaniards blended in various degrees. ${ }^{16}$ In many parts of the same continent he would meet with the most complex crosses between Negroes, Indians, and Europeans; and judging from the vegetable kingdom, such triple crosses afford the sererest test of the mutual fertility of the parent-forms. In one island of the Pacific he would find a small population of mingled Polynesian and English blood; and in the Fiji Archipelago a population of Polynesian and Negritos

15 'The Variation of Animals, \&s., vol. ii. p. 9:.

16 I. de Quatrefages has given ('Anthropolng. Review,' Jan. 1869, p. 22) as interesting account of the success and energy of the Paulistas in Brazil, who are a much crosserl race of Portuguese and Indians, with a mixture of the blood of othot races. 
crossed in all clegrees. Minn analogous cases could bo be adcod; for iustance, in Africa. Hence tice races of man are not sufficiently distinct to inhabit the same country without fusion; and the absence of fusion affords the usual and best test of specific distinctness.

Our naturalist would likerise be much disturbed as soon as he percoivid that the distiuctive characters of all the races were highly varialle. This fact strikes every one on first beholding tho negrc slaves in Brazil, who have been imported from all parts of Africn. The same remark holds good with the Polynesians, and with many other races. It may he doubted whethcr any character can be named which is distinctive of a race and is constant. Savages, eren within the limits of the same tribe, are not nearly so uniform in character, as has been often asserted. Hottentot women offer certain peculiarities, more strongly marked than those occurring in any other race, but these are known not to be of constant occurrence. In the several Amcrican tribes, colour and hairiness diff' $l^{\prime \prime}$ considerably; as does colour to a certain degree, and the shape of the features greatly, in the Negroes of Africa. The shape of the skmll varies much in some races; ${ }^{17}$ and so it is with every other character. Now all naturalists have learnt by dearly-bonght expericnce, how rash it is to attempt to define snecies by the aid of inconstant characters.

But the most woighty of all the argmments against treating the races of man as clistinct species, is that they graduate into oach other, independently in many cases, as far as we can judge, of their having intercrosscd. Man has been studied more carefully than any other animal, and yet thore is the greatest possible diversity amongrst capable judges whethor he should be classed as a single species or race, or as tro (Virey), as three (Jacquinot), as four (Kant), five (Blumenbach), six (Buffon), seven (Hunter), eight (Agrssiz), eleven (l'ickering), fifteen (Bory St. Vincent), sixteen (Desmoulins), twenty-two (IIorton), ixty (Crawfurd), or as sixty-three, according to Burke. ${ }^{18}$ This liversity of judgment does not prove that the races onght not :o be ranked as species, but it shers that they graduato into each

17 For instance with the aborigines of America aud Austrilia. P'r f. Iluxley says ("Trunsact. Internat. Congress of Prehist. Arch.' 1868. P. 105) that the skulls of many Nonth Germans and Swiss are "as shert and as broarl as those of "the Tirtini," Burs.
18 See a good discussion on this subject in W'aitz, "Introduct. to Anthropology,' Eng. translat, 1863, pp. 198-208, 227. I have taken some of the abore statements frum H. Tuttle's "Orisrin and Antiquuty of Physical Mian, Boston, 1866, j) 35. 
other, and that it is hardly possible to diseover clear distinctivo sharacters between them.

Every naturalist who has had the misfortune to undertake the description of a group of highly varying orgauisms, has encountered cases (I speak after experience) precisely like that of man; and if of a caations disposition, he will end by uniting all the forms which graduate into ench other, under a single species; for he will say to himself that he has no right to givo names to oljects which he cannot define. Cases of this kind occur in the Order which includes man, namely in certain gener: of monkers; whilst in other genera, as in Cercopithecus, most of the species can be determined with eertainty. In the American genus Cebus, the rarious forms are ranked by some naturalist:; as species, by others as mere geographical races. Now if numerous specimens of Cebus were collected from all parts of south America, and those forms which at present appear to be :pecifically distinct, were found to graduate into each other by close stejs, they would usually be ranked as mere varieties or: races; and this course lias been followed by most naturalists with respect to the races of man. Nevertheless, it must bo confessed that there are forms, at least in the vegetable kingdom, ${ }^{19}$ which we cannot aroid naming as species, but which are connected together by numberless gradations, independently of intercrossing.

Some naturalists have lately employed the tcrm "sub-species" to designate forms which possess many of the characteristics of true species, but which hardly deserve so high a rauk. Now if we reflect on the weighty arguments above given, for raising the races of man to the dignity of species, and the insuperalile difficulties on the other side in defining them, it seerns that the term "sul-species" might here be used with propriety. But from long habit the term "race" will porhaps always be employed. The choice of terms is only so far importunt in that it is clesirable, to use, as far as possible, the same texms for the same degrees of ditïrence. Unfortunately this can rarely be done: for the large: gencra enerally include closely-allied forms, which can bo distinguished only with much dificulty, whilst the smalle:" gencra within the same family include forms that are perfectly distirct; yet all must be ranked equally as species. So again, species within the same large genus by no means resemlle each other to the same degree: on the contrary, some of them

19 Prof. Nägeli has carefully described several striking cases in his 'Botanische Mittheilungen,' B. ii. 1866, s. 294-369. Prof. Asa Gray has made analonous remarlss on some ictermediate forms in the Compos tre of N. America. 
can generally be arranged in little groups round other species, iike satellites round planets. ${ }^{20}$

The question whether munkind consists of one or spveral species has of late years been wuch discussed by anthropologists, who are divided into the two schools of monogenists and polygenists. Those who do not admit the principle of evolution, must look at species as separate creations, or as in some manner as distinct entities; and they must decide what forms of man they will consider as species by the analugy of the method commonly pursued in ranking other organic beings as species. But it is a hopeless endeavour to decide this point, until some definition of the term "species" is generally accepted; and the definition must not include an indeterminate element such as an act of 'reation. We might as well attempt without any definition to lecide whether a certain number of houses should be called a village, town, or city. We have a practical illustration of the lifficulty in the never-ending doubts whether many closely-allied mammals, birds, insects, and plants, which represent each ither respectively in North America and Europe, should be ranked as speeies or geographical races; and the like holds true of the productions of many islands situated at some little distance from the nearest continent.

Those naturalists, on the other hand, who admit the principle of evolution, and this is now admitted by the majority of rising men, will feel no doubt that all the races of man are descended from a single primitive stock; whether or not they may think fit to designate the races as distinct species, for the sake of expressing their amount of difference. ${ }^{21}$ With our domestic animals the question whether the various races have arise $\mathrm{n}$ from one or more species is somewhat different. Although it may bo admitted that all the races, as well als all the natural species within the same genus, have sprung from the same primitive stock, yet it is a fit sulject for discussion, whether all the clomestic races of the dog, for instance, have acquired their jresent amount of difference since some one species was firę lomesticated by man; or whether they owe some of their characters to inheritance from distinct species, which had already been differentiated in a state of nature. With man no such question can arise, for he cannot be said to have been domesticated at any particular period.

During an early stage in the divergence of the races of man 2n 'Origin of Species,' 5th edit. in the 'Fortnightly Reriew.' 1865,
p. 275. F. 68 .

II See Pro:. Huxley to this effoct 
frum a common stock, the differences between the races ani their number must have becn small; consequently as far as their distinguishing characters are concerned, they then had less claim to rank as distinct species than the existing so-called races. Nevcrtheless, so arbitrary is the term of species, that such early races would perhaps have been ranked by some naturalists as distinct species, if their differences, although extremely slight, had been more constant than they are at present, and had not graduated into each other.

It is however possible, though far from probable, that the early progrenitors of man might formerly have diverged much in character, until they became more unlike each other than any now existing races; but that subsequently, as suggested by Vogt, ${ }^{22}$ they converged in character. When man selects the offspring of two distinct species for the same olject, he sometimes induces a considerable amount of convergence, as far as general appearance is concerned. This is the case, as shewn by Ton Nathusius,," with the improved breeds of the pig, which are descended from two distinct species; and in a less markerl manner with the improved breeds of cattle. A great anatomist, Gratiolet, maintains that the anthropomorphous apes do not form a natural sub-group; but that the orang is a highly developed gibbon or semnopithecus, the chimpanzee a highiy developed macacus, and the gorilla a highly developed mandrill. If this conclusion, which rests almost exclusively on braincharacters, be adnitted, we should have a case of convergence at least in extcrnal charactors, for the anthropomorphous apes are certainly more like ench other in many points, than they are to other apes. All analogical resemblances, as of a whale to a fish, may indeed be said to be cases of convergence; lout this term has never been applied to superficial and adaptive resemblances. It rould, however, be extremely rash to attribute to convergence close similarity of character in many points of structure amongst the modified descendints of wiclely distinct beings. The form of a crystal is determined solely by the molecular forces, and it is not surprising that dissimilar substances should sometimes assume the same form; but with organic beings we should bear in mind that the form of cach depends on an infinity of complex relations, namely on variations, due to causes far too intricate to be followed,-on the nature of the variations preserved, these depending on the physicial condi-

22 'Lectures on Man,' Eng. trinslut. 1864, p. 468 .

2.3 'Die Racen des Schwcines," 1850 , B. 46 "Vorstudien fir Ge- schichte, \&c., Schweineschïlel, $1864,8.104$. With respect to cattle, see M. de Quatrefages, 'Unité de l'Esspèce Humaine, 1861, p. 119 
tions, and still more on the surrounding caganisms which compete with each, - and lastly, on inheritance (in itsulf a fuctuating elemont) from innumerablis progenitors, all of which have had their forms determined through equally complex relations. It appears incredible that the modified descendants of two organ. isius, if these differed from each other in a marked manncr. shuuld ever afterwards converge so closely as to lead to a mear approach to identity thronghont their whole organisation. In the case of the convergent races of pigs ahove referred to, evidence of their desecnt from two primitive stocks is, according to Von Nathusius, still plainly retained, in certain boues of their skulls. If the races of man har descended, as is supposed by some naturalists, from two or more species, which differed from each other as much, or nearly as much, as does the orang from the gorilla, it can hardly be doubted that marked diffirences in the structure of certain bones would still be discoverable in man as he now exists.

Although the existing races of man differ in many respects, as in colour, hair, shape of skull, proportions of the body, \&c., yet if their whole structure be taken into consideration they asc found to resemble each other closely in a multitude of points. Many of these are of so unimportant or of so singular a nature, that it is extremely improbable that they should have been independently acquired by ahoriginally distinct species or races. The same remark holds gool with equal or greater force with respect to the numerous points of mental similarity between the most distinct races of man. The Ainerican aborigines, Negroes and Europeans are as different from each other in mind as any three races that can be named; yet I was incessantly struck, whilst living with the Fucgians on board the "Beagle," with the many little traits of character, showing how similar their minds wero to ours; and so it was with a full-blooded negro with whom I happened once to be intimate.

Ho who will read MIr. Tylor's and Sir J. Tubbock's interesting works ${ }^{24}$ can hardly fail to be decply impressed with the close similarity between the men of all races in tastes, dispositions and habits. This is shewn by the pleasure which they all take in: dancing, rude music, acting, painting, tattooing, and otherwise decorating themselves; in their mutual comprehension of gesturelanguage, by the same expression in their features, and by the same inarticulate cries, when excited by the same emotions. This similarity, or rather identity, is striking, when contrastcil

24 Tylor's 'Eariy Histcry of Mankind, 1855 : with respect to gesture- language, see p. 54. Lubboci is 'Prehistoric 'Times,' -nd edit. 18rit. 
with the different expressions and cries made by distinct species of monkeys. There is good evidence that the art of shouting with bows and arrows has not been handed down from any commion progenitor of mankind, yet as Westropp and Nilsson have remarlied, ${ }^{25}$ the stone arrow-heads, brought from the most distant parts of the world, and manufictured at the most remot periods, are al:uost identical ; and this fact can only be accounted for by tho various races haviug similar inventive or inental powers. The same olservation has been made by archrologists ${ }^{20}$ with respect to certain widely-prevalent ornaments, such as zigrags, dre; and with respect to various simple beliefs and custous, such as the burying of the dead under megalithic structures. I remmber olsurving in South America, ${ }^{27}$ that there, as in so many other parts of the world, men have generally chosen the sunimits of lotty hills, to throw up piles of stones, either as a record of some remarkable event, or for burying their dead.

Now when mituralists olserve a close agreement in numerous small details of habits, tastes, and dispositions between two or moro doncstic races, or between nearly-allied natural forms, they use this fact as an argument that they are descended from a common progenitor who was thus endowed; and conscruently that all should be classed under the same species. The same argument may be applied with much force to the races of man.

As it is improbable that the numerous and unimportant points of resemblance between the several races of man in bodily structuro and mental faculties (I do not here refer to similar customs) sliould all have been independently acquired, they must have been inherited from progenitors who had these same characters. We thus gain some insight into the carly state of man, before he had spread step by step over the face of the earth. The spreading of man to regions widely separated by the sca, no doubt, preceded any great amount of divergence of character in the several races; for otherwise we should sometimes meet with the same race in distinct continents; and this is never the case. Sir J. Lubbock, after comparing the arts now practised by savages in all parts of the world, specifies those which man could not have kmorn, when he first wandered from his original birth-place; for if once learnt they would never have been forgotten. ${ }^{28} \mathrm{Hc}$

25 'On Analogous Forms of Implements, in 'Menoirs of Anthropolog. Soc.o' by H. M. Westropp. "The Primitive Inhabitants of Scandinavia, Eng. translat. edited by Sir J. Lubbock, 1868, p. 104.

"Westropp, 'On Cromlechs,' \&c.,
'Journal of Ethnological Soce' as given in 'Screntific Opinion,' June 2nd, 1869, p. 3.

28 "Journal of Researches: Voyage of the "Bengle," " p. 46. 574. 
thus shews that "the spear", which is but a derelopment of the "knife-point, and the club, which is but a long hammor, are the "only things left." He adnits, however, that the art of makingr fire probably had been already discovered, for it is common to all the races now cxisting, and was known to the ancient caveinhabitants of Europe. Pcrhaps the art of making rude canocs or rafts was likewise known; but as man existed at a remote epoch, when the land in many places stood at a very different level to what it does now, he would have heen able, vithout the aid of canoes, to have spread widely. Sir J. Lubbock further remarks how improbable it is that our earliest ancestors could have "counted as high as ten, considering that so many races "now in existence cannot get beyond four." Nevertheless, at this early period, the intellectual and social faculties of man could hardly have been inferior in any extreme degree to those possessed at present by the lowest savages; otherwise primeval man could not have been so eminently successful in the struggle for life, as proved by his early and wide diffusion.

From the fundamental differences between certain languages, some philologists have inferred that when man first became widely diffused, he was not a speaking animal; but it may bo suspectcd that languages, far less perfect than any now spoken, aided by gestures, miglıt have been used, and yet have left no traces on subsequent and more highly-developed tonguos. Without the use of some language, however imperfect, it appears doubtful whether man's intellect could have risen to the standard implied by his dominant position at an early period.

Whether primeral man, when he possesscd but few arts, and those of the rudest kind, and when his power of language was extremely imperfect, would have deserved to be called man, must depend on the definition which we employ. In a series of forms graduating insensibly from some ape-like creature to man as he now exists, it would be impossible to fix on any definite point when the term "man" ought to be used. But this is a matter of very little importance. So ngain, it is almost a matter of indifference whether the so-called races of man are thus designated, or are ranked as species or sul 1-species; but the latter term appears the more appropriate. Einally, we may conclude that when the principle of evolution is gencrally accepted, as it surely will bo hefore long, the dispute between the monogenists and the polygenists will die a silent and unobserved death.

One other question ought not to be passed over without notice, namely, whether, as is sometimes assumed, each sub-species or zace of man has sprung from a single pair of progenitors. With 
our domestic animals a new mee can readily be formed by carefully matching the varying ollspring from a single pair, or eren from a sirgile indiridual posicessing some new character; but zinost of our races have been formed, not intentionally from a selected pair, but unconseionsly by the preservation of many individuals which have varied, however slightly, in some useful or desired manuer. If in one comtry stronger and heavier horses, and in another country lighter and flecter ones, were habitually preferred, we may feel sure that two distinct sub-breeds would be producel in the course of time, without any one pair having been separated and bred from, in either country. Minny races have been thus formed, and their manner of formation is closely analogous to that of natural species. We know, also, that the horses taken to the Falkland Islands have, during successive generations, become smalier and weaker, whilst those which have run wild on the Pampas have acquired larger and coarser heads: and such changes are manifestly due, not to any one pair, but to all the individuals having been subjected to the same conditions, aided, perhaps, by the principle of reversion. The new subbreeds in such cases are not descended from any single pair, but from many individuals which have varied in different degrees, but in the same general manner; and we may conclude that the races of man have been similarly produced, the modifications being either the direct result of exposure to different conditions, or the indirect result of some form of selection. But to this latter subject we shall presently return.

On the Extinction of the Races of Man.-The partial or complete extinction of many races and sub-races of man is historically known. Humboldt saw in South America a parrot which was the sole living creature that could speak a word of the language of a lost tribe. Ancient monuments and stone implements found in all parts of the world, about which no tradition has been preserved by the present inhabitants, indicatn much extinction. Some small and broken tribes, remuants o!' former races, still survive in isolated and gencrally mountainous districts. In Europe the ancicnt races were all, according to Scharfhausen, ${ }^{29}$ "lower in the scale than the rudest living savages;" they must therefore have differed, to a certain extent, from any existing race. The remains described by Professor Bruca from Les Eyzies, though they unfortunately appear to have belonged to a single family, indicate a race with a most singular combination of low or simious, and of high characteristics. This race is "entirely

$\approx$ Translation in :Anths opological Review, Oct. 1869, p. 43: 
"different from any other, ancient or modern, that we have ever "heard of." " It differed, therefore, from the quaternary race of the caverns of Belgium.

Man can long resist conditions which appear extremely unfarourable for his existence. ${ }^{31}$ He has long lived in the extreme recrions of the North, with no wood for his canoes or implements, and with only blubber as fuel, and melted snow as drink. In the southern extremity of America the Fuegians survive without the protection of clothes, or of any luilding worthy to be called a hovel. In South Africa the alsorigines wander over arid plains, where dangerous beasts alound. Man can withstand the doadly influence of the Terai at the foot of the Himalaya, and the pestilential shores of tropical Africa.

Extinction follows chictly from the competition of tribe with tribc, and race with race. Various checks are always in action, serving to kcep down the numbers of each savage tribe,-such as periodical famines, nomadic habits and the consequent deaths of infants, prolonged suckling, wars, accidents, sickness, licentiousness, the stealing of women, infanticide, and especially lessened fertility. If any one of these checks increases in power, even slightly, the tribe thus affected tends to decrease; and when of two adjoining tribes one becomes less numerous and less powerful than the other, the contest is soon settled by war, slaughter, cannibalism, slavery, and absorption. Even when a weaker tribe is not thus abruptly swept away, if it once begins to decrease, it generally goes on decreasing until it becomes extinct. ${ }^{32}$

When civilised nations come into contact with barbarians the struggle is short, except where a deadly climate gives its aid to the native race. Of the causes which lead to the victory of civilised nations, some are plain and simple, others complex and obscure. Wo can see that the cultivation of the land will be fatal in many ways to sarages, for they cannot, or will not, change their habits. Now diseases and rices have in some cases proved highly destructive; and it appears that a new disease often causes much death, until those who are most susceptible to its destructive influence are gradually weeded out; ${ }^{33}$ and so it way be with the evil effects from spirituous liquors, as well as with the unconquerably strong taste for them shewr by so many

30 'Transact. Internat. Congress 'f Prehistoric Arch,' 1868, pp. 172175. See-also Brosa (translation) In 'Anthropological Review, Oct. 1868, p. 410.

31 Dr. Gerlan.? 'Ueber das Auss- terben der Naturvölker,' 1868, s. 82. 32 Gerland (ibid. s. 12) gives tacts in support of this statement.

33 See remarks to this effect in Sir H. Holland's 'Medical Notes and Reflections,' 1839, p. 390. 
sarages. It further appears, mysterious as is tho fact that the first meeting of distinct and separated people gencrates

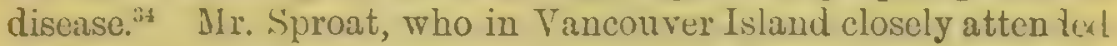
to tho subject of extinction, believed that changed habits of life, consequent on the advent of Europeans, induees much ill health. He lays, also, great stress on the apparently triding cause that the natives become " bewildered and dull by the new life around "them; they lose the motives for exertion, and get no new ones "in their place."

The grude of their civilisation seems to be a most important element in the success of competing nations. A few centuries ago Europe feared the inroads of Eastern barbarians; now any such fear would be ridiculous. It is a more curious fact, as Mr. Bagehot has remarked, that savages did not formerly wasto away before the classical nations, as they now do before moderu civiiised nations; had they done so, the old moralists would have mused over the event; but there is no lament in any writer of that period orer the perishing barbarians. ${ }^{36}$ The most potent of all the causes of extinction, appears in many cases to be lessened fertility and ill-health, especially amongst the children, arising from changed conditions of life, notwithstanding that the new conditious may not be injurious in themselves. I am much indebted to Mr. H. H. Howorth for having called my attention to this subject, and for having given me information respecting it. I have collected the following cases.

When Tasmania was first colonised the natives were roughly estimated by some at 7000 and by others at 20,000. Their number was soon greatly reduced, chiefly by fighting with the English and with each other. After the famous hunt by all the colonists, when the remaining natives (clivered themselves uj) to the government, they consisted only of 120 individuals, who were in $18: 32$ transported to Flinders Island. 'This island, situated betreen Tasmania and Australia, is forty miles long, and from twelve to eighteen miles broad: it seems healthy, and the natives were well treated. Nevertheless, they suffered greatly in health. In 1834 they consisted (Bonwick, p. 250) of forty-seven aclult males, forty-eight adult ferwales, and sixteen. children, or in all of 111 souls. In $103 \mathrm{~s}$ only one huudred were left.

* I have collected ('Journal of Researches, Voyage of the "Bengle," p. 43.5) a gond many cases bearing on this subject; see also Gerland, ibid. 8. 8. Hopplig speaks of the "treath of covilisition as poisonous "to savages."

as Sproat, Scenes and Studies of
Savaze Life,' 1868, p. 284.

36 Bagehot, "Physics and Politics,' 'Fortuightly lieview,' April $1,1868, \mathrm{p} .455$.

38 All the statements here given aie taken from "The last of the Tasmanians,' by J. Bonwick, 1870. 
As they continued rapidly to decrease, and as thry thomselves thought that they skould not perish so quickly elsewhere, they were removed in 1847 to Oyster Cove in the southern part of Tasmania. They then consisted (Dec. 20th, 1847) of fourteen men, twentytwo women and ten children. ${ }^{38}$ But the change of site did no grod. Disease and death still pursued them, and in 1864 one man (who died in 1869), and three elderly women alone survived. The infertility of the women is even a more remarkalule fact than the liability of all to ill-health and death. At the time whon only niue women were left at Oyster Cove, they told Mr. Bonwick (p. 386), that only two had ever borne children: and these two had together produced only three children!

With respect to the cause of this extraordinary state of things, Dr. Story remarks that death followed the attempts to civilise the natives. "If left to themselves to roam as they were wont " and undisturbed, they would have reared more children, and "there would have been less mortality." Another careful observer of the natives, Mr. Davis, remarts, "The births have "been few and the deaths numerous. This may have been in a "great measure owing to their change of living and food; but " more so to their banishment from the mainland of Van Diemen's "Land, and consequent depression of spirits" (Bonwick, pp. 388,390 ).

Similar fars have been observed in two widely different parts of Australia. The celebrated explorer, Mr. Gregory, told Mr. Bonwick, that in Queensland "the want of reproductions "was being already felt with the blacks, even in the most "recently settled parts, and that decay would set in." Of thirteen aborigines from Shark's Bay who visited Murchisor River, twelve died of consumption within three months. ${ }^{39}$

The decrease of the Maories of New Zealand has been carefully investigated by Mr. Fenton, in an admirable Report, from which all the following statements, with one exception, are taken. ${ }^{40}$ The decrease in number since 1830 is admitted by every one, including the natives themselres, and is still steadily progressing. Although it has hitherto been found impossible to take an actual census of the natives, their number's were carefully estimated by residents in many districts. The result seems trustworthy, and shows that during the fourteen years, prerious

38 This is the statement of the Tovernor of Tasmania, Sir W. Denisoa, 'Varieties of Vicc-Regal Life,' 1870 , rol. I. P. 67.

¿ For these cases, see Bonwich's 'Dasly Life of the Tasmanians,"
1870 , p. 90 ; and the 'Last of the Tasmanians,' 1870, p. 386.

10 'Observations on the Abnrigina? Inhabitants of New Zealand,' pub. lished by the Govermment, 1859 . 
to 1858 , the deerease was 19.42 per cent. Some of the tribes, thus carefully examined, lived above in hundred miles apart, some on the coast, some inland; and their means of sulsistenen and habits differed to a certain extent (p. 23). The total number in 1858 was beliered to be 53,700 , and in 1872 , after a second interval of fourteen years, amother census was taken, and the number is given as only 36,359 , shewing a decrease of 32.29 per cent.! ${ }^{\text {t1 }} \mathrm{Mr}$. Fenton, after shewing in detail the insufticiency of the various causes, usually assigned in explanation of this extraordinary decrease, such as new diseases, the profligacy of the women, drunkeuness, wars, \&c., concludes on weighty grounds that it depends chefly on the unproductiveness of the women, and on the extraordinary mortality of the young children (pp. 31, 34). In proof of this he shews (p. 33) that in 1814 there was one non-adult for every 2.57 adults; whereas in 1858 there was only one non-adult for ercry 327 adults. The mortality of the adults is also great. Ho adduces as a further cause of the decrease the inequality of the sexes; for ferver females are born than males. To this latter point, depending perhaps on a widely distinct cause, I shall return in a future chapter. Mr. Fenton contrasts with astonishment the decrease in New Zealand with the increase in Ircland; countries not very dissimilar in climate, and where the inhabitants now follow nearly similar habits. The Maories themselves (p. 35) " attribute their "decadence, in some measure, to the iutroduction of new food "and clothing, and the attendant change of habits;" and it will be secn, when we consider the influence of changed conditions on fertility, that they are probahly right. The diminution began: between the yuars 1830 and 1840; and Mr. Fenton sherws (p. 40) that about 1830, the art of manufacturing putrid corn (maizc), by loug steeping in water, was discovered and largely practised; and this proves that a change of habits was leginning amongst the natives, even when New Zealand was only thinly inhabited by Europeans. When I visited the Ray of Islands in 1835 the dress and food of the inhabitants bad already been much modified: they raised potatoes, maize, and other agricultural produce, and exchanged them for English manufactured goods and tobacco.

It is evident from many statements in the life of Bishop Patteson, ${ }^{42}$ that the Melanesians of the New Hobrides and neighbouring archipelagoes, suffered to an extraordinary dcgree in health, and perished in large numbers, when they were

1) 'New Zealnad, by Alex. Kennedy, 1873, p. 47.

42. "Life of J. C. Patteson," by
C. M. Younge, 1874; see mor especially rol. i. p. 530 . 
removed to New Zealand, Norfolk Island, and other salubrious places, in order to be educated as missionaries.

The decrease of the native population of the Sandwich Islands is as notorious as that of New Zealand. It has been roughly estimated by those best capable of judging, that when Cook discovered the Islands in 1779 , the population amounted to about 300,000. According to a loose census in 1823, the numbers then were 142,050. In 1832, and at sereral subsequent periods, an accurate census was officially taken, but I have been able to obtain only the following returns:

\begin{tabular}{|c|c|c|}
\hline YEAR. & $\begin{array}{l}\text { Natve Popdlation. } \\
\text { (Except during } 1832 \\
\text { and 1836, when the } \\
\text { few foreigners in the } \\
\text { islands were included). }\end{array}$ & $\begin{array}{l}\text { Annual rate of decrease } \\
\text { per cent., assuming it } \\
\text { to have been uniform be- } \\
\text { tween the successive cen- } \\
\text { suses; these censuses be- } \\
\text { ing taken at irregular } \\
\text { intervals. }\end{array}$ \\
\hline $\begin{array}{l}1832 \\
1836 \\
1853 \\
1860 \\
1866 \\
1872\end{array}$ & $\left.\begin{array}{r}130,313 \\
108,579 \\
71,019 \\
67,084 \\
58,765 \\
51,531\end{array}\right\}$ & $\begin{array}{l}4 \cdot 46 \\
2 \cdot 47 \\
0 \cdot 81 \\
2 \cdot 18 \\
2 \cdot 17\end{array}$ \\
\hline
\end{tabular}

We here see that in the interval of forty years, between 1832 and 1872 , the population has decreased no less than sixty-ejght per cent.! This has been attributed by most writers to the profligacy of the women, to former bloody wars, and to the severe labour imposed on conquered tribes and to newly introduced diseases, which have been on several occasions extremely destructive. No doubt these and other such causes have been highly efficient, and may account for the extraordinary rate of decrease between the years 1832 and 1836 ; but the most potent of all the causes secms to be lessened fertility. According to Dr. Ruschenberger of the U.S. Navy, who visited these islands hetwecn 1835 and 1837, in one district of Hawaii, only twenty-five men out of 1134 , and in another district only ten out of 637 , had a family with as many as three children. Of eighty married romen, only thirtynine had erer borne children; and " the official report gives ar "arerage of half a child to each married couple in the whole 
"island." This is almost exactly the same average as with the Trsmanians at Oyster Core. Jarves, who published his History in $1 s 13$, says that " families who have three children are freed from "all taxes; those having more, are rewarded by gifts of land and "other eneouragements." This unparalleled enactment by the government well shews how infertile the race had become. The Rev. A. Bishop) stated in the Hawaiian 'Spectator' in 1839, that a large proportion of the children die at early ages, and Bishop Stalcy informs me that this is still the case, just as in New Zealand. This has been attributed to the neglect of the children hy the women, but it is probably in large part due to innate weakness of constitution in the children, in relation to the lessened fertility of their parents. There is, moreorer, a further resemblance to the case of New Zealand, in the fact that there is a largo excess of male orer female births: the census of 1872 gives 31,650 males to 25,247 females of all ages, that is $125 * 36$ males for every 100 females; whereas in all civilised countries the females exceed the males. No doubt the profligacy of the women may in part account for their small fortility; but thoir changed habits of life is a manch more probable cause, and which will at the same time account for the increased mortality, especially of the children. The islands were visited by Cook in 1779 , by Vancouver in 1794, and often subsequently by whalers. In 1819 missionaries arrived, and found that idolatry had been already abolished, and other changes effected by the king. After this period there was a rapid change in almost all the habits of life of the natires, and they soon became "the most civilised of "the Pacific Islanders." One of my informants, Mr. Coan, who was born on the islands, remarks that the natives have undergone a greater change in their habits of life in the comrse of fifty years than Englishman during a thousand years. From information received from Bishop Staley, it does not appear that the poorer classes have ever much clianged their dict, although many new kinds of fruit have been introduced, and the sugarcane is in universal use. Owing, however, to their passion for imitating Europeans, they altered their manner of dressing at an early period, and the use of alcoholic drinks became very general. Although these changes appear inconsiderable, $I$ can well believe, from what is known with respect to animals, that they might suffice to lessen the fertility of the natives. ${ }^{+3}$

13 The foregoing statements are taken chiefly from the following works : 'Jarves' History of the Hawaiian lslands,' 1843, p. $400-407$. Cheever, "Life in the Sandwich
Islands,' 1851, p. 277. Ruschenberger is quoted by Bonwick, 'Last of the Tasmanians,' 1870, p. 378. Bishop is quoted by Sir E. Belcher, 'Voyage Lound the Worid,' 184:3, 
Lastly, Mr. Macnamara states ${ }^{* 1}$ that the low and degraded inhabitants of the Andanan Islands, on the eastern side of the Gulf of Benral, are "eminently susceptible to any change of "climate: in fact, take them array from their island homes, and " they are almost certain to die, and that independently of diet "or extraneous influences." $\quad H$ e further states that the inhabitants of the Valley of Nepâl, which is extremely hot in summer, and also the various hill-tribes of India, suffer from dysentery and fuver when on the plains; and they die if they attempt to pass the whole year there.

We thus see that many of the wilder races of man are apt to suffer much in hoalth when subjected to changed conditions or habits of life, and not exclusively from being transported to a new climate. Mere alterations in habits, which do nut appear injurious in thomselves, secm to have this same effect; and in several cases the children are particularly liable to suffer. It has often been said, as Mr. Macnamara remarks, that man can resist with impunity the greatest diversities of climate and other changes; but this is true only of the civilised races. Man in his wild condition seems to be in this respect almost as susceptible as his nearest allies, the antlropoid apes, which have never yet survived long, when removed from their native country.

Lessened fertility from changed conditions, as in the case of the Tasmanians, Maories, Sandwich Islanders, and apparently the Australians, is still more interesting than tbeir liability to ill-health and death; for even a slight degree of infertility, combined with those other causes which tend to check the increase of every population, would sooner or later lead to cxtinction. The diminution of fertility may be explained in some cases by the profligacy of the women (as until lately with the I'ahitians), but Mr. Fenton has shewn that this explanatior. by no means suffices with the New Zealanders, nor does it with the Tasmanians.

In the paper above quoted, Mr. Macnamara gives reasons for believing that the inlabitants of districts subject to malaria are npt to be sterile; but this cannot apply in several of the above eases. Some writers hare suggested that the aborigines of islands have suffered in fertility and health from long continued

vol. i., p. 272. I owe the census of the several years to the kindness of Mr. Coan, at the request of Dr. Youmans of New York; and in most cases I have comparea the Youmans figures with thuse given in sercril of the above-named works. I have omitted the census for 1850 , as I have seen two widely different numbers given.

14 The Indian Mediral Girette, Nor. 1, 1871, P. 240. 
inter-brecling; but in the abovo cases infertility has coincided too closely with the arrival of Europeans for us to admit this explanation. Nor have wo at present any reason to believe that man is highly sensitive to the evil effects of inter-breeding, especially in areas so large as New Zealand, and the Sandwich archipelago with its diversified stations. On the contrary, it is known that the present iuhabitants of Norfolk Island are nearly all cousins or near relations, as are the Todas in India, and the inhabitants of some of the Western Islands of Scotland; and yet they seem not to have suffered in fertility. ${ }^{5}$

A much moro probable riew is suggested by the analogy of the lower animals. The reproductive system can be shewn to be susceptible to an extraordinary degree (though why we know uot) to changed conditions of life; and this susceptibility leads both to beneficial and to evil resulus. A large collection of fucts on this subject is given in chap. $\mathbf{x}$ viii. of vol. ii. of my 'Variation of Animals and Plants under Domestication,' I can here give only the briefest abstract; and every one interested in the subject may consult the ubove work. Vory slight changes increase the health, vigour ard fertility of most or all organic beings, whilst other changes are known to render a large number of animals storile. One of the most familiar cases, is that of tamed elephants not breeding in India; though they often breed in Ara, where the females are allowed to roam about the forests to some extent, and are thus placed under more natural conditions. The case of various American monkeys, both sexes of which have been kept for many years topether in their own countries. and set have rery rarely or nerer bred, is a more apposito instance, because of their relationswip to man. It is remarkable how slight a change in the conditions often iuduces sterility in a wild animal when captured; and this is the moro strange as all our domesticated animals have becomo more fertilo than they were in a state of nature; and some of them can resist the most unnatural conditions with undiminished fertility. ${ }^{46}$ Cortain groups of animals are much moro liable than others to be affected by captirity; and generally all tho species of the same group are affected in the same manner. But sometimes a singlu specios in a group is rendered sterile, whilst the others aro not so; on the other hand, a single species may retain its fertility

1s (in the close relationship of the Norfolk Islauders, see Sir W. Denicon, 'Varieties of Vice-Regal Life," rol. i. $137(1$, p. 410. For the Todas, see Col. Marshall's work, 1873, p. 110. For the Western Islands of
Scotisnd, Dr. Mitchell, 'Edinburgh Medical Jourual,' March to June, 1865.

46 For the evileuce on this bead, see 'Variation of Animals" $\delta$ ki... rol. ii. p. 111. 
whilst most of the others fail to breed. The males and femalee of some species when confined, or when allowed to live almost, but not quite free, in their native country, never mite; others thus circumstanced frequently unite but never prorluce offspring; others again produce some offspring, but ferver than in a state of nature; and as bearing on the above cases of man, it is important to remark that the young are apt to be weak and sickly, or malformed, and to perish at an early age.

Secing how general is this law of the susceptilility of the reproductive system to changed conditions of life, and that it holds good with our nearest allies, the Quadrumana, I can hardly doubt that it applies to man in his primeval state. Hence if sarages of any race are induced suddenly to change their habits of life, they become more or less sterile, and their young offspring suffer in health, in the same manner and from the same cause, as do the elephant and hunting-leopard in India, many monkeys in America, and a host of animals of all kinds, on remoral from their natural conditions.

We can see why it is that aborigines, who hare long inhabited islands, and who must have been long exposed to nearly uniform conditions, should be specially affected by any change in their habits, as seems to be the case. Civilised races can certainly resist changes of all kinds far better than savages; and in this respect they resemble domesticated animals, for though the latter sometimes suffer in health (for instance Iuropean dogs in India), yet they are rarely rendered sterile, though a few such iustances hare been recorded. ${ }^{47}$ The immunity of civilised races and domesticated animals is probably due to their having been subjected to a greater cxtent, and therefore having grown somewhat more aceustomed, to diversified or varying conditions, than the majority of wild animals; and to their having formorly immigrated or been carried from country to country, and to different families or sub-races having inter-crossed. It appcars that a cross with civilised races at once gives to an aboriginal race an immunity from the evil consequences of changed conditions. Thus the crossed offspring from the Tahitians and English, when settled in Pitcairn Island, increased so rapidly that the island was soon overstocked; and in June 1856 they were removed to Norfolk Island. They then consisted of 60 married persons and 131 shildren, making a total of 194. Here they likewise increased so rapidly, that although sixteen of them returned to Pitcairn Island in 1859, they numbered in January 1868, 300 souls;

$$
\text { er 'Yariation of Animals,' \& } c \text { c., rol. ii., p } 16 .
$$


the males and fomales being in exactly eclual numbers. What a contrast does this case present with that of the Tasmanians; the Norfolk Islanders incressed in only twelve and a half years from $19 \pm$ to 300 ; whereas the Tasmanians decreased during fifteen years from 120 to 46 , of which latter number only ten were children. ${ }^{48}$

So agaiu in the interval between the census of 1866 and 1872 the natives of full blood in the Sandwich Islands decreased by S0s1, whilst the half-castes, who are believed to be healthier, increased by 847 ; but $I$ do not know whether the latter number includes the offispring from the half-castes, or only the half-castes of the first generation.

The cases which I have here giren all relate to aborigines, who hare been suljected to new conditions as the result of the immigration of cirilised men. But sterility and ill-health would prolably follow, if savages were compelled by any cause, such as the imroad of a conquering tribe, to desert their homes and to change their habits. It is an interesting circumstance that the chief check to wild animals becoming domesticated, which implies the power of their breeding freely when first captured, and one chicf check to wild men, when brought into contact with civilisation, surviving to form a civilised race, is the same, namely, sterility from changed conditions of life.

Finally, although the gradual decrease and ultimate extinctiou of the races of man is a highly complex problem, depending on many causes which differ in different places and at different times; it is the same problem as that presented by the extinction of one of the higher animals - of the fossil horse, for instance, which disanpeared from South America, soon aftcrwards; to be replaced, within the same districts, by countless troops of the Spanish horse. The New Zealander seems conscious of this parallelism, for he compares his future fate with that of the native rat now almost exterminated by the European rat. Though tho difficulty is great to our imagination, and really' great, if we wish to ascertain the precise causes and their manner of action, it ought not to be so to our reason, as long as we keep steadily in mind that the increase of each species and each race is constantly checked in various ways; so that if any new check, eren a slight on:e, be superadded, the race will surely decrease in number; and decreasing numbers will sooner or

48 These details are taken from "The Mutineers of the "Bounty," by Lady Belcher, 1870; and from 'Pitcairn Island,' ordered to be printed by the House of Commons,
May 29th, 1863. The followius statements about the Sandwich lslanders are from the "Honclidu Gazette,' and from Mr. Coan. 
Inicr laul to extinction; the cnd, in most rises, being promptly iletermined by the inroads of conquering tribes.

in the Formation of the Ruces of Mun.-In some cases thes erussing of distinct races has led to the formation of a new race. 'The singular fact that Europeans and Hindoos, who belong to the sams Aryan stock, and speak a language fundamentally the same, differ widely in appeararce, whilst Europeans differ but little from Jews, who belong to the Semitic stock, and speak yuite another language, has been accunted for by Broca, ${ }^{45}$ througl ccrtain Aryan branches having been largely crossed by indigenous tribes during their wide diffusion. When two xaces in close contact cross, the first result is a hetcrogeneous mixtme: thus Mr. Hunter, in describing the Santali or hill-tribes of India, says that hundreds of imperceptible gradations may be traced "from the black, squat tribes of the mountains to the tall "olire-coloured Bralıman, with his intellectual brow, calm ryes, "and high but narrow head;" so that it is necessary in courts of justice to ask the wituesses whether they are Santalis or Iindoos. ${ }^{60}$ Whether a heterogeneons people, such as the inhabitunts of somo of the Polynesian islands, formed by the crossing of two distinct races, with few or no pure members left, would ever become homogeneous, is not known from direct evidence. Put as with our domesticated animals, a cross-bueed can certainly Tw fixed and made uniform by careful selection ${ }^{51}$ in the course of a few gonerations, we may infer that the free intercrossing of a heterogeneous mixture during a long descent would supply tho place of selection, and orercome any tendency to reversion; so that the crossed unce Fould ultimately become homogeneous, though it might not partake in an equal degrec of the charactors of the two parent-races.

Of all the differences betreen the races of man, the colour of the skin is the most conspicuous and one of the best narked. I1 was formerly thought that differences of this kind could hat accounted for hy long exposure to different climates; but l'allas first shewed that this is not tenable, and he has since hean tollowed by almost all anthropologists.52 This view has knen rejected chiefly because the distribution of the variously coloured races, most of whom must have long inhalited their

\footnotetext{
49 'On Anthropology' translation 'Anthropolog. Review,' Jan. 1868, p. 38.

so 'The Annals of Rural Bengal,' a 868, p. 134 .

51 "The Variation of Animals and Plants under Domestication,' vol. ii. D. 19
}

s2 Pallas, "Act. Acad. St. Petorsburg,' 1780 , part ii. p. 69 . He was followed b5 Rudolphi, in his ' $\mathrm{Bey}$ trïge zur Anthropologie,' 1812. An excellent summary of the evidence is given by Goulson, "The l'tispèce,' 1859 , vol. ii. p. 2 216 , đc. 
present homes, does not coincide with corresponding differences of climate. Some little weight may be given to such cases as thrat of the Dutch families, who, as we hear on excellent authority, have not undergone the least change of colour after residing for three centuries in South Africa. An argument ou the same side may likewise be drawn from the uniform appearance in rarious parts of the world of gipsies and Jews, though the uniformity of the latter has been somewhat exaggerated. ${ }^{54}$ A rery damp or a rery dry atmosphere has heen supposed to be more influential in modifying the colour of the skin than mere heat; but as D'Orbigny in South America, and Livingstone in Africa, arrived at diametrically opposite conclusions with respect to dampness and dryness, any conclusion on this head must be considered as very doubtful..$^{55}$

Varions facts, which I have given elsewhere, prove that the colour of the skin and hair is sometimes correlated in a surprising manner with a complete immunity from the action of certain vegetable poisons, and from the attacks of certain parasites. Hence it occurred to me, that negroes and other dark races night have acquired their dark tints by the darker individuals escaping from the deadly influence of the miasma of their native countries, during a long series of generations.

I afterwards found that this same idea had long ago occurred to Dr. Wells. ${ }^{56}$ It has long been known that negroes, and even mulattoes, are almost completely exempt from the yellow-fever, so destructive in tropical America. ${ }^{57}$ They likewise escape to a large extent the fatal intermittent fovers, that prevail along at least 2600 miles of the shores of Africa, and which annually cause one-fifth of the white scttlers to die, and another fifth to return home invalided. ${ }^{58}$ This immunity in the negro seems to be partly inlerent, depending on some unknown peculiarity of constitution, and partly the result of acclimatisation. Pouchet ${ }^{53}$

53 Sir Andrew Smith, as quoted 1.y hnox, 'Races of Man' 1850, p. $4 \div: \cdots$

st See De Quatrefages on this hend, "Revue des Cours Scieatifiques,' Oct. 17, 1868, p. 731.

35 Livingstone's 'Travels and Researches in S. Africa,' 1857, pp. 338, 329. D’Orbigny, as quoted by Goulron, 'De l'Espece,' rol. ii. p. $26 \%$.

so See a paper read before the Roral Soc. in 1813, and published ir. his Essays in 1818. I hare given s. account of Dr. Wells' views in the Historical Sketch (p. xvi.) to $m y$ 'Origin of Species.' Various cases of colcur correlated with constitutional peculiarities are given in $\mathrm{my}$ - Variation of Animals under Domestication,' vol. ii. pp. 227, 335 .

57 See, for instance, Nott and Gliddon, 'Types of Mankind,' p. 68.

so Major Tulloch, in a praper read before the Statistical Society, Apri? $20 t h, 1840$, and given in the "Athe. næum,' 1840, p. 353.

59 'The Piurality of the Humas Race' (translat.), 1864, p. bo. 
states that the negro reciments recruited near the Soudan, and oorrowed from the Viceroy of Egypt for the Mexican war, escaped the yellow-ferer almost equally with the negroes originally brought from various parts of Africa and accustomed to the climate of the West Indies. That acclimatisation plays a part, is shewn by the many cases in which negroes have become somewhat liable to tropical fevers, after having resided for some time in a colder climate. ${ }^{60}$ The nature of the climate under which the white races have long resided, likewise has some influence on them; for during the fearful epidemic of yellow-fever in Demerara during 1837, Dr. Blair found that the death-rate of the immigrants was proportional to the latitude of the country whence they had come. With the negro the immunity, as far as it is the result of acclimatisation, implies exposure during a prodigious length of time; for the aborigines of tropical America who have resided there from time immemorial, are not exempt trom yellow fever; and the Rev. H. B. Tristram states, that there are districts in Northorn Africa which the native inhabitants are compelled annually to leave, though the negroes can remain with safety.

That the immunity of the negro is in any degree correlated with the colour of his skin is a mere conjecture: it may be correlated with some difference in his blood, nervous systom, or other tissues. Nevertheless, from the facts above alluded to, and from some connection apparently existing between complexion and a tendency to consumption, the conjecture seemed to me not improbable. Consequently I endeavoured, with but little success, ${ }^{61}$ to ascertain how far it holds good. The late Dr.

${ }^{60}$ Quatrefages, 'Unité de l'Espèce Humaine,' 1861, p. 205. Waitz, 'Introduct. to Anthropology,' translat. vol. i. 1863 , p. 124. Livingstone gires analogous cases in his 'Travels.'

61 In the spring of $1862 \mathrm{I} \mathrm{ob-}$ tained permission from the DirectorGeneral of the Medical department of the Army, to transmit to the surgeons of the various regiments on foreign service a blank table, with the following appended remarks, but I have received no returns. "As several well-marked "cases have been recorded with " our domestic animals of a relation "between the colour of the dermal " appendages and the constitution; "ad it being notorious that there "is some limited degree of relation " between the colour of the races of " man and the climate inhabited by "them; the following investiga"tion seems worth consideration. "Namely, whether there is any re"lation in Europeans between the "colour of their hair, and their" "liability to the diseases of tropica! "countr:es. If the surgeons of the " several regiments, when stationed "in unhealthy tropical districts, "would be so good as first to count, " as a standard of comprison, how "many men, in the force whence "the sick are drawn, have darts " and light-coloured hais, and hair" " of intermediate or doubtful ticts; " and if a similar account were "kept by the same medicai gentle- 
Daniell, who had long lived on the West Coast of Africa, told me that he did not believe in any such relation. He was himself unusually fair, and had withstood the climate in a wonderful manner. When he first arrived as a boy on the coast, an old and experienced negro chief predicted from his appearance that this would prove the case. Dr. Nicholson, of Antigua, after having attended to this subject, writes to me that he does not think that dark-coloured Europeans escape the yellow-fever more than those that are light-coloured. Mr. J. M. Harris altogether denies that Europeans with dark hair withstand a hot climate hetter than other men : on the contrary, experience has taught him in making a selection of men for service on the coast of Africa, to choose those with red hair. ${ }^{62}$ As far, therefore, as thcse slight indications go, there seems no foundation for the hypothesis, that blackness has resulted from the darker and darker individuals having survived better during long exposure to fever-generating miasma.

Dr. Sharpe remarks, ${ }^{63}$ that a tropical sun, which burns and blisters a white skin, does not injure a black one at all ; and, as he adds, this is not duo to habit in the individual, for children only six or eight months old are often carried about naked, and are not affected. I have been assured by a medical man, that some years ago during each summer, but not during the winter, his hands became marked with light brown patches, like,

"men, of all the men who suffered

"from malarious and yellow ferers,

" or from dysentery, it would soon

"be apparent, after" some thousand

"crses had been tabulated, whether

"there exists any relation between

"the colour of the hair and consti-

"tutional liability to tropical dis-

" eases. Pernaps no such relation

"would be discovered, but the in-

"vestigation is well worth making.

"In case any positive result were

" obtained, it might be of some

" practical use in selecting men for

"any particular service. Theoreti-

"cnlly the result would be of high

"interest, as indicating one means

" ky which a race of men inhabiting

"from a remote period an un-

" healthy tropical climate, might

"have become dark-coloured by

" the better preservation of dark-

" haired or dark-complexioned in-

* diriduals during a long succession
" of generations."

82 'Anthropological Review, Jan. 1866, p. xxi. D1. Shaxpe also says, with respect to India ("Man a Special Creation," 1873, p. 118), that "it has been noticed by some medi" cal officers that Europeans with "light hair and florid complexions "suffer less from diseases of tropical " countries than persons with dark "hair and sallow complexions; " and, so far as I know, there ap"pear to be good grounds for this "remark." On the other hand, Mr. Heddle, of Sierra Leone "who " has had more clerks killed under" "him than any other man," by the climate of the West Africnn Coast (W. Reade, 'African Sketch Book,' vol. ii. p. 522), holds a directly opposite view, as does Capt. Burton. 63 'Man a Speciai Creation,' 1873 p. 119. 
although larger than freckles, and that these patches were never affected by sun-burning, whilst the white parts of his skiu huve on several occasions becn much inflamed and blistered. With the lower animals there is, also, a constitutional difference in liability to the action of the sun between those parts of the skin clothed with white hair and other parts. ${ }^{64}$ Whether the saving of the skin from being thus burnt is of sufficient importance to account for a dark tint having been gradually acquired by man through natural selection, I am unable to judge. If it. be so, we should have to assume that the natives of tropical America have lived there for a much shorter time than the negroes in Africa, or the Papuans in the southern parts of the Malay archipelago, just as the lighter-coloured Hiudoos have resided in India for a shorter time than the darker aborigines of the central and southern parts of the peninsula.

Although with our present knowledge we cannot account for the differences of colour in the races of man, through any advantage thus gained, or from the direct action of climate; yet we must not quite ignore the latter agency, for there is good reason to believe that some inberited effect is thus produced..$^{6.5}$

We have seen in the second chapter that the conditions of life affect the development of the bodily frame in a direct manner, and that the effects are transmitted. Thus, as is generally admitted, the European settlers in the United States undergo a slight but extraordinarily rapid change of appearance. Their bodies and limbs become elongated; and I hear from Col. Bernys that during the late war in the United States, good evidence was afforded of this fact by the ridiculous apnearance presented by the German regiments, when dressed in ready-made clothes manufactured for the American market, and which were much too long for the men in erery way. There is, also, a consiclerable body of evidence sherwing that in the Southern States the house-slaves of the third generation present a markedly different appearance from the field-slaves. ${ }^{66}$

61 Variation of Animals and Plants under Domestication,' vol. ii. pp. 336, 337.

is See, for instance, Quatrefages ('Revue des Cours Scientifiques, Oct. 10, 1868, p. 724) on the effects of residence in Abyssinia and Arabia, and other analogous cases. Dr. holle ('Der Mensch, seine Abstammung,' \&c., 1865, 8. 99) states, on the authority of Khanikof, that the greater number of German families settled in Georgia, have acquired in the course of two generations dark hair and eyes. Mr. D. Forbes informs me that the Quichuas in the Andes vary greatly in colour, according to the position of the valleys inhabited by them.

66 Harlan, 'Medical Researches,' p. 532. Quatrefages ('Unité de I'Espèce Humaine,' 1861, p. 128) has collected much evidence on thi head. 
If, howevor, we look to the races of man as distributed over the world, we must infer that their characteristic differences cannot be accounted for by the direct action of different conuitions of life, eren after exposure to them for an enormous period of time. 'The Esquimaux lire exclusively on animal food; they are clothed in thick fur, and are exposed to intense cold and to 3)rolonged darkness; yet they do not differ in any extreme degrce from the inhalitants of Southern China, who live entirely on regetable food, and are exposed almost naked to a hot, glaring elimate. The unclothed Fuecians live on the marine productions of their inhospitable shores; the Botocudos of Brazil wander about the hot forests of the interior and live chiefly on vegetilble productions; jet these tribes resemble each other so closely that the Fuegians on board the "Beagle" were mistaken by some Brazilians for Butocudos. The Botocudos again, as well as the other inhabitants of tropical America, are wholly fifferent from the Negroes who inhabit the opposite shores of the Atlantic, are exposed to a near!y similar climate, and follow nearly the same habits of life.

Nor can the differences between the races of man be accounted for by the inherited effects of the increased or decreased use of parts, except to a quite insignificant degree. Men who habitually live in canoes, may have their legs somerwhat stunted; those who inlabit lofty regions may have their chests enlarged; and those who constantly use certain sense-organs may have the cavities in which they are lodged somewhat increased in size, and their features consequently a little modified. With civilised nations, the redueed size of the jaws from lessened use-the habitual play of different muscles serving to express different cmotions-and the increased size of the hrain from greater intellectual activity, have together produced a considerable effect on their gencral appearance when compared with savages. ${ }^{67}$ Increased bodily stature, without any correspondingr increase in the size of the brain, may (judging from the proviously adduced case of rabbits), have given to some races an alongated skull of the dolichocephalic type.

Lastly, the little-understood principle of correlated development has sometimes come into action, as in the case of great musculiu development and strongly projecting supra-orbital ridges. The colour of the skin and hair are plainly correlated, as is the texture of the hair with its colour in the Mandans of North America. ${ }^{68}$ The colour also of the skin, and the odour

o: See Prof. Schaafthansen, transsit. in 'Anthropological Review, Oc:. 1868, p. 429 .
68 Mr. Catlin states ('N. American Indians,' 3rd edit. 1842, vol. I, p. 49) that in the whole tribe of 
emitted by it, are likewise in some manner comnected. With the breeds of sheep the number of hairs within a given space and the number of the excretory pores are related. ${ }^{69}$ If we may judge from the analogy of our domesticated animals, many modifications of structure in man probably come under this principle of correlated development.

Te hare now secn that the external characteristic differences between the races of man cannot be accounted for in a satisfactory manner by the direct action of the conditions of life, nor by the effects of the continued use of parts, nor through the principle of correlation. We are therefore led to inquirc. whether slight individual differences, to which man is emi. nently liable, may not have been preserved and augmented during a long series of generations through natural selection. But here we are at once met by the objection that beneficial variations alone can be thus preserved; and as far as we are enabled to judge, although always liable to crr on this head, none of the differences between the races of man are of any direct or special service to him. The intellectual and moral or social facultics must of course be excepted from this remark. The great variability of all the external differences between the races of man, likewise indicates that they cannot be of much importance; for if important, they would long ago have been either fixed and preserved, or eliminated. In this respect man resembles those forms, called by naturalists protean or polymorphic, which have remained extremely variable, owing, as it seems, to such variations being of an indifferent nature, and to their laving thus escaped the action of natural selection.

We have thus far been baffled in all our attempts to account for the differences betwcen the races of man; but there remains one important agency, namely Sexual Selection, which appears to have acted powerfully on man, as on many other animals. I do not intend to assert that sexual selection will account for all the differences between the races. An unexplained residuum is left, about which $\pi$ e can only say, in our imnorance, that as individuals are continually boln. with, for instance, heads a little rounder or narrower, and with noses a little longer or shorter, such slight differences might become fixed and uniform, if the

the Mandans, about one in ten or twelve of the members, of all ages and both sexes, have bright silvery grey hair, which is hereditary. Now this hail is as coarse and barsh as that of a horse's mane, whilst the bair of other colours is fine and soft.

69 Un the odour of the skin, Godron, 'Sur l'Espece,' tom. ii. 1). 217. On the pores in the skin, Di. Wilckens, "Die Aufgabeu der Landwirth. Zootechnik,' 1869, s. ?. 
unknown agencies which induced them were to act in a more constant manner, aided ly long-continued intererossing. Such variations come under the provisional class, alluded to in our secoud chapter, which for the want of a better term are often called spontancous. Nor do I pretend that the effects of sexual selection can be indicated with scicntific precision; but it can be shewn that it would be an iuexplicable fact if man had not been modified by this agency, which appears to have acted powerfully on innumerable animals. It can further be shewn that the differences between the races of man, as in colour, hairiness, form of features, \&c., are of a kind which might have been expected to come under the influence of sexual selection. But in order to treat this subject properly, I have found it necessary to juss the whole animal kingdom in review. I have therefore leroted to it the Second Part of this work. It the close I shall return to man, and, after attempting to shew how far he has been modified through sexual selection, will give a brief summary of the chapters in this First Part.

\section{Nute or the Resemblances and Differences in the Structure and tue Developjext of the Brain in Man and Apes. Br Professor HuXLeY, F.R.S.}

The controversy respecting the nature and the extent of the differences in the structure of the brain in man and the apes, which arose some fifteen years ago, has not yet come to an eni, though the subject matter of the dispute is, at present, totally different. from what it was formerly. It was originally asserted and re-asserted, with singular pertinaeity, that the brain of all the apes, even the highest, differs from that of man, in the absence of such conspicuous structures as the posterior lobes of the cerebral hemispheres, with the posterior cornu of the lateral ventricle and the hippocampus minor, contained in those lobes, which are so obvious in man.

But the truth that the threo structures in question are as well developed in apes' as in human brains, or even better'; and that it is characteristic of all the Primates (if we exclude the Lemurs) to have these parts well developed, stands at present on as secure a basis as any propo-ition in comparitive anatomy. Morcover, it is almitted by every cne of the long series of anatomists who, of late years, have paid special attention to the arrangement of the complicated sulci and gyri which "ppear upon! the surfice of the corebral hemispheres in man and the higher ape:that they are disposed after the very same pattern in him, as in them. Fvery principal gyrus and sulcus of a chimpanzee's brain is clearly represented in that of a man, so that the terminology which applies to the one answers for the other. On this point there is no difference of opinion. Some years since, Professor Bischoff published a memoir ${ }^{\text {i0 }}$ on the cerebral convolutions of man and apes; and as the purpose of my learned colleague was certainly not to diminish the value of the

70 'Die G:osshira-Winclungen des Menschen;' 'Abhandlunger der K Bayerischen Akaderie:' Bl, x., 1868. 
differences between apes and men in this respect, I am grlarl to make a ritation from him.

"That the apes, and especially the orang, chimpanzee am erorillit, " come very ciose to man in their organisation, mucle nearer than to an! y "other animal, is a well known fact, disputed l:y nobody. Lookines at " the matter from the point of view of ormanisation alone, no one probulsly "would ever Lave disputer the view of Linnaus, that man should his "placed, merely as a neculiar speries, at the he aul of the mammalia and or "those apes. Both shew, in al! thcir orgitns, so close an aftinity, that tho " most exact anatomical investigation is needed in order to demonstrato "those differences which really exist. So it is with the brains. 'The " brairs of man, the orang, the chimpranzee, the gispilla, in spite of all "the important differences which they present, come very close to une "another" (1. c. p. 101).

There remains, then, no dispute as to the resemblance in fundamental characters, between the api"s brain and man's; nor any as to the wonderfully close similnrity between the chimpanzee, oring and man, in even the details of the arrangement of the gyri and sulci of the cerebral hemispheres. Nor, turning to the differences between the brains ot the highest apes and that of man, is there any serious question as tc the nature and extent of these differences. It is admitted that the man's cerebril hemispheres are absolutely and relatively larier than those of the orang and chimpanzee; that his frontall lubes cure less cxcaviterl by the upward protrusion of the roof of the orbits; that his fyri and mulei are, is a rule, less symmetrically disposed, aml present in crreater num'x:r of secondary plications. And it is admitted that, as a rule, in man, the: temporo-occipital or "external perpendicular" fissure, which is usial!!y so strongly marked a feature of the ape's brain is but faintly markin. But it is also clear, that none of theso differences constitutes $\Omega$ sharp demareation between the man's and the ape's brain. In respect to thr: external perpendicular fissure of (iratiulet, in the human lrain, for instance, Professor Turner romarks:71

"In some brains it appenrs simply as an indentation of the margin of " the hemisphere, but, in others, it extends for some listinc: more or less "transversely outwarls. I saw it in the right hemisphere of a female "brain pass more than two inches outwarls; and in another specimen, "also the right hemisphere, it proceenled for four-tenths of an inch ont"wards, and then extended downwards, as far as the lower margin of the " outer surface of the hemisphere. The imperfect definition of this fissure "in the majority of human brains, as enmpared with its remarkable dis"tinctness in the brain of most Quadrumana, is owing to the prosence, in "the former, of certain superficial, well marked, secondary convolutions "which hridge it over and connect the parietal with the occipital lobe. "The closer the first of these bridring gyri lies to the Inn ritudinal "fissure, the shorter is the exteruil paricto-oceipital fissure." (1. c. p. 12.; 'The obliteration of the cxternal perpendicular fissure of Gritiolet, therefore, is not a constint character of the human brain. On the other hand, its full development is not a coustaut character of the hivher apo's brain. For, in the chimpanzee, the more or less extensive oblir ar: tion of the external perpendicular sulcus by " bridging convolutions," (nu ons sicle or tha uther, has been noted over and over again by Prot

" Corvulutions of the Human Cerebrum Topographicaly Consilered. 1866, p. 12. 
Rolleston, Mr. Marshall, M. Brora and Professor Turner. At thu" conclusiun of a special paper un this subject the latter writes: ${ }^{72}$

.6 The three specimens of the train of a chimpanzee just describerl. "prove, that the generalisation which Gratiodet has attminted to draw of "the complete absence of the first ennerting convolution and the

" concralment of the second, as essentially charnctristie fiatues in the

"brain of this animal, is by uo means univer-ally applicable. In only one "spreimen did the bratu, in these particulars, follow the law which

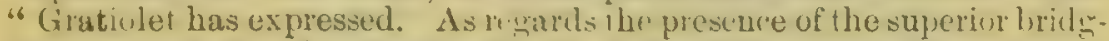

" in convolution, I am inclimed to think lhat it has existed in nne he mi.

"sphere, at least, in a majority of th. brainsut this animal which have. m,

"to this time, he en tigured or clescribul. Ihe superticial position of the.

" second bridering convolution is evidently less frequent, and has as yet,

"I helreve, only been seen in the lrain 1) recorled in this communi-

" cation. 'The asymmetrical arrangement in the cunvolutions of the

" two himispheres, whirh previous observers have reforred to in thein

"descriptions is also well illustrated in these specinens." (p). 8, 9.)

Even wero the presence of the temporo-occipital, or external perpendicular, sulcus a mark of distinetion hetween the higher apes and man, the value of such a distinctive character won!d be icudered vere doubtful by the strueture of the brain in the Platyrhine npes. In fuct while the temporonecipital is one of the most constant of sulei in the Calarhine, or ()ld World, apes, it is nerer very strongly developed in thr. New World apes; it is absent in the smaller Platyrhini; rudimentiry in l'ithecia $;{ }^{3}$ and mue or less obliterated by bridging convolutions in Ateles.

A rhararter" which is thus rariable within the limits of a single gron! can have no great taxonomic value.

It is further established, that the degree of asymmetry of the convolntion of the two sides in the human brain is subject to much individuis variation; ancl that, in those individuals of the Bushman race who has.. been examined, the gyri and sulci of the two hemispheres are considerably less complicated and more symmotriral than in the leuropeat brain, while, in some individnals of the ehmmonee, their enmplexity and asymmetry become notable. 'This is particularly the cass in thi" brain of a young male chimpanzes tigured by ML. Broca. ( Lindr. des Primates,' p. 165, fig. 11.)

A watin, as respects the question of absolute size, it is establisherl that the difterence lowween the larest amb the smallest healthy lumank brain is greater than the difference between the smallest healthy human brain and the largest chimpanzee's or orang's brain.

Moreorer, there is one circumstince in which the orang's nnd climpanzee's brains resenuble man's, but in which they diffir from the lnwer. apes, and thit is the presence of two corpora candicantia-tls. eymomorpha having but one.

In view of these facts I lo not liesitute in this year 1874, to rupurit

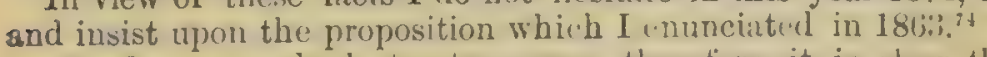

"So far as cerebral structure goes, therefore, it is clear that mair

72 Notes more especially on the bridging convolutions in the Brain of the Chimpanzee, 'Proceedings of the Royal Society of Edin irgin,' $1865-6$
${ }^{73}$ Flower" 'On the Anaturiry of Pithecia Monachus,' 'Proceedings of the Zoological Society,' 1862.

¿' 'Mau's Place in Nature,' p. 102. 
" diff urs less from the chimmuzee or the orang, than these do even "from the moukeys, and cnat the difference between the brain of the "chimpanzee and of min is almost insignificant, when compared with "that between the chimpunzee brain and that of a Lemur."

In the paper to which I have rufurred, Prulessor Bischoff does not deny the second part of this statement, but he first makes the irrelevant rewark that it is not wouderful if the brains of an orang and a Lemur are very ditfirent; and secondly, goes on to assert that, "If we succes- sively compare the brain of a man with that of an oranc; the brain of "this witlı that of a chimpanzee; of this with that of a yorilla, mind so "on of" a Hylobates, Semnopithecus, Cynocephalus, Cercopjithecus. Mucacus, "Cebus, eallithrix, Lemur, stenops, Hapale, we shall not meet with a "greater, or even as great a, break in the degree of devclopment of the "convolutions, as we find between the brain of a man and that of an "orang or chimpatize."

'To whirh I reply, firstly, that whether this assertion be true or false, it has nothing whatever to do with the proposition enunciated in 'Man's Place in Nature,' which refers not to the development of the convolutions alone, but to the structure of the whole brain. It Professor Bischoff had taken the trouble to refer to p. 96 of the work he criticises, in fact, ho would have found the following passage: "And it is a "remarkable circumstance that though, so fir as our present linow"ledge extends, there is one true structural break in the series of forms "of Simian brains, this hiatus does not lie between man and the "manlike apes, but between the lower and the lowest Simians, or in "other words, between the Old and New World npes and monkeys and "the Lemars. Every Lemur which has yet been examined, in fact, "his its cerebellum partially visible from above; and its posterior lobe, "with the contained posterior cornu and hippocampus minor, more or" "less rudimentary. Every marmoset, American monkey, Old World "monkey, baboon, or manlike ape, on the contrary, has iis cerebellum "entirely hidulen, posteriorly, by the cerebral lobes, and possesses a "large posterior cornu with a well-developed hippocampus minor."

This statement was a strictly accurate account of what was known when it was made; and it does not appear to me to be more than apparently weakened by the subsequent discovery of the relatively omall development of tho posterior lubes in the Siamang and in the Howling monkcy. Notwithstancling the excentional brevity of the posterior lobes in these two species, no one will pretend that their brains, in the slightest degree, approach those of the Lemurs. And If, instead of putting Hapale out of its natural plice, as Professor Bischoti most unaccountably does, wo write the series of animals he has chosen to mention as follows: Homo, Pithecus, Troglorlytes, Hylobates, Semnopithecus, Cynocephalus, Cercopithecus, Macacns, Cebus, Callithrix, Hapale, Lemur, Stensps, I venture to reafiirm that the great break in this series lies between Hapale and Lemur, and that this break is considerably greater than that between any other tro terms of that series. Professor Bischoff ignores the fact that lnng before he wrote, Gratiolet had suggested tho separation of the Lemurs from the nther Primates on the very ground of the difference in their cerebral characters; and that Professor Flower had made the following observations in the course of his description of the brain of the Javan Loris '5

is 'Transactions of the Zoological Societv', rol. $\nabla .1862$. 
"And it is espevially remarkable that, in the development of the" "posterior lobes, there is no approximation to the Lenurine, shout "hemisphered, brain, in those monkeys which are communly sujposer? " to approach this family in other respects, viz., the lower members of "the Platyrhine group."

So far as the structure of tho adult brain is concerned, then, the very cunsiderable additions to our knowledge, which have been made by the researches of so many investigators, during the past ten years, fully justify the statement which I made in 1863. But it tias hecan silil that, admitting the similarity between the adult brains of liaul and apes, they are novertheless, in reality, widely different, becauso the exhibit fundanental differences in the mode of their development. Nis one would be more reuly than I to admit the force of this argument, if such fuulamental differences of derelopment really exist. But I deny that they do exist. On tho contrary, there is a fundamentul agrecment in the development of the brain in men and apes.

Gratiolet originated the statement that there is a fundamental elifference in the development of the brains of apes and that of manconsistin; is this; that, in the apes, the sulci which first make their a)pearance aro situated on the posterior region of the cerebral hemispheres. while, in tho human fotus, the sulci first become visible on the frontal lobes. ${ }^{16}$

This general statement is based upon two observations, the one of a Giblon almost ready to be born, in which the posterior gyri were "well "developorl," while those of the frontal lobes were " hardly indicated "7 (1. c. p. $: 9)$ ), and the other of a human foetus at the 22 nd or 23 rd week of uterorestation, in which Gratiolet notes that the insula was uncovercl, but that nevertheless " des incisures sèment le lobe antirieur, " une scissure peu profonde indique la separation du lobe occipital, tres-

" "Chez tous les singes, les plis "pustérieurs se développent les pre" miers; les plis anterieurs se "développent plus tard, aussi la

"vertebre occipitale et la pariétale

"sont-elles relatirement très-grandes

" chez le fortus. L'Homme présente

46 une exception remarquable quant

"a l'époque de l'apparition des plis

"frontaux, qui sont les premier's

"indiqués; mais le développement

" général du lobe frontal, envisagé

"seulement par rapport a son

"volume, suit les mêmes lois que dans

" les singes:" Gratiolet, "Mémoire sur les plis cérébraux de l'Homme et des Primates,' p. 39, Tab. iv. fig. 3 .

${ }_{77}$ Gratiolet's words are (1. c. p. 39): "Dans le fotus dont il s'agit " les plis cérébraux postérieurs sont "bien développés, tandis que les "plis du lobe frontal sont 2 peine "indiqués." The figure, however (P..iv. fig. 3), shews the fissure of
Rolando, and one of the frontal sulci, plaixly enough. Nevertheless, M. Alix, in his 'Notice sul' les travaux anthropologiques de Gratiolet 'Mém. de la 'Société d'Anthropologie de Paris,' 1868, page 32.), writes thus: "Gratiolet a eu entre "les mains le cerveau d'un fœetus de "Gibbon, singe éminemment su"périeur, et tellement rapproché de "l'orang, que des naturalistes très"compétents l'ont rangé parmi les "anthropoides. M. Huxley, par ex" emple, n'hésite pas sur ce point. " Eh bien, c'est sur le cerveau d'un "fœtus de Gibbon que Gratiolet a "vu les circonvolutions du lobe tem"poro-sphénoidal déjà développécs "lorsqu'il n'existent pas encore de plis "sur le lobe frontal. Il était donc "bien autorisé à dire que, clez "l'homme les circonvolutions appa"raissent d' $\alpha$ en $\omega$, tandis que chez "les singes elles se développent "d'w en $\alpha$." 
" reiluit, d'ailleurs dies cette époque. Le reste de la surface cérebrale "est encoro absolurzent lisse."

'Three views of this brain are giren in Plat II. figs, 1, 2, 3, of tho work cited, shewing the upper, lateral and inferior views of the hem:spheres, but not the inner view. It is worthy of note that the figuro by no meuns bears out Gratilet is description, inasmuch as the fissure (interotemporal) on the posterior half of the fare of the bemisphere. is more marked than any of those vaguely indicated in the anterior half. If the figure is correct it in no way justities Gratiolet's conclusion : " Il y a donc entre ces cerveaux [those of a Callithrix and of a Cxibbn] ot " celui du foetus humain une dithérence fondamental. Chez celui-ci, long"temps avant qu" les plis temporaux apparaissent, les plis frontaux "essuyent d'exister."

Since Gratiolets time, however, the development of the grvi and sulci of the brain lats been marle the subject of renewerl investigntion by Schmidt, Bischofí, Pansch, ${ }^{i B}$ and more particularly by Ecker, ${ }^{79}$ whose work is not only the latest, but by tar the most complete, memoir on the subject.

The final results of their inquirifs may be summed up as follows:-

1. In the human foetus, the sylvian tissure is formed in the course of the third month of uterogestation. In this, and in the fourth month, the cerebral hemispheres are smooth and rounded (with the exception of the sylvian depression), and they project backwards far beyoud the cerebellum.

2. The sulei, properly so called, begin to appear in the interval between the end of the fourth and the becrinning of the sixth month of foctal life, but Ecker is careful to point out that, not mily the time, but the order, of their appearance is subject tn considirable indivilual variation. In no ease, however, are either the fruntal or the temporil sulci the carliest.

The first which appears, in fact, lies on the iuner face of the hemisphere (whence doubtless Gratiolet, who roes not seem to have examined that face in his foctus, overlonked it), and is either the internal perpendicular (occipito-parietel), or the cal'arine sulcus, these two heing close together and eventually running into one imother. As a rule the occipito-parietal is the earlier of the two.

3. At the latter part of this period, another sulcus, the "posterio. parictal," or "Fissure of Rolando" is developed, and it is followed, in the course of the sixth mmuth, by the other priucipal sulei of the fiontal, parietal, temponal and necipital lobes. There is, however, no clear evilence that me of these constantly appears before the other and it is remarkable that, in the brain at the periol deseribed and figured by Ecker (1 c. 1. $212-13$, Taf. II. figs. 1, 2, 3. 4), the anterotemporal sulcus (sciswure purallele) so characteristic ot the ape's brail, is as well, if not better developer than the fissure of Rolando, and is much more marked than the proper frontal sulci.

Taking the facts as they now stand, it appears to me that the order of the apjearance of the sulci and gyri in the fotal human brain is in perfect harmeny with the general loctrine of evolution, and with tho

78 'Ueber dis typische Anorinung der Furchen und Windungen anf den Grosshira-Hemisf..̈̈red des Menschen und der Atren.' 'Archiv Gur Anthropo!ogie,' iii., 1868.
79 ، Zur Entwickelungs Geschichte der Furchen und Windungen der Grosshirn-Hemisphären im Fœtu des Menschon.' 'Archiv für Anthro. molorgie, iii., 1868. 
view that man has becu evolved from some ape-like form; thourh thero can be no doubt thit that form was, in many respects, difierent from uny nember of the Primates now living.

Fon Baer taught us, half a century ago, that, in the comrse of thei (1. velopment, alli.d animals put on, at first, the characters of the greater groups to which they belong, and, by degrees, ussume those which restrict them within the limits of their family, genus, and species; and he proved, at the sime time, that no developmental stage of a highes inimal is precisely similar to the adult comblion of any lower animal. It is quite correct to say that a frog passes through the condition of a fish, inasnuch as at nue period of its life the tadpole bas all the chaactirs of a tish, aud, if it went no further, would have to be grouped ann wir lishes. liut it is equally true that a tulpole is very different from any known fish.

In like manner, the brain of a human fotus, at the fifth month, may correctly he sind to be, not only the brain of an ape, but that of an Aretupiluecine or marmoset-like ape; for its hemispheres, with their great posteriorlolster, and with no sulci but the sylvian and the caleurine, mesent the characteristics found only in the group of the Arctopithecin Primates. But it is equally true, as Gratiolet remarks, thant, in its widely (1) n sylvian fissure, it liffers from the brain of any actual marmoset. No Noubt it would be much more similar to the braiu of an advineed fatus of a marmoset. But we know nothing whatever of the development of the brain in the marmosets. In the Platyrhini fmper, th: only olservation with which I an acquanted is due to I'ansch, who found in the brain of a fotal Cebus Apella, in audition to the sylvian fissure and the deep calcarine fissure, only a very shallow suterotempornl fissure (scissure parallèle of Gratiolet.)

Now this fact, tilien together with the cirrumstance that the antrirotemporal sulcus is present in such Platyrhini as the Saimiri, which prevent mere traces of sulci on the anterior half of the exterine of the cerehral hemi-pheres, or none at all, muloubtedly, so fur as it goes, affirrls fair ovidence in favour of Gratiolet's hypothesis, that the posterior sulci appear before the anterinr, in the brains of the I'lutyrlini. But, it by no means fullows, that the rule which may hold grond for the Ilatyrhini extends to the Cuturhini. We have no infirmation whater respecting the develnpment of the hrain in the ('ynumorpha; aul, as regards the Anthroyomorpha, nothing but the account of the brain of the Gibbon, near birth, alrendy referred to. At the present monent, there is not a shuduw of evidence to shew that the sulci of $n$ chimpanzec's, or orang's, brain lo not apprear in the salmo order as a man's.

Gratiolet opens his preface with the aphorism. "Il est langereux " clans les sciences de conclure trop vitc." I fear he must have forgoiten this sound maxim by the time he had reached the discussion of the differences between men and apes, in the boily of his work. Nc loubt, the excellent author of one of the most remarkable contributions to the just unlerstanding of the mammalian brain which has ever bcen niale, would have been the first to admit the insufficiency of his data hal he lived to profit by the advance of inquiry. The misfortune is that his conclusions have been employed by persons incompetent to appreciate their foundation, as arguments in favour of obscurantism. ${ }^{80}$

${ }^{80}$ For example, M. l'A bbé Lecomte in his terrible pamphlet 'Le Dar- winisme et l'origine de l'Homme. 1873. 
But it is important to remark that, whether Gratiolet was right or wrong in his hypothesis respecting the relative order of appenrance of the temporal and frontal sulci, tho fact remains; that, before either temporil or frontal sulci, appear, the foetal brain of man presents characters which are found only in the lowest group of the Primates (leaviig out the Lemurs); and that this is exactly what we should expect to be the case, if man has resulted from the gradual modifieattion of the same form as thet from which the other I'rinates have spi:ang. 


\section{PART II.}

\section{SEXUAL SELECTION.}

\section{CHAPTER VIII. \\ rRINCIPles of Sexual Selection.}

Seconjiry sexual characters-Sexual selection-Manner of action-Ezcess of males-Polygamy-The male alone generally modified through sexual selection-Liagerness of the male-Variability of the maleChoice exerted by the female-Sezual compared with natural selection - Inheritance, at corresponding periods of life, at corresponding seasons of the year, and as limited by sex-Relations between the several forms of inheritance-Causes why one sex and the young are not modified through sexual selection-Supplement on the proportional numbers or the two sexes throughout the animal kingdom-The proportion of the seres in relation to natural selection.

NiтH animals which have their sexes separated, the males necessarily differ from the females in their organs of reproduction; and these are the primary sexual characters. But the sexes often differ in what Hunter has called secondary sexual characters, which are not directly connected with the act of reproduction; for instance, the male possesses certain organs of sense or locomotion, of which the female is quite destitute, or has them more himhly-developed, in order that he may readily find or reach her; or again the male has special organs of prehension for: holding her securely. These latter organs, of infinitely diversified kinds, graduate into those which aro commonly ranked as j)rimary, and in some cases can hardly be distinguished from them; we see instances of this in the complex appendages at the apex of the abdomen in male insects. Unless indeed we confine the term "primary" to the reproductive glands, it is scarcely possible to decide which ought to be called primary and which secondary.

The female often differs from the male in having organs for the nourishment or protection of her young, such as the mammary 
glands of mammals, and the abdominal sacks of the marsupials. In some fer cases also the male possesses similar organs, which are wanting in the female, such as the receptacles for the ova in certain male fishes, and those temporarily developed in certain male frogs. The females of most bees are provided with a special apparatus for collecting and carrying pollen, and their uvipositor is modificd into a sting for the defence of the larvæ and the community. Miany similar cases could be given, but they do not here concern us. There are, however, other sexual differences quite unconnected with the primary reproductive organs, and it with is these that wo are more especially concerned - such as the greater size, strength, and puguacity of the male, his weapons of offence or means of defence against rivals, his gaudy colouring and various ornaments, his power of song, and other such characters.

Besides the primary and secondary sexual differences, such as the foregoing, the males and females of some animals differ in : tructures related to different halits of life, and not at all, or unly indirectly, to the reproductive functions. Thus the females uf certain flics (Culicirlæ and Tabanidæ) are blood-suckers, whilst the males, living on flowers, hare mouths destitute of mandibles. ${ }^{1}$ The males of certain moths and of some crustaceans ( .g. Tanais) have imperfect, closed mouths, and cannot feed. J'he complemental males of certain Cirripedes live like epiphytic plants either on the female or the hermaphrodite form, and are clestitute of a mouth and of prehensile limbs. In these cases it is the male which has been modified, and has lost certain important organs, which the females yossess. In other cases it is the female which has lost such parts; for instance, the fomale glow-worm is destitute of wings, as also are many female moths, some of which never leave their cocoons. Many female parasitic crustaccans have lost their natatory legs. In some weevil-beetles (Curculionidæ) there is a great difference betreen the male and female in the length of the rostrum or snout; ${ }^{2}$ but the meaning of this and of many analogous differences, is not at all understood. 1)ifferences of structure between the two sexes in relation to (iifferent habits of life are generally confined to the lower animals; but with some few birds the beak of the male differs from that of the female. In the Huia of New Zealand the rlifference is wonderfully great, and we hear from Dr. Buller

1 Westrood, 'Modern Class. of Insects,' vol. ii. 1840 , p. 541. For the statement about Tanais, mentioned below, I am indebted t.o Fritz Nuiller.
2 Kirby and Spence, 'Introduction to Entomology, rol. iii. 1826, p. 309.

" 'Birds of New Tealand, 1872 p. 66 . 
that the male uses his strong beak in chiselling the larvæ of insects out of decayed wood, whilst the female probes the solter parts with her far longer, much curved and pliant beak: and thus they mutually aid each other. In most cases, differences of structure between the sexes are more or less directly connecter? with the propagation of the species: thus a female, which has to nourish a multitude of ova, requires more food than the male, and consequently requires special means for procuring it. A male animal, which lives for a very short time, might lose its organs for procuring food through disuse, without detriment; but he would retain his locomotire organs in a perfect state, so that he might reach the female. The female, on the other hand, might safely lose her organs for flying, swimming, or walking, if she gradually acquired habits which rendered such powers useless.

We are, however, here concerned only with sexual selection. This depends on the advantage which certain individuals have over others of the same sex and species solely in respect of reproduction. When, as in the cases above mentioned, the trio sc:xes differ in structure in relation to different habits of liie, they have no doubt been modified through natural selection, and $1, y$ inheritance limited to one and the same sex. So again the primary sexual organs, and those for nourishing or protecting the young, come under the same influence; for those individuals which gunerated or nourished their offspring best, would leave, coeteris vuribus, the greatest number to inherit their superiority; whilst those which generated or nourished their offspring badly, would leave but fer to inherit their weaker powers. As the male has to find the formale, he requires organs of sense and locomotion, . 'ut if these organs are nccessary for the other purposes of life, cad in generally the case, they will have been developed through natural selection. When the male has found the female, he sometimes absolutely requires prehensile organs to hold her; thus Dr. Wallace informs me that the males of certain moths cannot unite with the females if their tarsi or feet are broken. 'The males of many oceanic crustaceans, when adult, have their legs and antennæ modified in an extraordinary manner for the prehension of the female; hence we may suspect that it is because these animals are washed about by the wares of the open sea, that they require these organs in order to propagate their kind, and if so, their development has been the result of ordinary or natural selection. Some animals extremely low in the scale have been modified for this same purpose; thus the males of certain parasitic wurms, when fully grown, have the lower surface of the terminal part of their bodies rougheried 
like a rasp, and with this they coil round and permanently hold the females. ${ }^{4}$

When the two scres follow exactiy the same nabits of life, and the male has the sensory or locomotire organs more lighly developed than those of the female, it may he that the perfection of these is indispensable to the male for finding the female; int in the vast majority of cases, they serve only to give one male an advantage over another, for with sufficient time, the less wellendowed males would succeed in pairing with the females; and judging from the structure of the female, they would be in all other respects equally well adapted for their ordinary habits of life. Since in such cases the males have acquired their present structure, not from being better fitted to survive in the struggle for existence, but from having gained an advantage over other males, and from having transmitted this advantage to their male offspring alone, sexual selection must here have come into action. It was the importance of this distinction which led me to designate this form of selection as Sexual Selection. So again, if the chief service rendered to the male by his prehensile organs is to prevent the escape of the female before the arrival of other males, or when assaulted by them, these organs will have been perfected through sexual selection, that is by the advantage acquired by certain individuals over their rivals. But in most cases of this kind it is impossible to distinguish between the effects of natural and sexual selection. Whole chapters conld be filled with details on the differences between the sexes in their sensory, locomotive, and prehensile organs. As, however, these structures are not more interesting than others adapted for the ordinary purposes of life I shall pass them over almost entirely, giving only a fow instances under each class.

There are many other structures and instincts which must have been developed through sexual selection-such as the weapons of offence and the means of defence of the males for inghting with and driving away their rivals-their courage and pugnacity-their various ornaments-their contrivances for pro-

4 M. Perrier advances this case ('Revue Scientifique,' Feb. 1, 1873, p. 865 ) as one fiatal to the belief in sexual selection, inasmuch as he spnposes that I attribute all the differences between the sexes to sexual selection. This distinguished aaturalist, therefore, like so many other Frenchmen, has not taken the crouble to understand even the first principles of sexual selection. An Doglish naturiast insists that the claspers of certain male animals could not have been developed through the choice of the female? Had I not met with this remark, I should not have thought it possible for any one to bave read this chapter and to hare imagined that I maintain that the choice of the female had anything to do with the development of the preheusile organs in the male. 
ducing vocal or instrumental music-and their glands for emitting odours, most of theso latter structures serving only to allure or excite the female. It is clear that these characters are the result of sexual and not of ordinary selection, since unarmed, unornamented, or unattractive males would succeed equally well in the battle for life and in leaving a numerous progeny, but for the presence of better endowed males. We may infer that this would be the case, because the females, which are unarmed and mnornamented, are able to survive and procreate their kind. sccondary sexual characters of the kind just referred to, will be fully discussed in the following chapters, as being in many respects interesting, but especially as depending on the will, choice, and rivalry or the individuals of either sex. When we hehold two males fighting for the possession of the female, or sereral male birds displaying their gorgeous plumage, and performing strange antics before an assembled body of femoles, we caunot doubt that, though led by instinct, they know what they are about, and consciously exert their mental and bodily powers.

Just as man can improve the breed of his game-cocks by the selection of those birds which are victorious in the cockpit, so it appears that the strongest and most vigcrous males, or those provided with the best weapons, have prevailed under nature, and have led to the improvement of the natural breed or species. A slight degree of variability leading to some advantage, however slight, in reiterated deadly contests would suffice for the work of sexual selection; and it is certain that secondary sexual characters are eminently variable. Just as man can give beauty, according to his standard of taste, to his male poultry, or more strictly can modify the beauty originally acquired by the parent species, can give to tho Sebright bantam a new and elegant j'lumage, an erect and peculiar carriage-so it appears that female birds in a state of nature, have by a long selection of the more attractive males, added to their beauty or other attractive qualities. No doubt this implies powers of discrimination and taste on the part of the female which will at first appear extremely improbable; but by the facts to be adduced hereafter, I hope to be able to shew that the fomales actually have these powers. When, however, it is said that the lower animals have a sense of beauty, it must not be supposed that such sense is comparable with that of a cultivated man, with his multiform and complex associated ideas. A more just comparison would be between the taste for the beautiful in animals, and that in the lowest savages, who admire and deck themselves with any brilliant, glittering, or curious object.

From our ignorance on several points, the precise manner in 
which sexual selection acts is somewhat uncertain. Nerertheless if those naturalists who already believe in the mutability of species, will read tho following chapters, they will, I think, agrce with me, that scxual selection has played an important part in the history of the organic world. It is certain that amongst almost all animals there is a struggle between the males for the possession of the fomale. This fact is so notorious that it wonld be superiuous to give instances. Honce the females hare the opportunity of selecting one out of several males, on the suppysition that their mental capacity suffices for the excrtion of a choice. In many cases special circumstances tend to make the struggle between the males particularly serere. Thus the males of our migratory birds generally arrive at their places of breeding before the females, so that many males are realy to contend fir each female. I am informed by Mr. Jenner Weir, that the birlcatchers assert that this is invariably the case with the nightingale and blackcap, and with respect to the latter he can himself confirm the statement.

MIr. Swaysland of Brighton has been in the habit, during the last forty years, of catching our migratory bircls on their first arrival, and he has never known the females of any species to arrive before their males. During one spring he shot thirty-nine males of Ray's wagtail (Budytes Raii) before he saw a single female. Mr. Gould has ascertained by the dissection of tho-e snipes which arrive the first in this country, that the males cons before the females. And the like holds good with most of the migratory birds of the United States. ${ }^{5}$ The majority of the male salmon in our rivers, on coming up from the sea, are ready to breed before the females. So it appears to be with frogs and toads. Throughout the great class of inseets the males almost always are the first to emerge from the pupal state, so that they generally abound for a time before any females can be seen." The cause of this difference betwcen the males and females in their periods of arrival and maturity is sufficiently obvious. Those males which annually first migrated into any country, or which in the spring were first ready to breed, or were the most cager, would leave the largest number of offspring; and these

s.J. A. Allen, on the "Mammals nod Winter Birds of Florida,' Bull. Comp. Zoology, Harvard College, p. 268.

- Even with those plants in which the seres are separate, the male flowers are generally mature before the female. As first shewn $b_{j}$ C. K. Spreagel, many hormaph- rolite plants are dichogamous; that is, their male and female orgaus are not ready at the same time, so that they cannot be self-fertilised. Now in such flowers, the pollen is in general matured before the stigma. though there are exceptional cases in which the fomale organs are beforehard. 
would tend to inherit similar instincts ard constitutions. It must be borne in mind that it would hare been impossible to clange very materially the time of sexual maturity in the fimales, without at the same time interfering with the period of the production of the young-a period which must be determined by the seasons of the year. On the whole there can be no doubt that with almost all animals, in which the sexes are separate, there is a constantly recurrent struggle between the males for the possession of the females.

Our difficulty in regard to sexual selection lies in understanding how it is that the males which conquer other males, or those which prove the most attractive to the females, leave a greater number of offspring to inherit their superiority than their heaten and less attractive rivals. Unless this result does follow, the characters which gire to certain males an advantage over others, could not be perfected and augmented through sexual selection. When the scxes exist in exactly equal numbers, the morst-endowed males will (except where polygamy prevails), ultimately find females, and leave as many offspring, as well fitted for their general habits of life, as the best-endowed males. From various facts and considerations, I formerly inferred that with most animals, in which secondary sexual characters are well dercloped, the males considerably exceeded the females in number; but this is not by any means always true. If the males were to the females as two to one, or as three to two, or even in a somewhat lower ratio, the whole affair would be simple; for the better-armed or more attractive males would leave the largest number of offspring. Hut after investigating, as far as possible, the numerical proportion of the sexes, I do not helieve that any great inequality in number commonly exists. In most cases sexual selection appears to have been effective in the following manner.

Let us take any species, a bird for instance, and divide the fomales inhabiting a district into two equal bodies, the one consisting of the more vigorous and better-nourished individuals, and the other of the less vigorous and healthy. The former, there can be little doubt, would be ready to breed in the spring leefore the others; and this is the opinion of Mr. Jenner Weir, who has carefully attended to the halits of birds during niany yars. There can also be no doubt that the most vigorous, best-nourished and earliest breclers would on an average succeed in rearing the largest number of fine offspring. ${ }^{7}$ The males, as we have seen, are generally ready to breed before the

' Here is excellent evidence on the character of the offspring from

an experienced ornithologist. Mr. J. A. Allen, in speaking ('Mamnials 
females; the strongest, and with some species the best armed of the males, drivo away the weaker; and the former would then unite with tho more vigorous and better-nourished females, because they are the first to breed. ${ }^{8}$ Such vigorous pairs wonld surcly rear a larger number of offspring than the retarich females, which would be compelled to unite with the conquered and less powerful males, supposing the sexes to be numerically equal; and this is all that is wanted to add, in the course of successire generations, to the size, strength and courage of the males, or to improve their weapons.

But in very many cases the males which conçucr their rivals, do not obtain possession of the females, independently of the choice of the latter. The courtship of animals is by no means so simple and short an affair as might be thought. The females are most excited by, or prefer pairing with, the more ornamented males, or those which are the best songsters, or play the best antics; but it is obviously probable that they would at the same time prefer the more vigorous and lively males, and this has in some cases been confirmed by actual observation." Thus the more vigorous females, which are the first to breed, will have the choice of many males; and though they may not always select the strongest or best armed, they will select those which are vigorous and well armed, and in other respects the most attractive. Both sexes, therefore, of such early pairs would as abore explained, have an advantage over others in rearing offspring; and this apparently has sufficed during a long course of generations to add not only to the strength and fighting powers of the males, but likewise to their various ornaments or other attractions.

In the converse and much rarer case of the males selecting particular females, it is plain that those which were the most vigorous and had conquered others, would have the freest choice; and it is almost certain that they would select vigorous as well as attractive females. Such pairs would have an advan-

and Winter Birds of E. Florida, p. 229) of the later broods, after the accidental destruction of the first, says, that these "are found to be "smaller and paler-coloured than "those hatched earlier in the sea"son. In cases where several broods "are 1 taral each year, as a general " sile the birds of the earlier broods " seem in all respects the most per"fect and vigorous."

B Hermann Miller has come to t.! s same conclusion with respect to those female bees which are the first to emerge from the pupa each year. See his remarkable essay, 'Anwendung den Darwin'schen Lehre auf Bienen,' 'Verh. d. V. Jahrg.' xxix. p. 45.

With respect to poultry, I have. received information, hereafter to be given, to this effect. Lven with birds, such as pigeons, which pair for life, the female, as I hear fror Mr. Jenner Wcir, will desert her mate if he is injured or grows weak. 
tage in rearing offspring, more especially if the male had the power to defend the female during the pairing-season as occurs with some of the higher animals, or aided her in providing for the young. The same principles would apply if each sex preferred and selected certain individuals of the opposite scx; supposing tizat they selected not only the more attractive, but likewise the more vigorous individuals.

Numerical Propartion of the Two Sexes. -I hare remarked that sexual selection would be a simple affair if tho males were considerably more numerous than the females. Hence I was led to investigate, as far as I could, the proportions between the two sexes of as many animals as possible; but the materials are scanty. I will here give only a brief abstract of the results, retaining the details for a supplementary discussion, so as not to interfere with the course of my argument. Domesticated animals alone afford the means of ascertaining the proportional numbers at birth; but no records have been specially kept for this purpose. By indirect means, however, I have collected a considerable body of statistics, from which it appears that with most of our domestic animals the sexes aro nearly equal at birth. Thus 25,560 births of race-horses have been recorded during twenty-one years, and the male births were to the female births as 99.7 to 100 . In greyhounds the inequality is greater than with any other animal, for out of 6878 births during twelve years, the male births were to the femalo as $110 \cdot 1$ to 100 . It is, however, in some degree doubtful whether it is safe to infer that the proportion would be the samo under natural conditions as under domestication; for slight and unknown differences in the conditions affect the proportion of the sexes. Thus with mankind, the male births in Englaud are as $104 \%$, in Russia as 1089, and with the Jews of Livonia as 120 , to 100 female births. But I shall recur to this curious point of the exccss of male births in the supplement to this chapter. At the Cape of Good Hope, however, male children of European extraction have been born during several years in the proportion of between 90 and 99 to 100 female children.

For our present purpose we are concerned with the proportion of the sexes, not only at birth, but also at maturity, and this adds another element of doubt; for it is a well-ascertained fact that with man the number of males dying before or during birth, and during the first few year's of infuncy, is considerably larger than that of females. So it almost certainly is with male lambs, and probably with some other animals. The males of some species kill one another by fightins; or they drive one axother about 
until they become greatly cmaciated. They must also be often exposed to various dangers, whilst wandering about in eager search for the females. In many kinds of fish the males are much smaller than the females, and they are believed often to be lievoured by the latter, or by other fishes. The females of some birds appear to die earlier than the males; they are also liable to be destroyed on their nests, or whilst in charge of their young. With insects the female larræ are often larger than those of the males, and would consequently be more likely to be devoured. In some cases the mature fomales are less active and less rapid in their movements than the males, and could not escape so well from danger. Hence, with animals in a state of nature, we must rely on mere estimation, in order to judge of the proportions of the sexes at maturity; and this is but little trustworthy, except when the inequality is strongir marked. Nevertheless, as far as a judgment can be formed, we may conclude from the facts given in the supplement, that the males of some few mammals, of many birds, of some fish and insects, are considerably more numerous than the females.

The proportion between the sexes fluctuates slightly during successive years: thus with race-horses, for every 100 mares born the stallions varied from $107 \cdot 1$ in one year to 92.6 in another year, and with greyhounds from 116.3 to 95.3. But had larger numhers becn tabulated throughout an arca more extensive than England, these fluctuations would probably have disappeared; and such as they are, would hardly suffice to lead to effective sexual selection in a state of nature. Nerertheless, in the cases of some few wild animals, as shewn in the supplement, the proportions seem to fluctuate either during different scasons or in different localities in a sufficient degree to lead to such selection. For it should be observed that any advantage, gained during certain years or in certain localities by those males which were able to conquer their rivals, or were the most attractive to the females, would probably be transmitted to the offspring, and would not subsequently be eliminated. During the succeeding seasons, when, from the equality of the sexes, every male was able to procure a female, the stronger or more attractive males previously produced would still have at least as good a chance of leaving offispring as the weaker or less attractive.

Polygamy.-The practice of polygamy leads to the same results as would follow from an actual inequality in the number of the sexes; for if each male secures two or more femalts, many males cannot pair ; and the latter assuredly will be the weaker or less attractive individuals. Many mammals and some few birds arz 
polygamous, but with animals belonging to the lower classes I have found no evidence of this habit. The intellectual powers of such animals are, perhaps, not sufticient to lead them to collect and guard a harem of females. 'That some relation exists between polygamy and the derelopment of secondary sexual characters, appears nearly certain; and this supports the view that a numerical preponderance of males would be eminently favourable to the action of sexual selection. Nevertheless many animals, which are strictly monogamous, especially birds, display strongly-marked secondary sexual characters; whilst some few animals. which are polygamous, do not have such characters.

Te will first briefly run through the mammals, and then ture to birds. The gorilla scems to be polygamous, and the male differs consirlerably from the female; so it is with some baboons, which live in herds containing twice as many adult females as males. In South America the Mycetes carayre presents wellmirked sexual differences, in colour, beard, and vocal orgaus; and the male generally lires with two or three wives: the male of the Cebus cupucinus differs somewhat from the female, and appears to be polygamous. ${ }^{10}$ Little is known on this head with respect to most other monkeys, but some species are strictly monogamous. The ruminants are eminently polygamous, and they present sexual differences more frequently than almost any other group of mammals; this holds good, especially in their weapons, but also in other characters. Most deer, cattle, and shecp are polygamous; as are most antelopes, though some are monogamous. Sir Andrew Smith, in speaking of the antelopes of South Africa, says that in herds of about a dozen there was rarely more than one mature male. The Asiatic Antilope saigg appoars to be the most inordinate polyganist in the world; for Pallas ${ }^{11}$ states that the male drives away all rirals, and collects a herd of about a hundred females and kids together; the femaie is hornless and has softer hair, but does not otherwise differ much from the male. The wild horse of the Falkland Islands and of the Western States of N. Amcrica is polygamous, but, cxcept in lis greater size and in the proportions of his body, differs but little from the marc, The wild boar presents well-marked sexual

10 On the Gorilla, Savage and Wyman 'Boston Journal of Nat. Hist.' vol. v. 1845-47, p. 423. On Cynocephalus, Brehm, 'Illust. Thier" leben," B. i. 1864, s. 77. Oa Mycet es, Rengger, 'Naturgesch. : Såugethiere von Paraguay, 1830, s. 14, 20. Cebus, Brehm, ibid. s. 108.

i) Pallas, 'Spicilegia Zoolog.,
Fasc. xii. 1777, p. 29. Sir Andrew Smith, 'Illustrations of the Zoology of S. Africa,' 1849 , pl. 29 , on the Kobus. Owen, in his 'Anatomy of Vertebrates' (vol. iii. 1868, p. 633) gives a table shewing incidentally which species of antelopes are gregarious. 
characters, in his great tusks and some other points. In Europe and in India he leads a solitary life, except during the breerlingseason; but as is believed by Sir IV. Elliot, who has had many opportunities in India of observing this animal, he consorts at this scason with several females. Whether this holds good in Europe is doubtful, but it is supported by some eridence. The adult male Indian elephant, like the boar, passes much of his time in solitude; but as Dr. Campbell states, when with others, "it is rare to find more than one male with a whole herd "of females;" the larger males expelling or killing the smaller and weaker ones. The male differs from the female in his immense tusks, greater size, strength, and endurance; so great is the difference in these respects, that the males when caught are valued at one-fifth more than the females. ${ }^{12}$ The sexes of other pachydermatous animals differ very little or not at all, and, as far as known, they are not polygamists. Nor have I heard of any species in the Orders of Cheiroptera, Edentata, Insectivora and liodents being polygamous, excepting that amongst the Rodents, the common rat, according to some rat-catchers, lives with several temales. Nevertheless the two sexes of some sloths (Edentata) differ in the character and colour of certain patches of hair on their shoulders. ${ }^{13}$ And many kinds of bats (Cheiroptera) prescnt well-marked sexual differences, chiefly in the males possessing odoriferous glands and pouches, and by their being of a lighter colour. ${ }^{14}$ In the great order of Rodents, as far as I can learn, the sexes rarely differ, and when they do so, it is but slightly in the tint of the fur.

As I hear from Sir Andrew Smith, the lion in South Africa sometimes lives with a single female, but generally with more, and, in one case, was found with as many as five females; so that he is polygamous. As far as I can discover, he is the only polygamist amongst all the terrestrial Carnivora, and he alono presents well-marked sexual characters. If, however, we turn to the marine Carnivora, as we shall hereafter see, the case is widely different; for many species of seals offer extraordinary sexual differences, and they are eminently polygamous. Thus, according to Péron, the male sea-elephant of the Southern Ocean always possesses several females, and the sea-lion of Forster is said to be surrounded by from twenty to thirty females. In the North, the male sca-bear of Steller is accompanied by even a

12 Dr. Campbell, in 'Proc. Zoolog. Soc.' 1869, p. 138. See also an interesting paper, by Lieut. Jobגstone, in 'Proc. Asiati' Soc. of Bengal,' May. 1868.
${ }^{13}$ Dr. Gray, in 'Annals and Mag. of Nat. Hist.' 1871, p. 302.

1. See Dr. Dobson's excellent paper, in 'Proc. Zoolog. Soc.' 1873. p. 241 . 
greater number of females. It is an interesting fact, as Dr. Qill remarks, ${ }^{15}$ that in the monogamous species, "or those "living in small communities, there is little difference in size " between the males and females; in the social species, or rather "those of which the males have harems, the males are vastly "Iarger than the females."

Amongst birds, many species, the sexes of which differ greatly from each other, are certainly monogamous. In Great Britain we see well-marked sexual differences, for instance, in the wildduck which pairs with a single female, the common blackbird, and the bullfinch which is said to pair for life. I am informed by Mr. Wallace that the like is true of the Chatterers or Cotingida of South America, and of many other birds. In several groups I have not been able to discover whether the species are polygamous or monogamous. Lesson says that birds of paradise, so remarkablo for their sexual differences, are polygamous, but Mr. Wallace doubts whether he had sufficient evidence. Mr. Salvin tells me he has been led to believe that humming-birds aro polygamous. The male widow-bird, remarkable for his caudal plumes, certainly seems to be a polygamist. ${ }^{16}$ I have been assured by Mr. Jenner Weir and by others, that it is somewhat common for three starlings to frequent the same nest; but whether this is a case of polygamy or polyandry has not been ascertained.

The Gallinaceæ exhibit almost as strongly marked scrual differences as birds of paradise or humming-birds, and many of the species are, as is well known, polygamous; others being strictly monogamous. What a contrast is presented between the sexes of the polygamous peacock or pheasant, and the monogamous guinea-fowl or partridge! Many similar cases could be given, as in the grouse tribe, in which the males of the polygamous capercailzie and black-cock differ greatly from the females; whilst the sexes of the monogamous red grouse and ptarmigan differ very little. In the Cursores, except amongst the bustards, few species offer strongly-marked sexual differences, and the great bustard (Otis tardr ) is said to be polygamous. With the Grallatores, extremely few species differ sexually, but the ruff (llachetes pugnax) affords a marked

15 The Eared Seals, 'American Naturalist,' rol. iv., Jan, 1871.

18 'The Ibis,' vol. iii. $1861 \mathrm{p}$. 133, on the Progne Widow-bird. See also on the Vidua axillaris, ibid. vol. ii. $186^{\circ} 0$, p. 211 . On the polygamp of t'a C'apercailzie and
Great Bustard, see I. Lloyd, 'Game Birds of Swedez,' 1867, p. 19, and 182. Miontagu and Selby speak of the Black Grouse as polygamous and of the Rej Grouse as nacaogamous. 
exception, and this species is believed by Montagu to be a polygamist. Hence it appears that amongst liirds there often exists a close relation between polygamy and the development of strongly-marked sexual differences. I asked Mr. Bartlett, of the 'oological Gardens, who has had very large experience with birds, whether the male tragopan (one of the Galliuacex) was polygamous, and I was struck by his answering, "I do not "know, but should think so from his splendid colours."

It descrves notice that the instinct of pairing with a single female is easily lost under domestication. 'The wild-duck is strictiy monogamous, the domestic-duck lighly polygamous. 'The Rev. W. D. Fox informs me that out of some half-tamed wild-ducks, on a liuge pond in his neighbourhood, so many mallards were shot by the gamckeeper that only one was left for every seren or eight females; yet unusually large broods wero rcared. The guinea-fowl is stictly monogamous; but Mr. Fox finds that his birds suceed best when he kecps one cock to two or three hens. Canary-birds pair in a state of nature, but the breeders in England successfully put one male to four or five females. I have noticed these cases, as rendering it probable that wild monogamous species might readily become either temporarily or permanently polygamous.

Too little is known of the babits of reptiles and fishes to enable us to speak of their marriage arrangements. The stickle-back (Gasterosteus), however, is said to be a polygamist:1i and the male during tho breeding season differs conspicnously from the female.

To sum up on the moans through which, as far as we can judge, sexual selection has led to the development of secondary sexual characters. It has been shewn that the largest number of vigorous offspring will be reared from the pairing of the strongest and best-armed males, victorious in contests over other males, with the most vigorous and best-nourished females, which are the first to breed in the spring. If such females select the more attractive, and at the same time vigorous males, they will rear a larger number of offspring than the retarded females, which must prir with the lciss vigorous and less attractive males. So it will be if the more vigorons males select the more attractivo and at the same time healthy and vigorous females; and this will especially hold good if the malo defends the lemale, and aids in providing food for the young. The advantage thus gained by the more vigorous pairs in rearing a larger number of offspring has apparently sufficed to render sexual selection efficiont. But a large numerical preponderance

เ7 Noel Humphreys, 'Rirer Gardens,' 1857. 
of males over females will be still more effleient; whether tho preponderance is only occasional and local, or permanent; whether it occurs at birth, or afterwards from the greater destruction of the females; or whether it indirectly follows from the practice of polygamy.

The Male generally more molified than the Female.-Throughout tho animal kingdom, when the sexes differ in external appoarance. it is, with rare exceptions, the male which has been the more tnodified; for, generally, the female retains a closer resemblance to the young of her own species, and to other adult members of the same group. The cause of this seems to lie in the males of almost all animals having stronger passions than the fomales. Hence it is the males that fight together and sedulously display their charms before the females; and the victors transmit their superiority to their male offspring. Why both sexes do not thus acquire tho characters of their fathers, will be considered hereafter. That the males of all mammals eagerly pursuo the females is notorious to every one. So it is with birds; but many cock birds do not so much pursue the hen, as display their plumage, perform strange antics, and pour forth their song in her presence. The male in the fer fish observed scems much more eagcr than the female; and the same is true of alligators, and apparently of Batrachians. Throughout the cnormous class of insects, as Kirby remarks, ${ }^{18}$ " the law is, that the male shall seek "the female." Tro good anthorities, Mr. Blackwall and Mr. C. Spence Bate, tell me that the males of spiders and crustaceans are more active and more crratic in their habits than the females. When the organs of sense or locomotion are present in the one sex of insects and crustaceans and absent in the other, or when, as is frequently the case, they are more highly devcloped in the one than in the other, it is, as far as I can discover, almost. invariably the male which retains such organs, or has them most developed; and this shews that the malo is the more active member in the courtship of the sexes. ${ }^{19}$

18 Kirby and Spence, 'Introduction to Entomology,' vol. iii. 1826, p. 342 .

19 One parasitic Hymenopterous insect (Westwood, 'Modern Class, of Insects,' vol. ii. p. 160) forms an exception to the rule, as the male has rudimentary wings, and never quits the cell in which it is born, whilst the female has well-develcped rings. Aurrouin belieres that the females of this species are impregnated by the males which are born in the same cells with them; but it is much more probable that the females visit other cells, so that close interbreeding is thus aroidel. We shall hereafter meet in various classes, with a few exceptional cises, in which the female, instend of the male, is the seeker and wooer. 
The female, on the other hand, with the rarest exceptions, is less eager than the male. As the illustrious Hunter ${ }^{20}$ long aggo observed, she generally "requires to be courted;" she is coy, and may often be seen endeavouring for a long time to escape from the male. Every observer of the habits of animals will be able to call to mind instances of this lind. It is shown by various facts, given hereafter, and by the results fairly attributable to sexual selection, that the female, though comparatively passive, generally exerts some choice and accepts one male in preference to others. Or she may accept, as appearances would sometimes lead us to believe, not the male which is the most attractive to her, but the one which is the least distasteful. The exertion of some choice on the part of the female seems a law almost as general as the eagerness of the male.

We are naturally led to enquire why the male, in so many and such distinct classes, has become more eager than the female, so that he searches for her, and plays the more active part in courtship. It would be no advantage and some loss of power if each sex searched for the other; but why should the male almost always be the seeker? The ovules of plants after fertilisation have to be nourished for a time; hence the pollen is necessarily brought to the female organs-being placed on the stigma, by means of insects or the wind, or by the spontaneous movements of the stamens; and in the Algr, \&c., by the locomotive power of the antherozooids. With lowly-organised aquatic animals, permanently affixed to the same spot and having their sexes separate, the male element is invariably brought to the female; and of this wo can see the reason, for even if the ova were detached before fertilisation, and did not require subsequent nourishment or protection, there would yet be greater difficulty in transporting them than the male element, because, being larger than the latter, they are produced in far smaller numbers. So that many of the lower animals are, in this respect, analogous with plants. ${ }^{21}$ The males of affixed and aquatic animals having been led to emit their fertilising element in this way, it is natural that any of their descendants, which rose in the scale and became locomotive, should retain the same habit; and they would approach the female as closely as possible, in order not to risk the loss of the fertilising element in a long passage of it through the water. With some ferr of the lower

20 'Essays and Observations.' edited by Owen, vol. i. 1861, I. 194.

21 Prof. Sachs ('Lehrbuch de: Botanik,' 1870, s. 633) in speaking of the male and female reproductive cells, remarks, "verhält sich die "eine bei der Vereinigung actir, "... die anderc erscheint bei dez "Vereinigung passir." 
animals, the females alone are fixed, and the males of these must be the seckers. But it is difficult to understand why the males of species, of which the progenitors were primordially free, should invariably have acquired the habit of approaching the females, instead of being approached by them. But in all cases, in order. that the males should seek efficiently, it would be necessary that they should be endowed with strong passions; and the acquirement of such passions would naturally follow from the more eager leaving a larger number of offspring than the less eager.

The great eagerness of the males has thus indirectly led to their much more frequently developing secondary sexual characters than the females. But the derelopment of such characters would be much aided, if the males were more liable to vary than the females-as I concluded they were-after a long study of domesticated animals. Von Nathusius, who has had very wide experience, is strongly of the same opinion. ${ }^{22}$ Good evidence also in fuvour of this conclusion can be produced by a comparisor of the two sexes in mankind. During the Novara Expedition ${ }^{23}$ a vast number of measurements was made of various parts of the body in different races, and the men were found in almost cvery case to present a greater range of rariation than the women; but I shall have to recur to this subject in a future chapter. Mr. J. Wood, ${ }^{24}$ who has carefully attended to the variation of the muscles in man, puts in italics the conclusion that " the greatest number of "abnormalities in each subject is found in the males." He had previously remarked that "altogether in 102 subjects, the varieties "of redundancy were found to be half as many again as in "fumales, contrasting widely with the greater frequency of "deficiency in females bcfore described." Professor Macalister likewise remarks ${ }^{25}$ that variations in the muscles "are probably " more common in males than females." Certain muscles which are not normally present in mankind are also more frequently dereloped in the male than in the female sex, although exceptions to this rule are said to occur. Dr. Burt Wilder ${ }^{26}$ has tabulated the cases of 152 individuals with supernumerary digits, of which 86 were males, and 39 , or less than half, females, the remaining 27 being of unknown sex. It should not, however, be overlooked

22 'Vortrage iber Viehzucht,' 1872, p. 63.

23 'Reise der Novara: Anthropolog. Theil,' 1867, \&. 216-269. The results were calculated by Dr. Weisbach from measurements made by Drs, K. Scherzer and Schwarz. On the greater variability of the males of domesticated animals, see my 'Variation of Animals and Plants under Domestication,' vol, ii. 1868, p. 75 .

24 'Proceedings Royal Soc.' vol. xvi. Jul ${ }_{j}$ i868, pp. 519 and 524. 25 'Proc. Royal Irish Academy, vol. x. 1868, p. 123.

28 'Massachusetts Merlical Soc. rol. ii. No. 3,1868 , p. :. 
that women would more frequintly endearour to conceal a deformity of this kind than men. A gain, Dr. L. Meyer asserts that the ears of mall are more variable in form than those of woman. ${ }^{27}$ Lastly the temperature is more variable in man than in woman. ${ }^{28}$

The cause of the greater general variability in the male sex, than in the fenale is unknown, except in so far as secondary sexual characters are extraordinarily variable, and are usually confined to the males; and, as we shall presently see, this fact is to a certain extent, intelligible. Through the action of sexual and natural selection male animals have been rendered in very many instances widely different from their females; but independently of selection the two sexes, from differing constitutionally, tend to rary in a somewhat different manner. The female has to expend much organic matter in the formation of her ova, whereas the male expends much force in fierce contests with his rivals, in wandering about in search of the female, in exerting bis voice, pouring out odoriferous secretions, \&c. : and this expenditure is generally concentrated within a short period. The great vigour of the male luring the season of love seems often to intensify his colours, independently of any marked difrerence from the femalc." In mankind, and even as low down in the organic scale as in the Lepidoptera, the temperature of the body is bigher in the male than in the female, accompanied in the case of man by a slower pulsc.30 On the whole the expenditure of matter and force hy the two sexes is probably nearly equal, though effected in very different ways and at different rates.

From the causes just specified the two sexes can hardly fail to rliffer somewhat in constitution, at least during the brecding reason; and, although they may be subjecter to exactly the fame conditions, they will tend to vary in a different manner. If such rariations are of no scrvice to either sex, they will not be accumulated and increased by sexual or natural selection. Nevertheless, they may become permanent if the exciting cause acts

27 'Archir für Path. Anat. und Phys.' 1871, p. 488.

The conclusions recently arrived at by Dr. J. Stockton Hough, on the temperature of man, are given in the 'Pop. Science Review,' Jan. 1st, 1874, p. 97.

29 Prof. Mantegazza is inclined to believe ('Lettera a Carlo Darwin,' 'Archivio per l'Anthropologia, 1871 ; p. 300) that the bright colours, common in so many male enimals, are due to the presence and retention by them of the spermatic fluid; but this can hardly be the case; for many male birds, for instance young pheasants, become brightly coloured in the autumn of their first year.

${ }^{30}$ For mankind, see Dr. J. Stockton Hough, whose conclusions art given in the 'Pop. Science Review, 1874, p. 97. See Girard's observations on the Lepidoptera, as given in the 'Zoological Record,' $1869, \mathrm{p}$. $3+7$. 
permanently; and in accoidanco with a frequent form of inheriiance they may be transmitted to that sex alone in which they first appeared. In this case the two sexes will come to present permanent, yet innimportant, differences of character. For instance, Mr. Allen shews that with a large number of birds inhabiting the northern and southern United States, the speciwens from the sunth are darker-coloured than those from the north; and this serems to be the direct result of the difference in temperature, light, wc., ketween the two regions. Now, in some ferw cases, the two sexes of the same species appear to have been differently affecterl: in the Agelous phoeniceus the males have had their colours greatly intensified in the south; whereas with Car. dimulis virginiam... it is the females which have been thus affected; with Quisculus " jur the females have been rendered extremely variable in tint, whilst the males remain nearly uniform. ${ }^{31}$

A few exception:al cases occur in various classes of animals, in which the femalk:s instead of the males have acquired well pronounced secondary sexual characters, such as brighter colours, greater size, strength, or pugnacity. With birds there has sometimes been a complete transposition of the ordinary characters proper to each sex; the fermales having become the more eager in courtship, the males remaining comparatively passive, but apparently selocting the more attractive females, as we may infer from the results. Certain hen birds have thus been rendered more highly coloured or otherwise ornamented, as well as more powerful and prigniacious than the cocks; these characters being transmitted to the female offspring alone.

It may he suggested that in some cases a double process of selection bas beeu carried on; that the males have selected the more attractive females, and the latter the more attractive males. This process, however, though it might lead to the modification of loth sexes, would not make tho one sex different from the other, unless indeed their tastes for the beautiful differed; but this is a supposition too improbable to be worth considering in the case of any animal, excepting man. There are, however, many animals in which the sexes resemble each other, both being furnished with the same ornaments, which analogy wonld ifard us to attribute to the agency of sexual selection. In such cases it may be suggested with more plausibility, that there has been a double or mutual process of sexual selection; the more vigorous and precocious females selecting the more attrit ive and vigorous males, the latter rejecting all excent the more attractive females. But from what we know

21 'Mammals and Birds of E. Fiorida,' pp. 234, 280, 295. 
of tho habits of animals, this view is hardly probable, for the male is generally eager to pair with any female. It is moro probable that the ornaments common to both sexes were acquirc: by one sex, generally the male, and then transmitted to the otispring of both sexes. If, indeed, during a lengthened period the males of any species were greatly to exceed the females in sumber, and then during another lengthened period, but under different conditions, the reverse were to occur, a double, but not simultaneous, process of sexual selection might easily be carried on, by which the two sexes might be rendered wiriely different.

We shall hereafter see that many animals exist, of which neither sex is brilliantly coloured or provided with special ornaments, and yet the members of both sexes or of onc alone have probably acquired simple colour's, such as white or black, through sexual selection. The absence of bright tints or other ornaments may be the result of variations of the right kind never having occurred, or of the animals themselres having preferred plain black or white. Obscure tints have often been developed through natural selection for the sake of protection, and the acquirement through sexual selection of conspicuous colours, appears to have been sometimes checked from the danger thus incurred. But in other cases tho males during long ages may have struggrled togcther for the possession of the fomales, and yet no effect will have been produced, unless a larger number of offspring wero left by the more successful males to inherit their superiority, than by the less successful: and this, as previously shewn, depends on many complex contingencies.

Sexual selection acts in a less rigorous manner than natural selection. The latter produces its effects by the life or death at all ages of the more or less successful individuals. Death, indeed, not rarely ensues from the conflicts of rival males. But generally the less successful male merely fails to obtain a female, or obtains a retarded and less vigorous female later in the season, or, if polygamous, obtains fewer females; so that they leare fewer, less vigorous, or no offspring. In regard to structures acquired through ordinary or natural selection, there is in most cases, as long as the conditions of life remain the same, a limit to the amount of advantageous molification in relation to certain special purposes; but in regard to structures adapted to make one male victorious over another, either in fighting or in charming the feniale, there is no definite limit to the amount of advantageous modification; so that as long as the proper variations arise the work of sexual selection will go on. This circumstance may partly account for the frequent and extraordinary amount of variability presented 
hy secondary sexual characters. Nevertheless, natural selection will determine that such characters shall not be acquired by the victorious males, if they would bo highly injurious, either by expending too much of their vital powers, or by exposing them to any great danger. The development, however, of certain structures-of the horns, for instance, in certain stags-has been carried to a wonderful extreme; and in some cases to an cxtreme which, as far as the general conditions of life are concerned, must be slightly injurious to the male. From this fact we learn that the advantages which favoured males derive from conquering other males in battle or courtship, and thus leaving a numerous progeny, are in the long run greater than those derived from rather more perfect adaptation to their conditions of life. We shall further see, and it could never have been anticipated, that the power to charm the female bas sometimes been more important than the power to conquer other males in battle.

\section{LATWS OF INHERITANCE.}

In order to understand how sexual selection has actcd on many animals of many classes, and in the course of ages has produced a conspicuous result, it is necessary to bear in mind the laws of inheritance, as far as they are known. Two distinct elements are included under the term "inheritance"-the transmission, and the development of characters; but as these generally go together, the distinction is often orerlooked. We seo this distinction in those characters which are transmitted through the carly years of life, but are developed only at maturity or during old age. We sce the same distinction more clearly with secondary sexual characters, for these are transmitted through both sexes, though developed in one alone. That they are present in both sexes, is manifest when two species, having strongly-marked sexual characters, are crossed, for cach transmits the characters proper to its own male and femalescx to the hybrid offspring of either sex. The same fact is likerrise mani fest, when characters proper to the male are nccasionally dereloped in the female when she grows old or becomes discased, as, for instarce, when the common hen assumes the flowing tailfeathers, hackles, comb, spurs, voice, and cren pugnacity of the cock. Conversely, the same thing is evident, more or less plainly, with castrated males. Again, independently of old age or disease, characters are occasionally transferred from the male to the female, as when, in certain breeds of the forl, spurs regularly aprear in the young and healthy females. But in truth they are simply develupel in the female; for in crery breed ench cletail 
in the structure of the spur is transmitted through tho female to her male offspring. Many cases will hereafter be given, where the female exhibits, more or less perfectly, characters proper to the male, in whom they must have been first developed, and then 1 ransferied to the female. The converse case of the first development of characters in the female and of transference to the male, is less frequent; it will therefore be well to give one striking instance. With bees the pollen-collecting apparatus is usei ly the female alone for gathering pollen for the larvæ, yet in inost of the species it is partially developed in the maleto whom it is quite useless, and it is perfectly developer in the males of Bombus or the humble-bee. ${ }^{32}$ As not it single other Hymenopterous insect, not even the wasp, which is closely allied to the bee, is provided with a pollen-collectin: apparatus, we lave no grounds for supposing that male becs. primordially collected pollen as well as the females; althougi: we have some reason to suspect that male mammals primordially suckled their young as well as the females. Lastly, in all cases of reversion, characters are transmitted through two, three, or man! more generations, and are then developed under certain unknowil favourable conditions. This important distinction betwecL: transmission and development will be best kept in mind by the aid of the hypothesis of pangenesis. According to this hypothesis. every unit or cell of the body throws off gemmules or undeveloper atoms, which are transmitted to the offspring of both sexes, and are multiplied by self-division. They may remain undeveloped during the early years of life or during successive generations; and their development into units or cells, like those from which they were derived, depends on their affinity for, and unior with other units or cells previously developed in the duo order of growth.

Inheritance at corresponding Periods of Life..-This tendency is well estahlishod. A new character, appearing in a young animal, whether it lasts throughout life or is only transient, will, in general, reappear in the offspring at the same age and last for the same time. If, on the other hand, a new character "ppears at maturity, or even during old age, it tends to reappear in the offspring at the same advanced age. When deviations from this rule occur, the transmitted characters much 1) ftener appear before, than after the corresponding age. As I hare dwelt on this subject sufficiently in another work, ${ }^{33}$ I will

3: II. Miller, 'Anwendung der Darwin'schen Lehs'e,' dc. 'Verh. d. ฉ. V. Jahrg xxix. p. 42 .
33 'The Variation of' Animals and Plants uuler Domestication.' vol. ii. 1868, p. 75 . In the las? 
here merely gire two or three instances, for the sake of recalling: the subject to the reader's mind. In several breeis of the Fowl, the down-covered chickens, the young birds in their first true: plumage, and the adults differ greatly from one another, as well as from their common parent-form, the liallus brinkiva; and these characters are faithfully transmitted by each breed to their offspring at the corresponding periods of life. For instance, the chickens of spangled Hamburgs, whilst covered with down, have is few dark spots on the head and rump, but are not striped longitudinally, as in many other breeds; in their first true plumage, "they are beautifully pencilled," that is each featber is transversely marked by numerous dark bars; but in their second flumage the feathers all become spangled or tipped with a dark round spot. ${ }^{\text {s. }}$ Hence in this breed variations have occurred at, ind been transmitted to, three distinct periods of life. The l'igeon offers a more remarkable case, because the aboriginal parent species does not undergo any change of plumage with aldvancing age, excepting that at maturity the breast becomes more iridescent; yet there are breeds which do not acquire their characteristic colours until they have moulted two, three, or four times; and these modifications of plumage are regularly transmitted.

Inheritance at corresponding Seasons of the Icar.-With animals in a state of nature, innumerable instances occur of characters appearing periodically at different seasons. Wo see this in the horns of the stag, and in the fur of arctic animals which becomes thick and white during the winter. Many birds acquire bright "olours and other decorations during the breeding-season alone. P'allas states, ${ }^{95}$ that in Siberia domestic cattle and horses becomo lighter-coloured during the winter; and I have myself observed, and heard of similar strongly marked changes of colour, that is, from brownish cream-colour or reddish-brown to a perfect white, in several ponies in England. Although I do not know that this tendency to change the colour of the coat during different seasons

chapter but one, the provisional hypothesis of pangenesis, above alluded to, is fully explained.

34 These facts are given on the high authority of a great breeder, Mr. Teebay ; see Tegetmeier's 'Poultry Book, 1868, p. 158. On the characters of chickeus of different breeds, and on the breeds of the pireon, alluded to in the following paragraph, see "Variation of An:- mals, \&c., vol. i. pp. 160,249 ; vol. ii. p. 77.

35 'Nova species Quadrupedum e Glirium ordine," 1778, p. 7. On the transmission of colour by the h..l'se, see 'Variation of Animals, \&c., under Domestication, vol. i. p. 51. Also vol. ii. p. 71, for a gerneral discussion on "Inheritraice car lim:tad hy. Scx.' 
Is transmitted, yet it probably is so, as all shades of colour a:0 strongly inherited by the horse. Nor is this form of inheritance, as !imited by the seasons, more remarkable than its limitation by age or sex.

Inheritance as Limited by Sex.-The equal transmission of charncters to both sexes is the commonest form of inheritince, at least with those animals which do not present strongly-markicd sexual differences, and indeed with many of these. But characturs are somewhat commonly transferred exclusively to that $s(x$, in whice they first appear. Ample evidence on this hearl has heen adranced in my work on 'Variation under Domestication,' but a few instances nlay here be given. 'There are breeds of the sheep and goat, in whon the horns of the male differ greatly in shape from those of the female; and these differences, acquired under domestication, are regularly transmitted to the same sex. As a rule, it is the females alone in eats which are tortoise-shcll, the corresponding colour in the males being rusty-red. With most breeds of the forl, the characters proper to each sex are transmitted to the same sex alone. So general is this form of transmission that it is an anomaly when variations in certain breeds are transmitted equally to both sexes. There are also certain sub-brecds of the fowl in which the males can hardly be distinguished from one another, whilst the females differ considerably in colour. The sexes of the pigeon in the parent-species do not differ in any external character; nevertheless, in certain domesticated breeds the male is coloured differently from the female. $^{36}$ The wattle in the English Carricr pigeon, and the crop in the Pouter, are more highly developed in the male than in the female; and although these characters have been gained through long-continued selection by man, the slight differences hetwcen the sexes are wholly due to the form of inheritance which has prevailed; for they have arisen, not from, but rather in opposition to, the wish of the breeder.

Most of our domestic races have been formed by the accuminlation of many slight rariations; and as some of the successire steps have becn transmitted to one sex alone, and some to both sexes, we find in the different breeds of the same species ali gradations between great sexual dissimilarity and complete similarity. Instances have already been given with the brecils of the fowl and pigeon, and under nature analogous cases are

36 I)r. Chapuis, 'Le Pigeon Voyageur lielge,' 186.5 , p. 87. Boitard at Cortie, 'Les Pigeons de Volièrs,' şc., 18:24, p. 173. See, also, on similar differences in certain breeds at Modena, 'Le varitzioni dei Colombi domestici,' del Paolo Bow niz?i, 1873. 
conmon. With animals under domestication, but whethor in nature I will not renture to say, one sex may lose characters proper to it, and may thus come somewhat to resemble tho opposite sex; for instance, the males of some breeds of the fowl have lost their masculine tail-plumes and hackles. On the other hand, the differences between the sexes may be increased under domestication, as with merino. sheep, in which tho ewes have lost their horns. Again, characters proper to one sex may suddenly appear in the other sex; as in those subbreeds of the fowl in which the hens acquire spurs whilst young; or, as in certain Polish sub-breeds, in which the females, as there is reason to believe, originally acquired a crest, and subserquently transferred it to the males. Ali these cases are in. telligible on the hypothesis of pangenesis; for they depend on the gemmules of certain parts, although present in both sexes, becoming, through the influence of domestication, cither dormant or developed in either sex.

There is one difficult question which it will be convenient to defer to a future chapter; namely, whether a character at first developed in both sexes, could through selection be limited in its development to one sex alone. If, for instance, a breeder observed that some of his pigeons (of which the characters aro usually transferred in an equal degree to both sexes) varied into pale blue, could he by long-continued selection make a breed, in which the males alone should be of this tint, whilst the females remained unchanged? I will here only say, that this, though perhaps not impossible, would be extremely difficult; for the natural result of breeding from the pale-blue uales would be to change the whole stock of both sexes to this tint. If, however, rariations of the desired tint appeared, which were from the first limited in their development to the male sex, there would not be tho least difficulty in making a breed with the two sexes of a different colour, as indeed has leen effected with a Belgian breed, in which the males alone are streaked with black. In a similar manner, if any variation appeared in a femalo pigeor. which was from the first sexually limited in its development to the females, it would be easy to make a breed with the females alone thus characterised; but if the variation was not thus originally limited, the process would be extremely difficult, perhaps impossible. ${ }^{37}$

37 Since tue publication of the first edition of this work, it has been highly satisfactory to me to facl the following remarks (the Field, Sept. 1872) from so ex- perieuced a breeder as Mr. Tegetmeier. After describing some curious catses in piereus, of the transmission of colour by one sex alont, aud the formation of a sub-iodeed 
On the Relation between the Period of Development of "C'huructer and its Transmission to one Sex or to both Seres. - Why certain characters should be inherited by both sexes, and other characters by one sex alone, namely by that sex in which the character first appeared, is in most cases quite unknown. We cannot cren conjecture why with certain sub-breeds of the pigeon, black striæ, though transmitted through the feniale, should be developed in the male alone, whilst every other character is equally rransferred to both sexes. Why, again, witl cats, the tortoiseshell colour should, with rare exceptions, be developed in the female alone. The very same character, such as deficient or supernumerary digits, colour-blindness, \&c., may with mankind be, inherited by the males alone of one family, and in another family by the females alone, though in both cases transmitted through the opposite as well as through the same sex. ${ }^{38}$ Although we aro thus ignorant, the tro following rules seem often to hold goodthat variations which first appear in either sex at a late period of life, tend to be developed in the same sex alone; whilst rariations which first appear early in life in either sex tend to be developed in both sexes. I am, however, far from supposing that this is the sole determining cause. As I have not elsewhere discussed this subject, and as it has an important bearing on sexual selection, I must here enter into lengthy and somewhat intricate details.

It is in itself probable that any character appearing at an rarly age would tend to be inherited equally by both sexes, for the sexes do not differ much in constitution before the power of reproduction is gained. On the other hand, after this power has been gained and the sexes have come to diffor in constitution, the gemmules (if I may again use the language of pangenesis) which are cast off from each varying part in the one sex would he much more likely to possess the proper affinities for uniting with the tissues of the same sex, and thus becoming developed, than with those of the opposite sex.

I was first led to infer that a relation of this kind exists, from the fact that whenever and in whatever manner the adult malo rliffers from the adult female, he differs in the same manner from the young of both sexes. The generality of this fact is quite remariable: it holds good with almost all mammals, birds,

with this character, he says: "It is " a singular circumstance that Mr. "Darwin should have suggested the " possibility of modifying the sexual " colours of birds by a course of " artificial selection. When he did " so, he was in ignorance of these "facts that I have related; but wt " is remarkable how very closely " he suggested the right method of "procedure."

38 References are given in $\mathrm{my}$ Variation of Animals under Domestiration, vol. ii. p. 72. 
amphibians, and fishes; also with many crustaceans, spiders, and iome few insects, such as certain orthoptera and libellulæ. In :ll these cases the rariations, through the accumulation of whice ihe male acquired his proper masculine characters, must have vecurred at a somerihat late period of life; otherwise the young inales would have been similarly characterised; and conformably with our rule, the variations are transmitted to and developed in the adult males alone. When, on the other hand, the adult male closely resembles the young of both sexes (these, with raro (xceptions, being alike), he generally resembles the adult female; and in most of these cases the variations through which the young and oid accuired their present characters, probably occurred, itccording to our rule, during youth. But there is here room for loubt, for characters are sometimes transferred to the offspring at an earlier age than that at which they first appeared in the parents, so that the parents may have varied when adult, and have transferred their characters to their offspring whilst young. There are, moreover, many animals, in which the two sexes closely resemble each other, and yet both differ from their young; and here the characters of the adults must have been acquired late in life; nevertheless, these characters, in apparent contradiction to our rule, are transferred to both sexes. We must not, however, orerlook the possibility or even probability of successive variations of the same nature occurring, under exposure to similar conditions, simultaneously in both sexes at a rather late periou of life; and in this case the variations would be transferred to the offspring of both sexes at a corresponding late age; and there would then be no real contradiction to the rule that variations occurring late in life are transferred exclusively to the sex in which they first appeared. This latter rule seems to hold true more generally than the second one, namely, that variations which occur in either sex early in life tend to be transfurred to both sexes. As it was obviously impossible even to estimate in how large a number of cases throughout the animal kingdom these two propositions held good, it occurred to me to investigate some striking or crucial instances, and to rely on the result.

An excellent case for investigation is afforded by the Deer family. In all the species, but one, the horns are developed only in the males, though certainly transmitted through the females, and capable of abnormal development in them. In the reindeer, on the other hand, the female is provided with horns; so that in this species, the horns ought, according to our rule, to appear early in life, long before the two sexes aro mature and have come to differ much in constitution. In all the sther species the horns ought to appcar later in Iife, which 
would lead to their derelopment in that sex alone, in which (hey first appeared in the progenitor of the whole Family. Now iil seven species, belonging to distinct sections of the family and inhabiting different regions, in which the stags alone hear horns, I find that the horns first appear at periods, varying from nino months after birth in the roebuck, to ten, twelve or even more months in the stags of the six other and larger species. ${ }^{39}$ But witls the reindeer the case is widely different; for, as I hear from Prof. Nilsson, who kindly made special enquiries for me in Lapland, the horns appear in the young animals within four or live weeks after birth, and at the same time in both sexes. So that here we have a structure, developed at a most unusually (arly age in one species of the family, and likewise common to hoth sexes in this one species alone.

In several kinds of antelopes, only the males are provided with horns, whilst in the greater number both sexes bear horns. With respect to the period of development, Mr. Blyth informs me that there was at one time in the Zoological Gardens a young koodoo (Ant.strepsiceros), of which the males alone are horned, and also the young of a closely-allied species, the cland (Ant. (reus), in which both sexes are horned. Now it is in strict conformity with our rule, that in the young malo koodoo, although ten months old, the horns were remarkably small, considering the size nltimately attained by them; whilst in the young male eland, although only three months old, the horns were already very much larger than in the koodoo. It is :lso a noticcable fact that in the prong-horned antelope, cmly a fow of the females, ahout one in five, have horns, and these are in a rudimentary state, though sometimes above four inches long; so that as far as concerns the possession of horns hy the males alone, this species is in an intermediate condition, and the horns do not appear until about five or six months after hirth. Therefore in comparison with what little we know of the development of the horns in cther antelopes, and from what

39 I am much obliged to $\mathrm{Mr}$. Cupples for haring made enquiries fior me in regarl to the Roebuck ad Red Deer of Scotland from Mr. liobertson, the experienced headforester to the Marquis of Breadalhane. In regard to Fallow-deer, I have to thank Mr. Eyton and others for information. For the Cervus alces of N. America, see 'Land and Water,' 1868, Pp. 221 and 254 ; and for the $C$. Iirginianus nad strongyluceros of the same con- tinent, see J. D. Caton, in 'Ottawa Acad. of Nat. Sc. 1868, p. 13 . For Cervis Eldi of Pegu, see lieut. Bearan, 'Proc. Zoolog. Sc:' 18197, p. 762 .

40 Antilocapra Americana. I have to thank Dr. Canfield for information with respect to the horns of the female: see also his paper in 'Proc. Zoolng. Soc.' 1866, p. 1C9. Also Owen, 'Anitomy of Vertebrates, vol. iii. p. 627. 
we do know with respect to the horns of deer, cattle, cke, thoso of the prous-hurned antelope appear at an intermediate period of life,-that is, not very carly, as in cattle and sheep, nor very late, as in the larger deer and antelopes. The horns of sheep, soats, and cattle, which are well developed in both sexes, though not quite equal in size, can be felt, or even scen, at birth or soon afterwards." Our rule, howerer, seems to fail in some breeds of sheep, for instance merinos, in which the rams alone are horned; for I cannot find on enquiry,12 that the horns are dereloped later in life in this breed than in ordinary sheep in which both sexes are horned. But with domesticated sheep the presence or absence of horus is not a firmly fixed character; for a certain proportion of the merino ewes bear small horns, and some of the rams are hornless; and in most breeds hornless ewes are occasionally produced.

Dr. W. Marshall hats lately made a special study of the protuberances so common on the heads of birds, ${ }^{43}$ and he cornes to the following conclusion; - that with those species in which they are confined to the males, they are developed late in life; whereas with those species in which they are common to the two sexes, they are dereloped at a very early period. This is certainly a striking confirmation of my two laws of inheritance.

In most of the species of the splendid family of the Pheasants, the males differ conspicuously from the females, and they acquire their ornaments at a rather late period of life. The earerl pheasant (Crossoptilon auritum), however, offers a remarkable exception, for both sexes possess the fine caudal plumes, the large ear-tufts and the crimson velvet about the head; I find that all these characters appear very early in life in accordance with rule. The adult male can, however, bo distinguished from the adult female by the presence of spurs; and conformably

41 I have been assured that the horns of the sheep in North Wales can always be felt, and are sometimes even an inch in length, at birth. Youatt says ('Cattle,' 1834, p. 277), that the prominence of the frontal bune in cattle penetrates the cutis at birth, and that the horny matter is soon formed over it.

12 I am greatly indebted to Prof. Victor Carus for having made enquiries for me, from the highest authorities, with respect to the merino sheep of Saxony. On the Trisea coast of Africa there is, however, a breed of sheep in which, as with merinos, the rams alonc bear horns; and Mr. Winwood Reade informs me that in one casu observed by him, a young ram, born on Feb. 10th, first shewed horns on March 6th, so that in this instance, in conformity with rule, the development of the horns occurred at a later period of life than in Welsh sheep, in which both sexes are horned.

43 'Ueber die knöchernen Schädelhöcker der Vöge!' in the 'Niederlandiscnen Archir fuir Zoologie, Band I. Heft 2, 1872. 
with our rule, these do not begin to be developod before the age of six months, as I am assured by Mr. Bartiett, and ercn at this ige, the two scxes can hardly be distinguished. ${ }^{44}$ The male and female Peacock differ conspicuously from each other in almost every part of their plumage, except in the elegant head-crest, which is common to both sexes; and this is developed very early in life, long before the other ornaments, which are confined to the male. The wild-duck offers an analogous case, for the beautiful sreen speculum on the wings is common to both sexes, though riller and somewhat smaller in the female, and it is developer early in life, whilst the curled tail-feathers and other ornaments of the male are developed later. ${ }^{45}$ Between such extreme cases of close sexual resemblance and wide dissimilarity, as those of the Crossoptilon and peacock, many intermediate ones could be given, in which the characters follow our two rules in their order of development.

As most insects emerge from the pupal state in a mature condition, it is doubtful whether the period of development can letermine the transference of their characters to one or to both sexes. But we do not know that the coloured scales, for instance, in two species of butterflies, in one of which the sexes differ in ('olour, whilst in the other they are alike, are developed at the same relative age in the cocoon. Nor do we know whether all the scales are simultaneously dereloped on the wings of the same species of butterfly, in which certain coloured marks are confined

4 In the common percock (Pavo cristatus) the male alone possesses cpurs, whilst both sexes of the Java Peacock ( $P$. muticus) offer the unusual case of being furnished with spurs. Hence I fully expected that in the latter species they would have been developed earlier in life than in the common peacock; but M. Hegt of Amsterdam informs me, that with young birds of the previous year, of both species, compared on April 23rd, 1869, there was no difference in the developmeut of the spurs. The spurs, however, were as yet represented merely by slight knobs or elevations. I presume that I should have been informed if any difference in the rate of development had bcen observed subsequently.

45 In some other species of the !) uck family the speculum differ's w a greater degree in the two sexes; but I have not been able to discover whether its full derelop. ment occurs later in life in the males of such species, than in the male of the common duck, as ought to be the case according to our rule. With the allied Mergus cr: cullatus we have, however, a case of this kind: the two sexes differ con. spicuously in general plumage, and to a considerable degree in the speculum, which is pure white in the male and greyish-white in the female. Now the young males at first entirely resemble the females, and have a greyish-white speculum, which becomes pure white at an earliel" age than that at which the adult male acquires his other and more strongly-marked sexunl differences: see Audubon, 'Ornithological Biography,' vol. ii. 1835, pp. 249-250. 
to one sex, whilst others are common to both sexes. A differener of this kind in the period of development is not so improbable as it may at first appear; for with the Urthoptera, which assume their adult state, not by a single metamorphosis, but by a succession of moults, the young males of some species at first rescmble the females, and acquire their distinctive masculine characters only at a later moult. Strictly analogous cases occur at the successive moults of certain male crustaceans.

We have as yet considered the transference of characters, relatively to their period of development, only in species in a matural state; we will now turn to domesticated animals, and first touch on monstrosities and diseases. The presence of supernumerary digits, and the absence of certain phalanges, must be determined at an early embryonic period - the tendency to profuse bleeding is at least congenital, as is probally colour-blindnessyet these peculiarities, and other similar ones, are often limited in their transmission to one sex; so that the rule that characters, developed at an early period, tend to be transmitted to both sexes, here wholly fails. But this rule as hefore remarked, does not appear to be nearly so general as the converse one, namely, that characters which appear late in life in one sex are transmitted exclusively to the same sex. From the fact of the above abnormal peculiarities becoming attached to one sex, long before the sexual functions are active, we may infer that there must be some difference between the sexes at au extremely early age. With respect to sexually-limited diseases, we know too little of the period at which they originate, to draw any safe conclusion. Gout, however, seems to fall under our rule, for it is generally caused by intenpcrance during manhood, and is transmitted from the father to his sons in a much more marked manner than to his daughters.

In the various domestic breeds of sheep, goats, and cattle, the males differ from their respective females in the shape or development of their horns, forehead, mane, dewlap, tail, and hump on the shoulders; and these peculiarities, in accordance with onr. rule, are not fully developed until a rathcr late period of life. The sexes of dogs do not differ, except that in certain breeds, especially in the Scotch deer-hound, the male is much largur and heavier than the fomale; and, as we shall sce in a future chapter, the male goes on increasing in size to an unusually late: period of life, which, according to rule, will acceunt for his increased size being transmitted to his male offspring alone. On the other hand, the tortoisc-shell colour, which is confined to female cats, is cuite distinct at birth, and this case violates the rule. There is a breed of pigeons in which the males alone ar' 
streaked with black, and the streaks can bo detected even in tho nestlings; but they become more conspicuous at each successivo moult, so that this case partly opposes and partly supports the rule. With the English Carrier and Pouter pigcons, the full development of the wattle and the crop occurs rather late in life, and conformahly with the rule, these characters are transmitted in full perfection to the males alone. The following cases perhaps come within the class previously alluded to, in which both sexes have varied in the same manner at a rather late period of life, ard have consequently transferred their new characters to both sexes at a corresponding late period; and if so, these cases are not opposed to our rule:-there exist sub-breeds of the pigeon, described by Neumeister, ${ }^{46}$ in which both sexes change their colour during two or three moults (as is likewise the case with the Almond Tumbler), nevertheless, these changes, thougl? occurring rather late in life, are common to both sexes. Ono variety of the Canary-bird, namely the London Prize, offers a nearly analogous case.

With the breeds of the Fowl the inheritance of various characters by one or both sexes, scems generally determined by the period at which such characters are developed. Thus in all the many breeds in which the adult male differs greatly in colour from the female, as well as from the wild parent-species, he differs also from the young male, so that the newly-acquired characters must have appeared at a rather late period of life. On the other hand, in most of the brecds in which the two sexess resemble each other, the young are coloured in nearly the same manner as their parents, and this renders it probable that their colours first appeared early in life. Wo have instances of this fact in all black and white breeds, in which the young and old of both sexes are alike; nor can it be maintained that there is something peculiar in a black or whito plumage, which leads to its transference to both sexes; for the males alone of many natural species are either black or white, the females being differently coloured. With the so-cralied Cuckoo sub-breeds of the fowl, in which the feathers are transversely pencilled with dark stripes, both sexes and the chickens are coloured in nearly the same manner. The laced plumage of the Sebright bantam is the same in both sexes, and in the young chickens the wingfeathers are distinctly, though imperfectly laced. Spangled Hamburgs, however, offer a partial exception; for the two sexes, though not quite alike, resemble each other more closely than

46 'Das Ganze der Taubenzucht,' 1837 , s. 21,24 . For the case of the streaked pigeons, see Dr Cha- puis, 'Le pigeon royageur Belge,' 1865, r. $\varepsilon 7$. 
do the sexes of the aboriginal parent-species; yet they acquire their characteristic plumage late in life, for the clickens are distinctly peneilled. With respect to other characters besides colour, in the wild-parent species and in most of the domestic breeds, the males alone possess a well-developed comb; but in the young of the Spanish fowl it is largely dereloped at a very sarly age, and, in accordance with this early development in the male, it is of unusual size in the adult female. In the Game breeds pugnacity is developed at a wonderfully early age, of which curious proofs could be given; and this character is transmitted to both sexes, so that the hens, from their extremo pugnacity, are now gencrally exhibited in separate pens. With the Polish breeds the bony protuberance of the skull which supports the crest is partially developed even before the chickens are hatched, and the crest itself soon begins to grow, though at first feebly; ${ }^{i i}$ and in this breed the adults of both sexes are characterised by a great bony protuberance and an immense crest.

Finally, from what we have now seen of the relation which exists in many natural species and domesticated races, between the period of the development of their characters and the manner of their transmission-for example, the striking fact of the early growth of the horns in the reindeer, in which both sexes bear horns, in comparison with their much later growth in the other species in which the male alone bears horns-we may conclude that one, though not the sole cause of characters being exclusively inherited by one sex, is their development at a late age. And secondly, that one, though apparently a less efficient cause of characters being inherited by both sexes, is their development at an early age, whilst the sexes differ but little in constitution. It appears, however, that some difference must exist between the sexes eren during a very early embryonic period, for characters developed at this age not rarely become attached to one sex.

Sunmary and conctucling remarks. - From the foregoing discussion on the various laws of inheritance, we learn that the characters of the parents often, or eren gencrally, tend to bocomc developed in the offspring of the same sex, at the same age, and periodically at the samo season of the year, in which they first

47 For full particular's and references on all these points respectlng the several breeds of the Fowl, see "Variation of Animals and Plants under Domestication, rol. i. pp.
250,256 . In regird to the higher animals, the sexual differences which have arisen under domestication ar described in the sume work und: the hord of each species. 
appeared in the parents. But these rulcs, owing to unknown causes, are far from being fixcd. Heuce during the modification of a species, the successive changes may readily be transmitter? in difierent ways; some to one sex, and some to both; some to the offspring at one age, and some to the offspring at all ages. Not only are the laws of inheritance extremely complex, but so we the causes which induce and govern variability. The variations thus induced are preserved and accumulated by Eexual selection, which is in itself an extromely complex affair, lepending, as it does, on the ardour in love, the courage, and the rivalry of the males, as well as on the powers of perception, the taste, and will of the female. Sexual sclection will also be largely dominated boy natural selection tending towards the general welfare of the species. Hence the manner in which tho individuals of either or both sexes have been affected through sexual selection cannot fail to be complex in the highest degree.

When variations occur late in life in one sex, and are transmitted to the same sex at the same age, the other sex and the young are left unmodified. When they occur late in life, but wre transmitted to both sexes at the same age, the young alone are left unmodified. Variations, however, may occur at any period of life in one sex or in both, and be transmitted to both sexes at all ages, and then all the individuals of the species are similariy modified. In the following chapters it will be seen that all these cases frequently occur in nature.

Sexual selection can never act on any animal before the age for roproduction arrives. From the great eagerness of the malc it has generally acted on this sex and not on the females. The males have thus become provided with weapons for fighting with their rivals, with organs for discovering and securely. irolding the female, and for exciting or charming ber. When the sexes differ in theso respects, it is also, as we have seen, au extremely general law that the adult male differs more or less from the young male; and we may concludo from this fact that the successive variations, by which the adult male became moditied, did not generally occur much before the age for reproduction. Whenever some or many of the variations vecurred early in life, the young males would partake more or less of the characters of the adult males; and differences of this kind between the old and young males may be obserred in many species of animals.

It is probable that young male animals have often tonded to vary in a manner which would not only have been of no use to them at an carly age, but would have hecn actually injurious-- 
as by acquiring bright colours, which would render them conspicuous to their enemies, or by acquiring structures, such as gruat horns, which would expend much vital force in thei: development. Variations of this kind occurring in the young males would almost certainly be eliminated through natural sclection. With the adult and experienced males, on the other land, the advantages derived from the acquisition of such characters, would more than counterbalance some exposure to unnger, and some loss of vital force.

As variations which give to the male a better chance of conquering other males, or of finding, securing, on charming the opposite sex, would, if they happened to arise in the female, be of no service to her, they wonld not be preserved in her through sexual selection. We have also good evidence with domesticated animals, that variations of all kinds are, if not carefully selected, soon lost through intercrossing and accidental deaths. Consequently in a state of nature, if variations of the above kind chanced to arise in the female line, and to be transmitted exclusively in this line, they would be extremely liable to be lost. If, however, the females varied and transmitted their newly acquired characters to their offspring of both sexes, the characters whicn were adrantageous to the males would be preserved by them through sexual selection, and the two seres would in consequencts he modified in the same manner, although such characters were of no use to the females; but I shall hereafter have to recur to these, more intricate contingencies. Lastly, the females may acquire, and apparently hare often acquired by transference, characters from the male sex.

As variations occurring late in life, and transmitted to one sex alone, have incessantly been taken advantage of and accumulated through sexual selection in relation to the reproduction of the species; therefore it appcars, at first sight, an unaccountabju fact that similar variations have not frecquently been accumulated through natural selection, in relation to the ordinary habits of life. If this had occurred, the two scxes would often have been differently modified, for the sake, for instance, of capturing prey or of escaping from danger. Differences of this kind betwcen the two sexes do occasionally occur, especially ir. the iower classes. But this implies that the two sexes follow different habits in their struggles for existence, which is a raro circumstance with the higher animals. The case, however, is wideiy different with the reproductive functions, in which respect the sexes necessarily differ. For variations in structure which are related to these functions, have of ten provel of value to one ces and from having arisen at a 'ate period of life, linve been 
trausmitted to one sex alone; and such variations, thus preservad and transmitted, have giren rise to secondary sesual characters.

In the following chayters, I shall treat of the secondiry sexual characters in animals of all classes, and shall cudea vomr in each case to apply the principles explained in the present chapter. The lowest classes will drtain us for a very short timo, but the higher animals, especially birds, must be treated at considerable length. It should be borne in mind that for reasons already assigned, $I$ intend to give only a few illustrative instances of the innumerable structures by the aid of which the male finds the female, or, when found, holds her. On the other hand, all structures and instincts by the aid of which the nale conquers other males, and by which he allures or excites the female, will be fully discussed, as these are in many ways the most interesting.

\section{Supllement on the proportional numbers of the tuo sexes in animals belonging: to various classes.}

As no one, as far as I can ciscover, has paid attention to the relative numbers of the two sexes throughout the animal kingdom, I will here gire such materials as I have been able to collect, although they are extremely imperfect. They consist in only a few instances of actual cummeration, and the mumbers are not rery large. As the proportions are known with certainty only in mankind, I will first give them as a standard of comparison.

Man.-In England during ten years (from 1857 to 1866) the average number of children born alive yearly was 707,120, in the proportion of 104.5 males to 100 females. But in 1857 the male births thronghout England were as 105.2, and in 186.j as 101.0 to 100. Looking to separate districts, in Buckinghamshire (where about 5000 children are amnually born) the mun proportion of male to female births, during the mhole period of the above ten years, was as 102.8 to 100 ; whilst in $\mathrm{N}$. Wales (where the arerage annual births are 12,873) it was as high as 106.2 to 100. Taking a still smaller district, viz., Rutlandshire (where the annual births average only 739), in 1861 the male births were as 114.6 , and in 1862 as only $97^{\circ} 0$ to 100; but even in this small district the arerage of the 735.5 births during the whole ten Jears, was as 104.5 to 100 ; that is in the same ratio as throughout England. ${ }^{48}$ The proportions are sornetimes slightly disturbed by unknown causes; thus Prof.

40 'Twenty-nir'h Annual Peport of the Koristrar-Greneral for 1866.'
In this report (p. xii.) a special decennial table is giren. 
Faye states "that in some districts of Norway flut" has been "during a decennial period a steady deficieney of boys, whilst " in others the opposite condition has existed." In France cluring forty-four years the male to the femiale births have been as $106 \cdot 2$ to 100 ; but during this period it has occurred firo times in one department, and six times in another, that tho fiemale births have excecdeci the males. In Russia the average juroportion is as high as $105^{\circ} 9$, and in Philadelphia in the United states as 110.5 to 100.49 The arcrage for Europe, deduced by Bickes from about serenty million births, is 106 males to 100 females. On the other hand, with white children born at the Cape of Good Hope, the proportion of males is so low as to fluctnate duriug sucecssive years between 90 and 99 males for every 100 timales. It is a singular fact that with Jews the proportion of male births is decidedly larger than with Christians: thus in Prussia the proportion is as 113, in Breslau as 114, and in Livonia as 120 to 100 ; the Christian births in theso countries being the same as usual, for instance, in Lironia as 104 to 100.0 Prof. Faye remarks that " a still greater preponderance of " males would be met with, if death struck both sexes in equal " vroportion in the womb and during birth. But the fact is, that " for every 100 still-born females, we have in several countries "from 131.6 to 144.9 still-boru males. During the firet four or "five years of life, aliso, more male children die than females; "for example in England, during the first year, 126 boys die for " every 100 girls-a proportion which in France is still more " unfarourable." Dr. Stockton-Hough accounts for these facts in part by the moro frequent defective development of males than of females. Wo have before seen that the male sex is morc

49 For Norway and Russia, see abstract of Prof. Faye's researrhes, in 'British and Foreign MedicoChirurg. Review,' April, 181;7, pp. :343, 345. For France, the 'Annuilie pour l'An 1867,' p. 213. For Philadelphia, Dr. StocktonHough, 'Social Science Assoc.' 1874. For the Cape of Good Hope, Quetelet as quoted by D!. H. H. Zoutereen, in the Dutch 'Translatinn of this work (vol. i. p. 417), where much information is given on the proport.jon of the sexes.

so In regard to the Jews, see $M$. Thury, 'La Loi de Production des Sexes,' 1863, p. 25.

s1 'British and Foreign MedicoChimurg. Review; April, 1867, F.
343. Dr. Stark also remarks ('Tenth Annual Report of Births, Deaths, \&c., in Scotland,' 1867, p. xxviii.) that "These exampies may "sutfice to shew that, at almost " crery stage of life, the males in "Scotland have a greater liability" "to death and a higher death-r"ate "than the fimales. The fact, how"ever, of this peculiarity being " most strongly developed at that " intautile period of jife when the " dress, food, and genernl trentment " of both sexes are alike, scems tr "prove that the higher malo death"rate is an impressed, natural, ani "constitutional peculiarity due te "sex aluze." 
variable in : ructure than the female; and variations in important (1) . . 1s would generally be injurious. But the size of the body. as especially of the head, being greater in male than iemale ill...... is another cause: for the males are thus more liable to [n. jured during parturition. Consequently the stillborn maler ie more uumerous; and, as a highly competent judge, Dr. Crich w: : isrowne, ${ }^{52}$ believes, male infants often suffer in health for some 1,airs after birth. Owing to this excess in the death rate of $111 \therefore$ children, both at birth and for some time subsequently, whl owing to the exposure of grown men to various dangers, it it to their tendency to emigrate, the females in all old-settled "muntries, where statistical records have been kept, are found tw preponderate considerably over the males.

It seems at first sight a mysterious fact that in different nations, under different conditions and climates, in Naples, Prussia, Ih e phalia, Holland, France, England and the United States, the :xcess of male over female births is less when they: are illegitim. te than when legitimate. ${ }^{54}$ This has been explained by different writers in many different ways, as from the mothers being gencrully joung, from the large proportion of first presnancies, du: But wo have seen that male infants, from the large size of th" 'in heads, suffer more than female infants during parturition: and as the mothers of illegitimate children must be more liabl than other women to undergo bad labours, from various canvis, such as attempts at concealment by tight lacing, hard work distress of mind, \&c., their male infants would proportiondily suffer. And this probably is the most efficient of all the ratuses of the proportion of males to females bor'u alive being i iss amongst illegitimate children than amongst the legitimate. With most animals the greater size of the adult male than of the female, is due to the stronger males having conquered the weaker in their struggles for the possession of the females, and no doubt it is owing to this fact that the two sezes of at least some animals differ in size at birth. Thus

52 'West hiding Lunatic Asylum Reports,' vol. i. 1871, p. 8. Sir J. Simpson has proved that the head of the male intant exceeds that of the female by $3-8$ ths of an inch in circumference. and by $1-8$ th in transverse diameter. Quetelet has wown that woman is born smaller than man; see Dr. Duncan, 'Fecundity, Fertility, Sterility,' 1871, P. 382 .

ot With the sarige Guaranys of
Paraguay, according to the accurate Azara ('Voyages dans l'Amérique mérid.' tom. ii. 1809, p. 60,179 ), the women are to the men in the proportion of 14 to 13 .

34 Babbage, 'Edinburgh Journal of Science,' 1829 , rol. i. p. 88 ; also p. 90, on still-born children. OD illegitimate children in Englaud, see 'Report of Fegistrar-Genera) for 1866,' p. xv. 
we have the curious fact that we may attrilnts; the more irequent deaths of male than female infants, $\mathrm{ex}_{j}$. w. iy amongst the illigitimate, at least in part to sexual selectiun.

It has often been supposed that the relative age of the two parents determines the sex of the oflspriug; and Pro.. Leuckartio has alvanced what he considers sufficient ovidence, with respect to man and certain domesticated animals, that this is one important though not the sole factor in the result. So aysall the period of impregnation relatively to the state of the feniale has been thought by some to be the efficient canse; but rwent observations discountenance this belief. According to Di: stocktonIIough, ${ }^{56}$ the season of the year, the poverty or wealth of the parents, residence in the country ci is cities, the crossing of foreign immigrants, \&c., all infuence the proportion of the sexes. With mankind, polygamy has also been supposed to lead to the birth of a greater proportion of female infants; but Dr. J. Campbell ${ }^{57}$ carefully attended to this subject in the harems of Siam, and concludes that the proportion of male to female births is the same as from monogamous unions. Hardly any animal has been rendered so highly polygamous as the English racehorse, and we shall immediately see that his male and femalo offspring are almost exactly equal in number. I will now givc the facts which I have collected with respect to the proportional numbers of the sexes of various animals; and will then briefly discuss how far selection has come into play in determiuing tho result.

Horses.-Mr. Tegetmeier has been so kind as to tabulate for me from the 'Hacing Calentar' the births of race-horses during a perind of twenty-one years, viz., from 1846 to $1867 ; 1849$ being omitted, as no returns were that year published. The total births were $25,560,3^{38}$ consisting of $12,76: 3$ males and 12,797 females, or in the propurt on of $99 \cdot 7$ malis to 100 females. As these sumbers are tolerably large, and as tiey are druw from all purts of England, during several yiars, we may with much confidenre conclude that with the dommstic lurse, or at least with the race-horse, the two sexes are produced in almost equal zumbers. The fluctuations in the propotions during succt:ssive years

ss Leuckart (in Wayner' 'Hatdwörterbuch der Phys."1. iv. 185̆3, s. 774 .

so Social Science Assoc. of Philadelphia, 1874.

s7 'Anthropological Ripiew,' April, 1870, p. cviii.

ss During eleven years a record was kept of the number of mares vich proved barren or prematurely slipped their foals; and it deserves notice, as shewing how infertile these highly-unrtured and rather tosely-interbred animals have be. come, that not fin ficur une-third of the mases failed o prinluce livang foals. Thus during 1866,809 male colts ind 816 female colts were born, and 743 mares tailed to produce offspring. During $18157.830^{\circ}$ males and 902 females were born, and 794 mares failed. 
are closely likir the which orenr with mankind, when a small sed

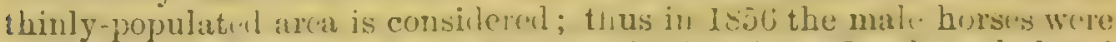

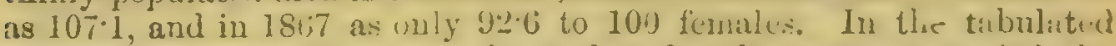
returns the proportums way in cycles, for the males exceeded the temales during six sucece ive years; and the fimales raceeded tho males during two periods cach of fomr years: this, howercr, may bo accidental; at least I cnn cletect nothing of the linil with man in the decennial table in the Registrar's Report for 1866.

Dogs:-During a period of twelve years, from 1857 to 1869 , the lirtie if a lirge number of greyhouids, throughout England, were sont to The 'Ficld' newspaper; and I am again iudebted to $/ 1 \mathrm{r}$. Tegetm ier for arefully tabulating tho results. The recorded hilths were 6578. consisting of 3605 males and 3273 fen ales, that is, in the proportim of 110.1 miles to 100 females. The greatest fluctuitions wecurred in 1864 , when the proportion was as $95: 3$ males, and in 1867 , as $116 \% 3$ males to 100 females. The above average proportion of $110 \cdot 1$ to 100 is frobably nearly correct in the case of the greylound, but whether it would hold with other domesticated breels is in some degrce donbtful. MIr. Cupples has enquired from severil great breeders of dogs, and find.s that all without exception believe that fimales are produced in cxcess; lut he suggests that this belief may have arisen from females being I) ss valued, and from the ennscquent disappointment producing a stronger impression on the mind.

Sheep.-'Ihe sexes of sheep are not ascertained by agriculturists until several months after birth, at the period when the miles are castrated; so that the following returis do not give the proportions at birth. Moreover, I find that several great breedurs in Sentlaus, who anuually raise some thousand sheep, are firmly conrincer that a larger proporticn of males than of females die cluring the first year or two. 'Therefore tho proportion of males would be somewhat larger at birth than at the age of castration. 'This is a remarkable coincilence with what, as we hive scu, occurs with mankincl, and both cases probably depend on tho atme cause. I have received returns from four gentlemen in England who have bred Lowland sheep, chicfly Leicestess, luring the last ten to sixteen years; they amount altngether to $8 ! 65$ births. consisting of 14117 males and 4558 females; that is in the propertion of 967 males to 100 females. With respect to Cheriot and black-faced sheep bred in Scotlaud, I have received returns from six breckers, two of them on a lavgo scale, chiefly for the years $1867-1869$, but some of the returns extend back to 1862. The totil numher recorded annomts to 50.685 , consisting of 25,071 males and 25,614 females, or in the proportion of 97.9 males to 100 females. If we take the English and Scotch returns together, the total number amounts to 59,650 , consisting of $29,47 \mathrm{~S}$ miles and :00,172 femiles, wr as 97.7 to 100 . So that with sheep at the age of castratinu the fomales are certainly in excess of the miales, but probably this would not hold gond at birth. ${ }^{59}$

(1) Catfle I have recive d returns from nine gentlemen of 982 births. ton fuw to be trusted; these cousisted of 477 bull-calves and 505 cons-

E9 I am much indebted to $\mathrm{Mr}$. Cripples for having procured for me the above returns from Scotland, as well as some of the following returns on cattle. Mr. R. Eilliot, of Laighwood, first called my atten- tion to the premature denths of the males, - a statement sursequently confirmed by $\mathrm{Mr}_{1}$. Aitchison and others. To this latter gentleman, and to Mr. Payan, 1 owe my thanks for lirge returas as to sheep. 
calves; i.e., in the proportion of $31 . \pm$ males to 100 fermales. The Rer. W. D. Fox informs Iue that in 18 ti out ef :it calves born on a farm in 1) crbyshire only one was a bull. Jr. Harrison Whir has enquired from arveral bre ders of Pigs, and mut of them estimate the mule to tho finnale births as about 7 to 6 . 'This same gentleman has bred liabbits for many years. and has noticel that a far greater number of bucks are produced thin does. But estimations are of little value.

(1) mamualia in a state of nature I have been ablo to learn very litile. I 1 regard to the common rat I hive received conflieting statement.s. MIr. R. Ellint, of Laighwool, informs me that a rat-catcher assulcel him that he had alwitys found the males in great excess, even with the young in the nest. In consequence of this, Mr. Llliot himself subsequently examined some lundred old ones, and found the stitciuent true. Mr. F. Bucklanil has bred a large number of white rats, ant he also believes that the males greatly exceed the femalos. In regitrd to MIole's, it is said that " the males are much more numerous "thisl the lemilles;" ${ }^{60}$ and as the catching of these animals is is special occupation, the statement may perhaps be trusted. Sir A. Sinith, in re-cribing an inte-lıpe of S. Afi ica (liobus ellipsiprymnus), remarks, that in thr. berds of this and other spreies, the males are few in number comparel with th. fomales: the natives believe that they are born in this yroprtion; others bilieve that th younger males are expelled frum the herls, and Sir A. Smith says, that though he has himself never seen herds consistiug of young males alone, others affirm chat this does occur. It appears probable that the young when expeiled from the heri, would often fall a prey to the many beasts of prey of the country.

\section{IRDS.}

With respect to the Foul, I have received only one account, namely, inat out of 1001 chickens of a hirhly-bred stuck of Crehins, reared dumg eight years by $M I r$. Streteh, ts? prowal males and 514 females; i.e., as 947 to 100 . In regrirl to domestice pigeons $t /$ ere is good evidence eitler that the males are producerl in excess. or thit they live loner ; for these birds invariably pair, and single males, as Mr. 'T'tgetmeier infurus me, can always be purchased chmper than fomales. Usually the two birds reared from the two exps laid in the same nest are a male and a femule; but Mr. Harrison Weir, who has been solarge a biceler, says that he has often bred two coclis from the same nest, and soldom two hens; morenver, the hen is gearrally the weaker of the two, and more lisble to perish.

Wuh rispect to birds in a state of nature, Mr. Fould and others ${ }^{62}$ are conviacerl that the males are generally the more numerous; and as the young males of many speries resenble the females, the latter would naturilly appear to be the more numerons. Ialge numbers of plu asitnis are reared by Mr. Balier of Learlenhall from eggs laicl by wild birds, and lee intorms MIr. Jenner Weir that four or five males to one fimale are generally produced. An experiencol observer remarks: ${ }^{63}$

60 Bell, 'History of British Quadrupeds,' p. 100.

61 'Illustrations of the Zoology of S. Africa.' 1849, pl. 29.

2 Brehm ('Inlust. Thierlebed, B. iv. s. 990) comes to the same conclusion.

${ }^{63} \mathrm{On}$ the authority of L. I.loyd, 'Game Birds of Streden," 1357 ' !'. $12,132$. 
: hat in Scandinavia the broods of the capercailzic and black-cock voutan more malcs than fomales, and that with the Dirl-ripla (a kinc: if ptarmigan) more males than females attend the leks of places of murtship; but this latter circumstance is accounted for by some thervers by a greater number of hen birds heing killed by vermin. From various ficts giren by White of Selburne, ${ }^{64}$ it seems clear that ihe males of the partridge must be in considerable excess in the sunth ri England; and I have becn assured that this is the case in Scotland. Mr. Weir on cuquiring from the dealers, who roceive at certain s asons l.rge numbers of rutls (Machetes pugnax), was told that the males are rnucl, the more numerous. This same naturalist has also enquired for ne from the birdcatchers, who amually catch an astonishing number if various small speries alive for the Londo: market, and he wis ml:psitatingly answered by an old and trustworthy man, that with the "haffinch the males are in large excess; he thought as high as 2 males to I female, or at least as high as 5 to $3^{.65}$ The males of the blackbird. he likewiso maintained, were by far the more numerous, whether 'aught by traps or by netting at night. These statements may apparently be trusted, because this same ma:? said that the sexes arc ahout equal with the lark, the twite (Limaric mortana), and gold tinch. On the other haud, he is certitin thit with the common linuet, the femiles preponclerate greatly, but unequally during different years: rluring some years l,e has found the females to the males as four to one. It should, howerer, be borne in mind, that the chief season for catching liris dres not begin till Septennber, sn tbat with some speci-s partial inigrations may have begun, and the flicks at this perind often consist if liens alone. Mr. Salvin paid particular attention to the sexes of the Lumming-birds in Central Ameriea, and he is convinced tiat with most of the species the male's are in excess; thus one year he procurert 204 specimens belonging to t-n specits, and these cousisted of $166^{\circ}$ males and of only 38 females. With two other species the females were in excess: but the proportions apparently vary either during difterent seasons or in different localities; for on one occusion the males of Campylopterus hemileucurus were to the femules as 5 to 2 , and on "nother occasion ${ }^{66}$ in exactly the reversed ratio. As bearing on this latter point, I may add, that Mr. Fowys found in Corfu and Èirus the sexes of the chafinch leeping apart. and "the fenales by far the " mnist numerous ;" whilst in l'alestine Mr. Trintram found "the malle "Alocks aplearing greatly to exceol the femile in number." ${ }_{67}$ So azain with tho Quiscalus majur, Mr. (․ 'Taylor ${ }^{68}$ says, that in Flnridu here were "very fow females in proportion to the males," whilst in iInduras the propurtion was the other way, the species there having the character of a polygamist.

- 'Nat. Hist. of Selborne,' letter' xrix. edit. of 1825 , vol. i. p. 139.

${ }_{65} \mathrm{Mr}$. Jenner Weir received similar inlormation, on making enqquiries during the following year. To shew the number of living chafriaches caught, I may mention that in 1869 there was a inatch between two experts, and one man caught in a day 62 , and another 40 , male chaffinches. Th: greatest number ever caught by one man in a single day was 70 .

${ }^{6 B}$ 'Ibis,' vol. ii. p. 260, gs queted 1n Gould's 'Trochilidx,' 1861, 1. 52. For the foregoing proportious, I am indebted to Mr. Salvin for a table of his results.

67 'Ibis,' 1860, p. 137; and 1867 p. 369 .

68 'Juis,' 1862, p. 137. 


\section{FISLI.}

Wish Fish the proportinusl numbers of the sexes can be ascelained unly by catching shem in the adult or nearly adult state; and there are many difficulties in arriving at any just conclusion. ${ }^{69}$ Infertile iomales mirht ruadily be misticken for males, as Dr. Günther bas renurkel to me in regard to trout. With some species the males are believed to die soon after fertilising the ova. With many species the inules are of much smaller size than the females, so that a laryo number of male's would escape from the same net by which the female's were caurht. AI. Carbonnier, ${ }^{70}$ who has especially attended to 1 lue natural histury of the pike ( $E$ *ox lucins), states that muny males, owing to their small size, are devoured by the larger females; and he believes that the males of ulwost all tish are exposed from this same cause to greater diunger than the females. Nevertheless, in the lew cases in which the proportional numbers have been actually observed, the males appear tu be largely in cxcess. Thus Mr. R. Buist, the superintendeat of the Stomonttield experiments, says that in 1865. out of 70 -almun first landed for the purpose of obtaining the ovia, upwards of 60 vere males. In 1867 he again "calls attention to the vast disproportion " of the mules to the femules. We had at the outset at least ten males "to one female." Afterwards feinales suthicient for obtaining ova were procured. He adds, "from the great proportion of th. males, they aro "constantly fighting and tearing each other on the spawning-beds." 'iłis disproportion. no doubt, ean be accounted for in part, but whether wholly is drubtful, by the males ascending the rivirs before the iemales. Mr. F. Buckland remarks in regard to trout, that " it is a "curious fact that the male's preponderate very largely iu number ove" " the females. It invarially happens that when the îrst ruah of fish is " made to the net, there will be at least seven or eight males to one - female found captive. I cannot quite account for this; either th. "males are more numerous than the fumales, or the latter scek safely "by concealment rather than flight." He then ards, that by carefully searching the banks sufficient females for obtaining ova can be found. $\mathrm{Mr}$. H. Lee informs me thit cut of $21 \%$ trout, taken for this purpose in Lord Portsmouth's park, 150 were males and 62 fenales.

The males of the Cyprinidie likewise seem to be in excess; br:t several wembers of this Family, viz., the carp, tench, brian aud uninnow, appear regularly to follow the practice, rure in the animal kingdom, of polyandry; for the female whilst spawning is always attended by two males, one on each side, and in the cisse of the bream by three or four males. This fact is so well known. that it is always recommended to stock a pond with two male tenches to one fimale. or at least with three males to two femules. With the minnuw. an excellent ubserver states, that on the spawuing-beds the males are tel: times as numerous as the females; when a female comes amongat the

49 Leuckart quotes Bloch (Wag. ner, 'Handwörterbuch der Phys." B. iv. 1853, s. 775), that with fish there are twice as many males as temales.

$$
\text { io ('usted in the 'Farmer,' Harch }
$$

18,1869 , p. 369 .

"1 "The Stormontfield Piscicnltural Experiments, 1866, po 23. The 'Field' newspaper, June $24: n$, 1867.

$$
72 \text { 'Inad aud Water,' 1868, p. } 14
$$


males, "she is immediutely pressed closely by a male on each side; "and when they have been in that situation for a time, are cuperseded "by other two males." 73

\section{INSECTS.}

In this great Class, the Lepidnpterr. almost alone afford mcans for jurging of the proportional numbers of the sexes; for they have been collected with special care by many good observers, anil bave been largely bred from the egg or caterpiliar siate. I had hoped that somo breeders of silk-moths might have kent an exact rerord, but after writing to France and Italy, and consulting various treatises, I cannct find that this has ever been done. The general opinion appeirs to be that the sexes are nearly cqual, but in Italy, as I heal from Professor Cunestrini, many breeders aro convinced that the femules are produced in excess. This same naturalist. however, informs we, that in the two yearly broods of the Ailanthus silk-moth (Bombyx ('ynthiu), the males greatly preponderate in the first, whilst in the second the two sexes are nearly equal, or the females rather in excess.

In revard to Butterflic's in a state of nature, several observers have been much struck by the apparently enormous proponderance of the males. ${ }^{7+}$ Thus Mr. Bates, ${ }^{73}$ in spealking of several species, about a hundred in number, which inlatbit the Upper Amazons, says that tho males are much wore mumcrous than the females, even in the proportion of a hundred to one. In North Americi, Edwards, who had great experience, estimates in the genus Papilio the males to the femules as four to one; and Mr. Walsh, who infirmed me of this statement. sars that with $P$. furmus this is certuinly the case. In South Afrie: MIr. $\dot{R}$. 'Trimen fond the males in excess in 19 spevies; $;^{; 6}$ and in one of these, which swarms in op n plisces. he estimated the number of males as fifty to one female. With wnother speces, in which the males are numerous in certain localities, he collected only five fenales during seven years. In the island of Bourbon, M. Mailiard states that the males of one species of Papilio are twenty times as numerous as the females. ${ }^{77}$ Mr. Trimen informs me that as far as he has hirnself seen, or heard from others, it is rare for the females of any buttertly to exceed the miles in number; but three Sonth African species perhaps offer an exception. Mr. Wallace is states that the females of Ornithoptera crssus, in th. Malay arehipelam, are more common and more easily caucht than the males; but this is a rare buttertly. I may

73 Yarrell, 'Hist. British Fishes,' vol.i. 1826, p. 307 ; on the Cyprinus carpio, p. 331 ; on the Tinca vulgaris, p. 331 ; on the Almamis brame, p. 336. See, for the minoow (Leuciscus phoxin's), 'Loudon's Mag. of Nat. Hist.' vol. v. 1832, p. 682.

it Leuckart quotes Meinecke (Wagner, 'Handwörterbuch der 'Phys.' B. iv. 1853, s, 775) that the males of Butterflies are three or four times as numerous as the females.

75 "The Naturalist on the Amazons,' vol. ii. 1863 , p. 228,347 .

${ }^{76}$ Four of these cases are given by Mr. Trimen in his - Rnopalocera Africæ Australis.'

7 Quoted by Trimen, "Transact. Ent. Soc.' vol. v. part iv. 1866, p. 330. 'Transact. Linn. Soc,' vol. zxv. p. 37. 
here ald, that iu Hyperytura, a genus of moths, Guence sars, thit from four to five females are sent in collections from India ior one male.

When this subject of the proportional numbers of the sexes of insects wis brought before the Entomological society, ${ }^{73}$ it was gonerilly arluitted that the males of mosi Lepidopteri, in the adult or imago st.u., are caucht in greater numbers than the fomales: but this fact was attributed ly various observers to the more retiring habits of the fentales, and to the males emerging earlier from the cocoon. 'This latter circumstince is well known to oceur with most Lepilloptera, as well as with other insects. So that, as M. Personnat remarks, the males of the lomesticated Bombyx Yumamai, are useless at the berinniug of the suison, and the females at the end, from the want of mittes. ${ }^{80}$ I cannot, howerer, persuade myself that these causes suffice to explain the great excess of miles, in the above cases of cortain butterthes which are extremely common in their native countries. Mr. staintou, who has pail very close attention during many years to the smitller moths, informs me that when he collected them in the imago state, he thount that the males were ten times as numerous as the females, but thut since he has reared them on a large scale from the catcrpillar state, ho is convinced that the females are the more nunierous. Several cntomologists concur in this view. Mr. Doubleday. however, and some others, take an opposite view, and are convincel that they have reared from the eggs and caterpillurs a larger proportion of males than of females.

Besides the more active habits of the males, their earlier emergence from the cucoon, and in some cases their frequenting more open stiztions, other cause's may be assigned for an apparent or real differenco in the proportional numbers of the sexes of Lepidoptera, when capturch in the imago state, and when reared from the igg or caterpillar stite. I hear from l'rofessor Canestrini, that it is believed by many breders in Italy, that the female caterpillar of the silk-moth suffere mure from the recent discase than the male; and Dr. Staudinger informs wo that in reariug Lepiloptera more females die in tho ro oon than males. With many species the female caterpillar is la'ger thin the male, and a collector would naturally choose tho tinest specimens, and thus unintentionally collect a larger number of fimales. There cullectors bave tuld me that this was their practice; but Ir. Willize is sure that most cullectors take all the specimens which they can find of the rarer kinds, which alone are worth tho tronble of reariun. Birds when sirrounder by caterpillars would probably devour the largest; and Professor Canestrini informs me thit in Italy some brecters belicre. thongh on insutheient evidence, that in the first brouds of the Ailanthus si k-moth, the wasps destroy a larger number of the femite than of the male catcrpillars. Dr. Wallite further remarks that female citerpillars, from leing larey than the males, require more time for their development, and cousume more fool and rnois ture; and thus they would be expessed during a longer time to danger from ichneumons, birds, sec, and in times of scarcity wonlit purish in greater numbers. Heuce it appcars quice possiblo that

;日 'Proc. Entomolog. Soc.' Feb. 1.th, 1868. 'Proc. Ent. Soc.' 3rd series, rol. $1867,1.487$.

"Qunted by $D_{3}$. Wallace in 
in a state of uature, fewer female Lepidoptera may reach maturity than males; nnd for our special object we are concerner with their relative numbers at maturity, when the sexes are ready to propagate their kind.

The manner in which the males of certain moths congregate in extraordinary numbers round a single female, apparently inclicates is great excess of malcs, though this fact nay purhaps be accounted for by the earlicr (mergence of the males from their cucnons. Mr. Stainton informs me that from twelve to twenty males, may often br. sien congregat.d round a female Elachistr rufocinerea. It is well linown that if a virgin Lasiocampa quercus or Suturnia carpini be exposed in a cage, vast numbers of males collect round her, and it confined in a room will even coine down the chimney to $\mathrm{h}$ ( $\mathrm{r}$. Mr Dombleday bulieves that he has seen from fifty to a hundred males of both these species attracted in the course of a single day by a female in confinement. In the Isle of Wight Mr. Trimen exposed a box in which a female of the Lasiocampa hid beren confined on the previous day, and five males soon endeavoured to gaiu admittance. In Australia, M. Verreaux, having placed the fenale of a small Bombyx in a box in his pocket, was followed by a crowd of males, so that about 200 entered the house with him. ${ }^{81}$

Mr. Doubleday has called my attention to $\mathbf{M}$. Staudinger's ${ }^{82}$ list of Lepidnptera, which gives the prices of the males and females of 300 species or well-marked varieties (if butterfies (Rhopalocera). The prices for both sexes of the very common species are of cuurse the same; but in $\mathbf{1 1 4}$ of the rarer species they differ; the males being in all cases, excepting one, the cheaper. On an average of the prices of the 113 species, the price of the mile to that of the female is as 100 to 149 ; and this apparently indicates that inversely the males exceed the females in the same proportion. Abuut 2000 species or varictics of moths (Heterocerii) are catalnguel, those with wingless females being herc. excluded on acciunt of the difference in habits between the two sexes: of these 2000 species, 141 differ in price according to $s e x$, the males of 130 being chenper, and those of only 11 being dearer than the females. The average price of the males of the 130 specics, to that of the females, is as 100 to 143 . With respect to the butterglies in this priced list, Mr. Doubleday thinlis (and no man in Euglaud has hat more (xperience), that there is nothing in the habits of the specie: which can account for the difference in the prices of the two sexes. and that it can be accounted for only by an excess in the number of the male's. But I am bound to add that Dr. Staudinger informs me, that be is himself of a different opinion. Ho: thinks that the less active unbits of the femiles and the earlier emergence of the males will account for his collectors securing a larger number of males than of femules, and consequently for the lower prices of the former. With respect to sperimens reared from the caterpillar-state, Dr. Staudinger believes, as previously stated, that a greater number of females than of males die whilst confined in the cocoons. He adds that with certain species one sex seems to preponderate over the other during certain years.

Of direct observations on the sexes of Lepidoptera, reared either

\footnotetext{
- Blaccharl, 'Métamorphoses, "Lepidopteren-Doub!e:ted Mours des Insectes, 18:8, pF. 2.5- Liste, Berlia, No. x. 1866.
} 22กั 
from eggs or catcrpillars, I have received only the few following cases:-

Males. | Femalte.

The Rev. J. Heilins ${ }^{83}$ of Exeter reared, during 1868,

$+153$
imagos of 73 species, which consisted of .

Mr. Albert Jones of Eltham reared, during 1868, imagos of 9 species, which consisted of . . .

During 1869 he reared imagos from 4 species, consisting of . . . . . . . . .

M. Buckler of Emsworth, Hants, during 1869, reared imagos from 74 species, consisting of.

Dr. Wallace of Colchester reared from one brood of Bombyx cynthia . . . . . . . .

Dr. Wallace raised, from cocoons of Bombyx Pernyi sent from China, during 1869 . . . .

153

159

114

180

52

224

Dr. Wallace raised, during 1868 and 1869 , from two lots of cocoons of Bombyx yama-mai

Total
112

169

123

137

\section{6}

\section{2}

8

So that in these eight lots of cocoons and eggs, males were producal in excess. Taken together the proportion of males is as 122.7 to 100 females. But the numbers are hardly large enough to be trustworthy.

On the whole, from these various sources of evillence, all pointing in the same direction, I infer that with inost species of Lepidoptera, the mature males generally exceed the females in uumber, whatever ihe proportions may be at their first emergence from the egg.

With reference to the other Urlers of insects, I have oeen able to collect very little reliable information. With the stas-beetle (Lucanus cervus) "tho males appear to be much moro numerous "than the females;" but when, as Cornelius remarked during 1867, i11 unusual number of these beetles appeared in one part of Germany, the femsiles appeared to exceed the males as six to one. With one of the Eliteridie, the males are said to be murh more numerous than the fenales, and "two or three are often found united with one fomale;" "sn that bere prlyandry seems to prevail." With Siagonium (Staphylinidæ), in which the males are furnished with horns, "tıe females are "far more numerous than the opposite sex." Mr. Janson stated at the Lntumological Society that the females of the bur-feeding Tomicne iillosus are so common as to be a plague, whilst the males are so rara us to be hardly known.

s This naturalist has been so kind as to send me some results from former years, in which the females seemed to preponderate; but so many of the figures were estimates, that I found it impossiblc :u tabulate them.
84 Ginther's "Record of Zoological Liternture,' 1867, p. 260. On the excess of female Lucanus, ibid..p. 250. On the majes of Lucanus in England, Westwood, "Modern Class, of Insects,' vol. ¿. p. 187. On the Siagonium, ibid. p. 172. 
It is hardly worth while aving nnything about the proportion of the sexes in certain sperie's and cren grompls of insect. fior the males are unknown or very rur, and the females are jarthenugenetie. Ihe. is, fertile without sextmil nuinn; excmples of this are attorded by several of the Cynipidie.s5 In all the Gall-making Cynifide Lnown to Mr. Willah, the females are four or five times in numerous an the males; and so it is, as he informs me, with the crall-naking (cecdomviia (Diptera). With some common species of Silw-tlies (J'mutherline) Mr. F. Simith has reured handreds of specimens from lamie of all sizes, but haw never reared a single male: on the rither hand. Curtis says, st that with certain species (1thalia). Jrerl hy him. the mi: los were to the fonales as six to one; whilst exictly the revers: cureured with the minture insects of the same species canglat in the dichls. In the fa!nily of 33 es, Hermann Müller. ${ }^{87}$ collented a litree number of specimeus of many specics, aud reared whers from tre cocons, and counterl the sexes. Ile found that the males of some spreries werty - xceeded the females in number; in others the reverse uncurreal: and iu nthers the two sexes were nearly equal. Inut as in most calses the males emerge from the cocoons before the fomales. they are at the conmencenent of the hrecding seasn practically in crcess. Hiuller also observed that the relutive number of the two sexes in sume species differed much in different localities. But as II. Müller has himself remarked to me, these remarks must be received with gome caution, as one scx might more earigy ereaje olservation than the other. 'Thus his brother Fritz Miillor has noticed in Brazil that the two sexes of the same species of bee smutimes frequent dificrent kinds of fluwers. With respert to the Orthoptera, I know iandly anything about the relative number if the sexe-: Körte, ${ }^{\text {bs }}$ hewerer, say's that out of 500 locusts which he eramineil, the males weres to the females as tive to six. With the Neuroptera, Mr. Wal.h states that in many, but by no means in all the species of the Udon.tous moup, there is a great overplus of males: in the genus Hetarina, also, the males are generally at least four times as numerous as the femile's. In certai : species in the genus Gompluus the males are effually in: cxcess, whilst in two other speries, the females are twice or thirie as mumernus as the males. In some Furnpenn species of P'son ns thomsanin of females maty be collected without a single male. Whilst nith wher species of the same gemus hoth sexes are cummon." in Iingland, Mr. MacLachlan has captured hundreds of the female Alatanin mulielris, hut las never sten the mile; and of liorms ligumulis uny four or tive malu's hive been secu here.90 With in st of thr se species (execpting the Tenthredine) there is at prosent no evildmen thit the females are subject to pirthenogenesis; ant ti us we se how ignorint we are of tho causcs of the apparent discrepancy in the proportion of the two sexes.

In ti,e other Classes of the Articulata I have been able to collect =lil!

83 Walsh, in 'The American linEomologist,' vol. i. 1869, p. 103. F. Smith, 'Record of Zoological Lite past pre,' 18677, p. 328.

86 'Liam lusects,' pp. 45-46.

8: 'Auweudung, der' Darwaschen

I.hre Verh. d. n. V. Jahrg. sxiv.'

- "Die Strich, Zug odec Witu- derheuschrecke,' 1828, p. 20.

89 'Observations on $\mathrm{N}$. Americin Neuroptera,' by H. Hagen and B. D. Walsh, 'Proc. Ent. Soc. Philadelphia,' Oct. 1863 , pp. 168,223 , 239.

90 'Proc. Ent. Soc, Londen,' Feb. $17,1868$. 
lars information. With Spilers, Mr. Ilackirall, who has carefully attencled to this class during many years, wites to me that the malesi from their more erratic halits are more commonly secen, and theretore appen wure numerous. 'This is netually the "ase with a few species; fut he mentions several spreies in six enenera, in whing the fomales aplear to be mueh more numerous than th: antes. ${ }^{91}$ 'I he small size of the males iu comparionn with tho females (it peculiarity which is sometimes cirriel to an extreme desree), and their wilely difierent appear. cuce, mity aceount in sme instinces for the ir rarity in collections.".

Some of the lower Crusticens are able to propigate their kind asexully, and this will aceount for the extreme tarity of the males: thu, Von sicbold "'3 carefully examined no less than 1:3,000 specimens of Apus from twenty-one localities, and amonest these he found only 319 males. Witı some other firms (as 'Tanais and Cypris), as Fritz Mull.r informs me, there is reason to believe that the males are much shorter-lived than the females; and this would explain their searcity, supposine the two sexes to be at first equal in uumber. On the other laund, Miuller has invariably taken far more males than females of the Diastylide and of Cypridiua on the shores of Brazil; thus with a species in the latter genus, ti3 specinens canght the same day included if male's; but he surgests that this prepunderance suay be due tc some unlinown difference iu the liabits of the two sexes. With onc of the hirher Brazilian crabs, namely a (jelasimus, Fritz Mülle? tound the wal's to be more numerotis than the females. Accordine to the l.irce experience of Mr. C. Spence Bate, the reverse secms tc be the case witu six common British crabs, the names of which he Las given me.

\section{The pioportion of the sexes in relation to nutural sclection.}

There is reason to suspect that in some cases man has by selection indirectly influenced his own sex-producing powors. Curtain women tend to produce during therr whole lives moro children of one sex than of the other: and the same holds good of many animals, for instance, cows and horses; thus Mr. Wright of Yeldersley House informs me that one of his Arab mares, though put seven times to different horses, produced seven fillies. Though I hare very little evidence on this head, analogy rould lead to the belicf, that the tendency to produce oither sex would he inherited like almost every other pectliarity, for instance, that of producing twins; and concerning the above tendency a good authority, Mr. J. Downing, has communicated to me facts which secm to prove that this does occur in certain families of short-horn cattle. Col. Marshall" has recently found on careful examination that the I'odas, a lill-tribe of India.

91 Another great authority with res].ect to this class, Prot. Thorell of Upsala ('On European Spiders,' $1869-70$, part i. p. 205) speaks as if female spiders were generally commoner than the males.

'See, on this subject, Mr.
O. P. Cambridge, as quoted in 'Quarterly Journal of Science, 1868, p. 429.

98 ' Beiträge zur Parthenczenesis, p. 174.

Q4 'The Todas,' 1873. pp, InO $111,194,196$. 
consist of 112 males and 84 females of all ages-that is in a ratio of 133.3 males to 100 females. The Todas, who are polyandrous in their marriages, during former times invariably practised female infanticide; but this practice has now been discontinued for a considerable period. Of the children born within late years, the males are more numerous than the females, in the proportior of 124 to 100. Colonel Marshall accounts for this fact in the: following ingenious manner. "Let us for the purpose of illustra"tion take three families as representing an arerage of the "entire tribe; say that one mother gives birth to six daughters " and no sons; a second mother has six sons only, whilst the "third mother has three sons and three daughters. The first "mother, following the tribal custom, destroys four daughters " and preserves two. The second retains her six sons. The third "kills two daughters and keeps one, as also her three sons. We " have then from the three families, nine sons and three daughters, " with which to continue the breed. But whilst the males "belong to families in which the tendency to produce sons is "great, the females are of those of a converse inclination. Thus " the bias strengthens with each generation, until, as we find, "families grow to have habitually more sons than daughters."

That this result would follow from the above form of infanticide scems almost certain; that is if we assume that a sex-producing tondency is inherited. But as the above numbers are so extremely scanty, I have scriched for additional evidence, but cannot decide whether what I have found is trustworthy; nevertheless the facts are, perhaps, worth giving. The Maories of New Zealand have long practics infanticide; and Mr. Fenton" states that he "has met with instances of women who have de"stroyed four, six, and even seven children, mostly females.

- However, the universal testimony of those best qualified to " judge, is conclusive that this custom has for many years becn " almost extinct. Probably the year 1835 may be named as the " period of its ceasing to exist." Now amongst the New Zealanders, as with the Todas, maln births are considerably in excess. IIr. Fenton remarks (p. 30), "Ore fact is certain, although the " exact period of the commencement of this singular condition of " the disproportion of the sexes cannot be demonstratively fixed, " it is quite clear that this course of decrease was in full opera"tion during the years 1830 to 1844, when the non-adult "population of 1844 was being produced, and has contiuued "with great energy up to the present time." The following statements are taken from Mr. Fenton (p. 26), but as the numbers 95 'Aboriginal lnhabitants of New Zealand; Gorernment Report,' 1859, p. 36. 
are not large, and as the census was not accurate, uniform results cannot be expected. It should be borne in mind in this and the following cases, that the normal state of every population is an excess of women, at least in all civilised countries, chiefly owing to the greater mortality of the male sex during youth, and partly to accidents of all kinds later in life. In 1858, the mative population of Now Zealand was estimated as consisting of 31,667 males and 21,303 females of all ages, that is in the ratio of 130.3 males to 100 females. But during this samie year, and in certain linited districts, the numbers were ascertained with much care, and the males of all ages were here 753 and the females 616 ; that is in the ratio of 122.2 males to 100 females. It is more important for us that during this same year of 1858, the non-adult males within the same district were found to be 178 , and the non-adult females 142 , that is in the ratio of 125.3 to 100 . It may be added that in 1844, at which period female infanticide had only lately ceased, the non-culult males in one district were 281 , and the non-adult. females only 194 , that is in the ratio of 144.8 males to 100 females.

In the Sandwich Islands, the males exceed the females in number. Infanticide was formerly practised there to a frightful ixtent, but was by no means confined to female infants, as is shewn by Mr. Ellis, ${ }^{96}$ and as I have been informed by Bishop Staley and the Rev. Mr. Coan. Nevertheless, another apparently trustworthy writer, Mr. Jarves, ${ }^{97}$ whose observations apply to the whole archipelago, remarks:- "Numbers of women are to " be found, who confess to the murder of from three to six or eight "children;" and he adds, "females from being considered less " useful than males were more often destroyed." From what is known to occur in other parts of the world, this statement is probable; but must be received with much caution. The practice of infanticide ceased about the year 1819, when idolatry was abolished and missionaries settled in the Islands. A careful census in 1839 of the adult and taxable men and women in the island of Kauai and in one district of Oahu (Jarves, p. 404), gives 4723 males and 3776 females; that is in the ratio of 125.08 to 100 . At the same time the number of males under fourteen years in Kauai and under eighteen in Oahu was 1797 , and of females of the same ages 1429 ; and here wo have the ratio of 12575 males to 100 females.

In a census of all the islands in $18500^{98}$ the males of all ages

30 "Narrative of a Tour through Hawaii,' 18:6, p. 298.

${ }_{98}$ 'History of the Sandwich Lslands,' 1843, p. 93.
98 This is given in the Rev. H. T. Cheever's 'Lite in the Sandwich l. lnods,' $1851, \mathrm{p} .277$. 
amount to 36,272 , and the females to 33,128 , or as $109 \cdot 49$ to 100. The males under seventeen years amounted to 10,773 , and the females under the same age to 9593 , or as 1123 to 100. From the census of 1872 , the proportion of males of all ages (including half-castes) to females, is as 12.36 to 100 . It must be borne in mind that all these returns for the Sandwich Islands give the proportion of living males to living females, and not of the births; and judging from all cirilised countries the proportion of males would have been considerably higher it the numbers had referred to births.99

From the several foregoing cases we have some reason to believe that infanticide practised in the manner above explained, tends to make a male-producing race; but I am far from supposing that this practice in the case of man, or some analogous process with other species, has been the sole determining cause of an excess of males. There may be some unknown law leading to this result in decreasing races, which have already become somewhat infertile. Besides the several causes previously

98 Dr. Coulter, in describing ('Journal R. Geograph. Soc.,' rol. จ. 1835, p. 67) the state of California about the year 1830 , says that the natives, reclaimed by the Spanish missionaries, have nearly all perished, or are perishing, although well treated, not drivea from their native land, and kept from the use of spirits. He attributes this, in great part, to the undoubted fact that the men greatly exceed the women in number; but he does not know whether this is due to a failure of female offspring, or to more females dying during early youth. The latter alternative, according to all analogy, is very improbable. He adds that "in"fanticide, properly so called, is "not common, though very fre"quent recourse is had to abor" tion." If Dr. Coulter is correct about infanticide, this case cannot be advanced in support of $\mathrm{Col}$. Marshall's view. From the rapid decrease of the reclaimed natives, we may suspect that, as in the cases lately given, their fertility has been diminished from changed labits of life.

I had hoped to gain some light on this subject from the breeding of dogs; inasmuch as in most breeds, with the exception, perhaps, of greyhounds, many more female puppies are destroyed than males, just as with the Toda infants. Mr. Cupples assures me that this is usual with Scotch deer-hounds. Unfortunately, I know nothing of the proportion of the sexes in any breed, excepting greyhounds, and there the male births are to the female as 110.1 to 100 . Now from enquiries made from many breeders, it seems that the females are in some respects more esteemed, though otherwise troublesome; and it does not appear that the female puppies of the best-bred dogs are systematically destroyed more than the males, though this does sometimes take place to a limited extent. Therefore I am unable to decide whether we can, on the above principles, account for the preponderance of male births in greyhounds. On the other hand, we have seen that with horses, cattle, and sheep, which are too valuable for the young of either sex to be destroyed, if there is any difference, the females are slightly in escess 
alluded to, the greater facility of parturition arıongst savages, and the less consequent injury to their male infints, would tend to increase the proportion of live-born males to females. There does not, however, seem to be any necessary connection butween savage life and a marked excess of males; that is if we may judge by the character of the scanty offspring of the lately existing Tasmanians and of the crossed offspring of the Tahitians now inhabiting Norfolk Island.

As the males and fumales of many animals differ somewhat in habits and are exposed in dificrent degrees to danger, it is probable that in many cases, more of one sex than of the other are habitually destroyed. But as far as I can trace out the complication of causes, an indiscriminate though large destruction of either sex would not tend to modify the sex-producing power of the species. With strictly social animals, such as bees or ants, which produce a vast number of sterile and fertile females in comparison with the males, and to whom this preponderance is of paramount importance, we can sce that those communities would flourish best which contained females having a strong inherited tendency to produce more and more females; and in such cases an unequal sex-producing tendency would be ultimatcly gained through natural selection. With animals living in herds or troops, in which the males come to the front and defend the herd, as with tho bisons of North Americn and certain baboons, it is conceivable that a male-producing teudency might be gained by natural selection; for the individuals of the better defended herds would leave more numerous descendants. In the case of mankind the advantage arising from having a preponderance of men in the tribe is supposed to be one chinf cause of the practice of female infanticide.

In no case, as far as we can see, would an inherited tendency to produce both sexes in equal numbers or to produce one sex in excess, be a direct advantage or disadvantage to certain individuals more than to others; for instance, an individual with a tendency to produce more males than females would not succeed better in the battle for life than an individual with an opposite tendency; and therefore a tendency of this kind could not be gained through natural selection. Nevertheless, there are certain animals (for instance, fishos and cirripedes) in which two or more males appear to be necessary for the fertilisation of the female; and the males accordingly largely preponderate, but it is by no means obvious how this male-producing tendency could havo been acquired. I formerly thought that when a tendency to produce the two sexes in equal numbers was advantagecus tc the epecies, it would follow from inatural selection, but I now 
see that the whole proulem is so intricate that it is safer to leave its solution for the future.

\section{CHAPTER IX.}

\section{Seoondaly Sexual Characters in the Lower Classeg of THE ANIMAL KingDom.}

These characters absent in the lowest classes-Brilliant colours-Mollusca -Annelids - Crustacea, secondary sexual characters strongly developed; dimorphisin; colour; characters not acquired before maturity-Spider's, sexual colours of; stridulation by the males-Myriapoda.

WrтH animals belonging to the lower classes, the two sexes are not rarely united in the same individual, and therefore secondary sexual characters cannot be developed. In many cases where the sexes are separate, both are permanently attached to some support, and the one cannot scarch or struggle for the other. Moreover it is almost certain that these animals have too imperfect senses and much too low mental powers, to appreciate each other's beauty or other attractions, or to feel rivalry.

Hence in these classes or sub-kingdoms, such as the Protozon, Colenterata, Echinodermata, Scolecida, secondary sexual characters, of the kind which we have to consider, do not occur; and this fact agrees with the belief that such characters in the higher classes have been acquired through sexual selection, which depends on the will, desire, and choice of either sex. Nevertheless some few apparent exceptions occur; thus, as I hear from Dr. Baird, the males of certain Entozoa, or internal parasitic worms, differ slightly in colour from the females; but we have no reason to suppose that such differences have been augmented through sexual selection. Contrivances by which the male holds the female, and which are indispensable for the propagation of the species, are independent of sexual selection, and have been acquired through ordinary selection.

Many of the lower animals, whether hermaphrodites or with separate sexes, are ornamented with the most brilliant tints, or wre shaded and striped in an elegant manner; for instance, many corals and sea-anemones (Actiniæ), some jelly-fish (Medusæ, Porpita, \&c.), some Planariæ, many star-fishes, Echini, Ascidians, \&c.; but wo may conclude from the reasons already indicated, namely the union of the two sexes in some of these animals, the permanently affixed condition of others, and the low mental powers of all, that such colours do not serve as a sexual attraction, and have not been acquired through sexual selection. 
It should be borne in mind that in no case have we sufficient evidence that colours have been thus acquired, except where one sex is much more brilliantly or conspicuously eoloured than the other, and where there is no differenco in habits between the sexes sufficient to account for their different colours. But the evidence is rendered as complste as it can ever be, only when the more ornamented individuals, almost always the malos, voluntarily display their attractions betore the other sex; for we cannot believe that such display is useless, and if it be advantageous, sexual selection will almost inevitably follow. We may, however, extend this conclusion to both sexes, when coloured alike, if their colours are plainly analogous to those of one sex alone in certain other species of the same group.

How, then, are we to account for the beautiful or even gorgeous colours of many animals in the lowest classes? It appears doubtful whether such colours often serve as a protection; but that we may easily err on this head, will be admitted by every one who reads MIr. Wallace's excellent essay on this subject. It would not, for instance, at first occur to any one that the transparency of the Medusæ, or jelly-fishes, is of the highest service to them as a protection; but when we are reminded by Häckel that not only the medusæ, but many floating mollusca, crustaceans, and even small oceanic fishes partake of this same glass-like appearance, often accompanied by prismatic colours, we can hardly doubt that they thus escape the notice of pelagic birds and other enemies. M. Giard is also convinced ${ }^{1}$ that the bright tints of certain sponges and ascidians serve as a protection. Conspicuous colours are likewise beneficial to many animals as a warning to their would-be devourers that they are distasteful, or that they possess some special means of defence; but this subject will be discussed more conveniently hereafter.

We can, in our ignorance of most of the lowest animals, only say that their bright tints result either from the chemical nature or the minute structure of their tissues, independently or any benefit thus derived. IIardly any colour is finer than that of arterial blood; but there is no reason to suppose that the colour of the biood is in itself any advantage; and though it adds to the beauty of the maiden's cheek, no one will pretend that it has been acquired for this purpose. So again with many animals, especially the lower oncs, the bile is richly coloured; thus, as I am informed by Mr. Hancock, the extreme beauty of the Eolidæ (naked sea-slugs) is chiefly due to the biliary glands 1 'Archivas de Zoolog. Ërrér.,' Oct. 1872, p. 563. 
being seen through the transluccnt integuments-this beauty being probably of no service to these animals. The tiuts of the: decaying leaves in an American forest are described by ercry one as gorgeouls; yet no one supposes that these tints are of the least advantage to the trees. Bearing in mind how many substances closely analogous to natural organic compounds hare been recently formed by chemists, and which exhibit the most. splendid colours, it would have been a strange fact if substances similarly coloured had not often originated, independently of any useful end thus gained, in the complex laboratory of living organisms.

I'ke sub-kingdom of the Mollusca.-Thronghont this great division of the animal kingdom, as far as I can discover, secondary sexual characters, such as we are here considering", never occur. Nor could they be expected in the three lowest classes, namely in the Ascidians, Polyzoa, and Brachiopods (constituting the Molluscoida of some authors), for most of these animals are permanently affixed to a support or have their sexes united in the same individual. In the Lamellibranchiata, or bivalve shells, hermaphroditism is not rare. In the next higher class of the Gasteropoda, or univalve shells, the sexes are either united or separate. But in the latter case the males never possess special organs for finding, sccuring, or charming the ferales, or for fighting with other males. As I am informed by Mr. Gwyn Jeffreys, the solc external difference between the sexes consists in the shell somctimes differing a little in form; for instance, the shell of the male periwinkle (Littorina littorea) is narrower and has a more elongated spire than that of the female. But differences of this nature, it may be presumed, are directly connected with the act of reproduction, or with the development of the ora.

The Gasteropoda, though capable of locomotion and furnished with imperfect eyes, do not appear to he endowed with sufficient mental powers for the members of the same sex to struggle together in rivalry, and thrs to acquire secondary sexual characters. Nevertheless with the pulmoniferous gasteropods, or land-snails, the pairing is preceded by courtship; for these animals, though hermaphrodites, are compelled by their structure to pair together. Agassiz remarks," "Quiconque a eu l'occasion "d'observer les amours des limaçons, ne saurait mettre en douto "la séduction déployéo dans les mouvements et les alluros qui "préparent et accomplissent le double embrassement de ces "hermaphrodites." These animals appear also susceptible of some degree of permanent attachment: an accurate ohserrer, " 'De l'Espèce et de la Classo' \&c., 1869, p. 106. 
Mr. Lonsdale, informs me that he placed a pair of land-snails, (Helix pomatiu), one of which was weakly, into a small and iliprovided garden. After a short time the strong and healthy individual disappeared, and was traced by its track of slimo over a wall into an adjoining well-stocked garden. Mr. Lonsdale concluded that it had deserted its sickly mate; but after an absence of twenty-four hours it returned, and apparently communicated the result of its successful exploration, for both then started along the same track and disappeared over the wall.

Even in the highest class of the Mollusea, the Cephalopoda or cuttlefishes, in which the sexes are separate, secondary sexual characters of the present kind do not, as far as I can discover, occur. This is a surprising circumstance, as these animals possess highly-developed sense-organs and have considerable mental powers, as will be admitted by every one who has watched their artful endeavour's to escape from an enemy. ${ }^{3}$ Certain. Cephalopoda, however, are characterised by one extraordinary sexual character, namely, that the male element collects within one of the arms or tentacles, which is then cast off, and clinging by its sucking-dises to the female, lives for a time an independent life. So completely does the cast-off arm resemble a separato animal, that it was descriked by Cuvier as a parasitic worm under the name of Hectocotyle. But this marvellous structure may be classed as a primary rather than as a secondary sexual character.

Although with the Mollusca sexual selection does not seem to have come into play; yet many univalve and bivalve shells, such as volutes, cones, scallops, \&c., are beantifully coloured and shaped. 'The colours do not appear in most cases to be of any use as a protection; they are probably the direct result, as in the lowest classes, of the nature of the tissues; the patterns. and the sculpture of the shell depending on its manner of growth. The amount of light secms to be influential to a certain extent; for although, as repeatedly stated by Mr. Gwyn Jeffreys, the shells of some species living at a profound depth are brightly coloured, yet we generally see the lower surfaces, in well as the parts covered by the mantle, less highly-coloured than the upper and exposed surfaces." In some cases, as with shclls

3 See, for instance, the account which I have given in my 'Journil of Researches,' 1845 , p. 7 .

4 I have given ("Geolog. Obserrations on Volcanic Islands,' 1844, p. 53) a curious instance of the influence of light on the colours of a froudescent incrustation, deposited by the sarf on the cuastrocks of Ascension, and formed by the solution of triturated sea-shells 
living amongst corals or brightly-tinted sea-weeds, the bright colour's may serve as a protection. ${ }^{5}$ But that many of the nudibranch mollusca, or sea-slugs, are as beautifully coloured as any shells, nay be seen in Messrs. Alder aud Hancock's magnificent work; and from information kindly given me by Mr. Hancock, it seems extremely doubtful whether these colours usually serve as a protection. With some species this may be the case, as with one kind which lives on the green leaves of alga, and is itself bright-green. But many brightly-coloured, white or otherwise conspicuous species, do not seek concealment; whilst again some equally conspicuous species, as well as other dull-coloured kinds, live under stones and in dark recesses. So that with these nudibranch molluses, colour apparently does not stand in any close relation to the nature of the places which they inhabit.

These naked sea-slugs are hermaphrodites, yet they pair together, as do land-snails, many of which have extremely pretty shells. It is conceivable that two hermaphrodites, attracted by each other's greater beauty, might unite and leave offspring which would inherit their parents' greater beauty. But with such lowly-organised creatures this is extremely improbable. Nor is it at all obvious how the offspring from the more beautiful pairs of hermaphrodites would have any advantage over the offspring of the less beautiful, so as to increase in number, unless indeed vigour and beauty generally coincided. We have not here the caso of a number of males becoming mature before the females, with the more beautiful males selected by the more vigorous females. If, indeed, brilliant colours were beneficial to a hermaphrodite animal in relation to its general habits of life, the move brightly-tinted individuals would succeed best and would increase in number; but this would be a case of natural and not of sexual selection.

Sub-kingdom of the Vermes: Class, Annelidu (or sea-worms).In this class, although the sexes, when separate, sometimes differ from each other in characters of such importance that they have been placed under distinct genera or even families, yet the differences do not seem of tho kind which can be safely attributed to sexual selection. These animals are often heautifully coloured, but as the sexes do not differ in this respect, we are but little concerned with them. Even the Nemertians, though so lowly organised, "vie in beauty and variety of "colouring with any other group in the invertebrate series;" yet

3 Dr. Morse has lately discussed this subject in his paper on the Adaptive Coloration of Mollusca,
'Proc. Boston Soc. of Nat. Hist.' rol. xiv., April, 1871. 
Dr. McIntosh ${ }^{6}$ cannot discover that these coloun's are of any service. The sedentary annelids become duller-coloured, according to M. Quatrefages, ${ }^{7}$ after the period of reproduction; and this I presume may be attributed to their less vigorous condition at that time. All these worm-like animals apparently stand too low in the scale for the individuals of either sex to exert any choice in selecting a partner, or for the individuals of the same sex to struggle together in rivalry.

Sicb-kinudom of the Arthropoda: Class, Crustacea.-In this great rlass we first meet with undoubted secondary sexual characters, often developed in a remarkable manner. Unfortunately the liabits of crustaceans are very imperfectly known, and we cannot explain the uses of many structures peculiar to one sex. With the lower parasitic species the males are of small size, and they alone are furnished with perfect swimming-legs, antennæ and sense-organs; the females being destitute of these organs, with their bodies often consisting of a mere distorted mass. But these extraordinary differences between the two sexes aro no aloubt related to their widely different habits of life, and consequently do not concern us. In various crustaceans, belonging to distinct families, the anterior antenna are furnished with peculiar thread-like bodies, which are believed to act as smelling-organs, and these are much more numerous in the males than in the females. As the males, without any unusual development of their olfactory organs, would almost certainly be able sooner or later to find the females, the increased number of the smellingthreads has probahly been acquired through sexual selection, by the better provided males having been the more successful in finding partners and in protucing offspring. Fritz Hüller has described a remarkalle dimorphic species of Tanais, in which the male is represented hy two distinct forms, which never gradunte into each other. In the one form the male is furnished with more numerous smelling-threads, and in the other form with more powerful and more elongated chelæ or pincers, which serve to hold the female. Fritz Müller suggests that these differences hetween the two male forms of the same species may have originated in certain individuals having varicd in the number of the smelling-threads, whilst other individuals varied in the shape and size of their chelæ; so that of the former, those which were hest able to find the female, and of the latter, those which

- See his beautiful monograph on

- Hritish Augelids,' part i. 1873,

T See M. Perrier, 'l'Origine de n. l'Homme d'après Darwin,' 'Rerue Scientifizue,' Feb. 1873, p. 866. 
were best able to hold her, have left the greatest number of progeny to inherit their respective advantages. ${ }^{8}$

In some of the lower crustaceans, the right anterior antenna

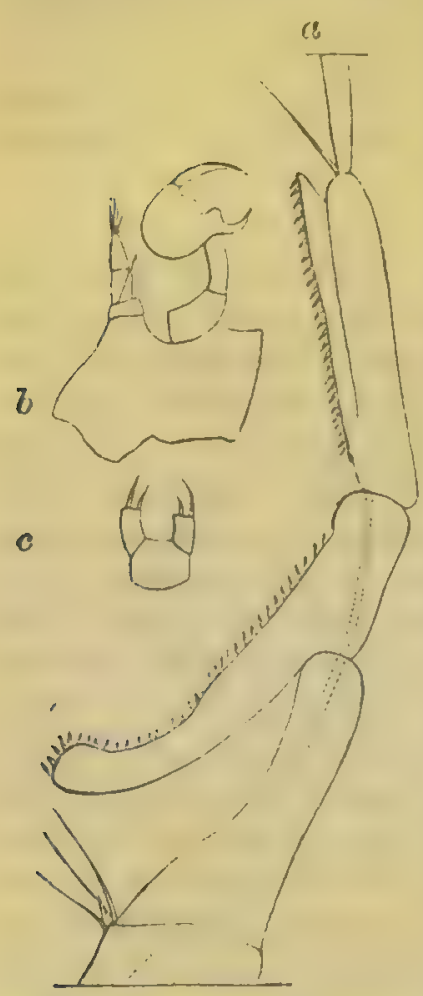

Fig. 4. Labidocera Darwinii (from Lubbock).

a. Part of right anterior antenna of male, forming a prehenstle organ.

b. Posterior pair of thoracic legs of male.

c. Ditto of female. of the male differs greatly in structure from the left, the latter resembling in its simple tapering joints the antennæ of the female. In the male the modified antenna is either swollen in the middle or angularly bent, or converted (fig. 4) into an elegant, and sometimes wonderfully complex, prehensile organ. It serves, as I hear from Sir J. Lubbock, to hold the female, and for this same purpose one of the two posterior legs (b) on the same side of the body is converted into a forceps. In another family the inferior or posterior antennæ are "curiously zigzagged" in the males alone.

In the higher crustaceans the anterior legs are developed into chelæ or pincers; and these are generally larger in the male than in the female, - so much so that the market value of the male edible crab (Cancer pagurus), according to Mr. C. Spence Bate, is five times as great as that of the female. In many species the chelæ are of unequal size on the opposite side of the body, the right-hand one being, as I am informed by Mr. Bate, generally; though not invariably, the largest. This inequality is also ofter much greater in the male than in the female. The two chelro of the male often differ in structure (figs. 5, 6, and 7), the smaller one resembling that of the female. What advantage is gained by their inequality in size on the opposite sides of tho

- Facts and Arguments for Darwin,' English translat. 1869, p. 20. See the previous discussion on the olfactory threads. Sars has described - a somewhat analogous case (as quoted in 'Nature,' 1870, p. 455) in a Norwegian crustacean, the Pontoporcia affinis.

D Sce Sir J. Lubbock in 'Annals and Mag. of Nat. Hist.' vol. xi. 1853, pl. i. and $x_{0}$; and rol. xii. (1853) pl. vii. See also Lubbock in 'Transact, Ent. Soc.' vol. iv, new series, 1856-1858, p. 8. With r'espect to the zig-zagged antenn mentioned below, see Fritz Miller. 'Facts and Arguments for Darwin, 1899.13 .40 . fivit-mite. 
body, and by the inequality being much greater in the male than in the female; and why, when they are of equal size, both are

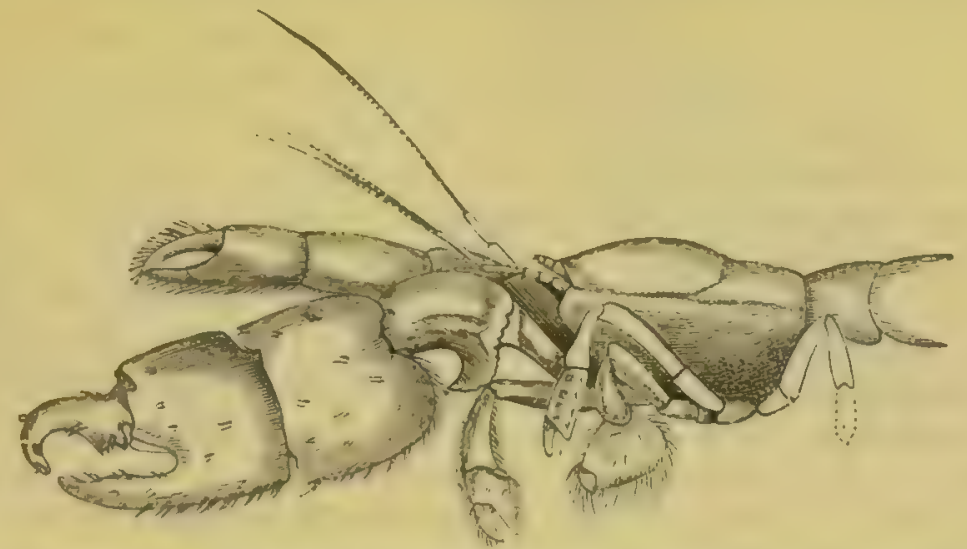

Fig. 5. Interior part of bouly of Callianassi (from Milne-lilwards), showing the unequal and differently-constructed right and left-bund chela of the male.

N.B-The artist by mistake has reversed the drawing, and made the left-hand chela the largest.

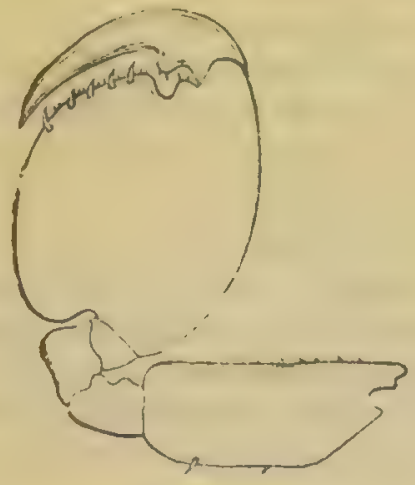

Fig. 6.

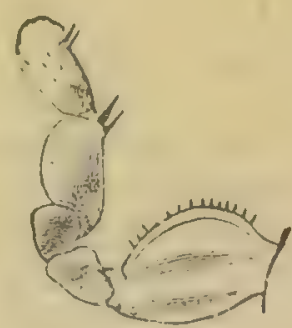

Fig. 7.

Fig. 6. Second leg of male Orcbestia Tucuratinga (from Fritz Muller).

Fig. 7. Ditto of female.

often much larger in the male than in the female, is not known. As I hear from Mr. Bate, the chelæ are sometimes of such length and size that they cannot possibly be used for carrying food to the mouth. In the males of certain fresh-water prawns (Palamon) the right leg is actually longer than the whole borly. ${ }^{10}$ The graat size of the one leg with its chelæ may aid the male in fighting with his rivals; but this will not account for their

10 See a paper by Mr. C. Spence Bate, with figures, in 'Proc. Zoolog. Soc.' 1868 , p. 363 ; and on the nomenclature of the genus, ibid. $p$.
585. I am greatly indebted to Mr. Spence Bate for nearly all the above statements with respect to the chelre of the higher crustaceans. 
inequality in the female on the opposite sides of of the body. In Gelasirnus, according to a statument quoted by Milne-Edwards, ${ }^{11}$ the male and the female live in the same burrow, and this shews that they pair; the male closes the mouth of the burrow with one of its chelæ, which is enormously developed; so that here it indirectly serves as a means of defence. Their main use, however, is probably to seize and to secure the female, and this in some instances, as with Gammarus, is known to be the case. The male of the hermit or soldier crab (l'ayurus) for wecks together, carries about the shell inhabited by the female. ${ }^{12}$ The sexes, however, of the common shore-crab (Carcinus manas), as Mr. Bate informs me, unite directly after the female has moulted her hard shell, when she is so soft that she would be injured if seized by the strong pincers of the male; but as she is caught and carried about by the male before moulting, she could then be seized with impunity.

Fritz Miiller states that certain species of Melita are distinguished from all other amphipods by the females having "the " coxal lamelle of the penultimate pair of feet produced into " hook-like processes, of which the males lay hold with the " hands of the first pair." The development of these hook-like processes has probably followed from those females which were the most securely held during the act of reproduction, having left the largest number of offspring. Another Brazilian amphipod (Orchestir Darvinii, fig. 8) presents a case of dimorphism, like that of Tanais; for there are two male forms, which differ in the structure of their chelæ. ${ }^{13}$ As either chela would certainly suffice to hold the female,-for both are now used for this purpose, - the two male forms probably originated by some having varied in one manner and some in another; both forms having derived certain special, but nearly equal advantages, from their differently shaped organs.

It is not known that male crustaceans fight together for the possession of the females, but it is probably the case; for with most animals when the male is larger than the fomale, he seems to owe his greater size to his ancestors having fought with other males during many generations. In most of the orders, especially in the highest or the Brachyura, the male is larger than the female; the parasitic genera, however, in which the sexes follow different habits of life, and most of the Entomostraca must be excepted. The chelre of many crustaceans are

11 'Hist. Nat, des Crust.' tom. ii. 18.37, p. 50 .

12 Mr. C. Spence Bate, 'Brit. Assoc., Fourth Report on the Fauna of $\$$ '. Devon.'

13 Fritz Miiller, "Facts and Arguments foy Darwin,' 186?, pp. 25-:8 
weapons well adapted for fighting. Thus when a Devil-crab (Portunus puber) was seen by a son of Mr. Bate fighting with a Carcinus moenas, the latter was soon thrown on its back, and had every limb torn from its body. When soveral males of a Brazilian. Gelasimus, a species furnished with immense pincers, were placed together in a glass vessel by Fritz Hüller, they mutilated and killed one another. Mr. Bate put a large male Carcinus
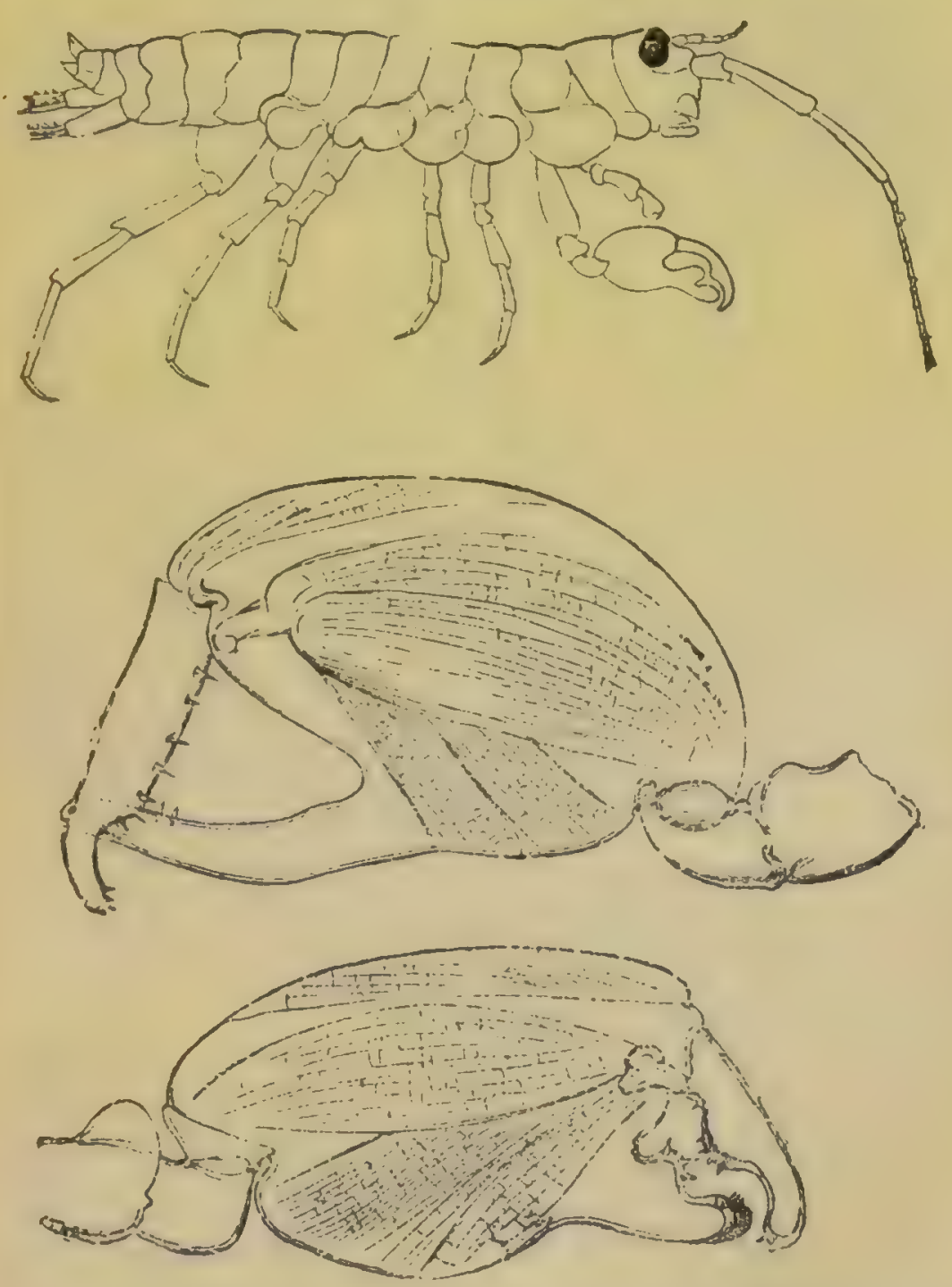

Fig. 8. Orchestia Darwinii (from Fritz Müller), showlng the differently-constructed chelæo of the two male forms.

moenas into a pan of water, inhabited by a femalc which was paired with a smaller male; but the latter was soon dispossessed. 
Mr. Bate adds, "if they fought, the victory was a bloodless one, " for I saw no wounds." This same naturalist separated a male sand-skipper (so common on our sea-shores), Gammarus marinus, from its female, both of whom were imprisoned in the same ressel with many individuals of the same species. The female, when thus divorced, soon joined the others. After a time the male was put again into the same vessel; and he then, after swimming about for a time, dashed into the crowd, and without any fighting at once took away his wife. This fact shews that in the Amphipoda, an order low in the scale, the males and females recognise each other, and are mutually attached.

'The mental powers of the Crustacea are probably higher than at first sight appears probable. Any one who tries to catch one of the shore-crabs, so common on tropical coasts, will perceive how wary and alert they are. There is a large crab (Birgus latro), found on coral islands, which makes a thick bed of the picked fibres of the cocoa-nut, at the bottom of a deep burrow. It feeds on the fallen fruit of this tree by tearing off the husk, fibre by fibre; and it always begins at that end where the three eye-like depressions are situated. It then breaks through one of these eyes by hammering with its heary front pincers, and turning round, extracts the albuminous core with its narrow posterior pincers. But these actions are probably instinctive, so that they would be performed as well by a young animal as by an old one. The following case, howerer, can hardly be so considered: a trustworthy naturalist, Mr. Gardner, ${ }^{14}$ whilst watching a shore-crab (Gelasimus) making its burrow, threw some shells towards the bole. One rolled in, and three other shells remained within a few inches of the mouth. In about five minutes the crab brought out the shell which had fallen in, and carried it away to the distance of a foot; it then saw the three other shells lying near, and evidently thinking that they might likewise roll in, carried them to the spot where it had laid the first. It would, I think, be difficult to distinguish this act from one performed by man hy the aid of reason.

Mr. Batc does not know of any well-marked case of difference of colour in the two sexes of our British crustaceans, in which respect the sexes of the higher animals so often differ. In some cases, however, the males and females differ slightly in tint, but Mr. Bate thinks not more than may be accounted for hy their diffcrent habits of life, such as by the male wandering more about, and being thus more exposed to the light. Dr. Power

14 "Travels in the Iiderior of Brazil,' 1846, p. 111. I have given, in my 'Journal of Researches,' $\mathrm{p}$.

463 , an account of the habits of the Birgus. 
tried to distinguish by colour the sexes of the several species which inhabit the Mauritius, but failed, except with one species of Squilla, probably $s$. styliferca, the male of which is described as being " of a beautiful bluish-green," with some of the appendages chcrry-red, whilst the female is clouded with brown and grey, "with the red about her much less virid than in the male." 15 In this case, we may suspect the agency of sexual selection. From MI. Bert's observations on Daphnia, when placed in a vessel illuminated by a prism, we have reason to believe that even the lowest crustaceans can distinguish colours. With Saphirina (an oceanic genus of Entomostraca), the males are furnished with minute shields or cell-like bodies, which exhibit beautiful changing colours; these are absent in the females, and in botb sexes of one species. ${ }^{18}$ It would, however, be extremely rash to conclude that these curious organs serve to attract the females. I am informed by Fritz Müller, that in the female of a Brazilian species of Gelasimus, the whole body is of a nearly uniform greyish-brown. In the male the posterior part of the cephalo-thorax is pure white, with the anterior part of a rich green, shading into dark brown; and it is remarkable that these colours are liable trs change in the course of a ferw minutes-the white becoming dirty grey or even black, the green "losing much "of its brilliancy." It deserves especial notice that the males do not acquire their bright colours until they become mature. The appear to be much more numerous than the females; they differ also in the larger size of their chelæ. In some species of the genus, probably in all, the sexes pair and inhabit the same burrow. They are also, as we have seen, highly intelligent animals. From these various considerations it seems probable that the male in this species has become gaily ornamented in order to attract or excite the female.

It has just been stated that the male Gelasimus does not acquire his conspicuous colours until mature and nearly rearly to breed. This scems a general rule in the whole class in respect to the many remarkable structural differences between the sexes. We shall hereafter find the same law prevailing throngliout the great sub-kingdom of the Vertebrata; and in all cases it is ominently distinctive of characters which havo been acquired through sexual selection. Fritz Muiller ${ }^{17}$ gires some striking instances of this law; thus the male sand-hopper (Orchestia) does not, until ncarly full grown, acquire his large claspers,

is MIr. Ci. Friser, in 'Proc. Zoglog. Soe?' 1869, p. 3. I am indebted so Mr. Bate for Dr. Power's statesent.
16 Claus, "Die freilebenden Cone. poden,' 1863, s. 35.

17 'Facts and Arguments,' \&. p. 72 . 
which are very diffcrently constructed from those of the femalo; whilst young, his claspers resemble those of the female.

Class, Aruchnida (Spiders). - The sexes do not generally diffor much in colour, but the males are often darker than the females, as may be seen in Mr. Blackwall's magnificent work. ${ }^{18}$ In some species, however, the difference is conspicuous: thus the female of Spurassus smaragdulus is dullish green, whilst the adult male has the abdomen of a fine yellow, with three longitudinal stripes of rich red. In certain speciec of Thomisus the sexes closely resemble each other, in others they differ much; and analogous cases occur in many other genera. It is often difficult to say which of the two sexes departs most from the ordinary coloration of the genus to which the species belong; but Mr. Blackwall thinks that, as a general rule, it is the male; and Canestrini ${ }^{10}$ remarks that in certain genera the males can be specifically distinguished with ease, but the females with great difficulty. I am informed by Mr. Blackwall that the sexes whilst young usually resemble each other; and both often undergo great changes in colour during their successive moults, before arriving at maturity. In other cases the male alone appcars to change colour. Thus the male of the above bright-coloured Sparassus at first resembles the female, and acquires his peculiar tints only when nearly adult. Spiders are possessed of acute senses, and exhibit much intelligence; as is well known, the females often shew the strongest affection for their eggs, which they carry about enveloped in a silken web. The males search eagerly for the females, and have been seen by Canestrini and others to fight for possession of them. This same author says that the union of the two sexes has been observed in about twenty species; and he asserts positively that the female rejects some of the males who court her, threatens them with open mandibles, and at last after long hesitation accepts the chosen onc. From these several considerations, we may admit with some confidence that the well-marked differences in colour between the sexes of certain species are the results of sexual selection; though we have not here the best kind of evidence,- - the display by the male of his ornaments. From the extreme variability of colour in the male of some species, for instance of Theridion lineatum, it would appear that these sexual characters of the males have not as yet become wcll fixed. Canestrini draws the same conclusion from.

18 'A History of the Spider's of livent Britain,' 1861-64. For' the inilowing facts, sce pp. 77, 88, 102.

12 This artinor has recently pubnol.t a vailinile essidy on the
' Caratteri sessuali secondarii degli Arachnidi,' in the 'Atti della Soc. Veneto-Trentina di Sc. Nat. Padera, rol. i. Fasc. 3, 1873. 
the fout that the males of certain species present two forms. differing from each other in the size and length of their jaws; and this reminds us of the above cases of dimorphic crustaceans.

The male is generally much smaller than the female, sometimes to an extraordinary degree, ${ }^{; 0}$ and he is forced to be extremely cautious in making his advances, as the female often carries her coyness to a dangerous pitch. De Geer saw a male that "in tho " midst of his preparatory caresses was seized ly the object of " his attentions, enveloped by her in a web and then devoured, a "sight which, as he adds, filled him with horror and indignation." "z The Rev. O. P. Cambridge 22 accounts in the following manner for the extreme smallness of the male in the genus Nephila. " M. Vinson gives a graphic account of the agile way in which "the diminutive male escapes from the ferocity of the female, by "gliding about and playing hide and seck over her body and " along her gigantic limbs : in such a pursuit it is evident that " the chances of escape would be in favour of the smallest males, "while the larger ones would fall early victims; thus gradually "a diminutive race of males would be selected, until at last they " would dwindle to the smallest possible size compatible with the " exercise of their generative functions, - in fact probably to the " size we now see them, i.e., so small as to be a sort of parasite " upon the female, and either beneath her notice, or too agile and " too small for her to catch without great difticulty."

Westring has made the interesting discovery that the males of several species of Theridion ${ }^{23}$ have the power of making a stridulating sound, whilst the females are mute. The apparatus consists of a serrated ridge at the base of the abdomen, against which the hard hinder part of the thorax is rubbed; and of this structure not a trace can be detected in the females. It deserves notice that several writers, including the well-known arachnologist Walckenaer, have declared that spiders are attracted by music. ${ }^{24}$ From the analogy of the Orthoptera and Homoptera,

20 Aug. Vinson ('Aranéides des lles de la Reunion,' pl. vi. figs. 1 and 2) gives a good instance of the small size of the male, in Epeira nigra. In this species, as I may add, the male is testaceous and the female black with legs banded with red. Other even more striking cases of inequality in size between the seres have been recorded ('Quarterly Journal of Science,' 1868, July, p. 429); but I have rot seen the original accounts.

"Kirhy and Spence, "Introduc- tion to Entomology,' vol. i. 1818, p. 280 .

22 'Proc. Zoolog. Soc.' 1871, p. 621.

23 Theridion (Asagena, Sund.) scrratipes, 4-pusctatum et guttatum; see Westring, in Kroyer, 'Naturhist. Tidskrift,' vol. iv. 184'$18+3$, p. 349 ; and vol. ii. 18461849 , p. 342. See, also, for other species, 'Aranex Suecicæ,' p. 184.

26 Dr. H. H. van Zouteveen, in his Dutch translation of this work (vol. i. p. 444), has collected several cases. 
to be described in the next chapter, we may feel almost sure that the stridulation serres, as Westring also believes, to call or to excite the female; and this is the first case known to me in the ascending scale of the animal kingdom of sounds emitted for this purpose. ${ }^{25}$

Class, Mlyriapodu.-In neither of the two orders in this class, the millipedes and centipedes, can I find any well-markea instances of such sexual differences as more particularly concern us. In Glomeris limbuta, however, and perhaps in some few other species, the males differ slightly in colour from the females; but this Glomeris is a highly variable species. In the males of the Diplopoda, the legs belonging either to one of the anterior or of the posterior segments of the body are modified into prehensile hooks which serve to secure the female. In some species of Iulus the tarsi of the male are furnished with membranous suckers for the same purpose. As we shall see when we treat of Insects, it is a much more unusual circumstance, that it is the female in Lithobius, which is furnished with prehensile appendages at the extremity of her body for holding the male. ${ }^{26}$

\section{CIIAPTER X. \\ Secondary Sexcal Characters of Insec'is.}

Diversified structures possessed by the males for seizing the femalesDifferences between the sexes, of which the meaning is not understoodDifference in size between the seres-Thysanura-Diptera-Hemiptera -Homoptera, musical powers possessed by the males alone-Orthoptera. musical instruments of the males, much diversified in structure; pugnacity; colours-Neuroptera, sexual differences in colour-Hymenoptera, pugnacity and colours-Coleoptera, colours; furnished with great horns, apparently as an ornament; battles; stridulating organs generally common to both sexes.

IN the immense class of insects the sexes sometimes differ in their locomotive-organs, and often in their sense-organs, as in the pectinated and beautifully plumose antennx of the males of many species. In Chloëon, one of the Ephemeræ, the male has great pillared eyes, of which the female is entirely destitute." The ocelli are alosent in the females of certain insects, as in the

25 Hilgendo rf, howerer, has lateIr called attention to an analogous structure in some of the higher crustaceans, which seerus adapted to produce sound; see 'Zoological Record,' 1869, p. 603.

2e Walckenaer et P. Gervais,
'Hist. Nat. des Insectes : Apteres,' tom. iv. 1847, pp. 17, 19, 68.

1 Six J. Lubbock, 'Trausact. Linnean Soc." vol. $\mathbf{x v}$. 1866, p. 484. With respect to the Mutillidxe see Westwood, "Modery Class. of Insects,' rol. ii. p. 213. 
Mutillidæ; and here the females are likewise wingless. But we are cliefly concerned with structures by which one male is enabled to conquer another, either in battle or courtship, through his strength, pugnacity, ornaments, or music. The innumerable contrivances, therefore, by which the male is able to seize the female, may be briefly passed over. Besides the complex structures at the apex of the abdomen, which ought perhaps to be ranked as primary organs, " it is astonishing," as .Ir. B. D. Walsh ${ }^{3}$ has remarked, "how many different organs are worked in by naturn "for the seemingly insignificant object of enabling the male to " grasp the femile firmly." The mandibles or jaws are somctimes used for this purpose; thus the male C'orydulis cornutus (a neuropterous insect in some degree allied to the Dragon-flies, \&c.) has immense curved jaws, many times longer than those of the female; and they are smooth instead of being toothed, so that he is thus enabled to seize her without injury." One of the stag-beetles of North America (Lucanus elaphus) uses his jars, which are much larger than those of the female, for the same purpose, but probably likewise for fighting. In one of the sand-wasps (Ammophilu) the jaws in the two sexes are closely :like, but are used for widely different purposes: the males, as Professor Westwood observes, "are exceedingly ardent, seizing "their partners round the neck with their sickle-shaped jaws;" " whilst the females use these organs for burrowing in sand-banks and making their nests.

The tarsi of the front-legs are dilated in many male beetles, $o r$ are furnished with broad cushions of hairs; and in many genera of water-beetles they are armed with a round flat sucker, so that the male may adhere to the slippery body of the female. It is a

2 These organs in the male often differ in closely-allied species, and afford excellent specific character's. But their importance, from a functional point of view, as Mr. R. MacLachlan has remarked to me, has probably. been overrated. It has been suggested, that slight differences in these organs would sulfice to prevent the intercrossing of well-marked varieties or incipient species, and would thus aid in their development. That this can hardly be the case, we may infer from the many recorded cases (see, for ininstance, Bronu, 'Geschichte der Natur, B. ii. 1843, s. 164; and Westwood, 'Transact. Ent. Soc.' rol. iii. 1842, p. 195) of distinct species having been observed in union. Mr. MacLachlan informs me (vide 'Stett. Ent. Zeitung; 1867 , s. 155) that when several species of Phryganidæ, which present strongly-pronounced differences of this kind, were confined together by Dr. Aug. Meyer, they coupled, and one pair produced fertile ova.

3 'The Practical Entomologist," Philadelphia, vol. ii. May, 1867, p. 88.

4r. Walsh, ibid. p. 107.

5 "Modern classification of In. sects, ${ }^{\prime}$ vol. ii. 1840, pp. 205, 206. Mi. Walsh, who called my attention to the double use of the jaws, says that he has repeatedly observed this fart. 
much more unusual circunstance that the female of some waterbectles (Dytiscus) have their clytra decply grooved, and in Acitius sulcutus thickly set with hairs, as an aid to the male.

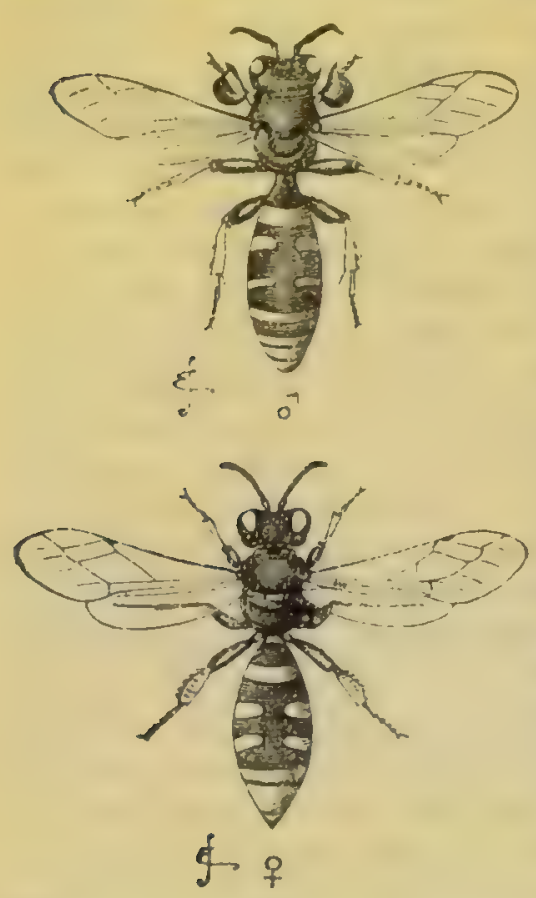

1'ig. 9. Crabro cribras lus. Upper figure, male; luwer tigure, feusale.

The females of some other waterbeetles (Hydroporus) have their elytra punctured for the same jurpose. ${ }^{6}$ In the male of Crabro cribrurius (fig. 9), it is the tibia which is dilated into a broad horny plate, with minute membraneous dots, giving to it a singular appearance like that of a riddle. ${ }^{7}$ In the male of Penthe (a genus of beetles) a few of the middle joints of the antennæ are dilated and furnished on the inferior surface with cushions of hair, exactly like those on the tarsi of the Carabidæ, "and obviously for "the same end." In male dragonflies, "the appendages at the tip " of the tail are modified in an " almost infinite variety of curious " patterns to enable them to em"brace the neck of the female." Lastly, in the males of many insects, the legs are furnished with jeculiar spines, knobs or spurs; or the whole leg is borred or thickened, but this is by no zeans invariably a sexual character; or one pair, or all three pairs are elongated, sometimes to an extravagant length. ${ }^{8}$

'The sexes of many species in all the orders present differences, of which the meaning is not understood. One curiuus case is that of a bectle (fig. 10), the male of which has the left mandible inuch enlarged; so that the mouth is greatly distorted. In another Carabiduus beetle, Eurygnathus, ${ }^{9}$ we have the case,

- We have here a curious and inexplicable case of dimorphism, for some of the females of four European species of Dytiscus, and of certain species of Hydroporus, have their elytra smooth; and no intermediate gradations between the sulcated or punctured, and the quite smooth elytra have been observed. See Dr. H. Schaum, as quoted in the 'Zoologist,' vol. v.-vi. 1847-48, p. 1895. 1100 Kirhy and simese?
'Introduction to Entomology,' vol. iii. 1826 , p. 305.

7 Westwood, 'Modern Class.' vol. ii. p. 193. The following statement about Penthe, and others in inverted commas, are taken from Mr. Walsh, 'Practical Entomologist,' Philadeiphia, rol. ii. p. 88.

B Kirby and Spence, 'Introduct.' \&c., vol. iii. pp. 332-336.

' 'Insecta Maderensia,' 1854, p. 
unique as fir as known to Mr. Wollastun, of the head of the female being much broader and larger, though in a variable degree, than that of the male. Any number of such cases could be given. They abound in the Lepidoptera: one of the most extraordinary is that certain male butterflies have their fore-legs more or less atrophied, with the tibire and tarsi reduced to mere rudimentary knobs. The wings, also, in the two sexes often differ in neuration, ${ }^{10}$ and sometimes considerably in outline, as in the Aricoris epritus, which was shewn to me in the British Museum by Mr. A. Butler. The males of certain Sonth American butterflics have tufts of hair on the margins of the wings, and holny excrescences on the dises of the posterior pair.11 In several British butterflies, as shewn by Mr. Wonfor, the males alone are in parts clothed with peculiar scales.

The use of the bright light of the female glow-worm has been subject to much discussion. The male is feebly luminous, as are the larvæ and even the eggs. It has been supposed by some authors that the light serves to frighten away enemies, and by others to guide the male to the female. At last, Mr. Belt ${ }^{12}$ appears to have solved the difficulty: he finds that all the Lampyridæ which he has tried are highly distasteful to insectivorous mammals and birds. Hence it is in accordance with Mr. Bates' view, hereafter to be explained, that many insects mimic the Laupyridæ closely, in order to be mistaken for them, and thus to escape destruction. He further believes that the luminous species profit by being at once recognised as unpalatable.
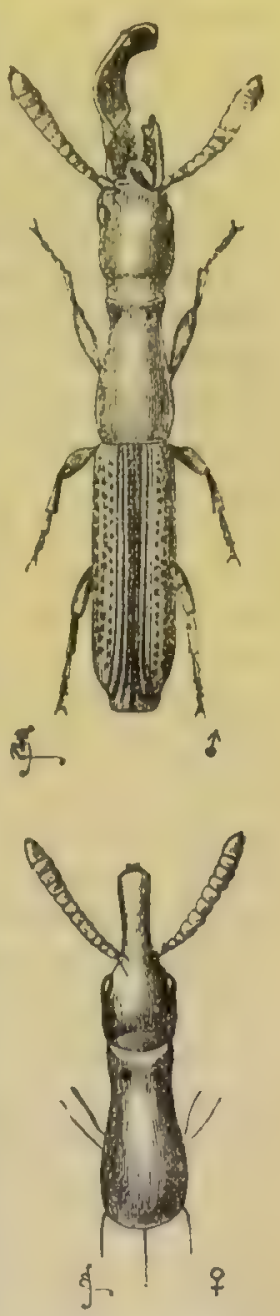

Fig. 10. Taphroderes distort us (much enlarged). Upper figure, male; lower figure, female. It is probable that the same explanation may be extended to tho

10 E. Doubleday, 'Annals and Mag. of Nat. Hist.' rol. i. 1848, p. 379. I may add that the wings in certain Hymenoptera (see Shuckard, 'Fossorial Hymenop.' 1837, pp. 3943) differ in neuration according to sex.

ii H. W. Bates, \& inuril of Proc. Linn. Soc.' vol. vi. 862 , p.
74. Mr. Wonfor's observations are quoted in 'Popular Science Review, 1868, p. 343.

12 'I'he Naturalist in Nicaragua; 1874, pp. 316-320. On the phosphorescence of the eggs, see 'Annals and Mag. of Nat. Hist.' 1871,' Nov., p. $37 \%$. 
Slaters, both sexes of which are highly luminous. It is not known why the wings of the female glow-worm hare not been developed; but in her present state she closely resembles a larva, and as larvæ aro so largely preyed on by many animals, ve can understand why she has been rendered so much more I uminous and conspicuous than the male; and why the larra themselves are likewise luminous.

Difference in Size between the Sexes.-With insects of all kinds the males are commonly smaller than the females; and this difference can often be detected even in the larval state. So considerable is the difference between the male and female cocoons of the silk-moth (Bombyx mori), that in France they are separated by a particular mode of weighing. ${ }^{13}$ In the lower classes of the animal kingdom, the greater size of the females seems generally to depend on their developing an enormous number of ova ; and this may to a certain extent hold good with insects. But Dr. Wallace has suggested a much more probable sxplanation. He finds, after carefully attending to the development of the caterpillars of Bombyx cynthic and yamamai, and especially to that of some dwarfed caterpillars reared from a second brood on unnatural food, "that in proportion as the in"dividual moth is fincr, so is the time required for its metamor"phosis longer; and for this reason the female, which is the "larger and heavier insect, from having to carry her numerous " eggs, will be preceded by the male, which is smaller and has "less to mature." 14 Now as most insects are short-lived, and as they are exposed to many dangers, it would manifestly be advantageous to the female to be impregnated as soon as possible. T'his end would be gained by the males being first matured in large numbers ready for the advent of the fomales; and this ngain would naturally follow, as Mr A. R. Wallace has remarked, ${ }^{15}$ through natural selection; for the smaller males would be first matured, and thus would procreate a large number of offspring which would inherit the rednced size of their male parents, whilst the larger males from being inatured later would leave fewer offspring.

There are, however, exceptions to the rule of male insects hoing smaller than the females: and some of these exceptions are intelligible. Size and strength would be an advantage to the males, which fight for the possession of the females; and in these cases, as with the stag-beetle (Lncanus), the males are larger than the females. There are, however, other beetles

13 Robinet, 'Vers à Soie,' 1848, rol. v. p. 486. ค. 207.

1. "Journal if Proc, Ent. Sico

"' 'Trapsact. Ent. Soc.' 3rd series, Feb. 4th, 1867, p. Ixxi. 
which are not known to fight together, of which the males exceed the females in size; and the meaning of this fact is not known; but in some of these cases, as with the huge Dynastes and Megasoma, we can at least see that there would be no necessity for the males to be smaller than the females, in order to be matured before them, for these beetles are not short-lived, and there would be ample time for the pairing of the sexes. So again, male dragon-flies (Libellulidx) are sometimes sensibly larger, and never smaller, than the females; ${ }^{16}$ and as Mr. MacLachlan believes, they do not generally pair with the females until a week or fortnight has elapsed, and until they have assumed their proper masculine colours. But the most curious case, shewing on what complex and easily-overlooked relations, so trifing a character as difference in size between the sexes may depend, is that of the aculeate Hymenoptera; for Mr. F. Sinith informs me that throughout nearly the whole of this large group, the males, in accordance with the general rule, are smaller than the females, and emerge about a week before them; but amongst the Bees, the males of Apis mellifica, Anthidium municutum, and Anthophora acervorum, and amongst the Fossores, the males of the Methoca ichneumunides, are larger than the females. The explauation of this anomaly is that a marriage flight is absolutely necessary with these species, and the male requires great strength and size in order to carry the female through the air. Increased size has here been acquired in opposition to the usual relation betricen size and the period of development, for the males, though larger, emerge before the smaller females.

We will now review the several Orders, selecting such facts as more particularly concern us. The Lepidoptera (Butterflies and Moths) will be retained for a separate chapter.

Order, Thysanura.-The members of this lowly organized order are wingless, dull-coloured, minute insects, with ugly, almost misshapen heads and bodies. Their sexes do not differ but they are interesting as sherving us that the males pay sedulous court to the females even low down in the animal scale. Sir J. Lubbock ${ }^{17}$ says: "it is very annusing to see these "little creatures (Smynthurus luteus) coquetting together. The " male, which is much smaller than the female, runs round her, "and they butt one another, standing fuce to face and moving

16. For this and other statements on the size of the sexes, see Kirby and Spence, ibid. vol. iii. p. $300^{\circ}$; on the duration of life in insects, see p. 344.

18 "Transact. I.innean Soc." ral. xхทі. 1868 , p. 296. 
"backward and forward like two playful lambs. Then the " female pretends to run away and the male runs after her with "a queer appearance of auger, gets in front and stands facing " her again; then she turns coyly round, but ke, quicker and "more active, scuttles round too, and seems to whip her "with his antennæ; then for a bit they stand face to face, "play with their antennæ, and seem to be all in all to one "another."

Order, Diptera (Flies).-The sexes liffer little in colour. The greatest difference, known to Mr. F. Walker, is in the genus Bibio, in which the males are blackish or quite black, and the females obscure brownish-orange. The genus Elaphomyia, discovered by Mr. Wallace ${ }^{18}$ in New Guiswa, is highly renarkable, as the males are furnished with horns, of which the females are quite destitute. The horns spring from beneath the eyes, and curiously resemble those of a stag, being either branched or palmated. In one of the species, they equal the whole body in length. They might be thought to be adapted for fighting, but as in one species they are of a bautiful pink colour, edged with black, with a pale central stripe, and as these insects have altogether a very elegant appearance, it is perhaps more probable that they serve as ornaments. That the males of some Diptera fight together is certain; for Prof. Westwood ${ }^{19}$ has several times seen this with the Tipulæ. The males of other Diptera apparently try to win the females by their music: H. Müller ${ }^{20}$ watched for some time two males of an Eristalis courting a female; they hovered above her, and flew from side to side, making a high humming noise at the same time. Gnats aud mosquitoes (Culicidæ, also seem to attract each other by humming; and Prof. Mayer has recently ascertained that the hairi on the antennæ of the male vibrate in unison with the notes of a tuning-fork, within the range of the sounds emitted by the female. 'The longer hairs vibrate sympathetically with the graver notes, and the shorter hairs with the higher ones. Landois also asserts that he has repeatedly drawn down a whole swarm of gnats by uttering a particular note. It may be added that the mental faculties of the Diptera are probably higher than in most other insects, in accordance with their highly developed nervous system.".J

18 'The Malay Archipelago,' vol. i. 1869, p. 313 .

18 'Modern Classificatiun of Insects,' vol. ii. 1840 , p. 526.

${ }^{20}$ Anwendung, \&c., 'Verh. d. n. V. Jahrg.' xxix. p. 80. Mayer, in 'American Naturalist,' 1874, jo. '2:it.
21 See Mr. B. T. Lowne's interesting work, 'On the Anatomy of the Blow-11y, Musca vomitoria,' 1870 , p. 14. He remarks (p. 33) that, "the "captured flies utter a peculiar "plaintive note, and that this sound "causes other" flies to disappeur." 
Order, Hemiptera (Field-Bugs).-Mr. J. W. Douglas, who has particularly attended to the British species, has kindly given me an account of their sexual differences. The males of some species are furnished with wings, whilst the females are wingless; th9 sexes differ in the form of their bodies, elytra, antennæ and tarsi ; but as the signification of these differences are unknown, they may be here passed over. The females are generally larger and more robust than the males. With British, and, as far as Mr. Douglas knows, with exotic species, the sexes do nos commonly differ much in colour; but in about six Britisls species the male is considerably darker than the female, and in about four other species the female is darker than the male. Both sexes of some species are beautifully coloured; and as these insects emit an extremely nauseous odour, their conspicuous colours may serve as a signal that they are unpalatable to insectivorous animals. In some few cases their colours appear to be directly protective: thus Prof. Hoffmann informs me that he could hardly distinguish a small pink and green species from the buds on the trunks of lime-trees, which this insect frequents.

Some species of Reduvidæ make a stridulating noise; and, in the case of Pirates strillulus, this is said ${ }^{22}$ to be effected by the movement of the neck within the pro-tboracic cavity. According to Westring, Reduvius personatus also stridulates. But I have no reason to suppose that this is a sexual character, excepting that with non-social insects there seems to be no use for sound-producing organs, unless it be as a sexual call.

Order, Homoptera.-Every one who has wandered in a tropical forest must have been astonished at the din made by tho male Cicadæ. The females are mute; as the Grecian poet. Xenarchus says, "Happy the Cicadas live, since they all have "voiceless wives." The noise thus made could be plainly heard on board the "Beagle," when anchored at a quarter of a milo from the shore of Brazil; and Crptain Hancock says it can be heard at the distance of a mile. The Greeks formerly kept, and the Chinese now keep these insects in cages for the sake of their song, so that it must be pleasing to the ears of some men.. ${ }^{2 \mathrm{~s}}$ The Cicadidæ usually sing during the dar, whilst the Fulgorida appear to be night-songsters. The sound, according to Landois,

28 Westwood, 'Modern Cliss. of Insects,' vol. ii. p. 473.

23 These particulars are taken srom Westwood's 'Modern Class. of Insects,' rol. ii 18t0, 1) +22. See. also, on the Fulgoridæ, Kirby and Spence, 'Introduct.' vol. ii. p. $4 \mathrm{M}$. 24 'Leitschrift fur wisseuschaf Zoolng.' B. xvii. 1867, s. 152-158. 
is produced by the vibration of the lips of the spiracles, which ure set into motion by a current of air emitted from the trachero; but this view has lately been disputed. Dr. Powell appears to have proved ${ }^{25}$ that it is produced by the vibration of a membrane, set into action by a special muscle. In the living insect, whilst stridulating, this mombrane can be seen to vibrate; and in the dead insect the proper sound is heard, if the muscle, when a little dried and hardened, is pulled with the point of a pin. In the female the whole complex musical apparatus is fresent, but is much less developed than in the male, and is never used for producing sound.

With respect to the object of the music, Dr. Hartman, in speaking of the Cicada septemdecim of the United States, says, ${ }^{26}$ " the drums are now (June 6th and 7th, 1851) heard in all "directions. This I believe to be the marital summons from "the males. Standing in thick chestnut sprouts about as high " as my head, where hundreds were around me, I observed the "females coming around the drumming males." He adds, "this " season (Aug. 1868) a dwarf pear-tree in my garden produced " about fifty larvæ of Cic. pruinosa; and I several times noticed "the females to alight near a male while he was uttering his "clanging notes." Fritz Müller writes to me from S. Brazil that he has often listened to a musical contest between two or three males of a species with a particularly loud voice, seated at a considerable distance from each other: as soon as one had finished his song, another immediately began, and then another. As there is so much rivalry between the males, it is probable that the females not only find them by their sounds, but that, like female birds, they are excited or allured by the male with the most attractive voice.

I have not heard of any well-marked cases of ornamental differences between the sexes of the Homoptera. Mr. Douglas informs me that there are three British species, in which the male is black or marked with black bands, whilst the females are pale-coloured or obscure.

Order, (Jrthoptera (Crickets and Grasshoppers).-The males in the three saltatorial families in this Order are remarkable for their musical powers, namely the Achetidm or crickets, the Locustidre for which there is no equivalent English name, and the Acridiide or grasshoppers. The stridulation produced by some

25 'Truusact. New Zealand In. stitute,' vol. v. 1873, ए. 286.

${ }^{86} \mathrm{I}$ am indebted to $\mathrm{Mr}$. Walsh for having aent me this extract from a 'Jourual of the Doings of Cicada septemderim' by Ds. Hart. man. 
of the Locusticix is so loud that it can be heard during the night at the distance of a mile; ${ }^{27}$ and that made by certain species is not unmusical even to the human ear, so that the Indians on the Amazons kcep them in wicker cages. All observers agree that the sounds serve either to call or excite the mute females. With respect to the migratory locusts of Russia, Körte has given ${ }^{28}$ an interesting case of selection by the female of a male. The males of this species (Puchytylus migratorius) whilst coupled with the fumale stridulate from anger or jealousy, if approached by other males. The house-cricket when surprised at night uses its voice to warn its fellows. ${ }^{29}$ In North America the Katy-did (I'letyy hiyllum conc(uvem, one of the Locustidæ) is described ${ }^{30}$ as mounting on the upper branches of a tree, and in the evening beginning " his noisy balble, while rival notes issue from the neighbouring "trees, and the groves resound with the call of Katy-did-she-did "the live-long night." Mr. Bates, in speaking of the European field-cricket (one of the Achetidro), says, "the male has " been observed to place him"self in the evening at the "entrance of his burrow, and "stridulate until a female ap"proaches, when the louder " notes are succeeded by a " more subdued tone, whilst "the successful musician ca"resses with his antennæ the "mate he has won." 11 Dr. Scudder was able to excite one of these insects to answer him, by rubbing on a file with a quill. $^{82}$ In both sexes a remarkable auditory apparatus

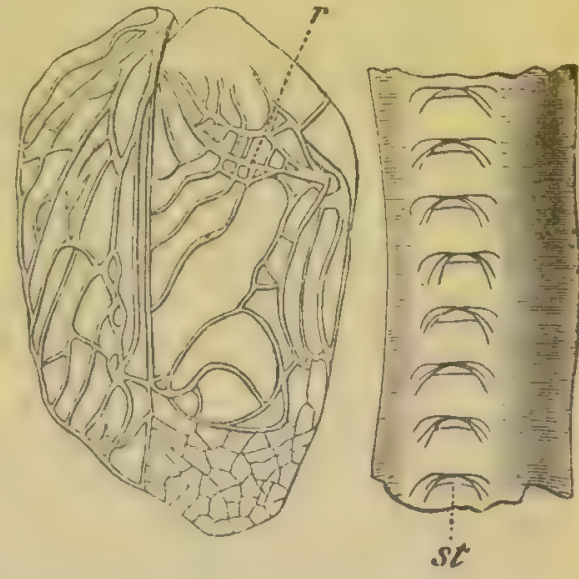

Fig. 11. Gryllus campestris (from Landois). Right-hand figure, under side of part of a wing-nervure, much magnified, showing the teeth, st.

Left-hand figure, upper surface of wingcover, with the projecting, smooth nervure, 2", scross which the teeth (st) are scraped. Las been discovered by Von Siebold, situated in the front legs. ${ }^{33}$

${ }_{27}$ L. Guilding, 'Transact Linn. Soc.' vol. xv. p. 154.

${ }^{28}$ I state this on the authority of Köppen, 'Ueber' die Heuschrecken in Sudrussland,' 1866, p. 32, for I have in vain cndeavoured to procure liörte's work.

${ }_{28}$ Gilber't White, 'Nat. Hist. of Selborne,' vol. ii. 1825 , p. 262.

${ }^{30}$ Harris, 'Insects of New England,' 1842, p. 128.

31' The Naturalist on the Ama- zons,' vol. i. 1863, p. 252. Mr. Bates gives a very interesting discussion on the gradations in the musical apparatus of the three families. See also Westwood, 'Modern Class.' vol. ii. pp. 445 and 453 .

38 'Proc. Boston Soc. of Nat. Hist.' vol. xi. April, 1868.

33 'Noureau Manuel d'Anat Comp.' (French translat.), tom. I 1850, p. 267. 
In the three Families the sounds are differently produced. In the males of the Achetidre both wing-covers have the same apparatus; and this in the field-cricket (imyllus cumpestris, fig. 11) consists, as described by Landois, ${ }^{34}$ of from 131 to 138 sharp, transverse ridges or teeth (st) on the under side of one of the nervures of the wing-cover. This toothed nervure is rapidly scraped across a projecting, smooth, hard ner-

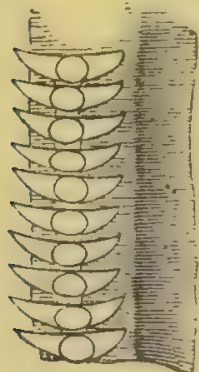

Fig. 12. Teeth of Nervure of $\mathrm{t}$, yllus domesticus (from Latndois). vure $(r)$ on the upper surface of the opposite wing. First one wing is rubbed over the other, and then the movement is reversed. Both wings are raised a little at the same time, so as to increase the resonance. In some species the wing-covers of the males are furnished at the base with a talc-like plate.".; I here give a drawing (fig. 12) of the teeth on the under side of the nervure of another species of Grvllus, viz., $G$. domesticus. With respect to the formation of these teeth, Dr. Gruber las shewn ${ }^{36}$ that they have been developed by the aid of selection, from the minute scales and hairs with which the wings and body are covered, and I came to the same conclusion with respect to those of the Coleoptera. But. Dr. Gruber further shews that their development is in prart directly due to the stimulus from the friction of one wing over the other.

In the Locustidn the opposite wing-covers differ from each other in structure (fig. 13), and the action cannot, as in the last family, be rerersed. The left wing, which acts as the bow, lies over the right wing which serres as the fiddle. One of the nervures (1) on the under surface of the former is finely serrated, and is scraped across the prominent nervures on the upper surface of the opposite or right wing. In our British P'hasgonura viridissimu it appeared to me that the serrated nervure is rubbed against the rounded hind-corner of the opposite wing, the edge of which is thickened, coloured. brown, and rery sharp. In the right wing; but not in the left, there is a little plate, as transparent as talc, surrounded by nervures, and called the speculum. In Ephipriger vitimn, is member of this same family, we have a curious subordinate. modification; for the wing-covers are greatly reduced in size, but " the posterior part of the pro-thorax is elevated into a kind

34 'Zeitschrift fiir wissenschaft. Zoolog.' B. xvii. 1867, s. 117.

35 Westwood, 'Mndern Class. of Insects,' rol. i. p. 440.
36 'Ueber der Tonapparat der Locustiden, ein Beitrag zum Da:winismus,' 'Zeitsch. fur wissensch. Zoolog.'B. xxii. 1872, p. 100. 
on the principle of the division of labour, the one to act exclusively as the bow, and the other as the fiddle. Dr. Gruber takes the same view, and has shewn that rudimentary tecth are commonly found on the inferior surface of the right wing. By what steps the more simple apparatus in the Achetidx originated, we do not know, but it is probable that the basal portions of the wing-covers originally overlapped each other as thcy do at present; and that the friction of the nervures produced a grating sound, as is now the case with the wing-cover's of the females. ${ }^{39}$ A grating sound thus occasionally and accidentaliy made by the males, if it served them erer so little as a love-call to the females, might readily have been intensified through sexual selection, by variations in the roughness of the nervures having been continually preserved.

In the last and third Family, namely the Acridiidæ or grasshoppers, the stridulation is produced in a very different manner, and according to Dr. Scudder, is not so shrill as in the preceding Families. The inner surface of the femur (fig. 14, r) is furnished with a longitudinal row of minute, elegant, lancetshaped, elastic teeth, from 85 to 93 in number ;0 and these are scraped across the sharp, projecting nervures on the wing-covers, which are thus made to vibrate and resound. Harris ${ }^{41}$ says
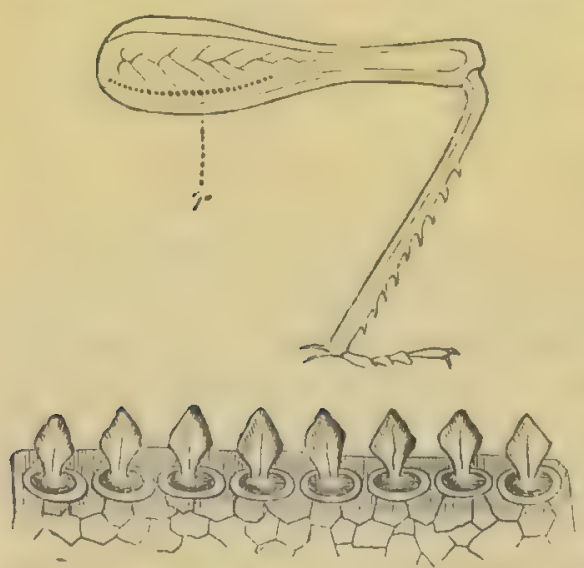

Fig. 14. Hind-leg of Stenobothrus pratorum: $r$, the stridulating ridge; lower figure, the teeth forming the ridge, much magnified (from Landois).

genus belonging to the same

${ }^{30} \mathrm{Mr}$. Walsh also informs me that he has noticed that the female of the Platyphyllum concavum, "when captured makes a feeble "grating noise by shufting her that when one of the males begins to play, he first " bends "the shank of the hind-leg " beneath the thigh, where it " is lodged in a furrow de"signed to receive it, and "then draws the leg briskly "up and down. He does not " play both fiddles together, "but alternately, first upon " one and then on the other." In many species, the base of the abdomen is hollowed out into a great cavity which is believed to act as a resounding board. In Pneumora (fig. 15), a S. African family, we meet with a new

\footnotetext{
"wing-covers together."

40 Landois, ibid. s. 113.

41 'Insects of New England? 1842, p. 133.
} 
and remarkable modification; in the males a small notched ridge projects obliquely from each side of the abdomen, against which the hind femora are rubbed. ${ }^{42}$ As the male is furnished with wings (the female being wingless), it is remarkable that the thighs are not rubbed in the usual manncr against the wing-corers; but this may perhaps be accounted for by the unusually small size of the hind-legs. I have not been able to examine the inner surface of the thighs, which, judging
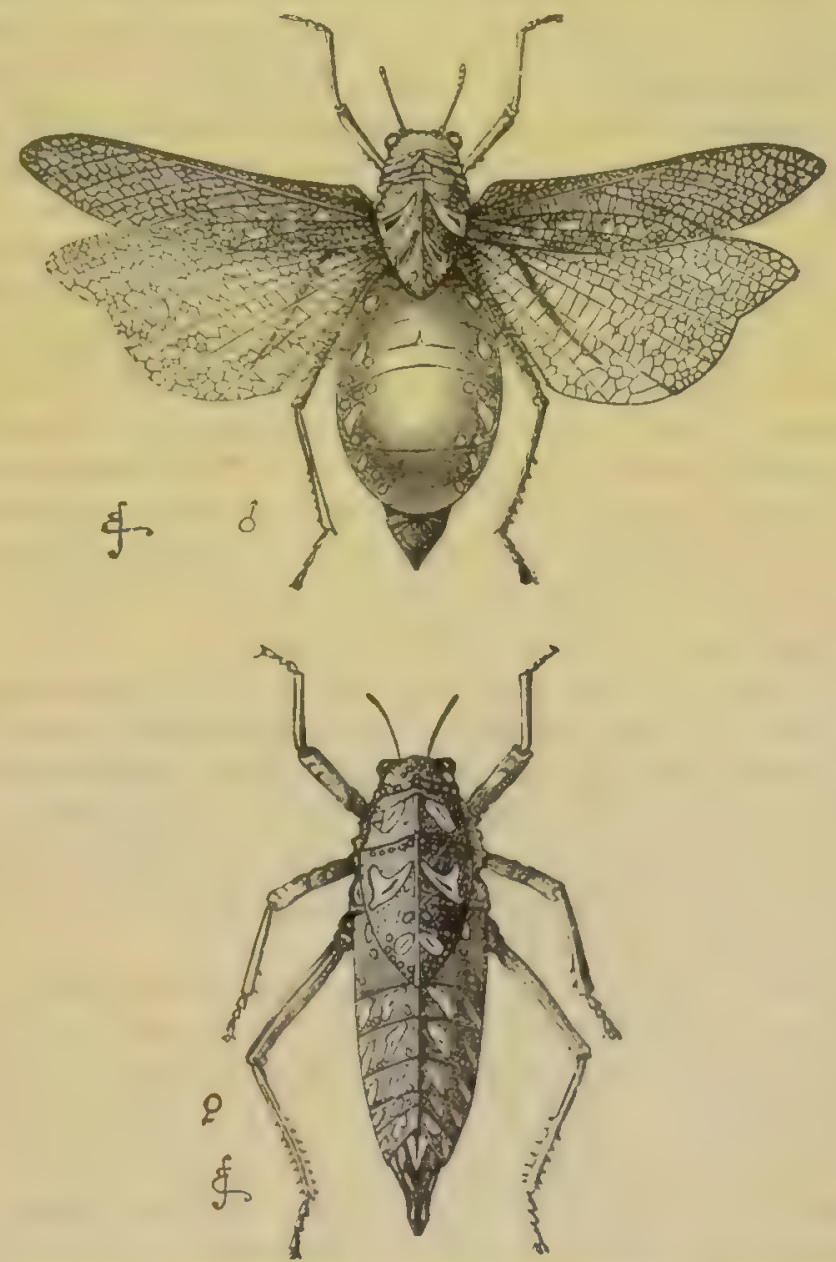

Fig. 15. Pneumora (from specimens in the British Museum). Upper figure, male lower figure, female.

from analogy, would be finely serrated. 'The species of Pneumora have been more profoundly modified for the sake of stridulation than any other orthopterous insect; for in the male the whole body has been converted into a musical instrument, being

12 Westrood, 'Moder'n Classification,' vol. i. p. 462. 
distended with air, like a great pellucid bladder, so as to increase the resonance. Mr. T'rimen informs me that at the Cape of Good Hope these insects make a wonderful noise during the night.

In the three foregoing families, the females are almost always destitute of an efficient musical apparatus. But there are a ferv exceptions to this rule, for Dr. Gruber has shewn that both. sexes of Ephippiger vitium are thus provided; though the organs differ in the male and female to a certain extent. Honce we cannot suppose that they have been transferred from the male to the female, as appears to havo been the case with the secondary sexual characters of many other animals. They must have been independently developed in the two sexes, which no doubt mutually call to each other during the season of love. In most other Locustidæ (but not according to Landois in Decticus) the females have rudiments of the stridulatory organs proper to the male; from whom it is probable that these have been transferred. Landois also found such rudiments on the under surface of the wing-covers of the female Achetidx, and on the femora of the female Acridiidr. In the Homoptera, also, the females have the yroper musical apparatus in a functionless state; and we shall hereafter meet in other divisions of the animal kingdom.with many instances of structures proper to the male being present in a rudimentary condition in the female.

Landois has olsserved another important fact, namely, that in the females of the Acridiidx, the stridulating teeth on the femora remain throughout life in the same condition in which they first appear during the larval state in both sexes. In the males, on the other hand, they become further developed, and acquire their perfect structure at the last moult, when the insect. is mature and ready to breed.

From the facts now given, we see that the means by which the males of the Orthoptera produce their sounds are extremely diversified, and are altogether different from those employed by the Homoptcra. ${ }^{3}$ But throughout the animal kingdom we often find the same object gained by the most diversified means; this seems due to the whole organisation having undergone multifarious changes in the course of ages, and as part after part varied different variations were taken advantage of for the same gencral purpose. The diversity of means for producing sound in the three families of the Orthoptera and in the

4 Tandois has recently found in marrasn Orthoptera rudimentary -tructures cios'ly similar to the sonad-prodzcing organs in the Ho- moptera; and this is a surprising fact. See 'Zeitschr. fir wissensch. Zoolug.' B. xxii. Heft 3, 1871, p 348. 
Homoptera, impresses the mind with the high importance of these structures to the males, for the sake of calling or alluring the females. We need fecl no surprise at the amount of modification which the Orthoptera have undergone in this respect, as we now snow, from Dr. Scudder's remarkable discovery, ${ }^{44}$ that there has been more than ample time. This naturalist has lately found a fossil insect in the Deronian formation of New Brunswick, which is furmished with "the well-known tympanum or stridu" lating apparatus of the male Locustidæ." The insect, though in most respects related to the Neuroptera, appears, as is so often the case with very ancient forms, to connect the two related Orders of the Neuroptera and Orthoptera.

I have but little more to say on the Orthoptera. Some of the species are very pugnacious: when two male field-crickets (Gryllus campestris) are confined together, they fight till one kills the other; and the species of Mantis are described as manœuvring with their sword-like front-limbs, like hussars with their sabres. Tho Chinese keep these insects in little bamboo cages, and match them like game-cocks. ${ }^{45}$ With respect to colour, some exotic locusts are beautifully ornamented; the posterior wings being marked with red, blue, and black; but as throughout the Order the sexes rarely differ much in colour, it is not probable that they owe their bright tints to sexual selection. Conspicuous colours may be of use to these insects, by giving notice that they are unpalatable. Thus it has been observed ${ }^{46}$ that a bright-coloured Indian locust was invariably rojected when offercd to birds and lizards. Some cases, however, are known of sexual differences in colour in this Order. The male of an American cricket ${ }^{47}$ is described as being as white as jvory, whilst the female varies from almost white to greenishyellow or dusky. Mr. Walsh informs me that the adult male of Spectrum femoratum (one of the Phasmidæ) "is of a shining " brownish-yellow colour; the adult female being of a dull, "opaque, cinereous brown; the young of both sexes being green." Lastly, I may mention that the male of one curious kind of

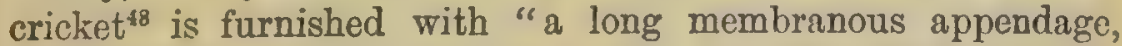
"which falls over the face like a veil," but what its use may be, is not known.

4 'Transact. Ent. Soc.' 3rd series, rol. ii. (Journal of Proceedings," p. 117.)

45 Westwood, 'Modern Class, of Insects,' vol. i. p. 427 ; for crickets, p. 445 .

so Mr. Ch. Hoine, in "Proc. Ent. Soc:' May 3, 1869. p. xii.
47 The Ecanthus nivalis. Harris, 'Insects of New England,' 1842, p. 124. The two sexes of $E$. pellucidus of Europe differ, as I hear from Victor Carus, in nearly the same manner.

40 Platyblemnus: W'estrood, 'Modern Class.' vol. i. p. $\mathbf{4 4 7 .}$ 
Order, Neuroptera.-Little need here be said, except as to colour. In the Ephemeridæ the sexes often differ slightly in their obscure tints; ${ }^{48}$ but it is not probable that the males are thus rendered attractive to the females. The Libellulidæ, or dragon-flies, are ornamented with splendid green, blue, yellow, and vermilion metallic tints; and the sexes often differ. Thus, as Prof. Westwood remarks, ${ }^{50}$ the males of some of the Agrionidæ, "are of a rich blue with black wings, whilst the "females are fine green with colourless wings." But in Agrion Ramburii these colours are exactly reversed in the two sexes. ${ }^{51}$ In the extensive N. American genus of Hetærina, the males alone have a beautiful carmine spot at the base of each wing. In Anax junius the basal part of the abdomen in the male is a vivid ultramarine blue, and in the female grass-green. In the allied genus Gomphus, on the other hand, and in some other genera, the sexes differ but little in colour. In closely-allied forms throughout the animal kingdom, similar cases of the sexes differing greatly, or very little, or not at all, are of frequent occurrence. Although there is so wide a difference in colour between the sexes of many Libellulidæ, it is often difficult to say which is the more brilliant; and the ordinary coloration of the two sexes is reversed, as we have just seen, in one species of Agrion. It is not probable that their colours in any case have been gained as a protection. Mr. MacLachlan, who has closely attended to this family, writes to me that dragon-flies-the tyrants of the insect-world-are the least liable of any insect to be attacked by birds or other enemies, and he believes that their bright colours serve as a sexual attraction. Certain dragon-flies apparently are attracted by particular colours: Mr. Patterson observed ${ }^{52}$ that the Agrionidm, of which the males are blue, settled in numbers on the blue float of a fishing line; whilst two other species wero attracted by shining white colours.

It is an interesting fact, first noticed by Schelver, that, in several genera belonging to two sub-families, the males on first emergence from the pupal state, are coloured exactly like the females; but that their bodies in a short time assume a conspicuous milky-blue tint, owing to the exudation of a kind of oil, soluble in ether and alcohol. Mr. MacLachlan believes that in the male of Libellula depressa this change of colour does not occur until nearly a fortnight after the metamorphosis, when the sexes are ready to pair.

49. D. Walsh, the 'Psendo-neuroptera of Illinois,' in 'Proc. Ent. Soc. of Philadelphia,' 1862, p. 361. c 'Modern Class.' vol. ii. p. 37.

3) Walsh, ibid. p. 381. I am indebted to this natuxalist for the following facts on Hetærina, Anax, and Gomphus.

32 'Transact. Ent. Soc.' vol. i. 1836 , p. Ixxxi. 
Certain species of Neurothemis present, according to Braner, ${ }^{63}$ a curious case of dimorphism, some of the females having ordinary wings, whilst others have them "very richly netted, as in the " males of the same species." Brauer "explains the phenomenon "on Darwinian principles by the supposition that the close "netting of the veins is a secondary sexual character in the "males, which has been abruptly transferred to some of the "females, instead of, as generally occurs, to all of them." Mr. IacLachlan informs me of another instance of dimorphism in several species of Agrion, in which some individuals are of :1n orange colour, and these are invariably females. This is 1: obably a case of reversion; for in the true Libellulæ, when the sexes differ in colour, the females are orange or yellow; - o that supposing Agrion to be descended from some primordial torm which resembled the typical Libellulæ in its sexual characters, it would not be surprising that a tendency to vary in this manner should occur in the females alone.

Although many dragon-flies are large, powerful, and fierce insects, the males have not been observed by Mr. MacLachlan to fight together, excepting, as he believes, in some of the smaller species of Agrion. In another group in this Order, namely, the Termites or white ants, both sexes at the time of swarming may be seen running about, "the male after the female, sometimes "two chasing one female, and contending with great eagerness "who shall win the prize."54 The Atropos pulsatorius is said to make a noise with its jaws, which is answered by other individuals. ${ }^{55}$

Order, Hymenoptera.-That inimitable observer, M. Fabre, ${ }^{j 6}$ in describing the habits of Cerceris, a wasp-like insect, remarks that "fights frequently ensue between the males for the possession of "some particular female, who sits an apparently anconcerned" "beholder of the struggle for supremacy, and when the victory" " is decided, quietly flies away in company with the conqueror." Westwood ${ }^{57}$ says that the males of one of the saw-flies (Tenthredinæ) "have been found fighting together, with their mandibles "locked." As M. Fabre speaks of the males of Cerceris striving to obtain a particular female, it may be well to bear in mind that insects belonging to this Order have the power of recognising

53 See abstract in the 'Zoological Record ' for 1867, p. 450 .

5t Kirby and Spence, 'Introduct. to Entomology;' vol. ii. 1818, p. 35 . ns Hcrizeau, "Les Facultés Mentales,' \&c. Tom. i. p. 104.
36 See an interesting articla 'The Writings of Fabre,' in 'Nat. Hist. Review, April 1862, p. 122. 37 'Journal of Proc. of Entomolog Soc.' Sept. 7th, 1863, p. 169. 
each other after long intcrvals of time, and are deeply attached. For instance, Pierre Huber, whose accuracy no one doubts, separated sume ants, and when, after an interval of four months, shey met others which had formerly belonged to the same 'ommunity, they recognised and caressed one another with their antennæ. Had they been strangers they would have fought rogether. Again, when two communities engage in a battle, the ants on the same side sometimes attuck each other in the general confusion, but they soon perceive their mistake, and the one ant soothes the other. ${ }^{68}$

In this Order slight differences in colour, according to sex, are common, but conspicuous differences are rare except in the family of Bees; yet both scxes of certain groups are so brilliantly coloured-for instance in Chrysis, in which vermilion and netallic grecns prevail-that we are tempted to attribute the result to sexual selection. In the Ichneumonidæ, according to Mr. Walsh, ${ }^{59}$ the males are alinost universally lighter-coloured than the females. On the other hand, in the Tenthredinidø the males are generally darker than the females. In the Siricidro the sexes frequently differ; thus the male of Sirex juvencus is banded with orange, whilst the female is dark purple; but it is difficult to say which sex is the more ornamented. In Tremex columbe the female is much brighter-coloured than the male. I am informed by Mr. F. Smith, that the male ants of several species are black, the females being testaceous.

In the family of Bees, especially in the solitary species, as I hear from the same entomologist, the sexes often differ in colour. 'The males are generally the brighter, and in Bombus as well as in Apathus, much more variable in colour than the females. In Anthophora retusa the male is of a rich fulvous-brown, whilst the female is quite black: so are the females of several species of Xylocopa, the males being bright yellow. On the other hand the females of some species, as of Andrenc fulva, are much irighter-coloured than the males. Such differences in colour can hardly be accounted for by the males being defenceless and thus requiring protection, whilst the females are well defended vy their stings. H. Muiller, ${ }^{60}$ who has particularly attended to the haioits of bees, attributes these differences in colour in chief part to sexual selection. That bees have a keen perception of colour is certain. He says that the males search eagerly and fight for the possession of the females; and he accounts through

52 P. Huber, 'Recherches zur' les Maurs des Fourmis,' 1810, pp. 150, 165.

- Proc. Entomolog. Soc. of
Philadelphia,' 1866', pp. 238-238.

ou 'Anwendung de: ' Lehre auf Bieney. $Y: a n$, a. a, Jahrg. xxix. 
such contosts for the mandibles of the males being in certain species larger than those of the femaies. In some cases the males are far more numerous than the females, either early in the season, or at all times and places, or locally; whereas the females in other cases are apparently in cxcess. In some species the more beautiful males appear to have been selected by the females; and in others the more beautiful females by the males. Consequently in certain genera (Miiller, p. 42), the males of the several species differ much in appearance, whilst the females aro almost indistinguishable; in other genera the reverse occurs. H. Muller believes (p. 82) that the colours gained by one sex throngh sexual selection have often been transferred in a variable degree to the other sex, just as the pollen-collecting apparatus of the female has often been transferred to the male, to whom it is absolutely useless. ${ }^{61}$

Mutila Europrer makes a stridulating noise; and according to Goureau ${ }^{62}$ both sexes have this power. He attributes the sound to the friction of the third and preceding abdominal segments, and I find that these surfaces are marked with very fine concentric ridges; but so is the projecting thoracic collar, into which the head articulates, and this collar, when scratched with the point of a needle, emits the proper sound. It is rather surprisingr tbat both sexes should have the power of stridulating, as the male is winged and the female wingless. It is notorious that Bees express certain emotions, as of anger, by the tone of their humming; and according to H. Muller (p. 80), the males of some species make a peculiar singing noise whilst pursuing tho females.

61 M. Perrier in his article "la Sélection sexuelle d'après Darwin'('Revue Scientifique,' Feb. 1873, p. 868), without apparently having reflected much on the subject, objects that as the males of social bees are known to be produced from unfertilised ova, they could not transmit new characters to their male offspring. This is an extraordinary objection. A female bee fertilised by a male, which presented some character facilitating the union of the sexes, or rendering him more attractive to the female, would lay eggs which would produce only females; but these young females would next year produce males, and will it be pretended that such males would not inherit the characters of their male grandfathers? To take a case with ordinary animals as nearly parallel as possible: if a female of any white quadruped or bird were crossed by a male of a black breed, and the male and female offspring were paired together, will it be pretended that the grandchildren would not inherit a tendency to blackness from their male grandfather? The acquirement of new characters by the sterile worker-beas is a much more difficult case, but I have endeavoured to show in my - Origin of Species, how these sterile beings are subjected to the power of natural selection.

2 Quoted by Westwood, 'Mouern Class. of Insects, vol. ii. p. 214 
Order, Coleoptera (Beetles).-Many beetles are coloured so as to resemble the surfaces which they habitually frequent, and they thus escape detection by their enemies. Other species, for instance diamond-bectles, are ornamented with splendid colours, which are often arranged in stripes, spots, crosses, and other elegant patterns. Such colours can hardly serve directly as a protection, except in the case of certain flower-fecding species; but they may serve as a warning or means of recognition, on the same principle as the phosphorescence of the glow-worm. As with beetles the colours of the two sexcs are generally alike, we have no evidence that they have been gained through sexual selection; but this is at least possible, for they may have been developed in one sex and then transferred to the other; and this view is even in some degree probable in those groups which possess other well-marked secondary sexual characters. Blind beetles, which cannot of course behold each other's beauty, never, as I hear from MIr. Waterlicuse, jun., exhibit bright colours, though they often have polished coats; but the explanation of their obscurity may be that they gencrally inlibit caves and other obscure stations.

Some Longicorns, especially certain Prionidæ, offer an exccption to the rule that the seres of beetles do not differ in colour. Most of these insects are large and splendidly coloured. The males in the genus Pyrodes, ${ }^{63}$ which I saw in Mr. Bates's collection, are generally redder but rather duller than the fomales, the latter being coloured of a more or less splendid golden-green. On the other hand, in one species the male is goldon-green, the female being richly tinted with red and purple. In the genus Esmeralda the seres differ so greatly in colour that they have beon ranked as distinct species; in one species both are of a veautiful shining green, but the male has a red thorax. On the whole, as far as I could judge, the females of those Prionidx, in

63 Pyrodes pulcherrimus, in which the sexes differ conspicuously, nas been described by Mr. Bates in 'Transact. Ent. Soc.' 1869, p. 50. I will specify the few other cases in which I have heard of a difference in colour between the sexes of beetles. Kirby and Spence ('Introduct. to Entomology, vol. iii. p. 301) mention a Cantharis, Meloe, Rhagium, and the Leptura testicea; the male of the latter being testaceous, with a black thoras, and the female of a dull red all over. Those two latte- beetles belong to the family of Longicorns. Messrs. R. Trimen and Waterhouse, jun., inform me of two Lamellicorns, viz., a Peritrichia and Trichius, the male of the latter being more obscurely coloured than the female. In Tillus elongatus the male is black, and the female always, as it is beliered, of a dark blue colour, with a red thorax. The male, also, of Orsodacna atra, as I heal from Mr. Walsh, is black, the female (the so-called $O$. ruficollis) having a ou fous thor:.x. 
Chap. X.

which the sexes differ, are coloured more richly than the males, and this does not accord with the common rule in regard to colour, when acquired through sexual selection.

A most remarkable distinction between the sexes of many beetles is presented by the great horns which rise from the head, thorax, and clypeus of the males; and in some few cases from the under surface of the body. These horns, in the great family of the Lamellicorns, resemble those of various quadrupeds, such as stags, rhinoceroses, \&c., and are wonderful both from their size and diversified shapes. Instead of describing them, I have given figures of the males and females of some of the more remarkable forms. (Figs. 16 to 20.) The fomales generally exhibit rudiments of the horns in the form of small knobs or ridges; but some are destitute of even the slightest rudiment. On the other hand, the horns are nearly as well developed in the female as in the male of Phanceus lancifer; and only a little less well developed in the females of some other species of this genus and of Copris. I am informed by Mr. Bates that the horns do not differ in any manner corresponding with the more important characteristic differences between the several subdivisions of the family: thus within the same section of the genus Onthophagus, there are species which have a single horn, and others which have two.
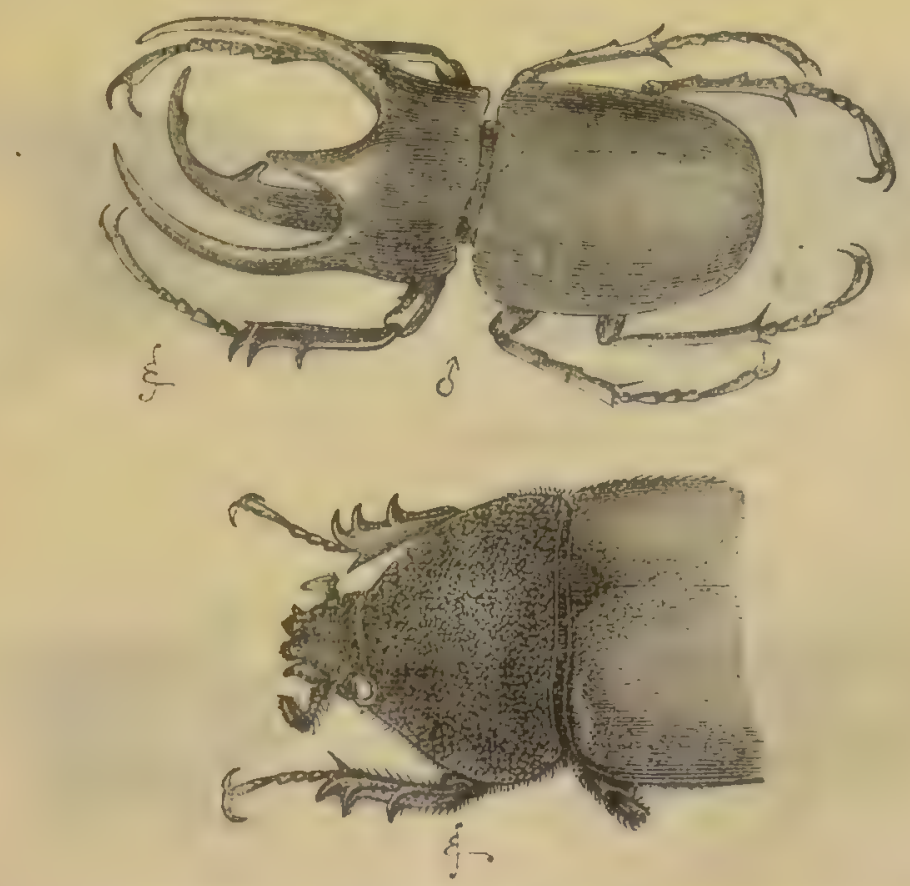

Fig 16. Chalcosoma atlas. Upper figure, male (reduccd); lower figure, femalo (nat. size). 

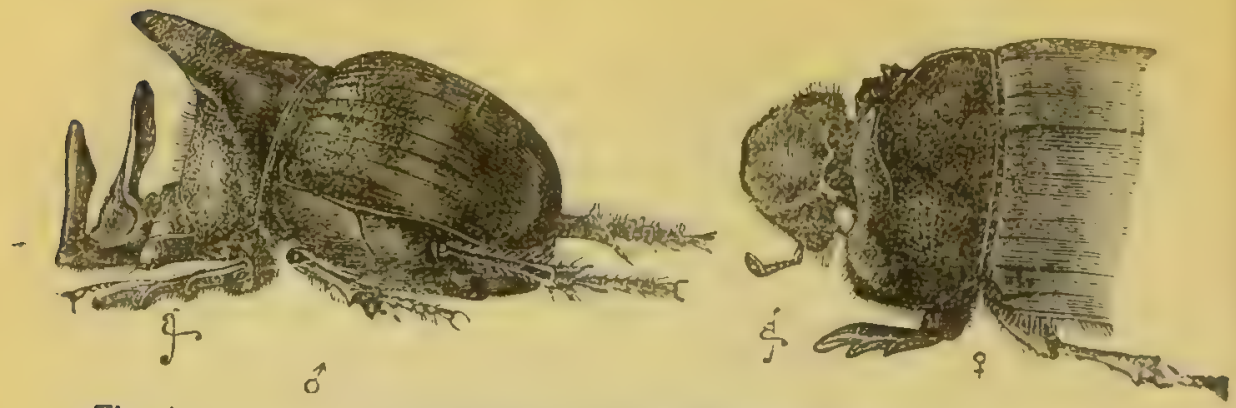

Fig. $1 \%$

Copris isidis. (Left-band figures, males.)
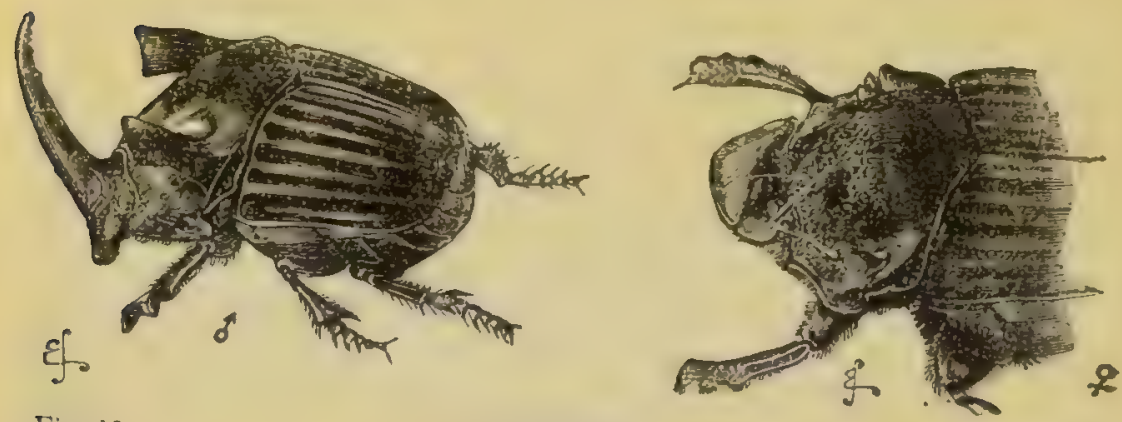

Fig. 18.

Thanæus faunus.

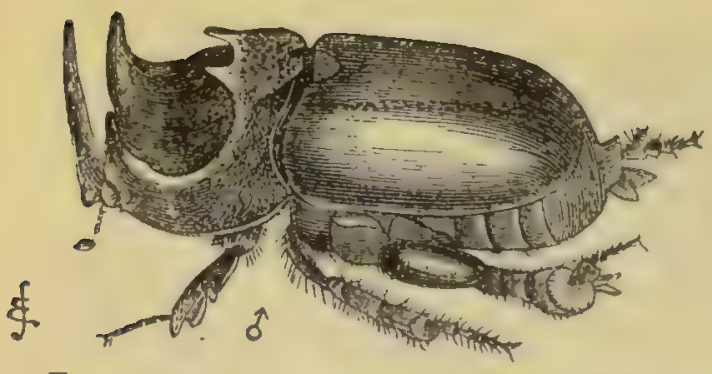

FIg. 19

Dípelicus cantori.
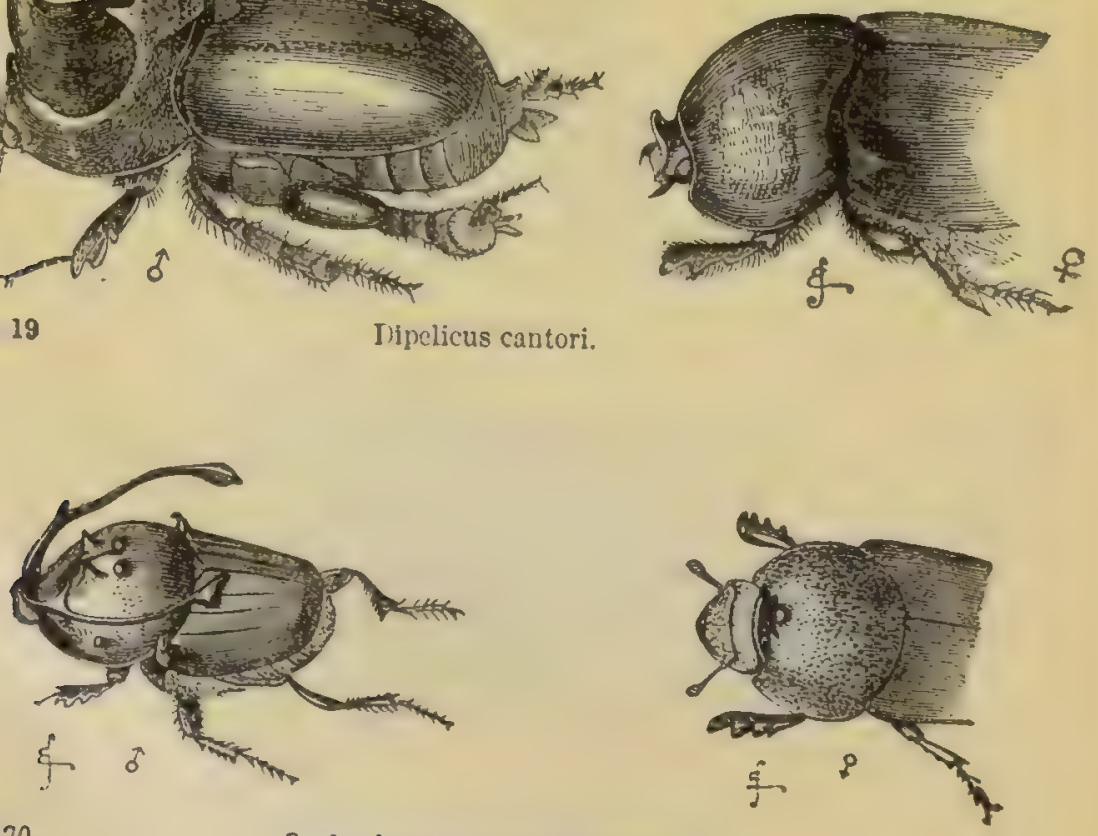

Fig. 20.

Ontbophacus rangifer. enlarged. 
In almost all cases, the horns are remarkable from their excessive variability; so that a graduated series call be formed. from the most highly developed males to others so degenerato that they can barely be distinguished from the females. Mr. Walsh ${ }^{64}$ found that in Phanceus carnifia the horus were thrice as long in some males as in others. Mr. Bates, after examining above a hundred males of Onthophagus rangifer (fig. 20), thought that he had at last discovered a species in which the horns did not vary; but further research proved the contrary.

The extraordinary size of the horns, and their widely different structure in closely-allied forms, indicate that they have been formed for some purpose; but their excessive variability in the males of the same species leads to the inference that this purpose cannot be of a definite nature. 'The horns do not show marks of friction, as if used for any ordinary work. Some authors suppose ${ }^{65}$ that as the males wander about much more than the females, they require horns as a defence against their enemies; but as the horns are often blunt, they do not seem well adapted for defence. The most obvious conjecture is that they are used by the males for fighting together; but the males have never been observed to fight; nor could Mr. Bates, after a careful examination of numerous species, find any sufficient evidence, in their mutilated or broken condition, of their having been thus used. If the males had been habitual fighters, the size of their bodies would probably have been increased through sexual selection, so as to have exceeded that of tho females; but Mr. Bates, after comparing the two sexes in above a hundred species of the Copridæ, did not find any marked difference in this respect amongst well-developed individuals. In Lethrus, moreover, a beetlo belonging to the same great division of the Lamellicorns, the males are known to fight, but are not provided with horns, though their mandibles are much larger than those of the female.

The conclusion that the horns have been acquired as ornaments is that which best agrees with the fact of their having been so immensely, yet not fixedly, developed, - as shewn by their extremo variability in the same species, and by their extreme diversity irs closely-allied species. This view will at first appear extremely improbable; but we shall hereafter find with many animals standing much higher in the scale, namely fishes, amphibians, reptiles and birds, that various kinds of crests, knobs, horns and combs have been developed apparently for this sole purpose.

The males of Onitis furcifer (fig. 21), and of some other

s4 'Yroc. Entomolog. Soc. of Philadelphia,' 1864, p. 228

os Kirby and Spence, 'Introduct. Entomolog.' vol. iii. p. 300 . 
species of the genus, are furnished with singular projections on their anterior femori, and with a great fork or pair of horns on

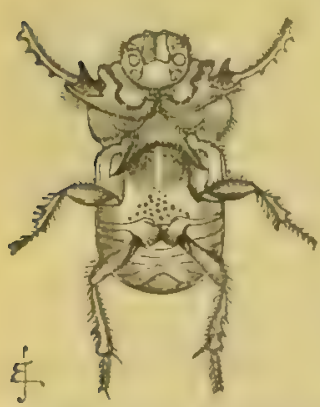

21. Onitis furcifer, male viewed from beneath. the lower surface of the thorax. Judging from other insects, these may aid the male in clinging to the female. Although the males have not even a trace of a horn on the upper surface of the body, yet the females plainly exhibit a rudiment of a single horn on the head (fig. 22, a), and of a crest (b) on the thorax. That the slight thoracic crest in the female is a rudiment of a projection proper to the male, though entirely absent in the male of this particular species, is clcar: for the female of Lubas bison (a genus which comes next to Onitis) has a similar slight crest on the thorax, and the male bears a great projection in the same situation. So, again, there can hardly be a doubt that the little point ( $a$ ) on the head of the female Onitis

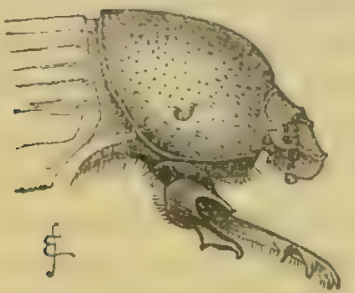

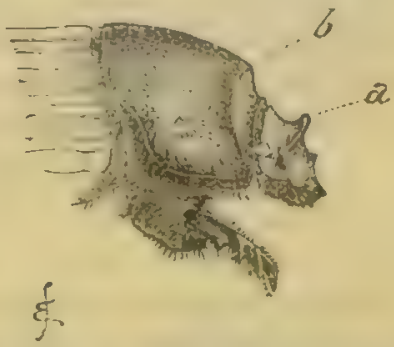

Fig. 22. Left-hand figure, male of Onitis furcifer, riewed laterally. Right-hand
figure, female. a. Rudiment of cephalic horn. $b$. Trace of thoracic horn or crest.

furcifer, as well as on the head of the females of two or three allied species, is a rudimentary representative of the cephalic horn, which is common to the males of so many Lamellicorn beetles, as in Phanæus (fig. 18).

The old belief that rudiments have been created to complete the scheme of nature is here so far from holding good, that we have a complete inversion of the ordinary state of things in the family. We may reasonably suspect that the males originally bore horns and transferred them to the females in a rudimentary condition, as in so many other Lamellicorns. Why the males subsequently lost their horns, we linow not; but this may hare been caused through the principle of componsation, owing to the development of the large horns and projections on the lower surface; and as these are confined to the males, the rudiments of the upper horns on the females would not have becn thus obliterated. 
The eases hitherto given refer to the Lamellicorns, but the males of some few other beetles, belonging to two widely distinc' groups, namely, the Curculionidæe and staphylinidæ, are furnished with horms-in the former on the lower surface of the body, ${ }^{60}$ in the latter on the upper surface of the head and thorax. In the Staphylimidee, the horus of the males are extraordinarily variable in the same specics, just as we havo seen with the Lancllicorns. In siagonimn we have a case of dimorphism, for the males can be divided into two sets, differing greatly in the size of their bodies and in the development of their horns, without intermediate gradations. In a species of Bledius (fig. 23), also belonging to the Staphylinidæ, Professor Westwood
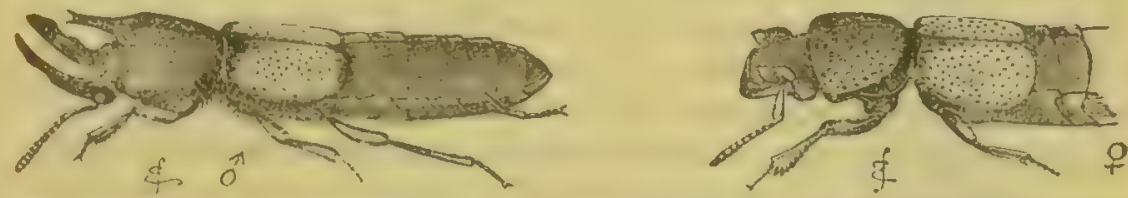

Fig. 23. Bledius tauris, m.ignitied. Left-hand figure, male; right-hand figure female.

states that, "male specimens can be found in the same locality " in which the central horn of the thorax is very large, but the " horns of the head quite rulimental; and others, in which the "thoracic horn is much shorter, whilst the protuberances on "the head are long." ${ }^{6}$ i Here we apparently have a case of compensation, which throws light on that just given of the supposed loss of the upper horns by the males of Onitis.

Law of Diuttle.-Some male beetles, which seem ill-fitted for fighting, nerertheless engage in conflicts for the possession of the females. Mr. Willace is saw two males of Leptorhynchus angustutus, a lincir beetle with a much clongated rostrum, "fighting for a female, who stood close by busy at her boring. * They pushed at each other with their rostra, and clawed and " thumped, apparently in the greatest rage." The smaller male, however, "soon ran away, acknowledging himself vanquished." In some few cases male beetles are well adapted for fighting, by possessing great toothed mandibles, much larger than those of the females. This is the case with the common stag-bectle (I.ucanus cervus), the males of which emerge from the pupal state about a weck before the other sex, so that several may often be seen pursuing the sime female. At this season they

66 Kirby and Spence, "Introduct. Entomolog.' vol. iii. p. 329.

67 'Modern Classification of Insects,' vol. i. p. 172: Siagonium, p. 172. In the British Museum I noticed one male specimen of Sil- gonium in an intermeriate condic tion, so that the dimorphism is not strict.

68 'The Malay Archipelago,' vol. ii. 1869 , p. 276. Riley, Sixth' 'Peport on insects of Missouri,' 1874, p. 115 
engage in fierce couflicts. When Mr. A. H. Davis ${ }^{6 \theta}$ enclosed two males with one female in a box, the larger male severely pinched the smaller one, until he resigned his pretensions. I friend informs me that when a boy he often put the males together to sce them fight, and he noticed that they were much bolder and fiercer than the females, as with the higher animals. The males would seize hold of his finger, if held in front of them, but not so the females, although they have stronger jaws. The males of many of the Lucanidre, as well as of the above-mentioned Leptorhynchus, are larger and more powerful insects than the females. The two sexes of Lethrus cephalotes (one of the Lamellicorns) inhabit the same burrow; and the male has larger mandibles than the female. If, during the breeding-season, a strange male attempts to enter the burrow, he is attacked; the female does not remain passive, but closes the mouth of the burrow, and encourages her mate by continually pushing him on from behind; and the battle lasts until the aggressor is killed or runs away. ${ }^{70}$ The two sexes of another Lamellicorn beetle, the Ateuchus cicatricosus, live in pairs, and seem much attached to each other; the male excites the female to roll the balls of dung in which the ova are deposited; and if she is removed, he becomes much agitated. If the male is removed the female ceases all work, and as M. Brulerie ${ }^{71}$ believes, would remain on the same spot until she died.

The great mandibles of the male Lucanidæ are extremely variable both in size and structure, and in this respect resemble the horns on the head and thorax of many male Lamellicorns and Staphylinidw. A perfect series can be formed from the best-provided to the worst-provided or degenerate males. Although the mandibles of the common stag-beetle, and probably of many other species, are used as efficient weapons for fighting, it is doubtful whether their great size can thus be accounted for. We have seen that they are used by the Lucanus elaphus of $\mathrm{N}$. America for seizing the female. As they are so conspicuous and so elegantly branched, and as owing to their great length they are not well adapted for pinching, the suspicion has crossed my mind that they may in addition serve as an Jrnament, like the horns on the head and thorax of the various species above described. The male Chiasognathus Grantii of S. Chile-a splendid beetle belonging to the same family-has

- 'Entomological Magazine,' vol. i. 1833, p. 82 . See also on the conflicts of this species, Kirby and Spence, ibid. vol. iii. p. 314 ; and Testwod, ibid. rol. i. p. 187.
70 Quoted from Fischer, in 'Dict. Class. d'llist. Nat.' tom. x. p. 324. 11 'Ann. Soc. Entomolog. France, 1866 , as quoted in 'Journal oi Travel,' by A. Mlurray, 1868, p. 135. 
enormously developed mandibles (fig. 24); he is bold and pug- nacious; when threatened he faces round, opens his great jaws, and at the same time stridulates loudly. But the mandibles were not strong enough to pinch my finger so as to canse actual pain.

Sexual selection, which implies the possession of considerable perceptive powers and of strong passions, stems to have been more effective with the Lamellicorns than with any other family of beetles. With some species the males are provided with weapons for fighting; some live in pairs and show mutual affection; many have the power of stridulating when excited; many are furnished with the most extraordinary horns, apparently for the sake of ornament; and some, which are diurnal in their habits, are gorgeously coloured. Lastly, several of the largest beetles in the world belong to this family, which was placed by Linnæus and Fabricius at the head of the Order. ${ }^{72}$

Stridulating organs.-Beetles belonging to many and widely distinct families possess these organs. The sound thus produced can sometimes be heard at the distance of several feet or even yards, ${ }^{73}$ but it is not comparable with that made by the Orthoptera. The rasp generally consists of a narrow, slightly-raised surface, crossed by very fine, parallel ribs, sometimes so fine as to cause iridescent colours, and having a very elegant appearance under the microscope. In some cases, as with Typhœus, minute, bristly or scale-like prominences, with which the whole
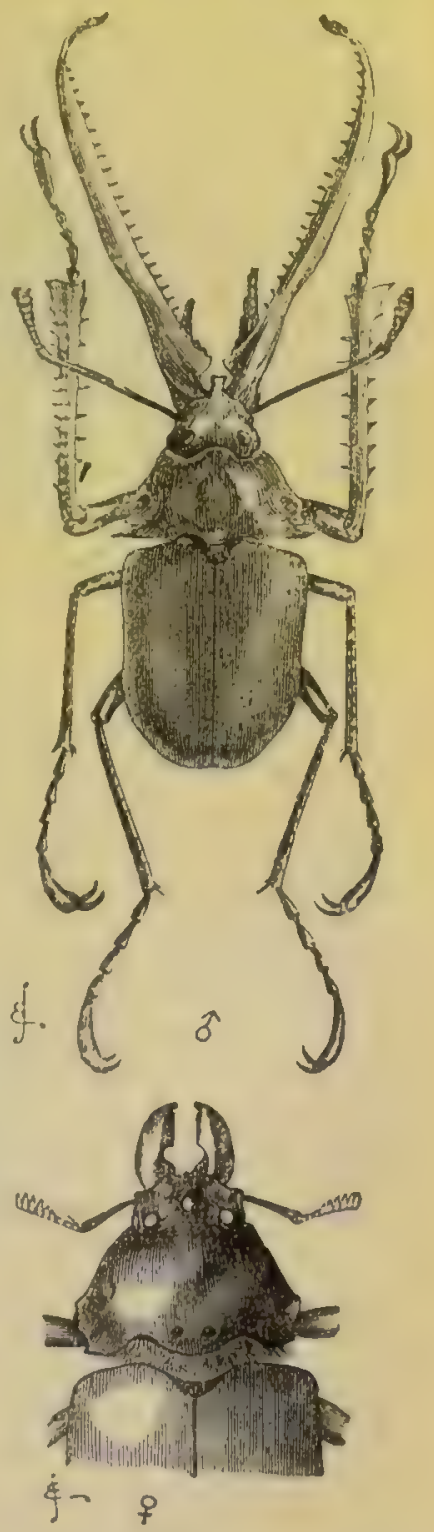

Fig. 24. Chiasognathus granti;, reduced. Upper figure, male; lower figure, female.

surrounding surface is covered in approximately parallel lines, could be traced passing into the ribs of the rasp. The

72 Westwood, 'Modern Class." vol. i. p. 184.

83 Wollaston, 'On certain Musical
Curculionidx,' 'Annals and Mag. of Nat. Hist.' vol, vi. 1860 , p. 14. 
transition takes place by their becoming confluent and straight, and at the same time more prominent and smooth. A hard ridge on an adjoining part of the body serves as the scraper for the rasp, but this scraper in some cases has been specially modified for the purpose. It is rapidly moved across the rasp, or conversely the rasp across the scraper.
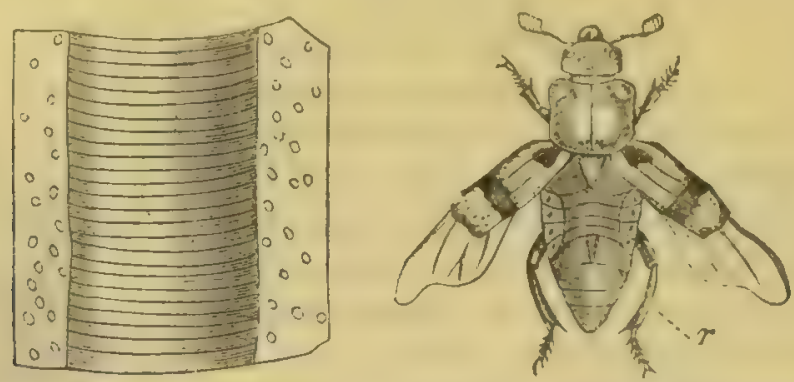

Fig. 25. Necrophorus (from Landois), $r$. The two rasps. Left-hand figure, part of the rasp highly magnified.

These organs are situated in widely different positions. In the carrion-beetles (Necrophorus) two parallel rasps ( $r$, fig. 25) stand on the dorsal surface of the fifth ahdominal segment, each rasp ${ }^{74}$ consisting of 126 to 140 fine ribs. These ribs are scraped against the posterior margins of the elytra, a small portion of which projects beyond the general outline. In many Crioceridr, and in Clyithra 4-punctata (one of the Chrysomelidx), and in some Tenebrionidæ, \&c., ${ }^{75}$ the rasp is seated on the dorsal apex of the abdomen, on the pygidium or pro-pygidium, and is scraped in the same manner by the elytra. In Heterocerus, which belongs to another family, the rasps are placed on the sides of the first abdominal segment, and are scraped by ridges on the femora. ${ }^{76}$ In certain Curculionidæ and Carabidx, ${ }^{77}$ the parts

74 Landois, 'Zcitschrift für wiss. Zoolog.' B. xvii. 1867, s. 127.

75 I am greatly indebted to $\mathrm{Mr}$. G. R. Crotch for having sent me - many prepared specimens of various beetles belonging to these three families and to others, as well as for valuable information. He believes that the power of stridulation in the Clythra has not been previously observed. I am also much indebted to Mr. E. W. Janson, for information and specimens. I may add that my son, Mr. F. Darwin, finds that Dermestes murinus stridulates, but he searched in vain for the apparatus. Scolytus has lately been described by $D_{1}$. Chapman as a stridulator, in the 'Entomologist's Monthly Magazine,' vol. vi. p. 130.

76 Schiödte, translated in 'Annals and Mag. of Nat. Hist.' vol. $x \mathbf{x}$. 1867, p. 37.

77 Westring has described (Kroyer, 'Naturhist. Tidskrift,' B. ii. 184849, p. 334 ) the stridulating organs in these two, as well as in other families. In the Carabida I have examined Elaphrus uliginosus and Blethisa multipunctata, sent to me by Mr. Crotch. In Blethisa the transverse ridges on the furrowed border of the abdominal segment do 
are completely reversed in position, for the rasps are seated on the inferior surface of the elytra, near their apices, or along their outer margins, and the edges of the abdominal segments serve as the scrapers. In Pelubius Mermunni (one of Dytiscidre or watcr-bcetles) a strong ridge runs parallel and near to the sutural margin of the elytra, and is crossed by ribs, coarse in the middle part, but becoming gradually finer at both ends, especially at the upper end; when this insect is held under water or in the air, a stridulating noise is produced by the extreme horny inargin of the abdomen being scraped against the rasps. In a great number of long-horned beetles (Longicornia) the organs are situated quite otherwise, the rasp being on the meso-thorax, which is rubbed against the pro-thorax; Landois counted 238 very fine rilus on the rasp of Cerambyx heros.

Many Lamellicorns have the power of stridulating, and the organs differ greatly in position. Some species stridulate very loudly, so that when Mr. F. Smith caught a Trox subulosus, a gamekeeper, who stood by, thought he had caught a mouse; but I failed to discover the proper organs in this beetle. In Geotrupes and Typhous a narrow ridge runs obliquely across ( $r$, fig. 26) the coxa of each hind-leg (having in $G$. stercorarius 84 ribs), which is scraped by a specially projecting part of one of the $a b$ dominal segments. In the nearly allied Copris lunaris, an excessively narrow fine rasp runs along the sutural margin of the elytra, with another short rasp near the basal outer margin; but in some other Coprini the rasp is seated, according to Leconte, ${ }^{78}$ on the dorsal surface of the abdomen. In Oryctes it is seated on the pro-pygidium; and, according to the same entomologist, in some other Dynastini, on the under surface of the elytra. Lastly, Westring states that in Omaloplia brunnea the rasp is placed on the pro-sternum, and the scraper on the meta-sternum, the parts thus

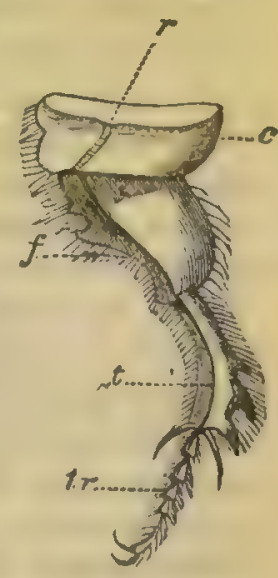

8

Fig. 26. Hind-leg of Geotrupes stercora rius (from Landoís).

r. Rasp. Coxa. $f$. Femur. $t$. Tibia tr. Tarsi. occupying the under surface of the body, instead of the upper surface as in the Longicorns.

We thus see that in the different coleopterous families the

not, as far as I could judge, come into play in scraping the rasps on the elytra.

${ }^{3}$ I am indebted to $\mathbf{M r}$. Walsh, of Illinois, for having sent me extracts from Leconte's 'Introduction to Entomology,' pp. 101, 143. 
etridulating organs are wonderfully diversified in position, but not much in structure. Within the same family some species are provided with these organs, and others are destitute of them. This diversity is intelligible, if we suppose that originally various heetles made a shuffling or hissing noise by the rubbing together of any hard and rough parts of their bodies, which happened to bo in contact; and that from the noise thus produced being in some way useful, the rough surfaces were gradually developed into regular stridulating organs. Some beetles as they move, now produce, either intentionally or unintentionally, a shuffling $n$ ise, without possessing any proper organs for the purpose. Mr. Wallace informs me that the Euchirus longimanus (a Lamellicorn, with the anterior legs wonderfully elongated in the male) "makes, whilst moving, a low hissing sound by the pro" trusion and contraction of the abdomen; and when seized it "produces a grating sound by rubbing its hind-legs against the "edges of the elytra." The hissing sound is clearly due to a narrow rasp running along the sutural margin of each elytron; and I could likewise make the grating sound by rubbing the shagreened surface of the femur against the granulated margin of the corresponding elytron; but I could not here detect any proper rasp; nor is it likely that I could have overlooked it in so large an insect. After examining Cychrus, and reading what Westring has written about this beetle, it seems very doubtful whether it possesses any true rasp, though it has the power of emitting a sound.

From the analogy of the Orthoptera and Homoptera, I expected to find the stridulating organs in the Coleoptera differing according to sex; but Landois, who has carefully examined several species, observed no such difference; nor did Westring; nor did Mr. G. R. Crotch in preparing the many specimens which he had the kindness to send me. Any difference in these organs, if slight, would, however, be difficult to detect, on account of their great variability. Thus, in the first pair of specimens of Necrophorus humator and of Pelobius which I examined, the rasp was considerably larger in the male than in the female; but not so with succeeding specimens. In Geotrupes stercorarius the rasp appeared to me thicker, opaquer, and more prominent in three males than in the same number of females; in order, therefore, to discover whether the sexes differed in their power of stridulating, my son, Mr. F. Darwin, collected fifty-seven living specimens, which he separated into two Ints, according as they made a greater or lesser noise, when held in the same manner. He then examined all these specimens, and found that the males were very nearly in the same proportion 
to the females in both the lots. Mr. F. Smith has kept alive numerous specimens of Monoynchus pseudacori (Curculionidæ), and is convinced that both sexes stridulate, and apparently in an equal degree.

Nevertheless, the power of stridulating is certainly a sexual character in some few Coleoptera. Mr. Crotch discovered that the males alone of two species of Heliopathes (Tenebrionidro) possess stridulating organs. I examined tive males of $H$. gibbus, and in all these there was a well-developed rasp, partially divided into two, on the dorsal surface of the terminal abdominal segment; whilst in the same number of females there was not even a rudiment of the rasp, the membrane of this segment being transparent, and much thinner than in the male. In H. cribrutostriatus the male has a similar rasp, excepting that it is not partially divided into two portions, and the female is completely destitute of this organ; the male in addition has on the apical margins of the elytra, on each side of the suture, three or four short longitudinal ridges, which are crossed by extremely fine ribs, parallel to and resembling those on the abdominal rasp; whether these ridges serve as an independent rasp, or as a scraper for the abdominal rasp, I could not decide: the female exhibits no trace of this latter structure.

Again, in three species of the Lamellicorn genus Oryctes, we have a nearly parallel case. In the females of 0 .gryphus and nasicornis the ribs on the rasp of the pro-pygidium are less continuous and less distinct than in the males; but the chief difference is that the whole upper surface of this segment, when held in the proper light, is seen to be clothed with hairs, which are absent or are represented by excessively fine down in the males. It should be noticed that in all Coleoptera the effective part of the rasp is destitute of hairs. In 0 . senegalensis the difference between the sexes is more strongly marked, and this is best seen when the proper abdominal segment is cleaned and viewed as a transparent object. In the female the whole surface is covered with little separate crests, bearing spines; whilst in the male these crests in proceeding towards the apex, become more and more confluent, regular, and naked; so that threefourths of the segment is covered with extremely fine paralle! rius, which are quite absent in the female. In the females, however, of all three species of Oryctes, a slight grating or stridulating sound is produced, when the abdomen of a softened specimen is pushed backwards and forwards.

In the case of the Heliopathes and Oryctes there can hardly be a doubt that the males stridulate in order to call or to excite the females; but with most beetles the stridulation 
upparently serves both sexes as a mutual call. Bectles stridulate under various emotions, in the same manner as birds use their voices for many purposes besides singing to their mates. The great Chiasognathus stridulates in anger or defiance; many species do the same from distress or fear, if held so that they cannot escape; by striking the hollow stems of trees in the Canary Islands, Messrs. Wollaston and Crotch were able to discover the presence of beetles belonging to the genus Acalles by their stridulation. Lastly, the male Ateuchus stridulates to encourage the female in her work, and from distress when she is removed. ${ }^{79}$ Some naturalists believe that beetles make this noise to frighten away their enemies; but I cannot think that a quadruped or bird, able to devour a large beetle, would be frightened by so slight a sound. The belief that the stridulation serves as a sexual call is supported by the fact that deathticks (Anobium tessellatum) are well known to answer each other's ticking, and, as I have myself observed, a tapping noise artificially made. Mr. Doubleday also informs me that he has sometimes observed a female ticking, ${ }^{80}$ and in an hour or two afterwards has found her united with a male, and on one occasion surrounded by several males. Finally, it is probable that the two sexes of many kinds of beetles were at first enabled to find each other by the slight shuffling noise produced by the rubbing together of the adjoining hard parts of their bodies; and that as those males or females which made the greatest noise succeeded best in finding partners, rugosities on various parts of their bodies were gradually developed by means of sexual selection into true stridulating organs.

70 M. P. de la Brulerie, as quoted in 'Journal of Travel,' A. Murray, vol. i. 1868, p. 135.

so According to Mr. Doubleday, "the noise is produced by the in" sect raising itself on its. Iegs as " high as it can, and then striking "its thorax five or six times, in " rapid succession, against the sub"stance upon which it is sitting." For. references on this subject sce
Landois; "Zeitschrift für wissen. Zoolog.' B. Ivii. s. 131. Oliver says (as quoted by Kirby and Spence, 'Introduct.' vol. ii. p. 395) that the female of Pimelia striata produces a rather loud sound by striking her abdomen against any hard substance, "and that the male, "obedient to this call, soss attends "her, sod they pair." 
CHAPTER XI.

Insects, continued.-ORDEI LEPIDOPTERA.

(BUTTERFLIES AND MOTHS.)

Courtshlp of butterflies-Battles-Ticking noise-Colours common to both sexes, or more brilliant in the males-Examples-Not due to the direct action of the conditions of life-Colours adapted for protectionColours of moths-Display-Perceptive powers of the LepidopteraVariability-Causes of the difference in colour between the males and females-Mimicry, female butterflies more brilliantly coloured than the males-Bright colours of caterpillars-Summary and concluding remarks on the secondary sexual characters of insects-Birds and insects compared.

IN this great Order the most interesting points for us are the differences in colour between the sexes of the same species, and between the distinct species of the same genus. Nearly the whole of the following chapter will be devoted to this subject; but I will first make a few remarks on one or two other points. Several males may often be seen pursuing and crowding round the same female. Their courtship appears to be a prolonged affair, for I have frequently watched one or more males pirouetting round a female until I was tired, without seeing the end of the courtship. Mr. A. G. Butler also informs me that he has several times. watched a male courting a female for a full quarter of an hour; but she pertinaciously refused him, and at last settled on the ground and closed her wings, so as to escape from his addresses.

Although butterflies are weak and fragile creatures, they are pugnacious, and an Empcror butterfly ${ }^{2}$ has been captured with the tips of its wings broken from a conflict-with another male. Mr. Collingwood, in speaking of the frequent battles between the butterflies of Borneo, says, "They whirl round each other with " the greatest rapidity, and appear to be incited by the greatest "ferocity."

The Ageronia feronic makes a noise like that produced by a toothed wheel passing under a spring catch, and which can bo heard at the distance of several yards: I noticed this sound at Rio de Janeiro, only when two of these butterflies were chasing each other in an irregular course, so that it is probably made. during the courtship of the sexes. ${ }^{2}$

1 Apatura Iris: "The Entomologist's Weekly Intelligence,' 1859, p. 139. For the Bornzan Butterflies, see C. Collingwood, "Rambles of a
Naturalist,' 1868, p. 183.

2 See my 'Journal of Researches, 1845, p. 33. Mr. Doubleday has detected ('Proc. Ent. Soc.' March 
Some moths also produce sounds; for instance, the males of Theophora fovea. On two occasions Mr. F. Buchanan Whites heard a sharp quick noise made by the male of Hylophilo prasinana, and which he believes to be produced, as in Cicada, by an elastic membrane, furnished with a muscle. He quotes, also, Guenée, that Setina produces a sound like the ticking of a watch, apparently by the aid of "two large tympaniform "vesicles, situated in the pectoral region;" and these "are much " more developed in the male than in the female." Hence the sound-producing organs in the Lepidoptera appear to stand in. some relation with the sexual functions. I have not alluded to the well-known noise made by the Death's Head Sphinx, for it is generally heard soon after the moth has emerged from its cocoon.

Girard has always observed that the musky odour, which is emitted by two species of Sphinx moths, is peculiar to the males ; and in the higher classes we shall meet with many instances of the males alone being odoriferous.

Every one must have admired the extreme beauty of many butterflies and of some moths; and it may be asked, are their colours and diversified patterns the result of the direct action of the physical conditions to which these insects have been exposed, without any benefit being thus derived? Or have successive variations been accumulated and determined as a protection, or for some unknown purpose, or that one sex may be attractive to the other? And, again, what is the meaning of the colours being widely different in the males and females of certain species, and alike in the two sexes of other species of the same genus? Before attempting to answer these questions a body of facts must be given.

With our beautiful English butterflies, the admiral, peacock, and painted lady (Vanesse), as well as many others, the sexes are alike. This is also the case with the magnificent Heliconidre, and most of the Danaidø in the tropics. But in certain other tropical groups, and in some of our English butterflies, as the purple emperor, orange-tip, \&c. (Apatura Iris and Anthocharis cardamines), the sexes differ either greatly or slightly in colour. No language suffices to describe the splendour of the males of

3rd, 1845, p. 123) a peculiar membranous sac at the base of the front wings, which is probably connected with the production of the suad. For the case of Thecophora, see 'Zoological Record,' 1869, p. 401. For Mr. Buchanan W:: : obserrations, "The Scottish Natural ist,' July 1872, p. 214.

' 'The Scottish Naturalist,' July 1872, p. 213. 347. 
somo tropical species. Even within the same genus we often find species presenting extraordinary differences between the sexes, whilst others have their sexes closely alike. Thus in the South American genus Epicalia, Mr. Bates, to whom I am indebted for most of the following facts, and for looking over this whole discussion, informs me that he knows twelve species, the two sexes of which haunt the same stations (and this is not always the case with butterflies), and which, therefore, cannot have been differently affected by external conditions. ${ }^{5}$ In nine of these twelve species the males rank amongst the most brilliant of all butterflies, and differ so greatly from the comparatively plain females that they were formerly placed in distinct genera. The females of these nine species resemble each other in their general type of coloration; and they likewise resemble both sexes of the species in several allied genera, found in various parts of the world. Hence we may infer that these nine species, and probably all the others of the genus, are descended from an ancestral form which was coloured in nearly the same manner. In the tenth species the female still retains the same general colouring, but the male resembles her, so that he is coloured in a much less gaudy and contrasted manner than the males of the previous species. In the eleventh and twelfth species, the females depart from the usual type, for they are gaily decorated almost like the males, but in a somewhat less degree. Hence in these two latter species the bright colours of the males seem to have been trausferred to the females; whilst in the tenth species the male has either retained or recovered the plain colours of the female, as well as of the parent-form of the genus. The sexes in these three cases have thus been rendered nearly alike, though in an opposite manner. In the allied genus Eubagis, both sexes of some of the species are plain-coloured and nearly alike; whilst with the greater number the males are decorated with beautiful metallic tints in a diversified manner, and differ much from their females. The females throughout the genus retain the same general style of colouring, so that they resemble one another much more closely than they resemble their own males.

In the genus Papilio, all the species of the Eneas group are remarkable for their conspicuous and strongly contrasted colours, and they illustrate the frequent tendency to gradation in the amount of difference between the sexes. In a few species, for instauce in $P$. ascanius, the males and fomales are alike; in

5 See also Mr. Bates's paper in 'Proc. Ent. Soc. of Philadelphia,' $88 f 5$, p. 206. Also Mr. Wallace on the same subject, in regard tc Diadema, in 'Transact. Entomolog. Soc. of Loudon,' 1869 , p. 278. 
others the mules are either a little brighter, or very much moro superi than the females. The genus Junonia, allied to our Vanessæ, offers a nearly parallel case, for although the sexes of most of the species resemble each other, and are destitute of rich colours, yet in certain species, as in $J$. cenone, the male is rather more bright-coloured than the female, and in a fow (for instance $J$. andremiaja) the male is so different from the female that he might be mistaken for an entirely distinct species.

Another striking case was pointed out to mo in the Britisli Museum by Mr. A. Butler, namely, one of the tropical American Theclæ, in which both sexes are nearly alike and wonderfu\}l: splendid; in another species the male is coloured in a similarly gorgeous mauner, whilst the whole upper surface of th, female is of a dull uniform brown. Our common little Englisis blue butterflies of the genus Lycæna, illustrate the various differences in colour between the sexes, almost as well, though not in so striking a manner, as the above exotic genera. In Lycam agrstis both sexes have wings of a brown colour, bordered with small ocellated orange spots, and are thus alike. In $L_{\text {. o cogo }}$ the wings of the male are of a fine blue, bordered with black whilst those of the female are brown, with a similar border, closely resembling the wings of $L$. agestis. Lastly, in L. arion botr. sexes are of a blue colour and are very like, though in the female the edges of the wings are rather duskier, with the black spots plainer; and in a bright blue Indian species both sexes are still more alike.

I have given the foregoing details in order to show, in the first place, that when the sexes of butterflies differ, the male as a general rule is the more beautiful, and departs more from the usual type of colouring of the group to which the species belongs. Hence in most groups the females of the several species resemble each other much more closely than do the males. In some cases, however, to which I shall hereafter allude, the females are coloured more splendidly than the males. In the second place, these details have been given to bring clearly before the mind that within the same genus, the two sexes frequently present every gradation from no difference in colour, to so great a difference that it was long before the two were placed by entomologists in the same genus. In the third place, we have seen that when the sexes nearly resemble each other, this appears due either to the malo having transferred his colours to the female, or to the male having retained, or perhaps recovered, the primordial colours of the group. It also deserves notice that in those groups in which the sexes differ, the females usually somewhat resemble the males, so that when 
the males are beautiful to an extraordinary degree, the females almost inrariably exhibit some degree of beauty. From the many cases of gradation in the amount of difference between the sexes, and from the prevalence of the same gencral type of coloration throughout the whole of the same group, we may conclude that the causes have generally been the same which have determined the brilliant colouring of the males alone of some species, and of both sexes of other species.

As so many gorgeous butterflies inhabit the tropies, it has often been supposed that they orve their colours to the great heat and moisture of these zones; but Mr. Bates ${ }^{6}$ has shewn by the comparison of various closely-allied groups of insects from the temperate and tropical regions, that this view cannot be maintained; and the evidence becomes conclusive when brilliantly-coloured males and plain-coloured females of the same species inhabit the same district, feed on the same food, and follow exactly the same habits of life. Even when the sexes resemble each other, we can hardly believe that their brilliant and beautifully-arranged colours are the purposeless result of the nature of the tissues and of the action of the surrounding conditions.

With animals of all kinds, whenever colour has been modified for some special purpose, this has been, as far as we can judge, either for direct or indirect protection, or as an attraction between the sexes. With many species of butterflies the upper surfaces of the wings are obscure; and this in all probability leads to their escaping observation and danger. But butterflies would be particularly liable to be attacked by their enemies when at rest; and most kinds whilst resting raise their wings vertically over their backs, so that the lower surface alone is exposed to view. Fience it is this side which is often coloured so as to imitate the objects on which these insects commonly rest. Dr. Rössler, I believe, first nnticed the similarity of the closed wings of certain Vanessæe and other butterflies to the bark of trees. Many analogous and striking facts could be given. The most interesting one is that recorded by Mr. Wallace ${ }^{7}$ of a common Indian and Sumatran butterfly (Kallima), which disappears like magic when it settles on a bush; for it hides its head and antennæ between its closed wings, which, in form, colour and veining, cannot be distinguished from a withered leaf with its footstalk. In some other cases the lower

a "The Naturalist on the Amaznns,' vo!. '. 1863 , p. 19.

7 See the interesting article in the 'Westminster Reriew,' July
1867, p. 10. A woodcut of the Kallima is given by $\mathrm{Mr}$. Wallace in 'Hardwicke's Science Gossip,'Se ju 1867, p. 196. 
surfaces of the wings are brilliantly coloured, and jet are. protective; thus in I'lecla rubi the wings when closed are of ar cmerald grecn, and resemble the young leaves of the bramble, nn which in spring this butterfly may often be seen seated. It is also remarkable that in very many species in which the sexes differ greatly in colour on their upper surface, the lower surface is closely similar or identical in both sezes, and serves as a protection. ${ }^{8}$

Although the obscure tints both of the upper and under sides of many butterflies no doubt serve to conceal them, yet we cannot extend this view to the brilliant and conspicuous colours on the upper surface of such species as our admiral and peacock Vanessæ, our white cabbage-butterflies (Pieris), or the great swallow-tail Papilio which haunts the open fens-for these butterflies are thus rendered visible to every living creature. In these species both sexes are alike; but in the common brimstone butterfly (Gonepteryx rhamni), the male is of an intense yellow, whilst the female is much paler; and in the orangetip (Anthocharis cardamines) the males alone have their wings tipped with bright orange. Both the males and females in these cases are conspicuous, and it is not credible that their difference in colour should stand in any relation to ordinary protection. Prof. Weismann remarks, ${ }^{9}$ that the female of one of the Lycænæ expands her brown wings when she settles on the ground, and is then almost invisible; the male, on the other hand, as if aware of the danger incurred from the bright blue of the upper surface of his wings, rests with them closed; and this shews that the blue colour cannot be in any way protective. Nevertheless, it is probable that conspicuous colours are indirectly beneficial to many species, as a warning that they are unpalatable. For in certain other cases, beauty has been gained through the imitation of other beautiful species, which inhabit the same district and enjoy an immunity from attack by being in some way offensive to their enemies; but then we have to account for the beauty of the imitated species.

As Mr. Walsh has remarkad to me, the females of nur orangetip butterfly, abore referred to, and of an American species (Anth. genutia) probably shew us the primordial colours of the parent-species of the genus; for both sexes of four or five widely-distributed species are coloured in nearly the same manncr. As in several previous cases, we may here infer that it is the males of Anth. cardamines and genutia which have departed from the usual type of the genus. In the Anth. sara

- Mr. G. Fraser, in 'Nature,' April 1871, p. 489.
- 'Einfluss der Isolirung auf di. Artbildung,' 1872, p. 58. 
from Califurnia, the orange-tips to the wings have been partially developed in the female; but they are paler than in the male, and slightly different in some other respects. In an allied Indian form, the I hices gluucippe, the orange-tips are fully developed in both sexes. In this Iphias, as pointed out to me by Mr. A. Butler, the under surface of the wings marvellously resembles a palecoloured leaf; and in our English orange-tip, the under surface resembles the flower-head of the wild parsley, on which the butterfly often rests at night. ${ }^{10}$ The same reason which compels us to believe that the lower surfaces have here been coloured for the sake of protection, leads us to deny that the wings have been tipped with bright orange for the same purpose, especially when this character is confined to the males.

Most Moths rest motionless during the whole or greater part of the day with their wings depressed; and the whole upper surface is often shaded and coloured in an admirable manner, as Mr. Wallace has remarked, for escaping detection. The frontwings of the Bombycidæ and Noctuidæ, ${ }^{11}$ when at rest, generally overlap and conceal the hind-wings; so that the latter might be lurightly coloured without much risk; and they are in fact often thus coloured. During Hight, moths would often be able to escape from their enemies; nevertheless, as the hind-wings are then fully exposed to view, their bright colours must generally havo been acquired at some little risk. But the following fact shews how cautious we onght to be in drawing conclusions on this head. The common Yellow Under-wings (Triphæna) often fly about during the day or early evening, and are then conspicuous from the colour of their hind-wings. It would naturally be thought that this would be a source of danger; but Mr. J. Jenner Weir believes that it actually serves them as a means of escnpe, for birds strike at these brightly coloured and fragile surfaces, instead of at the body. For instance, Mr. Weir turned into his aviary a vigorous specimen of Triphcena pronuba, which was instantly pursued by a robin; but the bird's attention being caught by the coloured wings, the moth was not captured until after about fifty attempts, and small portions of the wings were repeatedly broken off. He tried the same experiment, in the open air, with a swallow and $T$. fimbrix; but the large size of this moth probably interfered with its capture. ${ }^{12}$ We are thus reminded of a statement made

10 See the interesting observatious by Mr. T. W. Wood, 'The Student,' Sepr. 1858, p. 81.

II Mr. Wallace in 'Hardwicke's
Science Gossip,' Sept. 1867, p. 193. 12 See also, on this subject, $M r$. Weir's paper in 'Transact. Ent. Soc.' 1869. p. 23. 
by Mr. Wallace, ${ }^{13}$ namely, that in the Brazilian forests and Malayan islands, many common and highly-decorated butterflies aro weak flyers, though furnished with a broad expanse of wing; and they "aro often captured with pierced and broken wings, "as if they had been seized by birds, from which they had "escaped: if the wings had been much smaller in proportion "to the body, it seems probable that the insect would more "frequently have been struck or pierced in a vital part, and "thus the increased expanse of the wings may have been in" directly beneficial."

Display.-The bright colours of many butterflies and of some moths are specially arranged for display, so that they may be readily seen. During the night colours are not visible, and there can be no doubt that the nocturnal moths, taken as a body, are much less gaily decorated than butterflies, all of which are diurnal in their habits. But the moths of certain families, such as the Zygænidæ, several Sphingidæ, Uraniidæ, some Arctiidæe and Saturniidæ, fly about during the day or carly evening, and many of these are extremely beautiful, being: far brighter coloured than the strictly nocturnal linds. A few exceptional cases, however, of bright-coloured nocturnal species have been recorded. ${ }^{14}$

There is evidence of another kind in regard to display. Butterflies, as before remarked, elevate their wings when at rest, but whilst basking in the sunshine often alternately raise and depress them, thus exposing both surfaces to full view ; and although the lower surface is often coloured in an obscure manner as a protection, yet in many species it is as highly decorated as the upper surface, and sometimes in a very different manner. In some tropical species the lower surface is even more brilliantly coloured than the upper. ${ }^{15}$ In twe English fritillaries (Argynnis) the lower surface alone is ornamented with shining silver. Nevertheless, as a general rule, the upper surface, which is probably more fully exposed, is coloured more brightly and diversely than the lower. Hence the lower surface generally affords to entomologists the more

13 'Westminster Review,' July
1867 , p. 16.
14 For instance, Lithosia; but
Prof. Westwood ('Modern Class. of
Insects,' rol, ii. p. 390 ) seems sur-
prised at this case. On the relative
colours of diurnal and nocturnal
Lepidoptera, see ibid. pp. 333 and
892 ; also Harris, 'Treatise on the
Insects of New England,'1842, p. 315. ss Such differences between the upper and lower surfaces of the wings of several species of Papilio, may be seen in the beautiful plates to Mr. Wallace's 'Memoir on the Papilionida of the Malayan Region, in 'Transact. Linn. Soc.' vol. axv. part i. 1865. 
aseful character for detecting the affinities of the rariont. species. Fritz Miiller informs me that three species of Castnia are found near his house in S. Brazil : of two of them the hindwings are obscure, and are always covered by the front-wings when these butterflies are at rest; but the third species has black hind-wings, beautifully spotted with red and white, and these are fully expanded and displayed whenever the butterfy rests. Other such cases could be added.

If we now turn to the enormous group of moths, which, as I hear from Mr. Stainton, do not habitually expose the under surface of their wings to full view, we find this side very rarely coloured with a brightness greater than, or even equal to, that of the upper side. Some exceptions to the rule, either real or apparent, must be noticed, as the case of Hypopyra. ${ }^{16} \mathrm{Mr}$. Trimen informs me that in Guenée's great work, three moths: are figured, in which the under surface is much the more brilliant. For instance, in the Australian Gastrophora the upper surface of the fore-ring is pale greyish-ochreous, while the lower surface is unagnificently ornamented by an ocellus of cobalt-blue, placed in the midst of a black mark, surrounded by orange-yellow, and this by bluish-white. But the habits of these three moths are unknown; so that no explanation can be given of their unusual style of colouring. Mr. Trimen also informs me that the lower surface of the wings in certain other Geometræ ${ }^{17}$ and quadrifid Noctuæ are either more variegated or moro brightly-coloured than the upper surface; but some of these species have the habit of "holding their wings quite erect "orer their backs, retaining them in this position for a con" siderable time," and thus exposing the under surface to view. Other species, when settled on the ground or herbage, now and then suddenly and slightly lift up their wings. Hence the lower surface of the wings being brighter than the upper surfaco in certain moths is not so anomalous as it at first appears. The Saturniidro include some of the most beautiful of all moths, their wings being decorated, as in our British Emperor moth, with fine ocelli; and Mr. T. W. Wood ${ }^{18}$ observes that they resemble butterflies in some of their movements; "for " instance, in the gentle waving up and down of the wings as if "for display, which is more cLaracteristic of diurnal than of " nocturnal Lepidoptera."

16 See Mr. Wormald on this moth: 'Proc. Ent. Soc.' Mar'ch 2nd, 1868 .

17 See also an account of the $\mathrm{S}$. American genus Erateina (cne of the Geometre) in 'Transact. Ent. Soc.' new series, vol. v. pl. xv. and svi.

18 'Proc. Ent. Soc. of London; July $6, \gtreqless \$ 68$, p. xxviı. 
It is a singular fact that no British moths which are brilliantly coloured, and, as far as I can discover, hardly any foreign species, differ much in colour according to sex; though this is the case with many brilliant butterflies. The male, however, of ono American moth, the Saturnia Io, is described as having its fore-wings deep yellow, curiously marked with purplish-red spots; whilst the wings of the female are purple-brown, marked with grey lines. ${ }^{19}$ The British moths which differ sexually in colour are all brown, or of various dull yellow tints, or nearly white. In several species the males are much darker than the females, ${ }^{20}$ and these belong to groups which generally fly about rliring the afternoon. On the other hand, in many genera, as Mr. Stainton informs me, the males have the hind-wings whiter than those of the female-of which fact Agrotis exclamationis vffers a good instance. In the Ghost Moth (Hepialus humuli) the difference is more strongly marked; the males being white, and the females yellow with darker markings. ${ }^{21}$ It is probable that in these cases the males are thus rendered more conspicuous, and more easily seen by the females whilst flying about in the dusk.

From the several foregoing facts it is impossible to admit that the brilliant colours of butterflies, and of some few moths, have commonly been acquired for the sake of protection. We have seen that their colours and elegant patterns are arranged and exhibited as if for display. Hence I am led to believe that the females prefer or are most excited by the more brilliant

18 Harris, 'Treatise,' \&c., edited by Flint, 1862, p. 395.

${ }^{20}$ For instance, I observe in my son's cabinet that the males are darker than the females in the Lasiocampa quercus, Odonestis potatoria, Hypogymna dispar, Dasychira pudibunda, and Cycnia mendica. In this latter species the difference in colour between the two sexes is strongly marked; and Mr. Wallace informs me that we here have, as he believes, an instance of protective mimicry confined to ore sex, as will hereafter be more fully explained. The white female of the Cycnis resembles the very common Spilosoma menthrasti, both sexes of which are white; and $\mathrm{Mr}$. Stainton obserred that this latter moth was rejected with utter disçust by a whrile brond of young turkeys, which were fond of eating othes moths; so that if the Cycnia was commonly mistaken by British birds for the Spilosoma, it would escape being devoured, and its white deceptive colour would thus be highly beneficial.

21 It is remarkable, that in the Shetland Islands the male of this moth, instead of differing widely from the female, frequently resembles her closely in colour (see Mr. MacLachlan, 'Transact. Ent. Soc.' rol. ii. 1866, p. 459), Mr. G. Fraser suggests ('Nature, Apr:1 1871, p. 489) that at the season of the year when the ghost-moth ap. pears in these northern islands, the whiteness of the males would not be needed to render them visible to the females in the twilight night. 
males; for on any other supposition the males would, as far as we can see, be ornamented to no purpose. We know that ants and certain Lamellicorn beetles are capable of feeling an attachment for each other, and that ants recognise their fellows after an interval of several months. Hence there is no abstract improbability in the Lepidoptera, which probably stand nearly or quite as high in the scale as these insects, having sufficient mental capacity to admire bright colours. They certainly discover flowers by colour. The Humming-bird Sphinx may often be seen to swoop down from a distance on a bunch of flowers in the midst of green foliage; and I have been assured by two persons abroad, that these moths repeatedly visit flowers painted on the walls of a room, and vainly endeavour to insert their proboscis into them. Fritz Muiller informs me that severai kinds of butterflies in S. Brazil shew an unmistakable preference for certain colours over others: he observed that they very often visited the brilliant red flowers of five or six genera of plants, but never the white or yellow flowering species of the same and other genera, growing in the same garden; and $\bar{I}$ have received other accounts to the same effect. As I hear from Mr. Doubleday, the common white butterfly often flies down to a bit of paper on the ground, no doubt mistaking it for one of its own species. Mr. Collingwood ${ }^{22}$ in speaking of the difficulty in collecting certain butterflies in the Malay Archipelago, states that "a dead specimen pinned upon a " conspicuous twig will often arrest an insect of the same species " in its headlong flight, and bring it down within easy reach of "the net, especially if it be of the opposite sex."

The courtship of butterflies is, as before remarked, a prolonged affair. The males sometimes fight together in rivalry; and many may be seen pursuing or crowding round the same female. Unless, then, the females prefer one male to another, the pairing must be left to mere chance, and this does not appear probable. If, on the other hand, the females habitually, or even occasionally, prefer the more beautiful males, the colours of the latter will have been rendered brighter by degrees, and will have been transmitted to both sexes or to one sex, according to the law of inheritance which has prevailed. The process of sexual selection will have been much facilitated, if the conclusion can be trusted, arrived at from various kinds of evidence in the supplement to the ninth chapter; namely, that the males of many Lepidoptera, at least in the imago state, greatly exceed the females in number.

Dome facts, however, are opposed to the belief that female 22. 'Rambles of a Naturalist in the Chinese Seas,' 1868, 1) 182. 
butterflies prefer the more beautiful males; thus, as I have been assured by sereral collectors, fresh females may frequently be seen paired with battered, faded, or dingy males; but this is a circumstance which could hardly fail often to follow from the males emerging from their cocoons earlier than the fomales. With moths of the family of the Bombycidæ, the sexes pair immediately after assuming the imago state; for they cannot feed, owing to the rudimentary condition of their mouths. The females, as several entomologists have remarked to me, lie in an almost torpid state, and appear not to evince the least choice in regard to their partners. This is the case with the common silk-moth (B. mori), as I have been told by some continental and English breeders. Dr. Wallace, who has had great experience in breeding Bombyx cynthia, is convinced that the females evince no choice or preference. He has kept above 300 of these moths together, and has often found the most vigorous females mated with stunted males. The reverse appears to occur seldom; for, as he believes, the more vigorous inales pass over the weakly females, and are attracted by those undowed with most vitality. Nevertheless, the Bombycidæ, though obscurely-coloured, are often beautiful to our eyes from their elegant and mottled shades.

I have as yet only referred to the species in which the males are brighter coloured than the females, and I have attributed their beauty to the females for many generations having chosen and paired with the more attractive males. But converse cases occur, though rarely, in which the females are more brilliant than the males; and here, as I believe, the males have selected the more beautiful females, and have thus slowly added to their beauty. We do not know why in various classes of animals the males of some few species have sclected the more beautiful females instead of having gladly accepted any female. as seems to be the general rule in the animal kingdom; but it, contrary to what generally occurs with the Lepidoptera, the females were much more numerous than the males, the latter would be likely to pick out the more beautiful females. Mr. Butler shewed me several species of Calliaryas in the British Museum, in some of which the females equalled, and in others greatly surpassed the males in beauty; for the females alone have the borders of their wings suffused with crimson and orange, and spotted with black. The plainer males of these species closely resemble each other, showing that here the females have been modified; whereas in those cases, where the males are the more ornate, it is these which have been modified, the females remaining closely alike. 
In England we have some analogous cases, though not so marked. The females alone of two species of Thecla have a bright-purple or orange patch on their fore-wings. In Hipparchia the sexes do not differ much; but it is the female of $H$. janira which has a conspicuous light-brown patch on her wings; and the females of some of the other species are brighter coloured than their males. Again, the females of Colius edusa and hyale have "orange or yellow spots on the black marginal "border, represented in the males only by thin streaks;" and in Pieris it is the females which "are ornamented with black "spots on the fore-wings, and these are only partially present " in the males." Now the males of many butterflies are known to support the females during their marriage flight; but in the species just named it is the females which support the males; so that the part which the two sexes play is reversed, as is their relativo beauty. Throughout the animal kingdom the males commonly take the more active share in wooing, and their beauty scems to have been increased by the females having accepted the more attractive individuals; but with these butterflies, the females take the more active part in the final marriage ceremony, so that we may suppose that they likewise do so in the wooing; and in this case we can understand how it is that they have been rendered the more beautiful. Mr. Meldola, from whom the foregoing statements have been taken, says in conclusion; "Though I am not convinced of the action of " sexual selection in producing the colours of insects, it cannot "bo denied that these facts are strikingly corroborative of "Mr. Darwin's views." 28

As sexual selection primarily depends on variability, a few words must be added on this subject. In respect to colour there is no difficulty, for any number of highly rariable Lepidoptera could be named. One good instance will suffice. Mr. Bates shewed me a whele series of specimens of Papilio sesostris and $P$. childrence; in the latter the males varied much in the extent of the beautifully enamelled green patch on the forewings, and in the size of the white -mark, and of the splendid crimson stripe on the hind-wings; so that there was a great contrast amongst the males between the most and the least gaudy. The male of Papilio sesostris is much less beautiful than of $P$. childrence: and it likewise varies a little in the size of

23 'Nature,' April 27th, 1871, p. 508. Mr. Meldola quotes Donzol, in 'Soc. Ent. de France,' 1837, p. 77, on the flight of buttertlies whilst pairing. See also Mr. (r. Fraser, in 'Nature,' April 20th. 1871 , p. 489 , on the sexual differences of sereral British butterflios. 
the green patch on the fore-wings, and in the occasional appearance of the small crimson stripe on the hind-wings, borrowed, as it would seem, from its own female; for the females of this and of many other species in the Eneas group possess this crimson stripe. Hence between the brightest specimons of $P$. sesostris and the dullest of $P$. childrence, there was but a small interval; and it was evident that as far as mere variability is concerned, there would be no difficulty in permanently increasing the beauty of either species by means of selection. The variability is here almost confined to the male sex; but Mr. Wallace and Mr. Bates have shewn ${ }^{2 t}$ that the females of some species are extremely variable, the males being nearly constant. In a future chapter I shall have occasion to shew that the beautiful eye-like spots, or ocelli, found on the wings of many Lepidoptera, are eminently variable. I may here add that these ocelli offer a difficulty on the theory of sexual selection: for though appearing to us so ornamental, they are never present in one sex and absent in the other, nor do they ever differ much in the two sexes. ${ }^{25}$ This fact is at present inexplicable; but if it should hereafter be found that the formation of an ocellus is due to some change in the tissues of the wings, for instance, occurring at a very early period os development, we might expect, from what we know of the laws of inheritance, that it would be transmitted to both sexes, though arising and perfected in one sex alone.

On the whole, although many serious objections may be urged, it seems probable that most of the brilliantly coloured species of Lepidoptera owe their colours to sexual selection, excepting in certain cases, presently to be mentioned, in which conspicuous colours have been gained through mimicry as a protection. From the ardour of the male throughout the animal kingdom, he is generally willing to accept any female; and it is the female which usually exerts a choice. Hence, if sexual selection has been efficient with the Lepidoptera, the male, when the scxes differ, ought to be the more brilliantly coloured, and this undoubtedly is the case. When both sexes are brilliantly coloured and resemble each other, the characters acquired by the males appear to have been transmitted to both.

24 Wallace on the Papilionida of the Malayan Region, in 'Transact. Linn. Soc.' vol. $1 \times 18$. 1865 , pp. 8, 36. A striking case of a rare variety, strictly intermediate betreen two other well-marked female rarieties, is given by Mr. Wallace. dee also Mr. Bates, in 'Proc. Eu- t.omolog. Soc.' Nor. 19th, 1866, p. $x$.

${ }^{25} \mathrm{Mr}$. Bates was so kind as to lay this subject before the Entomo logical Society, and I have received answers to this effect from severa] entomoiogists. 
We are led to this conclusion by cases, even within the same genus, of gradation from an extraordinary amount of difference to identity in colour between the two sexes.

But it may be asked whether the differences in colour between the sexes may not be accounted for by other means besides sexual selection. Thus the males and females of the same species of butterfly are in several cases known ${ }^{26}$ to inhabit different stations, the former commonly basking in the sunshine, the latter haunting gloomy forests. It is therefore possible that different conditions of life may have acted directly on the two sexes; but this is not probable, ${ }^{27}$ as in the adu.t state they are cxposed to different conditions during a very short period; and the larvæ of both are exposed to time same conditions. Mr. Wallace believes that the difference between the sexes is due not so much to the males having been modified, as to the females having in all or almost all cases acquired dull colours for the sake of protection. It seems to me, on the contrary, far more probable that it is the males which have been chiefly modified through sexual selection, the females having been comparatively little changed. We can thus understand how it is that the females of allied species generally resemble one another so much more closely than do the males. They thus shew us approximately the primordial colouring of the parent-species of the group to which they belong. They have, however, almost always been somewhat modified by the transfer to them of some of the successive variations, through the accumulation of which the makes were rendered beautiful. But I do not wish to deny that the females alone of some species may have been specially modified for protection. In most cases the males and females of distinct species will have been exposed during their prolonged larval state to different conditions, and may have been thus affected; though with the males any slight change of colour thus caused will generally have been masked by the brilliant tints gained through sexual selection. When we treat of Birds, I shall have to discuss the whole question, as to how far the differences in colour between the sexes are due to the males having been modified through sexual selection for ornamental purposes, or to the females having been modified through natural selection for the sake of protection, so that I will here fay but little on the subject.

In all the cases in which the more common form of equal

2. H. W. Bates, "The Naturalist (1) the Amazons,' vol. ii. 1863, p. 228. A. R. Wallace, in 'Transact. Linn. Soc.' vol. IXv. 1865, p. 10.
27 On this whole subject see 'The Variation of Animals and Plants ander Domesticat' on,' 1868, rol. ii. chap. xxiii. 
inheritance by both sexes has prevailed, the selection of brightcoloured males would tend to make the females bright-coloured; and the selection of dull-coloured females would tend to make the males dull. If both processes were carried on simultaneously, they would tend to counteract each other; and the final result would depend on whether a greater number of females from being well protected by obscure colours, or a greater number of males by being brightly-coloured and thus finding partmers, succeeded in leaving more numerous offspring.

In order to account for the frequent transmission of characters to one sex alone, Mr. Wallace expresses his belief that the more common form of equal inheritance by both sexes can be changed through natural selection ato inheritance by one sex alone, but in favour of this view I can discover no evidence. We know from what occurs under domestication that new characters often appear, which from the first are transmitted to one sex alone; and by the selection of such variations there would not be the slightest difficulty in giving bright colours to the males alone, and at the same time or subsequently, dull colours to the females alone. In this manner the females of some butterflies and moths have, it is probable, been rendered inconspicuous for the sake of protection, and widely different from their males.

I am, however, unwilling without distinct evidence to admit that two complex processes of selection, each requiring the transference of new characters to one sex alone, have been carried on with a multitude of species, - that the males have been rendered more brilliant by beating their rivals, and the females more dull-coloured by having escaped from their enemies. The male, for instance, of the common brimstone butterfly (Gonepteryx), is of a far more intense yellow than the female, though she is equally conspicuous; and it does not seem probable that she specially acquired her pale tints as a protection, though it is probable that the male acquired his bright colours as a sexual attraction. The female of Anthocharis cardamines does not possess the beautiful orange wing-tips of the male; consequently she closely resembles the white butterflies (Pieris) so common in our gardens; but we have no evidence that this resemblance is beneficial to her. As, on the other hand, she resembles both sexes of several other species of the genus inhabiting various quarters of the world, it is probable that she has simply retained to a large extent her primordial colours.

Finally, as we have seen, various considerations lead to the conclusion that with the greater number of brilliantly-coloured Lepidoptera it is the male which has been chiefly modified through soxual selection; the arnount of difference betweon 
the sexes mostly depending on the form of inheritance which has prevailed. Inheritance is governed by so many nnknown laws or conditions, that it seems to us to act in a capricious manner; ${ }^{28}$ and we can thus, to a certain extent, understand how it is that with closely allied species the sexes either differ to an astonishing degree, or are identical in colour. As all the successive steps in the process of variation are necessarily transmitted throngh the female, a greater or less number of such steps might readily become developed in her; and thus we can understand the frequent gradations from an extreme difference to none at all vetween the sexes of allied species. These cases of gradation, it may be added, are much too common to favour the supposition that we here see females actually undergoing the process of transition and losing their brightness for the sake of protection; for we have every reason to conclude that at any one time the greater number of species are in a fixed condition.

Mimicry.-This principle was first made clear in an admirable paper by Mr. Bates, ${ }^{29}$ who thus threw a flood of light on many obscure problems. It had previously been observed that certain butterflies in S. America belonging to quite distinct families, resembled the Heliconidro so closely in every stripe and shade of colour, that they could not be distinguished save by an experienced entomologist. As the Heliconidæ are coloured in their usual manner, whilst the others depart from the usnal colouring of the groups to which they belong, it is clear that the latter are the imitators, and the Heliconidæ the imitated. Mr. Bates further observed that the imitating species are comparatively rare, whisst the imitated abound, and that the two sets live mingled together. From the fact of the Heliconidr being conspicuous and beautiful insects, yet so numerous in individuals and species, he concluded that they must be protected from the attacks of enemies by some secretion or odnur; and this conclusion has now been amply confirmed, ${ }^{30}$ especially by Mr. Belt. Hence Mr. Bates inferred that the butterfies which imitate the protected species have acquired their present marvellously deceptive appearance through variation and natural selection, in order to be mistaken for the protected kinds, ancl tlius to escape being devoured. No explanation is here attempted of the brilliant colours of the imitated, but only of the imitating: butterflies. We must account for the colours of the former in the same general manner, as in the cases previously discussed

2 "The Variation of Anumals and Plauts under Domestication,' vol. ii. chap. xii. p. 17.

20 'Transact. Linn. Soc.' vol.
Ixiii. 1862, p. 495.

30 'Prec. Ent. Soc.' Dec. 3rd, 1866, p. xlv. 
in this chapter. Since the publication of Mr. Bates' paper, similar and equally striking facts have been observed by Mr. Wallace in the Malayan region, by Mr. Trimen in South Africa, and by Mr. Riley in the United States. ${ }^{31}$

As some writers have felt much difficulty in understanding how the first steps in the process of mimicry could have been effected through natural selection, it may be well to remark that the process probably commenced long ago between forms not widely dissimilar in colour. In this case even a slight variation would be beneficial, if it rendered the one species more like the other; and afterwards the imitated species might be modified to an extreme degree through sexual selection or other means, and if the changes were gradual, the imitators might casily be led along the same track, until they differed to an equally extreme degree from their original condition; and they would thus ultimately assume an appearance or colouring wholly unlike that of the other members of the group to which they belonged. It should also be remembered that many species of Lepidoptera are liable to considerable and abrupt variations in colour. A few instances have heen given in this chapter; and many more may be found in the papers of Mr. Bates and Mr. Wallace.

With several species the sexes are alike, and imitate the two sexes of another species. But Mr. Trimen gives, in the paper already referred to, three cases in which the sexes of the imitated form differ from each other in colour, and the sexes of the imitating form differ in a like manner. Several cases have also been recorded where the females alone imitate brilliantlycoloured and protected species, the males retaining "the "normal aspect of their immediate congeners." It is here obvious that the successive variations by which the female has been modified have been transmitted to her alone. It is, however, probable that some of the many successive variations would have been transmitted to, and developed in, the males had not such males been eliminated by being thus rendered less nttractive to the fomales; so that only those variations were preserved which were from the first strictly limited in their transmission to the female sex. We have a partial illustration of these remarks in a statement by Mr. Belt; ${ }^{32}$ that

31 Will ace, 'Transact. Linn. Soc." vol. xxv. 1865, p. 1 ; also 'Transact. fint. S's.' vol. iv. (3rd series), 1867, p. 301. Trimen, 'Linn. Transact.' vol. xxvi. 1869, p. 497. Riley, 'Third Annual Report on the Noxious Insects of Missouri,' 1871, pp.
163-168. This latter essay is valuable, as Mr. Riley here discusses all the objections which have been raised against Mr. Bates' theory.

32 'The Naturalist in Nicaragor, 1874, p. 385. 
the males of some of the Leptalides, which imitate protected species, still retain in a concealed manner some of their original characters. Thus in the males "the upper half of the lower "wing is of a pure white, whilst a!l the rest of the wings is "barred and spotted with black, red and yellow, like the species "they mimic. The females have not this white patch, and the " males usually conceal it by covering it with the upper wing, " so that I cannot imagine its being of any other use to them " than as an attraction in courtship, when they exhibit it to the "females, and thus gratify their deep-seated preference for tha " normal colour of the Order to which the Leptalides belong."

Bright Colours of Caterpillars. - Whilst reflecting on the beauty of many butterflies, it occurred to me that some caterpillars were splendidly coloured; and as sexual selection could not possibly have here acted, it appeared rash to attribute the beauty of the mature insect to this agency, unless the bright colours of their larvæ could be somehow explained. In the first place, it may be observed that the colours of caterpillars cto not stand in any close correlation with those of the mature insect. Secondly, their bright colours do not serve in any ordinary manner as a protection. Mr. Bates informs me, as an instance of this, that the most conspicuous caterpillar which he ever beheld (that of a Sphinx) lived on the large green leaves of a tree on the open llanos of South America; it was about four inches in length, transversely banded with black and yellow, and with its head, legs, and tail of a bright red. Hence it caught the eye of any one who passed by, even at the distance of many yards, and no doubt that of every passing bird.

I then applied to $\mathrm{Mr}$. Wallace, who has an inuate genius for solving difficulties. After some consideration he replied: "Most. "caterpillars require protection, as may be inferred from some " kinds being furnished with spines or irritating hairs, and "from many being coloured green like the leaves on which they "feed, or being curiously like the twigs of the trees on which they "live." Another instance of protection, furnished me by Mr. J. Mansel Weale, may be added, namely, that there is a caterpillar of a moth which lives on the mimosas in South Africa, and. fabricates for itself a case quite indistinguishable from the surrounding thorns. From such considerations Mr. Wallace thought it probable that conspicuously-coloured caterpillars were protected by having a nauseous taste; but as their skin is extremely tender, and as their intestines readily protrude from a wound, a slight peck from the beak of a bird would be as fatal to them as if they had heen devoured. Hence, as 
IIr. Wallace remarks, "distastefulness alone would be insufficiont "to protect a caterpillar unless some outward sign indicated to "its would-be destroyer that its prey was a disgusting morsel." IInder these circumstances it would be highly advantageous to is caterpillar to be instantaneously and certainly recognised as impalatable by all birds and other animals. Thus the most saudy colours would be serviceable, and might have been gained by variation and the survival of the most easily-recognised individuals.

This hypothesis appears at first sight very bold, but when it was brought before the Entomological Society ${ }^{33}$ it was supported by various statements; and Mr. J. Jenner Weir, who keeps a large number of birds in an aviary, informs me that he has made many trials, and finds no exception to the rule, that all caterpillars of nocturnal and retiring habits with smooth skins, all of a green colour, and all which imitate twigs, are greedily devouren by his birds. The hairy and spinose kinds are invariably rejected, as were four conspicuously-coloured specios. When the birds rejected a caterpillar, they plainly shewed, by shaking their heads, and cleansing their beaks, that they were disgusted by the taste. Three conspicuous kinds of caterpillars and moths were also given to some lizards and frogs, by Mr. A. Butler, and were rejected, though other kinds wero eagerly eaten. Thus the probability of Mr. Wallace's view is confirmed, namely, that certain caterpillars have been mado ('onspicuous for their own good, so as to be easily recognised by rheir enemies, on nearly the same principle that poisons are sold in coloured bottles by druggists for the good of man. We cannot, however, at present thus explain the elegant diversity in the colours of many caterpillars; but any species which had at some former period acquired a dull, mottled, or striped appearance, either in imitation of surrounding objects, or from the direct action of climate, \&c., almost certainly would not hecome uniform in colour, when its tints were rendered intense and bright; for in order to make a caterpillar merely conspicuous, there would be no selection in any definite direction.

Summary and Concluding Remarlss on Insects.-Looking back

33 'Proc. Entomolog. Soc.' Dec. 3rd, 1866, p. xlv.; and March 4th, 1867 , p. lsxx.

3t See Mr. J. Jenner Weir's paper on Insects and Insectivorous Birds, in ' Transact. Ent. Soc.' 1869, p. 21; also Mr. Butler's paper, ibid. p. 27. Mr. Riley has given analogous facts in the "Third Annual Report on the Noxjous Insects of Missouri,' 1871, p. 148. Same opposed cases are, however, given by Dr. Wallace and M. H. d'Orville; see 'Zoolugical Record,' 1869, p. 
to the several Orders, we see that the sexes often differ in rarious characters, the meaning of which is not in the least uuderstood. The sexes, also, often differ in their organs of sense and means of locomotion, so that the males may quickly discover and reach the females. They differ still oftener in the males yossessing diversified contrivances for retaining the temales when found. We are, however, here concerned only in a secondary degree with scxual differences of these kinds.

In almost all the Orders, the males of some species, even of wcak and delicate kinds, are known to be highly pugnacious; and some ferw are furuished with special weapons for fighting with ineir rivals. But the law of battle does not prevail nearly so widely with insects as with the higher animals. Hence it probably arises, that it is in only a few cases that the males have been rendered larger and strouger than the females. On the contrary, they are usually smaller, so that they may be developed within a shorter time, to be ready in large numbers for the emergence of the females.

In two families of the Homoptera and in three of the Orthoptera, the males alone possess sound-producing o-nans in an efticient state. Those are used incessantly during tire breedingseason, not only for calling the females, but apparently for sharming or exciting them in rivalry with other males. No one who admits the agency of selection of any kind, will, after reading the above discussion, dispute that these musical instruments have been acquired through sexual selection. In four other Orders the members of one sex, or more commonly of both sexes, are providtd with organs for producing various sounds, which apparently serve merely as call-notes. When both sexes are thus provided, the individuals which were able to make the loudest or most coutinuous noise would gain partners before those which wero less noisy, so that their organs have probably been gained through sexual selection. It is instructive to reflect on the wonderful diversity of the means for producing sound, possessed by the males alone, or by both sexes, in no less than six Orders. We thus learn how effectual sexual selection has been in leading to modiflcations which sometimes, as with the Homoptera, relate to important parts of the organisation.

From the reasons assigned in the last chapter, it is probable that the great horns possessed by the males of many Lamellicorn, and some other beetles, have been acquired as ornaments. From the small size of insects, we are apt to undervalue their appearance. If we could imagine a male Chalcosoma (fig. 16), with its polished bronzed coat of mail, and its vast comples 
horns, magnified to the size of a horse, or even of a dog, it would be one of the most imposing animals in the world.

The colouring of insects is a complex and obscure subject. When the male differs slightly from the female, and neither are brilliantly-coloured, it is probable that the sexes have varied in a slightly different manner, and that the variations have been transmitted by each sex to the same, without any benefit or evil thus accruing. When the male is brilliantly-coloured and differs conspicuously from the female, as with some dragon-flies and many butterflies, it is probable that he owes his colours to sexual selection; whilst the female has retained a primordial or very ancient type of colouring, slightly modified by the agencies before explained. But in some cases the female has apparently heen made obscure by variations transmitted to her alone, as a means of direct protection; and it is almost certain that she has sometimes been made brilliant, so as to imitate other protected species inhabiting the same district. When the sexes resemble each other and both are obscurely coloured, there is no doubt that they have been in a multitude of cases so coloured for the sake of protection. So it is in some instances when both are brightly-coloured, for they thus imitate protected species, or resemble surrounding objects such as flowers; or they give notice to their enemies that they are unpalatable. In other cases in which the sexes resemble each other and are both brilliant, especially when the colours are arranged for display, we may conclude that they have been gained by the male sex as an attraction, and have been transferred to the female. We are more especially led to this conclusion whenever the same type of coloration prevails throughout a whole group, and we find that the males of some species differ widely in colour from the females, whilst others differ slightly or not at all, with intermediate gradations connecting these extreme states.

In the same manner as bright colours have often liecn partially transferred from the males to the females, so it has been with the extraordinary horns of many Lamellicorn and some other beetles. So again, the sound-producing organe proper to the males of the Homoptera and Orthoptera have generally been transferred in a rudimentary, or even in a nearly perfect condition, to the females; yet not sufficiently perfect to be of any use. It is also an interesting fact, as bearing ou sexual selection, that the stridulating organs of certain male Orthoptera are not fully developed until the last moult; and that the colours of certain inale dragon-flies are not fully developed until some little time after their emergence from the pupal state, and when they are ready to breed. 
Sexual selection implies that the more attractive individuals are preferred by the opposite sex; and as with insects, when tne sexes differ, it is the male which, with some rare exceptions, is the more ornamented, and departs more from the type to which the species belongs; - and as it is the male which searches engerly for the female, we must suppose that the females habitually or occasionally prefer the more beautiful males, and that these have thus acquired their beauty. That the females in most or all the orders would have the power of rejecting any particular male, is probable from the many singular contrivances possessed by the males, such as great jaws, adhesive cushions, spines, elongated legs, \&c., for seizing the female; for these contrivances shew that there is some difficulty in the act, so that her concurrence would seem necessary. Judging from what we know of the perceptire powers and affections of various insects, there is no antecedent improbability in sexual selection having come largely into play; but we have as yet no direct evidence on this head, and some facts are opposed to the belief. Nevertheless, when we see many males pursuing the same female, we can hardly believe that the pairing is left to blind chance-that the female exerts no choice, and is not influenced by the gorgeous colours or other ornaments with which the male is decorated.

If we admit that the females of the Homoptera and Orthopters appreciate the musical tones of their male partners, and that the various instruments have been perfected through sexual selection, there is little improbability in the females of other insects appreciating beauty in form or colour, and consequently in such characters having been thus gained by the males. But from the circumstance of colour being so variable, and from its having been so often modified for the sake of protection, it is difficult to decide in how large a proportion of cases sexual selection has played a part. This is more especially difficult in those Orders, such as Orthoptera, Hymenoptera, and Coleoptera, in which the tiro sexes rarely differ much in colour; for we are then left to mere analogy. With the Coleoptera, however, as before remarked, it is in the great Lamellicorn group, placed by some authors at the head of the Order, and in which we sometimes see a muttial attachment between the sexes, that we find the males of some species possessing weapons for sexual strife, others furnished with wonderful horns, many with stridulating organs, and others ornamented with splendid metallic tints. Hence it seems probable that all these characters have been gained through the same means, numely sexual selection. With butterflies we have the best evidence, as the males 
Bometimes take pains to display their beautiful colours; and we cannot believe that they would act thus, unless the display was of ase to them in their conrtship.

When we treat of Birds, we shall see that they present in their secondary sexual characters the closest analogy with insects. Thus, many male birds are highly pugnacious, and some are furnished with special weapons for fighting with their rivals. They possess organs which are used during the breedingseason for producing rocal and instrumental music. They are frequently ornamented with combs, horns, wattles and plumes of the most divcrsified kinds, and are decorated with beautiful colours, al! evidently for the sake of display. We shall find that, as with insects, both sexes in certain groups are equally beautiful, and are equally provided with ornaments which are usually confined to the male sex. In other groups both sexes are equally plain-coloured and unornamented. Lastly, in somre few anomalous cases, the females are more beautiful than the males. We shall often find, in the same group of birds, every gradation from no difference between the sexes, to an extreme difference. We shall see that female birds, like female insects, often possess more or less plain traces or rudiments of characters which properly belong to the males and are of use only to them. The analogy, indeed, in all these respects between birds and insects is curiously close. Whaterer explanation applies to tho one class probably applies to the other; and this explanation, as we shall hereafter attempt to shew in further detail, is sexual selection.

\section{CHAPTER XII.}

Secondary Sexdal Characters of Fishes, Ampribiang, AND REPTILES.

Frshes: Courtship and battles of the males-Larger size of the females -Males, bright colours and ornamental appendages; other strange character's-Colours and appendages acquired by the males durind the breeding-season alone-Fishes with both sexes brilliantly colunied -Protective colours-The less conspicuous colours of the female cannot be accounted for on the principle of protection-Male fishes building nests, and taking charge of the ova and young. Aurimbians: Differences in structure and colour between the seres-Vocal organs. REPTILES: Chelonians-Crocodiles-Snakes, colours in some cases protective-Lizards, battles of-Ornamental appendages-Strange differences in structure between the sexes-Colours-Sexual differences almost as great as with birds.

We have now arrived at the great sub-kingdom of the Vertehrata, and will commence with the lowest class. that of Fishes. The 
males of Plagiostomoas fishes (sharks, rays) and of Chimæroid fishes are provided with claspers which serve to retain the female, like the various structures possessed by many of the lower animals. Besides the claspers, the males of many rays have clusters of strong sharp spices on their heads, and several rows along "the upper outer surface of their pectoral fins." These are present in the males of some species, which have other parts of their bodies smooth. They are only temporarily developed during the breeding-season; and Dr. Guinther suspects that they are brought into action as prehensile organs by the doubling inwards and downwards of the two sides of the body. It is a remarkable fact that the females and not the males of some species, as of Raia cluvata, have their backs studded with large hook-formed spines. ${ }^{1}$

The males alone of the capelin (Mallotus villosus, one of Salmonidæ), are provided with a ridge of closely-set, brush-like scales, by the aid of which two males, one on each side, hold the female, whilst she runs with great swiftness on the sandy beach, and there deposits her spawn. ${ }^{2}$ The widely distinct Monacanthus scopas presents a somewliat analogous structure. The male, as Dr. Günther informs me, has a cluster of stiff, straight spines, like those of a comb, on the sides of the tail; and these in a specimen six inches long were nearly one and a half inches in length: the female has in the same place a cluster of bristles, which may be compared with those of a tooth-brush. In another species, $M$. peronii, the male has a brush like that possessed by the female of the last species, whilst the sides of the tail in the female are smooth. In some other species of the same genus the tail can be perceived to be a little roughened in the male and perfectly smooth in the female; and lastly in others, both sexes have smooth sides.

The males of many fish fight for the possession of the females. Thus the male stickleback (Gasterosteus leiurus) has been doscribed as " mad with delight," when the female comes out of her hiding-place and surveys the nest which he has made for her. "He darts round her in every direction, then to his accumulated "materials for the nest, then back again in an instant; and as "she does not advance he endeavours to push her with his snout, "and then tries to pull her by the tail and side-spine to the nest."

1 Yarrell's 'Hist, of British Fishes, " vol. ii. 1836, pp. 417, 42J, 436. Dr. Gunther informs me that tho spines in $R$. clavata are peculiar to the female.

2 'The American Naturalist, April
1871, p. 119.

3 See Mr. R. Warington's interesting articles in 'Aunals and Mag. of Nat. Hist' Oct. 1852 and Nov. 1855. 
The males are said to be polygamists; ${ }^{4}$ they are extraordinarily bold and pugnacious, whilst "the females are quite pacific." Their battles are at times desperate; "for these puny com" batants fasten tight on each other for several seconds, tumbling "over and over again, until their strength appears completely " cxhausted." With the rough-tailed stickleback (G. trachurus) the males whilst fighting swim round and round cach other, biting and endeavouring to pierce each other with their raised lateral spines. The same writer adds, "the bite of these little "furies is very severe. They also use their lateral spines with "such fatal effect, that I have seen one during a battle absolutely "rip his opponent quite open, so that he sank to the bottom and "died." When a fish is conquered, "his gallant bearing forsakes " him; his gay colours fade array; and he hides his disgrace "among his peaceable companions, but is for some time the "constant object of his conqueror's persecution."

The male salmon is as pugnacious as the little stickleback; and so is the male trout, as I hear from Dr. Günther. Mr. Shaw saw a violent contest between two male salmon which lasted the whole day; and Mr. R. Buist, Superintendent of Fisheries, informs me that he has often watched from the bridge at Perth the males driving away their rivals, whilst the females were sparnning. The males " are constantly fighting and tearing each " other on the spawning-beds, and many so injure each other as " to cause the death of numbers, many being seen swimming near " the banks of the river in a state of exhaustion, and apparently " in a dying state." Mr. Buist informs me, that in June 1868, the keeper of the Stormontfield brecding-ponds visited the northern Tyne and found about 300 dead salmon, all of which with one exception were males; and he was convinced that they had lost their lives by fighting.

The most curious point about the male salmon is that during the breeding-season, besides a slight change in colour, "the "lower jaw elongates, and a cartilaginous projection turns " upwards from the point, which, when the jaws are closed, " occupies a deep cavity between the intermaxillary bones of the .pper jaw." 7 (Figs. 27 and 28.) In our salmon this change of structure lasts only during the breeding-season; but in the

\footnotetext{
4 Noel Humphreys, 'River Gardens,' 1857.

'Loudon's 'Mag. of Nat. History,' rol. iii. 1830, p. 331.

- 'The Field,' June 29th, 1867. Fur Mr. Shaw's statement. see 'Enhourgh Reviou:' 1843. Aunther
} experienced observer (Scrope's 'Days of Salmon Fishing,' p. 60) remarks that like the stag, the male would, if he could, keep all other ma!es away.

7 Yarrell, "History of British Eishes,' vil. ii. 1836, p. 10 . 
Chap. XII.

Fishes.

Balmo lycaodon of $\mathrm{N}$. IV. America the change, as Mr. J. K. Lord believes, is permanent, and best marked in the older males which have previously ascended the rivers. In these old males the jilw becomes developed into an immense hook-like projection, and

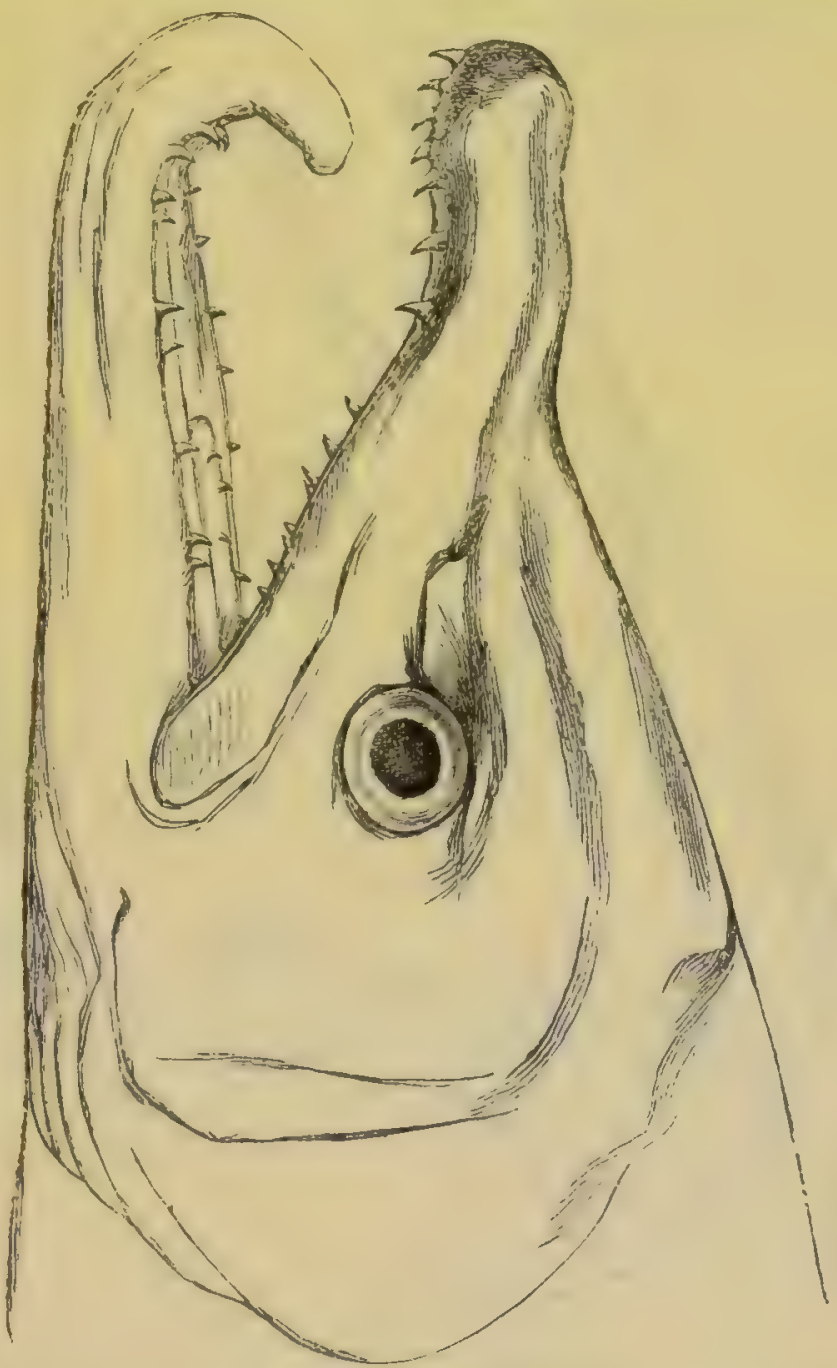

Fig. 27. Head of male common salmon (Salmo salar) during the breedinf;-season.

IThis drawing, as well as all the otbers in the present chaptor. have been executal by the well-known artist, Mr. G. Ford, from specimens in the British Museum, under the kind superintendence of Dr. Gilinther.]

the teeth grow into regular fangs, often more than half an inch in length. With the European salmon, according to Mr. Lloyd, the temporary hook-like structure serves to strengthen and

3 'The Naturalist in Vancourer's Island,' rol. $1866, \mathrm{p} 54$.

9 'Scandinarian Adventures,' vol, i. 1854, p. 100, 104. 
protect the jaws, when one male charges another with wonderful violence; but the greatly developed teeth of the male American salmon may be compared with the tusks of many male mammals, and they indicate an offensive rather than a protective purpose.

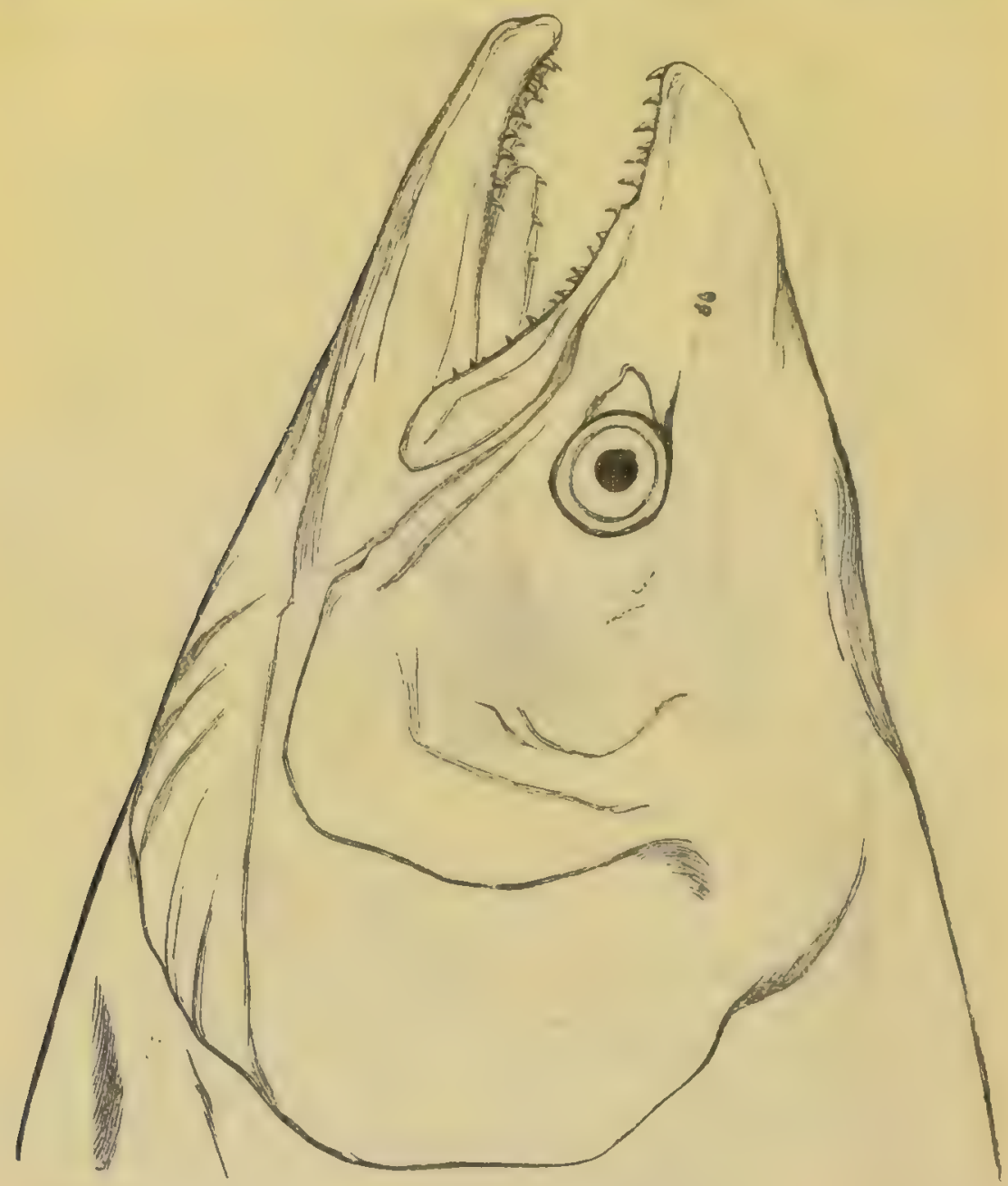

Fig 28

Head of female salmon.

The salmon is not the only fish in which the teeth differ in the two sexes; as this is the case with many rays. In the thornback (Raia clavata) the adult male has sharp, pointed teeth, directed backwards, whilst those of the female are broad and flat, and form a pavement; so that these teeth differ in the two sexes of the same species more than is usual in distinct genera of the same family. The teeth of the male hecome sharp only when he is adult: whilst young they are broad and flat 
like those of the female. As so frequently occurs with secondary sexual characters, both sexes of some species of rays (for instance h. batis), when adult, possess sharp pointed teeth; and here a character, proper to and primarily gained by the male, appears to have been transmitted to the offspring of both sexes. The tceth are likewise pointed in both sexes of $R$. maculata, but only when quite adult; the males acquiring them at an earlier age than the females. We shall hereafter meet with analogous cases in certain birds, in which the male acquires the plumage common to both sexes when adult, at a somewhat earlier age than does the female. With other species of rays the males even when old never possess sharp teeth, and consequently the adults of both sexes are provided with broad, flat teeth like those of the young, and like those of the mature females of the above-mentioned species. ${ }^{10}$ As the rays are bold, strong and voracious fish, we may suspect that the males require their sharp teeth for fighting with their rivals; but as they possess many parts modified and adapted for the prehension of the female, it is possible that their teeth may be used for this purpose.

In regard to size, M. Carbonnier ${ }^{11}$ maintains that the female of almost all fishes is larger than the male; and Dr. Günther does not know of $n$ single instance in which the male is actually larger than the female. With some Cyprinodonts the male is not even half as large. As in many kinds of fishes the males habitually fight together, it is surprising that they have not generally become larger and stronger than the females through the effects of sexual selection. The males suffer from their small size, for according to M. Carbonnier, they are liable to be devoured by the females of their own species when carnivorous, and no doubt by other species. Increased size must be in some manner of more importance to the females, than strength and size are to the males for fighting with other males; and this perhaps is to allow of the production of a rast number of ova.

In many species the male alone is ornamented with bright colours; or these are much brighter in the male than the female. The male, also, is sometimes provided with appendages which appear to be of no more use to him for the ordinary purposes of life, than are the tail feathers to the peacock. I am indebted for most of the following facts to the kindness of $\mathrm{Dr}$ Günther. There is reason to suspect that many tropical fishes differ sexually in colour and structure; and there are some striking cases with our British fishes. The male Callionymus lyr

10 See Yarrell's account of the rays in his 'Hist. of British Fishes,' vol. ii. 1836, p. 416, with an ex=

cellent figure, and p. 422, 432 .

11 As quoted in 'The Fanner, 1868 ; p. 369. 
has been called the yemmeous drugonet "from its briliiant gem"like colours." When fresh caught from the sea the body is yellow of various shades, striped and spotted with vivid blue on the head; the dorsal tons are pale brown with dark longitudinal bands; the ventral, caudal, and anal fins being bluish-black. The female, or sordid dragonet, was considered by Linnæus, and by many subsequent naturalists, as a distinct species; it is of a dingy reddish-brown, with the dorsal fin brown and the other
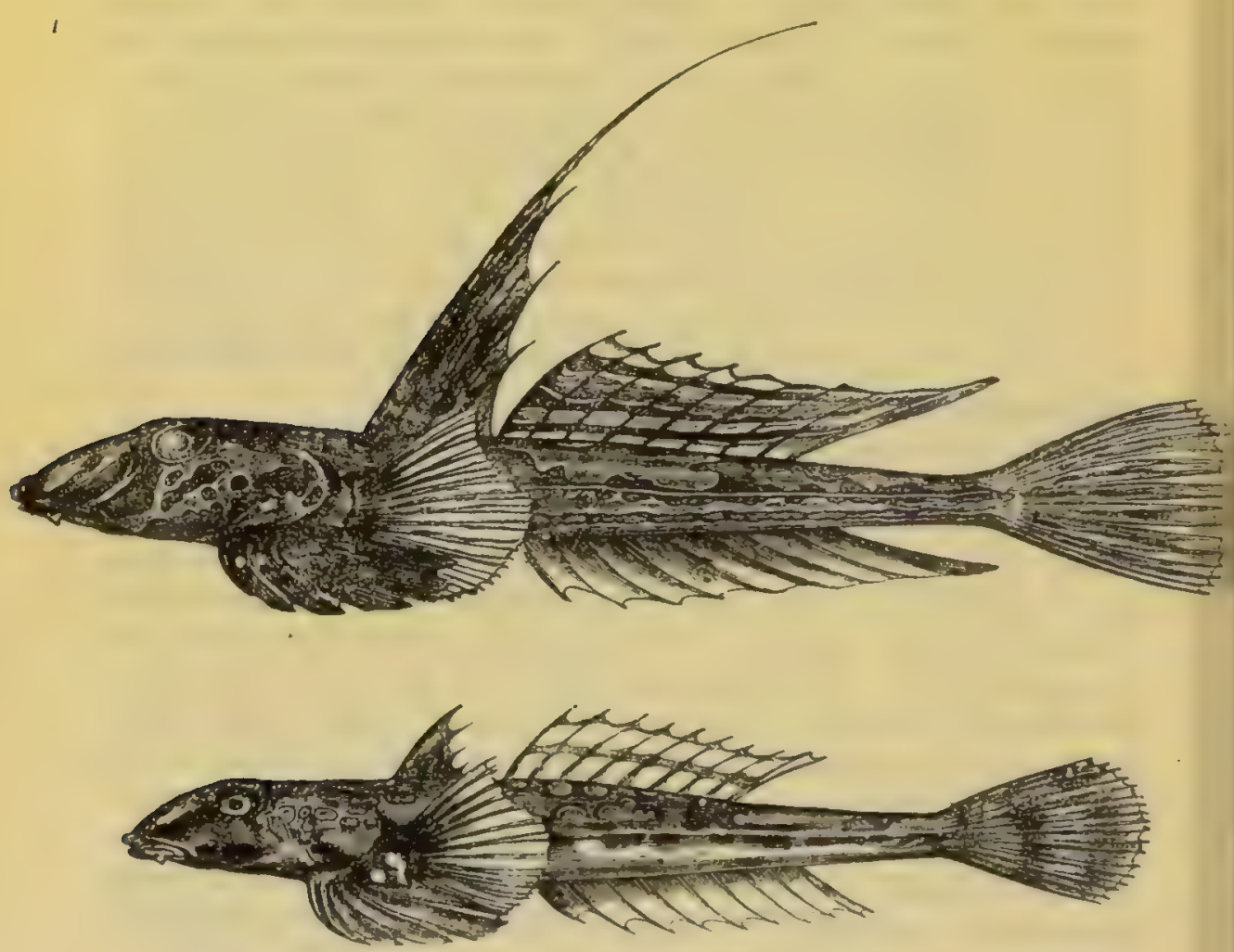

Fig. 29. Callionymus lyra. Upper figure, male; lower figure, female. N.B. The lower figure is more reduced than the upper.

fins white. The sexes differ also in the proportional size of the head and month, and in the position of the eyes ;2 but the most striking difference is the extraordinary elongation in the male (fig. 29) of the dorsal fin. Mr. W. Saville Kent remarks that this "singular appendage appears from my observations $\therefore$ of the species in confinement, to be subservient to the same " end as the wattles, crests, and other abnormal adjuncts of "the male in gallinaceous birds, for the purpose of fascinating

12 I hare drawn up this description from Yarrell's 'British Fishes,'rol. i. $1836, \mathrm{pp} .261$ and 266. 
"their mates." ${ }^{3}$ The young males resemble the adult females in structure and colour: Throughout the genus Callionymus, ${ }^{14}$ the male is generally much more brightly spotted than the female, and in severul species, not only the dorsal, but the anal fin is much elongated in the males.

The male of the l'ottus scorpius, or sea-scorpion, is slenderer and smaller than the female. There is also a great difference in colour between them. It is difficult, as Mr. Lloyd ${ }^{15}$ remarks, "for any one, who has not seen this fish during the spawning"season, when its hues are brightest, to conceive the admixture "of brilliant colours with which it, in other respects so ill"favourcd, is at that time adorned." Both sexes of the Labrus mixtus, although very different in colour, are beautiful; the male boing orauge with bright blue stripes, and the female bright red with some biack spots on the back.
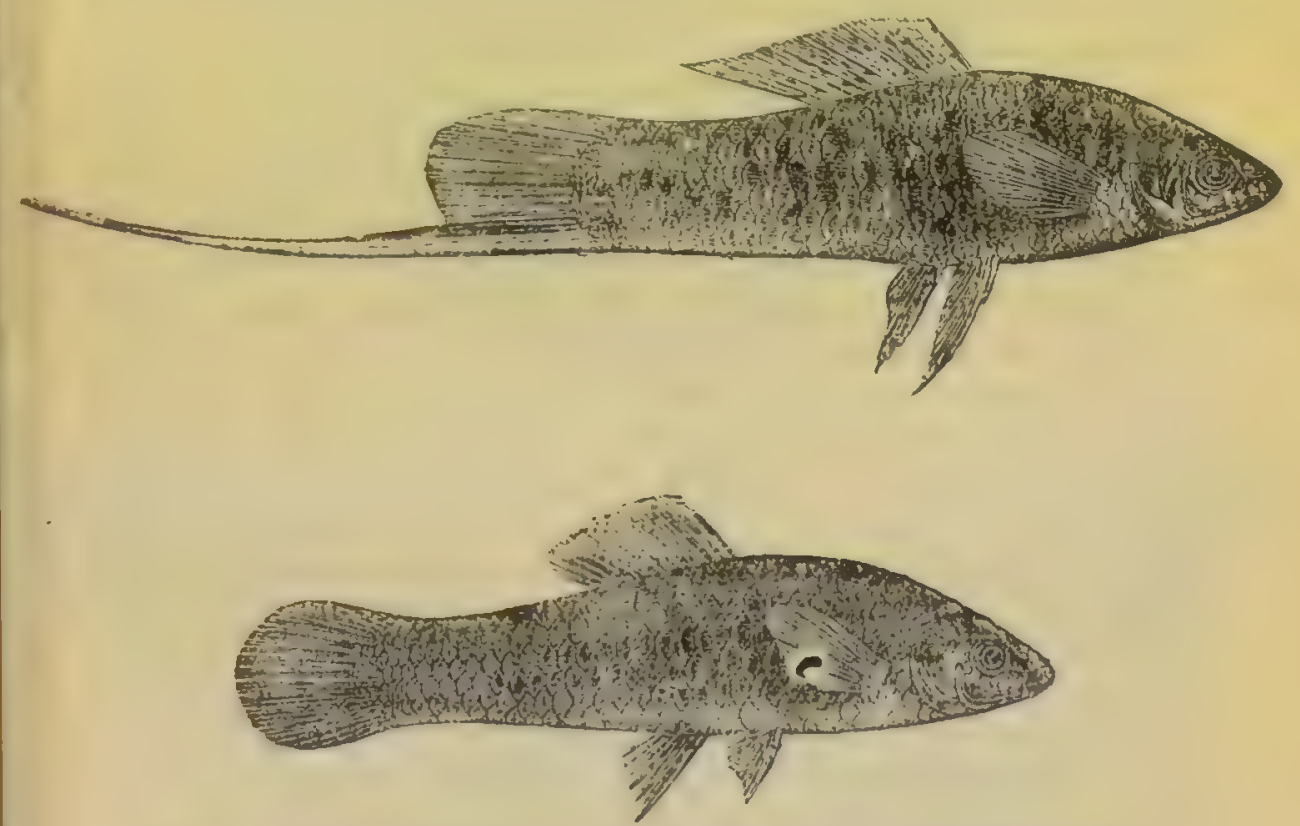

Fig. 30. Xiphophorus Helleni. Upper figure, male; Iower figure, femalc.

In the very distinct family of the Cyprinodontidæ-inhabitants of the fresh waters of foreign lands-the sexes sometimes differ much in various characters. In the male of the Mollienesin petenensis, ${ }^{16}$ the dorsal fin is greatly developed and is marked

'3 'Nature,' July 1873, p. 264.

14 'Catalogue of Acanth. Fishes in the British Museum, by Dr. Günther, 1861, pp. 138-151.

15 'Game Birds of Sweden,' \&c.. 1867, p. 466.
16 With respect to this and the following species I am indebted to Dr. Ginther for information: see also his paper on the "Fishes of Central America,' in 'Transact. Zoolog. Soc.' vol, vi 1868, p. 485. 
with a row of large, round, ocellated, bright-coloured spots; whilst the same fin in the female is smaller, of a different shape, and marked only with irregularly curved brown spots. In the male the basal margin of the anal fin is also a little produced and dark coloured. In the male of an allied form, the Xiphoithorus Hellerii (fig. 30), the inferior margin of the caudal fin is doveloped into a long filament, which, as I hear from Dr. Günther, 1s striped with bright colours. This filament does not contain any muscles, and apparently cannot be of any direct use to the fish. As in the case of the Callionymus, the males whilst young rosemble the adult females in colour and structure. Sexual -ifferences such as these may be strictly compared with those which are so frequent with gallinaceous birds. ${ }^{17}$

In a siluroid fish, inhabiting the fresh waters of South America, the Plecostomus barbatus ${ }^{18}$ (fig. 31), the male has its mouth and inter-operculum fringed with a beard of stiff hairs, of which the female shows hardly a trace. These hairs are of the nature of scales. In another species of the same genus, soft flexible tentacles project froin the front part of the head of the male, whick. are absent in the female. These tentacles are prolongations of tho true skin, and therefore are not homologous with the stifr bairs of the former species; but it can hardly be doubted that both serve the same purpose. What this purpose may bo, it is difficult to conjecture ornament does not here seem probable, but we can hardly suppose that stiff hairs and flexible filaments can be useful in any ordinary way to the males alone. In that strange monster, the Chimara monstrusa, the male has a hookshaped bone on the top of the head, directed forwards, with its cnd rounded and covered with sharp spines; in the female " this "crown is altogether absent," but what its use may be to the male is utterly unknown. ${ }^{19}$

The structures as yet referred to are permanent in the male nfter he has arrired at maturity ; but with some Blennies, and in another allied genus, ${ }^{20}$ a crest is developed on the head of ths male only during the breeding-seasen, and the body at the same time becomes more brightly-coloured. 'There can be little doubt that this crest serves as a temporary sexual ornament, for the female does not exhibit a trace of it. In other species of the same genus both sexes possess a crest, and in at least one sprcies

"Dr. Ginther makes this remark; 'Catalogue of Fish ss in the 'Britısh Museum,' vol. iii. $180 \ddot{1}$, p. $1+1$.

18 See Dr. Guinther on this genus, in 'Plnc. 7.oolog. Soc.' 1868, p. $23 \%$.

10 E Buckland, in 'Land and
Water,' July 1868, p. 377 , with a figure. Many other cases could be added of structures peculiar to the male, of which the uses are not known.

20 Dr. Guinther, 'Catalogue of Fishes,' rol. iii. pp. 221 and 240. 
Cinap. XII.

Fissios.
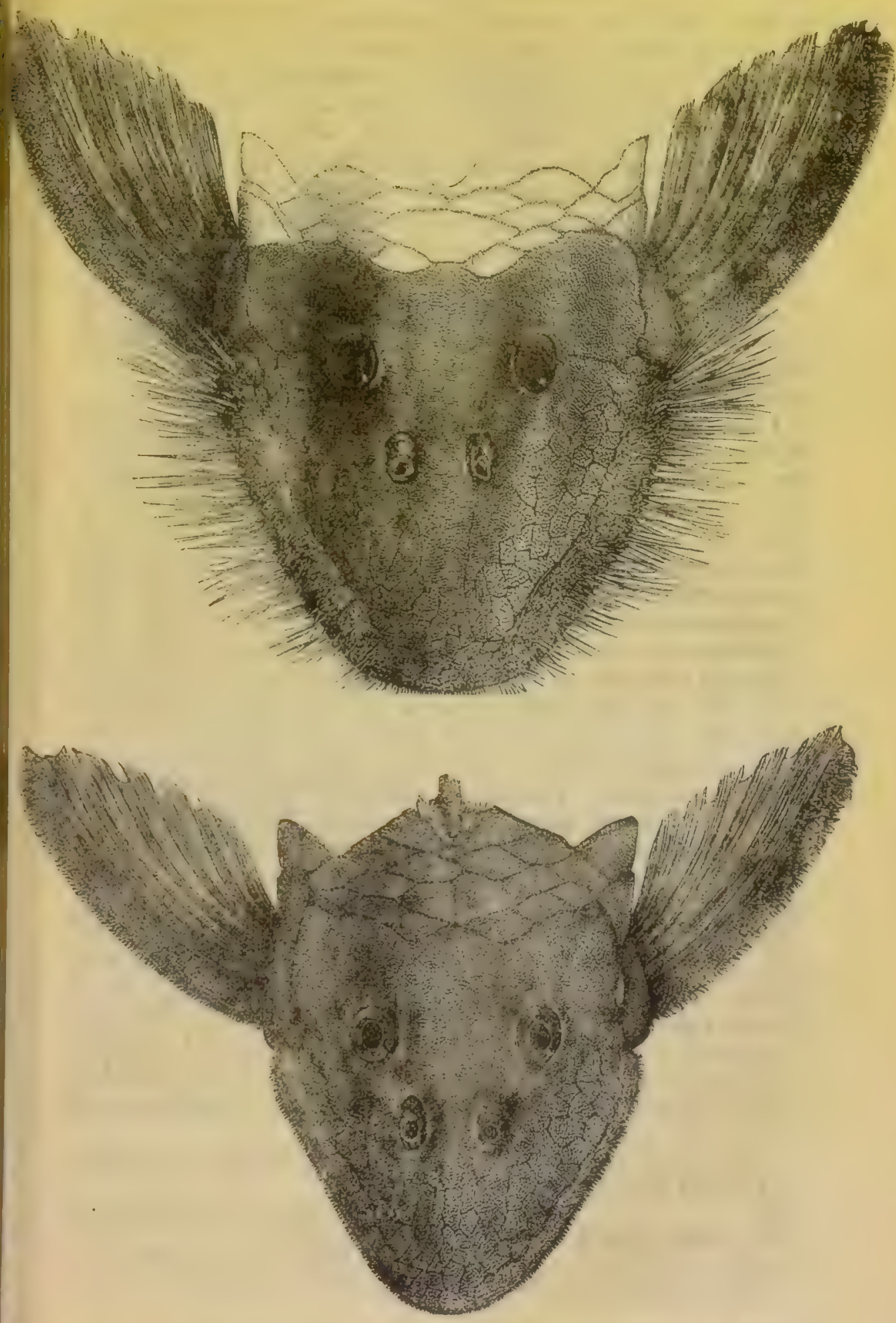

Fig. 31. Plecostomus barb.itus. Unper figure, head of male; lower fgure, femals 
neithor sex is thus provided. In many of the Chromidr, for instance in Geophagus and especially in Cichla, the males, as 1 hear from Professor Agassiz, ${ }^{21}$ have a conspicuous protuberance on the forehead, which is wholly wanting in the females and in the young males. Professor Agassiz adds, "I have oftcn " observed these fishes at the time of spawning when the pro"tuberance is largest, and at other seasons when it is totally "wanting, and the two sexes shew no difference whatever in tho " outline of the profile of the head. I never could ascertain that " it subserves any special function, and the Iudians on the "Amazon know nothing about its use." These protuberances resemble, in their periodical appearance, the fleshy caruncles on the heads of certain birds; but whether they serve as ornaments must remain at present doubtful.

I hear from Professor Agassiz and Dr. Günther, that the males of those fishes, which differ permanently in colour from the females, often become more brilliant during the breeding-season. This is likewise the case with a multitude of fishes, the sexes of which are identical in colour at all other seasons of the year. The tench, roach, and perch may be given as instances. The male salmon at this season is "marked on the cheeks with " orange-coloured stripes, which give it the appearance of a "Labrus, and the body partakes of a golden orange tinge. The "females are dark in colour, and are commonly called black"fish." 2 An analogous and even greater change takes place with the Sulmo eriox or bull trout; the males of the char ( $S$. umblu) are likewise at this season rather brighter in colour than the females. ${ }^{23}$ The colours of the pike (Esox reticulatus) of the United States, especially of the male, become, during the breeding-season, exceedingly intense, brilliant, and iridescent. ${ }^{24}$ Another striking instance out of many is afforded by the male stickleback (Gasterostens leiurus), which is described by Mr. Warington, ${ }^{25}$ as being then "beautiful beyond description." "The back and eyes of the female are simply brown, and the belly white. The eyes of the male, on the other hand, are " of the " most splendid green, having a metallic lustre like the green "feathers of some humming-birds. Tho throat and belly are " of a bright crimson, the back of an ashy-green, and the whole "fish appears as though it were somewhat translucent and

21 See also 'A Journey in Brazil,' by Prof, and Mrs. Agassiz, 1868, p. 220.

2: Turrell, 'British Fishes,' vol. ii. $1836, \mathrm{pp} .10,12,35$.

* W. Thompson, in 'Annals and
Mag. of Nat. History;' rol. vi. 1841, p. 440 .

24 'The American Agriculturist, 1868, p. 100.

${ }^{23}$ 'Anna!s and Mag. of Nat. Hist. 
"glowed with an internal incandescence." After the breedingseason these colours all change, the throat and belly become of a paler red, the back more green, and the glowing tints subside.

With respect to the courtship of fishes, other cases hare been observed since the first edition of this book appeared, besides that already given of the stickleback. Mr. W. S. Kent says that the male of the Labrus mixtus, which, as we have seen, differs in colour from the female, makes " a deep hollow in the sand of the " tank, and then endeavours in the most persuasive manner to in" duce a female of the same species to share it with him, swim" ming backwards and forwards between her and the completed " "mest, and plainly exhibiting the greatest anxiety for her to follow." The males of Cartharus lineatus become, during the breedingseason, of deep leaden-black; they then retire from the shoal, and excavate a hollow as a nest. "Each male now mounts vigilant " guard over his respective hollow, and vigorousty attacks and "drives away any other fish of the same sex. Towards his com"panions of the opposite sex his conduct is far different; many of " the latter are now distended with spawn, and these he endeavours "by all the means in his power to lure singly to his prepared " hollow, and there to deposit the myriad ova with which they are "s laden, which he then protects and guards with the greatest care. ${ }^{26}$

A more striking case of courtship, as well as of display, by the males of a Chinese Macropus has been given by M. Carbonnier, who carefully observed these fishes under confinement. ${ }^{27}$ The males are most beautifully coloured, more so than the females. During the breeding-season they contend for tho possession of the females; and, in the act of courtship, expand their fins, which are spotted and ornamented with brightly coloured rays, in the same manner, according to M. Carbonnier, as the peacock. They then also bound about the females with much vivacity, and appear by "l'étalage de leurs vires couleurs chercher à attircr "l'attention des femelles, lesquelles ne paraissaient indifférentes " à ce manége, elles nageaient avec une molle lenteur vers les "mâles et semblaient se complaire dans leur voisinage." After the male has won his bride, he makes a little disc of froth by blowing air and mucus out of his mouth. He then collects tho fertilised ova, dropped by the female, in his mouth; and this caused M. Carbonnier much alarm, as he thought that they wero groing to be devoured. But the male soon deposits them in the disc of froth, afterwards guarding them, repairing the froth, and taking care of the young when hatched. I mention these particulars because, as we shall presently sec, there are fishes, the

$$
\text { 2. 'Nature,' May, 1873, p. } 25 .
$$


males of which latch their eggs in their mouths; and those who do not believe in the principle of gradual evolution might ask how could such a habit have originated; but the difficulty is mucl diminished when we know that there are fishes which thus collect and carry the eggs; for if delayed by any cause in depositing them, the habit of hatching them in their mouths might have been acquired.

To return to our more immediate subject. The case stand: thus: female fishes, as far as I can icam, never willingly spamin except in the presence of the males; and the males never fertilise the ova except in the presence of the females. The males fight for the possession of the females. In many species, the malcs whilst young resemble the females in colour; but when adult become much more brilliant, and retain their colours throughout life. In other species the males become brighter than the females and otherwise more highly ornamented, only during the season of love. The males sedulously court the females, and in one case, as we have seen, take pains in displaying their beauty before them. Can it be believed that they would thus act to no purpose during their courtship? And this would be the case, unless the females exert some choice and select those males which please or excite them most. If the female exerts such choice, all the abore facts on the ormamentation of the males become at once intelligible by the aid of sexual selection.

We have next to enquire whether this view of the bright colours of certain male fishes having been acquired through sexual selection can, through the law of the equal transmission of characters to both sexes, be extended to those groups in which the males and females are brilliant in the same, or nearly the same degree and manner. In such a genus as Labrus, which includes some of the most splendid fishes in the world-for instance, the Peacock Labrus ( $L$. pavo), described, ${ }^{28}$ with pardonable exaggeration, as formod of polished scales of gold, encrusting lapis-lazuli, rubies, sapphires, emcralds, and amethysts-we may, with much probability, accept this belicf; for we have scen that the sexes in at least one species of the genus differ greatly in colour. With some fishes, as with many of the lowest animals, splondid colours may be the direct result of the nature of their tissues and of the surrounding conditions, without the aid of selection of any kind. The gold-fish (Cyprinus auratus), judging from the analogy of the golden variety of the common carp, is perhaps a case in point, as it may owe its splendid colours to a single abrupt variation, due to the conditions to which this fish has been subjected under

2a Borg de Snint Vincent, in 'Dict. Class. d'Hist. Nat.' tom. ix. 1226 p. 151. 
confinement. It is, however, more probable that these colours have been intensified through artificial selection, as this specios has been carefully bred in China from a remote period. ${ }^{29}$ Under watural conditions it does not seem probable that beings so highly organised as fishes, and which live under such complex rolations, should become brilliantly coloured without suffering some evil or receiving some benefit from so great a change, and consequently without the intervention of natural seloction.

What, then, are we to conclude in regard to the many fishes, both sexes of which are splendidly coloured? Mr. Wallace ${ }^{30}$ believes that the species which frequent reefs, where corals and other brightly-coloured organisms abound, are brightly colonred iu order to escape detection by their enemies; but according to my recollection they were thus rendered highly conspicuous. In the fresh-waters of the tropies there are no brilliantlycoloured corals or other organisms for the fishes to resemble; yet many species in the Amazons are beautifully coloured, and many of the carnivorous Cyprinidæe in India are ornamented with "bright longitudinal lines of rarious tints." 31 Mr. MrClelland, in describing these fishes, goes so far as to suppose that "the peculiar brilliancy of their colours" serves as "a better" " mark for king-fishers, terns, and other birds which are " destined to keep the number of these fishes in check;" but at the present day few naturalists will admit that any animal has been made conspicuous as an aid to its own destruction. It is possible that certain fishes may have been rendered conspicuous in order to warn birds and beasts of prey that they were unpalatable, as explained when treating of caterpillars; but it is not, I believe, known that any fish, at least any fresh-water fish, is rejected from being distasteful to fish-devouring animals. On the whole, the most probable view in regard to the fishes, of which both sexes are brilliantly coloured, is that their colours were acquired by the males as a sexual ornament, and were transferred equally, or nearly so, to the other sex.

29 Owing to some remarks on this subject, made in my work 'On the Variation of Animals under Domestication,' Mr. W. F. Mayers ('Chinese Nites and Queries,' Aug. 1868, $\mu$. 123) has searched the ancient Chinese encyclopedias. He finds that gold-fish were first renred in confinement during the Sung Dynasty, which commenced A.D. 960. In the year 1129 these fishes abounded. In annther place it is said that since the year 1548 inere has been "produced at Hangchow a "variety called the fire-fish, from its "intensely red colour. It is uni"versally admired, and there is not "a household where it is not cul. "tivated, in ricalry as to its colour, "and as a source of profit." 30 'Westminster Review,' July 1867, p. 7 .

31 'Indian Cyprinida,' by Mr. M'Clelland, "Asiatic Rosearches, vol. xix. part ii. 1339 , p. $\because 330$. 
We have now to consider whether, when the male differs in a marked manner from the female in colour or in other ornaments, he alone has been modified, the variations being inherited by his male offspring alone; or whether the female has been specially modified and rendered inconspicuous for the sake of protection, such modifications being inherited only by the females. It is impossible to doubt that colour has been gained by many fishes as a protection: no one can examine the speckled upper surface of a flounder, and overlook its resemblance to the sandy bed of the sea on which it lives. Certain fishes, moreover, can through the action of the nervons system, change their colours in adaptation to surrounding objects, and that within a short time. ${ }^{82}$ One of the most striking instances ever recorded of an animal being protected by its colour (as far as it can bo judged of in preserved specimens), as well as by its form, is that given by Dr. Guinther ${ }^{93}$ of a pipe-fish, which, with its reddish streaming filaments, is hardly distinguishable from the sea-weed to which it clings with its prehensile tail. But the question now under consideration is whether the females alone have been modified for this object. We can see that one sex will not be modified through natural selection for the sake of protection more than the other, supposing both to vary, unless one sex is exposed for a longer period to danger, or has less power of escaping from such danger than the other; and it does not appear that with fishes the sexes differ in these respects. As far as there is any difference, the males, from being generally smaller and from wandering more about, are exposed to greater danger than the females; and jet, when the sexes differ, the males are almost always the more conspicuously coloured. The ova are fertilised immediatcly after being deposited; and when this process lasts for several days, as in the case of the salmon, ${ }^{34}$ the female, during the whole time, is attended by the male. After the ora are fertilised they are, in most cases, left unprotected by both parents, so that the males and females, as far as oviposition is concerned, are equally exposed to danger, and both are equally important for the production of fertile ova: consequently the more or less brightly-coloured individuals of either sex would be equally liable to be destroyed or preserved, and both would have an equal influence on the colours of thcir offspring.

Certain fishes, belonging to several families, make nests, and some of them take care of their young when hatched. Both:

\footnotetext{
37 G. Pouchet, L'Institut. Nov. 1, 327, pl. xiv. and xv.

1871, p. 134

23 'Proc. Zoolog. Soc.' 1865, p.

ii. p. 'I
} 
sexes of the bright coloured Crenilabrus massa and meloxs work together in building their nests with sea-weed, shells, $\mathrm{Cr}^{35}$ But the nuales of certain fishes do all the work, and after'wards take exclusivo charge of the young. This is the case with the dullcoloured gohies, ${ }^{36}$ in which the sexes are not known to differ in colonr, and likewise with the sticklebacks (Gasterosteus), in which the males become brilliantly coloured during the spa wning season. The male of the smooth-tailed stickleback (G. leiurus) performs the duties of a nurse with exemplary care and vigilance during a long time, and is continually employed in gently leading back the young to the nest, when they stray too far. He courageously irives away all enemies, including the females of his own species. It would indeed be no small relief to the male, if the female, after depositing her eggs, were immediately devoured by some enemy, for he is forced incessantly to drive her from the nest. ${ }^{37}$

The males of certain other fishes inhabiting South America and Ceylon, belonging to two distinct Orders, have the extraordinary habit of hatching within their mouths or branchial cavities, the eggs laid by the females. ${ }^{38}$ I am informed by Professor Agassiz that the males of the Amazonian species which follow this habit, "not only are generally brighter than " the females, but the difference is greater at the spawning-season " than at any other time." The species of Geophagus act in the same manner; and in this genus, a conspicuous protuberance becomes developed on the forehead of the males during the breeding-season. With the various species of Chromids, as Professor Agassiz likewise informs me, sexual difficrences in colour may be observed, "whether they lay their eggs in the "water among aquatic plants, or deposit them in holes, leaving " them to come out without further care, or build shallow nests " in the river mud, over which they sit, as our Pomotis does. "It ought also to be observed that these sitters are among the " brightest species in their respective families; for instance, "Hygrogonus is bright green, with large black ocelli, encircled "with the most brilliant red." Whether with all the species of Chromids it is the male alone which sits on the cggs is not known. It is, however, manifest that the fact of the eggs being

3s According to the observatious of M. Gerbe ; see Ginther's 'Record of Zoolog. Literature,' 1865, p. 194.

38 Cuvier, 'Règne Animal,' vol. j. 1829, p. 242.

n See Mr. Warington's most interesting description of the habits of the Gasterosteus lciurus, in 'An- nals and Mag. of Nat. Hist.' Norember 1855 .

38 Prof. Wyman, in 'Proc. Boston Soc. of Nat. Hist.' Sept. 15, 1857. Also Prof. Turner, in 'Journal of Anatomy and Phys.' Nov. 1, 1866, p. 78. Dr. Günther has likewise described other cases. 
protected or unprotected by the parents, has had little or no influence on the differences in colour between the sexes. It is further manifest, in all the cases in which the males take exclusive charge of the nests and young, that the destruction of the brighter-coloured males would be far more influential on the character of the race, than the destruction of the brightercoloured females; for the death of the male during the period of incubation or nursing would entail the death of the young, so that they could not inherit his peculiarities; yet, in many of these very cases the males are more conspicuously coloured than the females.

In most of the Lophobranchii (Pipe-fish, Hippocampi, \&c.) the males have either marsupial sacks or hemispherical depressions on the abdomen, in which the ova laid by the female are hatched. The males also shew great attachment to their young. ${ }^{39}$ The sexes do not commonly differ much in colour; but Dr. Guinther believes that the male Hippocampi are rather brighter than the females. The genus Solenostoma, however, offers a curious exceptional case, ${ }^{40}$ for the female is much more vividly-coloured and spotted than the male, and she alone has a marsupial sack and hatches the eggs; so that the female of Solcnostoma differs from all the other Lophobranchii in this latter respect, and from almost all other fishes, in being more brightly-coloured than the male. It is improbable that this remarkable double inversion of character in the female should bo an accidental coincidence. As the males of sereral fishes, which take exclusive charge of the eggs and young, are more brightly coloured than the females, and as here the female Solenostoma takes the same charge and is brighter than the male, it might be argued that the conspicuous colours of that sex which is the more important of the two for the welfare of the offspring, must be in some manner protective. But from the large number of fishes, of which the males are either permanently or periodically brighter than the females, but whose life is not at all more important for the welfare of the species than that of the female, this view can hardly be maintained. When we treat of birds we shall meet with analogous cases, where there has been a complete inversion of the usual attributes of the two sexes, and we shall then give what appears to be the probable explanation, namely, that the males have selected the more attractive females, instead of the latter having selected, in

30 Yarrell, 'Hist. of British Fishes,' vol, ii. 1836, pp. 329, 338.

to Tr. Giinther, since publishing in accoung af ? !hs sprecias iu "The
Fishes of Zanzibar,' by Col. Playfair, 1866 , p. 137 , has re-examined the specimens. and has given me the abive information. 
scuordance with the usual rule throughout the animal kingdom, the more attractive males.

On the whole we may conclude, that with most fishes, in which the sexes differ in colour or in other ornamental characters, the males originally varied, with their rariations transmitted to the same sex, and accumulated through sexual selection by attracting or exciting the females. In many cases, however, such characters have been transferred, either partially or completely, to the females. In other cases, again, both sexes have been coloured alike for the sake of protection; but in no instance does it appear that the female alone has had her colours or other characters specially modified for this latter purpose.

The last point which need be noticed is that fishes are known to make various noises, some of which are described as being musical. Dr. Dufossé, who has especially attended to this subject, says that the sounds are voluntarily produced in several ways by different fishes: by the friction of the pharyngeal bones -by the vibration of certain muscles attached to the swimbladder, which serves as a resounding board-and by the vibration of the intrinsic muscles of the swim-bladder. By this latter means the Trigla produces pure and long-drawn sounds which range over nearly an octave. But the most interesting case for us is that of two species of Ophidium, in which the males alone are provided with a sound-producing apparatus, consisting of small movable bones, with proper muscles, in connection with the swim-bladder. ${ }^{41}$ The drumming of the Umbrinas in the European seas is said to bo audible from a depth of twenty fathoms; and the fishermen of Rochelle assert "that the males "alone make the noise during the spawning-time; and that it " is possible by imitating it, to take them without bait." 42 From this statement, and more especially from the case of Ophidium. it is almost certain that in this, the lowest class of the Vertebrata, as with so many insects and spiders, sound-produciner instruments have, at least in some cases, been developed through sexual selection, as a means for bringing the sexes together.

41 'Comptes Readus.' Tom. xlvi. 1858, p. 353. Tom. slvii. 1858, p. 916. Tom. liv. 1862, p. 393 . The noist uade by the Umbrinas (Scrana xquila), is said by some authors to be more like that of a flute or organ, tran drumming: Ir. \%outeveen, in the Dutch translation of this work (rol. ii., p. 36), gives some further particulars on the sounds made by fishes.

12 The Rev. C. Kingsley, in 'Nature,' May 1870, f. \$0. 


\section{A Mrimians.}

Urodela. - I will begin with the tailed amphibians. The sexes of salamanders or newts often differ much both in colour and structure. In some species prehensile claws are developed on the fore-legs of the males during the breeding-scason: and at this season in the male Triton pulmipes the hind-feet are provided with a swimming-web, which is almost completely absorbed during the winter; so that their fect then resemble
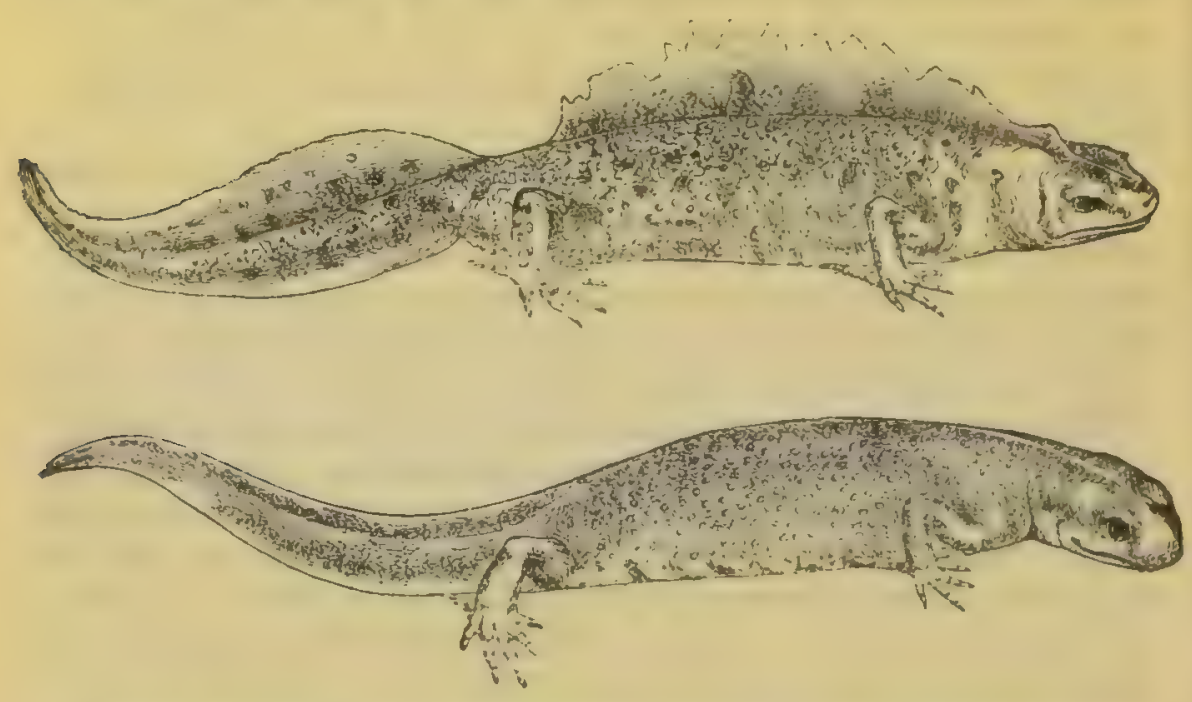

Fig. 32. Tritun crista'us (half natural size, from 13. ll's ' British Reptiles'). Upper tigure, male during the brealing-siason; lower tigure, female.

those of the female. ${ }^{43}$ This structure no doubt aids the male in his eager search and pursuit of the female. Whilst courting her he rapidly vibrates the end of his tail. With our common newts (Triton munctatus and cristatus) a deep, much indented crest is developed along the back and tail of the male during the breeding-season, which disappears during the winter. Mr. St. George Mivart informs me that it is not furnished with muscles, and therefore cannot be used for locomotion. As diuring the season of courtship it becomes edged with bright colours, thicre can hardly be a doubt that it is a masculine ornament. In many species the body presents strongly contrasted, though lurid tints, and these become more vivid during the breedingseason. The male, for instance, of our common little newt ('T'riton punctatus) is " brownish-grey above, passing into jellow

(3 Bell, 'History of British Reptiles,' 2nd edit. 1849, pp. 156-159. 
"beneath, which in the spring becomes a rich bright orange, " marked everywhere with round dark spots." The edgo of the crest also is then tipped with bright red or violet. The femalo is usually of a yellowish-brown colour with scattered brown dots, and the lower surface is often quite plain. ${ }^{4}$ The young are obscurely tinted. The ova are fertilised during the act of deposition, and are not subsequently tended by either parent. We may therefore conclude that the males have acquired their strongly-marked colours and ornamental appendages through sexual selection; these being transmitted either to the male offspring alone, or to both seres.

Anura or Butrachia.- With many frogs and toads the colours evidently serve as a protection, such as the bright green tints of tree-frogs and the obscure mottled shades of many terrestrial species. The most conspicuously-coloured toad whieh I ever saw, the Phrynisous niyricans, ${ }^{45}$ had the whole upper surface of the body as black as ink, with the soles of the feet and parts of the abdomen spotted with the brightest vermilion. It crawled about the bare sandy or open grassy plains of La Plata under a scorching sun, and could not fail to catch the eye of every passing creature. These colours are probably beneficial by making this animal known to all birds of prey as a nauseous mouthful.

In Nicaragua there is a little frog "dressed in a bright livery "of red and blue" which does not conceal itself like most othe:" species, but hops about during the daytime, and Mr. Belt says ${ }^{46}$ that as soon as he saw its happy sense of security, he felt sure that it was uneatable. After several trials he succeeded in tempting a young duck to snatch up a young one, but it was instantly rejected; and the duck "went about jerking its head, " as if trying to throw off some unpleasant taste."

With respect to sexual differonces of colour, Dr. Guinther does not know of any striking instance either with frogs or toads; yet he can often distinguish the male from the female, by the tints of the former being a little more intense. Nor does he know of any striking difference in external structure botween the sexes, excepting the prominences which become dereloped during the breeding-season on the front-legs of the male, by which he is enabled to hold the female. ${ }^{47}$ It is surprising that

14 Bell, "Hictory of British Reptiles,' 2nd edzt. 1849, pp. 146, 151.

4 'Zoology of the Voyage of the

"Beagle," "1843. Bell, ibid. p. 49.

46 'The Naturalist in Nicaragua,' 1874, p. 321.

47 The male alnoe of the Dufo sikimmensis (Dr. Anderson, 'Proc. Zoolog. Soc.,' 1871, p. 204) has tro plate-like callosities on the thorax and certain rugossties on the hingers, which perhaps subserve the same an " as the above-mertioned prominencen 
these animals have not acquired more strongly-marked sexual characters; for though cold-blooded their passions are stroug: Dr. Guinther intorms me that he has several times found ail anfortunate female toad dead and smothered from having been so closely embraced by three or four males. Frogs have been observed by Professor Floffman in Giessen fighting all day long during the breeding-season, and with so much violence, that one had its body ripped open.

Frogs and toads offer one interesting sexual difference, namely, in the musical powers possessed by the males; but to speak of music, when applied to the discordant and overwhelming sounds emitted by male bull-frogs and some other species, seems, according to our taste, a singularly inappropriate expression. Nevertheless, certain frogs sing in a decidedly pleasing mannor Near Rio Janeiro I used often to sit in the erening to listen to a number of little Hylæ, perched on blades of grass close to the water, which sent forth sweet chirping notes in harmony. The various sounds are emitted chicfly by the malns during the: brceding-season, as in the case of the croaking of our common frog. ${ }^{48}$ In accordance with this fact the vocal orrans of the males are more lighaly-developed than those of the females. In some genera the males alone are provided with sacs which open into the larynx. ${ }^{49}$ For instance, in the edible frog (Iianu esculenta) "the sacs are peculiar to the males, and become, when filled " with air in the act of croaking, large glubular bladders, stand" ing out one on each side of the head, near the corners of the " mouth." The croak of the male is thus rendered exceedingly powerful; whilst that of the female is only a slight groaning noise. ${ }^{50}$ In the several genera of the family the vocal organs cliffer considerably in structure, and their development in all cases may be attributed to sexual selection.

\section{RMPTILES.}

Chelonia.-Tortoises and turtles do not offer well-marked sexual differences. In some species, the tail of the male is longer than that of the female. In some, the plastron or lower surface of the slicll of the male is slightly concave in relation to the back of the female. The male of the mud-turtle of the United States (Chrysemys picta) has claws on its front-feet twice as long as those of the female; and these are used when

\footnotetext{
4 Bell, 'History of British Reptiles,' 1849 , p. 93.

48 J. Bishop, in 'Todd's Cyclop. of Anat. and Phys.' vol. iv. p. 1503 so Bell, ibid. p. 112-114.
} 
the sexes unite. ${ }^{51}$ With the huge tortoise of the Galapagos Islands (T'estudo nigra) the males are said to grow to a larger size than the females: during the pairing-season, and at no other time, the male utters a hoarse bellowing noise, which can be heard at the distance of more than a hundred yards; the female, on the other hand, never uses her voice..$^{52}$

With the Testudo eleguns of India, it is said " that tho combats " of the males may be heard at some distance, from the noise "they produce in butting against ench other." 53

Crocodilia.-The sexes apparently do not differ in colour; nor lo I know that the males fight together, though this is prohable, for sume kinds make a prodigious display before the icmales. Bartram ${ }^{54}$ describes the male alligator as striving to win the female by splashing and roaring in the midst of a lagoon, "swollen to an extent ready to burst, with its " head and tail lifted up, he spins or twirls round on the "surface of the water, like an Indian chief rehearsing his feats of war." During the season of love, a musky odour is emitted by the submaxillary glands of the crocodile, and pervades their haunts. ${ }^{35}$

Ophidia.-Dr. Gunther informs me that the males are always smaller than the fomales, and generally have longer and slenderer tails; but he knows of no other difference in external structure. In regard to colour, he can almost always distinguish the male from the female by his more strongly-pronounced tints; thus the black zigzag band on the back of the male English viper is nore distinctly detined than in the female. The differenco is much plainer in the rattle-snakes of $\mathrm{N}$. America, the male of which, as the keeper in the Zoological Gardens shewed me, can at once be distinguished from the female by having more lurid yellow about its whole body. In S. Africa the Eucephalus cupensis presents an analogous difference, for the fomalo "is "never so fully variegated with yellow on the sides as the "male." The male of the Indian Dipsas cynodon, on the other hand, is blackish-brown, with the belly partly black, whilst the female is reddish or yellowish-olive, with the belly either uniform yellowish or marbled with black. In the Trayops dispar of the same country, the male is bright green, and the

s1 Mr. C. J. Maynard, "The American Naturalist; Dec. 1869 , p. 5.55.

s2 See my "Journal of Researches during the Voyage of the "Beagle," 1845, p. 384.

s3 Dr. Günther, 'Repti!es of
British India,' 1864, p. 7.

st 'Travels through Carulian, \&c., 1791, p. 128.

ss Owen, 'Anatomy of Verte. 'Jrates,' vol. i. 1866, p. 615.

"Sir Andrew Smith, 'Zoolog. ol

§. Africa: Repilia,' 1849, pl. $\mathbf{~}$. 
female bronze-coloured. ${ }^{57}$ No doubt the colours of some snakes are protective, as shewn by the green tints of tree-snakes, and the various mottled shades of the species which live in sandy places; but it is doubtful whether the colours of many kinds, for instance of the common English snake and viper, serve to conceal them; and this is still more doubtful with the many foreign species which are coloured with extreme elegance. The colours of oertain species are very different in the adult and young states. ${ }^{58}$

During the breeding-season the anal scent-glands of snakes are in active function $;^{59}$ and so it is with the same glands in lizards, and as we have seen with the submaxillary glands of crocodiles. As the males of most animals search for the females, these odoriferous glands probably serve to excite or charm the ferrale, rather than to guide her to the spot where the male may be found. Male snakes, though appearing so sluggish, are amorous ; for many have been observed crowding round the same female, and even round her dead hody. They are not known to fight together from rivalry. Their intellectual powers are ligher than might have been anticipated. In the Zoological Gardens they soon learn not to strike at the iron bar with which their cages are cleaned; and Dr. Keen of Philadelphia informs me that some suakes which he kept, learned after four or five times to avoid a noose, with which they were at first easily caught. An excellent observor in Ceylon, Mr. E. Layard, saw ${ }^{60}$ a cobra thrust its head through a narrow hole and swallow a toad. "With this encumbrance he could not withdraw him"self; finding this, he reluctantly disgorged the precious mor" sel, which began to more off; this was too much for suake "philosophy to bear, and the toad was again seized, and again "was the snake, after violent efforts to escape, compelled to part "with its prey. This time, however, a lesson had been learnt, "and the toad was seized by one leg, withdrawn, and then "swallowed in triumph."

The keeper in the Zoological Gardens is positive that certain suakes, for instance Crotalus and Python, distinguish him from all other persons. Cobras kept together in the same cage apparently feel some attachment towards each other. ${ }^{61}$

s7 Dr. A. Guinther, 'Reptiles of British India,' Ray Soc. 1864, pp. $304,308$.

s8 Dr. Stoliczka, 'Journal of Aslatic Soc. o: Bengal,' vol. $\times x \times i x$. 1870, pp. 205, 211.

$$
\text { swen. "Aratoms of Verte- }
$$

brates,' rol. i. 1866, p. 615.

6o 'Rambles in Ceylon,' in 'Annals and Mag. of Nat. Hist.' 2nd serjes, vol. 1x. 1852, p. 38 s.

-1 Ir. Ginther, "Reptiles of British India, 1864, p 340 . 
It does not, however, follow because suakes have some reasoning power, strong jnscions and mutual affiction, that they hould likewise be endowed with sufticient taste to admire brilliant colours in their jartners, so as to lad to the alornment of the species through sexual selection. Nerertheless, it is difficult to account in any other nanner for the extreme beauty of certain species; for instance, of the cornl-snakes of S. Annerica, which are of a rich red with black and yellow transwerse bands. I well remember how much surprise I felt at the heauty of the first coral-snake which I saw cliding across a path in Brazil. suakes coloured in this peculiar manner, as Mr. Wallace states nn the autnority of I)r. Giinther ${ }^{62}$ are found nowhere else in the world except in S. America, and here no less thin fougenera occur. One of these, Flaps, is venomous; a secoud and widely-distinct genus is dolibtfully renomous, and the two nthers are quite harmless. The species belonging to these distinct genera iuhabit the same districts, and are so like each " "her, that no one "but a naturalist would distinguish the " harmless from the poisonous kinds." Hence, as Mr. Wallace believes, the innocuous kinds have probably acquired their colours as a protection, on the principle of imitation; for they rould naturally be thought dangerous by their enemies. The canse, horvever, of the hright colours of the renomous Elaps. remains to bo explained, and this may perhaps be sexual: selection.

Snakes produce other sounds besides hissing. The deadly Eithis curinutu has on its sides some oblique rows of scales of a peculiar structure with serrated edges; and when this snake is excited, these seales are rubbed against each other, which produces " a curious prolonged, almost hissing sound." ${ }^{3}$ With respect to the rattling of the rattle-snake, we have at last some definite information: for Profissor Aughey states, ${ }^{61}$ that on twc occasions, being hinself unseen, he watched from a little distance, a rattle-snake coiled up with head erect, which continued to rattle at short intervals for half an hour: and at last he saw another snake approach, and when they met they paired. Hence he is satisfied that one of the uses of the rattle is to bring the sexes together. Unfortunately he did not asccrtain whether it was the male or the female which remained stationary and called for the other. But it by no means follows from the above fact that the rattle may not be of use to these snakes in sther ways, as a warning to animals which would otherwise

68 ' Westminster Review,'July 1st, 1867, p. 32.

Wr. Anderson, 'Proc. Zoolog.
Soc.' 1871, p. 196.

of 'The American Naturalist, 1873, p. 85. 
attack them. Nor can I quite disbelieve the several accounts which have appearcd of their thus paralysing their prey with fear. Some other snakes also make a distinct noise by rapidly vibrating their tails against the surrounding stalks of plants ; and I have myself heard this in the case of a Trigonocephalus in S. America.

Lacertilia. - The males of some, probably of many kinds of lizards fight together from rivalry. Thus the arboreal Anotis cristatellus of S. America is extremely pugnacious: "During the "spring and early part of the summer, two adult males rarely " meet without a contest. On first seeing one another, they nod "their heads up and down three or four times, and at the same " time expanding the frill or pouch beneath the throat; their "eyes glisten with rage, and after waving their tails from " side to side for a few seconds, as if to gather energy, they dart "at each other furiously, rolling over and over, and holding "firmle with their teetl. The conflict generally ends in one of "tho combatants losing his tail, which is often devoured by the "victor." The male of this species is considerably larger than the female ${ }^{c^{5}}$ and this, as far as Dr. Günther has been able to ascertain, is tho general rule with lizards of all kinds. The males alone of the Cyrtoductylus rubidus of the Andaman Islands possesses pre-anal pores; and these pores judging from analogy probably serve to emit an odour. ${ }^{66}$

The rexes often differ greatly in various external characters. The male of the abore-mentioned Anolis is furnished with a crest which runs along the back and tail, and can be crected at pleasure; but of this crest the female does not exhibit a trace. In the Indian Cophotis ceylenica, the female has a dorsal crest, though much less developed than in the male; and so it is, as Dr. Gunther informs me, with the females of many Iguanas, Chameleons, and other iizards. In some species, horrever, the crest is equally developed in both sexos, as in the Iguana tuberculata. In the genus Sitana, the males alone are furnished with a large throat-pouch (fig. 33), which can be folded up like a fan, and is coloured blue, black, and red; but these splendid colours are exhibited only during the pairing-season. The female does not possess even a rudiment of this appendage. In the Anolis cristuteilus, according to Mr. Austen, the throat pouch, which is bright red marbled with yellow, is present in the female, though in a rudimental condition. Again, in certain other lizards, both sexes are equally well provided with throat pouches. Here we

${ }_{65} \mathrm{Mr}$. N. L. Austen kept these suimals alive for a considerable time; see 'Land and Water,' July 1867, p. 9.
-6 Stoliczka, 'Journal of Asiatic Soc. of Bengal,' vol, xxxir. 1870, p. 166. 
see with species belonging to the same group, as in so many previous cases, the same character either confined to the males, or more largely developed in them thin in the females, or again equally devoloped in both sexes. The little lizards of the genus Draco, which glide through the air on their ribsupported parachutes, and which in the beauty of their colours baffle description, are furnished with skinny appendages to the throat "like the wattles of gallinaceous birds." These become erected when the animal is excited. They occur in both sexes, but are best developed when the male arrives at maturity, at which age the middle appendage is

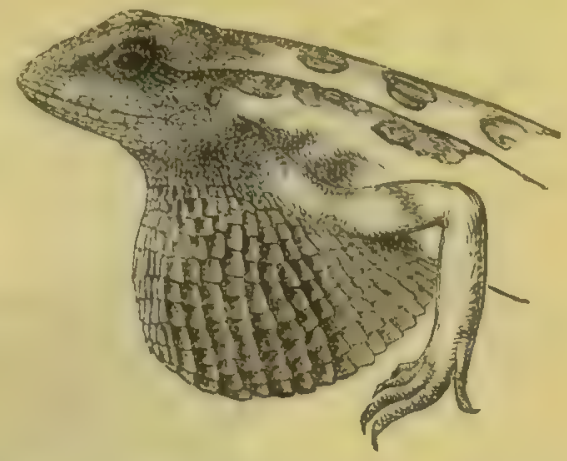

Fig. 33. Sitana minor. Male with the gular ponch expranded (from Cxünther's 'Reptiles of India').

sometimes twice as long as the head. Most of the species likewise have a low crest running along the neck; and this is much more dereloped in the full-grown males, than in the females or young males. ${ }^{67}$

A Chinese species is said to live in pairs during the spring; "and if "one is caught, the othcr falls from " the tree to the ground, and allows " itself to be captured with impu" nity,"-I presume from despair. ${ }^{88}$

'There are other and much more remarkable differences between the sexes of certain lizards. The male of Ceratophora aspera bears on the extremity of his snout an appendage half as long as the head. It is cylindrical, covered with scales, flexible, and apparently capable of erection: in the female it is quite rudimental. In a second species of the same genus a terminal scale

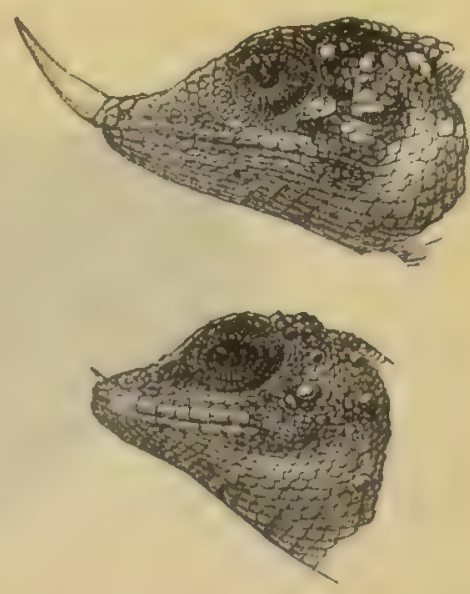

Fig. 34. Ceratophora Stoddartii Upper figure, male; lower figure, femille.

furms a minute horn on the summit of the flexible appendage;

67 All the foregoing statements and quotations, in regard to Cophotis, Sitana and Draco, as well as the following facts in regard to Ceratophorn and Chamaleon, are from Dr. Günther himself, or from his mag- nificent work ou the "Reptiles of British India,' Ray Soc. 1864, pp. $122,130,135$.

${ }_{68}^{8} \mathrm{Mr}$. Swirhoe, 'Proc. Zoolog. Soc.' 1870, p. 240. 
and in a third species (C. Stoddartii, fig. 34) the whole appendage is converted into a horn, which is usually of a white colour, but assumes a purplish tint when the animal is excited. In the adult male of this latter species the horn is half an inch in length, but it is of quite minute size in the female and in the young. These appendages, as Dr. Günther has remarked to me, may be compared with the combs of gallinaceous birds, and apparently serve as ornaments.
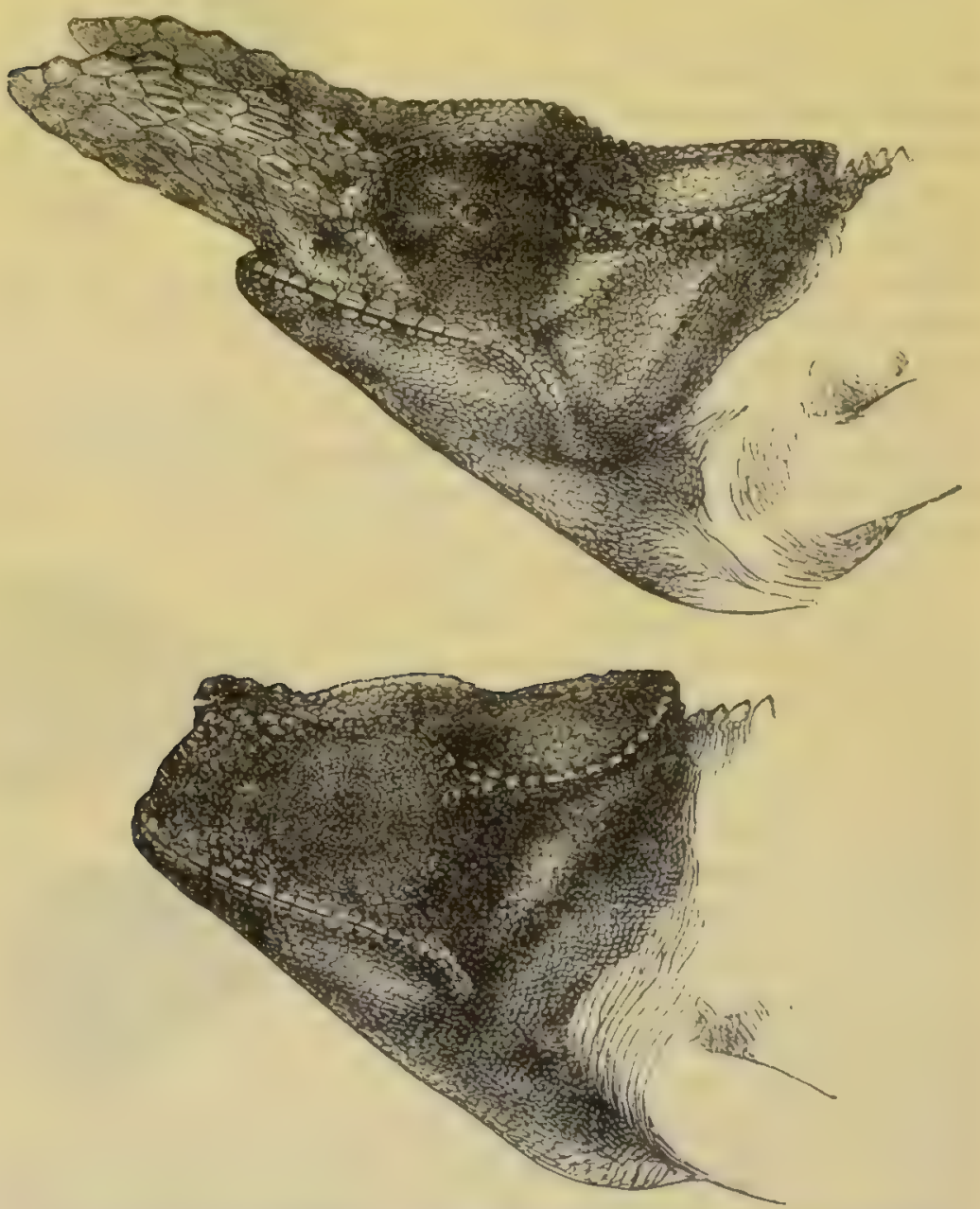

Fig. 35. Chamæicon bifurcus. Upper figure, male; lower figure, female.

In the genus Chamæleon we come to the acme of difference between the sexes. The upper part of the skull of the male C. bifurcus (fig. 35), an inhabitant of Madagascar, is produced into two great, solid, bony projections, covered with scales like the rest of the head; and of this wonderful modification of structure the female exhibits only a rudiment. $A$ gain, in 
Chamaleon Owenii (fig. 36), from the West Coast of Africa, the male bears on his snout and forehead three curious horus, of which the female has not a trace. These horns consist of an excrescence of bone covered with a smooth she:th, forming part of the general integuments of the body, so that they are identical in structure with those of a bull, goat, or other sheath-horned ruminant. Although the three horns differ so much in appearance from the two great prolongations of the skull in C. bifurcus, we can hardly doubt that they serve the same general purpose in the economy of these two ani-

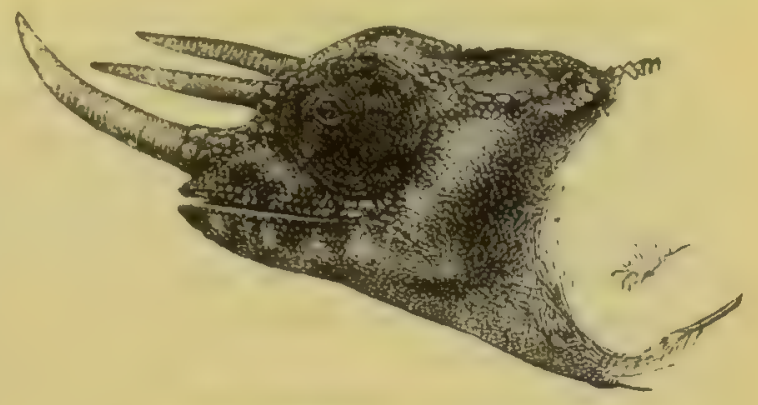
mals. The first con-

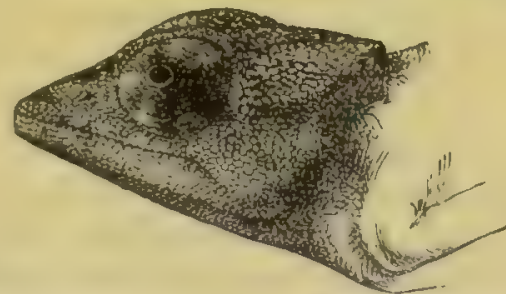

Fir 36. Chamseleon Owenii. Upper figure, male lower tigure, femule. jecture, which will occur to every one, is that they are uscd by the males for fighting together; and as these animals are very quarrelsome, ${ }^{69}$ this is probably a correct view. Mr. T. Wr. Wood also informs me that he once watched two individuals of r. pumilus, fighting violently on the branch of $\Omega$ tree; they flung their hearls about and tried to bite each other; they then restcd for a time, and afterwards continued their battle.

With many lizards, the sexes differ slightly in colour, the tints and stripes of the males being brighter and more distinctly defined, than in the females. This, for instance, is the case with the above Cophotis and with the Acunthoductylus capersis of S. Africa. In a Cordylus of the latter country, the male is either much redder or greener than the female. In the Indian Calutes nigrilebris there is a still greater difference; the lips also of the male are black, whilst those of the female are green. In our common little viviparous lizard (Zootocs vivipare) "the " under side of the hody and base of the tail in the male aro "bright orange, spotted with black; in the female these par's "are pale-greyish-green without spots." W0 We have seen that 69 Dr. Bucholz. 'Nonatsbericht ${ }^{70}$ Bell, 'History of British K. Preiss. Alado' Jan. 18i4, p. 78. Reptiles,' 2nd edit. 184y, p. 40. 
the males alone of Sitana possess a throat-pouch; and this is splendidly tinted with blue, black, and red. In the I'roctotretus tenuis of Chile the male alone is marked with spots of blue, Ereen, and coppery-red. if In many cases the males retain the same colours throughout the year, but in others they become much brighter during the breeding-season; I may gire as au additional instance the Calotes maria, which at this season has a bright red head, the rest of the body being green. ${ }^{72}$

Both sexes of many specics are beautifully coloured caact! alike; and there is no reason to suppose that such colours are protective. No doubt with the bright green kinds which live in the midst of vegetation, this colour serves to conceal them; and in N. Patagonia I saw a lizard (Proctotretus multimaculatus) which, when frightened, flattened its bods, closed its eyes, and then from its mottled tints was hardly distinguishable from the surromnding sand. But the bright colours with which so many lizards are ornamented, as well as their rarious curious appendages, were probably acquired by the males as an attraction, and then transmitted either to their male offspring alone, or to both sexes. Sexual selection, indeed, seems to have played almost as important a part with reptiles as with birds; and the less conspicuous colours of the females in comparison with the males cannot be accounted for, as Mr. Wallace believes to be the case with birds, by the greater exposure of the females to danger during incubation.

\section{CHAPTER XIII.}

\section{Secondary Sexual Characters of Birdo.}

Sexual differences-Law of battle - Special weapons-Vocal organsInstrumental music-Lore-antics and dances--Decorations, permanent and seasonal-Double and single annual moults-Display of ornaments by the males.

SECONDARY sexual characters are more diversified and conspicuous in birds, though not perhaps entailing more important changes of structure, than in any other class of animals. I shall, therefore, treat the subject at considerable length. Male birde sometimes, though rarely, possess special weapons for fighting

71 For Proctotretus see 'Zoology of the Voyage of the "Beagle:" Reptiles,' by Mr. Bell, p. 8. For the Lizards of S. Africa, see 'Zoology of S. Africa: Reptiles,' by Sir dodrew Smith, pl. 25 and 39. For the Indian Calotes, see 'Reptiles of British India,' by $\mathrm{D}_{1}$ Günther, $\mathrm{x}$. 143.

72 Giinther in 'Proc. : aolog. Soc." 1870 , p. 778, with a coloured figure. 
with each other. They charm the female by vocal or instrumental music of the most varied kinds. They are ornamented by all sorts of combs, wattles, protuberances, horns, air-distended sacks, top-knots, naked shafts, plumes and lengthened feathers gracefully springing from all parts of the body. The beak and naked skin about the head, and the feathers are often gorgeously coloured. The males sometimes pay their court by dancing, or by fantastic antics performed either on the ground or in the air. In one instance, at least, the male cmits a musky odour, which we may suppose serres to charm or excite the female; for that excellent observer, Mr. Ramsay, ${ }^{1}$ says of the Australian muskduck (Biziura lobata) that " the smell which the male emits " during the summer months is confined to that sex, and in "some individuals is retained throughout the year; I have "never, even in the brealing-season, shot a female which had "any smell of musk." So powerful is this odour during the pairing-season, that it can be detected long botore the bird can be seen." On the whole, birds appear to be the most æsthetic of all animals, excepting of course man, and they have nearly the samo taste for the beautiful as we have. This is shewn by our enjoyment of the singing of birds, and by our women, both civilised and savage, decking their heads with borrowed plumes, and using gems which are hardly more brilliantly coloured than the naked skin and wattles of certain birds. In man, however, when cultivated, the sense of beauty is manifestly a far more complex feeling, and is associated with various intellectual ideas.

Before treating of the sexual characters with which we are here more particularly concerned, I may just allude to certain differences between the sexes which apparently depend on differences in their habits of life; for such cases, though common in the lower, are rare in the higher classes. Two humming-birds belonging to the genus Eustephanus, which inhabit the island of Juan Fernandez, were long thought to be spccifically distinct, but are now known, as Mr. Gould informs me, to be the male and female of the same species, and they differ slightly in the form of the beak. In another genus of humming-birds (Grypus), the beak of the male is serrated along the margin and hooked at the extremity, thus differing muck from that of the female. In the Neomorpha of New Zealand, thero is, as we have seen, a still wider difference in the form of the beak in relation to the manner of feeding of the tiro sexes. Something of the same kind has been observed with the gold-

1 'Ibis,' vol. iii. (new series) 1867, p. 414.

2 Gould, 'Handbook to the Birds of Australia,' 1865, vol. ii. p. 883. 
finch (Carduelis elerims), for I am assured by Mr. J. Jenner Weir that the birdcatchers can distinguish the males by their slight? longer beaks. The flocks of males are often found feeding on the seeds of the teazle (Dipsacus), which they can reach with thoir elongated bcaks, whilst the females moro commonly feed on the seeds of the betony or Scrophularia. With a slight difference of this kind as a foundation, we can see how the beaks of the two sexes might be made to differ greatly through natural selection. In some of the above cases, however, it is possible that the bcaks of the males may have been first modified in rclation to their contests with other males; and that this afterwards led to slightly changed habits of life.

Law of Battle.-Almost all male birds are extremely pucmacious, using their beaks, wings, and legs for fighting together We see this every spring with our robins and sparrows. The smallest of all birds, namely the liumming-bird, is one of the most quarrelsome. Mr. Gosse ${ }^{3}$ describes a battle in which a pair seized hold of each other's beaks, and whirled round and round, till they almost fell to the ground; and $M$. Montes de Oca, in speaking of another genus of humming-bird, says that two males rarely meet without a fierce aërial encounter: when kept in cages "their fighting has mostly cnded in the splitting of "the tongue of owe of the two, which then surely dies from "locing unable to feed." "With Waders, the males of the common water-hen (Gallinula chloropus) "when pairing, fight " violently for the females: they stand nearly upright in the "water and strike with their feet." Two were seen to be thus engaged for half an hour, until one got hold of the head of the other, which would have been killed, had not the observer interfered; the female all the time looking on as a quiet spectator. ${ }^{5}$ Mr. Blyth informs mo that the males of an allied bird (frallicrex cristutus) are a third larger than the females, and are so pugnacious during the breeding-season, that they are kept by the natives of Eastern Bengal for the sake of fighting. Various other birds are kept in India for the same purpose, for instance, tho bulbuls (Pycumotus hamoritions) which "fight with great "spirit." 6

'The polygamons ruff (Machetes pugnax, fig. 37) is notorious for his extreme pugnacity; and in the sprins, the males, which are considerably larger than the females, congregate day after

' Quoted by Mr. Ciould, 'Introduction to the 'Trochilidæ,' 1861, p. 29.

4 Gould, ibid. p. 52.

W. Thompisue, "Nat. Hist. of
Ireland: Birds,' vol, ii. 1850, f. 327.

- Jerdon, 'Birds of Inaia,' $185{ }^{3}$, vol. ii. p. 96. 
day at a particular spot, where the females propose to lay their cgrss. The fowlers discover these spots by the turf being trampled somewhat bare. Here they fight rery mucì like gamecouks, seizing each other with their beaks and striking with their wings. The great ruff of feathers round the neck is then erected, and according to Col. Montagu "sweeps the ground as " a shield to defond the more tender parts;" and this is the only

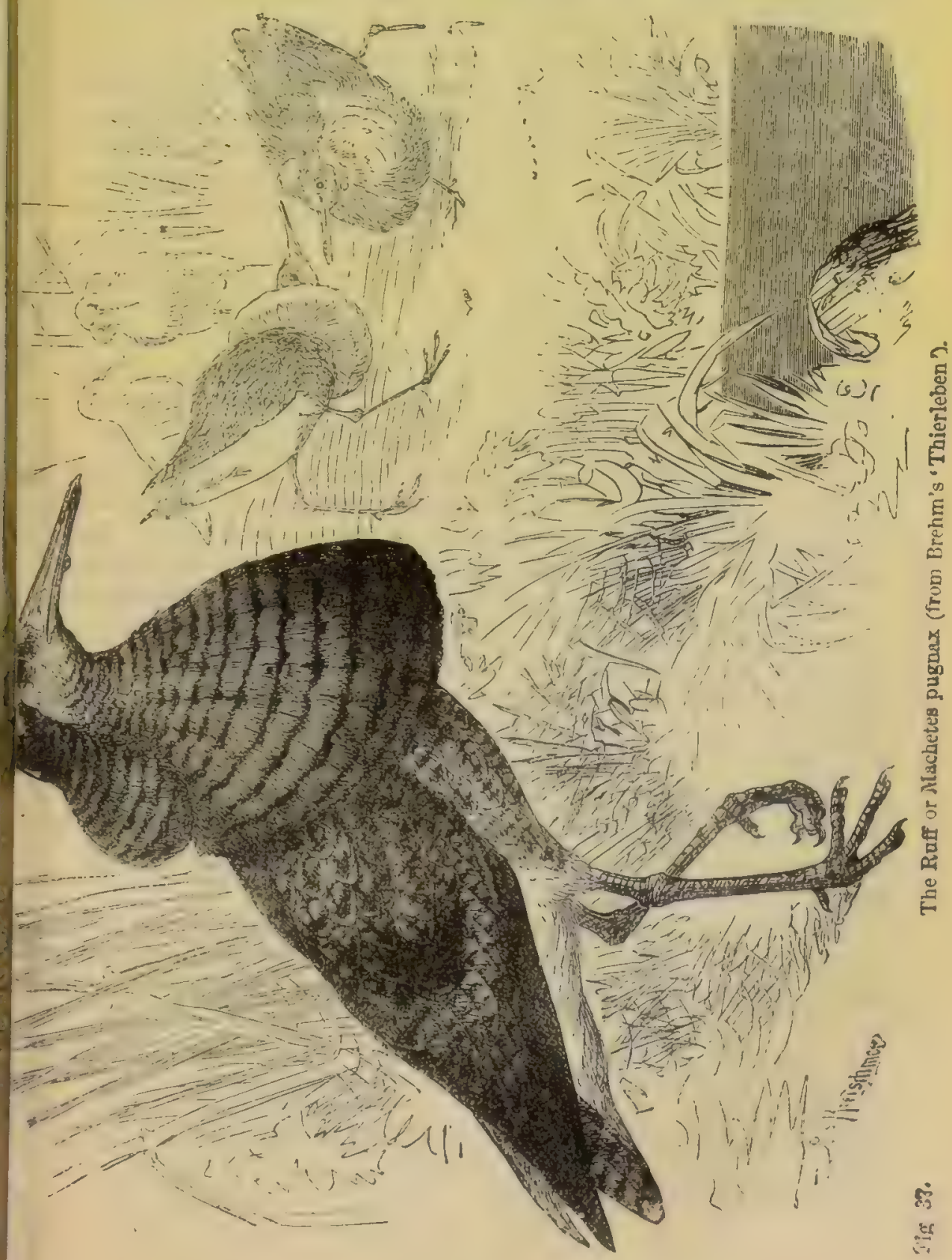


instance known to me in the case of birds, of any structure serving as a shicld. The ruff of feathers, however, from its varied and rich colours probably serves in chief part as an ornament. Like most pugnacious birds, they seem always ready to fight, and when closely confined often kill each other; but IIontagu observed that their pugnacity becomes greater during the spring, when the long feathers on their necks are fully dereloped; and at this period the least morement by any onc bird provokes a general battle. ${ }^{7}$ Of the pugnacity of web-footed birds, two instances will suffice: in Guiana "bloody fights occur "during the breeding-season between the males of the wild "musk-duck (Cairina moschatu); and where these fights have " occurred the river is covered for some distance with feathers." Birds which scem ill-adapted for fighting engage in fierce conflicts; thus the stronger males of the pelican drive arvay the weaker ones, snapping with their huge beaks and giving heavy blows with their wings. Male snipe fight together, "tugging " and pushing each other with their bills in the most curious " manner imaginable." Some few birds aro believed never to fight; this is the case, according to Audubon, with one of the woodpeckers of the United States (Picus auratus), although "the "hens are followed by even half a dozen of their gay suitors." "

The males of many birds are larger than the females, and this no doubt is the result of the advantage gained by the larger and stronger males over their rivals during many generations. The difference in size between the two sexes is carried to an extreme point in several Australian species; thus the male musk-duck (Biziura) and the male Cincloramphus cruratis (allied to our pipits) are by measurement actually twice as large as their respective females. ${ }^{10}$ With many other birds the females are larger than the males; and as formerly remarked, the explanation often given, namely, that the females have most of the work in feeding their young, will not suffice. In some few cases, as Twe shall hereafter see, the females apparently have acquired their greater size and strength for the sake of conquering other females and obtainiug possession of the males.

The males of many gallinaceous birds, especially of the polygamous kinds, are furnished with special weapons for fighting with their rivals, namely spurs, which can be used with fearful

' Margillirray, 'Hist. Brit. Birds,' vol. iv. 1852, pp. 177-181.

- Sir R. Schomburgk, in 'Journal of R. Geograph. Soc.' vol. xiii. 1843, p. 31.

\footnotetext{
'Oraithological Biography,' rol.
}

i. p. 191. For pelicans and snipes, see rol. iii. pp. 138, 477.

10 Gould, "Handbonk of Birds of Australia,' vol. i. p. 395 ; rol ii. p. 383 
effect. It has been recorded by a trustworthy writer ${ }^{11}$ that in Derbyshire a kite struck at a game-hen accompanied by her chickens, when the cock rushed to the rescue, and drove his spur right through the eye and skull of the aggressor. The spur was with difficulty drawn from the skull, and as the kite though dead retained his grasp, the two birds were firmly locked together; but the cock when disentangled was very little injured. The invincible courage of the game-cock is notorious: a gentleman who long ago witnessed the brutal scene, told me that a bird had both its legs broken by some accident in the cockpit, and the owner laid a wager that if the legs could be spliced so that the bird could stand upright, he would continue fighting. This was effectod on the spot, and the bird fought with undaunted courage until he received his deathstroke. In Ceylon a closely allied, wild species, the (iallus Stanlexi, is known to fight desperately "in defence of his "seraglio," so that one of the combatants is frequently found dead." An Indian partridge (Ortygornis gulcris), the male of which is furnished with strong and sharp spurs, is so quarrelsome, "that the scars of former fights disfigure the breast of "almcat every bird jou kill." ${ }^{3}$

The males of almost all gallinaceous birds, even those which are not furnished with spurs, engage during the breeding-season in fierce conflicts. The Capercailzie and Black-cock (Telraw urogallus and 7 '. tetrix), which are both polygamists, have regular appointed places, where during many weeks they congregate in aumbers to figit together and to display their charms before the females. Dr. WV. Kovalevsky informs me that in Russia he has sean the snow all bloody on the arenas where the capercailzie have fought; and the black-cocks "make the feathers fly in every "direction," when several "engage in a battle royal." The elder Brehm gives a curious account of the Balz, as the lovedances and love-songs of the Black-cock are called in Germany. The bird utters almost continuously the strangest noises: "he " holds his tail up and spreads it out like a fan, he lifts up his " head and neck with all the feathers erect, and stretches his "wings from the body. Then he takes $\&$ few jumps in different " directions, sometimes in a circle, and presses the under part of " his beak so hard against the ground that the chin feathers are "rubbed off. During these movements he beats his wings and "turns round and round. The more ardent he grows the moro " lively he becomes, until at last the bird appears like a frantic

$1 \mathrm{Mr}$. Hewitt in the 'Poultry

Bnol by Tegetmeier,' 1866, p. 137 .

- Lavard, 'Anials and Mig. of
Nat. Hist.' vol. xiv. 1854, p. 63.

13 Jerdon, 'Birds of India,' rol. iii. p. $5^{-4}$. 
"creature." At such times the black-cocks are so absorbed that they become almost blind and deaf, but less so than the caper(ailzie: hence bird after bird may he shot on the same spot, or even caught by the hand. After performing these antics tho males begin to fight: and the same black-cock, in order to prove his strength over sereral antagonists, will visit in the course of one moruing several Balz-places, which remain the same during successive years. ${ }^{1+}$

The peacock with his long train alppors more like a dandy than a warrior, but he sometimes engitges in fierce contests: the Rev. W. Darwin Fox informs me that at some little distance from Chester two peacocks became so excited whilst fighting, that they flew over the whole city, still engaged, until they alighted on the top of St. John's tower.

The spur, in those gallinaccous birds which are thus provided, is generally single; but Polyplectron (see fig. 51, p. 397) has two or more on each leg; and one of the Blood-pheasants (Ithaginis cruentus) has been seen with five spurs. The spurs are generally confined to the male, being represented hy mere knobs or rudiments in the female; but the fomales of the Java peacock (l'au'o muticus) and, as I am informed by Mr. Blyth, of the small firebacked pheasant (Enplocamus erythropthulmus) possess spurs. In Galloperdix it is usual for the males to have two spurs, and for the females to hare only one on each leg. ${ }^{15}$ Hence spurs may be considered as a masculine structure, which has been occasionally more or less transferred to the females. Like most other secondary sexual characters, the spurs are highly variable, both in number and derelopment, in the same species.

Various birds have spurs on their wings. But the Egyptian goose (Chenalopex crgyptiucus) has only "bare obtuse knobs," and these probably shew us the first steps by which true spurs have been developed in other species. In the spur-winged goose, Plectropterus gambensis, the males have much larger spurs thail the females; and they rise them, as I am informed by Mr. Bartlett, in fighting together, so that, in this case, the wing-spurs serve as sexual weapons; but according to Livingstone, they are chiefly used in the defence of the young. The Palameder (fig. 38) is armed with a pair of spurs on each wing; and these are such formidable weapons, that a single blow has been known to drive a dog howling awas. But it does not appear that the spurs in this case, or in that of some of the spur-winged rails,

14 Brehm, "Illust. Thierleben, 1867, B. iv. s. 351 . Sume of the faregoing statements are taken from L. Iloril, "The Gime Pinls of
Sweden,' \&c., 1867, p. 79.

16 Jerdon, 'Birds of India: on Ithaginis, vol. iii. p. 523; on Gallopwrlix, n. 541. 
racter. Thus in the znale of our common peewit (Vunellus cristatus) the tubercle on the shoulder of the wing becomes more prominent during the breeding-season, and the males fight together. In some species of Lobivanellus a similar tubercle becomes developed during the breeding-scason "into a short " horny spur." In the Australian I. lobatus both sexes have spurs, but these are much larger in the males than in the females. In an allied bird, the lloplopterus armatus, the spurs do not increase in size during the breeding-season; but these birds have been seen in Egypt to fight together, in the same manner as our peewits, by turning suddenly in the air and striking sideways at each other, sometimes with fatal results. Thus also they drive awray other enemies. ${ }^{17}$

The season of love is that of battle; but the males of some birds, as of the game-fowl and ruff, and even the young males of the wild turkey and grouse, ${ }^{18}$ are ready to fight whenever they meet. The presence of the female is the teterrimu belli causa. The Bengali baboos make the pretty little males of the amadavat (Estreldu amandava) fight together by placing three small cages in a row, with a female in the middle; after a little time the two males are turned loose, and immediately a desperate battle ensues. $^{19}$ When many males congregate at the same appointed spot and fight together, as in the case of grouse and various other birds, they are generally attended by the females, ${ }^{20}$ which afterwards pair with the victorious combatants. But in some cases the pairing precedcs insteard of succeeding the combat: thus according to Auclubon, ${ }^{21}$ several males of the Virginian goat-sucker (Caprimulyus virginumus) "court, in a highly entertaining " ranner the female, and no sooner has she made her choice, "than her approved gives chase to all intruders, and drives

medea, Brehm's 'Thierleben,' B. iv. s. 740. See also on this bird Azara, 'Voyages dans l'Amérique mérid.' tom. iv. 1809 , pp. 179, 253.

1: See, on our peewit, Mr. R. Carr in 'Land and Water,' Aug. 8th, $1868, p .46$. In regard to Lobivanellus, see Jerdon's 'Birds of India,' vol. iii. p. 647, and Gould's 'Handbook of Birds of Australia, vol. ii. p. 220. For the Holopterus, cee Mr. Allen in the 'Ibis,' vol. $\nabla$. 1863 , p. 156.

18 Audubon, 'Ornith. Biography, vol. ii. p. 492 ; rol. i. pp. 4-13.

19 Mr. Blyth, Land and Water, 1867, p. 212.
20 Richardson on Tetrao umbellus 'Fauna Bor. Amer.: Birds,' 1831, p. 343. L. Lloyd, 'Game Birds of Sweden?' 1867, pp. 22, 79, on the capercailzie and black-cock. Brehm, however, asserts ('Thierleben,' \&c., B. iv. 8. 352) thut in Germany the grey-hens do not generally attend the Balzen of the black-cocks, but this is an exception to the common rule; possibly the hens may lie hidden in the surrounding bushes, as is known to be the case with the grey-hens in Scandinavia, and with other species in N. America.

21 'Ornithological Biography, 
"them beyond his dominions." Generally the males try to drive away or kill their rivals before they pair. It cloes not, however, appear that the females invariably prefer the victorious males. I have indeed been assured by Dr. W. Kovalevsky that the temale capercailzie sometimes steals awar with a young malo who has not dared to enter the arena with the older cocks, in the same manner as occasionally happens with the does of the red-deer in Scotland. When two males contend in presonce of a single female, the victor, no doubt, commonly gains his desire; but some of these battles are caused by wandering males trying to distract the peace of an already mated pair.

Even with the most pugnacious species it is probable that the pairing does not depend exclusively on the mere strength and courage of the male; for such males are generally decorated with various ornaments, which often become more brilliant during the hreeding-season, and which are sedulously displayed before the temales. The males also endeavour to charm or excite their mates by love-notes, songs, and antics; and the courtship is, in many instances, a prolonged affair. Hence it is not probable that the females are indifferent to the charms of the opposite sex, or that they are invarially compelled to yield to the victorious males. It is more probable that the females are excited, either before or after the conflict, by certain males, and thus unconsciously prefer them. In the case of Tetrao umbellus, a good observer ${ }^{23}$ goes so far as to believe that the battles of the males "aro all a sham, performed to show themselves to the greatest. " advantage before the admiring females who assemlle around; for "I have never been able to find a maimed hero, and seldom more " than a broken feather." I shall have to recur to this subject but I may here add that with the Tetreo cupvilo of the Uniteo States, alout a score of males assemble at a particular spot, ano strutting about, make the whole air resound with thcir extra ordinary noises. At the first answer from a female the males begin to fight furiously, and the reaker give way; but then. according to Audubon, both the victors and vanquished search for the female, so that the females must either then exert a choice, or the battle must be renewed. So, again, with ono of the field-starlings of the United States (Sturnellu. ludoviciana) the males engage in fierce conflicts, "but at the sight of a female " they all fly after her, as if mad." ${ }^{24}$

22 Brenm, "Thierleben, \&ic., $\mathrm{B}$. iv. 1867, p. 990. Audubon, 'Ornith. Kiography, vol. ii. p. 492 . 23 'Land and Water', July 25th, 1868, p. 14.
24 Audubon's 'Ornitholog. B10graphy;' on Tetrao cupido, rol. ii, p. $49^{\circ}$ : on the Sturnus, vol. ii. P. 219. 
local and instrumental music. - With bilds tho voice serves to express various emotions, such as distress, fcar, anger, triumpl, o1 merc happiness. It is apparently sometimes used to excite terror, as in the case of the hissing noise made by some nestlingbirds. Auduhon ${ }^{25}$ relates that a night-heron (Avdew nycticorax, Limn.) which he lept tame, used to hide itself when a cat approached, and then "suddenly start up uttering one of the " most frightful cries, apparently enjoying the cat's alarm and "flight." The common domestic cock clucks to the hen, and the hen to her chickens, when a dainty morsel is found. 'T'he hen, when she has laid an egg, "repeats the same note very often, " and concludes with the sixth above, which she holds for a longer time;" 26 and thus she expresses her joy. Some social birds apparently call to each other for aid; and as they flit from tree to tree, the flock is kept together by chirp answering chirp. 1)uring the nocturnal migrations of geese and other water-fowl, sonorous clangs from the van may be heard in the darkness orerhead, answered by clangs in the rear. Certain cries serre as danger signals, which, as the sportsman lnnows to his cost, are understood by the same species and by others. The domestic cock crows, and the humming-bird chirps, in triumph over a defeated rival. The true song, however, of most biris and various strange cries are chiefly uttered during the breeding-season, and serve as a charm, or merely as a call-note, to the other sex.

Naturalists are much divider with respect to the object of the singing of birds. Fer more careful observers ever lired than Montagu, and he maintained that the "males of song-birds and " of many others do not in gencral search for the female, but, " on the contrary, their business in the spring is to perch on some "conspicuous spot, breathing out their full and amorous notes, "which, by instinct, the female knows, and repairs to the spot to "choose her mate." 27 Mr. Jeuner Weir informs me that this is certainly the case with tho uightingale. Bechstein, who rept lirds cluring his whole life, asserts, "that the female canary "always chooses the best singer, and that in a state of nature " tho female finch selects that male out of a h.undred whose? "notes please her most." 28 "'here can be no doubt that bircls closely attend to each other's song. Mr. Weir has told me of

23 'Ornithological Biograph.' vol. $\because$ p. 601 .

${ }_{26}$ The Hon. Daines Barrington, 'Philosoph. Transact.' 1773, p. 252. 27 'Ornithological Dictionary,' 1833, p. 475 .

28 -Natureschichte der Stuben- vögel,' 1840 , s. 4. Mr. Harrison Weir likewise writes to me:- " I

"am informed that the best siagiug "males generally get a mate first, "when they are bred in the sinws "room." 
the case of a bullfinch which had been taught to pipe a Gcrman waltz, and who was so good a performer that he cost ter: guineas; when this bird was first introduced into a room where other birds were kept and he began to sing, all the others, consisting of about twenty linnets and canaries, ranged themselves on the nearest side of their cages, and listened with the greatest interest to the new performer. Many naturalists believe that the singing of birds is almost exclusively "the effect of rivalry " and emulation," and not for the sake of charming their mates. This was the opinion of Daines Barrington and White of Selborne, who both especially attended to this subject. ${ }^{29}$ Barrington, however, admits that "superiority in song gives to "birds an amazing ascendancy over others, as is well known to "bird-catchers."

It is certain that there is an intense degree of rivalry between the males in their singing. Bird-fanciers match their birds to see which will sing longest; and I was told by Mr. Yarrell that a first-rate bird will sometimes sing till he drops down almost dead, or according to Bechstein, ${ }^{30}$ quite dead from rupturing a vessel in the lungs. Whatever the cause may be, male birds, as I hear from Mr. Weir, often die suddenly during the season of soug. That the habit of singing is sometimes quite independent of love is clear, for a sterile, hybrid canary-bird has been described ${ }^{31}$ as singing whilst viewing itself in a mirror, and then dashing at its own image; it likewise attacked with fury a female canary, when put into the same cage. The jealousy excited by the act of singing is constantly taken advantage of by bird-catchers; a male, in good song, is hidden and protected, whilst a stuffed bird, surrounded by limed twigs, is exposed to view. In this manner, as Mr. Weir informs $m \theta$, a man has in the course of a single day caught fifty, and in one instance seventy, male chaffinches. The power and inclination to sing differ so greatly with birds that although the price of an ordinary malo chaffinch is only sixpence, Mr. Weir saw one bird for which the bird-catcher asked three pounds; the test of a really good singer being that it will continue to sing whilst the cage is swung round the owner's head.

That male birds should sing from emulation as well as for charming the female, is not at all incompatible; and it might Lare been expected that these two habits would have concurred, like those of display and pugnacity. Some authors, however,

28 'Philosophical Transactions,' 1773, p. 263. White's 'Natural History of Selborne,' 1825, vol. i. p. 2 in. so 'Naturgesch, der Stubenvögel,' 1840, s. 252.

31 M1. Bold, 'Zoologist,' 1843-44, p. 659. 
argue that the song of the male cannot serve to charm the female, because the females of some few species, such as of the canary, robin, lark, and bullinch, especially when in a state of widowhood, as Bechstein remarks, pour forth fairly melodious strains. In some of these cases the habit of singing may be in part attributed to the females having been highly fed and confined, ${ }^{39}$ for this disturbs all the usual functions connected with the reproduction of the species. Many instances have already been given of the partial transference of secondary masculine characters to the female, so that it is not at all surprising that the females of some species should possess the power of song. It has also been argued, that the song of the male cannot serve as a charm, because the males of certain species, for instance of the robin, sing during the autumn..$^{33}$ But nothing is more common than for animals to take pleasure in practising whatever instinct they follow at other times for some real good. How often do we see birds which fly easily, gliding and sailing through the air obviously for pleasure? The cat plays with the captured mouse, and the cormorant with the captured fish. The weaver-bird (Ploceus), when confined in a cage, amuses itself by neatly weaving blades of grass between the wires of its cage. Birds which habitually fight during the breeding-season are gencrally ready to fight at all times; and the males of the capercailzie sometimes hold their Balzen or leks at the usual place of assemblage during tbe autumn. ${ }^{34}$ Hence it is not at all surprising that male birds should continue singing for their own amusement after the season for courtship is over.

As shewn in a previous chapter, singing is to a certain extent an art, and is much improved by practice. Birds can be taught various tunes, and even the unmelodious sparrow has learnt to sing like a linnet. They acquire the song of their foster parents, ${ }^{35}$ and sometimes that of their nelghbours. ${ }^{36}$. All the common songsters belong to the Order of Insessores, and their vocal organs are much more complex than those of most other birds; yet it is a singular fact that some of the Insessores, such as ravens, crots, and magpies, possess the proper apparatus, ${ }^{37}$

32 D. Barrington, 'Phil. Transact.' 1773 , p. 262. Bechsruin, 'Stubenrögel,' 1840, s. 4.

83 This is likewise the case with tise water-ouzel, see Mr. Hepburn in the 'Zoologist,' 1845-1846, p. 1068.

34 I. Lloyd, "Game Birds of Sweden,' 1867, p. 25.

s Barrington, ibid. p. 264.
Bechstein, ibid, 8. 5.

86 Dureau de la Malle gives a curious instance ('Annales des Sc. Nat,' 3rd series, Zoolog. tom. x. p. 118) of some wild blackbirds in his garden in Paris, which naturally learnt a republican air from a caged bird.

37 Bishop, in 'Todd's Cyclop. of Anat. and Phys.' vol. iv. p. 1496 
though they never sing, and do not naturally modulate thoir voices to any great extent. IIunter asserts ${ }^{98}$ that with the truo songsters the muscles of the larynx are stronger in the males than in the females; but with this slight exception there is no difference in the vocal organs of the two sexes, although the males of most species sing so much better and more continuously than the females.

It is remarkable that only small birds properly sing. The Australian genus Menura, however, must be excepted; for the Menura Albcrti, which is about the size of a half-grown turkey, not only mocks other birds, but "its own whistle is exceedingly " beautiful and varied." The males congregate and form "corrolorying places," where they sing, raising and spreading their tails like peacocks, and droopiug their wings. ${ }^{39}$ It is also remarka hle that birds which sing well are rarely decorated with brilliant colours or other ormaments. Of our British birds, excepting the bullfinch and goldfinch, the best songsters are plain-coloured. 'The kingfisher, bee-eater, roller, hoopoe, woodpeckers, \&c., utter harsh cries; and the brilliant birds of the tropies are hardly ever songsters. ${ }^{40}$ Hence bright colours and the power of song seem to replace each other. We can perceive that if the plumage did not vary in brightness, or if bright colours were dangerous to the species, other means would be exployed to charm the females; and melody of voice offers one such means.

In some birds the vocal organs differ greatly in the two sexes. In the Tetrco cupido (fig. 39) the male has two bare, orangecoloured sacks, one on each side of the neck; and these are largely inflated when the male, during the breeding-season, makes his curious hollow sound, audible at a great distance. Audubon proved that the sound was intimately connected with this apparatus (which reminds us of the air-sacks on each side ot the mouth of certain male frogs), for he found that the sound was much diminished when one of the sacks of a tame bird was pricked, and when both were pricked it was altogether stopped. The female has " a somewhat similar, though smaller naked space " of skin on the neck; but this is not capable of inflation." 41 Tho

38 As stated by Barrington in Philosoph. Trausact.' 1773, p. 262.

${ }^{39}$ Gould, "Handbook to the Birds of Australia,' vol. i. 1865, pp. 308310. See also Mr. T. W. Wood in the 'Student,' April 1870, p. 125.

to See remarks to this effect in Gould's 'Introduction to the Trochilidx,' 1861, p. 22.

1 'TLe Sportsman and Naturalist in Canada,' by Major W. Ross King, 1866, pp. 144-146. Mr. T. W. Wood gives in the 'Student' (April, 1870, p. 116) an excelleot account of the attitude and habits of this bird during its courtship. He states that the ear-tufts or neckplumes are erected, so that they meet over the crown of the head See his drawing, fig. 39. 
male of another kind of grouse (Tetrao urophasianus), whilst courting the female, has his "bare yellow osophagus inflated to "a prodigious size, fully half as large as the body;" and he then uttcr's various grating, deep, hollow tones. With his neck-

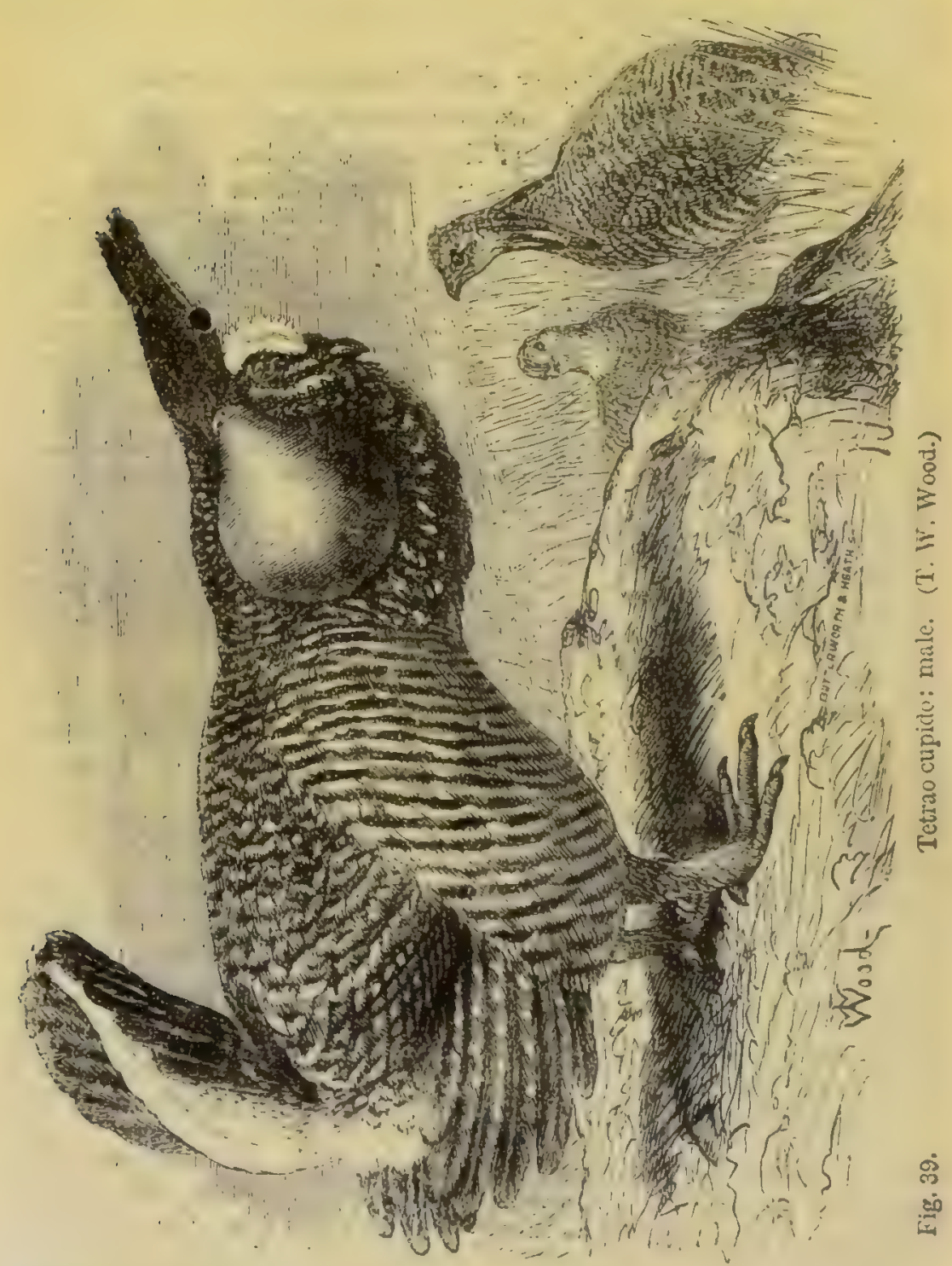

feathers erect, his wings lowered, and buzzing on the gound, and his long pointed tail spread out like a fan, he displays a variety of grotesque attitudes. The oesophagus of the fomale is not in any way remarkable:?

42 Richardson, 'Fauna Bor. American: Birds,' 1831, p. 359. Audubor bid. vol. ip. p. 507 . 
Chap. XUI.

It seems now well made out that the great throat pouch of the European male bustard (otis turlu), and of at least four other species, does not, as was formerly supposed, serve to lold water, but is connected with the utterance during the brecling-

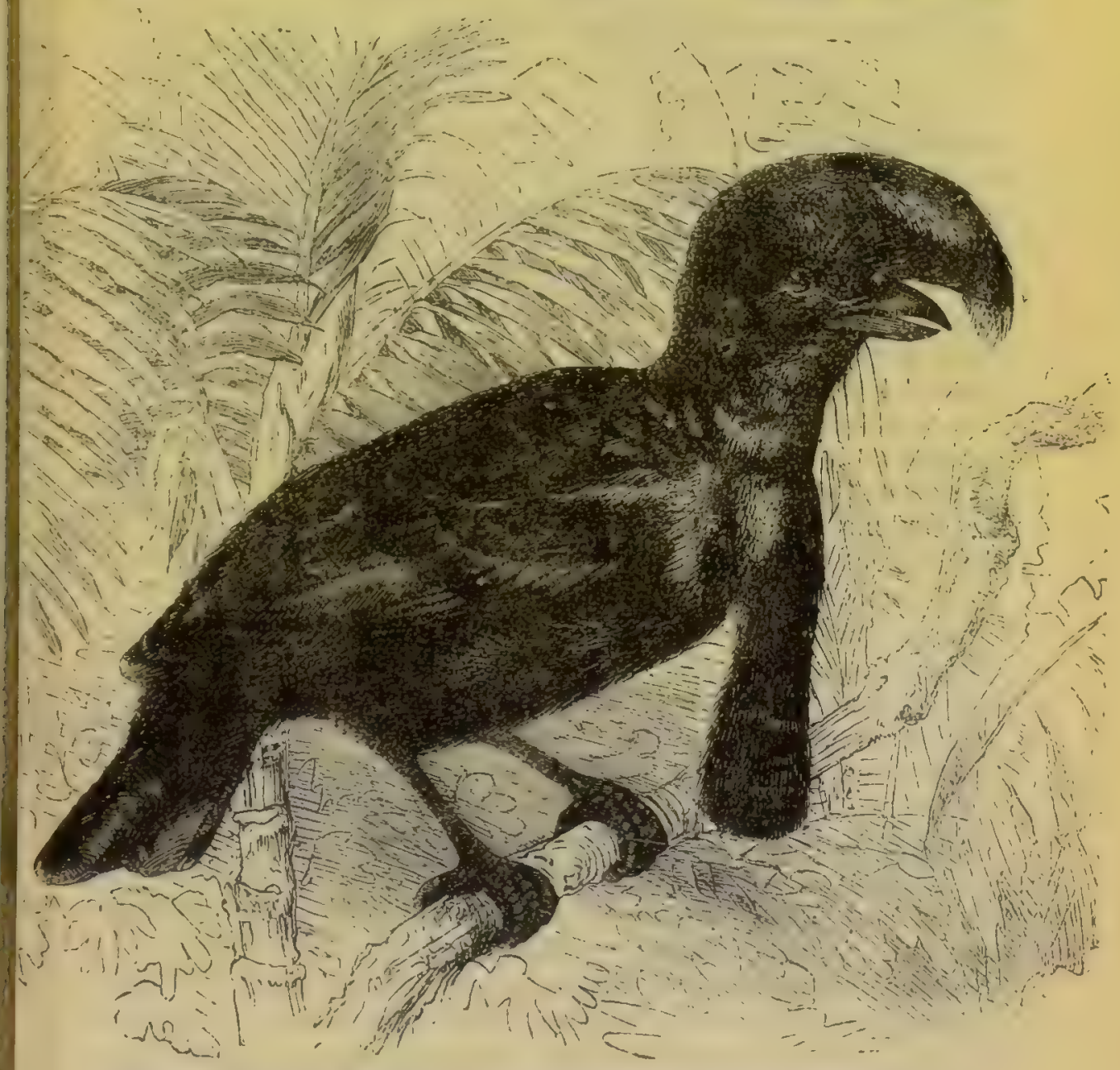

tig. 10. The Umbrelia-bird or Cephal(pecrus cmatus male from Brehm).

season of a peculiar sound resembling "oak." $\$ 3$ A crow-like bird inhabiting South America (C'ephulopterus ornatus, fig. 40) is called the umbrella-bird, from its immense top knot, formed of

is The following papers have been lately written on this subject: l'rof. A. Newton, in the 'Ibis,' 1862, p. 107, Dr. Cullen, ibrd. 1865, p. 145; Mr Flower, in 'Proc. Zool. Soc.' $1865, p .747$; and Dr Murie. 4ii 'Proc. 'Wol. Soc. 1868 ") 471
In this latter paper an excellenc figure is given of the male Austram lian Bustard in full display with the sack distended. It is a singular fact that the sack is not developed in nll the males of the same species. 
bare white quills surmounted by dark-blue plumes, which it can elevate into a great dome no less than five inches in diameter, covering the whole head. This bird has on its neck a long, thin, cylindrical fleshy appendage, which is thickly clothed with scalc:like blue feathers. It probably serves in part as an ornament, but likewise as a resounding apparatus; for Mr. Bates found that it is connected "with an unusual development of the "trachea and vocal organs." It is dilated when the bird utters its singularly deep, loud and long sustained fluty note. The headcrest and neck-appendage are rudimentary in the female.44

The vocal organs of various web-footed and wading birds are extraordinarily complex, and differ to a certain extent in the two sexes. In some cases the trachea is convoluted, like a French horn, and is deeply embedded in the sternum. In the wild swan (Cygnusferus) it is more deeply embedded in the adult male, than in the adult female or young male. In the male Merganser the enlarged portion of the trachea is furnished with an additional pair of muscles. ${ }^{45}$ In one of the ducks, however, namely Anas punctata, the bony enlargement is only a little more developed in the male than in the female. ${ }^{46}$ But the meaning of these differences in the trachea of the two sexes of the Anatidre is not understood; for the male is not always the more vociferous; thus with the common duck, the male hisses, whilst the female utters a loud quack. ${ }^{47}$ In both sexes of one of the cranes (Grus virgo) the trachea penetrates the sternum, but presents " certain "sexual modifications." In the male of the black stork there is also a well-marked sexual difference in the length and curvature of the bronchi. ${ }^{18}$ Highly important structures have, therefore, in these cases been modified according to sex.

It is often difficult to conjecture whether the many strango cries and notes uttered by male birds during the breedingseason, serve as a charm or merely as a call to the femalo. The soft cooing of the turtle-dove and of many pigeons, it may be presumed, pleases the female. When the female of the wild

4 Bates, "The Naturalist on the Amazons,' 1863, vol. ii. p. 284 ; Wallace, in 'Proc. Zool. Soc.' 1850 , .. 206. A new species, with a still larger neck-appendage (C. penduliger), has lately been discovered, see 'Ibis,' vol. i. p. 457.

45 Bishop, in Todd's 'Cyclop. of Lat. and Phys.' vol. iv. p. 1499.

4 Prof. liewton, 'Proc. Zoriog. Soc.' 1871 , p. 651 .

17 The spoonbill (Platalea) has its trachea convoluted into a figure

of eight, and yet this bird (Jerdon, 'Birds of India,' vol. iii. p. :63) is mute; but $\mathrm{Mr}$. Blyth informs rue that the convolutions are not constantly presecit, so that perhaps they ale now teuding towards abortion.

48 'Elements of Comp. Anat.' by R. Wagner, Eng. translat. 1845, p. 111. With respect to the swan, as given above, Yarrell's 'Hist. of British Birds,' 2nd edit. ¿845, vus. iii. p. 193. 
turkey utters her call in the morning, the male answers by a note which differs from the gobbling noise made, when with erected feathers, rustling wings and distended wattles, he puffs and struts before her.99 The spel of the black-cock certainly serves as a call to the female, for it has been known to bring four or five females from a distance to a male under confinement; but as the black-cock continues his spel for hours during successive days, and in the case of the capercailzie "with an agony of "passion," we are led to suppose that the females which are present are thus charmed. ${ }^{60}$ The voice of the common rook is known to alter during the breeding-season, and is therefore in some way sexual..1 But what shall we say about the harsh screams of, for instance, some kinds of macaws; have these birds as bad taste for musical sounds as they apparently have for colour, judging by the inharmonious contrast of their bright yellow and blue plumage? It is indeed possible that without any advantage being thus gained, the loud roices of many male birds may be the result of the inherited effects of the continued use of their rocal organs, when excited by the strong passions of love, jealousy and rage; but to this point we shall recur when we treat of quadrupeds.

We have as yet spoken only of the roice, but the males of various birds practise, during their courtship, what may be called instrumental music. Peacocks and Birds of Paradise rattle their quills together. Turkey-cocks scrape their wings against the ground, and some kinds of grouse thus produce a buzzing sound. Another North American grouse, the Tetrao umbellus, when with his tail erect, his ruffs displayed, "he shows off his finery to the "females, who lie hid in the neighbourhood," drums by rapidly striking his wings together above his back, according to Mr. R. Haymond, and not, as Audubon thought, by striking them against his sides. The sound thus produced is compared by some to distant thunder, and by others to the quick roll of a drum. The female never drums, "but flies directly to the place "where the male is thus engaged." The male of the Kalijpheasant, in the Himalayas, "often makes a singular drumming " noise with his wings, not unlike the sound produced by shaking " a stiff piece of cloth." On the west corst of Africa the little black-weavers (Ploceus?) congregate in a small party on the bushes round a small open space, and sing and glido through

19 C. L. Bonaparte, quoted in the 'Natulalist Library: 'Birds,' vol. ถir. p. 126.

so L. Lloyd, "The Game Birds of
Sweden,' \&c., 1867, pp. 22, 81.

31 Jenner, 'Philosoph. Tracsections,' 1824, p. 20. 
the air with quivering wings, "which make a rapid whirring "sound like a child's rattle." One bird after another thus performs for hours together, but only during the courting-season. At this season and at no other time, the males of certain night-jars (Caprimulgus) make a strange booming noise with their wings. 'The various species of wood-peckers strike a sonorous brauch with their beaks, with so rapid a vibratory morement that "the head "appears to be in two places at once." The sound thus proruced is audible at a considerable distance, but cannot he described; and I feel sure that its source would never be conjectured by any one hearing it for the first time. As this jarring sound is made chiefly during the breeding-season, it has been considered as a love-song; but it is perhaps more strictly a love-call. The female, when driven from her nest, has been observed thus to call her mate, who answered in the same manner and soon appeared. Lastly, the male Hoopoe (Upupcs epops) combines vocal and instrumental music; for during the breeding-season this bird, as Mr. Swinhoe observed, first diaws in air, and then taps the end of its beak perpendicular'y down against a stone or the trunk of a tree, "when the breatin being "forced down the tubular bill produces the correct sound." If the beak is not thus struck against some olject, the sound is quite different. Air is at the same time stwallowed, and the cesophagus thus becomes much swollen; and this probably acts as a resonator, not only with the hoopoe, but with pigeons and other birds. ${ }^{52}$

In the foregoing cases sounds are made by the aid of structures already present and otherwise necessary; but in the fcllowing cases certain feathers have been specially modified for the express purpose of producing sounds. The drumming, bleating, neighing, or thundering noise (as expressed by different observers) made by the common snipe (Scolopax gullinago) must have surprised every one who has ever heard it. This bird, during the pairing-season, flies to "pernaps a thousand feet in height," and

82 For the foregoing facts see, on Birds of Paradise, Brehm, -Thierleben,' Band iii. s. 325 . On ('Trouse, Richardson, 'Fauna Bor. Americ.: Birds,' pp. 343 and 359; Major W. Ross King, "The Sportsman in Canada,' 1866, p. $156 ; \mathrm{Mr}$. liaymond, in Prof. Cox's 'Geol. survey of Indiana, p. 227; Auduhon, "American Ornitholog. Bio"raph.' vol. i. p. 216. Ou the hallij-pheasant, Jerdon, 'Birds of India," vol. iti. p. 533. On the
Weavers, 'Livingstone's Expedition to the 'Zambesi,' 1865 , p. 425 . On Woodpeckers, Macgillivray, 'Hist. of British Birds,' vol. iii. 1840, pp. $84,88,89$, and 95 . On the Hoopoe, Mr. Swinhoe, in 'Proc. Zoolog. Soc.' June 23, 1863 and 1871, p. 348 On the Night-jar, Audubon, ibid. vol. ii. p. 255, and 'American Naturalist,' 1873 , p. 672 . 'The English Night-jar likewise makes in the spring a curious noise duriag it rapid fight. 
after zig-zagging about for a time descends to the earth in a curved line, with outspread tail and quivering pinions, and surprising velocity. The sound is emitted only during this rapid descent. No one was able to explain the cause, until II. Meves observed that on cach sicle of the tail the outer feathers are peculiarly formed (fig. I1), hasing a stift sabre-shaped shaft

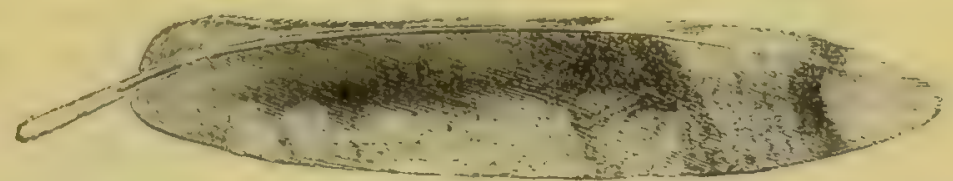

Fig. 41. Outer tail-feuther of Scoinnax gallinago (frum 'Proc. Zool. Soc.' 1858).

with the oblique harks of unusual length, the outer webs boing strongly bound together. He found that by blowing on these feathers, or by fastening them to a long thin stick and waving them rapidly through the air, he conld reproduce the drumming noise made by the living bird. Both sexes are furnished with these feathers, but they are senerally !arger in the male than in the female, and emit a deeper note. In some species, as in S. fiencida (fig. 42), four feathers, and in $S$. javensis (fig. 43), no less than eight on each side of the tail are greatly modified. Different tones are emitted by the feathers of the different species

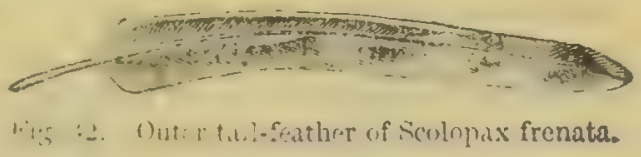

when waved through the air: ant the Scolonax Witsonii of the United States makes a switching noise whilst descending rapidly to the earth. ${ }^{53}$

In the male of the Chamcepetes unicolor (a large gallinaccous. bird of Anerica) the first primary wing-feather is arehed towards the tip and is much more attenrated than in the female. In an allied hird, the Penelope nigra, Mr. Salvin observed a male, which, whilst it flew downwards "with ontstretched wings, gave forth "a kind of crashing rushing noise," like the falling of a trec."

53 See M. Meves' interesting paper in 'Proc. Zool. Soc.' 1858, p. 199. For the habits of the snipe, Macgillivray, 'Hist. British Birds,' vol. iv. p. 371. For the American snipe, Capt. Blakiston, 'Jbis,' vol. v. $133^{\circ} 3$, p. 131. st Mr. Salvin, in 'Proc. Zool. Soc.' 1867, p. 160 . I am much indebted to this distinguished ornithologist for sketches of the feathers of the Chamxpetes, and for other infurmatinn. 
The male alone of one of the Indian bustards (Sypheotiaes curitus) has its primary wing-feathers greatly acuminated; and the male of an a!lied species is known to make a humming noise whilst courting the female. ${ }^{55}$ In a widely different group of birds,
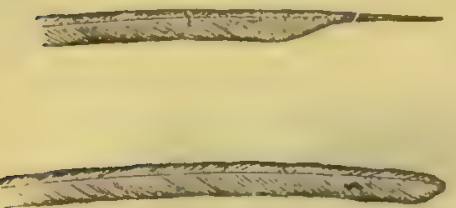

Fig. 44. Primary ning-feather of a Humming-bird, the selasphorus platycercus (from a sketch by Mr. Nalvin). Upper figure, that of male; lower figure corresponding featber of female. namely Humming-birds, the males alone of certain kinds have either the shafts of their primary wingfeathers broadly dilated, or the webs abruptly excised towards the extremity. The male, for instance, of Selasphorus platycercus, when adult, has the first primary wing-feather (fig. 44), thus excised. Whilst flying from flower to flower he makes "a shrill, almost whist-

ling noise;" 56 but it did not appear to Mr. Salvin that the noise was intentionally made.

Lastly, in several species of a sub-genus of Pipra or Manakin, the males, as described by Mr. Sclater, have their secondary wingfeathers modified in a still more remarkable manner. In the brilliantly-coloured $P$. deliciosa the first three secondaries are thick-stemmed and curved towards the body; in the fourth and fifth (fig. $45, a$ ) the change is greater; and in the sixth and seventh $(b, c)$ the shaft " is thickened to an extraordinary degree, "forming a solid horny lump." The barbs a's a are greatly changed in shape, in comparison with the corresponding feathers $(d, e, f)$ in the female. Even the bones of the wing, which support these singular feathers in the male, are said by Mr. Fraser to be much thickened. These little birds make an extraordinary noise, the first "sharp note being not unlike the " crack of a whip." 57

The diversity of the sounds, both vocal and instrumental, made by the males of many birds during the breeding-season, and the diversity of the means for producing such sounds, are highly remarkable. We thus gain a high idea of their importance for sexual purposes, and are reminded of the conclusion arrived at as to insects. It is not difficult to imagine the steps by which the notes of a bird, primarily used as a mere call or for some other purpose, might have been improved

35 Jerdon, 'Birds of India,' vol. iii. pp. 618, 621 .

56 Gould, "Introduction to the Trochilidæ,' 1861, p. 49. Salvin, 'Proc. Zoolog. Soc.' 1867, p. 160.
57 Sclater, in 'Proc. Zool. Soc.' 1860 , p. 90, and in 'Ibis,' vol. iv. 1862 , p. 175. Also Salvin, in 'Ibis,' 1860, p. 37. 
into a melodious love song. In the case of the modified feathers, by which the drumming, whistling, or roaring noises are produced, we know that some birds during their courtship flutter, shake, or rattle their unmodified feathers together; and
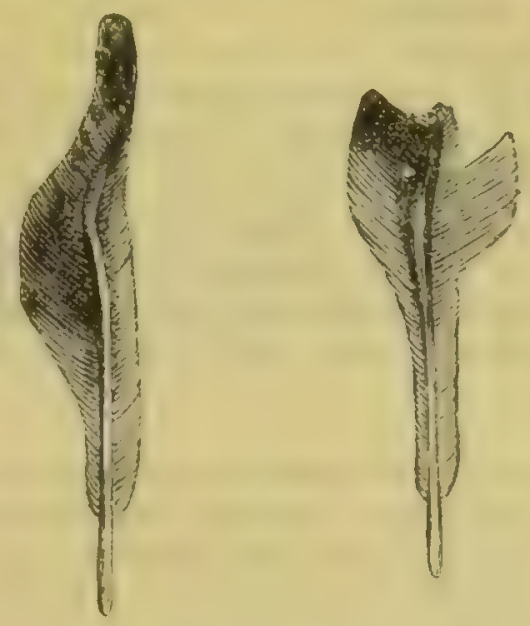

1

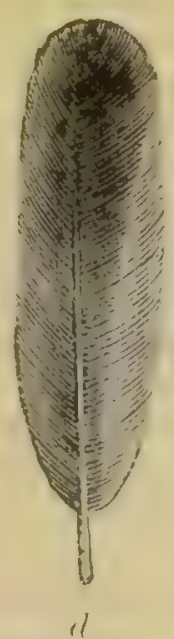

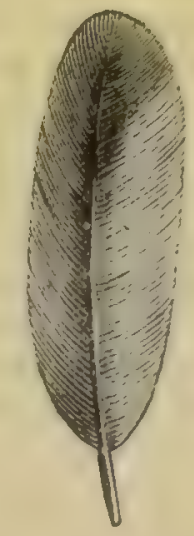

$\circ$

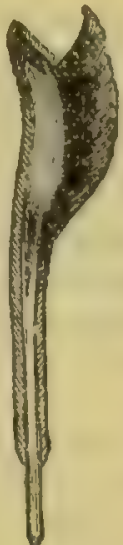

$e^{\circ}$

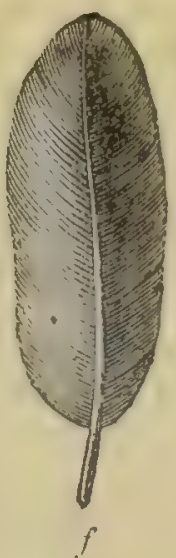

Fig. 45. Secondary wing-f eathers of Pipra deliciosa (from Mr. Sclater, in 'Proc. Znol. Soc.' 1860). 'The three upper fiathers, $a, b, c$, from the male; the three lower corresponding feathers, $\alpha, e, f$, from the female.

$a$ and $d$, fifth gecondary wing-feather of male and female, upper surface.

$b$ and $e$, sixth secondary, upper surface, $c$ and $f$, seventh secondary, lower surface.

if the females were led to select the best performers, the males which possessed the strongest or thickest, or most attenuated feathers, situated on any part of the body, would be tho most successful; and thus by slow degrees the feathers might be modified to almost any extent. The females, of course, would not notice each slight successive alteration in shape, but only 
. he sounds thus producel. It is a curious fact that in the same lass of animals, sounds so different as the drumming of tho "nipe's tail, the tapping of the woodpecker's beak, the harsh trumpet-like cry of certain water-fowl, the cooing of the turtlelove, and the song of the nightingale, should all be pleasing te the females of the several species. But we must not judge of the tastes of distinct species by a uniform standard; nor must we , udge by the standard of man's taste. Even with man, we should remember what discordant noises, the beating of tomtoms and the shrill notes of reeds, please the ears of savages. Sir S. Baker remarks, 58 that " as the stomach of the Arab prefers "the raw maat and recking liver taken lot from the animal, so "does his car prefer his equally coarse and discordant music to "all other."

Love-Antics and Inuces.-The curious lore gestures of somo birds have already been incidentally noticed; so that little need here be added. In Northern America, large numbers of a grouse, the T'truo plusicuellus, meet erery morning during the breedingseason on a selected level spot, and here they run round and round in a circle of about fiftecn or trenty feet in dianeter, $\mathrm{sc}$, that the ground is worn quite bare, Jike a fairy-ring. In thesc Partridge-dances, as they are called by the hunters, the birds assume the strangest attitudes, and run round, some to the left and some to the right. Audubon describes the males of a heron (Arrlec herodicas) as walking about on their long legs with great dignity before the females, bidding defiance to their rivals. With one of the disgusting carrion-vultures ('uthurtes jotu) the same maturalist states that "the gesticulations and parale of the "males at the berrinning of the love-season are extremuly "ludicrons." Certain birds perform their lore antics on the wing, as we have secn with the black African weaver, instead of on the cround. During the spring our little white-throat (Sylvic cinereu) often rises a few feet or yards in the air above some bush, and "flutters with a fitful and fantastic motion, singing all "the while, and then drops to its perch." The great English hustard throws himself into indescribably odd attitudes whilst courting the female, as has been figured by Wolf. An allied Indian bustard (Otis bengulensis) at such times "rises perpen"dicularly into the air with a hurried flapping of his wings, "raising his crest and puffing out the featleers of his neck and " breast, and then drops to the ground;" he repeats this inanouvre several times, at the same time humming in peculiar tone. Such females as happen to be near "obey this 
"saltatory summons," ana when they approach he trails his wings and spresds his tail like a turkey-cock. ${ }^{69}$

But the most curious case is afforded by three allied genera of S ustralian birds, the famous Boren-birds, - no doubt the co. disccndants of some ancient species which first acquired the strange instinct of constructing bowers for performing their live-antics. The bowers (fig. 46), which, as we shall hereafter see, are decorated with feathers, shells, hones, and leaves, are biilt on the ground for the sole purpose of courtship, for their ncsts are formed in trees. Both sexes assist in the erection of the bowers, but the male is the principal workman. So stroug is this instinct that it is practised under confinemen'; and Mr. strange has described ${ }^{6 n}$ the habits of some Satin Bower-birds which he kept in an aviary in New South Wales. "At times " the male will chase the female all over the aviary, then go to " the bower, pick up a gay feather or a large leaf, utter a curious " kind of note, set all his featbers erect, run round the bower and " hecome so excited that his eyes appear ready to start from his "head; he continues opening first one wing then the other, " uttering a low, whistling note, and, like the domestic cock, "seems to be picking up something from the ground until at "last the female goos gently towards him." Captain Stokes has described the habits and "play-houses" of another species, the Great Bower-bird, which was seen "amusing itself by flying "lackwards and forwards, taking a shell alternately from each "side, and carrying it through the archway in its mouth." These curious structures, formed solely as halls of assemblage, where both sexes amuso themselves and pay their court, must cust the birds much labour. The bower, for instance, of the Fawn-breasted speeies, is nearly four feet in length, eighteen inches in height, and is raised on a thick platform of sticks.

Decoration.-I will first discuss the cases in which the males tre ornamented either exclusively or in a much higher degreo than the females, and in a succeeding chapter those in which knth sexes are equally ornamented, and finally the rare cases in which the female is somewhat more brightly-coloured than the

50 For Tetrao phasianellus, see Pichnrdson, 'Fauna, Bor. America,' \%. 361 , and for further particulars Capt. Blakiston, 'Ibis,' 1863, p. 125. For the Cathartes and Ardea, Audubon, 'O:nith. Biography,' vol. ii. p. 51, and rol. iii. p. 89. On the White-throat, Macgillivray, 'Hist. British Birds,' vol. ii. p. 354 . On the Indian Bustard, Jerdon, 'Birds of India,' vol. iii. p. 618.

60 Gould, 'Handbook to the Birds of Australia,' vol. 1. pp. 444, 449, 455. The bower of the Satir Bower-bird may be seen in the Zoological Society's Gardens, Re. geut's Park. 
male. ' As with the artificial ornaments used by savage and civilised men, so with the natural ornaments of birds, the head is the chief seat of decoration. ${ }^{61}$ The ornaments, as mentioned

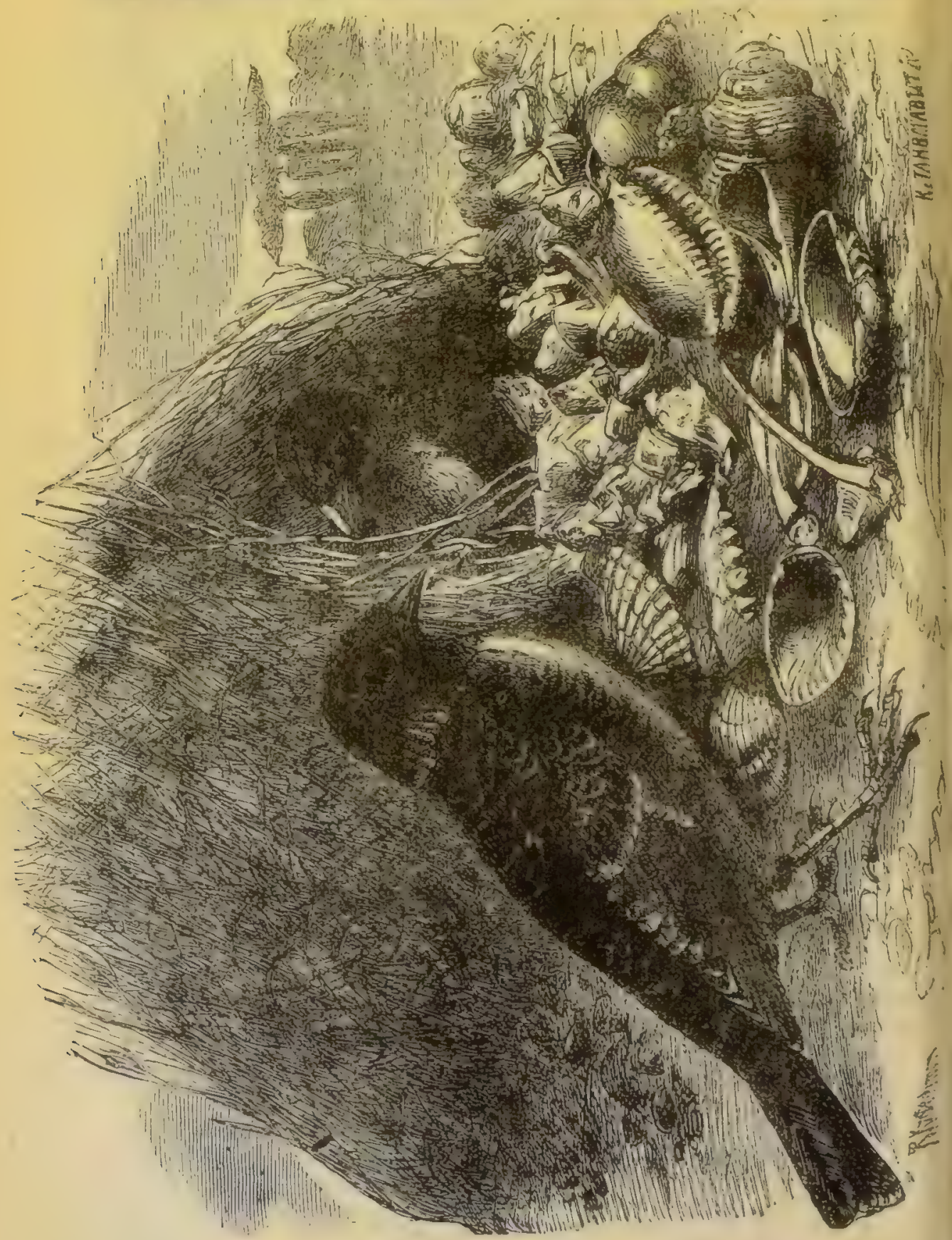

6) See remarks to this effect, on the "Fepling of Beauty among
Animals,' by Mr. J. Shaw, in the 'A thenxum, Nov. 24th, 1866 , p. 681. 
at the commencement of this chapter, are wonderfully diversified. The plumes on the front or back of the head consist of rariously-shaped feathers, sometimes capable of erection or expansion, by which their beautiful colours are fully displayed. Elegant ear-tufts (see fig. 39, ante) are occasionally present. The head is sometimes covered with velvety domn, as with tho pheasant; or is naked and vividly coloured. The throat, also, is sometimes ornamented with a beard, wattles, or caruncles. Such appendages are generally brightly-coloured, and no doubt serve as ormaments, though not always ornamental in our eyes; for whilst the male is in the act of courting the female, they often swcll and assume vivid tints, as in the male turkey. At such times the fleshy appendages about the head of the male Tragopan pheasant (Ceriornis Temminckii) swell into a large lappet on tho throat and into two horns, one on each side of the splendid top-knot; and these are then coloured of the most intense blue which I have ever beheld. ${ }^{62}$ The African hornbill (Bucora.r abyssinicus) inflates the scarlet bladder-like wattle on its neck, and with is wings drooping and tail expanded "makes quite a "grand appearance." ${ }^{3}$ Even the iris of the eye is sometimes more brightly-coloured in the male than in the female; and this is frequently the case with the beak, for instance, in our common blackbird. In Buceros corrugatus, the whole beak and immense casque are coloured more conspicuously in the male than in the female; and "the oblique grooves upon the sides of the lower "mandible are peculiar to the male sex." "64

The head, again, often supports fleshy appendages, filaments, and solid protuberances. These, if not common to both sexes, are always confined to the males. The solid protuberances haro been described in detail by Dr. W. Marshall, ${ }^{i 5}$ who shews that they are formed either of cancellated bone coated with skin, or of dermal and other tissues. With mammals true horns arc always supported on the frontal bones, but with birds various bones have been modified for this purpose; and in species of the same group the protuberances may have cores of bone, or be quite destitute of them, with intermediate gradations connecting these two extremes. Hence, as Dr. Marshall justly remarks, variations of the most different kinds have served for the development through sexual selection of these ornamenta' appendages. Elongated feathers or plumes spring from almost

62 See Dr. Murie's aocount wath coloured figures in 'Proc. Zoolog. Soc. 1872 , p. 730 .

* Mr. Monteiro, 'Ibis,' vol. iv $1 \times 62$, p. 338.
G 'Land and Water,' 1868, 1.

217.

65 'Ueber dıe Schädelhöcker' \& " . ' Niederländischen Archir für \%vo 'ogie,' B. I. Heft. 2, 1872. 
overs part of the body. The feathers on the throat and breast are sometimes developed into beautiful ruffs and collars. The tail-feathers are frequently increased in length; as wo see in tho tail-coverts of the peacock, and in the tail itself of the Argus pheasant. With the peacock even the bones of the tail have been modified to support the heary tail-coverts. ${ }^{66}$ The body of the Argus is not larger than that of a fowl; yet the length from the end of the beak to the extremity of the tail is no less than five feet three inches, ${ }^{67}$ and that of the beautifully ocellated secondary wing-feathers nearly three feet. In a small African night-jar (Cosmetornis vexillurius) one of the primary wingfeathers, during the breeding-season, attains a length of twentyfix inches, whilst the bird itself is only ten inches in length. In mother closely-allied genus of night-jars, the shafts of the elongated wing-feathers are naked, except at the extremity, whero there is a disc. ${ }^{68}$ Again, in another genus of night-jars, the tail-feathers are even still more prodigiously developed. In general the feathers of the tail are more often elongated than those of the wings, as any great elongation of the latter impedes ilight. We thus see that in closely-allied birds oruaments of the same kind have been gained by the males through the development of widely different feathers.

It is a curious fact that the feathers of species belonging to very distinct groups have been modified in almost exactly the same peculiar manner. Thus the wing-feathers in one of the above-mentioned night-jars are bare along the shaft, and terminate in a dise; or are, as they are sometimes called, spoon or racket-shaped. Feathers of this kind occur in the tail of a motmot (Eumonota superciliaris), of a king-fisher, finch, humming-bird, parrot, several Indian drongos (Dicrurus and Edolius, in one of which the disc stands vertically), and in the tail of certain birds of paradise. In these latter birds, similar feathers, heautifully ocellated, ornament the head, as is likewise the caso vith some gallinaceous birds. In an Indian bustard (Sypheotide. auritus) the feather's forming the ear-tufts, which are about fou: iuches in length, also terminate in dises ${ }^{69}$ It is a most singular fact that the motmots, as M.r. Salvin has clearly shewn, ${ }^{70}$ give to their tail feathers the racket-shape by biting off the barbs. end, further, that this continned mutilation has produced a certain amount of inlerited effect.

${ }^{66}$ Dr. W. Marshall. 'Üter den Vrgelschwanz' ibid. B. I. Heft 2, 1872. 8: Jardine's 'Naturalist Library : Birds,' vol. xiv. p. 166.

6r Sclater, in the 'Ibis,' rol. vi.
1864, p. 114. Liringst one, 'Expedıtion to the Zambesi,' 1865, p. 61 . iii. p. 620 .

${ }^{\circ}$ Jerdon, 'Birds of India,' vol.

io 'Proc. Zoolog. Sor:' 1873, p. 429. 
A wain, the barbs of the feathers in various widely-distinct birds are filamentous or plumose, as with some herons, ibises, birds of paradise, and Gallinacce. In other cases the barbs disappear, leaving the shafts bare from end to end; and these in the tail of the P'rmelisea apodu attain a length of thirty-four inches: $:^{71}$ in ''. P'spurna (fig. 47) they are much shorter and thin. Smaller feathers when thus denuded appear like bristles, as on the breast of the turkey-cock. As any fleeting fashion in dress comes to be admired by man, so with birds a change of almost any kind in the structure or colouring of the feathers in the male appears to have been admired by the female. The fact of the feathers in widely distinct groups, having heen modified in an analogous manner, no doubt depends primarily on all the feathers having nearly the same structure and manner of development, and consequently tending to vary in the same mamner. We often sce a tendency to analogous variability in the plumage of our domestic breeds belonging to distinct species. Thus top-knots hare appeared in several species. In au extinct variety of the turkey, the top-knot consisted of bart quills surmounted with plumes of down, so that they somewhat resembled the racket-shaped feathers above described. In certain breeds of the pigeon and fowl the feathers are plumose. with some tendency in the shafts to be naked. In the Sebastopol goose the scapular feathers are greatly elongated, curled, ur even spirally twisted, with the margins plumose. ${ }^{\text {. }}$

In regard to colour hardly anything need here be said, for every one knows how splendid are the tints of many birds, and how harmoniously they are combined. The colours are often metallic and iridescent. Circular spots are sometimes surrounded by one or more differently shaded zones, and are thus converted into ocelli. Nor need much be said on the wonderful difference between the sexes of many birds. The common peacock offers a striking instance. Female bircls of paradise ire obscurely coloured and destitute of all ornaments, whilst the males are probably the most highly decorated of all birds, and in so many different ways, that they must be seen to be appreciated. The elongated and golden-orange plumes which spring from beneath the wings of the Paradisea aporla, when vertically crected and made to vibrate, are described as forming a sort of halo, in the centre of which the head "looks like a little emerald "sun with its rays formed by the two plumes." 73 In another

"Wallace, in 'Annals and Mag. of Nat. Hist.' vol. Xx. 1857, p. 416 and in his 'Malay Archipelagc, vol, ii. 1869 , p. 390 .
12 See my work on "The Variation of Animals and Plants under Dumes. tication,' vol. i. Jip. 289, 293.

73 Quoted from M. de Iafiresnaye 
most beautiful species the head is bald, "and of a rich cobalt "blue, crossed by several lines of black relrety feathers." "iq

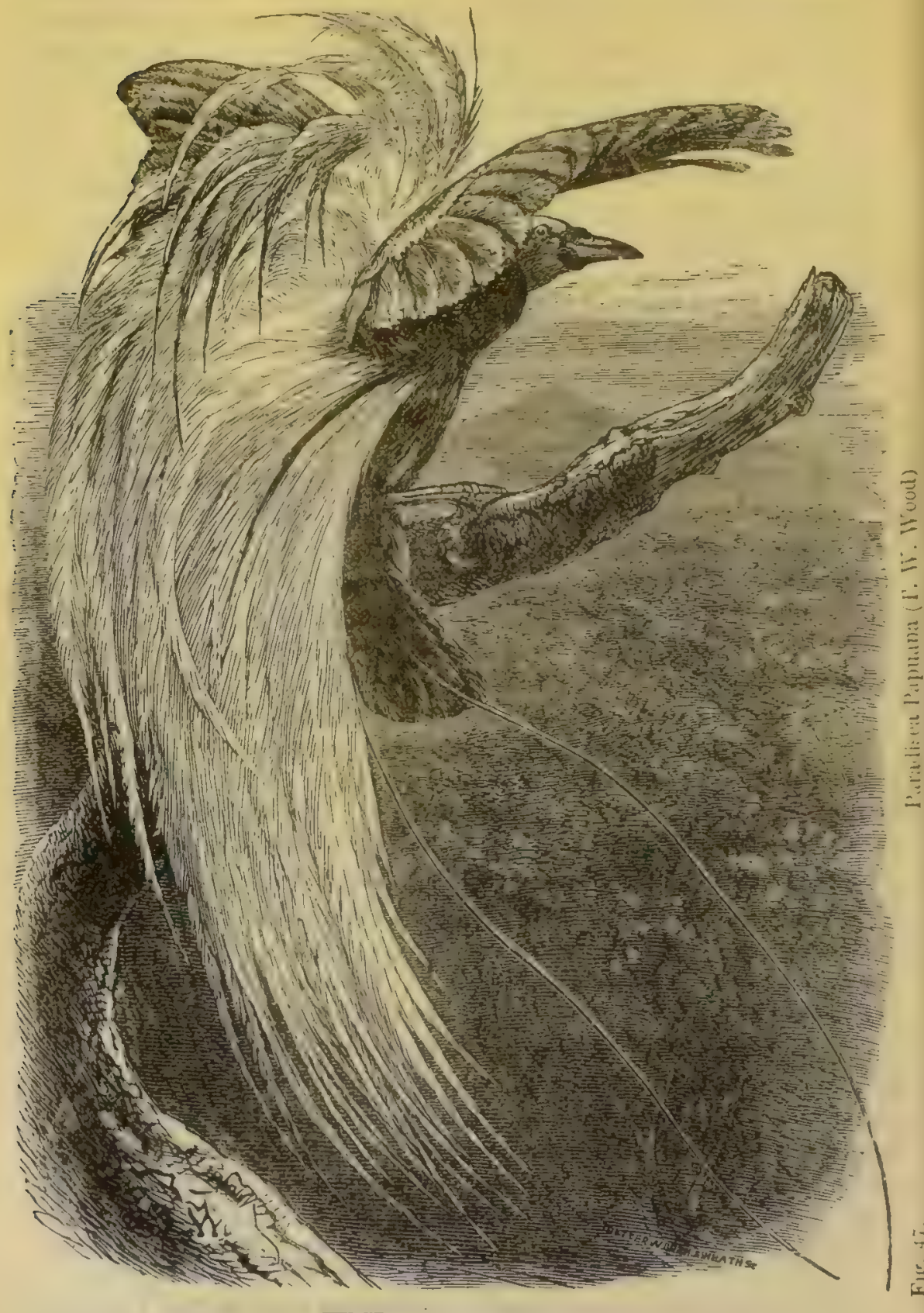

24 'Annais an Mage of Nat. Hist.' vni. xiii. 1854. p. 157 : see also $\mathrm{Mr}$. Wallace's much fuller account in vol. Ix. 1857, p. 412, and in his
'Malir Archipelago.'

"W Wallace, "The Malay Archipelago,' vol, ii. 1869, p. 405. 
Male humming-birds (figs. 48 and 49) almost vie with birds oi paradise in their beauty, as every one will admit who has seen Mr. Gould's splendid rolumes, or his rich collection. It is very remarkable in how many different ways these birds are ornamented. Almost every part of their plumage has been taken alvantage of, and modified; and the moditications have been

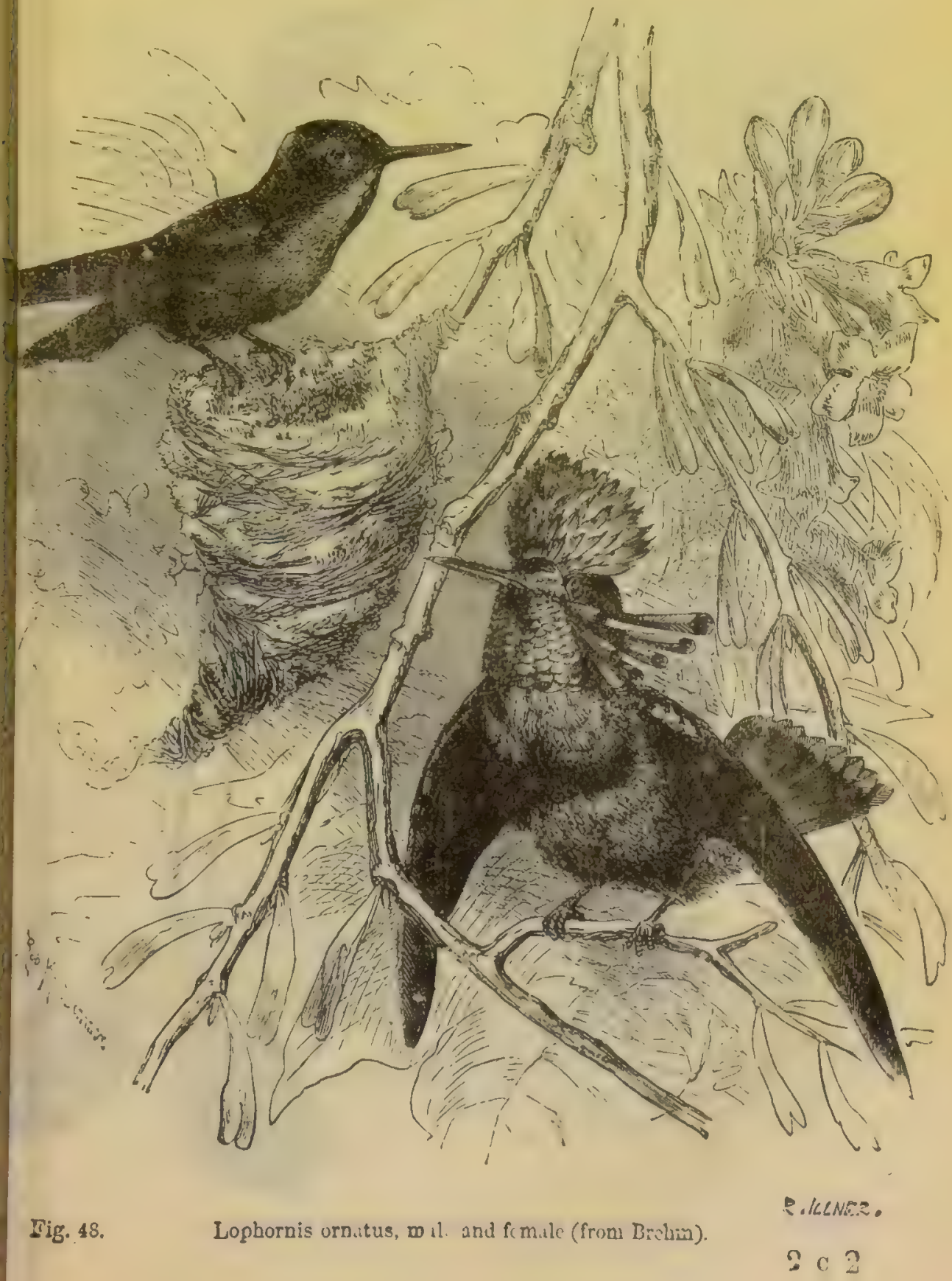


carried, as Mr. Gould shewed me, to a wonderful extreme in some species belonging to nearly every sub-group. Such cases are curiously like those which we see in our fancy breeds, reared by man for the sake of ornament: certain individuals originally varied in one character, and other individuals of the

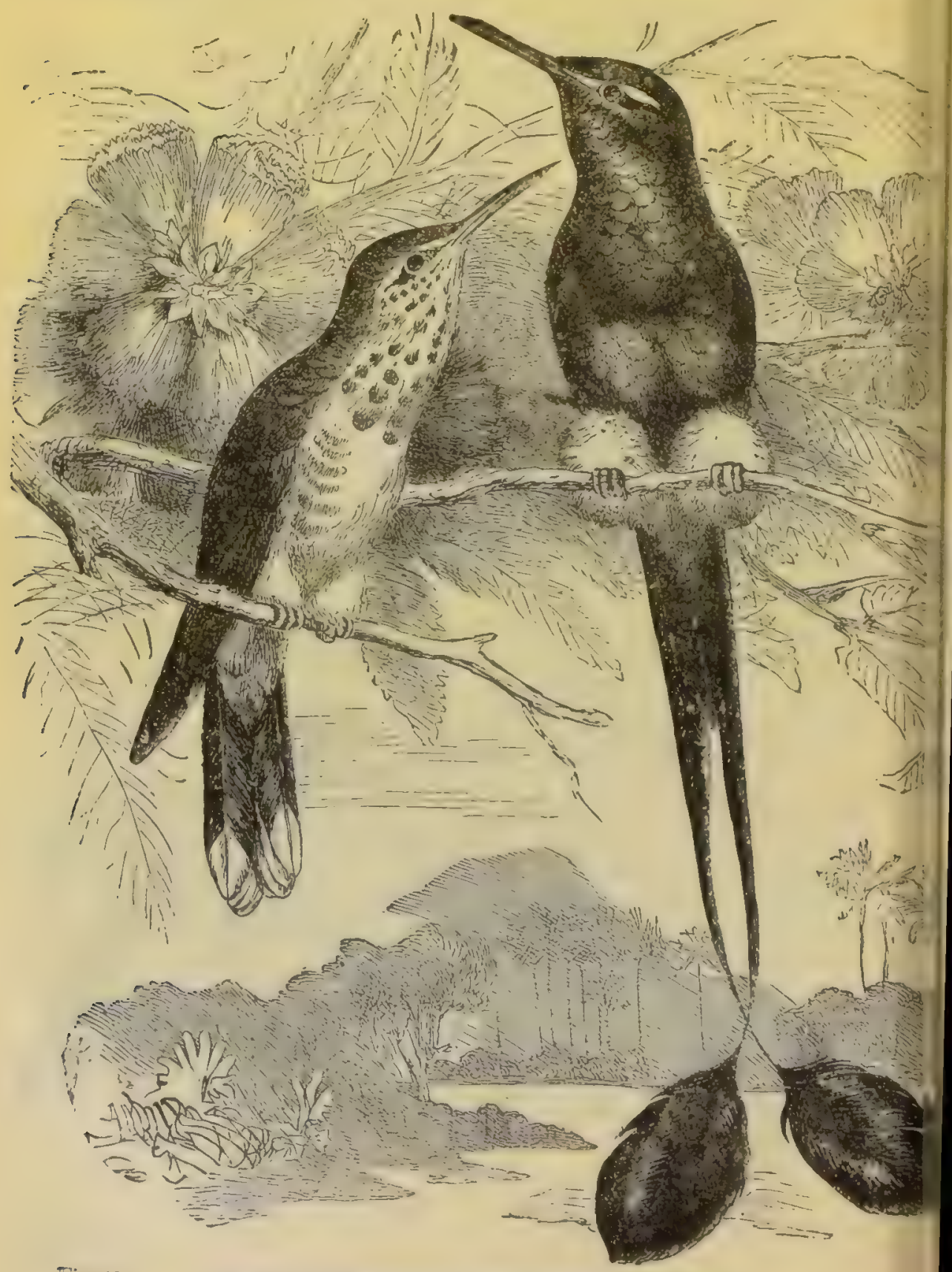

Fig. 49. Spathura underwoodi, male and femalc (from Brehm). 
same species in other characters; and these have been seized on by man and much augmented-as shewn by the tril of the fantail-pigeon, the hood of the jacobin, the beak and wattle of the carrier, and so forth. The sole difference between these cases is that in the one, the result is due to man's selection, whilst in the other, as with humming-birds, birds of paradise, \&c., it is due to the selection by the females of the more beautiful males.

I will mention only one other bird, remarkable from the extreme contrist in colour between the sexes, namely the famous hell-bird (C'husmorhynchus nivens) of S. America, the note of which can be distinguished at the distance of nearly three miles, and astonishes every one when first hearing it. The male is pure white, whilst the female is dusky-green; and white is a very rare colour in terrestrial species of moderate size and inoffensive habits. The male, also, as described by Waterton, has a spiral tube, nearly three inches in length, which rises from the base of the beak. It is jet-black, dotted over with minute downy feathers. This tube can be inflated with air, through a communication with the palate; and when not inflated hangs down on one side. The genus consists of four species, the males of which are very distinct, whilst the females, as described by Mr. Sclater in a very interesting paper, closely resemble each other, thus offering an excellent instance of the common rule that within the same group the males differ much more frons aach other than do the females. In a second species ( $C$. nudirollis) the male is likewise suow-white, with the exception of a large space of naked skin on the throat and round the eyes, which during the breeding-season is of a fine green colour. In a third species (C. tricurunculutus) the head and neck alone of the male are white, the rest of the body being chesnut-brown, and the male of this species is provided with three filamentous projections half as long as the body-one rising from the bass of the beak, and the two others from the corners of the mouth.i.

The coloured plumage and cortain other ornaments of the adult males are either retinined for life, or are periodically renewed during the summer and breeding-season. At this same season the beak and naked skin about the head frequently change colour, as with some herons, ibises, gulls, one of the bell-birds just noticed, \&c. In the white ibis, the cheeks, the inflatable skin of the throat, and the basal portion of the beak then become crimson. ${ }^{76}$ In one of the rails, Ciullicrex cristatus, a

" Mr. Sclater, 'Intellectual Observer,' Jan. 1867. 'Waterton's Wanderings,' p. 118. See also Mr. plate, in the 'Ibis,' 1865, p. 90. 394.

76 'Laud and Water,' J867, J.' Salvin's inceresting papel, with a 
large red caruncle is dereloped during this period on the head of the malo. So it is with a thin horny crest on the beak of one of the pelicans, P. erythrorkynchus; for after the brcedingseasou, these horny crests are shed, like horns from the heads of stags, and the shore of an island in a lake in Nevada was found covered with these curious exuviro. ${ }^{77}$

Changes of colour in the plumage according to the scason depend, firstly on a double annual moult, secondly on an actual change of colour in the feathers themselves, and thirdly on their dull-coloured margins being periodically shed, or on these three processes more or less combinet. The shedding of the deciduary margins may be compared with the shedding of their down by rery young birds; for the down in must cases arises from the summits of the first true feathers. ${ }^{78}$

With respect to the birds which annually undergo a donble moult, there are, firstly, some kiuds, for instance snipes, swallowplovers (Glareolæ), and curlews, in which the two sexes resemblo each other, and do not change colour at any season. I do not know whether the winter plumage is thicker and warmer than tha summer plumage, but warmth seems the most probable end attained of a double moult, where there is no change of colour. Secondly, there are birds, for instance, certain species of Totanus and other Grallatores, the sexes of which rescmble each other, but in which the summer and winter plumage differ slightly in colour. The difference, however, in these cases is so small that it can hardly be an advantage to them; and it may, perhaps, be attributed to the direct action of the different conditions to which the birds are exposed during the two seasons. 'Ihirdly;, there are mayy other birds the sexes of which aro alike, but which aro widely different in their summer and winter plumage. Fourthly, there are birds, the sexes of which differ from each other in colour; but the females, though moulting twice, retain the same colours throughout the year, whilst the males undergo is change of colour, sometimes a great one, as with certain bustards. Fifthly and lastly, there are birds the sexes of which differ from each other in both their summer and winter plumage; but the male undergoes a greater amount of change at each recur:ent season than the female-of which the ruff (Nachetes pugnux) offers a good instance.

With respect to the cause or purpose of the differences in colour between the summer and winter plumage, this may in some instances, as with the ptarmigan, ${ }^{i 9}$ serve during botic

"Mr. D. G. Elliot, in 'Proc. edited by P L. Sclater. Ray Soc Znol. Soc.' 1869, p. 589.

"Nitzsch's 'Pterylngraphy, 10 'The brown mottled summes 
seasons as a protection. When the difference between the two plumages is slight, it may perhaps be attributed, as alrcady remarked, to the direct action of the conditions of life. But with many birds there can hardly be a doubt that the summer phumage is ornamental, even when both sexes are alike. Wo may conclude that this is the caso with many herons, egrets, ce., for they acquire their beautiful plumes only during the breeding-season. Moreover, such plumes, top-knots, \&e., though possessicd by both sexes, are occasionitily a little more dereloped in the male than in the female; and they resemble the plumes and ormments possessed by the males alone of other birds. It is also known that confinement, by affecting the reproductivo system of male birds, frumently checks the development of their secondiary sexual characters, but has no immediate influenee on any other characters; and I an informed by Mr. Bartlett that eight or nine spocineens of the Innot (T'ringue cemutus) retained their madorned winter plumage in the Zoological Gardens thronghont the year, from which fact we may infer that the summer plumagre thongh common to both sexes partakes of the nature of the exelusively masculine plumage of many other birds.:

From the foregoing facts, more expecially from neither sex of ortain birds changing colour during either annual moult, or caasiging so slightly that the change can hardly be of any servico tothem, and from the females of other species moulting twice. yt retaining the same colours throughout the year, wo may ccislude that the halit of ainually moulting twice has not bees accuired in order that the male should assume an ornilmeral sharacter during the breeding-scason; but that the doul'e moult, having been originally acciuired for some distinet purpise, has subseruently been taken alvantage of in certain cases or gaining a nuptial plumage.

It appears at first sight a surprising circumstance that sonie closely allied species should regularly undergo a double annual

plumage of the ptarmigan is of as much imprtance to it, as a protection, a the white winter plumage; tor in Scandinavia, during the spring when the snow has disappeared this bird is known to suffer greaty from birds of prey, before it ha. acquired its summer dress: see Wlhelm von Wright, in Cloyd, 'Gam Birds of Swelen,' 867, p. 125.

* In regal to the prerints statements on moulting, see, on snipes, \&c., Macgillirray, 'Hist. Brit. Birds,' vol. iv, p. 371 ; on Glareolx, curlews, and bustards, Jerdon, 'Birds of India,' rol. iii. rp. $615,630,683$; on Totanus, ibid. p. 700 ; on the plumes of herons, ibiu. p. 738, and Macgillivray, vol. iv. pp. 435 and 444, and Mr. Stafford Aller, in the 'Ibis,' rol. v. 1863, p. 33. 
moult, and others only a single one. The ptarmigan, for instance, moults twice or eren thrice in the year, and the blackcock only once: some of the splendidly coloured honey-suckers (Nectarinix) of India and some sub-genera of olsseurcly coloured pipits (Anthus) have a double, whilst others have only a single annual moult. ${ }^{81}$ But the gradations in the manner of moulting, which are known to occur with various birds, shew us how species, or whole groups, might have originally acquired their double annual moult, or having once gained the habit, haro again lost it. With certain bustards and plovers the vernal moult is far from complete, some feathers being renewed, and some changed in colour. There is also reason to believe that with certain bustards and rail-like birds, which properly undergo a double moult, some of the older males retain their nuptial plumage throughout the year. A few highly modified feathers may merely be added during the spring to the plumage, as occurs with the disc-formed tail-feathers of certain drongos (Bhringa) in India, and with the elongated feathers on the back, neck, and crest of certain herons. By such steps as these, the vernal moult might be rendered more and more complete, until a perfect double moult was acquired. Some of the birds of paradise retain their nuptial feathers throughout the year, and thus have only a single moult; others cust them directl! after the breeding-season, and thus have a double moult; and others again cast them at this season during the first year, but not afterwards; so that these latter species are intermediate in their manner of moulting. There is also a great difference with many birds in the length of time during which the two annual plumages are retained; so that the one might come to be retained for the whole year, and the other completely lost. 'Lus in the spring Mucheles mumax retains his ruff for barelytwo months. In Natal the male widow-bird (chera proyne) aciuires his fine plumage and long tail-feathers in December or Ja'uary, and loses them in March; so that they are retained oly for about three months. Most species, which underero a louble moult, keep their oruamental feathers for about sis anths. The male, however, of the wild Gullus bankivu retaius hs neckhackles for nine or ten months; and when these are cas off, the underlying black feathers on the neck are fully exposcitc view. But with the domesticated descendant of this species, he necihackles of the male are immediately replaced by nerones; so

1) $\mathrm{O}$ the moulting of the ptarmigan, sae Gould's 'Burds of Great Britain.' On the honey-suckers, Jerdon, 'Birds of Irdig, vol. i. pp.
$359,305,369$. On thmoulting of Anthus, see B!yth, in Llis,' 1867, p. 32. 
that we here see, as to part of the plumage, a doublo moult changed under domestication into a single moult. ${ }^{82}$

The common drake (Anas boschus) after the breeding-season is well known to lose his male plumage for a period of three months, during which time he assumes that of the female. The male pintail-duck (-Inus acutu) loses his plumage for the shorter period of six weeks or two months; and Montagu remarks that " this double moult within so short a time is a most extra" ordinary circumstance, that seems to lid defiance to all human "reasoning." But the believer in the gradual modification of species will he far from feeling surprise at finding gradatiuns of all kinds. If the male pintail were to acyuire his new plumage within a still shorter period, the new male feathers would almost necessarily be mingled with the old, and both with some froper to the female; and this apparently is the case with the inale of a not distantly-allied bird, namely the Merganser serrator, for the males are said to "undergo a change of plumage, which "assimilates them in some measure to the female." By a little further acceleration in the process, the double moult would be completely lost. ${ }^{89}$

Some male birds, as before stated, become more brightly coloured in the sprirg, not by a vernal moult, but either ly an actual change of colour in the feathers, or by their obscurelycoloured deciduary margins being shed. Changes of colour thus caused may last for a longer or shorter time. In the Pelecanus onocrutulus a beautiful rosy tint, with lemon-coloured marks on the breast, orerspreads the whole plumage in the spring; but these tints, as Mr. Sclater states, "do not last long, disappearing "generally in about six weeks or two months after they have, "been attained." Certain finches shed the margins of their feathers in the spring, aud then become brighter coloured, while other finches undergo no such change. Thus the H'ringilla tristis of the United States (as well as many other American species)

es For the foregoing statements in regard to partial moults, and un old males retaining their nuptial plumage, see Jerdon, on bustards ind plover's, in 'Birds of Indra,' vol. iii. pp. $617,637,799,7: 1$. Also Blyth in 'Land and Watm:' 1867, \%. 84. On the moulting of Paradisen, see an interesting article by Dr. W. Marshall, 'Archives Neerlandaises, tom. vi. 1871. On the Vidua, 'Ibis," vol. iii. 1861 , p. 133. On the Drongo-shrikes, Jerdun, ibid. rol. i. p. 435 . On the rernal moult of the Herodias bubulcus, Mr. S. S. Allen, in 'Ibis,' 1863, p. 33. On Gallue bankiva, Blyth, in 'Annals and Mag. of Nat. Hist.' vol. i. 18t8, p. 455 : see, also, on this subject, my 'Vartation of Animals under' Domestication,' vol. i. p. 236.

${ }^{83}$ See Macgillivray, 'Hist. British Birds ' (rol. v. pp. 34, 70, and 223), on the moulting of the Anatidx; with quutations from Waterton and Montag' '. Also Yarrell, 'Hist. of British Birds,' vol. iii. p. 243. 
exhibits its bright colours only when the winter is past, whilst our goldfinch, which exactly represents this bird in habits, and our siskin, which represents it still more closely in structure, undergo no such annual change. But a difference of this kind in the plumage of allicd species is not surprising, for with tho common linnet, which belongs to the same family, the crimsons forehead and breast are displayed only during the surnmer in England, whilst in Madeira these colours are retained throughout the year. ${ }^{\text {ps }}$

Display by Male Birds of their Flumage.-Ornaments of all kinds, whether permanently or temporarily gained, are sedulously: displayed by the males, anil apparently scrve to excite, attrict, or fascinate the females. But the males will sometimes display their ornaments, when not in the presence of the females, as oceasionally occur's with grouse at their balz-places, aud as may be noticed with the peacock; this latter bird, however, cridently wishes for a spectator of some kind, and, as I hare often seen, will shew off his finery before poultry, or even pigs...5 All naturalists who have closely attended to the habits of birds, whether in a state of nature or under confinement, are unanimously of opinion that the males take delight in displaying their beauty. Andubon frequently speaks of the male as cndearouring in viluious ways to charm the female. MIr. Goukl, after describing some peculiarities in a male 'tumming-lired, says he has no doulbt that it has the porrer of displaying them to the greatest adrantage before the female. I)r. Jerdon ${ }^{8 \mathrm{c}}$ insists that the beantiful plumage of the male scrves "to fiscinate and attract the female." MIr. Bartlett, at the Zoologienl Gardens, expressed himself to me in the strongest terms to the same effect.

It must be a grand sight in the forests of India "to come "suddenly on trenty or thirty pea forwl, the males displaying "their gorgeous trains, and strutting ahout in al the pomp of "pride before the gratifiel females." The wild turkey-cock erects his glittering plumage, expands his finely-zoned tail and barred wing-featlicrs, and altogether, with his crimson and blue wattles, nakes a superb, though to our eyes, grotesque

84 On the pelican, see Sclatur, in 'Proc. Zool. Soc.' 1868, p. 265. On the American finches, see Audisbon, 'Ornith. Biography,' vol. i. pp. 174, 221, and Jerdon, "Birds of Inllia," rol. 1i. p. 383. On the Fringilla cannabina of Madeira, Mr. E. Verncn Harcourt, Ibis,' vol. v.,
1863, p. 230.

ss Sice also 'Ornamental Poultry, by Rer. E. S. Diron, 1848 , p. 8.

so 'Birds of India,' introduct. vol.

i. p. xxiv.; on the peacock, rol. iil. p. 507. See Gould's 'Introluction to the 'Trochulidx,' $1861, \mathrm{pp} .15$ and 111. 
appearance. Similar facts hare already been given with respect to grouse of various kinds. Turning to another Order. 'The male Riupicule crocca (fig. 50) is one of the most beautiful birds in the world, being of a splendid orange, with some of the feathers curiously truncated and plumose. The female is brownish-green, shaded with red, and has a much smaller crest. Sir R. Schomburgk has described their courtship; he found one

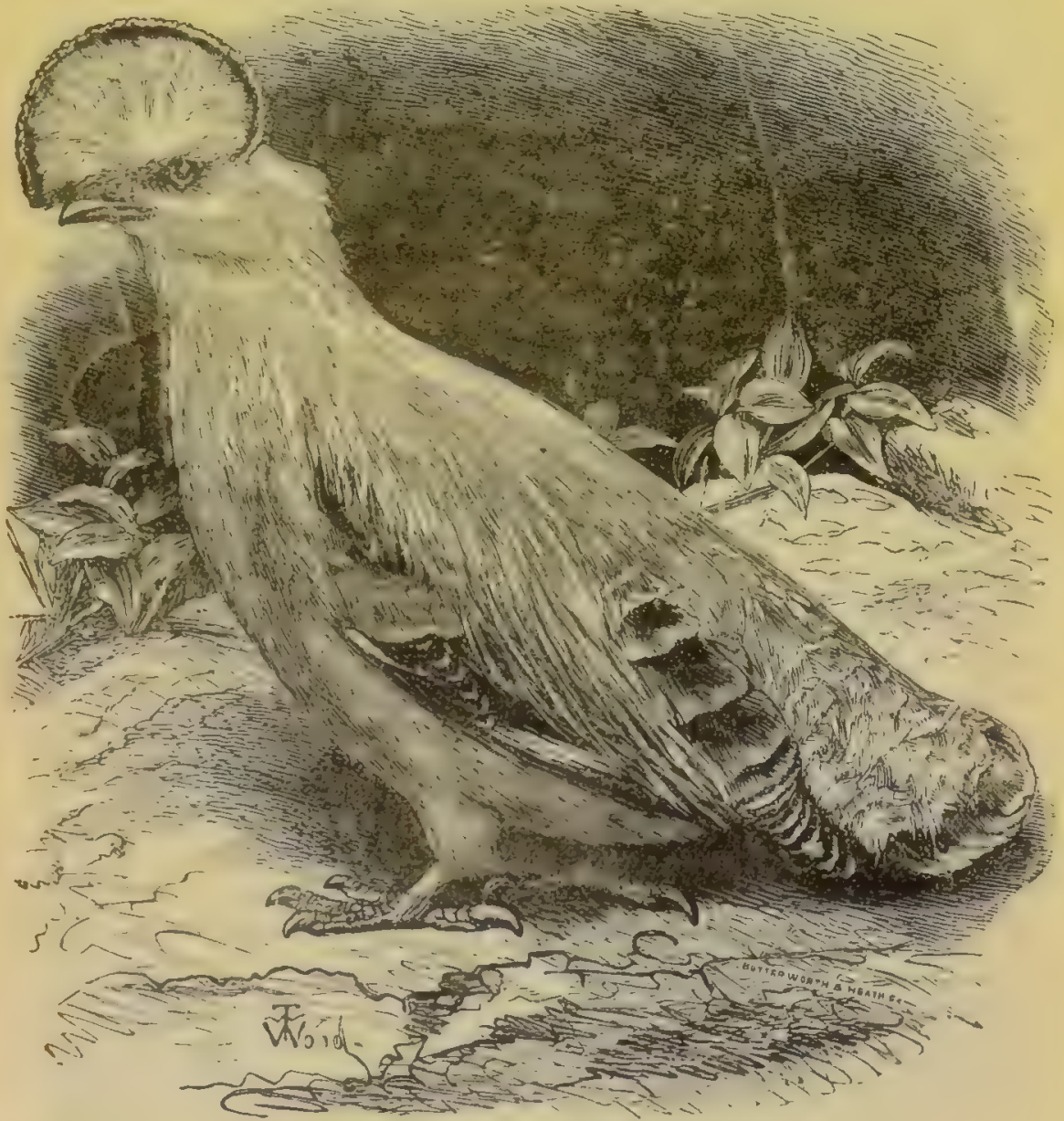

Fig. 50.

rupicola crocea, male (T. W. Wood).

of their meeting-places where ten males and two females wero present. The space was from four to five fect in diameter, and appeared to have been cleared of evcry blade of grass anl smoothed as if by human hands. A male "was capering, to the "apparent delight of several others. Now sprealing its wings, "throwing up its head, or opening its tail like a fan; now "strutting about with a hopping gait until tired, when it 
"gabbled some kind of note, and was relieved by another. Thus "three of then successively took the field, and then, with self" approbation, withdrew to rest." The Indians, in order to obtain their skins, wait at one of the meeting-places till the birds are cagerly engaged in dancing, and then are able to kill with their poisoned arrows four or five males, one after the other. ${ }^{87}$ With birds of paradise a dozen or more full-plumaged males congregate in a tree to hold a danciug-party, as it is called by the natives: and bere they fly alout, raise their wings, elevate their exquisite plumes, and make them vibrate, and the whole tree seems, as Mr. Wallace remarks, to be filled wijh waving plumes. When thus engaged, they become so absorbed that a skilful archer may shoot nearly the whole party. These birds, when kept in confinement in the Malay Archipelago, aro said to take much care in keeping thcir feathers clean; often spreading them out, examining them, and removing every speck of dirt. One observer, who kept several pairs alive, did not doubt that the display of the male was intended to please the female. ${ }^{88}$

The Gold and Amherst pheasants during their courtship not only expand and raise their splendid frills, but twist them, as I have myself seen, obliquely towards the female on whichever side she may be standing, obviously in order that a large surface may he displayed before her.". They likewise turn their beautiful tails and tail-coverts a little towards the same side. MLr. Bartlett hals observed a male Polyplectron (fig. 51) in the act of courtship, and has shewn me a specimen stuffed in the attitude then assumed. The tail and wing-feathers of this bird are oruamented with beautiful ocelli, like those on the peacock's train. Now when the peacock displays himself, he expands and erects his tail transversely to his body, for he stands in front of the fomale, and has to shew off, at the same time, his rich blue throat and breast. But the breast of the Polyplectron is obscurely coloured, and the ocelli are not confined to the tailfeathers. Consequently the Polyplectron does not stand in front of the female; but he erects and expands his tail-feathers a little obliquely, lowering the expanded wing on the same side, and raising that on the opposite side. In this attitude the ocelli over the whole body are exposed at the same time before the

"7 'Journal of R. Geograph. Soc.' vol. x. 1840, p. 236.

86 'Annals and Mag. of Nat. Hist.' rol. xiii. 1854, p. $15 \%$; also Wallace, ibid. vol $x x .1857$, p. 412, and 'The Malay frchipelagu,' vol. ii. 1869, p. 252. Also Dr. Bennett, as quoted by Brehm, 'Thierleben,' B. iii. 8.326 . so Mr. T. W. Wood has given ('The Student,' A pril 1870, p. 115) a full account of this manner of display, by the Gold pheasant and by the Japanese pheasant, $P h$. versicoior; and he cails it the lateral or one-sided dispiny. 
Chap. XiII.

eyes of the admiring female in one grand bespangled expanse. T'o whichever side she may turn, the expanded wings and the obliquely-held tail are turned towards her. 'The male Tragopan pheasant acts in nearly the same manner, for he raises the feather's of the body, though not the wing itself, on the side

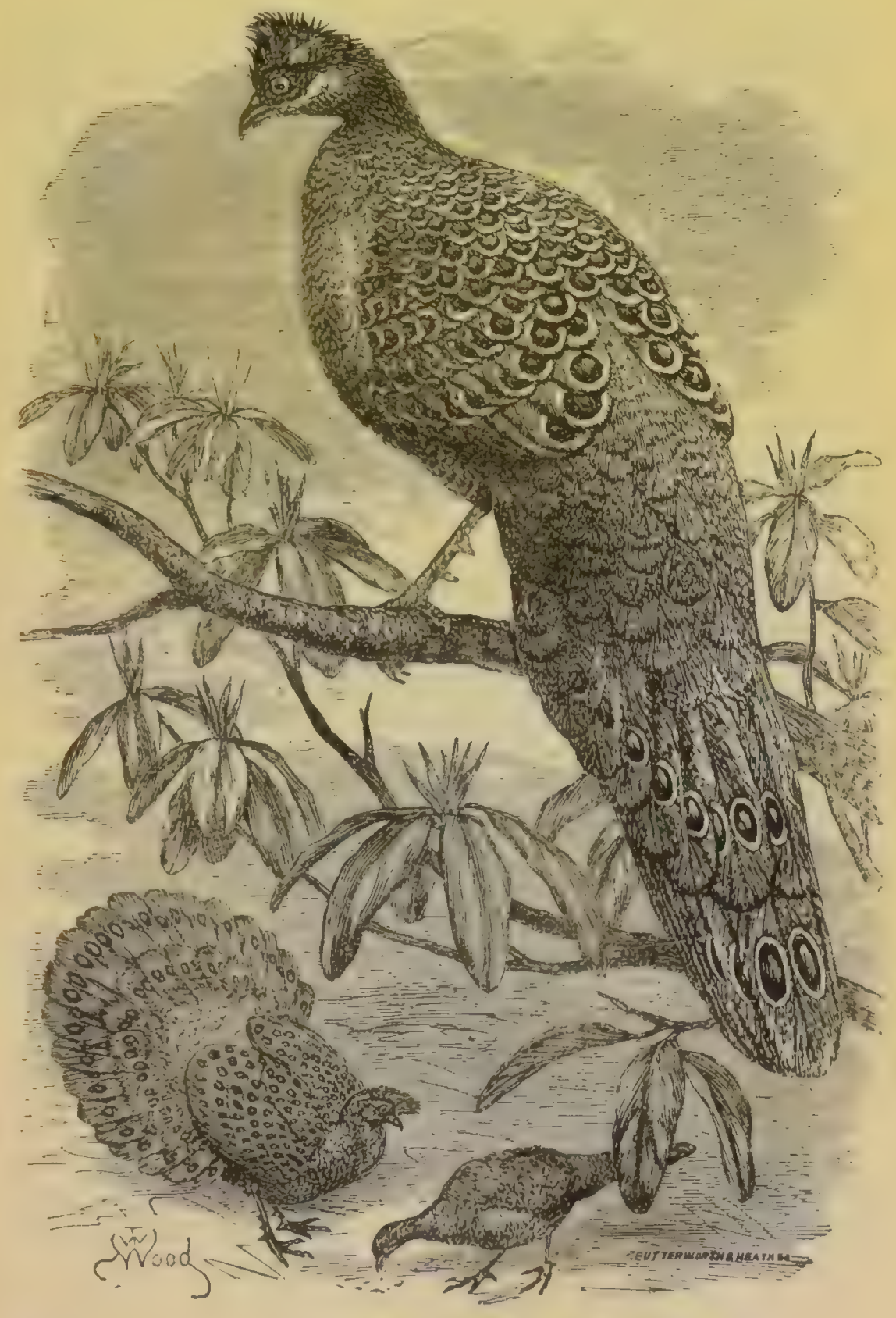

Fig. 51.

Polyplectron chirçuis. ma.e (T. W. Wood). 
"hich is opposite to the female, and which would otherwise be conccaled, so that nearly all the beautifully spotted feathors are crhibited at the same time.

The A rgus pheasant affords a much more remarkable case. The imroensely developed secondary wing-feathers are confined to the male; and cach is ornamented with a row of from twenty to twenty-three ocelli, above an inch in diameter. These fuathers nre also elegrantly marked with oblique stripes and rows of spots of a dark colour, like those on the skin of a tiger and leopard r'ombined. These heautiful ornaments are hidden until the male whers himself off hofore the female. Ile then erects his tail, and :xpands his wing-feathers into a great, almost upright, circular sun or shield, which is carried in front of the body. The neck and head are held on one side, so that they are concealed by the fun; but the bird in order to see the female, before whom he is displaying himself, somutimes pushes his head between two of the loug wing-feathers (as .Ir. Bartlett has seen), and then presents a grotesque appcarance. This must be a frequent labit with the bird in a state of nature, for Mr. Bartlett and his son on (xamining some porfect skins sent from the East, found a place hetween two of the feathers, which was much fraycel, as if the lead had here frequently becn pushed through. MIr. Wood thinks that the male can also peep at the female on one side, beyond the margin of the fan.

The ocelli on the wing-feathers are wonderful oljects; for they are so shaded that, as the Duke of Arryll remarks, ${ }^{90}$ they stand. out iike balls lying loosely within sockets. When I looked at the specimen in the British Museum, which is mounted with the wings expanded and trailing downwards, I was howerer greatly disappointed, for the ocolli appeared flat, or eren concare. But Ar. Gould soon made the case clear to me, for he held thio feathers erect, in the position in which they would naturally bo displayed, and now, from the light shining on them from above, cach ocellus at once resembled the ornament called a ball and socket. These feathers have been shemn to several artists, and all have expressed their admiration at the perfect shading. It may well he asked, could such artistically shaded ornaments lare been formed ly menns of sexual selection? But it will he convenient to defer giving an answer to this question, until we treat in the next chapter of the principle of gradation.

The foregoing remarks relate to the secondary wing-feathers, int the primary wing-feathers, which in most gallinaceous lirds are uniformly coloured, are in the Argus pheasant equally wonderful. They are of a soft brown tint with numercus dark

so 'The Keign of Law,' 1867 p. 203. 
spots, each of which consists of two or three black dots with a wirrounding dark zone. But the chief ornament is a space parallel to the dark-blue shaft, which in outline forms a perfuct second feather lying within the true feather. This inner part is colonrud of a lighter chesnut. and is thickly dotted with minute

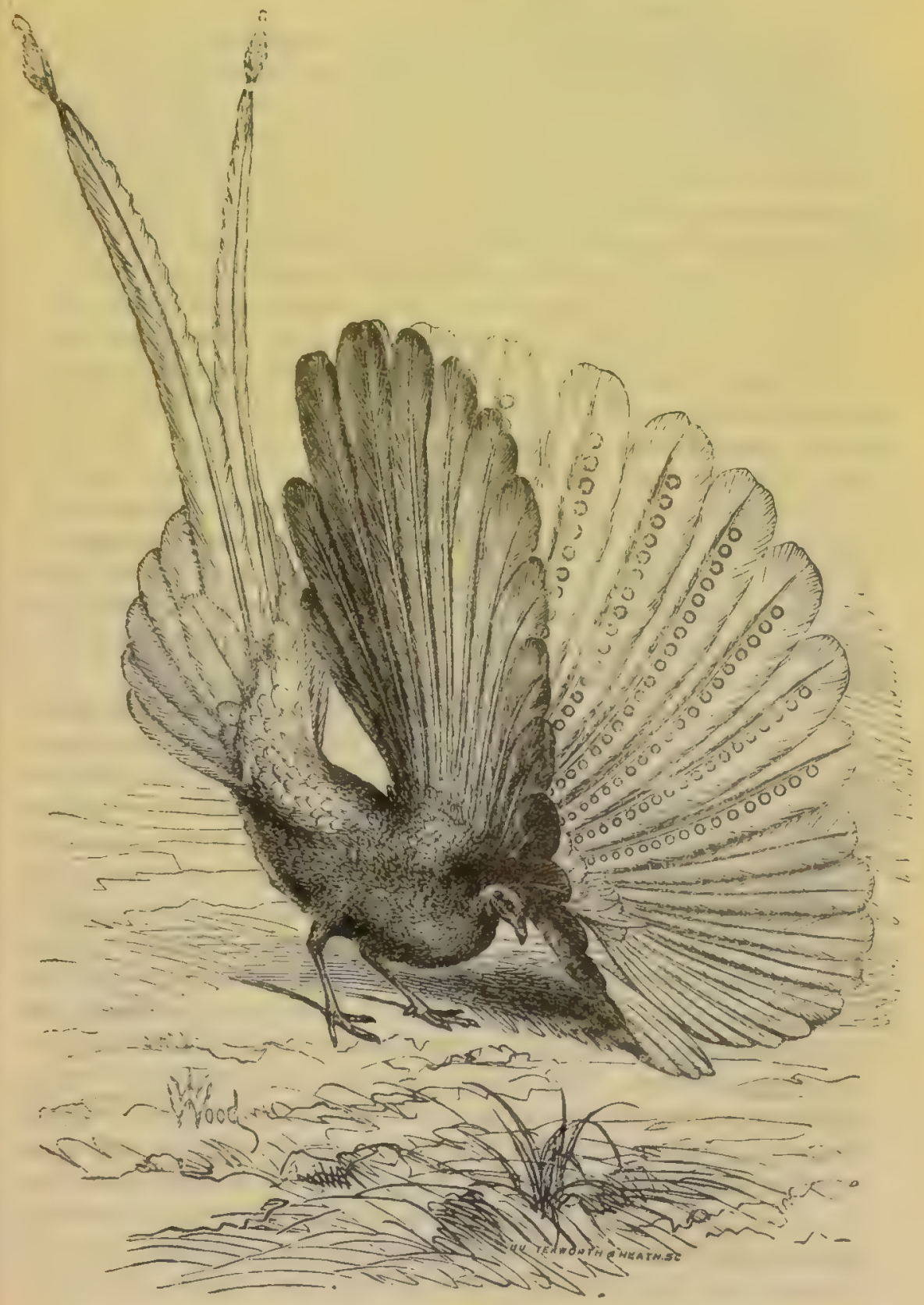

Fig. 52. Side view of male Argus pheasant, whilst displaying before tho fomale. ()bserved and sketcbed from nature by Mr. T. W. Woud. 
white points. I have shern this feather to several persons, and many have artmired it even wore than the ball and socket feathers, and have declared that it was more like a work of art than of nature. Now these feathers are quite hirlden on all ordinary oecasions, but are fully displayed, together with the long secondary feathers, when they are all expanded together so as to form the great fan or shield.

The case of the male Argus pheasant is eminently interesting, because it affords good evidence that the most refined beauty may serve as a sexual charm, and for no other purpose. We must conclude that this is the case, as the secondary and primary wingfeathers are not at all displayed, and the ball and socket ormaments are not exhibited in full perfection, until the male assumes the attitude of courtship. The Argus pheasant does not possess brilliant colours, so that his success in love appears to depend on the gruat size of his plumes, and on the elaboration of the most elegant patterns. Many will declare that it is utterly incredible that a female bird should be able to appreciate fine shading and exquisite patterns. It is undoubtedly a marvellous fact that she should possess this almost human degree of taste. He who thinks that he can safely gange the discrimination and taste of the lower animals may deny that the female Argus pheasant can appreciate such refined beanty; but he will then be compelled to admit that the extraordinary attitudes assumed by the male rluring the act of courtship, by which the wonderful beauty of his plumage is fully displayed, are purposeless; and this is a conclusion which I for one will never admit.

Although so many pheasants and allied gallinaceous birds carefully display their plumage before the females, it is remarkable, as Mr. Bartlett informs me, that this is not the case with the dull-coloured Eared and Cheer pheasants (Crossoptilon auritum and Phasiumus vallichii); so that these birds seem conscious that they have little beauty to display. Mr. Bartlett has never rren the males of either of these species fighting together, though he has not had such good opportunities for observing the Cheer as the Eared pheasant. Mr. Jenner Weir, also, finds that all male birds with rich or strongly-characterised plumage are more quarrelsome than the dull-coloured species belonging to the same groups. The goldfinch, for instance, is far more jugnacious than the linnet, and the blackbird than the thrush. Those birds which undergo a seasonal change of plumage likewise becomes much more pugnacious at the period when they are most gaily ornamented. No doubt the males of some obscurely-coloured birds fight desperately together, but it upnears that wher sexual selection has been highly influentis.l, 
and has giver bright colours to the males of any species, it he. also very often given a strong tendency to pugnacity. We shall meet with nearly analogous cases when we treat of mammals. On the other hand, with birds the power of song and brilliant colours have ravely been both acquired by the males of the same species; but in this case, the advautage gained would have been tho same, namely, success in charuing the female. Nevertheless it must be owned that the males of several brilliantly coloured birds have had their feathers specially modified for the sake of producing instrumental music, though the beaty of this cannot he compared, at least according to vur taste, with that of the vocal music of many sougsters.

We will now turu to male bircls which are not ornamented in any high degree, but which nevertheless display during their courtship whatever attractions they may possess. These cases are in some respects moro curious than the forcgoing, and have been but little noticed. I owe the following facts to Mr. Weir, who has long kept confined birds of many kinds, including all the British Fringillidx and Fmberizldx. The facts have been selected from a large body of valuable notes kindly sent me by him. The bullfinch makes his advances in front of the female, and then putt's out his breast, so that many more of the crimson feathers are seen at once than otherwise would be the case. At the same time he twists and lows his black tail from side to side in a ludicrous manuer. The male chafinch also stands in front of the female, thus shewing his red breast and "blue bell," as the fauciers call his head; the wines at the same time being slightly expanded, with the pure white linds on the shoulders thus rendered conspicuous. The (n)mun linnet distends his rosy breast, slightly expands his lrown wings and tail, so as to mali: the best of thein by cxhibiting their white edgrings. We must, however, be cautious in concludiug that the wings aro sprearl out solely for display, as some birds do so whose wings are not beautiful. 'This is the case with the domestic cock, but it is always the wing on the side opposite to the female which is expanded, and at the same time scraped on the ground. Tho male goldfiuch behaves differently from all other finches: his wings are heautiful, the shoulders being black, with the darktipped wing-feathers spotted with white and edged with golden yellow. When he courts the female, he sways his body from side to sicle, and quickly turns his slightly expanded wings first to one side, then to the other, with a golden flashing effect. Mr. Weir informs mo that no other British finch turns thus from side to side during his courtship, not even the closelyallied male siskin, for he wonld not thus add to his beauty. 
Most of the British Buntings are plain coloured birds; but in the spring the feathers on the head of the male recd-bunting (Emberiza schoenicullss) acquire a fine black colour by the abrasion of the dusky tips; and these are erected during the act of courtship. Mr. Weir has kept two species of Amadina from Australia: the A. cu:tanutis is a rery small and chastely coloured finch, with a dark tail, white rump, and jet-black upper tail-coverts, each of the latter being marked with thrce large conspicuous oval spots of white. ${ }^{91}$ This species, when courting the female, slightly spreads out and vibrates illese parti-coloured tail-coverts in a very peculinr manner. The male Amadin' Luthami behares very differently, exhibiting before the femalo his brilliantly spotted breast, scarlet rump, and scarlet upper tail-coverts. I may here add from Dr. Jerdon that the Incian bulbul (Pycronotus lixinom,ous) has its under tail-coverts of a crimson colour, and these, it might be thought, could never be well exhibited; but the bird " when excited often spreads them " out laterally, so that they can be seen even from above." The crimson under tail-coverts of some other bircls, as with one of the woodpeckers, l'icus majur, can be seen without any such display. The common pigeon has iridescent feathers on the breast, and erery one must have secn how the male inflates his breast whilst courting the female, thus shewing them off to the best adrantage. One of the beautiful bronze-winged pigeons of Australia (Ocyphaps lophutes) behares, as descrilod to me by Mr. Weir, rery differently: the male, whilst standing before the female, lowers his head almost to the ground, spreads out and raises his tail, and half expands his wings. He then alternately and slowly raises and depresses his body, so that the iridcscent metallic feathers are all scen at once, and glitter in the sun.

Sufficient facts have now been given to shew with what care male birds display their various charms, and this they do with the utmost skill. Whilst preening their feathers, they have frequent opportunities for admiring themselres, and of studying low best to exhibit their beauty. But as all the males of the same species display themselves in exactly the same manner, it appears that actions, at first perhaps intentional, hare become instinctive. If $\mathrm{S}($ ), we ought not to accuse hirds of conscious vanity; yet when we see a peacock strutting about, with espauled and quivering tail-feathers, he seems the very emblem of pride and vanity.

$\therefore$ For the description of these birds, see Gould's 'II andbook to the Birds of Australia," rol. i. 18655, p. 417.

92 'Birls of India,' $\nabla 01$. ii. P. 96. 
The various ormaments possessed ly the males are ccrtainly of the highest importance to them, fur in some cases they have been acquired at the expense of greatly impedud powers of flight or of running. The African night-jar (Cosmetornis), which during the pairing-season has one of its primary wing-feather's leveloped into a streamer of very great lungth, is thereby much retarded in its flight, although at other times remarkable for its swiftness. 'I'he "unwieldy size" of the secondary wing-feathers of the male Argus pheasant are said " almost eutirely to deprive " the bird of thight." The fine plumes of male birds of paradise trouble them during a high wiml. The extremely long tailfeathers of the male widow-birds (Vidua) of southern Africa renclur "their flight heary;" but as snon as these are cast off" they fly as well as the fumales. As birds always breed when food is abundant, the males probably do not suffer much inconvenience in searching for toul from their impected powers of movement; but there ean harilly be a doubt that they must be much more liable to be struck clown by birds of prey. Nor can we doubt that the long train of the peacock and the long tail and wing-feathers of the Argus pheasant must render them an easier prey to any prowling tiger-eat, than would otherwise be the ease. Even the lright colours of many male birds cannot fail to make them conspicuous to their enemies of all kinds. Hence, as Mr. Grould has remarked, it probably is that such birds are generally of a shy disposition, as if couscious that their beauty was a sourco of danger, and are much more difficult to discover or approach, than the sombre coloured and comparatively tamo females, or than the young and as yet unadorned males. ${ }^{93}$

It is a more curious fact that the males of some birds which are provided with special weapons for battle, and which in a state of nature are so pugnacious that they often kill each other, suffer from possessing certain ormaments. Cock-fighters trim the hackles and cut off the combs and gills of their cocks; and the birds are then said to be dubbed. An undubbed bird, as $\mathbf{M r}$. Tegetmeier insists, "is at a fearful disadrantage; the comb and "gills offer an easy hold to his adversary's beak, and as a cock "always strikes where he holds, when once he has seized his foe,

os Dn the Cosmetornis, see Liringstone's 'Expedition to the Zambesi,' 1865, p. 66 . On the Argus pheasiat, Jardine's 'Nat. Hist. Lib.: Birds,' vol. ziv. p. 167. On Birds of Paradise, Lesson, quoted by Brehm, 'Thierleben,' B. iii. s. 325. On the widow-bird, Barrow's 'Travels to Africa,' vol. i. p. '243, and 'Ibis,' vol. iii. 1861, p. 133. Mr. Gould, on the shyness of male birds, "Handbook to Birls of Australia,' rol. i. 1865, pp. $210,457$. 
" he has him entirely in his power. Even supposing that the "bird is not killed, the loss of blood suffered by an unduhbed "cock is much greater than that sustained by one that has been "trimmed." "94 Young turkey-cocks in fighting al ways seize hold of each other's wattles; and I presume that the old birds fight in the same manner. It may perhaps be objected that the comb and wattles are not ornamental, and cannot be of service to the birds in this way; but even to our eyes, the beauty of the glossy black Spanish cock is much enhanced by his white face and crimson comb; and no one who has ever seen the splendid blue wattles of the male Tragopan pheasant, distended in courtship can for a moment doubt that beauty is the object gained. Frow the foregoing facts we clearly see that the plumes and other ornaments of the males must be of the highest importance to them; and we further see that beauty is even sometimes moro important than success in battle.

\section{CHAPTER XIV.}

\section{BIRDs-continued.}

Choice exerted by the female-Length of courtship-Unpared birdsMental qualities and taste for the beautiful-Preference or antipathy shewn by the female for particular males-Variability of birds-Variations sometimes abrupt-Laws of variation-Formation of ocelliGradations of character-Case of Peacock, Argus pheasant, and Urosticte.

Whin the sexes differ in beauty, or in the power of singing, or in producing what I have called instrumental music, it is almost invariably the male who surpasses the female. These qualities, as wo have just seen, are evidently of high importance to the male. When they are gained for only a part of the year it is always before the breeding-season. It is the male alone who claborately displays his varied attractions, and often performs strange antics on the ground or in the air, in the presence of the fomale. Each male drives away, or if he can, kills his rivals. Ilence we may conclude, that it is the object of the male to induce the female to pair with him, and for this purpose he tries to excite or charm her in various ways; and this is the opinion of all those who have carefully studied the habits of living birds. But there remains a question which has an all-important bearing on sexual selection, namely, does every male of the same species excite and attract the female equally? Or does she exert a choice, and prefer certain males? This latter question can be answered in the affirmative by much direct and indirect evidence. It is far

"1 Tegetmeier, 'The Poultry Book,' 1866, p. 139. 
mure difficul's to decide what qualities determine the choice of the females; but here again wo have scme direct and indirect ovidence that it is to a large extent the external attractions of the male; though no doubt his vigour, courage, and other mental qualitics come into play. Te will begin with the incireet evidence.

I.nenth of C'ourtslip. - The lengthened period during which both sexes of certain birds meet day after day at an appointed place probably depends partly on the courtship being a prolonged affair, and partly on reiteration in the act of pairing. Thus in Germany and scamlinaria the balzing or leks of the blark-cocks last from the miclille of March, all through April into May. As many as forty or fifty, or even more birds congrecgate at the loks; and the same place is often frequented during successive years. The lek of the capercailzie lasts from the end of March to the middle or even end of May. In North America "the partridge dances" of the Tetras phasianelus "last for a month or more." Other kinds of grouse, both in North America and Eastern Siheria, ${ }^{1}$ follow nearly the same habits. The forlers discover the hillocks where the ruffs congregate by the grass being trampled bare, and this shews that the same spot is long frexuenterl. The Indians of Guiana are well acquainted with the cleared arenas, whore they expect to find the beantiful cocks of the Rock; and the natives of New Gruinen know the trees where from ten to twenty male birds of paradise in full plumage congregate. In this latter case it is not expressly stated that the females meet on the same trees, but the hunters, if not specially asked, would probably not mention their presence, as their skins are valueless. Small parties of an African weaver (I'locens) congregate, during the breeding-season, and perform for hours their graceful evolutions. Large numbers of the Solitary snipe (Scolopax mujor) assemble during dusk in a morass; and the same place is frequented for tho same purpose during successive years; here they may be scen runniag about "like so many large rats," puffing out their feathers, flapping their wings, and uttering the strangest cries."

3 Nordman describes ("Bull. Soc. Imp. des Nat. iloscou, '1861, tom. xxxiv. p. 26t) the balzen of Tetrao uragalloides in Amur Land. He estimated the number of birds assembled at above a huodred, not counting the females, which lie hid in the surrounding bushes. The noises uttered differ from those of T. urogallus.

With respect to the arsemblages of the above named grouse see Brehm, 'Thierleben,' B. iv. 8. 350; nlso L. Lloyd, 'Game Birds of Sweden,'1867, pp. 19, 78. Richardson, 'Fauna Bcr. Americana,' Birds. p. 362. Heferences in regard to the assemblages of other birds have alcealy been giren. On Paradisea see Wallace, in 'Annals and Mig. of Nat. Hist.' vol. xx. 1857, p. 413 On the snipe, I.lnyd, ibid. p. 221. 
Some of the above birds,-the black-cock, capercailzio, pheasant-grouse, ruff, Solitary snipe, and perliaps others, -are, ars is believed, polygamists. With such birds it might have been thought that the stronger males would simply have driven away the weaker, and then at once have taken possession of as many fimales as possible; but if it be indispensable for the male to excite or please the female, we can understand the length of the ('ourtship and the congregation of so many individuals of both r.xes at the same spot. Curtain strictly monogamous species likewise hold nuptial assemblages; this seems to be the case in Seandinavia with one of the ptarmigans, and their leks last from the middle of March to the middle of May. In Australia the lyre-bird (Menuru superbre) forms "small round hillocks," and the $M$. Alberti scratches for itself shallow holes, or, as they are called by the natives, corroborying places, where it is beliered hoth scxes assemble. The meetings of the $M$. superba are sometimes very large; and an account has lately been published ${ }^{3}$ by s traveller, who heard in a ralley bencath him, thickly corered with scrub, "a din which completely astonished" him; on rawling onwards he luheld to his amazement about one hunsred and fifty of the magnificent lyre-cocks, "ranged in order of "battle, and fighting with indescribalole fury." The howers of the Bower-birds are the resort of both sexes during the brecdingseason; and "here tho males meet and contend with each other "for the favours of the female, and here the latter asscmble and "coquet with the males." Writh two of the genera, the same lower is resorted to duriug inany years. ${ }^{4}$

The common magpie (Corus pirr, Linn.), as I have heen informed by the Rev. W. Darwin Fox, used to assemble from all parts of Delamere Forest, in order to celchrate the "great magjie marriage." Some years ago these hiris alounded in extraordinary numbers, so that a gamekecper killed in one morning nineteen males, and another killed ly a single shot seven birds nt roost together. They then had the habit of assembling very 'arly in the spring at particular spots, where they could be seen in flocks, chattering, sometimes fighting, bustling and flying ibout the trees. The whole affair was cvidently considered ly the hirds as one of the highest importance. Shortly after the meeting they all separated, and were then observed by Mr. Fox and others to be paired for the season. In any district in which n species does not exist in large numbers, grent assemblages ramnot, of course, he held, and the same specios may havi

Quoted by Mr. T. W. Wond in the "Student," A pril, 1870, p. 12.;.

- Gould, 'Handlook to the Birds of Australia,' rol. i. pp. $330,308$. 448,451 . On the ptarmigan, abope alluded to, see Lloyd, ibia. p. 128. 
different habits in different countries. For instance, I have leard of only one instance, from Mr. Wodderburn, of a regulur assemblage of blact game in Scothand, yet these assemblagee are so well known in Germany and scandinaria that they have received special namies.

Linquired birds.-From the farts now given, we may conclude that the courtship of birds, belonging to widely different groups, is often a prolonged, delicate, and troublesome affair. There is even reason to suspect, improballe as this will at first appear, that some males and females of the same species, inhabiting the same district, do not always please each other, and consequently du not pair. Many accounts have been published of either the unale or female of a pair having been shot, and quickly replaced ly another. This has been observed more frequently with the magpie than with any other bird, owing perhaps to its conspicnous appearance and nest. 'The illustrious Jenner states that in Wiltshire one of a pair was daily shot no less than seven times successively, "lut all to no purpose, for the remaining "magpie soon found another mate"; and the last pair reared their young. A new partner is generally found on the succeeding day; but Mr. Thompson gives the case of one being replaced on the evening of the same day. Even after the eggs are hatched, if one of the old birds is destroyed a mate will of ten be found; this nceurred after an interval of two days, in a case recently observed liy one of Sir J. Lubhock's kecpers. ${ }^{6}$ The first and most obvious ronjecture is that male magpies must be much more numerous than females; and that in the ahove cases, as well as in many others which could be given, the males alone had been killed. This apparently holds good in some instances, for the gamekecpers in Delamere Forest assured Mr. Fox that the magpies and carrion-crows which they formerly killed in succession in large numbers near their nests, were all males; and they accounted for this fact by the males being casily killed whilst bringing food to the sitting females. Macgillivray, however, gives, on the authority of an excellent observer, an instance of three magpies successively killed on the same nest, whish were all females; and another case of six magpies snceessively killed whilst sitting on the same eggs, which renders it probuble that most of them were females; though, as I hear from Mr. Fux, the male will sit on the nggs when the female is killed.

Sir J. Lubbock's gamekeeper has repeatedly shot, but how often he could not say, one of a pair of jiys (Giurrulus glandarius),

3 On magpies, Jenner, in 'Phil. Trinsact.' 1824, r. 21. Macgiliivray, 'Hist. Britis/ Birds,' vol. i.

p. 570. Thompson, in 'Anna's and Mag. of Nat. Hist.' rol. riii 19+2, p. 19 f́. 
and has never failed shortly afterwards to find the surviror re-matched. Mr. Fox, Mr. F. Bund, and others hare shot one of a pair of carrion-crows (Corvus corone), but the nest was soon again teuanted by a pair. These birds are rather common; but the peregrine-falcon (Fulco pregrinus) is rare, vet Mr. Thompsnn states that in Ireland "if either an old male or female be killed " in the breeding-season (not an uncommon circumstancc), " another mate is found within a very few days, so that the " eyries, notwithstanding such casualties, are sure to turn out " their complement of young." Mr. Jenner Weir has known the same thing with the peregrine-falcons at Beachy Head. The same observer informs me that three kestrels (Falco tinnunculus), all males, were killed one after the other whilst attending the same nest; two of these were in mature plumage, but the third was in the plumage of the previous year. Even with the rare golden eagle (Aquila chrysaëtos), Mr. Birkbeck was assured by a trustworthy gamekeeper in Scotland, that if one is killed, another is soon found. So with the white owl (Strix flammen), "tho "survivor readily found a mate, and the mischief went on."

White of Selborne, who gives the case of the owl, adds that he knew a man, who from believing that partridges when pairel were disturbed by the males fighting, used to shoot them; and though he had widowed the same female several times, sho always soon found a fresh partuer. This same maturalist ordered the sparrows, which deprived the house-martins of their nests, to be shot; but the one which was left, "be it cock or hen, " presently procured a mate, and so for several times following." I could add analogous cases relating to the chaffinch, nightiugale, and redstart. With respect to the latter bird (Yhopnicure ruticilla), a writer expresses much surprise how the sitting femalo could so soon have given effectual notice that she was a widow, for the species was not comamon in the neighbourhood. MIr. Jenner Weir has mentioned to me a nearly similar case; at Blackhenth he never sces or hears the note of the wild bullfinch, yet when one of his caged males has died, a wild one in the course of a few days has generally come and perched near the widowerl female, whose call-note is not lour. I will give only one other fact, on the authority of this same observer; one of a pair of starlings (curnus vulgaris) was shot in the morning; by noon a new mate was found; this was again shot, but before night the pair was complete; so that the disconsolate widow or widower was thrice consoled during the same day. Mr. Engleheart also informs me that he used during several ycars to shoot one of a pair of starlings which built in a bole in a house at Blackheath ; but the loss ras always immediately repairal. J)uring one 
season he kept an account, and found that he had shot thirty-five birds from the same nest; these consisted of both males and females, but in what proportion he could not say : nevertheless, after all this destruction, a brood was reared. ${ }^{6}$

These facts well deserve attention. Huw is it that there are birds enough, ready to replace immediately a lost mate of either. sex? Magpies, jays, carrion-crows, partridges, and somo other birds, are always seen during the spring in pairs, and never by themselves; and these offer at first sight the most perplexing cases. But birds of the same sex, although of course not truly paired, sometimes live in pairs or in smali parties, as is knowr. to be the case with pigeons and partridges. Birds also sometimes lire in triplets, as has been obserred with starlings, carrion-crows, parrots, and partriclges. With partriclges two females have becn known to live with one male, and two males with one female. In all such cases it is probable that the union would be easily luken; and one of the three would readily pair with a widow or widower. The males of certain birds may occasionally be heard pouring forth their lore-soug long after the proper time, shewing that they hare either lost or never gained a mate. Death from accident or discase of one of a pair, would leave the other free and single; and there is reason to believe that female birds during the breeding-season are especially liable to premature leath. Again, birds which have had their nests destroyed, or barren pairs, or retarded individuals, would easily be induced to lesert their mates, and would probably be glad to take what share they could of the pleasures and duties of rearing offspring: although not their own. ${ }^{\tau}$ Such contingencies as these probably explain most of the foregoing cases. ${ }^{8}$ Nevertheless, it is a strange

6 On the peregrine falcon see Thompson, 'Nat. Hist. of Ireland, Birds, rol. i. 1849, p. 39. On owls, sparrows, and partriliges, see White, 'Nat. Hist. of Selborne, edit. of 1825, vol. i. p. 139. On the Phonicura, see Loudon's 'Mag. of Nat. Hist.' vol. vii. 1834, p. 245. Br'ehm ('Thierleben,' B. ir. s. 991) also alludes to cases of birds thrice mated during the same day.

See White ('Nat. Hist. of Selborne,' 1825 , rol. i. p. 140) on the existence, early in the senson, of small coreys of male partridges, of which fact I have heard other instarces. See Jenner, on the retarded ktate of the generative organs in certain birls, in 'Phil. Transact.'
1824. In regard to birds living in triplets, I owe to Mr. Jenner Weir the cases of the starlings and parrots, and to Mr. Fox, of partridges; on carrion-crows, see the 'Field,' 1868 , p. 415. On various male birds singing after the proper period, see Rev. L. Jenyns, "Observations in Natural History,' 1846 , p. 87.

- The following case has been given ('The Times,' Aug. 6th, 180s) by the Rev. F. O. Murris, on the authority of the Hon, and Rev. 0 . W. Forester. "The gamekeeper "here found a hawk's nest this year, "with five young ones on it. He "took four" and killed them, but "left one with its wings clipped a* " a decoy to destroy the old ones by. 
fact that within the same district, during the height of the breeding-season, there should be so many males and females always ready to repair the loss of a mated bird. Why do not such spare birds immediately pair together? Hare we not some reason to suspect, and the suspicion has oceurred to Mr. Jenner Weir, that as the courtship of birds appears to be in many cases prolonged and tedions, so it occasionally happens that certain males and females do not succeed during the proper season, in cxciting cach other's love, and consequently do not frair? This suspicion will appear somewhat less improbable after we lave seen what strong antipathies and preferences f(male birds occasionally evince towards particular males.

Mlentul Qunlities of Birds, and their Taste for the Peautiful.Tiefore we further discuss the question whether the females sclect the more attractive males or accept the first whom they snay encounter, it will be advisable briefly to consider the mental powers of birds. Their reason is generally, and perhaps justly, ranked as low ; yet some facts could be given ${ }^{9}$ luading to an oiposite conclusion. Low powers of reasoning, however, are compatible, as wo see with mankiud, with strong affections, acute perecption, and a taste for the beautiful ; and it is with these latter qualities that we are here conccrned. It has often heen said that parrots become so decply attached to each other that when one dies the other pines for a long time; but Mr. Jenner Weir thinks that with most birds the strength of their affection has been much exagrerated. Nevertheless when one of a mir in a state of nature has been shot, the surriror has been heard for days afterwards uttering a plaintive call; and Mr. St. John gives varions facts proving the attachment of mated birds. ${ }^{10}$

"They were both shot next day, in "the act of feeding the young one, "and the keeper thought it was "done with. The next day he came "again and found two other chari"table hawks, who had come with "an adopted feeling to succour the "orphan. These $t$ wo he killed, and "then left the nest. On returning "afterwards he found two more "charitable individuals on the same "errand of mercy. One of these he "killed; the other he also shot, "but could not find. No more "came on the like firuitless errand." - I am indebted to Prof. Newton for the fol'owing passage from Mr. Adam's "Travels of a Naturalist,"
1870 , ก. 278. Speaking of Japanese nut-hatches in confinement he says: "Instead of the more yielding fruit " of the yew, which is the usual "food of the nut-hatch of Japan, at "one time I substituted hard hazel"nuts. As the bird was unable "to crack them, he placed them one "by one in his water-glass, evideatly "with the notion that they would "in time become softer-an interest"ing proof of intelligence on the "part of these birds."

10 'A Tour in Sutherlandshire, rol. i. 1849, p. 185 . Dr. Buller snys ('Birds of New Tenland,' 18:', p. 56) that a male King Lory was killer; and the female "fretted and 
Mr. Bennett relates ${ }^{1}$ that in China after a drake of the beautiful mandarin Teal had been stolen, the duck remained disconsolate, though sedulonsly courted by another mandarin drake, who displayed before her all his charms. After an interval of three weeks the stolen drake was recovered, and instantly the pair rncognised each other with extreme joy. On the other hand starlings, as we have seen, may be consoled thrice in the same day for the loss of their mates. P'igeons have such excellent local memories, that they have bech known to return to their former homes after an interval of nine months, yet, as I hear from Mr. Harrison Weir, if a pair which naturally would romain mated for life be separated for a few weeks during the winter, and afterwards matched with other birds, the two, when brought together again, rarely, if ever, recognise cach other.

Birds sometimes exhibit benevolent feelings; they will feed the deserted young ones eren of distinct species, but this perhaps ought to be considered as a mistaken instinct. They will feed, as shewn in an earlier part of this work, adult birds of their own species which have become blind. Mr. Buxton gives a curious account of a parrot which took care of a frost-bitten and crippled bird of a distinct species, cleansed her feathers, and defonded her from the attacks of the other parrots which roamed frecly about his garden. It is a still more curious fact that these birds apparently evince some sympathy for the pleasures of their fellows. Then a pair of cockatoos made a nest in an acacia tree, "it was ridiculous to see the extravagant interest taken in "the matter by the others of the same species." These parrots, also, evinced unbounded curiosity, and clearly had "the idea of " property and possession." ${ }^{12}$ They have good memories, for in the Zoological Gardens they have plainly recognised their former masters after an interval of some months.

Birds possess acute powers of olservation. Evory mated bird, of course, recognises its fellow. Audubon states that a certain number of mocking-thrushes (Mimus polyglutins) remain all the year round in Louisiana, whilst others migrate to the Eastern States; these latter, on their return, are instantly recogniscd, and always attacked, by their southeru brethren. Bircls under confinement distinguish different persons, as is proved by tho strong and permanent antipatly or affection which they shew, without any apparent cause, towards certain individuals. I

"moped, refused her food, an't died

" of a broken honte"

"1 "Wanderiags in New Soluth 4.'es: vol. ii. 18.34, p. 62 .
12 'Acslimatization of Parrots, by C. Y'uxton, M1.P'. 'Annals and Ming. of Nitt. Hist.' Nuv. 1868, p 381. 
have heard of numerous instances with jays, partridges, canaries, and especially bullfinches. Mr. Hussey has described in how extraordinary a manner a tamed partridge recomnised everybody; and its likes and dislikes were very strong. This hird seemed "fond of gray colours, and no new gown or cap could be put on "withont catching his attention." 13 MLr. Herritt has described the halits of some ducks (recently descended from wild birds), which, at the approach of a strange dog or cat, would rush headlong in to the water, and exhaust themselres in their attempts to escape; but they knew Mrr. Hewitt's own dogs and cats so well, that they would lie down and bask in the sun close to them. They always mored away from a strange man, and so they would from the lady who attended them, if she made any great change in her dress. Audubon relates that he reared and tamed a wild turkey which always ran away from any strange dog; this bird escaped into the woods, and some days afterwards Auduhon saw, as he thought, a wild turkey, and made his dog chase it; but to his astonishment, the bird did not run amay, and the dog, when he came mp, did not attack the bird, for they mutually recognised each other as old friends. ${ }^{14}$

Mr. Jenner Weir is convinced that birds pay particular attention to the colours of other birds, sometimes out of jealousy, and sometimes as a sign of kinship. Thus he turned a reed-bunting (Embrriza schoniculus), which bad acquired its black head-dress, into his aviary, and the new-comer was not noticed hy any bird, except by a bullfinch, which is likemise llack-headed. This bullfinch was a very quiet bird, and had nerer before quarrelled with ary of its comrades, including another reed-bunting, which had not as yet become black-headed: but the reed-bunting with a black head was so unmercifully treated, that it liad to be removed. Spiza cyanea, during the breeding-season, is of a bright whe colour; and though generally peacenble, it attacked S. ciris, which has only the head blue, and completely scalped the unfortunate bird. Mr. Weir was also obliged to turn out a robin, as it fiercely attacked all the birds in his aviary with any red in their plumage, bnt no other kinds; it actually killed a red-breasted crossbill, and nearly killed a goldfinch. On the other hand, he has observed that some birds, when first introduced, fly towards the species which resemble them most in colour, and settle by their sides.

As male birds display their fine plumage and other ornaments

13 'The 'Lonlogist,' 1847-1848, p. 1602.

is Hewitt on wild ducks, 'Journal of Horticulture,' Jan. 13, 1863, p. 39. Auduton on the wild tarkey, 'Ornith. Biozraphy,' rol. i. p. 14. On the moching-thruss, ibid. vol. i p. 110 . 
with so much care before the fumales, it is obviously probable that these appreciate the beauty of their suitors. It is, however, difficult to obtain direct evidence of their capacity to aprreciato beauty. When birds gaze at themselves in a looking-glass (of which many instanoes have been recorled) wo cannot feel swro that it is not from jealousy of a supposed rival, though this is nut the conclusion of some olsservers. In other cases it is difticult to listinguish between mere curiosity and admiration. It is perhaps the former feeling which, as stated by Lord Lilford, ${ }^{15}$ attriu'ts the ruff towards any bright object, so that, in the Ionian Islands, "it will dart down to a bright-coloured handkerchief, regardluss "of repeated shots." The common lark is drawn down from the sky, and is caught in large numbers, by a small mirror made to move and glitter in the sun. Is it admiration or curiosity which leads the magpie, raven, and some other birds to steal and socrete bright objects, such as silver articles or jewels?

Mr. Gould states that certain humming-birds decorate the outsides of their nests "with the utmost taste; they instinctirely "fasten thereon beautiful pieces of flat lichen, the larger pieces " in the middle, and the smaller on the part attached to the "branch. Now and then a pretty feather" is intertwined or "fastened to the outer sides, the stem being always so placed, "that the feather stands out beyond the surface." The best evidence, however, of a taste for the beantiful is afforded by the three genera of Australian bower-birds already mentioned. 'Their' bowers (see fig. 46 , p. 38\%), where the seses congregate and play strange antics, are variously constructed, but what most concerns us is, that they are decorated by the several species in a different manuer. The Satin bower-bird collects gaily-coloured articles, such as the blue tail-feathers of parrakeets, bleached bones and shells, which it sticks between the twigs, or arranges at tho entrance. Mr. Gould found in one bower a neatly-worked stone tomahawk and a slip of blue cotton, evidently procured from a native encampment. These objects are continually re-arrangerl, and carried about by the birds whilst at play. The bower of the Spotted bower-bird " is beautifully lined with tall grasses, so "disposed that the heads nearly meet, and the decorations aro "very profuse." Round stones are used to kcep the grass-stems in their proper places, and to make divergent paths leading to the bower. The stones and shells are often brought from a great distance. The Regent bird, as described by Mr. Ramsay, ornaments its short bower with bleached land-shells belonging to five or six species, and with "berries of various colours, blue, red, " and black, which give it when fresh, a very pretty appenranco

ss The 'Ibis,' rol. ii. 1860, p. 344. 
"Besides these there were several newly-picked leaves and " young shoots of a pinkish colour, the whole showing a de" cided taste for the beantiful." Well may Mr. Gould say, that "these highly decorated halls of assembly must be regarded as "the most wonderful instances of bird-architecture yet dis"curercd;" and the taste, as we seo, of the sereral species certainly differs. ${ }^{16}$

Preference for particular Mules by the Females.-Having made these preliminary remarks on the discrimination and taste of birds, I will give all the facts known to me, which bear on the preference shewn by the female for particular males. It is certain that distinct species of birds occasionally pair in a state of nature and produce hybrids. Many iustances could be given: thus Macgillivray relates how a male blackbird and female thush "fell in love with each other," and produced offspring. ${ }^{17}$ Several years ago eighteen cases had been recorded of the occurrence in Gireat Britain of bybrids between the black grouse and pheasant; ${ }^{18}$ but most of these cases may perhaps be accounted for by solitary birds not finding one of their own species to pair with. With other birds, as Mr. Jenner Weir has reason to believe, hybrids are sometimes the result of the casual intercourse of birds builring in close proximity. But these remarks do not apply to the many recorded instances of tamed or domestic birds, belonging to distinct species, which have become absolutely fascinated with each other, although living with their own species. Thus Waterton ${ }^{19}$ states that out of a flock of twenty-three Canada geese, a female paired with a solitary Cerniclo gander, althongh so different in appearance and size; and they produced hybricl offspring. A ruale widgeon (Marea penelope), living with females of the same species, has been known to pair witls a pintail duck, Querrudula acutu. Lloyd describes the remarkable attachment between a shielddrake (Tudorria vulpanser) and a common duck. Many ad-

16 On the ornamented nests of humming-birds, Gould, 'Introduction to the Trochilidx,' 1861 , p. 19. On the bower-birds, Gould, 'Handbook to the Birds of Australia, 1865 , rol. i. pp. 414-461. Ramsay, in the 'Ibis," 1867, p. 456.

17 'Hist. of British Birds,' vol, ii. p. 92.

18 'Zooicgist,' 1853-1854, p.

1s Waterton, 'Essays on Nat. Fist.' 2nd series, pp. 42 and 117.
For the following statements, see on the widgeon, Loudon's 'Mag. of Nat Hist.' vol. ix. p. 616 ; L. Lloyd, 'Scandinavian Adrentures,' vol. i. $185 t$, p. 452. Dixon, 'Ornamental and Domestic Poultry,' p. 137 ; Hewitt, in 'Journal of Horticulture,' Jay. 13,1863 , p. 40 ; Bechstein,' 'Stubenvögel,' 1840, s. 230. Mr. J. Jenner Weir has lately given me an anaingous case with ducks of twe spectes 
ditional instances could be given; and the Rev. E. S. Dizon remarks that "those who have kept many different species of "geese together, wcll know what. unaccountable attachmouts " they are frequently forming, and that they are quite as likely "to pair and rear young with individuals of a race (specier) "apparently the most alien to themselves, as with their ow: "stock."

The Rev. W. D. Fox informs me that he possessed at the same time a pair of Chinese geese (Anser cygnoides), and a common gander witl three geese. The two luts kept quite separate, until the Chinese gander seduced one of the common geese to live with him. Moreover, of the young birds batched from the eggrs of the common geese, only four were pure, the other eighteen proving hybrids; so that the Chinese gander seems to hare had prepotent charms over the common gander. I will give only one other case; Mrr. Hewitt states that a wild duck, reared iu captivity, "after breeding a couple of seasons with her" " own inallard, at once shook him off on my placing a male "Pintail on the water. It was evidently a case of love at first "sight, for she swam about the new-comer caressingly, though " he appeared evidently alarmed and averse to her overtures of "affection. From that hour she forgot her old partner. Winter "passed by, and the next spring the Pintail seemed to have " become a convert to her blandishments, for they nested and "produced seven or eight young ones."

What the charm may have been in these several cases, boyond mere novelty, we cannot even conjecture. Colour, however, sometimes comes into play; for in order to raise hybrids from the siskin (Fringilla sprinus) and the canary, it is much the best plan, according to Bechstein, to place birds of the same tint together. Mr. Jenner Weir turned a female canary into his aviary, where there were male linnets, goldfinches, siskins, greenfinches, chaftinches, and other birds, in order to see which she would choose; but there never was any doubt, and the greenfinch carried the day. They paired and produced hybril offspring.

The fact of the female preferring to pair with one male rather than with another of the same species, is not so likcly to excito attention, as when this occurs, as we have just seen, between distinct species. The former cases can best be observed with domesticated or confined birds; but these are cften pampered by high feeding, and sometimes have their instincts vitiated to an extreme degrce. Of this latter fact I could gire sufficient proofs with pigeons, aud especially with fowls, but they cannot we here related. Titiater instincts may also account for snme 
of the hybrid unions above mentioned; but in many of thuse cases the birds were allowed to range freely over large ponds, and there is no reason to suppose that they were unnaturally stimnlated by high feeding.

With respect to birds in a state of nature, the first and most obvious supposition which will occur to every one is that tho temale at the proper scason accepts the first male whom she may encounter; but she has at least the opportunity for exerting a choice, as she is almost invariably pursued by many males. Audubon-and we must remember that he spent a long life in mowling about the forests of the United States and observing the birds-does not doubt that the female deliberately chooses her mate; thus, speaking of a woodpecker, he says the hen is fullowed by half-a-dozen gay suitors, who continue performing strange antics, "until a marked preference is shewn for one." The female of the red-winged starling (Ayclaus phocniceus) is likewise pursued by several males, "until, becoming fatigued, "she alights, receives their addresses, and soon makes a choice." He describes also how several male night-jars repeatedly plunge through the air with astonishing rapidity, suddenly turning, and thus making a singular noise; "but no sooner has the female "made her choice, than the other males are driven arvay." With one of the vultures (Cuthurtes auru) of the United States, parties of eight, ten, or more males and fumales assemble on fallen logs, "exhibiting the strongest desire to please mutually," and after many caresses, each male leads off his partner on tho wing. Audubon likewise curefully observed the wild flocks of Canada geese (Anser cunullensis), and gives a graphic description of their love-antics; he says that the birds which had been freviously mated "renewed their courtship as early as the "mouth of January, while the others would be contending or " coquetting for hours every day, until all seemed satisfied with "the choice they had mide, after which, although they re. " mained together, any person could easily perceive that they " were careful to keep in pairs. I have observed also that the " olier the birds, the shorter were the preliminaries of their" " courtship. The bachelors and old maids, whether in regret, " or not caring to be disturbed by the bustle, quietly moved "aside and lay down at some distance from the rest." ${ }^{\circ}$ Many similar statements with respect to other birds could be cited from this same observer.

Turning now to domesticated and confined birds, I will commence by giving what little I have learnt respecting the 20 Audubon 'Ornitholog. Biography, vol. i. pp. 191, 349; vol. ii. pp. 42, 275 ; vol. iii. p. 2. 
courtahip of fowls. I have received long letters on this subject from Messrs. Hewitt and Tegetmeier, and almost an essay from the late Mr. Brent. It will bo admitted by every one that these gentlemen, so well known from their published works, are careful and experienced observers. They do not believe that the females prefer certain males on account of the beauty of their plumage; but some allowance must bo made for the artificial state under which these birds have loug been kept. Mr. T'egetmeier is convinced that a game-cock, though disfigured by being dubbed and with his backles trimmed, would be accepted as readily as a male retaining all his natural ornaments. Mr. Bient, howerer, almits that the beauty of the male probably aids in exciting the female; and her acquiescence is necessary. Mr. Hewitt is convinced that the union is by no means left to mere chance, for the femalo almost invariably prefers the most vigorous, defiant, and mettlesome male; hence it is almost useless, as he remarks, "to attempt true breeding if a game-cock " in good health and condition runs the locality, for almost " every hen on leaving the roosting-place will resort to the "game-cock, even though that bird may not actually drive "away the male of her own variety." Under ordinary circumstances the males and females of the forl seem to come to a mutual understanding by means of certain gestures, described to me by Mr. Brent. But hens will often avoid the officious attentions of young males. Old hens, and hens of a pugnacious disposition, as the same writer informs me, dislike strange males, and will not yield until well beaten into compliance. Ferguson, however, describes how a quarrelsome hen was subdued by the gentle courtship of a Shanghai cock. ${ }^{21}$

There is reason to believe that pigeons of both sexes prefer pairing with birds of the same breed; and dorecot-pigeons lislike all the highly improved breeds. ${ }^{22}$ Mr. Harrison Weir thas lately heard from a trustworthy observer, who keeps blue pigeons, that to ese drive away all other coloured varieties, such as white, red, and yellow; and from another observer, that a female dun carrier conld not, after repeated trials, be matched with a black male, but immediately paired with a dun. Again. Ir. Tegetmeier had a female blue turbit that obstinately refused to pair with two males of the same breed, which were successively shut up with her for weeks; but on being let out she would have immediately accepted the first blue dragon that offered. As she was a valuable bird, she was then shut up for

21 'Rare and Prize Poultry,' 185t, f. 27.

Plants under Domestication,' vol. i? p. 103. 
many weeks with a silrer (i.e., rery pale blue) male, and at last mated with him. Nevertheless, as a gencral rule, colour appears to have little influence on the pairing of pigeons. Mr. Tegetmeier, at my request, stained some of his birds with magenta. but they were not much noticed by the others.

Female pigeons occasionally feel a strong antipathy towards certain males, without any assignable cause. Thus MM. Boitard and Corbié, whose experience extended over forty-five years, state: "Quand une femelle ćprouve de l'antipathie pour un "mâle avec lequel on veut l'accoupler, malgré tous les feux " de l'amour, malgré l'alpiste et le chènevis dont on la nourrit "pour augmenter son ardeur, malgré un emprisonnement de "six mois et même d'un an, elle refuse constamment ses " caresses; les arances empressées, les agaceries, les tournoit"mens, les tendres roucoulemens, rien ne peut lui plaire ni "l'émouvoir"; gonflée, boudeuse, blottie dans un coin de sa " prison, elle n'en sort que pour boire et manger, ou pour re" pousscr arcc une cspèce de rage des caresses devenues trop pres" santes." 23 On the other hand, Mr. Harrison Weir has himself observed, and has heard from several breeders, that a female pigcon will occasionally take a strong fancy for a particular male, and will desert her own matc for him. Some females, according to another experienced observer, Riedel, ${ }^{24}$ are of a profligate disposition, and prefer almost any stranger to their own mate. Some amorous males, called by our English fanciers "gay hirds," are so successful in thcir gallantries, that, as Mr. H. Weir informs me, they mist be shut up on account of the :nischief which they cause.

Wild turkeys in the United States, according to Audubon, $\because$ sometimes pay their addresses to the domesticated females, " and are generally received by them with great pleasure." So that these females apparently prefer the wild to their own males. ${ }^{25}$

Here is a more curious case. Sir R. Heron during many years irept an account of the habits of the peafowl, which he bred in large numbers. Ho states that " the hens have frequently great "preference to a particular peacock. They were all so fond " of an old pied cock, that one year, when he was confined " though still in view, they were constantly assembled close to " the trellice-walls of his prison, and would not suffer a japanned

${ }^{23}$ Boitard and Corbié, 'Les Pigeons, \&c.', 1824, p. 12. Prosper Lucas ('Truité de l'Héréd. Nat.' tom. ii. 1850, p. 296) has himself observed nearly similar facts with pigeor.s
24 'Die Taubenzucht,' 1824, :. 86. 23 'Orn'thological Bi-graphy,' vol. i. p. 13. See to the same elfict, D1. Bryant, in 'Allen's Max mals and Birds of Florida? p. 344. 
"pacock to touch them. On his being let out in the autumn, "the oldest of the hens instantly courted him, and was success"ful in her courtship. The next year he was shut up in a stable, "and then the hens all courted his rival." 26 This rival was a japanned or black-winged peacock, to our cyes a more beautiful bird than the common kind.

Tichtenstein, who was a good ohserver and had excellent opportunities of observation at the Cape of Good Hope, assured Rudolphi that the fumale widow-bird (Chera progne) disowns the male, when robbed of the long tail-feathers with which he is crnamented during the breeding-season. I presume that this observation must have been male on birds under confinement. ${ }^{27}$ Here is an analogous case; Dr. Jaeger, ${ }^{28}$ director of the Zoological Gardens, of Vicnna, states that a male silver-pheasant, who had been triumphant orer all other males and was the accepter lover of the females, had his ornamental plumage spoiled. He was then immediately superseded by a rival, who got the upper hand and afterwards led the flock.

It is a remarkable fact, as shewing how important colour is in. the courtship of birds, that Mr. Boardman, a well-known collector and observer of birds for many years in the Northern United States, has never in his large experience seen an albino. paired with another bircl; yet he has had opportunities of observing many albinos belonging to several species. ${ }^{29}$ It can hardly bo maintained that albinos in a state of nature are incapable of brocding, as they can be raised with the greatest. facility under confinement. It appears, therefore, that we must attribute the fact that they do not pair, to their rejection by their normally coloured comrades.

Female birds not only exert a choice, but in some few cascs, they court the male, or even fight together for his possession. Sir R. Heron states that with peafowl, the first advances are always made by the female; something of the same kind takes place, according to Audubon, with the older females of the wild turkey. With tine capercailzie, the females flit round the male. whilst he is parading at one of the places of assemblage, and solicit his attention. ${ }^{30}$ We have seen that a tame wild-duck

28 'Proc. Zool. Soc.' 1835, p. 54. The japanned peacock is considered by Mr. Sclater as a distinct species, and has been named Pavo nigripennis; but the evidence seems to me to shew that it is only a variety.

27 Rudolphi, 'Beyträge zur Anth ropologie,' 1812 , s. 184.

* 'Dio Darwin'sche Theorie, und thre Stellung zu Moral und Religion,' 1869 , s. 59.

29 This statement is given by $\mathrm{M}_{1}$ A. Leith Adams, in his 'Field an Forest Rambles,' 1873, p. 76, and accords with his owa experience

30 ID regard to peafowl, see Sis

R. Horon, 'Proc, Zcolog. Soc.' 1835

p. 54, and the Rev. E. S. Dixom 
seduccd an unwilling pintail drake aftur a long courtship. Mr. Bartlett belicves that the Lophophorus, like many other gallinnceous birds, is naturally polygamous, but two fernales cannot $h_{\mu}$. placed in the same cage with a male, as they fight so much together. The following instance of rivalry is more surprising as it relates to bullfinches, which usually pair for life. Mr. Jenner Weir introduced a dull-coloured and ugly female into his aviary, and she immediately attacked another mated femalo so unmercifully, that the latter had to be separated. 'The new female did all the courtship, and was at last successful, for she paired with the male; but after a time she met with a just retribution, for, ceasing to be pugnacious, she was replaced by the old female, and the male then deserted his now and returned to his old love.

In all ordinary cases the male is so eager that he will accept any female, and does not, as far as we can judge, prefer one to the other; but, as we shall hereafter see, exceptions to this rule apparently occur in some few groups. With domesticated birds, I have heard of only one case of males shewing any preference for certain females, namely, that of the domestic cock, who, according to the high authority of Mr. Hewitt, prefers the younger to the older hens. On the other hand, in effecting hybrid unions between the male pheasant and common hens, Mr. Hewitt is convinced that the pheasant invariably prefers the older birds. He does not appear to be in the least influenced by their colour, but " is most capricious in his attachments:" 31 from some inexplicable cause he shews the mast determined aversion to certain hens, which no care on the part of the breeder can overcome. Mr. Hewitt informs me that some hens are quite unattractive even to the males of their own species, so that they may be kept with several cocks during a whole season, and not one egg out of forty or fifty will prove fertile. On the other hand, with the Long-tailed duck (IJareldre glacialis), "it has been remarked," says M. Ekström, "that certain females " are much more courted than the rest. Frequently, indeed, "one sees an individual surrounded by six or eight amorous "males." Whether this statement is credible, I know not; but the native sportsmen shoot these females in order to stuff then as decoys. ${ }^{\text {s }}$

With respect to female birds feeling a preference for particular

Ornamental Poultry,' 1848, p. \&. For the turkey, Audubon, ibia. p. 4. For she capercailzie, Lloyd, 'Gaue llird of Sweden," 1867, p. 23.
3: Mr. Hewitt, q'oted in 'Tegetmeier's Poultry Book,' 1866, p. 165.

32 Qunted in Lloyd's 'Game Birds of Sweden?' p. 34:. 
Inales, we must bear in mind that we ean judge of choice being exerted, only by analogy. If an inhabitant of another plauct were to behold a number of young rustics at a fair courting a pretty girl, and quarrelling about her like birds at one of their places of assemblage, he would, by the eagerness of the wooers to please her and to display their finery, infer that she had the power of choice. Now with birds, the evidence stancls thus; they have acute powers of observation, and they seem to have some taste for the beatiful both in colour and sound. It is certain that the females occasionally exhibit, from unknown causes, the strongest antipathies and preferences for particular males. When the sexes differ in colour or in other ornaments the males with rare exceptions are the more decorated, either permanently or temporarily during the breeding-season. The: sedulously display their various ornaments, exert their voices, and perform strange antics in the presence of the females. Even well-armed males, who, it might be thought, would altogether depend for success on the law of battle, are in most cases highly ornamented; and their ornaments have been acquired at the expense of some loss of power. In other cases ornaments have been acquired, at the cost of increased risk from birds and beasts of prey. With various species many individuals of both sexes congregate at the same spot, and their courtship is a prolonged affair. There is even reason to suspect that the males and females within the same district do not always succeed in pleasing each other and pairing.

What then are we to conclude from these facts and considerations? Does the male parade his charms with so much pomp and rivalry for no purpose? Are we not justified in believing that the female exerts a choice, and that she receives the addresses of the male who pleases her most? It is not probable that she conscionsly deliberates; but she is most excited or attracted by the most bcautiful, or melodious, or gallant males. Nor need it be supposed that the female studies each stripe or spot of colour; that the peahen, for instance, admires each detail in the gorgeous train of the peacock-she is probably struck only by the general effect. Nevertheless, after hearing how carcfully the inale Argus pheasant displays his clegant primary wing-feathers, and erects his ocellated plumes in the right position for their lull effect; or again, how the male goldfinch alternately displays: his gold-bespangled wings, we ought not to feel too sure that the female does not attend to each detail of bcauty. We can judge, as already renurked, of choice being exerted, only from analogy: and the mental porvers of birds do not differ fundamentally frum ours. From these various considerations we may couclude thut 
the pairing of birds is not left to chance; but that those males, which are best able by their various charms to please or excite the female, are under ordinary circumstances accepted. If this be admitted, there is not much difficulty in understanding how male birds have gradually acquired their ornamental characters. All animals present individual differences, and as man can modify his domesticated birds by selecting the indiriduals which appear to him the most beautiful, so the habitual or even occasional preference by the female of the more attractive males would almost certainly lead to their modification; and such modifications might in the course of time be angmented to almost any extent, compatible with the existence of the species.

Variability of Birds, and especiully of their Secondury Sexual Characters.-Variability and inheritance are the foundations for the work of selection. That domesticated birds have varied greatly, their variations being inherited, is certain. That birds in a state of nature have been modified into distinct races is now universally admitted. ${ }^{33}$ Variations may be divided into two classes ; those which appear to our ignorance to arise spontaneously, and those which are directly related to the surrounding conditions, so that all or nearly all the individuals of the same species are similarly modified. Cases of the latter kind have recently been observed with care by Mr. J. A. Allen, ${ }^{34}$ who shews

23 According to Dr. Blasius ('Ibis,' vol. ii. 1860, p. 297), there are 425 indubitable species of birds which breed in Europe, besides sixty forms, which are frequently regarded as distinct species. Of the latter, Blasius thinks that ouly ten are really doubtful, and that the other fifty ought to be united with their nearest allies; but this shews that there must be a considerable amount of variation with some of our European birds. It is also an unsettled point with naturalists, whether several North American birds ought to be rauked as specifically distinct from the corresponding European species. So again many North American forms which until lately were named as distinct species, are now considered to be local races.

24 'Mammals and Birds of East Florida,' also an 'Ornithological Reconnaissance of Kansas, \&c. Notrithstanding the influence of climate an the colours of birds, it is difficult to account for the dull or dark tints of almost all the species inhabiting certain countries, for instance, the Galapagos Islands under. the equator, the wide temperate plains of Patagonia, and, as it appears, Egypt (see Mr. Hartshorne in the 'American Naturalist,' 1873, p. 747). These countries are open, and afford little shelter to birds; but it seems doubtful whether the absence of brightly coloured species can be explained on the principle of protection, for on the Pampas, which are equalty open, though covered ky green grass, and where the birds would be equally exposed to danger, many brilliant and conspicuously coloured species are common. I have sometimes speculated whether the prevailing dull tints of the scenery in the above named countries may not have affected the appreciation of bright colours by the bircs inhabiting them. 
that in the United States many species of birds gradually become more strongly coloured in proceeding southward, and more lightly coloured in proceeding westward to the arid plains of the interior. Both sexes seem generally to be affected in a like manmer, but sometimes one sex more than the other. This result is not incompatible with the belief that the colours of birds are mainly due to the accumulation of successive variations through sexual selection; for even after the sexes have jeen greatly differentiated, climate might produce an equal effect on both sexes, or a greater effect on one sex than on the other, owing to some constitutional difference.

Individual differences hetween the nembers of the same species are admitted by crery one to occur under a state of vature. Sudden and strongly marked variations are rare; it is also doubtful whether if bencticial they would often be preserved through selection and transmitted to succeeding generations. ${ }^{35}$ Nevertheless, it may be worth while to give the few cases which I have been able to collect, relating chiefly to colour,--simple albinism and melanism being excluded. Mr. Gould is well known to admit the existence of few varieties, for he esteems very slight differences as specific; yet he states ${ }^{36}$ that near Bogota certain humming-birds belonging to the genus Cynanthus are divided into two or three races or varieties, which differ from each other in the colouring of the tail _- some having the "whole of the feathers blue, while others have the eight central " ones tipped with beautiful green." It does not appear that intermediato gradations have been observed in this or the following cases. In the males alone of one of the Australian parrakeets "the thighs in some are scarlet, in others grass"green." In another parrakeet of the same country "some "individuals have the band across the wing-coverts bright-

35 'Origin of Species,' fifth edit. 1869 , p. 104. I had always perceived, that rare and stronglymarked deviations of structure, deserving to be called monstrosities, could seldom be preserved through natural selection, and that the preservation of even highly-beneficial variations would depend to a certain extent on chance. I had also fully appreciated the importance of mere individual differences, and this led me to insist so strongly on the importance of that unconscious form of selection by man, which follows from the preservation of tha most valued individuals of ench breed, without any intention on his part to modify the characters of the breed. But until I read an ablo article in the 'North British Review ' (March 1867, p. 289, et seq.), which has been of more use to me than any other Review, I did not see how great the chances were against the preservation of variations, whether slight or strongly pronounced, occurring only in singie individuals.

36 "Introduct. to the Trochilidse, p. 102. 
" zellow, while in others the samo part is tinged with red." $3 *$ In the United States some few of the males of the Scarlet Tanager (Taragra rubra) have "a beautiful transrerse band of glorving "red on the smaller wing-corerts;" ${ }^{8}$ but this variation seems to be somewhat rare, so that its preservation through scxual selection would follow only under unusually favourable circumstances. In Bengal the Honey buzzard (Pernis cristatu) has either a small rudimental crest on its head, or none at all : so slight a difference, however, would not have been worth notice, had not this same species possessed in Sonthern India " a well" marked occipital crest formed of several graduated feathers." "s

The following case is in some respects more interesting. A pied rariety of the raven, with the head, breast, abdomon, and parts of the wings and tail-feathers white, is confined to the Feroe Islands. It is not very rare there, for Graba saw during his visit from eight to ten living specimens. Although the characters of this variety are not quite constant, yet it has been named by several distinguished ornithologists as a distinct species. The fact of the pied birds being pursued and persecuted with much clamour by the other ravens of the island was the chief cause which led Brünich to conclude that they were specifically distinct; but this is now known to be an error. ${ }^{48}$ This case seems analogous to that lately given of albino birds not pairing from being rejected by their comrades.

In various parts of the northern seas a remarkable variety of the common Guillemot (Uria troile) is found; and in Feroe, one out of every five birds, according to Graba's estimation, presents this variation. It is characterised ${ }^{41}$ by a pure white ring round the eye, with a curved narrow white line, an inch and a half in length, extending back from the ring. This conspicuous character has caused the bird to be ranked by several ornithologists as a distinct species under the name of U. licrymans, but it is now known to be merely a variety. It often pairs with the common kind, yet intermediate gradations have never been seen; nor is this surprising, for variations which appear suddenly, are often, as I have elsewhero shewn, ${ }^{42}$ transmitted either unaltered or not at all. We thus see that two distinct forms of the same species may co-exist in the same district, and we cannot doubt

27 Gould, "Handbook to Birds of Australia,' vol. ii. pp. 32 and 68.

38 Audubon, 'Ornitholng. BioEraphy,' 1838, rol. iv. p. 389.

2. Jerdon, 'Birds of India,' rol. i. p. 108; and $\mathrm{Mr}$. Blyth, in 'Land and Water,' 18158, p. 381 .

to Grabo 'Tigebuch Reise nach
Färo,' 1830, s. 51-54. Macgillivray, 'Hist. British Birds,' vol. iii. p. 745. 'Ibis,' vol. v. 1963, p. 469. 11 Graba, ibid. 5. 54. Macgillivray, ibid. vol. v. p. 327.

42 "Variation of Animals and Plants under Domestication,' vol. is p. 32. 
that if the one haci possessed any advantage iver the other, it would soon have been multiplied to the exclusion of the lattor. Ii, for instance, the male pied ravens, instead of being persecuted l.y their comrades, had been highly attractive (like the above pied peacock) to the black female ravens, their numbers would have rapidly increased. And this would have been a case of serual selection.

With respect to the slight individual differences which are common, in a greater or less degree, to all the members of the sime species, we have every reason to believe that they are by fir the most important for the work of selection. Secondary sexual characters are eminently liable to vary, both with animals in a state of nature and under domestication. ${ }^{43}$ There is also reason to believe, as we have seen in our eighth chapter, that variations are more apt to occur in the male than in the femalo sex. All these contingencies are highly favourable for sexual selection. Whether characters thus acquired are transmitted to one sex or to both sexes, depends, as we shall see in the following chapter, on the form of inheritance which prevails.

It is snmetimes difficult to form an opinion whether certain slight differences between the sexes of birds are simply the result of variability with sexually-limited inheritance, without the aid of sexual selection, or whether they have been augmented through this latter process. I do not here refer to the many instances where the male displays splendid colours or other ornaments, of which the female partakes to a slight degree; for these are almost certainly due to characters primarily acquired by the male having been more or less transferred to the female. But what are we to conclude with respect to certain birds in which, for instance, the eyes differ slightly in colour in the two scxes ? ${ }^{\text {th }}$ In some cases the eyes differ conspicuously; thus with the storks of the genus Xenorhynchus, those of the male are blackishhazel, whilst those of the females are gamboge-yellow; with many hornbills (Buceros), as I hear from Mr. Blyth, ${ }^{45}$ the males haro intense crimson eyes, and those of the females ar's white. In the Buceros bicornis, the hind margin of the casque and a stripe on the crest of the beak are black in the male, but not so in the fumale. Are we to suppose that these black marks and the crimson colour of the eyes have been preserved or augmented through sexual selection in the males? This is very doubtful;

43 On these points see also "Variation of Animals and Plants under Domestication,' rol. i. p. 253 ; rol. ii. pP. 73,75 .

4 See, for instance, on the irides of a Podica and Gallicrex in 'Ibis," vol. ii. 1860, p. 206 ; and rol. v. 1863, p. 426.

t5 See also Jerdon, 'Birds of Indin,' vol. i. pp. 243-245. 
for Mr. Bartlett shewed me in the Zoological Gardens that the inside of the mouth of this Buceros is black in the male and flesh-coloured in the female; and their external appearance or beauty would not be thus affected. I observed in Chili ${ }^{46}$ that the iris in the condor, when about a year old, is dark-brown, but changes at maturity into yellowish-brown in the male, and into bright red in the female. The male has also a small, longitudinal, leaden-coloured, fleshy crest or comb. The comb of many gallinaceous birds is highly ornamental, and assumes vivid colours during the act of courtship; but what are we to think of the dull-coloured comb of the condor, which does not appear to us in the least ornamental? The same question may be asked in regard to various other characters, such as the knob on the lase of the beak of the Chinese goose (Anser cygnoides), which is much larger in the male than in the female. No certain answer 'an be given to these questions; but we ought to be cautious in : sssuming that knobs and various fleshy appendages cannot be : ittractive to the female, when we remember that with savage races of man rarious hideous deformities-deep scars on the face with the flesh raised into protuberances, the septum of the nose pierced by sticks or bones, holes in the ears and lips stretched widely open-are all admired as ornamental.

Whether or not unimportant differences between the sexes, such as those just specified, have been preserved through sexual selection, these difierences, as well as all others, must primarily depend on the laws of variation. On the principle of correlated development, the plumage often varies on different parts of the body, or over the whole body, in the same manner. We sec this well illustrated in certain breeds of the fowl. In all the breeds the feathers on the neck and loins of the males are elongated, and are called hackles; now when both sexes acquire a top-knot, which is a new character in the genus, the feathers on the head of the male become hackle-shaped, evidently on the principle of correlation; whilst those on the head of the female are of the ordinary shape. The colour also of the hackles forming the top-knot of the male, is often correlated with that of the hackles or the neck and loins, as may be seen by comparing these feathers in the Golden and Silver-spangled Polish, the Houdans, and Crève-cour breeds. In some natural species wo may observe exactly the same correlation in the colours of these same fenthers, as in the males of the splendid Gold and Amherst pheasants.

'The structure of each individual feather generally causes any

48 'Zoology of the Voyage of H.M.S. Beagle,' 1841, p. 6. 
change in its colouring to be symmetrical; we see this in the various laced, spangled, and pencilled breeds of the fowl; and on the principle of correlation the feathers over the whole body are often coloured in the same manner. We are thus enabled without much trouble to rear breeds with their plumage marked almost as symmetrically as in natural species. In laced and spangled fowls the coloured margins of the feathers are abruptly lefined; but in a mongrel raised by me from a black Spanish rock glossed with green, and a white game-hen, all the feathers were greeuish-black, excepting towards their extremities, which were jellowish-white; but between the white extremities and the black bases, there was on each feather a symmetrical, curred zone of dark-brown. In some instances the shaft of the feather determines the distribution of the tints; thus with the bodyfeathers of a mongrel from the same black Spanish cock and a silver-spangled Polish hen, the shaft, together with a narrow space on each side, was greenish-black, and this was surrounded by a regular zone of dark-brown, edged with brownish-white. In these cases we linve feathers symmetrically shaded, like those which give so much elegance to the plumage of many natural species. I have also noticed a variety of the common pigeon with the wing-bars symmetrically zoned with three bright shades, instead of being simply black on a slaty-blue ground, as in the parent-species.

In many groups of birds the plumage is differently coloured in the several species, yet certain spots, marks, or stripes are retained by all. Analogous cases occur with the breeds of the pigeon, which usually retain the two wing-bars, though they may be coloured red, yellow, white, black, or blue, the rest of the plumage being of some wholly different tint. Here is a more curious case, in which certain marks are retained, though coloured in a manner almost exactly the opposite of what is natural; the aboriginal pigeon has a blue tail, with the terminal halves of the outer webs of the two outer tail feathers white; now there is a sub-variety having a white instead of a blue tail, with precisely that part black which is white in the parent-species. ${ }^{+7}$

Formation and Variability of the Ocelli or eye-like Spots on the Flumage of Birds.-As no ornaments are more beautiful than the ocelli on the feathers of various birds, on the hairy coats of some mammals, on the scales of reptiles and fishes, on the skin of amphibians, on the wings of many Lepidoptera and other insects, they deserve to be especially noticed. An occllus consists of a spot within a ring of another colour, like the pupil within the

17 Bechstein, 'Naturgeschicnte Deutschlands,' B. ir. 1795, s. 31, on a sub-variety of the Monsk figeon. 
iris, but the central spot is often surrounded by additional concentric zones. The ocelli on the tail-coverts of the peacock offer a familiar example, as well as those on the wings of the peacockbutterfly (Vanessa). Mr. Trimen has given me a description of a S. African moth (Gyananis isis), allied to our Emperor moth, in which a magnificent ocellus occupies ncarly the whole surface of each hinder wing; it consists of a black centre, including a semi-transparent crescent-shaped mark, surrounded by successive, ochre-yellow, black, ochre-yellow, pink, white, pink, brown, and whitish zones. Although we do not know the steps by which these wonderfully beautiful and complex ornaments have been developed, the process has probably been a simple one, at least with insects ; for, as Mr. Trimen writes to me, " no characters of " mere marking or cotoration are so unstable in the Lepidoptera "as the ocelli, both in number and sizc." Nr. Wallace, who first called my attention to this subject, shewed me a series of specimens of our common meadow-brown butterfly (IIipparchic janira) exhibiting numerous gradations from a simple minute black spot to an elegantly-shaded ocellus. In a S. African butterfly (Cyllo leda, Linn.), belonging to the same family, the ocelli are even still more variable. In some specimens (A, fig. 53) large spaces on the upper surface of the wings are coloured black, and include irregular white marks; and from this state a complete gradation can be traced into a tolerably perfect ocellus $\left(\mathrm{A}^{1}\right)$, and this results from the contraction of the irregular blotches of colour. In another scries of specimens a gradation can be followed from excessively minute white dots, surrounded by a scarcely visible black line (B), into perfectly symmetrical and large ocelli $\left(B^{i}\right){ }^{48}$ In cases like these, the development of a perfect ocellus does not require a long course of variation and selection.

With birds and many other animals, it seems to follow from the comparison of allied species that circular spots are often generated by the breaking up and contraction of stripes. In the Tragopan pheasant faint white lines in the female represent the beantiful white spots in the male; ${ }^{49}$ and something of the same kind nay be observed in the two sexes of the Argus pheasant. However this may be, appearances strongly favour the belief that on the one hand, a dark spot is often formed by the colouring

18 This woodcut has been engraved from a beautiful drawing, most kindly made for me by Mr. Trimen; see also his description of the wonderful amount of variation in the coloration and shape of the wings of thrs butterfly, in hie 'Rhopalocera Africx Australis,' fo. 186.

49 Jerdon, 'Birds of Iudis,' vol iii. p. 517. 
matter being drawn towards a central point from a surrounding zone, which latter is thus rendered lighter; and, on the other hand, that a white spot is often formed by the colour being driven away from a central point, so that it accumulates in a surrounding darker zone. In either case an ocellus is the result. The colouring matter seems to be a nearly constant quantity, but is redistributed, either centripetally or centrifugally: 'The feathers

A

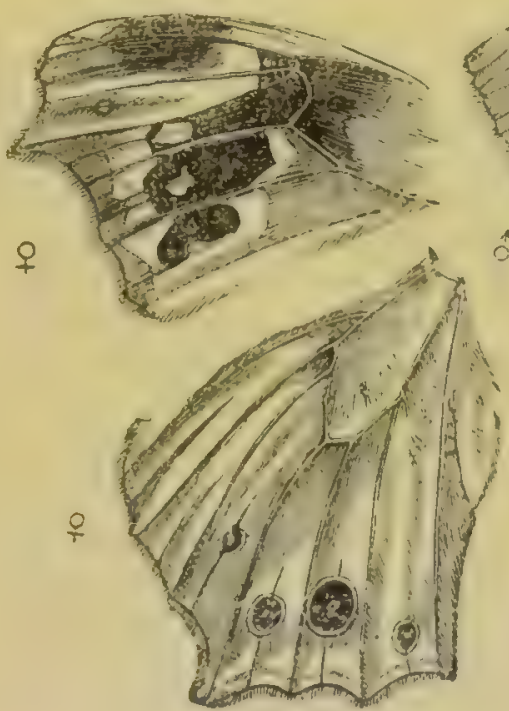

bi $\therefore$

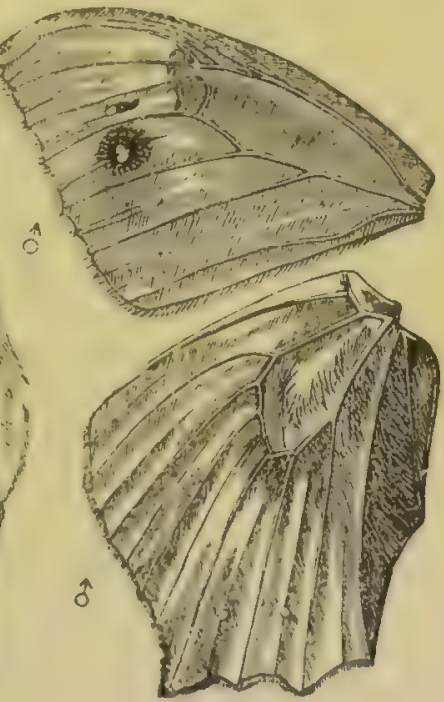

I3

Fig. 53. Cgllo leda, Linn., from a drawing by Mr. Trimen, shewing the extreme range of variation in the ocelli.

A. Siecimen, from Mauritius, upper surface of fore-wing

Al. Specimen, from Natal, ditto.
B. Specimen, from Java, upper surface of hind-wing.

B1. Specimen, from Mauritius, ciltto.

of the common guinea-forwl offer a good instance of white spots surrounded by darker zones; and wherever the white spots are large and stand near each other, the surrounding dark zones become confluent. In the same wing-feather of the $\Lambda$ rgus pheasant dark spots may be seen surrounded by a pale zone, and white spots by a dark zone. Thus the formation of an ocellus in its most elementary state appears to be a simple affair. By what further steps the more complex ocelli, which are surrounded by many successive zones of colour, have been generater. I will not pretend to say. But the zoned feathers of the mongre?:: from differently coloured fowls, and the extraordinary variability. of the ocelli on manv Lepidoptera, lead us to conclude that their formation is not a complex process, but depends on some slight and graduated change in the mature of the adjoining tissues. 
Gradation of Secondary Sexual Churacters.-Cases $n$. gradation are important, as shewing us that highly complex ornaments may be acquired by small successive steps. In order to discover the actual steps by which the male of any existing bird has acquired his magnificent colours or other ornaments, we ought to behold the long line of his extinct progenitors; but this is obviously impossible. Te may, however, generally gain a clue ky comparing all the species of the same group, if it be a large one; for some of them will probably retain, at least partially, traces of their former characters. Instead of entering on tedious details respecting various groups, in which striking instances of gradation could be given, it seems the best plan to take one or two strongly marked cases, for instance that of the peacock, in order to see if light can be thrown on the steps by which this bird has become so splendidly decorated. The peacock is chiefly remarkable from the extraordinary length of his tail-coverts; the tail itself not being much elongated. The barbs along nearly the whole length of these feathers stand separate or are decomposed; but this is the case with the feathers of many species, and with some varieties of the domestic forl and pigeon. 'The barbs coalesce towards the extremity of the shaft forming the oval disc or ocellus, which is certainly one of the most beautiful objects in the world. It consists of an iridescent, intensely blue, indented centre, surrounded by a rich green zone, this by a broad coppery-brown zone, and this by five other narrow zones of slightly different iridescent shades. A trifling character in the disc deserves notice; the barbs, for a space along one of the concentric zones are more or less destitute of their barbules, so that a part of the dise is surrounded by an almost transparent zone, which gives it a highly finished aspect. But I have elsewhere described ${ }^{50}$ an exactly analogous rariation in the hackles of a sub-variety of the game-cock, in which the tips, having a metallic lustre, "are separated from the lower part of the "feather by a symmetrically shaped transparent zone, composed "of the naked portions of the barbs." The lower margin or base of the dark-blue centre of the ocellus is deeply indented on the line of the shaft. The surrounding zones likewise shew traces, as may be secn in the drawing (fig. 54), of indentations, or rather breaks. These indentations are commion to the Indian and Javan peacocks (Pavo cristatus and P. muticus); and they seemen to deserve particular attention, as probably connected with the development of the ocellus; but for a long time I could not conjecture their meaning.

- Variation of Aninals and Plants under Domestication; voi. 1. p. 254 
wing-feathers, which are ornamented with numerous ocelli. I request the reader to turn back to the drawing (fig. 51, p. 397) of a Polyplectron. In $P$.napoleonis the ocelli are confined to the tail and the back is of a rich metallic blue; in which respects this species approaches the Tava peacock. P. hardwickii possesses a peculiar top-knot, which is also somewhat liko that of the Java peacock. In all the species the ocelli on the wings and tail are either circular or oval, and consist of a beautiful, iridescent, greenish-blue or greenish-purple disc, with, a black border. This border in $P$. chinquis shades into brown, elged with cream-colour, so that the ocellus is here surrounded with rariously shaded, though not bright, concentric zones. The unusual length of the tail-coverts is another remarkable character in Polyplectron; for in some of the species they are half, and in others two-thirds as long as the true tail-feathers. The tail"overts are ocellated as in the peacock. Thus the several species of Polyplectron manifestly make a graduated approach to the neacock in the length of their tail-corerts, in the zoning of the ocelli, and in some other characters.

Notwithstanding this approach, the first species of Polyplectron which I examined almost made me give up the search; for I found not only that the true tail-feathers, which in the peasock are quite plain, were ornamented with ocelli, but that the ocelli on all the feathers differed fundamentally from those of the peacock, in there being two on the same feather (fig. 55), one on each side of the shaft. Hence I concluded that the early progrenitors of the peacock could not have resembled a Polyplectron. But on continuing my search, I observed that in some of the *pecies the two ocelli stood very near each other; that in the tail-feathers of $P$. hardwickii they touched cach other; and. finally, that on the tail-corerts of this same species as woll as of P. malaccense (fig. 56) they were actually confluent. As the central part alono is confluent, an indentation is left at both the upper and lower ends; and the surrounding coloured zones are likewise indentcd. A single ocellus is thus formed on each tailcovert, though still plainly betraying its double origin. These confluent ocelli differ from the single ocelli of the pcacock in baving an iudentation at both ends, instead of only at the lower or basal end. The explanation, however, of this difference is not difficult; in some species of Polyplectron the two oral ocelli on the same feather stand parallel to each other; in other species (as in $P$. chinquis) they converge towards one end; now the partial confluence of two convergent occlli would manifestly leave a much deeper indentation at the divergent than at the convergent eud. It is also manifest that if the conrergence were 
strongly pronounced and the conflucnce complete, the indentation at the convergent end would tend to disappear.

The tail-feathers in both species of peacock are entirely destitute of ocelli, and this apparently is related to their being corered up and concealed by the long tailcoverts. In this respect they differ remarkably from the tailfeathers of Polyplectron, which in most of the species are ornamented with larger ocelli than those on the tail-coverts. Hence I was led carefully to examine the tail-feathers of the several species, in order to discover whether their ocelli shewed any tendency to disappear; and to my great satisfaction, this appeared to be so. 'The central tail-feathers of $P$. napoleonis have the two ocelli on each side of the shaft perfectly developed; but the inner ocellus becomes less and less conspicuous on the more exterior tail-feathers, until a mere shadow or rudiment is left on the inner side of the outermost feather. Again, in $P$. malaccense, the ocelli on the tail. coverts are, as we have seen, confluent; and these feathers are of unusual length, being twothirds of the length of the tailfeathers, so that in both these respects they approach the tailsoverts of the peacock. Now in $P$. malaccense the two central tailfeathers alone are ornamented, each with two brightly-coloured ocelli, the inner ocellus having completely disappeared from all the other tail-feathers. Conse-

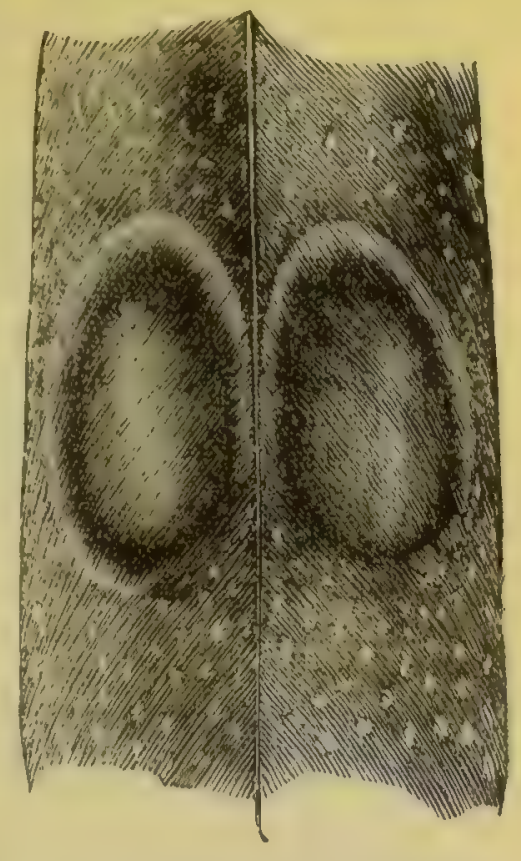

Fig. 55. Part of a tail-covert of Poly. plectron chinquis, with the two ocell of nat. size.

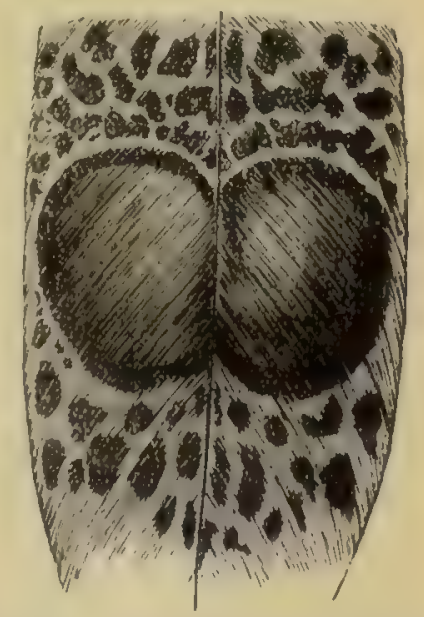

Fig. 56. Part of a tail-covert of Poly. plectron malaccense, with the two ocelli, partially confluent, of nat. size. quently the tail-coverts and tail-feathers of this species of Polyplectron make a near approach in structure and ornamentation to the corresponding feathers of the pcacock. 
As far, then, as gradation throws light on the steps by which the magnificent train of the peacock bas been acquircd, hardly anything more is necded. If we picture to ourselves a progenitor of the peacock in an almost exastly intermediate condition hetween the existing peacock, with his enormously elongated tail-coverts, ornamented with single ocelli, and an ordinary gallinaceous bird with short tail-coverts, merely spotted with some colour, we shall see a bird allied to Polyplectron-that is, with tail-coverts, capable of erection and cxpansion, ornamented with two partially confluent ocelli, and long enough almost to conceal the tail-feathers, the latter haring already partially lost their ocelli. The indentation of the central disc and of the: surrounding zones of the ocellus, in both species of peacock, speaks plainly in favour of this view, and is otherwise inexplicable. The males of Polyplectron are no doubt beautiful birds, but their beauty, when viered from a little distance, cannot be compared with that of the peacock. Many female progenitors of the peacock must, during a long line of descent, have appreciated this superiority; for they have unconsciousiy, by the continued preference of the most beautiful males, rendered the peacock the most splendid of living birds.

Argus pheasant.-Another excellent case for investigation is offered by the ocelli on the wing-feathers of the Argus pheasant, which are shaded in so wonderful a manner as to resemble balis lying loose within sockets, and consequently differ from ordinary ocelli. No one, I presume, will attribute the shading, which has excited the admiration of many expcrienced artists, to chance - to the fortuitous concourse of atoms of colouring matter. That these ornaments should have been formed through the selection of many successive variations, not one of which was originally intended to produce the ball-and-socket effect, seens as incredible, as that one of Raphael's Madonnas should have been formed by the sclection of chance daubs of paint marle by a long succession of young artists, not one of whom intended at first to draw the human figure. In ordel to discover how the ocelli have been developed, we cannot look to a long line of progenitors, nor to many closely-allied forms, for such do not now exist. But fortunately the several feathers on the wing suffice to give us a clue to the problem, and they prove to demonstration that a gradation is at least possible from a mere spot to a finished ball-and-socket ocellus.

The wing-feathers, bearing the ocelli, are covered with dark stripes (fig. 57) or with rows of dark spots (fig. 59), each stripe or row of spots running obliquely dorn the outer side of the 
Cirap. XIV. Birds-Gradation of Characters.

shaft to one of the ocelli. The spots are generaliy eiongated in a line transverse to the row in which they stand. They often become confluent, either in the line of the row-and then they form a longitudiual strinc-or transversely, that is, with the spots in the adjoining rows, and then they form transverse stripes. A spot sometimes breaks up into smaller spots, which still stand in their proper places.

It will be convenient first to describe a perfect ball - and - socket ocellus. This consists of an intensely black circular ring, surrounding a space shaded so as exactly to resemble a ball. The figure here given has been admirably drawn by Mr. Ford and well engraved, but a woodcut cannot exhibit the exquisite shading of the original. The ring is almost always slightly broken or interrupted (see fig. 57) at a point in the upper half, a little to the right of, and above the white shade on the enclosed ball; it is also sometimes broken towards the base on the

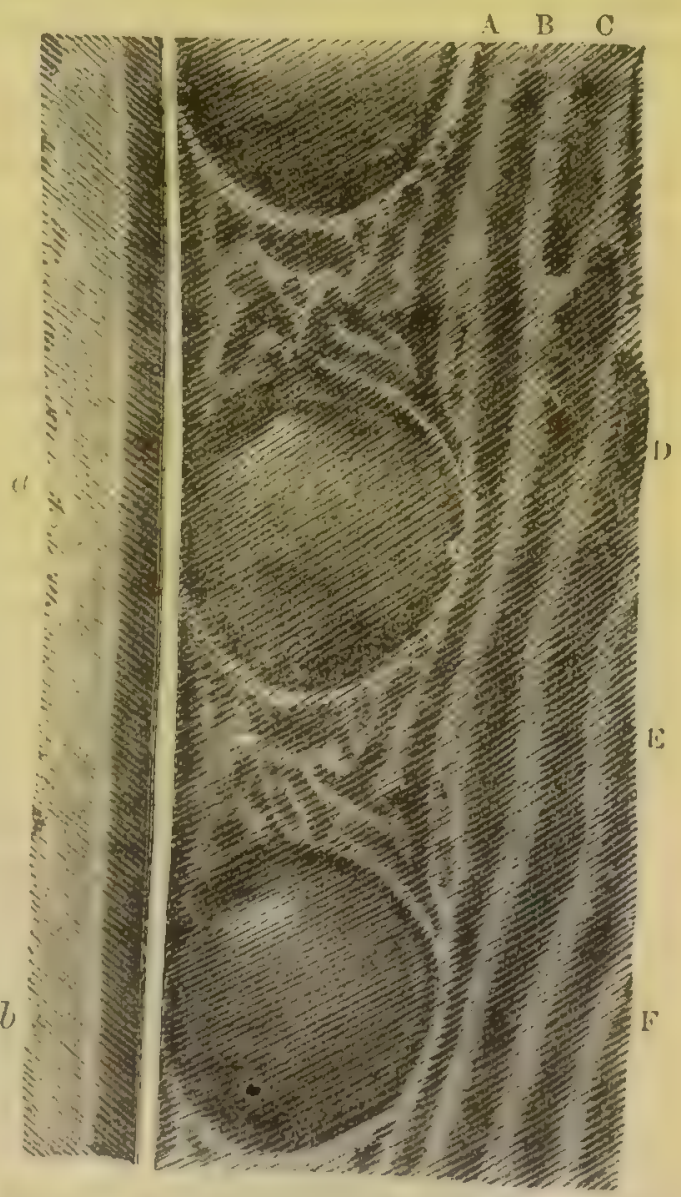

Fig. 57. laut of sicondery wing-feather of Argis pheasant. shewing two perfect ocelli, $a$ and $b$ A, B, C, D, \&c., are dark stripes running obliquely down, each to an occllus.

[Much of the web on both sides, especially to the left of the shaft, has been cut off.] right hand. These little breaks have an important meaning. The ring is al rway. much thickened, with the edges ill-defined towards the lefthand upper corner, the feather being held erect, in the position in which it is here drawn. Beneath this thickened part there is on the surface of the ball an oblique almost pure-white mark, which shades off downwards into a pale-leaden hue, and this into yellowish and bromn tints, which insensibly become 
darker and darker towards the lower part of the ball. It is this shading which gives so admirably the effect of light shining on a convex surface. If one of the balls be examined, it will be seen that the lower part is of a brown tint and is indistinctly separated by a curved oblique line from the upper part, which is yellower and more leaden; this curved oblique line runs at right angles to the longer axis of the white patch of light, and indeed. of all the shading; but this difference in colour, which cannot of course be shewn in the woodcut, does not in the least interfere with the perfect shading of the ball. It should be particularly observed that each ocellus stands in obvious connection either with a dark stripe, or with a longitudinal row of dark spots, for both occur indifferently on the same feather. Thus in fig. 57 stripe A runs to ocellus $a$; B runs to ocellus $b$; stripe $\mathrm{C}$ is broken in. the upper part, and runs down to the next succeeding ocellus,

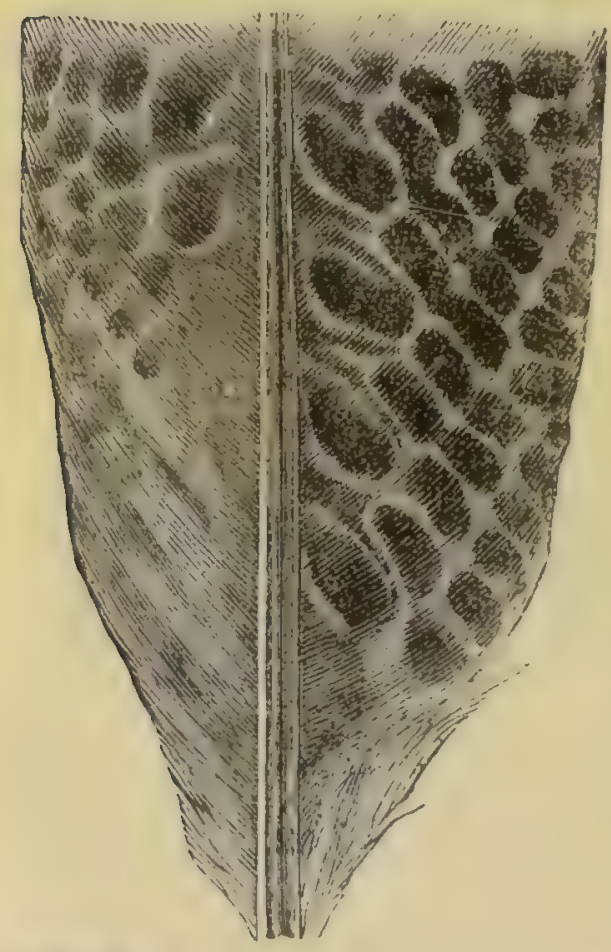

Fig. 58. Basal part of the secondary-wing feather, nearest to the bodv. not represented in the wood. cut; $\mathrm{D}$ to the next lower one, and co with the stripes $\mathrm{E}$ and F. Lastly, the several ocell are separated from each other by a pale surface bearing irregular black marks.

I will next describe tho other extreme of the series, namely, the first trace of an ocellus. The short secondary wing - feather (fig. 58), nearest to the body, is marked like the other feathers, with oblique, longitudinal, rather irregular, rows of very dark spots. The basal spot, or that nearest the shaft, in the five lower rows (excluding the lowest one) is a little larger than the other spots of the same row, and a little more elongated in a transverse direction. It diffurs also from the other spots by heing bordered on its upper side with some dull fulvous shading. But this spot is not in any way more remarkalle than those on the plumage of many birds, and might casily be orcrlooked. The next higher spot does not differ at all from the unper ones in 
the same row. 'The larger basal spots occupy exactly the sume relative position on these feathers, as do the perfect ocelli on the longer wing-feathers.

By looking to the next two or three succeeding wing-feathers, an absolutely insensible gradation can be traced from one of the last-described basal spots, together with the next higher one in the same row, to a curious ornament, which cannot be called an ocellus, and which I will name, from the want of a better term, an "elliptic ornament." These are shewn in the accompanying tigure (fig. :y). We here see several oblique rows, A, B, C, D,
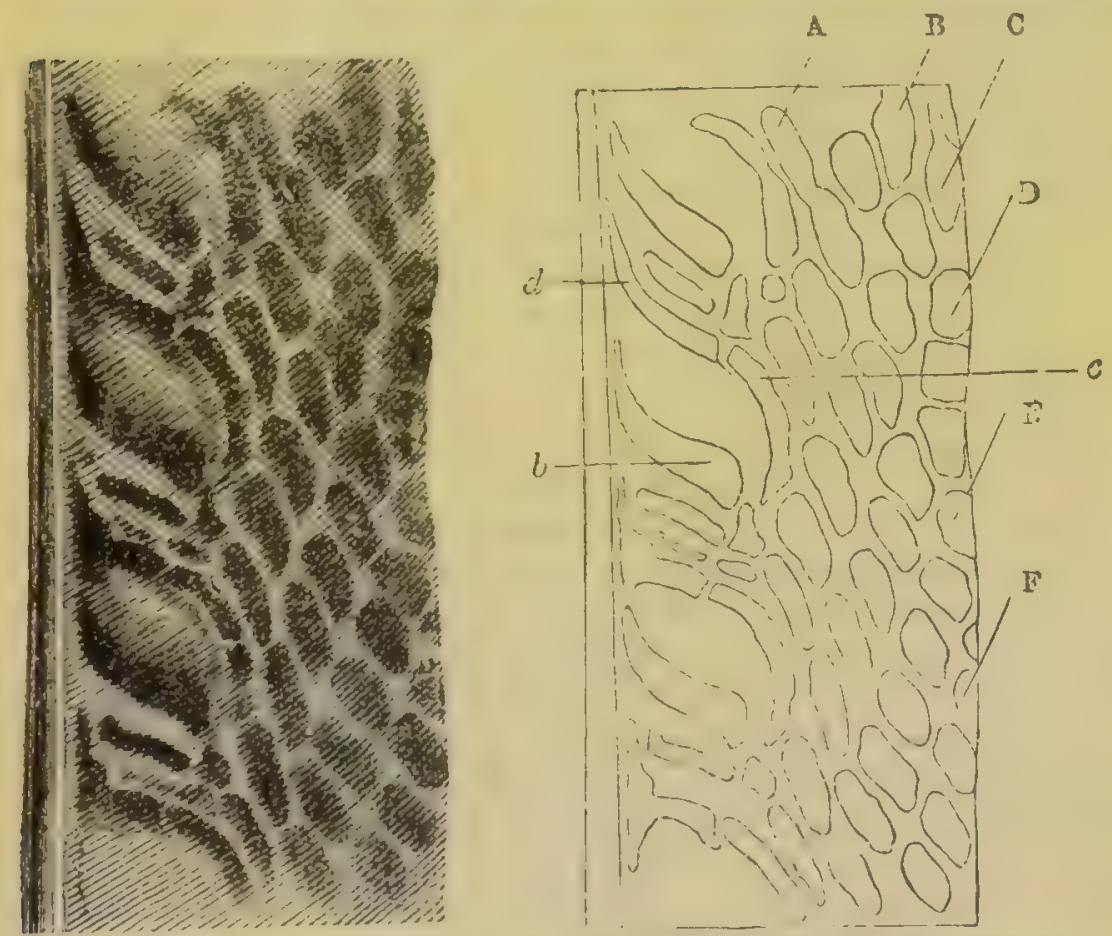

Fig. 59. Portion of one of the secondary wing fathers near to the body, shewing the so-called elliptic ornaments. The right-hand figure is givin mercly as a diagram for the sake of the letters of reference. A, 13, C, D, \&c. Rows of spots running
down to and forming the elliptic
ornaments.

8. Lowest spot or mark in row $\mathbf{B}$. c. The next succeding spot or mark in the same row.

d. Apparently a broken prolongation of the spot $c$ in the same row B

$\& c$. (see the lettered diagram on the right hand), of dark spots of the usual character. Each row of spots runs down to and is connected with one of the elliptic ornaments, in exactly the same manner as cach stripe in fig. 57 runs down to, and is connected with, one of the ball-and-socket ocelli. Looking to any one row, for instance, $\mathrm{B}$, in fig. 59 , the lowest mark $(b)$ is thicker and considerably longer than the upper spots, and has its left extremity pointed and curved upwards. This black mark 
is abruptly bordered on its upper side by a rather broad space of richly shaded tints, beginning with a narrow brown zone, which passes into orange, and this into a pale leaden tint, with the end towards the shaft much paler. These shaded tints together fill up) the whole inner space of the elliptic ornament. The mark (b) corresponds in every respect with the basal shaded spot of the simple feather described in the last paragraph (fig. 58), but is more highly developed and more brightly coloured. Above and to the right of this spot ( $b$ fig. 59), with its bright shading, there is. a long narrow, black mark (c), belonging to the same row, and which is arched a little downwards so as to faco $(b)$. This mark is sometimes broken into two portions. It is also narrowly edged on the lower side with a fulvous tint. To the left of and aloor $c$, in the same oblique direction, but always more or less distinct from it, there is another black mark $(d)$. This mark is generaliy sub-triangular and irregular in shape, but in the one lettered in the diagram it is unusually narrow, elongated, and regular. It apparently consists of a lateral and broken prolungation of the mark (c), together with its confluence with a broken and prolonged part of the next spot above; but I do not feel sure of this. These three marks, $b, c$, and $d$, with the intervening bright shades, form together the so-valled elliptic ornament. These ornaments placed parallel to the shaft, manifestly correspond in position with the ball-and-socket ocelli. Their extremely elegant appearance cannot be appreciated in the drawing, as the orange and leaden tints, contrasting so well with the black marks, cannot be shewn.

Between one of the elliptic ornaments and a perfect ball-andsocket ocellus, the gradation is so perfect that it is scarcely possible to decide when the latter term ought to be used. The passage from the one into the other is effected by the elongation and greater curvature in opposite directions of the lower llack mark ( $b$ fig. 59), and more especially of the upper one (c), together with the contraction of the elongated sub-triangular or narrow mark $(d)$, so that at last these three marks become confluent, forming an irregular elliptic ring. This ring is gradually rendered more and more circular and regular, increasing at the same time in diametcr. I have here given a drawing (fig. 60) of the natural size of an ocellus not as yet quite perfect. The lower part of the black ring is much more curved than is the lower mark in the elliptic ornament ( $b$ fig. 59). The upper part of the ring consists of two or three separate portions; and there is only a trace of the thickening of the portion which forms the biack mark above the white shade. This white shade itself is not as yet much concentrated; and beneath it the surface is brighter coloured than in a perfect ball-and-socket ocellus. Evep 
in the most perfect ocelli, traces of the junction of three or four clongated black marks, by which the ring has been formed, may ofteu be detected. The irregular sub-triangular or narrow mark (d fig. 59), manifestly forms, by its contraction and equalisation, the thickened portion of the ring above the white shade on a perfect balland-soeket ocellus. The lower part of the ring is invariably a little thicker than the other parts (see fig. 57), and this follows from the lower black mark of the elliptic ornament ( $b$ fig. 59) having originally been thicker than the upper mark (c). Every step can be followed in the process of confluence and modification; and the black ring which surrounds the ball of the ocellus is unquestionably formed by the union and modification of the three black marks, $b, c$, $d$, of the elliptic ornament. The irregular zigzag black marks between the successive ocelli (see again fig. 57) are plainly due to the breaking

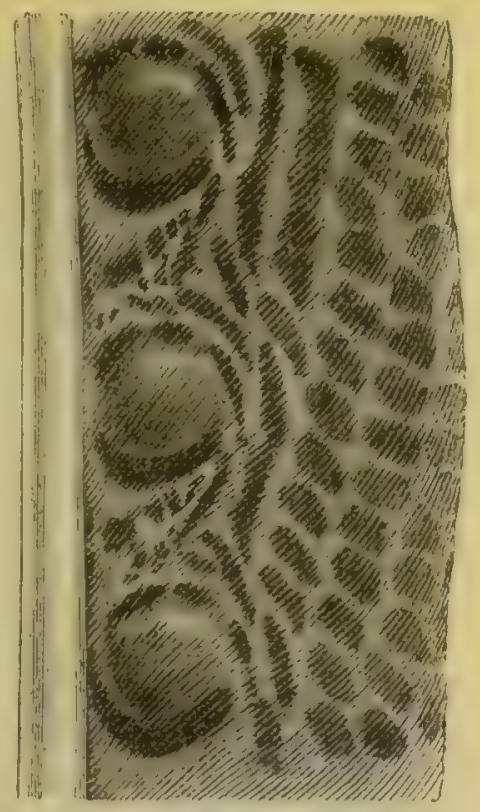

Fig. 60. An ocellus in an intermediate condition between the elliptic ornament and the perfect ball-and-socket ocellus.

up of the somewhat more regular but similar marks between the elliptic ornaments.

The successive steps in the shading of the ball-and-socket ocelli can be followed out with equal clearness. The brown, orange, and pale leaden narrow zones, which border the lower black mark of the elliptic ornament, can be seen gradually to become more and more softened and shaded into each other, with the upper lighter part towards the left-hand corner rendered still lighter, so as to become almost white, and at the same time more contracted. But even in the most perfect ball-andsocket ocelli a slight difference in the tints, thongh not in the shading, between the upper and lower parts of the ball can be perceived, as before noticed; and the line of separation is oblique, in the same direction as the bright-colourcd shades of the elliptic ornaments. Thus almost every minute detail in the shape and colouring of the ball-and-socket ocelli can be shewn to follow from gradual changes in the elliptic ornaments; and the development of the latter can be traced by equally small steps from the union of two almost simple spots, the lower one (fig. 5s) having some dull fulvous shading ou its upper side. 
The extremities of the longer secondary feathers wheh bear the perfect ball-and-socket ocelli, are peculiarly ornamented (fig. 61). The oblique longitudinal stripes suddenly cease (i) wards and hecome confused; and above this limit the wholc

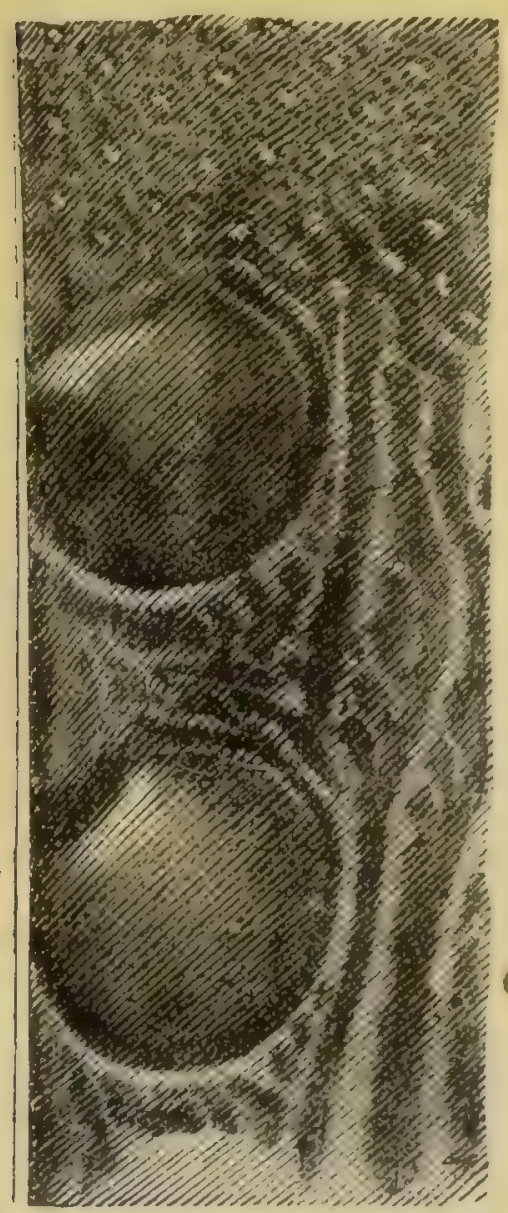

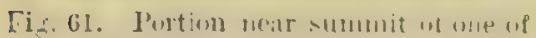
the secondary wing-fenthers, beariug perfect ball-and-socket ocelli.

r. Ornamented upper part.

b. Ulpermost, imperfect ball-and-socket ocellus. (The shading above the white mark on the summit of the ocellus is here a little too dark.)

$\therefore$ Perfect ocellus. upper end of the feather (11) is covered with white dots, surrounded by little black rings, standing on a dark ground. 'The oblique stripe belonging to the uppermost ocellus (b) is barely represented by a very short irregular black mark with the usual, curved, tranverse base. As this stripe is thus abruptly cut off, we can perhaps understand from what has gone before, how it is that the upper thickened part of the ring is here absent; for, as before stated, this thickened part apparently stands in some relation with a broken prolongation from the next higher spot. From the absence of the upper and thickened part of the ring, the uppermost ocellus, though perfect in all other respects, appears as if its top had been obliquely sliced off. It would, I think, perplex any one, who believes that the plumage of the Argus-pheasant was created as we now see it, to account for the imperfect condition of the uppermost ocellus. I should add that on the secondary wingfeather farthest from the body, all the ocelli are smaller and less perfect than on the other feathers, and have the upper

part of the ring deficient, as in the case just mentioned. The imperfection here seems to be connected with the fact that the spots on this feather shew less tendency than usual to become confluent into stripes; they are on the contrary, often broken ur. into smaller spots, so that two or threc rows run down to the same ocellus. 
There still remains another very curious point, first olserved by Mr. T. W. Wood,"1 which deserves attention. In a photograph. giren me by Mr. Ward, of a specimen mounted as in the act of display, it may be seen that on the feathers which are held perpendicularly, the white marks on the ocelli, representing light reflected from a convex surface, are at the upper or firther end, that is, are directed upwards; and the bird whilst displaying himself on the ground would naturally be illuminated from above. But here comes the curious point, the outer feathers are held almost horizontally, and their ocelli ought likewise to appear as if illuminated from above, and consequently the white marks ought to be placed on the upper sides of the ocelli; and wonderful as is the fact they are thus placed! Hence the oce!li on the several feathers, though occupying very different positions with respect to the light, all appear as if illuminated from above, just as an artist would have shaded them. Nevertheless they are not illuminated from strictly the same point as they ought to be; for the white marks on the ocelli of the feathers which are held almost horizontally, are placed rather ioo much towards the further end; that is they are not suffisiuntly lateral. We have, howerer, no right to expect absolute serfection in a part rendered ornamental through sexual selection, any more than we have in a part modified through natural sclection for real use; for instance in that wondrous organ the jumman eye. And we know what Helmholtz, the highest authority in Europe on the subject, has said about the human eyc; that if an optician had sold him an instrument so carelessly made, he sould have thought himself fully justified in returning it. ${ }^{52}$

We have now seen that a perfect series can be followed, from simple spots to the wonderful ball-and-socket ornaments. Mr. Could, who kindly gave me some of these feathers, fully agrees with me in the completeness of the gradation. It is obvious that the stages in development exhibited by the firthers on the :ame bird, do not at all necessarily shew us the steps passed through by the extinct progenitors of the species; but they probably give us the clue to the actual steps, and they at least prove to demonstration that a gradation is possible. Bearing in mind how carefully the male Argus pheasant displays his plumes hefore the female, as well as the many facts rendering it probablc that female birds prefer the more attractive males, no one who admits the agency of sexual selection in any case, will deny that a simple dark spot with some fulvous shading might be converted, through the approximation and modification of two adjoining

s1 The 'Field,' May 28, 1870.

s2 -Popular Lectures on Screutific
Subjects, Kng. trans. 1873, pp. 219, $227,269,391 \%$. 
spots, together with some slight increase of colour, into one of the so-called elliptic ornaments. These latter ornaments have been shewn to many persons, and all have admitted that they are beautiful, some thinking them eren more so than the ball-andsocket ocelli. As the secondary plumes became lengthened through sexual selection, and as the elliptic ornaments increased in diameter, their colours apparently became less bright; and then the ornamentation of the plumes had to bo gained by an improvement in the pattern and shading; and this process was carried on until the wonderful ball-and-socket ocelli were finally developed. Thus we can understand-and in no other way as it seems to me-the present condition and origin of the ornaments on the wing-feathers of the Argus pheasant.

From the light afforded by the principle of gradation-from what we know of the laws of variation-from the changes which have taken place in many of our domesticated birds-and, lastly, from the character (as we shall hereafter see more clearly) of the immature plumage of young birds-we can sometimes indicate with a certain amount of confidence, the probable steps by which the males have acquired their brilliant plumage and various ornaments; yet in many cases we are involved in complete? darkness. Mr. Gould scveral years ago pointed out to me a luumming-bird, the Urosticte benjumini, remarkable for the curious differences between the sexes. The male, besides a splendid gorget, has grecnish-black tail-feathers, with the four central ones tipped with white; in the female, as with most of the allied species, the three outer tail-feathers on each side are tipped with white, so that the male has the four central, whilst the female has the six exterior feathers ornamented with white tips. What makes the case more curious is that, although the colouring of the tail differs remarkably in both sexes of many kinds of humming-birds, Mr. Gould does not know a single species, besides the Urosticte, in which the male has the four central feathers tipped with white.

The Duke of Argyll, in commenting on this case, ${ }^{39}$ passes over sexual selection, and asks, "What explanation does the law of " natural selection give of such specific varieties as these?" He answers "none whatever;" and I quite agree with him. But san this be so confidently said of sexual selection? Seeing in how many ways the tail-feathers of humming-birds differ, why should not the four central feathers have varied in this one species alone, so as to have acquired white tips? The variations may have been gradual, or somewhat abrupt as in the case 38 'The Peign of Law,' 1867, p. 247. 
recently given of the humming-birds near Bogota, in which certain individuals alone have the "central tail-feathers tipped "with beautiful green." In the female of the Urosticte I noticed extremely minute or rudimental whito tips to the two outer of the four central black tail-feathers; so that here we have an indication of change of some kind in the plumage of this species. If we grant the possibility of the central tailfeathers of the male varying in whiteness, there is nothing strange in such variations having been sexually selected. The white tips, together with the small white ear-tufts, certainly add, a: the Duke of Argyll admits, to the beauty of the male; and whiteness is apparently appreciated by other birds, as may be inferred from such cases as the snow-white male of the Bell-bird. The statement made by Sir R. Herou should not be forgotten, namely, that his pealiens, when debarred from access to the pied peacock, would not unite with any other male, and during that. season produced no offspring. Nor is it strange that variations in the tail-feathers of the Urosticte should have been specially selected for the sake of ornament, for the next succeeding genus in the family takes its name of Metallura from the splendour of these feathers. We have, moreover, good evidence that hummingbirds take especial pains in displaying their tail-feathers; Mr. Belt, ${ }^{54}$ after describing the beauty of the Florisuga mellivora, says, "I have seen the female sitting on a branch, and two males " displaying their charms in front of hor. One would shoot up

" like a rocket, then suddenly expanding the snow-white tail, like " an inverted parachute, slowly descend in front of her, turning " round gradually to shew off back and front. ........ The " expanded white tril covered more space than all the rest of the " bird, and was eridently the grand feature in the performance. "Whilst one male was descending, the other would shoot up " and come slowly down expanded. The entertainment would " end in a fight between the two performers; but whether the "most beautiful or the most pugnacious was the accepted " suitor, I know not." Mr. Gould, after describing the peculiar plumage of the Urosticte, adds, "that ornament and variety is "the sole object, I have myself but little doubt." 55 If this too admitted, we can perceive that the males which auring former times were decked in the most elegant and novel manner would have gained an advantage, not in the ordinary struggle for life, but in rivalry with other males, and would have left a larger number of offspring to inherit their newly-acquired beanty.

\footnotetext{
34 'The Naturalist in Nicaragua, $187 \pm$, p. 112

5s "Introduction to the Trochi. lide,' 1861, p. 110.
} 


\title{
CHAPTER X V.
}

\author{
BIRDS-continued.
}

Discussion as to why the males alone of some species, and both eeres of others, are brightly coloured-On serually-limited inheritance, as apulied to various structures and to hrightly-coloured plumage-Nidification in relation to colour-Toss of nuptial plumage during the winter.

We have in this chapter to consider, why the females of many birds have not acquired the same ornaments as the male; and why, on the other hand, both sexes of many othex birds are equally, or almost equally, ornamented? In the following chapter we shall consider the few cases in which the female is more consuicuously coloured than the male.

In my "Origin of Species'1 I briefly suggested that the long tail of the peacock would be inconvenient, and the conspicuous: black colour of the male capercailzic dangerons, to the female during the period of incubation; and consequently that the transmission of these characters from the male to the female offspring had been checked through natural selection. I stil] think that this may have occurred in some ferv instances: but after mature reflection on all the facts which I have been able to cullect, I am now inclined to believe that when the sexes differ. the successive variations have generally been from the first limited in their transmission to the same sex in which they first arose. Since my remarks appearcd, the subject of sexual coloration has been discussed in some rery interesting papers by Mr. Wallace, who helicres that in almost all cases the succossive variations tended at first to be transmitted equally to both sexes; but that the female was saved, through natural selection, from acquiring the conspicuous colours of the male, owing to the danger which she would thus have incurred during incubation.

This view necessitates a tedious discussion on a difficult point, namely, whether the transmission of a character, which is at first inherited by both sexes, can be subsequently limited in its transmission to one sex alone by means of natural selection. Wo must bcar in mind, as shewn in the preliminary chapter on serual selection, that characters which are limited in their devciopment to one sex are always latent in the other. An

1 Fonth cdition, 1866, p. 241.

8 'Westarister Feriew, July,

1867. 'Journal of 'Trare?, rol i. 1868, D. $7: 3$. 
imaginary illustration will best aid us in seeing the difficulty of the case: we may suppose that a fancier wished to make a breed of pigeons, in which the males alone should bo colonred of a pale blue, whilst the females retained their formor slaty tint. As with pigeons characters of all kinds are usually transmitted to both sexes equally, the fancier would have to try to convert this latter form of inheritance into sexually-limited. transmission. All that he could do would be to persevere in solecting every male pigeon which was in the least degree of a paler blue; and the natural result of this process, if steadily carried on for a long time, and if the pale variations were strongly inherited or often recurred, would be to make his whole stock of a lighter blue. But our fancier would be compeller to match, generation after gencration, his pale blue males with slaty females, for he wishes to keep the latter of this colour. The result would generally be the production either of a mongrel piebald lot, or more probably the speedy and complete loss of the pale-blue tint; for the primordial slaty colour would be transmitted with prepotent force. Supposing, however, that some pale-blue males and slaty females were produced during each successive generation, and were always crossed together; then the slaty females would have, if I may use the expression, much blue blood in their veins, for their fathers, grandfathers, \&c., will all have been blue birds. Under these circumstances it is conceivable (though I know of no distinct facts rendering it probable) that the slaty females might acquire so strong a latent tendency to pale-blueness, that they would not destroy this colour in thcir male offspring, their female offspring still inheriting the slaty tint. If so the desired end of making a breed with the two scres permancntly different in colour might be gained.

'The extrome importance, or rather necessity in the above cass of the desired character, namely, pale-blueness, being present though in a latent state in the female, so that the male offspring should not be deteriorated, will be best appreciated as follows: the male of Sommerring's phensant has a tail thirty-seven inches in length, whilst that of the female is only eight inches; the tail of the male common pheasant is about twenty inches, and that of the female twelve inches long. Now if the female Sommerring pheasant with her short tail were crossed with the male common pheasant, there can be no doubt that tho mals: hybrid offspring would have a much longer tail than that of the pure offspring of the common pleasant. On the other hand, $i$ ? the female common pheasant, with a tail much longer than that of the female sommerring pheasant, were crossed with the male 
of the latter, the male hybrid offspring would have a much shorter tail than that of the pure offspring of Soemmerring's pheasant.

Our fancier, in order to make his new breed with the males of a pale-blue tint, and the females unchanged, would have to continue selecting the males during many generations; and each stage of palcness would have to be fixed in the males, and rendered latent in the females. The task would be an oxtremely difficult one, and has never been tried, but might possibly be successfully carried out. The chief obstaclo would be the early and complete loss of the pale-blue tint, from the necessity of reiterated crosses with the slaty female, the latter not having at first any latent tendency to produce palc-bine offspring.

On the other hand, if one or two males were to vary ever so slightly in paleness, and the variations were from the first limited in their transmission to the male sex, the task of making a new breed of the desired kind would be easy, for such males would simply have to be selected and matched with ordinary females. An analogous case has actually occurred, for there aro ireeds of the pigeon in Belgium in which the males alone are ruarked with black striæ. So again DIr. Tegetmeior has recently shewn ${ }^{6}$ that dragons not rarely produce silver-coloured birds, which are almost always hens; and he himself has bred ten snch females. It is on the other hand a very unusual ercnt Then a silver male is produced; so that nothing would be easier, if desired, than to make a breed of dragons with blue males and silver females. This tendency is indeed so strong that when Mr. Tegetmeier at last got a silver male aud matched him with one of the silver females, he cxpected to get a breed with both sexes thus coloured; he was howerer disappointed, for the young male reverted to the blue colour of his grandfather, the young female alone leing silver. No doubi with patience this tendency to reversion in the males, reared from an occasional silver male matched with a silver hen, might be eliminated, and then both sexes would be coloured alike; and this very process has been followed with success by Mr. Esquilant in the case of silver turbits.

With fowls, variations of colour, limited in their transmis. sion to the male sex, habitually occur. When this form of

3 Temminck says that the tail of the female Phasianus Sicmmerringii is only six inches long, 'Planches coloriées,' wnl. F. 1838, pp. 487 and 488: the measurements above giren were made for me by $\mathrm{Mr}$. Sclater.
For the common pheasant, sea Macgillirray, 'Hist. Brit. Birds,' vol. i. pp. 118-121.

- Dr. Chapuis, "Le Pigeon Vinga geur Belge,' 1865, p. 87.

s The 'Field,' Sept. 1872. 
inheritance prevails, it might well happen that some of the successive variations would be transferred to the fernale, who would then slightly resemble the male, as actually occurs in some breeds. Or again, the greater number, but not all, of the successive steps might be transferred to both sexes, and the female would then closely resemble the male. There can hardly be a doubt that this is the cause of the male pouter pigeon hizving a somewhat larger crop, and of the male carrier pigeon having somewhat larger wattles, than their respective females; fur fanciers hare not selected one sex more than the other, and have had no wish that these characters should be more strongly aisplayed in the male than in the female, yet this is the case with both breeds.

The same process would hare to be followed, and the same difficulties encountered, if it were desired to make a breed with the females alone of some new colvur.

Lastly, our fancier might wish to make a breed with the two sexes differing from each other, and both from the parentspecies. Here the difficulty would be extreme, unless the successive variations were from the first sexually limited on both sides, and then there would be no difficulty. We see this with the fowl; thus the two sexes of the pencilled Hamburghs differ greatiy from each other, and from the two sexes of the aboricinal Gallus bunkiva; and both are now kept constant to their standard of excellence by continued selection, which would be impossible unless the distinctive characters of both were limited in their transmission. The Spanish fowl offers a more curious case; the male has an immense comb, but some of the successive vuriations, by the accumulation of which it was acquired, appear to have been transferred to the female; for sne has a comb many times larger than that of the females of the parent-species. But the comb of the female differs in one respect from that of the male, for it is apt to lop over; and within a recent period it has ween ordered by the fancy that this should always be the case, and success has quickly followed the order. Now the lopping of the comb must be sexually limited in its transmission, otherwise it would prevent the comb of the male from being perfectly upright, which would be abhorrent to every fancier. On the otber hand, the uprightness of the comb in the male must likewise be a sexually-limited character, otherwise it would prevent the comb of the female from lopping over.

From the foregoing illustrations, we see that even with almost unlimited time at command, it wculd be an extremely difficult and complex, perhaps an impossikle process, to change une form of transmission into the other through selection. Therefore, 
without distinct cridence in each case, I nm unwilling to admit that this has been effected in natural species. On the other hand, by means of successive variations, which were from the first sexually limited in their transmission, there would not be the least difficulty in rendering a male bird widely different in colour or in any other character from the female; the latter being left unaltered, or slightly altered, or specially modified for the sake of protection.

As bright colours are of service to the males in their rivalry with other males, such colours would be selected, whether or not they wore transmitted exclusiveiy to the same sex. Consequently the females might be expected often to partake of the brightness of the males to a greater or less degree; and this occurs with a host of species. If all the successive variations were transmitted equally to both sexes, the females would be indistinguishable from the males; and this likewise occur's with many birds. If, however, dull colours were of high importance for the safety of the female during incubation, as with many ground birds, the females which varied in brightness, or which received iirough inheritance from the males any marked accession of brightness, wruld sooner or later be destroyed. But the tendency in the males to continue for an indefinite period transmitting to their female offspring their own brightness, would have to be eliminated by a change in the form of inheritance; and this, as shewn by our previous illustration, would be extremely difficult. The more probable result of the long-continued destruction of the more brightly-coloured females, supposing the equal form of transmission to prevail, would be the lessening or annihilation of the bright colours of the males, owing to their continual crossing with the duller females. It would be tedious to follow out all the other possible results; but I may remind the reader that if sexually-limited variations in brightness occurred in the females, even if they were not in the least injurious to them and consequently were not eliminated, yet they would not be faroured or selected, for the male usually accepts any female, and does not select the more attractive individuals; consequently these variations would be Liable to be lost, and would have little influence on the character of the race; and this will aid in accounting for the females being commonly duller-coloured than the males.

In the eighth chapter instances were given, to which many might here be added, of variations occurring at various ages, and inherited at the corresponding ago. It was also shewn that variations which occur late in life are commonly transmitted to the same sex in which they first apnear; whilst variations occurring 
rarly in life are apt to be transmitted to both sexes; not that all the cases of sexually-limited transmission can thus be accounted for. It was further shewn that if a male bird varied by beroming brighter whilst young, such variations would be of $\mathrm{no}$ service until the age for reproduction had arrived, and there was competition between rival males. But in the case of birds living on the ground and commonly in need of the protection of dull colours, bright tints would be far more dangerous to the young and inexperienced, than to the adult males. Conseunently the males which raried in brightness whilst young would suffer much destruction and be eliminated through watural selection; on the other hand, the males which varicd in this manner when nearly mature, notwithstanding that they were exposed to some additional danger, might survive, aud from being favoured through sexual selection, would procreate their kind. As a relation often exists between the period of variation and the form of transmission, if the bright-coloured young males were destroyed and the mature ones were successful in their courtship, the males alone would acquire brilliant colours and would transmit them exclusively to their male offspring. But I by no means wish to maintain that the influcrec or age on the form of transmission, is the sole cause of the great diffurence in brilliancy between the sexes of many birds.

When the sexes of birds differ in colour, it is interesting to determine whether the males alone have been moditied by sexual selection, the females having been left unchanged, or only partially and indirectly thus changed; or whether the females have been specially modified through natural selection for the sake of protection. I will therefore discuss this question at some length, even more fully than its intrinsic importance deserves; for various curious collateral points may thus be conveniently considered.

Before we enter on the subject of colour, more especially in reference to Mr. Wallace's conclusions, it may be useful to discuss some uther sexual differences under a similar point of view. A breed of fowls formerly existed in Germany "in which the hens were furnished with spurs; they were good layers, but they so greatly disturbed their nests with their spurs that they could not be allowed to sit on their own eggs. Hence at one time it appeared to me probable that with the females of the wild Gallinacer the development of spurs had been checked through natural selection, from the injury thus caused to their nests. This seemed all the more probable, as wing-spurs, which would pot be injurious during incubation, are often as well-derelopod

- Bechstein, 'Naturgesch. Deutschla ads,' 1793, B. iii. э. 339. 
in the female as in the male; though in not a few cases they are ather larger in the male. When the male is furmished witl k.g-spurs the female almost always exhibits rudiments of thern, - the rudiment sometimes consisting of a mere scale, as in Gallus. Hence it might be argued that the females had aboriginally been furnished with well-developed spurs, but that theso had subsequently been lost through disuse or natural selection. But if this view be admitted, it would have to be extended to innumerable other cases; and it implies that the femaie prowenitors of the existing spur-bearing species were once encumlered with an injurious appendage.

In some few genera and species, as in Galloperdix, Acomus, and the Javan peacock (Pavo muticus), the fernales, as well as the males, possess well-developed leg-spurs. Are we to infer from this fact, that they construct a different sort of nest from that made by their nearest allies, and not liable to be injured by their spurs; so that the spurs have not been removed. Or are we to suppose that the females of these several species especially require spurs for their defence? It is a more probable conclusion that both the presence and absence of spurs in the females result from different laws of inheritance having prevailed, independently of natural selection. With the many females in which spurs appear as rudiments, we may conclude that some few of the successive variations, through which they were developed in the males, occurred very early in life, and wore consequently transferred to the females. In the other and much rarer cases, in which the females possess fully developed spurs, we may "onclude that all the successive variations were transferred to them; and that they gradually acquired and inherited the habit of not disturbing their nests.

The vocal organs and the feathers variously-modificd for prolucing sound, as well as the proper instincts for using them, often differ in the two sexes, but are sometimes the same in both. Can such differences be accounted for by the males having acquired these organs and instincts, whilst the females have been saved from inheriting them, on account of the danger to which they would have been exposed by attracting the attention of birds or beasts of prey? This does not seem to me probable, when we think of the multitude of birds which with impunity gladden the country with their voices during the spring. ${ }^{7}$ It is

7 Daines Barrington, however, thought it probable ('Phil. Transact.' 1773, p. 164) that few female birds eing, because the talent would have beez dangerous to them during iu- cubation. He adds, that a similar view may possibly account for the inferurity of the female to the male in plumage. 
a safer conclusion that, as vocal and instrumental organs are of special service only to the males during their courtship, these organs were developed through sexual selection and their constant use in that sex alone-the successive variations and the effects of use having been from the first more or less limited in transmission to the male offspring.

Many analogous cases could be adduced; those for instance of the plumes on the head being generally longer in the male than in the female, sometimes of equal length in both sexes, and occasionally absent in the female,---these several cases occuring in the same group of birds. It would be difficult to account for such a difference between the sexes by the female having been benefitea by possessing a slightly shorter crest than the male, and its consequent diminution or complete suppression through natural selection. But I will take a more farourable case, namely the length of the tail. The long train of the peacock would have been not only inconvenient but dangerous to the peahen during the period of incubation and whilst accompanying her young. Hence there is not the least à priori improbability in the development of her tail having been checked through natural selection. But the females of various pheasants, which apparently are exposed on their open nests to as much danger as the peahen, have tails of considerable length. The females as well as the males of the Menura superba have long tails, and they build a domed nest, which is a great anomaly in so large a bird. Naturalists have wondered how the female Menura could manage her tail during incubation; but it is now known" that she "enters the nest head first, and then "furns round with her tail sometimes over her back, but more " often bent round by her side. Thus in time the tail becomes "quite askew, and is a tolerable guide to the length of time the " bird has been sitting." Both sexes of an Australian kingfisher (Tunysiptera sylvia) have the middle tail-feathers greatly lengthened, and the female makes her nest in a hole; and as I arn informed by Mr. R. B. Sharpe these feathers become much crumpled during incubation.

In these two latter cases the great length of the tail-feathers must be in some degree inconvenient to the female; and as in both species the tail.feathers of the female are somewhat shorter than those of the male, it might be argued that their full development bad been prevented through natural selection. But if the development of the tail of the peahen had becn checked only when it became inconveniently or dangerously great, she would have retained a much longer tail than she actually possesses:

- Mr. Ramsay, in 'Proc. Zoolog. Soc.' 1868, p. 50. 
for her tail is not nearly so long, relatively to the size of her body, as that of many female pheasants, nor longer than thai of the female turkey. It must also be borne in mind, that in accordance with this view as soon as the tail of the peahen became dangerously long, and its development was consequently checked, she would have continually reacted on her male progeny, and thus have prevented the peacock from acquiring his present magnificent train. We may therefore infer that the length of the tail in the peacock and its shortness in the peajen are the result of the requisite variations in the male having licen from the first transmitted to the male offspring alone.

We are led to a nearly similar conclusion with respect to the length of the tail in the various species of pheasants. In the Eared phessant (Crossoptilon auritum) the tail is of equal length in both sexes, namely, sixteen or seventeen inches; in the common pheasant it is about twenty inches long in the male and twelve in the female; in Sommerring's pheasant, thirty-seven inches in the male and only eight in the female; and lastly in Reeve's pheasant it is sometimes actually seventy-two inches long in the male and sixteen in the female. Thus in the several species, the tail of the female differs much in length, irrespectively of that of the male; and this can be accounted for, as it scems to me, witl much more probability, by the laws of inheritance,- - that is by the successive variations having been from the first more or less closely limited in their transmission to the male sex, than by the igency of natural selection, resulting from the length of tail being more or less injurious to the females of these sereral allied species.

We may now consider Mr. Wallace's arguments in regard to the sexual coloration of birds. He believes that the bright tints originally acquired through sexual selection by the males, would in all, or almost all cases, have been transmitted to the females, unless the transference had been checked through natural selection. I may here remind the reader that various facts opposed to this view have already been given under reptiles, amphibians, fishes, and lepidoptera. Mr. Wallace rests his belief chiefly: but not exclusively, as we shall see in the next chapter, on the following statement, ${ }^{9}$ that when both sexes are coloured in a rery conspicuous manner, the nest is of such a nature as to conceal the sitting bird; but when there is a marked contrast of colour between the sexes, the male being gay and the female dull-coloured, the nest is open and exposes the sitting bird to view. This coincidence, as far as it goes, certainly seems to favour the belief that the females which sit on

- 'Jnurnal of Travel,' edited by A. Murray, rol. i. 1868, p. 78. 
open nests have been specially modified for the sake of proteciion; but we shall presently see that there is another and moro probahle explanation, namely, that conspicuous females have acquired the instinct of building domed nests oftener than dullcoloured birds. Mr. Wallace admits that there are, as might have been expected, some exceptions to his two rules, but it is a question whether the exceptions are not so numerous as seriously to invalidate them.

There is in the first place much truth in the Duke of Argyll's remark ${ }^{10}$ that a large domed nest is more conspicuous to an enemy, especially to all tree-haunting carnivorous animals, than a smaller open nest. Nor must we forget that with many birds which build open nests, the male sits on the eggs and aids the fiemale in fecding the young: this is the case, for instance, with l'yranga astivu," one of the most splendid birds in the United States, the male being vermilion, and the female light brownishgreen. Now if brilliant colours had been extremely dangerous to birds whilst sitting on their open nests, the males in these cases would have suffered greatly. It might, however, be of such paramount importance to the male to be brilliantly coloured, in order to beat his rivals, that this may have more than compensated some additional danger.

Mr. Wallace admits that with the King-crows (Dicrurus), Orioles, and Pittidæ, the females are conspicuously coloured, yet build open nests; but he urges that the birds of the first group are highly pugnacious and could defend themselves; that those of the second group take extreme care in concealing their apen nests, but this does not invariably hold good; ${ }^{12}$ and that with the birds of the third group the females are brightly coloured chiefly on the under surface. Besides these cases, jigeons which aro sometimes brightly, and almost always conspicuously coloured, and which are notoriously liable to the attacks of birds of prey, offer a serious exception to the rule, for they almost always build open and exposed nests. In another large family, that of the humming-birds, all the species build open nests, yet with some of the most gorgeous species the sexes are alike; and in the majority, the females, though less brilliant than the males, are brightly coloured. Nor can it be maintnined that all female humming-birds, which are brightly coloured, escape detection by their tints being green, for some display on their upper surfaces red, blue, and other colours. ${ }^{13}$

10 'Journal of Travel,' edited by A. IInrray, vol. i. 1868, p. 281.

11 Audubon, "Oraitnolcgical Biography, rol. i. p. 233.
12 Jerdon, 'Birds of India,' $\left.v_{1}\right)$ ?. ii. p. 108. Govild's 'Handbook 's' the Birds cf Australia,'vol. i. p. 463. 13 For instance, the female Fupo 
In regard to birds which build in holes or construct domed nests, other advantages, as Mr. Wallace remarks, besides concealment are gained, such as shelter from the rain, greater warmth, and in hot countries protection from the sun $;^{14}$ so that it is no valid objection to his view that many birds having both sexes obscurely coloured build concealed nests. ${ }^{15}$ The female Horn-bill (Buceros), for instance, of India and Africa is protected during incubation with extraordinary care, for she plasters up with her own excrement the orifice of the hole in which she sits on her eggs, leaving only a small orifice through which the male; feeds her; she is thus kept a close prisoner during the whole period of incubation; ${ }^{16}$ yet female horn-bills are not more con spicuously coloured than many other birds of equal size which build open nests. It is a more serious objection to MIr. Wallace's view, as is admitted by him, that in some fer groups the males are brilliantly coloured and the females obscure, and yet the latter hatch their eggs in domed nests. This is the case with tho Grallinæ of Australia, the Superb Warblers (Maluridæ) of the same country, the Sun-birds (Nectariniæ), and with several of the Australian Honey-suckers or Meliphagidx. ${ }^{17}$

If wo look to the birds of England we shall see that there is mu close and general relation between the colours of the female and the nature of the nest which is constructed. About forty of onr British birds (excluding those of large size which could defend themselves) build in holes in banks, rocks, or trees, or construct. domed nests. If we take the colours of the female goldfinch, bullfinch, or blackbird, as a standard of the degree of conspicuousness, which is not highly dangerous to the sitting female, then out of the above forty birds, the females of only twelve can be considered as conspicnous to a dangerous degrce,

tomena macrourc has the head and tail dark blue with reddish loins; the female Lampornis porphymorus is blackish-green on the upper surface, with the lores and sides of the throat crimson; the female Eulampis jugularis has the top of the head and back green, but the loins and the tail are crimson. Many other instances of highly conspicuous females could be given. See Mr. Gould's magnificent work on this family.

$14 \mathrm{Mr}$. Salvin noticed in Guatemala ('Ibis,' 1864, p. 375) that hammiug-birds were much more as willing to leave their nests during very hot weather, when the sun was shining brightly, as if their eggs would be thus injured, than during cool, cloudy, or rainy weather.

is I may specify, as instances of dull-coloured birds building concealed nests, the species belonging to eight Australiun generu, described in Gould's 'Handbook of the Birds of Australia,' vol. i. pp. 340 , $362,365,383,387,389,391,414$.

16 Mr. C. Horne, 'Proc. Zoolog. Soc.' 1869, p. 243.

17 On the nititication and colours of these latter species, see Gcull's 'Han book,' \&c., rol. i.pp. 504527. 
the remaining twonty-eight being inconspicuous. ${ }^{18}$ Nor is there any close relation within the same genus between a well-pronounced difference in colonr between the sexes, and the nature of the nest constructed. 'I'hus the male house sparrow (I'asse' domesticus) differs much from the fimale, the male tree-sparrow (P. montanus) hardly at all, and yet both build well-concealed nests. The two sexes of the common fly-catcher (Musicapu grisolu) can hardly be distinguished, whilst the sexes of the pied fly-catcher ( $M$. luctuosa) differ considerably, and both species build in holes or conceal their nests. The fiemale blackbird ('Turdus merula) diffiers much, the female ring-ouzel ( $I$ '. torquatus) differs less, and the female common thrush (T. musicus) hardly at all from their rispective males; yet all build open nests. On the other hand, the not very distantly-allicd water-ouzel (Cinclus ayuaticus) builds a domed nest, and the sexes differ abont as much as in the rins-ouzel. The black and red grouse ('Teticuo tetrix and 'T'. scoticus) build open nests in equally wellconcealed spots, but in the one species the sexes differ greatly, and in the other very little.

Notwithstanding the foregoing objections, I cannot doubt, after reading Mr. Wallace's excellent essay, that looking to the hirds of the world, a largo majority of the species in which the females are conspicuously coloured (and in this case the males: with rare exceptions are equally conspicuous), build concealed nests for the sake of protection. Mr. Wallace enumerates ${ }^{19}$ it long series of groups in which this rule holds good; but it will suffice here to give, as instances, the more familiar groups of kingfishers, toucans, trogons, puff-birds (Capitonidæ), plantaineaters (IIusophagæ), woodpeckers, and parrots. Mr. Wallace believes that in these groups, as the males gradually acquired through sexual selection their brilliant colours, theso wer. transferred to the females and were not oliminated by natura! selection, owing to the protection which they already enjoyel

Is I have consulted, on this subject, Nacgillivray's 'British Birds,' and though doubts may be entertained in some chses in regard to the degree of concealment of the nest, and to the degree of conspicuousness of the female, yet the following birds, which all lay their. eggs in holes or in domed nests, can hardly be considered, by the above standard, as conspicuous: Passer, 2 species; Sturnus, of which the female is considerably less brilliant than the male; Cinclus; Motacilla bearula (?); Erithacus (?) ; Fruticola, 2 si..; Saxicoliı; liuticillı, sp.; Sylria, 3 sp.; Parus, 3 sp.; Mecistura; Anorthura; Certhia ; Sitta; Yunx; Muscieapar, 2 sp. ; Hirundo, 3 sp.; and Cypselus. The temales of the following 12 birds may be considered as cunspicuous, according to the same standard, viz., Pastor, Motacillit ilia, Parus major and $P$. cæruleus, (ipupr. Picus, 4 sp., Cor:icias, Alcedo, u. . Merops. 19 'Juurnal of 'Tiavel.' edited by A. Murray, vol. i. p. 78. 
from their manner of nidification. According to this view, their present manner of nesting was acquired before their present colours. But it seems to me much more probable that in most cases, as the females were gradually rendered more and mure brilliant from partaking of the colours of the male, they werc. gradually led to change their instincts (supposing that they originally built open nests), and to seek protection by building domed or concealed nests. No one who studies, or instance, Audubon's account of the differences in the nests of the sanie species in the Northern and Southern United States, ${ }^{20}$ will fecl any great difficulty in admitting that birds, either by a change (in the strict sense of the word) of their habits, or through the natural selection of so-called spontaneous variations of instinct, might readily be led to modify their manier of nesting.

This way of viewing the relation, as far as it holds grood, between the bright colours of female birds and their manner of nosting, receives some support from certain cases occurring in the Sahara Desert. Here, as in most other deserts, various birds, and many other animals, have had their colours adapted in a wonderful manner to the tints of the surrounding surface. Nevertheless there are, as I am informed by the Rev. Mr. Tristram, some curious exceptions to the rule; thus the male of the Monticola cyarea is conspicuous from his bright blue colour, and the female almost equally conspicuous from her mottled brown and white plumage; both sexes of two suecies of Dromolæa are of a lustrous black; so that these three species are far from receiving protection from their colours, yet they are able to survive, for they have acquired the habit of taking refuge from danger in holes or crevices in the rocks.

With respect to the above groups in which the females are conspicuonsly coloured and build concealed nests, it is not necessary to suppose that each separate species had its nidifying instinct specially modified; but only that the early progenitors of each group were gradually led to build domed or concealed nests, and afterwards transmitted this instinct, together witl their bright colours, to their modified descendants. As far as it can bo trusted, the conclusion is interesting, that sexual selection, together with equal or nearly equal inheritance by both sexes, have indirectly determined the manner of nidification of whole groups of birds.

According to Mr. Wallace, even in the groups in which the fernales, from being protected in domed nests during incubation,

20 See many statements in the 'Ornithological Biography.' See, giso, some curiotis cbsersations on the nests of Italian birds by Eugenio Bettoni, in the 'Atti della Societd Italiana,' vol. xi. 1869, p. 48 ?. 
have not had their bright colours eliminated through natura! selection, the males often differ in a slight, and occasionilly in a considerable degree, from the females. This is a significant fact, for such differences in colour must be accounted for by some of the variations in the males having been from the first limited in transmission to the same sex ; as it can hardly be maintained that these differences, especially when very slight, serve as a protection to the female. Thus all the species in the splendid group of the Trogons buiid in holes; and $\mathrm{Mr}$. Gould gires figures ${ }^{21}$ of both sexes of twenty-five species, in all of which, with one partial exception, the sexes differ sometimes slightly, sometimes conspciuously, in colour, - the males being always finer than tine females, though the latter are likewise beautiful. All the specio of kingfishers build in holes, and with most of the species the sexes are equally brilliant, and thus far Mr. Wallace's rule hold: grood; but in some of the Australian species the colours of the females aro rather less vivid than those of the male; and in onc splendidly-coloured species, the sexes differ so much that they were at first thought to be specifically distinct. ${ }^{22} \mathrm{Mr}$. R. B. Sharpe, who has especially studied this group, has shewn me some American species (Cergle) in which the breast of the male is belted with black. Again, in Carcineutes, the difference between the sexes is conspicuous: in the male the upper surface is dullblue banded with black, the lower surface being partly fawncoloured, and there is much red about the head; in the female the upper surface is reddish-brown banded with black, and the lower surface white with black markings. It is an interesting fact, as shewing how the same peculiar style of sexual colouring often characterises allied forms, that in three species of Dacelo the male differs from the female only in the tail being dull-blue banded with black, whilst that of the female is brown with blackish bars; so that here the tail differs in colour in the two sexes in exactly the same manner as the whole upper surface in the two sexes of Carcineutes.

With parrots, which.likewise build in holes, we find analogous cases: in most of the species both sexes ase brilliantly coloured and indistinguishable, but in not a few species the males are coloured rather more vividly than the females, or even very differently from them. 'Thus, besides other strongly-marked differences, the whole under surface of the male King Lory (Aprosmictus sccipulutus) is scarlet, whilst the throat and chest of the female is green tinged with red: in the Euphema silenulidu

${ }^{21}$ See his 'Monograph of the rrogonide, first edition.

${ }_{22}$ Nanely Cyanalcyon. Gould's
'Handbook to the firds of Australia,' rol. i. p. 13 ? ; see, also, t'p $130,136$. 
there is a similar difference, the face and wing-coverts moreover of the female being of a paicr blue than in the male. ${ }^{23}$ In the family of the tits (Purince), which build concealed nests, the female of our common blue tomtit (Parus caruleus) is "much "less brightly coloured" than the male; and in the magnificent Sultan yellow tit of India the difference is greater. ${ }^{2+}$

Again in the great group of the woodpeckers, ${ }^{25}$ the sexes are generally nearly alike, but in the Megapricus validus all those parts of the head, neck, and breast, which are crimson in the male are pale brown in the female. As in several woodpeckers the head of the male is bright crimson, whilst that of the female is plain, it occurred to me that this colour might possibly make the female dangerously conspicuous, whenever she put her head out of the hole containing her nest, and consequently that this colour, in accordance with Mr. Wallace's belief, had been eliminated. 'This view is strengthened by what Malherbe states with respect to Indopicus carlutta; namely, that the young females, like the young males, have some crimson about their heads, but that this colour disappears in the adult female, whilst it is intensified in the adult male. Nevertheless the following considerations render this view extremely doubtful: the male takes a fair share in incubation, ${ }^{26}$ and would be thus almost equally exposed to danger; both sexes of many species have their heads of an equally bright crimson; in other species the difference between the sexes in the amount of scarlet is so slight that it can hardly make any appreciable difference in the danger. incurred; and lastly, the colouring of the head in the two sexes often differs slightiy in other ways.

The cases, as yet given, of slight and graduated differences in colour hetween the males and females in the groups, in which as a general rule the sexes resemble each other, all relate to species which build domed or concealed nests. But similar gradations may likewise be observed in groups in which the sexes is a general rule resemble each other, but which build open nests. As I have before iustanced the Australian parrots, so I may here instance, without giving any details, the Australian pigeons. ${ }^{27}$ It deserves especial notice that in all these cases the slight

23 Fvery gradation of difference $b$ tween the sexes may be followed in the parrots of Australia. See Gould's 'Handbook,' \&c., vol. ii. pp. 14-102.

24 Macgillivray's 'British Birds,' vol. ii. p. 433. Jerdon, 'Birds of Iodia," vol. ii. p. 282.

2s All the following facts are taken from M. Malherbe's magnificent 'Mouographie des Picidees,' 1861.

26 Audubon's 'Ornithological Biography,' rol. ii. p. 75; see also the 'Ibis,' vol. i. p. 268.

${ }^{27}$ Gould's 'Handbook to the Birds of Australia, rol. ii. pp. 109 149. 
differences in plumage between the sexes are of the same general nature as the occasionally greater differences. A good illustration of this fact has already been afforded by those kingfishers in which either the tail alone or the whole upper surface of the plumage differs in the same manner in the two sexes. Similar cases may be ohserved with parrots and pigeons. The differences in colour between the sexes of the sarne species are, also, of the same general nature as the differences in colour between the distinct species of the same group. For when in a group in which the sexes are usually alike, the male differs considerably. from the female, he is not coloured in a quite new style. Hence we may infer that within the same group tho special colours of both sexos when they are alike, and the colours of the male, when he difficrs slightly or eren considerably from the female, havr. been in most cases determined by the same general cause; this being sexual selection.

It is not probalile, as has already been remarked, that differences in colour between the sexes, when very slight, can be of service to the feruale as a protection. Assuming, however, that they are of service, they might bo thought to be cases of transition; but we have no reason to believe that many species at any one time are undergoing change. Therefore we cals hardly admit that the numerous females which differ very slightly in colour from their males are now all commencing to becone obscure for the sake of protection. Even if we consider somewhat more marked sexual differences, is it probable, for instance, that the head of the female chaffinch, - the crimson on the breast of the female bullfinch,- the green of the female greenfinch, - the crest of the female golden-crested wren, have all been rendered less bright by the slow process of selection for the sake of protection? I cannot think so; and still less with the slight differences between the sexes of those birds which build concealed nests. On the other hand, the differences in colour beitween the sexes, whether great or small, may to a large extent be explained on the principle of the successive variations, acquired by the males through sexual selectior, having beer from the first more or less limited in their transmission to the females. That the degree of limitation should differ in different species of the same group will not surprise any one who has studied the laws of inheritance, for they are so complex that they appear to us in our ignorance to be capricious in their action. ${ }^{28}$

As far as I can discover there are few large groups of birds in which all the species have both sexes alike and brilliantly

23 See remarks to this effect in my work on "Variatiot rader Domestication,' vol. i. chap. xii. 
coloured, but I hear from MIr. Sclater, that this appears to bo the case with the Musophagre or plantain-eaters. Nor do I beliovo that any large group exists in which the scxes of all the species are widely dissimilar in colour: Mr. Wallace informs me that the cliatterers of S. America (Cotingidae) offer one of the best instances; but with some of the species, in which the male has a splendid red breast, the female exhibits some red on her breast; and the females of other species sher traces of the green and other colours of the males. Nevertheless we have a near approach to close sexual similarity or dissimilarity throughout several groups : and this, from what has just been said of the fluctuating nature of inheritance, is a somewhat surprising circumstance. But that the same laws should largely prevail with allied animals is not surprising. The domestic fowl has produced a great number of breeds and sub-brecds, and in these the sexes generally differ in plumage; so that it has been noticed as an unusual circumstance when in certain sub-breeds they resemble each other. On the other hand, the domestic pigeon has likewise produced a vast number of distinct breeds and sub-breeds, and in these, with rare exceptions, the two sexes are identically alike. Therefore if other species of Gallus and Columba were domesticated and raried, it would not be rash to predict that similar rules of sexual similarity and dissinilarity, depending on the form of transmission, would hold good in both cases. In like nunner the same form of transmission has generally prevailed under nature throughout the same groups, although marked exceptions to this rule occur. Thus within the same family or even genus, the sexes may be identically alike, or very different in colour. Instances have already been given in the same genus, as with sparrows, fly-catchers, thrushes and grouse. In the family of pheasants the sexes of almost all the species are wonderfully dissimilar, but are quite alike in the eared pheasant or C'rossoptilon auritum. In two spccies of Chloephaga, a genus of geese, the male cannot be distinguished from the females, except by size; whilst in two others, the sexes are so unlike that they might easily be mistaken for distinct species. ${ }^{29}$

Tho laws of inheritance can alone account for the following cases, in which the female acquires, late in life, certain characters proper to the male, and ultimately comes to resemble him more or less completely. Here protection can hardly have come into play. Mr. Blyth informs me that the temales of Oriolus melano. cephalus and of some allied species, when sufficiently mature to breed, differ considerably in plumage from the ardult males; but 
after the second or third moults they differ only in their beals having a slight greenish tinge. In the d r rarf bitterns (Ardetta), according to the same authority, "the male acquires his final "livery at the first moult, the female not before the third or "fourth moult; in the meanwhile she presents an intermediate " garb, which is ultimately exchanged for the same livery as " that of the male." So again the female Fulco peregrinus acquires her blue plumage more slomly than the male. Mr. Swinhoe states that with one of the Drongo shrikes (Dicrurus. macrocercus) the male whilst almost a nestling, moults his soft hrown plumage and becomes of a uniform glossy greenish-black; but the female retains for a long time the white striæ and spots on the axillary feathers; and does not completely assume the uniform black colour of the male for three years. The same excellent observer remarks that in the spring of the second year the female spoonbill (Platalea) of China resembles the male of the first year, and that apparently it is not until the third spring that she acquires the same adult plumage as that possessed by the male at a much earlier age. The female Bombycilla carolin"nsis differs very little from the male, knt the appendages, which like beads of red sealing-wax ornament the wing-feathers, ${ }^{30}$ are not developed in her so carly in life as in the male. In the male of an Indian parrakeet (Pulæornis jurunicus) the upper mandible is coral-red from his earliest youth, but in the female, as Mr. Blyth has observed with caged and wild birds, it is at first black and does not become red until the bird is at least a year old, at which age the sexes resemble each other in all respects. Both sexes of the wild turkey are ultimately furmished with a tuft of bristles on the breast, but in two-year-old birds the tuft is about four inches long in the male and hardly apparent in the female; when, however, the latter has reached her fourth year, it is from four to five inches in length. ${ }^{38}$

These cases must not be confounded with those where diseased or old females abnormal!y assume masculine characters, nor with

30 When the male courts the female, these ornaments are vibrated, and " are shewn off to great advan"tage," on the ontstretched wings: A. Leith Adams, "Field and Forest Rambles,'1873, p. 153.

s1 On Ardetta, Translation of Cuvier's 'Règne Animal,' by Mr. Blyth, footaote, p. 159. On the Peregrine Falcon, Mr. Blyth, in Charlesworth's 'Mag. of Nat. Hist.' vol. 1. 1837, p. 304. On Dicrurus, - Ibis,' 1863, p. 44. On the Platalea,
'Ibis,' rol. ri. 1864, p. 366 . On the Bombycilla, Auduboz's 'Ornitholog. Biography,' rol. i. p. 229. On the Palxornis, see, also, Jerdon, 'Birds of India,' rol. 1. p. 263. On the wild turkey, Audubon, ibid. vol. ふ. p. 15 ; but I hear from Judge Caton that in Illnois the fercale very rarely acquires a tuft. Analogous cases with the feutales of Petrocossyphus are given by $\mathrm{MI}_{5}$. R. B. Sharpe, 'Proc. Zoolog. Sca' $1972, \% .496$. 
those where fertile ímales, whilst young, acqaire the charactera of the male, through variation or some unknown cause. But all these cases have so much in common that they depend, iccording to the hypothesis of pangenesis, on gemmules derived from each part of the male being present, though latent, in the female; their development following on some slight cliange in the elective affinities of her constituent tissues.

A few words must be added on changes of plumage in relation to the season of the year. From reasons formerly assigned there can be little doubt that the elegant plumes, long pendant feathers, crests, \&c., of egrets, herons, and many other birds, which are developed and retained only during the summer, serve for ornamental and nuptial purposes, though common to both sexes. The female is thus rendered more conspicuous during the period of incubation than during the winter; but such birds as herons and egrets would be able to defend themselves. As, however, plumes would probably be inconvenient and certainly of no use during the winter, it is possible that the habit of moulting twice in the year may have been gradually acquired through natural selection for the sake of casting off inconvenicnt ornaments during the winter. But this view sannot be extended to the many waders, whose summer and winter plumages differ very little in colour. With defenceless species, in which both sexes, or the males alone, become extremely conspicuous during the breeding-season,-or when the males acquire at this season such long wing or tail-feathers as to impede their flight, as with Cosmetornis and Vidua,-it certainly at first appears highly probable that the second moult has been gained for the special purpose of throwing off these ornaments. We must, however, remember that many birds, such as some of the Birds of Paradise, the Argus pheasant and peacock, do not cast their plumes during the winter; and it can hardly be maintained that the constitution of these birds, at least of the Gallinacer, venders a double moult impossible, for the ptarmigan moults thrice in the year. ${ }^{33}$ Hence it must be considered as doubtful whether the many species which moult their ornamental plumes or lose their bright colours during the winter, have acquired this habit on account of the inconvenience or danger which they would otherwise have suffered.

\footnotetext{
82 Of these latter cases $\mathrm{Mr}$. Blyth has recorded (Traushation of Cuvier's 'Règne Animal,' p. 158) various instinces with Lanius, Ruticilla, Liraria, and Anas. Audubon has
}

also recorded a similar case ('Ornith Biog.' vol. จ. p. 519) witk. Pyranga astiva.

33 See Gou!d's 'Birds of Great Britain.' 
I conclude, therefore, that the habit of moulting twice in the ycar was in most or all cases first acquired for some distinct purpose, perhaps for gaining a warmer winter covering; and that vitriations in the plumage occurring during the summer were accumulated through sexual selection, and transmitted to the offspring at the same season of the year; that such variations were inherited either by hoth sexes or by the males alone, according to the form of inheritance which prevailed. This appears more probable than that the species in all cases originaily tended to retain their ornamental plumage during the winter, but were saved from this through natural selection, resulting from the inconvenience or danger thus caused.

I have endeavoured in this chapter to shew that the arguments are not trustworthy in favour of the view that weapons, bright colours, and various ornaments, are now confined to the males owing to the conversion, by natural selection, of the equal transmission of characters to both sexes, into transmission to the male sex alone. It is also doubtful whether the colours of many female birds are due to the preservation, for the sake of protection, of variations which were from the first limited in their transmission to the female sex. But it will be convenient to defer any further discussion on this subject until I treat, in the following chapter, of the differences in plumage between the young and old.

\section{C프APTER XVI.}

\section{Birds-concluded.}

Whe immature plumage in relation to the character of the plumage in both sexes when adult-Six classes of cases-Sexual differences betweer. the males of closely-allied or representative spacies-The female as. suming the characters of the male-Plumage of the yourg in relation to the summer and winter plumage of the adults-On the increase of beauty in the birls of the world-Protective colourng-Conspicuouslycoloured birds-Norelty appreciated-Summary of the four chapters on Yirds.

WE must now consider the transmission of characters, as limited by age, in reference to sexual selection. The truth and importance of the principle of inheritance at corresponding ages need not here be discussed, as enough has already been said or the subject. Before giving the several rather complex rules or cinsses of cases, under which the differences in plumage between the young and the old, as far as known to me, may be included, it will be well to make a few preliminary remarks. 
With animals of all kinds when the adults differ in coiour from the young, and the colours of the latter are not, as far as we can see, of any special service, they may generally be attributed, like various embryological Etructures, to the retention of a former character. But this riew can be maintained with confidence, only when the young of several species resemble ('ash other closely, and likewise resemble other adult species inelonging to the same group; for the latter are the living proofs that such a state of things was formerly possible. Young lions and pumss are marked with feeble stripes or rows of spots, and in many allied species both yonng and old are similarly marked, 110 believer in evolution will doubt that the progenitor of the lion and puma was a striped animal, and that the young have retained vestiges of the stripes, like the kittens of black cats, which are not in the least striped when grown up. Many species of deer, which when mature are not spotted, are whilst young covered with white spots, as are likewise some few species in the adult state. So again the young in the whole family of pigs (Suidæ), and in eertrin rather distantly allied animals, such as the tapir, are marked with dark Jongitudinal stripes; but here we have a character apparently derized from an extinct progenitor, and now preaerred by the young alone. In all such cases the old have had their colours clianged in the course of time, whilst the young have remained but little altered, and this has been effected through the principle of inheritance at corresponding ages.

This same prineiple applies to many birds belonging to various groups, in which the young closely rescmble each other, and differ much from their respective adult parents. The young of almost all the Gallinacere, and of some distantly allicd birds such as ostriches, are covered with longitudinally striped down; but this claracter points back to a state of things so remote that it hardly concerns us. Young cross-bills (Loxia) have at first straight beaks like those of other finches, and in their immature striated plumage they resemble the mature redpole and female siskin, as well as the young of the goldfinch, gruenfinch, and some other allied species. The young of many kinds of buntings (Emberiza) resemble one another, and likewise tho adult state of the common bunting, E. miliaria. In almost the whole large group of thrushes the young have their breasts spotted - a character which is retrined throughout life by many species, but is quite lost by others, as by the Turdus migralorius. So again with many thrushes, the feathers on the back are mottled before they are moulted for the first timc, and this character is retained for life by certain eastern specics. 
The young of many species of shrikes (Lanius), of some woodpeckers, and of an Indian pigeon (Chulcophaps indicus); aro transversely striped on the under surface; and certain alliect specios or whole genera are similarly marked when adult. In somo closely-allied and resplendent Indinn cuckoos (Chrysococcyx), the mature species differ considerably from one another in colour, but the young cannot be distinguished. The young of an Indian goose (Sarkidiornis melanonotus) closely resemble in plumage an allied genus, Dendrocygna, when mature.' similar facts will hereafter be given in regard to certain herons. Young black grouse (Tetrao tetrix) resemble the young as well it the old of certain other species, for instance the red grouse sr T. scoticus. Finally, as Mr. Blyth, who has attended closely to this subject, has well remarked, the natural affinities of many species are best exhibited in their immature plumage; and as the true affinities of all organic beings depend on thcir descent from a common progenitor, this remark strongly confirms the belief that the immature plumage approximately shews us the former or ancestral condition of the species.

Although many young birds, belonging to various families, thus give us a glimpse of the plumage of their remote prosenitors, yet there are many other birds, both dull-coloured and bright-coloured, in which the young closely resemble their parents. In such cases the young of the different species cannot resemble each other more closely than do the parents; nor can they strikiugly resemble allied forms when adult. They give us but little insigut into the plumage of their progenitors, excepting in so far that, when the young and the old are coloured in the same general manner throughout a whole group of species, it is probable that their progenitors were similarly coloured.

We may now consider the classes of cases, under which the differences and resemblances between the plumage of the young and the old, in both sexes or in one sex alone, may be grouped. Rules of this kind were first enounced by Cuvier; but with the progress of knowledge they require some modification and amplification. This I have attempted to do, as far as the extreme complexity of the subject permits, from information derived from various sources; but a full essay on this subject by some competent ornithologist is much needed. In order to ascertain

1 In regard to thrushes, shrikes, .nd woodpeckers, see Mr. Blyth, in Charlesworth's 'Mag. of Nat. Hist.' rol. i. 1837, p. 304; also footnote to his translation of Cuvier's 'Règne Animal,' p. 159. I give the case of Loxia on Mr. Blyth's information. ()n thrushes, see also Audubon, 'Ornith. Biogr:uphy,' vol. ii. p. 195. (In Chrysococcys and Chalcophaps, Jilyth, as quoted in Jerdon's 'Birds of India,' vol. iii. p. 485. On Sar. bidiornis, Blyth, in 'Ibis,' 1867, p. 175. 
to what extent each rule prevails, I have tabulated the facts given in four great works, namely, by Macgillivray on the birds of Britain, Audubon on those of North America, Jerdon on those of India, and Gould on those of Australia. I may here premise, first, that the several cases or rules graduate into cach other; and, secondly, that when the young are said to resemble their parents, it is not meant that they are identically alike, for their colours are almost always less vivid, and the foather's are softer and uften of a different shape.

\section{REIES OR CIASSES OF CASES.}

I. When the adult male is more beautiful or conspicuous than the adult female, the young of both sexes in their first plumage closely resemble the adult female, as with the common fowl and peacock; or, as occasionally occurs, they resemble her much more closely than they do the adult male.

II. When the adult female is more conspicuous than the adult male, as sometimes though rarely occurs, the young of both sexes in their first plumage resemble the adult male.

III. When the adult male resembles the adult female, the young of both sexes hare a peculiar first plumage of their own, as with the robin.

IV. When the adult male resembles the adult female, the young of both sexes in their first plumage resemble the adults, as with the kingfisher, many parrots, crows, hedge-warblers.

$\mathrm{V}$. When the adults of both sexes have a distinct winter and summer plumage, whether or not the male differs from the female, the young resemble the adults of both sexes in their winter dress, or much more rarely in their summer dress, $\mathrm{ol}^{*}$ they rescmble the femaies alone. Or the young may have an intermediate character; or again they may differ greatly from the adults in both their seasonal plumages.

VI. In some few cases the young in their first plumage differ. from each other according to scx; the young males resembling more or less closcly the adult males, and the young females; more or less closely the adult females.

Cuass I.-In this class, the young of both sexes more or less closely resemble the adult female, whilst the adult male differs from the adult female, often in the most conspicuous manner. Innumerable instances in all Orders could be given; it will suffice to call to mind the common pheasirt, duck, and housesparrow. The cases under this class graduate into others Thus the two sexes when adult may differ so slightly, and the roung so slightly from the adults, that it is doubtful whether 
such cases ought to come under the present, or under tire third or fourth classes. So again the young of the two sexes, iustead of being quite alike, may differ in a slight degree from each other. as in our sixth class. These transitional cases, however, are few, or at least are not strongly promounced, in comparison with thase which come strictly under the present class.

The force of the present law is well shewn in those groups, in which, as a general rule, the two seres and the young are all alike; for when in these groups the male does differ from the: femule, as with certain parrots, kingfishers, pigeons, \&c., the young of both sexes resemble the adult female. ${ }^{2}$ We see the same fact exhbited still more clear'y in certain anomalous cases; thus the male of /leliotirix auriculata (one of the hummingbirds) differs conspicuously from the female in having a splendid gorget and fine ear-tufts, but the female is remarkable from liaving a much longer tail than that of the male; now the youns. of both seres resemble (with the exception of the breast being spotted with bionze) the adult female in all other respects, including the length of her tail, so that the tail of the male actually becomes shorter as he reaches maturity, which is a most unusual circumstance. ${ }^{3}$ Again, the plumage of the male goosander (Meigus mergunser) is more conspicuously coloured than that of the female, with the scapular and secondary wing-feathers much longer; but differently from what occurs, as far as I know, in any other bird, the crest of the adult male, though broader than lhat of the female, is considerably shorter, being only a little above an inch in length; the crest of the female being two and a half inches long. Now the young of both sexes entirely resemble the adult female, so that their crests are actually of greater length, though narrower, than in the adult male."

When the young and the fomales closely resemble each other and botlı differ from the males, the most obvious conclusion is

2 See, for instance, Mr. Gould's account ('Handbook to the Birds of Australia,' vol. i. p. 133) of Cyanalcyon (une of the Kingfishers) in which, however, the young male, though resembling the adult female, is less billliantly coloured. In some apecies of Dacelo the males have blue tails, and the females brown ones; and Mr. R. B. Sharpe informs me that the tail of the young male of $D$. gaudichaudi is at first brown. Mr. Gould has described (ibid. vol. ii. pp. 14, 20,37) the sexes and the young of cortain black Cockatoos and of the King Lory, with which the same rule prevails. Also Jerdon ('Birds of India," vol. i. p. 260) on the Palsornis rosa, in which the young are more like the female than the male. See Audubon ('Ornith. Biograph.' vol. ii. p. 475) on the two seres and the young of Columba passerina.

I owe this information to Mr. Gould, who shewed me the specimens; see also his 'Introduction tc the Trochilidæ,' 1861, p. 120.

- Macgillivray, 'Hist. Brit. Biris, vol. v. pp. 207-214. 
that the males alone have been nucdified. Even in the anomalous cases of the Heliothrix and Mergus, it is probable that originally both adult sexes were furnished-the one species with a much elongated tail, and the other with a much elongatcil crest-these characters having since been partially lost by the atult males from some unexplained cause, and transmittert in their dimmished state to their male offspring alnne, when arrived at the correspunding age of maturity. The belief that in the present class the male alone has been modified, as far ac the differences between the male and the female together with her young are concerned, is strongly supported by some l\%marliahle facts recorded by Mr. Blyth, ${ }^{5}$ with respect to closelyallied species which represent each other in distinct countries. For with several of these representative species the adult males have undergone a certain amount of change and can be distincuished; the females and the young from the distinct countries buing indistinguishable, and therefore absolutely unchangerl. This is the case with certain Indian chats (Thamnobia), with certain honey-suckers (Nectarinia), shrikes (Tephrodornis), certain kingfishers (Tanysiptera), Kalij pheasants (Gallophasis), and tree-partridges (Arboricola).

In some analogous cases, namely with birds having a different summer and winter plumage, but with the two sexes nearly alike, certain closely-allied species can easily be distinguished in their summer or nuptial plumage, yet are indistinguishable in their winter as well as in their immature plumage. This is the case with some of the closely-allied Indian wag-tails or Motacillæ. Mr. Swinhoe ${ }^{6}$ informs me that three species of Ardeola, a genus of herons, which represent one another on separate continents. are "most strikingly different" when ornamented with their summer plumes, but are hardly, if at all, distinguishable during: the winter. The young also of these three species in their immature plumage closely resemble the adults in their winter dress. This case is all the more interesting, because with two wther species of Ardeola both sexes retain, during the winter and summer, nearly the same plumage as that possessed by the three first species during the winter and in their immature state; and this plumage, which is common to several distinct

s Sne his admirable paper in the 'Journal of the Asiatic Soc. of liensal,' vol. xix. 1850, p. 223 ; see Alsn I I rion, 'Birds of India,' vol. i. intretietion, p. xxix. In regard to Tinusiptera, Prof. Schlegel told Mr. Blpth that he could distiaguish several distinct races, solely by comparing the adult males.

- See also Mr. Swinhoe, in 'Iois,' July 1863, p. 131; and a previous palper, with an extract from a note by Mr. Blyth, in 'Sbis;' 'in. I86i, i) 25. 
quecies at different ages and seasons, probably shews us how the progenitors of the genus were coloured. In all these caseo the nuptial plumage which we may assume was originally acquired by the adult males during the breeding-season, and transmitted to the adults of both sexes at the corresponding season, has been modified, whilst the winter and immature plumages have been left unchanged.

The question naturally arises, how is it that in these latter cases the winter plumage of both sexes, and in the former cases the plumage of the adult females, as well as the immature plumage of the young, have not been at all affected? 'The species which represent each other in distinct countries will almost always have been exposed to somerwat different conditions, but we can hardly attribute to this action the modification of the plumage in the males alone, seeing that the females and the young, though similarly exposed, have not been affected. Hardly any fact shews us more clearly how subordinate in importance is the direct action of the conditions of life, in comparison with the accumulation through selection of indefinite variations, than the surprising difference between the sexes of many birds; for both will have consumed the same food, aud have been exposed to the same climate. Nevertheless we are not precluded from beliering that in the course of time new conditions may produce some direct effect either on both sexes, or from their constitutional differences chiefly on one sex. Wo see only that this is subordinate in importance to the accumulated results of selection. Judging, however, from is wide-spread analogy, when a species migrates into a now country (and this must precede the formation of representative. species), the changed conditions to which they will almost always have been exposed will cause them to undergo a certain amount of fluctuating variability. In this case sexual selection, which depends on an element liable to change-the taste or admiration of the female-will have had new shades of colour or other differences to act on and accumulate; and as sexual selection is always at work, it would (from what we know of the results on domestic animals of man's unintentionai selection), be surprising if animals luhabiting separate districts, which can never cross and thus blend their newly-acquired characters, were not, after a sufticient lapse of time, diffirently modified. These remarks likewise apply to the nuptial or summer plumage, whether confined to the males or common to both seres.

Although the females of the above closely-allied or representative species, togethor with their young, differ hardly at ull 
from one another, so that the males alono can be distinguished, yet the females of most species within the same genus obviously iliffer from each other. The differences, huwever, are rarely ins great as between the males. We see this clearly in the whole family of the Gallinaceæ: the females, for instance, of the comnon and Japan pheasant, and especially of the Gold and Imherst pheasant-of the silver pheasant and the wild fowl -resemble one another very closely in colour, whilst the males liffer to an extraordinary degree. So it is with the females of most of the Cotingida, Fringillidæ, and many other families. There can indeed be no doubt that, as a general rule, the females have been less modified than the males. Some few birds, however, offer a singular and inexplicable exception; thus the temales of Paradisen apoda and $Y$. papunna differ from each other more than do their respective males $;^{7}$ the female of the latter species having the under surface pure white, whilst the female $P$. apoda is deep brown beneath. So, again, as I hear from Professor Newton, the males of two species of Oxynotus (shrikes), which represent each other in the islands of Mauritius and Bourbon, ${ }^{,}$differ hut little in colour, whilst the females differ much. In the Bourbon species the female appears to have partially retained an immature coudition of plumage, for at first sight she "might be taken for the young of the Mauritian "species." These differences may be compared with those inexplicable ones, which occur independently of man's selection in certain sub-breeds of the game-fowl, in which the females are very different, whilst the males can hardly be distinguished. ${ }^{\circ}$

As I account so largely by sexual selection for the differences between the males of allied species, how can the differences between the fomales be accounted for in all ordinary cases? We need not here consider the species which belong to distinct genera; for with these, adaptation to different habits of life, and other agencies, will hare come into play. In regard to the lifferences between the females within the same genus, it appears to me almost certain, after looking through various large groups, that the chief agent has been the greater or loss transference to the female of the characters acquired by the males through serual selection. In the several British finches, the two sexes differ either very slightly or considerably; and if we compare the females of the greenfinch, chaffinch, goldtinch, bullfinch, crossbill, sparrow, \&c., we shall see that they differ from ono

- Wallace, 'The Malay Archipelago,' vol. ii. 1869, p. 394.

These species are described, with soionred ligures, by M. F. Polien, in
'Ibis,' 1866, p. 275.

- Variation of Animals, \&r.., under Domestication, vol. i. p. $2 \xi 1$ 
another chiefly in the points in which they partially resemble their respective males; and the colours of the males may safely be attributed to sexual selection. With many gallinaceous species the sexes differ to an extreme degree, as with the peacock, phensant, and fowl, whilst with other species there has been a partial or even complete transference of character from the male to the female. The females of the several species of Polyplectron exhibit in a dim condition, and chiefly on the tail, the splendid ocelli of their males. The female partridge differs from the male only in the red mark on her breast being smaller; and the female wild turkey only in her colours being much duller. In the guinea-forl the two sexes are indistinguishable. There is no improbalility in the plain, though peculiarly spotted plumage of this latter bird having been acquired through sexual selection l,y the males, and then transmitted to both sexes; for it is not essentially different from the much more beautifully spotted plumage, characteristic of the males alone of the Tragopan pheasants.

It should be observed that, in some instances, the transference of characters from the male to the female has been effected apparently at a remote period, the male having subsequently undergone great changes, without transferring to the female any of his later-gained characters. For instance, the female and the young of the black-grouse (Trtrao tetrix) resemble pretty closely both sexes and the young of the red-grouse ( $T$. scoticus); and we may consequently infer that the black-grouse is descended from some ancient species, of which both sexes were coloured in nearly the same manner as the red-grouse. As both sexes of this latter species are more distinctly barred during the breeding season than at any other time, and as the male differs slightly from the female in his more strongly-pronounced red and brown tints, ${ }^{10}$ we may conclude that his plumage has been influenced by sexual selection, at least to a certain extent. If so, we may further infer that the nearly similar plumage of the female klackgrouse was similarly produced at some former period. But since this period the male black-grouse has acquired his fine black plumage, with his forked and outwardly-curled tailfeathers; but of these characters there has hardly been any transference to the female, excepting that she shews in her tail a trace of the curved fork.

We may therefore conclude that the females of distinct though allied species have often had their plumage rendered more $o_{0}^{\circ}$ less different by the transference in various degrees, of characters auquired by the males through sexual selection, both during

10 Macgillivray, 'Hist. British Birds,' vol. i. pp. 172-174. 
former and recent times. But it deserves especial attention that brilliant colours have been transferred much more rarely thas other tints. For instance, the male of the red-throated bluebreast (Cyaneculu suecica) has a rich blue breast, including a subtriangular red mark; now marks of nearly the same shape have bcen transferred to the female, but the central space is fulvous instead of red, and is surrounded by mottled instead of blue leathers. The Gallinaceæ offer many analogous cases; for none of the species, such as partridges, quails, guinea-fowls, \&c., in which the colours of the plumage have been largely transterred from the male to the female, are brilliantly coloured. This is well exemplified with the pheasants, in which the male is generally; so much more brilliant than the female; but with the Eared and Cheer pheasants (Crossoptilon auritum and Phasianus wallichii) the sexes closely resemble each other and their colours are dull. We may go so far as to believe that if any part of the plumage in the males of these two pheasants had been brilliantly: coloured, it would not have heen translerred to the females. These facts strongly support Mr. Wallace's view that with birds which are exposed to much danger during incubation, the transference of bright colours from the male to the female has been checked through natural selection. We must not, however, forget that another explanation, before given, is possible ; namely, that the mailes which varied and became bright, whilst they were young and inexperienced, would have been exposed to much danger, and would generally have been destroyed; the older and more cautious males, on the other hand, if they varied in a like manner, would not only have been able to survive, but would have been favoured in their rivalry with other males. Now variations occurring late in life tend to be transmitted exclusively to the same sex, so that in this case extremely bright tints would not have been transmitted to the females. On the other hand. ornaments of a less conspicuous kind, such as those possessed by the Eared and Cheer pheasants, would not have been dangerous, and if they appeared during early youth, would generally have been transmitted to both sexes.

In addition to the effects of the partial transference of characters from the males to the females, some of the differences between the females of closely allied species may be attributed to the direct or definite action of the conditions of life. ${ }^{11}$ With the males, any sucii action would generally have been masked by the brilliant colours gained through sexual selection; but not so with the females. Each of the endless diversities in plumage,

"See, on this subject, char xxiii. in the "Variation of Aaimais and Plents under Domestica"ion 
which we see in our domesticated birds is, of course, the result of some definite cause; and under natural and more uniforn? conditions, some one tint, assuming that it was in no way injurious, would almost certainly sooner or later prevail. The free intercrossing of the many individuals belonging to the same species would ultimately tend to make any change of colour, thus induced, uniform in character.

No one doubts that both sexes of many birds have had their colours adapted for the sake of protection; and it is passible that the females alone of some species may have been modified for this ond. Although it would be a difficult, perhaps an impossible process, as shewn in the last chapter, to convert one form of transmission into another through selection, there would not be the least difficulty in adapting the colours of the female, independently of those of the male, to surrounding objects. through the accumulation of variations which were from the first limited in their transmission to the female sex. If the variations were not thus limited, the bright tints of the male vould be deteriorated or destroyed. Whether the females alone of many species hare bten thus specially modified, is at present very doubtful. I wish I could follow Mr. Wallace to the full extent 3 for the admission would remore some difficulties. Any variations which were of no service to the female as a protection would be at once obliterated, instead of being lost simply by not being selected, or from free intercrossing, or from being eliminated when transferred to the male and in any way injurious to lim. Thus the plumage of the female would be kept constant in character. It would also be a relief if wo could admit that the obscure tints of both sexes of many birds had been acquired and preserved for the sake of protection,-for example, of the hedge-warbler or kitty-wren (Accentor mouluris and Trogloriyfes vulyaris), with respect to which we hare no sufficient evidence of the action of sexual selection. We ought, however, to bc cautious in concluding that colours which appear to us dull, are not attractive to the females of certain species; we should bear in mind such cases as that of the common house-sparrow; in which the male differs much from the fewale, but does not exhibit any bright tints. No one probably will dispute that many gallinaceous birds which live on the open ground, have acquired their present colours, at least in part, for the suke of protection. We know how well they are thus concealed; we know that ptarmigans, whilst changing from their winter to their summer plumage, both of which are protective, suffer greatly from birds. of prey. But can we believe that the very slight differences in tiuts and markings between, for instance, the femalc black-grouse 
and rod-grouse serve as a protection? Are partridges, as they are now coloured, better protected than if they had resembled quails? Do the slight differences between the females of the common pheasant, the Japan and gold pheasants, serve as a protection, or might not their plumages have been interchanged with impunity? From what Mr. Wallace has observed of the habits ot certain gallinaceous birds in the East, he thinks that sacn slight differences are beneficial. For myself, I will only say that I am not convinced.

Formerly when I was inclined to lay much stress on protection as accounting for the duller colours of female birds, it occurred to me that possibly both sexes and the young might aboriginally have been equally bright coloured; but that subsequently, the females from the danger incurred during incubation, and the young from being inexperienced, had been rendered dull as a jrotection. But this view is not supported by any evidence, and is not probable; for we thus in imagination expose during past times the females and the young to danger, from which it has subsequently been necessary to shield their modified descendants. We have, also, to reduce, through a gradual process of selection, the females and the young to almost exactly the same tints and markings, and to transmit them to the corresponding sex and period of life. On the supposition that the females and the young have partaken during each stage of the process of modification of a tendency to be as brightly coloured as the males, it is also a somewhat strange fact that the females have never been rendered dull-coloured without the young participating in the same change; for there are no instances, as far as I can discover, of species with the females dull and the young bright coloured. A partial exception, however, is offered by the young of certain woodpeckers, for they have "the whole upper part of the head tinged with red," which afterwards either decreases into a mere circular red line in the adults of both sexes, or quite disappears in the adult females. ${ }^{12}$

Finally, with respect to our present class of cases, the most probable view appears to be that successive variations in hrightness or in other ornamental characters, occurring in the males at a lather late period of life have alone been preserved; and that most or all of these variations, owing to the late period of life at which they appeared, have been from the first transmitted only to the adult male offspring. Anv variations in lrightness occurring in the females or in the young, would have

12 Andubon, 'Oruith. Biography,' vol. i. p. 193. Macgilluvras, : Mist. Brit Birds' roi. iii. p. 85. See also the case before given of Inciw picus carlotta. 
been of no service to them, and rould not have been selected; and moreover, if dangerous, would have been eliminated. 'Thus the females and the young will either have becn left unmodified, or (as is much more common) will have been partially modified t.y receiving through transference from the males some of his siluccessive variatiors. Both sexes have perhaps been directly acted on by the conditions of life to which they have long hecn exposed: but the females from not being otherwise much modified, will best exhibit any such effects. These changes and all others will have been kept unitorm by the free intercrossing of many individuals. In some cases, especially with gromnd birds, the females and the young may possibly have been modified, independently of the males, for the sake of protection, so as to have acquired the same dull coloured plumage.

Cuass II. When the adult female is more conspicuous than the adult male, the young of both sexes in their first plumage resemble the adult mule.-This class is exactly the reverse of the last, for the females are here brighter coloured or more conspicuous than the males; and the young, as far as they are known, resemble the adult males instead of the adult fernales. But the difference between the sexes is never nearly so great as with many birds in the first class, and the cases are comparatively rare. Mr. Wallace, who first called attention to the singular relation which exists between the less bright colours of the males and their performing the duties of incubation, lays great stress on this point ${ }^{13}$ as a crucial test that obscure colours have been acquirod for the sake of protection during the period of nesting. A different view seems to me more probable. As the cases are curious and not numerous, I will briefly give all that I have been able to find.

In one section of the genus Turnix, quail-like birds, the female is invariably larger than the male (being nearly twice as large in one of the Australian species), and this is an unusual circumstance with the Gallinacer. In most of the species the female is more distinctly coloured and brighter than the male, ${ }^{1-4}$ but in some few species the sexes are alike. In Turnix tuingor of India the male "wants the black on the throat and neck, and the "whole tone of the plumage is lighter and less pronounced than "that of the female." The female appears to be noisier, and is certainly much more pugnacious than the male; so that the

13 'Westmuster Review, July, 1857, and A. Murray, 'Journal of' Travel,' 1868, p. 83.

14 For the Australian species, see Gould's 'Handbuok,' ¿́c., rol. ir. pp.
$178,180,186$, and 188 . In the British Museum specmens of the Australian Plain-winderer (Pedio nomus torquutus) may be seer shewin similar sexual difference: 
fcnales and not the males are often kept by the natives for tighting, like game-cocks. As male birds are exposed by the English bird-catchers for a decoy near a trap, in order to catch other males by exciting their rivalry, so the females of this 'Turnix are employed in India. When thus exposed the females soon begin their "loud purring call, which can be heard a long " "Tay off, and any females within ear-shot run rapidly to the "spot, and commence fighting with the caged bird." In this way from twelve to twenty birds, all breeding females, may be caught in the course of a single day. The natives assert that tre females after laying their eggs associate in flocks, and leave the males to sit on them. There is no reason to doubt the truth of this asscrtion, which is supported by some observations made in China by Mr. Swinhoe. ${ }^{15}$ Mr. Blyth believes, that the young of both sexes resemble the adult male.

The females of the three species of Painted Snipes (Rhynchæa, fig. 62) "are not only larger but much more richly coloured than " the males." 16 With all other birds in which the trachea differs in structure in the two sexes it is more developed and complex in the male than in the female; but in the Rhynchara australis it is simple in the male, whilst in the female it makes four distinct convolutions before entering the lungs. ${ }^{17}$ The female therefore of this species has acquired an eminently masculine charncter. Mr. Blyth ascertained, by examining many specimens, that the trachea is not convoluted in either sex of $l i$. bengalensis, which species resembles $R_{0}$ australis so closely, that it can hardly be distinguished except by its shorter toes. This fact is another striking instance of the law that secondary sexual characters are often widely different in closely-allied forms, though it is a very rare circumstance when such differences relate to the female sex. The young of both sexes of $l$. bengalensis in their first plumage are said to resemble the mature male. ${ }^{18}$ There is also reason to believe that the malo undertakes the duty of incubation, for Mr. Swinhoe ${ }^{19}$ found the females before the close of the summer nssociated in flocks, as occurs with the females of the Turnix.

The females of Phalaropus fulicarius and $P$. hyperboreus are larger, and in their summer plumage "more gaily attired than "the males." But the difference in colour betreen the sexes is far from conspicuous. According to Professor Steenstrup, the

18 Jerdon, 'Birds of India,' rol. iii. P. 596. Mr. Swinhoe, in 'Ibis,' : 865 , p. $542 ; 1866$, пp. 131, 405. i. p. $67 \%$.
17 Gould's 'Handbook to the Birds of Australia,' vol. ii. p. 275.

18 'The Indian Ficld,' Sept. 1858, p. 3.

19. 'Ibis,' 1866, p. 998. 
able to discover whether with these species the young resemble the adult males more closely than the adult females; for the comparison is somewhat difficult to make on account of the double moult.

Turning now to the Ostrich order: the male of the common cassowary (Casuarius guleatus) wonld be thought by any onc tr be the female, from his smaller size and from the appendages and naked skin about his head being much less brightly coloured; and I am informed by Mr. Bartlett that in the Zoological Gardens, it is certainly the male alone who sits on the eggs am takes care of the young. ${ }^{21}$ The female is said by Mr. T. W. Wood ${ }^{22}$ to exhibit during the breeding season a most pugnacious disposition; and her wattles then become enlarged and more brilliantly coloured. So again the female of one of the emus (Dromous irroratus) is considerably larger than the male, and she possesses a slight top-knot, but is otherwise indistinguisbable in plumage. She appcars, however, "to have greater power, "when angry or otherwise excited, of erecting, like a turkey" cock, the feathers of her neck and breast. She is usually the "more courageous and pugilistic. She makes a deep hollow " guttural boom especially at night, sounding like a small gong. "The male has a slenderer frame and is more docile, with no "voice bevond a suppressed hiss when angry, or a croak." He not only performs the whole duty of incubation, but has to defend the young from their mother; "for as soon ins she " catches sight of her progeny she becomes violently agitated, "and notwithstanding the resistance of the father appears to "use her utmost endeavours to destroy them. For moutlus "afterwards it is unsafe to put the parents together, violent "quarrels being the inevitable result, in which the female gene"rally comes off conqueror." "3 So that with this emu we have a complete reversal not only of the parental and incubating instincts, but of the usual moral qualities of the tro sexes; the females boing savage, quarrelsome, and noisy, the males gentle and good. The case is very different with the African ostrich, for the male is somewhat larger than the female and has finer

It 1s, as he informs me, with Limosa lapponica and some few other Waders, in which the females are larger and have more strongly contrasted colours than the males.

21 The natives of Ceram (Wallace, 'Malay Archipelago,'vol. ii. p. 150) assert that the male and female sit alternately on the eggs; but this assertion, as Mr. Bartlett thinks, may be accounted for by the female visiting the nest to lay her eggs. 124.

22 'The Student,' April, 1870, p.

23 See the excellent account of the habits of this bird under confinement, by Mr. A. W. Bennett, in 'Land and Water,' May, 1868, p. 233. 
plumes with more strongly contrasted colours; nevertheless he undertakes the whole duty of incubation. ${ }^{2 t}$

I will specify the few other cases known to me, in which the fernale is more conspicuously coloured than the male, although nothing is known about the manner of incubation. With the carrion-hawk of the Falkland Islands (Milvago leucurus) I was much surprised to find by dissection that the individuals, which had all their tints strongly pronounced, with the cere and legs orange-coloured, were the adult females; whilst those with duller plumage and grey legs were the males or the young. In an Australian tree-creeper (Climacteris erythrops) the female differs from the male in "being adorned with beautiful, ra" diated, rufous markings on the throat, the male having this "part quite plain." Lastly, in an Australian night-jar "tho "female always exceeds the male in size and in the brilliance " of her tiuts; the males, on the other hand, have two white "spots on the primaries more conspicuous than in the female." 2. .

We thus see that the cases in which female birds are more conspicuousiy coloured than the males, with the young in their immature plumage resembling the adult males instead of the adult females, as in the previous class, are not numerous, thougin they are distributed in various Orders. The amount of difference, also, between the sexes is incomparably less than that which frequently occurs in the last class; so that the cause of the difference, whatever it may have been has here acted on the females either less energetically or less persistently than on the

21 Mr. Sclater, on the incubation of the Struthiones, 'Proc. Zool. Soc.9' June 9,1863 . So it is with the Rhea darwini: : Captain Musters says ('At home with the Patagonians,' 1871 , p. 128), that the male is larger, stronger and swifter than the female, and of slightly darker colours; yet he trikes sole charge of the eggs and of the young, just as does the male of the common species of Rhea.

23 For the Milvago, see 'Zoology, of the Voyage of the Beagle, Birds, 1841, p. 16. For the Climacteris and night-jar (Eurostopodus), see Gould's 'Handbook to the Birds of Australia,' vol. i. pp. 602 and 97. The New Zealand shieldrake ( $T a-$ dorna rariegata) offers a quite anomalous case; the head of the female is pure white, and her back is redder than that of the male; the head of the male is of a rich dark bronzeil colour, and his back is clothed with finely pencilled slate-coloured feathers, so that altogether he may be considered as the more beautiful of the two. He is larger and more pugnacious than the female, and does not sit on the eggs. So that in all these respects this species comes under our first class of cases ; but Mr. Sclater ('Proc. Zool. Soe.' 1866, p. 150) was much surprised to observe that the young of both sexes, when about three months old, resembled in therr dark heads and necks the adult males, instead the adult females; so that it would appear in this case that the females have been modified, whilst the males and the young hare retained former state of plumage. 
males in the last class. Mr. Wallace believes that the males have hat their colours rendered less conspicuous for the sake of protection during the period of incubation; but the difference between the sexes in hardly any of the foregoing cases appears sufficiently great for this riew to be safely accepted. In some of the cases, the brighter tints of the female are almost confined to the lower surface, and the males, if thus coloured, would not have been exposed to danger whilst sitting on the eggs. It should also be borne in mund that the males are not only in it slight degree less conspicuously coloured than the females, but are smaller and weaker. They have, moreover, not only acquired the maternal instinct of incubation, but are less pugnacious and vociferous than the females, and in one instance have simpler vocal organs. Thus an almost complete transposition of the instincts, habits, disposition, colour, size, and of some points of structure, has been effected between the two sexes.

Now if we might assume that the males in the present class lave lost some of that ardour which is usual to their sex, so that they no longer search eagerly for the females; or, if we might assume that the females have become much more uumerous than the males-and in the case of one Indian Turnix the females are said to be "much more commonly met with than the "males." ${ }^{26}$ - then it is not improbable that the females would have been led to court the males, instead of being courted by them. This indeed is the case to a certain extent with some birds, as we have seen with the peahen, wild turkey, and certain kinds of grouse. Taking as our guide the habits of most male birds, the greater size and strength as well as the extraordinary pugnacity of the females of the Turnix and emu, must merv? that they endeavour to drive away rival females, in order to gain possession of the male; and on this view all the facts Lscome clear; for the males would probably be most charmed or excited by the females which were the most attractive to them hy their bright colours, other ornaments, or vocal powers. Sexual selection would then do its work, steadily adding to the attractions of the females; the males and the joung being left not at all, or but little modified.

Class III. When the adult male resembles the adult female, the. yourig of both sexes have a peculiur first plumage of their own.--In this class the sexes when adult resemble each other, and differ from the young. This occurs with many birds of many kinds. The male robin can hardly be distinguished from the fomale, but the young are widely different, with their mottled duskyolive and brown plumage. The male and female of the splendid 26 Jerdun, 'Birds of India,' rol. iii. v. 598. 
scarlet ibis are alike, whilst the young are brown; and the scarlet-colour, though common to both sexes, is apparently a sexual character, for it is not well developed in either sex under coufinement: and a loss of colour often occurs with brilliant males when they are confined. With many species of horons the young differ greatly from the aduits; and the summer plumase of the latter, though common to both sexes, clearly his a nuptial character. Young swans are slate-coloured, whilst the mature birds are pure white; but it would be superfluous to give additional instances. These differences between the young and the old apparently depend, as in the last two classes, on the young having retained a former or ancient state of plumage, whilst the old of both sexes have acquired a new one. When the adults are bright coloured, we may conclude from the remarks just made in relation to the scarlet ibis and to many herons, and from the analogy of the species in the first class, that such colours have been acquired through sexual selection by the nearly mature males; but that, differently from what occurs in the first two classes, the transmission, though limited to the same age, has not been limited to the same sex. Consequently, the sexes when mature resemble each other and differ from the young.

Cuass IV. When the adult male resembles the adult femule, the young of both sexes in their first plumage resemble the adults. - In this class the young and the adults of both sexes, whether brilliantly or obseurely coloured, resemble each other. Such cases are, I think, more common than those in the last class. We have in Ingland instances in the kingfisher, somo woodpeckers, the jar, luagpie, crow, and many small dull-coloured birds, such as the herlge-warbler or kitty-mren. But the similarity in plumage between the young and the old is never complete, and graduates away into dissimilarity. Thus the young of $\operatorname{some}$ members of the kingfisher family are not only less vividly coloured than the adn!ts, but many of the feathers on the lower surface are edged with brown, ${ }^{27}$ - a vestige probably of a former state of the plumage. Frequently in the same group of birds, even within thn same genus, for instance in an Australian genus of parroteets (Platycereus), the young of some species closely rescmble, whilst the young of other species differ considerably, from their parents of both sexes, which are alike. ${ }^{28}$ I3oth sexes and the coung of the common jay are closely similar; but in the Canada jay (Perisoreus cunudensis) the young differ so much from their parents that they were formerly described as distinct species. ${ }^{29}$

27 Jerdon, 'Birds of India,' vol. i. pp. 222, 228. Gould's 'Handbook to the Birds of Australia,' rol. i. pp. $124,130$.
${ }^{28}$ Gould, Ibid. vol. ii. pp. 37, 46, 56.

28 Aửubon, 'Oraith. Biography, ro!. ii. p. 55. 
I may remark before proceeding that, under the present and next two classes of cases, the fiuts are so complex and the conclusions so doubtful, that any one who fiecls no especial interest in the subject had better pass them over.

The brilliant or conspicuous colours which claracterise many birls in the present class, can rarely or never be of service to them as a jrotection; so that they have probably bern gained by the males thongh Bi.xual selection, and then transferred to the tentes and the youmer. It is, however, possible that the males may have selected the more attractive females; and if these transmitus their characters to then offispring of both sexes, the same results would follow as from the selertion of the more attractive males by the females. But there is evidence that this contingency has rarely. if ever, occurred in any of those groups of birds in which the sexes are generally alike: for, if even a few of the successive variations had failed to be transmitted to both sexes. the fenales would have slightly exceerled the males in beauty. Exactly the reverse occurs under nature; for, in almost erery large group in which the sexes geverally resemble each other, the males of some few species are in a slight degre more hrightly culoured than the females. It is again possible that the females may have selected the more beatiful males, these mules having reciprocally selected the more beantiful fermales; but it is doubtful whether this double nrocess of selection would be likely to orcur, owing to the greater eagerness of nue sex than the other. aud whether it would be more efficieut than selertion on one side alune. It is, therefore, the most probable view that sexual selection has acted, in the present ("litss, as far as ornamental characters are concerned, in acordance with the general rule throughout the animal kingdom, that is, on the males: and that these have transmitted their gralually-ancinired coluurs, either equally or almost equally, to their oftspring of both sexes.

Another point is more doubtful, namely, whether the successive variations first appeared in the males after they har become nearly msture, or whilst quite young. In either case sexual selection must have acted on the male when he had to compete with rivals for the possession of the female: and in both cases the characters thus acquired have been transmitted to both sexes and all nges. But these character's, if acquired by the males when alult, may have been transmitted at first in the adults alone. and at sone sulisequeut period transferred to the young. For it is kuown that, when the law of inheritance at corresponding age's fuils, the offispring often iuherit characters at an earlitr age than that at which they first appeared in their parents." ${ }^{30}$ Cases apparently of this kind have been obsterved with hirds in a state of nature. For instaner Mr. Blyth has seen specimens of Lanius rufus and of Colymbre glacialis which hast assumerl whilst yonug, in a quite anomalous manwer, the adult plumage of their parents. ${ }^{31}$ Araiu, the? young of the common swan (Cygnus olor) do not cast otif their lark fienther and become white until i ighteen mouths or two years uld : but Dr. F. Forel has described the case of three vigorous young biris, nut of a bruod of four, which were born pure white. These young birks

* 'Variation of Animals and Fiants uuder Lomestication,' vol. ii. D. 79
"1 Charlesworths' 'Mag. of Nat. Hist?' rol. i. 1837, pp. 305, 306. 
wire not albinoes, as shewn by the colour of their beaiss and legs, whict nearly resembled the same parts in the adults. ${ }^{32}$

It may be worth while to illustrate the above three nodes by which, in the present class, the two sexes and the young may have come to lest mble each other, ly the ("urinus case of the genus l'asser. ${ }^{33}$ In the house-sparrow ( $P$. domestims) the male lifters much from the female and from the young. 'Ithe young aud the femulis are alike, and ruscmble to a large extent bith sexes and the young of the sparrow of Palestine ( $P$. brachyrluctylus $)$, as well as of some alliel species. Wr: may therefore assume that the female and young of the house-sparrow approximately shew us the plumage of the prigenitor of the genus. Now with the tree-sparrow ( $P^{\prime}$. montanus) both sexes and the young elosely resemble the male of the house-sparrow; so that tixey have all been molitied in the same manner, and all depart from the typical colouring of their early progentor. 'This may have bien etiected by a male ancestor of the tree-sparrow having varied, firstly, when nearly mature; or, seendly, whilst quite young, and by having iu either case transmitted his moditied plunage to the females and the young; or, thirdly, he may have raried when adult aud transmitied his plumago to both arlult sexes, and, owing to the failure of the law of inhuritance at corresponding ages, at snue subseyuent period tu his young.

It is improssible to decile which of these three moles hils generally prevailed throughout the present class of cases. That the males varied whilst young, and transmitted their variations to their offispring of both sexes, is the must probable. I nay here add tuat I have, with little success, endeavoured, by consultiug various works, to dicide how far the period of variation in birds has creuerally determined the transmission of characters to one sex or to both. The two rules, often referred to (namely, that variations occurring late in life are transmitted to ono and the same sex, whilst those which vecur early in life arce transmitted to both sex('s), apparently hold gond in the first, ${ }^{34}$ sccond, and fourth classes of cases; but they fail in the third, often in the filth, ${ }^{35}$ and in the sixth small class. They apply, however, as far as I can judge, to a considerable majority of the speries; and we mast not forget the atriking generalisation by Dr. W. Marshall with respect to the protuberuuces on the heads of birls. Whether or not the two rules generally

22 'Bulletin de la Soc. Vaudoise des Sc. Nat.' vol. x. 1869, p. 132. The young of the Polish swan Cygnus immutabilis of Yarrell, are always white; but this species, as Mr. Sclater informs me, is believed to be nothing more than a variety of the domestic swan (Cygnus olor).

I am indebted to Mr. Blyth for information in regard to this genus. The sparrow of Palestine belongs to the sub-genus Petronia.

34 For instance, the males of Tanngra sestiva and Fringilla cyanea require three years, the mals of Fringilla ciris four years, to complate their benutiful plumage. (See
Aulubon, 'Ornith. Biography,' vol. i. p. $233,280,378$.) The Harlequin duck takes three years (ibid. vol. iii. p. 614). The male of the Gold pheasant, as I hear from Mr. Jenner Weir, can be distinguished from the female when about three months oid, but he does not acquire nis full splendour until the end of the September in the following year.

${ }^{35}$ Thus the Ibis tantalus and Grus americanus take four years, the Flamingo several Jears, and the Ardea ludovicana two years, before they acquire their pertect plumage. See Audubon, ibid. vol. i. p. 221 ; vol. iii. pp. 133, 139, 211. 
hold good, we may conclude from the farts given in the eighth chapter that the perind of variation is one inportant edement in determining ths form of transmission.

With birls it is diffionlt to recide hy what stanlard we ought to judee of the carliness or lateness of the periond of variation, whether by the age in reference to the duration of life, or to the power of reproduction or to the number of mults throngh which the species passes. 'Tlior moulting of hirk, even within the same family, sometimes disin. much without iny assignahle cause. Some birls moult sn early, that nearly all the body feathers are cast off bofore the first wing-fenther r are fully grown; and we cannot believe that this was the primordia: state of things. When the period of moulting has been accelerater, the age at which the colours of the alult plumage are first developer? will filsely appear to us to be earlicr than it really is. 'This may be illustrated by the practice followel by some bird-fanciers, who pull ont a few feathers from thr breast of nestline bullfinches, and from the: head or neck of young gold-pheasants, in wiler to ascertain their sex: for in the mules, these feathers are immeriately replaced by culourat ones.86 The actual duration of life is known in but few birds, so that we can hardly judge by this standard. And, with referunce to the period at which the puwer of reproduction is gained, it is a remarkahle fact that various birds occasionally breed whilst retainiug th, it immature plumage. ${ }^{37}$

The fitet of hirls breeding in their immature plumage seems oppose ? to the belief that sexual selection has played as important $\Omega$ part, a. I believe it his, in giving ornamental colours, plumes, \&c., to the mal's. and, by mens of equal transmission, $t$, the feinales of many speci $\mathrm{s}$. The objection wonld be a valid one, if the younger aml less ornamentid males were as successiul in winning temales and propugating theip kind, as the older and more beautiful males. But we have no renson) to suppose that this is the case. Aulubon speaks of the breeding if the iumature males of llis tantalus its a rare event, ns does Mr. Swinhoe, in regard to the immature male's of Oriolus. ${ }^{38}$ If the young of any species in their immature phunage were more suecessful in winning partners than the adults, the aclult plunnage would probably

${ }^{36}$ Mr. Blyth, in Charlesworth's - Mag. of Nat. Hist.' vol. i. 1837, p. 300. Mr. Bartlett has informed me in regard to gold-pheasants.

37 I have noticed the following cases in Audubon's 'Ornith. Biography.' The redstart of America, (Muscapica ruticilla, vol. i. p. 203). The Rois tantalus takes four years to crme to full maturity, but sometimes breeds in the second year (vol. iii. p. 133). The Grus americanus takes the same time, but breeds before acquiring its full plumage (vol. iii. p. 211). The sdults of Ardea crerulea are blue, and the young white; and white, mottled, and raature blue birds may all he seen breediug tugether (vol. iv. p.
58): but Mr. Blyth informs ine that certain herons apparently are dimorphic, for white and coloured individuals of the same age may be observed. 'The Harlequin duck (Anas histrionica, Linn.) takes three Jears to acquire its full plumage, though many birds breed in the secund year (vol. iii. p. 614). The White-headed Eagle (Falco leucocephalus, vol. iii. p. 210) is likewise known to breed in its immature state. Some species of Oriolus (nccording to Mis. Biyth and Mr. Swinhoe, in 'Ibis,' July 1863, p. 68) likewise breed before the? attain their full piumage.

28 Ste the last foot-note. 
oxin be loot, as the males would prevail, which retrined their immature drese ior the longest period, nud thus the charuct re the specier would ultinat ly be noditied. ${ }^{39}$ If, on the other hand, the young never stirooeded in obtaining a fimale, the habit of eurly repaluduction would in rhitpo he sonner or lnter eliunnated, frum being supertluous and estailing waste of power.

The plumage of cestain birls goes ou incrusing in beauty during umu! yiars after they are fully mature; this is the case with the train (if the peacock, with some of the birds of paralise, aud with the crest and plumes of certain herons, for instance, the Ardea ludoricuna." siat it is doubtful whether the continuel development of such feathers is the result of the selection of sucessice beneficial variations (though $\$ 1$ is is the most probable view with birds of paradise) or merely of continunus grow th. Most fishe cuntinue increasing in size, as long as they are in good health and have plenty of food; and a somewhat similar law may prevail with the plumes of birds.

C'Lass V. When the alults of both srxes have a distinct winter and Ezmmer plumage. whither or not the male difiers from the female, the y. ang resemble the adults of both sexes in their winter dress, or much incore rarely in their summer dress, or they resemble the jemales alone. Or the young may have an intermerliate character; or, ayain, they may difier greatly from the ald ilts in Loth their seasonal plumages.-The cases in this class are singularly complex; aror is this surprising, as they depend on inheritance, limited in a greater or less degree in three ditferent ways, namely, by s.x, age, ant the season of the year. In some cases the iudiviluals of the same species pass through at least five distinct states of plumage. With the species, in which the male ditters from the female during the summer season alone, or, which is rarer, during both sensons, "1 the youn generally resemble the females, -as with the so-called goldfincli of North America, and apparently with the splendid Malur of A ustralid. ${ }^{42}$ With those species, the sexes of which are alike during both the summer and winter, the joung mas

39 Other animals, belonging to quite distinct classes, are either habitually o1 occasionally capable of breeding before they have fully acouired their adult characters. I'his is the case with the young males of the salmon. Several amphibians have been kuown to breed wnilst retrining their larral structure. Fritz Müller has shewn "Facts and Arguments for Darwin,' Èng. trans. 1869, p. 79) that the males of several amphipod crustaceans become sexually mature whilst voung; and $I$ infer that this is a case of premature breeding, because they have not as yet acquired their fully-developed claspers. All such facts are highly interesting, as bearing on one means by which species may undergo great modifisarions of chiracter.
40 Jerdon, 'Birds of India,' vol. iii. p. 507, on the peacock. Dr. Marshall, thinks that the older and more brilliant males of birds of paradise, have an advantage over the younger males; see 'Archives Néerlandaises,' tom. vi. 1871.-On Ardea, Audubon, ibid, vol. iii. p. 139.

41 For illustrative cases see vil. iv. of Macgillivray's 'Hist. Brit. Birds ;' on T'ringa, \&c., pp. 223, 271 ; on the Machetes, p. 172; on the Ciraradrius hiaticulu, p. 118 ; on the Charadrius pluvialis, p. 94.

42 For the goldtinch of $\mathrm{N}$. A merica, Fringilla tristis, Linn., see Aucubon. 'Ornith. Biography,' rol. 1. p. 17 '. For the Maluri, Gould's 'Ilandbook to the Birds of Australia, vol. i. p 318 
resemble tlue adnlts, firstly, in their wiuter dress; secondly, and this is of much rarer occurrenee, in their sunmer liress; thirdly, they may be intermediate betwen these two stules; und, fourthly, they nay differ greatly from the adults at all seisons. We have an instance of the first of these four "ns's in one of the correts of Inuia (Buphus coromandus), in which the young and the arlults of both sexes are white Iuring the winter, the adul ts beeming solden-butf during the summer. With the gaper (Anastomus oscitcus) of Ind a we have a similar cuse, but the colours are reversed: fir the young and the adults of both rexes are grey and bluck during the winter, the milults becmuing white during the summer. ${ }^{43}$ As an instance of the secoud case, the young of the razor-bill (Alca torda, Linn.), in an early stite of plumage, are coloured like the adults during the summer; and the young of the white-crowned sparrow of North Anericit (Fringilla leucriplerys), as soon as fledged, have elengut white stripes on their heads, which are lost by the young and the old during the winter." With respect to the third case, namely, that of the young having an iutermediate character between the summer and winter alult plumages, Yarrell ${ }^{45}$ insists that this occurs wilh many waders. Lastly, in regard to the young ditfering greatly from both sexes in their aduit summer and winter plumages, this oecurs with some herons and egrets of North America and India,the young alone being white.

I will make only a few remarks on these complicated cases. When the young resemble the femules in their summer dress, or the adults of buth sexes in their winter dress, the cuses diffier from those given under Classes I. and III. only in the charactirs originally acquired by the males during the breeding-season, having been limited in their transmission to the corresponding season. When the adults have a distinct -ummer and winter plumage, and the young ditfer from both, the ca:o is more difficult to understand. We ma admit as probable that the voung hove retained an ancient state of plumare; we can acount by sexual selection for the summer or nuptial plumare of the adults, but how are we to account for their distinet winter ylumnge? If we could admit that this plumage serves in all cases as a frutection, its acquirement would be a simple affair; but there seems no good renson fir this admission. It may be sugrested that the widely difierent conditions of life during the winter and summer have acted in a direct manner on the plunage; this may have had some effect, hut I have nut much confidence in so great a difference as we sometimes seo between the two plumages, having been thus causch. A more probable explanation is, that an aucient style of plumage, partially modified throunh the transference of some characters from the sunmer plumage, has been retained by the adults during the winter. Finilly, all the cases in our present class apparently depend on characters acquired by the adult males, having been variously limited in their transmission :ccording to age, scason, and sex; but it would not be worth while to uttempt to follow out these complex relations.

43 I am indebted to Mr. Blyth for information as to the Buphus; see also Jerdon, 'Birds of India," vol. iii. p. 749. On the Anastomus, see Blyth, in 'Ibis,' 1867, p. 173.

41 On the Alcr, see Macgilliviay, Ilist. Brit. Birds,' vol. v. p. 347 .
On the Fringilla leucophrys, Audubon, ibid. vol. ii. p. 89. I shall have hereafter to refer to the young of certain berons and egrets being white.

45 'History of British Birds,' vol - 2239 p. 1 is. 
Cuass VI. The young in their first plumage difier from eush other according to sex; the y.nung males resembling more or less closely the athull males, and the young fomules more or less closely the adult fernaler. The cases in the present cliss. thuugh orcurringr in various groups, are not numerus; vet it seems the most natural thing that the young ghould at first sumewhat resemble the aduits of the same sex, and gradually become more and more like them. The adult male blickeap (Sylvia atricapilla, has a hlack he:al, that of the fomale being redilishbrown; and I am informed by Mr. Blyth, that the young of beth sexes can be distinguished by this character even as nestlings. In the fitmily of thrushes an unusual number of similar cases have been noticed; thus, the male blackbird (Turdus merula, can be distinguished in the nest from the female. 'The twi) sexes of thin nocking bird (Turdus polyghtens, Limu.) dittor very little from each other, yet the males can casily be distinguished at a very early age from the temales by shen ing mure pure white. ${ }^{46}$ The males of a forest-thrush and of a rock-thrush ((Iroceter erythrogastra and F'etrocincla cyanea) have much of thcir plumage of a fiue blue, whilst the females are brown; and the nestlingr males of both species have their main wing and tail-fenthers edged with blue, whilst thrse of the female are edged with brown. ${ }^{47}$ In the young blickbird the wing fouthers assune their mature character and become black after the others; on the other han 1 , in the two species just ramed the wing-feuthers become blue before the others. The most probable view with reference to the cases in the present cluss is that the males,

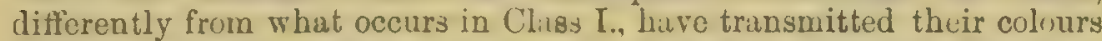
to their male offspring at an earlier age than that at which they were first acquired; for, if the males had inried whilst quite young, their characters would probably have been transmitted to both sexes. ${ }^{48}$

In Azthurus polytmus, a hummingr-bird, the male is splendjully coloured black int green, and two of the tail-feathers are immensely lengthened; the female has an urdinary tail and inconspicuous colours; now the young malcs, instear of resembling the arlult female, in accordance with the common rule, heren from the first to assume the colours proper to their sex, and their tail-teathers sonn ocome elongated. I owe this information to Mr. Goul.!, who has given mo the following more striking and as yet unpublished case. 'T'wo humming-birds belonging to tho geaus Eustephanus, both beautifully culoured, inlaabit tho small island of Juan Fernitndez, and have always been ranked as specifically distinct. But it has lat.ly been ascertained that the one, which is of a rich chesnut-brown colour with a golden-red head, is the male, whilst the other, which is elegrantly variggated with green and white with a metallic-green head is the female. Now the young from the tirst

46 Audubon, 'Ornith. Biography' 'Ornith. Biography' vol. iv. p. 392), vol. i. p. 113.

47 Mr. C. A. Wright, in 'Ibis,' rol. vi. 1864, p. 65 . Jerdon, 'Birds of India,' rol. i. p. 515 . See also on the blackbird, Blyth in Charlesworth's 'Mag. of Nat. History,' rol. i. 1837, p. 113 .

ts The following additional cases may be mentioned; the young males of Tanagra rubra can be distinguished from the young females (Avidubon. and so it is with the nestlings of a blue nuthatch, Dendroplita frontalis of India (Jerdon, 'Birds of India,' vol. i. p. 389). Mr. Blyth also informs me that the sexes of the stonechat, Saxicole rubicola, are distinguishable at a very early age. Mr. Salvin gives ('Proc. Zoolog. Soc.' 1870 , p. 206 ), the case of a humming-bird, like the following one of Eustephanus. 
somewlat resenble the adults of the corresponding sex, the restminace gradually becoming more and more complete.

In considering thi last case, if as befor we take the plumage of the yrung as our guicle, it 11 ould appear that hoth sexes have becu rendered De untiful indepentently; and nut that one sex has partially tran-fires its beauty to the other. The male apparently has acquired lis bright colours through sexual selection in the same manner as, for instunces, tho peacock or plieasint in our first class of cases; and the female in the same manner as the female Rhynchian or 'Tumix in our sicend class of cases. But there is much difliculty in understauding bow this could hive been eff eted at the same time wih the two sexes of tho rame species. Mr. Sulvin states, as we have scen in the eighth chapter, that with certain humming-birds the males grently exceed the finales in number, whilst with other species inhabiting the stume country the females greatly exced the males. If, then, we might assume that during some former lengthened period the males of the Juan Fernandez species had greatly exceeded the females in number, but that during another lengthened period the females had far exceeded the males, we could understand how the males at one time, and the fimal's at another, might have been rend.red beratiful by the sclection of the brighter-coloured individuals of e-jher scx; both sexes transmitting their character's to their young at a rather carlier age than usual. Whether this is the true explanation I will not pretend to say; but the caso ia too remarkable to be passed over without notice.

We have now seen in all six classes, that an intimate relation 3xists between the plumage of the young and the adults, either of one sex or both. These relations are fairly well explained on the principle that one sex-this being in the great majority of cases the male-first acquired through rariation and sexual selection bright colours or other ornaments, and transmitted them in various ways, in accordance with the recognised laws of inheritance. Why variations have occurred at different periods of life, even sometimes with species of the same group, we do not know, but with respect to the form of transmission, one important determining cause seems to be the age at which the varjations first appear.

From the principle of inheritance at corresponding ages, and from any variations in colour which occurred in the males at an early age not being then selected-on the contrary being often eliminated as dangerous-whilst similar variations occurring at or near the period of reproduction have been preserved, it follows that the plumage of the young will often have been left unmodified, or but little modifled. We thus get some insight into tho colouring of the progenitors of our existing species. In a vast number of species in five out of our six classes of cases, the adults of one sex or of both are bright coloured, at least during the breeding-season, whilst the young are invariably less orightly coloured than the adults, or are quite dull coloured: 
for no instance is known, as far as I can discorer, of the young of dull-coloured species displaying bright colonts, or of the young of bright-colvured species being nure brilliant than their parents. In the fourth class, howerer, in which the young and the old resemble each other, there are many species (though by no means all), of which the roung are bright-coloured, and as these form whole groups, we may infer that their early progenitors were likewise bright. With this exception, if we look to the birds of the world, it appears that their beauty has been much increased since that period, of which their immature plumage gives us a partial record.

On the Culour of the Plumage in relation to Protection. - It will have been seen that I cannot follow Mr. Wallace in the belief that dull colours, when confined to the females, have been in most cases specially gained for the sake of protection. There can, however, be no doubt, as formerly remarked, that both sexes of many birds have had their colours modified, so as to escape the notice of their enemies; or in some instances, so as to approach their prey unobscrved, just as owls have had their plumage rendered soft, that thes flight may not be overheard. Mr. Wallace remarks ${ }^{49}$ that " it is only in the tropies, "among forests which never lose their foliage, that we fincl "whole groups of birds, whose chief colour is green." It will be admitted by every one, who has ever tried, how difficult it is to distinguish parrots in a leaf-covered tree. Nevertheless, we nust remember that many parrots are ornamented with crimson, blue, and orange tints, which can hardly be protective. Woodpeckers are eminently arboreal, but besides green specios, there are many black, and black-and-white kinds-all the species being apparently exposed to nearly the same dangers. It is therefore probable that with tree-haunting birds, strongly-pronounced colours have becn acquired through sexual selection, but that a green tint has been acquired oftener than any other, from the additional advantage of protection.

In regard to birds which live on the ground, every one admits that they are coloured so as to imitate the surrounding surface. How difficult it is to see a partridge, snipe, woodcock, ccrtain plovers, larks, and night-jars when crouched on ground. Animals iuhabiting deserts offer the most striking cases, for the bare surface affords no concealment, ard nearly all the smallor quadrupeds, reptiles, and birds depead for safety on their colours. MIr. Tristram has remarked in regard to the inhabitants of the o'ahara, that all are protected by their "isabelline or sand10 'Westminster Reriew, July, 1867, p. 5. 
"colour." 50 Calling to my recollection the desert-birds of South America, as well as most of the ground-birds of Great Britain, it appeared to me that both sexes in such cases are generally coloured nearly alike. Accordingly, I applied tc Mr. Tristraun with respect to the birds of the Sahara, and he has kindly given me the following information. There are twenty-six species belonging to fifteen genera, which manifestly have their plumage coloured in a protective manner; and this colouring is: all the more striking, as with most of these birds it differs froun that of their congeners. Both sexes of thirteen out of the twenty-six species are coloured in the same manner; but these belong to genera in which this rule commonly prevails, so that they tell us nothing about the protective colours being the same in both sexes of desert-birds. Of the other thirteen species, three belong to genera in which the sexes usually differ from eacli other, yet here they bave the s6xes alike. In the romaining ten specios, the male differ's from the female; but the difference is confined chiefly to the under surface of the plumage, which is concealed when the bird crouches on the ground; the head and back being of the same sand-coloured hue in the two sexes. So that in these ten species the upper surfaces of both sexes havo been acted on and rendered alike, through natural selection, for the sake of protection; whilst the lomer surfaces of the males alone have been diversified, through sexual selection, for the sake of ornament. Here, as both sexes are equally well protected, we clearly see that the females have not been prevented by natural selection from iuheriting the colours of their male parents; so that we must look to the law of sexually-limited transmission.

In all parts of the world both sexes of many soft-billed birds, especially those which frequent reeds or seclges, are obscurely coloured. No doubt if their colours had been brilliant, they would have been much more conspicuous to their enemies; but whether their dull tints have been specially gained for the sake of protection scems, as far as I can judge, rather doubtful. It is still more doubtful whether such dull tints can have been gained for the sake of ornament. We must, however, bear in mind that male birds, though dull-coloured, often differ much from their females (as witl the common sparrow), and this leads to the belief that such colours have been gained through sezual sclection, from being attractive. Many of the soft-billed bircks are songsters; and a discussion in a former chapter should not

so 'Ibis,' 1859 , rol. i. p. 429 , et seq. Dr. Rohlfs, however, remarks to me in a letter that, according to nis experience of the Sahara, this statement is too strong. 
be forgotten, in which it was shewn that the best songsters are rarely ornamented with bright tints. It would appear that female wirds, as a general rule, have selected their mates either for their swcet voices or gay colours, but not for both charms combined. Some species, which are manifestly coloured for the sake of protection, such as the jack-snipe, woodcock, and night-jar, are likewise marked and shaded, according to our standard of taste, with extreme elegance. In such cases we may conclude that both natural and sexual selection have acted conjointly for protection and ornament. Whether any bird exists which does not possess some special attraction, by which to charm the ?pposite sex, may be doubted. When both sexes are so obscurcly coloured that it would be rash to assume the agency of sexual selection, and when no direct evidence can be advanced shewing that such colours servo as a protection, it is best to own complete ignorance of the canse, or, which comes to nearly the same thing, to attribute the result to the direct action of the conditions of life.

Both sexes of many birds are conspicuously, though not brilliantly coloured, such as the numerous black, white, or picbald species; and these colours are probably the result of sexual selection. With the common blackbird, capercailzic, blackcock, black scoter-duck (Oidemia), and even with one of the biris of paradise (Lophorince utra), the males alone are black, whilst the females are brown or mottled; and there can hardly be a doubt that blackness in these cases has been a sexually selected character. Therefore it is in some degree probable that the complete or partial blackness of both sexes in such birds as rrows, certain cockatoos, storks, and swans, and many marine birds, is likewise the result of sexual selection, accompanied by erfual transmission to both scxes; for blackness can hardly serve in any case as a protection. With several birds, in which the male alone is black, and in others in whicb both sexes are llack, the beak or skin about the head is brightly colourcd, and the coutrast thus afforded adds much to their heanty; we seo this in the bright yellow beak of the male blackbird, in the crimson skin orer the eyes of the black-cock and capercailzie, in the brightly and variously coloured beak of the scoter-drako (Oidemia), in the red beak of the chough ('orvus graculus, Limn.), of the black swan, and the black stork. 'This leads me to rominrk that it is not incredible that toucans may owe the enormous size of their beaks to sexual selection, for the sake of display ing the diversified and vivid stripes of colour, with which theso yrgans are ornamented.51 The naked skin, also, at the base (f the

51 No satisfactory explanation has size, and still less of the bright + ar ween offered of the immease coluurs. of the toucan's beal Jir 
neak and round the eyes is likewise often brilliantly coloured and Mr. Gould, in speaking of one species, ${ }^{52}$ says that the coloure of the beak "are doubtless in the finest and most brilliant state "during the time of pairing." There is no greater improbability that toncans should be encumbered with immense beaks, thongh rendered as light as possible by their cancellated structure, for the display of fine colonrs, (an olject falscly appoaring to us unimportant), than that the male Argus pheasant and some othor birds should be encumbered with plumes so lovg as to impede their flight.

In the same manner, as the males alone of various species are black, the females being dull-coloured; so in a few cases the males alone are either wholly or partially white, as with the several bell-birds of South America (Chasmorhyuchus), the Antaretic goose (Bernicla anturctica), the silver-pheasant, \&c., whilst the females are brown or obscurely mottled. Therefore, on the same principle as before, it is probable that both sexes of many birds, such as white cockatoos, sereral ogrets with their heautiful plumes, certain ibises, gulls, terns, dc., have acquired their morc or less completely white plumage through sexual selection. In some of these cases the plumage becomes white only at maturity. This is the case with certain gannets, tropicbirds, \&c., and with the snow-goose (Austr hyperboreus). As the 'atter breeds on the "barren grounds," when not covered with snow, and as it migrates southward during the winter, there is no reason to stuppose that its snow-white adult plumago serves as a protection. In the Anastorbus oscituns, we have still better evidence that the white plumage is a nuptial character, for it is developed only during the summer; the young in their immature state. and the adults in their winter dress, being grey and hack. With many kinds of gulls (Larus), the head and neck hecome pure white during the summer, being grey or mottled during the winter and in the young state. On the other hand,

Bates ("The Naturalist on the Amazons, vol. ii. 1863 , p. 341) states that they use their beaks for reaching fiuit at the extreme tips of the branches; and likewise, as stated by other authors, for extracting eggs and young birds from the nests of other birds. But, as Mx. Bates admits, the beak "can "scarcely be consiciered a very per"fectly-formed instrument for the "end to which it is applied." The great bulk of the beak, as shewn by its breadth, depth, as well as length, is not intelligible on the view, that it serves merely as an organ of prehension. Mr. Belt believes ('The Naturalist in $\mathbf{N}:$ : $a-$ ragua,' p. 197), that the principal use of the beak is as a defence against enemies, especially to the female whilst nesting in a bole in a tree.

32 Ramphastos carinatus, Gould'. ' Monngrayih of Ramphastida.' 
with the smaller gulls, or sea-mows (Gavia), and with some terns (Sterna), exactly the reverse occurs; for the heads of the young bircls during the first year, and of the alults during the winter, are either pure white, or much paler coloured than during tho hreeding-seas on. These latter eases offer another instance of the capricious manner in which sexual selection appears often to nave acted. ${ }^{53}$

That aquatic birds hare acquired a white plumage so much oftener than terrestrial birds, probably depends on their large size and strong power's of flight, sn that they can casily defenct themselves or escilpe from birds of prey, to which moreorer they are not much exposed. Conseriuently, sexual selection has not here been interfered with or suider for the sake of protection. to doulut with birds which roam orer the open ocean, the males and fimales could find each other much more easily, when madu: conspicuous either by being perfectly white or intensely blark; so that these colour's may possibly serve the same end as the call-notes of many land-birds. ${ }^{5}$ A white or black bird when it discovers and tlies down to a carcase floating on the sea or cast up on the buach, will be seen from a great distance, and will guide other birds of the same and other species, to the prey; but as this would be a disadvantage to the first finders, the indiricluals which were the whitest or blackest would not thus procure more food than the less strongly coloured individuals. Hence conspicuous colours cannot have been gradually acquired for this purpose through natural selection.

As sexual selection depends on so fluctating an element as taste, we can understand how it is that, within the same group of birds having nearly the same habits, there should exist white or nearly white, as well as black, or nearly black species,-for instance, both white and black cockatoos, storks, ibises, swans, terns, and petrels. Picbald birds likewiso sometimes occur in the same groups together with black and white species; for instance, the black-necked swan, certain terns, and the common magpie. That a strong contrast in colour is agreeable to birds, Te may conclude by looking through any large collection, for the sexes often differ from each other in tho male having tho paie

s3 On Larus, Gavia, and Sterna, see Macgillivray, 'Hist. Brit. Birds,' rol. v. p. 515, 584, 626. On the Anser hyperboreus, Audubon, 'Oraith. Biography,' vol. iv. p. 562. On the Anastomus, Mr. Blyth, in 'Ibis,' 1867, p. 173.

st It may be noticed that with rultures, which roam far and wide high in the air, like marine kirds over the ocean, three or four species are almost wholly or largely white. and that many others are black. So that here again conspicuous colours may possibly aid the sexes in finding each other during the brecdingseason. 
parts of a purer white, and the variously coloured dark parts o! still darker tints than the female.

It would even appear that mere novelty, or slight changes for' the sake of change, have sometimes acted on female birds as a charm, like changes of fashion with us. Thus the maies of some parrots can hardly be said to be more beautiful than the females, at least according to our taste, but they differ in such points, as in having a rose-coloured collar instead of "a bright "emeraldine narrorr green collar;" or in the male haring a black collar instead of "a yellow demi-collar in front," with a pale roseate instead of a plum-blue head..$^{.5}$ As so many male birds have elongated tail-feathers or elongated crects for their chicf ornament, the shortened tail, formerly descriled in the male of a humming-bird, and the shortened crest of the male goosand('t, seem like one of the many changes of fashion which we admire in our own dresses.

Some members of the heron family offer a still more curious case of novelty in colouring having, as it appears, been appreciated for the sake of novelty. The young of the Ardea usha are White, the adults being dark slate-coloured; and not only the young, but the adulis in their winter plumage, of the allied Buphus coromandus are white, this colour changing into a rich golden-buff during the breeding-season. It is incredible that the young of these two spécies, as well as of some other members of the same family, ${ }^{56}$ should for any special purpose have been rendered pure white and thus made conspicuous to their enemies; or that the adults of one of these two species shonld have been specially rendered white during the winter in a country which is never covered with snow. On the other hand wo have good reason to believo that whiteness has been gained by many hirds as a sexual ornament. To may thereiore conclucle that some early progenitor of the Arclea ashu and the Buphus acquired a white plumage for nuptial purposes, and transmittud this colour to their young; so that the young and the old became white like certain existing egrets; and that the whiteness was afterwards retained by the young, whilst it was exchanged by the adults for more strongly-pronounced tints. But if we conld look still further back to the still earlier progenitors of these two species, $\pi c$ should probably see the adults dark-

35 See Jerdon on the genus Palanrnis, 'Birds of India,' rol. $i$. p. $258-260$.

56. The young of Ardea rufescens and A. coerulea of the U. States are likewise white, the adults being solc: $1: 3$ is accordance with their specific names. Audubon ("Ornith. Biographe, rol. iii. p. 416 ; rol. ir. p. 58) seems rather pleased at the thought that this remarkable change of plumage will greatly "discoucert "the systematists." 
coloured. I infer that this would be the case, from the analu? of many other birds, which are dark whilst young, and whed adult are white; and more especially from the case of the didea yularis, the colours of which are the reverse of those of $d$. ashe, for the young are dark-coloured and the adults white, the young having retained a former state of plumage. It appears therefore that, during a long line of descent, the adult progenitors of the Ardeu ashu, the Buphus, and of some allies, have undergone the following changes of colour: first, a dark shade; secondly, pure white; and thirdly, owing to another change of fashion (if I may so express myself), their present slaty, reddish, or golden-buff tints. These successive changes are intelligiblo only on the principle of novelty having been admired by birds for its own sake.

Several writers have oljected to the whole theory of sexual selection, by assuming that with animals and savages the taste of the female for certain colours or other ornament; would not remain constant for many generations; that first one colour and then another would be admired, and conserquently that no permanent effect could be produced. We may admit that taste is fluctuating, but it is not quite arbitrary. It depends much on habit, as we see in mankind; and wo may infer that this would hold good with birds and other animals. Even in our own dress, the general character lasts long, and the changes are to a certain extent graduated. Abundant evidence will be given in two places in a future chapter, that savages of many races have admired for many generations the same cicatrices on the skin, the same hideously perforated lips, nostrils, or ears, distorted heads, \&c.; and these deformitics present some analogy to the natural ornaments of various animals. Nerertheless, with savages such fashions do not enduro (i) ever, as we may infer from the differences in this respect lutween allied tribes on the same continent. So again the raisers of fancy animals certainly have admired for many generatious and still admire the same breeds; they earnestly desire slight changes, which are considered as improrements, but any great or suchlen change is looked at as the greatest blemish. With birds in a state of nature we have no reason to suppose that they woull admire an entirely new style of coloration, even if great sud sudden variations often occurred, which is far from being the case. We know that dorecot pigeons do not willingly associate with the variously coloured fancy breeds; that albino birds do not commonly get partners in marriage; and that the: black ravens of the Feroe Islands chase away their piebald brethren. But this dislike of a sudden change would not 
preclude their appreciating slight changes, auy more than it does in the case of man. Hence with respect to taste, which depends on many elements, but partly on habit and partly on a love of novelty, there seems no improbability in animals admiring for a very long period the same general style of ornamontation or other attractions, and yet appreciating slight changes in colours, form, or sound.

Summary of the Four Chapters on Birds.-Most male birds are liighly pugnacious during the breeding-season, and some possess wcapons adapted for fighting with their rivals. But the most pugnacious and the best armed males rarely or never depend for success solely on their power to drive away or kill their rivals, but have special means for charming the female. With some it is the power of song, or of giving forth strange cries, or instrumental inusic, and the males in consequence differ from the females in their vocal organs, or in the structure of certain feathers. From the curiously diversified means for producing various sounds, we gain a high idea of the importance of this means of courtship. Many birds endeavour to charm the females by love-dances or antics, performed on the ground or in the air, and sometimes at prepared places. But ornaments of many kinds, the most briliant tints, combs and wattles, beantiful plumes, elongated feathers, top-knots, and so forth, are by far the commonest means. In some cases mere novelty appears to have acted as a charm. 'The ornaments of the males must be highly important to them, for they have been acquired in not a fer cases at the cost of increased danger from enemics, and even at some loss of power in fighting with their rivals. The males of very many species do not assume their ornanental dress until they arrive at maturity, or they assume it only during the breeding-season, or the tints then become more vivid. Curtain ornamental appendages become enlarged, turgid, and brightly coloured during the act of courtship. The males display their charms with elaborate care and to the best (feet; and this is dono in the presence of the females. The courtship is sometimes a prolonged affair, and many males and females congregate at an appointed place. To suppose that the females do not appreciate the beauty of the males, is to admit that their splendid decorations, all their pomp and display, are useless; and this is incredible. Birds have fine powers of discrimination, and in some ferv instances it can be shewn that they have a taste for the beautifu?. The females, moreover, are known occasionally to exhibit a marked preference or antipathy for certain individual males.

If it be admitted that the females prefer, or are unconsciously 
excital by the more beautiful males, then the males wotild slowly but surely be rendered more and more attractive throngh sexual selection. That it is this sex which has been chietly modified, we may infer from the fact that, in almost every genus where the sexes differ, the males differ much more from one another than do the females; this is well shewn in certain closely-allied representative species, in which the females can hardly he distinguished, whilst the males are quite distinct. Birds in a state of nature offer individual differences which would ainply suffice for the work of sexual selection; but wo have seen that they occasionally present more strongly-marked variations which recur so frequently that they would immediately be fixed, if they serred to allure the female. The laws of variation must determine the nature of the initial changes, and will have largely influenced the final result. The gradations, which may be obserred between the males of allied species, indicate the nature of the steps through which they bave passed. They explain also in the most interesting manner how certain characters have originated, such as the indented ocelli on the tail-feathers of the peacock, and the ball and socket ocelli on the wing-feathers of the Argus pheasant. It is evident that the brilliant colours, top-knots, fine plumes, \&c., of many male birds cannot have been acquired as a protection; indeed, they sometimes lead to danger. That they are not due to the direct and definite action of the conditions of life, we may feel assured, because the females have been exposed to the same conditions, and yet often differ from the males to an extremo degree. Although it is probable that changed conditions acting during a lengthened period have in some cases produced a definite effect on both sexes, or sometimes on one sex alone, the more important result will hare been an increastd tendency to vary or to present more strongly marked individual differences; and such differences will have afforded an excollent groundwork for the action of sexual selection.

The laws of inheritance, irrespectively of selection, appear to have determined whether the characters acquired by the males for the sake of ornament, for producing various sounds, and for fighting together, have been transmitted to the males alone or to both sexes, either permanently, or periodically during certain seasons of the year. Why various characters should liave becn transmitted sometimes in one way and sometimes in another, is not in most cases known; but the period of variability seems often to have been the determining cause. When the two sexes have inherited all characters in common they necessarily resomblo each other; but as the successive variations may be differentiy 
transwitted, overy josible gradation may be found, even within The same genus, from the closest similarity to the widest dissimilarity between the sexes. With many closely-allied species, fullowing mearly the same habits of life, the males have come tc differ from each other chiefly through the action of sexual selection; whilst the females have come to differ chiefly from partaking more or less of the characters thus acquired by the males. The effects, moreover, of the definite action of the conditions of life, will not have been masked in the females, as in the males, by the accumulation through sexual selection of strongly-prouounced colours and other ornaments. 'I'he individuals of both sexes, however affected, will have been kept at each successive period nearly uniform by the free intercrossing of many individuals.

With species, in which the sexes differ in colour, it is possible or probable that some of the successive variations often tended to be transmitted equally to both sexes; but that when this occurred the females were prevented from acquiring the bright colours of the males, by the destruction which they suffered during incubation. There is no cridence that it is possible by natural selection to convert one form of transmission into another. But there would not be the lcast difficulty in rendering a fomale dull-coloured, the male being still kept brighti-coloured, by the selection of successive variations, which were from the first limited in their transmission to the same sex. Whether the females of many species hare actually been thus modified, must at present remain doubtful. When, through the law of the equal transmission of characters to both sexes, the females were rendered as conspicuously coloured as the males, their instincts appear often to have been modified so that they were led to build domed or concealed nests.

In one small and curious class of cases the characters and habits of the two sexes have been completely transposed, for the females are larger, stronger, more rociferous and brighter coloured than the males. They hare, also, become so quarrelsome that they often fight together for the possession of the males, like the males of other pugnacions species for the possession of the females. If, as secms probable, such females habitually drire away their rivals, and by the display of their l,right colours or other charms endeavour to attract the males, we can understand how it is that they have gradually been rendered, by sexual selection and sexually-limited transmission, more beautiful than the males-the latter being left unmodified or only slightly modified.

Whenever the law of inheritance at corresponding ages prevails. 
but not that of sexually-limited transmission, then if the parents rary late in life-and we know that this constantly occurs with our poultry, and ocensionally with other birds-. the soung will be left mnaffected, whilst the adults of both sexes will be modified. If both these laws of inheritance prevail and either sex varies late in life, that sex alone will be modified, the other sex and the young being unaffected. When rariations in brightness or in other conspienous character's occur carly in life, as no doubt often happens, they will not be acted on through sexual selection until the period of reproduction arrires; consequently if dangerous to the young, they will be eliminated through natural selection. Thus we call understand how it is that variations arising late in life hare so often been preserved for the ornamentation of the males; the females and the young being left almost unaffected, and therefore like each other. Witl species having a distinct summer and winter plumage, the males of which either resentble or differ from the females during both seasons or during the summer alone, the degrees and linds of resemblance between the young and the old are exccedingly complex; and this complexity apparently depends on characters, first acruired by the males, being transmitted in various ways and degrces, as limited by age, sex, and season.

As the young of so many species have been but little modified in colour and in other ornaments, we are enabled to form some judgment with respect to the plumage of their carly progenitors; and wo may infer that the beauty of our existing species, if we look to the whole class, has been largely increased since that period, of which the immature plumage gives us an indirect record. Many birds, especially those which live much on the ground, have unitoubtedly been obscurely coloured for the sake of protection. In some instances the upper exposed surface of the plumage has been thus coloured in both sexes, whilst the lower surface in the males alone has been variously ornamented through sexual selection. Finally, from the facts given in these four chapters, we may conclude that weapons for battle, organs for producing sound, ornaments of many kinds, bright and conspicnous colours, have generally been acquired by the males through variation and sexual selection, and have been transinitted in various wass according to the several laws of inheritance-the females and the young being left comparatively out little modified..$^{\text {s? }}$

59 I am greatly indebted to the rindness of Mr. Sclater for haring looked over these four chapters on birds, and the two following ones on mammals. In this way I have been saved from making mistarce 


\section{CHAPTER XIII.}

\section{Secondary Sexual Characterg of miammals.}

The iaw of battle-Special weapons, confined to the males-Cause of absence of weapons in the female-Weapons commou to both sexes, yet primarily acquired by the male-Other uses of such weapons-Their high importance-Greater size of the male-Nieans of defence-On the prejerence shewn by either sex in the pairing of quadrupeds.

WrTH mammals the male appears to win the female much more through the law of battle than through the display of his charms. The most timid animals, not provided with any special weapons for fighting, engage in desperate conflicts during the season of love. Two male hares have been seen to fight together rutil one was killed; male moles often fight, and sometimes with fatal results; male squirrels engage in frequent contests, " and often wound each other severely;" as do male beavers, so that "hardly a skin is without scars." I observed the same fact with the hides of the guanacoes in Patagonia; and on one occasion several were so absorbed in fighting that they fearlesisy rushed close by me. Livingstone speaks of the males of the many animals in Southern Africa as almost invariably shewing the scars received in former contests.

The law of battle prevails with aquatic as with terrestrial mammals. It is notorious how desperately male scals fight, both with their teeth and claws, during the breeding-scason; and their hides are likewise often corered with scars. Male sperm-whales are very jealous at this season; and in their battles "they often lock their jaws together, and turn on their "sides and twist about;" so that their lower jaws often become distorted."

about the names of the species, and from stating anything as a fact which is known to this distinguished naturalist to be erroneous. But of course he is not at all answerable for the accuracy of the statements quoted by me from various authorities.

' Sse Watertun's account of two hares fighting, 'Zoologist,' vol. i. 1843, p. 211. On moles, Bell, 'Hist. of British Quadrupeds,' 1st edit. p. 100. On squirrels, Andubon and Bachman, 'Viviparous Quadrupeds of N. America,' 1846, p. 269. On benvers, Mr. A. H. Green, is 'Journal of Lin. Soc. Zoolog.' vol. $x$. 1865. p. 362.

2 Cn the battles of seals, see Capt. C. Abbott in 'Proc. Zonl. Soc.' 1868, p. 191; also Mr. R. Brown, ibid. 1868, p. 436; aiso L. Lioyd, 'Game Birds of Sweden,' 1867, p. 412 also Pennant. On the sperm-whale see Mr. J. H. Thompson, in 'Proc. Zool. Soc.' 1867, p. 246. 
All male animals which are furnished with special weapons for fighting, are well known to engage in fierce battles. The courage and the desperate conflicts of stags have often been described; their skeletons have been found in various parts of the world, with the horus incxtricably locked together, shewing how miscrably the victor and ranquished had perished. ${ }^{3}$ No animal in the world is so dangerous as an eleplant in must. Isord Tankerville has given me a graphic description of the battles between the wild bulls in Chillingham Park, the descendants, degenerated in size but not in courage, of the gigantic Bos primigenius. In 1861 sereral contended for mastery; and it. was obscrved that two of the younger bulls attacked in concert the old leader of the herd, orerthrew and disabled him, so that he was believed by the kecpers to be lying mortally wounded in a neighbouring wood. But a few days afterwards one of the young bulls approached the rood alone; and then the " monarch " of the chase," who had been lashing himself up for vengeance, "ame ont and, in a short time, killed his antagonist. He then 'plietly joined the herd, and long held undisputed sway. Admiral Sir J. B. Sulivan informs me that, when he lived in the Falkland Islands, he importer a $50 m n g$ English stallion, which fricquented the hills near Port William with eight mares. On these hills there were two wild stallions, each with a small troop of mares; "and it is certain that these stallions would never " liave approached each other without fighting. Both had tried "singiy to fight the English horse and drive away his mares, "but had ficiled. One day they came in together and attacked " him. This mas secn by the capitan who had charge of the " horses, and who, on riding to the spot, found one of the two "stallions engaged with the English horse, whilst the other was "driving away the mares, and had already separated four from " tho rest. The capitan settled the matter by driving the whole "party into the corral, for the wild stallions would not leave "the mares."

Mrle animals which are provided with efficient cutting or tearing teeth for the ordinary purposes of life, such as the caruirora, insectivora, and rodents, are seldom furnished with weapons especially adapted for fighting with their rivals. The case is very different with the males of many otler animals. We see this in the horns of stags and of certain kinds of

a See Scrope ("Art of Deer-stalking, p. 17) on the lncking of the borns with the Cervus elaphus. Richardson, in "Fanna Bor. Americers. 1829 , p. 252, says that the wapiti, moose, and re!n-deer have been found thus lockenl together. Sir A. Smith found at the Cape or Goorl Hope the skeletons of two gaus in the same condition. 
antelopes in which the females are hornless. With many animals the canine teeth in the upper or lower jaw, or in both, are much larger in the males than in the females, or are absent in the latter, with tho exception sometimes of a hidden rudiment. Certain antelopes, the musk-deer, camel, horse, boar, various apes, seals, and the walrus, offer instances. In the females of the walrus the tusks are sometimes quite absent." In the male elephant of India and in the male dugong ${ }^{\sigma}$ the upper incisors form offensive weapons. In the male narwhal the left canine alone is developed into the well-known, spirally-twisted, socallod horn, which is sometimes from nine to ten feet in length. It is believed that the males use these horns for fighting together; for " an unbroken one can rarely be got, and occasionally "one may be found with the point of another jammed into the "broken place." The tooth on the opposite side of the head in the malo consists of a rudiment about ten inches in length, which is embedded in the jaw ; but sometimes, though rarely, both are equally developed on the two sides. In the fomale both are always rudimentary. The male cachalot has a larger head than that of the female, and it no dount ajds him in his aquatic battles. Lastly, the adult male ornithorhynchus is provided with a remarkable apparatus, namcly a spur on the foreleg, closely resembling the poison-fang of a venomous snake; but ac.cording to Harting, the secretion from the gland is not poisonous; and on the leg of the female there is a hollow, apparently for the reception of the spur.?

When the males are provided with werpons which in the females are absent, there can hardly be a donbt that these scrve for fighting with other males; and that they were acquired through sexual selection, and were transmitted to the male sex alone. It is not probalue, at least in most cases, that the females have been prevented from acquiring such weapons, on account of their being useless, superfluous, or in some way injurious. On the contrary, as they are often used by the males for various

- Mr. Lamont ("Seasons with the Sen-Horses,'1861, p, 143) says that a good tusk of the male walrus weighs 4 pounds, and is longer than that of the female, which weighs about 3 pounds. The males are described as fighting ferociously. On the occasional absence of the tusks if the temale, see Mr. B. Brow a, 'Proc. Zool. Soc.' 1868, p. 429.

5 Owen, "Anatomy of Vertebrates, rol. vii. p. 283.
- Mr. R. Brown, in 'Proc. Zool. Soc.' 1869, p. 553. See Prof. Turner, in Journal of 'Anat. and Phys.' 1872 , p. 76 , on the homological nature of these tusks. Also Mr. J. W. Clarke on two tusks being develuped is the males, in 'P'roc. Zuolog. Soc.' 1871 , p. 42 .

7 Owen on the cachalot and Ornithorhynchus, ibid. vol. iii. rp. 638, 641. Harting is quoted by Dr. Zouteveen in the Dutch translat. of this work, rol. ii. p. 292. 
purposes, more espocially as a defence against their enemies, it is a surprising fact that they are so poorly developed, or quite absent, in the females of so many animals. With female does the development during each recurrent season of great branching horns, and with female elephants the development of immenso tusks, would be a great waste of vital powor, supposing that they were of no use to the females. Cousequently, they would have tonded to be climinated in the female through natural selection; that is, if the successive variations were limited in their transmission to the female ser, for otherwise the weapons of the males would have been injuriously affected, and this would have been a greater evil. On the whole, and from the consideration of the following facts, it seums probable that when the various weapons differ in the two sexes, this has generally depended on the kind of transmission whish has prevailed.

As the reindeer is the one species in the whole family of Deer, in which the female is furnished with horns, though they are somewhat smaller, thinner, and less branched than in tho male, it might naturally be thought that, at least in this case, they must be of some specinl service to her. The female retains her horns from the time when they are fully developed, namely, in September, thronghont the winter until A pril or May, when she brings forth lor young. Mr. Crotch made particular enquiries for me in Norway, and it appears that the females at this season conceal themselves for about a fortnight in order to bring forth their young, and then reapnear, gencrally hornless. In Nova Scotia, however, as I hear from Mr. H. Recks, the fomale sometimes retains her horns longer. The male on the other hand casts his horns much earlier, towards the ond of November. As both sexes have the same requirements and follow the same haluits of life, and as the male is destitute of horns during the winter, it is improbable that they can be of any special scrvice to the female during this scason, which inclucles the larger part of the time during which she is horned. Nor is it probable that she can have inherited horns from some ancient progenitor of the family of deer, for, from the fact of the females of so many species in all quarters of the globe not having horns, we may conclude that this was the primordial character of the sroup. ${ }^{8}$

The horns of the reindeer are developed at a most unusually

- On the structure and shedding If the horns of the reindeer, Holfoerg, 'Amcnitates Acad.' rol. iv. $17 \varepsilon 8$, p. 149. See Richardson, Fauna Bor. Anericana' p. 241, ir regard to the American variety oI species; also Major W. Joss Kín'g, 'The Sportsman in Cani da,' 186i, p. 80 . 
early age; but what the cause of this rnay be is not known. The effect has apparently been the transference of the horns to both sexes. We should bear in mind that horns are always transmitter through the female, and that she has a latent capacity for their derelopment, as $\pi$ e see in old or disensed females. ${ }^{9}$ Horeover the females of some cther species of decr exhibit, either normally or occasionally, rudiments of horns; thus the female of Cervulus moschatus lias "bristly tufts, ending in a "knol, instead of a horn;" and "in most specimens of the "female wapiti (Cervus canadensis) there is a sharp bony pro"tuberance in the place of the horn." 10 From these several considerations we may conclude that the possession of fairly mell-developed horns by the female reindeer, is due to the males having first acquired them as weapons for fighting with other males; and secondarily to their development from some niknown cause at an unusually carly age in the males, and their consequent transference to both sexes.

Turning to the sheath-horned ruminants: with antelopes a graduated series can be formed, heginning with species, the females of which are completely destitute of horns-passing on to those which have horus so small as to be almost rudimentary, (as with the Antilocapra americuna, in which species they are present in only one out of four or five females ${ }^{11}$ ) - to those which have fairly developed horns, but manifestly smaller and thinner than in the male and sometimes of a different shape, ${ }^{12}$-and ending with those in which both sexes have horns of equal size. As with the reindeer, so with antelopes there exists, as previously shewn, a relation between the period of the development of the horns and their transmission to one or both sexes; it is therefore probable that their presence or absence in the females of some species, and their more or l'ss perfect condition in the females of other species, depends, not on their being of any special use, but simply in inheritance. It accords with this

- Isidore Geoffroy St. Hilaire, 'Essais de Zoolog. Générale,' 1841, p. 513. Other masculine characters, besides the horns, are sometimes similarly transferred to the female; thus $\mathrm{Mr}$. Boner, in speaking of an old female chamois ("Chamois Hunting in the Mountains of BaTaria,' 1860, 2nd edit. p. 363), says, "not only was the head very male"looking, but along the back there "was a ridge of long hair, usually "to be found only in bucks." 10 On the Cerrulus, Dr. Gray,
' Catalogue of Mammalia in the British Museum,' part. iii. p. 220. On the Cervus canadensis or wapiti see Hon. J. D. Caton, 'Ottawa Acad. of Nat. Sciences,' May, 1868, p. 9.

"I I am indebted to Dr. Canfield, for this information, see also his paper in 'Proc. Zoolog. Soc.,' 1866, p. 105.

12 For instance the horns of the female Ant. euchore resemble those of a distinct species, viz. the Ant. dorcas var. Corine, see Desmarest, 'Mammalogie,' p. 455. 
viow that even in the same restricted genus both scres of some species, and the males alone of others, are thrs provided. It is ilso a remarkable fact that, althongh the females of Antilope bescoartica are normally destitute of horns, Mr. Blyth has seen no less than three females thus furnisherl; and there was no reason to suppose that they were old or diseased.

In all the wild species of goats and sheep the horns are larger in tho male than in the female, and are sometimes 'quite absent in the latter. ${ }^{13}$ In several domestic breeds of these two animals, the males alone are furnished with horns; and in some breeds, for instance, in the sheep of North Wales, thongh both sexes are properly horned, the ewes are very liable to be hornless. I have been informed by a trustworthy witness, who purposely inspected a fluck of these same sheep during the lambing season, that the horns at birth are generally more fully doveloped in the male than the female. Mr. J. Peel crossed his Lonk sheep, both sexes of which almays bear horns, with hornless Leicester's and hornless Shropshire Downs; and the result was that the male offspring had their horns considerably reduced, whilst the females wore wholly destitute of them. These several facts indicate that, with sheop, the horus are a much less firmly fixed character in the fomales than in the males; and this leads us to look at the horns as properly of musculine origin.

With the adult musk-ox (Ovibos moschatus) the horns of the male are larger than those of the female, and in the latter the bases do uot touch. ${ }^{14}$ In regard to ordinary cattle Mr. Blyth remarks: "In most of the wild bovine animals the horns are "both longer and thicker in the bull than in the cow, and in "the cow-banteng (Lios sondricus) the horns are remarkably "small, and inclined much backwards. In the domestic races " of cattle, both of the humped and humpless types, the horns "are short and thick in the bull, longer and more slender in the "corv and ox; and in the Indian buffalo, they are shorter ard "thicker in the bull, longer and more slender in the cow. In " the wild gaour (B. gaurus) the horns are mostly both longer " and thicker in the bull than in the cow." ${ }^{15}$ Dr. Forsyth Major also informs me that a fossil skull, believed to be that of the female Bos ctruscus, has been found in the Val d'Arno, which is wholly without horns. In the Rihinoceros simus, as I may add, the horns of the female are generally longer but less powerful than in the male; and in some otier species of rhinoceros they

13 Grav, 'Catalogue Mamm. Brit. ricana,' p. 278.

Mus.' pai't ỉi. 1852 , p. 160.

14 Riciardson, "Fauna Bor. Amo346

is 'Land and Water,' 1857, p. 
are said to be shorter in the female. ${ }^{16}$ From these various facts we may infer as probable that horns of all kinds, even when they are equaly developed in the two sexes, were primarily acquired by the $\mathrm{n} . \mathrm{ale}$ in order to conquor other males, and have been transferred mole or less completely to the female.

The effects of castration deservo notice, as throwing light on this same point. Stags after the operation never renew their horns. The male reindeer, howover, must be excepted, as after castration he does renew them. This fact, as well as the possession of horns by both sexes, secms at first to prore that the horus in this species do not constitute a sexual character ; ${ }^{17}$ but as they are developed at a very early age, before the sexes differ in constitution, it is not surprising that they should be. unaffected by castration, even if they were aboriginally acquired lyy the malo. With sheep both sexes properly bear horns; and I am informed that with Welch sheep the horus of the males are considerably reduced by castration; but the degree depends much on the age at which the operation is performed, as is likewise the case with other animals. Merino rams have large horns, whilst the ewes "generally speaking are without horns;" and in this breed, castration seems to produce a somewhat greater effect, so that if performed at an carly age the horns "remain "almost undeveloped." 18 On the Guinea coast there is a breed in which the females never bear horns, and, as Mr. Winwood Reade informs me, the rams after castration are quite destitute of them. With cattle, the horns of the males are much altcred by castration; for instead of being short and thick, they become longer than those of the cow, but otherwise rescmble them. The Antitope bezoartica offers a somewhat analogous case: the males have loug straight spiral horns, nearly parallel to each other, and directed backwards; the females oceasionally bear horns, but these when present are of a very different shape, for they are not spiral, and spreading widely, hend round with the points forwards. Now it is a remarkable fact that, in the castrated male, as Mr. Blyth informs me, the horns are of the same peculiar sluape as in the female, but longer and thicker. If we may judge from analogy, the female probably shows us, in these two cases of cattle and the antelope, the former

16 Sir Andrew Smith, 'Zoology of S. Africa,' pl. xix. Owen, 'Anatomy of Vertebrates,' vol. iii. p. 624.

if Thas is the conclusion of Seillitz, 'Die Darwinsche Theorie,' 1871, p. 47.

10 I an much obliged to Prof. Vuctor Carus, for having made en- quiries for me in Saxony on this subject. H. von Nathusius ("Viehzucht,' 1872 , p. 64 ) says that the hol'us of sheep castrited at an early period, either altugether disipjea* or remain as mere rudiments; bue I do not know whether he reter. to merinos or to ordinary breeds. 
condition of the horns in some early progenitor of each species. But why castration should lead to the reappearance of an early sondition of the horns cannot be explained with any certainty. Nevertheless, it seems probable, that in nearly the same manner as the constitutional disturbance in the offispring, caused by a cross between two distinct species or races, often leads to tho reappearance of long-lost characters; ${ }^{19}$ so here, the disturbance in the constitution of the individual, resulting from castration, produces the same effect.

The tusks of the elephant, in the different species or races, differ according to sex, nearly as do the horns of ruminants. In India and Malacea the males alone are provided with welldevelopel tusks. The elephant of Ceylon is considered by most naturalists as a distinct race, but ly some as a distinct species, and here "not one in a hundred is found with tusks, the fow " that possess them being exclusively males." 20 The African elephant is undoubtedly distinct, and the fermale has large welldeveloped tusks, though not so large as those of the male.

These differences in the tusks of the several races and species of elephants - the great variability of the horns of deer, as notably in the wild reindeer-the occasional presence of horus in the female Antilepe bezcartica, and their frequent absence in the female of Antilocupra americunn-the presence of two tusks in some few male narwhals-the complete absence of tusks in some female walnuses-are all instances of the extreme variability of secondary sexual characters, and of their liability to differ in closely-allied forms.

Although tusks and horns appear in all cases to have been primarily develoned as sexual weapons, they often serre other purposes. The elephant uses his tusks in attacking the tiger; according to Bruce, he scores the trunks of trees until they can be thrown down easily, and he likewise thus extracts the farinaceous cores of palms; in Africa he often uses one tusk, al ways the same, to probe the ground and thus ascertain whether it will bear his weight. The common bull defends the herd with his horns; and the elk in Sweden has been known, according to Lloyd, to strike a wolf dead with a single blow of his grent horns. Mrany similar facts could be given. One of the most curious secondary uses to which the horns of an animal may be occasionally put, is that observed by Captain IIutton "21 with

10 I have given various experiments and other evidence proving that this is the case, in my "Variation of Animals and Plants under Dumestication,' rol. ii., 1868, pp. 39 -47 .
20 Sir J. Emerson Teanect, 'CeyIon,' 1859, vol. ii. p. 274 . For Malacen, 'Journal of Indian Archipelago,' rol. iv. p. 357.

${ }_{21}$ 'Calcutta Journal of Nat. Hiat. rol. ii. 1843, p. 526 . 
the wild goat (Capra xongrus) of the Himalayas and, as it is also said, with the ibex, namely, that when the male accidentally falls from a height he bends inwards his head, and by alighting on his massive horns breaks the shock. 'The female cannot thus; use her horns, which are smaller, but from her more quiet (lisposition she does not need this strange kind of shield so inuchls.

Wach male animal uses his weapons in his own peculiar fishinon. The common ram makes a charge and butts with sulel force with the bases of his horns, that I have seen a powerful man knocked over like a child. Goats and certain species of sheep, for instance the ovis cycluceros of Afghanistan, ${ }^{22}$ rear on their hind legs, and then not only butt, but "make a cut down "and a jerk inp, with the ribbed front of their scimitar-shaped "horn, as with a sahre. When the $O$. cycluceros attacked a large " lomestic ram, who was a noted bruiser, he conquered him by "the sheer novelty of his mode of fighting, always closing at "once with his adversary, and catching him across the face and " nose with a sharp drawing jork of the head, and then bounding "out of the way before the blow conld he returned." In Pembrokeshire a male goat, the master of a flock which during soveral generations had run wild, was known to have killed sevcrai males in single combat; this goat possessed enormous horns, measuring thirty-nine inches in a straight line from tip to tip. The common bull, as every one knotrs, gores and tosses his opponent; but the Italian buffalo is said never to use his horns, he gives a tremendons blow with his convex forchead, and then tramples on his fallen enemy with his knees-an instinct which the common bull does not possess. ${ }^{23}$ Hence a dog who pins a luffialo by the nose is immediately crushed. We must, horrever, xumember that the Italian buffalo has been long domesticated, and it is by no means certain that the wild parent-form had similar horns. Mr. Bartlett informs me that when a female Cape buffalo (Bubalus caffer) was turned into an enclosure with a bull of the same species, she attacked him, and he is return pushed her about with great violence. But it was manifest to Mr. Bartlett that, had not the bull shewn dignifier forbenance, he conld easily have killed her by a single lateral thrust with his immense horns. The giraffe uses his short hair-corered horns, which are rather longer in the male than in the female, in a curious manner; for, with his long neck, he swings his head to either side, almost upside down, with such

22 Mr. Blyth, in ' Land and Water,' March, 1867, p. 134, on the authority of Capt. Hutton and others. For the wild Pembrokeshire goats see the 'Field,' 1869, p. 150.

28 M. E. M. Bailly, 'Sur l'usere des Cornes,' \&c., 'Ánnal. des Sc. Nat.' tom. i. 1824, p. 369. 
force, that I have seen a hard plank deeply indented by a singlo blow.

With antelopes it is sometimes difficult to imagine how they san possibly use their euriously-shaped horns; thus the springboc (Aut. euchore) has rather short upright horns, with the sharp points bent inwards almost at right augles, so as to fice each other; Mr. Bartlett does not know how they are used, lint suggests that they would inflict a fearful wound down each sile of the face of an antagonist. The slightly-curved horus of the

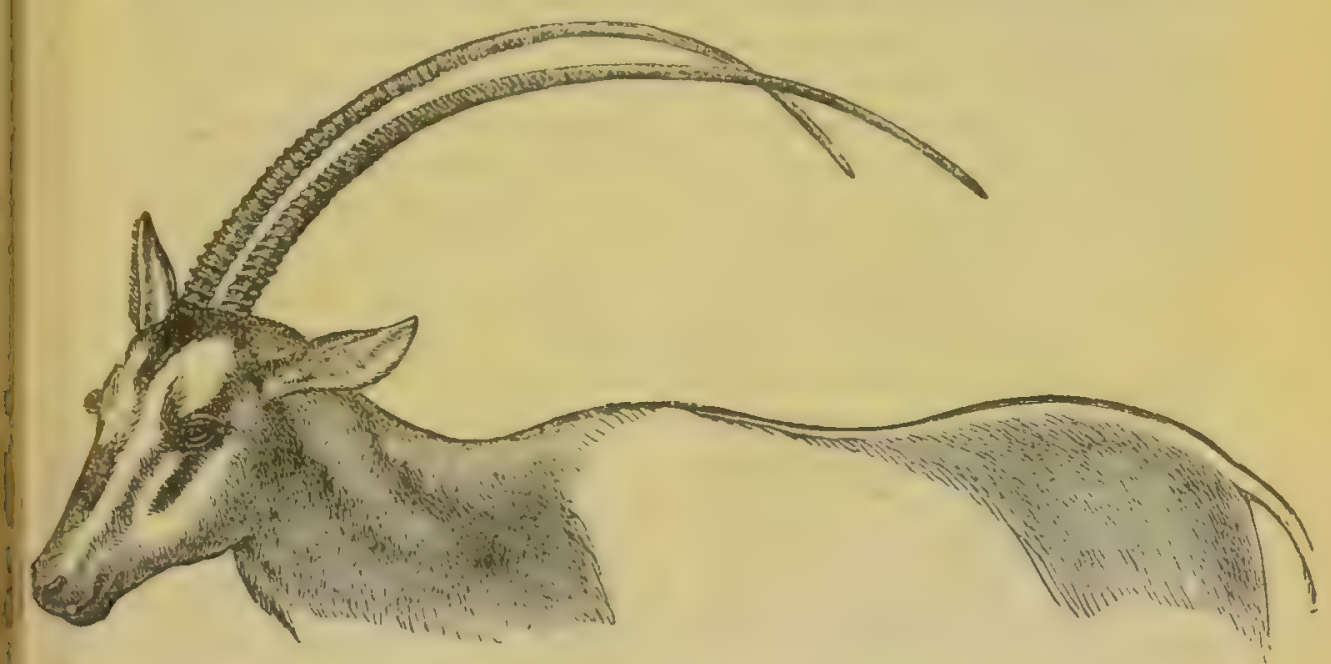

Fig. 63. Oryx leucoryx, male (from the Knowsley Menagerie).

Oryx leucoryx (fig. 63) are directed backwards, and are of such length that their points reach beyond the middle of the back, over which they extend in almost parallel lines. Thus they seem singularly ill-fitted for fighting; but Mr. Bartlett inform. me that when two of these animals prepare for battle, they knecl down, with their heads between their fore legs, and in this attitude the horns stand nearly parallel and close to the ground, with the points directed forwards and a little upwards. 'The combatants then gradually approach each other, and each endeavour's to get the upturned points under the body of the other; if one succeeds in doing this, he suddenly springs mp, throwing up his head at the same time, and can thus wound or perhaps even transfix his antagonist. Both animals always kneel down, so as to guard as far as possible against this manceurre. It has been recorded that one of these antelopes has used his horns with effect even against a lion; yet from being forced to place his head between the fore-legs in order to bring the points of the 
horns forward, he would generally be under a great disadrantage when attacked ly any other animal. It is, therefore, not probable that the horus have been modified into their present great longth and peculiar position, as a protection against beasts of prey. We can however see that, as soon as some ancient male progenitor of the Oryx acquired moderately l'nng horns, directed a little backwards, he would he compelled, in this hattles with rival males, to bend his head somewhat inwards or downwards, as is now done by certain stags; and it is not improbable that he might have acquired the habit of at first occasionally and afterwards of regularly kneeling down. In this case it is almost certain that the males which possessed the longest horns would have had a great advantage over others with shorter horns; and then the horns would gradually have been rendered longer and longer, through sexual selection, until they acquired their present extraordinary length and position.

With stags of many kinds the branches of the horns offer a curious case of difficulty; for certainly a single straight point would inflict a much more serious wound than several diverging ones. In Sir Plilip Egerton's museum there is a horn of the red-deer (Cervus eluphus), thirty inches in length, with "not "fewor than fifteen snags or branches;" and at Moritzburg there is still preserved a pair of antlers of a red-deer, shot in 1699 by Frederick I., one of which bears the astonishing number of thirty-three branches and the other twenty-seren, making altogether sixty branches. Richardson figures a pair of antlers of the wild reindeer with trenty-nine points. ${ }^{24}$ From the manner in which the horns are branched, and more especially from deer being known occasionally to fight together by kicking with their fore-feet, ${ }^{25} \mathrm{M}$. Bailly actually comes to the conclusion that their horns are more injurious than useful to them? But this author overlooks the pitched battlos between rival males. As I felt much perplexed about the use or advantage of the branches, I applied to Mr. McNeill of Colonsay, who has long and carefully observed the habits of red-deer, and he informs me that he has never seen some of the branches brought into use, but that the brow antlers, from inclining downwards, are a great protection to the forehead, and their points are likewise

24 On the horns of red-deer, Owen, 'British Fossil Mammals,' 1846, p. 478; Richardson on the horns of the reindeer, 'Fauna Bor. Americuna,' 1829, p. 240. I am indebted to Prof. Victor Carus, for the Moritzburg case.

s: Hon. J. D. Caton ('Ottawa
Acad. of Nat. Science, May, 1868, p. 9), says that the American deer fight with their fore-feet, after "the question of superiority has "been once settled and acknowledged "in the herd." Bailly, "Sur l'usage des Cornes,' 'Annales des Sc. Nat. tom. ii. 1824, p. 371. 
used in attack. Sir Philip Egerton also informs me both as to red-decr and fallow-deer that, in fighting, they suddenly dash together, and getting their hor'us tixed against each other's bodies, a desperate strugglc eusues. When one is at last forced to yield and turn round, the victor endeavours to plunge his brow antlers into his defeated foe. It thus appears that tho upper branches are used chiefly or exclusively for pushing and fencing. Nevertheless in some species the upper branches are used as meapons of offence; when a man was attacked by a wapiti deer (C'ervus conadensis) in Judge Caton's park in Ottawa, and several men tried to rescue him, the stag "never " raised his head from the ground; in fact, he kept his face almost "flat on the ground, with his nose nearly between his fore feet, " except when he rolled his head to ono side to take a new " observation preparatory to a plunge." In this position the ends of the,horns were directed against his adversaries. "In " rolling his head he necessarily raised it somewhat, because his " antlers were so long that he could not roll his head without " raising them on one side, while, on the other side, they touched "the ground." The stag by this procedure gradually drove the party of rescuers backwards, to a distance of 150 or 200 feet; and the attacked.man was killed. ${ }^{26}$

Although the horns of stags are efficient weapons, there can. I think be no doubt that a single point would have been much more dangerous than a branched antler; and Judge Caton, whe has had large experience with deer, fully concurs in this conclusion. Nor do the branching horns, though highly important as ¿ means of defence against rival stags, appear perfectly well :tdapted for this pu!poso, as they are liable to become interlocked. The suspicion his therefore crossed my mind that they may serve in part as ornaments. That the branched antlers of stags as well as the elegant lyrated horns of certain antelopes, with their graceful double curvature, (fig. 64), are ornamental in our eyes, no one will dispute. If, then, the horns, like the splendid accoutrements of the knights of old, add to the noble appearance of stags and antelopes, they may have been modified partly for this purpose, though mainly for actual scrvice in battle; but I Lave no evidence in favour of this belief.

An interesting case has lately becn published, from which it appears that the horns of a deer in one district in the United States are now being modified through sexual and uatural selection. A writer in an excellent American Journal ${ }^{27}$ says, that he has

26 See a most interesting account 1n the Appendix to Hon. J. D. 27 "The American Naturalist, Caton's paper, as above quoted. 
hunted for the last twenty-one years in the Adirondacks, where the Cervus virginianus abounds. About fourteen years ago he first heard of spike-liom bucks. These became from year to year more common; about five years ago he shot one, and afterwards another, and now they are frequently killed. "The spike-horn " differs greatly from the common antler of the C. virginianus.

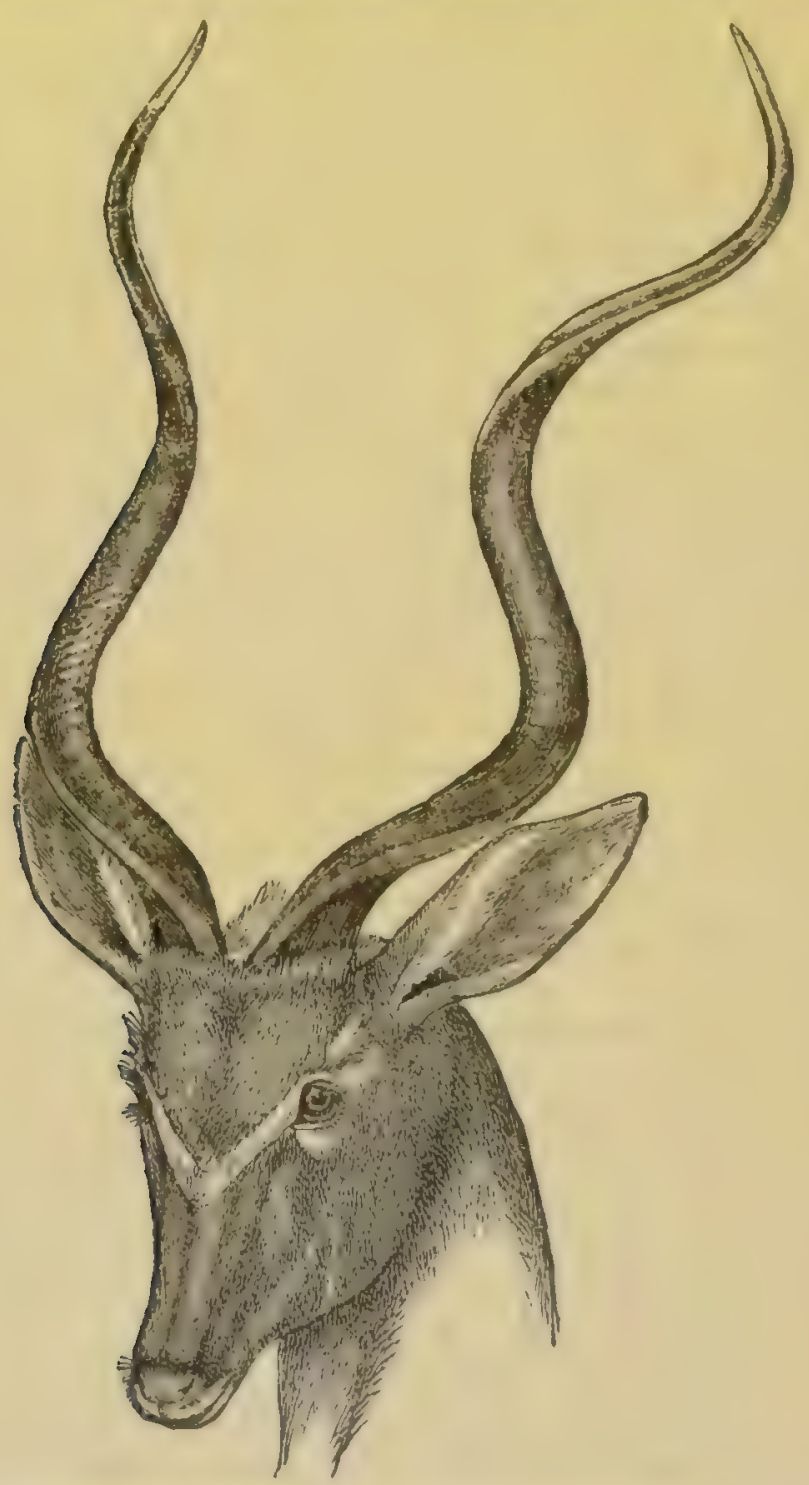

Fig. 64. Strensiceros Kudu (from Sir Andrew Smith's 'Zoology of South Africa'),

"It consists of a single spike, more slender than the antler, and "scarcely half so long, projecting forward from the brow, and "terminating in a very sharn point. It gives a considerable 
"advantage to its possessor over the common buck. Besides " enabling him to run more swiftly through the thick woods and "underbrush (every hunter knows that does and yearling " bucks run much inore rapidly than the large bucks when " armed with their cumbrous antlers), the spike-horn is a more "effective weapon than the common antler. With this advantage " the spike-horn bucks are gaining upon the common bucks, and " may, in time, entirely supersede them in the Adirondacks.

"Uudoubtedly, the first spike-horn buck was merely an acci" dental freak of nature. But his spike-horns gave him an "advantage, and enabled him to propagate his peculiarity. His "descendants having a like advantage, hare propagated the "peculiarity in a constantly increasing ratio, till they are "slowly crowding the antlered deer from the region they " inhabit." A critic has well objected to this account by asking, why, if the simple horas are now so advantageous, were the l:ranched antlers of the parent-form ever developed? To this I (an only answer by remarking, that a new mode of attack with nerw weapons might be a great advantage, as shewn by the case ut the Ovis cycloceros, who thus conquered a domestic ram famous tor his fighting power. Though the branched antlers of a stag are well adapted for fighting with his rivals, and though it might be an adrantage to the prong-horned variety slowly to acquire long and branched horns, if he had to fight only with others of the same kind, yet it by no means follows that branched horns would be the best fitted for conquering a foe lifferently armed. In the foregoing case of the Oryx leucoryx, it is almost certain that the victory would rest with an antelope having short horns, and who therefore did not need to kneel lown, though an oryx might profit by having still longer horns, if he fought only with his proper rivals.

Male quadrupeds, which are furnished with tusks, use them in rarious ways, as in the case of horns. The boar strikes laterally and upwards; the musk-deer downwards with serious effect. ${ }^{28}$ The walrus, though having so short a neck and so unwieldy a Twdy, "can strike either" upwards, or downwards, or sideways, with "equal dexterity."20 I was informed by the late Dr. Falconer, that the Indian elephant fights in a different manner according to the position and curvature of his tusks. When they are airected forwards and upwards he is able to fing a tiger to a great distance-it is said to even thirty feet; when thez are short and turned downwards he endeavours suddenly to pin the

28 Pallas, 'Spicilegia fasc. xiii. 1779, p. 18.
Zoologica,' s9 Lamont, 'Seasons with the Sea Horses,' 1861, p. 141. 
tiger to the ground and, in consequence, is dangerous to the rider, who is liable to be jerked off the howdah.:"

Very few male quadrupeds possess weapons of two distinct kinds specially adapted for fighting with rival males. The male muntjac-deer (Cervulus), however, offers an exception, as he is provided with horns and exserted canine teeth. But we may infer from what follows that one form of weapon has often been replaced in the course of ages by another. With ruminants the development of horns generally stands in an inverse relation with that of even moderately developed canine teeth. Thus camels, guanacoes, cherrotains, and musk-deer, are hornless, ind they have efficient canines; these teeth loing "always of "smaller size in the females than in the males." The Camclida: have, in addition to their true canines, a pair of canine-shaped incisors in their upper jaws. ${ }^{31}$ Male deer and antelopes, on the other hand, possess horns, and they rarely have canine tecth; and these, when present, are always of small size, so that it is doubtful whether they are of any service in their battles. In Antilope montance they exist only as rudiments in the young male, disappearing as he grows old; and they are ahsent in the female at all ages; but the females of certain other antelopes and of certain deer have been known occasionally to exhilit. rudiments of these teeth. ${ }^{32}$ Stallions have small canine teetb, which are either quite absent or rudimentary in the mare; but. they do not appear to be used in fighting, for stallions bite? with their incisors, and do not open their mouths wide like: camels and guanacoes. Whenever the adult male possesses canines, now inefficient, whilst the female has cither none or mere rudiments, we may conclude that the early male progenitor of the species was provided with efficiont canines, which have been partially transferred to the females. The reduction of these teeth in the males seems to have followed from some shange in their manner of fighting, often (but not in the horse) caused by the development of new weapons.

Tusks and horns are manifestly of high importance to their

${ }^{30}$ See also Corse ('Philosoph. Transact.' 1799, p. 212) on the manner in which the short-tusked Mooknah variety attacks other elephants.

s1 Owen, 'Anatomy of Vertebrates, vol. iii. p. 349 .

32 See Rurpell (in 'Proc. Zoolog Soc.' Jan. 12, 1836, p. 3) on thr canines in deer and antelopes, with a note by Mr. Martin on a female
American deer. See also Falconer ("Palwont. Memoirs and Notes, rol. i. 1868, p. 576) on canines in an arlult female deer. In old males of the musk-deer the canines (Pallas, 'Spic. Zoolog.' fasc. xiii. 1779, p. 18) sometimes grow to the length of three inches, whilst in old females a rudiment projects scarcely bals an inch above the gunss. 
possessors, for their development consumes much organised matter. A single tusk of the Asiatic elephant-one of the extinct woolly species-and of the African elephant, have been known to weigh respectively 150,160 , and 180 pounds; and "ren greater weights have been given by some authors. ${ }^{33}$ With deer, in which the horns are periodically renewed, the drain on the constitution must be greater; the horns, for instance, of the moose weigh from fifty to sixty pounds, and those of the extinet Irish elk from sixty to seventy pounds-the skull of the latter weighing on an average only five pounds and a quarter. Although tho horns are not periodically renewed in sheep, yet their derelopment, in the opinion of many agriculturists, entails a seusible loss to the breeder. Stags, moreover, in escaping from beasts of prey are loaded with an additional weight for the sace, and are greatly retarded in passing through a woody country. The moose, for instance, with horns extending five and a balf feet from tip to tip, although so skilful in their use that he will not touch or break a twig when walking quietly, canuot act so dexterously whilst rushing away from a pack of wolves. "During his progress he holds his nose up, so "as to lay the horns horizontally back; and in this attitude " camnot see the ground distinctly." ${ }^{4}$ The tips of the horns of the great Irish elk were actually eight feet apart! Whilst the horns are covered with velvet, which lasts with the red-deer for - ibout twelve weeks, they are extremely sensitive to a blow; so that in Germany the stags at this time somewhat change their hiabits, and avoiding dense forests, frecuent young woods and low thickuts. ${ }^{35}$ These facts remind us that male birds have icquired ornamental plumes at the cost of retarded flight, and other ornaments at the cost of some loss of power in their battles with rival males.

With mammals, when, as is often the case, the sexes differ in -ize, the males are almost always larger and stronger. I am informed by Mr. Gould, that this holds good in a marked manner with the marsupials of Australia, the males of which appear to continue grorving until an unusually late age. But the most extraordinary case is that of one of the seals (Cullorhinus ursinus), a full-grown female weighing less than one-sixth of a full-grown male. ${ }^{30}$ Dr. Gill remarks that it is with the

33 Emerson Tenneut, 'Ceylon, 1859, vol. ii. p. 275 ; Owen, 'British Fossil Mammals,' 1846, p. 245.

34 Richardson, 'Fauna Boi". Americana, on the moose, Alces palmata, pr. 236, 237; on the expanse of the horne, 'Land and Water,' $1869, j$.
143. See also Orren, 'British Fossil Mammals, on the Irish elk, pp. 447, 455.

35 'Forest Creatures,' by C. Boner, 1861, p. 60 .

36 See the very interesting paprer by Mr. J. A. Allen in 'Bull. Yus. 
polygamous seals, the males of which are well known to fight savagely together, that the sexes differ much in size; the monoramous species differing but little. Whales also afford evidenco of the relation existing between the pugnacity of the males and their large size compared with that of the female; the males of the right-whales do not fight together, and they are not larger, hut rather smaller, than their females; on the other hand, male -perm-whales, fight much together, and their bodies are "often "found scarred with the imprint of their rival's tecth," and they are double the size of the females. The greater strength of the male, as Hunter long ago remarked, ${ }^{37}$ is invariably displayed in those parts of the body which are brought into action in fighting with rival males-for iustance, in the massive nuck of the bull. Male quadrupeds are also more courageous and jugnacious than the females. There can be little doubt that these characters have been gained, partly through sexual selection, owing to a long series of victories by the stronger and more courageous males over the weaker, and partly through the. iwherited effects of use. It is probable that the successire variations in strength, size, and courage, whether due to mere variability or to the effects of use, by the accumulation of which inale quadrupeds have acquired these characteristic qualities, occurred rather late in life, and were consequently to a largo cxtent limited in their transmission to the same sex.

From these considerations I was anxious to oltain information. as to the Scotch deerhound, the sexes of which differ more in size than those of any other breed (though bloodhounds differ considerably), or than in any wild canine species known to me. Accordingly, I applied to Mr. Cupples, well-known for his success with this breed, who has weighed and measured many of his own dogs, and who has with great kindness collected for me the following facts from various sources. Fine male dogs, measured at the shoulder, range from 28 inches, which is lor, to 33 or even 34 inches in height; and in weight from 80 pounds, which is light, to 120 pounds, or even more. The fernales range in height from 23 to 27 , or eren to 28 inches; and in weight from 50 to 70 , or even 80 pounds. ${ }^{38}$ Mr. Cupples

Comp. Zoolog. of Cambridge, United i'tatrs,' vol. ii. No. 1, p. 82 . The weights were ascertained by a careful observer, Capt. Bryant. Dr. (rill in "The American Naturalist," Jan. 1871, J'rof. Shaler on the relative size of the sexes of whales, 'American Naturalist,' Jan. 1873.
3: 'Animal Economy,' p. 45.

38 See also Richardson's 'Manua; on the Dog,' p. 59. Much valuabio information on the Scottish decshound is given by Mr. McNeill, who first called attention to the inequality in size between the sexes in Scrope's "Art of Deer Stalking. 
conclucies that from 95 to 100 pounds for the male, and 70 for the female, would be a safe arerage; but there is reason to bliere that formerly both sexes attained a greater weight. MIr. Cupples has weighed puppies when a fortnight old; in one litter the arerage reight of four males exceeled that of two females by six and a half ounces; in another litter the average weight of four males exceeded that of one female by less than one ounce; the same males when three weeks old, exceeded the female by seven and a half uunces, and at the age of six weeks by nearly fourteen ounces. Mr. Wright of Yeldersley House, in a letter to Mr. Cupples, says: "I have taken notes on " the sizes and weights of puppies of many litters, and as far as "my experience goes, dog-puppies as a rule differ very little "from bitches till they arrive at about five or six months old; " and then the dogs begin to increase, gaining upon the bitches " both in weight and size. At birth, and for several weeks "afterwards, a bitch-puppy will oceasionally be larger than any " of the dogs, but they are invariably beaten by them later." IIr. McNeill, of Colonsay, concludes that "the males do not "attain their full growth till over two years old, though the "fumales attain it sooner." According to Mr. Cupples' experieuce, male $\operatorname{logs}$ go on growing in stature till they are from twelve to eighteen months old, and in weight till from eighteen to twenty-four months old ; whilst the females cease increasingr in stature at the age of from nine to fourteen or fifteen months, and in weight at the age of from twelve to fifteen months. From these various statements it is clear that the full difference in size between the male and female Scotch decrhound is not acquired until rather late in life. The males almost exclusively are used for coursing, for, as Mr. MeNeill informs me, the fomales have not sufficient strength and weight to pull down a full-grown deer. From the names used in old legends, it appears, as I hear from Mr. Cupples, that, at a very ancient period, thic males were the most celebrated, the females being mentioned only as the mothers of famous dogs. Hence, during many generations, it is the male which has heen chiefly tested for strength, size, speed, and courage, and the best will have been hred from. As, however, the males do not attain their full Timensions until rather late in life, they will have tended, in necordance with the law often indisated, to transmit their characters to their male offspring alone; and thus the grest inequality in size between the sexes of the Scotch deer-hound may probably be accounted for.

I hope that Mr. Cupples will keep to his intention of publishing a full account and history of this famous breed. 
The males of some few quadrupeds possess organs or parts developed solely as a means of defence against the attacks of other males. Some kinds of deer use, as we have seen, the upper branches of their horus chiefly or exclusively for defending themselves; and the Oryx antelope, as I am informed by Mr. Bartlett, fences most skilfully with his long, ?ntly curved horns; but these are likewise used as organs of offence. The same observer remarks that rhinoceroses in fighting, parry each other's sidelong blows with their horns, which clattcr loudly together, as do the tusks of toors. Although wild koal: fight desperately, they seldom, according to Brehm, receive fata? wounds, as the blows fall on each other's tusks, or on the laycr of gristly skin (overing the shoulder, called by the G(rman:

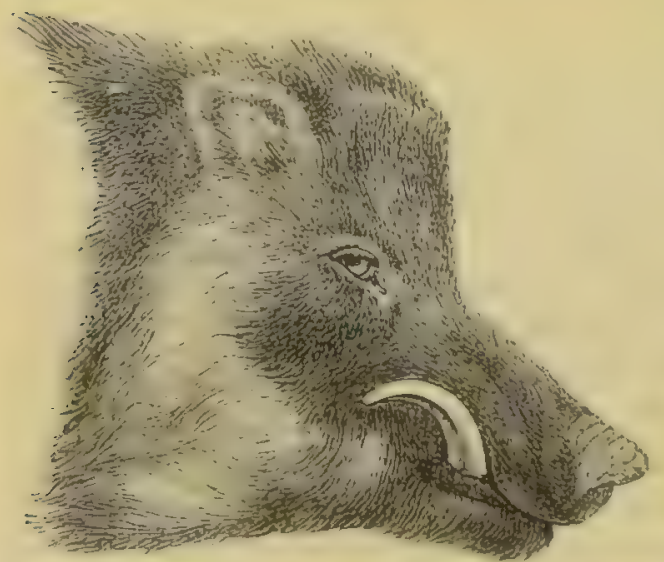

Fig. 65. Heat of (immun wihl hots, in frime of life (1rom Brehm).

hunters, the shicld; and here we have a part specially modified for defence. With hoars in the prinu. of life (sce fig. 65) the tusks in the lower jaw are used for fighting, but they become in old age, as Brehm states, so much curved inwards and upwards over the snout, that they can no longer be used in this way. They may, howerer, still serve, and even more effectively, as a means of defence. In compensation for the loss of the lower tusks as wcapons of offence, those in the upper jaw, which always project a little laterally, increase in old age so much in length and curve so much upwards, that they can be used for attack. Nevertheless, an old boar is not so dangerous to man as one at the age of six or seven years. ${ }^{39}$

In the full-grown male Baburisa pig of Celebes (fig. 66), the lower tusks are formidable weapons, like those of the European boar in the prime of life, whilst the upper tusks are so long and have their points so much curled inwards, sometimes cren touching the forehead, that they aro uttcrly useless as weapons of attack. They more nearly resemble horns than tecth, anci are so manifestly useless as teeth, that the animal mas formerly supposed to rest his head by hooking them on to a branch! 'Their convex surfaces, however, if the head wore held a little ${ }^{29}$ Brehm, 'Thierleben,' B. ii. s. 729-732. 
latcrally, wou!d serve as an excellent guard; and hence, perhaps, it is that in old animals they "are generally broken off, as if by "fighting." Ho Here, then, we have the curious case of the upper tusks of the Babirusa regularly assuming during the prime of life, a structure which apparently renders them fitted only for defence; whilst in the European boar the lower tusks assume in a less degree and only during old age, nearly the same form, nul theu sorve in like manner solely for defence.

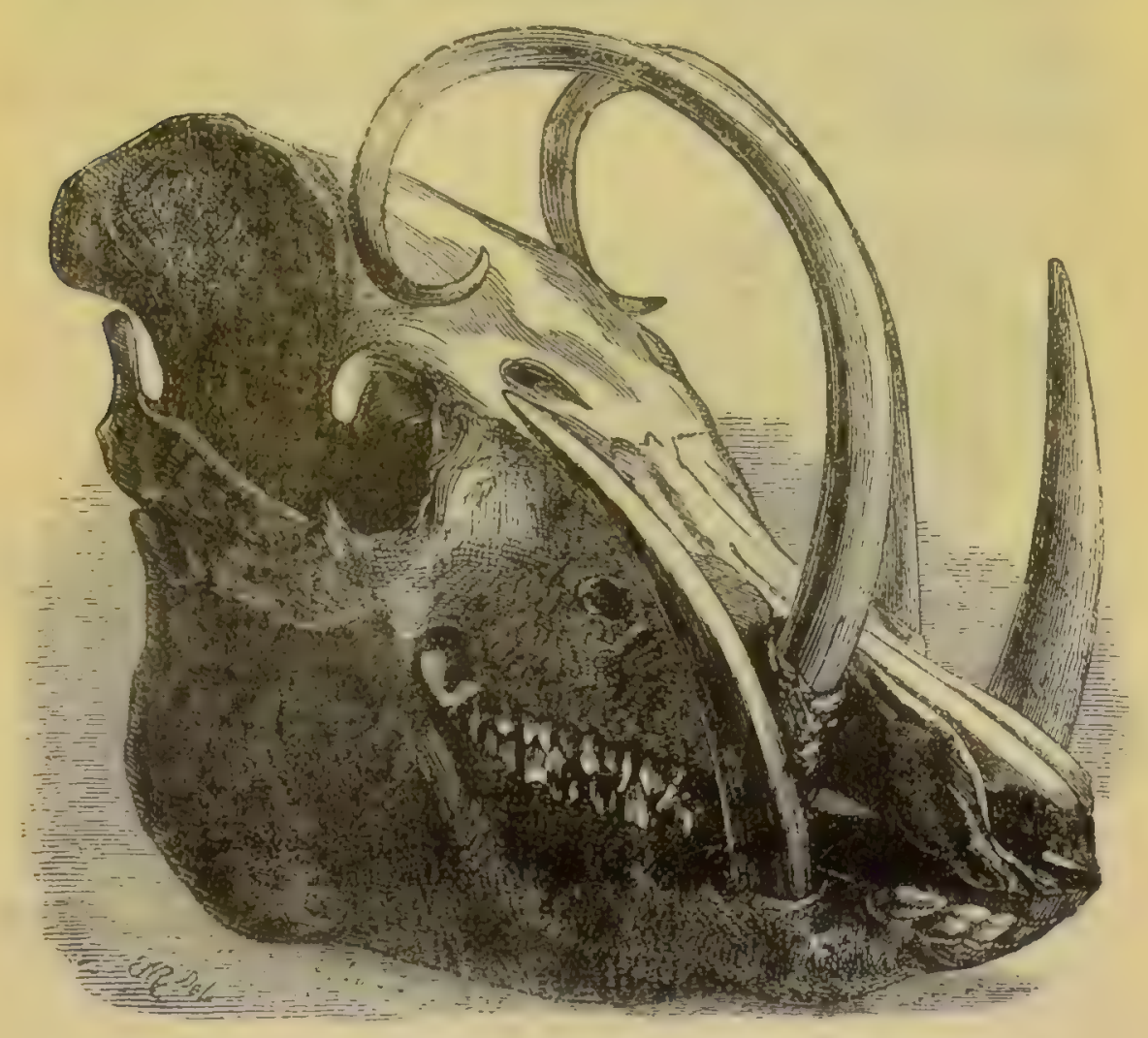

Fig. 66. Sikull of the Babirusa Pig (from Wallace's 'Maliy A Achinelago")

In the wart-hog (Plucochoerus cethiopicus, fig. 67) the tusks in the upper jaw of the male curve upwards during the prime of life, and from being pointed serve as formidable weapons. The tusks in the lower jaw are sharper than those in the upper, but from their shortness it seems hardly possible that they can be used as weapons of attack. They must, however, greatly strengthen those in the upper jaw, from being ground so as to fit closely against their bases. Neither tho upper nor the lower

40 See Mr. Wallace's interesting account of this ammal. "The Malay Archipelago,' 1869, vol. i. p. 43 . 
tusks appear to have been specially modified to act as guards, though no doubt they are to a certain extent used for this purpose. But the wart-hog is not destitute of other special means of protection, for it has, on each side of the face, beneath the eyes, a rather stiff, yet flexible, cartilaginous, oblong pad (fig. 67), which projects two or three inches ontwards; and it appeared to Mr. Bartlett and myself, when viewing the living animal, that these pads, when struck from beneath by the tusks of an opponent, would be turned upwards, and would thus admirably protect the somerwhat prominent eyes. I may add, on the authority of $\mathrm{Mr}$. Bartlett, that these hoars when fighting stand directly face to face.

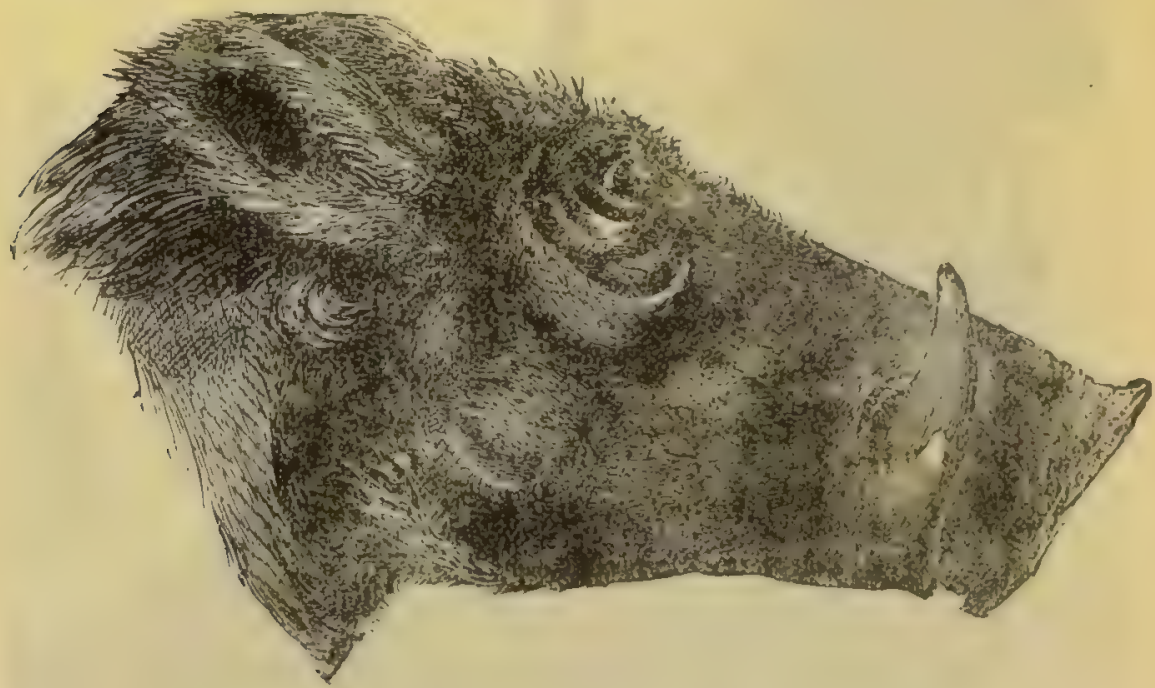

Fig. 67. Head of female Fthioplan wart-hng, from 'Proc. Zool. Soc.' 1'09, shewing the same characters as the male, though on a reduced scale.

N.B. When the engraving was first made, I was under the impression that it represented the male.

Lastly, the African rivor-hog (Potmmochnerus pencillatus) has a hard cartilaginous knob on each side of the face beneath the eyes, which answers to the flexible pad of the wart-hog; it has also two bony prominences on the upper jaw above the nostrils. A boar of this species in the Zoological Gardens recently broke into the cage of the mart-hog. They fonght all night long, and were found in the morning much exhausted, but not seriously wounded. It is a significant fact, as shewing the purpose of the above-described projections and excrescences, that these covered with blood, and were scored and abraded in an extrinordinary manner.

Although the males of so many mombers of the pig family are 
provided with weapons, and as we have just seen with means of defence, these weapons seem to have been acyuired within is rather late geological period. Dr. Forsyth Major specifiesil several miocene species, in none of which do the tusks appear to have been largely developed in the males ; and Prof. Rütimeyer was formerly struck with this same fact.

The mane of the lion forms a good defence against the attacks of rival lions, the one danger to which he is liable; for the males, as sir A. Smith informs me, engage in terrible battles, and a young lion dares not approach an old one. In 1857 a tiger at Bromwich broke into the cage of a lion and a fearful scene ensued: "the lion's mane saved his neck and head from " being much injured, but the tiger at last succeeded in rippin" "up his belly, and in a few minutes he was dead." 12 The broal ruff round the throat and chin of the Canadian lyux (Felis cunadensis) is much longer in the male than in the female; but whether it serves as a defence I do not know. Male seals are mell known to fight desperately together, and the males of certain kinds (Oturic jubuta) ${ }^{43}$ have great manes, whilst the females haro small ones or none. The male baboon of the Cape of Good Hope (C'ynocephalus porcarius) has a much longer mane and larger canine teeth than the female; and the mane probably serves as a protection, for, on asking the keepers in the Zoological Gardens, without giving them any clue to my object, whether any of the monkeys especially attacked each other by the nape of the neck, I was answered that this was not the case, except with the abore baboon. In the Hamadryas baboon, Ehrenberg compares the mane of the adult male to that of it young lion, whilst in the young of both sexes and in the female the mane is almost absent.

It appeared to me probable that the immense woolly mane of the male American bison, which reaches almost to the ground, and is much more dereloped in the males than in the females, served as a protection to them in their terrible battles; but an experienced liunter told Judge Caton that he had never observerl anything which favoured this belief. The stallion has a thicker and fuller mane than the mare; and I have made particulitr inquiries of two great trainers and breeders, who have had charge of many entire horses, and am assured that they "invariably

41 'Atti della Soc. Italiana di Sc. Nat.' 1873 , vol. $x$. fasc. iv.

42 'The Times,' Nov. 10th, 1857.

In regard to the Canadal lynx, see Audubon and Bachman, "Quadrupeds of N. America,' 18.th, p. 139.
43 Dr. Murie, on Otaria, 'Proc. Zoolog. Soc.' 1869, p. 109. Mr.J. A. Allen, in the paper above quotw. (p. 75), doubts whether the har. which is longer on the neck in the male than in the female, deserves $t:$ be called a mane. 
"endeavour to seize one another by the neck." It does not, however, follow from the foregoing statements, that when the hair on the neck serves as a defence, that it was originally developed for this purpose, though this is probable in some cases, as in that of the lion. I am informed by Mr. McNeill that the long hairs on the throat of the stag (Cervus elcephus) serve as a great protection to him when hunted, for the dogs generally endeavour to seize him by the throat; but it is not probable that these hairs were specially developed for this purpose; otherwise the young and the females would have been equally protected.

Choice in Pairing by either Sex of Quadrupeds.-Before describing in the next chapter, the differences between the sexes in voice, odours emitted, and ornaments, it will be convenient hero to consider whether the sexes exert any choice in their unions. Does the female prefer any particular male, either before or after the males may have fought together for supremacy; or does the male, when not a polygamist, select any particular female? The general impression amongst breeders seems to br that the male accepts any female; and this owing to his eagerness, is, in most cases, probably the truth. Whether the female as a general rule indifferently accepts any male is much morc doubtful. In the fourteenth chapter, on Birds, a considerable body of direct and indirect evidence was adranced, shewing that the female selects her partner; and it would be a strange anomaly if female quadrupeds, which stand higher in the scale and have higher mental powers, did not generally, or at least often, exert some choice. The female could in most cases escape, if wooed by a male that did not please or excite her; and when pursued by several males, as commonly occurs, she would often have the opportunity, whilst they were fighting together, of escaping with some one male, or at least of temporarily pairing with him. This latter contingency has often been obscrved in Scotland with female red-deer, as I am informed by Sir Philif Figerton and others."4

It is scarcely possible that much should be known about female quadrupeds in a state of nature making any choice in their marriage unions. The following curious details on the zourtship of one of the eared seals (Callorhinus ursinus) are

44 Mr. Boner, in his excellent escription of the habits of the redleer in Germany ('Forest Creatures,' 1861, p. 81 ) savs, "while the stag "is defending his rights against one "intruder, another inyades the "sanctuary of his harem, and car"ries off trophy after trophy." Ex. actly the same thing uccurs with seals, see Mr. J. A. Allen, ibid. $p$ 100. 
given ${ }^{45}$ on the authority of Capt. Bryant, who had ample opportunities for observation. He says, "Many of the females "on their arrival at the island where they breed appear desirous " of returning to some particular male, and frequently climb the "outlying rocks to overlook the rookeries, calling out and " listening as if for a familiar roice. Then changing to another "place they do the same again .... As soon as a female reaches "the shore, the nearest male goes down to meet her, making "meanwhile a noise like the clucking of a hen to her chickens.

"He bows to her and coaxes her until he gets between her and " the water so that she cannot escape him. Then his manner. "changes, and with a harsh growl he drives her to a place in " his harem. This continues until the lower row of harems is "nearly full. Then the males higher up select the time when " their more fortunate neiglubours are off their guard to steal "their wives. This they do by taking them in their mouths. "and lifting them orer the heads of the other fomales, and " carefully placing them in their own harem, carrying them as " cats do their kittens. Those still higher up pursne the same "method until the wholo space is occupied. Frequently a "strugchle ensues between two males for the possession of the "same female, and both seizing her at once pull her in two or " terribly lacerate her with their teeth. When the space is all "filled, the old male walks around complacently reviowing his "family, scolding those who crowd or disturb the others, aud " fiercely driving off all intruders. This surveillance always "keeps him actively occupied."

As so little is known about the courtship of animals in a state of nature, I have endeavoured to discover how far our domesticated quadrupeds evince any choice in their unions. Dogs offer the best opportunity for observation, as they are carefully attended to and well understond. Many breeders have expressed a strong opinion on this head. Thus, Mr. Mayhew remarks, "The females are able to bestow their affections; and tender "recollections are as potent over them as they are known to be "in other cases, where higher animals are concerned. Bitches "are not always prudent in their loves, but are ant to fling " themselves away on curs of low degree. If reared with a "companion of vulgar appearance, there often springs up " between the pair a devotion which no time can afterwards " subdue. The passion, for such it really is, becomes of a more "than romantic cndurance." Mr. Mayhew, who attended chiefly to the smaller breeds, is convinced that the females are ${ }^{4}$ Mr. J. A. Allen in 'Bull. Mus. Comp. Zoolog. of Cambridge, Unitel Btates,' vol. ii, No. 1, p. 99. 
strongly attracted by males of a large size. ${ }^{48}$ The well-known veterinary Blaine states ${ }^{47}$ that his own female pug became so attached to a spaniel, and a female setter to a cur, that in neither case would they pair with a dog of their own breed nntil several weeks had elapsed. Two sirniliar and trustworthy accounts have been given me in regard to a female retriever and a spaniel, both of which became enamoured with terrierdogs.

Mr. Cupples informs me that he can personally vouch for the accuracy of the following more remarkable case, in which a raluable and wonderfully-intelligent female terrier lored a retriever belonging to a neighbour to such a degree, that she had often to be dragged an'ay from him. After their permanent separation, although repeatedly shewing milk in her teats, she would never acknowledge the courtship of any other dog, and to the regret of her owner never bore puppies. Mr. Cupples also states, that in 1868, a female deerhound in his kennel thrice produced puppies, and on each occasion shewed a marked preference for one of the largest and handsomest, but not the most eager, of four deerhounds living with her, all in the prime of life. Mr. Cupples has observed that the female generally favours a dog whom she has associated with and knows; her shyness and timidity at first incline her against a strange dog. The male, on the contrary, seems rather inclined towards strange females. It appears to be rare when the male refuses any particular female, but Mr. Wright, of Ycldersley House, a great breeder of dogs, informs mo that he has known some instances; he cites the case of one of his own deerhounds, who would not take any notice of a particular female mastiff, so that another deerhound had to be employed. It would be superfluous to gire, as I could, other instances, and I will only add that Mr. Barr, who has carefully bred many bloodhounds, states that in almost every instance particular individuals of opposite sexes shew a decided preference for each other. Finally, Mr. Cupples, after attending to this subject for another year, has written to me, "I have had " full confirmation of my former statement, that dogs in breeding " form decided preferences for each other, being often influenced "by size, bright colour, and individual characters, as well as by "the degree of their previous familiarity."

In regard to horses, Mr. Blenkiron, the greatest breeder of race-horses in the world, informs me that stallions are so frequently capricious in their choice, rejecting one mare and

\footnotetext{
4o 'Dogs: their Management,' by E. Nayhew, M.R.C.V.S., 2nd edit. i864, pp. 187-192.

17 Quoted by Alex. Walker ' $\mathrm{Oa}$ Intermarriage," 1838 , p. 279 ; see also p. 244.
} 
without any apparent cause taking to another, that various artificos hare to be habitually used. The famous Monarque, for instance, would never consciously look at the dam of Gladiateur, and a trick had to be practised. We can partly see the reason why valuable race-horse stallions. which are in such demand as to be exhausted, should be so particular in their choice. Mr. Blenkiron lias never known a mare reject a horse; but this has occurred in MIr. Wright's stable, so that the mare had to be cheated. Prosper Lucas ${ }^{48}$ quotes various statements from French authorities, and remarks, "On voit des étalons qui s'éprennent d'une " jument, et négligent toutes les autres." He gives, on the muthority of Baïlen, similar facts in regard to bulls; and MIr. H. Reeks assures me that a famous short-horn bull belonging te his father " invariably refused to be matched with a black cow." Hoffberg, in describing the domesticated reindeer" of Lapland sayss, "Fœminæ majores et fortiores mares præ cætcris admittunt, " ad eos confugiunt, a junioribus agitatæ, qui hos in fugam " conjiciunt."19 A clergyman, who has bred many pigs, asserts that sows often reject one boar and immediately accept another.

From these facts there can be no doubt that, with most of onr domesticated quadrupeds, strong individual antipathies and preferences are frequently exhibited, and much more commonly by the female than by the male. This being the caso, it is improbable that the unions of quadrupeds in a state of nature should be left to mere chance. It is much more probable that the females are allured or excited by particular males, who possess certain characters in a higher degree than other males; but what these characters are, we can seldom or never discover with certainty.

\section{CHAPTER XVIII.}

\section{Secondary Sexdal Characters of Mlammalo-continued.}

Voice-Remarkable sexual peculiarities in seals-Oluur-Ferelopment of the hair-Colour of the hair and skin-Anomalous case of the female teing more ornamenterl than the male-Colour and ornaments due to sexual selection-Colour acquired for the sake of protection-Colour, though common to both sexes, often due to sexual selection-On the disappearance of spots and stripes in sult quadrupeds-On the colours and ornaments of the Quadrumana-Summary.

QUADRUPEDS use their voices for various purposes, as a signal of danger, as a call from one member of a troop to another, or from the mother to her lost offspring, or from the latter for protection

10 'Traité de l'Héréd. Nat.' tom. ii. 1850 , p. 296 .
19 'Amcnitates Aciol' rol. ir $1: 88$, p. 160 . 
to their mother; but such uses need not here be considered. We are concermed only with the difference between the voices of the sexes, for instance between that of the lion and lioness, or of the bull and cow. Almost all male animals use their voices much more during the rutting-season than at any other time; and some, as the girafie and porcupine, ${ }^{1}$ are said to be completely mute excepting at this season. As the throats (i.e. the larynx and thyroid bodies ${ }^{2}$ ) of stags periodically become enlarged at the beginning of the breeding-season, it might be thought that their powerful voices must be somehow of high importance to them; but this is very doubtful. From information given to me by two experienced observers, Mr. McNeill and Sir P. Egurton, it seems that young stags under three years old do not roar or bellow; and that the old ones begin bellowing at the commencement of the breeding-season, at first only occasionally and moderately, whilst they restlessly wander about in search of the temales. Their battles are prefaced by loud and prolonged bellowing, but during the actual conflict they are silent. Animals of all kinds which habitaally use their voices utter various noises under any strong emotion, as when enraged and proparing to fight; but this may merely be the result of nervous excitement, which leads to the spasmodic contraction of almost all the muscles of the borly, as when a man grinds his teeth and clenches his fists in rage or agony. No doubt stags challenge each other to mortal combat by bellowing; but those with the more powerful voices, unless at the same time the stronger, better-armed, and more courageous, would not gain any advantage over their rivals.

It is possible that the roaring of the lion may be of some service to him by striking terror into his adversary; for when enraged he likewise erects his mane and thus instinctircly tries to make himself appear as terrible as possible. But it can hardly be supposed that the bellowing of the stag, even if it be of service to him in this way, can have been important enough to have led to the periodical enlargement of the throat. Some writers suggest that the bellowing serves as a call to the female; but the experienced observers above quoted inform me that female deer do not search for the male, though the males search eagerly for the females, as indeed might be cxpected from what we know of the habits of other male quadrupeds. The voice of the female, on the other hnnd, quickly brings to her one or more stags, ${ }^{3}$ as is well known to the hunters who in wild countrier

\footnotetext{
'Owen, 'Anatomy of VerteBrates,' rol. iii. 1). 585 .

${ }^{2}$ lbid. p. 595.
}

3 See, for instance, Major W.
Ross King ('The Sportsman in
Canada' 1966, p. 53, 131) on the 
imitate her cry. If we could believe that the male had the jower to excite or allure the female by his voice, the periodical enlargement of his vocal organs would be intelligible on the principle of sexual selection, together with inhcritance limited to the same sex and season; but we have no evidence in favour of this view. As the case stands, the loud voice of the stag during the breeding-season does not seem to be of any special service to him, either during his courtship or battles, or in any other way. But may we not believe that the frequent use of the voice, under the strong excitement of love, jealousy, and rage, continued luring many generations, may at last have produced an inherited cffect on the vocal organs of the stag, as well as of other male animals? This appears to me, in our present state of knowledge, the most probable vien.

The voice of the adult male gorilla is tremendous, and he is furmished with a largngeal sack, as is the adult male orang." The gibbons rank among the noisiest of monkeys, and the Sumatra species (Iyllobates syndactylus) is also furnished with an air sack; but Hr. Blyth, who has had opportunities for observation, does not believe that the male is noisier than the female. IIence, these latter monkeys probably use their voices as a mutual call ; and this is certainly the case with some quadrupeds. for instance the beaver. ${ }^{\circ}$ Another gibbon, the H. agilis, is remarkable, from having the power of giving a complete and correct octare of musical notes, ${ }^{6}$ which we may reasonabiy sus . pect serves as a sexual charm; but I shall have to recur to this subject in the next chapter. The vocal organs of the American Mycetes curruyce are one-third larger in the male than in the female, and are wonderfully powerful. These monkeys in warm weather make the forests resound at morning and evening with their overwhelming voices. The males begin the dreadful concert, and often continue it during many hours, the females, sometimes joining in with their less powerful voices. An excellent observer, Rengger, ${ }^{7}$ could not perceive that they were excited to begin by any special cause; he thinks that, like many birds, they delight in their own music, and try to excel each other. Whether most of the foregoing monkeys have acquired their powerful voices in order to beat their rivals and charm the females-or whether the vocal organs have been strengthened

habits of the moose and wild reindeer.

- Owen, "Anatomy of Vertebrates.' vol. iii. p. 600 .

s Mr. Green, in 'Journal of Linn. Soc.' vol. x. 'Zoology, 1869, p. 362.
- C. L. Martin, 'General Introduction to the Nat. Hist. of Mamm Animals,' 1841, p. 431.

7 'Naturgeschichte der Säage thiere von Parnguay, 1830, s. 15, 21. 
and enlarged through the inherited effects of long-continued use without any particular good being thus gained-I will not preteud to say; but the former view, at least in the case of the Hylobates agitis, seems the most probable.

I may here mention two very curious sexual peculiarities necurring in seals, becanse they have been supposed by some writers to affect the roice. The nose of the male sca-elephant (Mucrorhinus proboscideus) becomes greatly elongated during the breeding-season, and can then be crected. In this state it is sometinus a foot in length. The female is not thus provided at any period of life. The male makes a wild, hoarse, gurgling noise, which is audible at a great distance and is beliered to be strengthened by the proboscis; the voice of the female being different. Lesson compares the erection of the proboscis, with the swelling of the wattles of male gallinaceous birds whilst courting the females. In another allied kind of seal, the bladdernose (Cystopliora cristata), the head is corered by a great hood or bladder. This is supported by the septum of the nose, which is produced far backwards and rises into an internal crest seren inches in height. The hood is clothed with short hair, and is muscular; it can be inflated until it more than equals the whole head in size! The males when rutting, fight furiously on the ice, and their roariug " is said to be sometimes so loud as to " be heard four miles off." When attacked they likewise roar or bellow; and whenever irritated the bladder is inflated and quivers. Some naturalists believe that the voice is thus strengthoned, but various other uses have been assigned to this extraordinary structure. Mr. R. Brown thinks that it serves as a protection against accidents of all kinds; but this is not probable, for, as I am assured by Mr. Lamont who killed 600 of these animals, the bood is rudimentary in the females, and it is not developed in the males during youth. ${ }^{8}$

Giduer.- Tith some animals, as with the notorious skunk of America, the overwhelming odour which they emit appears to serve exclusirely as a defence. With shrew-mice (Sorex) both rexes possess ahdominal scent-glands, and there can be little Inubt, from the rejection of their bodies by birds and beasts of prey, that the odour is protective; nevertheless, the glands become enlarged in the males during the breeding-season. In

${ }^{8}$ On the sea-elephant, see an article by Lesson, in 'Dict. Class. Hist. Nat.' tom. xiii. p. 418. For the Cystorihora or Stemmatepus, cor [1:. Dekay, 'Annals of Lyceum 12\%' Nat. Hist. New York,' rol. i.
1824 , p. 94. Pennant has also collected infurmation from the sealers on this animal. The fullest account is given by Mr. Brown, ins 'Proc. Zoolog. Soc.' 1868, p. 435. 
many other quadrupeds the glands aro of the same size in both seres, ${ }^{2}$ but their uses are not known. In other species the glands are confined to the males, or are more developed than in the females; and they almost al ways become more active during the rutting-season. At this period the glands on the sides of the face of the male elephant enlarge, and emit a secretion having a strong musky odour. The males, and rarely tho females, of many kinds of bats have glands and protrudable sacks situated in various parts; and it is belicred that these are odoriferous.

The rank efflurium of the male goat is well known, and that of certain male decr is wonderfully strong and persistent. On the banks of the Plata I perceived the air tainted with the odour of the male Cervus campestris, at half a mile to leeward of a herd; and a silk handkerchief, in which I carried home a skin, though often used and washed, retained, when first unfolded, traces of the odour for one year and seven months. This animal does not emit its strong odour until more than a year old, and if castrated whilst young nevor emits it. ${ }^{10}$ Besides the general odour, permeating the whole body of ccrtain rumirants (for instance, Bos moschatus) in the breeding-scason, many leer, antelopes, sheep, and goats, possess odoriferous glands in various situations, more especially on their faces. The so-called tear-sacks, or suborbital pits, come under this head. These glands secrete a semi-fluid fetid matter which is sometimes so copious as to stain the whole faco, as I have myself seen in an antelope. They are "usually larger in the male than in the "female, and their development is checked by castration." According to Desmarest they are altogether absent in the female of Antilope subgutturosa. Hence, there can be no doubt that they stand in close relation with the reproductive functions. They are also sometimes present, and sometimes absent, in nearly-allied forms. In the adult male musk-deer (Moschus. moschiferus), a naked space round the tail is bedewed with an

9 As with the castoreum of the veaver, see Mr. L H. Morgan's most interesting work, 'The American Benver,' 1868, p. 300. Pallas 'Spic. Zoolog.' fasc. viii. 1779, p. 23) has well discussed the odoriferous glands of mammals. Owen ('Anat. of Vertebrates,' vol. iii. p. 634) also gires an account of these glands, including those of the elephant, and (p. 763) those of shrewmice. On Inats, Mr. Dobson in 'Proc. Zoolog. Sicc.' 1873, p. 241.
10 Rengger, 'Naturgeschichte der Siugethiere von Paraguay,' 1830, s. 355 . This observer also gives some curious particulars in regard to the odour.

"Owen, 'Anatomy of Vertcbrates,' vol. iii. p. 632. See, also Dr. Murie's observations on these glands in the "Proc. Zoolog. Soc.' 1870, p. 340. Desmarest, On the Antilope subgutturosa, 'Mamma'agie,' 1820, p. 455. 
odoriferous fluid, whilst in the adult female, and in the male until two years old, this space is corered with hair and is not odoriferous. The proper musk-sack of this deer is from its position necessarily confined to the male, and forms an additional scent-organ. It is a singular fact that the matter secreted by this latter gland does not, according to Pallas, change in consistence, or increase in quantity, during the rutting-season; nevertheless this naturalist admits that its prescnce is in somo way connected with the act of reproduction. Ho gives, however. only a conjectural and unsatisfactory explanation of its use."?

In most cases, when only the male emits a strong odcar during the breeding-season, it probably serves to excite or allure. the female. We must not judge on this head by our own taste, for it is well known that rats are enticed ly certain essential oils, and cats by valerian, substances far from agreeable to us; and that dogs, thoirgl. they will not eat carrion, sniff and roll on it. From the reasons given when discussing the roice of the stag, we may reject the idea that the odour serres to bring the females from a distance to the males. Active and long-continued use cannot here have come into play, as in the case of the vocal organs. The odour emitted must be of considerable importance to the male, inasmuch as large and complex glands, furnished with muscles for everting the sack, and for closing or opening the orifice, have in some cases been developed. The development of these organs is intelligible through sexual selection, if the most odoriferous males are the most successful in winning the females, and in leaving offspring to inherit their graduallyperfected glauds and odours.

Development of the IIair.- We have seen that male quadrupeds often have the hair on their necks and shoulders much more developed than the females; and many additional instances could be given. This sometimes serves as a defence to the male during his battles; but whether the hair in most cases has been specially developed for this purpose, is vory doubtful. We may feel almost certain that this is not the case, when only a thin and narrow crest runs along the back; for a crest of this kini would afford scarcely any protection, and the ridge of the lanck is not a place likely to be injured; nevertheless such crests are sometimes confined to the males, or are much more developed in them than in the females. Two antelopes, the Trayelarkess scriptus ${ }^{13}$ (see fig. 70, p. 54.4) and Portax picta, may be given as

12 Pallas, 'Spicilegia Zoolog,' fisc. xiii. 1799, p. 24 ; Desmoulins,' Dict. Class, d'Hist. Na $\div$ ' tom. iii. p. 586.
13 Dr. Gray, 'Gleanings from the Menagerie at liacwsley,' $n]$. :8. 
instances. When stags, and the males of the wild goat, are enraged or terrified, these crests stand erect; $;^{14}$ but it cannot be supposed that they have becn developed morely for the sale of esciting fear in their enemies. One of the abore-nnmed antelopes, the Portax pictu, has a large well-defined brush of black hair on the throat, and this is much larger in the malo than in the female. In the Ammotragies trageliplius of North Africa, a member of the sheep-family, the fore-legs are almost concealed hy an extraordinary growth of hair, which depends from the neck and upper halves of the legs; but Mr. Bartlett docs not leclieve that this mantle is of the least use to the male, in whom it is much more developed than in the female.

Male quadrupeds of many kinds differ from the females in having more hair, or hair of a different character, on certain yarts of their faces. Thus the bull alone has curled hair on the forehead. ${ }^{15}$ In three closely-allied sub-genera of the goat family, only the males possess beards, sometimes of large size; in two other sub-gencra both sexes have a beard, but it disappears in some of the domestic breeds of the common goat; and neither sex of the Hemitragus has a beard. In the ibex the benrd is not developed during the summer, and it is so small at other times that it may be called rudimentary. ${ }^{16}$ With some monkeys the heard is confined to the male, as in the orang; or is much larger in the male than in the female, as in the Mycetes caraya and Pitheciu satanus (fig. 68). So it is with the whiskers of some species of Macacis, ${ }^{17}$ and, as we have seen, with the manes of some species of bahoons. But with most kinds of monkeys the various tufts of hair about the face and head are alike in both sexes.

The males of various members of the ox family (Bovidæ), and of certain antelopes, are furnished with a dewlap, or great fold of skin on the neck, which is much less developed in the female.

Now, what must we conclude with respect to such sexun! differences as these? No one will pretend that the beards of certain male goats, or the dewlap of the bull, or the crests of hair along the backs of certain male antelopes, are of any use to them in their ordinary habits. It is possible that the immense beard of the male Pithecia, and the large beard of the male orang, may protect their throats when fighting; for the keepers in the Zoological. Gardens inform me that many

14 Judge Caton on the Wapiti, p. 236

- Transact. Ottawa Acad. Nat. Sciences,' 1868, rp. 36, 40; Blyth, 'Land and Water,' on Capra ægxgrus, 1867, p. 37.

is 'Hunter's Essays and Observatione,' edited by Owen, 1861, -2l. $\%$

16 See Dr. Grav's 'Cat. of Mam. malia in British Museum, part iii. 1852 , p. 144 .

17 Rengger, 'Säugethiere,' \&c. s. 14; Desmarest, 'Mlammalogie,' f. క6. 
monkeys attack each other by the throat; but it is not probable that the beard has been developed for a distinct purpose from that served by the whiskers, moustache, and other tufts of hair on the face; and no one will suppose that these are uscful as a protection. Must we attribute all these appendages of hair or skin to mere purposeless variability in the male? It cannot bo denied that this is possible; for in many domesticated quadrupeds, certain characters, apparently not derived through re.rersion from any wild parent-form, are confined to the males,

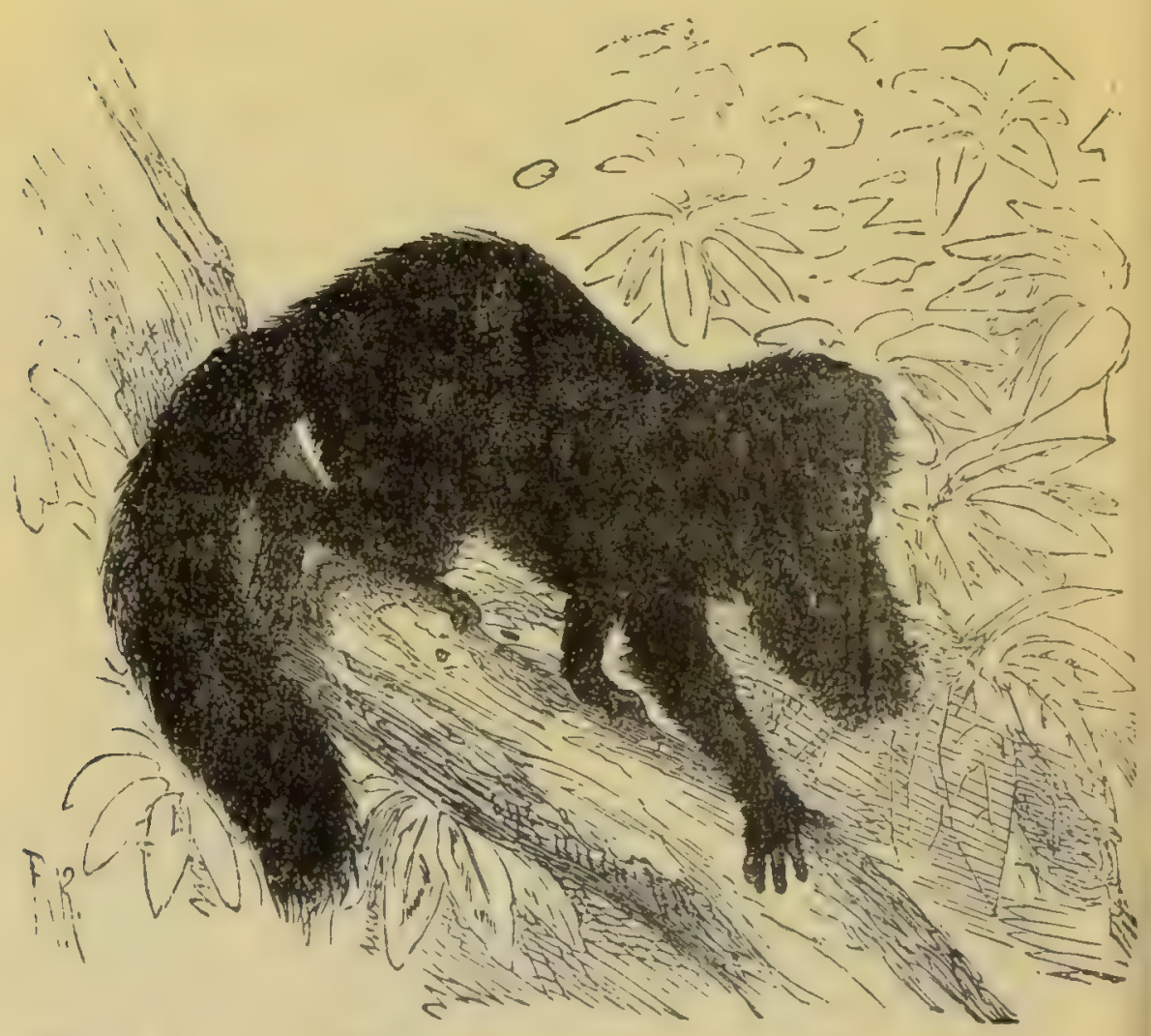

Fig 69.

Pit'iecis suttunas, male (From Brebm).

or are more developed in them than in the females-for instance, the hump on the male zebu-cattle of India, the tail of fat-tailed riums, the arehed outline of the forehead in the males of several hreerts of sheep, and, lastly, the mane, the long hairs on the hinil-legs, and the dewlap of the male of the Berbura goat. ${ }^{18}$ The mane, which occurs only in the rams of an African breed of

" Sce the chapters on these "Variation of Animals under Domesscrorsl animals in rol. i. of my tication;' also rol. ii. p. 73 ; also 
shecp, is a true secondary sexual character, for, as I hear from Mr. Winwood Reade, it is not developed if the animal ho castrated. Although wo ought to be extremely cautious, as shewn in my work on 'Variation under Domesticatiou.' is concluding that any character, even with animals kept ny semi-civilised people, has not been subjected to selection by man, and thus augmented, yet in the cases just specified this is improbable; more especially as the characters are confined to tho males, or are more strongly developed in them than in the females. If it were positively known that the above African ram is a descendant of the same prinitive stock as the other ireeds of sheep, and if the Berbura male-goat with his mane, llowlap, \&c., is descended from the same stock as other goats, then, assuming that selection has not been applied to these characters, they must be due to simple variability, together with sexually-limited inheritance.

Hence it appears reasonable to extend this same view to all analogous cases with animals in a state of nature. Nevertheless I cannot persuade myself that it generally holds good, as in the case of the extraordinary development of hair on the throat and fore-legs of the male Ammotragus, or in that of the immense beard of the male Pithecia. Such study as I have been able to give to nature makes me believe that parts or organs which are highly developed, were acquired at some period for a special purpose. With those antelopes in which the adult male is more strongly-coloured than the female, and with those monkeys ir which the hair on the face is elegantly arranged and colourert in a diversified manner, it seems probable that the crests and tufts of hair were gained as ornaments; and this I know is the opinion of some naturalists. If this be correct, there can lhe little doubt that they were gained or at least modified through sexual selection; but how far the same view may be extended to other mammals is doubtful.

Colour of the Hair and of the Naked Skin.-I will first givo briefly all the cases known to me, of male quadrupeds differing in colour from the females. With Marsupials, as I am informed by Mr. Gould, the sexes rarely differ in this respect; but the great red kangaroo offers a striking exception, "delicate blue "being the prevailing tint in those parts of the fomale, which " in the male are red." In the Didelphis opossum of Caycnze

chap. Ix. on the practice of selection by semi-civilised people. For the Berbura goat, see Ir. Gray, 'c'ata- logue,' ibid. p. 157.

${ }_{19}$ Osphranter rufus, Gould, 'Mam. mals of Australia,' 1863, rol. is 
the female is said to be a little more red than the male. Of the Rodents Dr. Gray remarks: "African squirrels, especially thoso "found in the tropical regions, have the fur much brighter "and more vivid at some seasons of the year than at others, $"$ and the fur of the male is generally brighter than that of "the fumale." zo Dr. Gray informs me that he specified the Ifrican squirrels, because, from their unusually bright colours, they best exhibit this difference. The female of the Mus minutu. af Russia is of a paler and dirtier tint than the male. In a large number of bats the fur of the male is lighter than in the female. ${ }^{21}$ Mr. Dobson also remarks, with respect to these animals: "Dif"ferences, depending partly or entirely on the possession by the " male of fur of a much more brilliant hue, or distinguished by " different markings or by the greater length of certain portions, " are met only, to any appreciable extent, in the frugivorous bats "in which the sense of sight is well developed." This last remark deserves attention, as bearing on the question whether lright colours are serviceable to male animals from being ornamental. In one genus of sloths, it is now estahlished, as Dr. Gray states, "that the males are ornamented differently from the "females-that is to say, that they have a patch of soft short " hair between the shoulders, which is gencrally of a more or less " orange colour, and in one species pure white. The females on "the contrary, are destitute of this mark."

The terrestrial Carnivora and Insectivora rarcly exhibit sexual differences of any kind, including colour. The occlot (Felis purdalis), however, is exceptional, for the colours of the female, compared with those of the male, are "moins apparentes, le " fauve étant plus terne, le blanc moins pur, les raies ayant "moins de largeur et les taches moins de diamètre." ${ }_{22}$ The sexes of the allied Felis mitis also differ, but in a less degree: the general hues of the female being rather paler than in the male, with the spots less black. The marine Carnivora or seals, on the other hand, sometimes differ considerably in colour, and they present, as wo have already seen, otber remarkable sexual differences. Thus the male of the Otaria nigrescens of the southern hemisphere is of a rich brown shade above; whilst the

On the Didelphis, Desmarest, 'Mammalogie,' p. 256.

20 'Annals and Mag. of Nat. Hist.' Nov. 1867, p. 325. On the Mus minutus, Desmarest, 'Mammalogie,' p. 304 .

21 J. A. Allen, in 'Bulletin of Mus. Comp. Zoolog. of Cambridge,
United States,' 1869, p. 207. MDobson on sexual characters in the Chiroptera, "Proc. Zoolog. Soc." 1873, p. 241. Dr. Gray on Sloths, ibid. 1871, p. 436.

${ }^{22}$ Desmarest, 'Mammalogie,' 1820 , p. 220. On Felis mitis, Kengger, 
fewale, who accuires her adult tiuts earlier in life than the male, is dark-grey above, the young of both sexes being of a deef chocolate colour. The male of the northern Phoru groenlandicu is tawny grey, with a curious saddle-shaped dark mark on the back; the female is much smaller, and has a very different appearance, being "dull white or yellowish straw-colour, with a " tawny lue on the back;" the young at first are pure white. and ean "hardly be distinguished among the icy hummocks and "snow, their colour thus anting as a protection." "2s

With Ruminants sexual differences of colour occur more commonly than in any other order. A difference of this kind is general in the Strepsicerene antelopes; thus the male nilghau (Portax picta) is bluish-grey and much darker than the female, with the square white patch on the throat, the white marks on the fetlocks, and the black spots on the ears all much more distinct. We have seen that in this species the crests and tufts of hair are likewise more developed in the male than in the hornless female. I am informed by $\mathrm{Mr}$. Blyth that the male, without shedding his hair, periodically becomes darker during the breeding-season. Young males cannot be distinguished from roung fomales until about twelve months old; and if the male is emasculatud before this period, he never, according to the same authority; changes colour. The importance of this latter fact, as evidence that the colouring of the Portax is of sexual origin becomes obvious, when we hear ${ }^{24}$ that neither the red summercoat nor the blue winter-coat of the Virginian deer is at all affected by omasculation. With most or all of the highly-ornamented species of Tragelaphus the males are darker than tho hornless females, and their crests of hair are more fully developed. In the male of that magnificent antelope, the Derbyan eland, the body is redder, the whole neck much blacker, and the white band which separates these colours, broader, than in the female. In the Cape eland also, the male is slightly darker than the fomale. ${ }^{25}$

In the Indian black-buck ( $A$. bezcortica), which belongs to another tribe of antelopes, the male is very dark, almost black; whilst the hornless female is fawn-coloured. We meet in this

23 Dr. Murie on the Otaria, 'Proc. Zool. Soc.' 1869, p. 108. Mr. R. Brown, on the P. grocnlandica, ibid. 1868 , p. 417 . See also on the colours of seals, Desmarest, ibid. p. $243,2+9$.

24 Judge Caton, in 'Trans. Ottawa Acar. of Nat. Sciences,' 1868, p. 4.

8: Dr. Gray, 'Cat, of Mrmm. in Brit. Mus.' part iii. 1852 , pp. 134
142 ; also Dr. Gray, 'Gleanings from the Menagerie of Knowsley, in which there is a splendid drawing of the Oreas derbianus: see the text on Tragelaphus. For the Cape eiand (Oreas canna), see Andrew Smith, 'Zoology of S. Africa,' pl. 41 and 42 . There are also many of these antelopes in the Zoological Garueas. 
apecies, as Mr. Blyth informs me, with an exactly similar series of facts, as in the Portax picta, namely, in the malo periodically changing colour during the breeding-season, in the effects of masculation on this change, and in the young of bcth sexes heing indistinguishable from each other. In the Antilope nigev the male is black, the female, as well as the young of both sexes, being lrown; in $A$. sing-sing the male is much brighter coloured than the hornless female, and his chest and belly are Wacker; in the male $A$. caama, the marks aud lines which occur on various parts of the body are black, instead of brown as in the female; in the brindled gnu ( $A$. gorgon) "the colours of the " male are nearly the same as those of the female, only deeper" " and of a brighter hue." 26 Other analogous cases could be added.

The Banteng bull (Bos sondaicus) of the Malayan Archipelago is almost black, with white legs and buttocks; the corv is of a bright dun, as are the young males until about the age of three years, when they rapidly change colour. The emasculated bull reverts to the colour of the female. The female Kemas goat is paler, and both it and the female Carra agagrus are said to be more uniformly tinted than their males. Icer rarely present any sexual differences in colour. Judge Caton, however, informs me that in the males of the wapiti deer (C'ervus canadensis) the neck, belly, and legs are much darker than in the female; but during the winter the darker tints gradually fade away and disappear. I may here mention that Judge Caton has in his park three races of the Virginian deer, which differ slightly in colour, but the differences are almost exclusively confined to the blue winter or breeding coat; so that this case may be compared with those given in a previous chapter of closely-allicd or representative species of birds, which differ from each other only in their breeding plumage. ${ }^{27}$ The females of Cervus paludosus of S. America, as well as the young of both sexes, do not possess the black stripes on the nose and the blackish-brown line on the breast, which are characteristic of the adult males. ${ }^{28}$ Lastly, as I am informed by Mr. Blyth, the

26 On the Ant. niger, see 'Proc. Zool. Soc.' 1850 , p. 133 . With respect to an allied species, in which there is an equal sexual difference in colour, see Sir S. Baker, 'The Albert Nyanza,' 1866, vol. ii. p. 327. For the A. sing-sing, Gray, Cat. B. Mus,' p. 100, Desmarest, Mammalogie,' p. 468 , on the $A$. nama. Andıew Smith, 'Zoology of S. Af: "'s, on the Gou.
27 "Ottawa Academy of Sciences," May, 21, 1868, pp. 3, 5 .

${ }_{28} \mathrm{~S}$. Muller, on the Banteng, 'Zoog. Indischen Archipel.' 18391844, tab. 35 ; see also Rafles, as quoted by Mr. Blyth, in 'Land and Water,' 1867, p. 476. On goats, Dr. Gray, 'Cat. Brit. Mus。' p. 146 ; Desmarest, 'Mammalogie,' p. 482. On the Cervus paludosus, Rengger. ibid. $8,345$. 
mature male of the beautifully coloured and spotted axis deer is considerably darker than the female; and this hue the castrated male never acquires.

The last Order which we need consider is that of the Primates. The male of the Lemur macuco is generally coal-black, whilst the female is brown. ${ }^{29}$ Of the Quadrumana of the New World, the females and young of Mycetes caraya are greyish-yellow and like each other; in the second year the young male becomes reddishlnown; in the third, black, excepting the stomach, which, however, becomes quite black in the fourth or tifth year. There is ilso a strongly-marked difference in colour between the sexes of Mycetes seniculus and Cebus capucinus; the young of the former, and I believe of the latter species, resembling the females. With Pithecia leucocephala the young likewise resemble the fomales, which are brownish-black above and light rusty-red benenth, the adult males being black. The ruff of hair round the face of Ateles marginatus is tinted yellow in the male and white in the female. Turning to the Old World, the males of Hylokites hoolock are always black, with the exception of a white band over the brows; the females vary from whity-brown to a dark tint mixed with black, but are never wholly black. ${ }^{30}$ In the beautiful Cercopithecus diana, the head of the adult male is of an intense black, whilst that of the female is dark grey; in the former the fur between the thighs is of an elegant fawncolour, in the latter it is paler. In the beautiful and curious moustache monkey (Cercopithecus cephus) the only difference between the sexes is that the tail of the male is chesnut and that of the female grey; but Mr. Bartlett informs me that all the liues becomes more pronounced in the male when adult, whilst in the female they remain as they were during youth. According to the coloured figures given by Solomon Müller, tho male of Seminopithecus chrysomelas is nearly black, the female being pale brown. In the Cercopithecus cynosurus and griseoviridis one part of the body, which is confined to the male sex, is of the most brilliant blue or green, and contrasts strikingly with the naked skin on the hinder part of the body, which is vivid red.

Lastly, in the baboon family, the adult male of Cynocepluculus hamadryus differs from the female not only by his immense

29 Sclater, 'Proc. Zcol. Soc.' 1866 , p. 1. The same fact has also been iully ascertained by MM. Pollen and van Dam. See, also, Dr. Gray in 'Annals and Mag. of Nat. Ilist.' Miay 1871 , p. 340 .

*o On Mrcetes, Keugger, ibid. s.
14 ; and Brehm, 'Illustrirtes 'Thicrleben,' B. i. s. 96, 107. Ou Atules Desmarest, 'Mammalogic', p. 75. On Hylobates, Bly'th, 'Land and Water,' 1867, p. 135. Ou the Semnopithecus, S. Muller, 'Zocg. Indischen Archipel.' tab. x. 
mane, but slightly in the colour of the hair and of the naked callosities. In the drill (C. leucophaus) the females and young are much paler-coloured, with less green, than the adult males. No other member in the whole class of mammals is coloured in so extraordinary a manner as the adult male mandrill ( $U_{\%}$ mormon). The face at this age becomes of a fine blue, with the ridge and tip of the nose of the most brilliant red. According to some authors, the face is also marked with whitish stripes, and

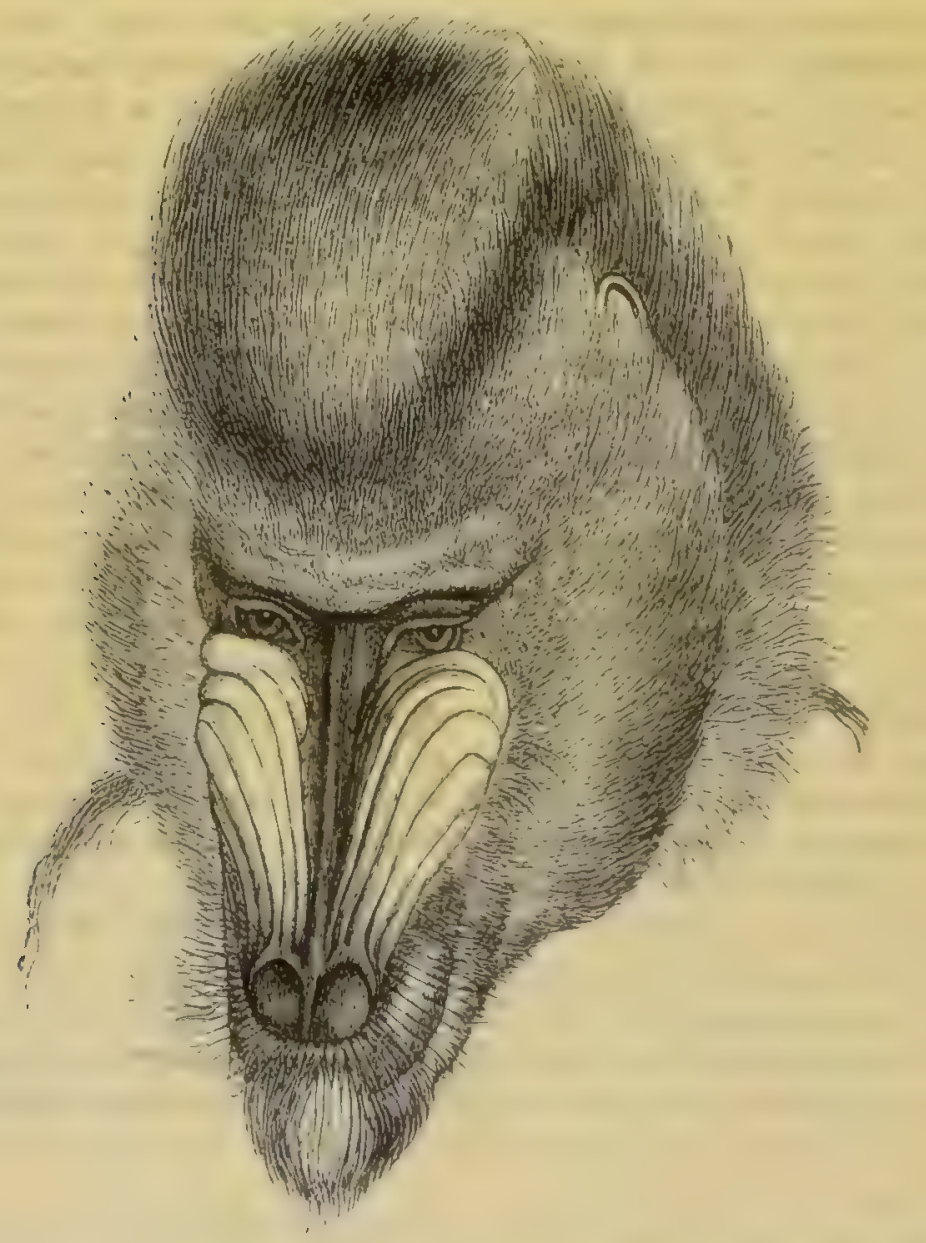

Fig. 69. Hearl of male Mandrill (from Gervais, 'Irist. Nat. des Mfammiferes').

is shaded in parts with black, but the colours appear to be variable. On the forehead there is a crest of hair, and on the chin a yellow beard. "Toutes les parties superieures de leurs "cuisses et le grand espace nu de leurs fesses sont également "colorés di rouge le plus vif, avec un mélange de bleu qui ne 
"manque réellement pas d'élégance." Wha the animal is excited all the uaked parts become much more rividly tinted. Several authors have used the strongest expressions in describing these resplendent colours, which they compare with those of the most brilliant birds. Another remarkable pecu! iarity is that when the great canine teeth are fully developed, unmense protuberances of bone are formed on each cheek, which are deeply furrowed longitudinally, and the naked skin over them is brilliantly-coloured, as just described. (Fig. 69.) In the adult females and in the young of both sexes these protuberances are scarcely perceptible; and the naked parts are much less bright coloured, the face being almost black, tinged with blue. In the adult female, however, the nose at certain regular intervals of time becomes tinted with red.

In all the cases hitherto given the male is more strongly or brighter coloured than the female, and differs from the young of both sexes. But as with some few birds it is the female which is brighter coloured than the male, so with the Rhesus monkey (Hucacus ricisus) the female has a large surface of naked skin round the tail, of a brilliant carmine red, which, as I was: assured by the keepers in the Zoological Gardens, periodicall: becomes even yet more vivid, and her face also is pale red. Ou the other hand, in the adult male and in the young of both sexes, (as I saw in the Gardens) neither the naked skin at the posterior end of the body, nor the face, shew a trace of red. It appears, however, from some published accounts, that the male does occasionally, or during certain seasons, exhibit some traces of the red. Although he is thus less ornamented than the femalo, yet in the iarger size of his body, larger canine teeth, more developed whiskers, more prominent superciliary ridges, he follows the common rule of the male excelling the female.

I hare now given all the cases known to me of a difference in colour between the sexes of mammals. Some of these may be the result of variations confined to one sex and transmitted to the same sez, without any good being gained, and therefore without the aid of selection. We have instances of this with our domesticated animals, as in the males of certain cats being rusty-red, whilst the females are tortoise-shell coloured. Analogous cases occur in eature: Mr. Bartlett has scen many black varieties of the jaguar, leopard, vulpine phalanger, and wombat:

31 Gervais, 'Hist. Nat. des Mammiferes,' 1854, p. 103. Figures are given of the skull of the male. Also
Desmarest, 'Mammalogie,' p. 70. Geoffroy St.-Hilaire and F. Cuvier, 'Hist. Nat. des Mamm? 18:4, tom. i 
and he is certain that all, or nearly all these animals, were males in the other hind, with wolves, foxes, and apparently American squirrels, both sexcs are occasionally born black. Hence it is quite possible that with some mammals a difference in colour netween the sexes, especially when this is congenital, may simply bo the result, without the aid of selection, of the occurrence of nite or more variations, which from the first were sexually limited in their transmission. Nerertheless it is improbable that the diversified, vivid, and contrasted colours of certain quadrupeds, fir instance, of the above monkeys and antelopes can thus be nccounted for. We should bear in mind that these colours do 1.ot appear in the male at birth, but only at or near maturity; and that unlike ordinary variations, they are lost if the male be cmasculated. It is on the whole probable that the stronglymarked colours and other ornamental characters of male r luadrupeds are beneficial to them in their rivalry with other males, and have consequently been acquired through sexual selection. This view is strengthened by the differences in colour between the sexes occurring almost exclusively, as may be collected from the previous details, in those groups and subfroups of mammals, which present other anci strongly-marked secondary sexual characters; these being likewise due to sexual selection.

Quadrupeds manifostly take notice of colour. Sir S. Baker repeatedly observed that the African elephant and rhinoceros attacked white or grey horses with special fury. I have elsewhere shewn ${ }^{32}$ that half-wild horses apparently prefer to pair with those of the same colour, and that herds of iallow-deer of lifferent colours, though living together, hare long kept distinct. It is a more significant fact that a female zebra would not ndmit the addresses of a male ass until he was painted so as to resemble a zebra, and then, as John Hunter remarks, "she received him very readily. In this curious fact, we have instinct excited by mere colour, which had so strong an effect " ns to get the better of everything else. But the male did not require this, the female being an animal somewhat similar tc " himself, was sufficient to rouse him." 33

In an earlier chapter we bave secn that the mental powers o: : ho higher animals do not differ in kind, though greatly ir ingree, from the corresponding powers of man, especially of the lorver and barbarous races; and it would appear that even their paste for the beautiful is not widely different from that of tho

32 'The Vuriation of Animals and P'ants under Domestication,' 1868, ro. ii. pp. 102, 103.
33 ' Essays and Oöservations $l: y$ J. Hunter,' edited by Owen; 186 L rol. i. p. 194. 
Quadrumana. As the negro of Africa raises the flesh on his iace into parallul ridges "or cicatrices, high above the natural "surface, which unsightly deformities, aro considered great "personal attractions;" - as negroes and savages in many parts of the world paint their faces with red, blue, white, or black bars,-so the male mandrill of Africa appears to have acquired his deeply-furrored and gaudily-coloured face from having been thus rendered attractive to the female. No doubt it is to us a most grotesque notion that the posterior end of the hody should be coloured for the sake of ornament even more brilliantly than the face; but this is not more strange than that the tails of many birds should bo especially decorated.

With mammals we do not at present possess any evidence that the males take pains to display their charms before the female; and the elaborate manner in which this is performed liy male birds and other animals, is the strongest argument in favour of the belief that the females almire, or are excited by, the ornaments and colours displayed before them. There is, however, a striking parallelism between mammals and birds in all their secondary sexual characters, namely in their weapon: for fighting with rival males, in their ornamental appendages, and in their colours. In both classes, when the male differs from the female, the young of both sexes almost always resemble each other, and in a large majority of cases resemble the adult female. In both classes the male assumes the characters proper to his sex shortly before the age of reproduction; and if emasculated at an early period, loses them. In both classes the change of colour is sometimes seasonal, and the tints of the naked parts sometimes hecome more vivid during the act of courtship. In buth classes the male is almost always more vividly or strongly coloured than the female, and is ornamented with larger crests of hair or feathers, or other such appendages. In a few exceptional cases the fernale in both classes is mor: highly ornamented than the male. With many mammals, ani at least in the case of one bird, the male is more odoriferous: than the female. In both classes the voice of the malo is more powerful than that of the female. Considering this paralleliss: there can be little doukt that the same cause, whatever it ma: be, has acted on mammals and birds; and the result, as far aornamental characters are concerned, may be attributed, as i: appears to me, to the long-continued preference of the indi riduals of one sex for certain individuals of the opposite se: rombined with their success in leaving a larger number of offspring to inherit their superior attractions.

"4 Sir S Baker, 'The Nile Tributaries of Abyssinia,' 1867. 
Equal transmission of ornamental characters to both sejes.-With many birds, ornaments, which analogy leads us to believe were primarily acquired by the males, have been transmitted equally, or almost equally, to both sexes; and we may now cuquire how far this view applies to mammals. With a considerable number of species, especially of the smaller kinds, both sexes have been coloured, independently of sexual selection, for the sake of protection; but not, as far as I can judge, in so many cases, nor in so striking a manner, as in most of the lower classes. Audubon remarks that he often mistook the musk-rat, ${ }^{35}$ whilst sitting on the banks of a muddy stream, for a clod of earth, so complete was the resemblance. The hare on her form is a familiar instance of concealment through colour; yet this principle partly fails in a closely-allied species, the rabbit, for when rumning to its burrow, it is made conspicuous to the sportsman, and no doubt to all beasts of prey, by its upturned white tail. No one doubts that the quadrupeds inhabiting snowr-clad regions have bcen rendered white to protect them from their enemies, or to farour their stealing on their prey. In regions where snow never lies for long, a whit? coat would be injurious; consequently, species of this colour are extremely rare in the hotter parts of the world. It deserves notice that many quadrupeds inhabiting moderately cold regions, although they do not assume a white winter dress, become paler during this season; and this apparently is the direct result of the conditions to which they hare long been exposed. Pallas ${ }^{36}$ states that in Siberia a change of this nature occurs with the wolf, two species of Mustela, the domestic horse, the Equus hemionus, tho domestic corr, two species of antelopes, the musk-deer, the roe, elk, and reindeer. The roe, for instance, has a red summer and a greyishwhite winter coat; and the latter may perhaps serve as a protection to the animal whilst wandering through the leafless thickets, sprinkled with snow and hoar-frost. If the abovenamed animals were gradually to extend their range into regions perpetually covered with snow, their pale winter-coats would probably be rendered through natural selection, whiter and whiter, until they became as white as snow.

Mr. Reeks has given me a curious instanco of an animal profiting by being peculiarly coloured. He raised from fifty to sixty white and brown piebald rabbits in a large walled orchard; and he had at the same time sorne similarly coloured cats in his:

3s Fiber zibcthicus, Audubon and Bachman, "Tha Quadrupeds of N. America,' 1846, p. 109.

'Novre species Quadrupedum e
Girium nrdine,' $1773 . \mathrm{i}$. . What I have called the roe is the Capreolus sibiricus subecaudatus of Pallas. 
house. Such cats, as I have often noticed, are very conspicuous during day; but as they used to lie in watch during the dusk at the months of the burrows, the rabbits apparently did not distinguish them from their parti-coloured brethren. The result was that, within eighteen months, every one of these particoloured rabbits was destroyed; and there was evidence that this was effected by the cats. Colour seems to be advantageous to another animal, the skunk, in a manner of which we have harl many instances in other classes. No animal will voluntarily attack one of these creatures on account of the dreadful odour which it emits when irritated; but during the dusk it would not easily be recognised and might be attacked by a beast of prey. Hence it is, as Mr. Belt helieres, ${ }^{37}$ that the skunk is provided with a great white bushy tail, which serves as a conspicuous warning.

Although we must admit that many quadrupeds have received their present tints either as a protection, or as an aid in procuring prey, yet with a host of species, the colours are far too conspicuous and too singularly arranged to allow us to suppose that they serve for these purposes. We may take as an illustration certain antelopes; when we see the square white patch on the throat, the white marks on the fetlocks, and the round black spots on the cars, all more distinct in the male of the Portax picta. than in the female;-when we see that the colours are mor. rivid, that the narrow white lines on the flank and the broad white bar on the shoulder are more distinct in the male Oreas ierbyanus than in the female;- when we see a similar difference: between the sexes of the curiously-ornamented Tragelaphu. scriptus (fig. 70),- - we caunot believe that differences of this kinci are of any service to either sex in their daily habits of life. It seems a much more probable conclusion that the various marks. were first acquired by the males and their colours intensifiecl through sexual selection, and then partially transferred to the females. If this view be admitted, there can be little doubt that the equally singular colours and marks of many other antelopes. though common to both sexes, have been gained and transmitted in a like manner. Both sexes, for instance, of the koodx) (Strepsiceros kiulu) (fig. 64) have narrow white rertical lines on their hind flaniss, and an elegant angular white mark on their foreheads. Both sexes in the genus Damalis are very oddly coloured; in D. pygarga the back and neck are purplish-red. shading on the flanks into black; and these colour's are abruptly separated from the white belly and from a large white space or the buttocks; the head is still more oddly coloured, a large oblong white mask, narrowly-edged with black, covers the faco yr 'The Natri:?list in Nicaragua,' p. 249. 
up to the eyes (fig. 71); there are three white stripes on the forehead, and the ears are marked with white. The fawns of this species are of a uniform pale yellowish-brown. In Damalis albifroms the colouring of the head differs from that in the last species in a single white stripe replacing the three stripes, and

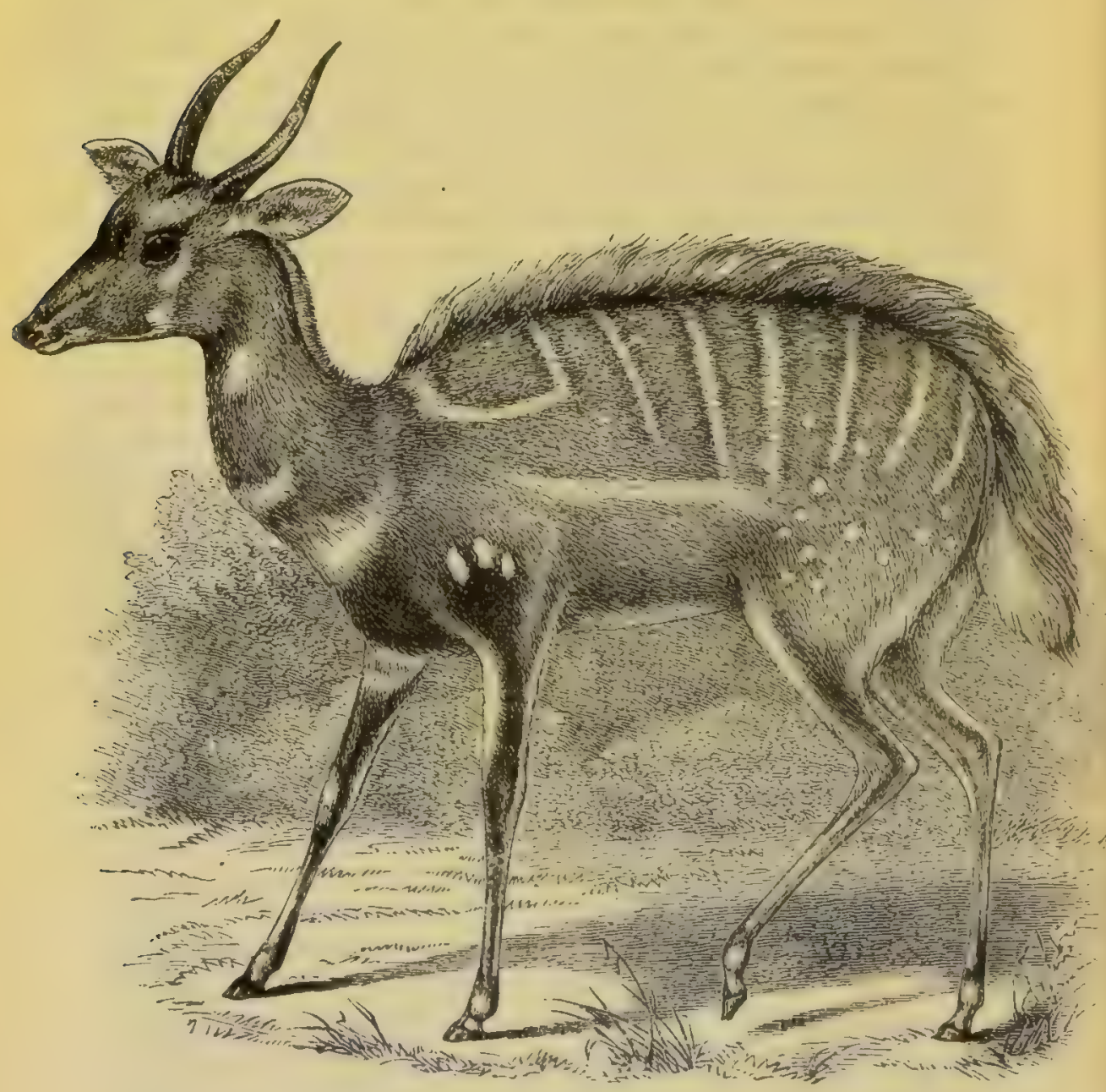

Hig. 70. . Tragelaphus scriptus, male (from the Knowsley Menagerie).

in the ears being almost wholly white. ${ }^{38}$ After having studied to the best of my ability the sexual differences of animals bxlonging to all classes, I cannot aroid the conclusion that the curiously-arranged colours of many antelopes, though common to both sexes, are the result of sexual selection primarily applicd to the male.

30 See the fine plates in A. Smith's 'Zoology of S. Africa,' and Dr. Gray's
'Glennings from the Menagcriu o: Knowsley.' 
The same conclusion may perhaps be extended to the tiger, one of the most beautiful animals in the world, the sexes of which cannot be distinguished by colour, even by the dealers in wild beasts. Mr. Wallace belicves ${ }^{39}$ that the striped coat of the tiger "so assimilates with the vertical stems of the bamboo, as to " assist greatiy in concealing him from his approaching prey." But this view does not appear to me satisfactory. We have some slight evidence that his beauty may be due to sexuci

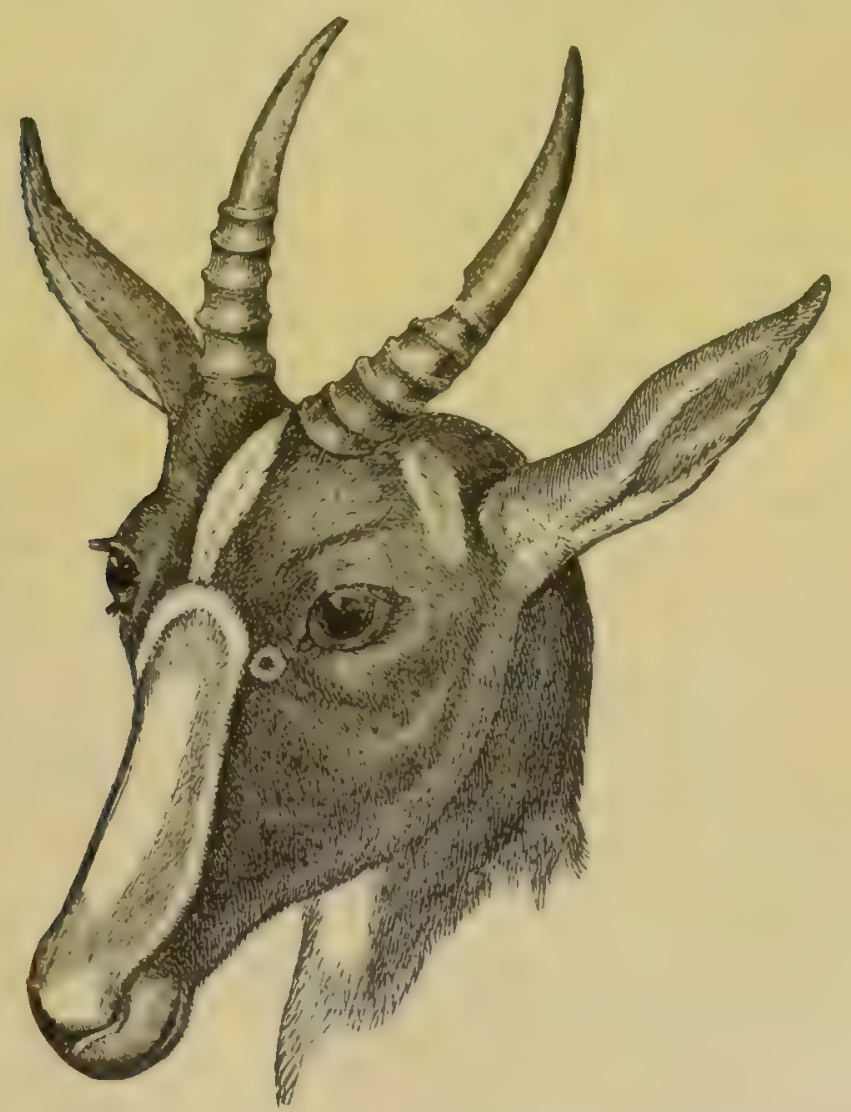

Fig. 71. Damalis pygarga, male (from the Knowsley Menagerie).

selection, for in two species of Felis the analogous marks and colours are rather brighter in the male than in the female. The zebra is conspicuously striped, and stripes cannot afford any protection on the open plains of Sonth A frica. Burchell ${ }^{40}$ in describing a herd says, "their sleek ribs glistened in the sun, and " the brightness and recrularity of their striped conts presenterl : "picture of extraordinary beanty, in which probably they ar" 39 'Westminster Review,' July 1 , 1867 , p. 5.

40 'Travels in South Africa,' 1824, vol. ii. p. 31\%. 
"not suryassed by any other quadruped." But as throughout the whole group of the Equidx the sexes are identical in colour, we have here no evidence of sexual selection. Nevertheless hos who attributes the white and dark vertical stripes on the flanks of various antelopes to this process, will probably extend the same view to the Royal Tiger and beautiful Zebra.

Wo have seen in a former chapter that when young animals lelonging to any class follow nearly the same habits of life as their parents, and yet are coloured in a different manner, it may be inferred that they have retained the colouring of some aucient and extinct progenitor. In the family of pigs, and in the tapirs, the young are marked with longitudinal striyes, ind thus differ from ali the existing adult species in these two groups. With many kinds of deer the young are marked with (legant white spots, of which their parents exhibit not a trace. A graduated series can be followed from the axis deer, both sexes of which at all ages and during all sensons are beautifully spotted (the male being rather more strongly coloured than the female), to species in which neither the old nor the young are spotted. I will specify some of the steps in this series. The Mantchurian deer (Cervus mantchuricus) is spotted during the whole year, but, as I bave seen in the Zoological Gardens, the spots are much plainer during the summer, when the general colour of the coat is lighter, than during the winter, when the general colour is darker and the horns are fully dereloped. In the hog-deer (IIylaphus porcinus) the spots are extremely conspicuous during the summer when the coat is reddish-brown, but quite disappear during the winter when the coat is brown. ${ }^{41}$ In both theso species the young are spotted. In the Virginian leer the young are likewise spotted, and about five per cent. of the adult animals living in Judge Caton's park, as I am informed by him, temporarily exhilit at the period when the red summer coat is being replaced by the bluish winter coat, a row of spots on each flank, which are always the same in number, though very variable in distinctness. From this condition there is but a very small step to the complete alsence of spots in the udults at all seasons; and, lastly, to their absence at all ages and seasons, as occurs with certain species. From the existence of this perfect series, and more especially from the fawns of so many species being spotted, we may conclude that the now living members of the deer family are the descendants of some ancient

11 Dr. Gray, 'Gleanings from the Menagerie of linowsley,' p. 64. Mr. Blyth, in speaking ("Land and Water, 1869, p. 42) of the hog- deer of Ceylon, says it is more brightly spotted with white than the common hog-deer, at the seasor when it ren: $\mathrm{w}$ s its Lorns. 
species which, like the axis deer, was spotted at all ages and seasons. A still more ancient progenitor probably somowhat resembled the IIyomoschus aquaticus-for this animal is spotted, and the hornless males have large exserted canine teeth, of which some few true deer still retain rudinents. Hyomoschus. also, offers one of those interesting cases of a form linking together two groups, for it is intermediate in certain osteological characters between the pachyderms and ruminants, which were formerly thought to be quite distinct. ${ }^{4}$

A clirious difficulty here arises. If we admit that coloured spots and stripes were first acquired as ornaments, how comes it that so many existing deer, the descendants of an aboriginally spotted animal, and all the species of pigs and tapirs, the descendants of an aboriginally striped animal, have lost in their adult state their former ornaments? I cannot atisfactorily answer this question. We may feol almost sure that the spots and stripes disappeared at or near maturity in the progenitors of our existing species, so that they were still retained by the young; and, owing to the law of inheritance at corresponding ages, were transmitted to the young of all succeeding generations. It may bave been a great advantage to the lion and puma, from the open nature of their usual haunts, to have lost their stripes, and to have been thus rendered less conspicuous to their prey; and if the successive variations, ly which this end was gained, occurred rather late in life, the young would have retained their stripes, as is now the case. As to deer, pigs, and tapirs, Fritz Müller has suggested to me that these animals, by the removal of their spots or stripes through natural selection, would hare been less casily seen by their enemies; and that they would have especially required this protection, as soon as the carnivora increased in size and number during the tertiary periods. This may be the true explanation, but it is rather strange that the young should not hare been thus protected, and still more so that the adults of some species should hrave retained their spots, cither partially or completely, during part of the year. We know that, when the domestic ass varies and becomes reddish-brown, grey, or black, the stripes on the shoulders and even on the spine frequently disappear, though we cannot explain the cause. Very few horses, except dun-coloured kinds, hare stripes on any part of their bodies, yet we have good reason to believe that the aboriginal horse was striped on the legs and spine, and probably on the shoulders. ${ }^{43}$ Hence the disappcarance of the spots and stripes in cur alult existing deer,

62 Falconer and Cautler, 'P'roc. Geclog. Soc.' 1843; and Falconer's 'Pa]. Memoirs,' rol. i. p. 196.
43 The lariation of Anımais and Plants under Domestication,' 1868 . vol. i. p. 61-64. 
pigs, and tapirs, may be due to a change in the general colour of their coats; but whether this change was effected through sexual or natural selection, or was due to the direct action of the conditions of life, or to some other unknown cause, it is impossille, to decide. An observation made by Mr. Sclater well illustrate: our ignorance of the laws which regulate the appearance and disappearance of stripes; the species of Asinus which inhaluit the Asiatic continent are destitute of stripes, not haring cren

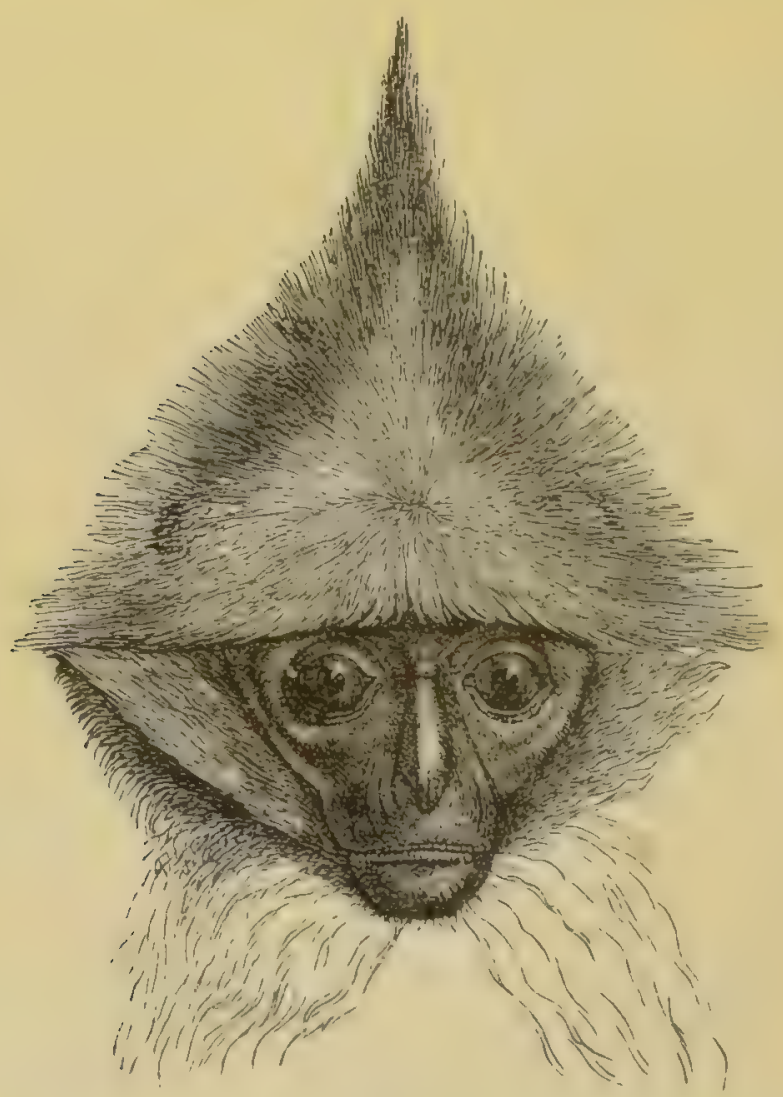

Fig. 72. Tead of Semnopithecus rubicundus. This and the following figures (frum? I'rof. (Gervais) are given to shew the odd arrangement and development of the hair on the head.

the cross shoulder-stripe, whilst those which inhabit Africa are conspicuously striped, with the partial exception of A. tarivimus, which has only the cross shoulder-stripe and generally some faint bars on the legs; and this species inhabits the almost intermediate region of Upper Egypt and Abyssinia. ${ }^{44}$

14 'Proc. 7ool. Soc.' 1862, p. 164. Landw. Bd. xliii. s. 222. See, also, Dr". Haltmann, 'Ann. d. 
Qundrumana.-Before we conclude, it will be well to add a few remarks on the ornaments of monkeys. In most of the species the sexes resemble each other in colour, but in some, as we have seen, the males differ from the females, especially in the "olour of the naked parts of the skin, in the derelopment of the beard, whiskers, and mane. Many species are coloured either in so extraordinary or so beautiful a manner, and are furnished with such curious and elegant crests of hair, that we can hardly avoil looking at these characters as having been gained for the sake of ormament. The accompanying figures (figs. 72 to 76 )

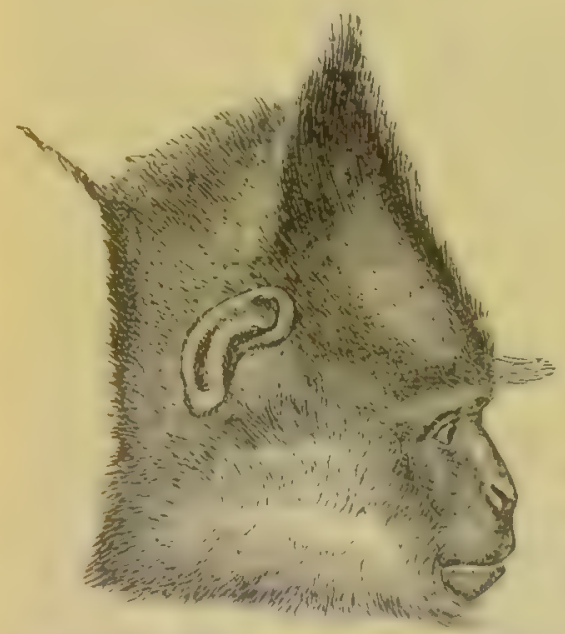

Mg. i3. Head of Semnopithecus comatus.

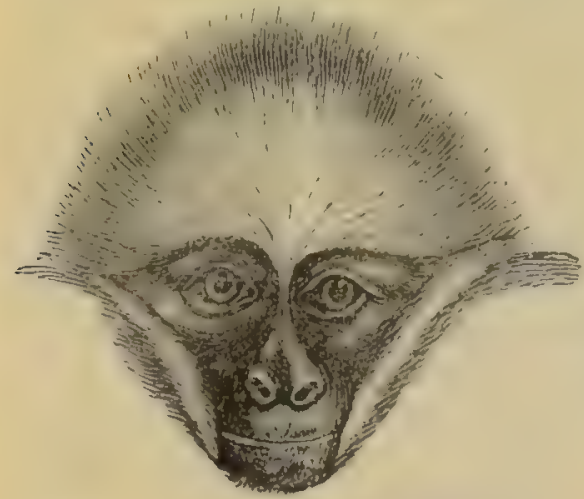

Fig. 75. Head of Ateles marainatus.

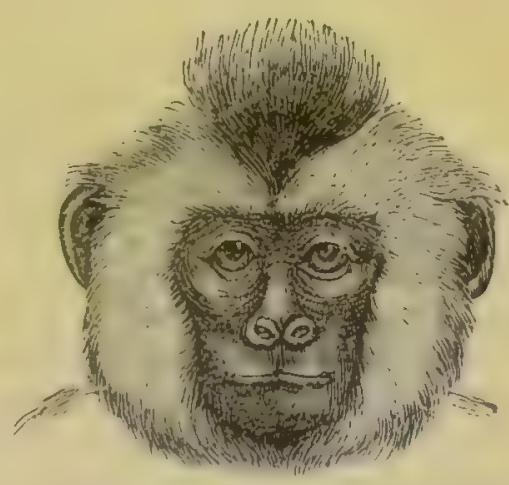

Fig. 74. Head of Cebus capucinus.

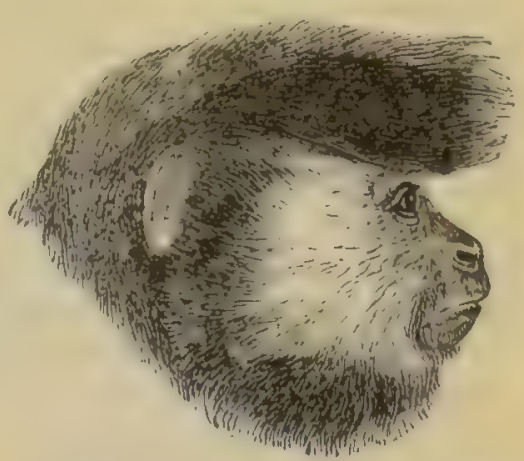

Fig. 76. Head of Cebus vellerosus.

serve to shew the arrangement of the hair on the face and head in several species. It is searcely conceivable that these crests of hair, and the strongly contrasted colonis of the fur and skin, can be the result of mere variability withont the aid of selection; 
and it is inconceivalile that they can he of use in any ordinary ray to these animals. If so, they have probahly bren gained through sexual selection, though transmitted equally, or almost equally, to both sexes. With mary of the Quadrumana, we have additional evidence of the action of sexual selection in the greater size and strength of the males, and in the greater development of their canine teeth, in comparison with the females.

A few instances will suffice of the strange manner in which both sexes of some species are coloured, and of the beauty of others. The face of the Cercopithecus jutcurista (fig. 77) is black, the whiskers and beard being white, with a defined, round, white spot on the nose, covered with short white hair, which gives to the animal an almost ludicrous aspect. The Semnopithecus frontatus likewise has a blackish face with a long black beard, and a large naked spot on the forehead of a bluish-white colour. The face of Macucus lusiotus is dirty flesh-coloured, with a defined red spot on each chcek. The appearance of Cercocebus "thiops is grotesque, with its black fuce, white whiskers and collar, chesnut head, and a large naked white spot over cach (yelid. In rery many species, the beard, whiskers, and crests of hail round the face are of a different colour from the rest of the head, and when different, are always of a lighter tint, ${ }^{45}$ being often pure white, sometimes bright yeliow, or reddish. The whole face of the South American Brachyurus calvus is of a "glowing scarlet hue;" but this colour does not appear until the animal is nearly mature. The naked skin of the face differs wonderfully in colour in the various species. It is often brown or flesh-colour, with parts perfectly white, and often as black as that of the most sooty negro. In the Brachyurus the scarlet tint is brighter than that of the most blushing Caucasian damsel. It is sometimes more distinctly orange than in any Mongolian, and in several species it is blue, passing into violet or grey. In all the species known to Mr. Bartlett, in which the adults of both sexes have strongly-coloured faces, the colours are dull or absent during early youth. This likewise holds good with the mandrill and Rhesus, in which the face and the posterior parts of the body are brilliantly coloured in one sex alone. In these latter cases we havo reason to believe that the colours were acquired through sexual selection; and we are naturally led to extend the samo view to the foregoing species, though both sexes when adult have their faces coloured in the same manner.

4s I nbserved this fact in the 7oological Gardens; and many cases may be seen in the coloured plates in Ceoffroy St.-Hilaire and F. Curier,
'Hist. Nat. des Mammiferes,' tom. i. 1824 .

46 Bates, "The Naturalist on the Amazons,' 1863 , rol. ii. p. 310. 
Chap. XVIII. Beauty of the Quadrumana.

Although many kinds of monkeys are far from beautiful according to our tuste, other species are universally admired for their elegant appearance and bright colours. The iemnopithecus nemerus, though peculiarly coloured, is described as extremely

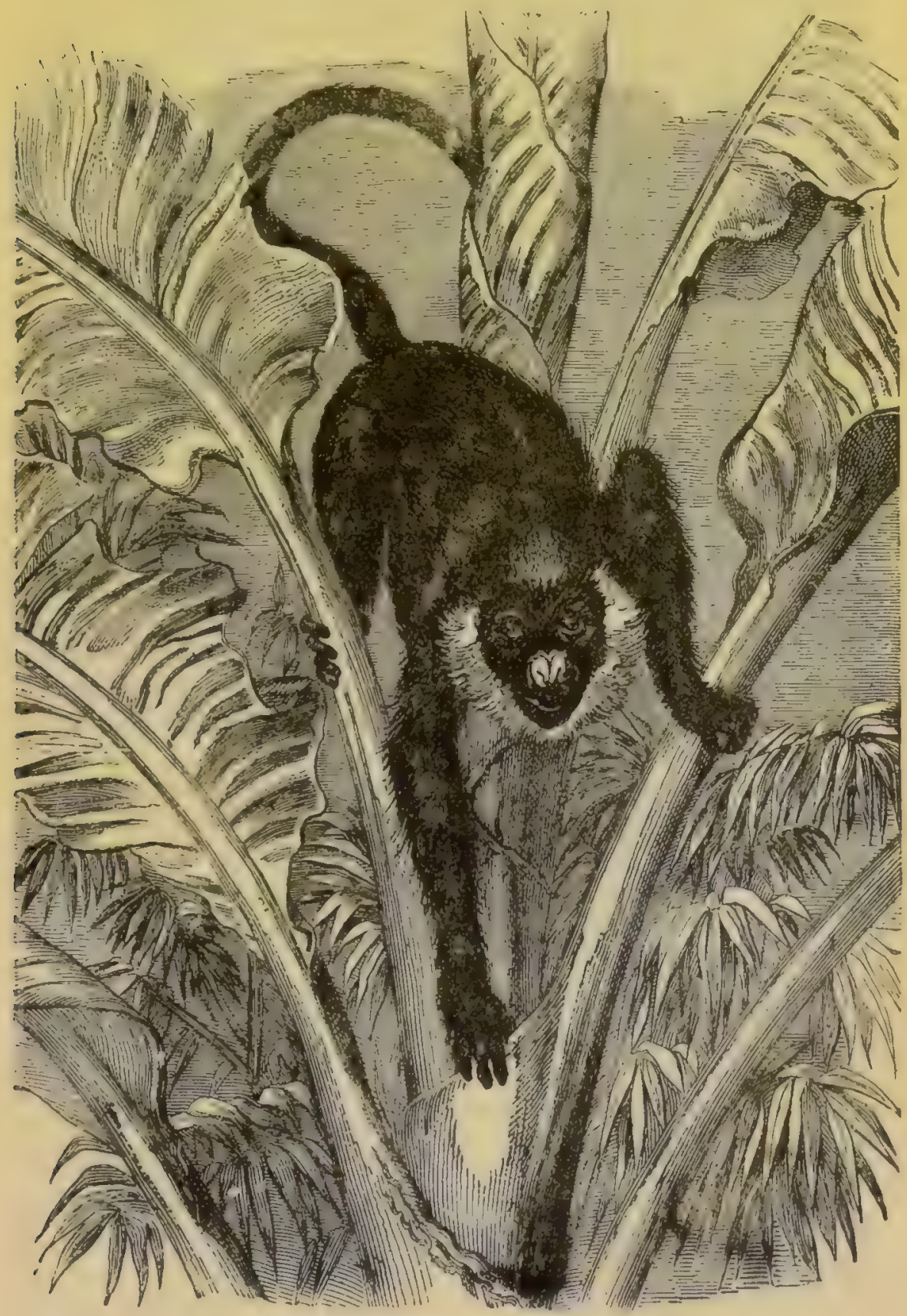

ตIg. 77.

Cercopithecus prtaurista (from Brohm). 
pretty; the orange-tinted face is surrounded by long whiskers of glossy whiteness, with a line of chesnut-red over the eyebrows; the fur on the back is of a delicate grey, with a square patch on the loins, the tail and the fore-arms being of a pure white; a gorget of chesnut surmounts the chest; the thighs are black, with the legs chesnut-red. I will mention only two other monkeys for their beauty; and I have selected these as presenting slight sexual differences in colour, which renders it in some degree probable that both scxes owe their elegant appearance to sexual selection. In the moustache-monkcy (Cercopithecus cephus) the general colour of the fur is mottledgreenish with the throat white; in the male the end of the tail is chesnut, but the face is the most ornamented part, the skin being chiefly bluish-grey, shading into a blackisti tint beneath the eyes, with the upper lip of a delicate blue, clothed on the lower edge with a thin black moustache; the whiskers are orange-coloured, with the upper part black, forming a band which extends backwards to the ears, the latter being clothed with whitish hairs. In the Zoological Society's Gardens I havo often overheard visitors admiring the beauty of another monkcy, deservedly called Cercopithecus diana (fig. 78); the general colour of the fur is grey; the chest and inner surface of the forelegs are white; a large triangular defined space on the hinder part of the back is rich chesnut; in the male the inner sides of the thighs and the abdomen are delicate fawn-colourecl, and the top of the head is black; the face and ears are intensely black, contrasting finely with a white transverse crest over the eye-brows and a long white peaked beard, of which the basal portion is black. ${ }^{47}$

In these and many other monkejs, the beauty and singular arrangement of their colours, and still more the dirersified and clegant arrangement of the crests and tufts of hair on their heads, force the conviction on my mind that these character. have been acquired through sexual sclection exclusively as ornaments.

Summary.-The law of battle for the possession of the female appears to prerail throughout the whole great class of mammals. Most naturalists will admit that the greater size, strength, courage, and pugnacity of the male, his special weapons of offence, as well as his special means of defence, have been

47 I have seen most of the above monkeys in the Zoological Society's Gardens. The description of the Semnopithecus nemseus is taken from

Mr. W. C. Martin's 'Nat. Hist. of Mammalin,' 1841, p. 460; als pp. 475 523. 
acquired or modified through that form of selection which I have called sexual. This does not depend on any superiority in the general struggle for life, but on certain individuals of one sex, generally the male, being successful in conquering other males, and leaving a larger number of offspring to inherit their superiority than do the less successful males,

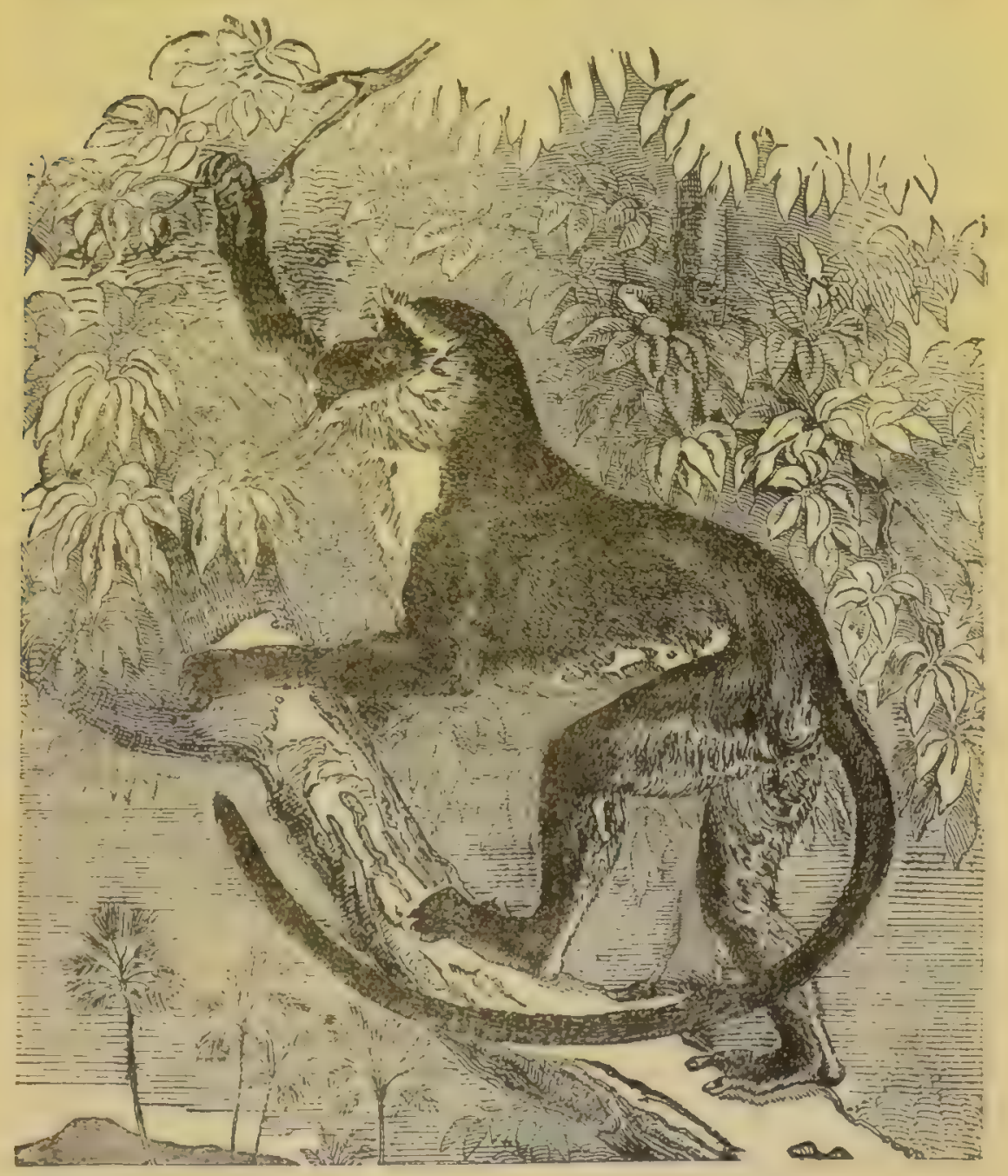

Fig. 78.

Cercopithecus diana (from Brehm).

Thero is another and more peaceful kind of contest, in which the males endeavour to excite or allure the females hy various rharms. This is probably carried on in some cases by the powerful odours emitted by the males during the breeding-season; the odoriferous glands having been acquirel through sexual selection. Whether the same view can be extended to the voice 
is doubtful, for the vocal organs of the males must have been strengthened by use during maturity, under the yowerful excitements of love, jealousy or rage, and will consequently have been transmitter to the same scx. Various crests, tufts, and mantles of hair, which are either confined to the male, or aro moro developed in this sex than in the female, seem in most cases to be merely ornamental, though they sometimes serve as a defence against rival males. There is even reason to suspect that the branching horns of stags, and the elegant horns of certain antelopes, though properly serving as weapons of offence or defence, have been partly modified for ornament.

When the male differs in colour from the female, he generally exhibits darker and more strongly-contrasted tints. We do not in this class meet with the splendid red, blue, yellow, and green tints, so common with male birds and many other animals. The naked parts, however, of certain Quadrumana must be excepted; for such parts, often oddly situated, are brilliantly coloured in some species. The colours of the male in other cascs may be due to simple variation, without the aid of selection. But when the colours are dirersified and strongly prononnced, when they are not developed until near maturity, and when they are lost after emasculation, we can hardly avoid the conclusion that they have been acquired through sexual selection for the sake of ornament, and have been transmitted exclusirely, or almost exclusively, to the same sex. When both sexes are coloured in the same manner, and the colours are conspicuous or chriously arranged, without being of the least apparent use as a protection, and especially when they are associated with varions other ornamental appendages, we are led by analogy to the same conclusion, namely, that they have been acquired through sexual selection, although transmitted to both sexes. That conspicuous and diversified colours, whether confined to the males or common to both sexes, are as a general rule associated in the same groups and sub-groups with other secondary sexual characters serving for war or for ornament, will be found to hold good, if we look back to the various eases given in this and the last chapter.

The law of the equal transmission of characters to both sexes, as far as colour and other ornaments are concerned, has prevailed far more extensively with mammals than with birds; but weapons, such as horns and tusks, hare often been transmitted either exclusively or much more perfectly to the males than to the females. This is surprising, for, as the males generally use their werpons for defence against enemies of all kinds, their weapons would have been of service to the females. As far as we can seo, their absence in this sex can he accounted. for only by the 
form of inheritance which has prevailed Finally, with quaclrupeds the contest between the individuals of the same ser, whether peaceful or bloody, has, with the rarest exceptions, been confined to the males; so that the latter have been modified through sexual selection, far more commonly than the fernalos, gither for fighting with each other or for alluring the opposite xis. 


\title{
PART III.
}

\section{SEXUAL SELECTION IN RELATION TO MAN,}

\author{
AND CONCLUSION.
}

CHAPTER XIX.

\section{Srcondary Sexdal Chatacters or Man.}

Differences between man and woman-Causes of such differences and of certain characters common to both sexes-Law of battle-Diflerences in mental powers, and voice-On the influence of beauty in determining the marriages of mankind-Attention paid by savages to ornamentsTheir ideas of beauty in woman-The tendency to exaggerate each natural peculiarity.

IVITH mankind the differences between the sexes are greater than in most of the Qriadrumana, but not so great as in some. for instance, the mandrill. Man on an arerage is considerably taller, heavier, and stronger than moman, with squarer shoulders and more plainly-pronounced muscles. Owing to the relation which exists between muscular development and the projection of the brows, ${ }^{1}$ the stuperciliary ridge is generally more marked in man than in woman. His hody, and especially his face, is more hairy, and his voice has a different and more powerful tone. In certain races the women are said to differ slightly in tint from the men. For jnstance, Schwcinfurth, in speaking of a negress belonging to the Monbuttoos, who inhabit the interior of Africa a few degrees north of the Equator, says, "Like all her race, she har? "a skin several shades lighter than her husband's, being some"thing of the colour of half-roasted coffee." 2 As the women labour in the ficlds and are quite unclothed, it is not likely that they differ in colour from the men owing to less exposure to the weather. European women are perhaps the brighter coloured of the two sexes, as may be seen when both ilave been equally exposed.

1 Schaaffhausen, transiarion in 'Aathropological Review,' Oct. 1868, pp. $419,420,427$.
2 'The Hart of Africa,' English Transl. 1873, rol. i. p. 5t4. 
Man is more courageous, pugnacious and energetic than woman, and has a more inventive genius. His brain is absolutely larger, but whether or not proportionately to his larger hody, has not, I believe, been fully ascertained. In woman the face is rounder; the jaws and the base of the skull smaller; the outlines of the body rounder, in parts more prominent; and her pelvis is broader than in man $;^{3}$ but this latter character may perhaps be considered rather as a primary than a secondary sexual character. She comes to maturity at an earlier age than man.

As with animals of all classes, so with man, the distinctive characters of the male sex are not fully developed until he is nearly mature; and if emasculated they never appear. The beard, for instance, is a secondary sexual character, and male children are beardless, though at an early age they have abundant hair on the head. It is probably due to the rather late appearance in life of the successive variations whereby man has acquired his masculine characters, that they are transmitted to the male sex alone. Male and female children resemble each other closely, like the young of so many other animals in which the adult sexes differ widely; they likewise resemble the mature fomale much more closely than the mature male. The female, however, ultimately assumes certain distinctive characters, and in the formation of her skull, is said to be intermediate between the child and the man. ${ }^{4}$ Again, as the young of closely allied though distinct species do not cliffer nearly so much from each other as do the adults, so it is with the chilaren of the different races of man. Some have even maintained that racedifferences cannot be detected in the infantile skuli. ${ }^{5}$ In regard to colour, the new-born negro child is reddish nut-brown, which soon becomes slaty-grey; the black colour being fully developed within a year in the Soudan, but not until three years in Egypt. The eyes of the negro are at first blue, and the hair chesnutbrown rather thin black, being curled only at the ends. The children of the Australians immediately after birth are yellowishbrown, and become dark at a later age. Those of the Guaranys of Paraguay are whitish-yellow, but they acquire in the course of a few weeks the yellowish-brown tint of their jarents. Similar observations have been made in other parts of America."

- Ecker, translation in 'Anthropological Reriew,' Oct. 1868, pp. 351356. The comparison of the form of the skull in men and women has been followed out with much care by Welcker.

- Fcker and Welcker, ibid. p. 352 ,
355 ; Vogt, ' Lectures on Mlan,' Eng. translat. p. 81.

5 Schauffhausen, 'Anthropolog. Review,' ibid. p. 429.

- Pruner-Bey, on vegro infants as quoted by Vogt, 'Lectures on Min,' Eng. trunslat. 1864, p. 189 : 
I have specified the foregoing differences between the male and femalo sex in mankind, because they are curiously like those of the Quadrumana. With these animals the female is mature at an earlier ago than the male; at least this is certainly the caso in the Cebus azara.? The males of most species are larger and stronger than the females, of which fact the gorilla affords a welk known instance. Even in so trifling a character as the greater prominence of the superciliary ridge, the males of certain monkeys differ from the females, ${ }^{8}$ and agree in this respect with mankind. In the gorilla and certain other monkeys, the cranium of the adult male presents a strongly-marked sagittal crest, which is absent in the female; and Ecker found a trace of a similar difference between the two sexes in the Australians. ${ }^{g}$ With monkeys when there is any difference in the voice, that of the male is the more powerful. We have seen that certain male monkeys have a well-developed beard, which is quite deficient, or much less developed in the female. No instance is known of the beard, whiskers, or moustache being larger in the female than in the male monkey. Even in the colour of the beard there is a curious parallelism between man and the Quadrumana, for with man when the beard differs in colour from the hair of the head, as is commonly the case, it is, I believe, almost always of a lighter tint, being often reddish. I have repeatedly observed this fact in England; but two gentlemen have lately written to me, saying that they form an exception to the rule. One of these gentlemen accounts for the fact by the wide difference in colour of the hair on the paternal and maternal sides of his family. Both had been long aware of this peculiarity (one of them haring often been accused of dyeing his beard), and had been thus led to observe other men, and were convinced that the exceptions were very rare. Dr. Hookcr attended to this little point for me in Russia, and found no exception to the rule. In Calcutta, Mr. J. Scott, of the Botanic Gardens, was so kind as to observe the many races of men to be seen there, as well as in some other parts of India, Lamely, two races in Sikhim, the Bhoteas, Hindoos, Burmese, and

for further facts on negro infants, as quoted from Winterbottom and Camper, see Lawrence, 'Lectures on Physiology,' \&c. 1822, p. 451. For the infants of the Guaranys, see Rengger, 'Süugethiere,' \&c. \&. 3. See also Godron, 'De l'Espèce,' tom. ii. 1859, p. 253. For the Australians, Waitz, "Introduct. to Anthropology,' Eng. translat. 1863, p. 99.
7 Rengger, 'Säugethiere,' \&c. $1830,8.49$.

- As in Macacus cynomolyus (Desmarest, 'Mammalogie,' p. 65), and in Hylobates agilis (Geoftroy St.Hilaire and F. Cuvier, 'Hist. Nat. des Mamm.' 1824, tom. i. p. 2).

'Anthropological Review,' Oct. 1868 , p. 353. 
Chinese, most of which races hare very little hair on the face and he always found that when there was any difference in colour between the hair of the head and the beard, the latter was invariably lighter. Now with monkeys, as has already benn stated, the beard frequently differs strikingly in colour from the hair of the head, and in such cases it is always of a lighter hue, being often pure white, sometimes yellow or reddish. ${ }^{10}$

In regard to the general hairiness of the body, the nomen in all races are less hairy than the men; and in some fow Quadrumana the under side of the body of the female is less hairy than that of the male. ${ }^{11}$ Lastly, male monkeys, like men, are bolder and fiercer than the females. They lead the troop, and when there is danger, come to the front. We thus see how close is the parallelism between the sexual differences of man and the Quadrumana. With some fer spceies, lowerer, as with certain baboons, the crang and the gorilla, there is a considerably greater difference between the sexes, as in the size of the canine teeth, in the development and colour of the hair, and especially in the colour of the naked parts of the skin, than in mankind.

All the secondary sexual characters of man are highly variable, even within the limits of the same race; and they differ much in the several races. These two rules hold good generally througl:out the animal kingdom. In the excellent observations made on board the Novara, ${ }^{12}$ the male Australians were found to exceed the females by only 65 millim. in height, whilst with the Javans the average excess was 218 millim. ; so that in this latter race the difference in height between the sexes is more than thrice as great as with the Australians. Numcrous mcasurements were carefully made of the stature, the cireumfereace of the nock and chest, the leugth of the back-bone and of the arms, in various

10 Mr. Blyth intorms me that he has only seen one instance of the beard, whiskers, \&uco in a monkey becoming white with old age, as is so commonly the case with us. This, bowever, occurred in an aged Macacus cynomolgus, kept in confincment, whose moustaches were "remarkably long and hu"man-like." Altogether this old monkey presented a ludicrous resemblance to one of the reigning monarchs of Europe, after whom he was universally nick-named. In certain races of man the hair on the bead hardly ever bscomes gray; thus Mr. D. Forbes has never, as he informs me, seen an instance with the Aymaras and Quichuas of $\mathbf{S}$. America.

11 This is the case with the fzmales of several species of Hylobate.in, see Geoffioy St.-Hiliare and F. Cuvier, 'Hist. Nat. des Mamm.' tom. i. See, also, on H. lar. 'Penny Cy.clopedia,' rol. ii. pp. 149, 150.

12 The results were dednced bp Dr. Weisuach from the measurements made by Dis. K. Seherzer and Schwarz, see 'Reise der Novara: Anthropolog. Theil,' 1867, 6s. 21e $231,234,236,239,269$. 
races; and nearly all these mcasurements shew that the males differ much more from one another than do the females. This fict indicates that, as far as these characters are concerned, it is the male which bas been chiefly modified, since the several races diverged from their common stock.

The development of the beard and the hairiness of the body differ remarkably in the men of distinct races, and even in different tribes or families of the same race. We Europeans seo this amongst ourselves. In the Island of St. Kilda, according to Martin, ${ }^{13}$ the men do not acquire beards until the age of thirty or upwards, and even then the beards are very thin. On the Europro-Asiatic continent, beards prevail until we pass heyond India; though with the natives of Ceylon they are often absent, as was noticed in ancient times by Diodorus. ${ }^{1 *}$ Eastward of India beards disappear, as with the Siamese, Malays, Kalmucks, Chinese, and Japanese; nevertheless the Ainos, ${ }^{15}$ who inhabit the nortbernmost islands of the Japan Archipelago, are the hairiest men in the world. With negroes the beard is scanty or wanting, and they rarely have whisiers; in both sexes the body is frequently almost destitute of fine down. ${ }^{16}$ On the other hand, the Papuans of the Malay Archipelago, who are nearly as black as negroes, possess well-developed beards. ${ }^{17}$ In the Pacific Ocean the inhabitants of the Fiji Archipclago havo large bushy beards, whilst those of the not distant archipelagoes of Tonga and Samoa are beardless; but these men belong to distinct races. In the Ellice group all the inhabitants belong to the same race; yet on one island alone, namely Nunemaya, "the men have splendid beards;" whilst on the other islands "they have, as a rule, a dozen straggling hairs for "a beard." 18

Throughout the great American continent the men may be said to be beardless; but in almost all the tribes a few short hairs are apt to appear on the face, especially in old age. With the tribes of North America, Catlin estimates that eighteen out of twenty men are completely destitute by nature of a beard;

13 'Voyage to St. Kilda' (3rd edit. 1753), p. 37.

14 Sir J. E. Tenuent, 'Ceylon, rol. 3i. 1859 , p. 107.

15 Quatrefages, 'Rerue des Cours Scientifiques,' Aug. 29, 1868, p. 630; Vogt 'Lectures on Man, Eng. translat. p. 127.

16 On the beards of negroes, Vogt, 'Lectures,' \&c. p. 127 ; Wait', 'Introriuct. to Anthropology,' Engl. sranslat. 1863, vol. i. p. 96 . It is remarkable that in the United States ('Investigations in Military and Anthropological Statistics of American Soldiers,' 1869, p. 569) the pure negroes and their crossed off spring seem to have bodies almos as hairy as Europeans.

18 Wallace, 'The Malay Arch. vol. ii. 1869, p. 178.

18 Dr. J. Baraard Daris On Oce. anc Races, in 'Anthropolog. Review, April, 1870, pp. 185, 191. 
hint occasionally there may be seen a man, who has neglectal to pluck ont the hairs at puberty, with a soft beard an inch or two in length. 'The Guaranys of Paraguay differ from all the surrounding tribes in having a small beird, and even some hair on the body, but no whiskers. ${ }^{19}$ I am informed by Mr. D. Forbes, who particularly atteuded to this point, that the Aymaras and Quichuas of the Cordillera are remarkably hairless, yet in old age a few straggling hairs occasiumally appear on the chin. The men of these two tribes have very little hair on the various parts of the body where hair grows abundantly in Europeans, and the women have none on the corresponding parts. The hair on the head, howerel, attains an extraordinary leugth in hoth sexes, often reaching almost to the ground; and this is likewise the case with some of the N. American tribes. In the amount of hair, and in the general shape of the body, tho sexes of the American aborigines do not differ so much from each other, as in most other races." This fact is analogous with what occurs with some closely allied monkeys; thus the scius of the chimpanzee are not as different as those of the orang or gorilla. ${ }^{21}$

In the previous chapters we have seen that with mammals, birds, fishes, insects, dc., many characters, which there is every. reason to believe were primarily gained through sexual selection by one sex, have been transferred to the other. As this same form of transmission has apparently prevailed much with mankind, it will save uscless repetition if we discuss the origin of characters peculiar to the male sex together with certain other characters common to both sexes.

Law of Battle. - With savages, for instance the Australians, the women are the constant cause of war hoth between members of the same tribe and between distinct tribes. So no doubt it was in ancient times; " nam fuit ante Helenam mulier teterrima belli "causa." With some of the North American Indians, the contest is reduced to a system. That excellent observer, Heamo, ${ }^{-2-}$

18 Catlin, 'North American Indians,' 3 rd edit. 1842, vol. is. p. 227. On the Guaranys, see Azara, 'Voyages dans l'Amérique Mérid.' tom. i. 1809 , p. 58 ; also Rengger, 'Säugethiere von Paraguay," s. 3.

20 Plof. and Mrs. Agthsiz ("Journey in Brazil,' p. 530) remark that the sexes of the American Indians differ less than those of the negroes and of the higher races. See also Rengger, ibid. p. 3, on the Guaranys.
21 Riitimeyer, 'Die Grenzen der Thierwelt; eine Betrachtung $\mathrm{zi}$ Darwin's Lehre,' 1868, s. 54.

22 'A Journey from Prince of Wales Fort.' 8vo. edit. Dublin, 1796. p. 104. Sir J. Lubbock (' Origin of Civilisation,' 1870 , p. 69) gives other and similar cases in North America. For the Guanas of S'. Ainticil see Azara, 'Voyages,' Su. toin. 11. p. 9.t. 
Bays:- "It has ever becn the custom among these people for " the men to wrestle fur any woman to whom tincy are at"tached; and, of courso, tho strongest party always carrics of " the prize. A weak man, unless he be a good hunter, and well" beloved, is seldom permitted to keep a wife that a stronger " man thinks worth his notice. This custom prevails througlh"out all the tribes, and causes a great spirit of emulation amoug " their youth, who are upon all occasions, from their childhood, "trying their strength and skill in wrestling." With the Guanas of South America, Azara states that the men rarely marry till twenty years old or more, as before that age they cannot conquer their rivals.

()ther similar facts could be given; but even if we had no cvidence on this head, we might fecl almost sure, from the analogy of the higher Quadrumana, ${ }^{23}$ that the law of battle had prevailed with man during the carly stages of his derelopment. 'The occasional appearance at the present day of canine tecth which project above the others, with traces of a diastema or open space for the reception of the opposite canines, is in all probability a case of reversion to a former state, when the progenitor's of man were provided with these weapons, like so many existing male Quadrumana. It was remarked in a former chapter that as man gradually became erect, and continually uscd his hands and arms for fighting with sticks and stoncs, as well as for the other purposes of life, he would have used his jaws and teeth less and less. The jaws, together with their muscles, would then have been reduced through disuse, as would the teeth through the not well understood principles of correlation and economy of growth; for we everywhere see that parts, which are no longer of service, are reduced in size. By such steps the original inequality between the jaws and tceth in tho two sexes of mankind would ultimately have lece obliterated. The case is almost parallel with that of mauy male Ruminants, in which the canine teeth hare licen recluced to mere rudiments, or have disappeared, apparently in cousequence of the development of horns. As the prodigious difference between the skulls of the two sexes in the orang and gorilla stands in close relation with the development of the immense

- canine teeth in the males, we may infer that the reduction of the jaws and teeth in the carly male progenitors of man must have led to a most striking and favourable change in his appearance.

23 On the fighting of the male gorillas, see I)r. Savage, in 'Boston Journa' of Nat. Hist." vcl. v. 1847

p. 423. On Presbytis cntellus, see the 'Indian Field,' 1859, , .146 
There can be little doubt that the greater size and strength of man, in comparison with woman, together with his broader shoulders, more developed muscles, rugged outline of body, his greater courage and pngnacity, are all due in chief part to inheritance from his half-human male ancestors. These characters would, however, have been preserved or even augmented during the long ages of man's savagery, by the success of the strongest and boldest men, both in the general struggle for life and in their contests for wives; a success which would hare ensured their leaving a more numerous progeny than their less faroured lrethren. It is not probable that the greater strength of man was primarily acquired through the inherited effects of his having worked harder than woman for his own subsistence and that of his family; for the women in all barbarous nations are compelled to work at least as lard as the men. With civilised people the arbitrament of battle for the possession of the women has long ceased; on the other hand, the men, as a feneral rule, have to work harder than the women for their joint subsistence, and thus their greater strength will have buen liept up.

Ififierence in the Mental Pourers of the two Sexes. - With respect to differences of this wature between man and woman, it is probable that sexual selection has played a highly important frart. I am aware that some writers doubt whether there is any such inherent difference; but this is at least probable from the analogy of the lower animals which present other secondary s:xual characters. No one disputes that the bull differs in - Lisfrusition from the cow, the wild-boar from the sow, the stallion from the mare, and, as is well known to the keepers of meuargeries, the wales of the larger apes from the females. Woman seems to differ from man in mental disposition, chicfly in her greater tenderness and less selfishness; and this lolds foud cven with savages, as shewn by a well-known passage in Mungo I'ark's Travels, and by statements made by many ofler travellers. Woman, owing to her maternal instincts, displays these qualities towards her infants in an eminent degree; therefore it is likely that she would often extend them towards her fellow-creatures. Nan is the rival of other men; le delights in competition, and this leads to ambition which passes too eilsily into selfishness. These latter qualities seem to be his natural and unfortunate birthright. It is generally admitted wat with woman the powers of intuition, of rapid perception, and perbaps of imitation, are more strongly marked than in man; but some, at least, of these facultieo ara characteristic 
of the lower races, and therefore of a past and lower state of civilisation.

The chief distinction in the intellectual powers of the two sexes is shewn by man's attaining to a higher cminence, in whatever he takes up, than can woman--whether requiring deep thought, reason, or imagination, or merely the use of the senses and lands. If tro lists were made of the most eminent men and women in poetry, painting, sculpture, music (inclusive looth of composition and performance), history, science, and philosophy, with half-a-dozen names under each subject, the two lists would not bear comparison. We may also infer, from the law of the deviation from arerages, so well illustrated by Mr. Galton, in his work on 'Hereditary Genius,' that if men are capable of a decided pre-cminence over women in many sulujects, the average of mental power in man must be above that of woman.

Amongst the half-human progenitors of man, and amongst suvages, there have becn struggles betwcen the males during: many generations for the possession of the females. But mer. bodily strength and size would do little for victory, unless associated with courage, perseverance, and determined encrgy. With social animals, the young males have to pass throngrl: many a contest before they win a female, and the older males have to retain their females by renerred battles. They have, also, in the case of mankind, to defend their females, as well as their young, from encmies of all kinds, and to hunt for their joint subsistence. But to avoid cnemies or to attack them with success, to capture wild animals, and to fashion wcapons, requires the aid of the higher mental faculties, namely, observation, reason, invention, or imagination. Theso various faculties will thus have been continually put to the test and selected during manhood; they will, moreover, have been strengthened by use rluring this same period of life. Consequently, in accordanec with the principle often alluded to, we might expect that they would at least tend to he transmitted chiefly to the male offspring at the corresponding period of manhood.

Now, when two men are put into competition, or a man with a woman, both possessed of erery mental quality in equal perfection, save that one has higher energy, perseverance, an. conrage, the latter will gencrally become more eminent in every pursuit, and will gain the ascendancy. ${ }^{24} \mathrm{He}$ may be said to possess genius-for genius has becn declared ly a great

21 J. Stuart Mill remarks ("The Sint.jection of Women,' 1869, p. 12:2), "The things in which mau most "ercels woman are those which "require most plodrling, and lone "hammering at single thoughts." What is this but energy and per- 
suthority to be pationce; and patience, in this sense, means unfliuching, undaunted perseverance. But this view of genius is perhaps deficient; for without the higher powers of the imagination and reason, no eminent success can be gained in many subjects. These latter faculties, as well as the former, will have been developed in man, partly through sexual selection,-that 1S, through the contest of rival males, and partly through natural selection,- that is, from success in the general struggle for life; and as in both cases the struggle will have been during maturity, the characters gained will have been transmitted more fully to the male than to the female offspring. It accords in a striking manner with this view of the modification and re-inforcement of many of our mental faculties by sexual selection, that, firstly, they notoriously undergo a considerable change at puberty, 2 ; and, secoudly, that eunuchs remain throughout life inferior in these same qualities. Thus man has ultimately become superior to woman. It is, indeed, fortunate that the law of the equal transmission of characters to both seres prevails with mammals; otherwise it is probable that man would have become as superior in mental eudowment to woman, as the peacock is in ornamental plumage to the peahen.

It must be borne in mind that the terdency in characters accinired by either sex late in life, to be transmitted to the same sex at the same age, and of early acquired characters to be transmitted to both sexes, are rules which, though general, do not always hold. If they always held good, we might conclude (but I here exceed my proper bounds) that the inherited effects of the early education of boys and girls would be transmitted equally to both sexes; so that the present inequality in mental jower between the sexes would not be effinced by a similar course of early training; nor can it have been caused by their dissimilar carly training. In order that woman should reach the same standard as man, she ought, when nearly adult, to be trained to energy and perseverance, and to have her reason and imagination exercised to the highest point; and then she would probably transmit these qualities chiefly to her adult daughters. All women, however, could not be thus raised, unless during many generations those who excelled in the above robust virtues wern married, and produced offspring in larger numbers than othei women. As before remarked of bodily strength, although mon do not now fight for their wives, and this form of selection has jassed away, yet during manhood, they generally undergo it scvere struggle in order to maintain themselves and their families; and this will tend to keep up or even increase their

थs Maudsley, 'Mind and Body,' p. 31. 
mental powers, and, as a consequence, the present inequality between the sexes. ${ }^{26}$

Voice and Musical Powers.-In some species of Quadrumana there is a great difference between the adult sexes, in the power of their voices and in the derelopment of the rocal organs; an.l man appears to have inherited this difference from his carly progenitors. His rocal cords are about one-third longer than in woman, or than in boys; and emasculation produces the same effect on him as on the lower animals, for it "arrests that pro" minent growth of the thyroid, \&c., which accompanies the " elongation of the cords." With respect to the cause of this difference between the sexes, I have nothing to ald to the remarks in the last chapter ou the probable effects of the longcontinued use of the vocal organs by the male under the excitement of love, rage and jealousy. According to Sir Duncan Gibb, ${ }^{28}$ the voice and the form of the larynx differ in the different races of mankind; but with the Tartars, Chinese, drc., the voico of the male is said not to differ so much from that of the femalc, as in most other races.

The capacity and love for singing or music, though not a sexual character in man, must not here be passed orer. Althongh the sounds emitted by animals of all kinds serve many purposes, a strong case can be made out, that the vocal organs were primarily used and perfected in relation to the propagation of the species. Insects and some few spiders are the lowest animals which voluntarily produce any sound; and this is generally effected by the aid of beatifully constructed stridulating organs, which are often confined to the males. The sounds thus produced consist, I believe in all cases, of the same note, repeated rhythmically; ${ }^{20}$ and this is sumetimes pleasing even to the ears of man. The chief and, in some cases, exclusive purpose appears to be either to call or charm the opposite sex.

The sounds produced by fishes are said in some cases to he made only by the males during the breeding-season. All the

20 An observation by Vogt bears on this subject: he says, "It is a "remarkable circumstance, that the "difference betwaen the sexes, as "regards the cranial carity, in"creases with the development of "the race, so that the male Euro"pean excels much more the female, "than the negro the negress. "Welcker confirms this statement "of Huschke from his measure"ments of : egro and German "skulls." But Vogt admits ("Lectures on Man,' Eng. translat. 18rit, p. 81) that more observations are requisite on this point.

27 Owen, 'Anatomy of Vertebrates,' vol. iii. p. 603 .

28 'Journal of the Anthropolng. Soc.' April, 1869, p. Ivii, and lxri.

29 Dr. Scudder, "Notes on Stridulation,' in 'P'roc. Boston Soc. of Nat. Hist.' vol, xi. April, 1868. 
air-breathing Vertebrata necessarily possess an apparatus for inhaling and expelling air, with a pipe capable of being closeci at one end. Hence when the primeval members of this class wero strongly excited and their muscles violently contracted, purposeless sounds would almost certainly have been produced: and these, if they proved in any way serviceable, might readily have been modified or intensified by the preservation of properly adapted variations. The lowest Vertebrates which breathe air are Amphibians; and of these, frogs and toads possess vocal organs, which are incessantly used during the breeding-season, .nd which are often more highly developed in the male than ir: the female. The male alone of the tortoise utters a noise, and this only during the season of love. Male alligators roar or bellow during the same season. Every one knows how much birds use their vocal organs as a means of courtship; and some species likewise perform what may be called instrumental music.

In the class of Mammals, with which we are here more particularly concerned, the males of almost all the species use their voices during the breeding-season much more than at any other time; and some are absolutely mute excepting at this season. With other species both sexes, or only the females, use their voices as a love-call. Considering these facts, and that the vocal organs of some quadrupeds are much more largely developed in the male than in the female, either permanently or temporarily luring the brecding-season; and considering that in most of the lower classes the sounds produced by the males, serve not only to call but to excite or allure the female, it is a surprising fact that we have not as yet any good evidence that these organs are used by male mammals to charm the females. The American Vycetes caraya perhaps forms an exception, as does the IIylubates agilis, an ape allied to man. This gibbon has an extremely loud but musical voice. Mr. Waterhouse states, "It appeared to " me that in ascending and descending the scale, the intervals "were always exactly half-tones; and I am sure that the highest " note was the exact octave to the lowest. The quality of the " notes is very musical ; and I do not doubt that a good violinist "would be able to give a correct ider of the gibbon's compo"sition, excepting as regards its londness." Mr. Waterhousc then gires the notes. Professor Owen, who is a musician, confirms the foreguing statement, and remarks, though erroneousiy, that this gibbon "alone of brute mammals may be said to "sing." It appears to be much excited after its performance.

so Given in W. C. L. Martin's 'General Introduct. to Nat. Hist. of Mamm. Animal.,' 1841, p. 432 ;
Owen, 'Anatomy of Vertebrates, vol. iii. p. 600 . 
Unfortunately, its habits have never been closely observed in a state of nature; but from the analogy of other animals, it is probable that it uses its musical powers more especially during the season of courtship.

This gibbon is not the only species in the genus which sings, for my son, Francis Darwiu, attentively listened in the Zoosogrical Gardens to $I 1$. leuciscus whilst singing a cadence of threo notes, in true musical intervals and with a clear musical tone. It is a more surprising fact that certain rodents utter musical sounds. Singing mice have often been mentioned and exhibited, but imposture has commonly been suspected. We have, however, at last a clear account by a well-known observer, the Rev. S. Lockwood, ${ }^{31}$ of the musical powers of an American species, the IIesperomys cognatus, belonging to a genus distinct from that of the English mouse. This little animal was kept in confiucment, and the performance was repeatedly heard. In one of the two chief songs, "the last bar would frequently be prolonged to "two or three; and she would sometimes change from C sharp " and D, to $C$ natural and $D$, then warble on these two notes " awhile, and wind up with a quick chirp on C sharp and D. "The distinctness between the semitones was very marked, and " easily appreciable to a good ear." Mr. Lockwood gives hoth songs in musical notation; and adds that thongh this little mouse " had no ear for time, yet she would keep to the key of I3 " (two flats) and strictly in a major key." ... "Her soft clear "voice falls an octave with all the precision possible; then at the - wind up, it rises again into a very quick trill on $\mathrm{C}$ sharp "and D."

A critic has asked how the cars of man, and he ought to have added of other animals, could have been adapted by selcction so as to distinguish musical notes. But this question shews some confusion on the subject; a noise is the sensation resulting from the co-existence of several aërial "simple vibrations" of various periods, each of which intermits so frequently that its separate existence cannot be perceived. It is only in the want of continuity of such vibrations, and in their want of harmony inter se, that a noise differs from a musical note. Thus an ear to be capable of discriminating noises-and the high importance of this power to all animals is admitted by every one-must be sensitive to musical notes. We have evidence of this capacity even low down in the animal scale: thus Crustaceans are provided with auditory hairs of different lengths, which have been scen to vibrate when the proper musical notes are struck. ${ }^{33}$ As stated

31 The 'American Naturalist,' 1871, p. 761 .
32 Helmholtz, 'Theorie Phys. de la Musique,' 1868, p. 187. 
in a previous chapter, similiar observations have been macle on the hairs of the antennæ of guats. It has been positively asserted by good olsservers that spiders are attracted by music. It is also well known that some dogs howl when hearing particular tones. ${ }^{33}$ Seals apparently appreciate music, and their fondness for it "was well known to the ancients, and is often " taken advantage of by the hunters at the present day." "it

Therefore, as far as the mere perception of nusical notes is concerned, there seems no special difticulty in the case of man or of any other animal. Helmholtz has explained on physiological principles why concords are agreeable, and discords disagrecable to the human ear; but we are littie concerned with these, as music in harmony is a late invention. We are more concerned with melody, and here again, according to Helmholtz, it is intelligible why the notes of our musical scale are used. The ear analyses all sounds into their component "simple vibrations," although we are not conscious of this analysis. In a musical note the lowest in pitch of these is generally predominant, and the others which are less marked are the octave, the tweltth, the second octare, \&c., all harmonies of the fundamental predominant note; any two notes of our scale have many of these harmonic over-tones in common. It seems pretty clear then, that if an animal always wished to sing precisely the same song, be would guide himself by sounding those notes in succession, which possess many over-tones in common-that is, he would choose for his song, notes which belong to our musical scale.

But if it be further asked why musical tones in a certain order and rhythm give man and other animals pleasure, we can no more give the reason than for the pleasantness of certain tastes and smells That they do gire pleasure of some kind to animals, we may infer from their being produced during the scason of courtship by many insects, spiders, fishes, amphibians, and birds; for unless the females were able to appreciate such sounds and were excited or charmed by them, the persevering efforts of the males, and the complex structures often possessed by them alone, would be useless; and this it is impossible to believe.

Human song is generally admitted to be the basis or origin of instrumental music. As neither the enjoyment nor the capacity of producing musical notes are faculties of the least

$3^{3}$ Several accounts have been published to this effect. Mr. Peach writes to me that he has repeatedly found that an old dog of his howis when B fit is sounded on the Hute, and to uo cther note. I may ald another instance of a dog always whining, when oue note on a concertina, which was out of tune, was played.

${ }_{34} \mathrm{Mr}$. K. Brown, in 'Proc. Zool. Soc.' 1868, 1. 410. 
use to man in reference to his daily habits of life, they must be ranked amongst the most mysterious with which he is endowed. They aro present, though in a very rude condition, in men of all races, even the most savage; but so different is the taste of the several races, that our music gives no pleasure to savages, and their music is to us in most cases hideous and unmeaning. Dr. Scemann, in some interesting remarks on this subject,"35 "doults "whether" even amongst the nations of Western Europe, in"timately connected as they are by close and frequent inter"course, the music of the one is interpreted in the same sense by "the otbers. By travelling eastwards we find that there is cer"tainly a different language of music. Songs of joy and danec"accompaniments are no longer, as with ns, in the major keys, "but always in the minor." Whether or not the half-human progenitors of man possessed, like the singing gibbons, the: capacity of producing, and therefore no doubt of appreciating, musical notes, we know that man possessed these faculties at a very remote period. M. Lartet has described two flutes, made out of the bones and horns of the reindeer, found in caves towether with flint tools and the remains of extinct animals. The arts of singing and of dancing are also very ancient, and are now practised by all or nearly all the lowest races of man. Poetry, which may be considered as the offspring of song, is likcwise so ancient, that many persons have felt astonished that it should have arisen during the earliest ages of which we have any record.

We see that the musical faculties, which are not wholly deficient in any race, rre capable of prompt and high development, for Hottentots and Negroes hare become excellent musicians, although in their native countries they rarely practise anything that we should consider music. Schweinfurth, however, was pleased with some of the simple melodies which he heard in the interior of Africa. But there is nothing anomalous in the musical faculties lying dormant in man: some species of birds which never naturally sing, can without much difficulty be taught to do so; thus a house-sparrow has learnt the song of a linnet. As these two speres are closely allied, and belong to the order of Insessores, which includes nearly all the singing-birds in the world, it is possible that a progenitor of the sparrow may have been a songster. It is more remarkable that parrots, belonging to a group distinct from the Insessores, and having different?:

35 'Journal of Anthropolog. Soc.' Oct. 1870 , p. clv. See also the several later chapters in Sir John Lubbock's 'Prehistoric 'Times,' se- ccad edition, 1869, which contain az admirable account of the habit: of savages. 
constructed rocal organs, can be taught not only to speak, but to pipe or whistle tunes invented lyy man, so that they must have some musical eapacity. Nerertheless it would be very rash to assume that parrots are descended from some ancient form which was a songster. Many cases could be advanced of organs and instincts originally adapted for one purpose, having becis utilised for some distinct purpose. ${ }^{36}$ Hence the capacity for high musical development, which the savage races of man possess, may be due either to the practice by our semi-human progenitors of some rudo form of music, or simply to their having acquired the proper rocal organs for a different purpose. But in this latter case we must assume, as in the abore instanco of parrots, and as seems to occur with many animals, that they already possessed some sense of melody.

Music arouses in us rarious emotious, but not the more terrible ones of horror, fear, rage; \&c. It awakens the gentler feelings of tenderness and love, which readily pass into derotion. In the Chinese annals it is said, "Music liath the power of " making hearen descend upon earth." It likewise stirs up in us the sense of triumph and the glorious ardour for war. These powerful and mingled feelings may well give rise to the senso of sublimity. We can concentrate, as Dr. Seemann observes, greater intensity of feeling in a single musical note than in pages of writing. It is probable that nearly the same emotions, but much weaker and far less complex, are felt by birds when the male pours forth his full volume of song, in rivalry with other males, to captivate the female. Love is still the commonest theme of our songs. As Herbert Spencer remarks, " inusic arouses dormant sentiments of which we had not " couceired the possibility, and do not know the meaning; or", " as Richter says, tells us of things we hare not secn and shall "not see." Conversely, when vivid emotions are folt and expressed by the orator, or even in common speech, musical carlenecs and rhythm are instinctively used. The negro in Africa when excited often bursts forth in song; "another will reply in song, "while the company, as if touched by a musical wave, murmur

36 Since this chapter was printed, I have seen a valuable article by Mi. Chauncey Wright ("North Amer. Review; Oct. 187i), pinge 293), who, in discussing the abore subject, remarks, "There are many "consequences of the ultimate laws " or uniformities of nature, through "which the acquisition of one use* ful power will luring with it mang "resulting advantiges as well is "limiting disadrantiges, actual or "possible, which the principle of "utility may not have comprehender "in its action." As I have attemptel to shew in an enrly chapter of this work, this princiule has an impor. tant benring on the acquisition by man of some of his mental charac. teristics. 
" a chorus in perfect unisou." "37 Even monkeys express strong feelings in different tones-anger and impatience by low,-lear and pain by high notes. ${ }^{38}$ The sensations and ideas thus excited in us by music, or expressed by the cadences of oratory, appear from their vasgueness, yet depth, like mental reversions to the emotions and thoughts of a long-past age.

All these facts with respect to music and impassioned speech become intelligible to a certain extent, if we may assume that uuusical tones and rhythm were used by our half-human aneestors, during the season of courtship, when animals of all kinds are excited not only by love, but by the strong passions of jealousy, rivalry, and triumph. From the deeply-laid principle of iullerited associations, musical tones in this case would be likely to call up vaguely and indefinitely the stroug emotions of a longpast age. As we have every reason to suppose that articulate speech is one of the latest, as it certainly is the highest, of the arts acquired by man, and as the instinctive power of producing musical notes and rhythms is dereloped low down in the animal series, it would be altogether opposed to the principle of evolution, if we were to admit that man's musical capacity has been developed from the tones used in impassioned speech. We must suppose that the rhythms and cadences of oratory are derived from previously developed musical powers. ${ }^{39}$ We can thus understand how it is that music, dancing, song, and poetry are such very ancient arts. We may go even further than this, and, as remarked in a former chapter, believe that musical sounds afforded one of the bases for the development of language. ${ }^{40}$

17 Winwood Rende, 'The Martyrdom of Man,' 1872 , p. 441, and 'Atrican Sketch Book,'1873, vol. ii. p. 313.

28 Rengger, 'Säugethiere von Paraguay, s. 49.

39 See the very interesting diseussion on the 'Origin and Function of Music,' by Mr. Herbert Spencer, in his coilected 'Essays,' 1858, p. 339. Mr. Spencer comes to an exactly opposite conclusion to that at which I have arrived. He coneludes, as did Diderot formerly, that the cadences used in emotiona! speech afford the founuation from which music has been developed; whilst I conclude that musical notes and rhythm were tirst acquired by the male or female progeuitors of wakind for the sake of charming the opposite sex. Thus musical tones became firmly associated with some of the strongest vassions an animal is capable of feelrng, and are consequently used instinctively, or through association, when strong emotions are expressed in speech. Mr. Spencer does not offer any satisfactory explanation, nor can I, why high or deep notes should be explessive, both with man and the lower animals, of certrin emotions. Mr. Spencer gives also an interesting discussion on the relations between poetry, recitative, and song.

to I find in Lord Monbodilo's 'Origin of Language,' vol.i. (1774), p. 469 , that Dr. Blacklock likewise thought "that the first language "among men was music, and that "before or $x$ ideas were expressed bt 
As the males of several quadiumanous animals hare their vocal organs much more developed than in the females, and as a gibbon, one of the anthropomorphous apes, pours forth a whole octave of musical notes and may be said to sing, it appears probable that the progenitors of man, either the males or females or both sexes, before acquiring the power of expressing their mutual love in articulate language, endearoured to clarm each other. with musical notes and rhythm. So little is known about the use of the voice by the Quadrumana during the season of lore. that we have no means of judging whether the habit of singing was first acquired br our male or female ancestors. Womeli are generally thought to possess sweeter voices than men, and it far $n$ s this serres as any guide, we may infer that they first acquired musical powers in order to attract the other sex. ${ }^{41}$ But if so, this must have occurred long ago, before our ancestors bait become sufticiently human to treat and value their women merely. as useful slaves. The impassioned orator, bard, or musician, when with his varied tones aud eadences he excites the strongent emotions in his hearers, little suspects that he uses the san:t means by which his half-human ancestors long ago aroused each other's ardent passions, during their courtship and rivalry.

The Influence of Beruty in thetermining the Mfurvings of Murkin..-In civilised life man is largely, hut by no means exclusively, influenced in the chcice of his wife by extcrnal appearance: but we are chiefly concerned with primeval times, and our only means of forming a judgment on this subject is to study the. habits of existing semi-civilised and savage nations. If it can be. shewn that the men of different races prefer women having various characteristics, or conversely with the women, we have then to enquire whether such choice, continued during many generations, would produce any sensible effect on the race. either on one sex ol both according to the form of inheritance which has prevailed.

It will be well first to shew in some detail that savages pay the greatest attention to their personal appenrance. ${ }^{22}$ That they have

"riculite sounds, they were com" municated by tones, varied accord-

"imer to ditherent degrees of gravity "iml acutenes."

\$See an interesting discussion on this subject by Häckcl, "Generelle Morph,' B. ii. 1866, s. 246.

48 A rull and excellent account of the manner in which savages in all narts of the world ornament them- selves, is given by the Italian traveller, Prof. Mantemazza, 'Rio de la Plata, Vinggi e Studi,' 1867, Plr. $525-545$; all the following stntements, when other references are not giren, :ire taken from this work. See, also, Waitz, 'Introduct. to Anthropulog.' Eng. transl. vol. i. 1863, p. 275, et passim. Lawrence also gires very full details in his 
a passion for ornament is notorious; and an English philosophor goes so far as to maintain, that clotbes were first mado for arnumont and not for warmth. As Professor Waitz remarks, " however poor and miscralle man is, he finds a pleasure in " adorning himself." The extravagance of the naked Indians of South America in decorating themselves is shewn "by a man of " large stature gaining with difficulty enough by the lahour of a "fortnight to procure in exchange the chica necessary to paint "himself red." 48 The ancient barbarians of Europe during the Reindeer period brought to their caves any brilliant or singular objects which they happened to find. Savages at the present day everywhere deck themselves with plumes, necklaces, armlets, ear-rings, \&c. They paint thomselves in the most diversified manner. "If painted nations," as Humboldt observes, "had "been examined with the same attention as clothed nations, it " would have been perceived that the most fertile imagination " and the most mutable caprice hare created the fashions of "painting, as well as those of garments."

In one part of Africa the eyelids are coloured black; in another the nails are coloured yellow or purple. In many places the hair is dyed of various tiuts. In different countries the teeth are stained black, red, blue, \&c., and in the Malay Archipelago it is thought shameful to have white teeth "like those of a dog." Not one great country can be named, from the Polar regions in the north to New Zealand in the south, in which the aborigines do not tattoo themselves. This practice was followed by the Jews of old, and by the ancient Britons. In Africa some of the natives tattoo themselves, but it is a much more common lractice to raise protuberances by rubbing salt into incisions made in rarious parts of the body; and these are considered by the inhabitants of Kordofan and Dnrfur" to be great personal "attractious." In the Arab countries no beanty can be perfect "ntil the checks "or temples have been gashed." 4t In South Amcrica, as Humboldt remarks, "a mother would be accused of " culpable indifference towards her children, if she did not " cmploy artificial means to shape the calf of the leg after the "fashion of the country." In the Old and New Worlds the

'Lectures on Physiology,' 1822. Since this chapter was written Sir $J$. Lubbock has published his 'Origin of Civilisation,' 1870 , in which there is an interesting chapter on the present subject, and from which (pp. 42,48 ) I have taken some facts about savages dyeing their teeth au! hair, and piercing their teeth.
${ }^{43}$ Humboldt, 'Personal Narrative, Eng. Translat. vol. iv. p. 515 ; on the imagination shewn in painting the body, p. 522 ; on modifying the form of the calf of the leg, p. 466.

14 'The Nile Tributaries,' 186 'The Albert N'yanza,' 1869, vol. i. p. 218. 
shape of the skull was formerly morlified during infancy in the most extraordinary manner, as is still the case in many places, and such deformities are considered ornamental. For instance, the savages of Colombia"s deem a much flattened head "an "essential point of beauty."

The hair is treated with especial care in rarious countries; it is allowed to grow to full length, so as to reach to the ground, or is combed into " a compact frizzled mop, which is the Papuan's "pride and glory." 46 In Northern Africa "a man requires a "period of from eight to ten years to perfect his coiffure." With (1) ther nations the head is shaved, and in parts of South America and Africa even the cyebrows and eyelashes are eradicated. 'The natives of the Upper Nile knock out the four front teeth, saying that they do not wish to resemble brutes. Further south, the Iratokas knock out only the two upper incisors, which, as Livingstone ${ }^{47}$ remarks, gires the face a hideous appearance, owing to the prominence of the lower jaw; but these people think the presence of the incisors most unsightly, and on beholding some Europeans, cried out, "Look at the great teeth!" The chief Sebituani tried in vain to alter this fashion. In various larts of Africa and in the Malay Archipelago the natives file the incisors into points like those of a saw, or pierce them with holes, into which they insert studs.

As the face with us is chielly admired for its beauty, so with savages it is the chief seat of mutilation. In all quarters of the world the septurn, and more rarely the wings of the nose are pierced; rings, sticks, feathers, and other ornaments being inscrted into the holes. The ears are cverywhere piereed and similarly ornamented, and with the Botocudos and Lenguas of South America the hole is gradually so much cnlarged that the lower edge touches the shoulder. In North and South America and in Africa either the upper or lower lip is pierced; and with the Botocudos the hole in the lower lip is so large that a dise of wood, four inches in cliameter, is placed in it. Mantegazza gives $a$ curious account of the shame felt by a Sonth American native, ind of the ridicule which he excited, when he sold his temb ta, the large coloured piece of wood which is passed through the hole. In Central Africa the women perforate the lower lip and liear a crystal, which, from the movement of the tongue, has "a "wriggling motion, indescribably ludicrous during conversation."

ts Quoterl by Prichard, 'Phys. Hist, of Maukind, 4th edit. vol. i. i $\$ 51$, p. 321.

is On the Prpuans, Wallace, ine Malay Archipelagu,' vol, ii. p.
445. On the coiffure of th:Afri. cans, Sir S. Baker, 'The Albart A"yanza," vol. i. p. 210. n ' 'Trarels,' p. 533. 
The wife of the chicf of Latooka told Sir S. Baker ${ }^{48}$ that Lady Baker "would be much improved if she would extract her four "front teeth from the lower jaw, and wear the long pointed " nolished crystal in her under lip." Further south with the Makalolo, the upper lip is perforated, and a large metal and hamboo ring, called a pelelé, is worn in the hole. "This caused "the lip in one case to project two inches beyond the tip of the " nose; nnd when the lady smiled the contraction of the muscles " clevated it over the eyes. "Why do the women wear these " 'things?' the venerable chief, Chinsurdi, was asked. Evidently " surprised at such a stupid question, he replied, 'For beauty! " "They are the only beautiful things women have; men have " "beards, women hare none. What kind of a person would she " "be without the pelelé? She would not be a woman at all " "with a mouth like a man, but no beard." "49

Hardly any part of the body, which can be unnaturally modified, has escaped. The amount of suffering thus caused must have been extreme, for many of the operations require several years for their completion, so that the idea of their necessity must be impcrative. The motives are various; the men paint their bodies to make themselves appear terrible in hattle; ccrtain mutilations are connected with religious rites, or they mark the age of pubcrty, or the rank of the man, or they Rerve to distinguish the tribes. Amongrst savages the same fashions prevail for long periods, ${ }^{50}$ and thus mutilations, from whatever cause first made, soon come to be ralued as distinctive marks. But self-adornment, vanity, and the admiration of others, seem to be the commonest motires. In regard to tattooing, I was told by the missionaries in New Zealand, that when they tried to persuade some girls to give up the practice, they "uswered, "We must just have a fer lines on our lips; else when " we grow old we shall he so rery ngly." With the men of Now Zcaland, a most capable judge ${ }^{51}$ says, " to have fine tattooed faces "was the great ambition of the young, both to render themselres "attractive to the ladies, and conspicuous in war." A star tattooed on the foreliead and a spot on the chin are thought by the women in one part of Africa to be irresistible attractions. ${ }^{52}$

18 'The Albert N'yanza,' 1866, rol. i. p. 217.

40 Livingstone, "British Assoria'ion,' 1860 ; report given in the 'Athenæum,' July 7, 1860, p. 29.

so Sir S. Bal:er (ibid. vol. i. p. 210) speaking of the natives of Central Afruca says, "every tribe $\therefore$ has a distuct and unchanging "fashion for dressing the hair." See Agassiz ('Journey in Brazil, 1868, p. 318 ) on the invariabilit of the tattooing of the Amazonian Indians.

51 Rev. R. Tay'or, 'New Zealand and its Inhabitants,' 1855, p. 152.

52 Mantegazza, "Viaggi e Studi, p. 542 . 
In most, but not all parts of the rorld, the men are more ornamented than the women, and often in a different manner; sometimes, thorigh rarely, the women are hardly at all ornamented. As tile women are mado by saviges to perform the greatest share of the work, and as they are not allowed to cat the best kilids of food, so it accords with the characteristic selfishness of man that they should not be allowed to obtain, or use the finest omaments. Lastly, it is a remarkable fact, as proved liy the foregoing quotations, that the same fashions in modifying the shime of the head, in ornamenting the hair, in painting, tattouing, in perforating the noso, lips, or ears, in removing or filing the teeth, \&c., now prevail, and have long prevailed, in the most distant quarters of the world. It is extremely improbable that these practices, followed by so many distinct nations, should be due to tradition from any common source. They indicate the close similarity of the mind of man. to whatever race he may belong, just as do the almost universa! habits of dancing, masquerading, and making rude pictures.

Haring made these preliminary remarks on the admiration felt by sarages for various ornameuts, and for deformities most unsightly in our eyes, let us see how far tho men are attracted by the applearance of their women, and what are their ideas of beanty. I have heard it maintained that savages are quite indifferent about the beauty of their women, valuing them solely as slaves; it may therefore be well to observe that this conclusion does not at all agree with the care which the women take iri ornamenting themselves, or with their vanity. Burchell ${ }^{53}$ gives an amusing account of a Bush-troman who used as mucli grease, red ochre, and shining powder "as would have ruined "any but a very rich husband." She displayed also "much "vanity and too evident a consciousness of her superiority." Mr. Winrood Reade informs me that the negroes of the West Coast often discuss the beanty of their women. Some competent observers have attributed the fearfully common practice of infanticide partly to the desire folt by the women to retain their mood looks. ${ }^{\text {gt }}$ In several regions the women wear charms and use love-philters to gain the affections of the men; and MIr. Brown enumerates four plants used for this purpose by the women of North-Western America. ${ }^{5}$

s3 'Travels in S. Africa,' 1824, vol. i. p. 414.

${ }^{34}$ See, tor references, Gerland - Ueber das Aussterben der Naturvölker,' 1863, s. $51,53,5 j$; also Azara,
'Voyages,' \&c. tom. ii. p. 116.

s3 On the regetable productions used by the North-Western American ludians, 'Pharmaceutical Jour anl,' rol. I. 
Hearne, 50 an excellent observer, who lived many years with the American Indians, says, in speaking of the momen, "Ask a . Northern Indian what is beauty, and he will answer, a broad - ilat face, small eyes, high cheek-bones, thrce or four broad "black lines across each check, a low forehead, a largo broad " chin, a clumsy hook nose, a tawny hide, and breasts hanging "down to the belt." Pallas, who visited the northern parts of the Chinese empire, says "those women are prefelred who liave "the Mandschú form; that is to say, a broad face, high check"bones, very broad noses, and enormous ears;" 57 and Togt. remarks that the obliquity of the eye, which is proper to tho Chinese and Japanese, is exaggerated in their pictures for the purpose, as it "secms, of exhibiting its beauty, as contrasted "with the eye of the red-haired barharians." It is well known, as Huc repeatedly remarks, that the Chinese of the interior think Europeans hideous, with their white skins and promincut noses. The nose is far from being too prominent, according to our ideas, in the natives of Ceylon; yet " the Chinese in the serenth " century, accustomed to the flat features of the Mongol races, " were surprised at the prominent noses of the Cingalese; and "Thsang described them as having "the beak of a bird, with the "s "body of a man."

Finlayson, after minutely describing the people of Cochin China, says that their rounded heads and faces are their chicf characteristics; and, he adds, "the roundness of the whole " countenance is more striking in the romen, who are reckoned " beautiful in proportion as they display this form of face." The Siamese have small noses with divergent nostrils, a wide mouth, rather thick lips, a remarkably large face, with rery high and broad cheek-bones. It is, thereforc, not wouderful that " beauty, " according to our notion is a stranger to them. Yet they con"sider their omn females to be much more beautiful than those " of Europe." 58

It is well known that with many Hottentot women the posterior part of the body projects in a wonderful manner; they are steatopygous; and Sir Andrew Smith is certain that this peculiarity is greatly admired by the men." Ho once saw a

56 'A Journey from Prince of Wales Fort,' 8ro. edit. 1796, p. 89.

37 Qunted by Prichard, 'Phy's. Hist. of Mankind,' $3 r$ d edit. vol. iv. 1844 , p. 519; Vogt, 'Lectures on Man, Eng. translat. p. 129. On the opinion of the Chinese on the Cingalese, E. Tennent, 'Ceylon,' 1859, vol. ii. p. 107.

* Prichad, as taken from Craw- furd and Finlayson, "Phys. Hist. o." Mankind,' vol. iv. Pp. 534, 535.

${ }^{39}$ Idem illustrissimus viator dixit mihi præcinctorium rel tibulam foeminx, quod nobis teterimum est, quondam permagno xstimari ab hominibus in hâc gente. Nunc res mutata est, et censent talem conformationem minime optandam esse. 
wonlin who was considered a leauty, and she was so immensely developed behind, that when scuted on level ground she could not rise, and had to push herself along until she came to a slope. some of the women in various negro tribes hive the same pecufiarity; and, according to Burton, the Somal men "are said to "choose therr wives by rauging them in a line, and by picking " her out who projects farthest a tergo. Nuthing can be more " hateful to a negro than the opposite form." " 60

With respect to colour, the negroes rallied Mungo Park on the whiteness of his skin and the prominence of his nose, both of which they considered as "unsightly and unnatural conforma"tions." Ire in return praised the glnssy jet of their skins and the lovely depression of their noses; this they said was, "honcy" mouth," nevertheless they gare him food. The African Moors, also, "lnitted their brows and seemed to shudiler" at the white. ness of his skin. On the eastern coast, the negro boys when they saw Burton, cried out "Look at the white man; does he not look "like a white ape?" On the western const, as Mr. Winwoou Reade informs me, the negroes admire a very black skin more than one of a lighter tint. But their horror of whiteness may be attributed, according to this same traveller, partly to the belicf held by most negroes that demons and spirits are white, and partly to their thinking it a sign of jll-health.

The Banyai of the more southern part of the continent are negroes, but " a great many of them are of a light coffee-and-milk "colour, and, indced, this colour is considered handsone "throughout the whole country;" so that here we have it different standard of taste. With the Kafirs, who differ much from negroes, "the skin, except among the tribes near Delago: "Bay, is not usually black, the prevailing colour being a mixturc "of black and red, the most common shade being chocolate. "Dark complexions, as being most common are naturally held in " the highest esteem. To be told that he is light-coloured, or" "like a white man, would be deemed a very poor compliment b! " a Kafir. I have heard of one unfortunate man who was so very "fair that no girl would marry him." One of the titles of the Zulu kiing is "Yo11 who are black." 61 Mr. Galton, in speakin!? to me ahout the natires of S. Africa, remarked that their ideas of

so 'The Anthropological Review; November, 1864, p. 237. For andditional references, see Waitz, 'Inrroduct. to Anthrop logy,' Eng. translat. 1863 , vol. i. p. 105.

o1 Mungo Park's 'Travels in Africs," 4to. 1816, pp. 53, 131.
Burton's statement is quoted by Schaaff' hausen, 'Archiv fir Anthropolog.' 1866, s. 163. On the Bany:i. Livingstone, 'Travels,' p. 64. $\mathrm{O}_{1}$ the Kafirs, the Rev. J. Shcoter. 'The Kafirs of Natal and the Zulu Country,' 1857, p. 1. 
heauty seem very different from ours; for in one tribe two slim, slight, and pretty girls were not admired by the natives.

Turning to other quarters of the world; in Java, a yellow, not a white girl, is considered, according to Madame Pfeiffer, a heauty. A man of Cochin China "spoke with contempt of the "wife of the Euglish Ambassador, that she had white tecth like "a dog, and a rosy colour like that of potato-flowers." We have seen that the Cbinese dislike our white skin, and that the N. Americans admire "a tawny hide." In S. America, the Yuracaras, who inhabit the wooded, damp slopes of the eastem Cordillera, aro remarkably pale-coloured, as their name in their own language expresses; nevertheless they cousider Luropean women as very inferior to their own. ${ }^{63}$

In several of the tribes of North America the hair on the head grows to a wonderful length; and Catlin gives a curions proof how much this is esteemed, for the chief of the Crows was elected to this office from having the longest hair of any man in the tribe, namcly ten feet and seven inches. The Aymaras and Quichuas of S. America, likewise have very long hair; and this, as Mr. D. Forbes informs me, is so much valued as a beauty, that cutting it off was the severest punishment which he conld inflict on them. In both the Northern and Southern halves of the continent the natives sometimes increase the apparent length of their hair by weaving into it fibrous substances. Although the hair on the head is thus cherished, that on the face is considered by the North American Indians "as rery vulgar," and ever'y hair is carefully eradicated. This practice prevails throughout the American continent from Vancourcr's Island in the north to Tierra del Fuego in the south. When York Minster, a Fuegian on board the 'Beagle,' was taken back to his country, the natives told him he ought to pull out the few short hairs on his face. They also threatened a young missionary, who was left for a time with them, to strip him naked, and pluck the hairs from his face and body, yet he was far frum being a hairy man. This fashion is carried so far that the Indians of Paraguay cradicate their eyebrows and eyelashes, saying that they do not wish to be like horses. ${ }^{63}$

a2 For the Jarans and CochinChinese, see Waitz, 'Introduct. to Anthropology,' Eng. transiat. vol. i. p. 305. On the Yura-caras, A. J'Orligny, as quoted in Prichard, 'Phys. Hist. of Mankind,' vol. v. 3rd odit. p. 476.

as 'North American Indians,' bv
G. Catlin, 3rd edit. 1842, rol, i. p. 49 ; vol. ii. p. 227 . On the natives of Vancouver's Island, see Sproat, 'Scenes and Studies of Savage Life, 1868 , p. 25. On the Indians of Paraguay, Azara, 'Voyages,' tom. ii. p. 105. 
It is remarkable that throughout the world the races which ire almost completely destitute of a beard, dislike hairs on the face and body, and take pains to cradicate them. The Kalmucks are beardless, and they are well known, like the Americans, to pluck out all straggling hairs; and so it is with the Polynesians, some of the Malays, and the Siamese. Mr. Veitch states that the Japancse ladies " all oljected to our whiskers, considering them "very ugly, and told us to cut them off, and be like Japanese " men." The New Zealanders have short, curled beards; yet they formerly plucked out the hairs on the face. They had a saying that " there is no woman for a hairy man ;" but it would appear that the fashion has changed in New Zealand, perhaps uwing to the presence of Europeans, and I am assured that. beards are now admired by the Maories. ${ }^{b-4}$

On the other hand, bearded races admire and greatly value their heards; among the Anglo-Saxons every part of the body had a recognised value; " the loss of the beard being estimated " at twenty shillings, while the breaking of a thigh was fixed at "only twelve." "In the East men swear solemnly by their heards. We have seen that Chinsurdi, the chief of the Makalolo in Africa, thought that beards were a great ornament. In the Pacific the Fijian's beard is "profuse and bushy, and is his "greatest pride;" whilst the inhabitants of the adjacent archipelagoes of Tonga and Samoa are "beardless, and abhor a rough "chin." In one island alone of the Ellice group "the men are "heavily bearded, and not a little proud thereof." 66

We thus see how widely the different races of man differ in their tasto for the boatiful. In every nation sufficiently adranced to lave made effigies of their gods or of their deified rulers, the sculptors no doubt have endeavoured to express their highest ideal of beauty and grandeur. ${ }^{67}$ Under this point of view it is well to compare in our mind the Jupiter or Apollo of the Greeks witb the Egyntian or Assyrian statues; and these with the hideous bas-reliefs on the ruined buildings of Central America.

I have met with very few statements opposed to this conclusion.

of On the Siamese, Prichard, ibid. vol. iv. p. 533. On the Japanese, Veitch in 'Gardeners' Chronicle,' 1860 , p. 1104. On the New Zealasders. Mantegnzza, "Viaggi e Studi,'1867, p. 526. For the other nations mentioned, see references in Lawrence, 'Lectures on Physiology,' \&c. 1822, p. 272.

as Lubbet, "Orisin of Cirilisa- tion,' 1870, p. 321.

6 Dr. Barnard Davis quotes Mr. Prichard and others for these facta in regard to the Polynesians, in 'Anthropological Review,' April, 1870 , p. $185,191$.

$67 \mathrm{Ch}$. Comte has remarks to this effect in his 'Traité de Législation,' 3rd edit. 1837, p. 136. 
YI. Winwood Rearle, however, who has had ample opportunities for olservation, not ouly with the negroes of the West Coast of Afriea, but with those of the interior who have never wssociated with Europeans, is convincel that their illeas of heauty are on the whole the same as ours; and Dr. Rolilfs writes to me to the same effect with respect to Bornu and the countries inhabited by the Pullo tribes. MIr. Feade found that he agreed with the negroes in their estimation of the beauty of the native wirls; and that their appreciation of the beanty of Emropean women corresponded with ours. 'They admire long hair, and use artificial means to make it appear abundant; they admire 'lso a beard, though themselves very scantily provicled. Mr. Reade feels doubtful what kind of nose is most appreciated: a :irl has been henrl to say, "I do not want to marry him, he has "got no nose;" and this shews that a very flat nose is not admired. We should, however, bear in mind that the depressed, broad noses and projecting jaws of the negroes of the West Coast aro (xceptional types with the inhalitants of Africa. Notwithstanding the foregoing statements, Mr. lieade admits that negroes " do not like the colour of our skin; they look on blue eyes with "aversion, and they think our noses too long and our lips too " thin." He does not think it probable that negroes would ever prefer the most beautiful European woman, on the mere grounds of physical admiration, to a good-looking negress. ${ }^{68}$

The general truth of the principle, long ago insisted on by Humboldt, ${ }^{\text {,i }}$ that man admires and often tries to exaggerate whatever characters zature may hare gircn him, is shewn in many ways. The practice of beardless races extirpating every trace of a beard, and often all the hairs on the body, affords one illustration. The skull has been greatly modified during ancient and modern times by many nations; and there can be little doubt that this has been practised, especially in $\mathrm{N}$. and $\mathrm{S}$. America, in order to exaggerate some natural and admired

68 The 'African Sketch Book,' vol. ii. $1873, \mathrm{pp} .253,394,521$. The Fnegians, as I have been informed by a missionary who long resided with them, consider European women as extremely beautiful; but from what wo have seen of the judgment of the other aborigines of America, I canot but think that this must be a mistake, unless indeed the statement refers to the few Fuegians who have lived for some time with Europeans, and who must consider us as superior beings. I should add that a most experienced observer, Capt. Burton, believes that a woman whom we consider beantiful is admired throughout the world, 'Anthropological Review,' March, 1864, p. 245.

69. 'Personal Nirrative, Eng. translat. vol. iv. p. 518 , and elsewhere, Mantegaxzi, in his "Vinggi e Studi,' 1867, strongly insists on this same principle. 
peculiarity. Minny American Indiuns are known to admire a head so extremely flattened as to appear to us idiotic. The natives on the north-western coast compress the head into a pointerl cone; and it is their constant practice to gather the hair into a knot on the top of the head, for the sake, as Dr. Wilson remarks, "of "increasing the apparent elevation of the favourite conoid form." The inhabitants of Arakhan "admire a broad, smooth forehead, " and in order to produce it, they fasten a plate of lead on the " heads of the new-born children." On the other hand, " a broad, "well-rounded occiput is considered a great beauty" by the natives of the Fiji islands. ${ }^{70}$

As with the skull, so with the nose; the ancient Huns during the age of Attila were accustomed to flatten the noses of their infants with bandages, "for the sake of exaggerating a naturai "conformation." With the Tahitians, to be called long-nose is considered as an insult, and they compress the noses and fore. heads of their children for the sake of beauty. The same holds with the Malays of Sumatra, the Hottentots, certain Negroes, and the natives of Brazil.i The Chinese have by nature unusually small feet; ${ }^{72}$ and it is well known that the womer of the unper classes distort their feet to make them still smaller. Lastly, Humboldt thinks that tho American Indians profer colouring their bodies with red paint in order to exaggerate their natural tint; and until recently European women added to their naturally bright colours by rouge and white cosmetics; but it may be doubted whether barbarous nations have generally had any such intention in painting themselves.

In the fashions of our own dress we see cxactly the same principle and the same desire to carry every point to an crtreme; we exhibit, also, the same spirit of cmulation. But the fashions of sevages are far more permanent than ours; and whenever their bodies are artificially modified, this is necessarily the case. 'The Arab women of the Upper Nile occupy about three days in dressing their hair; they never imitate other tribes, "but simply

90 On the skulls of the American tribes, see Nott and Gliddon, 'Types of Mankind,' 1854 , p. 440 ; Prichard, 'Phys. Hist. of Mankind,' vol. i. 3rd edit. p. 321 ; on the natives of Arakhan, .bid. vol. iv, p. 537. Wilson, 'Physical Ethnology,' Smithsonien Institution, 1863, p. 288 ; on the Fijians, p. 290. Sir J. Lubbock ('Prehistoric Times,' 2nd euit. 1869 , p. 506) gives an excallent résumé on this subjoct.
"On the Huns, Godron, 'De l'Fispece,' tom. ii. 1859 , p. 300. On the Tahitians, Waitz, "Anthropolog.' Eng. translat. vol. i. p. 305 Marsden, quoted by Prichard, 'Phys. Hist. of Mankind,' 3 rd edit. vol. $v$. p. 67. Lawrence, "Lectures on Physiology,' p. 337.

72 This fant was ascertained in the 'Reise der Novara: Anthropolog. 'Thiel,' Dr. Weisbrch, 1867, 8. 265. 
" vic with each other in the superlativeness of their own style." 1)r. Wilson, in speaking of the compressed sluulls of various American races, adds, "such usages are among the least eradi"cable, and long survive the shock of revolutions that change "dynasties and effuce more important national peculiarities." ${ }^{3}$ The same principle comes into play in the art of brceding; and we can thus understand, as I have elsewhere explained, ${ }^{7 *}$ the wonderful development of the many races of animals and plants, which have been kept merely for ornament. Fanciers always wish each character to be somewhat increased; they do not admire a medium standard; they certainly do not desire any great and abrupt change in the character of their brceds; they admire solely what they are accustomed to, but they ardently desire to see each characteristic feature a little more developed.

The senses of man and of the lowrer animals seem to be so constituted that brilliant colours and certain furms, as well as harmonious and rhythmical sounds, give pleasure and are called beautiful; but why this should be so, wo know not. It is certainly not true that there is in the mind of man any universal standard of beauty with respect to the human hody. It is, however, possible that certain tastes may in the course of time become inherited, though there is no evidence in farour of this helief; and if so, each race would possess its own inmate ideal standard of beauty. It has been argued ${ }^{75}$ that unliness consists in an approach to the structure of the lower animals, and no loubt this is partly true with the more civilised nations, in which intellect is highly appreciated; but this explanation will hardly apply to all forms of ugliness. The men of each race prefer what they are accustomed to; they cannot cndure any sreat change; but they like varicty, and admire each characteristic carried to a modcrate extreme. ${ }^{75}$ Men accustomed to a nearly oval face, to straight and regular features, and to bright colours, admire, as we Europeans know, these points when strongly developed. On the other hand, men accustomed to a broad face, with high cheek-bones, a depressed nose, and a black skin, admire these peculiarities when strongly marked.

73 'Smithsonian Institution,' 1863. 1. 289. On the fashions of Arab women, Sir S. Baker, 'The Nile 'Tributaries,' 1867, p. 121.

74 'The Variation of Animals and Plants unaer Dornestication,' rol. i. P. 214 ; vol. if. p. 240.

75 Srhat? :ausen, "Archjy fír
Anthropologie,' 1866, s. 164.

$76 \mathrm{Mr}$. Bain has collected ('Men. tal and Moral Science,' 1868, pp. 304-314) about a dozen more or less different theories of the idea $c_{s}^{s}$ betuty; but none are quite the same as that here giveo. 
No doubt characters of all kinds may be ton much developed for beauty. Hence a perfect beauty, which implies many characters modified in a particular manner, will be in every race a prodigy. As the great anatomist Bichat long ago said, if every one were cast in the samo mould, there would be no such thing as beanty. If all our women were to become as heautiful as the Venus de' Medici, we should for a time be charmed; but we should soon wish for variety; and as soon as we had obtained variety, wo should wish to sce certain characters a little exagrgerated beyoud the then existing common standard.

\section{CHAPTER XX.}

Secondary Srxual Characteris of Man-continucd.

On the efirects of the continued selection of women according to a dillerent standard of beauty in each race-On the causes which interfere witl sexual selection iu cirilised and sarage nations-Conditions farourable to sexual selection during primeral times-On the manner of action of sexual selection with mankind-On the women in savage tribes having some power to choose their husbands-Absence of hair on the body, and development of the beard-Colour of the skin-Summary.

We have seen in the last chapter that with all barbarous races ornaments, dress, and external appearance are highly valued; and that the men judge of the beauty of their women by widely different standards. We must next inquire whether this preference and the consequent selection during many generatious of those women, which appear to the men of each race the most ittractive, has altered the character either of the females alone, or of both sexes. With mammals the general rule appears to be that characters of all kinds are inherited equally by the: males and females; wo might therefore expect that with mankind any characters gained by the females or by the males through sexual selection, would commonly be transferrerl to the: offispring of both sexes. If any change has thus been effected, it is almost certain that the different races would be differently modified, as each has its own standard of beauty.

With mankind, especially with savages, many causes interfere with the action of sexual selection us far as the bodily frame is eoncerned. Civilised men are largely attracted by the mental charms of women, by their wealth, and especially by their social position; for men rarely marry into a much lower rank. The men who succeed in obtuining the more beautiful women, will not have a better chance of leaving a long line of descendants 
than other men with plainer wives, save the few who bequeath their fortunes according to primogeniture. With respect to the opposite form of selection, namely of the more attractive men by the women, although in civilised nations women have free or almost free choice, which is not the case with barlarous races, yet their choice is largely influenced by the social position and wealth of the men; and the success of the latter in life depends much on their intellectual powers and energy, or on the fruits of these same powers in their forefathers. No excuse is needed for treating this subject in some detail; for, as the German plilosopher Schopenhauer remarks, "the final aim of all love " intrigues, be they comic or tragic, is really of more importance "than all other ends in human life. What it all turns upon is " nothing less than the composition of the next generation. . . . "It is not the weal or woe of any one individual, but that of the " human race to come, which is here at stake." "

There is, however, reason to believe that in certain civilised and semi-civilised nations sexual selection has effected something in modifying the bodily frame of some of the members. Irany persons are convinced, as it appears to me with justice, that our aristocracy, including under this term all wealthy fumilies in which primogeniture has long prevailed, from having 1hosen during many gencrations from all classes the more beautiful women as their wives, have becolne handsomer, according to the European standard, than the middle classes; yet the middle ciasses are placed under equally favourable conditions of life for the perfect development of the body. Cook remarks that the superiority in personal appearance "which is olservable in "the erees or nobles in all the other islands (of the Pacific) is "found in the Sandwich islands;" but this may be chiefly due to their better food and manner of life.

The old traveller Chardin, in describing the Persians, says their "blood is now highly refined by frequent intermixtures "with the Georgians and Circassians, two mations which surpass " all the world in personal beauty. There is hardly a man of " rank in Persia who is not born of a Georgian or Circassian " mother." He adds that they inherit their beauty, "not from "their ancestors, for without the above mixture, the men of " rank in Persia, who are descendants of the Tartars, would be "extremely ugly." " Here is a morc curious case; the priestessos

1 'Schopenhauer and Darwinism,' in 'Journal of Anthropology,' Jan. 1871, p. 323.

2 These quotations are taken from Law gnce ('Lectures on Physiologr?' \&c. 1822, p. 39.i), who attributes the beaty of the upper classes in England to the men having long selected the more beautiful wcmen. 
who attended the temple of Yenus Erycina at San-Giuliano in Sicily, were selected for their beanty out of the whole of Greece; they were not vestal virgins, and Quatrefages, ${ }^{3}$ who states the firegoing fact, says that the women of San-Ginliano are now fimous as the most beautiful in the island, and are sought by artists as models. But it is obvious that the evidence in all the above cases is doubtful.

The following case, though relating to savages, is well worth giring from its curiosity. Mr. Winwood Reade informs me that the Jollofs, a tribe of negroes on the west coast of Africa, "are "remarkable for their uniformly fine appearance." A friend of his asked one of these men, "How is it that uvery one whom I " meet is so fine-looking, not only your men, but your women?" The Jollof answered, "It is very easily explained: it has always " been our custom to pick out our worse-looking slaves and to " sell them." It need hardly be added that with all savages, female slaves serve as coneubines. That this negro should have attributed, whether rightly or wrongly, the fine appearance of his tribe to the long-continued elimination of the ugly women is not so surprising as it may at first appear; for I have elsewhere shewn that negroes fully appreciate the importance of selection in the breeding of their domestic animals, and I could give from Mr. Reade additional evidence on this head.

The Cuns s which prevent or check the Action of Sexual Selection. with Savayes.-The chief causes are, first, so-called communal marriages or promiscuous intercourse; secondly, the consequences of female infanticide; thirdly, early betrothals; and lastly, the low estimation in which women are held, as mere slaves. Theso four points must be considered in some detail.

It is obvious that as long as the pairing of man, or of any other animal, is left to mere chance, with no choice exerted by either sex, there can be no sexual selection; and no effect will be produced on the offspring by certain individuals having had an advantage orcr others in their courtship. Now it is asserted that there exist at the r.resent day tribes which practise what Sir J. Luhbork ly courtesy calls communal marriagres; that is, all the men and women in the tribe are hushands aud wives to one another. The licentiousness of many savages is no doubt astonishing, lut it seems to me that morc evidence is requisite, hefore we fully admit that their intercourse is in any case promiscuous. Nerertheless all those who have most closely studied the subject,

3 'Anthropologie,' 'Iierue des Plants under Domestication,' rol. i. Cours Scientifiques,' Oct. 1868, p. p. 207.

:21.

${ }^{5}$ Sir J. Lubbock, "The Origin of

- 'The Variation of Animals and Civilisation,' 1870, chap. iii. especi- 
and whose julgment is worth much more than mine, believe that communal marriage (this expression heing variously gnarded? was the original and universal form throughout the world, including therein the intermarriage of hrothers and sisters. The lato Sir A. Smith, who had travelled widely in S. Africa, a knew much about the habits of savages there and elsewhere, ex. pressed to me the strongest opinion that no race exists in which woman is considered as the property of the community. I believe that his judgment was largely determined by what is implied by the term marriage. Throughout the following discussion I use the term in the same sense as when naturalists speak of animals as monogamous, meaning therchy that the male is accepted by or chooses a single female, and lives with her either duxing the breeding-season or for the whole year, keeping possession of her by the law of might; or, as when they speak of a polygamous species, meaning that the male lives with sercral fomales. This kind of marriage is all that concerns us here, as it suffices for the work of sexual solection. But I know that some of the writers above referred to, imply by the term marriage, a recognised right, protected by the tribe.

The indirect evidence in farour of the belief of the former prevalence of communal marriages is strong, and rests chicfly on the terms of relationship which are employed between the members of the same tribe, implying a connection with the tribe, and not with either parent. But the subject is too large and complex for even an abstract to be here given, and I will confine myself to a fer remarks. It is evident in the case of such marriages, or where the marriage tie is very loose, that the relationship of the child to its father cannot be known. But it seems almost incredible that the relationship of the child to its inother should ever be completely ignored, especially as the women in most sarage tribes nurse their infants for a long time. Accordingly, in many cases the lines of descent are traced through the mother alone, to the exclusion of the father. But in other cases the terms employed express a connection with the

ally pp. 60-67. Mr. M'Lennan, in his extremely valuable work on

' Primitive Marriage,' 1865, p. 163, :peaks of the union of the sexes "in the earliest times as loose, "transitory, and in some degree "promiscuous." Mr. M'Lennan and S. Jubbock have collected much eridence on the extreme licentiousness of savages at the present time. Str. L. H. Morgan, in his interesting memoir on the classificatory system of relationship ("Proc. American Acad. of Sciences,' vol. vii. Feb. 1868 , p. 475), concludes that polygamy and all forms of marriage during primeval times were essentially unknown. It appears also, from Sir J. Lubbock's work, that Bachofen likewise believes that communal intercurse originally prevailed. 
tribe alone, to the exclusion even of tho mother. It seems possible that the connection between the related members of the same barbarous tribe, exposed to all sorts of danger, might be so much more important, owing to the need of mutual protection and aid, tham that betwe on the mother and her child, as to lead to the sole use of terms expressive of the former relationships; but Mr. Horgan is courinced that this view is hy no means sufficient.

The terms of relationship uscd in different parts of the world may be divided, accorling to the anthor just quoted, into two great classes, the classificatory and descriptive,-the latter being employed ly' us.s. It is the classificatory system which so strongly lears to the belief, that communal and other extremely loose forms of marriage were originally universal. But as far as I can sce, there is no necessity on this ground for believing in absolutely promiseuons intercourse; and I am glad to find that this is Sir J. Lubbock's view. Men and women, like many of the lower animals, might formerly have entered into strict thoughi temporary unions for each birth, and in this case nearly as much confusion would have arisen in the terms of relationship, as in the case of promiscuous intercourse. As far as sexual selection is concerned, all that is required is that choice should be exerted before the parents unite, and it signifies little whether the unions last for life or only for a season.

Besides the evidence derived from the terms of relationship, other lines of reasoning indicate the former wide prevalence of communal marriage. Sir J. Lubbock accounts ${ }^{6}$ for the strange and widely-extended halit of exogamy-that is, the men of one tribe taking wives from a distinct tribe,-by communism having been the original form of intercourse; so that a man never obtained a wife for himself unless he captured her from a neignhouring and hostile tribe, and then she would naturally have become his sole and valuable property. Thus the practice of capturing wires might have arisen; and from the honour so gained it might ultimately have become the unirersal habit. According to Sir J. Lubbock, we can also thus understand " the "necessity of expiation for marringe as an infringement of tribal "rites, since, according to old ideas, a man had no right to "appropriate to himself that which belonged to the whole "tribe." Sir J. Lubbock further gives a curious body of facts shewing that in old times high honour was bestowed on women who were utterly licentious; and this, as he explains, is

- Address to British Association (1n the Social and Religious Con- dition of the Lower Rnces of Man, : 1870. p. 20. 
intelligible, if we admit that promiscuous intercourse was the aboriginal, and therefore long revered custom of the tribe.

Although the manner of development of the marriage-tie is an obscure subject, as we may infer from the divergent opinions un several points between the three authors who have studied it most closely, namely, Mr. Morgan, Mr. M'Lennan, and Sir J. Lubbock, yet from the foregoing and several other lines of evidence it seems probable ${ }^{8}$ that the habit of marriage, in any strict sense of the word. has been gradually developed; and that almost promiscuous or very loose intercourse was once extremely common throughout the world. Nevertheless from the; strength of the feeling of jealousy all through the animill kingdom, as well as from the analogy of the lower animals, mole particularly of those which come nearest to man, I cannots beliere that absolutely promiscuous intercourse pretailed in times past, shortly before man attained to his present rank in the zoological scale. Man, as I have attempted to shew, is certainly descended from some ape-like creature. With the existing Quadrumana, as far as their habits are known, the males of some species are monogamous, but live during only a part of the year with the females; of this the orang seerns to afford an instance. Several kinds, for example some of the Indian and American monkeys, are strictly monogamous, and associate all the year round with their wires. Others are polygamous, for example the gorilla and several American species, and each family lives separate. Even when this occurs, the families inhabiting the same district are probably somewhat social: the chimpanzee, for instance, is occasionally met with in large bands. Again, other species are polygamous, but sevural males, each with his own females, live associated in a body, as with several species of baboons. ${ }^{9}$ We may indeed conclude from what we know of the jealousy of all male quadrupeds, armed, as many of them are, with special weapons for battling with their rivals, that promiscuous intercourse in a state of nature is cxtremely

' 'Origin of Civilisation,' 1870, p. 86 . In the several works above quoted, there will be found copious eridence on relationslip through the females alone, or with the tribe slone.

${ }^{8}$ Mr. C. Staniland Wake argues strongly ('Anthropologia,' March, 1874, p. 197) against the views held py these three writers on the former prevaleace of almost promiscuous Latercourse; and he thinks that the classificatory system of relationship can be otherwise explained.

- Brehm ('Ilust. Theirleben,' B. i. p. 77) says Cynocephalus hamadryas lives in great troops contaiuing twice as many adult females as adult males. See Rengger on American polygamous species, and Uwed ('Anat. of Vertebrates,' rol. iii. ]. 746) on American monogamous species, Other references raight be added. 
improbable. The pairing may not last for life, but ouly for eaci birth; yet if the males which are the strongest and best able to defend or otherwise assist their females and young, were to select the more attractive females, this rould suffice for sexual selection.

Therefore, looking far enough back in the stream of time, and judging from the sooial habits of man as he now exists, the most probable view is that he aboriginally lired in small communities, each with a single wife, or if powerful with several, whom he fealously guarded against all other men. Or he may not have been a social animal, and yet have lived with several wives, like the gorilla; for all the natives "agree that but one adult male " is seen in a band; when the young male grows up, a contest "takes place for mastery, and the strongest, by killing and " driving out the others, establishes himself as the head of the "community." "The younger males, being thus expelled and wandering about, would, when at last suecessful in finding a partuer, prevent too close interbreeding within the limits of the same family.

Although savages are now extremely licentious, and although communal marriages may formerly have largely prevailed, yet many tribes practise some form of marriage, but of a far more lax nature than that of civilised nations. Polygamy, as just stated, is almost unirersally followed by the leading men in every tribe. Nerertheless there are tribes, standing almost at the bottom of the scale, which are strictly monogamous. This is the case with the Veddahs of Ceylon: they have a saying, according to Sir J. Lubbock," "that death alone cau separate husband and wifc." An intelligent Kandyan chief, of course a polygamist, "wais "perfectly scandalised at the utter barbarism of living with "only one wife, and never parting until scparated by death." It was, he said, "Just like the Wanderoo monkeys." Whether" savages who now enter into some form of marriage, either polygamous or monogamous, have retained this habit from primeval times, or whether they have returned to some form of marriage, after passing through a stage of promiscuous intercourse, I will not pretend to conjecture.

Infanticide.-This practice is now very common throughout the world, and there is reason to believe that it prevailed much more extensively during former times. ${ }^{12}$ Barbarians find it

10 Dr. Savage, in 'Boston Journal of Nat. Hist.' vol. v. 1945-47, p. 423.

11 'Prehistoric Times,' 1869, p.
12 Mr. M'Lennan, 'Primitive Marriage,' 1865. See especialiy on exogamy and infanticide, pp. 13J; 138,165 .

\section{4}


dificult to support themselves and their children, and it is a simple plan to kill their infants. In South America some tribes, according to Azara, formerly destroyed so many infauts of both sexes, that they were on the point of extinction. In the Polynesian Islands women have been knomn to kill from futn or five, to even ten of their children; and Ellis could not find it single voman who had not killed at least one. In a village on the castern frontier of India Colonel MacCulloch found not a single fomale child. Wherever infanticide ${ }^{13}$ prevails the struggrle for existence will he in so far less severe and all the members of the tribe will have an almost equally good chance of rearing their few surviving children. In most cases a larger number of female than of male infants are clestroyed, for it is obvious that the latter are of more value to the tribe, as they will, when grown up, aid in defending it, and can support thomselves. But the trouble experienced by the women in rearing children, their consequent loss of beanty, the higher estimation set on them when few and their happier fate, are assigned by the women themselves, and by various onservers, as additional motives for infanticide.

When, owing to female infanticide, the women of a tribe were few, the habit of capturing wives from neighbouring tribes would naturally arisc. Sir J. Lubbock, however, as we have seen, attributes the practice in chief part, to the former existence of communal marriage, and to the men haring consequently captured women from other tribes to hold as their sole property. Additional causes might he assigned, such as the communitics being very small, in which case, marriageable women would often be deficient. That the habit was most extensively practised during former times, even by the aucestors of civilised nations, is clearly shewn by the preserration of many curious customs and ceremonies, of which Mr. Mr'Lemnan has given an interesting account. In our own marriages the "best man" seems originally to have been the chicf abettor of the bridegroom in the act of capture. Now as long as men habitually procured their wives through violence and craft, they would have been glad to seize on any woman, and would not have selected the more attractj re ones. But as soon as the practice of procuring wives from a distinct tribe was effected through barter, as now occurs in many placer.

13 Dr. Gerland ('Ueber das Aussterben der Naturvölker,' 1868) has collected much information on infanticide, see especially s. 27,51 , 54. Azara ("Voyages," \&c. tom. ii. pp. 94, 116) enters in detail on the motires. See also M'Laman (ibid. p. 139) for cases in India. In the former reprints of the 2 nd edition of this book an incorrect quotation from Sir G. Grey was un fortunately given in the above passige and hida now been remored from the text. 
the more attractive momen wouid generally have been purchasch. The incessaut crossing, however, between tribe and tribe, which necessarily follows from any form of this habit, would tend to keep all the people inhabiting the same country nearly uniform in character; and this would interfere with the power of sexual selection in differentiating the tribes.

The scareity of women, consequent on female infinticide, leads, also, to another practice, that of polyandry, still common in several parts of the world, and which formerly, as Mr. MI'Lennan bolieves, prevailed almost universally; but this latter conclusion is doubted by Mr. Morgan and Sir J. Lubbock. ${ }^{\text {it }}$ Whenever trin or more men are compelled to marry one woman, it is certain that all the women of the tribe will get married, and there will be no selection by the men of the more attractire women. But under these circumstances the women no doubt will have tho power of choice, and will prefer the more attractive men. Azara, for instance, describes how carefully a Guana woman bargains fur all sorts of privileges, before accepting some one or more huslmuds; and the men in consequence take unusual care of their personal appearance. So amongst the Todas of India, who jractise polyandry the girls can accept or refuse any man. ${ }^{15}$ A very ugly man in these cases would perhaps altogether fail in getting a wife, or get one later in life; but the handsomer men, although more successful in obtaining wives, would not, as far as we can see, leave more offspring to inherit their beauty than the less handsome Lusbands of the same women.

Eurly Betrothals and. Sluvery of Women.-With many savages it is the custom to betroth the females whilst mere infants; and this would effectually prevent preference being exerted on either side according to personal appearance. But it would not prevent the mole attractive women from being afterwards stolen or taken by force from their hushands by the more powerful men; and this often happens in Australia, America, and elsewhere. The same consequences with reference to sexual selection would to a certain extent follow, whon women are valued almost solely as slares or beasts of burden, as is the case with many savages. The men, horvever, at all times would prefer the handsomest slaves according to their standard of beauty.

We thus see that several customs prevail with savages which must greatly interfere with, or completely stop, the action of sexual selection. On the other hand, the conditions of life to

14 'Primitive Marriage,' p. 208; Sir J. Lubbock, 'Origin of Civilisation,' p. 100 . See also Mr. Morgan, loc. cito, oz tice former prevaleuce of polyandry.

is Azara, 'Voyages,' \&c. tom. ii. pp. 9:-95, Colonel Marshall, 'Amorgst the Tudat, p. 212. 
which savages are exposed, and some of their habits, are favourable to natural selection; and this comes into play at the same time with sexual selection. Savages are known to suffer severely from recurrcnt famines; they do not increase their food by artificial means ; they rarely refrain from marriage ${ }^{16}$ and generally marry whilst young. Consequently they must be suljected to occasional hard struggles for existence, and the furoured individuals will alone survive.

At a very early period, before man attained to his present rank in the scale, many of his conditions would be different from what now obtains amongst savages. Judging from the analogy of the lower animals he would then either live with a single female. or be a polygamist. The most powerful and able males would succecd best in obtaining attractive females. They would also sueceed hest in the general struggle for life, and in defending their females, as well as their offispring, from enemies of all kinds. At this early period the ancestors of man would not be sufficiently adranced in intellect to lock forward to distant contingencies; they would not foresee that the rearing of all their children, especially their female children, would make the struggle for life severer for the tribe. They would be governed more by their instincts and less by their reason, than are savages at the present day. They would not at that period have partially lost one of the strongest of all instincts, common to all the lower animals, namely the love of their young offsyring; and conseguently they would not have practised female infanticide. Women would not have been thus rendered scarce, and polyandry would not hare been practised; for hardly any other cause, except the scarcity of women seems sufficient to break down the natural and widely prevalent feeling of jealousy, and the desire of each male to possess a female for himself. Polyandry wonld be a natural stepping-stone to communal marriages or almost jromiscuous intercourse; though the best authorities believe that this latter habit precerled polyandry. During primordial times there would be no carly betrothals, for this implies foresight. Nor would women be valued merely as useful slaves or beasts of burthen. Both sexes, if the females as well as the males were permitted to exert any choice, would choose their partners not for mental charms, or property, or social position, but almost solely from external appeurance. All the adults would marry or pair,

18 Burch 11 says ('Travels in S. Africa, vol. ii. 1824, p. 58), that among the wild nations of Southern Africa, neither men nor women erer pass their lives in a state of celibacy.
Azara ('Voyages dans l'Amérique Merid.' tom. ii. 1809 , p. 21) makes precisely the same remark in regard to the wild Indians of South Ame. rica. 
and all the offspring, as far as that was possible, would te reared; so that the struggle for existence would be periodically excessively severe. Thus during these times all the conditiens for sexual selection would have been more favourable than at a later period, when man had advanced in his intellectual powers lut had retrograded in his instincts. Therefore, whatever influence sexual selection may have had in producing the differences between the races of man, and between man and the higher Quadrumana, this influence would have been more powerful at a remote period than at the present day, though. probably not yet wholly lost.

The Mumner of Action of Sexual Selection with Mankind.- With primeval men under the favourable conditions just stated, and with those savages who at the present time enter into any marriage tie, sexual selection has probably acted in the following manner, subject to greater or less interference from female infinticide, early betrothals, \&c. The strongest and most vigorous men,- those who could best defend and hunt for their families, who were provided with the best weapons and possessed the most property, such as a large number of dogs or other animals, - would succeed in rearing a greater average number of offspring than the weaker and poorer members of the same tribes. There can, also, be no doubt that such men would scuerally be able to select the more attractive women. At jresent the chiefs of nearly every tribe throughout the world succeed in obtaining more than one wife. I hear from $\mathrm{Mr}$. Mantell, that until recently, almost every girl in New Zealand, who was pretty, or promised to le pretty, was tapu to some chief. With the Kafirs, as Mr. C. Hamilton states, ${ }^{17}$ " the "chiefs generally have the pick of the womon for many miles "round, and are most persevering in establishing or confirming "their privilege." We have seen that each race has its own style of beauty, and we know that it is natural to man to admire each characteristic point in his domestic animals, dress, ornaments, and personal appearance, when carricd a little beyond the arerage. If then the several foregoing propositions be admitted, and I cannot see that they are doubtful, it would be an inexplicable circumstance, if the selection of the more attractive women by the more powerful men of cach tribe, who would rear on an average a greater number of children, did not after the lapso of many generations somewhat modify the character of the tribe.

When a foreign breed of our domestic animals is introduced into a new country, or when a native breed is long and carefully

18 'Anthropological Review,' Jan. 1870, p. sw. 
attended to, either for use or ornament, it is found after severa? grenerations to have undergone a greater or less amount of change, whenever the means of comparison cxist. This follows from nnconscious sclection during a long series of gencrations-that is, the preservation of the must approved individuals-without any: wisl or expectation of such a result on the part of the breeder. So arrain, if during many years two careful breeders rear animals of the same family, and do not compare them together or with a common standard, the animals are found to have become, to the surprise of their owners, slightly different. ${ }^{18}$ Each breeder has impressed, as Von Nathusius well expresses it, the character of his own mind-his own taste and jutgment-on his animals. What reason, then, can be assigned why similar results should not follow from the long-continued selection of the most admired women by those men of each trilu, who were able to rear the greatest number of children? This would be unconscious selection, for an effect would be produced, independently of any wish or expectation on the part of the men who preferred certain women to others.

Let us suppose the members of a tribe, practising some form of marriage, to spread over an unoccupied enntinent, they woulc? soon split up into distinct hordes, scparated from each other by various barriers, and still more effectually by the incessant wars hetween all barharous nations. The hordes would thus be exposed to slightly different conditions and habits of life, and would sooner or later come to differ in some small degree. As soon as this occurred, cach isolated tribe would form for itself a slightly different standard of beauty; ${ }^{19}$ and then unconscious selection would come into action through the more powerful and leading men preferring certain women to others. Thus the differences between the tribes, at first rery slight, would gradually and inevitably be more or less increaserl.

With animals in a state of nature, many charncters propor to the males, such as size, strength, special weapons, courage and pusnacity, have been acquired through the law of battle. The semi-hmman progenitor's of man, like their allies the Quadrumana, nill almost certainly have been thus modified; and, as savages still fight for the possession of their women, a similar process of

18 'The Variation of Animals and Plants under Domestication,' rol. ii. pp. 210-217.

10 An ingenious writer argues, from a comparison of the pictures of Raphael, Rubens, and modern
French artists, that the idea of beauty is not absolutely the same even throughout Europe: see the 'Lires of IIaydn and Mozart,' by liombet (otherwise M. Berle), Euglish translat. p. $2 \% 9$. 
sulection has probably gone on in a greater or less degree to the present day. Other characters proper to the males of the lower animals, such as bright colour's and various ornaments, have been acquired by the more attractive males having been preferred by the females. 'L'here are, however', exceptional cases in which tho males are the selecters, instead of haring been the solected. Wo recoguise such cases by the females being more highly ornamented than thio males, - their ornamental characters having been transmitted exclusively or chiefly to their female offspring. One such case has been described in the order to which man belongs, that of the Rhesus monkey.

Man is more powerful in body and mind than woman, and in the savage state he keeps her in a far more abject state of bondage, than does the male of any other animal; therefore it is not surprising that he should have gained the power of selection. Women are every where conscious of the value of their own beauty; and when they have the means, they take more delight in decorating themselves with all sorts of ormaments than do men. They borrow the plumes of male hirds, with which nature has decked this sex in order to char'm the females. As women have long been selected for beanty, it is not surprising that some of their successive variations should have been transmitted exclusively to the same sex; conseruently that they should have transmitted beauty in a somewhat higher degree to their female than to their male offspring, and thus have become more beautiful, according to general olumion, than inen. Women however, certainly transmit most of their cliaracters, including some beauty, to their offspring of both scxes; so that the continued preference by the men of each race for the more attractive women, according to their standirrl of tasto, will hare touded to modify in the same manner all the inclividuals of both sexes belonging to the race.

With respect to the other form of scxual selection (which with the lower animals is much the more common), namely, when the females are the selecters, and accept only those males which excite or charn them most, we lare reason to believe that it formerly acted on our progenitors. Iran in all probability otres his beard, and perhaps somo other characters, to inheritance from an ancient j)rogenitor who thus gained his ornaments. But this form of selection may have occasionally acted during later times; for in uttcrly barbarous tribes the women have more power in choosing, rejecting, and tempting their lovers, or of afterwards changing their lussbands, than might have been expected. As this is a point of some importance, I will give in detail such evidence as I have been able to collect.

Elea:ve descrilus low a woman in one of the iribes of Arctic 
America repentedly ran away from her husband and joincd he? lover ; and with the Charruas of S. America, according to Azaril. divorce is quite optional. Amongst the Abipones, a man on choosing a wife, bargains with the parents about the price. But "it frequently happens that the girl rescinds what has been "agreed upon between the parents and the bridegroom, "obstinately rejecting the very mention of marriage." She often: runs away, hides herself, and thus cludes the bridegromm. Captain Musters who lived with the Patagonjaus, says that their. marriages are always settled by inclination; "if the parents "make a match contrary to the danghter's will, she refuses aud "is never compelled to comply." In Tierra del Fuego a youm: man first oltains the consent of the parents hy doing the some service, and then he attempts to carry off the girl; "but if she is "unwilling, she hides herself in the woods until her admirur is "heartily tired of looking for her, and gives up the pursuit; but "this seldom happens." In the Fiji Islands the mal suizes or the woman whom ho wishes for his wife by actual or pretenderl force; but " on reaching the home of her alductor, should she not "approve of the match, she runs to some one who can protect. "her : if, however, she is satisfied, the matter is settled forthwith." With the Kalmucks there is a regular race between the bride and bridegroom, the former having a fair start; and Clarke "was "assured that no instance occurs of a girl being caught, unless "she has a partiality to the pursuer." Amongst the wild tribes of the Malay Archipelago there is also a racing match; and it appears from M. Bouricn's account, as Sir J. Lubbock remarls, that " the race "is not to the swift, nor the battle to the strong," "but to the joung man who has the good fortune to please "his intended bride." A similar custom, with the same result, prevails with the Koraks of North-Eastern Asia.

Turning to Africa: the Kafirs buy their wives, and girls are severely beaten by their fathers if they will not accept a chosen husband; but it is manifest from many facts given by the Rer. Mr. Shooter, that they hare considcrable porrer of ehoice. Thus, very ugly, though rich men, have been known to fail in gettin: wives. The girls, before consenting to be betrothed, compel the. men to shew themselves off first in front and then behind, and "exhibit their paces." They have been known to propose to a man, and they not rarely run away with a favoured lover. So ngain, Mr. Leslie, who was intimately acquainted with the Kafirs, says, "it is a mistake to imagine that a chirl is sold by her father "in the same manner, and with the same authority, with wilich "he would dispose of a cow." Amongst the degraded Bushmen of S. Africa, "when a girl has grown up to womanhood 
" without having been betrothed, which, however, does not often " happen, her lover must gain her approbation, as well as that of " the parents." "0 Mr, Winwood Reade made inquiries for me with respect to the negroes of Western Africa, and ho informs me that " the women, at least among the more intelligent Pagau "tribes, have no difficulty in getting the husbands whom they "may desire, although it is considered unwomanly to ask a "man to marry them. They are quite capable of falling in love, "and of forming tender, passionate, and faithful attachments." Additional cases could be given.

We thus see that with sarages the romen are not in quite so alject a state in relation to marriage, as has often been supposed. They can tempt the men whom they prefer, and can sometimes reject those whom they dislike, either before or after marriage. Preference on the part of the women, steadily acting in any onc. direction, would ultimately affect the character of the tribe; for the women would generally choose not merely the handsomest men, accorling to their standard of taste, but those who were at the same time best able to defend and support them. Such wellendower pairs would commonly rear a larger number of offspring than the less favoured. The same result would obviously follow in a still more marked manner, if there was selection on both sides; that is if the more attractive, and at the same time more powerfu! men were to prefer, and were preferred by, the more attractive women. And this double form of sclection seems actually to have occurred, especially during the earlier periods of our long history.

We will now examine a little more closely some of the characters which distinguish the several races of man from one another and from the lower animals, namely, the greater or less deficicney of hair on the body, and the colour of the skin. We need say nothing about the great diversity in the shape of the features and of the skull between the different races, as we havo seen in the last chapter how different is the standard of beauty in these

20 Azara, 'Voyages,' \&c. tom. ii. p. 23. Dobrizhoffer, 'An Account of the Abipones,' vol. ii. 1822, $\mathrm{p}$. 207. Capt. Musters, in 'Proc. R. Geograph. Soc., vol. xv. p. 47. Williams on the Fiji Islanders, as quoted by Lubbock, 'Origin of Civilisation,' 1870 , p. 79 . On the Fuegians, King and FitzRoy, 'Voyages of the Adventure and Beagle,' vol. ii. 1839, p. 182 . On the Killmacks, quoted by M'Lennan, 'Pri- mitive Marriage,' 1865, p. 32. On the Malays, Lubbock, ibid. p. 7if. The Rev. J. Shuoter, 'On the Kafirs of Natal,' 1857, pp. 52-60. Mr. D. Leslie, 'Kafir Character' and Costoms,' 1871 , p. 4. On the Bush-men. Burchell, 'Travels in S. Africn.' vol. ii. 1824, p. 59. On the Koraks by McKennan, as quoted by $\mathrm{Mr}$. Wake, in 'Anthropolugia,' Oct. 187', p. 75 . 
respects. These characters will therefore prolably liave beet acted on through sexual selection; but we have no means of judging whether they have been acted ou chicfly from the male or female side. The musical faculties of man have likewise becn already discussed.

Absence of llair on the Body, and its Development on the liace and Ilecul.-From the presence of the woolly hair or lanugo on the human foetus, and of rudimentary hairs seattered over the body during maturity, we may infer that man is descended from some animal which was born hairy and remained so during life. The loss of hair is an inconvenience and probably an injury to man, even in a hot climate, for he is thus exposed to the scorching of the sun, and to sudden chills, especially during wet weather. As Nrr. Wallace remarks, the natives in all countries are glad to protect their naked backs and shoulder's with some slight covering. No one supposes that the nakedness of the skin is any direct advantage to man; his body therefore cannot have been divested of hair through natural selection. ${ }^{21}$ Nor, as shewn in a former chapter, have we any evidence that this can be due to the direct action of climate, $n r$ that it is the result of correlated development.

The absence of hair on the borly is to a certain extent a secondary sexual character; for in all parts of the world women are less hairy than men. Therefore we may reasonabiy suspect that this character has been gained through sexual selection. We know that the faces of several species of monkeys, and large surfaces at the posterior end of the body of other species, hare been denuded of hair; and this we may safcly a!tribute to sexual selection, for these surfaces are not only vividly coloured, but sometimes, as with the male mandrill and female rhesus, much more vividly in the one sex than in the other, especially during the breeding-season. I am informed by MIr. Bartlett that, as these animals gradually reach maturity, the uaked surfaces grow larger compared with the size of their hodies. The hair, however, appears to have been removed, not for the sake of nudity, but that the colour of the skin may be more fully displajed. So

:1 'Contributions to the Theory of Natural Selection,' 1870, p. 346 . II. Wallace believes (1. 350)" that

"sume intelligent power has guided

"or determiued the developinent of" "man;" and he considers the hairess condition of the shin as cominur under this head. The Rer. T. H. Stebling, in commentiug on this view ("Transactions of Devonshire Assoc. fur Science,' 1870) remarks, that had Mr. Wallace "emplored "his usual ingenuity on the ques"tinn of man's hairless skin, he " might have seen the Jossibility of "its selection through its superior "beauty or the health attachiug to 
again whth many birls, it appcars as if the heal and neck had heen divested of feathors through sexual selection, to exhibit tho brightly-coloured skin.

As the body in Foman is less hairy than in man, and as this character is common to all races, we may conclude that it was our female semi-human ancestors who were first divested of hair, and that this occurred at an extremely remote period before the several races hal diverged from a cormmon stock. Whilst our female ancestors were gradually acquiring this new charncter of uudity, they must have transmitted it almost equally to their offspring of both sexos whilst young; so that its transmission, as with the ornaments of many mammals and birds, has not been limited cither by sex or agc. There is nothing surprising in a partial loss of hair having been esteemed as an ornament by our ape-like progenitors, for we have scen that innumerable strange characters have been thus esteemed by animals of all kinds, and have consequently been gained through sexual selection. Nor is it surprising that a slightly injurious character should have been thus acyuired; for we kmow that this is the case with the plumes of certain birds, and with the horns of certain stags.

The females of some of the anthropoid apes, as stated in a former chapter, are somewliat less hairy on the under surface than the males; and here we have what might have afforded a commencement for the process of denudation. With respect to the completion of the process through sexual selection, it is well to bear in mind the New Zealand proverb, "Ihere is no woman "for a hairy man." All who have seen photographs of the siamese hairy family will arlmit how ludicrously hideous is the opposite cxtreme of excessive hairiness. And the king of Siam had to bribe a man to marry the first hairy woman in the family; and she transmitted this character to her young oflspring of both sexes. ${ }^{22}$

Some races are much nore hairy than others, especially the males; but it must not he assumed that the more hairy races, such as the European, have retained their primordial condition more completely than the naked races, such as the Kalmucks or Americans. It is more probable that the hairiness of the former is due to partial reversion; for characters which have been at some former period long inherited, are always apt to return. We have seen that iliots are often very hairy, and they are apt to rerert in other characters to a lower animal type. It does not appear that a cold climate has been influential in leading to this kind of rerersion; excepting perhaps with the

*\% 'The Variation of Animals and Plants 'under Domesticution.' vol. ii 1868, p. 327. 
negroes, who hare been reared during sereral generations in the United States, ${ }^{23}$ and possibly with the Ainos, who inhabit the northern islands of the Japan archipelago. But the laws of inheritance are so complex than we can seldom understand this action. If the greater hairiness of certain races be the result of reversion, uncliecked by any form of selection, its cxtreme variability, even within the limits of the same race, ceases to loc remarkable. ${ }^{24}$

With respect to the beard in man, if we turn to our best gruide, the Quadrumana, we find beards equally developed in both sexes of many species, but in some, either confined to the males, or more developed in them than in the females. From this fact and from the curious arrangement, as well as the bright colomrs of the hair about the heads of many monkeys, it is highly probable, as hefore explained, that the males first acquired their beards through sexual selection as an ornament, transmitting them in most cases, equally or nearly so, to their officpring of both sexes. We know from Eschricht ${ }^{25}$ that with mankind, tho female as well as the male foetus is furnished with much hair on the face, especially round the mouth; and this indicates that we are descended from progenitors, of whom both sexes were bearded. It appear's therefore at first sight prohable that man has retained his beard from a very early period, whilst mcman lost her beard at the same time that her body became aimos: completely divested of hair. Even the colour of our beards secms to have been inherited from an apc-like progenitor; for whu

23 'Investigations into Military and Anthropological Statistics of American Soldiers,' by B. A. Gould, 1869 ; p. 568 :-Observations were carefully made on the hairiness of 2129 black and coloured soldiers, whilst they were bathing; and by looking to the published table, "it " is manifest at a glance that there " is but little, if any, difference be"tween the white and the black "races in this respect." It is, however, certain that negroes in their native and much hotter land of Africa, have remarkably smooth bodies. It should be particularly observed, that both pure blacks and mulattoes were included in the abore enumeration; and this is an unfortunate circumstance, as in accordance trith a principle, th e truth of which I have elsewhere proved, crossed races of man would be eminently liable to revert to the primordial hairy character of their early apelike pingenitors.

24 Hardly any view advanced in this work has met with so much disfarour (see for instance, Spengel, 'Die Fortschritte des Darwinismus,' 1874, p. 80 ) as the above explanation of the loss of hair in mankind through sexual selection; but none of the opposed arguments seem to me of much weight, in comparison with the facts shewing that the nudity of the skin is to a certai: extent a secondary sexual characte: in man and in some of the Quadrumana.

25 - Ueber die Richtung der Haare am Menschlichen Förper, in Müller's 'Archiv für Anat. unu' Phys.'1837, s. 40. 
there is any differcnce in tint between the hair of the head anr? the beard, the latter is lighter coloured in all monkeys and in man. In those Quadrumana in which the male has a large ' beard than that of the female, it is fully developed only at. maturity, just as with mankind; and it is possible that only the later stages of development have been retained by man. In opposition to this view of the retention of the beard from an early period, is the fact of its great variability in different races, and even within the same race; for this indicates reversion,long lost characters being very apt to vary on re-appearance.

Nor must we overlook the part which sexual selection may have played in later times; for we know that with sarages, the men of the beardless races take intinite pains in eradicating every hair from their faces as something odious, whilst the men of the bearded races feel the greatest pride in their beards. Thrwomen, no doubt, participate in these feelings, and if so sexual selection can hardly hare failed to have effected something in the course of later times. It is also possible that the long-continued habit of eraclicating the hair may have produced an inherited effect. Dr. Brown-Séquard has shewn that if certain animals are operated on in a particular manner, their offspring are affected. Further evidence could be given of the inheritance of the effects of mutilations; but a fact lately ascertained by Mr. Salviu ${ }^{2 i}$ has a more direct bearing on the present question; for he has shewn that the motmots, which are known habitually to bite off the barbs of the two central tail-feathers, have the barbs of these feathers naturally somewhat reduced.:7 Nicvertheless with mankind, the habit of eradicating the beard and the hairs on the body would probably not have arisen until these had already becomo by some means reduced.

It is difficult to form any judgment as to how the hair on the head became developed to its present great length in many races. Eschricht ${ }^{23}$ states that in the human foetus the hair on the face during the fifth month is longer than that on the licad; and this indicates that our semi-human progenitors were not furnished with long tresses, which must therefore have been a late accluisiticn. This is likewise indicated by the extraordinary difference in the length of the lair in the different races; in the negro the hair forms a mere curly mat; with us

28 'On the tall-feather's of Momotus' 'Yroc. Zoolug. Suc.,' $187 i, \mathrm{p}$. 429 .

37 Mr. Sproat has suggested ('Scenes and Studies of Savage Life,'1868, p. 25) this same view.
Some distinguished ethnologists, amongst other's MI. Gosse of Generi, believe that artificial modifisations of the skull tend to be inherited.

28 'Ueber die Richtung,' ibid. co 40 
it is of great length, and with the American natires it not rarely reaches to the ground. Some species of Semnopithecus have their beads covered with moderately long hair, and this probably serves as an ornament and was acquired through sexual selection. The same view may perhaps be extended to mankind, for wo know that long tresses are now and were formerly nuch admired, as may be observed in the works of almost every poet; St. Paul says, "if a woman have long hair, it is a glory to her ;" and we have seen that in North America a chief was clected solely from the length of his hair.

Colour of the Skin.-The best kind of evidence that in man the colour of the skin has been modificed through sexual selection is scanty; for in most races the sexes do not differ in this respect, and only slightly, as we have seen, in others. We know, however, from the many facts already given that the coiour of the skin is regarded by the men of all races as a highly important elcment in their beauty; so that it is a character which would be likely to have been modified through selection, as has occurred in innumerable instances with the lower animals. It seems at first sight a monstrous supposition that the jet-blackness of the negro should have been gained through sexual selection; but this view is supported by various analogies, and we know that negroes admire their own colour. With mammals, when the sexes differ in colour, the male is often black or much darker than the female; and it depends merely on the form of inheritance whether this or any other tint is transmitted to both sexes or to one alone. The resemblance to a negro in minature of Pithecia sutunus with his jet black skin, white rolling ejeballs, and hair parted on the top of the head, is almost ludicrous.

The colour of the face differs much more widely in the various kinds of moukeys than it does in the races of man; and we have some reason to believe that the red, blue, ornnge, almost white and black tints of their skin, even when common to botlu sexes, as well as the bright colours of their fur, and the ornamental tufts about the head, have all been acquired throngh sexual selection. As the order of development during growth, generally indicates the order in which the characters of a species have been developed and modified during previous generations; and as the newly-born infants of the various races of man do not differ nearly as much in colour as do the adults, although their bodies are as completely destitute of hair, we have some slight evidence that the tints of the different races rere acquired at a period subsequent to the removal of the hair, which must have uccurred at a rery early period in the history of man. 
Summury:-We may conclude that the greater size, strength, sourage, pugnacity, and energy of mau, in comparison with moman, were acquired during primeval times, and have subsequently been auguented, chiefly through the contests of rival males for the possession of the females. The greater intellectual rigour and power of invention in man is probably due to natural selection, combined with the inherited effects of habit, for the most able men will have succeeded best in defending and providing for themselves and for their wives and offspring. As tire as the extreme intricacy of the subject permits us to judge, it appears that our male apc-like progenitors acquired their beards as an ormament to charm or excite the opposite sex, and transmitted them only to their male offspring. The females apparcntly first had their bodies denuded of hair, also as a sexual ormament; but they transmitted this character almost equally to both sexes. It is not improkable that the females were modified in other respects for the same purpose and by the samo means; so that women have acquired sweeter voices and lecome more beautiful than men.

It deserves attention that with mankind the conditions wero in many respects much more favourable for sexual selection, luring a very carly period, when man had only just attained to the rank of manhood, than during later times. For he would t'Len, as wo may safely conclude, have been guided more by his instinctive passions, and less by foresight or reason. He would have jealously guarded his wife or wircs. He would not have practised infanticide; nor ralued his wires merely as useful slaves; nor hare becn betrothed to them during infancy. Hence we may infer that the races of men welo differentiated, as far as sexual selection is concerned, in chief part at a very remote spoch; and this conclusion throws light on the remarliable fact that at the most ancient period, of which we have as yet any record, the races of man had already come to differ nearly or (quite as much as they do at the present day.

The viers hero advanced, on the part which sexual selection has played in the history of man, want scientific precision. He who does not admit this agency in the case of the lower auimals, will disregard all that I have written in the later chapters on man. We cannot positively say that this claracter, but not that, has been thus modified; it has, however, been shewn that the races of man differ from each other and from their neares: ullics, in certain characters which are of no service to them in theiv daily habits of life, and which it is extremely probable would have been modified through sexual selection. TVe have Been that with tho lowest savages the people of each trihe admirs 
their own charactcristic qualities, - the shape of the head and face, the squareness of the cheek-bones, the prominence or depression of the nose, the colour of the skin, the length of the inair on the head, the absence of hair on the face and body, or the presence of a great beard, and so forth. Hence these and other such points could hardly fail to be slowly and gradually cxaggerated, from the more powerful and able men in cach tribe, who would succeed in rearing the largest number of offspring, having selected during many generations for their wives the most strongly characterised and therefore most attractivo women. For my own part I conclude that of all the causes which have led to the differences in external appearance betwecn the races of man, and to a certain extent between man and the lower animals, sexual selection has been the most efficient.

\section{CHAPTER IXI. \\ Genkiral Summary and Conclugion.}

Main conclusion that man is descended from some lower form-Manner o: development-Genealogy of man-Intellectual and moral firculties-Sexual selection-Conclinding remarks.

A BRIEF summary will be sufficient to recall to the reader's mind the more salient points in this work. Many of the views which have been advanced are highly speculative, and some no doubt will prove erroneous; bat I have in every case given the reasons which have led me to one view rather than to another. It seemed worth while to try how far the principle of evolution would throw light on some of the more complex problems in the natural history of man. False facts are highly injurious to the irogress of science, for they often endure long; but false views, if supported ly some evidence, do little harm, for every one takes a salutary pleasure in proving their falseness; and when this is dune, one path towards error is closed and the road to frath is often at the same time opened.

The main conclusion here arrived at, and now held by many naturalists who are well competent to form a sound judgment, is that man is descended from some less highly organised form. The grounds upon which this conclusion rests will never be shaken, for the close similarity between man and the lower inimals in embryonic development, as well as in innumerable loints of structure and constitution, both of high and of the most trifling importance,- the rudiments which he retains, and the abuormal reversions to which he is occasionally liable,- 
are facts which cannot be disputed. They have long been known, but until recently they told us nothing with respect to the origin of man. Now when viewed by the light of our knowlerlge of the whole organic world, their meaning is unmistakable. 'I'lee great principle of evolution stands up clear and firm, when these groups of facts are considered in connection with others, such as the mutual affinities of the members of the same group, their geographical distribution in past and present times, and their geological succession. It is incredible that all these facts should speak falsely. He who is not content to look, like a sarage, at the phenomena of nature as disconnected, cannot any longer believe that man is the work of a separate act of creation. He will be forced to admit that the close resemblance of the embryo of man to that, for instance, of a dog-the construction of his skull, limbs and whole frame on the same plan with that of other mammals, independently of the uses to which the parts may be put--the occasional re-appearance of various structures, for instance of several muscles, which man does not normally pussess, but which are common to the Quadrumana-and a crowd of analogous facts-all point in the plainest manner to the conclusion that man is the co-descendant with other mammals of a common progenitor.

We have seen that man incessantly presents individual differences in all parts of his body and in his mental faculties. These differences or variations seem to be induced by the same general causes, and to obey the same laws as with the the lower animals. In both cases similar laws of inheritance prevail. Man tends to increase at a greater rate than his means of subsistence; consequently he is occasionally subjected to a severe struggle for existence, and natural selection will have effected whatever lies within its scope. A succession of strongly-marked variations of a similar nature is by no means requisite; slight fluctuating differences in the individual suffice for the work of untural selection; not that we have any reason to suppose that in the same species, all parts of the organisation tend to vary to the same degree. We may feel assured that the inherited effects of the long-continued use or disuse of parts will have done much in the same direction with natural selection. Modifications formerly of importance, though no longer of any special use, are longinherited. When one part is modified, other parts change through the principle of correlation, of which we have instances in many curious cases of correlated monstrosities. Something may be attributed to the direct and definite action of the surrounding conditions of life, such as abundant fond, heat or moisture and lastly, many characters of slight physiological 
importance, some indeed of considerable importance, hare beet gained through sexual selection.

No doubt man, as well as erery other animal, presents structures, which seem to our limited knowledge, not to be now of any service to him, nor to have been so formerly, either for the greneral conditions of life, or in the relations of one sex to the other. Such structures cannot be accounted for by any form of selection, or by the inherited effects of the use and disuse of parts. We know, however, that many strange and stronglymarked peculiarites of structure occasionally appear in our domesticated prodnctions, and if their unknown causes were to act more uniformly, they nould probably become common to all the individuals of the species. We may hope hereafter to understand something about the causes of such occasional modifications, especially through the study of monstrositics: hence the labours of experimentalists, such as those of M. Camille Dareste, are full of promise for the future. In general we can only say that the cause of each slight variation and of each monstrosity lies much more in the constitution of the organism, than in the nature of the surrounding conditions; though new and changed conditions certainly play an important part in cxciting organic changes of many kinds.

Through the means just specified, aided perhaps by others ns yet undiscovered, man has been raised to his present state. IBut since he attained to the rank of manhood, he has diverged into distinct races, or as they may be more fitly called, subspecies. Some of these, such as the Negro and European, are sn distinct that, if specimens hnd been brought to a naturalist without any further information, they would nndoubtedly have been considered by him as good and true species. Nevertheless all the races agree in so many unimportant details of structure and in so many mental peculiarities, that these can be accounted for only by inheritance from a common progenitor; and a progenitor thus characterised would probably deserve to rank as man.

It must not be supposed that the divergence of each race from the other races, and of all from a common stock, can be traced back to any one pair of progenitors. On the contrary, at erery stage in the process of modification, all the individuals which were in any way better fitted for their conditions of life, though in different degrees, would hive survived in greater numbers than the less well-fitted. The process would have been like that followed by man, when he does not intentionally select particular individuals, but breeds from all the superior individuals, and neglects the inferior. He thus slowly lint surely modifies his stock, and unconsciously forms a new strain. So with respect 
to modifications acquired independently of selection, and due to rariations arising from the nature cf the organism and the action of the surrounding conditions, or from changed habits of life, no single pair will have been modified much more than the other pairs inhabiting the same country, for all will have been continually blended through free intercrossing.

By considering the embryological structure of man,-the homologies which he presents with the lower animals,- the rudiments which he retaius, - and the reversions to which he is liable, we can partly recall in imagination the former condition of vur early progenitors; and can approximately place them in their proper place in the zoological series. We thus learn that mau is descended from a hairy, tailed quadruped, probably arborcal in its habits, and an iuhabitant of the old World. 'This creature, if its whole structure had been examined by a maturalist, would have been classed amongst the Quadrumana, as surelv as the still more ancient progenitor of the Old and New Vorld monkeys. The Quadrumana and all the higher manumals are probably derived from an ancient marsupial animal, and this through a long line of diversified forms, from some amphibian-like creature, and this again from some fish-liko auimal. In the dim obscurity of the past we can see that the early progenitor of all the Vertebrata must have been an aquatic animal, provided with branchire, with the two sexes united in the same individual, and with the most important organs of the body (such as the brain and heart) imperfectly or not at all developed. This animal seems to have been morn like the larvæ of the existing marine Ascidians than any other known form.

The high standard of our intellectual powers and moral disposition is the greatest difficulty which presents itself, after we have been driven to this conclusion on the origin of man. But every one who admits the principle of evolution, must sec that the mental powers of the higher animals, which are the same in kind with those of man, though so different in degree, aro capable of advancement. Thus the interval between the mental powers of one of the higher apes and of a fish, or between those of an ant and scale-insect, is immense; yet their development does not offer any special difficulty; for with our domesticated animals, the mental faculties are certainly variable, and the variations are inherited. No one doubts that they are of tho utmost importance to animals in a state of nature. Thereforo the conditions are favourable for their development through natural selection. The same conclusion may be extended to man the intellect must have been all-important to him, even at a very 
remote period, as enabling him to invent and use langnage, to make weapons, tools, traps, \&c., whcreby with the aid of his vocial habits, he long ago became the most dominant of all living creatures.

A great stride in the development of the intellect will have followed, as soon as the half-art and half-instinct of language came into use; for the continued use of language will have reacted on the brain and produced an inherited effect; and this ggain will have reacted on the improvement of language. As Mr. Chauncey Wright has well remarked, the largeness of the brain in man relatively to his body, compared with the lower animals, may be attributed in chief part to the early use of some simple form of language,- - that wonderful engine which affixes signs to all sorts of objects and qualities, and excites trains of thought. which would never arise from the mere impression of the senses, or if they did arise could not be followed out. The higher intellectual powers of man, such as those of ratiocinatior. abstraction, self-consciousness, \&c., probably follow from the continued improvement and exercise of the other mental faculties.

The development of the moral qualities is a more interesting problem. The foundation lies in the social instincts, including under this term the family ties. These instincts are highly complex, and in the case of the lower animals give special tendencies towards certain definite actions; but the more important elements are love, and the distiuct emotion of sympathy. Animals endowed with the social instincts take pleasure in one another's company, warn one another of danger, defend and aid one another in many ways. These instincts do not extend to all the individuals of the species, but only to those of the same community. As they are highly beneficial to the species, they have in all probability been acquired through natural selection.

A moral being is one who is capable of reflecting on his past actions and tneir motives-of approving of some and disapproving of others; and the fact that man is the one being who certainly deserves this designation, is the greatest of all distinctions between him and the lower animals. But in the lourth chapter I have endeavoured to shew that the moral sense follows, firstly, from the enduring and ever-present nature of the social instincts; secondly, from man's appreciation of the approvation and disapprobation of his fellows; and thirdly, from the high activity of his mental faculties, with past impressions extremely vivid; and in these latter respects he differs from the lower animals. Owing to this condition of mind, man cannot

1 "On the I.imits of Natural Selection," in the "North Anericar Reriew,' Oct. 1870, p. 295. 
avoid looking both backwards and forwards, and comparing past impressions. Hence after some temporary desire or passion has mastered his social instincts, he reflects and compares the now weakened impression of such past.impulses with the everpresent social instincts; and he then feels that sense of dissatisfaction which all unsatisfied instincts leave behind them, he therefore resolves to act differently for the future, - and this is conscience. Any instinct, permanently stronger or more enduring than another, gives rise to a feeling which we express by saying that it ought to be obeyed. A pointer dog, if able to reflect on his past conduct, would say to himself, I ought (as indeed wo say of him) to have pointed at that liare and not have yielded to the passing temptation of hunting it.

Social animals are impelled partly by $a$ wish to aid the members of their community in a seneral manner, but more commonly to perform certain definite actions. Man is impelled by the same general wish to aid his fellows; but has few or no special instincts. He differs also from the lower animals in the power of expressing his desires by words, which thus become a guide to the aid required and bestowed. The motive to give aid is likewise much modified in man : it no longer consists solely of a blind instinctive impulse, but is much influenced by the praise or blame of his fellows. The appreciation and the bestowal of praise and blame both rest on sympathy; and this emotion, as we have seen, is one of the most important clements of the social instincts. Sympathy, though gained as an instinct, is also much strengthened by exercise or habit. As all men desire their own happiness, praise or blame is bestowed on actions and motives, according as they lead to this end; and as happiness is an essential part of the general good, the greatest-happiness principle indirectly serves as a nearly safe standard of right and wrong. As the reasoning powers advance and experience is gained, the remoter effects of certain lines of conduct on the character of the individual, and on the general good, are porceiverl; and then the selfregarding virtues come within the scope of public opinion, and receive praise, and their opposites blame. But with the less civilised nations reason often errs, and many bad customs and base superstitions come within the same scope, and are then esteemed as high virtues, and their breach as heavy crimes.

The moral faculties are generally and justly esteemed as of higher value than the intellectual powers. But we should bear in mind that the activity of the mind in vividly recalling past impressions is one of the fundamental though secondary bases of conscience. This affords the strongest argument for educating and stimulating in all possible ways the intellectual faculties of 
Every human being. No doubt a man with a torpid mind, if his social affections and sympathies are well developed, will be led to good actions, and may have a fairly scusitive conscience. But whatever renders the imagination more vivid and strengthens the habit of recalling and comparing past impressions, will make the conscicuce more sensitive, and may even somewhat compensate for weak social affections and sympathies.

The moral nature of man has reached its present standard. jartly through the advancement of his reasoning powers and consequently of a just public opinion, but especially from his sympathies having been rendered more tender and widely diffused through the effects of habit, example, instruction, and reflection. It is not improbable that after long practice virtuons tordencies may be inherited. With the more civilised races, tho conviction of the existence of an all-seeing Deity has had a potent influence on the advance of morality. Tltimately man does not accept the praise or blame of his fellows as his sole guide, though few escape this influence, but his habitual convictions, controlled by reason, afford him the safest rulc. His conscience then becomes the supreme judge and monitor. Nevertheless the first foundation or origin of the moral sense lies in the social instincts, including sympathy; and these instincts no doubt were primarily gained, as in the case of the lnwer animals, through natural selection.

The belief in God has often been advanced as not only the greatest, but the most complete of all the distinctions between man and the lower animals. It is howerer impossiblo, as we have seen, to maintain that this belicf is innate or instinctive in man. On the other hand a belief in all-pervading spiritual agencies seems to be universal; and apparently follows from a considerable advance in man's reason, and from a still greater advance in his faculties of imagination, curiosity and wonder. I am aware that the assumed instinctive belicf in God has been used by many persons as an argument for His existence. But this is a rash argument, as we should thus be compelled to believe in the existence of many cruel and malignant spirits, only a little more powerful than man; for the belief in them is far more general than in a beneficent Deity. The idea of a universal and bemeficent Creator does not seem to arise in the mind of man, mntil he has been elevated by long-continued culture.

He who belieres in the advancement of man from some low organised form, will naturally ask how does this hear on the belicf in the immortality of the soul. The barbarous races of man, as Sir J. Lubbock has shewn, possess no zlear belief of this kind: 
but arguments derived from the primeval beliefs of savages are, as we have just seen, of little or no avail. Few persons feel any anxiety from the impossibility of determining at what precisu period in the development of the individual, from the first trau of a minute germinal vesicle, man becomes an immortal being; and there is no greater cause for anxiety because the periou cannot possibly be determined in the gradually ascending organic scale. ${ }^{2}$

I am aware that the conclusions arrived at in this work will be denounced by some as highly irreligious; but he who deriounces them is bound to shew why it is more jrreligious to explain the origin of man as a distinct species by descent from some lower form, through the laws of variation and natural selection, than to explain the birth of the individual through the laws of ordinary reproduction. The birth both of the species and of the individual are equally parts of that grand sequence of events, which our minds reruse to accept as the result of blind chance. The understanding revolts at such a conclusion, whether or not we are able to believe that every slight variation of structure,- the union of each pair in marriage,the dissemination of each seed,- -and other such events, have all been ordained for some special purpose.

Sexual selection has been treated at great length in this work; for, as I have attempted to shew, it has played an important part in the history of the organic world. I an aware that much remains donbtful, but I have endeavoured to give a fair view of the whole case. In the lower divisions of the animal kingdom, sexual selection seems to have done nothing: such arimals are often affixed for life to the same spot, or have the sexes combined in the same individual, or what is still more important, their perceptive and intellectual faculties are not sufficiently advanced to allow of the feelings of love and jealousy, or of the exertion of choice. When, however, wo come to the Arthropoda and Vertebrata, even to the lowest classes in these two great Sub-Kingdoms, sexual selection has effected much.

In the several great classes of the animal kingdom,-in mammals, birds, reptiles, fishes, insects, and even crustaceans, - the differences between the sexes follow nearly the same rules. The males are almost always the wooers; and they alone are armed with special weapons for fighting with their rivals. They are generally stronger and larger than the females,

${ }^{2}$ The Rev. J. A. Picton gives a discussion to this effect in his 'New Theories and the Ola Faith, 1870. 
and are endowed with the requisite qualities of courage and pugnacity. They are provided, either exclusively or in a much higher degree than the females, with crgans for vocal or instrumental music, and with odoriferous glands. They are ornamented with infinitely diversified appendages, and with the most brilliant or conspicuous colours, often arranged in elegant matterns, whilst the females are unadorned. When the sexes differ in more important structures, it is the male which is provided with special sense-organs for discovering the female, with locomotive organs for reaching her, and often with prehensile organs for holding her. These various structures for charming or securing the female are often developed in the male during only part of the year, namely the breeding-season. They nave in many cases been more or less transferred to the females; and in the latter case they often appear in her as mere rudiments They are lost or never gained by the males after emasculation. Generally they are not dereloped in the male during oarly youth, but appear a short time before the age for reproduction. Hence in most cases the young of both sexes resemble each other"; and the female somewhat resembles her young offspring throughout life. In almost every great class a few anomalous cases occur, where there has been an almost complete transposition of the characters proper to the two sexes; the fomales assuming characters which properly belong to the males. This surprising uniformity in the laws regulating the differences between the scxes in so many and such widely separated classes, is intelligible if we admit the action of one common cause, namely sexual selection.

Sexual selection depends on the success of certain individuals over others of the same sex, in relation to the propagation of the species; whilst natural selection depends on the success of both sexes, at all ages, in relation to the general conditions of life. The sexual struggle is of two kinds; in the one it is between the individuals of the same sex, generally the males, in order to drivo aтvay or kill their rivals, the females remaining passire; whilst in the other, the struggle is likewise between the individuals of the same sex, in order to excite or charm those of the opposite sex, generally the females, which no longer remain passive, but select the more agreeable partners. This latter kind of selection is closely analogous to that which man unintentionally, yet effectually, brings to bear ou ins domesticated productions, when he preserves during a long period the most pleasing or nseful individuals, without any wish to modify the breed.

The laws of inheritance determine whether characters gained through sexual selection iy e:ther sex shall be transmitted to the 
same sex, or to both; as well as the age at which they shall be developed. It appears that variations arising late in life are commonly transmitted to one and the scme sex. Variability is the necessary basis for the action of selection, and is wholly independent of it. It follows from this, that variations of the same gencral nature have often been taken advantage of and accumulated through sexual selection in relation to the propagation of the species, as well as through natural selection ir relation to the gencrul purposes of life. Hence secondary sexual characters, when equilly transmitted to both sexes can bo Cistinguished from ordinary specific characters only by the light of analogy. The modifications acquired through sexual selection are often so strongly pronounced that the two sexes have liequently been ranked as distiuct species, or even as distinct genera. Such strongly-marked diffitences must be in some manner highly important; and we know that they have been acquired in some instaices at the cost not only of inconvenience, but of exposure to actual danger.

The luelief in the power of sexual selection rests chiefly on the folluwing consideratious. Certain characters are confined to one sex; and this alone renders it probable that in most cases they are connected with the act of reproduction. In innumerable instances these characters are fully developed only at maturity, and often during only a part of the year, which is always the breeding-season. The males (passing over a fer exceptional cases) are the more active in courtship; they are the hetter armed, and are rendered the more attractive in various ways. It is to be especially observed that the males display their attractions with elaborate care in the presence of the females; and that they rarely or never display them excepting during the season of love. It is incredible that all this should be purposeless. Lastly we have distinct evidence with some quadrupeds and birds, that the individuals of one sex are capable of feeling a strong antipathy or preference for certain individuals of the other sex.

Bearing in mind these facts, and the marked results of mau's unconscious selection, when applied to domesticated animals aud cultivated plants, it seems to me almost certain that if the individuals of one sex were during a long serics of generations to prefer pairing with certain individuals of the other sex, characterised in some peculiar manner, the offspring would slowly but surely become modified in this same manner. I have noi attempted to conceal that, excepting when the males are more numerous than the females, or when polygamy prevails, it is doubtful how the zaore attractive males succeed in leaving a 
iarger number of offspring to inherit their superiority in ornaments or other charms than the less attractive nales; but I have shewn that this would probably follow from the females,especially the more vigorous ones, which would be the first to breed,-preferring not only the more attractive but at the same time the more vigorous and victorious males.

Although we have some positive evidence that birds ajppreciate bright and beautiful objects, as with the bower-birds of Australia, and although they certainly appreciate the power of song, yet I fully admit that it is astonishing that the females of many birds and some mammals should be endowed with sufficient taste to appreciate ornaments, which we have reason to attribute to sexual selection; and this is even more astonisling in the case of reptiles, fish, and insects. But we really know little about the minds of the lower animals. It cannot be supposed, for instance, that male birds of paradise or peacocks should take such pains in erecting, spreading, and vibrating their beautiful plumes before the females for no purpose. We should remember the fact given on excellent authority in a former chapter, that several peahens, when debarred from an admired male, remained widows during a whole season rather than pair with another bird.

Nevertheless I know of no fact in natural history more wonderful than that the female Argus pheasant should appreciate the exquisite shading of the ball-and-socket ornaments and the elegant patterns on the wing-feathers of the male. He who thinks that the male was created as he now exists must admit that the great plumes, which prevent the wings from being used for flight, and which are displayed during courtship and at no other time in a manner quite peculiar to this one species, were given to him as an ornament. If so, he must likewise admit that the female was created and endowed with the capacity of appreciating such ornaments. I differ only in the conviction that the male Argus pheasant acquired his beauty gradually, through the preference of the females during many generations for the more highly ornamented males; the æsthetic capacity of the females having been advanced through exercise or habit, just as our own taste is gradually improved. In the male through the fortunate chance of a few feathers being left unchanged, we can distinctly trace how simple spots with a little fulvous shading on one side may have been developed by small steps into the wonderful lall-and-socket ornaments; and it is probable that they were sctually thus developed.

Everyone who admits the principle of evolution, and yet fcels great difficulty in admitting that female mammals, birds, 
reptiles, and fish, could have acquired the high tasto implied by the beauty of the males, and which generally coincides with our own standard, should reflect that the nerve-cells of the brain in the highest as well as in the lowest members of the Vertebrato series, are derived from those of the commou progenitor of this great Kingdom. For we can thus see how it has come to pass that certain mental faculties, in various and widely distinct groups of animals, have been developed in nearly the same munner and to nearly the same degree.

The reader who has taken the trouble to go through the several chapters devoted to sexual selection, will be able to judge how far the conclusions at which I lave arrived are supported by sufficient evidence. If he accepts these conclusions he may, I think, safely extend them to mankind; but it would be superfluous here to repeat what I have so lately said on the manner in which sexual selection apparently has acted on man, both on the male and female side, causing the two sexes to differ in body and mind, and the several races to differ from each other in various characters, as well as from their ancient and lowly-organised progenitors.

He who admits the orinciple of sexual selection will be led to the remarkable conclusion that the nervous system not only regulates most of the existing functions of the body, but has indirectly influenced the progressive development of various bodily structures and of certain mental qualities. Courage, pugnacity, perseverance, strength and size of body, weapons of all kinds, musical organs, both vocal and instrumental, bright colours and ornamental appendages, have all been indirectly gained by the one sex or the other, through the exertion of choice, the infuence of love and jealousy, and th appreciation of the beautiful in sound, colour or form; and these powers of the mind manifestly depend on the development of the brain.

Man scans with scrupulous care the character and pedigre: of his horses, cattle, and dogs before he matches them; but when he comes to bis own marriage he rarely, or never, take's any such care. He is impelled by nearly the same motives as the lower animals, when they are left to their own free choice, though be is in so far superior to them that he highly values mental charms and virtues. On the other hand he is strongly attracted by mere wealth or rank. Yet he might by selection do something not only for the bodily constitution and frame of his affspring, but for their intellectual and moral qualities. Both sexes ought to refrain from marriage if they are in any marked degree inferior in body or mind; but such hopes are Utopian and 
will never be eren partially realised until the laws of inheritanco are thoroughly known. Lveryone does good service, who aidi towards this end. When the principles of breeding and inheritance are better uuderstord, we shall not hear iguorant members of our legislature rejecting with scorn a plan fur ascertaining whether or not consanguineous marriges are injurious to man.

The advancement of the welfare of mankind is a most intricate problem: all ought to refrain from marriage who caunot avoil abject poverty for their children; for poverty is not only a great cvil, lut tends to its own increase by leading to recklessmess in marriage. On the other hand, as Mr. Galton lias rcmarked, il the prudent avoid marriage, whilst the reckless marry, the inferior members tend to supplant the better members 0 : society. Man, like every other animal, has no doubt advancec: to his present high condition through a struggle for existence consequent on his rapid multiplication; and if he is to advance. still higher, it is to be feared that he must remain subject to a severe struggle. Otherwise he would sink into indolence, and the moro gifted men would not be more successful in the battle. of life than the less gifted. Hence our natural rate of increase, though leading to many and obvious evils, must not be greatly diminished by any means. There should be open conpetition. for all men; and the most able should not be prevented by laws or customs from succeeding best and rearing the largest number of offspring. Important as the struggle for existeuce has been and even still is, yot as far as the highest part of man's nature is concerned there are other agencies more important. For the moral qualities are advanced, either directly or indirectly, much more through the effects of habit, the reasoming powers, instruction, religion, \&c., than through natural sclection; though to this latter agency may be safcly attributed the social instincts, which afforded the basis for the derelopment of the moral sense.

The main conclusion arrived at in this work, namely that man is descended from some lowly organised form, will, I regret to thiuk, be highly distasteful to many. But there can hardly. be a doubt that we are descended from barbarians. The astonishment which I felt on first seeing a party of Feugrians on it wild and broken shore will nerer be forgotten by me, for the reflection at once rushed into my mind-such were our ancestors. These men were absolutely naked and bedaubed with paint, their long hair was tangled, their mouths frothed with excitement, and their expression was wild, startled, and distrustful. 
They possessed hardly any arts, and like wild animals lived on what they could catch; they had no government, and were merciless to every one not of their own small tribe. He who has secn a savage in his native land will not focl much shame, if forced to acknowledge that the blood of some more humble creature flows in his veins. For my own part I rould as soon be descended from that heroic little monkey, who braved his dreaded enemy in order to save the life of his keeper, or from that old baboon, who descending from the mountains, carried away in triumph his young comrade from a crowd of astonished dogs-as from a savage who delights to torture his enemies, offers up bloody sacrifices, practises infanticide without remorse, treats his wives like slaves, knows no decency, and is haunted by the grossest superstitions.

Man may be cxcused for feeling some pride at having risen, though not through his own exertions, to the very summit of the organic scale; and the fact of his having thus risen, instead of having been aboriginally placed there, may give him hope for a still higher destiny in the distant future. But we are not here concerned with hopes or fears, only with the truth as far as our reason permits us to discover it; and I have given the evidence to the best of my ability. We must, however, acknowledge, as it seems to me, that man with all his noble qualities, with sympathy which feels for the most debased, with benevolence which extends not only to other men but to the humblest living creature, with his god-like intellect which has penctrated into the movements and constitution of the solar system-with all these exalted powers-Man still benrs in his boduly trane tho indulible st:wup of his low!y origin. 


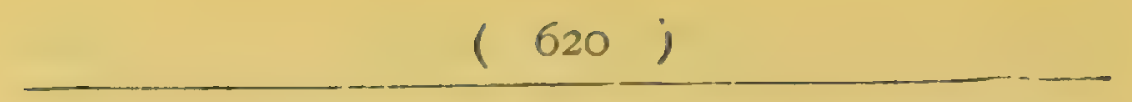

\title{
SUPPLEMENTAL NOTE
}

\author{
uN \\ SEXUAL SELECTION IN RELATION TO MONKEYI,
}

(Reprinted from NATURE, November 2, 1876, p. 18.)

IN the discussion on Sexual Selection in my 'Descent of Man, no case interested and perplexed me so much as the brightlycoloured hinder ends and adjoining parts of certain monkeys. As these parts are more brightly coloured in one sex than the other, and as they become more brilliant during the season of love, I concluded that the colours had been gained as a sexual attraction. I was well aware that I thus laid myself open to ridicule; though in fact it is not more surprising that a monkey should display his bright-red hinder end than that a peacock should display his magnificent tail. I had, however, at that time no evidence of monkeys exhibiting this part of their bodies during their courtship; and such display in the case of birds affords the best evidence that the ormaments of the males are of service to them by attracting or exciting the females. I have lately read an article by Joh. von Fischer, of Gotha, published in 'Der Zoologische Garten,' April 1876, on the expression of inonkeys under various emotions, which is well worthy of study ly any one interested in the subject, and which shows that the author is a careful and acute observer. In this article there is an account of the behaviour of a young male mandrill when he first beheld himself in a looking-glass, and it is added, that after a time he turned round and presented his red hinder end to tho glass. Accordingly I wrote to Herr J. vou Fischer to ask what he supposed was the meaning of this strange action, and he has sent me two long letters full of new and curious details, which will, I hope, be hereafter published. He says that he was himsolf at first perplexed by the above action, and was thus led carefully to observe sereral individuals of various other species of monkeys, which he has long kept in his house. He finds that 
not only the mandrill (Cynocephatus mormon) but the drill ( $C$ : leucophicus) and three other kinds of bahoons (C. lamaulryas, splinx, and bubouin), also (ynopithecus niyer, and dlacacus rhesus and nemestrinus, turn this part of their bodies, which in all these species is more ur less brightly coloured, to him when they are pleased, and to other persons as a sort of greeting. He took pains to clire a Macacus rhesus, which he had kept for five years, of this indecorous habit, and at last succeeded. These monkeys are particularly apt to act in this manner, grimning at the same time, when first iutroduced to a new monkey, but often also to their old monkey friends; and after this mutual display they begin to play together. The young mandrill ceased spontaneously after a time to act in this manner towards his master, Iron Fischer, but continued to do so towards persons who were strangers and to new monkeys. A young Cynopithecus niger. never acted, excepting on one occasion, in this way towards his master, but frequently towards strangers, and continues to do so up to the present time. From these facts Vou Fischer concludes that the monkeys which behaved in this manner before a looking-glass (viz. the mandrill, drill, Cynopithecus niger, Macacus: rhesus and nemestrinus) acted as if their reflection were a new acquaintance. The mandrill and drill, which have their hinder ends especially ornamented, display it even whilst quite young, more frequently and more ostentatiously than do the other. kinds. Next in order comes Cynocephatus hamadryas, whilst the other species act in this manner seldomer. The individuals, however, of the same species vary in this respect, and some: which were very shy never displiyed their hinder ends. It deserves especial attention that Von Fischer has never seen any species purposely exhibit the hinder part of its body, if not at all coloured. This remark applies to many individuals of Macacus cynomolgus and Cercocebus radiatus (which is closely allied to M.rhiesus), to three species of Cercopithecus and several American monkeys. The habit of turning the hinder ends as a greeting to an old friend or new acquaintance, which seems to us so odd, is not really more so than tho liabits of many savages, for instance that of rubbing their bellies with their hands, or rubbing noses together. The habit with the mandrill and drill seems to be instinctive or inherited, as it was followed by very young animals; but it is modified or guided, like so many other instincts, by olsservation, for Von Fischer says that they take pains to make their display fully; and if made before two observers, they turn to him who seems to pay the most attention.

With respect to the origin of the habit, Von Fischer remarlks 
that Jis monkeys like to have their naked hinder ends patted or stroked, and that they then grunt with pleasure. They often also turn this part of their bodies to other monkers to have bits of dirt picked off, and so no doubt it would be with respect to thorns. But the habit with adult animals is connected to a certain extent with sexual feelings, for Von Fischer watched through a glass door a female Cynopithecus niger, and she during several days, "umdrehte und dem Männchen mit gurgelnden Tönen die stark geröthete Sitzfläche zeigte, was ich fruher nie an diesem Thier bemerkt hatte. Beim Anblick dieses Gegenstandes erregte sich das Männchen sichtlich, denn es polterte heftig an den Stäben, ebenfalls gurgelnde Lante ausstossend." As all the monkeys which have the hinder parts of their bodies more or less brightly coloured live, according to Von Fischer, in open rocky places, he thinks that these colours serve to render one sex conspicuous at a distance to the other; but, as monkeys are such gregarious animals, I should have thought that there was no need for the sexes to recognise each other at a distance. It seems to me more probable that the bright colours, whether on the face or hinder end, or, as in the mandrill, on both, serve as a sexual ornament and attraction. Anyhow, as we now know that monkeys have the habit of turning their hinder pnds towards other monkeys, it ceases to be at all surprising hat it should have been this part of their bodies which has been more or less decorated. The fact that it is only the monkeys thus characterised which, as far as at present known, act in this manner as a greeting towards other monkeys renders it doubtful whether the habit was first acquired from some independent cause, and that afterwards the parts in question were coloured as a sexual ornament; or whether the colouring and the habit of turning round were first acquired through variation and sexual selection, and that afterwards the habit was retained as a sign of pleasure or as a greeting, through the principle of inherited association. This principle apparently comes into play on many occasions: thus it is generally admitted that the songs of birds serve mainly as an attraction during the season of love, and that the leks, or great congregations of the black grouse, are connected with their courtship; but the hahit of singiug has been retained by some birds when they feel happy, for instance by the common robin, and the habit of congregating lias heen retained by the black grouse during other seasons of the year.

I heg leave to refer to one other point in relation to sezual selection. It has been objected that this form of selection, as far as the ornaments of the maies are concerned, implies that all 
the femaies within the same district must possess and excrciso axactly the same taste. It should, however, be observed, in the first place, that although the range of variation of a species may be very large, it is by no means indefinite. I have elsewhere given a good instance of this fact in the pigeon, of which there are at least a hundred varieties differing widely in their colours, and at least a score of rarieties of the fowl differing in the same kind of way; but the range of colour in these two species is extremely distinct. Therefore the females of natural species cannot bave an unlimited scope for their taste. In the second place, I presume that no supnorter of the principle of sexual selection believes that the females select particular points of beauty in the males; they are merely excited or attracted in a greater degree by one male than by another, and this seems often to depend, especially with birds, on brillant colouring. Even man, excepting perhaps an artist, does not analyse the slight differences in the features of the woman whom he may admire, on which her beauty depends. The male mandrill has not only the hinder end of his hods, but his face gorgeously coloured and marked with oblique ridges, a yellow beard, and other ornaments. We may infer from what we see of the variation of znimals under domestication, that the above several ornaments of the mandrill were gradually acquirerl by one individual varying a little in one way, and another individual in another way. The males which were the handsomest or the most attractive in any manner to the females would pair oftenest, and would leave rather more off'spring than other males. The offspring of the former, although variously intercrossed, would either inherit the peculiarities of their fathers or transwit an increased tendency to vary in the same manner. Consequently the whole body of males inhabiting the same country would tend from the effects cf constant intercrossing to become modified almost uniformly, but sometimes a little more in one character and sometimes in another, though at an extremely slow rate; all ultimately being thus rendered more attractive to the females. The process is like that which I have called unconscious selection by man, ard of which I have given sereral instances. In one country the inhabitants value a fleet or light dog or horse, and in another country a heavier and more powerful one; in neither country is there any selection of individual animals with lighter or stronger bodies and limbs ; neverthcless after a considerable la! se of time the individuals are found to hare been modified in the desired manner almost uniformly, though differently in each country. In two absolutely distinct countries inhabiter by the same specics, the individuals of which can never duringr long 
ages have intermigrated and intercrossed, and where, moreover the rariations will probably not have been identically the sume. sexual selection might canse the males to differ. Nor does the heliet appear to me altogether fanciful that two sets of females, surrounded by a very different environment, would be apt to ncquire somewhat different tastes with respect to form, solunr', or colour. However this may be, I have given in my 'Descer's of Man' instances of closely-allied birds inhabiting distinet countries, of which the young and the females cannot he distingruished, whilst the adult males differ considerably, and this: may be attributed with much probability to the action of sexusu selection. 


\section{N D E X.}

A.

Aibert, C., on the battles of seils, 500.

Abductor of the fifth metatarsal, presence of, in $\mathrm{man}, 42$.

Abercrombie, Dr., on disease of the brain affecting speech, 88 .

Abipones, marriage customs of the, 598.

A bou-Simbol, caves of, 168 .

Abortion, prevalence of the practice of, 46 .

Abstraction, power of, in animals, 83.

Acalles, stridulation of, 306 .

Acanthodactylus capensis, sexual diflerences of colour in, 357 .

Accentor modularis, 473.

Acclimatisation, difference of, in different races of men, 167.

Achctidx, stridulation of the, 282 , 283,285 ; rudimentary stridulating organs in female, 288.

Acilius sulcatus, elytra of the female, 276.

Acomus, development of spurs in the female of, 450 .

Acridiidæ stridulation of the, 282, 286 ; rudimentary stridulating 01 gans in female, 288.

Acromio-basilar muscle, and quadl'upedal gait, 42 .

Acting, 178.

Actinic, bright colours of, 260 .

Adams, Mr., migration of birds, 108 ; intelligence of nut-hatch, 418 ; on the Bombycilla carolinensis, 461 .

Admiral butterfly, 312 .

Adoption of the young of other animals by female monkeys, 70 .

Advancement in the crganic scale, Von Baer's definition of, 164 .

seby, on the difference between the skulls of man and the quadrumana, 149.

Esthetic faculty, not highly dereloped in savages, 93.

Affection, maternal, 70 ; manifestation of, by animals, 70 ; parental and filial, partly the result of natural selection, 105; mutual, of birds, 410 ; shewn by birds in confinement, for certain persons, 411 .

Africa, probably the birthplace of man, 155; South, crossed population of, 174; South, retention of colour by the Dutch in, 193 ; South. proportion of the sexes in the butterflies of, 250 ; tattooing practised in, 574 ; Northern, coiffure of uatives of, 575 .

Agassiz, L., on conscience in dog 3 , 103 ; on the coincidence of the races of man with zoological provinces, 169 ; on the number of species of man, 174 ; on the courtship of the land-snails, 262 ; on the brightness of the colours of mile fishes during the breeding season, 340 ; on the frontai protuluerance of the males of Geophayus and Cichla, 340, 345; male fishes hatching ova in their mouths, 345 ; sexual differences in colour of chromids, 345 ; on the slight sexual differences of the South Americans, 561 ; on the tattooing of the Am:tzonian Indians, 576.

Age, in relation to the transmission of character's in birds, 463 ; variation in accordance with, in birds, 484.

Ageloens phoniceus, 225, 416.

Ageronia feronia, noise produced by, 307.

Agrion, dimorphism in, 290. 
Agrion Rambirii, seres of, 290.

Agrionidx, difference in the sexes of, 290.

Agrotis exclamationis, 316.

Ague, tertian, dog suffering from, 8 .

Aithurus politmus, young of, 487 .

Ainos, hairiness of the, 560 .

Albino birds, 419

Alca torda, young of, 486 .

Alces palmata, 515 .

Alder and Hancock, MM., on the nudi-branch mollusca, 264.

Allen, J. A., vigour of birds earliest hatched, 212,213 ; effect of difference of temperature, light, \&c., on birds, 225 ; colours of birds, 422 ; on the relative size of the sexes of Callorhinus ursinus, 515; on the mane of Otaria jubata, 521 ; on the pairing of seals, 523 ; on sexual differences in the colour of bats, 534 .

- S., on the habits of Hoplopterus, 366 ; on the plumes of herons, 391 ; on the vernal moult of Herodias bubulcus, 393.

Alligator, courtship of the male, 221, 351 ; roaring of the male, 567.

Amadavat, pugnacity of male, 366 .

A madina Lathami, display of plumage by the male, 402 .

- castanotis, display of plumage by the male, 402 .

imazons, butterties of the, 250 ; fishes of the, 343 .

America, variation in the skulls of aborigines of, 26 ; wide range of aborigines of, 169 ; lice of the ratives of, 170 ; general beardlessness of the natives of, 560 .

$\longrightarrow$ North, buttertlies of, 250; Indians of, women a cause of strife among the, 561; Indians of, their notions of female beauty, 577 , 580.

- South, character of the natives of, 168; population of parts of, 173 ; piles of stones in, 179 ; extinction of the fossil horse of, 191 ; desert-birds of, 490 ; slight sexual difference of the aborigines of, 561 ; prevalence of infanticide in, 592.

American languages, often highly artificial, 91.

dmericans, wide geographical zange of, 29 ; native, variability of, 174 ; and negroes, difference of 197 ; avel'sion of, to hair on the face, 580 . Amrnophila, on the jaws of, 275.

Ammotragus tragelaphus, haviy forelegs of, 531,533 .

Amphibia, affinity of, to the ganoid fishes, 159 ; rocal organs of the, 566.

Amphibians, 165, 348; breeding whilst immature, 485

Amphioxus, 159.

Amphipoda, males sexualiy mature while young, 485.

Amunoph III., negro character of featules of, 168 .

Anal appendages of insects, 275.

Analogous variation in the plumage of birds, 385 .

Anas, 462.

- acuta, male plumage of, 393 .

boschas, male plumage of, 393.

histrionica, 484.

punctata, 374.

Anastomus oscitans, seres and young of, 486 ; white auptial plumage of, 492.

Anatidx, voices of, 374 .

Anax junius, differences in the seres of, 290 .

Andaman islanders, susceptible to change of climate, 188.

Anderson, Dr., on the tail of Macacus brunneus, 59; the Bufo sikimmen. sis, 349 ; sounds of Echis carinata, 353.

Andræna fulva, 292.

Anglo-Saxons, estimation of the beard among the, 581 .

Animals, domesticated, more fertil than wild, 45 ; cruelty of savages to, 118; characters common to man and, 146 ; Comestic, change of breeds of, 596 .

Annelida, 264; colours of, 265.

Anobium tessellatum, sounds producer by, 306.

Anolis cristatellus, male, crest of, 354 ; pugnacity of the male, 354 ; throat. pouch of, 354 .

Anser canadensis, 416.

cygnoides, 415 ; knob at the bass of the beak of, 426 .

hyperboreus, whiteness of, 49?.

Antelope, prong-horned, horns of, 231 . 
Antelopes, gunerally polygamo 1 s, 217 ; horns of, 234, 504; canine teeth of some male, 502 ; use of horns of 509 ; dorsul crests in, 530 ; dewlaps of, 531 ; winter chauge of two species of, 543 ; peculiar markings of, 543 .

Antenzx, furnished with sushions in the male of Ponthe, 276.

Anthidium manicatum, large male of, 279.

Anthocharis cardamines, 308, 312; sexual difference of colonr in, 322 .

- genutin, 312.

- sara, 312 .

Anthophora acervorum, large male of, 279.

$$
292 .
$$

Anthropidæ, 152.

Anthus, moulting of, 392.

Antics of birds, 380 .

Antigua, Dr. Nicholson's observations on yellow fever in, 195.

Antilocapra americana, horns of, 234, 504, 507.

Antilope bezoartica, horned females of, $505,506,507$; sexual difference iu the colour of, 535 .

- Dorcas and euchore, 504.

- euchore, horns of, 509 .

- montana, rudimentary canines in the young male of, 514 .

- niger, sing-sing, caama, and gorgon, sexual differences in the colours of, 536 .

- oreas, horns of, 234.

- saiga, polygamous habits of, 217.

- strepsiceros, horns of, 234.

subgutturosa, absence of suborbital pits in, 529 .

Antipathy, shewn by birds in confinement, to certain persons, 411.

Ants, 147; large size of the cerebral ganglia in, 54 ; soldier-, large jaws of, 63 ; playing together, 69 ; memory in, 74 ; intcommunication of, by means of the antennx, 89 ; habits of, 147 ; difference of the sexes in, 292; recognition of each other by, after separation, 292.

White, babits of, 291.

Auurr, 349.

Apatiria muliebris, male unknown, 25 .
Apathics, dificrence of the seres is, 292.

Apatura Tris, 307, 308.

Apes, difference of the young, from the aluit, 8 ; semi-erect attitude of some, 52 ; mastoid processes of, 53 ; influences of the jaw-muscles on the physiognomy of, 54; femile, destitute of large canines, 63 ; building platforms, 82 ; imitative faculties of, 129; anthropomorphous, 153; probible speedy extermination of the, 156 ; Gratiolet on the evolution of, 177 ; canine teeth of male, 502 ; females of some, less hairy beneath than the males, 601.

- Iong-ar'med, their mode of progression, 5?.

A phasia, Dr. Bateman on, 88.

Apis mellifica, large male of, 279.

Apollo, Greek statues of, 581 .

Apoplexy in Celus Azarx, 7.

Appendages, anal, of insects, 276.

A pprobation, influence of the love of, $109,116,131$.

Aprosmictus scapulatus, 457.

Apus, proportion of sexes, 255.

Aquatic birds, frequency of white plumage in, 495.

Aquila chrysaëtos, 408.

drab women, elaborate and peculiar coiffure of, 583.

Arabs, fertility of crosses with other races, 171; gashing of cheeks and temples among the, 574 .

Arachnida, 272.

Arakhan, artificial widening of the forehead by the natives of, $58: 3$.

Arboricola, young of, 468 .

Archeopteryx, 158.

Arctiidx, coloration of the, 314 .

Ardea asha, rufescens, and cxmulein, change of colour in, 494, 495 .

- cremilea, breeding in immature plumage, 484. 495 .

gularis, change of plumage in, - herodias, love-gestures of the male, 380.

ludoviciana, age of mature plumage in, 483 ; continued growth of crest and plumes in the male of, 485.

- nycticorax, cries of, 368 . 
Ardeola, young of, 468 .

Ardetta, changes of plumage in, 461 . Argenteuil, 22.

Argus pheasant, $384,403,462$; display of plumage by the male, 398 ; ocellated spots of the, 428 ; gradation of characters in the, 434 .

Argyll, Duke of, on the physical weakness of $\mathrm{man}, 63$; the fashioning of implements peculiar to man, 32 ; on the contest in man between right and wrong, 125 ; on the primitive civilisation of $\operatorname{man}, 143$; on the plumage of the male Argus pheasart, 398; on Urosticte Benjamini, 442, 443; on the nests of birds, 453.

Argynnis, colouring of the lower surface of, 314.

Aricoris epitus, sexual differences in the wings of, 277.

Aristocracy, increased beauty of the, 586.

Arms, proportions of, in soldiers and sailors, 32 ; direction of the hair on the, 151.

- and hands, fiee use of, indirectly correlated with diminution of canines, 53.

Arrest of development, 35,36 .

Arrow-heads, stone, general resemblance of, 179 .

Arrows, use of, 179.

Arteries, variations in the course of the, 26.

Artery, effect of tying, upon the lateral channels, 32 .

Arthropoda, 265.

Arts practised by savages, 179 .

Ascension, coloured incrustation on the roeks of, 263.

Ascidia, affinity of the lancelet to, 159 ; tadpole-like larvæ of, 159.

Ascidians, 262; bright colours of some, 260.

Asinus, Asiatic and African species of, $5+8$.

- taniopus, 548.

Ass, coluur-variations of the, 547 .

Ateles, effects of brandy on an, 7 ; absence of the thumb in, 51 .

beelzebuth, ears of, 15 .

marginatus, colour of the ruff

of, 537 ; hair on the head of, 59 .

Ateuchus, stridalation of, 306.
Atcuchus, cicatricosus, habits of, 300 .

Athalia, proportions of the sexes in, 254.

Atropus pulsatorius, 291.

Attention, manifestations of, in whimals, 73 .

Audouin, V., on a hymenopterous pa. rasite with a selentary male, $2 £ 1$.

Audubon, J. J., on the pinioned goose, 105 ; on the speculum of Mergus cucullatus, 236; on the pugnacity of male birds, 362,366 ; on Tetrao cupido, 367 ; on Ardea nycticorax, 368 ; on Sturnclla ludoviciana, 368 ; on the vocal organs of Tetrao cupido, 371 ; on the drumming of the male Tetrao umbellus, 375 ; on sounds produced by the nightjar, 376 ; on Ardea herodias and Cathartes jota, 380 ; on Mimus polyglottus, 393; on display in male birds, 394 ; on the spring change of colour in some finches, 394 ; recognition of a dog by a turkey, 412 ; selection of mate by female birds, 416 ; on th.e turkey, $411,412,419$; on variation in the male scarlet tanager, 424; on the musk-rat, 542 ; on the habits of Pyranja astiva, 453 ; on local differences in the nests of the same species of birds, 456 ; on the habits of woodpeckers, 458 ; on Bombycilla carobinensis, 461 ; on young females of 'Tyranga astiva aequiring male charncters, 462 ; on the immature plumage of thrushes, 464 ; on the immature plumage of birds, 465 et seq.; on birds breeding in immature plumage, 484; on the growth of the crest and plumes in the male Ardea ludoviciana, 485; on the change of colour in some species of Arcléc, 4.94

Audubon and Bachman, M.M., on squirrels fighting, 500 ; on the Canadian lynx, 521 .

Aughey, Prof, on rattlesnakes, 353.

Austen, N.L., on Anolis cristatellus, 354.

$\angle$ ustralia, not the birthplace of man, 155; half-castes killed by the natives of, 170 ; lice of the natives $c f, 170$; prevalence of female iusaticide in, 592. 
Anstralia, South, variation in the skulls of aborigines of, 26.

Australians, colour of newborn children of, 557 ; relative height of the sexes of, 559 ; women a cause of war among the, 561.

Axis deer, sexual difference in the colour of the, 537.

Aymaras, measurements of the, 34 ; no grey hair among the, 559; hairlessness of the face in the, 561 ; long hair of the, 580 .

Azara, on the proportion of mes and women among the Guaranys, 244; on Palamedea cornuta, 366 ; on the beards of the Guaranys, 561 ; on strife for women among the Guanas, 561 ; on infanticide, 577,592 ; on the eradication of the eyebrows and eyelashes by the Indians of Paraguay, 580 ; on polyandry among the Guanas, 593 ; celibacy unknown among the savages of South America, 594; on the freedom of divorce among the Charruas, 598.

\section{B.}

Brobage, C., on the greater proportion of illegitimate female births, 244.

Babixusa, tusks of the, 518 .

Baboon, revenge in $\mathrm{a}, 69$; rage excited in, by reading, 71 ; manifestation of memory by a, 74; employing a mat for shelter against the sun, 82 ; protected from punishment by its companions, 103.

- Cape, mane of the male, 521; Hamadryas, mane of the male, 521.

Baboons, effects of intoxicatung liquors on, 7 ; ears of, 15 ; diversity of the mental faculties in, 27 ; bands of, 50 ; habits of, 51 ; variability of the tail in, 58 ; manifestation of maternal affection by, 70; using stones and sticks as weapons, 81 ; co-operation of, 101 ; silence of, on plundering expeditions, 104; apparent polygamy of, 217 ; polygamous and social habits of, 590 .

Bachman, Dr., on the fertility of mulattnes, 171.

Baer, K. E. von, on embryoaic dev 3lopment, 9.
Bagehot, $W_{\text {., }}$ on the social virtues among primitive men, 117 ; slavery formerly beneficial, 117; on the value of obedience, 130 ; on human progress, 132 ; on the persistence of savage tribes in classical times, 183.

Bailly, E. Mr, on the unode of fighting of the Italian buffalo, 508 ; on the fighting of stags, 510 .

Bain, A., on the sense of duty, 98 ; aid springing from sympathy, 103 ; on the basis of sympathy, 106 ; on love of approbation, \&c., 109; on the idea of beauty, 584 .

Baird, $W_{\text {, }}$ on a difference in colour between the males and females of some Entozor, 260.

Baker, Mr., observation on the proportion of the seres in pheasantchicks, 247.

- Sir S., on the fondness of the Arabs for discordant music, 380 ; on sexual difference in the colours of an antelope, 536 ; on the elephant and rhinoceros attacking white or grey horses, 540 ; on the disfigurements practised by the negroes, 541 ; on the gashing of the cheeks and temples practised in Arab countries, 574; on the coiffure of the North Africans, 575; on the perforation of the lower lip by the women of Latooka, 575 ; on the distinctive characters of the coiffure of central African tribes, 576 ; on the coiffure of Arab women, 584.

"Balz" of the Black-cock, 363, 405.

Bantam, Sebright, 211, 238.

Banteng, horns of, 505 ; sexual differences in the colours of the, 536 .

Banyal, colour of the, 579 .

Barbarism, primitive, of civilised nations, 143.

Barbs, filamentous, of the feathers, in certain birds, 385,430 .

Barrago, $F_{4}$, on the Simian resem. blances of $\operatorname{man}, 3$.

Barr, Mr., on sexual preference is dogs, 524 .

Barrington, Daines, on the language of birds, 86 ; on the clucking of the hen, 368 ; on the object of the song of birds, 369 ; on the singing of female birds, 370 on birds 
acquiring the songs of other birds, 370 ; on the muscles of the larynx in song birds, 371 ; on the want of the power of song by female birds, 450.

Barrow, on the widow-bird, 403.

Bartels, Dr., supernumerary mamma in men, 37.

Bartlett, A. D., period of haiching of birds' eggs, 165 ; on the tragopan, 220 ; on the development of the spurs in Crossoptilon auritum, 236 ; on the fighting of the males of Ilectropterus gamibensis, 364 ; on the knot, 391 ; on display in male birds, 394 ; on the display of plumage by the male Polyploctron, 396 ; on Crossoptilon auvitum and Thasianus Wallichii, 400 ; on the habits of Lophophorus, 420 ; on the colour of the mouth in Buceros bicormis, 426 ; on the incubation of the cassowary, 478 ; on the Cape Buffalo, 508; on the use of the horns of antelopes, 509 ; on the fighting of male wart-hogs, 520 ; on Ammotragus tragelaphus, 531; on the colours of Cercopithecus cephus, 537 ; on the colours of the faces of monkeys, 550 ; on the naked surfaces of monkeys, 600 .

Bartram, on the courtship of the male alligator, 351 .

Basque language, highly artificial, 91.

Bate, C. S., on the superior activity of male crustacea, 221 ; on the proportions of the sexes in crabs, 255; on the chela of crustacea, 266 ; on the relative size of the sexes in crustacen, 268 ; on the colours of crustacen, 270.

Bateman, Dr., tendency to imitation in certain diseased states, 72 ; on A phasia, 88.

Bates, $H_{0}$ W. ' on variation in the form of the head of Amazonian Indians, 28 ; on the proportion of the sexes among Amazonian butterflies, 250 ; on sexual differences in the wings of buttertlies, 277 ; on the field-cricket, 283 ; on Pyrodes pulcherrimus, 294; on the horus of Lamellicorn beetles, 295 , 297 ; on the colours of Epicalio, teo, 309 ; on the coloration of tropical butterflies, 311 ; on ths variability of Papilio Sesostris and Childience, 320 ; on miale and female butterflies inhabiting different stations, 321 ; on mimicry, 323 ; on the caterpillar of a Sphinx, 325; on the vocal organs of the umbrella-bird, 374; on the toucans, 492 ; on Brachyurus calvus, 550.

Batokas, knocking out two upper incisors, 575.

Batrachis, 349 ; eagerness of male, 221.

Bats, scent-glands, 529 ; serual differences in the colour of, 534; fur of male frugivorous, 534 .

Battle, law of, 144; among beetles, 299; among birds, 360 ; among mammals, 500 et seq.; in man, 561.

Beak, serual difference in the forms of the, 359 ; in the coloul of the, 383.

Beaks, of birds, bright colour's of, 491 .

Beard, development of, in man, 557 ; analogy of the, in man and the quadrumana, 558 ; variation of the development of the, in different races of men, 559 ; estimation of, among bearded nations, 581 ; probable origin of the, 602 .

__ in monkeys, 150 ; of mannals, 531.

Beautiful, taste for the, in kirds, 410 ; in the quadrumana, 540 .

Beauty, sense of, in animals, 92 ; appreciation of, hy birds, 413 ; $1 \mathrm{n}$ fluence of, 573,576 ; variability of the standard of, 596 .

Beavan, Lieut., on the development of the horns in Cervus Eldi, 234.

Beaver, instinct and intelligence of the, 67,68 ; roice of the, 527 ; castoreum of the, 529.

Beavers, battles of male, 500 .

Bechstein, on female birds choosing the best singers among the males, 368 ; on rivalry in song - birds, 369 ; on the singing of female birds, 370 ; on birds acquiring the songs of other birds, 370; on pairing the canary and siskin, 415 ; on a subvariety of the monk pigeon, 427 ; on spurred hens, 449.

Beddue, Dr., on causes of difference 10 stature, 31. 
Bee-eater, 371.

Bees, 99 ; pol'en-baskets and stings of, 63 ; destruction of drones and queens by, 106 ; female, secondary sexual characters of, 208 ; proportion of sezes, 254; difference of the sexes in colour and sexual selection, 292.

Beetle, luminous larva of a, 277.

Beetles, 294; size of the cerebral ganglia in, 54; dilatation of the fore tarsi in male, 275 ; klind, 294; stridulation of, 301.

Belgium, ancient inhabitants of, 182.

Bell, Sir C., on emotional muscles in man, 3 ; "snarling muscles," 41 ; on the hand, 51.

, T., on the numcrical proportion of the seres in moles, 247 ; on the newts, 348 ; on the croaking of the frog, 350; on the difference in the coloration of the seres in Zootoca vivipara, 357 ; on moles fighting, 500.

Bell-bird, serual difference in the colour of the, 389.

Bell-birds, colours of, 492 .

Belt, Mr., on the nakedness of tropical mankind, 57 ; on a spider-monkey and eagle, 102 ; habits of ants; 147 ; Lampyridæe distasteful to mammals, 277 ; mimicry of Leptalides, 325 ; colours of Nicaraguan frogs, 349 ; display of humming-birds, 443 ; on the toucans, 492 ; protective colouring of skunk, 543 .

Benerolence, manifested by birds, 411.

Bennett, A. W., attachment of mated birds, 411 ; on the habits of $D, 0$ mocus irroratus, 478.

_- Dr., on birds of paradise, 396.

Berbers, fertility of crosses with other races, 171.

Bernicla antarctica colours of, 492.

Bernicle gander pairing with a Canada goose, 414.

Bert; M., crustacenns distinguish colours, 271.

Bertillon, M., arrested development and polydactylism, 37 .

Lettoni, E., on local differences in the nests of Italian birds, 456 .

Beyle, M., spe Bombet. 13hoteas, colour of the beard in, 558 .

Bhringa, disciform tail-feathers of, 392.

Bianconi, Prof., on structures as explained through mechanical principles, 24.

Bibio, sexual differences in the genus, 280.

Fichat, on beauty, 585 .

Bickes, proportion of seres in man, 243.

Bile, coloured, in many animals, 261. Bimana, 149.

Birds, imitations of the songs of other birds by, 73 ; dreaming; 74 ; killed by telegraph wires, 80 ; language of, 86 ; sense of beauty in, 92 pleasure of in incubation, 105 ; male, incubation by, 163 ; and reptiles, alliance of, 165 ; sexual differences in the beak of some, 208 ; migratory, arrival of the male before the female, 212 ; apparent relation between polygamy and inarked sexual differences in, 220 ; monogamous, becoming polygamous under domestication, 220 ; eagerness of male in pursuit of the female, 221 ; wild, numerical proportion of the sexes in, 247 ; secondary sexual characters of, 358 ; differ ence of size in the sexes of, 362 ; fights of male, witnessed by females, 367 ; display of male, to captivate the females, 367 ; close attention of, to the songs of others, 368 ; acquiring the song of their fosterparents, 370 ; brilliant, rarely good songster's, 371; love-nntics and dances of, 380 ; coloration of, 385 et seq.; moulting of, 390 et seq.; unpaired, 407 ; male, singing out of senson, 409 ; mutual affection of, 410 ; in confinement, distinguish persons, 411; hybrid, production of, 414 ; Albino, 419 ; European, number of species of, 422 ; variability of, 422; geographical distribution of colonring, 422 ; gradation of secondary sexual chnracters in, 430 ; obscurely coloured, building concenled nests, 454 ; young female, acquiring male characters; 462 : breeding in immature plumage 484 ; moulting of, 484 ; 'squatic 
frequency of white plumage in, 493; vocal courtship of, 567 ; naked skin of the hoad and neck in, 601.

Birgus latro, habits of, 270 .

lirkbeck, Mr., on the finding of new mates by golden eagles, 408 .

Birthplace of man, 155 .

Births, numerical proportions of the sexes in, in animals and man, 215 , 216 ; male and female, numerical proportion of, in England, 242.

Bischoff, Prof., on the agreement between the brains of man and of the orang, 6 ; figure of the embryo of the dog, 10 ; on the convolutions of the brain in the human foetus, 11 ; on the difference between the skulls of man and the quadrumana, 149 ; resemblance between the ape's and man's, 200.

Bishop, J., on the vocal organs of frogs, 350 ; on the vocal organs of corvine birds, 370 ; on the trachea of the Merganser, 374 .

Bison, American, co-operation of, 101; mane of the male, 521.

Bitterns, dwarf, coloration of the sexes of, 461.

Bizinara lobata, musky odour of the male, 359 ; large size of male, 362 .

Blackbird, sexual differences in the, 219 ; proportion of the sexes in the, 248 ; acquisition of a song by, 370 ; colour of the beak in the sexes of the, 383,491 ; pairing with a thrush, 414 ; colours and nidification of the, 455 ; young of the, 487 ; sexual difference in coloration of the, 491 .

Black-buck, Indian, sexual difference in the colour of the 535 .

Blackcap, arrival of the male, before the female, 212; young of the, 487.

Black-cock, polygamous, 219 ; proportion of the sexes in the, 248 ; pugnacity and love-dance of the, 363 ; call of the, 375 ; moulting of the, 392 ; duration of the courtship of the, 405 ; and pheasant, hybrids of, 414 ; sexual difference in colorition of the, 191 ; crimson ere-cere of the, 491.

Blacklock, Dr, ou music, 572.
Black-grouse, characters of young, $465,471$.

Blackwall, J., on the speaking of the magpie, 90 ; on the desertion or their young by swallows, 108 ; on the superior activity of male spiders, 221: on the proportion of the sexes in spiders, 254; on sexual variation of colour in spiders, 272 ; on male spiders, 272.

Bladder-nose Seal, hood of the, 528.

Blaine, on the affections of dogs, 523.

Blair, Dr., on the relative liability of Europeans to yellow fever, 194.

Blake, C. C., on the jaw from La Naulette, 40.

Blakiston, Capt., on the American snipe, 377 ; on the dances of Tetras phasianellus, 381.

Blasius, Dr., on the species of European birds, 422.

Bledius taurus, hornlike processes of male, 299.

Bleeding, tendency to profuse, 237.

Blenkiron, Mr., on sexual preference in horses, 524.

Blennies, crest developed on the head of male, during the breeding season, 338.

Blethisa multipunctata, stridulation of, 302.

Bloch, on the proportions of the sexes in fishes, 249.

Blood, arterial, red colour of, 261.

- pheasant, number of spurs in, 364.

Bluebreast, red-throated, sexual differences of the, 472 .

Blumenbach, on Man, 28; on the large size of the nasal cavities in American aborigines, 34 ; on the position of man, 149 ; on the number of species of man, 174 .

Blyth, $E_{\text {. }}$, on the structure of the hand in the species of Hylobates, 51 ; observations on Indian crou's, 102 ; on the development of the horns in the Koodoo and Eland antelopes, 234; on the pugnacity of the males of Gallinula cristata, 360 ; on the presence of spurs in the female Euplocamus erythrophthalmus, 364 ; on the pugaacity of the amadavat. 366 ; on the sfoonbill, 374 ; on the 
moulting of Anthrs, 392; on the moulting of bustards, plovers, and Gallus bankivx, 392 ; on the Indian honey-buzzard, 424 ; on sexual differences in the colour of the eyes of hurnbills, 425; on Oriolus melanocephalus, 460; on Palcoornis javanicus, 461 ; on the genus Ar$\operatorname{detta}, 461$; on the peregrune falcon, 461 ; on young female bixds acquiring male characters, 461 ; on the inmmature plumage of birds, 465 ; on representative species of birds, 468 ; on the young of Turnix, 476 ; on anomalcus young of Lanius rufus and Colymbus glacialis, 482 ; on the sexes and young of the sparrows, 483 ; on dimorphism in some herons, 484 ; on the ascertainment of the sex of nestling bullfinches by pulling out breast-feathers, 484 ; on orioles breeding in immature plumage, 484; on the sexes and young of Buphus and Anastomus, 486 ; on the young of the blackcap and blackbird, 487 ; on the young of the stonechat, 487 ; on the white plumage of Anastomus, 493 ; on the horns of Bovine animals, 505 ; on the horns of Antilope bezoartica, 507 ; on the mode of fighting of Ovis cycloceros, 508 ; on the voice of the Gibbons, 527 ; on the crest of the male wild goat, 531 ; on the colours of Portax picta, 535 ; on the colours of Antilope bezoartica, 536 ; on the colour of the Axis deer, 536 ; on sexual difference of colour in Hylobates hoolock, 537 ; on the hog-deer, 546 ; ou the beard and whiskers in a monkey becoming white with age, 559.

Boar, wild, polygamous in India, 217 ; use of the tusks by the, 513 ; fighting of, 518.

Buardman, Mr., Albino birds in U.S., 419.

Bcitard and Corbié, MM., on the transmission of sexual peculiarities in pigeons, 230 ; on the antipathy shewn by some fernale pigeons to certain males, 418 .

Bold, Mr., on the singing of a sterile kybrid canary, 369 .
Bombet, on the variability of the standard of beauty in Europe, 596. Bombus, difference of the sexes in, 292.

Bombycidr, coloration of, 313 ; pairing of the, 318 ; colours of, 318.

Bombycilla carolinensis, red appendages of, 461 .

Bomibyx cynthia, 278; proportion of the sexes in, 250, 253; pairing ot; 318.

- mori, difference of size of the male and female cocoons of, 278 ; pairing of, 318 .

Pernyi, proportion of sexes of, 253.

Yamamai, 278; M. Personnat on, 251 ; proportion of sexes of, 253.

Bonaparte, C. L., on the call-notes of the wild turkey, 375 :

Bond, F., on the finding of new mases by crows, 408.

Bone, implements of, skill displayed in making, 49.

Boner, C., on the transfer of male characters to an old female chamois, 504 ; on the habits of stags, 515 ; on the pairing of red deer, 522 .

Bones, increase of, in length and thickness, when carrying a greater weight, 32.

Bonizzi, P., difference of colour in sexes of pigeons, 230.

Bonnet monkey, 151.

Bonwick, J., extinction of Tasmanians, $183,184$.

Boomerang, 145.

Boreus hyemalis, scarcity of the male, 254.

Bory St. Vincent, on the number of species of man, 174 ; on the colour's of Labrus pavo, 342 .

Bos etruscus, 505.

- gaurus, horns of, 505 .

- moschatus, 529.

primigenius, 501.

sondaicus, horns of, 505 ; colours of, 536 .

Botocudos, 144; mode of life of, 197 ; disfigurement of the ears and lower lip of the, 575 .

Boucher de Perthes, J. C. de, on the antiquity of man, 2.

Bourbon, proportion of the seres in a species of Favilio trom, 250 
Bournen, on the marriage-customs of the savages of the Malay Archipelago, 598.

Bovidæ, dewlaps of, 531 .

Bower-birds, 406 ; habits of the, 381 ; ornamented playing-places of, 92 , $41 \%$.

Bows, use of, 179 .

Brachycephalic structure, possible explanation of, 56 .

Brachyura, 268.

Brachyurus calvus, scarlet face of, 550 .

Bradley, Mr., abductor ossis metatarsi quinti in $\operatorname{man}, 42$.

Brain, of man, agreement of the, with that of lower animals, 6 ; convolutions of, in the human foetus, 11 ; influence of development of ment:l ficulties upon the size of the, 54 ; influence of the development of, on the spinal column and skull, 55; larger in some existing mammals than in their tertiary prototypes, 81; relation of the development of the, to the progress of language, 87 ; disease of the, affecting speech, 88; difference in the convolutions of, in different races of men, 167 ; supplement on, by Prof. Huxley, 199 ; development of the gyri and sulci, 204.

Brakenridge, Dr, on the influence of climate, 32.

Brandt, A., on hairy mea, 19.

Braubach, Prof., on the quasi-religious feeling of a dog towards his master, 96 ; on the self-restraint of dogs, 103.

Braver, F., on dimorphism in Neuro. themis, 291.

Brazil, skulls found in cares of, 168 ; population of, 173 ; compression of the nose by the natives of, 583 .

Break between man and the apes, 156.

Bream, proportion of the sexes in the, $2+9$.

Breeding, age of, in birds, 484.

- season, sexcal characters making their appearance in the, in birds, 290 .

Wrehm, on the effects of intoxicating liqunrs on monkeys, 7 ; on the recognition of women by male Cyno. cephali, 8 ; on the dirersity of the mental faculties of monkeys, 27 ; on the habits of baboons, 51 ; on revenge taken by monkeys, 69 ; on manifestations of maternal affection by monkeys and baboons, 70 ; on the instinctive dread of monkeys for serpents, 71; on the use of stones as missiles by baboons, 81 : on a baboon using a mat for shelter fiom the sun, 82 ; on the signalcries of monkeys, 87 ; on sentinels posted by monkeys, 101 ; on co-opejation of animals, 101 ; on an eagle attacking a young Cercopithecus, 101 ; on baboons in confinement protecting one of theix number from punishment, 103; on the habits of baboons when plundering, 104 ; on polygamy in Cynocephalus and Cebus, 217 ; on the numerical proportion of the sexes in birds, 247 ; on the love-dunce of the black-cock, 363 ; on Palamsdea cornuta, 366; on the habits of the Black-grouse, 366 ; on sounds produced by birds of pradise, 376 ; on assemblages of grouse, 405 ; on the finding of new mates by birds, 409 ; on the fighting of wild boars, 518 ; on the habits of Cynocephalus hamadryas, 590.

Blent, Mre, on the courtship of fowls, 417 .

Breslau, numerical proportion of male and female births in, 243 .

Bridgman, Laura, 88.

Brimstone butterfly, 312 ; sexual difference of colour in the, 322 .

British, ancient, tattooing practised by, 574 ,

Broca, Prof., on the occurrence of the supra-condyloid foramen in the humàn humerus, 22 ; anthropomorphous apes more bipedal than quadrupedal, 53 ; on the capacity of l'urisian skulls at different periods, 55; compalisou of modern and medixval skulls, 55 ; on tails of quadrupeds, 58 ; on the influence of natural selection, 61 ; on hybridity in mun, 170; on human remains from Les Eyzies, 181 ; on the cause of the difference between Europeans and Hindoos, $19 ?$. 
Brodie, Sir $\mathrm{B}_{\text {, }}$ on the origin of the moral seuse in man, 98 .

Bronn, H. G., on the copulation of insects of distinct species, .775 .

Bronze perind, men of, in Europe, 128.

Brown, R., sentinels of seals gcnerally females, 100 ; on the batties of seals, 500 ; on the narwhal, 502 ; on the occasional absence of the tusks in the female walrus, 502 ; on the bladder-nose seal, 528 ; on the colours of the sexes in Phoca Gronlandica, 535; on the appre. ciation of music by seals, 569 ; on plants used as love-philters, by North American women, 577.

Brown, Dr. Crichton, injury to infants during parturition, 244.

Brown-Séquard, Dro, on the inheritance of the effects of operations by guinea-pigs, 60, 603.

Bruce, on the use of the elephant's tusks, 507.

Brulerie, $P$. de la, on the habits of Ateuchus cicatricosus, $300:$ on the stridulation of Atcuchus, 306.

Britunich, on the pied ravens of the Feroe islands, 424.

Bryant, Dr, preference of tame pigeon for wild mate, 418.

Capt, on the courtship of Caliorhinus ursinus, 522 ,

Bubas bison, thoracic projection of, 298.

Bucephalus capensis, difference of the seres of, in colour, 351.

Buceros, nidification and incubation of, 454.

bicornis, sexual differences in the colouring of the casque, beak, and mouth in, 425 ,

- corrugatus, sexual differences in the beak of, 383 .

Btichner, L., on the origin of man, 3 ; on the use of the human foot as a prehensile organ, 52 ; on the mode of progression of the apes, 52 ; on want of self-consciousness, \&c., in savages, 83.

Bucholz., Dr.g quarrels of chamxleons, 357.

Buckland, F, on the numerical proportion of the sexes in rats, 247 ; on the proportion of the sexes in the trout, 249 ; on Chimara monstrosa, 338 .

Buckland, W., on the complexity of crinoids, 91.

Buckler, W., proportion of sexes of Lepidoptera reared by, 253.

Buckinghamshire, numerical proportion of male and female births in, 242.

Bucorax abyssinicus, inflation of the neck-wattle of the male during courtship, 383.

Bullites Paii, 212.

Buffilo, Cape, 508 .

_- Indian, horns of the, 505.

- Italian, mode of fighting of the, 508.

Buffon, on the number of species of man, 174.

Bufo sikimmensis, 349.

Bugs, 281.

Buist, R., on the proportion of the sexes in salmon, 249 ; on the pug. nacity of the male salmon, 332 .

Bulbul, pugnacity of the male, 360 ; display of under tail-coverts by the male, 402.

Bull, mode of fighting of the, 508 ; curled frontal hair of the, 531.

Buller, Dr., on the Huia, 208; the attachment of birds, 410 .

Bullfinch, sexual differences in the, 219 ; piping, 369 ; female, singing of the, 370 ; courtship of the, 401 ; widowed, finding a new mate, 408 ; attacking a reed-bunting, 412 ; nestling, sex ascertained by pulling out breast-feathers, 484 ,

Bullfinches distinguishing persons, 412 ; rivalry of female, 420 .

Bulls, two young, attacking an old one, 101; wild, battles of, 501 .

Bull-trout, male, colouring of, during the breeding season, 340 .

liunting, reed, head feathers of the male, 402 ; attacked by a bullfinch, 412.

Buntings, characters of young, 464 .

Buphus coromandus, sexes and young of, 486 ; change of colour in, 494 , 495 .

Burchell, Dr., on the zebra, 545 ; on the extravagance of a bushwoman in adorning herse'f, 577 ; celibany unknown among the savages of South Africa, 594; on the mar. 
riage-customs of the Bushwomen, 596.

Burke, on the number of species of man, 174.

Burmese, colour of the beard in, 558 .

Burton, Capt., on negro ideas of female heauty, 579 ; on a universal ideal of beauty, 582 .

Bushmen, 64.

Bushwoman, extravagant ornamentation of a, 577.

Bushwomen. hair of, 167 ; marriagecustoms of 598 .

Bustara, inroat-pouch of the male, 373 ; humming noise produced by a male, 377 ; Indian, ear-tufts of, 394.

Bustards, occurrence of sexual differences and of polygamy among the, 219 ; love-gestures of the male, 380 ; double moult in, 390, 392.

Butler, A. $G_{\circ}$, on serual differences in the wings of Aricoris epitus, 277 ; courtship of butterflies, 307 ; on the colouring of the seres in species of Thecla, 310; on the resemblance of Iphias glaucippe to a leaf, 313 ; on the rejection of certain moths and caterpillars by lizards and frogs, 326.

Butterfly, noise produced by $a, 307$; Emperor, 307, 308 ; meadow brown, instability of the ocellated spots of, 428.

Butterflies, proportion of the sexes in, 250 ; forelegs atrophied in some male, 277 ; sexual difference in the neuration of the wings of, 277 ; pugnacity of male, 307 ; protective resemblances of the lower surface of, 311 ; display of the wings by, 314 ; white, alighting upon bits of paper, 317 ; attracted by a dead specimen of the same species, 317 ; courtship of, 317 ; male and female, inhabiting different stations, 321.

Buxton, C., observations on macaws, 102 ; on an instance of benevolence in a parrot, 411.

Buzzard, Indian honey-, variation in the crest of, 424 .

c.

Caibage butterfies, 312.

Cachalot, large head of the male, 502.
Cadences, musical, perception of, by animals, 569 .

Cæcum, 20; large, in the early pro genitors of man, 160 .

Cairina moschata, pugnacity of the male, 362.

Californian Indians, decrease of, 258.

Callianassa, chelæ of, figured, 267.

Callidryas, colours of seres, 318.

Callionymus lyra, characters of the male, 335.

Callorhinus ursinus. relative size of the sexes of, 515 ; courtship of, 522.

Calotes maria, 358.

nigrilabris, sexual difference in the colour of, 357.

Cambridge, O. Pickard, on the sexes of spiders, 255 ; on the size of male Nephila, 273.

Camel, canine teeth of male, 502, 514.

Campbell, J., on the Indian elephant. 218 ; on the proportion of male and female births in the harems of Siam, 245.

Campylopterus hemileucurus, 248.

Canaries distinguishing persons, 412

Canary, polygamy of the, 220 ; change of plumage in, after moulting, 238, female, selecting the best singing male, 268; sterile hybrid, singing of $a, 369$; female, singing of the, 370 ; selecting a greenfinch, 415 ; and siskin, pairing of, 415 .

Canestrini, $G_{\text {, }}$ on rudimentary characters and the origin of man, 3 ; on rudimentary characters, 11 ; on the movement of the ear in man, 14 ; on the variability of the vermiform appendage in man, 21 ; on the abnormal division of the malar bone in man, 39 ; on abnormal conditions of the human uterus, 39 ; on the persistence of the frontal suture in $\operatorname{man}, 39$; on the proportion of the sexes in silk-moths, 250 , 251 ; secondary serual characters of spiders, 272 .

Cancer pagurus, 266.

Canfield, Dr., on the horns of the Antilocapra 234.

Canine teeth in man, 46 ; diminution of, in man, 53 ; diminution of, in horses, 53 ; disappearance of, is 
male ruminants, 53 ; large, in the early progenitors of man, 160.

Canines, and horns, inverse derelop. ment of, 514 .

Canoes, use of, $48,180$.

Cantharis, difference of colour in the sexes of a species of, 294.

Cantharus lineatus, 341.

Capercailzie, polygamous, 219 ; proportion of the sexes in the, 248 ; pugnacity of the male, 363 ; pairing of the, 367 ; autumn meetings of the, 370 ; call of the, 375 ; duration of the courtship of, 405 ; behavivur of the female, 419 ; inconvenience of black colour to the fernale, 444 ; sexual difference in the colora. tion of the, 491 ; crimson eye-cere of the male, 491.

Capitonidre, colours and nidification of the, 455 .

Capra agagrus, 508; crest of the male, 531 ; sexual difference in the colour of, 536.

Capreolus Sibiricus subecanulatus, 542.

Caprice, common to man and animals, 93.

Caprimulgus, noise made by the males of some species of, with their wings, 376 .

- virginianus, pairing of, 366 .

Carabida, 302.

Carbonnier, on the natural history of the pike, 249 ; on the relative size of the sexes in fishes, 335 ; courtship of Chinese Macropus, 341.

Carcineutes, sexual difference of colour in, 457.

Carcinus manas, 268, 269.

Cardinalis virginianus, 225.

Carduelis elegans, sexual differences of the beak in, 360 .

Carnivora, marine, polygamous habits of 218 ; sexual differences in the colours of, 534 .

Carp, numerical proportion of the sexes in the, 249.

Carr, R., on the peewit, 366.

Carrier pigeon, late development of the wattle in the, 238.

Carrion beetles, stridulation of, 302 .

Carus, Prof. V., on the development of the horns in merino sheep, 235.

Cassowary, sezes and incubation of the, 473.
Custina, mode of holding wings, 315.

Castoreum, 529.

Casuarius galeatus, 478.

Cat, convoluted body in the extremity of the tail of $\mathrm{a}, 23$; sick, sympathy of a dog with a, 103.

Cataract in Cebus Azarce, 7.

Catarth, liability of Cebus Azarce to, 7.

Catarrhine monkeys, 153.

Caterpillars, bright colours of, 325 .

Cathartes aura, 416.

- jota, love-gestures of the male, 380.

Catlin, G., correlation of colour and texture of hair in the Mandins, 197 ; on the development of the beard among North American Indians, 560 ; on the great length of the hair in some North American tribes, 580 .

Caton, J. D., on the development of the horns in Cervus virginianus and strongyloceros, 234 ; on the presence of traces of holns in the female wapiti, 504; on the fighting of deer, 510 ; on the crest of the male wapiti, 531; on the colours of the Virginian deer, 535 ; on sexual ditferences of colour in the wapiti, 536 ; on the spots of the Virgiaian deer, 546 .

Cats, dreaming, 74; tortoise-shell, 230 , 232,237 ; enticed by valerian, 530 ; colours of, 543 ,

Cattle, rapid increase of, in Solth America, 47 ; domestic, lighter is: winter in Siberia, 229; hor'ns of, 234. 505 ; domestic. sexual differences of, late developed, 238 ; numerical proportion of the seres in, 246 .

Caudal vertebræ, number of, in macaques and baboons, 58 ; basal, of monkeys, imbedded in the body, 59 .

Cavolini, observations on Serranus, 162.

Cebus, maternal affection in a, 70 ; gradation of species of, 175 . Apella, 205.

Azara, liability of, to the same diseases as man, 7; distinct souuds produced by, 84; early maturity of the female, 558 .

capucinus, polygamous, 217 sexual differences of colour in, 537 , hair on the head of, 549 . 
Cebrus vellorosrus, hair on the head of, 549 .

Cecidomyidx, proportions of the seres in, 354 .

Celibacy, unknown among the savages of South Africa and South America. 594.

Centipedes, 274.

Cephalopoda, absence of secondary serual cha-ricters in, 263.

Cephalopterus ornatus, 373.

penduliger, 374.

Cerambyx heros, stridulant organ of, 303.

Cexatodus, paddle of, 37 .

Ceratophora aspera, nasal appendages of, 355.

Stoddartii, asal horn of, 355.

Cerceris, habits of, 291.

Cercocebus athiops, whiskers, \&c., of, 550.

Cercopithecus, young, seized by an eagle and rescued by the troop, 101 ; definition of species of, 175 .

- cephus, sexual difference of colour in, $537,552$.

- cynosurus and griseoviridis, colour of the scrotum in, 537.

Diana, sexual differences of colour in, $537,552,553$.

griseo-viridis, 101.

$$
550 \text {. }
$$

petaurista, whiskers, \&rc., of,

Ceres, of birds, bright colours of, 491 .

Ceriornis Temminckii, swelling of the wattles of the male during courtship, 383.

Cervulus, weapons of, 514 .

- moschatus, rudimentary horns of the female, 504 .

Cervus alces, 234.

- campestris, odour of, 529.

canadensis, traces of horns in

the female, 504; attacking a man,

511 ; sexual difference in the colour of, 536 .

- elaphus, battles of male, 501 ; horns of, with numerous points, 510.

- Eldi, 234.

- mantchuricus, 546.

- paludosus, colours of, 536 .

- strongyloceros, 234.

- virginianus, 234; horns of, in cutrese of modification, 511.
Ceryle, male black-belted in some species of, 457 .

Cetacea, nakedness of, 56.

Ceylon, frequent absence of beard in the natives of, 560 .

Chaffinch, proportion of the sexes in the, 248 ; courtship of the, 401 .

Chaffinches, 369; new mates found by, 408.

Chalcophaps indicus, characters of young, 465.

Chalcosoma atlas, sexual differences of, 295.

Chamceleo, serual difierences in the genus, 356.

- bifurcus, $356,357$.

Owenii, 357.

- pumilus, 357 .

Chamopete's unicolor, modified wingfeather in the male, 377.

Chameleons, 354.

Chamois, danger-signals of 100 ; transfer of male character's to an old female, 504 .

Champneys, $\mathbf{M r}$., acromjo-basilar muscle and quadrupedal gait, 42.

Chapuis, Dr., on the transinission of sexual peculiarities in pigeons, 230 ; on streaked Belgian pigeons, 238, 446.

Char, male, colouring of, during the breeding season, 340 .

Characters, male, developed in females, 227 ; secondary sexual, transmitted through both sexes, 227 ; natu:al, artificial, exaggeration of, by man, 582 .

Charadrits hiaticula and piucialis, sexes and young of, 485 .

Chardin on the Yersians, 586.

Charmas, worn by women, 577 .

Charruas, freedom of divorce among the, 598.

Chasmorhynchus, difference of colour in the seres of, 389 ; colours of, 492 .

- niveus, 389.

- tricarunculatus, 389.

Chastity, early estimation of, 119 .

Chatterers, sexual difterences in, 219.

Cheever, Rev. H. T., census of the Sandwich Islands, 257.

Cheiroptera, absence of secondary sexual characters in, 218.

Chelæ of crustacea, 266, 271.

Chelonia, sexual differences in 350 . 
Cheralopes agyptiacus, wing-knobs of, 364.

Chera progne, 392, 419.

Chest, proportions of, in soldiers and sailors, 32 ; large, of the Quechua and Aymara Indians, 34.

Chevrotains, canine teeth of, 514 .

Chiasognathus, stridulation of, 306.

- Grantii, mandibles of, 300 .

Children, legitimate and illegitimate, proportion of the sexes in, 243.

Chiloe lice of the natives of, 170 ; population of, 173.

Chimara monstrosa, bony process on the head of the male, 338 .

Chimæroid fishes, prehensile organs of male, 331.

Chimpanzee, 561; ears of the, 14; representatives of the eyebrows in the, 19 ; hands of the, 50 ; absence of mastoid processes in the, 53 ; platforms built by the, 66 ; cracking nuts with a stone, 81 ; direction of the hair on the arms of the, 151 ; supposed evolution of the, 177; polygamous and social habits of the, 590 .

China, North, idea of ferale beauty in, 578 .

- Southern, inhabitants of, 197

Chinese, use of flint tools by the, 145 ; difficulty of distinguishing the races of the, 167; colour of the beard in, 558 ; general beardlessness of the, 560 ; opinions of the, on the appearance of Europeans and Cingalese, 578 ; compression of the feet of, 583 .

Chinsurdi, his opinion of beards, 576 , 581.

Chlamydera maculata, 382.

Chloëon, pedunculated eyes of the male of, 274.

Chloephaga, coloration of the sexes in, 460.

Chlorocalus Tanana (figured), 285.

Chorda Dorsalis, 161.

Chough, red beak of the, 491 .

Chromidx, frontal protuberance in male, 340 ; sexual differences in colour of, 345 .

Chrysemys picta, long claws of the male, 350 .

Chrysococcyx, characters of young of, 4 ค 5.
Chrysomelidæ, stridulation of, 302 .

Cicada pruinosa, 282.

- septendecim, 282.

Cicalix, songs of the, 281 ; rudimentary sound-organs in females of, 288.

Cicatris of a burn, causing moditication of the facial bones, 55 .

Cichla, frontal protuberance of male, 340.

Cimetière du Sud, Paris, 22.

Cincloramphus cruralis, large size of male, 362.

Cinclus aquaticus, 455 .

Cingalese, Chinese opiuion of the ap. pearance of the, 578 .

Cirripedes, complemental males of 208.

Civilisation, effects of, upon natural selection, 133; influence of, in the competition of nations, 183.

Clazging of geese, \&c., 368.

Claparede, $E_{\text {., }}$ on natural selection applied to man, 49 .

Clarke, on the marriage-customs of the Kalmucks, 598.

Classification, 148.

Claus, C., on the sexes of Saphirina, 271.

Cleft-palate, inherited, 35.

Climacteris erythrops, sexes of, 479 .

Climate, 31 ; cool, favourable to human progress, 133 ; power of supporting extremes of, by man, 182 ; want of connexion of, with colour, 192.

Cloaca, existence of $a$, in the early progenitors of mau, 161.

Cloacal passage existing in the human embryo, 9 .

Clubs, used as weapons before dispersion of mankind, 180.

Clucking of fowls, 368.

Clythra 4-punctata, stridulation of, 302.

Coan, Mr., Sandwich-islanders, 187.

Colbe, Miss, on morality in hypothetical bee-community, 99.

Cobra, ingenuity of a, 352 .

Coccus, 147.

Coccyx, 22, 23; in the human em. bryo, 9 ; convoluted body at the extremity of the, 23 ; imbedded in the body, 59.

Cochia-China, notions of beacty 6 ? the inbabitants of, 578,580 . 
Cock, blind, fed by its companions, 103; game, killing a kite, 363 ; cumb and wattles of the, 403 ; preference shewn by the, for young hens, 420 ; game, transparent zone in the hackles of a, 430 .

Cock of the rock, 405 .

Cockatoos, 491, 492, 493 ; nestling, 411 ; black, immature plumage of, 467 .

Cælenterata, absance of seccndary sexual characters in, 260.

Coffee, fondness of monkeys for, 7 .

Cold, supposed effects of, 32 ; power of supporting, by man, 182.

Coleoptera, 294 ; stridulation of, 284 ; stridulant organs of, discussed, 303.

Colias edusa and hyale, 319.

Collingwood, $\mathrm{C}_{\text {., on the pugnacity of }}$ the butterflies of Bornco, 307 ; on butterflies being attracted by a dead specimen of the same species, 317.

Colobus, absence of the thumb, 51 .

Colombia, flattened heads of savages of, 575 .

Colonists, success of the English as, 142 .

Coloration, protective, in birds, 489 .

Colour, supposed to be dependent on light and heat, 32 ; correlation of, with immunity from certain poisons and parasites, 193 ; purpose of, in 'epidoptera, 316 ; relation of, to sexual functions, in fishes, 343 ; difference of, in the sexes of snakes, 351 ; sexual differences of, in lizards, 357; influence of, in the pairing of birds of different species, 415 ; relation of, to uidification, 453,456 ; sexual differences of, in mammals, 533,540 ; recognition of, by quadrupeds, 540 ; of children, in different races of $\mathrm{man}, 557$; of the skin in man, 604 .

Colours, admired alike by man and animals, 93 ; bright, due to sexual selection, 261 ; bright, among the lower animals, 261, 262; bright, protective to hutterflies and moths, 313 ; bright, in male fishes, 335 , 340 ; transmission of, in birds, 448 . Colquhoun, example of reasoning in 2 retriever, 78 .

Cclussha prsserina, young of, 467
Colymbus glacialis, anomalous young of, 482 .

Comb, derelopment of in fowis, 239.

Combs and wattles in male birds, 403.

Community, preservation of variations useful to the, by natural selection, 62.

Compositæ, gradation of species among the, 175.

Comte, C., on the expression of the idenl of beauty by sculpture, 581 .

Conditions of life, action of changed, upon man, 30 ; influence of, on plumage of birds, 472 .

Condor, eyes and comb of the, 472 .

Conjugations, origin of, 91.

Conscience, 114, 126; absence of, in some criminals, 116.

Constitution, difference of, in different races of men, 168 .

Consumption, liability of Cebus Azara to, 7 ; connexion between complexion and, 194.

Convergence of characters, 177.

Cooing of pigeons and doves, 374.

Cook, Capt., on the nobles of tne Sand wich Islands, 586.

Cope, E. D., on the Dinosauria, 158.

Cophotis ceylanica, sexual differences of, $354,357$.

Copris, 295.

- Isidis, sexual differences of, 296.

- lunaris, stridulation of, 303.

Corals, bright colours of, 260 .

Coral-snakes, 353.

Cordylus, sesual difference of colour in a species of. 357 .

Corfu, hatits of the Chaffinch in, $2+8$.

Cornelius, on the proportions of the sexes in Lucanus Cervus, 253.

Corpora Wolffina, 161; agree:nent of, with the kidneys of fishes, 11 .

Correlated variation, 43.

Correlation, influence of, in the production of races, 197.

Corse, on the mode of fighting of the elephant, 514.

Corvus corone, 408 .

graculus, -ed beak of, 491 . 406.

pica, ncptial assembly of,

Corydalis cornutus, laige jaws of the male, 275.

Cosmetornis, 462. 
Cosmetornis vexillarius, elongation of wiug-feathers in, 384, 403.

Cotingidæ, sexual differences in, 219 ; coloration of the sexes of, 460 ; resemblance of the females of distinct species of, 470 .

Cottus scorpirs, sexual differences in, 337.

Coulter, Dr., on the Californian Indians, 258.

Counting, origin of, 144 ; limited power of, in primeval man, 180 .

courage, variability of, in the same species, 69 ; universal high appreciation of, 118; importance of, i 30 ; characteristic or $m \in n, 564$.

Courtship, greater eagerness of males in, 221 ; of fishes, 331,341 ; of birds, $367,4 \mathrm{C5}$.

Cow, wister change of colour, 542.

Crab, devil, 269.

- shure, habits of, 268.

('rabro cribrarins, dilated tibire of the male, 276.

Crabs, proportions of the sexes in, 255.

Cranz, on the inheritance of dexterity in seal catching, 33 .

Crawfuld, on the number of species of $\mathrm{man}, 174$.

Crenilabrus massa and C. melops, nests built by, 345 .

Crest, origin of, in Polish fowls, 231.

Crests, of birds, difference of, in the sexes, 467 ; dorsal hairy, of mammals, 530 .

Crivket, field-, stridulation of the, 283 ; pugnacity of male, 289.

- house-, stridulation of the 283,284 .

Crickets, sexual differences in, 289.

Crioceridx, stridulation of the, 302.

Crinoids, complexity of, 91.

Croaking of frogs, 350.

Crocodiles, musky odour of, during the breeding season, 351.

Crocodilia, 351.

Crossbills, characters of young, $40^{\circ} 4$.

Crosses in man, 173.

Crossing of races, effects of the, 192 .

Crossoptilon auritum, 400, 452, 472 ; adornment of both sexes of, 235 ; sexes alike in, 460 .

Crotch, G. Ro, on the stridulation of Leetles, 302,304 ; on the stridu- lation of Heliopathes, 305 ; on the stridulation of Acalles, 306; habit of female deer at breeding time, 503 . Crow Indians, long hair of the, 580 .

- young of the, 481 .

Crows, 491 ; rocal organs of the, 370 ; living in triplets, 409.

407.

- Indian, feeding their blind companions, 103.

Cruelty of savages to animals, 118.

Crustacea, parasitic, loss of limbs by female, 208; prehensile t'eet and antennæ of, 209 ; male, more active than female, 221 ; parthenogenesis in, 255 ; secondary sexual characters of, 265 ; amphipod, males sexually mature while young, 485 ; auditory hairs of, 568 .

Crystal worn in the lower lip by some Central African women, 575.

Cuckoo fowls, 238.

Culicidx, 208, 280; attracted by exch other's humning, 280.

Cullen, Dr., on the throat-pouch o. the male bustard, 373.

Cultivation of plants, probable origin of, 133.

Cupples, Mre, on the numerical pro. portion of the sexes in dogs, sheep, and cattle, 246; on the Scotch deerhound, 516; on sexual preference in dogs, 524 .

Curculionidx, sexual difference in length of snout in some, 208: hornlike processes in male, 299 ; musical, 301, 302.

Curiosity, manifestations of, by auimals, 71 .

Curlews, double moult in, 390.

Cursores, comparative absence of sexual differences among the, 219.

Curtis, J., on the proportion of the sexes in Athatia, 254.

Cuvier, F., on the recognition of women by male quadrumana, 8 .

- G., on tise number of caudal vertebræ in the mandrill, 58 ; on instinct and intelligeace, 67 ; views of, as to the position of man, 149 ; on the position of the seals, 150 ; on Hectocotyle, 263.

Cy'anecula suecica, sexual differentes of, 472 . 
Cyanalcyon, sexual difference in colours of, 457 ; immature plumage of, 467 .

Sychrus, sounds produced by, 304.

Cycria mendica, sexual difference of, in colour, 316.

Ignus ferus, trachea of, 374.

olor, white young of, 482 .

Cyllo Leda, instability of the ocellated spots of, 428.

Cynant/lus, variation in the genus, 423.

Cynipidx, proportions of the sexes in, 254.

Cynocephalus, difference of the young from the adult, 8; male, recognition of women by, 8 ; polygamous habits of species of, 217 .

- chacma. 70.

- gelada, 81 .

- hamadryas, 81,590 ; sexual difference of colour in, 537.

leucophus, colours of the sexes of, 538 .

- mormon, colours of the male, $538,540,550$.

- porcarius, mane of the male, 521.

Cypridina, proportions of the sexes in, 255.

Cyprinidx, proportion of the sexes in the, 249.

$\longrightarrow$, Indian, 343.

Cyprinodontidx, sexual differences in the, $335,337$.

Cyprinus auratus, 342.

Cypris, relations of the seres in, 255 .

Cyrtodactylus rubidus, 354.

Cystophora cristata, hood of, 528.

D.

Dacelo, sexual difference of colour in, 457.

- Gaudichaudi, young male of, 467.

Dal-ripa, a kind of ptarmigan, 248 .

Damalis allifrons, peculiar markings of, 544 .

- pygarga, peculiar markings of, 543.

Dampaess of climate, supposed influence of, on the coluur of the skin, 32,193 .

คarajỏ, 308
Dances of birds, 380 .

Dancing, universality of, 178 .

Daniell, Dr., his experience of rasidence in West Africa, 195.

Darfur, frotuberances artificially produced by natives of, 574 .

Darwin, $F_{\circ}$, on the stridulation of Dermestes murinus, 302.

Dasychira pudibunda, sexual difference of colour in, 316.

Davis, A. $H_{\text {. }}$, on the pugnacity of the male stag-beetle, 300 .

- J. B., on the capacity of the skull in various races of men, 54 ; on the beards of the Polynesians. 560.

Death-rate higher in towns than in rural districts, 139.

Death-tick, 306.

De Candolle, Alph., on a case of inherited power of moving the scalp, 13.

Declensions, origin of, 91 .

Decoration in birds, 381 .

Decticus, 285.

Deel, 233 ; development of the horns in, 233 ; spots of young, 464,546 ; horns of, 503, 506; use of horn. of, 510,518 ; horns of $a$, in course of modification, 511 ; size of the horns of, 515 ; female, pairing with one male, whilst others are fighting for her, 522 ; male, attracted by the voice of the female, 527 ; male, odour emitted by, 529.

- Axis, sexual difference in the colour of the, 537 .

, fallow, different coloured herds of, 540 .

- Mantchurian, 546.

- Virginian, 546 ; colour of the, not affected by castration, 535 ; colours of, 536 .

Deerhound, Scotch, greater size of the male, $237,516$.

Defensive organs of mammals, 518.

De Geer, C. on a female spider destroying a male, 273.

Dekay, Dr., on the bladder-nose sez" 528.

Delorenzi, G., division of malis bone, 39.

Demerara, yellow fever in, 194.

Dendracygna, 465.

Dendrophila frontalis, young of, 487 . 
Tenison, Sir W., manner of ridding themselves of vermin among the Australians, 57 ; extinction of Tasmanians, 184.

Denny, H., on the lice of domestic animals, 169.

Dermestes nurinus, stridulation of, 302.

Descent traced through the mother alone, 588.

Deserts, protective colouring of animals inhabiting, 489 .

j)esmarest, on the absence of suborbital pits in Antilope subgrtturosa, 529; on the whiskers of Macacus, 531; on the colour of the opossum, 534; on the colours of the soxes of Mus minutus, 534 ; on the colouring of the ocelot, 534 ; on the colours of seals, 535 ; on Antilope caama, 536; on the colours of goats, 536 ; on sexual difference of colour in Ateles marginatus, 537 ; on the mandrill, 539 ; on Macacus cynomolgus, 558.

Desmoulins, on the number of species of man, 174; on the musk-deer, 530.

Desor, on the imitation of man by monkeys, 72.

Despine, P., on criminals destitute of conscience, 116.

Development, embryonic, of man, 9 , 11 ; correlated, 426.

Devil, not believed in by the Fuegians, 95 .

Devil-crab, 269.

Devonian, fossil insect from the, 289.

Dewlaps, of cattle and antelopes, 531.

Diadema, sexual differences of colouring in the species of, 309 .

Diamond-beetles, bright colours of, 294.

Diastema, occurrence of, in man, 35 .

Diastylidæ, proportion of the sexes in, 255.

Dicrurus, racket-shaped feathers in, 384 ; nidification of, 453 .

- macrocercus, change of plumage in, 461.

Didelphis opossum, sexnal difference in the colour of, 533 .

Differences, comparative, between different species of birds of the same sax, 470 .
Digits, supernumerary, more freg̨uent in men than in women, 223 ; super. numerary, inheritance of, 232; supernumerary, early devel. praent of, 237.

Dimorphism in females of waterbeetles, 276; in Neurothemis and Agrion, 291.

Diodorus, on the absence of beard in the natives of Ceylon, 560 .

Dipelicus Cantori, sexual differences of, 296.

Diplopoda, prehensile limbs of the male, 274.

Dipsas cynodon, sexual difference in the colour of, 351.

Diptera, 280.

Disease, generated by the contact of distinct peoples, 183.

Diseases common to man and the lower animals, 7 ; difference of liability to, in different races of men, 167 ; new, effects of, upon savages, 182; sexually limited, 237.

Display, coloration of Lepidoptera for, 314 ; of plumage by male birds, 394, 402 .

Distribution, wide, of $\operatorname{man}, 48$; geographical, as evidence of specific distinctness in man, 169.

Disuse, effects of, in producing rudimentary organs, 12 ; and use of parts, effects of, 32 ; of parts, inHuence of, on the races of men, 197.

Divorce, freedom of, among the Charruas, 598 .

Dixon, E. S., on the pairing of different species of geese, 415 ; on the court ship of peafowl, 419 .

Dobrizhoffer, on the inarriage-customs of the Abipones, 599 .

Dobson, Di., on the Cheiroptera, 218 ; scent-glands of bats, 529 ; frugivorous bats, 534 .

Dogs, suffering from Tertian ague, 8 ; memory of, 74; dreaming, 74; diverging when drawing sledges over thin ice, 75 ; exercise of reasoning faculties by, 78; domestic, progress of, in moral qualities, 80 ; distinct tones uttered by, 84; parallelism between his affection for his master and religious feeling, 96 ; sociability of the, 100 ; sympathy of 2 T 2 
with a sick cat, 103 ; sympathy of, with his master, 103 ; their possession of conscience, 103; possible use of the hair on the fore-legs of the, 151; races of the, 176; numerical proportion of male and female births in, 246; sexual affection between indiriduals of, 524; howling at certain notes, 569 ; rolling in carrion, 530 .

Dolichocephalic structure, possible cause of, 56.

Dolphins, nakedness of, 56 .

Domestic animals, races of, 176 ; change of breeds of, 596 .

Domestication, infuence of, in removing the sterilit.y of hybrids, 172

D'Orbigny, A., on the influence of dampness and dryness on the coloril of the skin, 193; on the Yuracaras, 582.

Dotterel, 477.

Doubleday, E., on sexual differences in the wings of butterflies, 277.

$\longrightarrow, H$. on the proportion of the sexes in the smaller moths, 251 ; males of Lasiocampa quercus and on the attraction of the $\mathrm{Sa}$ turnia carpini by the female 252 ; on the proportion of the sexes in the Lepidoptera, 252 ; on the ticlsing of Anobium tesselatum, 306 ; on the structure of Ageronia feronia, 307 ; on white butterflies alighting upon paper, 317.

Douglas, J. W., on the sexual differences of the Hemiptera, 281 ; on the colours of British Homoptera, 282.

Down, of birds, 390 .

Draco, gular appendages of, 355 .

Dragonet, Gemmeons, 336.

Dragon-flies, caudal appendages of male, 276 ; relative size of the seres of, 279 ; difference in the sexes of, 290 ; want of pugnacity by the male, 291.

Drake, breeding plumage of the, 393.

Dreams, 74 ; a possible source of the belief in spiritual agencies, 94 .

Drill, sexual difference of colong in the, 538 .

Dromaus, irroratus, 478.

Dromolac, Saharan species of, 456 .

Drongo shrike, 461.

Drongos, racket-shaped feathers in the tuils of, $254,392$.
Dryness, of climate, supposed influence of, on the colour of the skin, 193.

Dryopithecus, 155.

Duck, harlequin, age of mature plumage in the, 483 : breeding in immature plumage 484 .

- long-tailed, preference of male, for certain females, 420 .

- pintail, pairing with a wigeon, 414.

- voice of the, 374 ; pairing with a shield-drake, 414; immature plumage of the, 466 .

wild, sexual differences in the 219 ; speculum and male characters of, 236 ; pairing with a pintai\} drake, 415.

Ducks, wild, becoming polygamous under partial domestication, 219 ; dogs and cats recognised by, 412 .

Dufossé, Dr., sounds produced by fish, 347.

Dugong, nakedness of, 55 ; tusks of, 502.

Dujardin, on the relative size of the cerebral ganglia in insects, 54 .

Duncan, Dr., on the fertility of early marriages, 138 ; comparative health of married and single, 140 .

Dupont, M., on the occurrence of the supri-condyloid formen in the humerus of man, 22.

Durand, J. $P_{\text {, }}$ on canses of variation, 30.

Dureau de la Malle, on the songs of birds, 86 ; on the acquisition of an air by blackbirds, 370 .

Dutch, retention of their colour by the, in South Africa, 193.

Duty, sense of, 97.

Duvaucel, female Hy lobates washing her young, 70.

Dyaks, pride of, in mere homicide, 117. Dymastes, large size of males of, 27.4 . Dynastini, stridulation of, 303.

Dytiscus, dimorphism of females of, 276 ; grooved elytra of the femile. 276.

\section{$\mathbf{E}$}

Eagle, young Cercopithecus rescued from, by the troop, 101.

-, white-headed, breeding in im. mature plumage, 484 . 
Eagles, golden, new mates found by, 4118.

Ear, motion of the, 13; external shell of the, useless in man, 14; rudimentary point of the, in man, 15 .

Ears, more variable in men than women, 224; piercing and ornamentation of the, 575 .

¿arwigs, parental feeling in, 106.

Echidna, 156.

Echini, bright colours of sone, 260.

Echinodermata, absence of secondary sexual characters in, 260.

Echis carinata, 353.

Ecker, figure of the human embryo, $10 ;$ on the development of the gyri and sulci of the brain, 204 ; on the sexual differences in the pelvis in $\operatorname{man}, 557$; on the preseace of a sagittal crest in Australians, 558 .

Edentata, former wide range of in America, 169 ; absence of secondary sexual characters in, 218.

Ėlolius, racket-shaped feathers in, 384.

Elwards. Mr., on the proportion of the sexes in North American species of Papilio, 250.

Eels, hermaphroditism of, 162 .

Egerton, Sir P., on the use of the antlers of deer, 510 ; on the pairing of red deer, 522 ; on the bellowing of stags, 526.

liggs, hatched by male fishes, 345 .

Eoret, Indian, seres and young of, 486 .

Egrets, breeding plumage of, 391 ; white, 492.

Ehrenberg, on the mane of the male Hamadiyas baboon, 521.

Ekström, M., on Harelda glacialis, 420.

Elachista rufocinerea, habits of male, 252.

Eland, derelopment of the horns of the, 234.

Eiands, sexual differences of colour in 535

Elaphomyia, sexual differences in, 280 .

E'laphrus uliginosus, stridulation of, 302.

Elcaps, 353.

Elateridæ, proportions of the sexes in, 253.

Elaters, lumincus, 278.
Elephant, $156^{\circ}$; ricte of increase of the, 47 ; nakedness of the, 57 ; ln. dian, forbearance to his keeper, 104; polygamous habits of the, 218 ; pugnacity of the male, 501 ; tusks of, 502, 503, 507, 515, Indian, mode of fighting of the, 513 ; male, odour emitted by the, 529 ; attacking white or grey horses, 540 .

Elevation of abode, modifying influeace of. 35 .

Elimination of inferior indivicuals, 137.

Elk, 507; winter change of the, 542

- Irish, horns of the, 515 .

Ellice Islands, beards of the natives, $560,581$.

Elliut, $R_{\text {., }}$ on the numerical proportion of the sexes in young rats, 247 ; on the proportion of the sexes in sheep, 246.

- D. G., on Pelecanus erythro. rhynchus, 390.

- Sir W., on the polygamous habits of the Indian wild boar, 218.

F.llis, on the prevalence of infanticide in Polynesia, 592.

Elphinstone, Mr., on local differences of stature among the Hindoos, 31 ; on the difficulty of distinguishing the native races of Iadia, 167.

lilytra, of the females of Dytiscus, Acilius, Hydroporus, 276.

Eimberiza, characters of young, 464 .

- miliaria, 464.

- schoniclus, 412; head-feathers of the male, 402 .

Embryo of man, 9, 10; of the dog, 10 .

Embryos of mammals, resenclance of the, 25.

Emigration, 137.

Fimotions experienced by the lower animals in common with man, 69 ; manifested by animals, 71 .

Emperor moth, 315.

Ėmulation of singing-birds, 369.

Emu, sexes and incubation of, 478 .

Endirance, estimation of, 118.

Energy, a characteristic of men, 565.

England, numerical propertion of male and femile births in, 242.

Engleheart, Mr., on the finding of new mates by starlings, 408 . 
Finglish, success of, as colonists, 142.

Engravers, short-sighted, 33.

Entomostraca, 268.

Entozoa, difference of colour between the males and females of some, 260 .

Envy, persistence of, 112.

Eocene period, possible divergence of man during the, 156.

Eolidx, colours of, produced by the biliary glands, 261.

Epeira nigra, small size of the male of, 273

Ephemerx, 274.

Ephemeridx, 290.

Ephippiger vitium, stridulating organs of, $284,288$.

Epicalia, sexual differences of colouring in the species of, 309 .

Equus homionus, winter change of, 542.

Eratcina, coloration of, 315 .

Ercolani, Prof., hermaphroditism in eels, 162.

Erect attitude of $\operatorname{man}, 51,52$.

Eristalis, courting of, 280 .

Eschricht, on the development of hair in man, 18; on a lanuginous moustache in a female fotus, 19 ; on the want of definition between the scalp and the forehead in some children, 151 ; on the arrangement of the hair in the human fotus, 152 ; on the halluness of the face in the human foetus of both sexes, 602,603 .

Esmeralda, difference of colour an the sexes of, 294.

Esox lucius, 249.

- reticulatus, 340 .

Esquimaux, 64, 133; their belief in the inheritance of dexterity in seal-catching, 33 ; mode of life of 197.

Estrelda amandava, pugnacity of the male, 366.

Eubagis, sexual differences of colouring in the species of, 309.

Euchirus longimanus, sound produced by, 304 .

Iiudromias morinellus, 477.

Eulampis jugularis, colours of the female, 454.

Euler, on the rate of increase in the United States, 44.

Evmomota superciliaris, racket-shaped featners in the tail of, 384 .
Eupetomena macroura, colours of the female, 453.

Euphema splendidi, 457.

Euplocamus erythrophthalmus, possession of spurs by the female, 364.

Europe, ancient inhabitants of, 181.

Europeans, difference of, from Hindoos, 192; hairiness of, probably. due to reversion, 601 .

Eurostopodus, sexes of, 479 .

Eurygnathus, different proportions of the head in the sexes of, 276 .

Eustephanus, sexual difterences of syecies of, 359 ; young of, 487 .

Exaggeration of natural characters by $\operatorname{man}, 582$.

Exogamy, 588, 591.

Expression, resemblauces in, betweer man and the apes, 150.

Extinction of races, causes of, 181 .

Eye, destruction of the, 32; change of position in, 55 ; obliquity ot, regarded as a beauty by the Chinese and Japanese, 578.

Eyebrows, elevation of, 13 ; development of long hairs in, 19 ; in monkeys, 151 ; eradicated in parts of South America and Africa, 575. eradication of, by the Indians of Paraguay, 580 .

Eyelashes, eradication of, by the Indians of Paraguay, 580 .

Eyelids, coloured black, in part of Africa, 574.

Eyes, pillared, of the male of Chloëon, 274; difference in the colour of, in the sexes of birds, 425 .

Eyton. T. C., observations on the development of the horns in the fallow-deer, 234.

Eyzies, Les, human remains from, 181.

\section{F.}

Fabre, M., on the habits of Cerceris, 291.

Facial bones, causes of modification of the, 55 .

Faculties, diversity of, in the same race of men, 26 ; inheritance of, 27 ; diversity of, in animals of the same species, 28 ; mental, variation of, in the same species, 66 ; of birds, 410. 
Fakirs, Indian, tortures undergone by, 118.

Falco leucocephahus, 484.

- peregrinus, $408,461$. tinnunculus, 408.

Falcon, peregrine, new mate found by, 408.

Falconer, H., on the mode of tighting of the Indian elephant, 513; on canines in a female deer, 514 ; on

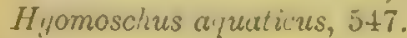

Falkland Islands, horses of, 181.

Fallow-deer, different coloured herds of, 540 .

Famincs, frequency of, among savages, 46.

Farr, Dr., on the structure of the uterus, 38 ; on the effects of profligacy, 137; on the influence of marriage on mortality, 139, 140.

Farral, F. W., on the origin of language, 87 ; on the crossing or blending of languages, 91 ; on the absence of the idea of God in celtain races of men, 93; on early marrages of the poor, 138 ; on the middle ages, 141.

Fashions, long prevalence of, among savages, 576,584 .

Fave, Prof, on the numerical proportion of male and female births in Norwiny and Russia, 243; on the grenter mortality of male children at and before birth, 243 .

Feathers, modified, producing sounds, 377 et seq., 450; elongated, in male birds, 383, 403 ; racketshaped, 384; barbless and with filamentous barbs in certain birds, 385 ; shedding of margins of, 393.

Feeding, high, probable influence of, in the pairing of birds of different species, 415.

Fect, thickening of the skin on the soles of the, 33 ; modification of, in $\operatorname{man}, 52$.

Felis canadensis, throat-ruff of, 521 .

pardalis and $F$. mitis, sexual differences in the colouring of, 534 .

Femaie, behaviour of the, during courtship, 22?.

birds, differences of, 470 .

Females, presence of rudimentary male organs in, 162 ; preference of, for certain males, 214 ; pursuit of, by males, 221 ; occurrence or secondary sexual characters in, 225 ; development of male charac. ters by, 227.

Females and males, comparative num bers of, 213, 215; comparative mol: tality of. while young, 216 .

Femur and tibia, proportions of, in the Aymara Indians, 34.

Fenton, Mr., decrease of Maoles, 184 ; infanticide amongst the Maories, 256.

Ferguson, $\mathrm{Mr}^{\circ}$, on the courtship of fowls, 417.

Fertility lessened uuder changed couditions, 188.

Fertilisation, phenomena of, in plants, 222 in the lower animals, 222.

Fevers, immunity of Negroes and Mulattoes from, 193.

Fiber zibethicus, protective colonrin:" of it, 542 .

Fick, H., effect of conscription for military service, 134.

Fidelity of savages to one another, 118 ; importance of, 124.

Field-slaves, difference of, from houseslaves, 196.

Fijians, burying their old and sick parents alive, 102; estimation of the beard among the, 581 ; admiration of, for a broad occiput. 583.

Fiji Archipelago, population of the, 173.

Islands, beards of the natires, 560,581 ; marriage-customs of the, 598 .

Filial affection, partly the result or natural selection, 105.

Filum terminale, 23.

Finch, racket-shaped feathers in the tail of $a, 384$.

Finches, spring change of colour in, 393 ; British, temales of the, 460 .

Fingers, partially coherent, in species of Hylobates, 51.

Finlayson, on the Cochin Chinese, 578.

Fire, use of, 49, 145, 180.

Fischer, on the pugnacity of the male of Lethrus cephalotes, 300 .

Fish, eagerness of male, 221 ; proportion of the seres in, 249 ; sourds produced by, 347. 
"ishes, kiduers of", represented by Colpora Wolfiana in the human embryo, 11; male, hatching ovs in their mouths, 163 ; receptacles for ova possessed by, 208 ; relative size of the sexcs in, 335 ; freshwater, of the tropics, 343 ; protective resemblances in, 344 ; change of colour in, 344 ; nest-building, 345 ; spawning of, 345 ; sounds produced by, 347,566 ; continued growth of, 485 .

Flamingo, age of mature flumage, 483.

Flexor pollicis longus, similar variation of, in man, 42 .

Flint tools, 145.

Flints, difficulty of chipping into form, 49 .

Floresuga mellivora, 443.

Florida, Quiscalus major in, 248.

Flounder, coloration of the, $3 \mathbf{4} 4$.

Hlower, W. H., on the abductor of the tifth metatarsai in apes, 42 ; on the position of the Seals, 150 ; on the Pithecia monachus, 201; on the throat-pouch of the male bustard, 373 .

Fly-catchers, colours and nidinention of, 455 .

Fœtus, human, woolly covering of the, 19 ; arringenent of the hair on, 152 .

Food, influence of, upon stature, 31.

Fnot, prehensile power of the, retained in some savages, 52 ; prehensile. in the early progenitoris of man, 160.

Woramen, supra-condyloid, exceptional occurrence of in the humerus of $\operatorname{man}, 21,43$; in the early progenitors of $\operatorname{man}, 160$.

Eo:bes, D., on the Aymara Indians, 34 ; on local variation of colour in the Quichuas, 196; on the hairlessness of the Aymaras and Quichuas, 561; on the long hair of the Aymaras and Quichuas, 559, is 8 (1).

Erel, $f_{\text {, }}$ on white young swans, $28:-2$.

Formica rufa, size of the carebral ganglia in, 54.

Fossils, absence of, connccting man wititi the apes, 1 is
Fowl, occurrence of spurs in the female, 227 ; game, early pugnacity of, 239 ; Polish, early development of cranial peculiarities of, 239; variations in plumage of, 385 ; examples of correlated developm $\in \mathbf{a}^{4}$ in the, 426 ; domestic, breeds an subbreeds of, 460 .

Fowls, spangled Hamburgh, 229, 238 ; inheritance of changes of plumage by, 229 ; sexual peculiarities iu, transmitted ouly to the same sex, 230 ; loss of secondary sexual characters by male, 231 ; Polish, origin of the crest in, 231 ; period of inheritance of characters b5, 238 ; cuckoo-, 238 ; development of the comb in, 239 ; numerical proportion of the sexes in, 247 ; courtship oi, 417 ; mongrel, between a black spanish cock and tifferent hens, 427 ; pencilled Hamburgh, difference of the sexes in, 447 ; Spanish, sexual differences of the comb in. 447 ; spurred, in both sexes, 449.

Fox, W. D., on some half-tamed wild ducks becoming polygamous, and on polygamy in the guinea-fowl and canary-bird, 220 ; on the proportion of the sexes in cattle, 247 ; on the pugnacity of the peacock, 364 ; on a nuptial assembly of magpies, 406 ; on the finding of new mates by crows, 407 ; on partridges living in triplets, 409 ; on the pairing of a goose with a Chinese gander, 415 .

Foxes, wariness of young, in hunting districts, 80 ; black, 540 .

Fraser, C., on the different colours of the sexes in a species of Squilla, 271.

- G., colours of Thecla, 312.

Fiere, Hookham, quoting Theognis on selection in mankind, 29.

Fringilla cannabina, 394 . 483

- ciris, age of mature plumage in,

- cyanea, age of matrare plumage in, 483.

- leucophrys, young of, 486 .

spinus, 415.

tristis, change of colonr in, in spring, 393 ; young of, 485 .

Fringillida, rssemblance of the fe. males of dintinct species of, $4 \% 0$. 
Fings, 549; male, tomporary receptacles for ova possessed by, 2ur; ready to breed before the females, 212 ; n̂ghting of, 349 ; vocal organs of, 350 .

Frontal bone, persistence of the suture iu, 39.

Fruits, poisonous, avoided by animals, b6.

Fuegians, 133, 143; difference of stature among the, 31 ; power of sight in the, 33 ; skill of, in stone-throwing, 49 ; resistance of the, to their serere climate, 63,182 ; mental capacity of the, 65 ; quasi-religious sentiments of the, 95 ; resemblance of, in mental characters, to Europeans, 178; mode of life of the, 197 ; aversion of, to hais on the fitce, 580 ; suid to admire European women, 582.

Fulgoridx, songs of the, 281.

fur, whiteness of, in arctic animals, in winter, 229.

Fur-bearing animals, acquired sagacity of, 80 .

\section{G.}

Gallicrex, sexual difference in the colour of the irides in, 425 .

cristatus, pugnacity of male, 360 ; red caruncle occurring in the male during the breedingseason, 399.

Gallinacex, frequency of polygamous habits and of sexual differences in the, 219 ; love-gestures of, 380 ; decomposer feathers in, 385 ; stripes of young, 464 ; comparative sexual differences between the species of, 470,471 ; plumage of, 472 .

Gallinaceous birds, weapons of the male, 362 ; racket-shaped feathers on the heads of, 384.

Gallinula chloropus, pugnacity of the male. 360.

360.

cristata, pugnacity of the male,

Galloperdix, spurs of, 364 ; development of syars in the female, 450 .

Gallophasis, young of, 468 .

Gallus banliva, 447 ; neck-hackles of, $: i 9:$.

Starleyi, pugnacity of the male, isi.?.
Galls, 60.

Galton, Mr., on hereditary genius, 28 gregariousness and independence. in animals, 104; on the struggle between the social and personal impulses, 125; on the effects of natural selection on civilised nations, 133; on the stelility of sole daughters, 135; on the degree of fertility of people of genius, 136 . on the early marriages of the poor, 138 ; on the ancient Greeks, 140 ; on the Middle Ages, 141 ; on the progress of the United States, 142 ; on South African noticns of beauty, 579.

Gammarus, use of the chela of, 268.

marinus, 270.

Gannets, white only when nature, 492.

Ganoid fishes, $159,165$.

Gatour, hol'ns of the, 505.

Gip between man and the apes, 156.

Grper, sexes and young of, 486 .

Gardnor, on an example of ratiouality in a Gilcimisis, 270.

Garrulus glandarines, 407.

Gartner, on sterility of hybrid plants, 172.

Gisteropoda, 272; pulnuonifp:ous, courtship of, 262.

Casterostcus, 220 ; nilification o: 345.

- leiurus, 331, 340, 345.

trachurus, 332.

Gastrophora, wings of, brightly coloured beneath, 315 .

Gauchos, want of humauity among the, 123.

Ciludiy, MI, on a fossil monkes, 154.

ricuic, seasonal change of plumage in, 493.

Geese, clanging noise made by, 368 pairing of different species of, 415 ; Canada, selection of mates by, 416 .

Gegenbaur, $C$. on the number of digits in the Ichthyopterygin, 37 ; on the hermaphroditism of the remote progenitors of the vertebrata, 161 ; two types of nipple in mammals, 162.

Gelasimus, proporticns of the sexes in a species of, 254 ; use of the cularged chelre of the male, 268 ; Iugnacity of males of, 269 ; rational 
actions of $a, 270$; difference of colour in the sexes of a species of, 271.

Gemmules, dormant in one sr.x, 231.

Genius, 28 ; hereditary, 564.

\section{$136^{\circ}$}

Geoffroy-Saint-Hilaire, Isid., on the recognition of women by male quadrumana, 8; on monstrosities, 30 ; coincidences of arrested development with polydactylism, 37 ; ou animal-like anomalies in the human structure, 40 ; on the correlation of monstrosities, 44 ; on the distribution of hair in man and monkeys, 57; on the caudal vertebrac of moneys, 58; on correlated variability, 60 ; on the classification of $\operatorname{man}, 147$; on the long hair on the heads of species of Semnopithecus, 151 ; on the hair in monkeys, 152; on the derelopment of horns in female deer, 504 ; and $F$. Cuvier, on the mandrill, 539 ; on Hylobates, 558, 559.

Geogriphical distribution, as evidence of specific distinctions in man, 169.

Geometræ, brightly coloured beneath, 31 J.

Geophagus, frontal protuberance of male, 340 , 345 ; eggs hatched by the male, in the mouth or bran. chial cavity, 345.

Georgia, change of colour in Germans settled in, 196.

Geotrupes, stridulation of, $303,304$.

Gerbe, M., on the nest-building of Crenilabrus massa and C. melops, 345.

Gerland, Dr., on the prevalence of infanticide, $117,577,592$; on the extinction of races, 182.

Gervais, $P$. on the hairiness of the gorilla, 57; on the mandrill, 538.

Gesture-language, 178.

Shost-moth, serual difference of colour in the, 316.

Gibbs, Sir D., on differences of the voice in different races of men, 566 .

Gibbon, Hoolock, nose of, 150.

Gibbous, voice of, 527 .

Gill, Dr., male seals larger than females, 219 ; sexual differences in seats, $2: 5$
Girafie, its mode of using the hores, 508 ; mute, except is the rutting season, 526 .

Girard, M., disputes descent of vertibrates from Ascidians, 160 ; colour of sponges and Ascidians, 261: musky odour of Sphins, 308.

Giraud-Teulon, on the cause of short sight, 34.

Glanders, communicable to man from the lower animals, 7.

Glands, odoriferous, in mammals, 529 . 530.

Glareola, double moult in, 390 .

Glomeris limbata, difference of colour in the sexes of, 274.

Glow-worm, female, apterous, 208 ; luminosity of the, 277.

Gnats, dances of, 280 ; auditory powers of, 569 .

Gnu, sexual differences in the colour of the, 536 .

Goat, male, wild, falling on his horns, 508 ; male, odour emitted by, 529 ; male, wild, crest of the, 531 ; Berbura, mane, dewlap, \&c., of the male, 532; Kemas, sexual difference in the colour of the, 536 .

Goats, sexual differences in the horns of, 230 ; herus of, 235, 505; mode of fighting of, 508 ; domestic, sexual differences of, late developed, 237 ; beards of, 531.

Goatsucker, Virginian, pairing of the, 366.

Gobies, nidification of 345 .

God, want of the idea of, in some races of men, 93.

Godron, M., on variability, 29 ; on difference of stature, 31; on the want of connexiou between climate and the colour of the skin, 192; on the odour of the skin, 198; on the colour of intants, 558 .

Goldfinch, 371, 394; proportion of the sexes in the, 248 ; sexual differences of the beak in the, 359 ; courtship of the, 401 .

- North American, young of, 485 Gold-fish, 342.

Gomphus, proportions of the seres in, 254 ; difference in the sexes of, ?(11).

$G$ ompteryr Rhumni, 312 ; sexual dif. ference of colour in, 322. 
Goodsir, Prof, on the affinity of the lancelet to the ascidians, 159.

Goosander, young of, 467 .

Goose, Artarctic, colours of the, 492. - Canada, pairing with a Bernicle gauder, 414.

- Chinese, knob on the beak of the, 426.

-, Egyptian, 364.

- Sebastopol, plumage of, 385 .

- Snow-, whiteness of the, 492.

-_. Spur-winged, 364.

Gorilla, 561 ; semi-erect attitude of the, 52 ; mastoid processes of the, 53 ; direction of the hair on the arms of the, 151 ; manner of sitting, 151 ; supposed to be a kind of mandrill, 177 ; polygany of the 217 . 590,591 ; voice of the, 527 ; crnnium of, 558 ; fighting of male, 562.

Gosse, P. H., on the pugnacity of the male Humming-bird, 360.

- M., on tne inheritance of artificial modifications of the skull, 603 .

Gould, B. A, on variation in the length of the legs in man, 26 ; measurements of American soldiers, 30,32 ; on the proportions of the body and capacity of the lungs in different races of men, 167 ; on the the inferior vitality of mulattoes, 171.

- J., on migration of swifts, 108 ; on the arrival of male snipes before the females, 212 ; on the numerical proportion of the sexes in birds, 247 ; on Neomorpha Grypus, 359 ; on the species of Eustephanus, 359 ; on the Australian musk-duck, 359 ; on the relative size of the sexes in Briziura lobata and Cincloramphus cruralis, 362 ; on Lobivanellus lobatus, 366 ; on the habits of Menura Alberti, 371 ; on the rarity of song in brilliant birds, 371 ; on Selasphorus platycercus, 378 ; on the Bower-birds, 381,406 ; on the ornamental plumage of the Humming-birds, 387 ; on the moulting of the ptarmigan, 392 ; on the disrlay of plumage by the male Humming-birds, 394 ; on the shyness of adorned male birds, 403 ; on the decoration of the bowers of Bower- birds, 413; on the decoration of their nests by Humming-birds, 413; on variation in the geaus Cynanthus, 423; on the colour of the thighs in a male parakeet, 424 ; on Urosticte Benjamini, 442, 443; on the nidification of the Orioles, 454 ; on obscurely-coloured birds building concealed nests, 454 ; on trogons and kingfishers, 456 ; on Australan parrots, 458 ; on Australian pigeons, 458 ; on the moulting of the ptarmigan, 462 ; on the immature plumage of birds, 466 et seq.; on the Australian species of Turnix, 473 ; on the young of Aithurus poly. tmus, 487 ; on the colours of the bills of tolicans, 491; on the relative size of the sexes in the marsupials of Australia, 515; on the colours of the Marsupials, 533.

Goureaux. on the stridulation of $\mathbf{M u}$ tille curopie', 293.

Gout, sexually transmitted, 237.

Graba, on the Pied Ravens of the Feroe Islands, 424 ; variety of the Guillemot, 424.

Gradation of secondary sexual characters in birds, 430 .

Grallatores, absence of secondary sexual charicters in, 219 ; double moult in some, 390 .

Grallina, nidification of, 454 .

Grasshopper's, stridulation of the, 286.

Gratiolet, Prof., on the anthropomorphous apes, 154; on the evo lution of the anthropomorphous apes, 177 ; on the difference in the development of the brains of apes and of $\operatorname{man}, 203$.

Gray, Asa, on the gradation of species among the Compositx, 175.

_- J. $\mathrm{E}$, on the caudial vertebry of monkeys, 58 ; on the presence of rudiments of horns in the female of Cervulis mosihatus. 504; on the horns of goats and sheep, 505 ; un the beard of the ibex, 531 ; on the Berbura goat, 533 ; on serual ditferences in the coloration of Rodents, 534 ; ornaments of male sloth, 534 ; on the colours of the Elands, 535 , on the Sing-sing antelope, 536; on the colours of goats, 536 ; on the nog-deer, 546 . 
"Freatest happineis principle," 120, $\therefore 1$.

Greeks, ancient, 140.

Green, A. H., on beavers fighting, 500 ; on the voice of the beaver, 527.

Greenfinch, selected by a female canary, 415.

Greg, W. R., on the effects of natural selection on civilised nations, 133 ; on the early marriages of the poor, 138; on the Ancient Greeks, 141.

Grenadiers, Prussian, 29.

Greyhounds, numerical proportion of the sexes in, 215, 216; numerical proportion of male and female births in, 246, 258.

Grouse, red, monogamous, 219 ; pugnacity of young male, 366 ; producing a sound by scraping their wings upon the ground, 374; duration of courtship of, 405 ; colour's and nidification of, 455 .

Giuber, Dr., on the occurrence of the supra-condyloid foramen in the humerus of man, 21; on dirision of malar bone, 39 ; stridulation of locust, 284.

I rus americanus, age of mature plumage in, 483 ; breeding in immature plumage, 484 .

- virgo, trachea of, 374.

Gryllus campestris, 284; pugnacity of male, 289.

doinestiius, 284.

Trypus, sexual differences in the beak in, 359.

Guanacoes, battles of, 500 ; canine teeth of, 514.

ruimas, strife for women among the 562 ; polyandry among the, $59 \%$.

Guanche skeletons, occurrence of the supra-condyloid foramen in the humerus of, 22.

Guaranys, proportion of men and women among, 244 ; colour of newboln childuen of the, 557 ; beirds of the, $50 \mathrm{i}$.

STuence, $A_{\text {. }}$, on the sexes of Hyperythra, 25 .

Suilding, L., on the stridulation of the Locustidx, 283.

Fuillemot, variety of the, 424.
Guinea, sheep of, with males only horned, 234.

Guinea-fowl, monogamous, 219 ; uccasional polygamy of the, 220 ; markiugs of the, 429.

Guinea-pigs, inheritance of the effects of operations by, 603 .

Gulls, seasonal change of plumage in, 492 ; white, 492.

Günther, Dr., on paddle of Ceratodis, 37 ; on hermaphroditism in Serranus, 162 ; on male fishes hatching ova in their mouths, 163,345 ; on mistaking infertile female fishes for males, 249; on the prehensile organs of male Plagiostomous fishes, 331 ; spines and brushes on fishes, $3: 31$; on the pugnacity of the male salmon and trout, 332 ; on the relative size of the sexes in fishes, 335 ; on sexual differences in fishes, 336 et seq.; on the genus Callio. nymus, 337 ; on a protective resemblance of a pipe-fish, 344 ; on the genus Solenostoma, 346 ; on the coloration of frogs and toads, 349 ; combat of iestudo elegans, $3 \dot{1}$; on the sexual differences in the Ophidia, 351; un differences of the sexes of lizards, 354 et seq.

Gynanisa Isis, ocellated spots of, 428.

Gypsies, uniformity of, in rarious parts of the world, 193.

H.

Habits, bad, ficilitated by familiarity, 123 ; variability of the force of, 125.

Hïckel, E., on the origin of man, 3 ; on rudimentary characters, 11 ; on death caused by inflammation of the vermiform appendage, 21 ; on the canine teeth in $\mathrm{man}, 40 ;$ on the steps by which man became a biped, 52 ; on man as a member of the Catarrhine group, 155 ; on the position of the Lemuridx, 157 ; on the genealogy of the Mammalia, 158 ; on the lancelet, 159 ; on the transparency of pelagic animals, 261 ; on the musical powers of wemen, 573. 
IIigen, H., and Walsh, B. D., on American Neuroptera, 254.

II:ir, development of, in man, 18; character of, supposed to be determined by light and heat, 32 ; distribution of, in man, 57,600 ; possibly removed for ornamental purposes, 58 ; arrangement and direction of, 151 ; of the early progenitors of man, 160; different texture of, in distinct races, 167 ; and skin, correlation of colour of, 197 ; development of, in mammals, 530 ; management of, among different peoples, 575; great length of in some North American tribes, 580 ; elongation of the, on the human head, t;03.

Hairiness, difference of, in the seres in $\mathrm{man}, 559$; variation of, in races (if men, 559.

Il:uirs and excretory pores, numerical relation of, in sheep, 198.

Hairy family, Siamese, 601.

IIalbertsma, Prof., hermaphroditism in Serranus, 162.

Hamadryas baboon, turning over stones, 101 ; mane of the male, 521.

Hamilton, C., on the cruelty of the litfirs to animals, 118; on the rngrossment of the women by the Kaffir chiefs, 595.

Hnmmering, difticulty of, 49 .

Haucock, A., on the colours of the cudibranch Mollusca, 261, 264.

Hands, larger at birth, in the children of labourers, 33 ; structure of, in the quadrumana, 50 ; and arms, freedom of, indirectly correlated with diminution of canines, 53.

Hatudwriting, inherited, 88.

liandyside, Dr., supernumerary mammx in men, 37.

Harcourt, E. Vernon, on Fringilla cannabina 394.

Ilarelda glacialis, 420.

Ifare. protective colouring of the, 542.

Hares, battles of male, 500 .

Harlan, Dr, on the difference between field-and house-slares, 196.

Ilarris, J. M., on the relation of complexion to climate, 195.

- , T. W., on the Katy-did locust, 283 ; on the stridulation of the grasshoppers, 280; on (E)canllius niculis, 289 ; on the colouring $\omega^{\prime}$ Lepidoptera, 314 ; on the colouring of Saturnia Io, 316.

Harting, spur of the Ornithorhynchns, 502.

Hartman, Dr., on the singing of Cicada septendecim, 282.

Hatred, persistence of, 112.

Haughton, S., on a variation of tha flexor pollicis longus in $\mathrm{man}_{4} 4 \%$.

Hawks, feeding orphan nestling, 409.

Hayes, Dr., on the direrging of sledgedogs on thin ice, 75.

Haymond, $R$., on the drumming of themale Tetrao umbellus, 375 ; on the drumming of birds, 376 .

Head, altered position of, to suit the erect attitude of man, 55 ; hairiness of, in man, 57 ; processes of, in male beetles, 295 ; artificial alterations of the form of the, 583 .

Hearne, on strife for women among the North American Indians, 361: on the North American Indians" noticn of female beaty, 578 ; repented elopements of a North American woman, 597.

Heart, in the human embryo, 8.

Heat, supposed effects of, 32.

IIectocotyle, 263.

Hedge-warblex, 473 ; young of the, 481.

ITeel, small projection of, in the Aymara Indians, 35.

llegt, M., on the development of the spurs in peacocks, 236 .

Heliconidx, 308; mimicry of, by other buttexflies, 323.

Heliopathes, stridulation peculiar it the male, 305.

Heliothrix auriculate, young of, $46 T_{\text {, }}$ 468.

Helix pomatia, example of individu:! attachment in, 263.

Hellins, J., proporticns of sexes 0 ? Lepidoptera reared by, 253.

Helmholtz, on pleasure derived from harmonies, 92 ; on the ribration of the auditory hairs of crustacen, 568 ; the physiology of harmony, 659.

Hemiptera, 281.

Hemitragus, benrdless in both sexw, 531. 
Hemsbach, M. von, on medial mamma in $\operatorname{man}, 37$.

Hepburn, Mr., on the autumn song of the water-ouzel, 370 .

IIepialus humuli, sexual difference of colour in the, 316 .

terbs, poisonous, avoided by animals, 66.

Hermaphroditism of embryos, 161 .

Irorodias bubulcus, vernal moult of, 393.

Heron, Sir R., on the habits of peafowl, $418,419,443$.

- love-gestures of $\mathrm{a}, 380$

Herons, decomposed feathers in, 385 ; breeding plumage of, 391,392 ; young of the, 481 ; sometimes dimorphic, 484; continued growth of crest and plumes in the males of some, 485 ; change of colour in some, 494.

IIesperomys cognatus, 568 .

IIetarina, proportion of the sexes in, 254; difference in the seres of, 290.

Heterocerus, stridulation of, 302.

Hewitt, Mr., on a game-cock killing a kite, 363 ; on the recognition of dogs and cats by ducks, 412 ; on the pairing of a wild duck with a pintail drake, 415 ; on the courtship of fowls, 417 ; on the coupling of pheasants with common hens, 420.

Hilgendorf, sounds produced by crustaceans, 274.

Hindoo, his horror of breaking his caste, 122, 124.

Hindoos, local difference of stature among, 31; difference of, from Europeans, 192; colour of the beard in, 558 .

Hipparchia Janira, 319 ; instability of the ocellated spots of, 428 .

Ilippocampus, development of, 163 ; marsupial receptacles of the male, 346.

- minor, 202.

llippopotamus, nakedness of, 56 .

ilips, proportions of, in soldiers and sailors, 32.

Hodgson, S., on the sense of duty, 97.

lloffberg, on the horns of the reindeer, 503 ; on sexual preferences shown by reindecr, 525 .
Hoffrrar, Profo, protective colours 281 ; fighting of frogs, 350 .

Hog-deer, 546

Hog, wart-, 519 ; river-, 520.

Holland, Sir H., on the effects of new diseases. 182.

Homologous structures, correlated varition of, $4: 3$.

Homoptera, 281; stridulation of the and Orthoptera, discussed, 268.

Honduras, Quiscalus major in, 248.

Honey-buzzard of India, variation is the crest of, 424 .

Honey-suckers, moulting of the, 392 Anstralian, nidification of, 454 .

Honour, law of, 121.

Hooker, Dr., forbearauce of elephant to his keeper, 104; on the colour. of the beard in man, 558 .

Hookham, Mr., on mental concepts in animals, 83.

Hoolock Gibbon, nose of, 150 .

Hoopoe, 371 ; sounds produced by the male, 376.

Hoplopterus armatus, wing-spurs of, 366.

Hornbill, African, inflation of the neck-wattle of the male during courtship, 383.

Hornbills, sexual difference in the colour of the eyes in, 425 ; nidification and incubation of, 454.

Horne, C., on the rejection of a brightly-coloured locust by lizards and birds, 289.

Horns, sexual differences of, in sheep and goats, 230 ; loss of, in female merino sheep, 231 ; derelopment of, in deer, 233 ; development of, in antelopes, 234; from the head and thorax, in male beetles, 297 ; of deer, 503, 506, 515; and canine teeth, inverse development of, 514.

Hurse, fossil, extinction of the, in South America, 191; polygamous, 217 ; canine teeth of male, 502 ; winter change of colour, 542 .

Horses, rapid increase of, in South Americn, 47 ; diminution of canine teeth in, 53; dreaming, 74; of the Falkland Islands and Pampas, 181 ; numerical proportion of the sexes in, 215, 216; lighter in winter in Siberia, 229; sexual 
preferences in, 524; pairing preferently with thuse of the same colour, $5 \pm 0$; numerical proportion of male and female births in, 245 ; formerly striped, 547 .

IIottentot women, peculiarities of, 174 . Hottentots, lice of, 170 ; readily become musicians, 570 ; notions of female beauty of the, 578 ; compression of nose by, 583 .

llough, Dr. S., men's temperature more variable than women's, 224; proportion of sexes in man, 243.

Ilouse-slaves, difference of, from fieldslaves, 196.

Houzeau, on the baying of the dog, 75 ; on reason in dogs, 76 ; birds killed by telegraph wires, 80 ; on the cries of domestic fowls and parrots, 85, 87; animals feel no pity, 102; suicide in the Aleutian islands, 117.

lloworth, H. H., extinction of savages, 183.

Huber, P., on ants playing together, 69 ; on memory in ants, 74 ; on the intercommunication of ants, 89 ; on the recognition of each other by ants after separation, 292.

Huc, on Chinese opinions of the appearance of Europeans, 578 .

Huia, the, of New Zealand, 208.

Human, man classed alone in a, kingdom, 147.

- sacrifices, 96.

Humanity, unknown among some savages, 118 ; deficiency of, among savages, 123.

Humboldt, A. von, on the rationality of mules, 78 ; on a parrot preserving the language of a lost tribe, 181; on the cosmetic arts of savages, 574 ; on the exaggeration of natural characters by man, 582 ; on the red painting of American Indians, 583.

Hume, D., on sympathetic feelings, 109.

Humming-bird, racket-shaped feathers in the tail of $a, 384$; display of plumage by the male, 394 .

H umming-birds, ornament their nests, 92,413 ; polygamous, 219 ; proportion of the sexes in, 248, 488 ; sexual differences in, 359,442 ; pugnacity of male, 360 ; modined primaries of male, 378 ; coloration of the sexes of, 387; display by, 443 nidification of the, 453 ; colours of female, 453 ; young of, 487 .

Humphreys, H. N., on the habits of the stickle-back, $220,332$.

Hunger, instinct of, 112.

Huns, ancient, thattening of the ncse by the, 583 .

Hunter, $J_{a}$, on the number of species of man, 174; on secoudary sexual characters, 207; on the general behaviour of female animals during courtship, 222 ; on the muscles of the larynx in song-birds, 371 ; ou the curled frontal hair of the bull, 531 ; on the rejection of an ass by a female zebra, 540 .

Hunter, W. W., on the recent rapid increase of the Santali, 45 ; on the Santali, 192.

Huss, Dr. Max, on mammary glands, 162.

Hussey, Mr., on a partridge distinguishing persons, 412 .

Hutchinson, Col., example of reasoning in a retriever, 78.

Hutton, Capt., on the male wild goat falling on his horns, 507 .

Huxley, T. $H_{.}$, on the structural agreement of man with the apes, 2 ; on the agreement of the brain in man with that of lower animals, $6 ;$ on the adult age of the orang, 8 ; on the embryonic development of $\operatorname{man}, 9$; on the origin of $\operatorname{man}$, 3,11 ; on variation in the skulls of the natives of Australia, 26; on the abductor of the fifth metatarsal in apes, 42 ; on the nature of the reasoning power, 77 ; on the position of man, 150; on the suborders of primates, 152 ; on the Lemuridx, 157 ; on the Dinosauria, 158 ; on the amphibian affinities of the Ichthyosaurians, 159 ; on variability of the skull in certain races of man, 174 ; on the races of man, 176 ; supplement on the brain, 199 . Hybrid birds, production of, 414 . Hydrophobia communicable betwee man and the lower animals, 7.

IIydroporus, dimoritisism of femaled of, 276 . 
IJyclaphus porcinus, 546.

IIygrogonus, 345.

IIyla, singing species of, 350 .

Iylobutes, absence of the thumb in, 51 ; upright progression of some species of, 52 ; maternal affection iu a, 70 ; direction of the hair on the arms of species of, 151 ; females of, less hairy below than males, 558 .

- agilis, 51 ; hair on the arms of, 151 ; musical voice of the, 527 ; superciliary ridge of, 558 ; voice of, 567.

- hoolock, sexual difference of colour in, 537.

- lar, 51; hair on the arms; ol, 151.

- leuciscus, 51 ; song of, 568.

synductyius, 51 ; linyngeal sac: of, 527 .

Hylophila prasinana, 308.

Hymenoptera, 291; large size of the cerebral ganglia in, 54 ; classification of, 148 ; sexual differences in the wings of, 277 ; aculeate, relative size of the sexes of, 279.

Hymenopteron, parasitic, with a sedentary male, 221.

I/yomoschus aquaticus, 54.7.

IIIyperythra, proportion of the sexes in, 251.

Hijpogymna dispar, sexual difference of colour in, 316 .

Hypopyra, coloration of, 315.

\section{I.}

lbex, male, falling on his horns, 508 ; beard of the, 531 .

ibis, white, change of cnlour of naked skin in, during the breeding season, 389 ; scarlet, young of the, 481.

_- tantalus, age of matnre plumage in, 483 ; breeding in immature plumage, 484 .

Ibises, decomposed feathers in, 385 ; white, 492 ; and black, $49 \%$.

Ichnenmonida, difference of the sexes in, 292.

Ichthyopterygia, 37.

Ich thyosaurians, 159.

Idiots,. microcephalous, their characters and balits, 35 ; hairiness and animal aature of their actinns, $3 i$; microcephalous, imitative tacuitie日 of, 87.

Iguana tuberculata, 354 .

Iguanas, 354.

lllegitimate and legitimate children, proportion of the sexes in, 244.

Imagination, existence of, in animals, 74.

Imitation, 68 ; of man by monkeys, 72 ; tendency to, in monkeys, micrccephalous idiots and sarages, 87 ; influence of, 129.

Immature plumage of birds, 463,466 . Implacentata, 157.

Implements, employed by monkeys, 81 ; fashioning of peculiar to man, 82.

Impregnation, period of, influence of upon sex, 245.

Improvement, progressive, man alone supposed to be capable of, 79 .

Incisor teeth, knocked out or filed by some savages, 575 .

Increase, rate of, 44 ; necessity of checks in, 47.

Indecency, hatred of, a modern rirtue, 119.

India, difficulty of distinguishing the native races of, 167 ; Cyprinidx of, 343 ; colour of the beard in races of men of, 558 .

Indian, North American, honoured for scalping a man of another tribe, 117.

Individuality, in animals. 83.

Indopicus carlotta, colours of the sexes of, 458 .

Infanticide, prevalence of, 46,117 , 256 ; supposed cause of, 577 ; prevalence and causes of, 591 et seq.

Inferiority, supjosed physicial, of inan, 64 .

Inflammation of the bowels, occur. rence of, in Cebus Azura, 7.

Inheritance, 27; of long and short sight, 33; of effects of use of vocal and mental organs, 88 ; of moril teudencies, 123, 126; laws of, 227 ; sexunl, 232; sexually limited, 444.

Inquisition, influence of the, 141.

Iasanity, hereditary, 28.

Insect, fusisil, from the Dernnian, 289. Insectivora, 534 ; absence of secendary sexual charicters in, 218. 
I gauglia in, 54; male, appearance of, before the females, 212 ; pursuit of female, by the males, 221 ; period of development of sexua' "haracters in, 236 ; secondary sexual characters of, 274 ; stridulation, 566 .

Insessores, rocal organs of, 370 .

Irstep, depth of, in soldiers and sailors, 32.

Instinct and intelligence, 67 .

-, migratory, vanquishing the maternal, 107, 113.

Instinctire actions, the result of inheritance, 105.

- impulses, difference of the force of, 110, 111; and moral impulses, slliance of, 110 .

Instincts, 66 ; complex origin of, through natural selection, 67 ; possible origin of some, 67 ; acquired, of domestic animais, 104: variability of the force of, 107 ; difference of force between the social and other, 111,126 ; utilised for new purposes, 571 .

Iustrumental music of birds, 375,378 .

intellect, influence of, in natural selection in civilised society, 136.

Intellectual faculties, their influence on natural selection in man, 127 ; probaljly perfected through natural selection, 128.

Intelligence, Mr. H. Spencer on the dawa of, 67.

Intemperance, no reproach among savages, 119 ; its destructiveness, $13 \%$.

Intoxication in monkeys, 7.

Iphias glaucippe, 313.

Iris, sexual difference in the cosour of the, in birds, $383,425$.

Ischio-pubic muscle, 41.

Ithayinis cruentus, number of spurs in, 364.

Iulus, tarsal suckers of the males of, $\because 74$

\section{J.}

Jackals learning from dogs to bark, 73.

Jack-snipe, coloration of the, 491

Jacquinot, on the number of species of $\operatorname{man}, 174$.

Jaeger, Dr., lingth of bones increased from carrying weignts, 32 ; on the difficulty of approaching herus of wild animals, 100; male Silverpheasant, rejected when his plumage was spoilt, 419.

Jaguars, black, 539.

Janson, k. W., un the propiortions of the sexes in Tomicus villosus, 253; on stridulant beetles, 302 .

Japan, encouragement of licentiousness in, 46.

Japanese, general beardlessness of the 560 ; aversion of the, to whiskers, 581.

Jardine, Sir W., on the Argus pheasint, 384, 403.

Jarrold, Dr., on modifications of the skull induced by uncatural position, 56.

Jarres, Mr., on infinticide in the Sandwich Islands, 257.

Javins, relative height of the sexes of, 559 ; notions of female beauty, 580.

Jaw, influence of the muscles of the, upon the physiognomy of the apes, 54.

Jaws, smaller proportionately to the extremities, 33 ; influonce of food upon the size of, 33; diminution of, in man, $53 ; \vdots$ in $\operatorname{men}$, reduced by correlation, 562 .

Jay, young of the, 481; Canada, young of the, 481 .

Jays, new mates found by, 407 ; distinguishing persons, 412.

Jeffreys, J. Gwyn, on the form of the shell in the sexes of the Gasteropoda, 262 ; on the influence of light upon the colours of shells, 263.

Jelly-fish, bright colours of some, 260.

Jenuer, Dr., on the voice of the rook, 375 ; on the finding of new mates by magpies, 407 ; on retardation of the generative functions in birds, 409.

Jenyns, $L_{\text {., }}$ on the desertion of their young by swallows, 108 ; on male birds singing after the proper seascn, 409 .

Jerdon, Dr., on birds dreaming. 74; on the pugnacity of the mate bal. bul, 360 ; on the pugnacity of the male Ortygornis gularis, 363; on the spurs of Galloperdix, 364 ; on 
the habits of Lobivanellus, 366 ; on the spounbill, 374 ; on the drumming of the lialij-pheasant, 376 ; on Indian bustards, 378 ; on ot is benyalensis, 381; on the ear-tults of Sypheotides auritus, 384; on the double moults of certain birds, 391 ; on the moulting of the honeysuckers, 392 ; on the moulting of bustards, plovers, and drongos, 393 ; on the spring change of colour in some finches, 393 ; on display in male bircio, 394; on the display of the under-tail coverts by the male bulbul, $40 \%$; on the Indian honeybuzzard, 424 ; on sexual differences in the colour of the eyes of hornbills, 425 ; on the markings of the Tragopan pheasant, 428 ; on the nidification of the Orioles, 453 ; on the nidification of the hornbills, 454 ; on the Sultan yellow-tit, 458 ; on Palcornis javanicus, 461 ; on the immature plumage of birds, 465 et seq.; on representative species of birds, 468 ; on the habits of Turnix, 476 ; on the continued increase of beauty of the peacock, 485 ; on colorition in the genus Paloomis, 494.

Jevons, W. S., un the migrations of man, 47.

Jews, ancient use of flunt tools by the, 145; uniformity of, in various parts of the world, 193 ; numerical proportion of male and female births among the, 243; ancient, tattooing practised by, 574 .

Johnstone, Lieut., on the Indian elephant, 218.

Jollofs, fine appearance of the, 587 .

Jones, Albert, proportion of sexes of Lepidoptera, reared by, 253.

Juan Fernandez, humming-birds of, 487.

Junonia, sexual differences of colouring in species of, 310 .

Jupiter, comparison with Assyrian effigies, $58 i$.

\section{K.}

Kaffir skuil, occurrence of the diastema in a, 40 .

Kaffirs, their cruelty to animals, 118 ; lice of the, 170; coloar of the, 579 ; engrossment of the nandsomest women by the chief's of the, 595 ; marriage-customs of the, 598. lialij-pheasant, drumming of the male, 375 ; young of: 468 .

Tallima, resemblance of, to a withered leaf, 311.

Kialmucks, general boardlessness of, 560 ; aversion of, to hairs on the face, 581; marriage-customs of the, 598.

Kangaroo, great red, sexual difference in the colour of, 533 .

liant, Inm., on duty, 97 ; on selfrestraint, 110 ; on the number of species of $\operatorname{man}, 174$.

Katy-did, stridulation of the, 283.

Kieen, Dr., on the mental powers of snakes, 3ว2.

Keller, Dr., on the difficulty of fashioning stone implements, 49 .

Kent, W. S, elongation of dorsal fin of Callionymus lyra, 336 ; courtship of Labrus mixtus, 341 ; colours and courtship of Cuntharus lineatus. 341.

Kestrels, new mates found by, 408 .

Kidney, one, doing double work in disease, 32.

King, W. K., on the vocal organs of Tetruo cupido, 371 ; on the drumming of grouse, 376 ; on the reindeer, 503; on the attraction of male deer by the voice of the female, 526 .

King and Fitzroy, on the marriagecustoms of the Fuegians, 599 .

king-crows, nidification of, 453 .

Kingfisher, 371 ; racket-shaped feather's in the tail of $a, 384$.

Kingfishers, colours and nidification of the, 455, 457, 459; immature plumage of the, 467,468 ; young of the, 481 .

King Lory, 457 ; immature plumage of the, 467 .

Kingsley, C., on the sounds produced by Ünbrina, 347.

Kirby and Spence, on sexual differ. ences in the length of the suout in Curculionidx, 208; on the courtship of insects, 221; on the elytra of Dytiscus, 276 ; on peculiarities in the legs of male insects, $276^{\circ}$ : 
on the relative size of the seses in insects, 279; on the Fulgoriln, 281 ; on the habits of Termites, 291 ; on difference of colour in the seres of beetles, 294 ; on the horns of the male lamellicorn beetles, 297 ; on hornlike processes in male Curculionidx, 299; on the pugnacity of the male stag-beetle, 299.

Kite, killed by a game-cock, 363 .

hinot, retention of wiuter plumage hy the, 391

Knox, R., on the semilunar fold, 17 ; on the occurrence of the supracondyloid foramen in the humerus of min, 21; on the features of the young Memnon, 168.

hioala, length of the cocum in, 20.

hobus ellipsiprymnus, propostion of the sexes in, 247.

Kölreuter, on the sterility of hybrid plants, 172.

lioodoo, development of the horns of the, 234; markings of the, 543.

Köppen, F. T., on the migratory locust, 283.

Kordofan, protuberances artificially produced by natives of, 574 .

horaks, marriage customs of, 598.

Konle, on the proportion of sexes in locusts, 254 ; Russian locusts, 283.

Kovalersky, A., on the affinity of the Ascidia to the Vertebrata, 159, 160.

- W., on the pugnacity of the male capercailzie, 363 ; on the pairing of the capercailzie, 367 .

Frause, on a conroluted body at the extremity of the tail in \& Macacus and a cat, 23.

Kupffer, Prof, on the affinity of the Ascidia to the Vertebiata, 160.

\section{I.}

La $a^{7}$ idocera Darwini, prenensile organs of the male, 266

Labrus, splendid colours of the species of, 342 .

mixtus, sexual differences in, $337,341$.

paoo, 342.

Lacertilia, sexual differences of, 354.

Lafresnaye, M. de, on birds of paraduse, 385.
Lamarck, on the origin of man, 3.

Lamellibranchiata, 262.

Lamellicorn beetles, horn-like processes from the head and tho: $A s$ of, 295,298 ; intluence of sexwal selection on, 301 .

Lamellicornia, stridulation of, 303 .

Lamont, Mr., on the tusks of the walrus, 502 ; on the use of its tusks by the walrus, 513 ; on the bladder-nose seal, 528 .

Lampornis porphyrurus, colours of the female, 454.

Lampyridx, distasteful to mammals, $27 \%$

Lancelet, 159, 165.

Lindois, $H$., gnats attracted by sound, 280 ; on the production of sound by the Cicadx, 281 ; on the stridulating organ of the crickets, 284; on Decticus, 285 ; on the stridulating organs of the Acridiid 2,286 ; stridulating apparatus in Orthopteren, 288 ; sounds produced by Atropus, 291 ; on the stridulation of Necrophorus, 302 ; on the stridulant organ of Cerambyx heros, 303 ; on the stridulant organ of Geotrupes, 303 ; on the stridulating nrgans in the Coleoptera, 304; on the ticking of Anobium, 306.

Landor, Dr., on remorse for zot obey ing tribal custom, 114.

Tanguage an art, 86 ; articulate, origın of, 86 ; relation of the progress of, to the development of the brain, 87 ; effects of inheritance in production of, 88 ; complex structure of, among barbarous nations, 91 . natural selection in, 91 ; gesture. 178 ; primeval, 180 ; of a lost tribe preserved by a par'ot, 181.

Languages, presence of rudiments ic, 90 ; classification of, 90 ; variability of, 90 ; crossing or blending of, 90 ; complexity of, no test of perfectiou or proof of special creation, 92 ; re. semblance of, evidence of ccmmunity of origin, 148.

and species, identity of eridence of their gradual developmen. $\delta 0$.

Lanins, 462; characters of young, 464.

482.

rufus, anomalous young sf, 
Laskester, R. Ji, un comparative lonGevity, 133, 136; on the destrucive elfects of intemperance, 137.

iaure of the bumin fotus, 19, 600.

iappocian lasuruage, highly artifichal, 91.

Lark, proportion of the seres in the, 248 ; female, singing of the, 370 .

[arks, attracted by a mirror, 413 .

Lartet, E., complarison of cranial caparities of skulls of recent and tertiary mammals, 55 ; on the size of the brain in maromals, 81 ; on Dryopithecus, 155 ; on pre-historic flutes, 570

¿ctrus, seanmat wange of plumage in, 492.

Larva, Iuminous, of a Brazilian beetle, 278.

Larynx, muscles of the, in song-hirds, 371.

isasiocam?u quercus, attraction of males by the female, 252 ; sexual differeuce of colour in, 316.

Latham, R. G., on the migrations of man, 48 .

Latooka, ferforition of the lower lip by the wommu of, 57 (;)

Iaurallarl, on the ahormal dirision of the malar bone in $\operatorname{man}, 39$.

Lawreuce, W., on the superionity of sarages to Europeans in power of sight, 33 ; on the colour of negro infiants, 5.58 ; on the fondnews it savages for ornaments, 578 ; on beardless races, 581 ; on the beatuty of the English aristocrucy, $580^{\circ}$.

Layard, E. I.., on an instance of rationality in a cobra, 3.52 ; ou the pugnacity of Gallus Stanleyi, 363.

Laycock, Dr., on vital periodicity, 8 ; thes oid nature of idiots. 36 .

Leaves, autumn, tints useless, 262.

Lecky, Mr., on the sense of duty, 97 ; on suicide, 117 ; on the practice of celibacy, 119; his view of the crimes of savages, 119 ; on the cradual rise of morality, 125 .

Leconte, J. L., on the stridulant orgau in the Coprini and Dynastini, 303.

Lue $H$. , on the numerical proportion of the sexes in the trout, 249.

Leg, calf of the; trtificially modise: 574.
Legitimate ani illegitimate children, proportion cf the sexes in, 244.

Legs, variation of the length of the, in man, 26; proportions of, in soldiers and sailors, 32 ; frort, atrophied in some male butterflies, 277 : peculiarities of, in male insects, 277.

Leguny, on the occurrence of the supra-condyloid foramen in the humerus of man, 22.

"Lek" of the black-cock and capercailzie, 405.

Lemoine, Albert, on the origin of language, 87.

Limur inacaco, sexual difference of colour in, 537.

Lemurida, 152 ; ears of the, 15 ; variability of the muscles in the, 41 ; position and derivation of the, 157 ; their origin, 165.

l.emurs, uterus in the, 38.

Lenguas, disfigurement of the ears of the, 575 .

l.eopards, black, 539.

Lepidopteri, 307 ; numerical proportions of the sexes in the, 250 ; colouring of, 308 ; ocellated spots of, 427.

Lepidosiren, 159, 165.

l.eptalides, mimicry of, 325 .

Leptorhynchus angustatus, pugnacity of male, 299.

Leptura testucea, difference of colour in the sexes of. 294.

l.eroy, on the wariness of young foxes in hunting-districts, 80 ; on the desertion of their young by swallows, 108.

Lesire, $\mathrm{D}_{\text {e. }}$ marriage customs of Kaffirs, 598.

Lesse, valley of the, 22.

Lesson, on the birds of paradise, 219 , 403 ; on the sea-elephant, 528.

Lessona, M., observations on Serranus, 162.

Lethrus cephalotes, pugnacity of the males of, 297,300 .

Leuckart, $\mathrm{K}$., on the vesicula prostatica, 24; on the influence of the age of parcnts on the sex of offspring, 24:

Levator clavicula muscle, 42.

Iibellula depressa, colour of the male, 290.

Libellulitix, relative size of the sexts 
of, 279 ; difierence in the seres of, 29 ().

Lice $\cap t^{\circ}$ domestic animals and man, $1 ; 9$.

Licentiossness, a check upon populatron, t6; prevalcuce of, among savages, $1: 9$.

Lichtenstein, on Chera progne, 419.

Life, inheritance at corresponding periods of, 228, 232 .

Light, effects on complexion, 32 ; influence of, upon the colours of shells, 263.

Lilford, Lord, the ruff attracted by blight objects, 413 .

Limosa lapponica, 478.

Jinuria, tii-2.

mont:

Lindsay, Dr. W. L., disenses communicated from animals to man, 7 ; madness in animals, 79; the dos considers his master his God, 96.

Linnacus, views of; as to the position of $\operatorname{man}, 149$.

Linnet, nurerical proportion of the sexes in the, 248 ; crimson forehead and breast of the, 394 ; courtship of the, 401.

lion, polygnmous, 218 ; mane of the, defensive, 521 ; roaring of the, 526 .

Jions, stripes of young, 464 .

Lips, piercing of the, by savages, 575 .

Lilhobius, prehensile appendages of the female, 274.

Jithosia, coloration in, 314.

Littorina littorea, 262.

Livingstone, Dr., mauner of sitting of gorilla, 151; on the influence of ilampness and dryness on the colour of the skin, 193; on the liability of negroes to tropical fevers after resilence in a cold climate, 194; on the spur-winged goose, 364 ; on weaver-birds, 376 ; on an African night-jar, 384,403 ; on the battlescars of South African male mammals, 500 ; on the removal of the upper incisors by the Batokas, 575 ; on the perforation of the upper lip by the Makalolo, 576; on the Banyai, 579.

Livonia, numerical proportion of male and female births in, 215,243 .

Cizards, relative size of the sexes of, 354 ; gular pouches of, 354 .
Lloyd, Ln, on the poljyiamy of tha capercalzie and bustad, 219; on the numerical proportion of the sores in the capercailzie and blackcock, 248; on the salmon, 333 ; on the culours of the sea-scolpion. 337 ; on the puguacity of male grouse, 364; on the capercailzie ind black-cock, 306, 370; on tha call of the capercailzie, 375 ; on assemblages of grouse and snipes. 405 ; on the pairing of a shielddrake with a common duck, 414 ; on the battles of seals, 500 ; on the elk, 507.

Lobivanellus, wing-spurs in, 366.

Local influences, ellect of, upon stature, 31.

Lockwood, Mr., on the development of Hippocampus, 1 li3.

_-_, Rev. S., musical mouse, 568.

Locust, bright-coloured, rejected br lizards and birds, 289.

- migratory, 2S3; selection by female, 283.

Locusts, proportion of sexes in, 254 ; stridulation of, 284 .

Locustidx, stridulation of the, 282. 284 ; descent of the, 285.

Longicol'n beetles, difference of the sexes of, in colour, 294 ; stridulation of, 303.

Lunsdale, Mr., on an example of per sonal attachment in Helix pomatia. 263.

Lophobranchii, marsupial receptacles of the males, $3 \pm 6$.

Lophophorus, habits of, 420 .

Lophorina atra, sexual difference in coloration of, 491 .

Lophornis orratus, 38 ?

Lord, J. K., on Salmo lycandon, 333.

lory, King, 457 ; immature plumage of the, 467 .

Love-antics and dances of birds, 380 .

Lowne, B. T., on IIusca voinitoria, $54,280$.

Loxia, characters of young of, 464 .

Lubbock, Sir J., on the antiguity $"{ }^{\prime}$ $\operatorname{man}, 2$; on the origin of man, 3 on the mental capacity of suvage: 65 ; on the origin of implement. 82 ; on the simplification of lau guages, 92 ; on the is isence of th. idea of fod among rertain races n: 
men, $94 ;$ on the origin of the bolief in spiritual agencies, 95 , on superstitions, 96 ; on the sense of duty, 97 ; on the practice of burying the old and sick among the Fijians, 102; on the immorality of savaces, 119 ; on $\mathrm{Mr}$. Wallace's clairn to the origination of the idea of natural selection, 49 ; on the absence of remorse among savages, 131 ; on the former barbarism of civilised nations, 143 ; on improrements in the arts among sivages, 144 ; on resemblances of the mental characters in different laces of men, 178 ; on the arts practised by savages, 179 ; on the power of counting in primeval man, 180; on the prehensile organs of the male Labidocera Darwinii, 266 ; ou Chloëon, 274; on Smynthurus luteus, 279; finding of new mates by jays, 407 ; on strife for women among the North American Indians, 561 ; on music, 570 ; on the ornamental practices of sarages, 574 ; on the estimation of the beard among the Anglo-Saxons, 581; on artificial deformation of the skull, 583; on " communal marriages," 587,588 ; on exogamy, 589,592 ; on the Veddahs, 591 ; on polyandry, 593 .

Lucanidæ, variability of the mandibles in the male, 300 .

Lucanus, large size of males of, 278. - cervus, numerical proportion of sexes of, 253 ; weapons of the male, 299.

_ claphus, use of mandibles of, 300 ; large jarvs of male, 275.

Lucas, Prosper, on pigeons, 418 ; on sexual preference in horses and bulls, 525 .

Lunar periods, 8, 164.

Lund, Dr., on skulls found in Brazilian caves, 168

Lungs, enlargement of, in the Quichua and Aymara Indians, 34; a modified swim-bladder, 161 ; different capacity of in races of man, 167.

Luminosity in insects, 277.

Enschka, Prof., on the termination of the coccy $x, 23$
Luxury, expectation of life untrfluenced by, 136.

Lycana, stxual differences of colouring in species of, 310 .

Lyell, Sir. C., on the antiquity of man, 2 ; on the origin of man, 3 ; on the parallelism of the development of species and languages, 90 ; on the extinction of languages, 90 ; on the Inquisition, 141 ; on the fossil remains of vertebrita, 157; on the fertility of mulattoes, 171.

Lynx, Canadian, throat-ruff of the, 521 .

Lyre-bird, assemblies of, 406 .

\section{M.}

Macacus, ears of, 15; convoluted body in the extremity of the tail of, 23 ; variability of the tail in species of, 58 ; whiskers of species of, 531 .

brunneus, 59.

cynomolyus, superciliary ridge of, 558 ; beard and whisker's of, becoming white with age, 559 .

- ecaudatus, 60 .

- lasictus, facial spots of, 550 .

- radiatus, 151.

- rhesus, sexual difference in the colour of, 539,550 .

Macalister, Prof., on variations of the palmaris accessorins muscle, 27 ; on muscular abnormalities in man, 42,43 ; on the greater variability of the muscles in men than in women, 223.

Macaws, Mr. Buxton's observations on, 102 ; screams of, 375.

McCanu, J., on mental individuality, 84.

McClelland, J, on the Indian Cyprinidæ, 343.

Macculloch, Col., on an Indian village without any femule children, 592.

, Dr., on tertian ague in a dog, 8. Macgillivray, W., on the vocal organs of birds, 90 ; on the Egyptian goose, 355 , on the habits of woodpeckers, 376 ; on the habits of the snipe, 377 ; on the whitethroat, 381 ; on the moulting of the snipee 
? 1; on the moulting of the Anatidx, 393 ; on the finding of rew mates by magpies, $\$ 07$; on ilso pairing of a blackbird and ihrush, 414 ; on pied ravens, 424 ; on the guillemots, 424 ; on the colours of the tits, 458 ; on the immature plumage of birds, $466^{\circ}$ et seq.

31achetes, seres and young of, 485 ;

prgnax, supposed to be polygamous, 219 ; numerical proportion of the sexes in, 218 ; pugnacity of the male, 360; double moult in, 390.

Mcintosh, Dr. colours of the Nemertians, 265.

WuKenuan, marriage customs of Koraks, 598.

Mackintosh, on the morul sense, 97.

MacLachlan, R., on Apatania mulicbris and Bureus hyemulis, 254; on the anal appendages of male Insects, 275; on the pairing of dragon-flies, 279 ; on dragon-flies, 290,291 ; on dimorphism in Agriois, 291; on the want of pugnacity in male dragon-flies, 291; colour of ghost-moth in the Shetland Islands, 316.

McLennan, Mr., on infanticide, 46 , 591 ; on the origin of the belief in spiritual agencies, 94 ; on the prevalence of licentiousness among savages, 119,588 ; on the primitive barbarism of civilised nations, 143 ; on traces of the custom of the forcible capture of wives, 144, 592 ; on polyandry, 593.

Macnamara, Mr., susceptibility of Andaman islanders and Nepâlese to change, 188.

McNeill, Mr., on the use of the antlers of deer, 510 ; on the Scotch deerhound, 516 ; on the long hairs on the throat of the stag, 522 ; on the bellowing of stags, 526 .

Macropus, courtship of, $3 \pm 1$.

Macrorhinus proboscideus, structure of the nose of, 528 .

Magpie, power of speech of, 90 ; nuptial assemblies of, 406 ; new mates found by, 407; stealing bright objects, 413 ; young of the, 481 ; coloration of the, 493 .

Maypies, vocal organs of the, 370
Maillard, M., on the proportion of the sexes in a species of Yapilio from Bourbon, 250.

Maine, Sir Henry, on the absorption of one tribe by another, 1:8; is desire for improvement not general, 13 \%.

Major, Dr. C. Forsyth, on fossil Italian apes, 155; skull of Bos etruscus, 505; tusks of miocene pigs, 521 .

Makalulo, perforation of the upper lip by the, 576 .

Malar bone, abnormal division of, in $\operatorname{man}, 39$.

Mality, Archipelago, masriage-customs of the savages of the, 598 .

Malays, line of separation between the Papuans and the, 169 ; general beardlessness of the, 560 ; staining of the teeth among, 574 ; aversion of some, to hair's on the face, 581.

- and Papuans, contrasted characters of, 168.

Male animals, struggles of, for the possession of the females, 212,213 ; eagerness of, in courtship, 221, 222 ; generally more modified than female, 221,223 ; differ in the, same way trom females and young, 232. cbaracter , developed in temales, 227 ; transter of, to female birds, 471 .

L sedentary, of a hymenopterous parasite, 221.

Milefactors, 137.

Wales, presence of rudimentary female organs in, 162.

- and females, comparative number's of, 213,215 ; comparative mortality of, while young, 216 .

Malherbe, on the woodpeckers, 458.

Mallotus peronia, 331.

- villosus, 331.

Malthus, T., on the rate of increase of population, $44,45.46$.

Maluridæ, nidification of the, 454 .

Malurus, young of, 485 .

Mammæ, 208; rudimentary, in male mammals, $11,23,161,162,163$; supernumerary, in women, 36 ; of male human subject, 37.

Mammalia, Prof. Owen's classificat! u of, 148; genealogy of the, 158. 
Mammals, recent and tertiary, comyarison of cranial cafacity of, 5.5; nipples of, 162 ; pursuit of female, by the males, 221; secondary sexual characters of, 500; weapons of, 501 ; relative size of the sexes of, 515 ; parallelism of, with birds in secondary sexual characters, 541; roices of, used especially during the breeding season, 567 .

Min, variability of, 26 ; erroneously regarded as mole domesticated than other animals, 28; migrations of, 47 ; wide distribution of, 48 ; causes of the nakedness of, 57 ; supposed physical inferiority of, 64 ; a member of the Catarrhine group, 155 ; early progenitors of, 160 ; transition from ape indefinite, 180 ; numerical proportions of the sexes in, 215 ; difference between the sexes, 223 ; proportion of sexes amongst the illegitimate, 244; difierent complexion of male and female negroes, 556 ; secondary sexual character's of, 556 ; primeral condition of, 594 .

Mandans, correlation of colour and texture of hair in the, 197.

Maudible, left, enlarged in the male of Taphroderes distortus, 276.

Mandibles, use of the, in Ammoplita, 275 ; large, of Corydalis cornutus, 275 ; large, of male Lucanus claphus, 275.

Mandrill, number of caudal vertebrac in the, 58 ; colours of the male, $538,541,550$.

Mantegazza, Prof., on last molar teeth of $\operatorname{man}, 20$; bright colours in male animals, 224 ; on the ornaments of savages 573 et seq.; on the beardlessness of the New Zealanders, 581 ; on the exaggeration of natural character's by man, 582.

Mantell, W., on the engrossment of pretty girls by the New Zealand chiefs, 595.

Mantis, pugnacity of species of, 289 .

Maories, mortality of, 184 ; infunticide and proportion of sexes, 236 ; distaste for hairines amongst men, 581.

Marcus Aurelius, on the origin of the moral sense, 98 ; on the influerce of hatoitul thom hts, 123.
Mareca penelipe, 414.

Marks, retained throughout groups of birds, 427 .

Marriage, restraints upon, among savages, 46 ; influeuce of, upon morals, 119; influence of, on mortality, 139 ; development of, 590 .

Mirriages, early, 138, 139 ; communal, 587, 589.

Marshall, Dr. W., protuoerances on birds' heads, 235,383 ; on the inoulting of birds, 393 ; adrantage to older birds of paradise, 485 .

- Col., interbreeding amongst 'Todas, 189 ; infanticide and proportion of sexes with Todas, 255 ; choice of husbands amongst Todas, 593.

- Mre, on the brain of a Bushwoman, 167 .

Marsupials, 157 ; development of the uictitating membrane in, 17 ; uterus of, 39 ; possession of nipples by, 162 ; their origin fiom Monotremata, 165; abdominal sacks of, 208 ; relative size of the sexes of, 515 ; colours of, 533 .

Mis'supium, rudimentary, in male maxsupials, 161.

Martin, W. C. L., on alarm manifeste by an orang at the sight of a turtle, 72 ; on the hair in Hylobates, 152; on a female American deer, 514 ; on the roice of Hylobates ayilic, 527 ; on Semnopithecus nemaus, 5:5? on the beards of the inhabitants of St. Kilda, 560 .

Martins deserting their young, 108 .

$\longrightarrow, C_{.}$, on denth caused by intammation of the vermiform appendage, 21.

Mastoid processes in man and ap 2s, $5 . ;$. Minudsley, Dl., on the influence of the sense of smell in man, 18; ois idiots smelling their foud, 36 ; w Laura Brixgman, 88 ; on the derelopment of the rocal organs, 89 ; moral sense failing in incipicnt madness, 124; change of mental faculties at puberty in man, 565.

Mayers, W. F., on the domestication of the goldfish in China, 343 .

Mayhew, l., on the affection between individuals of different sexes in the dog, 52:i. 
Magnard, C. J, on the sexes of Chry$\therefore .12$, s p. pucta, 351 .

Aleckel, on sorrelated variation of the inussles of the arm aul leg, 44 .

Nedicines, effect produced by, the same in man and in monkeys, 7.

. Yedusce, bright colours of some, 260 .

Megnlithic structures, prevalcace of, 179.

H'ergyicus validus, sexual difference of colour in, 458 .

Ifegasoma, large size of males of, $\because 73$.

Meigs, D1. A, on variation in the skulls of the natives of America, 26.

Meinecke, ou the numerical propostion of the sexes in butterflies, 250.

Melanesians, decrense of, $18 J$.

Meldola, Mr., colours and marriage Alight of Colias and Picris, 319.

Meliphagidre, Australian, nidification of, $45 \pm$.

Jelita, secondary sexual charncters of, 268.

Meloë, difference of colour in the sexes of a species of, 294 .

Memory, manifestations of, in aninusls, 74 .

Memnon, young, 168.

Mental character's, difference of, in different races of men, 167.

- faculties, diversity of, in the same race of men, 26 ; inheritance of, 27 ; variation of, in the sume species, 27,66 ; similarity of the in different races of $\operatorname{man}, 178$; of birds, 410 .

- powers, difference of, in the tiro seres in man, 563.

Jienura Alberti, 406 ; ssigg of, 371.

- superba, 406 ; long tails of both sexes of, 451.

Meryanser, trachea s: the male, 374.

- serrator, male plumage of, 393.

Jlergus cucullatus, speculam of, 236.

- merganser, young of, 467.

. Netallura, splendid tail-feathers of, $+43$.

if thoca ichneunonicls, large male of, $\because 9$.

bieves, M., of the drumming of the เuipe, 377.
Mexicaus, civilisation of the, wot foreign, 145.

Meyer, on a conroluted body at thas extremity of the tail in a Macacus and a cat, 23.

- Dr. A, on the copulation of Phryganida of distinct species, 27.

$\rightarrow$ Prof. L., on development of helix of ear, 15, 16; men's ears more variable than women's, 224 ; antenna serving as ears, 280.

Migrations of man, effects of, 47 .

Migratory instinct of birds, 105 ; vanquishing the maternal, 107, 113.

Mill, J. S., on the origin of the moral sense, 98 ; on the "greatest happiness principle," 120 ; on the difference of the mental powers in the seres of $\operatorname{man}, 564$.

Millipedes, 274.

Milne-Edwards, $H$., on the use of the enlarged chelæ of the male Gelasimus, 267.

Milvayo leucurus, sexes and joung of, 479.

Mimicry, 323.

Mimus polyglottus, 411.

Mind, difference of, in man and the highest animals, 126 ; similarity of the, in different races, 178.

Minnow, proportion of the sexes in the, 249.

Mir'or, larks attracted by, 413.

Mitchell, Dr., interbreeding in the Hebrides, 189.

Mitford, selection of chiluren in Sparta, 29.

Mivart, St. George, on the reduction of organs, 12 ; on the ears of the lemuroidea, 15 ; on variability 0 , the muscles in lemuroiden, 41,48 ; on the caudal vertebra of monkeys, 58 ; on the classification of the primates, 153 ; on the orang anil on man, 154 ; on differences in the leinuroidea, 155 ; on the crest of the male newt, 348 .

Möbius, Prof., on reasoning power: in a pike, 75 .

Mncking-thrush, partial migration sit, 411 ; young of the, 487 .

Modifications, unserviceable, 62.

Mioggridge, J. T., on habits of spidentin $69 ;$ on habits of ants. 147. 
Moles, numerical Droportion of the rexes in, 247 ; battles of raale, 500 .

Mollienesia petenensis, sexual difference in, 337.

Mollusca, beautiful colours and shapes of, 263 ; absence of secondary sexual characters in the, 262.

Molluscoida, 159, 262.

Monacanthus scopas and $M$. Peronii, 331.

Mongolians, perfection of the senses in, 34.

Munkey, protecting his keeper from a baboon, 103, 110; bonnet-, 151; rhesus-, sexual difference in colour of the, 539, 550; moustache-, coloul's of the, 537 .

Monkeys, liability of, to the same diseases as man, 7; male, recognition of women by, 8 ; diversity of the mental faculties in, 27 ; breaking hard fruits with stones, 50 ; hands of the, 50,51 ; basal crudal vertebrx of, imbedded in the body, 59; revenge taken by, 69 ; maternal affection in, 70 ; variability of the faculty of attention in, 74; American, manifestation of reason in, 77 ; using stones and sticks, 81; imitative faculties of, 87 ; signal-cries of, 87 ; mutual kindnesses of, 101; sentinels posted by, 101; human character's of, 150; American, direction of the hair on the arms of some, 151; gradation of species of, 175 ; beards of, 531 ; ornamental characters of, 749; analogy of serual differences of, with those of mmn, 558; difterent degrees of difference in the sexes of, 561 ; expression of emotions by, 572; generally mouogamous habits of, 590 ; polygamous nabits of some, 590 ; naked surfaces of, 600 .

Monogamy, not primitive, 144.

Monogenists, 176.

Mononychus pseudacori, stridulation of, 305 .

Monotremata, 157 ; development of the nicitating membrane in, 17 ; 'actiferous glands of, 162 ; connectIog mammals with reptiles, 165 .

Monstrosities, analogous, in man and io ver animals, 30 ; caused by arrest of development, 35 ; correlation of 44 ; transmission of, 173.

Montagu, G., on the habits of the black and red grouse, 219 ; on the pugnacity of the ruff, 361 ; on the singing of birds, 368 ; on the double moult of the male pintail, 393.

Monteiro, Mi., on Bucoras abyssinicus, 383.

Montes de Oca, M., on the pugnacity of male Humming-bilds, 360 .

Monticola cyanea, $\mathbf{4 5 6}$.

Monuments, as traces of extinct tribes, 181.

Moose, battles of, 501 ; horns of the, an incumbrance, 515.

Moral and instinctive impulses, alliance of, 111.

faculties, their influence on natural selection in man, 127.

rules, distinction between the higher and lower, 122.

_ sense, so-called, derived from the social instincts, 120,121 ; origin of the, 124.

- tendencies, inheritance of, 124.

Morality, supposed to be founded in selfishness, 120 ; test of, the general welfare of the community, 121; gradual rise of, 125 ; influence of a high standard of, 132 .

Molgan, L. H., on the beaver, 67 ; on the reasoning power's of the beaver, 75 ; on the forcible capture of wives, 144; on the castoreum of the beaver, 529 ; marriage unknown in primeval times, 588; on poly. andry, 593.

Morley. J., on the appreciation of praise and fear of blame, 146 .

Morris, $F$. 0 , on hawks feeding an orphan nestling, 409.

Morse, Dr., colours of mollusca, 264.

Morselli, E., division of the malar bone, 39.

Mortality, comparative, of females and males, $216,243$.

Morton, on the number of species of man, 174.

Moschkau, Dr. A., on a speaking starling, 85.

Moschus moschiferus, odoriferous organs of, 529 .

Mutacilla, Indian, young of, 468 . 
Moths, 31:3; àsonce of mouth in nome maies, 203; apterous female, 208; male, prehensile use of the tursi by, 209; male, attracted by temales, 252; coloration of, $315^{\circ}$; sexual differences of colour in, 316 .

Mutmot, iuheritance of mutilation of tail feathers, 60,603 ; racketshaped feathers in the tail of $\mathrm{a}$, 384 .

Misult, double, 463 ; double annual, in birds, 390 .

Moulting of birds, 484 .

Moults, partial, 392 ,

Mouse, song of, 568 .

Moustache-monkey, colours of the, $537,552$.

Moustaches, in moukeys, 150.

Mud-turtle, long claws of the male, 350 .

Mulattoes, persistent fertility of, 171; immunity of, from yellow tever, 193.

Wule, sterility and strong vitality of the, 171.

Mules, rational, 78.

Miiller, Ferd., on the Mexicanz and Peruvians, 145.

- Fritz, on astomatous males of Tanais, 208 ; on the disappearance of spots and stxipes in adult mammals, 547 ; on the proportions $0_{2}^{t^{\circ}}$ the sexes in some Crustacea, 255 ; on secondary sexual characters in various Crustaceans, 265 et seq.; musical contest between male $C_{i-}$ creda, 282; mode of holding wings in Castnia, 315 ; on birds shewing a preference for certain colours, 317 ; on the sexual maturity of young amphipod Crustacea, 485.

_- Hermann, emergeace of bees from pupa, 214; pollen-gathering of bees, 228 ; proportion of sexes In bees, 254 ; courting of Eristalis, 280: colour and sexual selection with bees, $29 \%$.

- J., on the nictitating membrine ind semilunar fold, 17.

_- Max, on the origin of language,

187 ; language implies power of general conception, 88 ; struggle for life among the words, \&c., ot sanguages, 91.

- S., on the vanteng $53 b^{\circ}$; on the colours of Semropithecus chrysimeias, $5: 37$.

Muntjic-deer, weapons of the, 514.

Murie, J., on the reduction of organs, 12 ; ou the ear's of the Lemuroidea, 15 ; on variability of the muscles in the Lemuroidea, 41 ; 48 ; basal caudal vertebri of Macacus brurneus imbedded in the body, 59; on the manner of sitting in shorttailed apes, 59; on differences in the Lemuroidea, 155; on the throat-pouch of the male bustard, 373 ; on the mane of (taria jubata, 521 ; on the sub-orbital pits of Ruminituts, 529; on the colours of the sexes in Otaria nigrescens, 535 .

Murray, $A_{0}$, on the Pediculi of ditferent races of men, 169.

- T. A., on the fertility of Australian women with white men, 170.

Jus coninga, 80.

minutus, sexual difference in the

colour of, 534.

Musca vomitoria, 54.

Muscicapa grisola, 455 .

—_ luctuosa, 455 .

ruticilla, breeding in immature plumage, 484.

Muscle, ischio-pubic, 41.

Muscles, rudimentary, occurrence of, in man, 12 ; variability of the, 26 ; effects of use and disuse upon, 32 ; animal-like abnormalities of, in man, 41 ; correlated variation of, in the arm and leg, 44 ; variability of, in the hands and feet, 48 ; of the jaws, influence of, on the physiognomy of the Apes, 54 ; habitual spasms of, causing modifications of the facial bones, 55 ; of the early" progenitors of man, 160 ; greates variability of the, in men than in women, 223.

Musculus sternalis, Prof. Turner on the, 13.

Music, 178 ; of birds, 368 ; discordant, love of savages for, 380 ; reitson of power of perception of note: in animals, 568 ; poiver of distinguishing notes, 569 ; its counection with primeval speech, 570 ; different appreciation of, $\mathrm{Lj}$ differeut peoples, 570 ; origin of, 565,573 etiects of, 571 . 
Musical cadences, perception of, by auimals, $5 \mathrm{u}^{\circ}$; powers of mau, $566^{\circ}$ et seq.

Musk-dear, canine teeth of mile, 502 , 513,514 ; male, odiferous orgass of the, 529 ; winter change of the, i) +2 .

Insk-duck, Australian, 359; large size of male, 362 ; of Guiana, pugnacity of the male, 362 .

Musk-0x, holns of, 505.

II usk-rat, protective resemblance of the, to a clod of earth, 542 .

Musophaga, colours and nidification of the, 455 ; both sexes of, equilly brilliant, 460 .

Mussels opened by monkeys, 50 .

IU ustela, winter change of two species of, 542 .

Nuster's, Capt, on Rhea Iiarwinii. 479 ; marriages amongst Patagonians, 598.

Mlutilations, healing of, 8 ; inheritance of, 60 .

Wutilla europaca, stridulation of, 2,92 .

Mutillida, absence of ocelli in female, 275.

Mycetes caraya, polyganuus, 217 ; rocal organs of, 527 ; beard of, 531 ; sexual differences of culour in, 537 ; voice of, 567 .

- scniculus, sexual differeaces of colnur in, 537.

Myritipoda, 274.

N.

Nägeli, on the influence of natural selection on plints, 61 ; on the gradation of species of plants, 175.

Diails, coloured yellow or purple in part of Africa, 574.

Narwhal, tusks of the, 502, 507.

Nasal cavities, large size of, in American aborigines, 34 .

Nascent organs, 12.

Nathusius, H. von, on the improved breeds of pigs, 177 ; male domesticated animals more variable than females, 223; horns of castrated sheep, 506; on the breeding of domestic arimals, 596 .

latural selection, its effects on the early progenitors of $\mathrm{man}, 47$; insivence of. on man, 60,62 ; lirritis- tion of the principle, 61 ; influence of, on social animals, $62 ; 1 . \mathrm{L}$. Wallace on the limitation of, by the influence of the mental faculties in nın, 127 ; influence of, in the progr'ess of the United States, 142 ; it relation to sex, 259 .

Natural and sexual selection contrasted, 226.

Nanlette, jaw from, large size of the canines in, 40.

Neanderthal skull, capacity of the, 55 .

Neck, proportion of, in soldiers am sailors, 32.

Necrophorus, stridulation of, $3 m$ 304.

Nectarinia, young of, 468 .

Nectarinice, moulting of the, 38: nidification of, 454 .

Negro, resemblance of a, to Europeans in mental characters, 178.

Negro-women, their kindness to Muugc Park, 118.

Negroes, Caucasian features in, 167 ; character of, 168 ; lice of, 170 ; fertility of, when crossed with other races, 171 ; blackness of, 170,173 ; variability oft, 174,175 ; inm munify of, from yellow fever, 193 ; ditference of, from Americins, 197 ; disfigurements of the, 541 ; colour of newborn childreu of, 557 ; comprative beardlessness of, 560 ; rendily berome musicians, 570 ; appreciation of beauty of their women by, 577 , 579 ; idea of beauty among, 582 ; compression of the nose by some, 583.

Nemertians, colours of, 264.

Neolithic period, 145.

Neomoryha, sexual ditrerence of the beak in, 359 .

Nephila, size of male, 273.

Nests, made by fishes, 345 ; decora. tion of, by Humming-birds, 413 .

Neumeister, on a ch:nge of colour is pigeons after screral moultingrs. 238.

Neuration, differcuce of, in the :wo sexes of some buttertics and hr. menoptera, 277.

Neuroptera, 254, 290.

icurotiemis, diuorphism in, ne?.

New Zealanl, expecration by the 
aatives of, of their cxtinction, 191 ; practice of tattooing in, 576 ; arelvion of aatives of, to hairs on the :ace, 581; pretty girls engrossed by the chiefs in, 595 .

Newton, A., on the throat-pouch of the male bustard, 373 ; on the ditfereuce between the females of two speries of Uxyn tus, 470 ; on the labits of the Phalarope, dotterel, and godwit, 477 .

Newts, $3 \pm 8$.

Nicholson, Dr., on the non-immunity of dark kuropeans from yellow feror, 195.

Nictitating membrane, 17, 161.

Yidification, of fishes, 344 ; relation of, to colour, 453,456 ; of British bi:ds, 454.

Night-herou, cries of the, 368 .

Nightingale, arrival of the male before the female, 212 ; object of the song of the, 368 .

Nightingales, new mates found by 408.

Nightjar, selection of $\AA$ mate by the female, 416; Australian, sexes of 479 ; coloration of the, 491 .

Nightjars, noise made by some male, with their wings, 376 ; elongated fertiner's in, $384,403$.

Nilghau, sexual differences of colour in the, 535 .

Silsson, Prof., on the resemblance of stone arrow-heads from various places, 179 ; on the development of the holns in the reindeer, 234.

Nipples, absence of, in Monotremata, 162.

Nitsche, Dr., ear of foetal orang, 17.

Nitzsch, C. L., on the dowa of birds, 390.

Noctux, brightly-coloured beneath, 315.

Noctuid $x$, coloration of, 313.

Nomadic habits, unfavourable to human progress, 133.

Nordmann, A., on Tetrao urogalloides, 405.

Norfolk island, half-breeds on, 190.

Norway, numerical proportion of male and female births in, 243.

Nose, resemblance of, in man and the apes, 153; piercing and ornamentatios of the, 575 ; very flat, not admired in negroes, 582 ; flattenirg of the, 583 .

Nott and Gliddon, on the features of Rameses II., 168; on the features of Amunoph 1Il., 168; on skulls from Brazilian caves, 168 ; on the immunity of negroes and mulattoes from yellow fever, 193 ; on the deformation of the skull among American tribes, 583 .

Novara, voyage of the, suicide in New Zealand, 117.

Nudibranch Mollusca, bright colours ot, $26 t$.

Numerals, Roman, 144; origin of, 264.

Nunemaya, natives of, bearded, 349 , 560.

Nut-hatch of Japan, intelligence of, 410 .

\section{0.}

Obedience, value of, 130 .

Ouservation, powers of, possessed by birus, 411.

Occupations, sometimes a cause of diminished stature, 31 ; effect of, upon the proportions of the body, 31.

Oculli, atsence of, in female Mutillidac, 274.

- of birds, formation and rariability of the, 427 .

Ocelot, sexual differences in the colouring of the, 534 .

Ocyphaps lophotes, 402 .

Odonata, 254.

Odonestis potatoria, sexual difference of colour in, 316.

Odour, correlation of, with colour of skin, 197 ; cmitted by saakes in the breeding-season, 352 ; of mammals, 528.

Ecanthus nivalis, difierence of colous in the seres of, 289 . pellucidus, 289.

Ogle, Dr. W., relation between colcisı and powel of smell, 18.

Oidemia, 491.

Olivier, on sounds produced by Pimelia striata, 306.

Omaloplia brunnea, strillulation nt 303.

Cnitis furcifer, processes of anteris: 
fernora of the male, and on the hend and thorax of the female, 297.

Onthophagres, 295.

- ranyifer, sexial differences of, 296 ; variation in the horns of the male, 297.

Ophidia, sexual differences of, 351 .

Ophidium, 347.

Opossum, wide range of, in America, 169.

Optic nerve, atrophy of the, caused oy destruction of the eye, 32.

Orang-Outan, 561; Bischotf on the agreement of the brain of the, with that of man, 6 ; adult age of the, 8 ; ears of the, 14 ; rermiform appendage of, 21 ; hands of the, 50 ; absence of mastoid processes in the, 53 ; platforms built by the, 66 ; alarmed at the sight of a turtle, 72 ; using a stick as a lever, 81 ; using missiles, 81 ; using the leaves of the Pandanus as a night covering, 82 ; direction of the harr on the arms of the, 151; its aherrant characters, 154 ; supposed evolution of the, 177 ; voice of the, 527; monogamous habits of the, 590 ; male, benrd of the, 531.

Oranges, treatment of, by monkeys, 50.

Urange-tip butterfly, 308, 312, 313.

Orchestia Daroinil, dimorphism of males of, 268.

Tucuratinga, limbs of, 267, 271.

Ordeal, trial by, 96.

Oreas canna, colours of, 535 .

Derbianus, colours of, 535,543 .

Organs, prehensile, 209; utilised for new purposes, 571.

Organic scale, von Baer's definition of j)ogress in, 164.

Orioles, nidification of, 453 .

Oriolus, species of, breeding in immature plumage, 484.

- mclanocephalus, coloration of the sexes in, 460 .

Ornaments, prevalence of similar, 179 ; of male birds, 367 ; fondness of savages for, 574 .

Drnamental characters, equal transmission of, to both sexes, in man: mals, 541 ; of monkeys, 549 .
Ornithoptera crcosus, 250.

Ornithorhynchus, 156; reptilisn tea". dency of, 159 ; spur of the nale, 502.

Orocetes erythrogastra, young of, 497 .

Orrony, Grotto of, 22 .

Orsodacna atra, difference of colour in the sexes of, 294.

Orthoptera, 282; metamorphosis of. 237; stridulating apparatus of, 283,288 ; colours of, 289 ; rudimentary stridulating organs in female, 288; stridulation of the, and Homoptera, discussed, 288.

Ortygornis gularis, pugnacity of the male, 363 .

Oryctes, stridulation of, 303 ; sexual differences in the stridulant organs of, 305 .

Oryx leucoryx, use of the horns of, $509,518$.

Osphranter rufus, sexual diflerence in the colour of, 533 .

Ostrich, African, sexes and incubation of the, 478 .

Ostriches, stripes of young, 464 .

Otaria jubata, maue of the male, 521.

- nigrescens, difference in the coloration of the sexes of, $53 t$.

Otis bengalensis, love-antics of the male, 380.

- tarda, throat-pouch of the male, 373 ; polygamous, 219.

Ouzel, ring-, colours and nidification of the, 455 .

- water-, colour's and nidification of the, 455 .

(ivibos moschatus, horns of, 505 .

Ovipositor of insects, 208.

Uvis cycloceros, mode of fighting of, $508,513$.

Ovule of man, 9 .

Owen, Prof., on the Corpora Wolffiana, 11; on the great toe in man, 11 ; on the nictitating membrane and semilunar fold, 17 ; on the development of the posterior molars in different races of man, 20 ; on the length of the coecum in the Koala, 20 ; on the coccygeal reltebræ, 23 ; on rudimentary structures belonging to the reproductive system, 24; on abnormal condi. tions of the human uterus, 38 , 
on the number of digits in the Ichthyopterygia, 37 ; on the canine teeth in man, 40 ; on the walking of the chimpanzee and orang, 50 ; on the mastoid processes in the hignel apes, 53 ; on the hairiness of elephants in elevated districts, 57 ; on the culudal rertebre of monkeys, 58 ; classification of mammalia, 148 ; on the hair in monkeys, 152 ; ou the piscine affinities of the Ichthyosaurians, 159; on pologamy and monogany among the antelopes, 217 ; on the horns (1) Antilocapra americana, $2: 3 t$; on the musky odour of crocodiles during the breeding season, 351 ; on the scent-glands of snakes, 352 ; on the Dugong, Cachalot and Ornithorhynchus, 502 ; on the antlers of the red deer, 510 ; on the dentition of the Camelidx, 514 ; on the horns of the Irish elk, 515; on the voice in the giraffe, porcupine, and stag, 526; on the laryngeal sac of the govilla and orang, 527 ; on the odoriferous glands of mammals, 528, 529; on the effects of enasculation on the vocal organs of men, 566 ; on the roice of Hylobates agilis, 567 ; on American monogamous monkeys, 567.

Owls, white, ce: mates found by, 408.

Oxynotus, difference of the females of two species of, 470 .

\section{P.}

Pachydermata, 218.

Pachytylus migratorius, 283.

Paget, on the abnormal development of hairs in man, 19 ; on the thickness of the skin on the soles of the feet of infants, 33.

Painting, pleasure of savages in, 178.

Palamon, che' $x$ of a species of, 267.

Palcornis, sexual differences of colour in, 494.

461.

javanicus, colour of beak of, rosa, 7 sung of, 467 .

Palamedea cornuta, spurs on the wings, 364 .
Paleolithic period, 145.

Palestine, habits of the chaffrech in, 248.

Pallas, on the perfection of the senses in the Mongolians, 34; on the want of connexion between climate and the colour of the skin, 192 ; on the polygarnous habits of Antilope Saiga, 217 ; on the lighter colour of horses and cattle in winter in Siberia, 229 ; on the tusks of the musk-deer, 513,514 ; on the odoriferous glands of mammals, 529; on the odoriferous glands of the musk-deer, 530 ; on winter changes of colour in mammals, 542 ; on the ideal of female beauty in North China, 578.

Palmaris accessorius, muscle variations of the, 27.

Pampas, horses of the, 181.

Pangenesis, hypothesis of, 228, 231.

Panniculus carnosus. 13.

Pansch, on the brain of a foetal Cebus apclla, 205.

Papilio, proportion of the sexes in North American species of, 250 ; sexual differences of colouring in species of, 309 ; coloration of the wings in species of, 312 .

- ascanius, 309.

Sesostris and Chithrence, variability of, 319 .

Turnus, 250

Papilionidx, variability in the, 319 .

Papuans, line of separation between the, and the Malays, 169 ; beards of the, 560 ; hair of, 575 .

- and Malays, contrast in characters of, 168 .

Paralise, Birds of, 405,462 ; supposed by Lesson to be polygamous, 219 : rattling of their quills by, 375 : racket-shaped fenthers in, 384: sexual differences ip solour of, 385 : decomposed feathers in, 385,403 display of plumage by the male, 395.

Paradisea apoda, barbless feathers in the tail of, 385 ; plumage of, 385 and $P$. papuana, 385 ; divergence of the females of, 470 ; increase 3 s beauty with age, 485 .

Paraguay, Iudians of, eradication of eyebrows and eyelashes by, 580 . 
"'arakcet, Australan, variation un the? colour of the thighs of a male, 423.

Parallelism of development of species and languages, 90.

arasites on man and animals, 7,8 ; as evidence of specific identity or distinctness, 169 ; immunity from, correlated with colour, 193.

Parental feeling in earwigs, starnshes, and spiders, 106; affection, partly a result of natural selection, 105.

l'arents, age of, influence upon sex of offspring, 245.

l'arinx, sexual difference of colour in. 458.

Park, Mungo, negro-women teaching their children to love the truth. 118 ; his treatment by the negrowomen, 118,562 ; on negro opinions of the appearance of white men, 579.

Parker, Mr., no bird or reptile in line of mammalian descent, 158.

Parrot, racket-shaped feathers in the tail of a, 384 ; instance of benerolence in a, 411.

Parrots, change of colour in, 60; imitative faculties of, 73 ; living in triplets, 409 ; affection of, 410 ; colours and nidification of the, 455 , 457,458 ; immature plumage of the, 467 ; colours of, 489 ; sexual ditierences of colour in, 494 ; musical powers of, 570 .

Parthenogenesis in the Tenthredinx. 254 ; in Cynipidæ, 254 ; in Crustacea, 255 .

Partridge, monomamnis, 219 : proportion of the seres in the, 248 ; female, 471 .

"L_-dances," 380, 4.05

Jartridges, living in tlaplets, 409: spring coveys of male, 409 ; distinguishing persons, 412.

Parus caruleus, 458.

J'asser, sexes and young of, 48.3 .

- brachydactylus, 483 .

- domesticus, $455,48.3$.

- montanus, $455,483$.

l'atagonians, self-sacrifice bv, 111; marriages of, 598.

Eatterson, Mr., on the A.r. 2 ila. 280.
Patteson, Bishop, decrease of $\mathrm{X}, \mathrm{az}, \mathrm{m}$ sians, 185.

Paulistas of Brazil, 173.

Pavo cristatus, 236, 430.

muticus, 236, 430; possessior il spurs by the female, 364,450 .

- nigripennis, 419.

l'ayaguas Indians, thin legs and thick arms of the, 32 .

Payan, Mr., on the proportion of the sexes in sheep, 246.

Peacock, polygamous, 219 ; sexza? characters of, 236 ; pugnacity of the, 364 ; rattling of the quills by, 375 ; elongated tail-coverts of the, 384,402 ; love of display of the, 394,431 ; ocellated spots of the, 430 ; inconvenience of long tail of the, to the female, $444,451,452$; continitu: inclease of beauty of the, 485 . -butterfly, 312.

Peafowl, preference of females for a particular male, 418 ; first advances made by the female, 419 .

Pcticuli of domestic animals and man 169.

Pedigree of man, 165.

Pedionomus torquatus, sexes of, 473.

Peel, J., on horned sheep, 505.

Peewit, wing-tubercles of the male, 366.

Pelagic animals, transparency of, 261.

Pelecanus erythrorhynchus, holny cres: on the beak of the male, durjug th. breeding season, 390 . 393

Pelele, an African ornament, 576.

Pelicnn, blind, fed by his companions, 102 ; young, guided by old birrs, 102 ; puguacity of the male, 362 .

Pelicans, fishing in concert, 101.

Pelobius Flermanni, stridulation of, 303, 304.

Pelvis, alteration of, to sust the erect attitude of man, 53 ; differences of the, in the sexes in man, 557.

Penelope nigra, sound produced by the male, 377.

Pennant, or, the batties of seals, 500 : on the bladder-nose seal, 528.

Penthe, antennal cushions of the $x$ ele, 276.

Perch, brightness of male, duinis breeding seasno, 340 . 
Peregriac falcon, new mate found by, 408.

Period of variability, relation $0:$, to sexual selection, 240 .

l'eriodicity, vital, Dr. Laycock, on, 8.

Periods, lunar, followed by functions in man and animals, 8, 164.

- of life, inheritance at corresponding, 228, 232,

Perisorcus canadensis, young of, 481 .

Peritrichia, difference of colour in the sexes of a species of, 294.

Periwinkle, 262.

Pernis cristata, 424.

l'errier, M., on sexual selection, 210 ; on bees, 292.

['ersererance, a characteristic of man, 5 it.

P'ersians, said to be improred by intermixture with Georgians and Ci1cassians, 5 S6.

l'ersonnat, M., on Bumbyx Yamamai, 251.

Peruvians, civilisation of the, not forelgn, 145.

Petrels, colours of, 493.

Petrocincla cyanea, young of, 487 .

Petrocossyplius, 461.

Petronia, 483.

Pfeiffer Ida, on Javan idens of beauty, 580.

Phacochoerus othiopicus, tusks and pads of, 519.

Phalanger, Vulpiue, black varieties of the, 539.

Phalaropus fulicarius, 476.

- hyperboreus, 476.

Phancus, 298.

- carnifex, variation of the holus of the male, 297. 296.

faunus, sexual differences of, lancifer, 295.

Phaseolarctus cincreus, taste for rum and tobacco, 7.

Phasgonura viridissima, stridulation of, 284, 285.

Phasianus Sammerrinuie, 446.

versicolor, 396.

Wallichii, 400, 472.

Pheasant, polygamous, 219 ; and black grouse, hybrids of, 414 ; production of hybrids with the common fowl, 420 immat_re plumage of the, $466^{\circ}$
Phersant, Amherst, display of, 396

—- Argus, 334, 46:; display of plumage by the male, 398 ; ocel. lated spots of the 428, 434 ; gradition of character's in the, 434 .

- - Blood-, 364 .

-. Cheer, 400, 472 .

- Erred, 235, 400, 472; length of the tail in the, 452 ; sexes alike in the, 460 .

- Golden, display of plumag: by the male, $396^{\circ}$; age of mature plumage in the, 483 ; ses of young, ascertained by pulling cut headfeathers, 484 .

- Kalij, drumming of the male, 375.

- Reeve's, length of the tail in, 452.

, Silver, triumphant male, de posed on account of spoiled plumage, 419 ; sexual coloration of the, 492 .

- Sommerring's, 445, 452 .

- Tragopan, 38:3; display of plumage by the male, 397 ; markings of the sexes of the, 428 .

Pheasants, period of acquisitioc of male characters in the family of the, 235 ; proportion of sexes in chicks of, 247 ; length of the tail in, $44 \mathrm{~J}$, $451,452$.

Philters, worn by women, 577 .

I'hoca grenlandica, sexuil ditlerence in the coloration of, 535.

I'hanicura ruticilla, 408.

Phosphorescence of insects, 277.

Phryganid $x$, copulation of distinct species ot, $275^{\circ}$.

Phryniscus nigricans, 349 .

Physical inferiority, supposed, of m:u, i4.

Pickering, on the number of spresics of man, 174.

Picton, J.A., on the soul of man, 613.

Picus auratus, 362. major, 402 .

Picris, $312,319$.

l'igeon, female, deserting a weakened mate, 214; corrier, late development of the wattle in, 238 . pouter, late development of the crop in, 238; domestic, breeds and sub-breeds of, 460 .

Pigeons, nestling, fed by the secretiue

$2 \mathrm{x}$ 
of the crop of both parents, 63 ; changes of plumage in, 229 ; transmission of sexual peculiaritıes in, 230 ; Belgian, with black-streaked males, 231, 238, 446 ; changing colour after several moultings, 238 ; numerical proportion of the sexes in, 247 ; cooing of, 374 ; variations in plumage of, 385 ; display of plumage by male, 402 ; local memory of, 411 ; antipathy of female, to certain males, 418 ; pairing of, 418; profligate male and female, 418 ; wing-hars and tail-feathers of, 427 ; suppositious breed of, 445 ; pouter and carrier, peculiarities of, predominant in males, 447 ; nidification of, 453; Australian, 458; immature plumage of the, 467 .

Pigs, origin of the improved breeds of, 177 ; numerical proportion of the sexes in, 247 ; stripes of roung, 464,546 ; tusks of miocene, 521 ; sexual preference shewn by, 525 .

Pike, American, brilliant colours of the male, during the breeding geason, 340 .

_- reasoning powers of, 75 ; male, devoured by females, 249.

Pike, L. O., on the psychical elements of religion, 95.

Pimelia striata, sounds produced by the female, 306 .

Pinel, hairiness in idints, 36.

Pintail, drake, plumage of, 393 ; pairing with a wild duck, 415 . 414.

Pipe-fish, filamentous, 344; marsupial receptacles of the male, 346.

Pipits, moulting of the, 392.

Pipra, modified secondary wingfeathers of male, 378.

deliciosa, 378, 379 .

Pirates stridulus, stridulation of, 281.

Pitcairn island, half-breeds on, 190 .

Pithccia leucocephala, sexual differences of colour in, 537.

Satancs, beard of, 531, 532; resemblance of, to a negro, 604 .

lits, suborbital, of Ruminants, 529.

rittidæ, nidification of, 453 .

Placentata, 157.

Plagiostomous fishes, 331 .

Plain-wanderer, Austrairan, 473.
Planaria, bright colours of some, 260.

Plantain-eaters, colours and nidification of the, 455 ; both sexes of, equally brilliant, 460 .

Plants, cultivated, more fertile than wild, 45 ; Nägeli, on natural selec. tion in, 61 ; male flowers of, mature before the female, 212 ; phenomena of fertilisation in 222.

Platalea, 374 ; change of plumage in, 461.

Platyblemnus, 289.

Platycercus, young of, 481.

Platyphyllum concavum, 283, 286.

Platyrrhine monkeys, 153.

Platysma myoides, 13.

Plecostomus, head-tentacles of the males of a species of, 338 .

barbatus, peculiar beard of the male, 338.

Plectropterus gambensis, spurred wings of, 364.

Ploceus, 370, 375, 405.

Plovers, wing-spurs of, 365 ; double moult in, 392.

Pluma'e, changes of, inheritance of, by fowls, 227 ; teudency to analogous variation in, 385 ; display of, by male birds, 394,402 ; changes of, in relation to season, 462 ; immature, of birds, 464,465 ; colour of, in relation to protection, 489 .

Plumes on the head in birds, difference of, in the sexes, 451.

Pneumora, structure of, $286^{\circ}$.

Podica, sexual difference in the colour of the irides of, 425 .

Poeppig, on the contact of civilised and savage races, 183.

Poison, avoidance of, by animals, 80 .

Poiscnous fruits and herbs aroided br animals. 66.

Poisons, immunity from, correlated with colour, 193.

Polish fowls, origin of the crest in. 231.

Pollen and van Dam, on the cclours of, Lemur macaco, 537.

Polyandry, 593; in celtain Cyprinidx, 219; among the tlaterida, 253.

Polydactylism in man, 37.

Polygarny, nfluence of; upon sexual selection: 216; superinduced br 
domestication, 220 ; supposed increase of female births by, 245 ; in the stickleback, 332.

Polygenists, 176.

Polynesia, prevalence of infanticide in, 592.

Polynesians, wide geographical range of 29 ; difference of stature among the, 31 ; crosses of, 173 ; variability of, 174 ; heterogeneity of the, 192 ; aversion of, to hairs on the face, 581.

"'olyplectron, number of spurs in, 364 ; display of plumage by the male, 396; gradation of characters in, 431 ; female of, 471.

- chinquis, 397, 432.

- Hardurickii, 432.

- malaccense, $432,433$.

- Napoleonis, 432, 433.

Polyzoa, 262.

Pontoporeia affinis, 266.

Porcupine, mute, except in the rutting season, 526 .

['ores, excretory, numerical relation of, to the hairs in sheep, 198.

Porpita, bright colours of some, 260.

Portax picta, dorsal crest and throattuft of, 530 ; sexual differences of colour in, 535,543 .

Portunus puber, pugnacity of, 269.

Potamochoemes penicillatus, tusks and facial knobs of the, 520 .

Pouchet, $G_{\text {. }}$, the relation of instinct to intelligence, 67 ; on the instincts of ants, 147 ; on the cares of Abou-Simbel, 168; on the immunity of negroes from yellow fever, 193; change of colour in fishes, 344.

Pouter pigeon, late development of the large crop in, 238.

Powell, Dr., on stridulation, 281.

Power, Dr., on the different colours of the sexes in a species of Squilla, 271.

l'owys, Mr., on the habits of the chaffinch in Corfu, 248.

Pre-eminence of $\mathrm{man}, 48$

Preference for males by female birds, 114,420 ; shewn by mammals, in pairing, 522 .

Prehensile organs, 209.

Presbytis. entellus, fighting of the male, $56 \%$.
Preyer, Dr., on function of shell of ear, 14; on supernumerary manmæ in women, 37.

Prichard, on the difference of stature among the Polynesians, 31 ; on the connection between the brcadth of the skull in the Mongolians and the perfection of their senses, 34 ; on the capacity of British skulls oi different ages, 55 ; on the flattened heads of the Colombian savages, 575 ; on Siamese notions of beauty, 578 ; on the beardlessness of the Siamese, 581 ; on the deformation of the head among American tribes and the natives of Arakhan, 583.

Primary sexual organs, 207.

Primates, 149, 205; sexual differences of colour in, 537 .

Primogeniture, evils of, 135.

Prionidx, difference of the sexes in colour, 294.

Proctotretus multimaculatus, 358. tenuis, sexnal difference in the colour of, 358.

Profligacy, 137.

Progenitors, early, of man, 160.

Progress, not the normal rule in human society, 133; elements of, 141.

Prong-horn antelope, horns of, 234.

Proportions, difference of, in distinct races, 167.

Protective colouring in butterflies, 312 ; in lizards, 358 ; in birds, 473 , 489 ; in mammals, 542.

- nature of the dull colouring of female Lepidoptera, 321, 322, 324.

- resemblances in fishes, 344 .

Protozoa, absence of secondary sexual character's in, 260.

Pruner-Bey, on the occurrence of the supra-condyloid foramen in the humerus of man, 22 ; on the colour of negro infants, 557 .

Prussia, numerical proportion of male and female births in, 243 .

$P$ socus, proportions of the sexes in, 254.

Ptarmigan, monoganous, 219 ; sum. mer and winter plumage of the. 390,392 ; nuptial assemblages of, 406 ; triple moult of the, $462 ;$; protective coloration of, 473 .

Puff-birds, colours anü nidification of the, 455 . 
Pugnacity of fine-plumaged male birds, 400.

Pumas, stripes of young, 464.

Puppies learning from cats to cluan their faces, 73.

Pucnonotus homorrhous, pugnacity of the male, 360 ; uisplay of under tail coverts by the male, 402 .

Pyranga astiva, male aiding in incubatinn, 453.

Pyrodes, difference of the sexes n colour, 294.

\section{Q.}

Quadrumana, hands of, 50 ; differences between man and the, 149 ; serual differences of coloux in, 537 ; ornamental characters of, 549 ; analog! of sexual differences of, with those of man, 558; fighting of males for the females, 562 ; monogamous habits of, 590 ; beards of the, 602 .

Quain, $R$., on the variation of the muscles in man, 26.

Quatrefages, A. de, on the occurrence of a rudimentary tail in man, 22 ; on variability, 30 ; on the moral sense as a distinction between man and animals, 97 ; civilised men stronger than savages, 136 ; on the fertility of Australian women with white men, 170; on the Paulistas of Brazil, 173; on the evolution of the breeds of cattle, 177 ; on the Jews, 193; on the liability or negroes to tropical fevers aftel residence in a cold climate, 194 ; on the difference between ficldand house-slaves, 196 ; on the inAluence of climate on colour, 196; colours of annelids, 265; on the Ainos, 560; on the women of San Giuliano, 586.

Querquedula acuta, 414.

Quetelet, proportion of sexes in man, 343; relative size in man and woman, 244.

Qzichua Indians, 34; local variation of colour in the, 196; no grey hair among the, 559 ; hairlessness of the, 561 ; long hair of the, 580 .

Quiscalus major, 225 ; proportions of the seres of, in F!crida and Honduras, 2 tc.
R.

Rabbit, white tail of the, 542 .

Rabbits, domestic, elongation of the skull in, 56 ; modification of the skull, in by the lopping of the ear, 56 ; danger-signals of, 100 ; numerical proportion of the seres in, 247.

Races, distinctive characters of, 167 , 168 ; or species of man, 168; crossed, fertility or sterility of, 170 ; of man, variability of the, 174 ; of man, resemblance of, in menta characters, 178 ; formation of, 181 ; of man, extinction of, 181 ; effects of the crossing of, 192; of man, formation of the, 192; of man, children of the, 557 ; beardless, aversion of, to hairs on the ince, 580 .

Raftes, Sir So, on the banteng, 536.

Rafts, use of, 48,180 .

lagge, manifested by animals, 69 .

Raiu batis, teeth of, 335 .

clavata, female spined on the back, 331 ; serual difference in the tecth of, 334.

- maculata, teeth of, 335.

Rails, spur-winged, 364.

litm, mode of fighting of the 508 ; African, mane of an, 532 ; fattailed, 532.

Rameses II., features of, 168.

Ramsay, Mr., on the Australiax musk-duck, 359 ; on the regentbird, 413 ; on the incubation of Menura superba, 451.

lianx esculentu, rocal sacs of, 350 .

Rat, common, general dispersion of, a consequence of superior cunning. 80 ; supplantation of the native, in New Zealand, by the European rat, 191 ; common, said to be polygarnous, 218 ; numerical proportion of the sexes in, 247.

Rats, enticed by essential oils, 530 .

Rationality of birds, 410 .

Rattle-snakes, difference of the sexes in the, 351 ; rattles as a call, 353 .

Raven, vocal organs of the 370 ; stealing bright objects, 413 ; pied, of the Feroe Islands, 424.

lisys, prehersile orgsins of male, 331. 
Hazor-bill, young of the, 486 .

lieade. Winwood, suicide among savages in Africa, 117 ; mulattoes not prolific, 171 ; effect of castration of horned sheep, 506 ; on the Guinea sheep, 235 ; on the occurrence of a mane in an African ram, 533 ; on the negroes' appreciation of the beauty of their women, 577 ; on the admiration of negroes for a black skin, 579 ; on the idea of beauty amoug negrocs, 582 ; on the Jollofs, 587 ; on the marriage-customs of the negroes, 599.

Reasox, in animals, 75 .

Redstart, American, breeding in immature plumage, 484 .

Redstarts, new mates found by, 408 .

Reduvidæ, stridulation of, 281.

Reed-bunting, head-feathers of the male, 402 ; attacked by a bull-finch, 412.

Reefs, fishes frequenting, 343 .

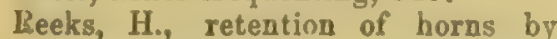
breeding deer, 503 ; cow rejected by a bull, 525 ; destruction of piebald rabbits by cats, 542 .

Regeneration, partial, of lost parts in man, 8.

Regent-bird, 413.

Peindeer, horns of the, 233 ; battles of, 501 ; horns of the female, 503 ; antlers of, with numerous points, 510 ; winter change of the, 542 ; sexual preferences shewn by, 552 .

Relationship, terms of, 590 .

Peligion, deficiency of, among certain races, 93 ; psychical elements of, 95 .

Kemorse, 114; deficiency of, among savages, 131 .

Rergger, on the diseases of Ccbus Azara, 7 ; on the diversity of the mental faculties of monkeys, 27 ; on the Payaguas Indians, 32 ; on the inferiority of Europeans to savages in their senses, 33 ; revenge taken by monkeys, 69 ; on maternal affection in a Cebus, 70 ; on the reasoning powers of American monkeys, 77 ; on the use of stones by monkeys for cracking hard nuts, 81 ; wn the sounds attered by Cebus Azara, 84 ; on the signal-cries of monkeys, 87 ; on the polygamous habits of Mycetes caraya, 217 ; on the roice of the howling monkeys, 527 ; on the odour of Cervus campestris, 529 ; on the beards of Mycetes caraya and Pithecio Satanas, 531; on the colours of Fe'is mitis, 534 ; on the colours of Cervus paludosus, 536 ; on sexual difierences of colour in Mycetes, 537 ; on the colour of the infant Guaranys, 558 ; on the early maturity of the female of Cebuis azara, 558 ; on the beards of tne Guaranys, 561 ; on the emotional notes employed by monkeys, 572 ; on American polygamous monkeys, 590.

Representative species, of birds, 468 .

Reproduction, unity of phenomena of, throughout the mammalia, 8 ; period of, in birds, 484 .

Reproductive system, rudimentary structures in the, 23 ; accessory parts of, 161 .

Reptiles, 350.

- and birds, alliance of, 165 .

Resemblances, small, between man and the apes, 150 .

Retrievers, exercise of reasoning faculties by, 78 .

Revenge, manifested by animals, 69 .

Reversion, 36 ; perhaps the cause of some bad dispositions, 137.

Rhagium, difference of colour in the sexes of a species of, 294.

Rhamphastos carinatus, 492.

Rhea darwinii, 479.

Rhinoceros, nakedness of, 57 ; hor us of, 505 ; hor'us of, used defensively, 518; attacking white or grey horses, 540 .

Rinynchaea, sexes and young of, 476 . australis, 476 .

bengalensis, 476 .

capensis, 477.

lihythm, perception of, by animals, 569.

Richard, M., on rudimentary muscles in $\operatorname{man}, 12$.

Fichardson, Sis J., on the pairing at Tetrio umielius, 366 ; on Titres. urophasianus, 372 ; on the drumming of grouse, 376 ; on the dancess of Tetriv phasianclius, 381; on 
assemblages of gronse, 405 ; on the battles of male deer, 501; on the reindeer, 503; on the horns of the musk-0x, 505; on antlers of the rendeer with numerous points, 510 ; on the monse, 515 .

Richardson, on the Scotch deerhound, 516.

Richter, Jean Paul, on imagination, 74.

Riedel, on profligate female pigeons, 218.

Riley, Mr., on mimicry in butterflies, 324; birds' disgust at taste of cer'tain caterpillars, 326.

Ring-ouzel, colours and nidification of the, 455 .

Ripa, Father, on the difficulty of distinguishing the races of the Chinese, 167.

Rivalry, in singing, between male birds, 369.

River-hog, African, tusks and knobs of the, 520 .

Rivers, analogy of, to islands, 159.

Buach, brightness of male during breeding-season, 340 .

Robbery, of strangers, considered honourabse, 117.

Robertson, Mr., remarks on the development of the horns in the roebuck and red-deer, 234.

Robin, pugnacity of the male, 360 ; autumn song of the, 370 ; fernale singing of the, 370 ; attacking other birds with red in their plumage, 412 ; young of the, 480 .

Nobinet, on the difference of size of the male and female cocoons of the silk-moth, 278:

Rodents, uterus in the, 38 ; absence of secondary sexzal characters in, 218 ; sexual differences in the colours of, 534 .

Roe, winter change of the, 542 .

Rohlfs, Dr., Caucasian features in negro, 167 ; fertility of mixed races in Sahara, 171 ; colours of birds in Sahara, 490 ; ideas of beauty amongst the Bornuans, 582.

Rolle, $F_{\text {., }}$ on the origin of man, 3 ; ou a change in German families settled in Georgia, 196.

Roller, harsh cry of, 371.

Romans, ancient, gladiatorial exhibitions of the, 123 .
Ronjou, M. A., coincidence of arrested development with polydactylism 37.

Rook, voice of the, 375 .

Rössler, Dr., on the resemblance of the lower surface of butterfies to the bark of trees, 311.

Rostrum, sexual difference in the length of, in some weevils, 208.

Royer, Madlle., mammals giving suck, 163.

Rudimentary organs, 11 ; origin of, 24.

Rudiments, presence of, in languages, 90.

Rudolphi, on the want of connexion between climate and the colour of the skin, 192.

Ruff, supposed to be polygamous, 219; proportion of the sexes in the, 248 ; pugnacity of the, 361 ; double moult in, 390,392 ; duration of dances of, 405 ; attraction of the, to bright objects, 413 .

Ruminants, male, disappearance of canine teeth in, 53,562 ; generally polygamous, 217 ; suborbital pits of, 529 ; sexual differences of colour in, 535 .

Rupicola crocea, display of plumage by the male, 395 .

Rüppell, on canine teeth in deer and antelopes, 514 .

Russia, numerical proportion of male and female births in, $215,243$.

Ruticilla, 462.

Rütimeyer, Prof., on the physiognomy of the apes, 54 ; on the sexual differences of monkeys, 551 .

Rutlandshire, numerical proportion of male and female births in, 242 .

\section{8.}

Sachs, Prof, on the behaviour of the male and female elements in fertilisation, 222.

Sacrifices, human, 144.

Sagittal crest in male rpes and Australians, 558.

Sahara, fertility of mixed races in, 171 ; birds of the, 456 ; animal inhabitants of the, 489 .

Sailors, growth of, delayed by conditions of life, 31 ; long-sightec, 33. 
Salors and soldiers, difference in the proportions of, 32 .

St. John, Mr., on the attachment of mated birds. 410 .

St. Kilda, beards of the inhabitants of, 560 .

Salmo crinx, and S. umila, colouring of the male, during the breeding season, 340 .

— ly audon, 333.

- salur, 3333 .

Salmon leaping out of fresh water, 107 ; male, ready to breed before the ferale, 212 ; proportion of the sexes in, 249; male, pugnacity of the, 332 ; male, characters of, during the breeding season, 332 , 340 ; spawaing of the, 344 ; breeding of immature male, 485 .

Salvin, 0 , inheritance of mutilated feathers, $60,384,603$; on the Humming-birds, 219,454 ; on the numerical proportion of the sexes in Humming-birds, 248,487 ; on Chamapetes and Penclope, 377 ; on Selasphorus platycercus, 378; Pipra deliciosa, 378; on Chasmorhynchus, 389.

Samoa Islands, beardlessness of the natives of, 560,581 .

Sanù-skipper, 270.

Sandwich Islands, variation in the skulls of the natives of the, 26 ; decrease of native population, 186 ; populaticn of, 257 ; superiority of the nobles in the, 587 .

- Islanders, lice of, 170.

San-Giuliano, women of, 586 .

Santali, recent rapid increase of the, 45; Mr. Hunter on the, 192.

Saphirina, characters of the males of, 271.

Sarlidiornis melunonotus, characters of the young, 465 .

Sars, O., on Pontoporcia affinis, 266.

Saturnia carpini, attraction of males by the female, 252 .

Io, difference of coloration in the sears vi, 316.

Salurniida, coloratios of the, 314, 315.

Sarage, Dr., on the fighting of the male gorillas, 562 ; on the habits of the gorilla, 591 .
Savage and Wymitu on the polyg::mous hathits of the gorlla, 217 .

Savages, uniformity of, exuggerated, 28 ; long-sighted, 33 ; rate of increase among, usually swall, 45; retention of the prehensile powes of the feet by, 52 ; imitative facul. ties of, 87 ; 129; causes of low morality of, 119 ; tribes of, supplanting one another, 128 ; improvements in the arts amons. 144; arts of, 179 ; fondness of, for rougn music, 380 ; attention paid by, to personal appearance, 574 ; relation of the sexes among, 591.

Saviotti, Dr., division of malar bone, 39.

Saw-fly, pugnacity of a male, 291.

Saw-flies, proportions of the sexes in, 254.

Saxicola rubicola, young of, 487 .

Scalp, motion of the, 13 .

Scent-glands in snakes, 352.

Schaaffhausen, Prof., on the development of the posterior molars in different races of man, 20 ; on the jaw from La Naulette, 40 ; on the correlation between muscularity and prominent supra-orbital ridges, 44 ; on the mastoid processes of man, 53 ; on modifications of the cranial bones, 56 ; on human sacrifices, 144 ; on the probable speedy extermination of the anthropomorphous apes, 156 ; on the ancient inhabitants of Europe, 181; on the effects of use and disuse ot parts, 197 ; on the superciliary ridge in mau, 556; on the absence of race-differences in the infant skull in man, 557 ; on ugliness, 584.

Schaum, H., on the elytra of Dytiscus and Hydroporus, 276.

Schelver, on dragon-flies, 290.

Schiodte, on the stridulation of Heteroverus, 302.

Schlegel, F. von, on the complexity of the languages of uncivilised peoples, 91 .

- Prof, on Tanysiptera, 468.

Schleicher, Prof., on the origin of language, 87.

Sc'omburgk, Sir R., on the pognacity 
of the male musk-duck of Guiana, 362 ; on the courtship of Rupicols crocea, 395.

Schoolcraft, Mro, on the difficulty of fashioning stone implements, 49 .

Schweinfurth, complexion of negroes, 556.

Sciana aquila, 347.

Sclater, $P$. L., on modified secondary wing-feather's in the males of Pipri, 378 ; on elongated feathers in nightjars, 384 ; on the species of Chasmorhynchus, 385 ; on the plumage of Pelecanus onocrotalus, 393 ; on the plantain-eaters, 460 ; on the sexes and young of Tadorna variegata, 479 ; on the colours of Lemur macaco, 537 ; on the stripes in asses, 548 .

Scolecida, absence of secondary serual characters in, 260.

Scolopax frenata, tail-feathers of, 377.

- gallinago, drumming of, 376 .

javensis, tail-feathers of, $37 \%$.

major, assemblies of, 405 .

377.

Wilsonii, sound produced by,

Scolytus, stridulation of, 302 .

Scoter-duck, black, sexual difference in coloration of tho, 491 ; bright beak of male, 491 .

Scott, Dr., on idiots smelling their food, 36.

- J., on the colour of the beard in $\operatorname{man}, 558$.

Scrope, on the pugnacity of the male salmon, 332 ; on the battles of stags, 501.

Scudder, S. H., imitation of the stridulation of the Orthoptera, 283 ; on the stridulation of the Acridiidæ, 286 ; on a Devonian insect, 289 ; on stridulation, 566 .

Sculpture, expression of the ideal of beauty by, 581 .

Sea-anemonies, bright colours of, 260 .

Sea-bear, polygamous, 218.

Sea-elephant, male, structure of the nose of the, 527 ; polygamous, 218.

Sea-lion, polygamous, 218.

Seal, bladder-nose, 528.

Seals, therr sentinels generally females, 100 ; evidence furnished by, on classification, 150; jolygaruous hauits of, 218 ; battles of male 500 ; canine teeth of malc, 502; sexual differences, 515 ; pairing of, 522 ; sexual peculiarities of, 528 ; in the coloration of, 534 ; appreciation of music by, 569 .

Sea-scorpion, sexual differences in, 337.

Season, changes of colour in birds, in accordance with the, 390 ; chang'es of plumage of birds in relation to, 462 .

Seasons, inheritance at corresponding, 230.

Sebituani, African chief, trying to alter at Aahion, 575.

Sebright Bantam, 238.

Secondary sexual characters, 207 ; relations of polygamy to, 21\%: transmitted through both sexes 226 ; gradation of, in birds, 430 .

Sedgwick, W., on hereditary tendency to produce twins, 45 .

Seemann, Dr., on the different appreciation of music by different peoples, 570 ; on the effects of music, 571.

Seidlitz, on horns of reindeer, 506 .

Selasphorus platycercus, acuminite first primary of the male, 378 .

Selby, P. J., on the habits of the black and red grouse, 219.

Selection, double, 225.

_ of male by female birds, 404 , 421.

-, methodical, of Prussian grenथdiers, 29.

- sexual, explanation of, 209,213 , 220 ; influence of, on the colouring of Lepidoptera, 321.

- , sexual and natural, contrasted, 226.

Self-command, habit of, inherited, 115 ; estimation of, 118 .

Self-consciousness, in animals, 83.

Self-preservation, instinct of, 112 .

Self-sacrifice, by savages, 111 ; esti mation of, 118.

Sernilunar fold, 17.

Sernnopithecus, 154; long hasr on the heads of species of, $150,60 t$.

_chrysomehis, sexual differences of colour in, 537.

- comatus, ornamental hair on the hend of, 549 .

- jiontatus, beard, \&c., of. 556 . 
Seminnpithecus nasica, uose of, 150 .

— nemens, coluuring of, 551. rubrcundus, ornamental hair on the head of, 548 .

Scuses, inferiority of Europeans to savages in the, 33.

Sentinels, among animals, 100, 107.

Serpents, instinctively dreaded by apes and monkeys, 67, 71 .

serranus, hermaphroditism in, 161.

Sex, inheritance lumited by, 230 .

Sexes, relative proportions of, in man, 242,558 ; probable relation of the, in primeval man, 591 .

Sexual characters, secondary, 207 ; relations of polygamy to, 217; transmitted through both sexes, 226 ; gradation of, in birds, 430 .

- and natural selection, contrasted, 226.

- characters, effects of the loss of 231 ; limitation of, 231.

differences in man, 8.

selection, explanation of, 209,

213,220 ; influence of, on the colouring of Lepidoptera, 319 ; objections to, 495 ; action of, in mankind, 595 .

similarity, 255.

Shaler, Prof., sizes of sexes in whales, 516.

Sharks, prehensile organs of male, 331.

Sharpe, Dr., Europeans in the tropics, 195.

- R. B., ou Tunysiptera sylvia, 451 ; on Ceryle, 457 ; on the young male of Dacelo Gaudichaudi, 467.

Shaw, Mr., on the pugnacity of the male salmon, 332.

- J., on the decorations of birds, 382.

Sheep, danger-signals of, 100 ; sexual differences in the horns of, 230 ; horns of, 235,505 ; domestic, sexual differences of, late developed, 237 ; numerical proportion of the sexes in, 246 ; inheritance of horns by oue ser, 505; effect of castration, 506 ; mode of fighting of, 508 ; arched foreheads of some, $5: 32$.

- Merino, loss of horns in females of, 231 ; horns of, 235.

Shcils, difference in form of, in male and renale Gasteropoda, 2tiz; beautiful colours and shapes of, 264.

Shield-drake, pairing with a common duck, 414; New Zealand, sexes and young of, 479 .

Shooter, J., on the Kaffirs, 579 ; on the marriage-customs of the liaffirs, 598.

Shrew-mice, odour of, 528 .

Shrike, Drongo, 461.

Shrikes, characters of young, 465 .

Shuckard, W. E., on sexual äifferences in the wings of Hymenoptera, 277.

Sinyness of adorned male birds, 403.

Siagonium, proportions of the sexes in, 253 ; dimorphism in males of, 299.

Siam, proportion of male and femals births in, 245.

Siamese, general beardlessness of the, 560 ; notions of beauty of the, 578 ; hairy family of, 601 .

Sidgwick, $\mathrm{H}_{\text {., }}$ on morality in hypothetical bee community, 99 ; our actions not entirely directed by pain and pleasure, 120.

Siebold, C. T. von, on the proportion of sexes in the Apus, 255 ; on the auditory apparatus of the stridulant Orthoptera, 283.

Sight, inheritance of long and short, 33.

Signal-cries of monkeys, 87.

Silk-moth, proportion of the sexes in, 250, 251; Ailanthus, Prof. Canestrini, on the destruction of its larv $x$ by wasps, 251 ; difference of size of the male and female cocoons of the, 278 ; pairing of the, 318.

Simiadx, 152; their origin and divisions, 165.

Similarity, sexual, 225.

Singing of the Cicadst and Fulgoridan, 281 ; of tree-frogs, 350 ; of birds, object of the, 368 .

Sirenia, nakedness of, 50 .

Sirex juvencus, 292.

Siricidx, difference of the sexes in, 3⿻ 2.

Siskin, 394; pairing with a canary, 415.

SHcne throat pouch of the males of, U..., $\therefore$. 
Size, relative, of the sexes of unsects, 278.

Skin, movement of the, 13 ; nakedness of, in man, 56 ; colour of the, 192.

- and hair, correlation of colour of, 197.

Skull, variation of, in $\operatorname{man}, 26$; cubic contents of, no absolute test of intellect, 54; Neanderthal, capacity of the, 55 ; causes of modilication of the, 55 ; difference of, in form and capacity, in different races of men, 168; variability of the shape of the, 174; differences of, in the sexes in man, 557 ; artificial modification of the shape of, 575.

Skunk, odour emitted by the, 528 ; white tail of, protective, 543 .

Slavery, prevalence of, 117 ; of women, 593.

Slaves, difference between field and house-slaves, 196.

Sloth, ornaments of male, 534 .

Smell, sense of, in man and animals, 17.

Smith, Adam, on the basis of sympathy, 106.

- Sir A, on the recognition of women by male Cynocephali, 8 ; on revenge by a baboon, 69 ; on an instance of memory in a baboon, 74 ; on the retention of their colour by the Dutch in South Africa, 193; on the polygamy of the South African antelopes, 217 ; on the polygamy of the lion, 218 ; on the proportion of the seres in Kobus ellipsiprymnus, 247 ; on Bucephalus capensis, 351; on South African luzards, 358 ; on fighting gnus, 501 ; on the horns of rhinoceroses, 506 ; on the fighting of lions, 521 ; on the colours of the Cape Eland, 535 ; on the colours of the gnu, 536 ; on Hottentot notions of beauty, 578 ; disbelief in communistic marriages, 588 .

- F., on the Cynipidx and Tenthredinidre, 254; on the relative size of the sexes of Aculeate Hymen. optera, 279 ; on the difference betreen the sexes of ants and bees. 292; on the stridulation of Trox sabulosus, 303 ; on the stridulation of Mononychus pseudacori, 305.

Smynthurus liteus, courtship of, 279. Snakes, sexual differences of, 351 ; mental powers of, 352 ; male, ardency of, 352.

"Snarling muscles," 41.

Suipe, drumming of the, 376 ; coloration of the, 491.

- painted, sexes and young of, 476.

- solitary, assemblies of, 405 .

Snipes, arrival of male before the temale, 212; pugnacity of male, 362; double woult in, 390 .

Snow-goose, whiteness of the, 492.

Social animals, affection of, for each other, 102; defence of, by the males, 107.

Sociability, the sense of duty connected with, 98 ; impulse to, in animals, 105; manifestations of ; in $\operatorname{man}, 108$; instinct of, in naimals, 109.

Sociality, probable, of primeval meu, 62 ; influence of, on the development of the intellectual faculties, 128 ; origin of, in man, 129.

Soldiers, American, measurements of, 29.

- and sailors, difference in the proportions of, 32 .

Solenostoma, bright colours and malsupial sack of the females of, 346.

Song of male birds appreciated by their females, 92 ; want of, in brilliant plumaged birds, 401 ; of birds, 450 .

Sorex, odour of, 528.

Sounds admired alike by man and animals, 92; produced by fishes, 347 ; produced by male frogs and toads, 350 ; instrumentally produced by birds, 376 et seq.

Spain, decadence of, 141.

Sparussus smaragdulus, difference of colour in the sexes of, 272 .

Sparrow, pugnacity of the male, 360 ; acquisition of the Linnet's song by a, 370; coloration of the, 473 ; irsmature plumage of the, 466 .

-, white-crowned, young of the. 486.

Sparrows, house- and tree-, $45 \pi$. 
Sparrows, new mates found by, 408. -, seres and young of, 483 ; learning to sing, 570 .

Spathura Underwoodi, 388.

Spawning of fishes, 341, 344.

Sperr, used before dispersion of man, 180.

Species, causes of the advancement, of, 137 ; distinctive characters of, 166 ; or racas of man, 168 ; sterility and fertility of, when crossed, 170 ; supposed, of man, 174 ; gradation of, 175 ; difficulty of defining, 175 ; representative, of birds, 468 ; of birds, comparative differences between the sexes of distinct, 469.

Spectrum femoratum, difference of colour in the seres of, 289 .

Speech, connection between the brain and the faculty of, 88 ; connection of intonaticn with music, 570 .

"Spel" of the black-cock, 375 .

Spencer, Herbert, on the influence of food on the size of the jaws, 33 ; on the dawn of intelligence, 67 ; on the origin of the belief in spiritaal agencies, 94 ; on the origin of the moral sense, 123; on music, 571,572 .

Spengel, disagrees with explanation of man's hairlessness, 602.

Sperm-whales, battles of male, 500 .

Sphingidx, coloration of the, 314.

Sphinx, Humming-bird, 317.

, Mr. Bates on the caterpillar of $\mathrm{a}, 325$.

moth, musky odour of, 308 .

Spiders, 272; parental feeling in, 106 ; male, more active than female, 221 ; proportion of the sexes in, 254 ; secoudary sexual characters of, 272 ; courtship of male, 273 ; attracted by music, 273 ; male, small size of, 273.

Spilosoma menthastri, rejected by turkeys, $\mathbf{3 1 6 .}$

Spine, alteration of, to suit the erect attitude of man, 53 .

Spirits, fondness of monkeys for, 7 .

Spiritual agencies, belief in, almost nniversal, 94.

Spiza cyanea and civis, 412.

Spoonbill, 374; Chinese, change of plumage 10, 461 .
Spots, retained throughout groups of birds, 427 ; disappearance of, iu adult mammals, 546 .

Sprengel, C. K, on the sexuality of plants, 212.

Spring-boc, horns of the, 509 .

Sproat, Mr.g on the extinction of savages in Vancouver: Island, 183 ; on the eradication of faoial hair by the natives of Vancouver Island, 580 ; on the eradication of the beard by the Indians of $V$ ancourel Island, 603.

Spurs, occurrence of, in female fowls, 227,231 ; development of, in various species of Phasianidæ, 235 ; of Gallinaceous birds, 362, 364: development of, in female $\mathrm{Gal}$. linacea, 449.

Squilla, different colours of the sexe: of a species of, 271.

Squirrels, battles of male, 500; African, sexual differences in the colouring of, 534 ; black, 540 .

Stag, long hairs of the throat of, 521 ; horns of the, 227, 229; battles of, 501; horms of the, with numerous branches, 510 ; bellowing of the, 526 ; crest of the, 531.

- - beetle, numerical proportion of sezes of, 253 ; large size of male, 278 ; weapons of the male, 299.

Stainton, H. T., on the numerical proportion of the sexes in the smaller moths, 251 ; habits of Elachista rufocinerea, 252 ; on the coloration of moths, 315 ; on the rejection of Spilosoma menthastri. by turkeys, 316; on the sexes of Agrotis exclamationis, 316.

Staley, Bishop, mortality of infant Maries, 187.

Stallion, mane of the, 521 .

Stallions, two, attacking a third, 101 ; fighting, 501; small canine teeth of, 514 .

Stansbury, Capt, observations on pelicans, 102.

Staphylınidx, hornlike processes io male, 299.

Starfishes, parental feeling in, 106 ; bright colours of some, 260.

Stark, Dr., on the death-rate in towns and rural districts, 138; on the influence of marriage on mortality. 
139 ; on the higher murtality of males in Scotland, $2+3$.

Starling, American field-, pugnacity of male, 367.

- red-winged, selection of a mate by the female, 416 .

Starlings, three, frequenting the same nest, 219, 409; new mates found by, 408 .

Statues, Greek, Egyptian, Assyrian, \&c., contrasted, 581.

Stature, dependence of, upon local influences. 31.

Staudinger, Dr., on breeding Lepidoptera, 251; his list of Lepidoptern, 252.

Staunton. Sir G., hatred of indecency a modern virtue, 119.

Stealing of bright objects by birds, 413.

Stebbing, T. R., on the nakedness of the human body, 600 .

Stemmatopus, $52 x$.

Stendhal, sec Bombet.

Stenobothrus pratorum, stridulation, 286.

Stephen, Mr. L., on the difference in the minds of men and animals, 78 ; on general concepts in animals, 89; distinction between material and formal morality, 111.

Sterility, general, of sole daughters, 135; when crossed, a distinctive character of species, 166 ; under changed conditions, 189, 191.

iterna, seasonal change of plumage in, 493.

Stickle-back, polygamous, 220 ; male, courtship of the, 331 ; male, brilliant colouring of, during the breeding season, 340 ; nidification of the, 345 .

Sticks used as implements and weapons by monkeys, 81 .

Sting in bees, 208.

Stokes, Capt., on the habits of the great bower-bird, 381 .

Stoliczka, Dro, on colours in snakes, 352.

Stonechat, young of the, 487 .

Stone implements, difficulty of making, 49 ; as traces of extinct tribes, 181.

Stones, used by $m$ znkeys for breaking hard fruits and as missiles, 50 ; piles of, 179.
Stork, black, sexual ditterences in the bronchi of the, 374 ; red beak of the, 491 .

Storks, 491, 493; sexual difference in the colour of the eyes of, 425 .

Strange, Mr., on the satin bowerbild, 381.

Stretch, Mr., on the samcrical prom portion in the sexes of chickon, 247.

Strepsiceros kudu, horns of, 512 ; mark ings of, 543.

Stridulation, by males of Theridion, 274 ; of the Orthoptera and Homoptera discussed, 289; of beetles, 301.

Stripes, retained throughout gromps of birds, 427 ; disappearance of, in adult mammals, 546 .

Strix flannmea, 408.

Structure, existence of unserviceable modifications of, 61 .

Struggle for existence, in man, 142, 146.

Struthers, Dr., on the occurrence of the supra-condyloid foramen in the humerus of man. 21.

Sturnella ludoviciana, pugnacity of the male, 367.

Sturnus vulgaris, 408.

Sub-species, 175.

Suffering, in straugers, indifference of savages to, 117.

Suicide, 137 ; formerly not regarded as a crime, 117 ; rarely practised among the lowest savages, 117.

Suidx, stripes of young, 464 .

Sulivan, Sir B. J., on speaking of parrots, 85 ; on two stallions attacking a third, 501.

Sumatra, compression of the nose ky the Malays of, 583.

Sumner, Archb., man alone capable of progressive isprovement, 79 .

Sun-birds, nidification of, 454 .

Superstitions, 144 ; prevalence of, 122.

Superstitious customs, 96.

Superciliary ridge in man, 556, 558 .

Supernumerary digits, more frequent in men than in women, 223 ; in. heritance of, 232 ; early derelopment of, 237.

Supri-condyloid foramen in the easly progenitors of man, 160. 
Suspicion, prevalence of, among animals, 69 .

Swallow-tail butterfiy, 312.

Swallows deserting their young, 108 , 113.

Swan, black, wild, trachea of the, 374 ; white young of, 482 ; red beak of the, 491 ; black-necked, 493.

Strans, 491, 493; young, 481.

Swaysland, Mr., on the arrival of migxatory birds, 212.

Siwifts, migration of, 108 .

Swinhne, R., on the common rat in formosa and China, 80 ; behaviour of lizards when caught, 355 ; on the sounds produced by the male hoopoe, 376 ; on Dicrurus macrocercus and the spoonbill, 461 ; on the young of Ardeola, 468; on the habits of Turnix, 476 ; on the habits of Rhynchica bengalensis, 476 ; on Orioles breeding in immature plumage, 484.

Sylvia atricapilla, young of, 487 .

_ cinerea, acrial love-dance of the male, 380

Sympathy, 134 ; among animals, 102 ; its supposed basis, 106.

Sympathies, gradual widening of, 123.

Syngnathous fishes, nudominal pouch in male, 163 .

Sypheotides auritus, acuminated primaries of the male, 378 ; entr-tufts of, ::84

\section{T.}

Tabanidæe, habits of, 208.

Tadorna varicgata, sexes and young of, 479 .

- rulpanser, 414.

T'ahitians, 145; compression of the nose by the, 583 .

Tail, rudimentary, occurrence of, in man, 22 ; convoluted body in the extremity of the, 23 ; absence of, in man and the higher apes, 58; variability of, in species of Macacus and in baboons, 58 ; presence of, in the early progenitors of man, 160 ; length of, in pheasants, 445, 451, 452 ; difference of length of the, in the two sexes of birds, 451.

Tait, Lavison, on the cffects of na- tur a' selection on civilised nations. 133.

Tanager, scarlet, variation in the male, 424.

Tanagra astiva, age of mature plu. mage in, 483.

- rubra 424; young of, 487.

Tanais, absence of mouth in the males of some species of, 208; relations of the sexes in, 255; dimorplice males of a species of, 265 .

Tankerville, Earl, on the battles of wild bulls, 501 .

Tanysiptera, races of, determined from adult males, 468 .

sylvia, long tail-feathers of, 451.

Taphroderes distortus, enlarged left mandible of the male, 277.

Tapirs, longitudinal stripes of youns? 464,546 .

Tarsi, dilatation of front, in male beetles, 275 .

Tursius, 156.

Tasmania, half-castes killed by th.e natives of, 170 .

Tasmanians, extinction of, 184.

Taste, in the Quadrumana, 541.

Tattooing, 178 ; universality of, 57 t

Taylor, G., on Quiscalus major, 248.

Tea, fondness of monkeys for, 7 .

'l'ear-sacks, of Ruminants, 529.

Teebay, Mr., on changes of plumage in spangled Hamburgh fowls, 229.

Teeth, rudimentary incisor, in Ruminants, 11 ; posterior molar, in man, 20 ; wisdom, 20 ; diversity of, 26 : canine, in the enrly progenitors of man, 160 ; canine, of male mammals, 502; is man, reduced by correlation, 562 ; staining of the. 574 ; front, lnocked out or filed bJ some savages, 575 .

Tegetmeier, Mr., on the transmission of colours in pigeons by one sex alone, 231 ; aumerical proportion of male and female births in dogs, 246 ; on the abundance of male pigeons, 247 ; on the wattles of game-cocks, 403 ; on the courtship of fowls, 417 ; on the loves of pigeons, 418; on dyed pigeons, 418; blue dragon pigeons, 446 .

Tembeta, S. American ornament, 575. Temper, in dogs aud horses, inherited. 6y. 
Tench, proportions of the sexas in the 249 ; brightness of male, during breeding season, 340 .

Tunebrionidæ, stridulation of, 302.

Tennent, Sir J. E., on the tusks of the Ceylon Elephant, 507, 515; on the frequent absence of beard in the natives of Ceylon, 560 ; on the Chinese opinion of the aspect of the Cingalese, 578.

Tennyson, A., on the controi of thought, 123.

Fenthredinidæ, proportions of the sexes in, 254; fighting habits of male, 291; difference of the seres in, 292.

Tephrodornis, young of, 468 .

Terai, in India, 182.

Termites, habits of, 291.

Jerns, white, 492 ; and black, 493.

_- seasonal change of plumage in, 492.

Ferror, common action of, upon the lower animals and man, 69 .

T'estudo elegans, 351.

- nigra, 351 .

Ietrao crpido, battles of, 367 ; sexual difference in the vocal organs of, 371.

- phasianellus, dances of, 380 ; duration of dances of, 405 .

scoticus $455,465,471$.

tetrix, $455,465,471$; pugnacity of the male, 363 .

umbellus, pairing of, 367 ; battles of, 367 ; drumming of the male, 375.

- urogalloides, dances of, 405.

- urogallus, pugaacity of the male, 363.

- urophasianus, inflation of the cesophagus in the male, 372.

Thamnobia, young of, 468 .

Thaumalea picta, display of plumage by the male, 396.

Thecla, sexual differences of colouring in species of, 310 .

rubi, protective colouring of, 312 .

Thecophora foveo, 308.

Theognis, selection in mankind, 29.

Therdion, stridulation of males of, 273.

- lineatum, 272.

Thomisus citreus, and $r$ floricolens, difference of colour in the seres of, 272.

Thompson, J. H., on the battles of sperm-whales, 500 .

- W., on the colouring of the male char during the breeding season, 340 ; on the pugnacity of the males of Gallinula chloropus, 360 ; on the finding of new mates by magpies, 407 ; on the finding ot new mates by Peregrine falcons, 408.

Thorax, processes of, in male beetles, 295.

Thorell, T., on the proportion of the sexes in spiders, 255.

Thornback, difference in the teeth of the two sexes of the, 334 .

Thoughts, control of, 123.

Thrush, pairing with a blackbird, 414; colours and nidification of the, 455 .

Thrushes, characters of young, $45 \bar{\xi}$, 464.

Thug, remor'se of a, 117.

'Thumb, absence of, in Ateles and $\boldsymbol{H}_{y-}$ lobates, 51.

Thury, M., on the numerical proportion of male and female births among the Jews, 243.

Thylacinus, possession of the marsupial sack by the male, 161

Thysanura, 279.

Tibia, dilated, of the male Crabo cribrarius, 276.

- and femur, proportions of, in the Aymara Indians, 34.

Tierra del Fuego, marriage-customs of, 598 .

Tiger, colours and markings of the, 545 .

Tigers, depopulation of districts by, in India, 46.

Tillus elongatus, difference of coiour in the sexes of, 294.

Timidity, variability of, in the same species, 69 .

Tineina, proportion of the seres in. 250.

Tipula, pugnacity of male, 280 .

Tits, sexual difference of colour in, 458.

Toads, 349 ; male, treatment of ova by some, 163 ; male, ready to breed before the female, 212 . 
Tolas, iufanticide and proportion of seres, 255; practise polyandry, 593 ; choice of husbands amongst, 593.

Toe, great, condition of, in the human embryo, 11.

Tomicus villosus proportion of the seres in, 253.

Tomtit, blue, sexual difference of colour in the, 458 .

Tonga Islands, beardlessness of the natives of, 560,581 .

Tooke, Horne, on language, 86.

Tools, flint, 145 ; used by monkeys, 81 ; use of, 48 .

Topknots in birds, 384.

Tortoise, voice of the male, 567 ,

Tortures, submitted to by American savages, 118.

Totanus, double moult in, 390 .

loucans, colours and nidification of the, 455; beaks and ceres of the, 491.

Towns, residence in, a cause of diminished stature, 31 .

Toynbee, J., on the external shell of the car in man, 14.

Trachea, convoluted and imbedded in the sternum, in some birds, 374; structure of the, in $R$ hynchaca, 476.

Trades, affecting the form of the skull, 56.

Tragelaphus, sexual differences of colous in, 535

— scriptus, dorsal crest of, 530 ; markings of, $543,544$.

Tragopan, 220; swelling of the watthes of the male, during courtship, 383 ; display of plumage by the inale, 397; markings of the sexes of the, 428 .

Tragops disprur, sexual difference in the colour of, 351.

Training, effect of, on the mental difference between the sexes of $\operatorname{man}, 565$.

Transfer of male characters to female birds, 470 .

Transmission, equal, of ornamental characters, to both sexes in mammals, 542 .

Traps, avoidance of, by animals, 80 ; use of, 48.

Treachery, to comrades aroidance of, by savages, 111
Tremex columbur, 292.

Tribes, extinct, 1\%3; extınction of. 182.

Trichine, difference of colour in the sexes of a species of, 294.

Trigla, 347.

Trimen, R., on the proportion of the seres in South African butterfies, 250 ; on the attraction of males by the female of Lasiocampa quercus, 252 ; on Pneumora, 288; on difo ference of colour in the sexes of beetles, 294 ; on moths brilliantly coloured beneath, 315 ; on mimicry in butterflies, 325 ; on Gynanisa Isis, and on the ocellated spots of Lepidoptera, 428; on Cyllo Ledu, 429.

Tringa, sexes and young of, 485 .

- cornuta, 391.

Triphena, coloration of the species of, 313.

Tristram, H. Ba, on unhealthy districts in North Africa, 194; or the habits of the chaffinch in Palestine, 248; on the birds of the Sahara, 456; on the animals inhabiting the Sahara, 489.

Triton cristatus, 348.

- palmipes, 348.

- punctatus, 348.

Troglodyte skulls, greater than those of modern Frenchmen, 55.

Troglodytes vulgaris, 473 .

Trogons, colours and nidification of the, $455,456$.

Tropic-birds, white only when mature, 492.

Tropics, freshwater fishes of the, 343.

Trout, froportion of the sexes in, 249 ; male, pugnacity of the, 332 .

Trox sabulosus, stridulation of, 303 .

Truth, not rare between members of the same tribe, 118; more highly appreciated by certain tribes, 122 .

Tulloch, Major, on the immusity of the negro from certain fevers, 193.

Tumbler, almond, change of plumage in the, 238.

Turdus merulc, 455 ; young of, 487 .

- migratorius, 464 .

- musicus, 455.

- polyglottus, young of, 487 .

_- torquatus, 455 
Turkay, wild, pugnacity of young male, 366 ; wild, notes of th? 375 ; swolling of the wattles of th : male, 383 ; variety of, with a top-knot, 384 ; recognition of a dog by a, 412 ; male, wild, acceptable to domesticated females, 418 ; wild, first advances sade by older females, 419 ; wild, breast-tuft of bristles of the, 461 .

Turkey-cock, scraping of tho wings of, upon the ground, 375 ; wild, display of plumage by, 394; fighting habits of, 404 .

Turner, Prof. W., on muscular fasciculi in man referable to the panniculus carnosus, 13 ; on the occurrence of the supra-condy loid foramen in the hnman humerus, 21 ; on muscles attached to the coccyx in man, $22 ;$ on the filum terminale in man, 23 ; on the variability of the muscles, 26 ; on abnormal conditions of the human uterus, 39 ; on the development of the mammary glands, 162 ; on male fishes hatching ova in their mouths, 163,345 ; on the external perpendicular fissure of the brain, 200; on the bridging convolutions in the brain of a chimpanzee, 201.

Turnix, scxes of some species of, 475 ; 480.

Turtle-dove, cooing of the, 374.

Tuttle, H., on the number of species of $\operatorname{man}, 174$.

Tylor, E. B., on emotional cries, gestures, \&r., of man, 85; on the origin of the belief in spiritual agencies, 94 ; remorse for violation of tribal usage in marrying, 115 ; on the primitive barbarism of civilised nations, 143 ; on the origiu of couvting, 144; inventions of savages, 145 ; on resemblances, of the mental character's in different races of man, 178.

Type of structure, prevalence of, 164 .

Typhaus, stridulating organs of, 301 ; stridulation of, 303 .

Tyranga astiva, 462.

Trvins, tendency to produce, hereditary, 45.

Twite, proportion of the seres in the, 248.

\section{U.}

Ugliness, said to consist in an approach to the lower animals, 534

Uimbrella-bird, 373 ,

Uinbrina, sounds produced by, 347.

United States, rate of increase in, 44 ; influence of natural selection on the progress of, 142 ; change undergone by Europeans in the, 196.

Upupa epops, sounds produced by the male, 376.

Uraniida, coloration of the, 314 .

Uria troile, variety of $(=U$. lacry. mans), 424.

Urodela, 348.

Urosticte Benjamini, sexual differences in, 442.

Use and disuse of parts, effects of, 32 . influence of, on the races of man, 197.

Uterus, reversion in the, 38 ; more or less divided, in the human subject, 38,43 ; double, in the early progenitors of man, 161 .

\section{V.}

Vaccination, influence of, 134.

Vancouver Island, Mr. Sproat on the savages of, 183 ; natives of, eradication of facial hair by the, 580 .

Vanellus cristatus, wing tubercles of the male, 366.

Vanesse, 308 ; resemblance of lower surface of, to bar $\mathrm{k}$ of trees, 311 .

Variability, causes of, 28 ; in man, analogous to that in the lower animals, 29 ; of the races of man, 174; greater an men than in women, 223 ; period of, relation of the, to sexual selection, 240 ; of birds, 422 ; of secondary serual charncters in man, 559.

Variation, laws of, 29 ; correlated, 43 ; in man, 146; analogous, 152 ; analogous, in plumage of birds, 385 .

Variations, spontaneous, 44.

Varieties, absence of, between two species, evidence of their distinctness, 167.

Variety, an object in nature, 493.

Variola, communicable between matn and the lower animals, 7. 
Vauréal, humaa bones from, 22.

Veddahs, monogamous habits of, 591 .

Veitch, Mr, on the aversion of Japanese ladies to whiskers, 581.

Vengeance, instinct of, 113.

Venus Erycina, priestesses of, 587.

Vermes, 264.

Vermiform appendage, 21.

Verreaur, M., on the attraction of numerous males by the female of an Anstralian Bombyx, 252.

Yertebrx, caudal, number of, in macaques and baboons, 58 ; of monkeys, partly imbedded in the body, 59 .

Vertebrata, 330 ; common origin of the, 158 ; most ancient progenitors of, 161 ; origin of the voice in airbreathing, 567 .

Vesicula prostatica, the homologue of the uterus, 24, 161.

Vibrissæ, represented by long hairs in the eyebrows, 19.

Vidua, 403, 462. axillaris, 219.

Villerme, M., on the influence of plenty upon stature, 31 .

Vinson, Aug., courtship of male spider, 273; on the male of Epeira nigra, 273.

Viper, difference of the sexes in the, 351.

Virey, on the number of species of man, 174.

Virtues, originally social only, 116 ; gradual appreciation of, 131 .

Viscera, variability of, in $\mathrm{man}, 27$.

Vlacovich, Prof, on the ischio-pubic muscle, 41.

Tocal music of birds, 368 .

organs of man, 87 ; of birds, 90 , 450 ; of frogs, 350 ; of the Insessores, 370 ; difference of, in the sexes of birds, 371 ; primarily used in relation to the propagation of the species, 566.

Vogt, Karl, on the origin of species, 1 ; on the origin of man, 3 ; on the semilunar fold in $\operatorname{man}, 17$; on microcephalous idiots, 35 ; on the imitative faculties of microcephalons idiots, 87 ; on slzulls from Brazilian caves, 168 ; on the evolution of the races of man, 177 ; on the formation of the skull in women, 557 ; on the
Ainos and negroes, 560; on the increased cranial difierence of the sexes in man with race developmen $t$, 566 ; on the obliquity of the eye in the Chinese and Japanese, 578.

Voice in mammals, 525 ; in monkeys and $\operatorname{man}, 558$; in $\operatorname{man}, 566$; origin of, in air-breathing vertebratas, 567

Von Baer, definition of advancement in the organic scale, 164.

Vulpian, Prof, on the resemblance between the brains of man and of the higher apes, 6 .

Vultures, selection of a mate by the female, 416 ; colours of 493 .

\section{W.}

Waders, young of, 488 .

Wagner, $R_{\text {. }}$, on the occurrence of the diastema in a Kaftir skull, 40 ; OB the bronchi of the black stork, 374 .

Wagtail, Ray's, aurival of the male before the female, 212.

Wagtails, Indian, young of, 468 .

Waist, proportions of, in soldier's and sailors, 32.

Waitz, Prof., on the number of species of man, 174; on the liability of negroes to tropical fevers after residence in a cold climate, 194; on the colour of Australian infants, 558 ; on the beardlessness of negroes, 560 ; on the fondness of mankind for ornaments, 573; or negro ideas of female beauty, 579 ; on Javan and Cochin Chinese ideras of beauty, 580 .

Walckenaer and Gervais, spider attracted by music, 273 ; on the Myriapoda, 274.

Waldeyer, M., on the hermaphroditism of the vertebrate embryo, 161.

Wales, North, numerical proportion of male and female births in, 242.

Walker, Alex., on the large size of the hands of labourers' children, 33.

__. $F_{\text {, }}$, on sexual differences in the diptera, 280.

Wallace, Dr. A., on the prehensile use of the tarsi in male moths, 209; on the rearing of the Ailanthus silkmoth, 251; on breeding Lepidoptera, 251 ; propurtion of sexes of Bombyx cynthia, B. yamamai, and 
B. Pernyi reared by, 253 ; on the development of Bombyx cynthia and $B$. yamamai, 278 ; on the pairing of Eombyx cynthin, 318.

Waliace, A. R., on the origin of man, 3 ; on the power of imitation in man, 68 ; on the use of missiles by the orang, 82 ; on the varying appreciation of truth among different tribes, 122; on the limits of natural selection in $\operatorname{man}, 49,127$; on the occurrence of remorse among savages, 131; on the effects of natural selertion on civilised nations, 133 ; on the use of the convergence of the hair at the elbow in the orang, 151 ; on the contrast in the characters of the Malays and Papuans, 168 ; on the line of separation between the Papuans and Malays, 169; on the birds of paradise, 219 ; on the sexes of Ornithoptera Crcesus, 250 ; on protective resemblances, 261 ; on the relativesizes of the seres of insects, 278 ; on Elaphomyin, 280 ; on the pugnacity of the males of Leptorhynchus angustatus, 299; on sounds produced by Euchirus longimanus, 304 ; on the colours of Diadema, 309 ; on $\mathrm{Kal}$ lima, 311; on the protective colouring of moths, 313 ; on bright color'dration as protective in butterflies, 314; on variability in the Papilionidx, 320 ; on male and female buttertlies inhabiting different stations, 321 ; on the protective nature of the dull colouring of female buttertiles, $321,322,325$; on mimicry in butterfies, 324 ; on the bright colours of caterpillars, 325 ; on brightly-coloured fishes frequenting reefs, 343 ; on the coral snakes, 353 ; on P(radisea apoda, 385; on the display of plumage by male birds of paradise, 395 ; on assemblies of birds of paradise, 405 on the instability of the ocellated spots in Hipjarchia Janira, 428; on sexually limited inheritance, 444 ; on the sexual coloration of birds, 452,472 , $473,475,480$; on the relation between the colours and nidification of birds, 452,455 ; on the coloration of the Cotingids, 460 ; on the females of Paradisea apoda and paprana, 470; on the incubation of the cassowary, 478 ; on protective coloration in birds, 489 ; on the Babirusa, 519; on the markings of the tiger, 545 ; on the beards of the Papuans, 500; on the hair of the Papuans, 575; on the distribution of hair on the human body, 600 .

Walrus, development of the nictitating membrane in the, 17 ; tusks of the, 502,507 ; use of the tusks by the, 513 .

Walsh, B. D., on the propertion of the sexes in Papilio Turnus, 250. on the Cynipidx and Cecidomyidx, 254; on the jaws of Ammophila, 275 ; on Comydalis cornutus, 275 ; on the prehensile organs of maie insects, 275; on the antennz of Penthe, 275; on the caudal appendages of dragon-flies, 276 ; on Platyphyllum concavum, 286 ; on the sexes of the Ephemeridæ, 289; on the difference of colour in the sexes of Spectrum femoratum, 289; on sexes of arragon-flies, 290 ; on the difference of the sexes in the Ichneumonidx, 292; on the sexes of Orsodacna atra, 294; on the variation of the horns of the male Phanaus carnifex, 297 ; on the coloration of the species of Anthocharis, 312.

Wapiti, battles of, 501 ; traces of horns in the female, 504; attacking a man, 511 ; crest of the male, 531 : sexual difference in the colour of the, 536.

Warbler, hedge-, 473 ; young of the, 481.

Warblers, superb, nidification of, 454 .

Wariness, acquired b- animnls, 80 .

Warington, $R_{\text {., }}$ on the habits of the stickle-backs, 331,345 ; on the brilliant colours of the male stickle-back during the breeding season, 340 .

Wart-hog, tusks and pads of the, 519 .

Watchmakers, short-sighted, 33 .

Waterhen, 360 .

Waterhouse, C. O., on blind beetles, 294 ; on difference of colour in the sexes of beetles, 294 .

G. R., on the voice of Hylobates agilis, 567 
Water-ouzel, 455; autuma song of the, 370 .

Waterton, C., on the Bell-bird, 389 ; on the pairing of a Canada goose with a Bernicle gander, 414 ; on hares fighting, 500 .

Wattles, disadvantageous to male hirds in fighting, 404.

Weale, J. Mansel, on a South Afric:ı caterpillar, 325 .

Wealth, influence of, 134 .

Weapons, used by man, 48 ; emplored by monkeys, 81 ; otfensive, of males, 210; of mammals, 501 et seq.

Weaver-bird, 370 .

Weaver-birds, rattling of the wings of, 375 ; assemblies of, 405 .

Webb, Dr., on the wisdom teeth, 20.

Wedderburn, Mr., assembly of black game, 407.

Wedgwood, Hensleigh, on the origin of language, 87.

Weevils, sexual difference in length of snout in some, 208.

Weir, Harrison, on the numerical proportion of the seres in pigs and labbits, 247 ; on the sexes of young pigeons, 247; on the songs of birds, 368 ; on pigeons, 411 ; on the lislike of blue pigeons to other coloured varieties, 417 ; on the desertion of their mates by femaie pigeons, 418.

- J. Jenner, on the nightingale and blackcap, 212 ; on the relative sexual maturity of male birds, 213 ; on female pigeons deserting a feeblo mate, 214 ; on three starlings frequenting the same nest, 219 ; on the proportion of the sexes in Mut chetes pugnax and other birds, 247 , 248 ; on the coloration of the Triphena, 313; on the rejection of certain caterpillars by birds, 326 ; on sexual differences of the beak ic the goldfinch, 360 ; on a piping bullfinch, 369 ; on the object of the nightingale's song, 368 ; on songbirds, 369 ; on the pugnacity of male fine-plumaged birds, 400 ; on the courtship of birds, 401 ; on the fir ling of new mates by Peregriaefalcons and Kestrels, 408; on the ballfinch and starliag, 408 ; on the cause of birds remaining unpaired
409 ; on starlings and parrots living in triplets, 409 ; on recognition of colour by birds, 411 ; on hybrid birits, 414 ; on the selection of a greentinch by at female canary, +15 ; on a case of rivalry of female bullfinches, 420 ; on the maturity of the golden-pheasant, 483.

Weisbach, Dr., measurement of men of different races, 167 ; on the greater variability of men than of women, 223 ; on the relative proportions of the body in the sexes of different races of man, 559 .

W eismanin, Prof., colours of Lycœnce, :3:?.

Welcker, M., on brachycephaly and dolichocephaly, 56 ; on sexual differences in the skull in $\operatorname{man}, 557$.

Wells, Dr., on the immunity of caloured races from certain poisons, 193.

Westring, on the stridulation of maies of Theridion, 273 ; on the striduIation of Reduvius personatus, 281; on the stridulation of beetles, 302 ; on the stridulation of Omaloplia brunnea, 303 ; on the stridulatirg organs of the Coleoptera, 304; "n sounds prodnced bJ Cychrus, :31) 4 .

Westropp, H. M., on reason in a bear, 76 ; on the prevalence of certaiu forms of ornamentation, 179.

Westwood, J. 0 ., on the classification of the Hymeaptera, 148; on the Culicidx and Tabanidx, 208; on a Hymenopterous parasite with a sedentary male, 221 ; on the proportions of the sexes in Ircanus cercus and Srayonium, 253; on the absence of ocalli in female $\mathrm{mr}_{\mathrm{a}}$ tillidx, 274; on the jaws of $\mathrm{Am}$ mophila, 275; on the copulation of insects of distinct species, 275 ; ox the male of Crabro cribrarius, $27 b^{\circ}$; on the pugnacity of male Tipuix: 280 ; on the stridulation of Pirrites stridulus, 281 ; on the Cicadæ, 281 ; on the stridulating organs of the crickets, 284 ; on Ephippiger vitiur, 284, 288; on Pneumora, 287 ; oy the pugnacity of the Mantides, 289, on Plutyllemnus, 289 ; on difereare in tbe sexes of the Agrinnida. 290. 
on the pugnacity of the males of a spccies of Tenthredina, 291; on the pugnacity of the male stagbeetle, 299; on Bledius taurus and Siagonium, 299; on lamellicorn heetles, 301 ; on the coloration of Lithosia, 314.

Whale, Sperm-, battles of male, 500 .

Whales, aakedness of, 56 .

Whately, Archb., language not peculiar to man, 84 ; on the primitive civilisation of man, 143.

Whewell, Prof., on maternal affection, 70.

Whiskers, in monkeys, 150.

White, F. B., noise produced by Hyla phila, 308.

- Gilbert, on the proportion of the sexes in the partridge, 248 ; on the house-cricket, 283 ; on the object of the song of birds, 369 ; on the finding of new mates by white owls, 408 ; on spring coveys of male partridges, 409 .

Whiteness, a sexual ornament in some birds, 494; of mammals inhabiting snowy countries, 542 .

White-throat, aërial love-dance of the male, 380 .

Witney, Prof, on the development of language, 86 ; language not indispensable for thought, 88 .

Widow-bird, polygamous, 219 ; breeding plumage of the male, 392 , 403 ; female, rejecting the unadorned male, 419 .

Widows and widowers, mortality of, 140.

Wigeon, pairing with a pintail duck, 414.

Wilckens, Dr., on the modification of domestic animals in mountainous regions, 35 ; on a numerical relation between the hairs and excretory pores in sheep, 198.

Wilder, Dr. Burt, on the greater frequency of supernumerary digits in men than in women, 223.

Williams, on the marriage-customs of the Fijians, 599.

Wilson, Dr., on the conical heads of the natives of North-Western America, 583 ; on the Fijians, 583 ; on the persistence of the fashion of oompressing the skull, 584 .
Wing-spurs, 449.

Wings, differences of, in the two sexes of butterflies and Hymenoptera, 277 ; play of, in the courtship of birds, 401.

Winter, change of colour of mammals in, 542 .

Witcheraft, 96.

Wives, traces of the forcible capture of, 144.

Wolf, winter change of the, 542 .

Wolff, on the variability of the viscera in man, 27.

Wollaston, T. V., on Eumgnathus, 277 ; on musical Curculionidæ, 301 ; on the stridulation of Acalles, 306 .

Wolves learning to bark from dogs, 73 ; honting in packs, 101.

- black, 540 .

Wombat, black varieties of the, 539. Women distinguished from men by male monkeys, 8 ; preponderance of, in numbers, 244 ; selection of, for beauty, 387 ; effects of selection of, in accordance with different standards of beauty, 584 ; practice of capturing, 589, 592; early betrothals and slavery of, 593 ; freedom of selection $\mathrm{by}_{2}$ in savage tribes, 598.

Wonder, manifestations of, by animals, 71 .

Wonfor, Mr., on sexual peculiarities in the wings of butterfies, 277.

Wood, J., on muscular variations in man, $26,41,43$; on the greater rariability of the muscles in men than in women, 223.

- T. W., on the colouring of the orange-tip butterfly, 313 ; on the habits of the Saturniidæ, 315 ; quarrels of chameleons, 357 ; on the habits of Menura Alberti, 371 . on Tetrao cupido, 371 ; on the display of plumage by male pheasants, 396 ; on the ocellated spots of the Argus pheasant, 441 ; on the habits of the female cassowary, 478 .

Woodcock, coloration of the, 491.

Woodpecker, selection of a mate by the female, 416 .

Woodpeckers, 371 ; tapping of, 376 ; colours and ridification of the, 455 , 458,489 ; characters of young, 465 . 474,481 . 
Woolner, Mr., observations on the ear in $\operatorname{man}, 15$.

Wormald, Mr., on the coloration of Bypopyra, 315.

Wounds, healing of, 8.

Wren, 473 ; young of the, 481 .

Wright, C. A., on the young of Urocetes and Petrocincla, 487.

- Chauncey, great brain-pover requisite for language, 48 ; on cor relative acquisition, 571 ; on the enlargement of the brain in man, 610 ,

Mr., on the Scotch deerhound, 517 ; on sesual preference in dogs, 524 ; on the rejection of a horse by a mare, 525 .

- W. von, on the profective piumage of the Ptarmigan, 391.

Writing, 144.

Wyman, Prof, on the prolongation of the coccy $x$ in the human embryo, 11 ; on the condition of the great toe in the human embryo, 11; on the occurrence of the supra-condyloid foramen in the humerus of man, 22 ; on variation in the skulls of the natives of the Sandwich Islands, 26 ; on the hatching of the eggs in the mouths and branchial cavities of male fishes, 163,345 .

\section{X.}

Xenarchus, on the Cicadæ, 281.

Xenophon, selection in mankind advo. cated by, 29.

Xenorhynchus, sexual difference in the colour of the eyes in, 425 .

Xiphophorus Hellerii, peculiar anal fin of the male, $337,338$.

Xylocopa, diffarence of the sexes in, 292.
Y.

Yarrell, W., on the habits of the Cyprinidx, 250 ; on Raia clavata, 331 ; on the sharacters of the male salmon during the breeding season, 332,342 ; on the characters of the rays, 334 ; on the gemmeous dragonet, 336 ; on tne spawning of the salmon, 344; on the incubation of the Lophobranchii, 346 ; on rivalry in song-birds, 369 ; on the trachea of the swan, 374 ; on the moulting of the Anatidx, 393 ; on the young of the waders, 486 .

Yellow fever, immunity of negroes and mulattoes from, 193.

Youatt, Mr., on the development of the horns in cattle, 235.

Yura-caras, their notions of beauty, 580.

\section{2.}

Zebra, rejection of an ass by a female, 540 ; stripes of the, 545

Zebus, humps of, 532 .

Zigzags, prevalence of, as ornaments. 179.

Zincke, Mr., on European emigration to America, 142.

Zootoca vivipara, sexual difference in the colour of, 357.

Zouteveen, Dr., polydactylism, 37 ; proportion of sexes at Cape of Good Hope, 243; spiders attracted by music, 273 ; on sounds produced by fish, 347.

Zygænidæ, coloration of the, 314 .

THE FND. 




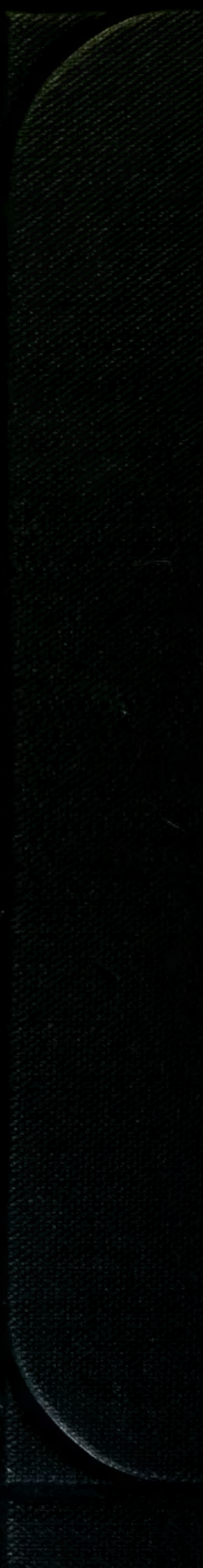